\title{
H. E.JEANPERT
}

\section{VADE-MECUM}

\section{du Botaniste}

dans $1 \mathrm{a}$

\section{Région Parisienne}

I

1634 figures

\section{PARIS}

LIBRAIRIE gES SCIENCES NATURELLES

Paul Klincksieck

LÉON LHOMME Succ $=$

3. Rue Corneille.3 
THE UNIVERSITY

OF ILLINOIS

LIBRARY

$$
\begin{gathered}
581.94436 \\
J 34 r
\end{gathered}
$$

BIOLOGY 


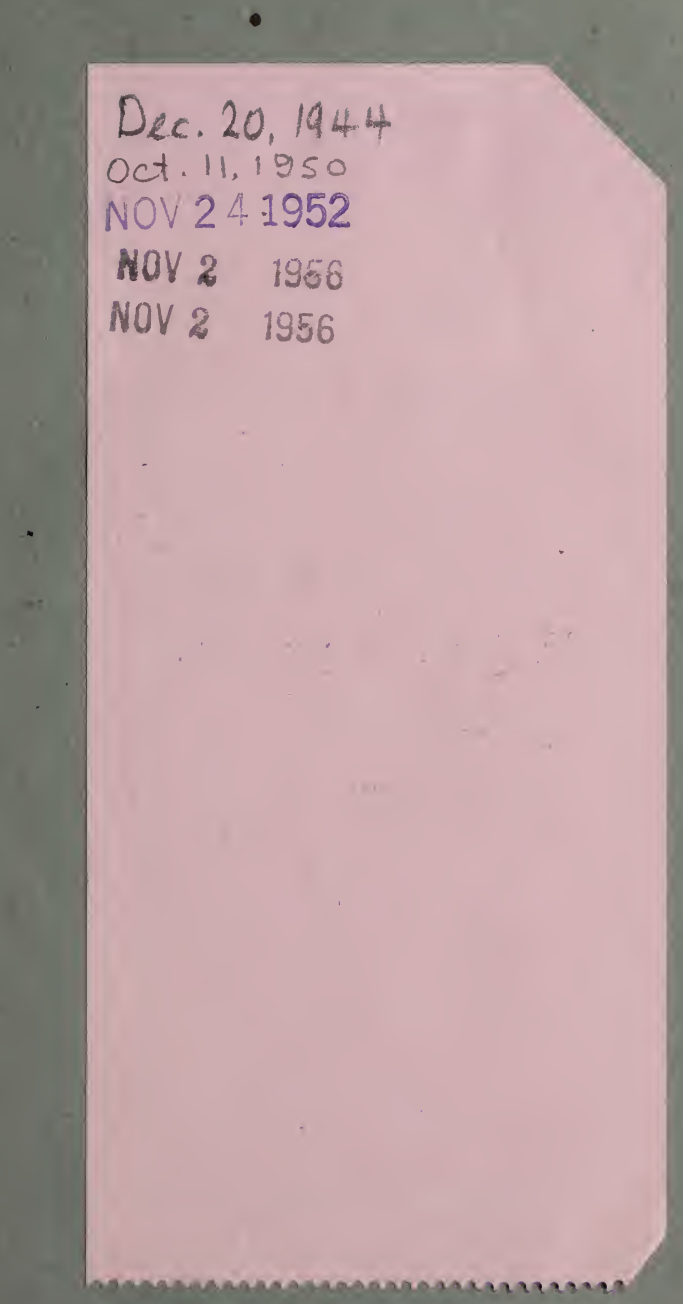




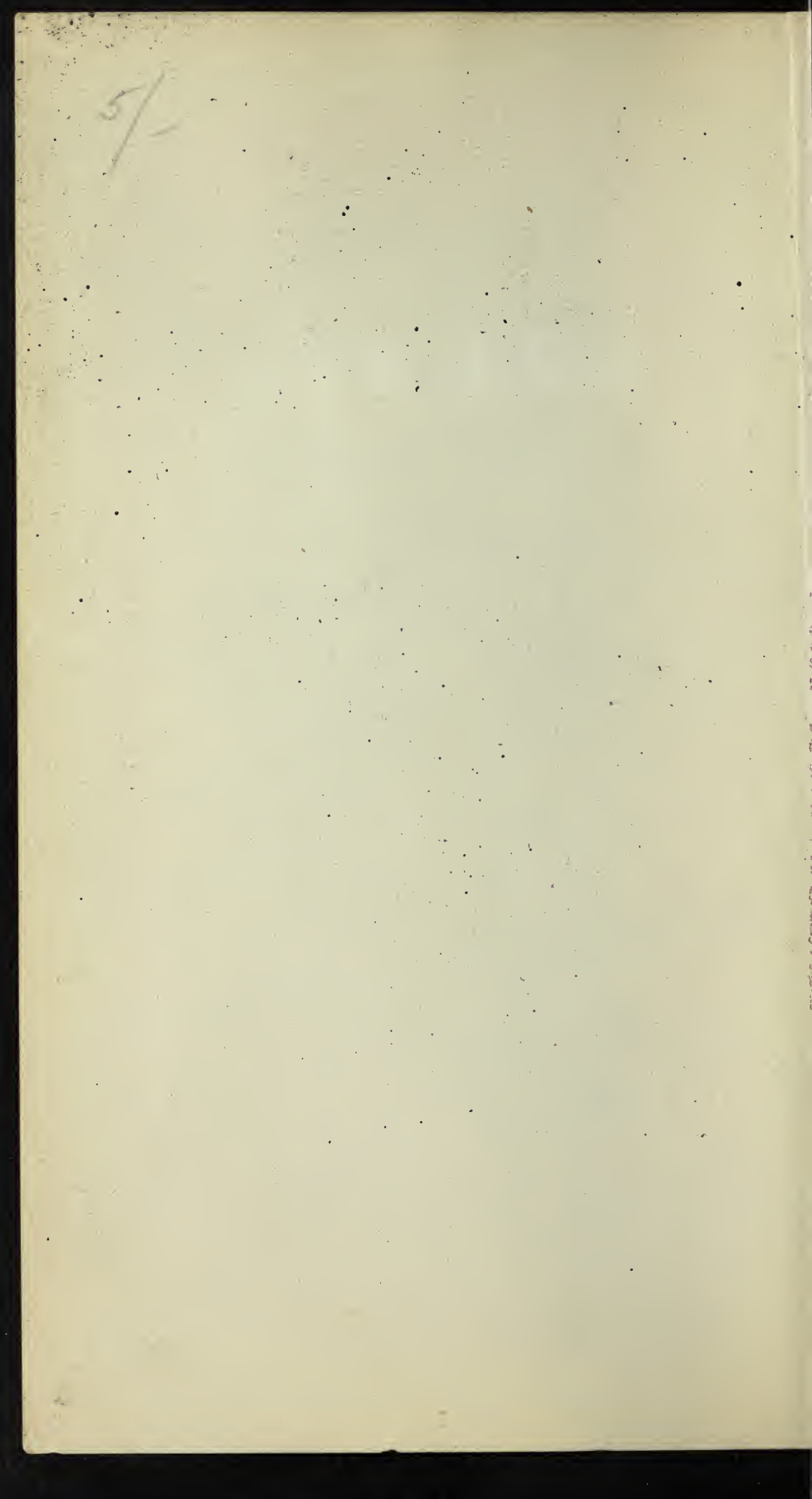


VADE-MEGUM DU NaTURALISTE 
Ce livre a appartenu et a été annoté par M

$$
\text { Le }
$$

SIGNATURE 


\section{VADE-MECUM DU BOTANISTE}

DANS LA

\section{Région Parisienne}

TABLEAUX SYNOPTIQUUES DES FAMILLES, GENRES, ESPĖCES ET VARIÉTÉS

ET

1634 FIGURES

de toutes les Espèces de Plantes croissant

dans la Région Parisienne

PAR

\section{H.-E. JEANPERT}

VICE-PRÉSIDENT DE LA SOCIÉTÉ BOtANIQUE DE FRANCE avec une préface de

M. H. LECOM T E

Professeur au Museum

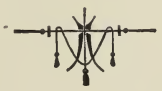

PARIS

LIBRAIRIE DES SGIENGES NATURELLES PAUL KLINCKSIECK

LÉON LHOMME, SuCc ${ }^{r}$

3, rue Corneille, 3 


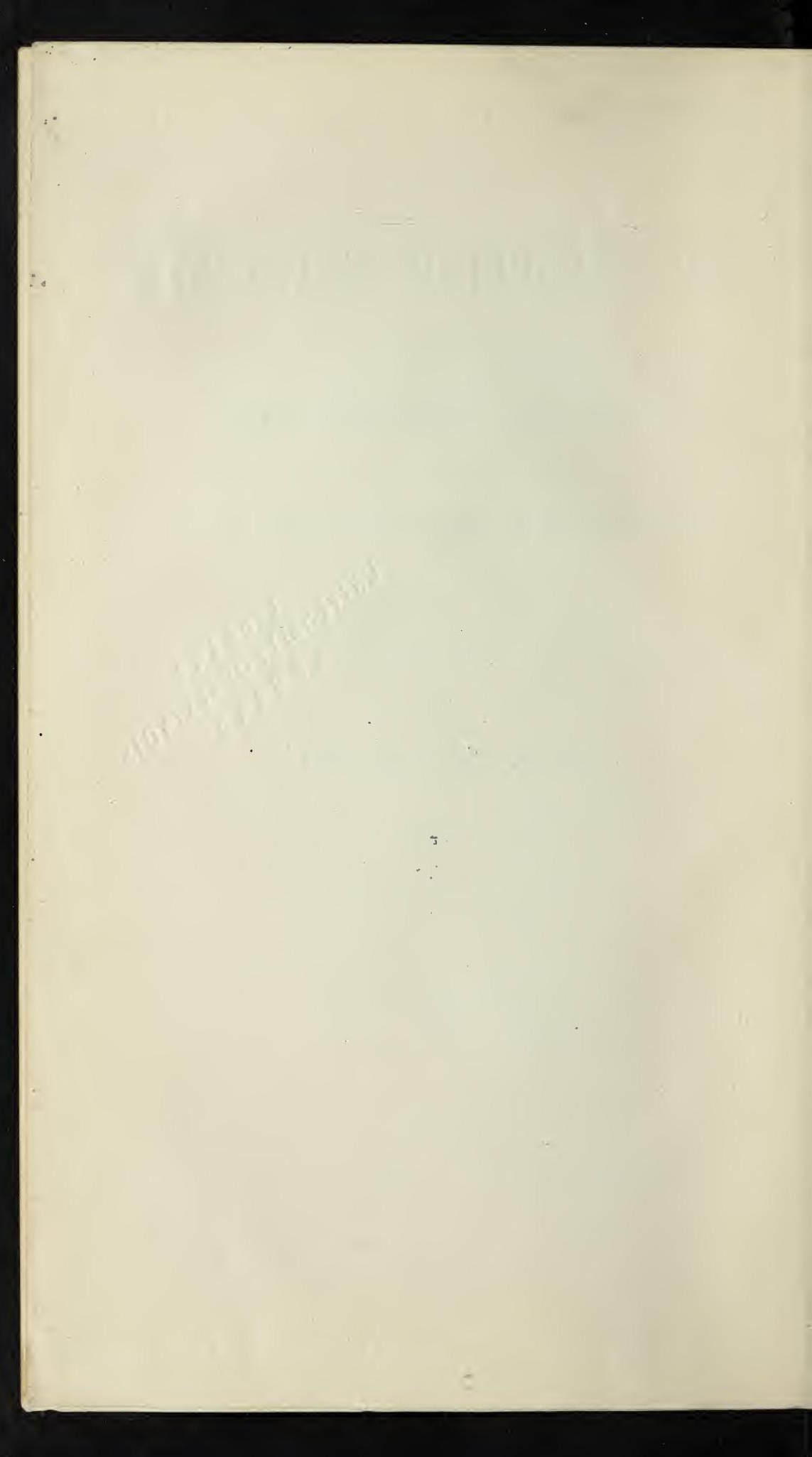




\section{PRÉFACE}

Le Vade-Mecum du Bolaniste dans la région parisienne par mon savant et dévoué collaborateur M. H.-E. Jeanpert comprend, dans sa première partie, des tableaux synoptiques ingénieusement combinés et assez complets pour permettre au chercheur attentif d'arriver avec certitude à une détermination exacte des genres et des espèces. L'auteur a eu soin d'utiliser le plus grand nombre possible de caractères; il en résulte que l'absence d'un organe ne déroute pas le chercheur, comme le fait se produit trop souvent dans l'emploi des clefs dichotomiques ordinaires. Ces tableaux présentent en outre l'avantage de réunir, sous les yeux du lecteur, l'ensemble des caractères qui distinguent les genres d'une famille ou les espèces d'un genre et permettent, par conséquent, de saisir avec beaucoup de netteté les ressemblances ou les dissemblances entre deux unités données; tandis que la méthode dichotomique, au contraire, qui conduit mécaniquement aux genres et aux espèces, ne se prète guère aux comparaisons.

Les tableaux synoṕtiques présentent un autre avantage très appréciable, car ils peuvent remplacer les descriptions spéciales des genres et des espèces qui caractérisent les flores descriptives. Il suffit en effet de comparer les descriptions successives, dans une telle flore, pour se rendre compte des répétitions nombreuses qu'elles comportent et de là possibilité de les éviter. C'est ce dernier résultat qui me parait avoir été atteint par l'auteur du VadeMecum. A certaines espèces ne correspondent pas moins de quatre lignes d'un texte condensé comprenant de nombreux caractères dont M. Jeanpert a pu apprécier la valeur pratique dans ses fréquentes herborisations à la campagne et dans le contact des botanistes herborisants les plus instruits et les plus avisés. 11 résulte nécessairement de cette disposition que si on parcourt successivement, et en remontant, toutes les subdivisions du tableau synoptique des espèces d'un genre, on peut retrouver tous les caractères d'une espèce donnée, de façon à pouvoir reconstituer sa diagnose complète; il en est de même pour les genres d'une famille. En sorte qu'une flore analytique ainsi comprise contient à peu près tous les caractères contenus dans une flore descriptive, avec cet avantage que la plupart des répétitions se trouvent évitées.

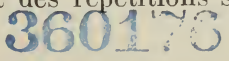


L'éditeur M. Lhomme a mis à la disposition de l'auteur les figures de la Flore descriptive et illustrée de la France par I'abbé Coste. Mais au lieu de se trouver dans le texte et en correspondance avec les espèces qu'elles représentent, ces figures se trouvent toutes reportées dans un appendice qui termine l'ouvrage. Chacune d'elles est accompagnée de l'indication des localités où se rencontrent les plantes rares et il n'est pas inutile de dire en passant que beaucoup de ces localités sont le résultat des observations personnelles de l'auteur. En outre chaque figure est accompagnée de deux numéros dont l'un correspond au numéro de l'espèce dans les tableaux synoptiques du Vade-Iecum et l'autre aux figures de la Flore descriptive et illustrée de l'abbé Coste. ll en résulte que le botaniste herborisant, après avoir utilisé les tableaux synoptiques de son Vade-Mecum, a la possibilité de vérifier immédiatement l'exactitude de sa détermination en consultant la figure de son ouvrage et que, rentré chez lui, il pourra encore compléter cette vérification par la lecture de la description donnée dans la Flore de Coste.

Personne n'était plus qualifié que M. H.-E. Jeanpert pour établir ce Vade-Mecum du Botaniste dans la région parisienne, car personne ne connaît mieux que lui la flore de cette région, personne ne l'a explorée avec plus de persévérance et de sagacité, personne n'a découvert plus d'espèces jusque-là inconnues pour la flore parisienne ou de localités nouvelles d'espèces rares déjà connues. Je suis donc heureux de souhaiter au Vade-Mecum tout le succès qu'il mérite.

Paris, le 10 avril 1911.

H. LECOMTE. 


\section{AVANT-PROPOS}

La journée s'annonce belle; le soleil, dont les premiers rayons obliques dorent seulement les nuages qui moutonnent au zénith, n'a pas encore réchauffé l'atmosphère.

Paris sommeille toujours, et dans cette aube magnifique d'un beau dimanche d'été, seuls sur le boulevard, les arroseurs inondent la chaussée.

Le col relevé, les mains dans les poches, de rares passants frileux dans leur léger vètement d'été se hâtent vers la gare.

Plusieurs d'entre eux portent en bandoulière une longue boîte verte, et bientôt, dans la salle des pas perdus, un premier noyau se forme. Petit à petit arrivent de toutes les rues avoisinantes d'autres voyageurs et d'autres encore, et l'on peut voir chaque nouvel arrivant, semblable à la molécule attirée par la masse, se diriger délibérément dans le hall, vers le groupe de ralliement.

On se retrouve avec plaisir, on s'accueille avec de cordiales poignées de main, on cause, on babille, et telle une compagnie de moineaux franes saluant le soleil levant, tous parlent à la fois.

Ce sont des herboristes, dit un maraîcher qui arrive de la banlieue; ce sont des botanistes, corrige quelqu'un de mieux renseigné.

Eh! oui, ce sont des botanistes! des botanistes qui désirant oublier en commun les soucis des affaires et les mille tracas de la vie, vont se griser d'air pur, et chercher dans la forêt, les uns, des plantes et des mousses, les autres, des champignons. Ce sont des naturalistes qui aiment et admirent la nature et qui, peu à peu, cherchent à lui arracher ses secrets pour la mieux connaitre afin de la mieux aimer.

L'heure du départ approche et sous la conduite du dévoué secrétaire qui détient le billet collectif à tarif réduit, on se dirige vers les compartiments de $3^{\text {e }}$ classe réservés aux membres de la Société.

Les naturalistes sont généralement économes, et comme les bourses les plus modestes sont représentées parmi eux, c'est toujours la moins garnie qui fixera le taux des dépenses.

Le signal est donné, le train part, mais à la dernière minute un . intrus se faufile dans notre compartiment, s'y installe et peu après, intéressé par notre conversation et par notre joiecommunicative, il questionne: 
"Où done allez-vous ainsi? Dans quel but? Pourquoi ces boìtes? " et après quelques réponses, il ajoute : « Et qu'est-ce que tout cela vous rapporte?

Ah! le voilà donc posé ce gros point d'interrogation. Qu'est-ce que cela rapporte au naturaliste de s'occuper d'histoire naturelle? Qu'est-ce que cela rapporte au botaniste de fouiller une forêt dans ses recoins les plus mystérieux et d'y picorer, ȩà et là, quelques brins d'herbe. Eh bien, interlocuteur naïf, la botanique, à l'instar de toutes les autres sciences naturelles, ne rapporte rien du tout au naturaliste, elle lui coûte même de l'argent; mais indirectement, outre les mille satisfactions intimes que tu ne peux estimer et l'orgueilleuse joie d'aider à une science qui s'édifie tous les jours, elle l'oblige à une vie laborieuse et par conséquent économique.

Notre homme hocha la tète, tourna les pouces et finit par s'endormir.

$$
\text { *** }
$$

Il fut done inutile de lui apprendre qu'un naturaliste vraiment digne de ce nom ne sait pas se limiter; son champ d'investigation est tellement vaste, ses moyens d'action tellement faibles, les mille et mille problèmes qu'il envisage tellement intéressants, l'œuvre du Créateur tellement infinie, que le temps lui manquera toujours. Vivrait-il cent ans, deux cents ans, plus longtemps encore que le légendaire patriarche Mathusalem, il ne peut voir tout ce qu'il voudrait voir, étudier tout ce qu'il voudrait étudier ; aussi, pour satisfaire à son impérieuse curiosité, le naturaliste organisera-t-il son existence de telle façon qu'il n'en puisse gaspiller une seule minute.

Après avoir rempli consciencieusement la tâche journalière qui lui assure le pain quotidien, sans perdre une seconde, il se plonge avec délices dans l'étude de sa science préférée.

Elle devient ainsi son délassement, son plaisir, sa passion; elle lui fait oublier et dédaigner les distractions coûteuses des oisifs.

Cette louable passion le tient, l'anime et le domine souverainement. Matinal, patient, exact et observateur, le naturaliste devient de plus, par la force même de ses qualités, un homme d'ordre ayant toujours à classer dans son esprit et dans ses tiroirs ses nombreuses notes et ses matériaux d'études.

Voilà pourquoi il faudrait inculquer, je dirai mème inoculer à la jeunesse des deux sexes, cette passion noble et salutaire qui, comme un sérum, tuerait dans l'esprit de l'enfant les germes des passions mauvaises et ruineuses.

Pour cet heureux résultat, il suffirait qu'on fit suivre aux jeunes gens quelques excursions instructives, où ils trouveraient, en dehors de l'agrément du voyage, l'enseignement de professeurs actifs, bienveillants et gais, dont l'enthousiasme exciterait en eux le feu sacré de la science. 
Ils apprendraient ainsi qu'un naturaliste n'est pas seulement le savant qui passa toute sa vie à déchiffrer de vieux parchemins, mais que l'enfant qui sait regarder avec plaisir voler ou courir un insecte, pousser une plante, s'intéresser à la construction d'un nid, à l'éclosion d'une fleur est aussi un naturaliste, un vrai naturaliste qui, bien dirigé, pourra rendre plus tard de grands services à la science.

Aujourd'hui, la jeunesse se porte de plus en plus vers les sports, mais comme elle est toujours tentée d'exagérer, ce sont les sports violents qui l'attirent le plus; on fait du $80 \mathrm{ou} \mathrm{du} 100$ à l'heure, on se fatigue, on se blesse même dans des parties retentissantes de foot-ball; aux applaudissements de la galerie, on veut enlever le championnat de la journée, et le soir venu, on vient se vanter au cercle, d'avoir fait du 120 à l'heure, et battu un glorieux record. Le triomphateur proclame bien haut ses victoires, sans avouer jamais l'argent et le temps qu'elles lui ont coûté.

Le naturaliste est lui aussi un homme de sport; son sport préféré est la marche, marche en forêt, marche en montagne, avec arrêts fréquents, pour ses recherches. Si pendant l'excursion, il détient le record de lenteur, il sait, à la nuit tombante, fournir une course de vitesse, et gagner allègrement l'étape ou la gare, sous le poids de ses précieuses récoltes.

Loin de moi la pensée de critiquer les autres sports, bicyclette, automobile, voire même plus tard aéroplane (de cette façon on ne me taxera pas de rétrograde); je les préconise même avec ardeur, à la condition toutefois qu'on assouplisse ces nouveaux moyens de locomotion aux besoins de l'histoire naturelle.

Il m'a été donné de faire quelques excursions géologiques et botaniques en voiture automobile, et je ne vous cache pas l'agrément que j'y ai trouvé.

Un auto permet de brûler les localités peu intéressantes, et de s'arrêter longuement dans celles qui offrent quelque profit scientifique sans l'obsédante préoccupation de l'heure des trains.

La machine attend patiemment dans une cour d'auberge ou à l'orée $d u$ bois ; son coffre devient le laboratoire où très souvent la presse à sécher les plantes, voisine avec le marteau du géologue et le filet fauchoir de l'entomologiste, bagages nécessaires et indispensables, d'autant que plusieurs amis se sont recommandés avant le départ, les uns pour des plantes, d'autres pour des minéraux, des fossiles ou des insectes, et qu'il serait vraiment fâcheux de manquer d'outils au moment de faire tant d'heureux.

Enfin, après avoir travaillé jusqu'au crépuscule, la machine vous ramène sans que la récolte, même considérable, ne pèse bien lourd aux épaules des enragés. 
Mais aujourd'hui nous n'avons pas d'automobile et le train qui nous emporte a fait du chemin depuis tout à l'heure; il arrive à Fontainebleau, où nous devons descendre. Sur le quai se trouvent quelques botanistes venus à notre rencontre, et en groupes plus ou moins serrés, on s'achemine vers la forèt.

Le soleil maintenant se montre radieux et réchauffe les plus frileux; les gouttelettes de rosées perlent au bout de chaque brin d'herbe, les oiseaux saluent leurs amis de mille cris joyeux, et dans cette belle forêt, où flotte encore un peu de brouillard, l'odeur de l'humus humide et des résineux embaume l'air.

On se groupe par affinité, et bientòt l'on s'égrène en tirailleurs dans les taillis, en gardant toutefois un même point de direction.

Les boites s'emplissent, les carnets de notes se noircissent; les jeunes, heureux d'une trouvaille, vont la présenter aux maitres de la science, qui prodiguent alors des explications; gràce à leurs fins jarrets et à leurs yeux perçants, ce sont souvent des enfants qui apportent à l'admiration de tous un échantillon inespéré, dont on parlera encore dans de nombreuses années.

Midi approche, on se dirige vers l'auberge, où le déjeuner a été retenu pour certains; d'autres, les plus courageux, ont emporté des provisions, et tous, soit sur l'herbe, soit sous la tonnelle, mangent avec appétit un déjeuner frugal assaisonné de beaucoup de bonne humeur.

Le temps est trop précieux pour qu'on le gaspille à table, aussi repart-on bientôt; la chaleur est plus lourde sous les arbres, les moustiques deviennent plus taquins, mais ces détails n'arrêtent pas la marche du botaniste.

De nature fort endurante, il sait supporter d'une âme égale, le chaud et le froid, la faim et la soif; sous le soleil brûlant ou sous la pluie fine, il marche gaillardement, et au souvenir de quelques excursions pénibles, il trouve agréable sa promenade d'aujourd'hui.

Le temps passe rapidement, et il faut songer à regagner la gare pour l'heure du départ. Le train arrive; on s'installe le plus commodément possible dans des compartiments déjà bien garnis, on cause moins que ce matin, et c'est en réfléchissant aux trouvailles de la journée que l'on traverse la banlieue et que Paris apparaît dans le crépuscule.

Paris rempli de monde, de poussière et de cris, Paris fiévreux et malsain, fait un contraste si grand avec la solitude fraìche et silencieuse de la forèt, que l'on rentre chez soi, satisfait de la bonne journée vécue au grand air, plein de force et de courage pour reprendre la lutte, ravi des découvertes imprévues et des récoltes faites, enchanté de la franche camaraderie qui n'a cessé de régner au cours de l'excursion, en un mot, heureux et fier d'ètre un naturaliste.

L. L. 


\title{
PRINGIPALES ABRÉVIATIONS
}

\author{
Admises dans le Vade-Mecum
}

abond. . abondamment.

accr. . accrescent.

acum. . acuminé.

alt.. . . alterne.

altern. . . alternativement.

alv. . . alvéolé.

ang. . . . anguleux.

ann. . . annuel.

anth.. . . anthère.

apic. . . apiculé.

append.. . appendice.

- . . appendiculé.

aquat. . aquatique.

aran.. . . aranéeux.

arist.. . . aristé.

arq. ... arqué.

artic.. . . articulé.

artific. . . artificiellement.

ascend.. . ascendant.

axill.. . axillaire.

bract. . bractée.

cal.. . calice.

cap. . . capitule.

capill. . capillaire.

caps. . . capsule.

car.. . . carène.

caronc.. . caroncule.

carp. . . carpelle.

caul. . . caulinaire.

ch.. . . champs.

cor. . . corolle.

cot. . . cotylédon.

crén.. . . crénelé.

déh. . . déhiscent.

dens.. . densément.

dentic. . . denticulé.

dess. . . dessiccation.

diff. . . diffus.

dil... dilaté.

disp. . . . disperme.

divar. . . divariqué.

dr. . . . droit.

éch. . . échancré.

émarg. . . émarginé. épill.. . . épillets.

épin.. . épineux.

ét. ... étamine.

étr.. . . étroit.

- . . . étroitement.

faisc.. . . faisceaux.

fasc. . . fascicule.

fem. . . femelle.

fibr. . . fibreux.

filif. . . filiforme.

flor. . . . floral.

_... floraison.

fol.. . . foliole.

follic.. . follicule.

fr. . . . f fruit.

fructif. . . fructification.

- . . fructifère.

gazonn . . gazonnant.

gl. . . . glabre.

glabr. . glabrescent.

gland. . glanduleux.

glom.. . . glomérule.

gr. . . grand.

hér. . . hérissé.

herb.. . . herbacé.

imbriq.. . imbriqué.

imparip. . imparipenné.

incl. . . . incliné.

indéh. . . indéhiscent.

inflor. . . inflorescence.

int.. . . . intérieur.

interm.. . intermédiaire.

interr. . interrompu.

intr. . . . introduit.

invol. . . involucre.

lac.. . . lacinié.

làch. . . lâchement.

lain. . . laineux.

lan... lanières.

lanc. . . lancéolé.

lat.. . . latéral.

lentic. . lenticulaire.

lign. . . ligneux.

lin.. . . linéaire. 
lob. .. lobules.

maréc. . marécages.

mat. . maturité.

- . . maturation.

membr. membraneux.

mon.. . monoïque.

monosp. . monosperme.

mucr. . mucroné.

nat. . . naturalisé.

nerv.. . nervures.

_... nervé.

—.. nervation.

omb. . . ombelle.

орp. . . opposé.

orb. . . orbiculaire.

ov.. . . ovoïde.

_... ovale.

pan. . . panicule.

pédic. . pédicelle.

pédonc.. . pédoncule.

pér. . . pérennant.

pét. . . pétale.

pivot. . pivotant.

pl. . . plante.

plum. . plumeux.

poil. . . poilu.

polysp.. . polysperme.

princ. . principal.

pub. . . pubescent.

purp.. . purpurin.

quadrang. quadrangulaire.

rac. . . racine.

rad. . . radical.

ram. . rameaux.

- .. rameux.

ramp. . rampant.

réfr. . . réfracté.

renf. . . renfermé.

_.. renfermant.

renfl.. . renflé.

_.. renflement.

rét. . . rétu.

rétic.. . réticulé.

rétr. . . rétréci.

rhomb. . rhomboïde.

_ . rhomboïdal.

rudim. . rudimentaire. rug. . . rugueux.

sabl. . . sablonneux.

sarment. sarmenteux.

scar... . scarieux.

segm. . segments.

sép. . . sépales.

sét.. . . sétacé.

sil.. . siliceux.

silic. . . silicule.

siliq. . . silique.

sill. . . sillon.

- . . sillonné.

spath. . spathulé.

spic. . . spiciforme.

spin... spinescent.

stip. . . stipule.

stolon. . stolonifère.

sub. . . subulé.

subfilif.. . subfiliforme.

submerg. submergé.

subobt.. subobtus.

suborb.. suborbiculaire.

subsp. . subspontané.

t. .. tige.

term... terminal.

tétr. . . tétragone.

tom... tomenteux.

tourb. . tourbière.

- . tourbeux.

tr. . . . très.

transvers.. transversal.

- transversalement.

trisann. . trisannuel.

tronq. . . tronqué.

tuberc. . tubercule.

- . tuberculeux.

tubul. . tubuleux.

unilat. . unilatéral.

uniloc. . uniloculaire.

utric.. . utricule.

var. . varie.

_... variété.

vein... veiné.

vel. . . velu.

vert. . verticillé.

visq. . . visqueux.

viv. . . vivace. 


\section{VADE-MEGUM DU BOTANISTE}

\section{DANS LA RÉGION PARISIENNE}

\section{TABLE ANALTTIQUE DES FAMILLES}

+ Fl. complète, ayant cal., cor., ét. et pistil.

X Cor. polypétale composée de pét. libres se détachant séparément.

(POLYPÉTALES

Pét. et ét. insérés sur le récept. ou sur un disque hypogyne, sans aulhérence avec le cal.; ovaire libre ou supère, pét. et ét. insérés sur un disque adhérent au tube calicinal.

\section{THALAMIFLORES}

Pét. et ét. insérés sur le cal.; ovaire tantôt libre et supère, tantôt adhérent au tube du cal. et infère . CALICIFLORES II

X Cor. monopétale ent. ou à div. plus ou moins soudée et ne formant qu'une seule pièce . . . . . MONOPÉTALES III

+ Fl. incomplète, manquant de l'une au moins de ses quatre parties.

= Pl. pourvues d'ét. et de pistil, se reproduisant par des graines; embryon à $1-\ddot{j}$ cot.

Pl. herb. ou lign. munies de nervures ramifiées; pistil composé d'un ovaire recourrant l'ovule, d'un style ou d'un stiginate; périanthe à 4- $\ddot{3}$ divis.; embryon à 2 cotylédons.

MONOCHLAMYDÉES IV

Irbres ou arbriss. résineux, ord. toujours verts, à fl. persist., tr. rar. cad., en forme d'aiguilles ou d'écailles; pistil réduit à l'ovule nu, sans ovaire, ni style, ni stigmale; 2 ou plusieurs cot.

GYMNOSPERMES V

Pí. presque toujours herb., à f. munies de nervures parallèles ou courbes, rar. ramifićes; pistil composé d'un ovaire recouvrant l'ovule, d'un style ou d'un stigmate; périanthe le plus souvent à 6 divis. sur 2 rangs; un seul cot.

MONOCOTYLÉDONES VI

$=$ Pl. sans ét. ni pistil, se reproduisant par des spores; embryon sans cot................................

\section{I. - THALAMIFLORES.}

= Et. nombr. libres; pét. ent. ou échancrés; cal. à ̈̈ divis.; fr. formé de carp. indéh., de follic. s'ouvrant en dedans ou rar. d'une bais:

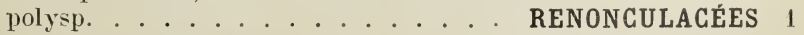

$=$ lit. nombr., soit soudées, soit libres mais fr. caps. déhiscent ou indéh. ou ét. peu nombr.

- Et. peu nombr., soit $\ddot{3}$, mais 2 filets prolongés en appendice, soit 6 diadelphes ou tétradynames ou 8, à filets soudés aux pét. ou ét. nombr., libres, pl. herb.

Inth. bilobées à lobes s'ouvrant par une valvule qui se rétache de la base au sommet; it. 1-6; baie à 1-3 graines ou capsule. 
Anth. souvrant en long ou par un pore terminal.

Pl. aquat. flott. à f. çr. arrondies en cœur à la base; pét. nombr.;

ét. nomb. à filets pétaloïdes; stigmates sessiles, rayonnants;

fr.indéh. à plus. loges, contenant plus. graines; fl. gr., blanches

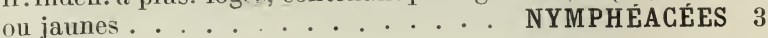

Pl. terrestres.

1. 2 sép.

Fl. régul ; sép. herl. ; ‘ pél.; ét. nombr.; fr. caps. déh. à graines nombr. . . . . . . . PAPAVERACÉES 4

Fl. irrégul.; sép. colorés; 4 pét. connivents, le sup. plus gr., en éperon ou en bosse à la basse; ét. 6 , diadelphes soudées par les filets en 2 fasc. le 3 anth. chacfue, les 2 anth. latér. unilobées, la centr. bilobée; fr. sec déh. ou indéh.

FUMARIAGÉES 引̋

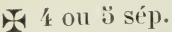

ơ 6 ét. dont 2 pluscourtes (tétradynames), \& sép, 4 pét., fr. sec.

GRUCIFËRES 6

ơt. non tétradynames.

○ Pét. égaux; él. nombr.; sép. 3-̈̈; caps. à 2-3 loges incompl., à plus. graines, à ə2-3 valves; stigmate trilobé.

CISTINÉES 7

○ Pét. inégaux.

† Fl. éperonnée; cal. à :i sép. inégaux prolongés à la base en append.; pét. inf. plus gr. prolongé en éperon; 5 ét. à filets courts et élargis, les 2 filets antérieurs prolongés en appendice nectarifère qui se loge dans l'éperon; caps. à 1 loge, à 3 valves à plus. graines; 1 . stip.

\section{VIOLARIÉES 8}

む Fl. non éperonnée.

Fr. formé de 3-6 carp. soudés en caps. à 1 loge ou libres et étalés en éloile; 10-25 ét. ; 3-6 styles; 4-6 pét. inégaux, laciniés; 4-6 sép. inégaux; fl. blanches ou jaunâtres . . . . . . . . . RÉSEDACÉES 9

Fr. caps. comprimé-émarginé à 2 loges monosp.; 8 ét. à filets soudés avec les pét. à anth. unilobées et s'ouvrant par un pore term., rémnies 4 à 4 en 2 faisceaux; 1 style à stigmate bifide; 3 pét. inégaux, l'inf. plus gr., courbé en carène, lacinié-frangé; 5 sép. très inégaux, les 2 int. gr., pétaloïles, en forme d'ailes; fl. blenes, roses ou blanches. ........... POLYGALÉES 10

Et. peu nombr. à filets non prolongés à la base, ni diadelphes, ni tétradynames, ni à filets soudés aux pét. ou ét. nombr. réunies en faisc., rar. libres; dans ce cas, arbre et pédonc. soudé avec une bractée membr.

+ Pl. herb. à fleurs régul., rar. arbre à ét. nombr.; fr. caps. à 1 loge, ou à $\ddot{b}-10$ loges monospermes ou à $3-1$ loges polyspermes ou carp.

X Et. libres, fr. caps. ou baie ou fr. indéhiscent, arbre.

I Fr. capss. déhiscent ou haie.

- Caps. à une loge, rar. baie indéh. à 3 loges.

F. toutes rad., cil.-gland. à limbe rétréci en pétiole ou i. non cil. mais 1 caul. ; caps. à $3-\not 3$ valves; fl. blanches solit. ou en grappes, ÿ ét. . . . DROSÉRACÉES 11

F. caul. opp. ou vert.; caps. s'ourrant par 2-10 dents ou valves ou haie indéhiscente; 3 -10 ét., rarement 2-4.

CARYOPHYLLEES 12

- Caps. à 3-10 loges. 
Caps. à 3-1 loges polyspermes; f. opp. ou vert., stip.; cal. à 2-́ sép.; 3,6 ou 8 ét. libres, 3 -4 stýles; graines cyl. à côtes longit. et à stries transversales.

ELATINEES 13

Caps. à วั-10 loges monosp.; feuilles alt. ou opp., sans stip.; cal. à 3 , rar. 4 sép.; :j ét., rar. 4 souclées en anneau à la base; כ̆, rar. 4 styles; graines ovalescomprimées, lisses ........ LINÉES 14

Fr. caps. inıléh., glob., coriace à 1 loge et à 1-2 graines;

fl. blanchâtres ou jaunâtres en corymbes axillaires portés sur un pédonc. commun soudé dans une partie de sa longueur aves une long. bract. membr.; ét. nombr. filets libres; f. alt., pétiolées, dentées, à stip. cad. ; arbre.

TILIAGÉES 13

X Et. soudées en faisc. ou en tube ou libres, mais fr. formé de 5 carp. vert.

Et. monadelphes soudées en tube; cal. ord. double; l'ext. ou calicule à 3-12 divisions libres ou soudées à la base, l'int. monosép. et à $\check{l}$ lobes; fr. sec formé de carp. monosp. : i. alt. lobées ou découpées; anth. réniformes, unilobées, s'ourrant par une fente semi-circulaire.

MALVAGÉES 16

Et. réunies en faisc. ou libres.

10 ét. libres, dont :3 quelquefois réduites aux filets ; f. palmatinervées, stip.; $\breve{s t y l e s ~ s o u d e ́ s ~ a v e c ~ l e ~ p r o l o n g e-~}$ ment de l'axe, à $\mathbf{j}$ stigmates filiformes; $\mathbf{f} \mathrm{r}^{2}$. composé de 5 carp. monosp. terminés par 1 long bec, vert. antour d'un axe central . . . . . . GÉRANIACÉES 17

Étamines nombreuses, réunies à la base en 3-3̈ faisceaux; feuilles entières opposées, sans stipules; $3-ð$ styles à stigmates renflés; fruit capsulaire plus ou moins déhiscent à 1-ï loges ou baie indéhiscente.

HYPÉRICINÉES 18

+ Pl. lign. à fleur régulière ou pl. herb. à 8-10 ét., caps. à :3 loges, poly̨sl., rar. pl. décolorée, sans f., ou pl. à fl. irrégul.

\| Fr. sec formí de 2 samares long. ailées, monosp., indéh., se séparant à la maturité: fl. régul., polygames ou dioïques; 8 ét.; f. opp., pétiolées, palmatilobées ou pennées, saus stip.; arbre . . . . ACÉRINÉES 19

I| Fr. caps., baie ou samare unique.

o Pl. sarmenteuse munie de vrilles rameuses, opp. aux f. palmatilobées ou palmatiséquées, munies de stip.; ร̆ pét.,

¿ ét., haie à 1 loge à 5 graines . . AMPÉLIDÉES 20

† Pl. dépourvue de vrilles.

o+ Fleurs irrigul.

Arbre; f. digitées à 7-9 fol.; caps. très grosse, glob., épin., à 3 valves à $1-2$ graines trìs grosses; fl. blanches ou roses à pét. pubescents; cal. monosépale à 5 dents non prolongées en éperon; 7 it. HIPPOCASTANÉES 21

Pl. herb.; f. simples; caps. oblongue à 5 loges polysp., à ¿̈ valves s'ouvrant avec élasticití et s'enroulant en ledans de la base au sommet; fl. jaunes ou rouges, glabres; cal. pétaloïde à 53 sép., le postérieur très gr. prolongé en íperon; ¿̈ ét. à anth. soudées.

Ot Fleurs régul. 
to F. à 3 fol. en cour renversé; כ̉ pét.; 10 ét.; J styles et stigmates; caps. à bै loges polysp. à ว̆ valves; graines entourées d'un arille...... OXALIDÉES 23

to F. simples ou pennées ou pas de $\mathrm{f}$.

‡ Caps. arrondie à $4-\not ̈$ lobes, ou baie ou samare.

* Caps. à 4-ä lobes.

F. 1 ou 2 fois pennatiséquées alt.; 4 pét.; 8 ét.; fl. jaunes; caps. subglob. à $4-5$ lobes arrondis.

RUTACÉES 24

F. oblongues, dentées, opp.; 4 pét. ; 4 ét.; fl. blanc verdàtre; caps. rougeà tre à 4 lobes arrondis ; grain€s blanches à arille rouge; arbuste.

CÉLASTRINÉES $2:$

\# Baie ou samare, arbre ou arbuste.

$\div$ Baie; 4-3 ét.

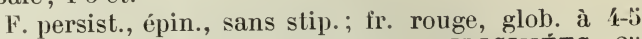
noyaux triang.; fl. blanches. . ILICINÉES 23

F. non persist., non épin., munies de stip.; fr. noir glob. ou ovale à 2-4 noyaux osseux; fl. verdâtres.

RHAMNÉES 27

† Samare; 2 ou 10 ét., f. pennatiséquées.

Cal. et cor. à b̆ divis.; 10 ét.; f. alt. imparip. à 1133 fol. tronquées ou en coeur à la base, dentées à dents gland. en dessous; samare tordue.

SIMARUBACÉES 28

Cal. et cor. à 4 divis. ; 2 ét.; f. opp. imparip. à 7-13 fol. ovales-lanc., dentées en scie; samare non tordue. . . . . . . FRAXINÉES 29

† Caps. déh. à 4-3̉ loges polysp.; stigmate à 4-6 lobes; fl. en grappes.

Caps. à 5 loges polysp. ¿ 10 él.; fl. blanches; f. persist., rad., ovales ou suborb.; pl. verte . PIROLÉES 30 Caps. à 4-3 loges polysp.; 8-10 ét.; fl. d'un blanc jaunàtre; pl. décolorée d'un blanc jaunâtre, sans f., à nombr. écailles dressées .. MONOTROPÉES 31

\section{II. - CALICIFLORES.}

I Fr. formant une gousse ou légume; cor. papilionacée; très rar. cor. à 3-5̆ pét., fl. polygames, 3-10 ét. libres. . PAPILIONACÉES 32 F Fr. n'étant jamais une gousse; cor. non papilionacée.

X Et. nombr., rar. 1-5̆, insérées avec les pét. à la gorge du cal.

F. éparses munies de stip.; ovaire supère ou infère, à 1 ou plus. carp.; fr. sec ou charnu, non caps. polysp. . . ROSACÉES 33

F. opp. sans stip.; fr. caps., soudé avec le tube du cal., caps., déh., très polysp. à 3-10 loges . . . . PHILADELPHÉES 34

$X$ Et. peu nombr. 2 à 12 ou ét. et pét. nombr., mais pl. charnues succulentes.

= Fl. axillaires, en grappe ou en panicule, rar. en corymbe, mais pl. herb. non parasite.

+ F. ov. lanc. ou lin. ou pl. munies de vrilles à f. dentées ou lobées.

* Pl. sans vrilles, ovaire infère, caps. à 4 loges polysp. ou à 1-2

loges monosp............ ONAGRARIÉES 33

o Pl. munies de vrilles, ovaire inf., ou sans vrilles ovaire sup.

- Fr. caps. ou baie.

F. sans stip. ni connées à la base.

Cal. monosép). 
Cal. à 8-12 dents disposées sur 2 rangs; $3-12$ ét:; caps. à 2 loges polysp.; f. oblongues-lanc. ou obovales; fl. roses ou blane rosé; pas de vrilles. . . LYTHRARIÉES 40

Cal. a ỏ lobes; $\vdots$ ét.; fr. charnu à plus. graines; f. palmatinervées, dentées ou lobées; pl. munie de vrilles; fl. blanches, blanc verdàtre ou jaunes. . CUCURBITACÉES 4

Cal. polys. à 2-3 sép.; f. opp. ou alt. oblongues; caps. à 1 loge s'ouvrant circulairement (pyxide) PORTULACÉES 42

F. munies de stip. ou non, alors opp. à base connée scarieuse; caps. indéh. ou déh. à 1 graine PARONYCHIÉES 43

- Fr. composé de plusieurs follic. s'ouvrant en dedans; pl. charnues; ét. $3-40$; pét. 3-20.

CRASSULAGEES 44

+ F. palmatilobées ou arrondies ou incisées crénelées, alt.; pl. sans vrilles.

Fr. bacciforme, uniloculaire, polysp., ovaire adlıérent; ¿ ét.;

fl. verdàtres ou rougeàtres; arbustes. GROSSULARIÉES 400

Fr. biloculaire, à loges polysp., à 2 valves; 10 ét. ; fl. blanches ;

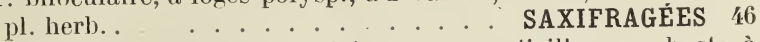

= Fl. en ombelle, rar. en tètes épin. ou en verticille ou arbuste à

f. opp., fl. en corymbe ou en cyme, mais parasite.

2 styles, fr. sec, formí de 2 méricarpes munis de còtes.

OMBELLIFĖRES 47

1 style ou stigmate, fr. bacciforme.

Fl. hermaphrodites en ombelle ou en corymbes, pl. non parasite.

ARALIAGÉES 48

Fl. diö̈ques en pelites tètes sessiles; sous arbrissean parasite à tiges articulées dichotomes. . . . LORANTHACÉES 49

\section{III. - MONOPÉTALES}

+ Ovaire infère, caps. à 2-’̉ loges, fr. sec, monosp. ou disp. ou baie.

$X$ Fl. non agglomérées en cap., f. opp. ou verticillées.

= Et. 3-ö.

Fr. bacciforme à 1-3̈ loges; f. opp. 4-¿̉ ét. CAPRIFOLIACÉES 49

Fr. sec, didyme, formé de 2 carp. monosp.; f. vert.; ét. $3-\partial ̈$.

RUBIACÉES 50

= Et. 1-3; fr. sec, indéh. à 1 ou 3 loges, à 1 seule graine, couronné par les dents du cal. on par 1 aigrette. VALÉRIANÉES う̋

Fl. en cap. sur un récept. commun ou non réunies en cap., mais f. alt.

Q Fr. secs uniloculaires monosp., rar. disp.

- Et. ' , insérées sur le tube de la cor., à anth. libres; fr. monosp.; fl. en tètes entourées d'un invol., toutes sessiles sur un récept. commun garni de paillettes ou de soies; cal. double et persist., l'extérieur, calicule ou involucelle à tube entourant étroitement le fr., marqué de fossettes et de côtes à limbe scarieıx entier ou denté, l'intérieur soudé au fr., en coupe dentée ou divisé en arètes. . . . . . . . DIPSACÉES 52

- Et. 4-כ̈.

Et. insérées sur le tube de la cor., à anth. biloculaires soudées en tube traversé par le style filiforme et bifide; fr. monosp., non renfermé dans un péricarpe ligneux; fl. hermaphrodites, unisexuées ou neutres, sessiles et róunies en cap. sur un récept. commun; cap. entourés d'un invol. composé de fol. souvent sur plusieurs rangs; réceptacle nu ou

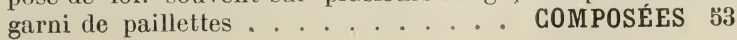


Et. à anth. libres; fr. sec, coriace, épin., indéh. term. par 2 bees libres ou soudés contenant 2 graines nues; fl. monoïques, les màles en tètes glob., sessiles sur un récept. commun et entourées d'un invol. sur 1 rang; les feuilles 1 ou 2 renfermées dans un involucre clos, lign. à la maturitẻ, hér. d'épin.

AMBROSIACEES 5'k

Q Fr. caps. ou haies.

Fr. caps.

Fl. irrégul., en grappes spiciformes; cor. plus ou moins bilabiée; caps. à 2-3 loges, à plus. graines, s'ourrant au sommet par 2-3 valves .... . LOBÉLIACÉES $5: 3$

Fl. régul., en tètes, épis, grappes, panicules, corymbes ou solit.; caps. à 2-3 loges polysp., s'ouvrant par des trous ou des valves. . . . . . CAMPANULACÉES $\$ 6$

\% Fr. bacciformes.

Fr. à 1-3̈ loges polysp., 8-10 ét. libres à anth. bilobées s'ouvrant par 2 trous au sommet, style simple à stigmate en tète; ґ. simples alt........ VACGINIÉES $\$ 7$

Fr. à 3-; loges polysp., rar. disp., ;j ét. triadelphes, à anth. unilobées, à lobe sinueux, s'ouvrant en long.; style simple; 3-3 stigmates; f. palmatipartites ou palmatilobées, munies de vrilles; fl. dioïques ou monoïques.

CUCURBITACÉES (part.)

+ Ovaire supère, tr. rar. infère, mais caps. uniloc.

$\times$ Fl. non agglom. en cap., pas d’invol. commun, ni plus de 8 ét. à filets libres, ni caps. à 3 valves ou baie à noyaux.

= Caps. à 4 logres polysp., à déhiscence loculicide ou septifrage; f. simples, petites, opp. ou vert., persist.; 8 ét.; anth. à 2 loges s'ouvrant au sommet par 2 trous el souvent munies de 2 cornes.

ERICINÉES 58

= Caps. à 1 ou 2 loges, rar. 2-4́, déh., ou caps. indéh., ou follic., ou carp. ou baie à 2 loges.

a Caps. uniloc.; fl. irrégul. éperonnées ou régul.

FI. irrégul. éperonnées; cor. personée ou bilabiée à lèvre inf. prolongée en éperon; 2 ét. à anth. uniloc.; style très court; stigmate à 2 lèvres, la sup. très courte; caps. à 2 valves ou s'ouvrant en travers. . . . . LENTIBULARIÉES $\$ 9$

Fleurs ordinairement régulières, non éperonnées; 4-7 étamines à anthères bilobées; style à stigmate simple; capsule s'ouvrant en long à $\ddot{3}$ valves ou seulement au sommet en $2-\ddot{z}$ valves, quelquefois en travers; oraire rarement infère.

PRIMULACÉES 60

@ Caps. biloc., ou baie, ou follic., ou carp., rar: uniloc. mais fl. irrégul. sans éperon.

- Et. 2; capsule biloc. à 2 valves, à $2-4$ graines ailées ou baie à 2 loges à $2-4$ graines. . . . . OLÉACÉES 61

- Et. 4-j, très rar. 2 , mais avec fr. formé de carpelles.

Fr. formé de 1-2 follic.; כ̋ ét.

1 style renflé au sommet; graines sans aigrette.

APOCYNEEES 62

2 styles réunis sous un large sligmate à 6 angles; graines surmontées d'une aigrette soyeuse . . . ASGLÉPIADÉES 63

Fr. caps., baie ou carp.

م Caps. indéh. polysp., ou baie, ou caps. déhisc. en long, rar. en travers au-dessus de la base (pl. sans f.) ou au sommet.

† Fl. régul.

$\odot$ F. opp. ou pl. aquat. à f. suborb. ou à 3 fol.; caps. à 1-2 loges, à 2 valves déhisc. ou presque indéh. GENTIANÉES 64 
$\odot$ F. all

Caps. glob. indéh. à 2-4 graines, cor. en cloche, pl. volubiles ou $\mathrm{pl}$. parasites sans f., à tiges filiformes, à caps. glob. à 2-1 graines s'ouvrart irrégul. au sommet ou circul. en travers vers la base. . CONVOLVULACÉES $6: 3$

琎 Fr. formé de 4 carp., ou baie, ou capsule à 2 valves ou s'ouvrant en travers au sommet.

Carp. 4, uniloc., monosp.; pl. rutles; fl. souvent en grappes scorpioides. . . . . . BORRAGINÉES 66

Baie indéh. à 2 loges, ou capsule à 2 loges, à 2-4 valves ou s'ouviant au sommet par un comvercle. SOLANEES 67

ઇ Fl. irrégul., sans éperon, ét. 4, didynames, rar. 2.

O Fr. caps.

Pl. verte à f. alt. ou opp. ; caps. à 2 loges s'ouvrant par 2 ou plusieurs valves ou par 1-3 trous vers le sommet.

SCROFUIARINÉES 68

P. jamais verles, colorées, charnues, munies d'écailles; fr. à 1 loge, à 2 valves souvrant de haut en bas ou seulement vers le milieu; 4 ét. didynames. . OROBANGHÉES 69

ㅇ Fr. formé de carp.; f. opp.; 4 él. didynames, rar. 2.

Fr. formé de 4 carp. libres simulant 4 graines nues au fond du cal.; style naissant de la base des carp. LABIÉES 70

Fr. formé de 4 carp. d'abord soudés en caps. ovoïde; style naissant du sommet des carp. . . VERBÉNACÉES 71

Caps. indèh. monosp. ou caps. déh. à 2-4 loges, à 2 ou plusieurs graines s'ouvrant circul. en travers au-dessus de la base; pl. munie de f.; cal. et cor. à divis.; '́tét. PLANTAGINÉES 72

Fl. agglomérées en capitules ou en tètes, ou non agglomérées, mais à capsule à 3 valves ou 7 carpelles polyspermes, ou baie à noyaux ou étamines à filets soudés en tube.

Fl. agglom. en cap. ou en têtes sur un récept. commun muni de paillettes.

Fl. régul.; cor. à כ̋ pét. à limbe scarieux plissé,à 弓̆ nervures et à 5 lobes; cal. en entonnoir, à tube muni de $3-10$ còtes poilues;

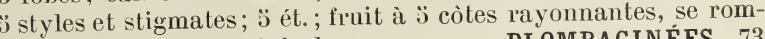
pant irrégulièrement à la base. ... PLOMBAGINEES 73

Fleurs irrég. à 2 lèvres, la sup. courte et bifide, l'inf. profondément tripartite; cal. tubuleux à $̈$ div. inégales, fermé à la gorge par des poils; 1 style filiforme à stigmate bilobé; 4 ét. didynames; fr. indéh......... GLOBULARIEES 74

葸 Fl. non réunies en cap.

Et. en nombre indéfini à filets soudés en colonne; fr. composé de carp. monosp. . . . . . . . . . . MALVACÉES 16

Et. 3-15, libres.

Baie rouge à 2-6 noyaux, 4-6 ét.; arbuste ou arbre à $\mathrm{f}$. persist. dentées épin. ...... ILICINEES 26

I Caps. ou carp. polysp., herb.

Caps. à 3 valves et à 3 graines; 3 -̈̈ ét.; f. opp. oblongues.

PORTULACEES 42

3̈ carp. polysp.; 10 ét. ; f. alt. peltées-ombiliques.

GRASSULACÉES

\section{IV. - MONOCHLAMYDÉES}

+ Fr. monosp. uniloc. non réunis en tète, rar. à tube soudé avec l'ovaire, mais dans ce cas plantes sans stip. à f. alt. ou fr. à 2-3 coques ou samare arrondie ou fr. à l'intérieur d'un récept. charnu, ou caps. à 6 loges polysp. ou bien arbre et arbuste à fl., au moins les mâles en chatons. 
X Fr. monosp. uniloc.; f. sans stip. ou ì stip. engainantes.

$=$ Pl. herb. ou arbriss. sans épines.

Q Pl. herb. ou $\mathrm{pl}$. lign. non parasite ni à rameaux dichotomes.

- Ovaire libre ou supère.

ä 2-4 styles ou stigmates; périanthe à divis. libres on soudées à la base.

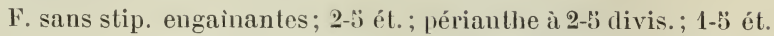

SALSOLACEES $\because \because$

F. munies de stip. engainantes membr.: périanthe à 4 - $\mathbf{0}$ divis.; 丂-8 ét. . . . . . . . . . . POLYGONEES 76

o: 1 style court à sligmate en tète; périan the lubuleux à flobes; fr. sec ou charnu; 8 ét.; plantes lign. rar. herb. DAPHNOIDEES 77

- Ovaire infère; périanthe à tube soudé avec l'ovaire à 4-’̉ divis.; 4-¿̈ ét.; fl. petites, blanclı̂tres, en grappes, à 3 bract., la médiane plus longue. . . . . . . . . . . SANTALAGËES 78

Q Pl. lign. parasite à rameaux dichotomes articulés, à f. opp. ; ovaire adhérent; fl. lioïques, les miles à $3-4$ divis. portant 1 anth. sessile au milien de chaque divis., les femelles à tube soudé avec l'ovaire, ì 2-4 divis.; stigmate sessile; fr. bacciforme, mucilagrineux à 1 seule graine . . . . . LORANTHACÉES 79

= Arbriss. épin. à fl. diö̈ques, les màles en épis ou chatons courts; périanthe à 2 divis.; fr. (lrupacé subglob., jaune-orangé, indéh.;

f. sans stip., argentées et parsemées d'écailles rousses en dessous.

ËLÉAGNÉES 80

X Fr. monosp. uniloc., ou fr. à 2-3 coques, ou samare arrondie ou fr. à

l’intérieur d’un récept. charnı, on caps. à 6 loges polysp.

O Fl, non en chatons.

む. Fr. caps. polysp.

Fr. coriace s'ourrant irrécul. ou par 6 valves; fl. hermaphrodites; style court, en colonne, à 6 sligmates rayonnants; ovaire adhérent ou semi adhérent; f. alt. ou opp. larg. en cueur à la base.

ARISTOLOCHIEES 81

Fr. caps. à 2-3 coques ou à 3 valves contenant chacune 1-2 graines, s'ourant orlinairement avec élasticité, suivant la nervure dorsale, en se sćparant d'un axe central; fl. monoïques ou diö̈ques.

EUPHORBIAGEES 82

む Fr. monosp., ou samares, ou fr. à l'intérieur d'un réceplacle charnu. - Fr. sec; 1. stipulées.

Fr. uniloc., monosp., renfermé dans le périanthe; diö̈ques, monoüques ou polygames. ........... . URTIGEES 83

Fr., samare, aplani, échancré an sommel, entouré d'une aile large, foliacée, veiı., uniloc., monosp., indéh.; fl. hermaphrodiles paraissant arant les f. alt., à bases inégales dentées, penninervées. . . . . . . . . . ULMACEES 84

- Fr. drupacés très pelits renfermés dans le récept. accrescent; f. palmatilobées à 3-7 lobes; fl. monoïques réunies dans l’intérieur d'un récept. en poire, à peine ouvert au sommet.

ARTOCARPEES 83

o Fl., au moins les mâles, en chatons.

Fi. màles en chatons.

q Fl. femelles nombr. en tètes glob. ou cyl.; arbre, quelquefois arbuste, à 1. ovales, ent. ou lobées, denlées. . MORÉES 86

q Fl. femelles peu nombr.

F. imparip. à ว้-9 fol., sans slip.; fl. mâles en chatons allongés, cyl., pend.; fl. fem. 1-4 dans un petit bourgeon à 4 écailles cad.; fr. drupacé, arrondi, formé d'un brou charnu et d'une noix à 2 valves ligneuses ridíes, renfermant une amande à 4 lobes sinués-lobulís. . . . . . JUGLANDÉES 87 
F. simples, dentées ou sinuées-lobées, stip.; fl. miles en chatons cyl. ou globuleux; fl. femelles $1-i j$ dans $11 n$ bourgeon ou invol., ou en chatons; fr. 1-3 dans un invol. accrescent, épin., coriace ou foliacé. . . . . . . . CUPULIFĖRES 88

Toutes les fl. en chatons.

Fl. dioïques; périanthe réduit à 1-2 glandes ou à 1 cupule; chatons cyl. ou ovoïdes; 2-20 ét.; 1. stip.; fr. caps. petit ovoüde ou conique, uniloc., s'ouvrant du sommet à la base en 2 valves qui se roulent en dehors; graines munies à la base de longs

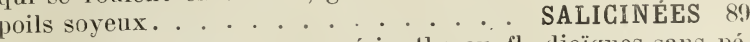

Fl. monoïques avec ou sans périantlıe ou fl. dioïques sans périanthe.

Fl. monoïques avec ou sans périanthe.

Chatons glob. naissant avec les $\mathrm{f}$.; périanthe remplacé par des écailles lin. spathulées; ét. en nombre indéfini; style simple, en alène; fr. secs en petiles massues entouries de poils à la båse, uniloc.; f. palmatilobées . . . PLATANEES 90 Chatons cyl. ou ovoides, naissant avant les f.; périanthe mâle, 1 écaille ou $3-4$ divisions, le femelle nul; 4 it. ; 2 styles filiformes; fr. sec, uniloc., monosp., indéh., souvent ailé; f. simples, dentées ou crénelées.

BETULINEES 91

L Fl. dioïques; pas de périanthe; arbriss. résineux à f. oblongues elliptiques, uninervíes; 46 ét.; 2 styles courls, stigmatifères ; fr. un peu drupacé, ovoüde-comprimé, poncluć-résineux, uniloc., monosp., indéh; fl. dispos. en chatons cyl. ou ovoïdes.

MYRIGINÉES 92

+ Fr. monosp. uniloc. réunis en tête ou fr. non réunis en tète, mais enfoncés dans le tube du calice avec des f. opp. ou slip. ou 2-3 carp. dans le tube du cal. ou follic., ou caps. à 2, 4- $\ddot{j}$ valves, à 2-4 loges polyps. ou 4 coques ou plantes aquat. à í. pectinées ou vert. ou arbre à samares allongées.

Fr. monosp., réunis en tìle, on follic., on caps. à 4 -ï valves ou arbres à samares.

- Fr. monosp. réunis en tète ou follic.; fl. dépourvues de cor. à cal. pélaloïde. . . . . . . . . RENONGULAGEES 1

- Caps., baie ou samares.

Caps. à 4-ż valves; f. opp., ent. . . . CARYOPHYLLÉES 12

Samare double; f. орр., pétiolées, pennées; arlore.

AliLRINÉES 1!

Baie; 1. ovales, denticulées; arbuste. . RHAMNLES 27

Samare simple atténuée anx 2 bouts; fl. paraissant avant les $f$. opp.; arbre élevé. . . . . . . . . FRAXINEES 29

| Fr. monosp., rar. disp. non réunis en tète ou fr. à 1-2, 4 loges ou 24 coques.

X Fr. sec, 1-3 carp. dans le lube du cal.; ovaire infère; f. stip.

X Fr. sec, 1 carp. dans le tube du cal., 1 . non stip. ou fr. $n u$ ou caps. ou ovaire supère.

= Fr. tétragone à 4 loges, ovaire infère.

Caps. obovale à 4 loges polyspermes, 4 divis. au périanthe ; f. opp., ovales, ent.; style caduc, stiginate en tìle.

ONAGRARIEES 33

Fr. à 4 loges formé de 4 carp. monosp.; f. vert., vennaliséquéespectinées à lanières capillaires; 4 stigmales subsessiles; 8 ét.; fl. en vert. ou épis term., les màles au sommet.

HALORAGÉES 36

= Fr. monosp. ou caps. à 1 ou 2 loges ou fr. à 2-1 coques à ovairc supère. 
F. opp., 1 ét., ou f. vert.; 1 ét. ou 12-20 ét.; pl. aquat.

II F. vert. par 8-12, ent.; 1 ét. insérée au sommet du tube calicinal ; ovaire infère; 1 style en alène . HIPPURIDÉES 37

II F. opp. ou f. vert. à lanières bifides et denticulées; ovaire sıpère.

F. opp, tronquées au sommet élargi, connées à la base; caps. à 4 coques carénées, monosp. ; 1 ét. à anth. réniforme; cal. et cor. réduits à 2 bract. manquant souvent; fl. monö̈ques ou polygames; 2 styles. . . . . . CALITRICHINÉES 38

F. vert.; fr. sec, ovoüde terminé en ćpine, à 1 loge et 1 graine ; 12-20 ét. à anth. sessiles tricuspidées au sommet; cal. et cor. remplacés par 1 invol. herb. à 10-12 divis.; fl. monoïques; 1 style en alène courbe . . . . CÉRATOPHYLLÉES 39

彁 F. opp., 2-l0 ét. ou f. alt. ; pl. terr., rar. aquat.

- Ovaire libre ou supère ; ํ-6 ét.

Caps. glob. ; cal. évasé à 12 dents ; 6 ét. ; style très court.

LYTHRARIÉES 40

Fr. monosp. indéh.; f. à stip. scarienses ; $2-3$ ét.; 2 stigmates subsessiles. . . . . PARONYGHIEES (part) 43

- Ovaire infère ou adhérent.

o $\mathrm{F}$. opp., ronnées à la base, sans stip.; fr. monosp., indéh., renfermć dans le tube du cal.; 10 ét.; 2 styles.

PARONYCHIÉES (part) 43

\% F. alt.

Caps. à 1 loge, à 2 valves polysp.; fl. en cyme corymbiforme ; 8-10 ét.; 2 styles; pl. gazonnantes, succulentes, hér. de poils blanes....... . . SAXIFRAGÉES 46

Fr. sec, 1-2 graines, term. par 2 becs; fl. monoïques, les màles en tètes glob., les femelles, 1 ou 2 renfermées dans un

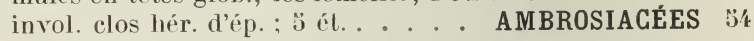

\section{V. - GYMNOSPERMES}

Fl. monoïques ou diö̈ques, en chaton, sans périanthe, réduites aux anth. et aux ovules; chatons màles formés d'écailles portant chacune deux ou plus. anth. subsessiles, à loge unique s'ouvrant en dedans; chatons femelles formés d'écailles portant chacune à leur base un ou plusieurs ovules; cenx-ci nus, sans style, ni stigmate; fr. tantôt simple et en forme de baie indéh., tantôt composé et en cône ligneux et déh.; fll. jaunâtres ou vertes; f. éparses, opp. ou fasc., en forme d'aiguilles ou d'écailles, ent. glabres, presque toujours persist.

CONIFËRES 93

\section{VI. - MONOCOTYLEDONES}

- Périanthe à 6 divis., rar. 4 ou 8 sur 2 rangs toutes ou les intérieures pétaloïdes.

$\times$ Fl. régul.

$\odot$ Pl. aquat., divis. extér. du périanthe herb.

Fl. dioïques, styles courts, fr. indél. . HYDROGHARIDÉES 94

Fl. hermaphrodites ou monoïques, styles nombreux, fr. composé de carpelles. . . . . . . . ALISMAGÉES 9ð̆

$\odot$ Pl. terr.

= Ovaire supère.

Styles 3, filiformes tr. longs; souche bulbeuse.

COLGHIGACÉES 96

Styles 1, rar. 4.

Fr. sec caps. s'ouvrant en 3 valves, souche bulbeuse ou fasciculée. . . . . . . . . . LILIAGÉES 97 
Fr. charnu, bacciforme, glob. indéh.; souche tracante.

= Ovaire infère.

Fl. diö̈ques, fr. bacciforme indéh.; ¡. cordées à nervures ramifiées.............. DIOSCORÉES 99

Fl. hermaphrodites; caps. à 3 loges, à plus. graines.

Ét. 3 , stigmates dilatés ou pétaloïdes; 1 . en glaive, caul. et radic.; un rhizome. . . . . . . . IRIDEES 100)

Et. 6, stigmates ent. ou trilobés; f. lin. toutes rad.; sonche

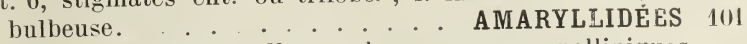

X Fl. irrégul., I ét. fertile, pollen agglom. en masses polliniques.

\section{ORCHIDEES 102}

- Périanthe à div. herb. ou scarieuses, souvent nul.

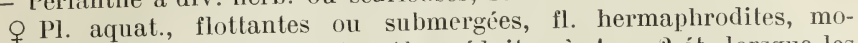
noïques ou dioïques; fl. màles réduites à 1 ou 2 ét. lorsque les pl. sont monoïques.

Périanthe à 4 divis., ou nul et remplacé par des bract., ou en forme de coupe; fr. de $2-8$ carp. . . . POTAMEES 103

Périanthe nul remplacé par une spathe; pl. allongées à f. sinuées dentées opp.; fr. simple, indél., monosp. . NAIADÉES 10'.

Pas de périanthe; pl. tr. petites réduites à des frondes lenticulaires flottantes; fl. naissant dans une fente des frondes.

LEMNAGEES 100

† Pl. terr., rar. aquat. et dans ce cas pl. monoïques, fl. màles nombr. réunies en épi ou en cap.

- Monoïque.

Fl. en spadice, renfermées dans une spathe, sessiles autour d'un axe charnu, f. cordées ou sagittées, à mesures ramifiées.

AROIDÉES 106

Fl. sessiles unisexuelles réunies en உِ épis compacts smperposés ou en têtes globul.; partie sup. màle. . . TYPHACÉES 107

- Hermaphrodite, rar. monoïque ou diö̈que (voir Cypéracées).

of Périanthe à 6 divis. sur 2 rangs, fr. délı.

Fl. en longue grappe spiciforme; périanthe herb. caduc; $3-6$ styles ; stigmate épais; carp. monosp. . . JONCAGINÉES 108

Fl. en cymes ou en corymbes; périanthe scarieıx, persist.; 1 style ; 3 stigmates filiformes; caps. polysp. à 3 valves.

JONGÉES 109

*. Périanthe nul ou réduit à des écailles ou soies, fr. indéh., fl. réunies en épis ou épillels.

Périanthe nul ou remplacé par des soies ou par une écaille à bords soudés, utricule, enveloppant un fr. sec, achaine; anth. insérées sur le filet par leur base; stigmates filiformes; f. tristiques à gaines non fendues. . . . CYPERAGEES 110 Périanthe nul ou réduit à de petites écailles, glumellules; fl. avec 2 bractéoles, glumelles; chaque épillet muni à la base de 2 bract., glumes; fruit sec monosp., indéh., nu ou enveloppé par les glumelles, caryopse; anth. insérées sur le filet par leur dos; stigmates allongés plumeux; 1 . distiques, à gaine fendue terminée à la naissance du limbe par une membr., ligule; t. creuses renfl. en noeuds au niveau de l'insertion des $f$.

GRAMINÉES 111

\section{VII. - CRYPTOGAMES}

\# Pl. pourvues de f. ou frondes; t. nulle ou non articulée, sans rameaux vert.

- Fructifications constituées par des capsules, sporanges, soit réunis en groupes, sores, disposés à la face inf. des frondes, soit plus rar. 
disposés en épi ou en pan. term., exceptionnellement médiane; frondes plurinervées, gr. ou petites, souvent divisées, rarement ent., ord. roulées en crosse dans leur jeunesse, tr. rar. non enroulées . ........... FOUGÈRES 112

- Fructifications naissant, soit à l'aisselle de très petites f. au sommet des t., soit sur le rhizòme.

Fructifications, sporocarpes, glob., coriaces à 4 loges et 4 valves, naissant sur le rhizòme filiforme, allongé et renfermant des sporanges de 2 sortes, les uns gros à une seule spore, macrospore, les autres petits à spores tr. nombr. et tr. petites, microspores; fr. fasc., filiformes en alène, roulées en crosse dans leur jeunesse.

RHIZOCARPÉES 113

Fructifications, sporanges uniloculaires, disposées à l'aisselle des f. ou des bract. sup., en rein ou subglob., membr. ou peu coriaces, s'ouvrant en 2 valves par une fente transversale, renfermant des spores tr. petites, toutes semblables: f. non roulées en crosse, tr. petites, lanc. ou lin., ent. ou denticulées, imbriquées sur les tramenses, dicholomes....... LYGOPODIAGÉES 114

\# Pl. à f. nulles, remplacées à chaque noud de la lige par une gaine membr. dentée; rhizòme souterrain long. traçant, muni de racines; t. aériennes cyl., articulées, strićes ou sillonnées, simples ou à rameaux vert.; fructifications en épi term. composé d'écailles peltées ayant la forme de clous, vert. 4-9) sur plus. rangs superposés, ì sporanges uniformes, uniloc., s'ouvrant en long par une fente, placés à la face supérieure de ces écailles; spores uniformes, glob., entourées de \& filamenls élastiques, d́atìres, dilatés en spathule an sommet, roulés en spirale autour de la spore et se déroulant par la sécheresse.

EQUISÉTAGÉES $11:$

\section{1. - THALAMIFLORES}

\section{FAMILE 1. - RENONCULACÉES}

+ Fr. secs monosp., achaines.

$\times$ Fl. munies de cal. cl de cor.

= Pét. munis d'une écaille nectarifìre, carp. réunies en tête glob. ou oblongue.

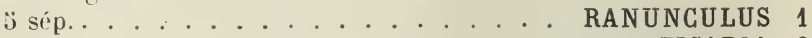

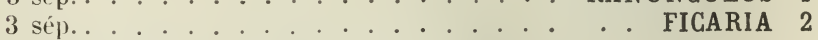

$=$ Pét. sans écaille nectarifère, carp. nombr., réunis en épi.

¿3 sép. prolongés en éperon, $\tilde{b}$ pét. jaunàtres à onglet plus long que le limbe; f. toutes rad., dressées, lin., ent. . MYOSURUS 3

5 sép. pétaloïdes, 3-12 pét. rouges, rar. jaunes brièvement onguiculés; f. rađt. et caul. multifides à lanières lin.. . ADONIS 4

$\times$ Fl. dépourrues de cor.

- F. opp, carp. term. par le style accru et plumeux.

GLEMATIS 5

- F. alt., carp. peu nombr., 1-12, à stries longit., term. par le style non plumeux.......... THALICTRUM 6

- F. caul. ternées formant invol. au-dessous des fl solit. ou en ombelle, carp. nombr. en tête globul. sur un récept. renflé, terminés en pointe cotirte ou en arète plumeuse. . ANEMONE 7

+ Fr secs polysp. déh.

$\times$ Fl. régul.

= Cor. nulle, sép. pétalö̈les jaunes, 5゙-12 follic. libres

= Cor. à pét. très petits \pm tubuleux ou onguiculés. 
đ Sép. persist. verdàtres; carp. mùrs renfl. . . HELLEBORUS 9

ơ Sép. cadues.

Follic. 1-3, libres, sép. blanes . . . . . ISOPYRUM 10

Follic. ¿-10 soudés dans leur moitié inférieure, rar. jusqu'au sommet; sép. d'un blanc bleùitre . . . . NIGELLA 11

$\times$ Fl. irrégul.

Fl. dressées.

Cal. à ÿ sép. pétalö̈des cad. le sup. prolongé en éperon; follic.

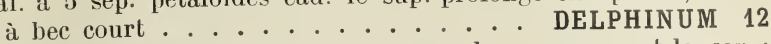

Cal. à 5 sép. pétaloïdes le sup. en capuchon recouvrant la cor.; pét. 2-3̈ irrégul.; follic. à bec médiocre . . . ACONITUM 13

Fl. penchées; cor. à ä pét. prolongés chacun en éperon; cal. à 3 sép. pétaloïdes; follic. à hec allongé . . . . . AQUILEGIA 14

+ Fr. bacciforme indéh. noir; cal. à '́ sép. pétaloïdes blancs cadues, pét. \& spathulés peu apparents. ....... ACTÆA 15

\section{Genre 1. - RANUNCULUS L.} + Pl. aquat. à fl. blanches; pédonc. fructif. arqués; carp. ridés trans-
vers.

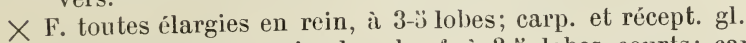

Pét. dépassant à peine le cal.; 1. à 3-3 lobes courts; carp. obtus.

Ruiss., fossés des terrains silic. - Mai-Jt

R. hederaceus L. 1

Pét. 1-2 fois plus longs que le cal.; f. à 3-ว̈ lobes profonds; carp. acumin. . . . . . . R. Lenormandi Schultz 2 Mares. - Mai-Jt.

X F. flottantes élargies en rein, les autres subınergées et capillaires ou f. toutes capillaires.

$=$ F. flottantes élargies en rein, les autres capillaires; récept. poilu. Q Stipules des f. sup. adhérentes au pétiole dans leur tiers inf; ; ét. peu nombr.

Fl. très petites, $3-6 \mathrm{~mm}$.; pét. à peine plus longs que le cal., à onglet jaune; ét. $3-10$; carp. peu nombr. à bec grèle et court.

Mares et fossés. - Mai-Jt.

R. tripartitus DG. 3

Fl. assez gr., 12-20 mm.; pét. 1-2 fois plus longs que le cal., ent. blancs; ét. 12-20; carp. assez nombr. à bec long.

Mares et fossés. - Mai-Jt.

R. hololeucos Lloyd 4

Q Stip. des f. sup. adhérentes au pétiole au moins dans les 2 tiers inférieurs; ét. nombr. ; carp. nombr.

Pédnnc. bien plus longs que les f.; récept. conique, fin. poilu; carp. petits, souvent glabres, non renfl. au sommet.

\section{Mares. - Mai-Jn.}

R. confusus Gren. Godr. 5

Pédonc. dépassant peu les f.; récept. glob., hér.; carp. assez gros, hér., renfl. au sommet; fl. gr. . . R. aquatilis L. 6 Eaux stagnantes. - $\Lambda \mathrm{v}$.-Jt.

$=\mathrm{F}$. toutes divisées en lanières capillaires, tr. rar. quelques f. élargies en rein.

— F. à lanières longues, parallèles; rícept. subglob., gl.; carp. gl., arrondis au sommet; ét. nombr., fl. gr. R. fluitans Lamk 7 Eaux courantes. - Mai-Jt.

- F. à lanières courtes, non parallèles; récept. poilu; ét. peu nombr., fl. moyennes ou petites. 
Lanières des f. étalées en cercle; récept. glob.; carp. gl. ou peu poilus, atténués en bec saillant; pédonc. $3-4$ fois plus longs que les f.; stip. très courtes entièrement adhérentes au pétiole, sans oreillettes; jamais de f. flottantes réniformes.

R. divaricatus Schrank 8

Étangs, rivières. - Mai-Jt.

Lanières des f. plus ou moins divariquées; récept. ovoïde; carł. hér., à sommet un peu aigu, rarement gl.; pédone. ne dépassant pas la f. à la floraison; stip. à gaine ventrue, à oreillettes libres dans la moitié sup.; quelquefois des f. flottantes, réniformes......... R. trichophyllus Chaix 9 Mares, étangs. - Av.-Jn.

+ Pl. terr., à fl. jaunes; pédonc. fructif. dressés; carp. lisses ou tuberculeux.

$X$ F. ent. ou dentécs.

= Pédonc. axillaires; carp. non carénés; souche vivace, chevelue, à fibres épaisses; f. lanc.-lin., ent., nervées. R. gramineus L. 10 Pelouses sèches, sabl. - Mai.

= Pédonc. opposés aux f.; carp. carénés.

Q Pl. viv., dépassant ord. 30 cent. à fl. assez longuement pédonc.

F. de la t. acuminées; fl. gr.; carp. comprimé. R. Lingua L. 11 Mlarais, fossés aquat. - Jl-At.

F. de la t. non acuminées; fl. petites; carp. renfl.

Prés maréc, fossés. - Mai-Sepl.

R. Flammula L. 12 Var. ¿̀ l. couchée radicante, f. presque lin.

Q. Pl. ann, grèle, rameuse dicholome de ì à $30 \mathrm{~cm}$. à fl. tr. petites, sessiles ou subsessiles, lat. ou occupant l'angle des dichotomies; carp. . . . . . . . . . R. nodiflorus L. 13 Mares des ter. silic. - Mai-Jn.

X F. découpées.

= Pl. ann.; carp. ridés, tuberc. ou épin.

Q Pét. dépourvus d'écaille nectarifère; cap. fructif. oblongs; carp. tr. petits, fin. ridés à bec très court. . . R. sceleratus L. 14 Mares et fossés. - Mai-Sept.

Q Pét. munis d'un nectaire à la base; capl. fructif. arrondis; carp. tuberc. ou épin.

- Sép. réfléchis, carp. petits caducs.

Pét. égalant à peine le cal.; récept. glabre; carp. peu nombr., étroitement bordés à faces couvertes de petits tuberc. saillants, à bec large recourbé; pl. étalée, diffuse, rameuse.

R. parviflorus 15

Ch. cult., vignes, fossés. - Mai-Jn.

Pét. dépassant le cal. ; récept. poilu ; carp. nombr., petils, compr., carénés, à faces fin. tuberc., offrant près du bord une ou plusieurs rangées de tuberc., rar. lisses, à bec court, à peine courbé. . . . . . . . R. sardous Crantz 16 Ch. humides, bords des mares. - Mai-At.

- Sép. étalés, carp. gr. persistants, à faces épin., rarement tuberc. (var. tuberculatus) ou veinées (var. reticulatus), à bec linéaire presque droit. . . . . . . . R. arvensis L. 17 Moiss, et ch. cult. - Mai-Jt.

= Pl. viv. ; carp. lisses.

Q Souches à fibres rad. charnues mêlées à des fibrilles filiformes; cap. fructif. ovales ou oblongs; sép. étalés, carp. à bec presque droit. . . . . . . . . R. chaerophyllos L. 18 Pelouses siches des terr. sabl. - Mai-Jn.

a Souche simple ou bulbiforme, à fibres rad. toutes filiformes; cap. fructif. glob. 
- Récept. gl. ou glabrescent, pédonc. fructif. arrondi.

Pl. gl., per élevée: carp. renflés, pubescents, à bee fortement recourbé; f. caul. digitées, les rad. arrondies en rein, crénelées ou trifides; pét. souvent avorlés. R. auricomus L. 19 Bois. - Arr.-Ju.

Pl. velue, élevée: carp. gl., compr. fortement Jordís, à bec un peu recourbé; f. palmatiparlites. . . . R. acris L. 20 Bois, prés. - Mai-sept.

Varie à lobes des f. élr. (R. Borzamus Jord.).

- Récept poilu, pédonc. fructif. sillonné.

F. rad. pentagonales dans leur pourtour à 3-3 lobes sessiles.

Achaines à bec plus ou moins élargi à la base, plus ou moins roulé en cercle aı sommet; f. se couvrant plus ou moins par leurs bords. . . . . . . R. nemorosus DC. 21 Bois et forcis. - Mai-Jt.

Varie à lobes des f. larges se recouvrant par leurs bords, bee de l'achaine roulé en cercle, fortement épaissi (R. Amansii), lobes des f. étr. se recourrant un peu, bee de l'achaine it peine enroulé, peu épaissi ( $R$. Delacouri), lobes des f, très choils, lin. se recouvrant un peu, bee fort. enroule ( $R$. Questieri).

Achaines à bec étroit à la base, enroulé au sommet en décrivant une demi circonférence; f. ne se recouvrant pas par leurs bords . . . . . . R. polyanthemoides Bor. 22 Marais tourbeux. - Mai-Jt.

F. ovales dans leur pourtour à lobe moyen pétiolé; carp. à bec court un peu courbé.

Sép. étalés; souche rampante munie de stolons allongés, feuillés.

R. repens L. 23

Prés, fossés. - Mai-Sept.

Sép. réfléchis, souche renflée en bulbe arrondi non stolonifère . . . . . . . . . R. bulbosus L. 24 Pelouses. prés. - Avr.-Jt.

\section{Genre 2. - FICARIA Dill.}

Souche vivace à fibres fasciculées, renflées en massue; f. ovales en coeur, ent. ou sinuées: fl. jaunes solit.; 6-12 pét.; carp. en tête glob., pub. renfl. sans bec. . . . . . F. ranunculoides Roth 25 Haies, bois humides. - Mars-Mai.

\section{Gexre 3. - MYOSURUS L.}

Ann.; f. toutes rad. dressées, lin. ent.; hampe de $3-10 \mathrm{~cm}$. ; fl. vert jaunâtre, petites, solit. ; ’’-10 ét.; carp. en épi allongé, nombreux, imbriqués à bec dressé, aigu. . . . . . . M. minimus L. 26 Ch. hum. - Avr.-Jn.

\section{Gexre 4. - ADONIS L.}

+ Sép. étalés, non appliqués contre les pét. concaves obovales d'un pourpre foncé; carp. à bord sup. sans dent. A. autumnalis L. 27

Moiss. des terr. cale. - Mai-Jt.

+ Sép. appliqués contre les pét. plans; carp. à bord sup. muni d'une dent.

Sép. gl.; : ¿-10 pét. oblongs rouge clair ou jaune citron; carp. à bec concolore, à dent ćloignée du bec; épi fructif. lense, ohlong cyl.

A. aestivalis L. 28

Moiss. des terr. rale. - Mai-Jt.

Sép. velus; $3-6$ pét. étroils oblongs, souvent trìs imégaux; carp. à bec noiràtre, à dent trìs rapprochée du bec; épi fruclif. assez làche, allongé cyl. . . . . . A. flammea Jacı. 29 Moiss. des terr. eale. - Mai-Jt. 


\section{Genre §̈. -- GLEMATIS L.}

Tige sarmenteuse; f. pennées à-7 fol. gr. ovales-lanc., ent. ou dentées; sép. tom.; récept. velu; carp. peu compr. à arête plumeuse longue et flexueuse . . . . . . . . . . G. vitalba L. 30 Haies, buissons. - Jn-At.

On cultive C. Flammula L., tige sarmenteuse, feuilles à 3-7 fol. assez petites, ovales ou lanc., ent., rar. trilobées; sép. pub. en dehors, gl. en dedans; récept. gl. ; carp. trìs compr. ì arête plumeuse assez courte.

On cultive C. recta L., t. herbacée, dressée; $f$. pennées à 2-3 paires de fol. gr., ovales lanc., ent.; fl. blanches; sép. presque gl. à bords tom. ; carp. compr. ì arète plumeuse.

On cultive aussi $C$. viticella $\mathrm{L}$.

\section{Genre 6. - THALICTRUM L.}

+ F. aussi larg. (que long. dans leur pourtour, triang. ternatiséquées; ét. pendantes; anth. apic.

Souche grèle à nombreux rhizòmes allongés. . . T. minus L. 31 Coteaux, bois. - Jn-Jt.

Souche épaisse sans stolons. . . . . . T. majus Jacq. 32 Bois. - Jn.

+ F. plus long. que larg. bi-tripennatiséquées; dressées.

Panic. en corymbe; fl. rapprochées en glom. denses; anth. mutiques. Prés hum, fossés. - Jn-At.

T. flavum L. 33

Pan. ovale pyramidale à rameaux étalés; fl. éparses; anth. apic. Bois hum. - Ju-Jt.

T. gallicum Rouy et Fouc. 34

\section{Genre 7. - ANEMONE L.}

+ Invol. entourant la fl. ord. bleue comme un cal. à 3 sép.; f. à 3 lobes ent. et égaux. . . . . . . . . . A. Hepatica L. 35 Bois et coteaux cale. - Ivr.-Mai.

+ Invol. éloigné de la fl.

X Carp. oblongs, velus, à longue arête plumeuse; f. bi-tripennatiséquées; invol. à fol. sessiles divis. jusquà la base en lanières lin. ;

fl. rougeâtres ou violettes, gr., solit. . . A. Pulsatilla L. $3 \hat{~}$ Coteaux secs sabl. calc. - Ivr.-Jn.

X Carp. à pointe courte non plumeuse; f. biternées ou palmatiséquées ; invol. à fol. pétiolées semblables aux 1 . radic.; fl. blanches, roses ou jaunes.

= Fl. jaunes, solit. ou 2-3 en ombelle; carp. à bec aussi long qu'eux ; souche allongée, charnue. . . . . A. ranunculoides 37 Bois hum. - Avr.-Mai.

= Fl. blanches ou roses, solit.; carp. à bec bien plus court qu'eux. Carp. laineux; pl. poilue; fl. gr. Jlanche; f. palmatiséquées à כै segments sessiles; souche courte à racines fasc.

A. silvestris L. 38

Coteaux calc. boisés. - Mai-Jn.

Carp. pub.; pl. presque gl.; fl. blanche ou rose; f. palmatiséquées à $3-j 3$ segments pétiolulés; souche allongée, charnue.

Bois. - Mars-Mai.

A. nemorosa L. 39

\section{Genre 8. - GALTHA L.}

T. de 20-40 cm. gl. luisante; f. long. pétiolées en coeur arrondies, crénelées ou dentées, les sup. sessiles; fl. gr., jaune d'or, solit.; follic. ridés en travers à bec court divergent, droit ou crochu.

Fossés, prés humides, marécages. - Avr.-Ju.

C. palustris L. 40 


\section{Gexre 9. - HELLEBORUS L.}

T. annuelle, pauciflore, nue jusqu'aux rameaux; f. rad. pédalées non persist., les caul. digitées, sessiles; fl. dressées, peu nombr. à sép. ćtalés plus longs que les ét.; pét. dépassant la moitié des ét.

H. viridis L. 41

Haies, pentes boisées sourent à l'exposition nord ou nord-ouest. - Avril.

T. rohuste, persist., multiflore, nue à la base, tr. feuillée sous les rameaux; f. toutes caul., coriaces, pédalées, persist. ; fl.penchées, nombr., ¿ sép. dressés, connivents, égalant les ét.; pét. égalant la moitié des c. . . . . . . . . . . H. foetidus L. 42 Coteaux pierreux calc. - Janv.-Mai.

On eultive $H$. niger L., Rose de Noel. F. Loutes rad.; fl. blanches, gr. solit. ou géminées; $t$ portant 1-3 bract. ovales.

On cultive Eranthis hyemalis Salisb. à fl. jaunes ì invol. semblable aux f. orb. pennatiséquées, fl. Février-Mars.

\section{GeNRE 10. - ISOPYRUM L.}

Souche viv. ramp. à fibres épaisses fasc.; t. de 10-23 $\mathrm{cm}$. grêle, nue à la base, gl.; f. gl. biternées à fol. trilobées; stip. membr.; fl. d'un hlanc pur peu nombr., pédonculées; pét. 3 tr. petits, en cornet.

Bois ombragés. - Avr.-Mai.

I. thalictroides L. 43

\section{Genre 11. - Nigella L.}

Ann.; t. de 10-30 cm., dressée ou étalée à rameaux longs divariqués; f. multifides à lanières aig.; pas d'invol. autour de la fleur; anth. apic.; follic. soudés jusqu'au delà du milieu . . N. arvensis L. 44 Ch. sabl. - Jn- Il.

On cultive $N$. damascena $\mathrm{L}$. Fl: munies d'un invol. ; anth. mutiques; follic. soudés jusqu'au sommet formant une caps. glob.

\section{Genre 12. - Delphinium L.}

Bract. des pédicelles inférieurs découpées; t. élancée à rameaux dressés à grappes allongées; follic. pub. . . . . . D. Ajacis L. 45 Cult. et subsps. - Jn-Jt.

Bract. simples et ent.; t. basse à rameaux étalés à grappe courte; follic. glabres ........... D. Consolida L. 46 Ch. moiss. - Jn- Il.

On cult. D. orientale Gay, voisin de D. Ajacis, se reconnaît ì sa grappe serrée, ses fl. violettes, ses follic. pub. visq.

\section{Genre 13. - ACONITUM L.}

Racine à tuberc. napiformes; tige de 1 à $2 \mathrm{~m}$.; f. palmatiséquées; fl. bleu foncé................. Napellus L. 47 Prairies tourb.

\section{Gexre 14. - AQUILEGIA L.}

Pl. de $30 \mathrm{~cm}$. à $1 \mathrm{~m}$. pub., rameuse sup.; f. inf. long. péliolées, biternées, à fol. larg., les sup. sessiles; fl. bleues; follic. gr., ventrus.

Bois et prés ombragés ou hum. - Mai-Jl.

\section{Genre 1:3. - AGTÆA L.}

Souche viv., épaisse, noirâtre; pl. de 30 à $80 \mathrm{~cm}$. nue à la base, munie de 2-3 f. sup., gl.; f. bi-triternatiséquées à fol. ovales acum. incisées dentées; fl. blanches, petites en grappe ovale, serrée; haie noire à graines nomb. . . . . . . . . . . A. spicata L. 49 Bois montueux ombracés. - Mai-Jl. 


\section{Famile 2. - BERBÉRIDÉES}

Irbriss. épin. de 1-3 m. à f. obovales-oblongues, denticulées; sép., pét. et ét. 6 .; baie oblongue, rouge à 1-3 graines; fl. jaunes en grappes ser-

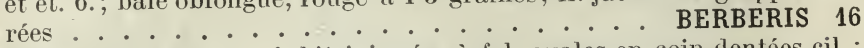

P. herb. de $20-40 \mathrm{~cm}$; ґ. bitripinnées à fol. ovales en coin dentées-cil.; sép., ét. 4 ; pét. 8; caps. à siliq. atténuée en bec. EPIMEDIUM 17

\section{Gexre 16. - BERBERIS L.}

Arbriss. à rameaux dressés, gl.; f. en faisc. munies au-dessous d'une long. épine à 3 branches; grappes florales plus long. que les f. cad.

Haies, coteaux. - F1. Miti-Jn. - Fr. Sept.-1)et.

B. vulgaris L. 50

On plante souvent dans les pares ef les bois le Mohonia Aquifolium Null. sous-arbriss. it f. persist., imparipennese ; fl. jaune clair, en grappes; inflor. term., le reste comme daus Berberis.

\section{GeNre 17. - EPIMEDIUM L.}

Pl. à souche horizontale écailleuse; fl. petites, brunes, en grappes làches velues glanduleuses; les 4 pét. int. sont plans, les ext. en cuiller, presquée à 2 lèvres, éperonníe. . . . . . E. alpinum L. 51 Pl. introduite el nat. - Maii-Jn.

\section{Famile 3. - NYMPHÉACEES}

F. blanches; 4 sép. lanc.; pét. sans fossette nectarifère dépassant te cal.; fr. glob. muni de cicatrices . . . . . . NYMPHÆA 18

Fl. jaunes; 3̈ sép. suhorb.; pét. à fosselte nectarifère sur le dos 3 fois plus courts que le cal.; fr. subconique sans cicatrice. NUPHAR 19

Gexre 18. - NYMPHÆA L. - Nénuphar.

F. larg. suborb. en cour: pét. nombreux lanc. soudés avec la partie int. de l'ovaire............................ 52

Nares, étangs, riviires. - In-Sepl.

Varie dans les tourb. ì f. el fl. beaucoup plus petites el pét. moins nombr. (var. minor DC.).

\section{GeNRe 19. - NUPHAR Sibth. et Sm.}

F. ovales arrondies en corur; pét. nombr. obovales sans adhérence aver N. luteum Sibt. et Sm. 53 Nlares, étangs, rivières. - In-Sepl.

Les f. qui vivent sous leau sont membran., minces, ondulées et de plus grr. taille que les nageantes.

\section{FAMILLE 4. - PAPAVÉRACÉES}

+ Caps. courte, renfl., s'ourrant an sommet par des pores sous le disque; 4-13 stigmates rayounants sessiles sur un disque plan; fl. rouges ou blanches . . . . . . . . PAPAVER 20

+ Caps. allongée, lin., souvrant en long, 2-4 stigmates non rayonnants; fl. jaunes.

Fl. gr. sol., 2 stigmates en tête: caps. lin. long. de 12 à 20 cent., à 2 loges, séparées par une cloison s'onvrant du sommet à la base en 2 valves; graines sur un rang . . . . . GLAUCIUM 21 Fl. petites en ombelle simple à péd. inígaıx; 2 stigmates obliques; caps. lin. long. de $3-4$ cent. à 1 loge à 2 valves s'ouvrant de bas en haut; graines sur 2 rangs...... CHELIDONIUM 22 
Genre 20. - PAPAVER L. - Pavot.

+ Caps. hér. de soies; disque des stigmates sinué, non lobé.

Caps. ovoïde, arrondie à la base, toute hér. de soies, étaléesarquées; pét. d’un rouge violacé . . . P. hispidum Lam. 54 Ch., moiss. - Mai-Jt.

Caps. en massue, atténuée à la base, parsemée de soies arquéesdressées; pét. d'un rouge pàle . . . . . P. Argemone L. 55 Ch. sees, moiss. - Mai-Jt.

+ Caps. gl.; disques des sligmates régulièrement lobé.

X F. de la t. embrassantes; filets des ét. en massue; caps. grosses subglob.; fl. rougeàtres, rosées ou blanches. P. somniferum L. 56 Cult. et subsp. (Pavol). - Mai-Jt

X F. de la $\mathrm{t}$. non embrassantes; filets des ét. en alène, caps. petites. Caps. subgloh. ou obovales, courtes; pét. l'un rouge vif; stigmates 7-12 sur un disque lobé à lobes se recouvrant par les bords . . . . . . . . . . P. Rhœas L. 57 Ch., moiss. - Mai-Jt.

Caps. oblongues, en massue, atténuées à la base; pét. d’un rouge vif ou orangé; stigmates 4-12, sur un disque à lobes peu marqués, se recouvrant peu ou point par les bords.

$$
\text { Ch., moiss. - Mai-Jt. }
$$

P. dubium L. 58

\section{Genre 21. - GLAUCIUM Giartn.}

Pl. bisan. gl. ou hér. à la base; f. glauques, épaisses, lyrées peunatifides à lobes incisés dentés, les sup. embrassantes.

$$
\text { Décombres. - Jn-Sept. }
$$

G. flavum Crantz 59

\section{GENRE 22. - GHELIDONIUM L.}

Pl. viv. à suc jaune; t. vel.; f. pennatiséquées à :̈-8 segments ovales, incisés-lobés, glauques en dessous. . . . . . C. majus L. 60 Vieux murs ombragés, lieux ineultes.

Var. ì pét. incisés el lobes des segments élroils (C. laciniatum Mill.).

\section{Famile Э. - FUMARIACÉES}

Fr. oblong, en silique, comp. déh. à 2 valves, à 2 ou plusieurs graines lenticulaires, noires, luisantes; grappes pauciflores. CORYDALIS 23 Fr. court, glob., indéh. à 1 graine; grappes multiflores. FUMARIA 24

\section{GenRe 23. - CORYDALIS IDC.}

+ Fl. jaunes ou blanches en grappes opposées aux f.; éperon court et obtus; racine fibreuse.

F1. jaunes, plus foncées au sommet; pédic. écralant la caps.; graines luisantes, finement ponctuées à arille lacéré. C C. lutea IJC. 61 Vieux murs, pl. introduite. - Mai-Sept.

Fl. blanches ou d'un blanc jaunàtre; pédic. plus courts que la silique; graines opaques, fort. ponctuées, scabres, à arille presque entier . . . . . . . . C. ochroleuca lioch 62 Vieux murs, pl. introduile. - Mai-Sepl

+ Fl. purpurines en grappe term.; éperon allongé; souche renfl. en bulbe plein et solide; t. de $10-30 \mathrm{~cm}$., simple, portant $2-4 \mathrm{f}$, avec 1-3 écailles au-dessous; bract. incisées dicritées, rar. ent.; graines lisses. . . . . . . . . . . . C. solida Swartz 63 Bois ombratés, haies. - Avr.

Coryclatis cava Sehweigr, autrefois nal. ì Versailles et Malesherbes, diffère de $C$. solida par sa souche renflie en bulbe, quelquefois volumineuse, devenant rreuse, par sa I. dépourvue d'écailles, par ses bracl. ent.; les fl. varient du blanc au ronge. 


\section{GExLE 2年. - FUMARIA}

+ Fl. assez grandes long. le $1 \mathrm{~cm}$.; ailes des pét. ćtroites, n’atteignant pas leur sommet.

Pédic. fructif. recourbés; fl. Blanchitres ou lavées de roure; fr. sphérique, obtus, lisse . . . - - ivr.-Sept

F. capreolata I. 64

Pédic. fructif. droils; fl. purpurines; fr. suliglob. rugueux, rar

lisse inaes, buisons cull, mur - irr-sept.

ci rentrent Fremaria Borea Jord., fl. d'un beall rose, base du fr. élroite ne díhordant pas le sommet du preflie. : et F. Bustardi Bor., fl. rose pale ou

blanchitre, base du fr. élarye débordant to sommet du pédic.

+ Fl. petites de moins de $1 \mathrm{~cm}$. : ailes des pét. larg., atteignant environ leur sommet.

X Fl. assez petites, purpurines; síp. égalant le tiers de la cor.; lobes tes $\mathrm{f}$. lanc. oblongs.

Fr. plus large que long subémarginé; sép. lanc. plus étroits que F. officinalis L. 66 la cor. - irr. - isple.

Fr. glob., apiculé; sép. suborb. bien plus larges que la cor.

Lieux cult. - Mai-Sept.

$\times$ Fl. tr. petites; sip. des f. canaliculís; fr. glob. un peu atténué vers le sommet en pointe obtuse . . . . F. parviflora Lamk. 68 Lienx cull. - Mai-Jl.

Fl. rosées; sép. liu., plus citroits que les pédic.; lobes des f. plans; fr. glol. arrondi an sommet ..... F. Vaillantii Lois. 69 Lieux cult. - Mai-Jl.

\section{FaMLLE 6. - CRUCIFÈRES}

+ Fr. allongé, lin. ou lanc., au moins trois fois plus long que large, silique, très rarement fr. court, silicule, mais graines non ailées ponctuées ou alvéolées sur deux rangs, valves de la silic. sans nervures et fl. jaunes, petites.

X Siliq. indéh., terminće en bec long, conique, renfl. spongieuse non articulée, lisse ou formée d'articles transvers., fort. nervées; fl. blanches, jaunâtres ou violettes, vein.; graines glob. d'un brun rougeàtre, alvéolées, sur un rang; f. inf. lyrées, les sup. dentées Siliq. déh.

$=$ Valves de la siliq, convexes.

ô Siliq. à bec allongé.

Graines unisériées, stigmate entier ou émarginé; fl. jaunes.

Sép. très étalés; $\mathrm{pl}$, verle à $\mathrm{f}$. non embrassantes; bec conique oll comprimé en sabre........ SINAPIS 26 Sép. uressés ou peu étalés; pl. glauque à f. embrassantes ou non; bec conique.......... BRASSICA 27 Graines bisériées: stigmate fendu en 2 lobes connivents; fl. blanches ou jaunes veinées de violet; bec comprimé en sabre.

ERUCA 28

ot Siliq. à bec court.

- Graines lisses sur 2 rangs; fl. jaunes; siliq. écartées de l'axe, lin., compr. ...... DIPLOTAXIS 29

- Graines sur 1 rang, ou graines sur 2 rangs, mais ponctuées ou alvéolées. 
a Graines sur 1 rang.

o Siliq. cyl. ou tétragones à I nervure.

o Siliq. cyl. bosselées; fl. jaunes ou purpurines.

Fl. jaunes; stigmate entier ou émarginé; f. pennalipartites.

ERUCASTRUM 30

Fl. purpurines, rarement blanches; stigmate fendu en 2 petites lames obtuses et conniventes; f. dentées.

HESPERIS 31

† Siliq. tétragones ou subtétragones, quelquefois un peı comprimées; fl. jaunes ou blanchìtres.

- Stigmate à 2 lobes divergents arrondis; pl. suffrutescente ; siliques létragones comprimées, blanchàtres; graines ovales comprimées, un peu ailées au sommet.

CHEIRANTHUS 32

- Stigmate entier ou émarginé; pl. herb.

Siliq. tétragones; graines ailées ou non; f. ent., embrassantes dentelées, sinuées à poils trifiıles. ERYSIMUM 33

Siliq. cyl. subtétragones; graines non ailées; f. incisées ou lyrées pennatifides; les caul. embrassantes auriculées.

BARBAREA 34

○ Siliq. cyl. à 3 nervures; graines lisses, striées ou ponctuées; stigmate entier ou à peine échancré; fl. blanches on jaunes ; f. simples ou découpées . . . SISYMBRIUM (part.) 35

Graines sur 2 rangs, fin. poncluées ou alvéolées, valves sans nervures.

Grappes très feuillées; siliq. hispidules; petites fl. blanches; f. pétiolées, pennatifides .. SISYMBRIUM (part.) 35

Grappes nues; siliq. ou silic. luberculeuses ou lisses; fl. jaunes ou blanches; f. pennatipartites ou pennatiséquées.

NASTURTIUM 36

= Valves de la siliq. planes.

o Silicf. à 1 nervure ou à plus. fines nervures; bec nul; graines comprimées souvent ailées; f. ent. ou dentées; rar. les rad. lyrées. . . . . . . . . . . . ARABIS 37 o Siliq. sans nervures à bec court ou long, s'ouvrant avec élasticité et se roulant de bas en haut; graines ovales, comp., rarement ailées; f. caul. pennatiséfuées, rar. simples, les rad. quelquefois lyrées.

siliq. lin. à bec ord. court; funicules filiformes ou coniques : souche rar. écailleuse; graines rar. ailées. CARDAMINE 38

Siliq. lanc.-lin. à bec allongé; funicules dilatés ailés; souche charnue et écailleuse; graines non ailées. . DENTARIA 39

+ Fr. court, aussi large que long ou à peine 2 fois plus long que large, silicule; pas de pl. à fl. jaunes, à graines ponctuées ou alvéolées sur 2 rangs.

X Silic. gr., ovales, obluses, compr. arrondies aux 2 bouts; graines peu nomb., grosses, en rein, compr., ailées, sur 2 rangs; fl. violettes; f. gr., ovales, en coéur, dentées, les inf. opposíes.

LUNARIA 40

X Silic. petiles, fl. blanches ou jaunàtres, rarement violacées.

= Silic. compr. par la face ou non comprimées déhise.

o Valves sans nervures, filets des ét. courtes munis d'appendices.

Loges à plus. graines comprimées ailées, sur 2 rangs; fl. blanches à pét. profondément bifides ...... FARSETIA 41 1-ł graines comprimées, ailées, dans clıaque loge; fl blanc jaunàtre ou jaunes à pét. ent. ou éclıancrés. ALYSSUM 42

Q. Valves à I nervure, graines sur deux rangs.

- Valves sans appendices. 
Silic. oblongues elliptiques à valves non vein.; fl. blanches, très petites à pét. arrondis ou bifides. . . . . DRABA 43

Silic. subglobuleuses à valves veinées en réseau; fl. blanches, petites, à pét. ent...... . COCHLEARIA 44

- Valves terminées en appendice appliqué sur la base du style; silic. obovales ou en poire, renfl.; fl. jaunes petites; graines ovoïdes, non ailées :f. caul. embrassantes auriculéès.

CAMELINA 45

= Silic. compr. par le côté, déh., ou silic. compr. ou non, indéh.

○ Silic. indéh. aplaties presque planes à 1 ou 2 loges, ou glob. à 1 logre tétragone à 2 ou 4 loges ou silic. déh.

む Silic. indéh.

- Silic. glob. ou tétragones.

Silic. glob. ridées en réseau à 1 graine.

Fl. jaunes: grappe fructif. allongée, 'à pédonc. grêles, étalés, 2-4 fois plus longs que les silic. glob.; style filiforme; pl. vel. . . . . . . . . NESLIA 46

Fl. blanches; grappe fructif. allongée, étroite, à pédic. arqués ascendants, 2-2 3 fois plus longs que les silic. ovoïdes glob.; style court, épais, conique; pl. gl. . . . CALEPINA 47

送 Silic. tétragones-ovol̈des à 2 ou 4 loges superposées 2 à 2 ; style très court; fl. jaunes; pl. plus ou moins vel., à f. rad. roncinées-pinnalifides . . . . . BUNIAS 48

- Silic. presque planes, comprimées par le côté; fl. jaunes.

Silic. pendante, oblongue en coin, noire à la maturité, à 1 loge el à 1 graine; style nul..... . ISATIS 49

Silic. échancrée au sommet et à la base, didyme, formée de 2 lobes orb., monosp., réunis à l'axe par un còté et se détachant à la base à la maturité; style filiforme.

BISCUTELLA 50

む Silic. déh.

Fl. en corymbe, loges à 1 graine; pét. inégaux, les 2 extr. plus grr., rayonnants; style filiforme; f. spathulées à 2-4 dents de chaque côté.......... IBERIS 51

- Fl. en grappes.

Valves ailées, loges polysp.

Loges à 2 graines; filets des ét. munis à la base d'une écaille blanche; pl. petites à l. presque toutes rad., lyrées pennatifides. . . . . . TEESDALIA 52 Loges à 2-6 graines; filets des ét. sans aile ni dent; pl. à f. caul. ovales oblongues ou oblongues embrassantes auriculées dentelées ou presque ent. . . THLASPI 53

Valves non ailées, ou ail. mais loges monospermes.

t Plus. graines dans chaque loge.

Silic. triang. tronquées au sommel; 10-15̆ graines oblongues compr. dans chaque loge; f. caul. embrassantes auriculées... $\quad$. . . . . CAPSELLA 54 Silic. ovales; 2 graines ovales compr. dans chaque loge ; f. caul. sessiles, pennatiséquées. HUTCHINSIA 55

む Une seule graine dans chaque loge, silic. ovales ou orb., ailées ou non. . . . . . LEPIDIUM (part.) 56

Silic. indéh. en rein, cordiformes ou à 2 lobes; à 2 loges monosp.

Silic. en coeur, non échancrée, ni carénée ; fl. blanches, assez grandes, en panicule corymbiforme ; f. oblongues sinuéesdentées. . . . . . . . . LEPIDIUM (part) 56

Silic. en rein, plus large que longue, ridée rugueuse; fl. blanches, petites, en grappes courtes, opp. aux f. pennatipartites. . . . . . . . . SENEBIERA 57 


\section{GienRE 2\%. - RAPHANUS L.}

Siliq. renfl. spongieuses, non articulées, lisses; fl. violettes ou blanches; racine charnue, soit petite, rose (radis) ou volumineuse, noire (radis noir) extr. . . . . . . . . R. Sativus L. 70 Cult. - Mai-Sept.

Siliq. formées d'articles transversaux, fort. nervées; fl. jaunàtres ou blanchàtres; racine grêle. . . . . . R. Raphanistrum L. 71 Lieux cult. - Rarenette. - Mai-Jl.

$$
\text { Genre 26. - SINAPIS L. - Moutarde. }
$$

+ Siliq. écartées de l'axe ; valves à 3-§̊ nervures.

Bec conique en alène, plus court que la siliq.; f. sup. sessiles, sinuées dentées . . . . . . . S. arvensis L. 72

Lieux cult. - Moutarde des champs. - Mai-Sept,

Bec comprimé en sabre, plus long que la siliq.; f. toutes pétiolées et pennatifides; t. et siliq. hér. . . . . . . . S. alba L. 73

Moiss., terrains calc. ou argileux. Moutarde blanche. - Mai-Jt.

La pl. cult. a les graines blanchàtres; la spontanée, les graines noires.

+ Siliq. serrées contre l'axe; valves à 1 nervure.

Siliq. cyl., à bec renflé au milieu en une boule monosp.; graines ovoïdes brunes; pl. velue blanchâtre à poils réfléchis.

Lieux incultes. - Jn-Sept.

S. incana L. 74

Siliq. presque quadrangulaires, à bec conique, sans graine au milieu; graines glob., noires, ponctuées; pl. vel. hér. seulement à la base. . . . . . . . . . S. nigra L. 75 Bords des rivières, lieux cult. Moutarde noire. - Jn-Sept.

\section{GeNRe 27. - BRASSIGA L.}

+ F. supér. sessiles ou embrassantes; pl. cult.

$X$ Sép. dressés ; ét. toutes dressées; f. charnues, les supér. demi embrassantes; graines lisses.. . . . . . B. oleracea L. 76 Cult.

Chou; variétés nombreuses : 1 . courte, choux pommés; t. élevée, choux verts, choux rouges, choux cavalier ; f. ondulées frisées, choux frisés; des bourgeons axillaires très développés en automne, choux de bruxelles; $t$. renflée à la base en un renflement charmu, chourave; axe de l'inflor., pédone. et fl. changés en une masse charnue, blanchìtre, chou-fleur.

Sép. étalés; ét. latérales ascendantes; f. non charnues, les supér. embrassantes auriculées.

F. toutes glauques glabre ou légèrement poilues; fl. en grappes làches avant l'épanouissement; graines fin. ponctuées.

Cult. - Avr.-Jn.

B. Napus L. 77

Varie ì racine grosse cliaruue (navel) ou à racine grêle (colza).

F. rad. vertes et cil. hér.; fl. en grappes serrées avant l'épanouissement; graines lisses. . . . . . . . B. Rapa L. 78 Cull. - Avr.-Jn.

Var. ì racine grosse, charnue (Rave) ou à racine grêle (Navelte).

+ F. toutes pétiolées, pennatifides; les supér. à lobes lanc. ou lin.; siliq. long., bosselées à 3 nervures fortes; graines brunes ponctuées............. B. Cheiranthus Vill. 79 Lieux sabl. - Mai-Jt.

$$
\text { Genre 28. - ERUGA DG. - Roquetle. }
$$

PI. ann., hér. à la base; f. épaisses lyrées pennatifides à lohes incisés dentés; grappe fructif. longue à pédicelles courts et épais; graines lisses ........... . . . sativa Lamk 80 Coteaux crayeux, décombres. - Avr.-Jn. 
Genre 29. - DIPLOTAXIS DC.

+ Sép. étalés; pédic. 3 fois plus longs que les sép., égalant à peu près les siliq.; pl. viv. feuillée dans sa moitié inférieure; pét. 2 fois plus longs que le cal. . . . . . . D. tenuifolia DG. 81 Décombres, lieux incultes. - Mai-Sept.

+ Sép. dressés; pédic. égalant les sép. ou une fois plus longs qu’eux; pl. ann. ou bisan., feuillée seulement à la hase.

Pédic. 1 fois plus longs que le cal., égalant le tiers de la siliq.; pét. 1 fois plus longs que les sép. . . . . . D. muralis DG. 82 Lieux sabl. - Mai-0ct.

Pédic. égalant les sép. et le quart de la silique; pét. dépassant à peine le cal. ........ . D. viminea DC. 83 Lieux cult., vignes. - Mai-Sept.

Genre 30. - ERUGastrum Presl. - Fausse Roquette.

Fl. d’un blanc jaunàtre, les infér. munies de lract.; sép. dressés; siliq. étalées; pl. ann. . . . . . . . E. Pollichii Spenn. 84 Lieux sabl., décombres, voies ferrées. - Nai-Sept.

Fl. jaunes, toutes sans bract.; sép. très étalés; siliq. redressées sur les pédic. étalés; pl. bisan. ou viv. . . . E. obtusangulum Reich. 85 Lieux arides, pierreux, décombres. - Mai-Jl.

\section{Genre 31. - HESPERIS L. - Julienne.}

Bisan. ou viv., t. dressée; f. rudes; grappe fructif. longue; siliq. ascendantes, grêles, flexueuses ou courbées . . . H. matronalis L. 86 Haies et buissons ombragés, souvent échappí des jardins. - Mai-Jn.

Le Malcomia maritima $\mathbf{R}$. Br. souvent cult. se recomnait aux earactires suivants: ann., vert cendré; f. oblongues ent. ou denticulées, fl. violettes, siliq. grêtes, it poils en navette; valves it 1 nervure, bec conique.

Matthiola incana R. Br. bisan. ou viv. tom. blanchâtre, lign. ì la base, portant infér. les cicatrices des anciennes f.; f. oblongues arrondies au sommet; fl. rouges, violacées ou blauches: silir. tomenteuses, ì bec gros, court; valves convexes it 1 nervure; sligmale it lobes comivents.

\section{Genre 32. - Gheiranthus L. - Giroflée.}

Viv., à poils couchés; f. lanc. aig. ent.; siliques dressées.

Vieux murs, ruines, rochers calc. - Ivr.-Jn.

C. Gheiri L. 87

\section{GeNRe 33. - ERYSIMUM L. - Vélar.}

+ Pét. blanchàtres, à limbe dressé; f. très gl., glauques, les caul. embrassantes en cœur. ... E. orientale R. Br. 88

Moiss. et ch. calc. - Mai-Jt.

+ Pét. jaunes, à limbe étalé; f. poilues non embrassantes.

Fl. très petites; sép. égaux à la base; stigmate entier; pédic. 2-3 fois plus longs que le cal.; f. ent. ou denticulées.

Ch. hum. - Nai-Sept.

E. cheiranthoides L. 89

Fl. gr.; sép. lat. bossus à la base; stigmate émarginé; pédic. à peine plus courts que le cal.; f. sinuées-dentées; bisan.

Var. cheiriflorum Wallr.

E. hieracifolium L. 90

Coteaux et ch. calc.

$E$. murale Desf. se raproche de $E$. cheiranthoides L. dont il diffère par les pédic. très courts, non étalés, les fl. moins nombr., plus gr., les siliy. pub. tom. : Sèvres, Saint-Gloud; n'est pas indigène. 
Genre 3'́ - BARBAREA Beckm.

+ F. supér. ovales, dentées ou incisées; siliø. term. en pointe longrue el effilée; pl. ì saveur nauséeuse . . . . B. vulgaris R. Br. 91 Lieux frais ou hum. - Mai-Jl.

Varie ì jeunes siliqf. arquées incurvées (B. areuata lieieh.) à lobes latéraux des f. rad. tr. petits, à silif. serrées contre l'axe (B. ricularis Martr.)

+ F. supér. pennatipartites à lobe terminal plus grand; silic. terminées en pointe courte.

Siliq. courtes de $2-3 \mathrm{~cm}$., à pointe lrès courte, rapprochées et plus ou moins appliquées contre l'axe; fl. petites à pét. dépassant peu le cal.; pl. à saveur amère . . . . B. intermedia Bov. 92 Talus hum. - Mai-Jn.

Siliq. long. de 4-6 cm., à pointe tròs courte, espacées, étalées, dressées; fl. gr.; pl. à saveur piquante . . B. praecox R. Br. 93 Ciull. el subsp. (Cresicon de terre).

\section{GENRE 3ə̈. - SISYMBRIUM L.}

+ Fl. blanches.

$\times$ F. ent. ou dentées; graines oblongrues.

F. caul. oblongues, ent. ou dentées, sessiles; pl. grêle ann.

S. Thalianum Gay

Cih. sabl., murs. - Ivr.-Jt.

F. caul. ovales en coeur, dentées, péliolées; pl. robuste bisan. à
. . . . . Alliaria Scop. 95

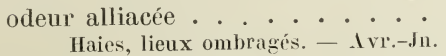

F. roncinées pinnatifides, graines ovoïdes sur 2 rangs; fl. en grappe très feuillées; siliq. sans nervures . . . . . S. supinum L. 96

Lieux sabl. hum., bords des rivières, lourb. desséchćes. - Jn-At.

+ Fl. jaunes.

$=$ Siliq. courtes de $2-3 \mathrm{~cm}$.

F. inf. roncinées pennatifides, les sup. hastées pub., sép. égalant le pédic.; siliq. appliquées contre l'axe, courtes, élargies à la base, atténuées au sommet, vel., rar. gl. (var. leiocarpum I)C.); graines brunes, fin. ponctuées . . . . S. officinale L 97 Décombres, lieux incultes. - Mai-sept.

F. bitripennatiséquées à lobes lin.; síp. 2-3 fois plus courts que le pédic.; siliq. gl. ascendantes arquées grèles; graines jaunes, lisses . . . . . . . . . . S. Sophia L. 98 Ch. lieux sabl. - Mai-Sept.

$=$ Siliq. allongées dépassant $3 \mathrm{~cm}$. ; f. roncinées-pennatificles à lobe denté, le term. plus grand. hasté et allongé dans les f. supér.; 2-4 fois plus comrls que le pédic.; siliq. ascendantes, longues. grèles, gl.; graines jaunes, lisses . . . . S. Iris L. 9! Décombres, bords des chemins, berges des rivières. - Mai-Jt.

Sisymbrium strictissimum L., viv., robuste f. lane., dentées, fl. jaunes, silir. long., eyl., grèle, nat. à Clamart et au bois de Boulogne.

Sisymbrium Sinapistrum lir., viv. f. infér. roncinées peunatifides, les supér. pennatiséquées, fl. jaune pàle, siliq. long., grètes ; velu à la base, gl. dans les $2 / 3$ supér., a élé trouvé dans les décombress à Irgenteuil, Gentilly et sur les murs ì compiègne.

Sisymbrium Columnae Jace, bis. vel., gris.; f. roncinées pennalifider. les moyennes hastées, les supér. lin.; fl. jaune pàle; siliø. lrès lonir., a été trouvé dans les décombres, lientilly, Ireueil, Fontainebleau.

\section{Genre 36. - NASTURTIUM R. Br.}

+ Fl. blanches; siliq. étalćes, courtes, cyl. arquées, plus long. que les pédic.; graines ovoïdes, brunes, poncluces; f. pennaliséquées, ì lobe terminal plus gr. que les latéraux, quelquefois tous les lobes presque égaux (var. siifolium) . . . . N. officinale R. Br. 100

Sources, fontaines, ruiss. - Mai-Sept. 
+ Fl. jaunes.

$\times$ Fr. allongé on siliq., cyl., un peu compr. souvent plus long que te pédic.

Siliq. tuberculeuses-rudes; pédic. épais, bien plus courts que la siliq., ann. .......... N. asperum Coss. 101 Graviers hum., Lossís. - Mai-Jt.

Siliq. lin., lisses; pédic. grêles, presque aussi lonğs ou plus longs que la siliq.; vir. . . . . . . . . N. silvestre R. Br. 102 Bords des rivières, lieux inondés l'hiver. - Jn-Sept.

$\times \mathrm{Fr}$. court ou silic., jamais plus long que le pédic.

Q Silicules elliptiques olılongues égalant le pédic., pét. petits égalant les sép. . . . . . . . . N. palustre DG. 103 Fossés, bords des mares, lieux fangeux - Ju-Sept.

Q Silic. ovoïdes ou grlob., 2-3 fois plus courtes que le pédic., pét. dépassant les sép.

T. élancées fistuleuses, radicantes à la hase; f. caul. oblongues on dentées incisées. . . . . . N. amphibium R. Br. 104 Bords des eaux, - In Sept.

T. peu élevées, grè̉es, pleines, non radicantes; f. caul. pennatiséquées à lobes lin. . . . . . N. pyrenaicum R. Br. 105 Pelouses et fossés sabl. secs. - Mai-Jn.

\section{Gexre 3i. - ARABIS L.}

+ F. rad. Iyrées pennatifides, les caul. sessiles, atténućes à la base; 1 . violettes ou rosées; siliø. étalées ascendantes; graines un peu ailées au sommet............ A. arenosa Scop. 106 Rochers, vieux murs. - Ivr.-Jn.

+ F. rad. ent. ou sinuées dentées, les caul. embrassantes; fl. blanches; siliq. serrées contre l'axe.

Graines non ailées sur 2 ranıss; fl. d'un blanc jaunàtre; f. rad. velues, sinuées dentées en rosette, les caul. gl. embrassantes auriculées.

Bois sabl., murs. - Mai-Jt.

A. perfoliata Lamk 107

Graines non ou étroitement ailées sur 1 rang; fl. blanches; pl. vel. hér. à f. ent. ou dentées, les caul. embrassantes.

A. hirsuta Scop.

Bois, secs, lieux pierreux. - Mai-Jt.

L'Arabis Turrita L. se reconnait à sa t. robuste, pub, à ses f. oblongues denticulées, les caul. amplexicaules à oreillettes arrondies, à ses fl. d'un blanc jaunitre; à ses siliq. très long. unilatérales, graines larọ. bordées.

\section{GenRe 38. - GARDAMine L.}

+ Pét. larges, étalés, 2-3 fois plus longs que les sép.

Pét. d'un blanc pur, rar. violacés; anth. violettes; style filiforme. aigu; f. pennatiséquées, toutes à fol. larg., obovales, anguleuses dentées . . . . . . . . C. amara I. 109 Bords des sources, des ruiss. - Avr.-Mai.

Pét. lilas ou roses, rar. blancs; style court et obtus; f. inf. lyrées, les sup. pennées à folioles lanc. lin. ent. . G. pratensis L. 110 Prés humides. - I vr.-Jn.

+ Pét. étroits, dressés, dépassant peu le cal.

$X$ Fl. dépassées par les jeunes siliq.; grappes fructif. courtes; pl. hér. à la hase; f. non auriculées.

F. de la t. 1-3, petiles, à $\$$ lobes lin. ou oblongs; 4 ét.; ann.

G. hirsuta L. 111

Murs ombragés, talus, bords des rivières. - Avr.-Jt.

F. de la t. 6-12 gr. à : $;-11$ lobes obovales; 6 ét.; bisan.

Berges des ruiss. silic. - Avr.-Jn.

G. silvatica Link 112 
X El. non dépassées par les jeunes siliq.; grappes fructif. long.; pl. presq., glabre; f́. caul. auriculées; pét. égalant à peine les sép.

Berges des rivières et des ruiss. - Yai-Jn.

G. impatiens L. 113

\section{Genre 39. - DENTARIA L.}

F. de la t. 8-1: , munies de bulbilles à leur aisselle, les supér. simples: pét. oblongs. . . . . . . . . . . D. bulbifera L. 114 Bois montueux ombragés. - Ivr.-Mai.

F. de la t. 2-4, sans bulbilles, toutes pennies, pét. larges obovales.

Bois montueux et pierreux ombragés. - Arr.-Mai

$$
\text { GenRe 40. - LUNARIA L. - Lunaire. }
$$

Pl. bisan. de $40 \mathrm{~cm}$. à $1 \mathrm{~m}$. vel. à poils étalés; fl. assez grandes; silic. stipitées, grandes, à cloison d'un blanc nacré. L. biennis Noench 116 Cult. et subsp. - Mai-Jt.

\section{Genre 41. - FARSETia R. Br.}

PI. bisan., pub. blanchàtre; t. de 20 -30 $\mathrm{cm}$. dressées; f. lanc. ent. ou un peu sinuées; grappes fructif. longues à pédic. grèles dressés, 2 fois plus longs que les silic.; silic. assez petites, elliptiques oblongues, dressées . . . . . . . . F. incana R. Br. 117 Lieux incultes, subsp. - In-It

\section{GeNRE 42. - ALYSSUM L.}

PI. ann.; pét. dépassant peu les sép., à limbe dressé d'un janne pâle, à la fin blanchàtres; sép. persistants; filets des ét. filiformes, ceux des 2 courtes munis à la base de 2 longs appendices sítacés; style 10 fois plus court que la silic. . . . . . . A. calycinum L. 118 Lieux arides, sabl. ou pierreux. - Ivr.-Jn

PI. viv.; pét. une fois plus longs que les sép., à limbe étalé d'un beau jaune; sép. caducs; filets des ét. long., ailés, ceux des 2 courtes munis à la base d'un appendice oblong; style égalant la silic. ou 1 fois plus court . . . . . . . . . A. montanum L. 119 Lieux secs, sabl. ou rocailleux. - Mai-Jt.

On cultive A. saxatile L. ì ft. d'un beau jaune, ì silic. glabre, à appendice des filets des ét. court, arrondi.

\section{Genre 13. - DRABA L.}

Pét. profondément bifides; i. toutes en rosette radicale; petites pl. de 3-15 cm. . . . . . . . . . . D. verna L. 120 Lieux sabl., murs. - Mars-Jn.

Pét. ent.; f. de la t. assez nombr. embrassantes, auriculées.

Lieux sabl., murs, talus. - Ivr.-Jn.

D. muralis L. 121

\section{Giente 44. - COCHLEARIA L.}

Grappes fructif. allongées et lìches; filets des ét. droits et divergents; f. rad. gr. ovales oblongues, crénelées, les sup. sessiles; pl. verte viv. . . . . . . . . . A. Armoracia L. 122 Cult. el subsp. (Raifort). - Mai-Jt.

Grappes fructif. courtes et serrées; filets des ét. arqués connivents, f. gr. ent., les rad. oblongues, les caul. lanc., embrassantes auriculées: pl. glauque ann. . . . . . . . . C. glastifolia L. 123 Nat, vieux murs, coteaux pierreux. - Mai-Jn.

Myagrum perfolixtum L., anu., gl. et slauque ; f. rad. sinuces, dentées, les caul. embrassantes auriculées, denticulées; fl. jaunes, petites; silic. indéh. subtriang. à 3 loges, les 2 sup. villes, l’inf. ì 1 graine; pédic. épais, creux, plus courts que les silic., a été rencoutró subsp. ì Montlignon, Alfort, Rueil. 


\section{Genre 1̈. - CAMELINA Crantz. - Cameline.}

Silic. en paire oblongue, ventrues, peu renfl., à valves jaunatres, dures; grappes fructif. et pédone. assez allongís.

C. sativa Crantz. 124.

Ciult. el subsp. - Jn-Ji.

Silic. en poire obovale, convexes, ni renfl. ni ventrues, à valves grisàtres, dnres; grappes et pódonc. très allongís.

C. silvestris Wallr. 125

Moiss. ch. - Ju-Jt.

Camelina fotida fries a ité reneontri dans les eh. de lin. Grappes fructif. eourles; silic. en toupie, tronquées, échaneries au sommet, tr. renfl. it ralves molles.

\section{(ienre 46. - NESLIA Jesv.}

Plante ann. dressés; f. rad. oblongues ent. ou peu dentrées; les caul. lancéol., aig., embrassantes-auriculíes . N. paniculata Jjesv. 126 Ch. rale., moiss. - Mai-Jt.

\section{Genre $4 \bar{i}$. - Calepina Idans.}

Plante ann. un peu glauque ì tiges italies ascendantes; f. rad. en roselte lyrées ou sinures, les caul. ent. ou dentíes, embrassanlesauriculées. . . . G. Corvini Adans. 127 Lieux incultes, nat. - Mai-Jı.

\section{Genre 18. - BUNIAS R. Br.}

Plante bisan. ou viv.; $\mathrm{t}$. de $40 \mathrm{~cm}$. ̀े $1 \mathrm{~m}$. pub. rudes.

B. orientalis L. 128

Pl. istroduite. - Nai-Jl.

B. Erucago L., observé à Dreux, ann. ; silir. sublétragones renfl. it it angles ailés et dentés en crète: style filiforme ígalant la moitió de la silie.

\section{Genre 49. - ISATIS L. - Pastel.}

Pl. bisan.; fl. pelites; grappes fruclif. dressées en corymbe ì pídic. filiformes, réfléchis, plus courts que les silic.

I. tinctoria L. Pastel 129

Lieux incultes, arides, carrieres. - Mai-Ju.

Cult. autrefois pour la teinture; ses $\mathrm{f}$. Pournissaicust l'indigo indigene.

\section{Grare 30. - BisGutella L. - Lunelière.}

Pl. viv. à sonche ípaisse el lign.; f. rad. dentíes ou pinnatifides, rar. ent.; les caul. auriculées embrassantes. . . . B. lævigata L. 130 liochers et roteaux rale. - Mai-Jn.

\section{Genre :1. - IBERIS L.}

Pl. ann. ou bisan. à t. rameuses; silic. suborbiculaires imarginées à lobes triang.; fl. blanches. . . . . . . . I. amara L. 131 Ch. cale. - Mai-It.

Var. ì fl. violettes, petites; style long. saillant. (I. arvatied Jord.) Iberis intermedia Guers. irdiqué entre Mantes el Rouen, se distingue à ses f. lin. ent., à ses silic. fort. Chancrées à lobes larges triang., aig., divergents.

On cult. I. umbellata L.; ann., fl. roses, grappe fruclif. courte en corymbe dense; silic. à lobes dressés sur des pédic. dressés.

On cult. aussi $I$. sempervirens $\mathrm{L}$., vir.; liqu. a la base; fl. blanches ; grape fructif. assez làclıe, à pédic. étalés ou réfléchis; silic. ù lobes ovales subaigus.

Gente 32. - teesdalia R. Br.

Petite pl. ann. à t. ord. nombr., la centr. dressce et nue, les lat. ascendantes et à $2-3$ petites f.; silic. ovales-arrondies ou peu atténuées à la base. . . . . . . . T. nudicaulis R. Br. 132 Lieux sabl. - Ivr.-Jn. 


\section{Genre 33. - THLASPI L.}

F. infér. sinućes dentées, les supér. à oreillettes aig.; pl. d’un vert gai à odeur alliacée; graines strićes. . . . . . T. arvense L. 133 Lieux cult., décombres, vignes. (Monnoyère.) - Mai-Sept.

F. ent. ou denticulćes, ì oreillettes obtuses ou subaiguës; pl. plus ou moins glauque, inodore; graines lisses.

Style bien plus court que les lobes de la silicule; anth. jaunatres; pl. ann. . . . . . T. perfoliatum L. 134 Ch. calc., vignes. - Avr.-Mai.

Style dépassant les lobes de la silicule; anth. lilas; viv.

T. montanum L. 135

Bois, rochers et coteaux calc. - Avr.-Mai.

\section{Genre 3 \%. - CAPSELLA Medik.}

Silic. allongées plus long̣. (fue larg., à bords latéraux formant une ligne droite ou convexe; cal. verlâtre 2 fois plus court que la cor.

C. Bursa-Pastoris Moench. 136

Lieux cult., ch. - Mars-Nor

Silic. courtes presque aussi larè. que long., à bords lat. arqués en dedans et concaves; cal. rougeâtre égalant presque la cor.

Lieux sees, berges des rivières. - Avr.-Mai.

C. rubella Reut. 137

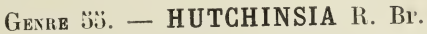

Petite pl. ann. à fl. très pelites; pét. dépassant à peine le cal.; pédic. fructif. étalés 2 fois plus longrs que les silic. . H. petraea R. Br. 138 Lieux pierreux, rochers, murs. - Avr.

\section{GeNRe 36. - LEPIDIUM L.}

+ Silic. larg. ailées, échancrées au sommet; pédonc. fructif. égalant environ la silic.

X Silic. orb.; pédonc. dressés; f. infér. 1-2 fois pennatiséquées, les supér. lin., sessiles; pl. glabre. . . . . . L. sativum L. 139

Cult. et subsp. (Gresson alénois.). - Jn-Jt.

X Silic. ovales ou oblongues; pédonc. étalés; f. oblongues, les rad. ent. ou sinuées dentíes, les supér. élargies, embrassantes auriculées; pl. poilue.

Style inclus ou dépassant peu l'échancrure; silic. couverte de petites écailles; ann. ou bisan. . . L. campestre R. Br. 140 Lieux arides. - Mai-Jt.

Style dépassant beaucoup l'échancrure; silic. sans écailles; viv.

Pelouses sèches sabl. - Mai-Jn.

L. heterophyllum Benth. 141

+ Silic. non ou à peine ailées, ent. ou à peine échancrées; pédonc. fructif. 2-4 fois plus longs que la silic.

= F. de la t. larg., ovales ou oblongues.

F. embrassantes auriculées; panicule serrée en corymbe; silic. indéh., en coeur, non échancrées, style tr. saillant

\section{Draba L. 142}

Ch., décombres. - Mai-Jt.

F. non embrassantes; pan. pyramidale; silic. orb., un peu échancrées; style tr. court.. . . . L. latifolium L. 143 Prés hum., bords des rivières. - Jn-Jt.

= F. de la t. lane.-linéaires ou linéaires.

Q Silic. ovoïdes, aiguës, non échancríes; style court, pl. rameuse dès la base, viv. . . . . . L. graminifolium L. 144 Lieux incultes et secs. - Jn-0et. 
Q. Silic. un peu échancrées au sommet; style nul; pl. rameuses supérieurement, ann.

Silic. larg. ovales non ailées; pét. avortés 2 ét.; f. infér. pennatifides, les sup. linéaires ent. . . . . L. ruderale L. 145 Décombres, pied des murs. - In-.It.

Silic. orbiculaires, ét. ailíes; pét. dépassant le cal.; 6 ét.; 1 . inf. dentées ou incisées, les supér. lin. denties.

Décombres, plante américaine introduite. - Mai-.It.

L. virginicum L. 146

Lepidium apetaluin Willd. pl. américaine, a été rencontrée subsp. à Chantilly ; diffère de $L$. virginimu, par silic. plus petites, f. rad. pennatifides, graines ì cotylédons incombants (dans $L$. virginicum les cotylédons sont accumbants).

\section{Gente $: \bar{i}$. - SENEBIERA Poir.}

Pl. gl. à t. conchées-ítalées, rameuses, srappes fruclif. courtes à pédic. égalant les silic. ou plus courts. . . . . . S. Coronopus Poir. 147 Décombres, chemins. - Mai-.ll.

s. pinnatifida DC., pl. américaine, a les t. vel. hér., les grappes fructif. allongées, à pédic. plus longs que les silic. bilohées.

Rapistrum migosum .1ll, ann., vel., fl. jaunes, silic. ì 2 articles indéh., le sup. plus gros, glob., rugucux, l'inf. ovale; f. inf. lyrées, les sup. lam., dentées.

\section{Fayille 7. - CISTINÉES.}

Stigmate trilobé à lobes peu marıués, ét. toutes ferliles; graines sans raphé; f., au moins les inf. opp. . . . HELIANTHEMUM 58

Stigmate trilobé, presque trifide; íl. extérieurs stíriles à filets grèles moniliformes; graines pourvues d'un raphé; f. iparses.

FUMANA 59

\section{Genre :8. - heliANTHEMUM Gaertn.}

+ T. lign., 3 sép. égaux; f. lin. à bords enroulés, sans stip.; fl. blanches. Bois et bruyères sabl. - Iai-Jn.

H. umbellatum Mill. 148

+ T. herb. ou lign. à la base; $\ddot{3}$ síp. inégaux, les 2 ext. plus petits.

$\times$ Style court, droit, ét. sur 1 rang; fl. jaunes souvent tachées de noir à l'onglet; ann. . . . . . . . H. guttatum Mill. 149 Lieux sabl. - Mai-It.

$\times$ Style long, genouillé ou contonrní à la base; ét. sur plusieurs rangs ; pl. viv.

= F. sans stip.; pét. petits dépassant peu les sép.; style contourné en cercle. . . . . . . H. montanum Vis. 150 Pelouses et coteaux cale. (H. caıum Dun). - Ilai-It.

= F. stip.; péi. gr. bien plus longs que les sép.; style genouillé.

Fl. blanches; sép. tom.; stip. en alène. H. polifolium DC. 151 Pelouses sèches, côteaux calc. - Mai-Jt.

Fl. jaunes; sép. à peine poilus. . . . H. vulgare Gaertn. 152 Lieux secs, pelouses. - Nai-.It.

\section{Genre :9. - FUMANA Spach.}

Pl. lign. à la base, étalée diffuse, à rameaux couchís; f. alternes, sans stip.; fl. solit. jaunes, 1-4 ì la partie sup. des rameaux, toutes laterales, sans bractées. . . . . . F. procumbens Gren. G. 153 Coteaux pierreux calcaires. - Mai-Jt. 


\section{Famille 8. - VIOLARIEES}

\section{Genre 60. - VIOLA L.}

+ Les 2 pét. sup. redressés, les latéraux étalés; sligmate en crochet aig. ou tronđuué au sommet.

X Stigmate épaissi et obliquement tronqué au sommet; pl. aeaule, gl. à souche émettant des rhizòmes souterrains blanchàtres; $\mathrm{f}$. arrondies en rein crénelées; fl. petites d'un lilas pâle, veinćes de violet . . . . . . . . . . . V. palustris L. 154 Marais tourb., silic. - Mai.

X Stigmate atténué et courbé en crochet aiğu au sommet.

= Sép. ovales obtus; f. pub. toutes rad. ou insérées sur des rejels ramp.; raps. arrondie.

Q Souche sans stolons ni rejets ramp.; fl. inodores.

Prés, coteaux, surtout calc. - Mars-Mai.

V. hirta L. 155

a Souche munie de stolons ou de rejets ramp.; fl. odorantes.

Souche à rejets courts non radirants; stip. lin. lancéolées; fl. blanches à éperon jaunàtre. . . . . V. alba Bess. 156 Bois, haies des terrains calc. - Mars- Irr.

Souche longuement ramp.-stolonifère; stip. ovales-lanc.; fl. d'un violet foncé; rar. carnées ou blanches, à éperon violacé.

Bois, haies. - Mars-Mai.

V. odorata L. 157

= Sép. lanc. aig.; f. gl. ou pub. alt. sur les t. dressées; caps. trigone

Q T. florifère naissant de la souche; pas de rosette centrale.

- Pl. et f. gl.; fl. petites bleu pàle; t. de 10 à $20 \mathrm{~cm}$.

踏 F. ovales-oblongues en cœur à la base; stip. du milieu de la t. linéaires-aiguës, 2-3 fois plus courtes que le pétiole non ailé . . . . . . . . . . V. canina L. 158 Prés argileux, pelouses. - Mai-Jn.

- F. ovales allongées décurrentes sur le pétiole; stip. du milieu de la t. lanc. égalant la moitié du pétiole ailé ou plus longues que lui.

F. ovales allongées arrondies ou en roin à la base; stip. lanc. oblongues incisées dentées plus longues que le pétiole.

Prairies argileuses. - Mai.

V. pumila Vill. 159

F. ovales lanc. en cour à la base; slip. lanc. aiguës, finement dentées, celles du milieu égalant la moitié et les supér. la totalité du pétiole ...... V. stagnina Kit. 160 Prairies argileuses. - Mai.

- Pl. et f. pub. ; fl. gr. bleuàtres; t. de 20 à $50 \mathrm{~cm}$. ; f. pub., lanc. acuminées, presque en coeur à la base, à pétiole ailé; stip. ovales lanc., foliacées, incisées dentées, celles du milieu plus longues que le pétiole ....... V. elatior Fr. 161 Prairies argileuses, buissons. - Mai.

Q T. florifères naissant à l'aisselle des f. d'une rosette centrale sté-

rile; f. ovales en cour... . . . V. silvestris Laink. 162 Bois. - Avr.-Hai.

Varie à éperon étroit, violacé, fl. asse\% nelites (V. Reichenbachiaun, Jord.) ou à éperon épais et blanchitre, fl. gr. (V. Riviniana Reich.).

+ Les 4 pét. sup. redressés; stigmate élargi en entonnoir.

¿ Pl. ann. ou bisan. gl. ou légèr. pub.; stip. à lobe terminal crénelé. Pét. dépassant le cal., les supér. violels, les latér. et l'infér. jaunes ou violets........... V. tricolor L. 163 Cult. el ch. - Avr.-Sept. 
Pét. plus courts que le cal. ou de sa longueur, jaunes, rar. un peu striés de violet. . . . . . . . V. arvensis Murr. 164 Ch. cult. - Avr.-Sept.

o Pl. viv., vel. hér. grisâtre; stip. à lobe lerminal grand, ent.; fl. violettes, grandes ..... . V. rothomagensis Iesf. 165 Coteaux calc. - Air.-Sept.

\section{Fayille 9. - RÉSÉDACÉES}

Fr. caps. s'ouvrant au sommet, formé de 3-ł cap. soudés, à 1 loge renf. pl. graines, à 3-4 dents et ì 3-4 angles. . . . . . . RESEDA 61 Fr. formé de ỳ carp. isolés, étalés en étoile, s'ouvrant en dedans, renfermant chacun une graine......... ASTROCARPUS 62

\section{Genre 61. - RESEDA L.}

+ Pét. blanchâtres, caps. penchíes; graines rugueuses.

Sép. s'accroissant après la floraison; filets des ct. dilatés au sommet; anth. jamintres; caps. obovale . . . R. Phyteuma L. 166 Ch. pierreux. - Mai-Sepl.

Sép. s'accroissant à peine après la floraison; filets des ét. non dilatés; anth. rougeâtres; caps. courte, renfl. . R. odorata L. 167 Cult. pour ses fl. odor. (Résérla). - Mai-Sept.

+ Pét. jaunàtres ou verdâtres; caps. dressées; graines lisses.

F. de la t. pennatifides; 6 sép. et 6 pét.; caps. oblongues; viv. ou

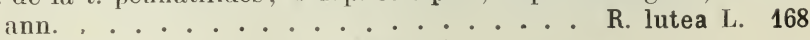
Lieux sees et pierreux. - Mai-Sept.

F. oblongues lancéolées; 4 síp. et 4 pét.; caps. petites subgrlob.; pl. bisann.. . . . . . . . . R. Luteola L. 169 Ch. incultes, murs, rochers. (Gaude.) - Mai-Sepl.

La Gaude fournit une teinlure jaune.

\section{Genre 62. - ASTROCARPUS Neck.}

T. simples ou rameuses, ascendantes on diffuses; f. rad. oblongues spathulées, les caul. lin.; fl. hlanches en grappes efililíes tr. allongées; 12-10̈ ét. à filets scabres. . . . A. purpurascens Raf. 170 Coteaux et ch. sabl. on pierreux. - Mai-Sept.

\section{Famile 10。 - POLYGALÉES \\ Gexre 63. - POLYGALA L.}

+ T. sans rosettes de f.; f. infér. plus petites que celles de la tige.

$\times$ F. inf. et des ram. stériles opp.; grappes paraissant lat, bract. plus courtes que le péd.; t. grèles couchées étalées rameuses à fl. bleu pâle ou blanches. . . . . P. serpyllacea Weihe 171 Bruyères et bois silic. - Mai-Sept.

X F. toutes alt. ou éparses; grappes term., bract. moyenne égalant ou dépassant le pédic.

Grappe allongée lâche mnilat.; fl. assez gr. blenes, roses ou blanches; bract. peu proéminentes; nervures des ailes nettement anastomosées........... . . . . vulgaris L. 172

Pelouses, prés. - Mai-Jl.

Grappe serrée, conique; fl. assez petites, roses; bract. très proéminentes au sommet de la jeune grappe; nervures des ailes obsc. anastomosées; pl. un peu lign. à la base. P. comosa Schk. 173 Pelouses et lieux herbeux des coteaux calc. - Mai-Jt.

+ T. munies de rosettes de $\mathrm{f}$.; f. inf. plus gr. que celles de la tige.

Bract. plıs courtes que le pédic.; caps. petite, plus long. et plus large que les ailes; ailes de $3-\dot{3} \mathrm{~mm}$. à 3 nervures à peine ramifiées non anaslomosíes au sommet; pl. à racine grêle, à saveur amère; fl. tr. petites blanchàlres ou blentitres. P. amara L. 174 Prairies tourb., prés, pelouses des terrains cal. - Mai-Jt. 
Bract. moyenne dépassant le pédic.; caps. assez gr. plus courte et ord. plus large que les ailes; ailes de 6-8 $\mathrm{mm}$. à 3-3 nervures ramifiées anastomosées au sommet; pl. à souche dure à saveur herbacée; fl. assez gr., bleues, roses ou blanches.

$$
\begin{aligned}
& \text { P. calcarea Schultz } \\
& \text { Pelouses et coteaux calc. herbeux. - Mai-Jt. }
\end{aligned}
$$

\section{FAMille 11. - DROSÉRACÉES}

F. toutes en rosette rad., à limbe couvert de cils gland. rouges; fl. blanches petites, dépourvues d'écailles nectarifères, en grappe term.; styles 3 ; caps. à 3 valves. . . . . . . . . . DROSERA 64

F. en rosette radic. et 1 seule sur la t., gl., vertes, opaques; fl. blanches, gr., solit., term., présentant 5 écailles nectarifères laciniées opp. aux pét.; 4 stigmates sessiles; caps. à 4 valves. . PARNASSIA 65

\section{GenRe 64. - DROSERA L. - Rossolis.}

+ F. appliq. sur le sol, à limbe orb., brusq. rétr. en pétiole vel.; hampes dr. naissant du centre de la rosette, 3-4 fois plus long. que les f.; graines fusiformes ailées aux 2 bouts. D. rotundifolia L. 176 Marais tourb. - Jn-At.

$+\mathrm{F}$. dress. à limbe lin. oblong ou obovale.

$X$ Hampes courbées à la base, naissant lat. sous la rosette, dépassant à peine les f. à limbe obovale; graines obovales, tuberc. non ailées . . . . . . D. intermedia Hayn. 177 Marais tourb. sil. - Jt-At.

$\times$ Hampes dr. naissant du centre de la rosette.

F. à limbe lin. oblong; caps. cyl. dépassant un peu le cal.; graines fusiformes, ailées aux 2 bouts, chagrinées. D. longifolia L. 178 Marais tourb. des terrains calc. - Jt-At.

F. à limbe obovale; caps. 1-2 fois plus courte que le cal. souvent stérile . . . . . . D. obovata M. et K. 179 Narais tourb. - Jt-At.

\section{Genre 6. - PARNASSIA L.}

Pl. viv. gl.; t. dress.; 1 f. caul. ovale en cœur, sessile, embrass.; f. rad. en rosette, long. pétiolées à nervures converg.; pét. veinés 2-3 fois plus longs que le cal. . . . . . . . . . P. palustris L. 180 Marais tourb., coteaux argil. et calc. - At-Sept.

\section{Famile 12. - CARYOPHYLLÉES}

+ Cal. monosépale, à divis. soudées au moins dans leur moitié infér., onglet ord. très long (Silénées).

$\times$ 3-3 styles; cal. muni de nervures commissurales; caps. s'ouvrant par క-10 dents ou baie indéh.

$=3$ styles, baie, ou caps. s'ouvrant par 6 dents.

Baie glob., noire, à 3 loges; cal. en cloche, tr. évasé au sommel.

CUCUBALUS 66

Caps. à 1 loge, s'ouvrant par 6 dents; cal. peu ou point évasé au sommet....................... SILENE 67

$=\mathbf{5}$ styles, caps. s'ouvrant par 5 ou 10 dents . . . LYGHNIS 68

$\times 2$ styles; cal. sans nervures commissurales; caps. s'ouvrant par 4 dents.

Q Cal. sans calicule ni écailles à la base, graines en rein portant l'ombilic sur le côté.

Cal. tubul. à "̉̉ dents; onglet allongé, lin., muni de bandelettes ailées, caps. oblongue .......... SAPONARIA 69 
Cal. en eloche à 3 lobes profonds, onglet tr. court en coin; caps. voïde _. . GYPSOPHILA 70

a Cal. muni d'un calicule ou d'écailles à la base; graines en bouclier

à ombilic central . . . . . . . . . . . DIANTHUS 71

+ Cal. polysép.; à divis. libres ou à peine soudées à la base; pót. à onglet très court, rarement nuls (Alsinées).

- F. non stipulées, simplement opl.

oaj Caps. s'ouvrant par 3-3̈ valves entières.

4-כ̆ styles; caps. à 4-ว̆ valves; fl. solit. sur de longs pédonc. axill. ou terminaux ................ SAGINA 72

3 styles; caps. à 3 valves; fl. en cymes ou en panic. ALSINE 73

\& Caps. s'ouvrant par 3 valves bidentées, par 6 valves ou par $6-10$ dents ; graines ord. tuberculeuses.

○ 3 styles.

Pét. ent. à peine émarg.; caps. à 8-10 dents; 10 ét.; graines en rein ARENARIA 74 Pét. bifides, rar. nuls; caps. s'ouvrant au sommet en 6 valves profondes et ent. ; 10 ét., rar. 2-i); graines arrondies; compriSTELLARIA 75

Pét. denticulés; caps. cyl., plus longue que le cal., à 6 dents profondes, ent., roulées en dehors; 3 - 3 ét.; graines peltées.

HOLOSTEUM 76

○ 4-3̈ styles; caps. ovoïde ou cyl. s'ouvrant au sommet par 8-10 dents ent.; graines en rein; fl. en cymes dichotomes.

GERASTIUM 77

- F. stipulées souvent fasc. on verticillées.

¿i styles, caps. s'ouvrant dans le haut par è valves opp. aux sép.

3 styles, caps. s'ourrant jusque près de la base par 3 valves alt. avec les sép.

\section{Genre 66. - GUCUBALUS L.}

Pl. viv., pub., à souche ramp.; t. de 40-80 cm. étalées-divariquées, cassantes; f. ovales aiguës, brièv. pétiolées; fl. d'un blanc verdàtre penchées à $\ddot{3}$ pét. bifides avec 1 dent à la gorge, onglet long; 10 ét.

$$
\text { Haies, buissons. - Jt-Sept. }
$$

G. baccifer L. 181

\section{Genre 67. - SILENE L.}

+ Cal. fructif. renfl. en vessie, à 20-30 nervures.

Viv.; cal. subglob., gl., veiné en réseau, à dents larg. triang.; caps. subglob., 3 fois plus long. que le carpophore gl.; fl. blanches, rar.

rosées.

Ann.; cal. conique, pub., à 30 neroun carpophore; fl. roses.

alène; caps, ovoïde-conique, sans carpophor, S. conica L.

Champs sabl. - Mai-Jt.

+ Cal. iructif. non renfl. en vessie, à 10 nervures.

X Cal.gl., t. visqueuse supér.

F1. dioïques ou polygrames en petits vert. formant une pan. étroite; pét. lin. ent., vert jaunâtre; caps. sessile. . S. Otites L. 184 Lieux sabl., coleaux arides. - Mai-At.

Fl. hermaphrodites en cymes formant une ample pan. lâche; pétales profond. bipartits, d'un blanc sale, caps. stipitée à peine plus long. que le carpophore . . . . . S. catholica Oth. 185 Bois, taillis, nat. - Jt-Sept. 
$\times$ Cal. poilu.

$=\mathrm{Pl}$. viv. à fl. blanches ou rougeâtres disposées en long. panic. unilat., làche; pét. bipartits, couronnés d'écailles lanc. aiguës; filets des ét. glab. ; caps. petite, ovale conique, 3-4 fois plus long. que le carpophore pub. . . . . . . . S. nutans L. 186 Bois secs et sabl. - Mai-Jt.

$=$ Pl. ann. à fl. en grappes ou en cymes dichotomes pauciflores.

Fl. blanchâtres ou rosées en grappes unilat.; pét. ent. ou émarg.; caps. ovoïde à carpophore très court; filets des ét. vel. à la base.

Ch. sabl. - Mai-Sept.

S. gallica L. 187

Fl. roses en dessus, jaunatres en dessous en cymes dichotomes ; pét. bifides; caps. ovoïde conique 6-8 plus longue que le carpophore vel.; filets des ét. glab. . . . . S. noctiflora L. 188 Ch. calc. ou argil. - Jt-Oct.

\section{Genre 68. - LYGHNIS L.}

+ Cal. hér.; pl. velue.

X Pl. ann. blanchâtre, velue soyeuse; fl. hermaphrodites; caps. à כ̌ dents ; f. lin., tr. long.; fl. rouges à pét. ent. ou émarg., sans écailles à la gorge, à onglet muni de bandelettes ailées. L. Githago Scop. 189

$$
\text { Ch., moiss. - Jn-Jt. }
$$

X Pl. viv., verdâtres; fl. diö̈ques; caps. à 10 dents, pét. bifides: ovales.

Pl. vel., non gland.; fl. rouges; caps. petite, subglob. à dents fori . enroulées . . . . . . . . . L. diurna Sibth. 190 Bois hum., haies. - Mai-Jt.

Pl. vel. gland.; fl. blanches ou un peu rosées; caps. grosse ovale conique à dents dressées . . . . . . L. vespertina Sibth. 191 Lieux incultes et cult. - Mai-Sept.

+ Cal. gl.; pl. vertes glab. ou pubérulentes; fl. roses ou rouges; f. oblongues lanc., les sup. lin., ciliées à la base.

Pét. profond. découp. en lanières lin.; carpophore nul; tige hispidule surtout à la base. . . . . . . L. Flos-cuculi L. 192 Prairies et bois humides. - Mai-Jt.

Pét. tronqués, à peine émarg. ; caps. ovoïde égalant le carpophore gl.; t. glab., très visq. supér. . . . . . L. Viscaria L. 193 Bois secs, sabl. - Mai-Jn.

On cultive $L$. coronaria Lamk, pl. tom. soyeuse, blanchâtre, fl. rouges à pédonc. allongés uniflores; cal. à côtes saillantes; pét. échancrés, caps.
sessile.

\section{Gente 69. - SAPONARIA L.}

Pl. ann., glab. et glauque; fl. long. pédonc., en pan.; cal. ovoïde à $\breve{5}$ angles verts et ailés; pét. roses, nus à la gorge. . . . S. Vaccaria L. 194 Moiss. des terrains calc. ou argil. - Jn-Jt.

Pl. viv.; fl. brièv. pédonc. en cyme compacte; cal. cylind. à 1:̈-20 nervures; pèt. couronnés d'écailles lin. et planes. S. officinalis L. 195 Lieux incultes, bords des chemins. - Jn-Sept.

\section{Genre 70. - GYPSOPHiLA L.}

Petite plante ann., rameuse dès la base; f. lin. atlénuées aux 2 bouts; fl. roses, veinées, petites, long. pédonc. en cyme dichotome irrégul.;
pét. denticulés ou émarg.; cajs. à carpophore court.

Champs sabl, un peu hum., mares desséchées. - Jt-Sept. 


\section{Genre 71. - Dianthus}

+ Cal. court à 3 angles verdâtres; écailles du calicule ovales obtuses, dépassant le cal., ent. scarieuses; capsule elliptique; fl. rose pâle, tr. petites, réunies 1-6 en tête serrée dans un invol. scarieux; pét. à limbe dress., émarg., 4-ŏ fois plus court que l'onglet.

Lieux arides. - Nai-Sept.

+ Cal. cylind., couvert de nervures parallèles rapprochées; écailles du calicule non ent. scarieuses; caps. cylind.

X Fl. réunies en tètes entourées de long. bractées.

Écailles du calicule herb., égalant ou dépassant le cal.; gaînes des f. aussi long. que larg.; cal. et calicule vel.; pl. bisan., pub.

Bois, coteaux. - Jn-Jt.

Écailles du calicule coriaces; gaines des f. plus long. que larg.; pl. viv., glabre........ D. Carthusianorum L. 199 Bois et coteaux. - Jn-Sept.

$X$ Fl. solit. ou réunies 2-3, non entourées de bractées.

$=$ Pét. profond. laciniés jusqu'au delà du milieu, hér. de poils pourpres au-dessus de l'onglet; fl. roses ou lilacées, gr., odor., solit. ou géminées, en pan.; f. molles, lanc. lin. aiguës, les inf. obtuses; écailles du calicule larg. ovales égalant le quart du calice.

Bois sabl., prairies hum. - Jt-Sept.

D. superbus L. 200

= Pét. ent., crén. ou dentés.

Écailles du calicule larg., courtes, brusq. contractées en pointe, striées seulement au sommet; t. gl., glanques; f. des fasc. stériles lin. long. de $5-10 \mathrm{~cm}$; fl. rouges, roses ou blanches odor.

Ruines, vieux châteaux. - Jn-Sept.

D. Caryophyllus L. 201

Écailles du calicule étroites, atténuées en pointe longue, striées au moins dans leur moitié sup.; t. pubérulentes, scabres; f. des fasc. stériles lin. elliptiques long. de 1-2 cm.; fl. rouges avec un cercle pourpre autour du centre . . . D. deltoides L. 202 Pelouses et bois sabl. - Jn-Sept.

\section{Genre 72. - SAGINA L.}

+ 4 sép., 4 ét., caps. à 4 valves, pét. plus courts que les sép. ou nuls. $X \mathrm{Pl}$. viv. gl., couchée radicante; pédonc. courbés en crochet après la flor., puis redressés, glabres . . . . S. procumbens L. 203 Lieux frais, pied des murs. - Av.-0ct.

X Pl. ann., ascendante ou dressée, non radicantes; pédonc. droits ou légèr. courbés.

Sép. ovales, obtus, plus courts que la caps., établis en croix à la maturité ; f. ciliées à la base ....... S. apetala L. 204 Champs sabl., murs. - Mai-Oet.

Sép. appliqués sur la caps. et l'égalant, quelquefois plus courts; les 2 sép. extér. aig.; f. glabres ou ciliées. . S. ciliata Fr. 205 Champs sabl., mares desséchées. - Mai-Sept.

+5 sép. et pét.; 10 ou 5 ét.; caps. à 5 valves.

T. naissant d'une rosette cent. ; fl. en grappes, brièv. pédonc., axill. et term. pédic. dress.; lin. à peine mucronées, les supér. tr. courtes, fasc. et rendant la t. comme noueuse; 10 ét.; pét. 2 fois plus longs que les sép. . . . . . . . S. nodosa Fenzl. 206

Gazons hum., bords sabl. des marais, pr. tourb. - Jn-Sept.

T. florifères naissant de cal.; pédic. se recourbant en crochet au sommet après la flor., redressés à la maturité; f. lin. aristées, cil.; 5 ét.

Lieux sabl. humides. - Mai-Jt. 


\section{Genre 73. - ALSINE Vahl.}

Pét. petits, plus courts que les sép.; pl. ann., gl. ou pub.-gland. (var. viscidula G. et G.); caps. oblongue conique; graines chagrinées.

Lieux sabl., murs. - Mai-Sept.

A. tenuifolia Crantz 208

Pét. plus longs que le cal.; pl. viv., à souche rameuse; caps. ovoïde; graines tuberculeuses . . . . . . . A. setacea M. et K. 209 Coteaux sabl. arides. - Mai-Jt.

\section{GenRe 74. - ARENARIA L.}

+ F. coriaces, lin.-lanc., aristées, à nervure dorsale tr. forte, à bords épaissis; sép. membr. à 1 nervure: pét. une fois plus longs que le cal.; pl. vivace. . . . . . . A. grandiflora L. 210 Coteaux sabl. arides. - Mai-Jn.

+ F. ovales, aiguës, molles, planes, à bords non épaissis; pl. ann., pét. plus courts que le cal.

X F. pétiolées à 3-: 3 nervures, pédic. 3 -4 fois plus longs que les fl.: caps. plus courte que le cal. à dents enroulées; gr. lisses.

Bois couverts, haies, buissons. - Mai-Jt.

A. trinervia L. 211

X F. sessiles à 1 nervure, pédic. égalant ou dépassant 1 fois les fl.; caps. dépassant le cal., à dents dressées; graines chagrinées.

Caps. ovale ventrue, coriace; sép. ovales acuminés; pl. diffuse, tr. rameuse, assez épaisse. . . . . A. serpyllifolia L. 212 Murs, bords des chemins. - Mai-Jt.

Caps. cylindro-conique, non ventrue, à parois minces; sép. lanc. long. acum.; pl. grèle. . . . . . A. leptoclados Guss. 213 Murs, bords des chemins. - Mai-Jt.

\section{Genre 73. - STELLARIA L.}

+ F. ovales ou en cœur, les inf. pétiolées; t. arrondies.

Pét. gr. 2-3 fois plus longs que les sép.; caps. cylind. dépassant long. le cal.; pl. vivace, à t. pub. . . . . . . . S. nemorum L. 214 Bords des ruiss. - Jn-Jt.

Pét. petits atteignant à peine les sép., ou nuls; caps. ovoïde un peu plus longue que le cal.; pl. ann. ou pérennante; t. avec 1 ligne de poils alternant d'un nœud à l'autre. . . S. media Cyr. 215 Lieux cult. et incultes. - Av.-Oct.

Varie ì f. gr., pét. égalant le cal., 10 ét. (S. neglecta Weihe) ou f. petites, pét. nuls, 2-3 ét. (S. Boræana Jord.).

+ F. oblongues, lanc. ou lin., sessiles, t. quadrangulaires.

$X$ Pét. à lobes rapprochés, pl. vertes des haies et des bois.

Pét. 2 fois plus longs que les sép.; bract. herb. cil.; caps. subglob.

égalant le cal. ; f. scabres . . . . . . . S. Holostea L. 216 Bois, haies. - Av.-Jn.

Pét. égalant ou dépassant peu les sép.; bract. scarieuses cil.; caps. oblongue dépassant le cal.; f. ciliées. . . S. graminea L. 217 Bois, haies. - Jn-Jt.

$X$ Pét. à lobes divergents; pl. glauques des lieux hum., tr. rar. vertes

F. lanc. ou lin., lisses, non cil.; cyme term. unique, pét. 1-2 fois plus longs que les sép. . . . . S. palustris Ehrh 218 Prés maréc. - Jn-Jt.

F. oblongues lanc., cil. à la base; cymes lat. et term.; pét. plus courts que le cal. . . . . . . . S. uliginosa Murr 219 Fossés, mares. - Jn-Sept. 


\section{Grare 76. - HOLOSTEUM L.}

Petite pl. ann., glauque, pub. gland. supér.; f. oblongues, les infér. en rosette, les caul. 2-3 paires sessiles; fl. blanches en omb. term. à pédic. inégaux, réfractés après la flor., puis redressés.

Ch. sabl., murs. - Av.-Mai.

H. umbellatum L. 220

\section{GenRe 77. - GERASTIUM L.}

+ 4 sép.; 4 pét. ent.; 4 styles; caps. s'ouvrant par 8 dents, plus courte que le cal.; petite pl. ann. glabre et glauque.

C. erectum Coss. et G. 221

Lieux sabl., mares silic. desséchées. $-\Lambda \mathrm{v}$.-Jn.

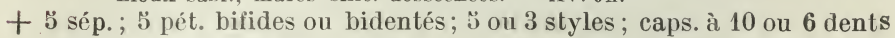
égalant ou dépassant le cal.

$X \mathrm{~F}$. ovales en coeur, larges de 2 à $3 \mathrm{~cm}$.; styles alternant avec les sép.; caps. ovoïde à "̈ valves bidentées . C. aquaticum L. 222 Lieux hum. - Jn-0ct.

F. jamais en cour moins larges; styles opp. aux sép.; caps. cylind. à 10 dents.

= Pl. ann. dépourvues de rejets stériles; pét. petits plus courts que le cal. ou l'égalant, rar. plus longs.

Q Pét. ou filets des ét. cil. à la base; sommets des sép. barbus et dépassés par les poils.

Fl. agglom., en pan. serrẻe; pédic. fructif. égalant à peine le cal.

$$
\text { Ch. cult. }-A v \text {.-Jn. }
$$

C. glomeratum Thuill. 223

Fl. en cymes laxiflores formant une pan. lâche; pédic. 2-3 fois plus longs que le cal. . . . C. brachypetalum Desp. 224 Ch. cult., talus, murs. - Av.-Nai.

a Pét. et filets des ét. glabres; sommet des sép. glabres.

Bract. et sép. larg. scarieux; pét. bidentés plus courts que le cal. . . . . . . . C. semidecandrum L. 225 Ch. et lieux sabl. - Iv.-Jn.

Bract. et sép. herb. ou à peine scarieux; pét. bifides égalant ou dépassant le cal. ............ C. pumilum 226 Ch. sabl. - Av.-Jn.

Var. à pét. une fois plus longs que le cal. C. litigiosum De Lens.

= Pl. viv. ou pér. à rejets stériles; pét. grands dépassant le cal.

II Fl. en pan. dichotome pluriflore; pét. dépassant à peine les sép.; pl. pérennante. . . . . . . . C. triviale Link 227 Lieux incultes. - Av.-Sept.

II Fl. en cymes pauciflores; pét. dépassant beaucoup les sép.; pl. viv. Pl. blanche tom. à f. lin. oblongues, obtuses; caps. cyl. à dents droites; t. stériles allongées . . $\quad$ C. tomentosum L. 228 Cultivè. - Nai-Jn.

Pl. pub., verte, à f. lanc. ou lin.; caps. cyl. un peu courbée, à dents souvent récurvées; t. stériles peu allongées.

$$
\text { Lieux stèriles, talus. - Av.-Jt. }
$$

C. arvense L. 229

\section{Gente 78. - SPERGULA L.}

+ Graines chagrinées subglob. légèr. compr., entourées d'un rebord tr. étr. chargées ou non de papilles jaunâtres; f. munies en dessous d'un sillon longit. . . . . . . . . . S. arvensis L. 230 Ch. sabl. - Jn-Sept.

+ Graines.aplaties larg. ailées; f. non sillonnées en dessous.

Pét. lanc. aig.; graines lisses, larg. ailées à aile blanche aussi large qu'elles

S. pentandra L. 231 Gh. et lieux sabl. - Av.-Nai. 
Pét. orales obtus; graines ponctuées aux horts, à aile rousse moins large qu'elles . . . . . . . . . S. Morisonii Bor. 232 Lieux sabl., bruyères. - Av.-Jn.

\section{Gente 79. - SPERGULARIA Pers.}

Sép. aigus, blanes scarieux, à carène verte; pl. ent. glabre, dressée; fl. blanches, en cymes làches non feuillées, à pét. de moitié plus courts que les sép. sur des pédic. capillaires 2-4 fois plus longs que

le cal. dépassant la caps. . . . . . . S. segetalis Pers. 233 Moiss. des terrains sil., mares sil. desséchées. - Mai-Jt.

Sép. oblongs, obtus, non carénés; pl. couchées étalées, pub. gland. sup);

fl. roses en cymes courtes, lâches, feuillées à pét. plus courts que les

sép. égalant environ la caps. . . . . . . S. rubra Pers. 234

Bords des chemins, quais, décombres. - Mai-It.

\section{Famlle 13. - ÉLATINÉES \\ Genre 80. - ÉLATINE L.}

+ F. et fl. vert. et sessiles; pl. viv., robuste, ayant le port de l'Hippuris vulgaris; 4 pét. et sép.; 8 ét.; 4 styles; caps. à 4 valves; graines presque droites jaunâtres. . . . E. Alsinastrum L. 235 Fossés, mares, étangs. - Jn-Sept.

+ F. opp., rétrécies en pétiole; fl. non vert.; pl. ann., grêles.

Graines recourbées en fer à cheval; cal. à 4 sép. plus longs que les 4 pét.; 8 ét. ; 4 styles; fl. sessiles ou subsessiles; caps. à 4 valves; feuilles à pétiole plus long que le limbe.

Bords des étangs. - Mai-Sept.

E. Hydropiper Schk. 236

Graines un peu arquées; cal. à 3 sép.; 3 pét. un peu plus longs que les sép.; 6 ét. ; 3 styles; caps. à 3 valves; $\mathrm{f}$. à pétiole plus court que le limbe. . . . . . . . . E. hexandra DC. 237 Bords des élangs et des mares. - Jn Sept.

Varie à fl. tétramères; 4 sép., 1 pét., 8 ét., caps. ì 4 valves, pl. plus robuste (E. major Braun).

\section{FAMILLE 14. - LINÉES}

Fl. pentamères : כ̈ sép., libres, ent.; ̋̈ pét. plus longs que les sép.; 5 ét.; caps. à 10 loges monosp.; pl. dépassant $10 \mathrm{~cm}$. . LINUI 81 Fl. tétramères : 4 sép. soudés à la base, bi-trifides; 4 pét. égalant les sép.; 1 ét.; caps. à 8 loges monosp.; petite pl. de $3-8 \mathrm{~cm}$.

RADIOLA 82

\section{Genre 81. - LINUM L.}

+ Fl. jaunes, petites, à pét. seulement 1 fois plus longs que le cal., à pédic. courts égalant le cal.; f. alt., lin.-lanc.; stigmates en tête.

Ch. hum. - Jn-Sept.

L. gallicum L. 238

+ Fl. bleues, roses ou blanches.

X F. toutes opp., obovales ou oblongues; fl. blanches, petites, ì pét. 1 fois seulement plus longs que le cal., à pédic. longs; stigmates en tète. . . . . . . . . L. catharticum L. 239 Prés, bois, bords des chemins hum. - Jn-Jt.

K F. toutes alt. ou éparses, lanc. ou lin.; fl. gr. à pét. 2 fois au moins plus longs que le cal.

= Fl. carnées, sép. tous ciliées gland.; stigmates en tête.

L. tenuifolium L. 240 Coteaux et pelouses sèches des terrains calc. - Mai-JI. 
= Fl. bleues; sép. tous, ou les ext., non ciliés gland.

a Sép. bien plus courts que la caps., les 3 int. ovales obtus, non cil.; stigmates en tête; graines ternes . . L. alpinum L. 241 Lieux pierreux, coteaux calc. arides. - Mai-Jt.

Q. Sép. égalant presque la caps., tous ovales-acum.; stigmates en massue; graines luisantes.

Fl. d'un bleu clair, assez gr., à pét. 2 fois plus longs que le cal.; sép. int. cil.; caps. à cloisons barbues; graines non rostrées; t. ascendantes . . . . . . L. angustifolium Huds. 242 Coteaux, pelouses. - Mai-Jt.

Fl. d'un bleu vif, gr., à pét. 3 fois plus longs que le cal.; sép. tous gl.; caps. à cloisons non barbues; graines rostrées; t. solit. dressées . . . . . . . L. usitatissimum L. 243 Cult. et subsp. (Lin). - Mai-Jt.

\section{Genre 82. - RADIOLA L.}

Pl. ann., gl., tr. grêle, tr. rameuse; f. opp. ovales aiguës à 1 nervure;

fl. blanches, tr. petites en pan. dichotome. • R. linoides Roth. 244 Pelouses hum., allées sabl. hum. - Jn-Sept.

\section{Famlle 15. - TILIACÉES \\ Genre 83. - TILIA L.}

+ F. vertes ou glauques en dessous, à aiselles garnies de poils.

$X$ Bourgeons velus à 3 écailles apparentes; f. grandes, vertes, mollement velues en dessous, à aisselles garnies de poils blanchâtres; fr. gros, obovoïde, à parois ligneuses, à כ̉ côtes tr. saillantes.

Bois. - Fl. Jn-Jt; fr. Oct.

T. platyphylla Scop. 245

X Bourgeons glabres à 2 écailles apparentes; f. gl. ou glabrescentes en dessous, à aisselles garnies de poils roussâtres.

F. assez grandes, vertes et glabrescentes en dessous; fr. assez gros, elliptique, à parois épaisses et résistantes, à 5̆ còtes saillantes.

T. intermedia DC. 246

Pares, bois. - Fl. Jn-Jt; fr. Oet.

F. petites, glauques et gl. en dessous; fr. pelit, glob., à parois minces et fragiles, dépourvu de côtes saillantes.

Bois. - Fl. Jt; fr. Oct.

T. parvifolia Ehrh. 247

+ F. blanches cotonneuses en dessous, à aisselles dépourvues de poils; bourgeons cotonneux; fr. ovoïde, à côtes peu saillantes.

T. argentea Desf. 248

Pares, hords des chemins. - Fl. Jn-Jt; fr. Oct.

\section{FAMille 16. - MALVACÉES}

Calicule à 3 fol. distinctes, libres, naissant de la base du calic.; stig

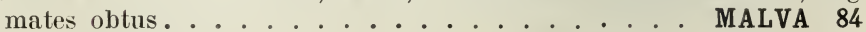

Calicule à 6-9 divis. soudées infér., naissant du pédonc.; stigmates sé-

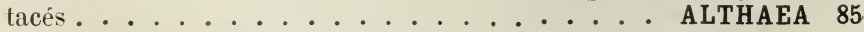

\section{Genre 8'. - MALVA L.}

+ Fl. axill. solit., les term. seules fasc.; cal. enveloppant entièr. les carp. noirs à la maturité; cor. 2-3 fois plus long. que le cal.; pl. vivace, dressée.

Calicule à fol. ovales ou lanc.; carp. gl. ou glabrescents, ridés sur les faces; pl. à poils étoilés. . . . . . . . M. Alcea L. 249 Bords des bois, prés. - Jn·Sept. 
Calicule à fol. lin. étroites, atténuées aux deux bouts; carp. vel. hér., lisses; pl. à poils simples. . . . . . M. moschata L. 250 Bords des bois, prés, prairies artificielles.

+ Fl. axill. et term. toutes agglom. en fasc.; cal. ne recouvrant pas les carp. jaunàtres à la maturité; cor. égalant lo cal. ou 1-3 fois plus long que le cal.; pl. ann., bisan. ou pér. dressée ou étalée.

X F. palmatifides ou palmatilobées, à lobes plus ou moins profonds ; calicule à fol. ovales ou oblongues; cor. gr. 3-4 fois plus long. que le cal.; carp. glabres, ridés; t. dressées ou ascendantes.

M. silvestris L. 251

Décombres, ch. - Jn-Sept.

X F. toutes suborb., superf. lobées, crén.; calicule à fol. lin. étr.,plus courtes que le cal.; cor. petite, égalant le cal. ou 1-2 fois plus longue que lui; carp. pub.; t. couchées ou étalées, ann. ou bisan. Cor. 1-2 fois plus longue que le cal.; carp. lisses ou à peine ridés.

Décombres, cl. - Mai-Sept.

M. rotundifolia L. 252

Cor. dépassant à peine le cal.; carp. ridés réticulés en travers presque alvéolés à la maturité.. . . M. borealis Wallm. 253 Bords des chemins. - Mai-Sept.

\section{Genre 85. - ALTHAEA}

Pl. bisan. dress. 1 à 2 m., poilue; f. rugueuses à $\breve{-7} 7$ lobes; fl. tr. gr., blanches, jaunes, rouges, en grappe spiciforme, term.; carp. velus à bords ailés membraneux. . . . . . . A. rosea Cav. 254 Cult. - Jn-At.

Pl. ann., couchée ou ascendante, hér. de poils raides; f. inf. orb., crén., les autres palmatipartites; fl. axill., solit., bleuâtres sur des pédonc. plus longs que la f.; carp. glabres arrondis sur le dos.

Ch. calc. - Mai-Jt.

A. hirsuta L. 255

On cult. la Guimauve, A. officinalis L. Pl. viv. veloutée blanchàtre à $t$. dress. robustes, à f. tom. à 3-b̆ lobes peu profonds; fl. d'un blanc rosé, fasc., ì cor. 2 fois plus long. que le cal.; carp. tom.

\section{Famille 17. - GÉRANIACÉES}

F. aussi larg. que long.; 10 ét. ord. toutes fertiles; carp. déh., à arêtes gl. en dedans, se détachant en arc de la base au sommet.

GERANIUM 86

F. plus long. que larg.; :̈ ét. fertiles et $\ddot{3}$ sans ant.; carp. indéh. à arêtes poilues en dedans, se roulant en spirale du sommet à la base.

ERODIUM 87

\section{Genre 86. - GeraniUM L.}

+ Pét. à onglet aussi long ou plus long que le limbe ent.; sép. dress.

X F. orb., en rein, palmatifides, à lobes peu profonds, incisés crén. ; cal. gl., ridé en travers à $\mathbf{5}$ angles très saillants; pl. inodore.

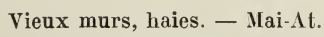

G. lucidum L. 256

$\chi^{\prime}$ F. triang. pentagonales, palmatiséquées, à segments pétiolulés et pennatifides; cal. velu gland., non ridé en travers; pl. à odeur fétide.

Pét. 2 fois plus longs que le cal. à limbe brusq. contracté en onglet; anth. rouges ; carp. glabres ridés en travers.

G. Robertianum L. $2: 7$

Haies, murs. - Av.-Sept.

Pét. dépassant peu le cal. à limbe long. atténué en onglet; anth. jaunes, puis brunes; carp. pub., rar. glabre.

Haies, murs. - Av.-Sept.

G. purpureum Vill. 258 
+ Pét. à onglet beaucoup plus court que le limbe; sép. étalés.

$\times$ Pl. ann. ou bisan. à racine grêle, pivotante; fl. pelites à pét. dépassant peu ou point le cal.

= F. palmatiséquées, découpées en segments lin, atteignant presque le pétiole; sép. aristés; pét. échancrés à onglets courts ciliés.

Pédone. beaucoup plus longs que les f. ; pédic. ¿’-6 fois plus longs que le cal.; carp. glabres. . . . G. columbinum L. 259 Ch., haies. - Mai-At.

Pédonc. plus courts que les f. ou les égalant; pédic. à peine plus longs que le cal.; carp. pub.glanduleux. G. dissectum L. 260 Ch., haies. - Mai-At.

= F. palmatifides, à lobes en coin dépassant rar. le milieu du limbe; sép. très brièv. mucronés.

II Pédonc. plus courts que les f. long. pétiolées; pét. ent., glabres à l'onglet; carp. pub., lisses. . . . G. rotundifolium L. 261 Ch., haies, surtout calc. - Mai-Sept.

II Pédonc. plus longs que les f. supér. subsessiles; pét. bifides, ciliés au-dessus de l'onglet.

T. couvertes de poils étalés; pét. rouges dépassant le cal. ; 10 ét. fertiles à filets glabres; carp. glabres ridés . G. molle L. 262 Ch., chemins. - Mai-Sept.

T. fin. pub.; pét. rose violacé dépassant à peine le cal.; \&̋ ét.

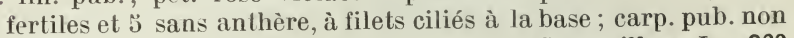
ridés.............. G. pusillum L. 263 Ch., chemins. - Mai-Sept.

X Pl. viv. à souche épaisse; fl. gr., à pét. dépassant long. le cal., à onglet et filets des ét. ciliés.

Pl. hér. de longs poils étalés; pédonc. unillores ; fl. rouges, veinểes, tr. gr. ; sép. aristés; carp. poilus au sommet, non ridés.

G. sanguineum L. 264

Bois secs, coteaux sabl.

Pl. mollement pub.; pédonc. biflores; fl. violet-bleuâtre, assez grandes; sép. à peine mucronés; carp. finem. pub., non ridés.

Prés, ch. - Jn-Jt.

G. pyrenaicum L. 265

Varie à f. caul. trilobées (var. trilobum Camus), St-Germain.

On rencontre quelquefois (Arpajon, Malesherbes) le Geranium pratense L. Viv., l. dress., robustes, pub., gland. au sommet: fl. d'un blen purpurin, gr. à pét. 1-2 fois plus longs que le cal., à onglet court et cilié; sép. aristés; carp. vel. gland., non ridés.

\section{Genre 87. - ERODIUM L'Hérit.}

F. pennatiséquées à segments incisés-dentés, écartés, subpétiolés; bractéoles non acum.; filets des ét. fertiles dilatés et bidentés à la base; pl. à forte odeur de musc à stip. membr. très larges.

E. moschatum L'Hérit. 266

Décombres, bords des chemins. - Mai-Sept.

F. pennatiséquées ou bipennatiséquées à segments pennatifides ou pennatiséqués; bractéoles acum.; filets des ét. sans dents à la base; pl. à odeur faible, non musquée; polymorphe.

E. cicutarium L'Hérit. 267

Lieux incultes, pelouses. $-\Lambda v \cdot-$ Oct.

\section{FAMLLE 18. - HYPÉRICINÉES}

Sép. tr. inégaux; ét. réunies à la base en 丂̆ faisc.; fr. charnu avant la maturité, indéh. ou s'ouvrant seulement au sommet.

ANDROSÆMUM 88

Sép. presque égaux; ét. réunies à la base en 3 faisc.; fr. sec, caps., à valves se séparant jusqu'à la base. 
Pét. dressés ; 3 glandes pétaloïdes, bifides, alt. avec les faisc. d'ét.; caps. à 1 loge s'ouvrant en 3 valves; t. molles, ramp. stolonifères à la base..................... HELODES 89

Pét. étalés; pas de glandes pétaloïdes; caps. à 3 loges s'ouvrant en 3 valves; t. dures, raides, non ramp. stolonifères. HYPERICUM 90

\section{GenRe 88. - ANDROSEMUM All.}

Fl. en corymbe ; ét. plus longues que les pét.; 3 styles plus courts que les pét.; pédonc. fructif. dressé; baie subglob. indéh.; t. à 2 lignes saillantes; f. ovales-obtuses . . . . . A. officinale All. 268 Bois frais. - Jn-At.

Fl. solit.; ét. plus courtes que les pét.; З̌ styles égalant les ét.; pédonc. fructif. penché; caps. oblongue déh. au sommet; t. tétragone étalée à terre; f. elliptiques oblongues. . . . A. calycinum Coste 269 Cult. et subsp. - Jn-Jt.

\section{Genre 89. - HELODES Spach.}

Pl. vel. tom., grisàtre; f. demi embrass., arrondies, fin. ponctuées transparentes; fl. jaunes, assez gr., peu nombr., en cyme courte ; sép. ovales bordés de cils gland. purpurins; pét. dress. 3-1 fois plus longs que le cal........... H. palustris Spach 270 Mares des terrains sil. - Jn-Sept.

\section{Genre 90. - HYPERIGUM L.}

+ Pl. pub. verdàtre à t. dépourvues de lignes saillantes; sép. à bords cil. gland. ; fl. en panicule étroite. . . . H. hirsutum I. 271 Bois, haies, ruiss. - Jn-Sept.

+ Pl. entièr. glabre.

$=\mathrm{T}$. offrant 2 ou 4 lignes plus ou moins saillantes; sép. ord. non cil.

$\odot$ T. de 5 - $20 \mathrm{~cm}$., munies de 2 lignes faibles filiformes, couchées ou ascendantes; fl. solit. ou en petites cymes feuillées; 12-20 ét.

Ch. sabl., pelouses hum. - Jn-Sept.

H. humifusum L. 272

$\odot$ T. dépassant $20 \mathrm{~cm}$. raides, dressées; fl. nomb. en corymbe ou en. pan.; ét. en nombre indéfini.

$\checkmark$ T. offrant seulement 2 lignes longit.; caps. munie de 1-3 canaux et de vésicules nombr. irrégul. disposés. H. perforatum L. 273

Lieux secs incultes. - Mai-Jt.

$\sigma^{*} \mathrm{~T}$. offrant 4 angles ou 4 ailes; caps. munie de nombr. canaux longit., sans vésicules.

T. à 4 angles ailés; f. élargies à la base et demi-embrass. ponctuées; fl. petites d'un jaune pâle, à pét. clépassant peu les sép. lancéolés aigus. . . . . . . H. tetrapterum Fries 274 Lieux hum. - Bords des eaux. - Jn-Sept.

T. à 4 angles non ailés; f. rétrécies à la base et simpl. sessiles munies ou dépourvues de ponctuations pellucides (var. imperforatum); fl. gr. d'un jaune doré, à pét. bien plus longrs que les sép. lancéolés aigus érodés ou subulés au sommet.

Bois et terrains hum. - Jt-Sept.

H. Desetangsii Lamotte 275 Var. imperforatum G.; le type est rare.

= T. cyl. sans lignes saillantes; sép. bordés de cils glanil.

F. ovales obtuses, embrass. en coeur, toutes ponctuées transparentes; fl. en pan. allongée, étroite; sép. ovales obtus, bordés de glandes sessiles... . . . . H. pulchrum L. 276 Bruyères et bois sil. - Jn-At.

F. ovales-lanc., sessiles, les sup. seules ponctućes transparentes; fl. en corymbe court et serré; sép. lanc. aig., bordés de glandes stipitées............ H. montanum L. 277 Coteaux boisés. - Jn- $1 \mathrm{t}$. 


\section{Famille 19. - ACÉRINÉES \\ Genre 91. - AGER L.}

+ Fl. apétales, dioïques; f. pennatiséquées à 3-3 fol. pétiolulées, ovales lanc. acum., dentées ou incisées; fl. màles fasc. naissant avant les f.; fl. femelles en grappes paraissant en même temps que les f.; fr. à coques oblongues comprimées, nervées, soudées et en pointe à la base, à ailes dressées convergentes . . A. Negundo L. 278

Souvent planté aux bords des chemins.

+ Fl. pétalées, polygames; f. palmatilobées.

$\odot$ Fl. en grappes pédonc. ou en corymbes; f. à 3 lobes acum. ou aigus. Fl. en grappes allongées, pendantes; filets des ét. pub.; coques convexes et renflées, à ailes étalées dressées; 1 . opaques, vertes et glabres en dessus, pub. blanchàtres en dessous.

Bois souvent planté. - Fl. Mai; fr. Sept.

A. Pseudo-platanus L. 279

Fl. en corymbes rameux, dressés ; filets des ét. glabres; coques compr. et planes, à ailes étalées presque horiz.,; f. minces, glabres, vertes et luisantes en dessous . . . . . A. platanoides L. 280 Bois et pares. - Fl. Av.-Mai; fr. Sept.

$\odot$ Fl. en grappes sessiles; f. à 5 lobes obtus ou subaigus.

Fl. en grappes corymbiformes, pendantes; fr. à coques très convexes à ailes dressées étalées; f. blanchâtres en dessous.

Bois et pares. - Fl. Av., fr. Sept.

A. opulifolium Vill. 281

Fl. en corymbes rameux, dressés; fr. à coques peu renflées, à ailes étalées horiz.; f. vertes sur les 2 faces. . A. campestre L. 282 Bois. - Fl. Mai ; fr. Sept.

\section{Famile 20. - AMPÉLIDÉES}

Fl. en thyr'se dense; pét. soudés au sommet; f. palmatilobées, en cour à la base; stigmate sessile. . . . . . . . . VITIS 92 Fl. en cymes corymbiformes; pét. étalés, non soudés au sommet; f. composées digitées; un style........ AMPELOPSIS 93

\section{Genre 92. - VITIS L.}

Arbuste sarmenteux, grimpant, muni de vrilles opp. aux f.; f. palmati-

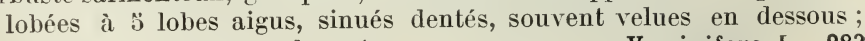
fl. petites verdàtres, odorantes . . . . . V. vinifera L. 283 Cult. et subsp. - Fl. Jn; fr. Sept.-0ct.

\section{Genre 93. - AMPELOPSIS Mich.}

Arbuste sarmenteux muni de vrilles; f. digitées à : 8 fol. pétiolulées, ovales acum., dentées en scie; fl. petites. A. hederacea Mich. 284 Cult. et subsp. - Fl.

\section{FAMILLE 21. - HIPPOCASTANÉES \\ Gerre 94. - ÆSGULUS}

Caractères de la famille. . . . . . E. Hippocastanum L. 285 Cult. comme ornement.

\section{Famile 22. - BALSAMINÉES \\ GenRe 95. - IMPATIENS L.}

$\odot$ Fl. jaunes; f. alt.

Fl. grandes, pendantes, ponctuées de rouge intér., à éperon recourbé en crochet; f. ovales làchement dentées. I. Noli-tangere L. 288 Bois hum., bords des ruisseaux. - Jt- $\mathrm{At}$. 
Fl. petites, dressées, jaune pâle, à éperon long, conique, droit; f. ovales acumin., dentées en scie. . . . I. parviflora DC. 287

Pl. introduite et nat. - Jn-At.

Fl. rouges, gr. à éperon très court; f. alt. ou ternées oblongues acuminées, dentées en scie, munies vers la base et sur le pétiole de grosses glandes pédic; fl. en petites grappes formant corymbe ; caps. obovale à bec long.. . . . . . I. Roylei Walp. 286

Cult. et subsp. - Jt-Sept.

\section{FAMILLE 23. - OXALIDÉES}

\section{Genre 96. - OXALIS L.}

+ P1. sans t., à f. et pédonc. naissant de la souche; pédonc. uniflores; fl. blanches, roses ou violacées à pét. $3-3$ fois plus longs que le cal.; souche écailleuse. . . . . 0. Acetosella L. 289 Lieux ombragés hum. - Avr.-Mai.

+ Pl. à t. portant des f. et des pédonc. term. par 2-4 petites fl. jaunes à pét. une fois seulement plus longs que le cal.; pas de souche écailleuse.

Pl. viv. émettant des stolons fragiles et charnus; t. dress. non radicantes; f. sans stip.; pédic. fructif. dressés ou étalés.

Lieux cult., sabl. - Jn-0et.

0. stricta L. 290

Pl. ann. ou pér. sans stolons; t. couchées-diffuses, souvent radicantes;

f. stip.; pédic. fructif. réfractés . . . . 0. corniculata L. 291

Lieux cult., jardins, décombres, introduit. - Mai-0ct.

Var. ì t. redressées, non radicantes; stip. tr. petites, sourent nulles (O. Navieri Jord.).

\section{Famille 24. - RUTACÉES}

\section{Gente 97. - RUTA L.}

Pl. de 30-80 cm. glauque, gl. ; f. pétiolées, 2-3 fois pennatiséquées; bract. et sép. lanc. aig.; pét. ovales oblongs denticulés.

R. graveolens L. 292 Coteaux pierreux, ruines des vieux chàteaux, nat. - Mai-At.

\section{FAMLLE 2\%. - CÉLASTRINÉES}

\section{Genre 98. - EVONYMUS}

Jeunes rameaux tétragones; f. oblongues acum.; fl. 2-:̈ par cyme; pét. oblongs; caps. ord. à 4 lobes arrondis . . . E. vulgaris Scop. 293 Bois, haies. - Fl. Avr.-Mai. - Fr. Sept.-Oct.

On rencontre dans les parcs $E$. verrucosus Scop. Rameaux verruqueux, f. arrondies à la base; pét. suborb.

On rencontre aussi plus rarement $E$. latifolius Scop. Jeunes rameaux arrondis ; f. gr. ovales oblongues ; fl. pourprées "̈-10 par cyme; pét. ovales arrondis ; caps. à "̈ lobes très comprimés, ailés.

\section{FAMLLE 26. - ILICINÉES}

\section{Genre 99. - ILEX L.}

Arbuste ou petit arbre de 2-10 m. ; f. alt., brièv, pétiolées, coriaces ; fl. en fasc. axill.; cal. persist. $4-3$ lobes, petits; cor. en roule à $4-\ddot{3}$ pét. soudés à la base entre eux et avec les filets des ét.; $4-\ddot{z}$ ét. alt. avec les pét.; fl. souvent unisexuelles par avortement.

I. Aquifolium L. 294

Bois, haies. - Fl. Mai. - Fr. Sept.-0et. 


\section{FAMLLE 27. - RHAMNÉES \\ Genre 100. - RHAMNUS L.}

F. paraissant opp. sur les jeunes rameaux opp., fasc. sur les anciens rameaux term. en épine; fl. polygames ou dioïques à 4 divis.; f. ovales ou elliptiques, denticulées, munies de chaque côté de la nervure médiane de 3-4 nervures converg.; stigmates 2-4. R. cathartica L. 295 Bois et haies. - Fl. Mai-Jn. - Fr. It-Sept.

F. toutes alt.; rameaux alt. jamais épin.; fl. hermaphrodites à $\breve{~ d i v i s . ~ ; ~}$ f. ovales ou elliptiques, ent. ou un peu sinuées, munies de chaque côté de la nervure médiane de 8-12 nervures parallèles, presque droites; 1 stigmate. . . . . . . . . R. Frangula L. 296 Bois et haies. - Fl. Ivr.-J. - Fr. At-Sept.

On cultive $R$. Alaternus L., quelquefois subspontané comme à Giverny ; f. persist., cal. à ä lobes et fl. diö̈ques.

\section{Famille 28. - SIMARUBACÉES \\ Genre 101. - AILANTHUS DC.}

Arbre élevé; fl. verdàtres en pan. axill. dressés; כ̋ pét. étalés; fr. samarö̈de, tordu, oblong, elliptique, ailé, veiné. A. glandulosa Desf. 297 Pares, promenades.

\section{FAMILLE 29. - FRAXINÉES \\ Genre 102. - FRAXINUS L.}

Fl. brunàtres, paraissant avant les f.; cal. et cor. nuls; anth. presque sessiles; arbre élevé. . . . . . . . F. excelsior L. 298 Bois. - Fl. Avr.-Mai. - Fr. Sept.

Fl. blanchâtres se développant avec les f.; cal. et cor. à 4 divis.; auth. portées sur de longs filets; arbre peu élevé. . . . F. Ornus L. 299 Pares. - Fl. Mai. - Fr. At-Sept.

\section{Famille 30. - PIROLÉES \\ Genre 103. - PIROLA L.}

+ Fl. 1-6 en omb.; t. lign. portant 1-3 vert. de f. oblongues ou lanc. fort. dentées; filets des ét. à base trigone et courbée en dehors; caps. dress. à valves glabres aux bords; souche longuement ramp. Fl. roses assez petites, 3-6; f. oblongues en coin fort. dentées; filets des ét. glabres au milieu . . . . . . . P. umbellata L. 300 Bois secs, bruyères. - Jn-Jt.

Fl. blanches gr., 1-3, très odor.; f. ovales-lanc. arrondies ou atténuées à la base làchement dentées en scie, à nervures maculées de blanc; filets des ét. poilus au milieu. . P. maculata L. 301 Bois secs. - Jt.

+ Fl. nombr. en grappes; t. herb. munies de quelques écailles; f. ovales arrondies crén. ou fin. dentées ramassées au bas de la t.; filets des ét. lin., en alène, ascendants dès la base; caps. penchée à valves poilues aux bords.

F. ovales arrondies, à pétiole ord. plus court que le limbe; ét. conniventes sur l'ovaire; style dressé, droit, ne dépassant pas la cor., plus court que l'ovaire; stigmates étalés. . . P. minor L. 302 Bois. - Jn-Jt.

F. suborb., à pét. plus long que le limbe; ét. arquées ascendantes; style plus long que les pétales; incliné dès la base, courbé ascendant et term. en anneau débordant les stigmates dressés et soudés.

P. rotundifolia L. 303 Bois. - Jn-Jt. 


\section{FAMILLE 31. - MONOTROPEES}

\section{Genre 10\%. - MONOTROPA L.}

Ecailles, bract. et sép. vel. hér., rar. glabre (var. glabra Roth).

Bois, principalement sous les pins. - Jn-At.

\section{II. - CALICIFLORES}

\section{FAMILLE 32. - PAPILIONACÉES}

+ Et. 3-10 libres; cor. à 3-3̈ pét. peu inégaux; fl. polygames.

GLEDITSCHIA 105

+ Et. plus ou moins soudées.

$\times$ Et. monadelphes, toutes 10 soudées en tube par les filets; f. simples, trifoliolées ou imparipennées.

= Cal. à dents inégales disposées en 1 ou 2 lèvres.

C Cal. à 1 ou 2 lèvres fendues jusqu'à la base; f. simples; fl. jaunes.

Cal. â 2 lèvres distinctes vel. ou pub. ; cor. dépassant peu le cal.; gousse courte, vel., presque incluse à 4-6 graines caronculées; f. et rameaux épineux. . . . . . . . ULEX 106

Cal. à 1 seule lèvre coupée obliquement, gl.; cor. très long. saillante; gousse lin., presque gl., allongée, à 12-18 graines non caronculées; f. et rameaux non épin. . . . SPARTIUM 107

Q Cal. à 2 lèvres non fendues jusqu'à la base; f. simples ou trifoliolées.

- Style enroulé ou fortement courbé en cercle; cal. scarieux tr. court à 2 lèvres divariquées; f. inf. trifoliolées, les supérieures simples . . . . . . . SAROTHAMNUS 108

- Style ascendant, simp. arqué, jamais contourné en cercle; cal. ord. non scarieux.

Cal. à lèvres dressées, rar. divariquées; étendard assez étr. ord. non redressé; carène droite ou à peine courbée; f. simples.

GENISTA 109

Cal. à lèvres presque toujours divariquées; étendard large, redressé; carène courbée; f. trifolioliées. . . . GYTISUS 110

$=$ Cal. à $\breve{~ d e n t s, ~ e ́ g a l e s ~ o u ~ p r e s q u e ~ e ́ g a l e s, ~ n o n ~ d i s p o s e ́ e s ~ e n ~ l e ̀ v r e s . ~}$

Cal. en cloche, à " divis. profond.; f. simp. ou trifoliolées; fol. dentées ou crén. munies de stip. . . . . . ONONIS 111

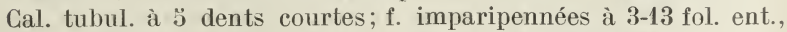
sans stip.. . . . . . . . . ANTHYLLIS 112

Et. diadelphes, tr. rar. monadelphes avec f. paripennées.

Gousse continue, droite ou contournée en spirale, jamais articulée transvers., déhiscente longit. en 2 valves.

م F. trifoliolées ou imparipennées.

ち Cal. à $\%$ divis., non bilabié; carène, style et ét. non tordu en spirale; gousse uniloc. continue sans épaiss. entre les graines.

(. F. trifoliolées.

Stip. non foliacées, bien distinctes des fol., souvent dentées.

ㅇ Gousse plus ou moins saillante; cor. ead.; fl. ord. en grappes ou en omb.; fol. dentées ou crén. au sommet.

Fl. en grappes courtes ou en omb., parfois solit. ou géminées; gousse plus ou moins arquée, ou contournée en spirale, à graines ord. nombreuses.

Gousse courte, contournée en rein, en faux ou en hélice, jamais droite, souvent épineuse . . . MEDICAGO 113 
Gousse allongée, lin., à peine arquée, jamais contournée en hélice, ni épineuse. . . . . . . . TRIGONELLA 114

Fl. en grappes spiciformes allongées; gousse courte, glob. ou ovale, dr. à 1-2 graines. . . . . . MELILOTUS 115

† Gousse renfermée dans le cal. ou dans la cor. persist.; fol. ent. ou denticulées........ TRIFOLIUM 116

Stip. foliacées, tr. ent, plus ou moins semblables aux folioles.

Gousse quadrangulaire, grosse, munie de 4 ailes membr. ; style épaissi au sommet; fl. gr. solit. TETRAGONOLOBUS 117

Gousse cyl. ou oblongue, grêle, non ailée; style filiforme, atténué au sommet; fl. en omb., rar. solit. . . LOTUS 118 - F. imparipennées.

\$1 Gousses arquées ou vésiculeuses.

Gousses arquées, cyl. ou trigones. . ASTRAGALUS 119

Gousses amples, renfl. en vessie, transparentes, gl., stipitées.

COLUTEA 120

I Gousses compr., ou lin.-cyl., glabre, munie d'étranglements.

Gousse oblongue-comprimée, stipitée, pendante; arbre à rameaux épineux ........... ROBINIA 121

Gousse lin.-cyl., étalée ascendan te, bosselée, obliquement striée ; pl. herb. sans épin.; ét. à peine diadelphes, la $10^{\circ}$ soudée jusqu'au milieu au tube des 9 autres. . . . GALEGA 122

む Cal. bilabié; cor. à carène contournée en spirale avec le style et les ét. ; gousse présentant, avant la maturité, des épaississements celluleux entre les graines, comme divisée; f. à 3 fol.

PHASEOLUS 123

○ F. paripennées à rachis term. en vrilles simples ou rameuses, quelquefois réduites au rachis simulant une f. ent., sans vrilles ou dépourvues de fol., mais munies de vrilles; tr. rar. f. imparipennées à fol. dentées en scie sans vrilles.

| Tube des ét. tronqué obliquement; style filiforme.

Tube des ét. tronqué tr. obliquement; style compr. par le côté ou d'avant en arrière, barbu sous le stigmate ou pub. soit au sommet, soit sur la face sup. ou tout autour; f. paripennées, munies de vrilles...... . . . . . . . VICIA 124

Tube des ét. court, tronqué obliq. au sommet; style subulé, glabre au sommet; f. imparip., dentées sans vrilles. C GICER 125

| Tube des ét. tronqué transvers. ; style élargi.

Cal. et stip. foliacés, ces dernières plus gr. que les fol.; style genouillé à la base, plié en long, arqué, élargi et comprimé latér. au sommet............... PISUM 126 Cal. et stip. non foliacés; style droit ou arqué, souvent tordu sur son axe, non genouillé, élargi et compr. d'avant en arrière

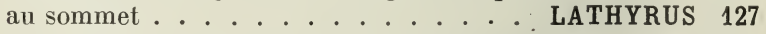

Gousse indéh., divisée transvers. en articles se séparant à la maturité, ou non articulée et réduite à un seul article monosp. à bords dentés; f. imparipennées.

Il Gousse lin., polysp., compr. ou non sans échancrures profond. Carène courbée, term. en bec acum.; gousse cyl. ou anguleuse à articles renfl.; pédic. et cal. gl. CORONILLA 128 Carène presque dr., obtuse; gousse compr., veinée en réseau, à articles resserrés aux 2 bouts; pédic. et cal. pub.

ORNITHOPUS 129

II Gousse tr. compr., polysp., à échancrures profondes ou gousse monosp. dentée.

Gousse sinueuse, creusée d'échancrures profondes correspondant aux graines; fl. jaunes; carène terminée en bec acum.

HIPPOCREPIS 130 
Gousse suborb. compr., à faces réticulées-alvéolées, tuberc. ou épin.; fl. roses ou blanches; carène tronquée obliquement................ ONOBRYGHIS 131

Genre 103. - GLEDITSGHiA L.

Arbre à grosses épines trifides ou simples; f. fasc. $10 u 2$ fois paripennées; fl. en petites grappes courtes latér., pédonc.; cal. à 3-’゙ lobes soudés en cupule à la base; gousse pendante, grosse, de 20-30 cm., 10 fois plus longue que large; graines compr. . . . G. triacanthos L. 305

Souvent planté aux bords des chemins. - Jn-Jt.

$$
\text { Genre 106. - ULEX Sm. }
$$

Arbriss. de $30-80 \mathrm{~cm}$. tr. diffus, souvent couché, à épines grêles, très nombreuses; fleurs petites, 7-8 mm.; bractéoles lanc., plus étroites que le pédic.; ailes plus courtes que la carène courbée; gousse large de $4 \mathrm{~mm}$; plus courte que le cal. glabrescent. . . U. nanus Sm. 306 Landes, lieux stériles siliceux. - Jt-0ct.

Arbrisseau de 1-2 m., dressé, à épines robustes, très vulnérantes; fl. j., gr., $13 \mathrm{~mm}$., bractéoles ovales, plus larges que le pédic.; ailes dépassant un peu la carène droite; gousse large de 6-7 mm., plus longue que le cal. velu. . . . . . . . . U. europaeus L. 307

Landes, lieux stériles silic. - Janv.-Mai.

\section{Genre 107. - SPARTIUM L.}

Arbriss. de 1-3 m., dressé, à rameaux effilés, cyl., jonciformes, tr. gl. peu feuillés; f. oblongues-lanc., ent.; fl. jaunes, gr. en grappes terminales; ét. monadelphes; gousse presque gl., noire. S. junceum L. 308 Cult. et subsp. (Genêt d'Espagne.) - Mai-Jt.

\section{Genre 108. - SAROThaMnUS Wimm.}

Arbriss. de 1-2 m. dressé, à rameaux lâches, allongés, tr. anguleux; f. inf. trifoliolées, pétiolées, les sup. simpl. et sessiles, obovales ou lanc., pub.-soyeuses en dessous; fl. jaunes, gr., solit. ou géminées aux nœuds en grappes lâches et feuillées; gousse noire, tr. compr., hér. de longs poils sur les bords à 8-12 graines caronculées, luisantes.

Landes, bruyères, bois sablonneux. - Avr.-Jt.

S. scoparius Koch 309

Genre 109. - GENISTA L.

+ Sous-arbriss. épineux.

Jeunes rameaux épin., étalés, gl. à épines simples; fl. petites, en grappes term. courtes, feuillées; gousse gl., renfl.-cyl., à 5-10 graines ovoïdes, noires. . . . . . . G. anglica L. 310 Bruyères, landes. - Avr.-Jn.

Jeunes rameaux inermes, dress. vel., les anciens munis d'épines rameuses; fl. petites en grappes term. non feuillées; gousse velue, ovale-rhomboïdale à 2-1 graines ovoïdes, brunes.

Bois secs. - Mai-Jn.

G. germanica L. 311

+ Sous-arbriss. non épineux.

X Rameaux redressés, allongés compr. à ailes foliacées; f. écartées ovales ou lanc., sans stip. ; fl. en grappes term. denses; gousse vel. à 3-6 graines. . . . . . . . . . G. sagittalis L. 312 Coteaux sablonneux, pelouses sèches. - Mai-Jt.

X Rameaux cyl., non compr.-ailés.

= Cal. en cloche, à tube court, à lèvres divariquées, la sup. simpl. bidentée; pédic. bractéolés $2-4$ fois plus longs que le cal.; f. pétiolées sans stip.; fl. en long. grappes unilat. feuillées; gousse velue, rar. glabrescente......... G. prostata Lamk 313 Coteaux calc. - Mai-Jn. 
= Cal. tubul. à lèvres rapprochées égalant le tube, la sup. profond. bipartite; pédic. bractéolés ou non, plus courts que le cal. ou l'égalant.

Sous-arbriss. à t. couchées-radicantes; pédic. non bractéolés plus courts que le cal.; f. pliées elliptiques-oblongues, pub.-soyeuses en dessous munies de 2 petites stip.; cor. pub.-soyeuse; gousse vel. à 3-7 graines; fl. en longues grappes unilat. feuillées.

G. pilosa L. 314

Bruyères, bois sablonneax, coteaux arides. - Mai-Jt.

Sous-arbriss., à t. dressées ou ascendantes; pédic. munis de 2 bractéoles, égalant le tube du cal.; f. lanc. ou ovales, planes, glabres ou ciliées munies de stip. en alène; étendard gl. égalant la carène; gousse gl., rar. pub. à b̉-12 graines; fl. en grappes term. feuillées ........ . . . tinctoria L. 315 Coteaux incultes. - Mai-At.

\section{GenRe 110. - CYTISUS L.}

Fl. jaune pâle en longues grappes pendantes, axill., feuillées à la base; gousse glabrescente, d'abord velue soyeuse, stipitée, bosselée-étranglée, à suture supérieure très épaissie. Arbuste de 3-6 m. à rameaux gl. ou à pubescence apprimée; cal. en cloche à lèvres inégales; f. gr., long. pétiolées à fol. ovales-oblongues, obtuses, mucronulées.

C. Laburnum L. 316

Subsp. ou natur. dans les bois surtout calcaires. (Faux ébénier.) - Avr.-Jn.

Fl. d'un jaune intense en têtes term. feuillées à la base; gousse velue hérissée, sessile ou tr. brièv. stipitée à sutures non épaissies, ni ailées; sous-arbrisseau de $20-60 \mathrm{~cm}$. couché rampant à rameaux étalés, hér. de poils étalés; cal. hér., tubul. à lèvres divariquées; f. petites, pétiolées à fol. oblongues ou obovales, velues....... C. supinus L. 317 Coteaux calc. arides. - Mai-Jt.

$r$. copitatus Jacq.. voisin de $C$. supinus, quelquefois naturalisé, se reconnait ì ses rameaux dressés et ses têtes terminales multiflores.

Genre 111. - ONONIS L.

+ Fl. roses, rar. blanches.

Souche verticale, non traçante; t. dress. ou ascendantes, non radicantes, épin., à épin. souvent géminées, poilues sur 2 lignes; fol. lin. oblongues; gousse égalant ou dépassant le cal.

Lieux arides, bords des chemins. - Jn-At.

0 . campestris Koch 318

Souche long. ramp.; t. couchées ou redressées, souvent radicantes, à épines solit., ou inermes, pub. gland. tout autour; fol. obovales ou oblongues; gousse plus courte que le cal. $\quad$ o. repens L. 319 Bords des chemins. - Jn-Sept.

+ Fleurs jaunes.

Pédonc. longs égalant ou dépassant les f., articulés, aristés; fl. gr., jaunes, striées de pourpre; cor. 1 fois plus longue que le cal.; gousse velue, dépassant tr. long. le cal.; pl. de $30-50 \mathrm{~cm}$. rameuse et visqueuse ............ 0. Natrix L. 320 Lieux pierreux ou sabl. calc. - Mai-Sept.

Pédonc. presque sessiles, plus courts que le tube du cal., non articulés, ni aristés; fl. pet. jaunes, souvent avortées; cor. égalant environ le cal.; gousse pub., ovale rhomboïdale, égalant le cal. ou un peu plus courte; pl. de $8-23 \mathrm{~cm}$. pub. gland. 0. Columnae All. 321 Lieux pierreux ou sabl. calc. - Jn-At. 


\section{Genre 112. - ANTHYLLIS L.}

Pl. viv. herb. à tiges couchées ou ascendantes, pub. ; f. infér. à 3-3̆ fol. tr. inégales, la term. plus gr.; fl. jaunes ou rougeàtres, en têtes denses, souvent géminées, entourées de bract. foliacées; cal. renflé en vessie, velu; gousse ovale, glabre, à 1-2 graines ovoïdes, lisses.

Pelouses sèches. - Mai-.It.

A. Vulneraria L. 322

\section{Genre 113. - MEDICAGO L.}

+ Gousse dépourvue d'épines et de tubercules.

$X$ Gousse gl. ou pub., en rein, convexe sur les 2 faces, tr. petite, 2-3 mm. de diamètre, à 1 seule graine, à faces munies de nervures arquées obliquement concentriques; fleurs en grappes courtes, serrées, multiflores ...... M. Lupulina L. 323 Lieux incultes, pâturages. (Minette.) - Mai-Oct.

$X$ Gousse en faux, en anneau ou en hélice, gr. de plus de $3 \mathrm{~mm}$.; contenant plusieurs graines; fl. de plus de $3 \mathrm{~mm}$.

= Fl. gr., blanchâtres jaunâtres ou violacées; gousse en faux ou en spirale; pl. vivace.

Fl. violettes ou bleuâtres en grappes oblongues; pédic. plus courts que le tube du cal.; fol. obovales ou oblongues; t. dress. ou ascendantes; gousse gl. ou pub. à 2-3 tours de spire.

M. sativa L. 324

Varie à fleurs versicolores jaunàtres, violacées ou blanchâtres, gousse courbée en anneau ( $M$. media Pers.; $M$. cyclocarpa Hy).

Cult. et subsp. (Luzerne.) - Jn-Sept.

Fl. jaunàtres en grappes ovales; pédic. plus longs que le tube du cal.; fol. étr. oblongues; t. couchées ascendantes; gousse pub., courbée en faucille ou en annean. . . . . M. falcata L. 325 Talus, bords des chemins. - Nai-Sept.

= Fl. 1-3, petites, d'un beau jaune; gousse de 10-18 mm. de diamètre contournée en hélice, lenticulaire, à 3-6 tours de spire, à faces convexes munies de nervures rayonnantes; fol. obovales en coin, dentées supér.; ann. . . . . M. orbicularis All. 326 Pelouses sèches, talus. - Mai-Jt.

+ Gousse normalement pourvue d'épines ou de tubercules, pl. ann. à fl. jaunes, petites.

X Gousses à spires làches, à épines sillonnées ou canaliculées à la base; jeunes gousses faisant saillie par côté entre les lobes du cal. après la flor.; pédonc. $2-8 \mathrm{fl}$.

$=$ Gousse glob. ou subglob., arrondie aux 2 bouts, à $3-6$ tours de spire; fl. 2-6 sur chaque pédonc.; stip. dentées ou ent.

Gousse assez gr., gl., à épines divergentes, entrecroisées, non crochues à la pointe; pédonc. plus courts que la f.; pl. verte, presque gl. à fol. souvent tachées de brun. . M. maculata Willd. 327 Prairies, lieux incultes. - Mai-Jt.

Gousse petite, pub., à épines dressées, rapprochées, un peu crochues à la pointe; péd. égalant souvent la f.; pl. pub. blanchàtre.

M. minima Grufb. 328

Lieux sabl. ou rocailleux arides. - Mai-Jt.

$=$ Gousse gl., discoïde, à faces planes, fort. veinée en réseau à $2-4$ tours de spire écartés; fl. 4-8 sur chaque pédone.; stip. laciniées; bords de la gousse minces, munis de chaque côté d'une rangée d'épines, soit droites n'égalant pas la moitié du diamètre de la gousse (var. apiculata), soit crochues au sommet, égalant ou dépassant la moitié du diamètre de la gousse (var. denticulata).

Ch., moiss. - Mai-Jt.

M. polycarpa Willd. 329

La var. denticulala rare. 
X Gousse pub. ou vel. à spires densément contiguës, discö̈de subcyl. ou en barillet, à épines écartées, coniques, oncinées, non sillonnées à la base; jeunes gousses restant dans le fond du cal. après la flor.; pédonc. aristés à 1-2 fl.; stip. laciniées; fol. obovales en coin, dentées; pl. vel. ou pub. . . . M. Gerardi Willd. 330 Pelouses sèches. - Mai-Jt.

\section{Genre 114. - TRIGONELLA L.}

F1. d'un blanc rougeâtre, 1-3, sur des pédonc. axill. bien plus courts que la f. long. pétiolée à fol. obovales en coin, dentées en scie; stip. ent.; gousse dressée, légèr. pub., sans nervures, dépassant peu le cal.; graines ovoïdes, lisses, noiràtres; pl. couchée-étalée, glabre.

Pelouses rases. - Mai-Jt.

T. ornithopodioides DC. 331

Fl. jaunes, tr. petites, 4-12 en omb. lat. sessiles; fol. en coin, dentées sup.; stip. dentées à la base; gousses étalées en étoile, pub., arquées, munies de nervures obliques bien plus longues que le cal.; graines cyl., tuberc.; pl. couchée ou dressée, pub. T. monspeliaca L. 332 Lieux secs et pierreux, pelouses sèches. - Mai-Jt.

\section{Genre 113. - MELILOTUS Adans.}

+ Gouśse subglob., apiculée gl., petite, $2-3 \mathrm{~mm}$., à faces ridées rétic. pl. ann. de 10-40 cm. à fl. jaunes en grappes serrées, tr. petites, 2-3 mm., à étendard plus long que les ailes et la carène égales.

Ch., bords des chemins, pl. introduite. - Mai-Jt.

M. parviflora Desf. 333

+ Gousse ovale ou elliptique-aiguë gl. ou pub., mucronée ou acum. de 3-6 mm.; pl. bisan. ou pér. de $40 \mathrm{~cm}$. à $1 \mathrm{~m}$. 50; fl. jaunes ou blanches en grappes assez longues.

X Gousse jaunàtre à la maturité, à faces munies de côtes transversales, écartées, un peu arquées; grappes un peu lâches; fl. jaunes; étendard plus long que les ailes dépassant la carène; fol. sup. oblongues, dentées; slip. lanc.; pl. de 40-80 cm.

Lieux incultes. - Mai-Sept.

M. arvensis Wallr. 334

X Gousse noire à la maturité, à faces ridées-réticulées, alvéolées; grappes longues et serrées; pl. de $50 \mathrm{~cm}$. à $1 \mathrm{~m}$. $ّ 0$.

Fl. jaunes, odor.; pét. tous égaux; gousse couverte de poils appliqués, longue de 4-6 mm., ovale-acuminée, à bord sup. aminci en carène aiguë . . . . . . . M. altissima Thuill. 335

Lieux frais, bords des fossés. - Jn-Sept.

F1. blanches, inodores à étendard plus long que les ailes et la carène égales; gousse gl. de $4 \mathrm{~mm}$. à sommet obtus, apic., à bord supér. non caréné. ......... M. alba 336

Bords des chemins, voies ferrées, lieux incultes: - Jn-Sept.

\section{Genre 116. - TRIFOLIUM L.}

+ Fl. jaunes; gousse nett. stipitée à 1 graine ovoïde; ann. ou bisan.

$\times$ Fol. oblongues ou ovales oblongues; style aussi long ou à peine plus court que la gousse; fl. d'un beau jaune; ailes diverg.

Fleurs en têtes ovales fournies et serrées; pédonc. épais, égalant ou dépassant peu la feuille; fol. term. sessile; stip. lanc. plus long. que le pétiole. . . . . . . . T. aureum Poll. 337

Lisière des bois ; prairies montueuses. - Jt-Sept.

Fl. en têtes hémisph. peu fournies et lâches; pédonc. grêles bien plus longs que la f.; fol. term. souvent pétiolulée, stip. ovales, plus courtes que le pétiole. . . . . T. patens Schreb 338 Prairies hum., prés. - Mai-Jt. 
Fol. obovales en coin, la term. pétiolulée; style 4-6 fois plus court que la gousse; fl. jaune soufre ou jaune pâle.

$=$ Fl. jaune soufre, $1 \%$-40 en tètes ovoïdes serrées ; étendard fort. strié, plan, courbé en cuiller au sommet; ailes diverg.; t. et pédone. assez robustes........ T. campestre Schreb 339 Champs et coteaux. - Mai-At.

= Fl. jaune pâle, 2-13̆ en têtes glob. lâches; étendard lisse, caréné sur le dos, à la fin un peu courbé au sommet; ailes non diverg.; $t$. et pédonc. grêles, filiformes.

Fl. 6-13, rar. 2-6, rappr. ou un peu imbriquées; pédic. plus courts que le tube du cal.; fol. term. plus long. pétiolulée que les lat.; stip. dil. à la base plus courtes que le pétiole. T. minus Rehl. 340 Pelouses, lieux sablonneux. - Mai-Sept.

Fl. 2-6 écartées, non imbriquées, à pédonc. capillaires, flexueux; pédic. plus longs que le tube du cal.; folioles toutes égalem. et brièvem. pétiolulées; stip. non dilatées. plus longues que le pétiole......... . T. micranthum Viv. 341 Pelouses des terrains sabl. - Nai-Jt.

+ Fl. rouges, roses, blanches ou blanc jaunàtre; gousse non ou brièv. stipitée.

Q Cal. renflé en vessie après la flor.; fl. munies de bractéoles, gr., lanc., réunies en un invol. aussi long que les cal.; fl. roses, sessiles réunies en cap. subglob.; axill., long. pédonc.; pl. vivace, couchée radicante . . . . . . T. fragiferum L. 342 Bords des chemins, pelouses. - Jn-Sept.

Q Cal. jamais renflé en vessie après la floraison.

— Cal. gl. ainsi que toute la pl.; fl. munies de bractéoles en têtes glob.

Pl. viv., gazonnantes à souche plus ou moins épaisse; gousse saillante à 2-4 graines.

§ T. ascend. ou dress., à pédonc. naissant à l'aisselle de presque toutes les f.; pl. à souche courte, gousse stipitée à $2-3$ graines. T. couchées-ascendantes, pleines, fermes, non compressibles; fol. obovales-lanc., à dents nombr.; étendard 1 fois plus long que le calice ......... T. elegans Savi 343 Bois, clairières, pàturages, souvent naturalisé. - Jn-At.

T. dressées, creuses, molles, facil. compressibles ; fol. larg. obovales-rhomboïdales, à dents assez nombr.; étendard 2-3 fois plus long que le cal. ...... T. fistulosum Gilib. 344 Cult. et subsp. - Jn-At.

T. couchées-radicantes, souvent allongées; pédonc. axill., naissant vers le bas des t.; fol. larg., obovales, faibl. nervées ; stip. brusq. termin. en alène; fl. blanches ou rosées; gousse non stipitée à $3-4$ graines . . . . . . T. repens L. 345 Prés, pelouses. - Mai-0ct.

z Pl. ann. à racines grêles; gousse saillante ou incluse à 1-2 graines,

fl. roses, petites.

Pl. dress. ou ascend.; fol. oblongues ou lanc.-lin., denticulées gland.; stip. denticulées gland., obt., soudées en tube évasé triang.; fl. sessiles en têtes glob. serrées sur des pédonc. allongés, axill. et terminaux . . T. laevigatum Desf. 346 Pelouses sabl. - Nai-Jn.

Pl. couchée ou ascend.; fol. obovales en coin, fort. nervées, denticulées, à dentic. non gland.; stip. entiers, aigus, aristées, non soudées en tube évasé; fl. sessiles en têtes glob., axill., sessiles . . . . . . . T. glomeratum L. 347 Pelouses sabl. - Mai-Jn.

- Cal. velu ou cilié, au moins sur les dents; fl. ord. dépourvues de bractéoles. 
† Fl. 2-3 blanc jaunàtre, réfléchies après la flor., sur des pédonc. axill. à la fin recourbés et s'enfonçant dans le sol; gousse incluse, subglob., à 1 graine; fol. en cœur renversé; pl. ann., pub., à t. couchées, flexueuses.

T. subterraneum L. 348 Pelouses sabl., bords des chemins.

ち Fl. nombr., en tètes term., ou les unes term. et les autres axill., à pédonc. jamais recourbés; gousse incluse à 1 seule graine.

- Pl. viv., gazonnantes, à souche ligneuse ou traçante.

Fl. blanches on jaunàtres, cal. à dents lanc. acum.

Fl. blanches promptement réfléchies, en tètes ovoïdes long. pédonc. ; cal. fructif. à dents jamais arquées-réfléchies; f. alt. ; à fol. glab. en lessus, dentic. . . . T. montanum L. 349 Pelouses sèches. - Mai-Jt.

Fl. jaunâtres, dresscées, en tètes glob., puis ovales, sessiles ou brièv. pédonc.; cal. fructif. à dent infér. arquée-réfléchie; f. à folioles entières velues sur les 2 faces, les supér. opp.

T. ochroleucum Huds. 350

Prés, coteaux. - Jn-Jt.

Fl. purpurines, rar. blanchâtres; eal. à denls liu. sétacées.

† Fol. oblongues lanc., coriaces, fort. nervées, dentic.; tube du cal. à 20 nervures; fl. en grosses têtes oblongues, spiciformes, pédonculées. . . . . . . . T. rubens L. 351 Bois, coteaux calc. - Jn- It.

q Fol. ovales ou oblongues, molles, faibl. nervées, presque entières; tube du cal. à 10 nervures.

Cal. à tube glabre en dehors, velu et ouvert à la gorge; stip. à partie libre étroitement lanc. acum.; ent., écartée du pétiole; f. toutes pétiolées; fol. elliptiques-oblongues; souche traçante... . . . . . T. medium L. 352 Bois, coleaux. - Jn-It.

Cal. à tube poilu en dehors, gl. et muni d'un anneau calleux à la gorge; stip. à partie libre larg. triang. brusq. term. en pointe appliquée; f. supér. subsessiles; fol. ovales; souche verticale. . . . . . . T. pratense L. 353 Prés, bois. (Trèfle.) - Mai-Jt. - Souvent cultivé.

Pl. ann., non gazonnantes, à racine grêle.

FI. en tètes ovö̈les ou oblongues, axill. et term., toutes sessiles.

Fol. à nervures lat. arquées en dehors; cal. coriace à gorge fermée par 2 lèvres calleuses, à dents raides, spinuleuses, à la fin courbées en dehors; stip. supér. non dilatées; fl. blanches ......... T. scabrum L. 354 Pelouses sèches. - Mai-Jt.

Fol. à nervures lat. non arquées en dehors; cal. à gorge ouverle, velu, à dents dressées étalées, nor courbées en dehors; stip. supér. dilatées; fleur's rosées . . T. striatum L. 355 Pelouses et prés secs. - Mai-Jt.

Fl. en tètes axill. pédonculées ou toutes les tètes terminales.

Fl. rosées en tètes petites, nombr., obtuses, velues soyeuses; cor. plus courte que les dents du cal. subulées sétacées, plumeuses ou ciliées; fol. lin. oblongues, dentic. au sommet; stip. étroites à partie libre linéaire en alène. T. arvense L. 356 Lieux et champs sabl. - Mai-Sept.

Fl. d'un pourpre vif, rar. blanches, en tètes grosses oblonguesconiques, puis cyl.; cor. plus longue que le cal. à dents velues lin. aig.; fol. larg. obovales en coin, dentic. au sommet; stip. gr., à partie libre courte, ovale-obtuse, dentée.

T. incarnatum L. 357

Cult. et subsp. (Farouche.) - Mai-Jt. 
Genre 117. - Tetragonolobus Scop.

Pl. viv., pub., ascend., à souche écailleuse; fol. obovales en coin, glaucescentes; stip. ovales-aiguës, dépassant le péliole; fl. jaune pâle sur des pédonc. 2-3 fois plus longs que la f. munis d'une petite f. au sommet ............ . . . siliquosus Roth 358 Prés hum. ou argil. - Mai-At.

\section{Genre 118. - LOTUS L.}

+ Fol. et stip. lin. ou lin. lanc. aiguë; fl. 1-ð par omb. sur des pédonc. filiformes; pl. glabrescente à t. diffuses . . . L. tenuis Kit. 359 Prairies argil. - Jn-Sept.

+ Fol. obovales ou oblongues; stip. ovales; pédonc. non filiformes portant des omb., 3-12 fleurs; pl. glabre ou pub.

F1. 3-6 par omb. ; cal. à dents dressées conniv. avant la flor.; carène fort. courbée en angle dr.; t. pleines couchées ou ascend.; souche dure non stolon.; pl. glabre ou velue . L. corniculatus L. 360 Prés, bois, coteaux. - Mai-Sept.

Fl. 6-12 par omb.; cal. à dents étalées-réfléchies avant la flor.; carène un peu courbée en angle tr. obtus; t. creuses dress. ou ascend.; souche ramp. stolon. pl. glabrescente ou velue.

Prés et bois hum. - Jn-Sept.

L. uliginosus Schk. 361

\section{Genre 119. - ASTRAGALUS L.}

Pl. presque acaule; f. imparipennées, à 10-20 paires de fol. ellipliques; stip. soudées, lanc. lin.; fl. purpurines ou violacées en grappes ovales sur des pédonc. rad. égalant ou dépassant les f. ; gousses pub. subcyl., arquées. . . . . . . . . A. monspessulanus L. 362 Coteaux cale. - Mai-Jn.

Pl. à t. couchées ou ascend.; f. imparipennées, à 6-12 paires de fol. gr., ovales; stip. sup. libres, lanc. acum.; fl. d'un jaune verdâtre ou livides en grappes ovales sur des pédonc. axill. 2 fois plus courts que la $\mathrm{f}$.; gousse gl., cyl. trigones, arquées-conniv. . A. glycyphyllos L. 363 Bois, lieux herbeux. - Mai-At.

\section{Genre 120. - GOLUTEA L.}

Arbriss. de 2-3 m.; fl. jaunes, penchées, 2-6 en petites grappes axill. pédonc. plus courtes que la f. imparipennée à 3-כ̋ paires de fol. obovales ou obcordées, entières. . . . . G. arborescens L. 364 Souvent planté. - Mai-Jt.

\section{Genre 121. - ROBINIA L.}

Arbre élevé; f. imparipennées à ว̆-12 paires de fol. ovales, ent., munies chacune d'une stipelle en alène; stip. remplacées par 2 forts aiguillons; fl. blanches, gr., odor. en long., grappes axill., pendantes, lâches, plus courtes que la f. . . . . . R. Pseudo-Acacia L. 365

Origin. de l'Amér. du Nord, souv. planté ou nat. (Acacia.) - Fl. Mai-Jn; fr. Sept.

\section{Genre 122. - GALEGA L.}

Pl. viv., gl., dress.; f. imparipennées à $\breve{3}-8$ paires de fol. oblongues ou lancéolées; stip. libres, gr., acum.; fl. bleuâtres ou blanchâtres, nombr. en grappes oblongues, axill., long. pédonculées, à pédoncules plus longs que la f. . . . . . . . . G. officinalis L. 366 Prés, nat. - Jn-Jt. 


\section{GenRe 123. - PHASEOLUS}

Fl. blanc-jaunàtres ou lilacées en grappes pauciflores plus courtes que la

f.; bract. ovales plus courtes que le cal.; gousses pendantes, glabre droites; graines grosses, en rein. . . . . . . P. Pulgaris L. 367 Cultivé. (Haricot.) - Jn-At.

Fl. ent. rouges ou à étendard rouge, à carène et ailes blanches en grappes multiflores dépassant la f.; bract. ovales-oblongues égalant presque le cal.; gousses pendantes, velues dans leur jeunesse, un peu courbées-falciformes; graines très grosses. P. multiflorus Willd. 368 Cultivé. (Haricot d'Espagne.) - Jn-At.

\section{GeNRE 12\%. - VIGIA L.}

+ Fl. 1 ou 2 subsessiles à l'aisselle des f.

$X$ Cal. irrégul., à dents inégales; gousse oblongue, stipitée, pendante à la maturité; fl. jaunàtres.

Étendard velu en dehors; cal. à dents peu inégales, plus courtes que le tube; poils de la gousse non tuberc. à la base; fol. tronquées ou échancrées . . . . . . . . V. hybrida L. 369 Ch., introduit. - Nai-Jn.

Étendard tr. gl.; cal. à dents inégales, l’inf. plus long. que le tube; poils de la gousse renfl.-tuberc. à la base; fol. lin.-oblongues, arrondies et mucronulées au sommet. . V. lutea L. 370 Ch. sabl. - Nai-Jt.

X Cal. régul., à dents égales; gousse lin., non stipitée, dressée ou étalée à la maturité.

$=\mathrm{T}$. couchées étalées; f. à vrilles simples; fl. tr. petites, lilacées; gousses de 20-30 cm. de long.; graines presque cubiques, ponctuées-tuberc.; stip. ent., non tachées. . V. lathyroides L. 371 Pelouses sabl. - Av.-Jn.

$=\mathrm{T}$. ascend. ou dress.; f. term. en vrilles rameuses; fl. gr. ; gousses de 30-60 mm. de long.; graines lisses, subglob.; stip. dentées, souvent tachées.

Fl. n'atteignant pas $2 \mathrm{~cm}$., d'un rouge vif ou à étendard violacé avec les ailes rouges; gousse de $30-40 \mathrm{~mm}$. sur 4-7 mm., étr. cyl., peu compr., non bosselée, noire à la maturité, gl.; fol. sup. étroites, aiguës, obtuses ou tronquées.

Lieux incultes, prés sabl. - Mai-Jt.

V. angustifolia All. 372

Fl. grandes de $2-3 \mathrm{~cm}$., à étendard violacé, à ailes d'un pourpre brun; gousse de 40-60 mm. sur 6-10 mm., largement lin., compr., bosselée, d'un fauve pâle et glabrescente à la maturité; fol. largement tronquées ou échancrées . . . . V. sativa L. 373 Lieux cult. et incult.; souvent cult. (Vesce.) - Mai-Jt.

+ Fl. en grappe sur un pédonc. commun, parfois très court, rar. solit. et pédonc.

O F. à 1-3 paires de folioles grandes, gousse non stipitée.

Fl. blanches avec les ailes noires; gousse tr. gr., long. de 10-20 cm., renflée, charnue, pubérulente; graines de 2-3 cm. de long, ovalesdéprimées; vrilles simples; fol. entières . . . V. Faba L. 374 Cult. (Fève.) - Mai-Jt.

Fl. d'un pourpre foncé; gousse de $3-6 \mathrm{~cm}$. de long., compr. gl. sur les faces, dentic. tuberc. sur les sutures; graines médiocres, subglob.; vrilles sup. rameuses; fol. dentées ou presque entières.

Lisière des bois, clairières.

V. serratifolia Jacq. 375

Q F., au moins les sup., portant plus de 3 paires de fol.; gousse stipitée.

- Fl. dépassant $1 \mathrm{~cm}$., souvent nombr.; pl. ann. ou vivaces. 
Fl. 1-5, sur un pédonc. commun plus court que l'une des fl., toujours beaucoup plus court que la $\mathrm{f}$.

Pl. viv., à souche rampante stol.; fol. ovales-obtuses, larg. de $1 \mathrm{~cm}$; fl. d'un violet sale, striées de pourpre, rar. blanchâtres; étendard gl.; gousses gl. et noires à la maturité; stip. inciséesdentées, tachées . . . . . . V. sepium L. 376 Haies, bois. - Mai-Sept.

Pl. ann., à racine grêle; fol. oblongues, larges d'un demi-centimètre; fl. purpurines, veinées, rar. jaunàtres $(\boldsymbol{V}$. pannonica Crantz); étendard velu soyeux; gousses velues-soyeuses; stip. entièr. tachées . . . . . . V. purpurascens DC. 377 Ch., moissons.

La var. pannonica, T. R.

Fl. nombr., blenes ou violettes, sur un pédonc. commun allongé.

Fl. s'ouvrant successivement de bas en haut, en grappes d'abord triang., oblongues, étendard à limbe plus long que l'onglet ou l'égalant; $p l$. vivace de 1-2 m.

Fl. d'un bleu pâle mèlé de blanc, en grappes plus long. que la f.; étendard à limbe 1 fois plus long et aussi large que l'onglet; gousses larges de 6-8 mm., atténuées en un pied égalant le tube du cal. . . . . . . V. tenuifolia Roth 378 Coteaùx, bois découverts. - Mai-At.

Fl. d'un bleu violet, en grappes égalant ou dépassant un peu la f.; étendard à limbe de mème long. et un peu plus étroit que l'onglet; gousses larges de 5̋-6 mm., contractées en un pied plus court que le tube du cal. . . . . . V. Gracca L. 379 Buissons, prés. - Jn-At.

Fl. violettes s'ouvrant presque toutes en mème temps, en grappes rhomboïdales oblongues; étendard à limbe 1 fois plus court que l'onglet; pl. ann. ou bisan.

Pl. glabrescente, ordinairement peu robuste, à poils appliqués; fl. en grappe, non plumeuse avant la flor. V. varia Host. 380 Ch. et moiss. - Jn-At.

Pl. robuste, hér., à poils étalés; fl. en grappe plumeuse avant la flor., les dents lin. du cal. étant longuement velues.

Ch. et moiss, introduit. - Jn-At.

V. villosa Roth 381

- Fl. petites, atteignant rar. $1 \mathrm{~cm}$., pàles, 1-4 (rarement 5-8) sur chaque pédonc.; pl. annuelle.

† Cor. dépassant longuement les dents du cal., gousses glabres.

Fl. 1-2, petites, 4-3̈ mm., sur des pédonc. plus courts que la f. ou l'égalant, non aristés; gousses longues de 9-12 mm. à 3-4 graines; hile oblong-linéaire, égalant le cinquième du contour de la graine; fol. lin.-oblongues, obtuses.

$$
\text { Ch., buissons. - Mai-Jt. }
$$

V. tetrasperma Iøench.

Fl. 2-5, assez petites, 6-7 mm., sur des pédonc. aristés, à la fin bien plus longs que la f.; gousses longues de 12-16 mm., ì t-6 graines; hile ovale, égalant au plus le huitième du contour de la graine; fol. étroites, lin., ord. aiguës. V. gracilis Lois. 383

Ch. arides, moiss. des terrains calc. - Nai-Jt.

む Cor. dépassant peu les dents du cal. ou plus courte qu'elles.

T. flexueuses, grimpantes; vrille rameuse; cor. d'un blanc bleuàtre de 3-3̈ mm. dépassant le cal.; gousses lin.-oblongues, de $8-10 \mathrm{~mm}$. sur 3 -4, bosselées, velues, à 2 graines subglob., non échancrées au sommet, noires à la maturité.

Champs, haies. - Mai-Sept. 
T. dress., non grimpantes; vrille simple ou bifurquée; cor. d'un blanc bleuàtre, de $3-7 \mathrm{~mm}$., un peu plus courte que le calice; gousses rhomboïdales, de $15 \mathrm{~mm}$. sur 8-10, compr., glabres, échancrées en croissant sous le sommet, à 2 graines lenticulaires, jaunàtres ou brunes . . . V. Lens Coss. et G. 385 Cult. et subsy. (Lentille.) - Mai-It.

\section{Genre 12:3. - GIGER L.}

Inn. vel. gland., dress. sans vrilles; f. imparipennées à 6-8 paires de fol. ovales, dentées en scie; fl. bleuàtres ou blanches, solit. sur des pédonc. axill., articulés et bractéolés vers le milieu, plus courts que la 1.; cor. dépassant à peine le cal.; gousses grosses, tr. renfl., rousses, à 2 graines ridées . . . . . . . . G. arietinum L. 386

Cult. rar. (Pois ehiche.) - Jn-Jt.

GeNre 126. - PISUM L.

Fl. assez gr., moins de $2 \mathrm{~cm}$., rougeàtres ou bleuàtres, à ailes pourpre foncé; gousses de 1-כ̆ $\mathrm{cm}$. sur $9 \mathrm{~mm}$.; graines pressées les unes contre les autres, déprimées, anguleuses, lisses, tachées de brun; hile ovale; t. assez grèles; f. à 2-6 fol., ovales, ent. ou crén. P. arvense L. 387 Cult. et subsp. (Pois gris.) - Mai-Jt.

Fl. ¿rr., plus de $2 \mathrm{~cm}$., blanches on blanchâtres, rosées ou bleuâtres à ailes d'un violet noiràtre; gousse de 6-7 cm. sur 12-15 mm.; graines glob., lisses, jaune pàle ou vert grisàtre; hile lin.-oblong; t. robustes, f. à 2-orandes fol. ovales, ent. ou sinuées-ondulées.

$$
\begin{aligned}
& \text { Cult. (Pois.) - Mai-Sept. } \\
& \text { Genre 127. - LATHYRUS L. }
\end{aligned}
$$

\section{Genre 127. - LATHYRUS L.}$$
\text { P. sativum L. } 388
$$

+ F. simples ou réduites à la vrille; pl. ann.; graine de 2 1/2 à 3 mm.

F. réduites à la vrille, remplacées par 2 grandes stip., ovalessagittées, imitant 2 f. opp.; fl. jaunes, assez petites, 8-10 mm., à cor. dépassant peu le calice, 1-2 sur des pédonc. gl., plus longs que les stip. et les vrilles; gousses de $2-3 \mathrm{~cm}$., gl., arquées en sabre à $4-i$ graines lisses, noires, brillantes. . . . L. Aphaca L. 389 Lieux incultes, ch. - Mai-Jt.

F. simples, lin. lanc., sans vrille; stip. presque nulles; fl. rougeâtres, asse $z$ petites, 10-12 $\mathbf{m m}$., à corolle 1 fois plus longue que le cal., 1-2 sur des pédonc. ord. pub., plus courts que la f.; gousse de 4-6 cm., glabresc., veinée en long, étroite linéaire, droite à nombr. graines chagrinées-rugueuses d'un brun noiràtre, mates. L. Nissolia 390 Ch., haies. - Mai-Jt.

+ F. paripennées, à une ou plus. paires de fol.

- Pédonc. portant 1-3 fl.; pl. ann. à 1 paire de fol.

= T. ailées ; fl. gr. 10-1̈̈ mm.; style tordu sur son axe.

a. Pédonc. 2-3 fois plus longs que la f., poilus, 1-3 fl.; gousses velues tuberc.; graines glob. de 4 -z̈ mm. mates, brunâtres.

Pl. glabrescente ou velue; fol. lin. oblongues; fl. violacées ou bleuâtres, assez gr., 8-12 mm.; cal. à dents égalant le tube ; graines tuberc. . . . . . . . . L. hirsutus L. 391 Ch., moiss., talus. - Mai-Jt.

Pl. hérissée scabre; fol. gr. ovales ou oblongues, mucronées; fl. tr. odor., grandes $25-30 \mathrm{~mm}$., mèlées de rouge, de blanc et de bleu; cal. à dents plus longues que le tube; graines lisses ou tr. finem. chagrinées. . . . . . L. odoratus L. 392 Cult. et subsp. - Mai-Jt.

@. Pédonc. plus courts que la f., gl., uniflores; gousses gl. ; graines lisses, anguleuses, grosses de כ̌-8 mm. sur 4-6. 
Fl. rouges, de 10-13 mm. de long; gousse oblongue, large de $8-10 \mathrm{~mm}$., canaliculée sur le dos, à 2 rebords courts, non ailés; stip. égalant le pétiole; graines gris-rougeàtres de כ̋ mm. sur 4.

Cultivé et subsp. (Gesse, Garot.) - Mai-Jt.

L. Cicera L. 393

Fl. blanches, rosées ou bleuâtres, longues de $130 \mathrm{~mm}$. environ; gousse ovale rhomboïdale, large de $12-13 \mathrm{~mm}$, munie sur le dos de 2 ailes foliacées; stip. plas courtes que le pétiole; graines blanc-jaunàtres de $8 \mathrm{~mm}$. sur 6 . . L. sativus L. 394 Cult. et subsp. (Gesse.) - Mai-Jt.

= T. anguleuses, non ailées; fl. petites, 4-10 mm., solit.; style non tordu; pédonc. long. aristés; gousses non stipitées, étr., 3-6 mm., gl.; fol. lanc. lin.. aig.; graines de 2 1/2 à 3 1/2 mm., noirâtres.

Pédonc. égalant à peine le pétiole; stip. plus long. que le pétiole ; vrilles toutes simples; fl. d'un rouge brique; gousse bosselée, tr. veinée en long; graines glob., lisses. L. sphaericus Retz. 395 Champs, pl. introduite.

Pédonc. 4-6 fois plus longs que le pétiole; stip. égalant le pétiole; vrilles sup. rameuses; fl. d'un rouge-bleuâtre; gousse non bosselée, à peine veinée; graines anguleuses-cubiques, tuberc.

\section{Ch. - Mai-Jt.}

L. angulatus L. 396

Pédonc. portant 3-12 fl.; pl. vivace.

Fl. jaunes; t. non ailées; f. à 1 paire de fol. lanc.; stip. gr., ovales, lanc.; cal. à dents presque égales, égalant le tube; gousses, 2-3 cm., veinées, gl. ou pub.; graines lisses, glob., brillantes, brun rougeâtre de $21 / 2 \mathrm{~mm}$.. . $\quad$ L. pratensis L. 397 Haies, prés, bois. - Mai-At.

Fl. rouges, bleuàtres ou violacées; gousses glabres.

む F. term. par une simple pointe à 2-6 paires de fol.; t. dress., non grimpantes; gousses noires de $35-50 \mathrm{~cm}$.; stip. semi-sagittées. Pétioles étr. ailés, plus courts que les stip. ou les égalant, term. par un mucron; t. ailées; f. à $2-4$ paires de fol. courtes, ovales, oblongues ou lanc., rar. lin.; gousse vein., lin. cyl.; stipules ovales-lanc.; grappes de 2-3̆ fl.; graines glob., lisses, mates, grisàtres de $3 \mathrm{~mm}$. . L. macrorhizus Wimm. 398 Bois, prés. - Av.-Jn.

Pétioles non ailés, bien plus longs que les stip., term. par un mucron; t. anguleuses ; f. à 4-6 paires de fol. ovales ou elliptiques, glauques en dessous; gousse veinée en réseau, lin., compr.; stip. lin. en alène; grappes de 4-8 fl.; pl. noircissant par la dessiccation; graines ovoïdes, lisses, brillantes, brunàtres de 4 mm. sur 3. . . . . . . L. niger Bernh. 399 Bois calc. - Jn-Jt.

む F. term. par une vrille rameuse; graines glob. noiràtres.

$=\mathrm{T}$. anguleuses non ou étr. ailées, atteignant au plus 1 mètre; graines lisses de $4 \mathrm{~mm}$. de diamètre.

F. à une seule paire de fol.; elliptiques ou oblongues; fl. d'un rose vif odor., à pédonc. plus long que la f.; style arqué, tordu sur son axe; souche renflée-tuberc.; gousse lin. cyl., veinée, fauve; hile égalant le cinquième de la circonférence de la graine... . . . . . . . . L. tuberosus L. 400 Ch. moiss. - Jn-Sept.

F. à 2-4 paires de fol. oblongues ou lanc.; fl. d'un pourpre bleuâtre, à pédonc. égalant ou dépassant la f.; style droit, non tordu; souche grêle, non tuberc.; gousse larg. lin., compr., veinée en réseau noirâtre, hile égalant presque le tiers de la circonférence ....... . L. palustris L. 401

Prairies hum. - Jn-At. 
= T. larg. ailées, long. de 1-2 m.; style arqué-ascendant, tordu sur son axe; f. à une paire de fol.; pédonc. dépassant la f.; graines chagrinées de 4 à 4 1/2 $\mathrm{mm}$.

Fl. d'un rose sale mêlé de vert, assez grandes, 14-18 mm.: gousses long. de $5-6$ cm., compr., munies sur le dos de 3 còtes peu saillantes, dentic.; graines chagrinées de $4 \mathrm{~mm}$.; hile égalant presque la moitié du contour de la graine; fol. lanc.

Boies, haies. - Jn-At.

L. silvestris L. 402

Fl. d'un rose vif, gr., $20-25 \mathrm{~mm}$; gousses longues de $6.8 \mathrm{~cm}$; subcyl., munies sur le dos de 3 côtes lisses, la médiane saillante et tranchante; graines rugueuses, chagrinées de $41 / 2 \mathrm{~mm}$.; hile égalant à peine le tiers du contour de la graine; fol. ovales ou lanc. . . . . . . . L. latifolius L. 403 Buissons, subsp. - Jn-At.

\section{Genre 128. - GORONILLA L.}

Fl. assez gr., $1 \mathrm{~cm}$., panachées de blanc, de rose et de violet, 10-13 en omb. sur des pédonc. dépassant les f.; pédic. 2 fois plus longs que le cal.; gousses dressées, à 3-6 articles ; f. imparipennées à 7-12 paires de fol. oblongues. . . . . . . . . . G. varia L. 404

Coteaux pierreux. - Mai-At.

Fl. petites, $\breve{3}-7 \mathrm{~mm}$., jaunes, $\breve{3}-10$ en omb. sur des pédonc. 2-3 fois plus longs que la f.; pédic. à peine plus longs que le tube du cal.; gousses pendantes, de $20-25 \mathrm{~mm}$., à 2-3 articles; f. imparipennées à $3-4$ paires de fol. petites, obovales en coin, épaisses; plante glauque à tiges presque ligneuses . . . . . . . C. minima L. 405

Coteaux calc. - Nai-Jt.

\section{GenRe 129. - ORNITHOPUS L.}

Pl. ann., pub., étalée ou redressée; f. à "̌-12 paires de fol. ovales ou oblongues stip.; fl. tr. petites, blanc rosé, de 4-3 mm., 3-8 en omb. sur des pédonc. plus courts ou un plus longs que la f.; gousse étalée-dressée, un peu arquée, pub. ou glabrescente, noirâtre, étranglée aux articulations ....... 0. perpusillus L. 406 Lieux sabl. - Nai-Sept.

\section{GENRE 130. - HIPPOGREPIS L.}

PI. viv. glabrescente, à souche un peu ligneuse; f. à 4-7 paires de fol., obovales ou oblongues; fl. gr., 8-10 mm., "̆-12 en omb. sur des pédonc. 2-3 fois plus longs que la f.; gousses nombr., pendantes, longues de 2-3 cm., couvertes de glandes rougeàtres, à 2-6 articles, à échancrures et graines arquées en demi-cercle ...... H. comosa L. 407

Coteaux surtout calc. - Mai-Jt.

\section{Genre 131. - ONOBRYGHIS Adams.}

Pl. viv., pub., dress. ou ascend.; f. à 6-12 paires de fol. oblongues ou lin.; fl. ord. roses, striées de rouge, en long. grappes serrées sur des pédonc. plus longs que la f.; gousses pub., munies de tubercules ou épines. . . . . . . . . . . 0. sativa Lamk. 408 Cult. et subsp. (Sainfoin). - Mai-Jt.

+ Cal. libre.

\section{FaMille 33. - ROSACÉES}

$\times$ Arbres ou arbriss. à fr. charnu, drupe ou baie, indéh. à un seul noyau contenant 1-2 graines; cal. caduc; 1 style.

$=$ Fl. sessiles ; fr. pub. ou velouté glob.

Fl. d'un rose vif; noyaux subglob. tr. rugueux creusé d'anfractuosités profond.; jeunes f. pliées en long. . P PERSICA 132 
Fl. blanches ou lavées de rose; noyau ovale-comprimé, lisse sur les faces non creusées; jeunes f. enroulées. ARMENIACA 133

= Fl. distinct. pédonc. d'nn blanc pur; fr. glabre ou glauque pulvérurulent.

F1. brièv. pédonc.; pédonc. fructif. plus courts que le fr.; noyau plus ou moins déprimé; jennes f. enroulées. PRUNUS 134

Fl. long. pédonc.; pédonc. fructif. plus longs que le fr.; noyau compr.; jeunes f. pliées en long. ... GERASUS 135

$\times \mathrm{Pl}$. herb. ou lign. à fr. sec, rar. bacciforme formé de carp. drupacés rapprochés en tête sur un récept. charnu.

- Pl. sans épines, fr. sec.

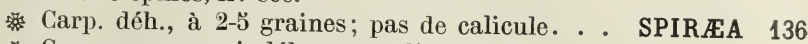

Carp. monosp., indéh.; un calicule.

† Styles term., accrescents après la flor.; f. lyrées pennatiséquées. . . . . . . . . . . . GEUM 137

o Styles lat.; f. trifoliolées, digitées ou imparipennées.

† Récept. sec ou spongieux, persistant.

Récept. sec; pét. arrondis ou émarginés; fl. jaunes, blanches ou roses ; f. trifoliolées, digitées ou imparipennées.

POTENTILLA 138

Récept. spongieux velu ; pét. aigus, pourpre-foncé; f. imparipennées................ COMARUM 139

\& Récept. charnu, caduc; fl. blanches ; f. trifoliolées.

FRAGARIA 140

- Pl. ligneuse, sarment., munie d'aiguillons; fr. formé de petites drupes réunies en tête glob. sur un récept. charnu; f. trifoliolées, digitées ou pennatiséquées; fl. blanches ou roses ; pas de

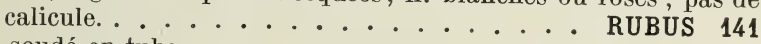

+ Calice soudé en tube.

X Pl. ligneuse, dressée ou sarment., munie d'aiguillons; f. imparipennées ; cal. à tube urcéolé, resserré au sommet, s'accroissant après la flor. surmonté de こ̌ sép. ent. ou appendic.; styles lat., libres ou soudés en colonne à stigmates rapprochés en tête ; carp. nombr., hér., libres, groupés au fond du tube du cal. devenant charnu;

fl. blanches ou rouges, rar. jaunes. . . . . ROSA 142

$X$ Pl. herb. ou lign. avec ou sans épines; jamais d'aiguillons.

$=$ Pl. herbacée.

o Une cor. ; fl. jaunes; cal. hér. de soies ; 2 styles ; fr. simple obconique, renfermant 1 ou 2 graines; fl. jaunes en grappes term. spiciformes; f. pennatiséquées.. . . . . AGRIMONIA 143

ơ Pas de cor.

- Cal. à 4-5 lobes ou dents, sans calicule ; fl. en tête; f. imparipennées.

F1. polygames ou monoïques ; 20-30 ét. longues et pendantes; 2 styles filiformes; fr. à faces rugueuses à 2-3 carpelles.

POTERIUM 144

Fl. hermaphrodites ; 4 ét.; 1 style court; fr. à faces planes à 1 carpelle.............. SANGUISORBA 145

- Cal. à 8 lobes, calicule compris; fl. en cymes corymbiformes ou fasc.; f. palmatilobées ou palmatipartites; 1-4 ét. ; 1-2 graines renfermées dans le tube du cal. . . ALCHEMILLA 146

$=\mathrm{Pl}$. lign., arbres ou arbrisseaux.

* Fr. à noyaux osseux.

5 noyaux ; 5 styles; cal. à divis. foliacées ; f. ent.; fl. solit.

1-3 noyaux; styles ; MESPILUS 147

1-3 noyaux; つ’ styles; cal. à lobes courts; f. lobées; fl. en co畋 Fr. à pépins. 
ro Loges contenant chacune 10-15 graines; fl. solit.

CYDONIA 149

'o Loges contenant chacune 1-2 graines; fl. en corymbes, ombelles ou grappes.

† Fl. en fasc. ombelliformes; fr. à endocarpe cartilagineux; arbres général. épineux à l'état sauvage.

Anth. rouges; styles compl. libres; fr. en poire, ombiliqué seulement all sommet. . . . . . PIRUS 150 Anth. blanchàtres; styles soudés à la base; fr. en pomme, ombiliqué au sommet et plus profondément à la base.

MALUS 151

む Fl. en corymbe composé ou en grappes simples; ir. à endocarpe crustacé fragile; arbres ou arbriss. non épineux.

Fl. en corymbe rameux; pét. larges, suborb. ou obovales; fr. mùr rouge ou brun; f. gr., dentées, lobées ou pennées.

SORBUS 152

F1. en grappes simples ; pét. étroits lancéolés-oblongs ; fr. mûr noir bleuatre ; f. simples, petites, fin. dentées.

AMELANCHIER 153

\section{Genre 132. - PERSiGA Mill. - Pècher.}

Arbriss. de 2-5̆ m. non épin. à rameaux effilés, gl.; f. lanc., dentées en scie, gl. ; fl. naissant avant les f., solit. ou géminées ; drupe grosse, glob., pub. veloutée ou lisse et gl. (P. laevis DC. Brugnon); noyau à 1-2 amandes amères. . . . . . . . . P. vulgaris Mill. 409

Cult., quelquefois subsp. - Fl. Mars-Av.; fr. Jt-Sept.

\section{Genre 133. - ARMENIAGA Juss. - Abricotier.}

Arbuste de 3-6 m. non épin. à rameaux étalés ou ascendants; f. à pétiole gland., ovales en coeur, acum., doublement dentées, gl.; fl. naissant avant les f., solit. ou géminces; drupe grosse, glob., pub. veloutée; noyau caréné à 2 sillons sur un bord, obtus sur l'autre, à 1-2 amandes amères.. . . . . . . A. vulgaris Lamk. 410 Cult. - Fl. Fév.-Iv.; fr. Jt.

\section{GENRE 13\%. - PRUNUS L.}

- Arbres ou arbriss. élevés non ou à peine épin.; pédonc. pub., ord. géminés; drupe grosse, penchée à saveur douce, glob., ovale ou oblongue, jaunâtre, rougeàtre ou violacée ; noyau rugueux sur les faces; fl. naissant avec les $\mathrm{f}$.

Jeunes rameaux gl.; f. gl. ou légèr. pub., en dessous; cal. poilu à l'intér.; drupe ord. oblongue, rougeàtre ou violacée.

Cult, et subsp. (Prunes). - Fl. Nars-Av.; fr. Jt-Sept.

P. domestica L. 411 Jeunes rameaux pub. ou tom.; f. velue en dessous, surtout sur les
nervures; cal. gl. à l'intér.; drupe glob. ou ovale, violacée ou jaunâtre........... . P. insititia L. 412

Cult. et subsp. (Reines-Claude.) - Fl. Mars-Av.; fr. Jt-Sept.

- Arbriss. épin. à fr. bleuâtre on non épin. à fr. rouge ; pédonc. gl. ou pubérulents ord. solit., quelquefois géminés; drupe petite glob., dressée ou penchée, acerbe, noyau presque lisse.

綎 Arbriss. épin. à fr. bleuâtre, dressé, jeunes rameaux pub. ; fl. naissant ord. avant les f.

Arbriss. élancé à rameaux peu épin. ; f. adultes larges de 150-2:3 mm., velues en dessous surtout sur les nervures; fr. assez petit, à noyau ovoüde, déprimé ...... P. fruticans Weihe 413

Haies, bois. - Fl. Av.-Mai.; fr. It-Sept. 
Arbriss. buissonneux à rameaux divariqués et tr. épin.; f. étr., d'abord pubescent, puis glabre; fr. petit à noyau subglob., à peine déprimé . . . . . . . . . . P. spinosa L. 414 Iraies, bois (Prunelles) - Fl. Av.; fr. Sept-Nov.

㮸 Arbriss. élevé ord. non épin., à fr. glob., de la grosseur d'une cerise, rouge, pendant, à pédonc. aussi long que le fr.; jeunes rameaux gl.; fl. naissant avec les feuilles. . P. cerasifera Ehrh. 415 Haies, taillis, snbsp. - Fl. Av.; fr. At.

Sert ì greffer.

\section{Genre 135. - CERASUS Juss.}

+ Fl. en fasc. ombelliformes s'épanouissant avant ou avec les feuilles; drupe à saveur douce ou acide.

Arbre élevé à rameaux dressés-étalés; i. pub. en dessous; pétiole offrant au sommet 2 glandes rougeàtres: drupe à saveur douce.

C. avium Moench. 416

Bois, haies. (Mérisier.) - Fl. Avr.-Mai. - Fr. Jn-Jt.

Arbre peu élevé, à rameaux étalés-pendants; f. gl. dès leur jeunesse ; pétiole sans glandes; drupe ì saveur acide.

G. vulgaris Mill.

Cult. (Cerises aigres.) - Fl. Avr.-Mai. - Fr. Jn-At.

+ Fl. en corymbes ou en grappes, assez petites, s'épanouissant avec ou après les f.; drupe à saveur acerbe, amère.

Fl. en petits corymbes dress.; sép. non cil.; f. ovales en coeur, à dents arquées, calleuses-glanduleuses . . C. Mahaleb Mill. 418 Bois et coteaux calc. - Fl. Avr.-Mai. - Fr. Jt-It.

Fl. en longues grappes pendantes; sép. cil.-gland.; f. obovales à dents étalées, non gland. ....... C. Padus DC. 419 Bois, nat. - Fl. Avr. Mai. - Fr. Jn-It.

\section{Genre 136. - SPIRAEA L.}

+ F. sans stip., obovales, ent. ou crén. dentées; t. lign.; fl. blanches, petites, long. pédonc., 4-8 en fasc. lat., feuillés à la base, rapprochés en pan. long. et étroit; 3-̋̃ carp. dress., déhiscent.

Vieux murs, taillis secs, introduit. - Mai-Jn.

S. hypericifolia L. 420

+ F. munies de stip. soudées au pétiole, imparipennées; inflor. en corymbe; ’ -9 carp. indéhiscent.

F. à $5-9$ paires de segments larg., écartés, dentés blancs tom. ou verts en dessous; carp. gl., contournés en spirale; ét. plus longues que les pét.; racine fibreuse non renfl. S. Ulmaria L. 421 Lieux hum. - Jn-At.

F. à 10 -20 paires de segments, étroits, presque contigus, pennatifides à lobes cil.; carp. pub., non contournés; ét. plus courtes que les pét.; racines term. par des renfl. ovoïdes.

S. Filipendula L. 422

Bois secs et sabl., rar. prairies hum. (Fontenay-sur-Loing). - Mai-Jt. On cult. dans les pares et on rencontre quelquefois (Fontainebleau, Compiègne) S. opulifolia Willd, arbuste à f. trilobées à lobes crén., à fl. ßlanches en corymbes term.

\section{Genre 137. - GEUM L.}

+ Fl. rougeâtres ou d'un blanc jaunâtre, penchées, en cyme pauciflore; pét. dressés, veinés, tronqués ou émarginés, à long onglet, égalant le cal.; carp. en tête long. stipitée à carpophore égalant le cal., à arête longue, plumeuse; cal. à divis. dress. après la flor.

Bois hum., bords des ruiss. - Mai-Jt.

G. rivale L. 423 
+ Fl. jaunes, dress., rar. inclinées, en cyme pauciflore; pét. étalés, arrondis au sommet égalant ou dépassant un peu le cal.; carp. en tète sessile ou brièv. stipitée à arète gl. ou brièv. plumeuse; cal. à divisions étalées ou réfractées.

Fl. dress.; carp. en tête sessile à arête gl.; cal. à divis. réfractées.

Bois et haies. - Mai-Sept.

G. urbanum L. 424

Fl. dress., rar. inclinées; carp. en tête sessile ou brièv. stipitée à arête brièv. plumeuse; cal. à divis. étalées, rar. réfléchies.

Bois hum. - Nai-Jt.

G. intermedium Coss. et G. 425

Varie à fl. dress., divis. du cal. réfléchies, carpophore nul (G. mubifolium Lej.) ou fl. inclinées, cal. à divisions étalées, un carpophore court (G. umbrosum Dumort).

\section{Genre 138. - POTENTILla L.}

+ Fl. blanches; f. rad. à 3 fol.; carp. velu seulement à l'ombilic.

Folioles obovales-oblongues munies seul. au sommet de 5-7 dents courtes, conniv.; pét. gr. 1-2 fois plus longs que le cal.; fibres rad. quelquefois renfl. fusiformes. . . P. splendens Ram. 426 Bois sees et sabl. - Avr.-Mai.

Fol. obovales-arrondies munies tout autour de 8-12 dents prof., larg. et écartées; pét. dépassant à peine le cal.

Bois, prés, lieux sees. - Mars-Mai.

P. Fragariastrum Ehrh. 427 + Fl. jaunes.

X F. imparipennées; fl. solit. à l'aisselle des f. ou à l'angle des rameaux; carp. glabre.

T. ramp.-stolonifères; f. soyeuses-argentées en dessous à 13̈-20 fol.; fl. gr., à pét. 2 fois plus longs que le cal. P. Anserina L. 428 Prés, fossés. - Mai-Sept.

T. couchées étalées, non radicantes, rar. dress.; f. vertes sur les 2 faces, à כ̆-11 fol.; fl. petites, à pét. plus courts que le cal.

Bords des étangs silic. - Jt-Sept.

P. supina L. 429

$X \mathrm{~F}$. trifoliolées ou digitées.

= Fl. axill., solit. ou en cymes feuillées.

Q T. radicantes dans toute leur long.; f. pétiolées à 30 fol. dentées tout autour; calicule à 5 lobes plus gr. que ceux du cal.; cor. de 130 -30 mm. à ${ }^{3}$ pét. . . . . . . . . P. reptans L. 430

Fossés, bords des chemins. - Jn-0ct.

Q T. non radicantes ou seulement au sommet; f. subsessiles ou brièv. pétiolées à 3-3 fol. dentées sup. ; calicule à 4-3̈ lobes égalant ceux du cal. ou plus petits; cor. de $8-\mathbf{1 8 ~} \mathrm{mm}$.

T. à la fin un peu radicantes au sommet; f. pétiolées à 3-b̆ fol.; calicule à 4-气̆ lobes égalant presque ceux du cal.; cor. de 14-18 mm. à 4-3 pét. . . . . . P. procumbens Sibth. 431 Pelouses, lieux herbeux silic. - Jn Sept.

T. jamais radicantes; f. caul. subsessiles, à 3 fol.; calicule à 4 lobes plus petits que ceux du cal.; cor. de 8-12 mm., à 4 pét.

P. Tormentilla Neck 432

Pelouses et lieux herbeux surtout silic. - Jn-Sept.

$=$ Fl. term., en cymes corymbiformes.

- T. assez robustes, dress. ou ascend., feuillées; fol. à dents assez nombr., blanches ou grisâtres tom. en dessous.

Fol. grisâtres-tom. en dessous, oblongues-lanc., planes, fort. dentées; carp. obscurément bordés. . P. inclinata Vill. 433

Lieux secs, vieux murs, nat. - Jn-Jt. 
Fol. blanches tom. en dessous, larg. obovales en coin, à bords un peu roulés, profond. incisées dentées; carp. non bordés.

Lieux secs. - Mai-At.

P. argentea L. 434

- T. grêles, flexueuses, couchées, ascend. seul. au sommet, naissant à l'aisselle des f. inf. d'une rosette term. les divis. du rhizôme; f. rad. digitées à כ̆-7 fol. pub., vertes, à dents peu nombr., la term. plus petite; fl. en cyme lâche pauciflore à pét. émarg. dépassant le cal. . . . . . . . . . P. verna L. 435 Lieux secs et arides. - Mars-Jn.

Les $P$. pennsilvanica L., recta L., hirta L. ont été autrefois observẻs dans nos environs; nat.; t. dress., fl. term. jaunes, gr., en corymbes. $P$. pennsilvanica a les $\mathrm{f}$. pennatiséquées, les 2 autres les feuilles digitées à $50-7$ fol. $P$. hirta la t. hér. de longs poils blanes, fol. dentées seulement sup. $P$. recta la $t$. vel., les fol. dentées tout autour.

\section{Genre 139. - GOMARUM L.}

Pl. viv. pub. à souche long. ramp.; t. ascend. feuillées; f. imparipennées à 5-7 fol. oblongues, vertes en dessus, glauques en dessous, dentées en scie; stip. larg. soudées; fl. en cymes irrégul.; calicule à ò lobes plus petits que ceux du cal. dress. appliqués sur le fr.; carp. gl. et lisses.

Marais tourb., fossés. - Jn-At.

C. palustre L. 436

\section{Genre 140. - FRAGARIA L.}

+ Cal. fructif. étalé ou réfléchi; stolons munis d'une écaille dans l'intervalle des nouds feuillés.

Pédic. à poils étalés; fl. gr., 20-25 mm., fr. rétréci et sans carp. à la base; fol. gr. toutes pétiolulées. . . . . F. elatior Ehrh. 437 Bois ombragés, haies, fleurit rar. - Avr-Jn.

Pédic. à poils appliqués; fl. moyennes $12-15 \mathrm{~mm}$.; fruit élargi et pourvu de carp. à la base; fol. assez gr., les lat. sessiles.

Bois découverts. - Avr.-Jn.

F. vesca L. 438

+ Cal. appliqué sur le fr. rétréci et sans carp. à la base; pédic. à poils appliqués ou peu étalés; fl. assez gr. $15-20 \mathrm{~mm}$. ; fol. assez petites, pub. soyeuses en dessous, sessiles ou pétiolulées; stolons dépourvus d'écaille dans l'intervalle des nouds feuillés; ét. une fois plus longues que l'ovaire . . . . . . . F. collina Ehrh. 439 Bois et coteaux, surtout calc. - Mai-Jn.

Var. à folioles pétiolulées, la terminale longuement; stolons munis d'une écaille, ét. égalant l'ovaire (F. Hagenbachiane Lang).

\section{Genre 141. - RUBUS L.}

+ Turion herb., faible inerme ou muni de quelques fins acicules; rameaux florifères naissant sur la souche à la base du turion; stip. adhérant brièv. à la base du pétiole; drupéoles gl., rougeâtres à la maturité, peu nombr., 2-6; 5̆-8 fl. en petit corymbe term. le rameau florifère à pét. blancs lanc. oblongs; f. minces, vertes en dessous à 3 fol.,la term. ovale rhomboïdale . R. saxatilis L. 440 Clairières des bois secs et sabl. herbeux. - Mai-Jn.

+ Turion lignifié, bisan.; rameaux florifères naissant, la seconde année, successivement des bourgeons situés à l'aisselle des f.; stip. adhérant long. au pétiole; drupéoles rouges et tom. ou noires.

$X$. Fr. rouge à la maturité, se détachant du récept. conique; drupéoles tom., petites, tr. nombr.; f. la plupart imparipennées, blanchestom. en dessous à $\breve{-7}$ fol., celles des rameaux florifères à 3 fol. fl. blanches à pét. lanc., petits ...... R. idaeus L. 441 Bois frais et humides. - Mai-Jn. 
X Fr. mur noiràtre ou bleuâtre, entraìnant dans sa chute la partie sup. ramollie du récept.; drupéoles gl. ou glauques-puineuses; f. digitées ou ternées.

$=$ Aiguillons égaux; acicules et glandes stipitées nuls ou accidentels.

a. Turion dress., anguleux, gl.; $\mathrm{f}$. vertes sur les 2 faces, rar. grisàtres en dessous; sép. verts sur le dos, bordés de blanc; espèces à flor. précoce.

- F. glabrescentes, non tomenteuses en dessous.

Aiguillons du turion subulés, droits, à base conique étr.; ét. plus longues que les styles, sép. étalés; fl. blanches.

Lisières des bois siliceux. - Jn.

R. suberectus Anders. 442

Aiguillous du turion assez robustes, à base dilatée et allongée.

○ Sép. étalés, concaves pendant et après l'anthèse.

Et. plus courtes que les styles ou les égalant à peine; pét. rosés; f. munies de poils épars sur les 2 faces, souvent plissées.

R. plicatus W. et N. 443

Clairières des bois, surtout sil. - Jn.

Etam. longues, dépassant sensiblement les styles; pét. blancs;

f. glabrescentes, non plissées. . . R. biformis Boul. 444

Clairières, bords des chemins. - Jn.

○ Sép. réfléchis dès l'anthèse jusqu'à la fin.

Turion à faces planes; fol. caul. term. tronquée ou obtuse à la base; inflor. développée, à pédonc. rameux.

Clairières et lisières des bois. - Jn-Jt.

R. nitidus W. et N. 445

Turion à faces fort. canaliculées; fol. caul. term. en coeur à la base; inflor. en grappe ord. simple. R. sulcatus Vest. 446 Bords des bois, - J̦n.

— F., au moins les raméales sup., grisâtres tom. en dessous; pét. roses on blanes; inflor. rameuse; turion à faces planes ou un peu canal.; f. à : :- $-\bar{t}$ fol. ondulées aux bords.

$$
\text { Bois. - Jn-Jt. }
$$

R. affinis W. et N. 447

a Turion arcqué procombant, gl. ou vel.; f. vertes, grises ou blanches en dessous; sép. grisàtres ou blanchâtres sur le dos; espèces à flor. non précoce.

む F. verles, plus rar. grisàtres-tom. en dessous; sép. gris-tom. sur le dos; espèces fleurissant en moyenne saison, habitant les bois et les lieux ombragés.

$\odot$ F. caul. vertes en dessous.

Et. plus courtes que les styles ou les égalant à peine; pl. relativement faible. . . . R. Sprengelii Weihe 448 Bois-Jt.

Et. dépassant les styles, pl. robustes.

q Fl. d'un rose vif, à pét. souvent bilobés.

Turion garni d'une villosité dense et rude, ainsi que les f., sur les 2 faces; inflor. pyramidale, à pédonc. longs, tr. étalés...... R. Schlechtendalii Weihe 449 Bois. - Jn-Jt.

Turion gl., à faces planes; f. gl. ou glabrescentes; pét. bilobés; inflor. étr. à pédonc. peu allongés.

Bois, haies. - Jn-Jt.

R. Questieri Lef. et Muell. 450

Fl. blanches ou d'un rose pâle, à pét. arrondis au sommet.

Turion subcyl. jusque vers le milieu, à aiguillons denses, petits; à base peu dilatée; fol. term. un peu atténuée à la base; jeunes carp. vel. . . R. silvaticus W. et N. 451 Bois siliceux. 
Turion nett. anguleux dès au-dessous du milieu, à aiguillons espacés, médiocres, dilatés; fol. term. arrondie à la base; jeunes earp. gl.

Turions vigoureux, élancés plus ou moins canal. sur les faces; f. amples, d'un vert obscur, presque gl. en dessous.

Bois sabl. - Jn-Jt.

R. macrophyllus W. et N. 452

Turions de taille moyenne, à faces planes; $\mathrm{f}$. épaisses munies en dessous d'une villosité veloutée, dense, jaunàtre.

Bois. - Jt.

R. pyramidalis Kalt. 453

$\odot$ F. caul. plus ou moins grisàtres-tom. en dessous; turion gl., canal. sur les faces; pét. blancs; ét. dépassant un peu les styles .. . . . . R. cardiophyllus Lef. et Muell. 454 Bois. - Jt.

† F. blanches-tom. en dessous; sép. blanc-tom. sur le dos; espèces à flor. tardive, croissant dans les lieux éclairés et découverts.

F., au moins les raméales sup., tom. en dessus; pét. d'un blanc jaunâtre; pl. faible, déprimée, offrant souvent des soies et des glandes stipitées . . . . R. tomentosus Borckh. 455 Lieux sees. - Jn-Jt.

F. gl. ou munies de poils rudes et épars en dessus; pét. roses ou blancs; pl. robustes n'offrant ni soies, ni glandes stipitées.

1. Et. égalant ou dépassant peu les styles.

Turion à faces planes; axe florifère à aiguillons droits; jeunes carp. plus ou moins poilns. . . . R. bifrons Vest. 456 Lieux secs. - Jn-Jt

Turion à faces canaliculées; axe florifère à aiguillons général. faleiformes; jeunes carp. gl. . R. ulmifolius Schott 457 Lieux ensoleillés. - Jn-At.

Et. dépassant long. les styles.

Turion faibl. lign., gl., à faces vivement canal. pédonc. ascend.; fl. blanches ou rose pàle.

Lieux déeouverts. - Jn-Jt.

R. thyrsoideus Wimm. 458

Turion dur, bien lign. gl., à faces planes; pédonc. tr. étalés; fl. roses; ét. pàles; styles verdàtres.

Clairières des bois. - Jt-At.

R. cuspidifer Muell. et Lef. 459

= Aiguillons inégaux, les plus petits sétacés; soies glandulifères et glandes stipitées souvent abondantes.

|l Turion faible, déprimé, cyl., glaucescent; drupéoles peu nombr., 2-ə̆, grosses, bleuâtres et glauques à la maturité; flor. précoce.

Lieux frais. - Jn-Jt.

R. caesius L. 460

II Turion plus robuste; drupéoles nombr., noires et non glauques à la maturité; espèces à flor. tardive.

+ Turion anguleux à aiguillons, les uns faibles, les autres robustes tr. vulnérants; f. vertes ou grisàtres tom. en dessous; pét. ord. larges et rosés; espèces des bois et des lieux découverts:.

$X \mathrm{~F}$, au moins les raméales, sup., blanches ou grisàtres-tom. en dessous.

= Turion gl. ow glabreseent à faces planes; pl. robuste, élevée inflor. pyramidale ........ R. Radula Weihe 461 Bois. - It.

$=$ Turion garni d'une villosité dense.

Glandes stipitées et petits aiguillons tuberc. épars; turions anguleux; inflor. pyramidale, à pédonc. très étalés.

Bois, haies. - Jt.

R. hypoleucus Lef. et Muell.

462 
Glandes stipitées apparentes nombr.

Turion obtusément anguleux assez rude au toucher; f. d'un vert sombre, les caul. ord. vertes en dessous, pét. blanes, rar. rosés ........ R. fuscus Weihe 463

Bois, coteaux. - Jt.

Turion anguleux, âpre au toucher par l'abondance des soies raides et des aiguillons tuberc.; f. blanches tom. en dessous, pét. roses....... R. Genevieri Bor. 464 Haies, bois. - Jt.

$\times \mathrm{F}$. vertes en dessous, soies et glandes, en général, abondantes. Q Pét. larges, ovales ou obovales, d'un rose vif, ainsi que les ét. et les styles.

- Turion obtusément anguleux, plus ou moins vel.; f. vel. sur les 2 faces; inflor. pyramidale.

Turion garni d'une villosité rude tr. apparente; fol. term. ovale-suborb.; axes florifères munis d'aiguillons droits.

\section{Bois. - Jt.}

R. aegocladus Muell. 465

Turion garni d'une villosité rare et peu apparente; fol. term. oblongue-elliptique; axes florifères munis de longs aiguillons un peu courbés . . . . R. Lejeunei Weihe 466 Bois, haies. - Jt.

- Turion anguleux, glabrescent; f. glabrescentes en dessus;inflor. subcorymbiforme, obtuse; fol. term. larg. ovale en cœur.

R. rosaceus Weihe 467

Bois, clairières. - Jt.

Q Pét. étr. blancs ou faiblement rosés; turion subanguleux, gl. ou glabrescent; aiguillons et soies longs et denses.

R. Koehleri Weihe 468

Haies, bois. - Jt-At.

+ Turion ord. cyl., peu élevé, à aiguillons tous faibles, sét.; f. vertes en dessous, la plupart à 3 fol.; pét. petits, ord. lanc. et blancs, espèces croissant dans les forèts humides; glandes, soies, aiguillons, feuillage, d'un vert jaunâtre.

Aiguillons à base dilatée, allongée; turion subanguleux, à aiguillons en partie vulnérants, falciformes ou crochus sur le rameau florifère; ét. dépassant les styles. R. Schleicheri Weihe 469

Clairières des bois. - Jt-At.

Aiguillons à base conique restreinte; glandes abondantes, fines, masquées en grande partie par la villosité; pl. faible et grêle.

Lisières des bois. - Jt-At.

R. tereticaulis Muell. 470

\section{GenRe 142. - ROSA L.}

+ Styles soudés ou agglutinés en une colonne saillante au-dessus du disque qui recouvre le tube du cal.; fr. oblongs ou subglob.

Styles soudés en colonne grêle, aussi longue que les ét.; disque presque plan; sép. ovales-aigus, ent. ou à append. tr. étr., petits; t. sarment., décombantes à aiguillons épars; fl. blanches, solit., plus rar. en corymbe à pédic. gland.; f. minces, ord. gl., glaucescentes en dessous à dents simples . . R. arvensis Huds. 471

Bois, haies. - Mai-Jt.

Styles agglutinés en colonne plus courte que les ét. et peu saillante; disque conique tr. saillant; sép. à append. nombr. très apparents; t. à peine sarment., non décombantes à aiguillons assez numbr.; fl. blanches ou rosées en corymbe, à pédic. lisses ou hispides gland.; f. assez épaisses, souvent luisantes en dessus, ord. pub. sur les nervures, à dents simples ou composées.

R. stylosa Desv. 
+ Styles libres, inclus.

T. de l'année, et souvent les florifères inermes ou couvertes d'aiguillons droits, grêles, inégaux, entremèlés de soies et de glandes; arbriss. peu élevés croissant souvent en colonies; fr. glob.

= Fl. d'un beau jaune; 50-9 fol. elliptiques ou ovales, doublement dentées à dents glanduleuses, tom. gland. sur le rachis et les nervures principales; stip. élargies sup. et bordées de glandes; $\mathbf{f}$. à odeur de punaise. . . . . . . R. lutea Mill. 473 Nat, haies. - Jn-Jt.

= Fl. roses ou blanc jaunàtre; sép. ent.

Stip. des f. sup. étr., non dilat.; fl. solit. d'un blanc jaunàtre, rar. roses; f. à 7-9 fol. petites, arrondies gl., ord. simpl. dentées; aiguillons tr. nombr., droits, inégaux, entremèlés d'acicules; souche long. traçante. . . . . . R. pimpinellifolia L. 474 Lieux secs arides et sabl. - Mai-Jt.

Stip. longues, tr. élargies au sommet; rameaux inermes; f. à 5’-7 fol. lanc. elliptiques en coin à la base et pétiolulées, glauques en dessous, simpl. dentées ...... . R. blanda Ait. 475 Pl. américaine, nat. - Jn.

T. toutes armées d'aiguillons plus ou moins robustes, dr. ou crochus, rar. mèlés de soies ou de glandes; arbriss. croissant isolément à stip. sup. et bract. dilat.

a Fol. couvertes en dessous, sur toute leur surface, de glandes apparentes, souvent à odeur de pomme rainette, à dents composées gland.

- Fol. oblongues, atténuées à la base et au sommet; stigmates en tête gl. ou peu vel.; pédic. longs, lisses; fl. blanches; sép. non gland. sur le dos.

Coteaux, haies. - Jn-Jt.

R. agrestis Savi 476

- Fol. ovales-elliptiques ou arrondies, non ou peu atténuées à la base et au sommet; pédic. hispides gland.; sép. gland. sur le dos à append. courts, assez larg.

Sép. réfléchis après la flor. et promptement cad.; stigmates en tête glabrescente; fol. ovales-elliptiques; aiguillons rar. entremêlés d'acicules; arbriss. lâche, à jeunes t. flexueuses; fl. roses.

\section{Haies. - Jn-Jt.}

R. micrantha Sm. 477

Sép. ord. redressés et persistant longtemps sur le fr.; stigmates en tête vel. hér.; fol. ovales-arrondies ou larg. elliptiques; aiguillons souvent entremêlés d'acicules; arbriss. touffu, à jeunes t. raides; fl. rouges. . . . . R. Rubiginosa L. 478 Bois et haies. - Jn-At.

Q Fol. non gland. ou à glandes exhalant une odeur de résine; t. non hétéracanthes.

Fol. mollement vel. soyeuses sur les 2 faces, gland. en dessous à dents composées-gland.; pédic. longs, ordin. hispides gland.; fl. d'un rose pâle . . . . . . . R. tomentosa Sm. 479 Bords des bois, haies. - Jn-At.

Fol. gl., pub. ou velues, non gland. ou à quelques glandes éparses.

Fol. ovales-obtuses ou brièv. aiguës, assez petites, pub., simpl. dentées, à nervures secondaires tr. saillantes; aiguillons courts, fort. crochus, épaissis et larg. implantés à la base; il. blanches à pédic. lisses; sép. à append. larg., foliacés, incisés; stigmates en tête presque gl.

$$
\text { Haies. - Jn. }
$$

R. obtusifolia Desv. 
Fol. ovales-aig., gl. ou pub., à dents simples, doubles ou composées, à nervures secondaires peu saillantes; aignillons forts, crochus ou arqués, dilat. à la hase; fl. roses ou blanches à pédic. lisses ou hispides-gland.; sép. append. à append. rar. incisés; stigmates en tête vel. ou gl.

R. canina L. 481

$$
\text { Haies. - Mai-Jt. }
$$

On cultive R. gallica L., arbrisseau à souche long. traçante; aiguillons très inégaux, les uns forls et crochus, les autres faibles et droits entremêlés d'acicules gland.; f. ord. à 5゙ fol gr. ovales ou orb., pub. blanchâtres et ì nervures saillantes en dessous, à denls composées gland. ou simples; fl. grandes, rouge pourpre ord. solit. ; pédic. longs, gland.; sẻp. append. ; stigmates en tête vel.; fr. subglob., gros, rouge foncé.

\section{Genre 143. - AGRIMONIA L.}

Fr. obconique, fort. sillonné dans toute sa long., à soies toutes étaléesascend.; fol. ovales lanc., dentées, cendrées tom. sans glandes odor. en dessous; t. simple, ord. peu rameuse; un seul carp.

Lieux incultes et sees. - Jn-Sept.

A. Eupatoria L. 482

Fr. presque hémisph., faibl. sillonné, surtout dans le bas, à soies du rang ext. réfléchis; fol. ovales lanc., allongées, vertes-pub., munies en dessous de nombr. glandes rẻsineuses odor., d'un jaune brillant; deux carp. . . . . . . . . A. odorata S. 483 Bois, haies, terrains sil. - Jn-Sept.

\section{GENRE 144. - POTERIUM L.}

Fr. à faces ridées en réseau, superf. alvéolées, sans fossettes profond. à angles subobtus ent. ou peu sinués. P. dictyocarpum Spach. 484 Lieux incultes, prés. - Mai-Sept.

Fr. à faces creusées de fossettes profondes à bords dentés, à angles minces, tranchants, sinués. . . . . P. muricatum Spach. 485 Lieux secs, prairies artificielles. - Mai-Sept.

\section{GeNRE 145. - SANGUISORBA L.}

Pl. viv. de $40 \mathrm{~cm}$. à $1 \mathrm{~m}$; fl. pourpre foncé, entremèlées de bract. lanc., disposées en têtes term. ovoïdes ou oblongues. S. officinalis L. 486 Prairies humid. - Jt-Sept.

\section{Genre 146. - ALCHEMILLA L.}

Fl. en fasc. lat., opp. aux f.; 1-2 ét.; pl. ann. de 3-20 cm., à t. ascend. ou étalées en cercle; $f$. brièv. pétiolées, tripartites à divis. incisées lobées; stip. foliacées incisées conniv. formant une sorte de cornet.

Lieux sablonneux. - Avr-Jt.

A. arvensis Scop. 487

Fl. è cymes corymbiformes term. et lat.; ord. 4 ét.; pl. viv. à t. de 10-30 cm. ascendantes ou dressées; f. suborb., à 7-11 lobes peu profonds, dentés en scie; stip. foliacées incisées ou dentées soudées en tube court . . . . . . . . . . . . A. vulgaris L. 488

Prés, bois, chemins herbeux ombragés. - Mai-Sept.

\section{Gente 147. - MESPILUS L.}

Arbuste tortueux, à rameaux épin.; f. oblongues ent. ou dentic. dans la moitié sup.; fl. gr., blanches, solit., subsessiles, term.; cal. à 6 lobes foliacés, persist., plus longs que la cor.; fr. assez gros en toupie couronné par les lobes du cal. . . . . . . . M. germanica L. 489

Bois, taillis. - Fl. Mai; fr. Oet. 
Genre 148. - GRATAEgUS L.

Arbriss. tr. épin. à f. larg. ovales, dentées au sommet, pennatipartites, à 3-7 lobes profonds, écartés, à nervures secondaires inf., courbées en dehors; 1 style; fr. à 1 noyau . . . . . . C. monogyna Jacq. 490 Bois, haies. - Fl. Arr.-Jn ; fr. Sept-0ct.

Arbriss. épin. à f. obovales, dentées presque dès la base, à $3-\check{\text { lobes }}$ peu profonds, conniv., à nervures secondaires toutes courbées en dedans; 2-3 styles; fruit à 2-3 noyaux.

Bois ombragés. - Fl. Avr.-Mai ; fr. Sept.-Oct.

C. oxyacanthoides Thuill. 491

\section{Genre 149. - GYDONIA Tourn. - Coignassier.}

Arbriss. ou arbuste, tortueux, sans épin.; f. orales-arrondies, ent. blanchâtres-tom. en dessous; fl. gr. d'un blanc rosé, solit., subsessiles, term.; cal. à lobes foliacés, dentés gland:; fr. gros, en poire, étr. ombiliqué au sommet, cotonneux, à bै loges. G. vulgaris Pers. 492 Cult. - Fl. Avr.-Mai ; fr. Sept.-Oet.

$$
\text { Gexre 1500. - PIRUS Tourn. - Poirier. }
$$

F. gl. à l'état adulte, à limbe ovale, égal au pétiole ou un peu plus long; fl. grandes, $23-30 \mathrm{~mm}$., à pédonc. gl. ou un peu vel.; bourgeons et onglet des pét. gl.; fr. subglob. ou obovale; arbre épin.

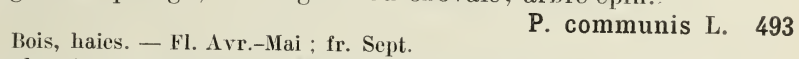

F. blanches-tom. en dessous à l'état adulte à limbe obovale ou oblong, 1-2 fois plus long que le pétiole; fl. assez gr., à pédonc. longs et tom.; bourgeons tom.; pét. un peu barlous à l'onglet; fr. obovale, atténué à la base, long. pédone,; arbre . . . . . . P. salvifolia DC. 494 Planté aux bords des routes. - Fl. Avr.-Mai ; fr. Sept.

\section{Gexre 151. - MALUS Tourn. - Pommier.}

Arbre assez élevé, à rameaux peu ou point épin.; f. adultes, ovales, crén. dentées, grises-tom. en dessous; fr. douceàtre.

M. communis Poir. 495

Haies, bords des champs, subsp. - Fl. Avr.-Mai ; fr. Sept.

Arbre peu élevé, à rameaux épin.; f. adultes ovales-acum., dentéescrén., gl. sur les 2 faces; fr. acerbe.... . M. acerba Mérat 496 Bois, haies. - Fl. Mai ; fr. Sept.

\section{Gente 132. - SORBUS L.}

千 F. imparipennées à 11-17 fol.; 3 - ¿ styles.

Bourgeons gl. et visq.; cal. à lohes courbés en dehors après la flor.; ̋̈ styles; fr. assez gros, en poire, brunàtre à la maturité.

\section{S. planté (Cormier). - El. Mai ; fr. Oct.}

S. domestica L. 497

Bourgeons vel.; cal. à lobes courbés en dedans après la flor.; 3 styles; fr. petit, subglob., rouge vif à la maturité.

Bois et forêts. - Fl. Mai ; fr. Oet.

S. Aucuparia L. 498

+ F. simples, dentées ou lobées, 2 styles.

$\times$ F. adultes profond. lobées, élargies à la base, gl. et luisantes sur les 2 faces à 3-8 paires de nervures secondaires; slyles gl., soudés inf.; fruit brun . . . . . . S torminalis Crantz 499 Bois et forêts. - Fi. Mai; fr. Oct.

F. adultes tom. en dessous à 6-12 paires de nervures secondaires; styles libres, vel. à la base. 
F. ovales ou elliptiques ridées en dessus, tr. blanches tom. en dessous, dentées ou à peine lobées, à dents et lobules décroissant de haut en bas, à nervures un peu convexes en dehors; fr. ovoïde, rouge orangé. . . . . . . S. Aria Crantz 500 Bois, surtout calc. - Fl. Mai : fr. Oct.

F. larg. ovales, légèr ridées en dessus; grises tom. en dessous, lobées dentées, à lobes décroissant de bas en haut, à nervures inf. diverg.; fr. rongeàtre ou brunâtre ... S. latifolia Pers. 501 Bois et rochers. - Fl. Mai ; fr. Oct.

\section{Genre 153. - AMELANCHIER Medik.}

Arbriss. de 1-3 m., à bourgeons gl. et brillants; fl. blanches en petites grappes corymbiformes; f. d'abord blanches tom. en dessous, à la fin gl. et coriaces; fr. glob. du volume d'un gros pois.

A. vulgaris Møench. 502 Rochers sil. ou calc., coteaux secs et pierreux. - Fl. Avr.-Mai; fr. Sept.

\section{Famille 34. - PHILAdELPHÉEs \\ Genre 154. - PHilladelPhuS L.}

Arbuste de 1-3 m.; fl. blanches, gr., en grappes; f. ovales-acum., dentic. trinerviées, glabrescentes; styles $4-\breve{5}$, cohérents à la base.

Cult. (Seringat). - Mai-Jn.

P. coronarius L. 503

\section{FAMLLE 3̋. - ONAGRARIÉES}

+ 8 ét.; stigmate en massue ou à 4 lobes; caps. allongée à 4 loges et à 4 valves.

Fl. blanches ou rouges; caps. lin.; graines surmontées d'une ai-

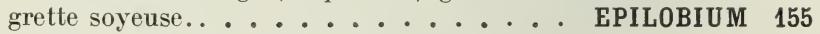

Fl. jaunes; caps. oblongue; graines sans aigrette.

CENOTHERA 156

+ 2-4 ét.; stigmates en tête ou bilobé; caps. courte, en massue ou subglob.

$\times \mathrm{F}$. toutes semblables, ovales aig.; caps. petite, $4 \mathrm{~mm}$.

Pét. nuls ; 4 ét. ; caps. petite obovale tétragone; stigmate en tête.

ISNARDIA 157

2 pét.; 2 sép.; 2 ét.; caps. petite, obovale, en massue, hér. de poils crochus; stigmate bilobé....... CIRCÆA 158

$\times$ F. de 2 sortes, les sup. rhomboïdales dentées, les inf. pennatiséquées pectinées; caps. grosse, $2 \mathrm{~cm}$., monosp. munie de 4 épines robustes; stigmate en tête.......... TRAPA 159

\section{GenRe 13\%5. - EPILOBIUM L.}

+ F. toutes éparses; ét. et style penchés; fl. en roue à pét. inégaux, ent. ou à peine émarg.; souche ramp. . E. spicatum Lamk. 504 Bois et forêts. - Jn-Sept.

+ F. inf. opp.; ét. et styles dress. ; fl. en entonnoir à pét. égaux, bilobés ou échancrés.

$\times$ Stigmates 4 étalés en croix; t. arrondies sans lignes saillantes.

$=\mathrm{T}$. mollement vel.; f. de la tige sessiles ou embrass.; fl. dress. avant la flor.

Fl. gr., 2 cm., d'un rose pourpre; sép. mucronés; f. demi embrass., un peu décurrentes; souche émettant des rhizomes épais, charnus ; pl. à poils étalés mêlés de poils gland.

Endroits hum. - Jt-Sept.

E. hirsutum L. 505 
Fl. petites, 6-7 mm. d'un rose pàle ; sép. non mucronés; f. sessiles, non embrass.; souche tronquée, émettant de courtes rosettes.

Lieux hum. - Jn-Sept.

E. parviflorum Schreb. $\mathbf{5 0 6}$

= T. gl. ou fin. pub.; f. toutes pétiolées; fl. penchées avant la fl.

ơ F. ovales-lanc., arrondies à la base, brièv. pétiolées, toutes opp., sauf les florales; souche ord. non stolonifère; fl. roses.

Bois humides. - Jn-Sept.

E. montanum L. 507

đ̛ F. moyennes et sup. oblongues-lanc. ou lanc. plus ou moins atténuées à la base et pétiolées, les inf. seules opp.; fl. d'abord blanchâtres, puis roses.

T. de 10-30 cm. ascend., ord. tr. rameuse dès la base; f. petites, presque ovales, rapprochées, un peu atténuées à la base; à pétiole court de 3 -4 mm.; graines oblongues, atténuées à la base......... . . . E. collinum Gmel. 508 Rocailles, murs. - Jt-Sept.

T. de $20-60 \mathrm{~cm}$. dress., simple ou peu rameuse; f. oblongues lanc., en coin et ent. à la base, à pétiole long de $4-8 \mathrm{~mm}$.; graines obovales, arrondies aux 2 bouts.

E. lanceolatum Séb. et Mauri 509

Talus, haies, vieux murs, bois. - Jn-Sept.

X Stigmate ent., en massue; t. souvent minces, à lignes saillantes.

- Souche dépourvue de stolons, émettant des bourgeons ou de courtes rosettes de $\mathrm{f}$.; t. dress. de $30-80 \mathrm{~cm}$., rar. radicantes à la base.

F. toutes assez long. pétiolées, ovales lanc. à nervures saillantes; fl. d'un rose pâle, petites penchées avant la fl.

Lieux hum., fossés. - Jn-Sept.

E. roseum Schreb. $\mathbf{5 1 0}$

F. étr. lanc. sessiles ou subsessiles, rar. pétiolulées ( $E$. Lamyi Schultz), à nervures peu saillantes; fl. roses, petites, dress. avant la flor. . . . . . . . E. tetragonum L. 511

Lieux hum., fossés. - Jn-Sept.

- Souche émettant des stolons filiformes et allongés; t. souvent couchées et radicantes à la base.

T. munie de 2-4 lignes un peu saillantes; f. lanc. ou ovales lanc., dentic., planes; fl. dress. avant la flor.; stolons munis de petites f. opp., pétiolulées. . . E. obscurum Schreb. 512 Bois hum., fossés. - Jt-Sept.

T. arrondie sans lignes saillantes, glabrescente plus rar. pub., à 2-4 lignes de poils peu apparentes; f. lin. ou lanc., ent., à bords enroulés; fl. penchées avant la flor.; stolons tr. grêles, blanchâtres se terminant par un bourgeon renflé.

Marais tourb., sables hum. - Jt-Sept.

E. palustre L. 513

\section{Genre 136. - OENOTHERA L.}

Plante bisann. de $50 \mathrm{~cm}$. à $1 \mathrm{~m}$., vel., tr. feuillée; f. rad. oblongues, pétiolées, en rosette, les caul. lanc., subsessiles, dentic.; fl. gr. 4-̋̈ cm., en long épi feuillé. . . . . . . . . . E. biennis L. 514 I.ieux sabl., plante américaine devenue TC. - Jn-Sept.

\section{Genre 157. - ISNARDIA L.}

Pl. viv., grèle, couchée radicante ou nageante, gl.; f. opp., ent.; fl. verdâtres, petites, peu apparentes, solit., axill.; pas de pét.; caps. à 4 loges polysp. ............ I. palustris L. 515 Lieux maréc., étangs. - Jn-Sept. 


\section{GenRe 138. - GIRCAeA L.}

Pl. viv. à souche traçante, de $30-60 \mathrm{~cm}$; fl. petites, blanches à pédic. pub. gland., dépourvues de bract., disposées en grappes term. non feuillées; t. dress. à f. opp., pétiolées, dentées.

Bois hum. - Jn-Sept.

$$
\text { Genre 159. - TRAPA L. }
$$

Pl. aquat., nageante; pétiole des f. sup. renflé en vessie au milieu à la flor.; fl. blanches axill., solit., brièv. pédonc. à 4 pét. ent. dépassant le cal.; 4 ét.; cal. à tube court à 4 lobes persist. devenant épin.

$$
\text { Mares, étangs, nat. - Jn-At. }
$$

T. natans L. 517

$$
\begin{aligned}
& \text { Famille 36. - HALORAGÉs } \\
& \text { Genre 160. - MYRIOPHYLLUM L. }
\end{aligned}
$$

+ Epi floral tr. grèle, pauciflore, court d'ahord penché, term. par des fl.; fl. jaunàtres alt., les inf. pourvues de f., les autres à l'aisselle de bract. plus courtes qu'elles . . . . M. alterniflorum DG. 518 Étangs, mares et fossés. - Jt-Sept.

+ Epi floral multiflore. allongé; fl. rosées.

Epi floral dr., terminé par des fl. vert. munies de bract. incisées plus courtes que les fl. sup. . . . . . . . M. spicatum L. 519 Mares, étangs, rivières. - Jt-Sept.

Epi floral tr. allongé, feuillé au sommet, term. par des fl. vert. munies de f. florales presque semblables aux autres $\mathrm{f}$. et beaucoup plus longues que les fl. . . . . M. verticillatum L. 520 Étangs, mares. - Jn- $\Lambda$ t.

\section{Famile 37. - HIPPURIDÉES \\ GeNre 161. - HIPPURIS L.}

Pl. aquat. viv., gl.; à rhizome horiz.; t. dress., simple, en partie aérienne, cyl., creuse; f. verticillées par 8-12, sessiles, sans stip.; fl. hermaphrodites, verdàtres, petites, sessiles, vert. à l'aisselle des f.

Fossés, mares, rivières. - Mai-At.

H. vulgaris L. 521

\section{Famille 38. - CALLitrichinées \\ Genre 162. - GALLitriche L.}

+ F. toutes lin. ou les inf. et les moyennes lin.; les sup. parfois obovales: bract. florales courbées en crosse ou en crochet, cad., souvent nulles; coques de la caps. rapprochées parall 2 à 2 et presque ent. soudées à carène ailée; styles tr. longs, réfléchis sur le fruit, cadues. . . . . . . . G. hamulata Kütz 522 Mares, fossés. - Jn-Sept.

+ F. toutes ou la plupart obovales; bract. florales persist.; coques de la caps. non contiguës dans leur moitié sup.

Styles dressés ou ascendants, cad.; fr. obovales en cœur, sessiles; coques à carène aig., non ailée. . . . . C. vernalis liütz. 523 Nares et fossés. - Avr.-0ct.

Styles diverg., puis réfléchis, persistants; fr. suborb., subsessiles; coques à carène ailée; parfois ondulée. C. stagnalis Scop. 524 Mares et fossés. - Avr.-0ct. 


\section{Famlle 39. - CERATOPHYLLÉES}

\section{GenRe 163. - GERATOPHYLLUM I.}

Fr. muni de 3 épin.; 2 lat. recourbées, la $3^{\text {c }}$ term. au moins aussi longue que lui; f. 1-2 fois dichotomes, à segments lin., un peu élargis.

Mares, fossés, rivières. - Jn-Sept.

C. demersum L. 525

Fr. muni d'une seule épin. term. beaucoup plus courte que lui, sans épin. lat. ; f. 3-4 fois dichotomes, à segments capill.

Mares. - Jn-Sept.

C. submersum L. 526

\section{FAMLLE 40. - LYTHRARIÉES}

Cal. allongé, tubul., pourvu de còtes; style allongé, filiforme; capsoblongue ou cyl., compl. enveloppée par le cal. . . LYTHRUM 164 Cal. court, en cloche, sans côtes saillantes; caps. glob. ou ovoïde dépassant le tube du cal............... . . . PEPLIS 165

\section{GenRe 164. - LYTHRUM L.}

Fl. gr., 10-12 mm., rouges en faisc. vert. formant un long épi term.; cal. vel. sans bract.: f. presque toutes opp.; pl. vivace dress., robuste, pub.: 12 ét. dont 6 saillantes . . . . . . . L. Salicaria L. 527 Lieux hum. - Jn-Sept.

Fl. roses ou lilacées, petites, solit. à l'aisselle de presque toutes les f. ; cal. gl., accompagné de 2 bract. sub. tr. petites; f. alt.; pl. ann. dress. ou ascend. quelquefois couchée radicante inf.; 气゙-6 ét. incluses.

Fossés, ch. et lieux hum., étangs. - Jn-Sept.

L. Hyssopifolia L. 528

\section{Genre 16\%. - PEPLIS L.}

Pl. ann. de :3-30 cm. couchée radicante, parfois flottante, gl.; f. obovales-spathulées, rétrécies en pétiole; fl. lilas clair, tr. petites, subsessiles, solit., axill.; caps. glob., dépassant le tube du cal.

Fossés, mares, lieux hum. silic. - Jn-Sept.

P. Portula L. 529

\section{Famile 41. - CUCURBITACÉES}

+ Pl. viv., grimp., dioïque; fr. petit, bacciforme, glob., dress., rouge à 6 graines ou moins; fl. petites d'un blanc verdâtre; racine $t r$. grosse, charnue, cyl. . . . . . . . BRYONIA 166

+ Pl. ann.; fl. monoïques ou polygames ; fr. gros glob., cyl.en massue ou étranglé au milieu; graines nombr.

X T. grimp.; fl. blanches; vrilles rameuses; graines émarg. à rebord épaissi; fr. gros, lign.; allongé en forme de massue, ou ventru inf. ou rétréci au milieu, ayant ainsi 2 renfl. le sup. plus gros.

\section{LAGENARIA 167}

X T. non grimp.; fl. jaunes; pédonc. axill. uniflores, les fl. màles solitaires ou agrégées.

Anth. mucronées par le connectif, à 2 loges avec une seule courbure; graines à bord mince; fl. mâles souvent aggrígées.

Anth. mutiques à 1 loge avec plus. sinuosités; graines à rebord épaissi; fl. mâles solit. ........ GUGURBITA 169 
 \\ GenRe 166. - BRYONIA L.}

Pl. hérissée de petits poils renflés à la base; t. très long., munies de vrilles contournées en spirale, opp. aux f.; f. palmatilobées, en cœur à la base à 3-3̆ lobes aigus, sinués-dentés; fl. vein. en fasc. axill., les mâles plus gr. et plus long. pédonc.; graines elliptiques.

Haies et buissons. - Jn-Jt.

B. dioica Jacq. 530

\section{Genre 167. - LAGENARIA Ser.}

T. grimp. à vrilles rameuses à f. molles, amples, cordées, arrondies, sinuées, pub., munies de 2 glandes à la base ; pédonc. axill. uniflores, fasc.; fl. odor. . . . . . . . . L. vulgaris Ser. 531 Gult. (Gourde, calebasse).

\section{GenRe 168. - GUCUMIS L.}

Fr. ovoïdes ou glob., quelquefois déprimés, marqués de 8-12 sillons, à écorce lisse, réticulée ou verruqueuse ; f. à 5 lobes obtus, inég. dentic. Cult. (Melon). - Fl. Mai-Jt; fr. Jt-Sept.

C. melo L. 532

Fr. cyl., d'abord rugueux, verts et hér., devenant gl. et jaunes; f. à lobes anguleux, aig., inég. dentic., le term. plus gr.

C. sativus L. 533 Cult. (Cornichon, concombre). - Fl. Mai-Jt; fr. Août-Sept.

\section{Gevre 169. - GUCURBItA L.}

Cor. campanulée, resserrée à la base, à limbe dress.; f. à :" lobes échancrés lobulés, dentic. scabres; fr. glob. ou oblong, lisse.

Cult. (Citrouille). - Fl. Jn-At; fr. Sept.-Oct.

C. pepo DC. 534

Cor. tr. gr. à lobes étalés réfléchis; f. ridées, en cœur, obscur. lobées à lobes arrondis ; fr. énorme, glob., déprimé aux extrémités.

Cult. (Potiron). - Fl. Jn-At; fr. Sept.-Oct.

C. maxima DC. 535

\section{FAMILLE 42. - PORTULACÉES}

Fl. jaunes sessiles ; sép. cad.; 6-12 ét.; caps. s'ouvrant circul. à graines nombr. ................. PORTULACA 170

Fl. blanches, pédonc.; sép. persist.; 3-å ét.; caps. s'ouvrant par 3 valves,

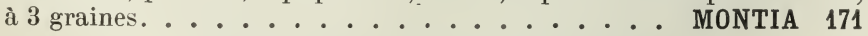

\section{GenRe 170. - PORTULACA L.}

Pl. ann., rameuse, couchée, charnue; f. opp., obovales oblongues, sessiles, épaisses, luisantes; fl. solit. ou agglom. à l'aisselle et au sommet des rameaux, involucrées par les f. sup.; 2 sép. inégaux, obtus, carénés sous le sommet; 4-6 pét.; graines noires, luisantes.

Lieux cult. et ch. sabl. (Pourpier). - Mai-Oct.

P. oleracea L. 536

\section{Genre 171. - MONTIA L.}

Petite pl. de 2-8 cm., terrestre jaunâtre; cymes la plupart term.; graines d'un noir mat, tuberc., ternes . . . . M. minor Gmel. 537

Ch. hum., bords des mares silic. - Avr.-Jn.

Plante de 10-30 cm., souvent flottante, verte; cymes la pupart lat.; graines d'un noir brillant, presque lisses, luisantes.

M. rivularis Gmel. 538

Ruiss., sources, fossés des terrains silic. - Mai-Sept. 


\section{FAMLle 43. - PARONYCHIÉES}

+ F. opp. ou vert., à stip. scarieuses; pét. plus courts que le cal.ou nuls.

Sép. scarieux argentés, épaissis-spongieux, voûtés en capuchon et terminés par une arête fine ; 3 stigmates sessiles; caps. à 1 graine, s'ouvrant à la base par š valves. $\quad$ ILLECEBRUM 172

Sép. herbacés à peine concaves terminés ou non par une soie; 2 stigmates sessiles; caps. enveloppée par le cal., à 1 graine, indéh.

HERNIARIA 173

+ F. alt. stip. ou opp. sans stip.; pét. égalant le cal. ou nuls.

F. alt. munies de stip. scarieuses; 5 pét. blanes égalant ou dépassant un peu le cal.; 5 ét.; 3 stigmates subsessiles; caps. enveloppée par le cal. ovoïde, trigone, indéh. à 1 seule graine.

CORRIGIOLA 174

F. opp., sans stip.; pét. nuls; 10 ét., rar. 5 ou 2 ; 2 styles filiformes à stigmates en tête; caps. renfermée dans le tube du cal., endurci-osseux et cad. à la maturité, indéh. à 1 seule graine.

SCLERANTHUS 175

\section{GeNRe 172. - ILLEGEBRUM L.}

Pl. ann. ou bisan., gl., à t. grêles, couchées-étalées, radicantes, rougeâtres; f. ovales arrondies; fl. blanches, sessiles, en petits vert. à l'aisselle de presque toutes les f.; כ̌ sép. rudimentaires; ’’ ét.

I. verticillatum L. 539

Ch. sabl. hum., mares silic. desséchées. - Jt-Sept.

\section{GENRE 173. - HERNIARIA L.}

Pl. pér. ou viv. gl. ou glabrescente, d'un vert clair; f. gl. oblongues ou lanc., les inf. opp.; sép. oblongs, obtus, gl.; stip. petites, ovales,

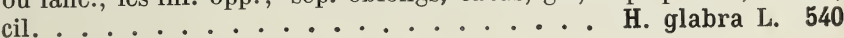
Ch. sabl. - Mai-Sept.

Var. à f. cil. (var. subciliata).

Pl. ann. ou bisan. vel. hér., grisâtre; f. hispides-cil.,lanc., les inf. opp. ; sép. lanc., vel., term. par une longue soie; stip. ovales ou oblongues.

Ch. sabl. - Mai-At.

H. hirsuta L. 541

\section{GENRE 174. - CORRIGIOLA L.}

Pl. ann. glaucescente; f. lin. ou oblongues-lanc.; fl. pédic. en têtes petites, serrées, axill. et term.; sép. blancs scarieux aux bords.

Ch. sabl., grèves des étangs, - Jn-Sept.

C. littoralis L. 542

\section{GeNre 17\%. - SGLERANTHUS L.}

Pl. viv. un peu glauque gazonnante à souche épaise; t. étalées redress. pübérulentes fl.; d'un blanc mêlé de vert; sép.oblongs-obtus, larg. bordés de blanc, rapprochés et conniv. à la maturité égalant le tube du cal. ou un peu plus long que lui........ S. perennis L. 543 Lieux sabl., rochers silic. - Nai-Sept.

Pl. ann., verte à racine grêle; t. étalées-ascendantes, pub.; fl. verdàtres; sép. lanc.-lin., étr. marginés, écartés et un peu ouverts après la flor., atténués en pointe droite, égalant le tube du cal.

Ch. sabl. - Mai-Sept.

S. annuus L. 544 


\section{FAMLLE 44. - CRASSULACÉES}

+ Pét. libres; ét. sur 1 ou 2 rangs.

Fl. à 3-4 sép., pét. et carp.; 3-4 écailles nectariformes ou nulles; 3-4

ét. sur un rang; pl. ann. de $2-6 \mathrm{~cm}$. gl.. . . TILLAEA 176

Fl. à 5, rar. 4, 6-8 sép., pét. et carp.; 5 écailles nectarifères, rar. 4 ou 6-8, courtes, ovales, ent. ou émarg.; 10, rar. 4-5 ou 12-16 ét., le plus souvent sur 2 rangs; pl. ann. ou viv. . . SEDUM 177

+ Pét. plus ou moins soudés inf., ét. sur 2 rangs.

F1. roses à 6-20 sép. ; 6-20 pét. un peu soudés à la base; 12-40 ét.; 6-20 cap.; f. des rejets stériles rapprochées en rosettes denses; f. oblongues sessiles ........ SEMPERVIVUM 178

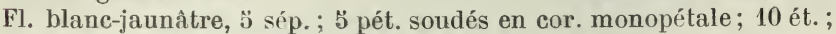
5 carp. ; pas de rosettes; f. rad. orb., peltées ombiliquées long. pétiolées, les caul. en coin; souche tubéreuse . UMBILICUS 179

\section{Genre 176. - TILlaEA L.}

Fl. sessiles, axill., formant des épis interrompus; carp. à 2 graines; f. ovales aiguës, rapprochées et comme imbriquées.

T. muscosa L. 545

Lieux sabl. - Avr.-Jn.

Fl. long. pédic., en cymes irrégul.; carp. à plus. graines; f. lin. oblongues-subobtuses espacées. . . . . . . . T. Vaillantii Willd. 546

Lieux sabl. hum., mares silie. - Mai-At.

\section{Genre 17\%. - SEDUM L.}

+ Pl. ann. ou bisan. à racine grêle; t. grêles solit., sans rejets stériles.

X F. planes, obovales, ord. opp. ou vert.; fl. blanches ou rosées, pédic. en petites grappes étalées formant une longue pan.; sép. lanc.-aig.; pét. lanc. aristés $2-3$ fois plus longs gue le cal.; earp. dressés, oblongs, acum., fin. ridés en long. . S. Cepaea L. 547 Haies, bois, talus. - Jn-At.

$\times$ F. cylin., lin., obtuses, alt. ou éparses; fl. en cymes ou en corymbe, d'un blanc rosé.

F1. sessiles, unilat.; carp. diverg., tuberc. étr. acum. par le style égalant 1-2 mm.; 马 sép. ovales-triang.; : 3 pét. lanc.-aristés, 3 fois plus longs que le cal.; 丂̆ ét. . . . . S. rubens L. 548 Vignes, talus, ch. sabl. - Mai-Jt.

Fl. distinct. pédic., à pédic. plus longs que les fl.; carp. dress. pub. gland., term. par le style égalant la moitié de leur long.; ๖ sép. oblongs lane.; כ̋ pét. ovales-aig. non aristés, 2-3 fois plus longs que le cal.; 丂r-10 ét.. . . .... S. villosum L. 549 Mares desséchées silic. - Mai-Jt.

+ Pl. viv., à souche épaisse ou émettant des rejets stériles pér.

= F. dentées ou crén., planes, larg., les inf. brièv. pétiolées, les sup. sessiles et arrondies à la base; fl. purpurines ou d'un blanc rosé; y pét. étalés, recourbés en dehors: 10 èt.; ; carp. dressés, acum. sillonnés sur le dos. . . . . S. purpurascens Koch 550 Bois et haies. - Jt-Sept.

= F. cyl., semi-cyl. ovoïdes ou subglob.

$\sigma^{1}$ Fl. blanches ou rosées à pét. 2-3 fois plus longs que le cal.

- F. cyl., gl., long. de 8-15 mm., éparses; fl. blanches à pét. oblongs obtus non aristés; carp. dress. ovales oblongs; pl. de $10-30 \mathrm{~cm}$. . . . . . . . S. album L. 551 Murs, rochers. - Jn-At.

Var. à fl. plus petites, rosées; f. des rosettes stériles étalées ascendantes, courtes, plus renfl. (S. micranthum Bast.) 
- F. oblongues en massue, ovoïdes ou subglob. gl. ou pub.; fl. rosées; pl. de $4-12 \mathrm{~cm}$.

F. vel. hér., oblongues en massue, atténuées à la base, toutes alt. ou éparses; pét. oblongs lanc. aristés; carp. dress. pub. gland.; pl. d'un vert pâle pub. gland. S. hirsutum All. 552 Rochers silic. - Mai-Jn.

F. ord. opp. sur les t. florales, obovoïdes, comprimées en dedans, renfl. gibbeuses sur le dos, lâchement imbr. sur les rejets stériles, gl. ou pub.-gland. (S. glanduliferum Guss.); pét. ovales, obtus; carp. dress., acum., gl. ou pub. gland.; pl. glauque. . . . . . . . . S. dasyphyllum L. 553 Vieux murs, nat. - Jn-Jt.

ơ Fl. jaunes ou jaunàtres.

F. renfl. obtuses, mutiques, non mucronées; carp. diverg.; fl. sessiles ou subsessiles en petite cyme formée de 2-3 épis; f. des rejets stériles imbriq. disposées sur 6 rangs.

F. courtes ovoïdes-triang., non prolongées à la base; fl. d'un jaune vif 2-ว̆ sur chaque épi; sép. ovoïdes, prolongés à la base; graines non tuberc.; pl. à saveur très piquante . . . S. acre L. 554 Lieux sees, murs. - Mai-At.

F. lin.-cyl., prolongées en éperon à la base; fl. d'un jaune pâle, 3̆-10 sur chaque épi; sép. subcyl. non prolongés à la base; graines tuber.; pl. à saveur herbacée $\mathrm{S}$. sexangulare 555 Licux pierreux, graviers. - Jn-Jt.

F. lin., en alène cuspidées; carp. dress.; fl. subsessiles en corymbe.

Rejets stériles terminẽs pâr une rosette de f. très dense subglob. ou obconique; f. lin. compr., ponctuées; sép. plans obtus; ét. à filets gl.; fl. jaune d'or. . . . . S. elegans Lej. 556 Lieux sabl. - Jn-Jt.

Rejets stériles à f. làchement imbr., non rapprochées en cône; f. lin.-cyl. non ponctuées; sép. épaissis au sommet, aig.; ét. à filets poilus à la base; fl. d'un jaune pâle ou vif.

S. reflexum L. 557

Lieux secs, murs. - Jn-At.

GenRe 178. - SEMPERVIVUM L.

Pl. viv. de 20 à $50 \mathrm{~cm}$., robuste mollement vel.; fl. rose pâle, gr. (20-30 mm.) pédic. ou subsessiles, en pan. thyrsoïde ou corymbiforme; pét. étalés lanc. lin. pub., 2 fois plus longs que le cal.; carp. oblongs acum.; rosettes grandes, $\mathrm{b}^{-} 8 \mathrm{~cm}$. à f. obovales oblongues peu rétrécies à la base, gl. . . . . . . S. tectorum L. 558 Murs, toits où il est planté. - Jn-At.

\section{Genre 179. - UMBILIGUS DC.}

Pl. viv. de 10-40 cm., gl. verte; t. peu feuillées; fl. d'un blanc-jaunàtre, pédic., pendantes, nombr., formant une longue grappe bractéolée occupant presque toute la t.; cor. tubul. 4 fois plus longue que le cal............ U. pendulinus DC. 559 Vieux murs ombragés. - Nai-Jt.

\section{FamLle 4:3. - GROSSULARIÉES}

\section{GEX̉RE 180. - RIBES L.}

Sous-arbriss. épin., à aiguillons ternés; fl. solit. ou géminées, verdâtres ou un peu rougeàtres, court. pédic.; baies assez grosses, verdâtres, jaunâtres ou rougenitres, à la fin gl.

R. Uva-crispa L. 560

Haies, bois, buissons. - Fl. Avr.-Mai ; fr. Jn-Lt. 
+ Sous-arbriss. non épin.; fl. en grappes axill. multiflores pendantes.

Fl. rougeâtres; bract. vel., aig.; cal. tom. en cloche; baies noires à saveur aromatique. . . . . . . R. nigrum L. 561 Cult. - Fl. Avr.-Mai; fr. Jt-At.

Fl. verdâtres; bract., gl., obtuses; cal. gl., à limbe plan; baies rouges oublanchâtres à saveur acide. . . . R. rubrum L. 562 Bois, haies. - Fl. Avr.-Mai ; fr. Jt-At.

On cultive dans les pares $R$. Alpinum L., sous-arbriss. non épin. à fl. verdâtres dioïques en petites grappes dress.; bract. gl. ou cil., aig. : baies rouges, petites, gl., à saveur fade.

\section{Famille 46. - SAXIFRAGÉES}

Cal. à 5 sép. ; 5 pét. blancs égalant ou dépassant le cal.; 10 ét.; caps, à 2 loges; pl. des lieux secs non gazonnantes. . SAXIFRAGA 181 Cal. à 4 sép., rar. 5 ; pét. nuls; 8 ét., rar. 10 ; caps. à 1 loge; fl. jaunâtres involucrées par les f. florales; pl. viv., gazonnantes, succulentes, fragiles, hér. de poils blancs croissant dans les endroits

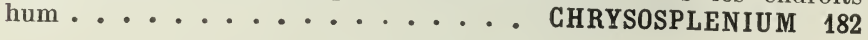

\section{Genre 181. - SAXIFRAGA L.}

Pl. ann. de 2-10 cm.; racine sans bulbilles; f. rad. spathulées, ent. ou trilobées; fl. petites, 4-6 mm,, en cyme dichotome irrégul., à pédic. filiformes, la plupart 3-5 fois plus longs que le cal.; caps. ovoïde, incluse . . . . . . S. tridactylites L. 563 Murs, lieux sabl. - Avr.-Mai.

Pl. viv. de $20-50 \mathrm{~cm}$. à racine munie de bulbilles arrondis; f. rad. en rein, incisées-crén.; fl. gr., 12-15 mm. en corymbe tr. lâche, à pédic. fructif. égalant environ le cal.; caps. saillante.

$$
\text { Prés, talus et bois sabl. - Avr.-Jn. }
$$

S. granulata L. 564

\section{GenRe 182. - GHRYSOSPLENIUM L.}

F. alt., suborb., en rein, échancrées à la base, fort. crén.; t. dress. ou ascend. . . . . . . . C. alternifolium L. 565 Bois hum., bords des ruiss., sources. - $\Lambda$ vr.-Mai.

F. opp., demi orb., tronquées ou en coin à la base, faibl. crén.; t. étalées ascend., radicantes à la base. ... G. oppositifolium L. 566 Bois hum., bords des ruiss., sources. $-\Lambda$ vr.-Mai.

\section{FAMILLE 47. - OMBELLIFĖRES}

+ F. suborb. peltées, palmatipartites ou épin.

X F. suborb. peltées; t. grèle ramp.; fl. petites subsessiles 4-6 en 1-3 vert. rapprochés sur des pédonc. axill. nus plus courts que les pétioles; méricarpes à š côtes filiformes.. HYDROCOTYLE 183

$X$ F. palmatipartites ou épin.; t. dress.; fl. réunies en tête disposées en omb. ou sessiles; méricarpes sans côtes apparentes.

F. palmatipartites; fl. sessiles en têtes glob. disposées en omb. irrégul. à 3-ă rayons tr. inég.; fr. subglob., hér. d’aignillons crochus; pl. non épin. ........ SANICULA 184

F. épin. 1-2 fois pennatipartites; fl. sessiles en têtes glob. ou ovoïdes sur un récept. garni de paillettes, entourées d'inn invol. épin.; fr. obovoïde, muni d'écailles. . . . E ERYNGIUM 185

+ F. pennatiséquées ou pinnatifides, rar. ent.

= F. hér. d'aiguillons plus ou moins allongés, souvent crochus ; méricarpes à 9 côtes dont 4 secondaires plus gr. 
$\sigma^{7}$ Fr. compr. par le dos, paral. à la commissure; graines à faces commissurales planes; f. bi-tripennatiséquées.

0mb. à $8-40$ rayons; invol. à fol. pennatiséquées; méricarpes à côtes secondaires ailées, armées d'aiguillons disposées sur un seul rang. . . . . . . . . . DAUCUS 186

Omb. à 2-8 rayons; invol. à fol. ent., rar. trifides; méricarpes à côtes secondaires carénées, armées d'aiguillons disposés sur 2-3 rangs . . . . . . . . . . . . ORLAYA 187

$\sigma^{7} \mathrm{Fr}$. compr. par le côté, perpend. à la commissure; graines à faces commissurales canaliculées.

- F. pennatiséquées, à segments décurrents et pennatifides; invol. à 2-4 fol. oblongues, presque ent. membr.; cal. à dents sét., fr. presque didyme à côtes toutes semblables et à aiguillons rougeâtres disposes sur 2-3 rangs. . . . . . . TURGENIA 188

- F. bi-tripennatiséquées; invol. nul ou à 1-5 fol. lin., en alène; cal. à dents lanc.; fr. à section transvers.-elliptique à côtes secondaires plus développées ou non distinctes.

Aiguillons du fr. disposés régul. sur les côtes; fr. elliptique ou oblong, long de $8-10 \mathrm{~mm}$., à côtes secondaires ailées et armées d'aiguillons sur 1-3 rangs; omb. à 2-4 rayons. CAUCALIS 189

Aiguillons du fr. disposés sans ordre apparent sur toute sa surface; fr. petit, ovoïde, long de $2-3 \mathrm{~mm}$., à còtes secondaires non distinctes, recouvertes de plusieurs rangs d'aiguillons.

= Fr. non hér. d'aiguillons.

TORILIS 190

Fr. didyme ou globulenx.

Fr. didyme; méricarpes glob.-renfl., réticulés, faibl. rugueux à $\check{b}$ sillons, à côtes secondaires larges, peu saillantes.

BIFORA 191

Fr. glob. ; méricarpes hémisph. à 9 côtes, $\ddot{3}$ primaires flexueuses, déprimées, 4 second. saillantes, carénées. CORIANDRUM 192 Fr. ovoïde ou cylindrique, comprimé ou non.

'o Fr. comprimé parallèlement à la commissure.

む Fr. non lenticulaire, vallécules à 1 bandelette.

Méricarpe à 9 côtes; 5 primaires filiformes, hér., 4 second. ailées-ondulées; cal. à "̋ dents petites, triang., en alène; pét. émarg.

Méricarpe à 5 còtes; cal. à limbe nul.

Pét. ent.; méricarpes à 5 còtes, les 3 dorsales filiformes et rapprochées; les 2 marginales dilatées en ailes membr.; omb. à 20-40 rayons........ ANGELICA 194

Pét. échancrés; méricarpes à 5 côtes toutes ailées, les 2 lat. à ailes membr. deux fois plus larges que les dorsales; omb. à

3-20 rayons. . . . . . . . SELINUM 195

ち Fr. lenticulaire.

$\odot$ Pl. gl.; cal. à 3 dents, rar. nulles; pét. émarg. ou presque ent.; méricarpes à 5 côtes, 3 dorsales filiform es, 2 marginales dilatées en aile; vallécules à 1-3 bandelettes.

$\odot$ Pl. vel.

PEUCEDANUM 196

El. jaunes; cal. à limbe nul ; pét. ent.; méricarpes à 5 côtes, 3 dorsales filiformes, les marginales dilatées en ailes minces et aplanies, vallécules à 1 bandelette . . PASTINACA 197

Fl. blanches ou rosées; pét. émarginés.

Invol. nul; cal. à $\mathrm{Z}$ dents; méricarpes à 5 côtes, 3 dorsales filiformes, 2 marginales dilatées en aile aplanie; vallécules à 1 bandelette élargie à la base, dépassant à peine la moitié du méricarpe....... HERACLEUM 198 
Invol. à plus. fol. lin., en alène; cal. à 5 dents lin., en alène; fr. hér. ou tuberc. au centre; méricarpes à 5 côtes, 3 dorsales filiformes, 2 marginales dilatées en bordure spongieuse; vallécules à 1 bandelette. . . TORDYLIUM 199

'O Fr. non comprimé ou comprimé par le côté.

ㅇ Fr. cylindrique ou ovoïde non comprimé.

Fr. à côtes bien marquées; cal. à limbe nul ou non accrescent.

F Fr. oblong; fl. blanches ou jaunes; pét. ent. ou émarg.

Il Vallécules sans bandelette; fl. jaunâtres; pét. à peine échancrés à nervure dorsale pub. ; méricarpes à 5 côtes carénées.

SILAUS 200

II Vallécules à 1 bandelette; fl. blanches ou jaunes.

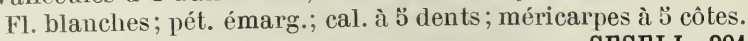

SESELI 201

Fl. jaunes; pét. ent.; cal. à limbe presque nul; méricarpes à ¿ côtes saillantes. . . . . . F FENIGULUM 202

F Fr. ovoïde subglob.; pét. émarg.; méricarpes à 5 côtes; fl. blanches; cal. à limbe nul . . . . . E ETHUSA 203

Fr. oblong à côtes peu marquées; cal. à 5 dents accrescentes; pét. émarg.; méricarpes à $\breve{~ c o ̂ t e s ~ f i n e s ; ~ v a l l e ́ c u l e s ~ a ̀ ~} 1$ bandelette; racines souvent charnues. . . . ENANTHE 204

o Fr. compr. par le côté.

I F. ent.; cal. à limbe nul; pét. ent., jaunes; styles tr. courts; fr. oblong, ovoïde ou subglob.; méricarpes à ว̌ côtes égales; vallécules avec ou sans bandelettes . . BUPLEURUM 205

F. divisées.

+ Fr. non atténué au sommet à côtes filiformes égales.

$\times$ Vallécules à plus. bandelettes.

Cal. à 3 dents, courtes, aig.; invol. et involucelle à plus. fol.; styles réfléchis sur le stylopode conique; carpophore bifide, adhérent aux carpelles ...... SIUM 206 Cal. à limbe nul; ni invol., ni involucelle; styles filiformes stylopode discoïde; carpophore libre, bifide.

PIMPINELLA 207

$\times$ Vallécules sans bandelettes ou à 1 bandelette.

= Méricarpes à $̋$ còtes filiformes.

o Racine renfl. en bulbe arrondi; cal. à 5 dents très courtes; styles réfléchis; stylopode déprimé, hémisph.

BUNIUM 208

o Racine non renfl. en bulbe.

- Fr. oblong ou lin.; fl. blanches.

Pédonc. à rayons nombr. non filiformes, ni opp. aux f. ou à rayons filiformes mais f. bipennatiséquées à lan. capill.; fr. ovoïde ou ovoïde-oblong.

'o Invol. à fol. ent. ou nul, styles réfléchis.

8-13̆ rayons, filiformes presque égaux ou 6-12 rayons tr. inégaux; vallécules à 1 bandelette; stylopode déprimé ...................... 209 12-20 rayons presque égaux; ni invol., ni bandelette; styles réfléchis 3 fois plus longs que le stylopode conique. . . . . . $\mathbb{E}$ EGOPODIUM 210

'o Invol. à fol. pennatiséquées ou triséquées; vallécules à 1 bandelette; styles à la fin réfléchis; stylopode discoïde. . . . . . . . . AMMI 211

Pédonc. à peu de rayons, 2-9, inég., ou opp. aux f.; ou pédonc. à rayons nombr., filiformes, mais f. rad. cartilagineuses à segments lin. lanc. finement dentés. 
む Styles étalés ou réfléchis.

- Styles très courts, étalés; cal. à limbe nul; invol. à 1-3 fol. lin.; bisann. ....... SISON 212

- Styles allongés, réfléchis ou étalés.

㮫 Cal. à 5 dents.

Fr. lin.; invol. et involucelle à fol. sét. ; pét. émar'g.; styles réfléchis ...... FALCARIA 213

Fr. ovoïde ou oblong; invol. nul ou à fol. lanc.; pét. ent.; styles courts; omb. opp. aux f.

HELOSGIADIUM 214

送 Cal. à limbe nul; styles réfléchis plus longs que le stylopode déprimé, pét. ent., fr. ovoïde.

む Styles dress., tr. courts; fr. ovoïde.

TRINIA 215

- Fr. subglob., cal. à limbe nul.

PETROSELINUM (part) 216

Fl. vert jaunâtre, en omb. long. pédonc.; styles longs, réfléchis; stylopode convexe.

PETROSELINUM (part) 216

Fl. blanchâtres, en omb. brièv. pédonc. ou subsessiles; styles courts, étalés; stylopode déprimé. APIUM 217

= Méricarpes à 5 côtes, aplanies, larges; fr. petit plus large que long; cal. à ä dents larges, aig., membran.; pét. émarg.; styles arqués plus longs que le stylopode; racine grosse, creuse, cloisonnée, à odeur vireuse. . . CICUTA 218

+ Fr. atténué au sommet ou fr. non atténué mais à côtes saillantes, obtuses, ondulées.

† Fr. atténué au sommet, méricarpes à faces commissurales canaliculées.

Fr. term. en bec.

Fr. oblong lin., rude, hér, à bec 4 fois plus long que les méricarpes, pét. obovales, tronqués ou à peine émarg. ; styles dressés, 2 fois aussi long que les stylopodes.

SCANDIX 219

Bec plus court que la graine, pét. obovales, émarg.; styles dress. ou un peu étalés; fr. lisse ou spinuleux.

桑 Fr. ovoïde ou allongé sans bec.

ANTHRISGUS 220

Racine renfl. en bulbe; pét. émarg.; styles dress. sur un stylopode conique; fr. ovoïde oblong. CONOPODIUM 221

Racine non renfl. en bulbe; pét. tronqués ou émarg.; styles à la fin courbés en dehors égalant le stylopode conique; fr. oblong lin. . . . . CHAEROPHYLLUM 222

○ Fr. subglob., presque didyme, atténué au sommet, à côtes saillantes obtuses, ondulées, crén.; pét. obovales émarg. styles courts, épais, un peu divergents. . . CONIUM 223

\section{GENRE 183. - HYDROCOTYLE L.}

Pl. viv. à f. crén. long. pétiolées, gl.; fl. blanches ou rosées; pét. ovales, ent., aig.; fr. suborb. un peu plus large que long, échancré au sommet et à la base, compr. par le côté. . . . . H. vulgaris L. 567 Lieux humides. - Jn-Sept.

\section{Genre 184. - SANIGULA L.}

Pl. viv., gl. de $20-30$ cm.; f. rad. long. pétiolées, les caul. subsessiles ; carpophore adhérent aux carp., ent. . . . S. europaea L. 568 Bois, lieux couverts. - Mai-Jt. 


\section{$-84-$ \\ GeNre 185. - ERYNGIUM L.}

Pl. viv., vert blanchàtre, tr. épin., à souche épaisse; f. coriaces, larg. ovales, à segments décurrents lobés dentés, épineux, à pétiole auriculé-épin.; fl. blanches; invol. blanchàtre, à 4-6 fol. étalées, étr., lin. acum., ent. ou dentées; cal. fructif. à dents dress.

Lieux arides et incultes. - Jt-Sept.

E. campestre L. 569

E. planum L. a eté trouvé près Mantes. Il diffère de $E$. campestris par la couleur blanc-bleuatre de la t. simple dans la moitié ou les deux tiers infér., peu rameuse au sommet; par les f. rad. et de la moitié inf. de la $t$. simples, non découpées, ovales, cordées à la base, dentées aux bords, les sup. découpées en $\mathbf{5}$ segments à dents spinuleuses.

\section{Gexre 186. - DAUGUS L.}

Pl. bisann. de $30-80 \mathrm{~cm}$. ; f. bipennatiséquées à segments ovales ou oblongs, incisés-dentés; fl. blanches ou rosées, celles de la circonférence rayonnantes, la centr. presque toujours purpurine; involucelle à fol. lin. acum., membr. aux bords, ent. ou trifides; fr. ellipsoïde, à aiguillons en alène égalant environ sa largeur . . . . . . D. Carota L. 570 Ch., coteaux. - Nai-0et.

\section{Gexre 187. - ORLAYA Hoffm.}

Ann.; f. inf. pétiolées, tripennatiséquées, à lobes lin. lanc., les sup. sessiles sur une gaìne membr.; fl. blanches, celles de la circonférence rayonnantes à pét. ext. tr. gr.; fr. ovoïde, assez gros, $8 \mathrm{~mm}$. de long, à aiguillons en alène, crochus, plus courts que la larg. du fr.

Ch. cale. et argil. - Jt-Sept.

0. grandiflora Hoffm. 571

\section{Genre 188. - TURGENiA Hoffm.}

Pl. ann., hér.-scabre; fl. rouges ou roses, en omb. à $2-4$ rayons inég. opp. aux f.; pét. échancrés, les ext. rayonnants, bifides; fr. gros, $1 \mathrm{~cm}$. de long, ovoïde; méricarpe à 9 côtes presque égales.

T. latifolia Hoffm. 572

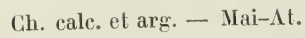

Genre 189. - GAUCALis Hoffm.

Pl. ann. gl. ou à poils rares et étalés, hispide à la base; fl. blanches ou rosées en omb. pédonc. à 2-4 rayons robustes; invol. nul ou à 1-2 fol.; involucelle à fol. inég., hispides; styles égalant le stylopode conique.

$$
\text { Ch. surtout cale. - Mai-Jt. }
$$

C. daucoides L. 573

\section{Genre 190. - TORILIS Adans.}

Omb. presque sessiles, subglob., compactes, opp. aux f., à 2-3 rayons courts et inég.; t. décombante, diffuse; fr. courts, ovoïdes, ceux du centre de l'ombelle tuberc., les ext. hér. en dehors d'aiguillons dr., en alène, rudes............ T. nodosa Gaertn. 574

Lieux secs et incultes. - Mai-At.

0mb. term., long. pédonc. à 3-12 rayons; fr. hér. d'aiguillons sur toute leur surface.

Invol. nul ou à 1-2 fol. courtes; omb. planes à 3-8 rayons; fl. de la circonférence rayonnantes; fr. couvert d'aiguillons dr., renfl. hér. au sommet. . . . . . . . . . T. helvetica Gmel. 575

Ch. surtout calc. - Jn-Sept.

Invol. à 4-b̆ fol. lin. en alène; omb. convexes à 5̆-12 rayons; fl. de la circonférence à peine plus gr. ; fr. couvert d'aiguillons courbés-ascendants, à pointe fine et dr. . . . . T. Anthriscus Gmel. 576 Haies, bois, - Mai-At. 
GenRe 191. - BIFORA Hoffm.

Pl. ann.gl.; f. rad. pennatiséquées, les caul. bipennatiséquées à segments lin.; fl. blanches, celles de la circonfér. rayonnantes; omb. à $30-7$ rayons ; invol. et involucelle nuls ou à 1 fol., styles 3 fois plus longs que le stylopode............. B. radians Bieb. 577 Ch.. nat. - Mai-Jn.

\section{Gexre 192. - GORIANDRUM L.}

Pl. ann., gl. et luisante, fétide; f. inf. pennatiséquées, les sup. bi-tripennatiséquées à lan. lin.-aig.; fl. blanches ou rosées, les ext. rayonnantes; omb. à 3-8 rayons; invol. nul ou à 1 fol.; involucelle à $3-5$ fol. lin., réfléchies; styles plus longs que le stylopode conique.

$$
\begin{aligned}
& \text { Subsp. (Coriandre) - Jn-At. } \\
& \text { C. sativum L. } 578
\end{aligned}
$$

\section{Genre 193. - LASERPITIUM L.}

Pl. viv., robuste; f. inf. amples, bi-tripennées, à fol. larges, ovales, en cœur à la base et pétiolulées, dentées en scie, scabres en dessous; fl. blanches; omb. grandes à $20-30$ rayons; invol. à plus. fol., gl., réfléchies; styles réfléchis ......... L. latifolium L. 579

Bois secs, rochers. - Jt-At.

\section{Genre 194. - ANGELIGA L.}

Pl. bisann. ou viv. glauque, robuste; f. très amples, bi-tripennées à fol. écartées, ovales lanc., dentées en scie; fl. blanches ou rosées; omb. gr. à 20-30 rayons pub.; invol. ord. nul; involucelle à plus. fol.; pét. à pointe dressée; pétiole des f. sup. dilaté en gaine ventrue.

Bords des eaux. - Jt-Sept.

A. silvestris L. 580

\section{Genre 195. - Selinum L.}

Pl. viv., gl., à souche fasciculée; f. inf. oblongues dans leur pourtour, bi-tripennatiséquées, à segments divisés en lan. lin.-lanc., mucronées; fl. blanches; omb. denses à 10-15 rayons gl. ou pubérulents; invol. nul; involucelle à plus. fol.; pét. conniv. . . S. Carvifolia L. 581 Prairies tourb., bois hum. - Jt-Sept.

\section{Genre 196. - PEUGEDANUM L.}

+ Invol. nul ou à 1-4 fol. cad.; f. inf. bipennatiséquées, ou tripennatiséquées, à segments découpés en lan. lin. ent. divariquées ou en croix autour du pétiole.

Fl. blanches ou rosées; f. inf. tripennatiséquées à segments pétiolulés, découpés en lan. lin., ent., raides divariquées; invol. nul ou à $1-4$ fol. cad.; involucelle à 4-8 fol. lin.; vallécules à 1 bandelette. . . . . . . . P. gallicum Latourr. 582 Bois, bruyères. - Jt-Sept.

Fl. d'un blanc verdâtre ou jaunàtre; f. inf. bipennatiséquées à segments sessiles, découpés en lan. lin. lanc., en croix autour du pétiole; invol. nul ou à 1 fol.; involucelle à $1-4$ fol. tr. inég.; vallécules à 3 bandelettes. . . . . . P. carvifolium Vill. 583 Prés humides, berges des rivières. - Jn-Sept.

+ Invol. à plus. fol. persist., réfléchies; segments des f. ovales ou elliptiques ou divisés en lan. lobées ou dentées; vallécules à 1 bandelette.

X T. creuse; pétiole cyl. subcanal. en dessus; f. inf. $3-4$ fois pennatiséquées, découpées en lan. courtes lanc. lin. à pointe calleuse; omb. gr. à 1̋̈-30 rayons. ..... P. palustre Moench, 584 Prairies tourb. - Jt-Sept. 
T. pleine; pétiole triang., canal. en dessus; f. à segments élargis, ovales ou en coin, dentés ou incisés.

F. vertes sur les 2 faces, à fol. divariquées, ovales en coin, trifides au sommet à lobes calleux et à peine mucronés; pétioles et pétiolules flexueux divariqués; omb. à 10-20 rayons; fr. suborb. à bord large. . . . . . . P. Oreoselinum Moench. 585 Bois sabl. secs. - Jt-Sept.

F. glauques en dessous, à fol. étalées, ovales ou elliptiques-lanc., lobées-dentées, à dents cuspidées et spinescentes; pétioles et pétiolules $\mathrm{dr}$., à peine sinueux; omb. à 1 b̆-30 rayons; fr. ovale elliptique à bord étroit. . . . . . P. Cervaria Lapeyr. 586 Bois et coteaux calc. - Jt-Sept.

\section{Gexre 197. - PASTINACA L.}

Pl. bisann. à racine pivotante; $\mathrm{f}$. inf. pennatiséquées à segments ovales ou oblongs incisés lobés, inég. dentés; les sup. lin., ent. ou tridentées; omb. à 6-13 rayons inég.; invol. et involucelle nuls ou à 1-2 fol.

$$
\text { Ch. incultes. - Jt-Sept. }
$$

P. silvestris Mill. 587

\section{GENRE 198. - HERACLEUM L.}

Pl. viv., à tige robuste, sillonnée-anguleuse, creuse, vel. hér.; f. gr., pub.-blanchâtres en dessous, pennatiséquées à 3 - segments ovales oblongs ou lanc., pétiolulés, rar. palmatiséqués à lobes allongés lanc. ou lin. (var. stenophyllum) dentés; fl. blanches à pétales ext. rayonnants ................ Sphondylium L. 588 Prés et bois hum. - Jn-Sept.

\section{Gente 199. - TORDYlium L.}

Pl. ann., toute hérissće de poils scabres à t. sillonnée anguleuse; f. vel. scabres, pennatiséquées, les sup. à segments lanc., le terminal tr. allongé, incisé-denté; omb. compactes à 3 -10 rayons courts, inég., hispides; fl. de la circonférence à 3 pétales rayonnants.

Lieux incultes, secs et pierreux, bords des chemins. - Jn-At.

\section{GEXRe 200. - SILAUS Bernh.}

Pl. viv. gl. à souche rameuse; f. inf. bi-tripennatiséquées à segments divisés en lan. allongés, lanc. lin., mucronulées; omb. à 6-15̆ rayons, les int. plus courts; invol. nul ou à 1-2 fol.; involucelle à plus. fol. lin.

Prés hum., fossés. - Jt-At.

S. pratensis Bess. 590

\section{Genre 201. - SESELi L.}

+ T. sillonnée anguleuse; invol. à fol. nombr., persist., pub., lin.acum. ; fr. pub.; cal. à dents allongées, en alène, caduques; f. oblongues dans leur pourtour, 1-3 fois pennatiséquées.

Coteaux calc. - Jt-Sept.

\section{S. Libanotis Kioch 591}

+ T. seulement striée; invol. nul ou à 1-4 fol. cad.; fr. glabrescent; cal. à dents courtes, un peu épaisses, persist.

$0 \mathrm{mb}$. à 6-12 rayons; involucelle à fol. à peine scarieuses aux bords plus courtes que l'ombellule; souche vivace, rameuse, émettant plus. t. ; pl. gl. et glauque; styles réfléchis, plus longs que le stylopode.. . . . . . . . S. montanum L. 592 Coteaux eale. - Jt-0ct. 
Omb. à 10̈-30 rayons; involucelle à fol. larg. scarieuses aux bords égalant ou dépassant l'ombellule; pl. bisan., rar. viv., glabrescente, verte ou rougeàtre à souche pivotante, munie de fibres au sommet, émettant 1 seule t.; styles égalant le stylopode.

Coteaux sabl. calc. - Jt-Sept.

S. annuum L. 593

\section{GeNre 202. - FOENIGULUM And.}

Pl. viv. de 1-2 m. gl., un peu glauque, tr. aromatique; f. 3-4 fois pennatiséquées, à lan. nombr., filiformes, tr. allongées, les sup. à gaine plus longue que le limbe; omb. à 10-30 rayons gl.; fr. glaucescent, à odeur d'anis . . . . . . . . . F. officinale All. 594

Lieux arides (Fenouil). - Jt-0ct.

\section{Genre 203. - ÆTHUSA L.}

Pl. ann. gl. d'un vert sombre; t. striée, creuse, rameuse souvent glaucescente et sillonnée de lignes rougeâtres; f. triang. dans leur pourtour, bi-tripennatiséquées, à segments ovales-lane., incisés en lobes lanc.-lin.; omb. à 5-12 rayons inég.; invol. nul ou à 1 fol.; involucelle à 3-5̆ fol. lin., réfléchies, plus longues que l'ombellule; méricarpes à côtes épaisses, carénées, les marginales un peu plus larges.

Ch. cult., décombres (Petite Ciguë). - Jn-Sept.

E. Cynapium L. 595

\section{Genre 204. - ENANTHE L.}

+ F. bi-tripennatiséquées à segments découpés en lobes tr. petits oblongs, ent. ou incisés, tr. nombr.; omb. brièv. pédonc., la plupart lat. et opp. aux f.; fl. toutes égales, pédic. et fertiles; cal. à dents très petites; fr. ovoïde, atténué au sommet. $\quad$ E. Phellandrium Lamk 596 Mares et étangs. - Jt-Sept.

+ F. caul. à lobes lin. allongés; omb. long. pédonc., term.; fl. centr. des ombellules subsessiles et fertiles, les ext. rayonnantes, pédi-
cellées et stériles.

$X$ F. rad. à segments obovales ou en coin; omb. à 7-30 rayons grêles; invol. à 1-̋̆ fol. cad. ou nul; fr. oblong atténué aux 2 bouts, sans anneau à la base; fibres rad. ord. renfl. en massue allongée.

Prairies tourb. - Jt-Sept.

E. Lachenalii Gmel. 597

$\times \mathrm{F}$. toutes presque de mème forme, à segments lin. ou oblongs; omb. à 2-10 rayons; invol. nul ou à 1-3 fol.

$=0 \mathrm{mb}$. fructif. à 5 - $\mathbf{1 0}$ rayons allongés; ombellules fructif. convexes hémisph.; tige sillonnée anguleuse; fibres rad. renfl. en massue. $0 \mathrm{mb}$. à rayons toujours grêles; fr. mùr elliptique, atténué aux 2 bouts, sans anneau calleux à la base; styles contigus-adhérents à la base; pét. rayonnants en coin, fendus jusqu'au tiers; pl. assez grêle, verte (OE. filipenduloides Thuill.).

Prairies hum. - Jn-At.

E. peucedanifolia Poll. 598

$0 \mathrm{mb}$. à rayons tr. épaissis après la flor.; fr. mùr cyl. subtétragone, non contracté au sommet, muni d'un anneau calleux à la base; styles distants, mème à la base; pét. rayonnants arrondis à la base, bipartits; pl. assez robuste, glaucescente (OE'. silaifolia I. B.). . . . . . E. media Gris. 599

$=0 \mathrm{mb}$. fructif. à 2-3 rayons courts, épaissis à la maturité; ombellules fructif. glob.; tige striée, creuse, munie de stolons allongés; fibres rad. grêles ou renfl. en fuseau; f. inf. bi-tripennati- 
séquées, à segments petits, lin. ou oblongs en coin, les sup. à lobes lin.; styles aussi longs que le fr. obovale subtétragone.

E. fistulosa L. 600

Marais et fossés. - Jn-Sept.

On rencontre subsp. dans les prés (St-Cloud) $E_{E}$. pimpinelloides L. Fibres radic. grèles, tr. long. termin. par un tuberc. ovoüde ou subglob.; f. inf. bipennatiséquées, à segments ovales en coin, les sup. pennatiséquées à segm. lin.; omb. à 7-12 rayons assez courts, épaissis après la floraison; invol. à fol. caduques; styles égalant le fr. cyl. muni d'un anneau calleux à la base. On a signalé $E$. crocata L. Pl. robuste d'environ $1 \mathrm{~m}$. à sou che formée de gros tuberc. sessiles allongés en fuseau, à suc jaune; f. gr., vertes, bipennatiséquées à segments ovales en coin; omb. à 15-30 rayons assez grêles; invol. à plus. fol. ou nul; styles un peu plus courts que le fruit cyl., arrondi ì la base, sans anneau.

\section{GeNRe 20ð. - BUPLEURUM L.}

+ Pl. viv. à souche rameuse; f. inf. ovales ou oblongues, les sup. lin.lanc. sessiles; involucelles à $\breve{b}-6$ fol. lanc. ou lin. plus courtes que les ombellules; invol. à 1-4 fol. lin., inég.; fr. ovoïde à côtes saillantes; vallécules à 3-6 bandelettes. . . . . B. falcatum L. 601 Bois et coteaux cal. - Jt-0ct

+ PI. ann.; f. perfoliées ou linéaires; involucelles à fol. égalant ou dépassant l'ombellule.

$X$ F. perfoliées; ovales suborb., obtuses à nervures rayonnantes; invol. nul; involucelle à fol. larg. ovales, cuspidées, dépassant long. l'ombellule, dress. après la flor.; fr. oblong, lisse à côtes saillantes, sans bandelettes . . . . . B. rotundifolium L. 602 Ch. et moiss. des terrains calc. - Jn-At.

X F. non perfoliées, lin. ou lanc., tr. aig. à nervures parallèles; invol. à 1-ă fol. persist.; involucelles à fol. long. acum.

Invol. à fol. larges, ovales-lanc., dépassant long. les rayons de l'omb.; involucelle à fol. glumacées membr., ovoles-lanc., aristées, cachant les fl. et les fr.; pl. à rameaux raides, dichotomes très ćtalés; $\mathrm{fr}$. ovoïde, lisse à côtes fines; omb. denses, term. à 2-5 rayons courts, inég. . . . . . B. aristatum Barth. 603 Pelouses sèches. - Jn-Jt

Invol. à fol. étr. lin. et inég., plus courtes que les rayons de l'omb.; involucelle à 3-o fol. lin. acum., dépassant les fl., mais égalant à peine les fr. mùrs; pl. glauque ou d'un vert sombre, rameuse dès la base, à rameaux grêles flexueux, florifère dans presque toute sa long.; fr. subglob. granuleux-tuberculeux, à côtes saillantes ondulées-crispées; omb. termin. à 2-4 rayons inég., tr. courts, les lat. nombr. réduites à des ombellules de 2-5 fleurs espacées.

Pelouses arides et sabl. - At-0ct.

B. tenuissimum L. 604

On cultive quelquefois et on rencontre à l'état subsp. B. fruticosum L. Pl. lign. de 1 à $2 \mathrm{~m}$., à rameaux tr. feuillés; f. oblongues vein. en réseau; omb. à 8-20 rayons égaux; invol. et involucelle à plus. fol. réfléchies plus courtes que les rayons et les pédic.; fr. oblong à côtes saillantes aig.; vallécules à une bandelette.

\section{GenRe 206. - SIUM L.}

Fol. toutes régul. et fin. dentées; t. robuste, d'environ 1 mètre, cannelée anguleuse, rameuse; omb. term. à 20-3ð rayons presque égaux; invol. à fol. dentées ou incisées; styles filiformes plus longs que le stylopode; fr. ovoïde; méricarpes à bords contigus, à côtes saillantes, obtuses.

Marais, bords des rivières. - Jt-Sept. 
Fol. irrégul. incisées-dentées; pl. de $40-80 \mathrm{~cm}$., à souche rampante stolonifère à t. fin. sillonnée; omb. la plupart lat., opp. aux f., brièv. pédonc. à 8-20 rayons inég.; invol. à fol. incisées lobées ou pennatifides; styles élargis à la base, 2 fois plus longs que le stylopode; fr. subglob.; méricarpes à bords écartés, à côtes peu saillantes.

Marais, fossés. - Jn-Sept.

\section{Genre 207. - PIMPINELLA L.}

T. creuse, sillonnée-anguleuse, feuillée; f. rad. à fol. larges de 2-4 cm., pétiolulées, dentées, les sup. plus petites et en coin; omb. à 8-16 rayons presque égaux; styles réfléchis plus longs que l'ovaire; fr. assez gros, ovale, un peu rugueux. . . . . . . . . . P. magna L. 607 Bois frais, haies. - Jn-At.

Var. à segments des f. inf. pennatifides, à lobes lin.-lanc. (var. dissecto Retz.). T. pleine, arrondie, fin. striée presque nue sup.; f. rad. à fol. larges de 1-2 cm., sessiles, dentées, incisées ou pennatifides, les sup. à segments étr. ou réduits au pétiole; styles réfléchis plus courts que l'ovaire; fr. petit, ovoïde, lisse. . . . . . . . . . P. Saxifraga L. 608 Coteaux et pâturages secs. - Jt-0ct.

Var. à segments des f. inf. découpés en lobes lanc.-lin. (var. disectifỏia Koch).

\section{Genre 208. - BUNIUM L.}

Pl. viv. à t. dress., rameuse, peu feuillée; f. bi-tripennatiséquées à lan; lin., les caul. sessiles sur une gaìne allongée; omb. à 8.20 rayons. invol. à 6-10 fol. lanc.-lin.; fr. ovoïde-oblong.

Champs calc. ou argil. - Jn-Jt.

B. Bulbocastanum L. 609

\section{Genre 209. - GARUM L.}

Invol. et involucelle à fol. nombr., lin.; omb. fructif. à 8-15 rayons presque égaux, étalés-dressés; pl. viv., à racine formée de fibres épaissies en massue, à souche chevelue; f. long. et étr. bipennatiséquées à lan. capill. courtes, comme vert.; styles 2 fois plus longs que le stylopode.......... C. verticillatum Koch 610 Landes et prés maréc. - Jn-Sept.

Invol. et involucelle nuls ou à 1-4 fol.; omb. fructif. à 6-12 rayons tr. inég. dressés et rapprochés; pl. bisan., à racine charnue, long. pivotante en fuseau, nue au sommet, odor.; f. oblongues, bipennatiséquées, à lan. lin. courtes, paraissant en croix sur le pétiole; styles 1 fois plus long's que le stylopode. . . . . . . . C. Carvi L. 611 Prés, quelquefois subsp. - Mai-Jt.

\section{GENRE 210. - ÆGOPODIUM L。}

Pl. viv. à souche long. ramp.; f. inf. long. pétiolées, biternées, à fol. ovales lanc., aig., dentées en scie, les caul. sessiles sur la gaine et ternées; pas d’involucelle; pét. obovales, émarg.; pl. envahissante.

Æ. Podagraria L. 612

Lieux frais et ombragés, bords des ruiss., fleurit rarement. - Mai-At.

\section{Genre 211. - AMMI L.}

PI ann. glaucescente, à racine pivotante; f. inf. pennatiséquées à segments ovales ou lancéolés dentés en scie ou incisés dentés, rarement bipennatiséquées à segments lin., entiers ou à 1 à 2 dents (var. glaucifolium); f. sup. bipennatiséquées à segments lin., dentés; omb. à rayons nombreux; involucelles à fol. filiformes dépassant souvent les rayons de l'ombellule. ........... A. majus L. 613 


\section{Genre 212. - SISON L.}

Pl. gl., à racine longue, pivotante, à odeur désagréable; f. inf. pennatiséquées à 5"9 segments ovales-oblongs, incisés-dentés, les sup. divisées en lobes lin.; omb. nombr., petites, à $3-6$ rayons inég., filiformes, divariqués; pét. bifides; fr. ovoïde. . . . . . . S. Amonum L. 614 Lieux frais, fossés, haies. - Jt-Sept.

\section{Genre 213. - FALCARIA Riv.}

Pl. viv. ou bisann. gl. et glauque à racine tr. longue en fuseau; $f$. coriaces, les rad. simples ou ternées, les caul. pennatiséquées, à segments lin.-lanc., allongés, souvent courbées en faux, bordées de dents fines, tr. serrées, mucronées-cartilagineuses; omb. à 10-20 rayons filiformes; styles plus longs que le stylopode conique; méricarpes à bords contigus. . . . . . . . F. Rivini Host 615 Ch. calc. - Jt-Sept.

\section{Genre 214. - HELOSGIADIUM Koch.}

+ F. toutes aériennes, pennatiséquées à segments ovales; omb. à 3-12 rayons; involucelle à fol. scarieuses-blanchâtres aux bords; fl. d'un blanc un peu verdàtre; styles plus longs que le stylopode.

Pl. de $30 \mathrm{~cm}$. à $1 \mathrm{~m}$. à $\mathrm{t}$. robustes, ascend. ou couchées, radicantes aux nœuds inf. ; omb. sessiles ou à pédonc. plus courts que les rayons, à 4-12 rayons; invol. nul, rar. à 1-2 fol. cad.; fr. ovoïde; segments desf. ovales-lanc. . . . H. nodiflorum Koch 616 Marais, ruiss. - Jn-Sept.

Var. à liges grèles, couchées radicantes; omb. pédonc. à pédonc. quelquefois plus long que les rayons.

Pl. de $10-50 \mathrm{~cm}$. à t. grêles, couchées, radicantes à tous les nœuds; omb. à pédonc. ord. plus longs que les rayons; invol. à th-b̆ fol. persist.; fr. subglob.; segments des f. ovales ou presque orb.

Sables hum., marais. - Jn-Sept.

H. repens Koch 617

+ F. submergées bi-tripennatiséquées à lan. capill., les aériennes pennatiséquées à segments en coin, trifides au sommet; omb. à 2-3 rayons, à pédonc. aussi longs ou plus longs que les rayons; invol. nul; involucelle à 3 fol. herb. étalées ou réfléchies; styles plus courts que le stylopode; fr. oblong; fl. blanches, 3-6 par ombellule. . . . . . . . H. inundatum Koch. 618 Mares tourb. silic, fossés. - Jn-Jt.

\section{GeNRE 215. - TRINIA Hoffm.}

Pl. bisann. ou viv., gl. et glauque, à souche verticale, épaisse couronnée par les débris des anciennes f.; t flexueuse, très rameuse, à rameaux étalés; f. triang. dans leur pourtour, bi-tripennatiséquées, à lobes lin.; fl. dioïques ou monoïques en omb. nombr., à 4-8 rayons tr. inég.; invol. et involucelle nuls ou à 1 fol.. . T. vulgaris DG. 619 Pelouses sèches, coteaux calc. - Mai-Jt.

\section{GenRe 216. - PETROSELINUM Hoffm.}

Fl. blanches ou rosées, en omb. à 2-3̈ rayons tr. inég.; styles dress. plus courts que le stylopode; fr. ovoïdes tr. inég. pédonc.; f. lanc. dans leur pourtour, pennatiséquées à 13-19 segments ovales-oblongs, incisés-dentés. .......... P. segetum Koch 620 Ch., fossés, haies. - Jt-Sept. 
Fl. d'un vert-jaunàtre, en omb. à 8-20 rayons presque égaux; styles réfléchis plus longs que le stylopode; fr. subglob. à pédic. presque égaux; f. triang. dans leur pourtour, les inf. bi-tripennatiséquées à segments ovales en coin, incisés dentés, les sup. ord. à 3 segments ent., lanc.-lin.; pl. aromatique.. . . . . P. sativum Hoffm. 621 Cult. et subsp. (Persil). - Jn-Sept.

\section{Genre 217. - APIUM L.}

Pl. bisann., gl., luisante, aromatique à souche courte munie de fibres un peu charnues; t. creuse, sillonnée anguleuse tr. rameuse; f. inf. pennatiséquées à segments ovales en coin, incisés-lobés, les sup. à 3 segments plus petits et plus étr.; invol. et involucelle nuls; pét. ent.; fr. petit à còtes blanchâtres. A. graveolens L. 622 Cult. (Céleri). - Jn-Sept.

\section{Genre 218. - GiGUTA L.}

Pl. vivace d'environ 1 m., gl., à t. robuste, creuse, striée, rameuse; f. inf. à long pétiole tubul. cyl., bi-tripennatiséquées, à segments lanc. étr., dentés en scie; fl. blanches, en omb. gr., à 10-2b rayons allongés, égaux; invol. nul; involucelle à $3-5$ fol. lin. en alène; fr. petit, plus large que long. . . . . . . . . . C. virosa L. 623 Marais, fossés, étangs tourb. - Jt-At.

\section{Genre 219. - SCANDIX L.}

Pl. ann., pub.-hér.; f. ovales dans leur pourtour bi-tripennatiséquées, découpées en lobes lin., mucronulés, rudes aux bords; omb. simples ou à 2-3 rayons robustes, plus courts que le fr.; invol. nul ou à 1 fol. pennatiséquée; involucelle à 5 fol. bi-trifides ou pennatiséquées, rar. ent. . . . . . . . . . . . S. Pecten-Veneris L. 624 Ch. - Mai-At.

\section{GenRe 220. - ANTHRISGUS Hoffm.}

+ 0mb. la plupart lat., sessiles ou brièv. pédonc., à 3-7 rayons; styles dressés conniv.; fr. ovoïde ou lin. à bec très distinct; pl. ann. à racine pivotante; lobes des f. obtus-mucronés.

Fr. ovoïde-aig., couvert de petits aiguillons crochus, muni à la base d'un cercle de poils, à bec 3 fois plus court que les méricarpes; omb. à rayons gl.; involucelle à 4-5̆ fol. étalées; pl. fétide à f. molles, poilues, les inf. tri-pennatiséquées à segments pennatifides à lobes courts. . . . . A. vulgaris Pers. 625 Lieux incultes. - Mai-Jn.

Fr. lin. allongé, lisse et luisant, dépourvu de poils à sa base, à bec égalant la moitié de la long. des méricarpes; omb. à rayons pub.; involucelle à 2-3 fol. réfléchies; pl. aromatique à f. luisantes, fin. poilues, bipennatiséquées, à segments ovales, pennalipartits, à lobes courts .... A. Cerefolium Hoffm 626 Cult. (Cerfeuil). - Mai-At.

+ 0mb. toutes term., assez long. pédonc., à 7-16 rayons; styles étalésdressés; fr. oblong-lin., lisse, rétréci en bec tr. court, peu apparent; pl. viv., à souche épaisse, d'environ 1 m., gl. sup., poilue inf.; f. luisantes, tripennatiséquées, à segments oblongs-lanc. subaigus. . . . . . . . . A. silvestris Hoffm. 627 Prés, bois, haies. - Mai-Jt.

\section{GeNre 221. - GONOPODIUM Koch.}

Pl. viv.; f. bi-tripennatiséquées, les inf. triang. dans leur pourtour à lobes lanc. lin., les caul. à lan. lin.; omb. à 7-12 rayons, grêles, gl.; invol. nul ou à 1-2 fol.; involucelle à 2-š fol. lin. C. denudatum Koch 628

Prés et bois sabl. - Mai-Jn. 
GENRE 222. - GHÆROPHYLLUM L.

Pl. bisann. de $30 \mathrm{~cm}$. à $1 \mathrm{~m}$., vel. hér., à racine grêle, pivotante; t. fort. renfl. sous les nouds, tachée de brun; f. vert sombre, bipennatiséquées, à lobes ovales-obtus, mucronulés; omb. à 6-12 rayons inég., pub.; invol. nul ou à 1 fol.; involucelle à

Haies, buissons. - Jn-Jt.

C. temulum L. 629

\section{GeNre 223. - CONIUM L.}

PI. bisann. d'environ $1 \mathrm{~m}$., gl. à odeur vireuse; t. robuste, glaucescente, tachée de pourpre inf.; f. inf. gr., 3-3̆ fois pennatiséquées, à segments ovales lanc., pennatipartits, à lohes courts; omb. à 10-20 rayons inég.; invol. à 3-כ̆ fol. courtes, réfléchies; involucelle à 3 fol. courtes.

Haies, décombres (Ciguë). - Jn-At.

C. maculatum L. 630

\section{Famile 48. - ARALIACÉES}

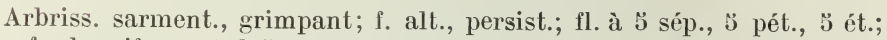
fr. bacciforme à 2-5 noyaux distincts. . . . . HEDERA 224

Arbriss. dress., non grimp.; f. opp., ead.; fl. à 4 sép., 4 pét., 4 ét.;

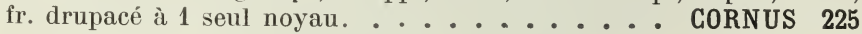

\section{Gevre 22\%. - HEDERA L.}

T. couchées radicantes sur le sol ou grimp. par des crampons; f. alt., pétiolées, coriaces, luisantes, persist., les caul. palmatinervées, à 3-̋ lobes triang.; celles des rameaux florifères ent., ovales acum.; fl. d'un jaune verdâtre en omb. term. ....... H. Helix L. 631 Bois, murs (Lierre). - Fl. Sept.-Oct. ; fr. Mars-Mai.

\section{GeNre 22\%. - GORNUS L.}

Fl. jaunes, paraissant avant les f., disposées en omb. simples, munies d'un invol. à 4 fol.; drupe elliptique, rouge à la maturité, tr. acidule, de $1 \mathrm{~cm}$. de long.; f. ovales acum., brièv. pétiolées, un peu luisantes, souvent plus pâles le long des nervures; arbriss. à rameaux grisâtres ou verdâtres. . . . . . . . . C. mas L. 632 Bois et haies des terrains calc. (Cornouiller). - Fl. Mars; fr. Sept.

Var. à drupe jaunâtre (var. chlorocarpa.)

Fl. blanches paraissant après les f., disposées en corymbes rameux, dépourvus d'invol.; drupe glob., noire à la maturité, amère, de 今 mm. de diamètre; f. ovales elliptiques brièv. acum., courtement pétiolées; arbriss. à jeunes rameaux rougeâtres.

Bois, haies. - FI. Mai-Jn ; fr. Sept.-Oct.

C. Sanguinea L. 633

\section{III. - MONOPÉTALES}

\section{Famille 49. - CAPRIFOLIACÉES}

+ Pl. peu élevée, herb.; cal. à 2-3 lobes; 4-3̈ ét. à filets bipartits, chaque division portant 1 loge de l'anth.; baie glob., verdâtre, à 4-こ̆ loges monosp.; 4-3̆ styles en alène . . . . A ADOXA 226

+ Pl. élevées, robustes, ord. lign.; cal. à 4-z̆ dents tr. courtes; 4-כ̌ ét.

X F. imparipennées à 5-11 fol. dentées en scie; cor. en roue; style nul; baie à 3 graines. . . . . . . SAMBUCUS 227 
X F. ent., dentées ou lobées; cor. tubul., en entonnoir ou en cloche, rarement en roue; baie à 1 ou plus. graines.

$=$ Fl. en corymbes term., rameux, ombelliformes; cor. régul. en cloche ou en roue; style nul; 3 stigmates sessiles; baie à 1 loge et à 1 graine. ........... VIBURNUM 228

$=$ Fl. axill. ou en têtes term.; style filiforme; baie à $2-4$ loges à 2 ou plusieurs graines.

Cor. irrégul., tubul., à 2 lèvres; baie rouge ou noire, à 2-3 loges et à plus. graines. . . . . . . . LONIGERA 229 Cor. presque régul., à 4-5̆ lobes presque égaux; baie blanche à 4 loges dont 2 stériles, à 2 graines. SYMPHORIGARPOS 230

\section{Genre 226. - ADOXA L.}

Pl. de t. grèle dress. portant 2 f. opp., ternées, brièv. pétiolées; f. rad. long. pétiolées, biternées; fl. verdàtres, 4-6 sessiles en tête term. cubique; cor. en roue à $4-3$ lobes plans. . A. Moschatellina L. 634 Bois frais et ombragés. - Mars-Mai.

\section{Genre 227. - SAMBUCUS L.}

T. herb., robuste, sillonnée; f. à 7-11 folioles lanc.-acumin., dentées à peine pétiolulées; stip. gr., foliacées, ovales; fl. blanches ou rosées, à anth. rouges, en corymbe; baies noires. . . . S. Ebulus L. 635 Terrains incultes argil.-calc. - Fl. Jn-At; fr. Sept.-0ct.

T. et rameaux lign., verruqueux-grisâtres; f. à ̆-7 fol. pétiolulées; stip. nulles ou tr. petites; fl. blanches ou jaunàtres, à anth. jaunes.

Fl. blanches, odor., en large corymbe plan, paraissant après les f.; baies noires, rar. blanchàtres; rameaux remplis de moelle blanche.

Bois, haies (Sureau). - Fl. Jn ; fr. Sept.

S. nigra L. 636

Var. ì fol. pennatiséquées, à lan. étr. (S. laciniata Mill.).

Fl. d'un blanc jaunâtre, peu odor., en pan. ou thyrses ovales et denses, paraissant avec les $\mathrm{f}$.; baies rouges; rameaux remplis de moelle jaunâtre. . . . . . . . . . S. racemosa L. 637 Planté çà et là dans les bois. - Fl. Avr.-Mai ; fr. Jt-At.

\section{GenRe 228. - VIBURNUM L.}

F. palmatilobées, minces, glabrescentes, à 3-ð̆ lobes, sinués-dentés, aig.; pétiole allongé, gl.; stip. lin.; fl. ext. bien plus grandes, en roue; à lobes inég.; baies rouges. . . . . . . . V. Opulus L. 638 Bois hum. - Fl. Mai-Jn; fr. Sept.

F. ovales, dentées, en cœur à la base, épaisses, tom.-grisâtres ou verdâtres en dessous; pétiole court, poilu; pas de stip.; fl. toutes égales, en cloche, à lobes égaux; baies d'abord rouges puis noires.

V. Lantana L. 639

Haies et bois, surtout calc. - Fl. Avr.-MIai ; fr. At-Sept.

\section{GenRe 229. - LONIGERA L.}

T. sarment., volubiles; f. sup. sessiles; fl. d'un blanc jaunâtre ou rougeâtre, odor., sessiles, vert. en têtes term. long. pédonc., cor. pub.gland.; style gl.; baies ovoïdes, rouges. . L. Periclymenum L. 640 Bois, haies, surtout silic. - Jn-Sept. 
T. dress., non volubiles; f. toutes brièv. petiolées; fl. d'un blanc-jau-nàtre, inodor., géminées au sommet de pédonc. axill.; cor. vel., style vel. ; baies géminées, distinctes, à peine soudées à la base, rouges.

Bois, haies. - Mai Jn.

L. Xylosteum L. 641

On cult. L. Caprifotium L. (Chèvrefeuille), voisin de L. Periclymenum; en diffère par les $\mathrm{f}$. sup. perfoliées, les fl. en têtes sessiles. On cult. aussi $L$. etrusca Santi, voisin de $L$. Periclymenum; s'en distingue par ses $\mathbf{f}$. sup. perfoliées et sa cor. gl.

\section{GeNRE 230. - SYMPHORICARPOS Dill.}

Arbriss. dress., touffu, à f. ovales un peu pétiolées, ent., dentées ou lobées sur les jeunes rameaux; fl. petites, blanches ou rosées en tête term., interrompue ......... S. racemosus Mich. 642 Cult. - FI. Jn-Sept. ; fr. Automne.

\section{Fanille 50. - RUBIACÉES}

+ Fruit nu au sommet ne présentant aucun vestige des dents du cal.; cal. à 4 dents très courtes ou nulles.

$\times$ Fr. charnu, formé de 1-2 baies noires presque de la grosseur d'un pois, ne se séparant point à la maturité; cor. en roue étalée, ord. à "s lobes; t. tr. scabres, grimp.-accrochantes. RUBIA 231

$\times$ Fr. sec, formé de 2 carp. plus petits, se séparant à la maturité; cor. ord. à 4 lobes; t. lisses ou scabres.

Cor. en roue ou en étoile, plane à tube nul ou tr. court; fl. blanches, jaunes, verdàtres ou rougeâtres. . . . GALIUM 232

Cor. en cloche ou en entonnoir, à tube plus ou moins allongé ;

fl. blanches, rougeâtres ou bleues. . . . A ASPERULA 233

+ Fr. couronné par les 6 dents profondes, accrescentes et persist. du cal., formé par 2 carp. monosp.; fl. d'un rose lilas, en têtes term. involucrées. . . . . . . . SHERARDIA 234

\section{Genre 231. - RUBIA L.}

F. ovales-lanc., coriaces-cartilagineuses, persist., non vein. en réseau en dessous; cor. à lobes long. aristés; anth. ovales; stigmates en tête; fl. jaune-pâle, en petites cymes . . . . R. peregrina L. 643 Bois pierreux calc. - Jn-At.

F. lanc., membr., non persist., vein. en réseau en dessous; cor. à lobes apiculés, non aristés; anth. lin. oblongues; stigmates en massue; fl. d'un jaune assez vif, en petites cymes. . . R. tinctorum L. 644 Nat. çà et là, provenant d'anciennes cult. - Jn-At.

\section{Genre 232. - GALIUM L.}

$+\mathrm{F}$. trinervées, obtuses, mutiques, vert. par 4 .

$X$ Fl. jaunes, polygames, en cymes axillaires plus courtes que les f.; pédonc. fructif. courbés en arc, cachant les fr. sous les f. réfléchies; fr. lisses, gl.; f. ovales ou lane.

Pédone. munis de bract. foliacées; pl. hér. de longs poils blancs étalés; f. ovales ou elliptiques, vel. . . G. Gruciata Scop. 645 Bois, haies. - Avr.-Jn.

Pédonc. dépourvus de bract.; pl. gl. ou pub.; f. ovales ou lanc., gl. ou pub. . . . . . . . . G. vernum Scop. 646 Bois, buissons, nat. - Mai-Jn.

Fl. blanches, hermaphrodites en pan. term.; pédonc. fructif. dr., étalés ou dress. non cachés par les f.; fr. rugueux gl.; f. lanc. ou lanc. lin. ............ G. boreale L. 647 Prairies hum. - Jn-Jt.

+ F. à 1 seule nervure, mucronées ou cuspidées. 
T. ord. garnies sur les angles de petits aiguillons réfléchis, qui les rendent rudes de bas en haut; pl. ann. ou viv. à racine grêle.

- Pl. viv., croissant dans les lieux maréc. ou tr. hum.; cor. blanche, rar. rosée, plns large que le fr. mùr qui est gl.

T. tr. scabres et accrochantes; f. lanc. lin., acum.-mucronées. vert. par 6-7; anth. jaunes; pl. ne noircissant pas par la dessiccation . . . . . . . . G. uliginosum L. 648 Prairies tourb., fossés. - Jn-Sept.

s. T. un peu scabres ou lisses; f. oblongues ou lin., non mucronées, vert. par 4-6; anth. purpurines; pl. noircissant par la dessiccation.

○ Pédic. fructif. étalés-diverg. plus longs que les fr. chagrinés; f. vert. par 4-כ̆, à dentic. dirigés vers la base ou dirigés vers la base et vers le sommet.

T. nombr. faibles, $20-40 \mathrm{~cm}$., diffuses étalées-ascend.; f. oblongues ou lin.-oblongues, $1 \mathrm{~cm}$. à $1 \mathrm{~cm} .1 / 2$ de long, à dentic. dirigés vers la base; fr. petit, $1 \mathrm{~mm}$.; pan. assez étr. à rameaux étalés réfléchis après la flor. . . . G G. palustre L. 649 Marais, fossés. - Mai-At.

T. peu nomb., peı robustes, allongées, $40 \mathrm{~cm}$. à $1 \mathrm{~m}$. ascend.; f. oblongues lin., 2 à $4 \mathrm{~cm}$. de long, à 2 rangs de dentic., dirigés, les uns vers le haut, les autres vers la base; fr. assez petit, $2 \mathrm{~mm}$.; cor. de $4 \mathrm{~mm}$.; pan. ample à rameaux étalés après la flor. . . . . . G. elongatum Presl. 650 Fossés, prẻs maréc. - Mai-Jt.

Pédic. fructif. dressés, rapprochés plus courts que les fr. tuberc. ou les égalant; f. lanc.-lin. ou lin. subaig., vert. par 6 sur la t., par 4 sur les rameaux secondaires, à dent. dirigés vers le sommet; t. grêles, $10-40 \mathrm{~cm}$., dress. ou ascend.; pan. étr., allongée à rameaux étalẻs-dressés.

Mares, lieux tourb. - Mai-Jt.

G. constrictum Chamb. 651

- Pl. ann., croissant dans les lieux secs; cor. d'un blanc verdâtre, jaunâtre ou rougeâtre, tr. petite, moins large que le fruit mûr qui est gl. ou hispide.

क T. assez robustes, tr. scabres et accrochantes ; fl. blanchâtres, en petites cymes axill. pédonc.; fr. ayant au moins $2 \mathrm{~mm}$. de diamètre.

`o Fl. en cymes multiflores plus longues que les f.; pédic. fructif. dr., divariqués; f. hispides à la face sup.

T. raides, assez grêles, non renfl. ni vel., hér. aux nœuds; f. étr. lanc.-lin., acum.; fr. assez petit, 2 mm., gl., chagriné. rar. hér. de poils non tuberc. à la base. (G. Vaillantii DC.).

$$
\text { Ch. cult. - Jn-At. }
$$

G. spurium L. 652

T. diffuses, ascend., renfl. aux nœuds et hér. au-dessus; f. lin. oblongues ou oblongues, mucronées; fr. gros, 3-4 mm., hér. de poils crochus naissant d'un tuberc., rar. seul. tuberc. (G. intermedium Mérat) . . . . . G. Aparine L. 653 Haies, buissons. - Mai-At.

'o Fl. en cymes triflores plus courtes que les f.; pédic. fructif. recourbés ou penchés; f. non hér. à la face sup. ; fr. 2-3 couverts de petits tuberc. saillants; $t$. ascend., tr. scabres et accrochantes. . . . . . . G. tricorne With. 654 Ch. cult., surtout calc. - Jn-Sept.

T. tr. grêles souvent filiformes, rudes ou lisses; fl. peu apparentes d'un vert jaunàtre ou rougeâtre en pan. term. ou en vert. axill.; fr. tr. petit, à peine $1 \mathrm{~mm}$. 
Pan. large, tr. lâche, à rameaux filiformes, allongés, étalés, à ramuscules capill. 6-10 fois aussi longs que les bract. fructif.; f. lin., vert. par 6-7, étalées, non réfléchies à la fin ; t. dress., lisses au sommet; fr. gl., chagriné.

Pelouses sèches, lieux sabl. - Mai-Jt.

G. divaricatum Lamk. 655

Pan. étr., allongée, assez serrée, à rameaux courts, étalésdress., à ramuscules 3-6 fois aussi longs que les bract. fructif.; f. lin.-lanc., vert. par 6 , à la fin réfléchies ; t. étalées-diffuses, rudes dans toute leur long.; fr. chagrinés, rar. hispides. . . . . . . G. parisiense L. 656 Ch. secs, vieux murs. - Mai-At.

T. gl. et lisses, ou vel., mais sans aiguillons réfléchis sur les angles; pl. viv., à souche souvent épaisse.

Q T. assez robustes, ord. dress. ou ascend.; fl. en pan. pyramidale dress.

Fl. jaunes, odor. en pan. longue, étr., dress.; cor. à lobes subaig., non aristés; f. vert. par 8-12, étr. lin., mucronées, à bords enroulés; t. raides, dress. ou ascend., arrondies; péd. fructif. étalés nn peu plus longs que le fr. lisse; pl. noircissant par la dessiccation.. . . . . . . G. verum L. 657 Pelouses, prés. - Jn-Sept.

渎 Fl. blanches en pan. étroite ou très ample; cor. à lobes aristés; f. vert. par 6-8, obovales, oblongues ou lanc. lin., mucronées, non enroulées aux bords ; t. dress. ou décombantes, quadrang., renfl. aux nœuds; pédic. fructif. dressés ou divariqués plus longs que le fr. chagriné ; pl. ne noircissant pas par la dessiccation.

Fl. blanchàtres, petites, $3 \mathrm{~mm}$., en pan. ample, à rameaux étalés ou déjetés; pédic. fructif. divariqués; f. obovales ou oblongues-lanc., mucronées, minces, vein.-réticulées, à nervure médiane peu saillante.. . . . G. Mollugo L. 658 Haies, bois. - Jn-At.

Fl. blanches assez petites, $4 \mathrm{~mm}$., en pan. étr., oblongue, à rameaux dressés-étalés; pédic. fructif. dress.; f. oblongues ou lanc.-lin., mucronées, épaisses, non vein.-réticulées, à nervure médiane tr. saillante.. . G. erectum Huds. 659 Prés, bois. - Mai-Jt.

Q T. grêles, décombantes; fl. en pan. étalée ou diffuse, en corymbes ou en petites cymes; pl. peu élevées, souvent gazonnantes.

Pl. étalées-diffuses, non densément gazonnantes; fl. en pan. ovale formée de corymbes irrégul., à rameaux peu nombr., non entrelacés; f. lanc.-lin. vert. par 6-9 enroulées aux bords; fr. chagriné ; fl. petites $2-3 \mathrm{~mm}$.; t. étalées-ascend., radicantes et stolon . . . . . . . . G. silvestre Poll. 660 Bois secs, pelouses. - Jn-Jt.

Var. à t. gl. (G. laeve Thuill.) ou hispide inf. (G. nitidulum Thuill.). Une pl. tr. voisine, G. Jordani Lov. et Barr. Coste $\mathrm{n}^{\circ} 1695$, a été indiquée à Port-Villez, S.-0. Elle se distingue de G. silvestre par sa pan. oblongue, étr.; ses rameaux entrelacés; ses fl. de 3-4 mm.; ses t. couchées-diffuses sans stolons; f. verticillées par 6-8 comme dans G. silvestre.

Pl. couchées, densément gazonnantes; fl. blanches en pan. corymbiforme un peu serrée, formée de petites cymes axill. et term.; f. obovales ou lanc., mucronées, minces, vert. par 4-7, rappr., sur les t. stériles; fr. densément tuberc.; fl. petites; pl. gl. noircissant en herbier.. . . . . . G. saxatile L. 661 Bruyères, pelouses et rochers humides, lieux tourb. - Jn-At. 


\section{Genre 233. - ASPERULA L.}

+ Fl. bleues, en tètes term., entourées d'un invol. à plus. fol. lin., bordées de longs poils blancs; pl. ann.; t. dress., rameuse sup.; f. inf. vert. par 4 , obovales, les autres par 6-8, lin., obtuses, cil. scabres aux bords; cor. à tube plus long que le limbe; fr. gl.,

lisse... . . . . . . . . . A. arvensis L. 662 Ch., moiss. des terrains calc. - Mai-Jn.

+ Fl. blanches ou rosées, en pan. ou en corymbes rameux, sans invol.; pl. viv.

$\times \mathrm{F}$. oblongues lanc., mucronées, vert. par $6-8$; fr. hér. de poils crochus; fl. en corymbe term. non feuillé ; cor. en cloche à tube à peine aussi long que le limbe; bract. sét. ; pl. odor. par la dessiccation................ odorata L. 663 Bois frais. - Mai-Jn.

$\times$ F. étr. lin., allongées; fr. gl.

$=$ T. dress., rameuses au sommet ; f. caul. vert. par 6-8; fl. blanches en cloche; fr. lisse.

T. robustes, subcyl., renfl. aux nœuds; f. glauques, scabres, les caul. vert. par 8 ; bract. lin. en alène; cor. à tube plus court que le limbe à 4 lobes aig.; ne noircit pas en séchant.

A. galioides M. Bieb. 664 Bords des chemins, prés, prairies artificielles; introduit. - Mai-Jt.

T. grêles, quadrang., non renfl.; feuilles vertes, presque lisses, les caulinaires verticillées par 4-6; bractées ovales-aiguës; corolle rosée à tube un peu plus long que le limbe, à 3-4 lobes ; plante noircissant par la dessiccation.. . A. tinctoria L. 665 Bois montueux. - Jn-Jt.

$=\mathrm{T}$. grèles, quadrangulaires, couchées-diffuses ou ascend., très rameuses dès la souche; f. ord. vert. par 4; fl. rosées en entonnoir, à tube à peine plus long que le limbe à 4 lobes; fr. fin. tuberc.; bract. lanc. en alène; ne noircit pas.. . A. cynanchica L. 666 Lieux secs, rochers et coteaux calc. - Jn-Sept.

\section{GenRe 234. - SHERARDIA L.}

Pl. ann. hispide, à racine grêle; t. nombr., couchées-étalées; f. ovales ou lanc., mucronées, vert. par 6 , tr. scabres; corolle en entonnoir à tube allongé à 4 lobes étalés; 4 ét. saillantes; fr. sec, brièv. hispide.

Ch., bords des chemins. - Avr.-Sept.

S. arvensis L. 667

\section{FAMILLE 0 1. - VALÉRIANÉES}

+ Cal. à limbe roulé en dedans pendant la flor. et simulant un rebord saillant; fr. couronné par une aigrette plumeuse à 1 seule loge ; inflor. trichotome ou en grappes; pl. vivaces.

Cor. à tube muni d'un éperon vers la base; 1 ét.; pl. gl. et glauque.

GENTRANTHUS 235

Cor. dépourvue d'éperon, 3 ét.; pl. gl. ou vel. VALERIANA 236

+ Cal. à limbe dress., non enroulé pendant la flor.; fr. couronné par les dents du cal., membr. ou herb., jamais plumeuses, à 3 loges, dont une fertile et deux stériles; inflor. en cymes dichotomes; 3 ét.; pl. ann........... VALERIANELLA 237

\section{Genre 235. - GeNTRANTHUS DC.}

PI. à t. dress.; f. ovales ou elliptiques-lanc. ent. ou à peine dentelées ; fl. rouges on blanches, odor. en corymbe serré, s'allongeant ensuite en pan. trichotome. . . . . . . G. ruber DG. 668 Vieux murs; nat. - Mai-Sept. 
GENRE 236. - VALERIANA L.

+ T. nett. sillonnée, atteignant au moins $50 \mathrm{~cm}$. ; fl. hermaphrodites; souche courte, fibreuse, à odeur fétide, émettant des stolons terminés par une rosette; f. infér. pennatiséquées.

F. à 7-11 segments ovales ou oblongs, grossièrement dentés; stolons épigés terminé par une rosette de $2-4$ f. à 3-ă segments larg. ovales; fl. en corymbes assez serrés ; pl. robuste, élevée de 1-2 m.

Bords des rivières, prairies hum. - Jn-At.

V. excelsa Poir. 669

F. à 13-21 segments lanc., ent. ou superf. dentés; stolons hypogés, term. par une rosette de f. à segments nombr. et étr.; fl. en corymbes assez serrés; pl. de $50 \mathrm{~cm}$. à $1 \mathrm{~m}$.

Bois hum. ou sabl. - Mai-Jt.

V. officinalis L. 670

Varie à f. à segments lin.-lanc. ent.; pl. plus petite ( $V$. angustifolia Tausch.).

+ T. fin. striée de $10-40 \mathrm{~cm}$; fl. dioïques, les màles du double plus gr. et en corymbes làches, les femelles en corymbes contractés; souche grêle, oblique, long. ramp. et stolon.; f. inf. ovales ou elliptiques, ent., les sup. pennatiséquées à 5-9 segments, le term. bien plus grand. . . . . . . . . . V. dioica L. 671 Bois maréc., prairies tourb. - Avr.-Mai.

\section{GeNre 237. - VALERIANELLA Hall.}

+ Cal. à limbe presque nul et non distinct sur le fr.; fl. d'un bleu cendré ou blanchàtres, en têtes glob. serrées.

Fr. plus large que long, ovale-arrondi, compr., un peu ridé en travers, muni de 2-3 petites côtes sur chaque face; loge fertile épaissie spongieuse sur le dos, les 2 stériles plus gr., contiguës, à cloison incomplète... V. olitoria Poll. 672 Ch. cult. - Avr.-Jn.

Fr. nett. plus long que large, oblong-quadrang., creusé d'un profond sillon sur une face, faibl. caréné sur l'autre; loge fertile non épaissie sur le dos, les 2 stériles à section transvers. semi-lunaire. à cloison complète. . . . . . . . . V. carinata Lois. 673 Ch. cult. - Avr.-Jn.

+ Cal. à limbe toujours distinct sur le fr.; fl. roses, lilacées ou blanchâtres.

$\times$ Cal. fructif. à limbe tr. petit, bien plus court et plus étroit que le fr. à 1-3 dents.

Fr. ovoïde subglob., renfl., à peine plus long que large, creusé sur la face ventrale d'un sillon profond, étr; loges stériles contiguës, plus grandes que la loge fertile; cal. à limbe 3 fois plus court que le fr., obliq. tronqué en oreille aig., ent. ou dentic. à la base; bract. lin.; fr. gl. ou vel. (var. dasycarpa Bor.).

V. Auricula DC. 674

Fr. ovoïde conique, non renfl., nett. plus long que large, à face ventrale offrant une dépression ovale-oblongue, circonscrite par un bourrelet; loges stériles séparées par la dépression et réduites à 2 canaux capill.; cal. à limbe 2 fois plus c rurt que le fr., obliq. tronqué en oreille aig., dentic. à la base; bract. lanc.; fr. gl. ou vel, (var. mixta S. W.). . . . V. Morisonii UG. 675 Ch., lieux cult. - Mai-Jt.

Cal. fructif. à limbe veiné en réseau aussi long et aussi large ou plus large que le fr., à 5 - 6 dents triang. 
Fr. cadıc, en tètes compactes planes en dessus; limb. du cal. obliq. tronqué aussi large que le fr., formant presque une couronne complète à วั-6 dents dr., les antérieures plus courtes; bract. lanc.; fr. hispide, quelquefois gl. (var. leiocarpa Auct.) offrant à la face ventrale une dépression ovale-oblongue, circonscrite par un bourrelet; loges stériles séparées par la dépression et réduite à 2 canaux capill.; f. ent. ou dentées; pl. rameuse dès la base.

Ch. sees, vignes, talus - Mai-Jn.

V. eriocarpa Desv. 676

Fr. persist., en têtes compactes glob.; limbe du cal. évasé, en cloche, en coupe régul., membran. plus large que le fr., divisé jusqu'au milieu en 6 dents triang. aristées, presque égales, crochues au sommet; bract. ovales, larg. scarieuses; fr. vel. offrant à la face ventrale une dépression oblongue, bordée d'un bourrelet; loges stériles, plus petites que la fertile et séparées par la dépression; 1. dentées-incisées ou pennatifides; pl. élancée, rameuse-dichotome dans sa partie sup. V. coronata DC. 677 Champs secs, talus. - Jn-Jt.

\section{Famille 22. - DIPSACÉES}

+ Invol. coriace, à fol. épin. ou semblables aux paillettes du réceptacle; cal. en forme de cupule ciliée un peu tétragone; t. munies d'aiguillons . . . . . . . . . . . . . DIPSACUS 238

+ Invol. herb. à fol. ni épin. ni semblables aux paillettes du récept. ; cal. en cupule cil. ou à arètes rayonnantes; t. sans aiguillons.

Récept. hér. de soies, dépourvu de paillettes; calicule un peu stipité, comprimé subtétragone, non sillonné; cal. couronné par 8 arêtes dress................... KNAUTIA 239

Récept. garni de paillettes; calicule sessile cyl. creusé de sillons profonds; cal. couronné par ร̋ arètes sét. étalées en étoile.

\section{Genre 238. - DIPSAGUS L.}

SCABIOSA 240

+ Fl. blanchâtres, en têtes glob. petites, 2 cm., d'abord penchées, puis dress.; f. ovales ou oblongues-acum., dentées, toutes pétiolées, munies à la base du limbe de 2 segments inégaux; fol. de l'involucre étalées réfléchies, lanc. lin., spinescentes, hér. de longs poils étalés, plus courtes que la tête florale; paillettes du récept. dr., spinescentes, hér. de long. soies étalées, égalant presque les fleurs.

D. pilosus L. 678

Lieux frais et ombragés; bords des ruisseaux. - Jn-Sept.

+ Fl. rosées en têtes ovales ou ovales-cylindracées, grosses, long. de 4-8 cm., larges de 3-4 cm.; f. caul. connées.

Inv. à fol. plus courtes que la long. de la tête florale, lanc.-lin., étalées; paillettes du récept. égalant presque lesfl., pub. scabres, brusq. term. en pointe courbée en dehors. D. fullonum Mill. 679 Quelquefois cult. en grand pour le cardage des laines. - Jn-At.

Invol. à fol. arquées-ascendantes, dépassant long. la tête florale, lin. en alène, épine; paillettes du récept. aristées plus long. que les fl., pub., brusq. term. en pointe épin. D. silvestris Mill. 680 Lieux incultes, fossés. - Jt-Sept.

\section{Genre 239. - KNAUTIA Coult.}

Pl. velue; f. inf. ent. dentées ou pennatifides, à lobes lanc.-lin., aig. les moyennes ord. pennatiséquées ; fl. roses ou lilas, les ext. rayonnantes, en têtes hémisph.; invol. à fol. lanc. plus courtes que les fleurs.............. K. arvensis Koch. 681 Ch. prés, coteaax. - Jn-At. 


\section{GeNRE 240. - SCABIOSA L.}

+ Calicule tr. vel., à limbe herb., divisé en 4 lobes dress., ovales-aig.; fl. toutes semblables, non rayonnantes à 4 lobes égaux; fol. de l'invol. imbriquées sur 2-3 rangs; f. toutes ent. ou dentées, ovales ou oblongues, les sup. lanc.; têtes fructif. glob.; arêtes calicinales noirâtres . . . . . . S. succisa L. 682 Bois et prés hum. - Jt-0ct.

+ Calicule à limbe scarieux, ondulé ou crén. ; fl. ext. plus gr., rayonnantes, toutes à כ̆ lobes inég.; fol. de l'invol. sur 1-2 rangs.

X Calicule à tube arrondi, vel. et non sillonné dans sa moitié inf., gl. et creusé de 8 fossettes au sommet, surmonté d'une couronne blanchâtre plus courte que le tube; arêtes calicinales, roussâtres, 2-3 fois plus longues que la couronne; fl. d'un blanc jaunâtre ou bleuâtre, rayonnantes; f. rad. ent., les caul. pennatiséquées à segments ent. . . . . . S. ucranica L. 683

Lieux sabl. arides, nat. - At-Sept.

$X$ Calicule à tube parcouru dans toute sa long. par 8 sillons, vel. ou pub. ; fl. d'un bleu clair.

Arêtes calicinales blanchàtres, courtes, 1 fois plus longues que la couronne; têtes fructif. ovoïdes, petites, $5-10 \mathrm{~mm}$; f. rad. oblongues ou lanc., tr. ent., les caul. pennatiséquées, à segments ent. . . . . . . . . . . S. suaveolens Desf. 684 Lieux sabl. secs. - At-Sept.

Arètes calicinales noiràtres, 3-4 fois plus long. que la couronne; tètes fructif. ovoïdes-subglob., assez gr., $10-20 \mathrm{~mm}$.; f. rad. crén. ou incisées-lyrées, les caul. pennatiséquées, à segments ord. pennatifides ou incisés ...... S. columbaria L. 685 Prés et coteaux secs. - Jn-0ct.

On cultive quelquefois $S$. atropurpurea L. F. rad. obovales ou spathulées, atténuées en pétiole, dentées ou incisées, les caul. pennatiséquées à lobes ent. ou dentés; têtes fructif. ovoïdes; calicule à limbe scarieux, court, ondulé, à tube creusé de 8 sillons; fl. d'un pourpre foncé en têtes planes.

\section{FAMille 33 . - COMPOSÉES}

Tableau des sous-familles :

Cap. offrant au centre des fl. hermaphrodites, tubul., régul., et à la circonférence des fl. femelles ou stériles, ligulées, ord. rayonnantes, rar. tubul.; style non renfl. ni articulé au-dessous des branches.

CORYMBIFĖRES I

Cap. à fl. toutes tubul., hermaphrodites, rar. stériles ou unisexuées; style renfl. en noud au-dessous des branches.

GINAROCÉPHALES II

Cap. à fl. toutes ligulées, hermaphrodites, les ext. ord. rayonnantes; style non renflé .......... LIGULIFLORES III

\section{Sous-Famille I. - CORYMBIFĖRES (Radiées)}

+ Récept. dépourvu d'écailles (paillettes) ou offrant rar. quelques écailles à la circonférence.

X F. opp. à 3-5 segments, dentés, rar. simples; cap. cyl. oblongs pauciflores; fl. toutes tubul.; cap. purpurins en corymbes.

EUPATORIUM 241

X F. alt. ou rad., quelquefois opp. mais alors ent.; fl. ligulées ou tubul.

= Achaines tous ou la plupart pourvus d'une aigrette de soies capill.

a Anth. dépourvues d'append. basilaires.

- F. toutes rad., les caul. réduites à des écailles foliacées. 
Cap. rougeâtres, en grappes portés par une t. chargée d'écailles foliacées, larges, demi embrass. et paraissant avant ou avec les f. ; fl. toutes tubul.; pl. presque diö̈que.

PETASITES 242

Cap. solit., jaune, porté par une t. chargée d'écailles et paraissant avant les f.; fl. de la circonférence ligulées.

TUSSILAGO 243

- F. caul. bien développées.

o. Invol. à fol. imbriq. sur plus. rangs.

$\curvearrowright$ Feuilles alt.

† Cap. petits, $2 \mathrm{~cm}$. au plus, fl. jaunes, blanches ou bleues.

$\odot$ Fl. jaunes.

Fl. ligulées ; cap. en grappes unilat. ou en pan.; f. ovales oblongues ou lanc., dentées; achaines cylindriques sans côtes; aigrette à poils unisériés . . . SOLIDAG0 244

Fl. tubul. ; cap. en corymbes; f. lin., ent.; achaines oblongs, sans côtes vel. soyeux; aigrette à poils bisériés.

LINOSYRIS 245

- Fl. blanches, roses, violacées ou bleues.

Récept. à peine alvéolé, soies sur 1 rang; fl. blanches ou rose violacé; cap. en pan. ou en corymbe; achaines oblongs, compr., sans côtes . . . . ERIGERON 246

Récept. tuberc. ou fort. alvéolé; soies sur 2 rangs; cap. en corymbe.

Récept. hémisplı., fin. tuberc. ; aigrettes de 2 sortes, celles des achaines de la circonférence à soies courtes unisériées, celles des achaines du centre à soies disposées sur 2 rangs, les ext. tr. courtes; ligules blanches.

STENAGTIS 247

Récept. plan, alvéolé, à alvéoles pourvues d'un rebord denté; aigrette à poils simples disposés sur plus. rangs ; ligules bleues. . . . . . . . . . ASTER 248

ち Cap. gr., ร̌ cm., term., solit. ou peu nombr.; fl. jaunes; souche à rhizômes à extrémité charnue.

DORONIGUM 249

F. caul. opp.; les rad. étalées en rosette; achaines à côtes faibles, couronnés d'une aigrette de poils disposés sur un seul rang; fl. gr., jaune orangé. . . . . . ARNICA 250

活 Invol. à fol. disposées sur un seul rang, muni à sa base d'un calicule à fol. courtes; achaines presque cyl. pourvus de côtes et couronnés d'une aigrette de soies capill. disposées sur plus. rangs; fl. ligulées jaunes. . . . . SENECIO 251 a Anth. pourvues d'append. basilaires.

Pl. vertes, plus ou moins pub., jamais tomenteuses.

Achaines surmontés d'une aigrette simple à soies disposées sur un seul rang et dépourvus de couronne. . . . INULA 252

Achaines surmontés d'une couronne dentée ou laciniée qui entoure la base de l'aigrette. . . . . . PULICARIA 253

Pl. ent. tomenteuses, blanchâtres ou jaunâtres.

‡ Récept. ent. nu, dépourvu d'écailles à la circonférence; involucre non conique, ni anguleux.

Fol. de l'invol. étalées en étoile à la maturité.

GNAPHALIUM 254

Fol. de l'invol. dressées, non étalées en étoile à la maturité; pl. diö̈ques. . . . . . . . . ANTENNARIA 255

ๆ Récept. muni à la circonférence d'écailles entremèlées aux fl. femelles; invol. ovoïde conique, anguleux.

Achaines tous libres. . . . . . . . FILAG0 
Achaines extérieurs renfermés dans les fol. de l'invol. soudées inf. par la base .......... LOGFIA 257 $=$ Achaines dépourvus d'aigrette de soies capill.

Toutes les fl. tubul.

F F. ent.; pl. tom. blanchâtre; fol. int. de l'invol. pliées en forme de capuchon et retenant les achaines . . MICROPUS 258

先 F. pennatipartites ou pennatiséquées.

Achaines pourvus de côtes longit. et term. par un disque égalant leur sommet, surmonté d'un rebord membr.

TANAGETUM 259

Achaines dépourvus de côtes, term. par un disque plus étroit que leur sommet privé de rebord membr. ARTEMISIA 260

Fl. du centre seules tubul., celles de la circonférence ligulées, rayonnantes.

I Achaines tr. irrégul., rostrés et arqués ou courbés en anneau, les ext. armés de pointes sur le dos; ligules jaunes; ann.

GALENDULA 261

| Achaines tous conformes et régul. jamais épin. ni falciformes.

|| Achaines fortement comprimés, dépourvus de côtes, entourés d'une bordure saillante obtuse. . . . . . BELLIS 262

II Achaines subtétragones ou subcyl. non ou faibl. compr., pourvus de côtes ou de stries.

to Récept. plan ou convexe non conique.

Ligules jaunes . . . . . . CHRYSANTHEMUM 263 Ligules blanches. . . . . LEUGANTHEMUM 264

to Récept. allongé, conique à la maturité; ligules blanches.

MATRIGARIA 265

+ Récept. garni d'écailles, paillettes; achaines dépourvus d'aigrette de soies capill., mais parfois surmontés de quelques arètes épin.

$X$ Invol. à fol. imbriq. non foliacées; ligules blanches.

Récept. oblong-conique; achaines subcyl. ou lég. tétragones, munis de côtes; ligules à limbe oblong ou elliptique.

ANTHEMIS 266

Récept. plan ou un peu convexe; achaines compr. oblongs, marginés, dépourvus de côtes; ligules à limbe suborb. . ACHILLEA 267

$\times$ Invol. à fol. imbriq., les ext. foliacées; fl. tubul. ou ligulées, jaunes,

Achaines compr., oblongs cunéiformes, élargis et tronqués au sommet, surmontés de 2-3̆ arêtes sub., épin.; fl. tubul., rar. ligulées; f. simples ou tripartites à segments lanc. dentés.

BIDENS 268

Achaines subtétragones, un peu compr. surmontés par 2-4 écailles cad.; ligules jaunes; cap. de plus de $4 \mathrm{~cm}$.; f. ovales cordées

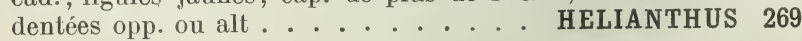

\section{GenRe 241. - EUPATORIUM Tourn.}

Pl. viv. à t. dress., simple ou rameuse, pub.; invol. à fol. int. scarieuses, oblongues-lin., obtuses, les ext. ovales.

Lieux hum., hord des eaux. - Jt-At.

E. cannabinum L. 686

\section{Genre 242. - PETASITES Tourn.}

Cor. des fl. femelles brièv. ligulée; f. paraissant en même temps que les fl., vertes sur les 2 faces, gl. en dessus, un peu pubescentes en dessous, à limbe orb. bordé de dents fines et régulières, profond. cordé; cap. d'un violet clair en grappe courte et lâche; invol. à fol. int., lanc., aig., foliacées . . . . . . . P. fragrans Presl. 687 Nat. - Janv.-Mars. 
Toutes les fl. tubul.; f., se développant après les fl., tr. amples, pub., grisâtres en dessous, à limbe réniforme ou suborb., inég. denté, profond. cordé; cap. à fl. rougeâtres en grappe serrée, oblongue; invol. ‘̀ fol. int. oblongues, scarieuses et violettes sur les bords.

Prairies hum., lieux maréc. - Mars-Avr.

\section{Genre 243. - TUSSILAGO Tourn.}

Pl. viv., à tige cotonneuse, pourvue d'écailles ovales-lanc., obtuses, demi-embrass.; f. toutes rad., vertes en dessus, blanches ou grisâtrestom. en dessous, à limbe suborb., sinué denté, cordé; cap. penché après la flor. . . . . T. Farfara L. 689 Lieux incultes un peu humides des terrains argileux. - Mars- $\Lambda$ vr.

\section{GenRe 244. - SOLIDAGO L.}

+ Cap. médiocres, en grappes feuillées formant une pan. oblongue, à rameaux dressés, rapprochés de la t.; f. dentées penninervées, les rad. ovales ou ovales-lanc., atténuées en pétiole, les sup. lanc. quelquefois ent., rétrécies aux 2 extrémités; ligules gr. $6 \mathrm{~mm}$.; oblongues-lin. . . . . . . . . S. Virga-aurea L. 690

Bois des terrains sil. - Jt-Sept.

+ Cap. tr. petits en grappes unilat. étalées et arquées, formant une pan. pyramidale; f. lanc., aeum., dentées ou ent. à 3 nervures; ligules petites $1-2 \mathrm{~mm}$.

T. gl., quelquefois glauque; f. gl. rudes aux bords, acum., rétrécies à la base; ligules 7-15 assez petites; achaines fin. pub.

S. glabra Desf. 691

Bords des rivières, originaire de l'Amérique septentrionale, nat. çì et là, - Jt-Sept.

T. hér., pub. ou pubérulente; f. pub., aig. tr. rétrécies à la base, les sup. plus petites, ent.; ligules $9-1 \%$, petites; achaines gl. ou quelquefois pub......... . . . canadensis L. 692

Originaire de l'Amérique septentrionale, assez fréquemment nat. Jt-Sept.

\section{GENRE 243. - LINOSYRIS DG.}

Pl. viv., gl.; t. simple, dress., grèle; f. étr. lin., aig., tr. nombr.; invol. à fol. làches, les int. oblongues, les ext. lin.-aig.

Bois et coteaux calc. - At-0ct.

\section{GeNRE 246. - ERIGERON L.}

Cap. tr. petits, 3-5 mm., tr. nombr., en longue pan. presque pyramidale; fl. ext. d'un blanc sale; pl. ann., dress., rameuse pub.-hispide, tr. feuillée; f. pub., étr. lanc. ou lin., aig., ent. ou lâchement dentées.

E. canadensis L. 694

Lieux incultes, originaire de l'Amérique du Nord. - Jt-Oct.

Cap. médiocres, $1 \mathrm{~cm}$., solit. ou en corymbe peu fourni; fl. ligulées d'un rose violet ou bleuâtre; pl. bisann., dress., rameuse, pub., rar. gl.; f. pub., rar. gl., lanc.-lin., sessiles, ent. . . . . E. acris L. 695 Lieux incultes, pierreux ou sabl. - Jn-Sept.

\section{Genre 247. - STENACTIS Nees.}

Pl. bisann. de $30 \mathrm{~cm}$. à $1 \mathrm{~m}$., à t. dress., rameuse au sommet, glabrescente; f. rad. long. pétiolées, presque gl., obtuses, à limbe obovale pourvu de dents obtuses, écartées; cap. en grappes corymbiformes.

S. annua Nees 696

Talus herbeux, ch., originaire de l'Amérique septentrionale. - Jt- $\mathbf{A t}$. 


\section{Genre 248. - ASTER L}

Pl. viv. de $150-50 \mathrm{~cm}$., à t. dress., simple ou rameuse au sommet, brièv. pub.; f. pub., rudes sur les 2 faces, ent., les inf. ovales-oblongues atténuées en pétiole, les suivantes sessiles, oblongues-lanc., aig.; invol. à fol. vel., les ext. tr. obtuses à sommet recourbé en dehors; cap., 2-6, en corymbe court ou solit. . . . . A. amellus L. 697 Bois calc. - At-Sept.

On rencontre quelquefois, échappé des jardins plus. espèces américaines à t. presque gl., élevées, ì fl. ligulées blanches, lilas ou violettes; A. Novi Belgii, cap. nombr. formant une pan., f. lanc., dentées, demi embrass., fl. ligulées violettes: A. salignus Willd., cap. petits en pan., f. étr., lin. ent., fl. ligulées blanches ou lilas.

\section{GeNre 249. - DORONIGUM Tourn.}

F. rad. et caul. inf. tr. profond. cordées, les moyennes brusq. contractées, larg. embrass.; t. pub., feuillée, rameuse sup. à 3-8 cap., rar. simple monocéphale; récept. vel. . . . . . D. cordatum Lamk 698 Bois, probablement naturalisé. - Mai-Jt.

F. rad. à limbe ovale, atténué, un peu' décurrent sur le pétiole, non cordées; f. caul. demi embrass.; t. simple, monocéphale ou bifurquée, presque gl., pub.-gland. au sommet, peu feuillée ; récept. gl. ou fin. pub. . . . . . . . . . D. plantagineum L. 699 Bois. - Avr.-Nai.

Doronicum emarginatum Le Grand (D. Willdenowii Rouy) est quelquefois adventice et diffère de $D$. plantagineum par ses $f$. rad. à limbe un peu échancré ou faibl. cordé ì la base, ses f. caul. embrass.

\section{GeNRE 2\%0. - ARNICA L.}

Pl. viv. à t. dress., simple ou peu rameuse, brièv. pub. gland.; f. ovales ou oblongues-lanc., ent. ou très obscur. dentées, sessiles, les caul. opp.; cap. gr., solit. ou 3-4 terminant les rameaux opp. A. montana L. 700 Pâturages, landes. - Jn-Jt.

\section{Genre 2ö1. - SENEGIO Tourn.}

+ F. plus ou moins profond. découpées.

$X$ Fl. de la circonférence ligulées à ligule tr. courte ord. roulée en dehors ou fl. toutes tubul.; pl. ann. à f. pennatifides ou pennatipartites; invol. cyl.

$=$ Fl. toutes tubul.; invol. petit, 7-9 mm. de long, gl. à fol. tachées de noir au sommet, muni d'un calicule de 8-10 très petites fol.; achaines pub. ........... . . . vulgaris L. 701 Lieux cult. presque toute l'année.

$=$ Fl. de la circonférence ligulées à ligule tr. courte et roulée en dehors.

Calicule à fol. dépassant le tiers de la long. de l'invol.; achaines gl. ; invol. médiocre, 10-12 mm. de long; pl. vel., visq.

S. viscosus L. 702

Bois sabl. - Jt-Sept.

Calicule à fol. tr. courtes; achaines pub., invol. petit, 7-9 mm. de long; pl. brièv. pub., un peu gland. . S. silvaticus L. 703 Bois sabl., bruyères. - Jn-Sept.

× Fl. de la circonférence ligulées, à ligules étalées, rayonnantes; invol. campanulé ou hémisph.; pl. bisann. ou viv.

Q F. gl., bitripennatiséquées, subdivisées en lan. lin. presque filiformes, les inf. pétiolées, les sup. sessiles; invol. ovoïde, à fol. lanc. lin. épaissies en côtes, courbées en gouttière; cap. assez petits en corymbe compact ombelliforme; achaines gl.

S. adonidifolius Lois. 704

Bois, coteaux sil. - Jt-At. 
Q F. non découpées en lan. filiformes, lyrées, pennatiséquées ou pennatipartites à segments profonds, les sup. embrass. ord. la $t$. par 2 oreillettes.

- Souche ramp. ; fol. du calicule nombr. égalant environ la moitié de la long. de l'invol.; achaines tous pub. ; f. d'un vert sombre, gl. en dessus, pub. ou cotonneuses-grisâtres en dessous.

Lieux incultes. - Jt-Sept.

S. erucifolius L. 705

e courte, tronquée, fol. du calicule tr. courtes ou presque nulles; achaines de la circonférence gl., ceux du centre pub.

F. pennatipartites, toutes divisées jusque vers leur sommet en segments oblongs presque égaux; cap. en corymbe ombelliforme. . . . . . . . . . S. Jacobaea L. 706 Prairies, pàturages. - Jn-At.

Varie à fl. toutes tubul. (S. flosculosus Jord.) Béthisy (Oise).

F. lyrées, les moyennes et les inf. à segment terminal tr. ample bien plus grand que les autres, à lobes lat. des f. caul. obliques; cap. en corymbes lâches, à rameaux étalés-dress.

Prairies hum. - Jn-At.

S. aquaticus Huds. 707

Var. à lobes lat. des f. caul. étalés à angl. dr., à rameaux du corymbe étalés, divariqués ( $S$. barbareifolius Krock).

+ F. indivises, dentées, crén. ou ent., cap. en corymbes.

Invol. muni à sa base d'un calicule tr. apparent; f. ovales ou lanc., dentées; achaines gl.

Fl. ligulées peu nombr., 3-כ̆; invol. gl. subcyl., 2 fois plus long que large, à 8-10 fol. oblongues-lin. à pointe obtuse; f. pétiolées ovales ou lanc., vertes, gl. ou un peu pub. en dessous, fin et régul. dentées, à dents étalées, cartilagineuses. S. Fuchsii Gmel. 708

Bois, fossés. - Jt-At.

Fl. ligulées assez nombr., 10-16; invol. hémisp. à 18-20 fol. lin. aig. vel. au sommet; f. sessiles, gl. en dessus, pub.-grisâtres en dessous, fin. dentées, à dents égales, courbées et dirigées en haut.

Marais, bords des eaux. - Jn-At.

S. paludosus L. 709

* Invol. absolument dépourvu de calicule; achaines hispides; pl. laineuse; f. blanches-tom. en dessous, blanchâtres ou vertes et aranéeuses en dessus; les inf. à limbe ovale, spathulé, tronqué ou subcordé à la base, ent. ou faibl. crén., invol. laineux ou tom.

Taillis humides, prés tourb - Mai-Jn.

S. lanceolatus Puel 710

On a trouvé autrefois dans le marais de Bretel près Saint-Germer (0ise) $S$. palustris qui diffère de $S$. lanceolatus par achaines gl., feuilles tr. long., lin. ou lin. lanc. ondulées ou sinuées-dentées, un peu poilues, ses cap. en corymbe composé, sa t. épaisse, pl. ann. ou bisann.

\section{Genre 202. - INULA L.}

+ Invol. à fol. int. oblongues, obtuses, les ext. larg. ovales, tom.; achaines subtétragones, gl., blonds, tronqués au sommet à côtes peu marquées; pl. viv. robuste, pub., rameuse au sommet; f. inf. grandes, elliptiques-oblongues, dentées, blanchâtres tom. en dessous, les sup. ovales-lancéolées, sessiles, embrassantes; ligules long., rayonnantes. . . . . . . . . I. Helenium L. 711 Prés humides, bois, haies. - Jt-At.

+ Invol. à fol. aig., les ext. lanc.; achaines cyl.

X Achaines pourvus de côtes, tronqués ou atténués au sommet; soies de l'aigrette non insérées sur une cupule; pl. viv.

= Fl. de la circonférence ligulées, rayonnantes, dépassant long. l’invol. 
F. pub. ou vel. soyeuses.

Cap. en corymbes, rar. solit.; f. molles, lanc., vel., soyeuses, les caul. demi-embrass.; achaines vel.; invol. à fol. molles lin. vel. soyeuses; ligules gland. . . . I. britannica L. 712 Prés hum., bords des eaux. - Jt-Sept.

Cap. ord. solit.; f. coriaces, vel. hér., les caul. sessiles; achaines gl.; invol. à fol. dress., raides, lanc.-lin., à longs cils raides; ligules ni poilues ni glanduleuses.. . . . I. hirta L. 713 Coteaux calc. - Jn-Jt.

F. gl. ou presque gl., coriaces, oblongues-lanc., les caul. sessiles, demi-embrass.; cap. solit. ou 2-3 au sommet des rameaux; achaines gl.; invol. à fol. raides, lanc. cil. les ext. recourbés au sommet. ... . . I. salicina L. 714

Prés hum., coteaux herbeux. - Jt-At.

= Fl. jaunatres ou rougeàtres toutes tubul. ou les ext. à peine ligulées, non rayonnantes, ne dépassant pas l'invol. vel. à fol. int. dress. lin. aig., scarieuses et rougeâtres au sommet beaucoup plus longues que les ext. très courtes, lanc. aig., recourbées au sommet; f. oblongues ou lanc., ent. ou dentic, tom. en dessous, fin. pub. en dessus, les caul. sessiles; achaines hispides.

Lieux secs et incultes. - Jt-Sept.

I. Conyza DC. 715

Achaines dépourvus de côtes, contractés en col au sommet élargi en forme de cupule, sur laquelle sont insérées les soies de l'aigrette; pl. ann. pub.-gland.; t. tr. rameuse; f. lin. sessiles, ent. ou obscur. dentic. ; cap. petits, tr. nombr., en long. pan. pyramidale; fl. jaunes ne dépassant pas l'invol., les ext. non rayonnantes souvent violacées. … I. graveolens Desf. 716 Lieux incultes sabl. un peu hum. - At-0ct.

\section{Genre 253. - PUliGaria Gærtn.}

Fl. de la circonférence rayonnantes, à ligules dépassant long. l'invol.; pl. viv. à t. dress., pub. laineuses ou tomenteuses; f. caul. fort. embrass. et auriculées. . . . . P. dysenterica Giertn. 717 Fossés, lieux hum. - Jt-Sept.

Fl. de la circonférence à ligule dress., dépassant à peine l'invol.; pl. ann. à tiges dress. ou ascend., pub. ou presque gl.; f. caul. sessiles, arrondies à la base, demi-embrass., non auriculées.

P. vulgaris Grertn. 718

Lieux inondés l'hiver, fossés. - Jt-Sept.

\section{GENRE 2\%4. - GNAPHALIUM L.}

+ Cap. serrés en glom. arrondis, disposés en corymbes; aigrette à poils unisériés, libres, non soudés.

Cap. en glom. non feuillés; f. sessiles, demi-èmbrass., oblongues, arrondies et obtuses au sommet; achaines brun rougeâtre; invol. à fol. luisantes, d'un blanc nacré, les ext. lanc. presque gl.

G. Iuteo-album L. 719

Lieux hum., bord des mares. - Jt-Sept.

Cap. en glom. feuillés jusqu'au sommet; f. sessiles, lanc.-lin., atténuées à la base, aig. au sommet; achaines fauves, muriqués ou lisses; invol. brun ou jaunâtre à fol. ext. vel.

Lieux hum. - Jt-0ct.

G. uliginosum L. 720

+ Cap. nombr. en grappe ou pan. spiciforme étr., réunis en fasc. peu fournis à l'aisselle des $\mathrm{f}$. ; aigrette à poils unisériés soudés en anneau à la base; f. lanc-lin.; invol. à fol. scarieuses, bordées de brun; achaines brun rougeàtre. . . . . G. silvaticum L. 721 Bois des terrains sil. - Jt-Sept. 


\section{GENRE 20̌ว. - ANTENNARIA R. Br.}

Pl. viv. émettant des rejets couchés avec des rosettes de f.; t. dress., coton. term. par un petit corymbe serré de 3-8 cap. ; f. blanches tom. en dessous, vertes en dessus, les inf. obovales-spathulées, les caul. lin.-lanc.; invol. à fol. obovales blanches dans les cap. mâles, oblongues, roses dans les cap. femelles; achaines gl.

Pâturages, bruyères. - Mai-Jn.

\section{A. dioica Girtn. 722}

\section{Genre 256. - FILAG0 Tourn.}

+ Invol. à fol. cuspidées ne s'étalant pas en étoile à la maturité; capi tules nombr. dans chaque glomérule.

X Glom. munis à la base de $3-5$ f. qui les dépassent long.; cap. à כ angles aigus très saillants; pl. rameuse dès la base.

$$
\text { Ch. - Jt-Sept. }
$$

F. spathulata Presl. 723

X Glom. dépourvus de f. florales à la base; cap. à 5 angles peu marquées; pl. rameuse au sommet.

Pl. blanche-tom.; f. lin. aig. ; fol. de l'invol. à pointe jaunâtre.

$$
\text { Ch. sabl. - Jt-Sept. }
$$

F. canescens Jord. 724

Pl. jaunâtre-tom.; f. élargies, obtuses ou subspathulées; fol. de l'invol. à pointe purp. . . . F. apiculata G.-E. Smith. 725 Gh. sabl. - Jt-Sept.

+ Invol. à fol. non cuspidées, s'étalant en étoile à la maturité; glomérules petits ne renf. que $2-7$ capitules.

Invol. à angles peu marqués, à fol. extérieures tom. jusqu'au sommet, les int. scarieuses; glom. plongés dans un tom. épais, munis de f. bract. dépassant ou non les fl. et formant une longue pan.

F. arvensis L. 726

Lieux sabl., ch. - Jt-At.

Invol. à 5 angles tr. prononcés, à fol. ext. carénées, vel. sur le dos, scarieuses, gl. et obtuses au somm.; glom. tr. petits. lat. et term., dépassant les f. bract. ....... F. minima Fr. 727 Lieux sabl, bruyères. - Jt-Sept.

\section{Genre 237. - LOGFIA Cass.}

Pl. ann., blanche ou verdâtre, à tige dressée, rameuse souvent dès la base; f. lin. tr. aig. ; invol à fol. obtuses, vel. sur le dos, scarieuses et gl. au sommet; cap. tr. petits, à 5 angles saillants et obtus, réunis par 2-7 en petits glom. lat. et term., à f. invol. lin. sub. dépassant long. les fl. . . . . . . . L. gallica Coss. et G. 728

Ch. sabl. un peu hum. - Jt-Sept.

\section{GENRE 2马8. - MICROPUS L.}

Pl. ann. couverte d'un tom. blanc., dress., simple ou rameuse; f. olslongues-spathulées dress.-étalées; invol. laineux-tom., à 5-7 angles obtus; glom. médiocres, subglob., lat. et term. à f. bract. aussi longues qu'eux et plus long. ............ M. erectus L. 729 Ch. pierreux des coteaux calc. - Jn-At.

\section{Genke 299. - TANAGETUM Tourn.}

Pl. viv. dr., gl., rameuse sup.; f. pennatiséquées, à rachis ailé denté sup.; segments pennatifides; invol. à fol. coriaces, obtuses; fl. jaunes.

Lieux incultes, berges des rivières. - Jt-Sept. 


\section{GeNRe 260. - ARTEMISIA Tourn.}

+ F. caul. soit ent., soit pennatipartites à segments lanc.; récept. gl.

$X$ Souche non ou à peine ramp.; pl. rameuse dès la partie inf.

F. pennatipartites ou bipennatipartites, auriculées à la base, blanches-tom. en dessous; cap. ovoïdes-oblongs; pl. peu odor.

Lieux incultes. - Jt-Sept.

A. vulgaris 731

F. ent., lanc-lin., vertes, odor., et à saveur âcre; cap. hémisph.; pl. tr. odor. ......... A. Dracunculus L. 732 Cult. (Estragon). - At-Sept.

Souche long. traçante produisant un grand nombre de $t$. raides, dr., nues dans la partie inf., les stériles nombr. et simples, peu élevées, les florifères élevées plus ou moins rameuses dans la partie sup.; f. caul. à segments allongés presque égaux; cap. ovoïdes-oblongs, solit., à fleurs rougeâtres disposés en grappes presque unilat.; pl. à odeur forte (A. Verlotorum Lam.).

Décombres, bords des chemins, pl. nat.

A. selengensis Turcz. 733

+ F. caul. bipennatiséquées à segments tr. étr., lin., mucronulés ; invol. gl. et luisant; cap. ovoïdes formant une gr. pan. feuilletée à f. lin., ent.; récept. gl. . . . . . . A. campestris L. 734 Coteaux secs, lieux sabl. sil. - At-Sept.

A. Absinthium L. (absinthe) est quelquefois subsp. Pl. blanchàtre; f. caul. bipennatiséquées ; cap. penchés en pan. feuillée à rameaux dress.; récept. poilu ; pl. tr. odor.

\section{Genre 261. - Galendula L.}

F. oblongues-lanc., les inf. atténuées en pétiole; cap. assez gr. à fl. jaune pâle; ligules de $10-13 \mathrm{~mm}$. égalant au plus le double de l'invol., achaines de deux sortes, les ext. arqués, épin. sur le dos, à long bec droit, les int. roulés en anneau, lisses ou épin., brièv. apiculés.

Lieux cult., vignes. - Av.-0ct.

G. arvensis L. 735

F. oblongues-spathulées, les inf. long. atténuées en pétiole; cap. gr. à fl. jaune doré ou safrané; ligules de $20-30 \mathrm{~mm}$, 2 ou 3 fois plus long. que l'invol.; achaines ord. tous conformes, roulés en anneaux, brièv. apiculés. . . . . . . . . C. officinalis L. 736 Cult. (Souci). - Jt-Sept.

\section{Genre 262. - BELLiS Tourn.}

Viv.; t. scapiforme, nue, pub.; f. toutes rad., en rosette, à limbe obovale-spathulé, uninervé, superf. crén., nett. pétiolées; invol. pub. à fol. lanc.; achaines vel., marginés; cap. sol.; ligules blanches ou purp. une fois plus long. que l'invol. . . . . B. perennis L. 737 Pelouses, prés. - Mars-Nov.

\section{GENRE 263. - GHRYSANTHEMUM Tourn.}

Pl. ann., gl. et glauque, dress., rameuse; f. inf. pennatifides, rétrécies en pétiole, les suivantes oblongues multifides ou trifides, dentées, les sup. oblongues-lanc., embrass., dentées ou ent.; invol. à fol. int. oblongues, larg. scarieuses au sommet; achaines de la circonf. à 2 ailes lat., ceux du centre cyl.; cap. gr., solit. au sommet épaissi des rameaux. . . . . . . . . G. segetum L. 738 Ch., moiss. un peu hum. - Jn-At. 


\section{Genre 264. - LEUGANTHEMUM Tourn.}

F. lobées ou pennatifides, irrégul. dentées, les inf. obovales ou spathulées, long. pétiolées, les suivantes oblongues, sessiles, demi-embrass. et auriculées; cap. gr., solit. au sommet de la t. et des rameaux; achaines dépourvus de couronne. . . . . . L. vulgare Lamk 739

Prairies, coteaux. - Mai-At.

F. pennatiséquées, à $3-6$ paires de segments pennatifides ou pennati, partits à lobes incisés, les sup. confluents; cap. assez petits, rar. sans ligules, en corymbe feuillé; achaines surmontés d'une couronne courte, étalée-lobulée; pl. aromatique . . L. Parthenium G. G. 740 Lieux incultes, vieux murs (grande Camomille). - Jn-At.

\section{Genre 265. - MATRIGARIA Tourn.}

+ El. ligulées tr. apparentes, blanches.

Récept. conique et aig., creux à l'int.; achaines tr. petits, $1 \mathrm{~mm}$.,

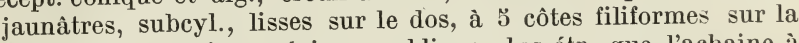
face interne, à disque épigyne oblique plus étr. que l'achaine à rebord très court; f. bipennatiséquées à segments presque filiformes; invol. à fol. int. oblongues obovales larg. scarieuses; ligules $10-20$; pl. aromatique. . . . . M. Chamomilla L. 741 Ch. - Mai-0ct.

Récept. obtus, plein; achaines petits, 1 1/2-2 mm., brun noirâtre, rugueux sur le dos, subtétragones, munies de 3 côtes à la face interne, à disque épigyne non oblique surmonté d'un rebord saillant plus large que l'achaine; i. bipennatiséquées à segments lin., mucronulés; invol. à fol. int. oblongues souvent brunâtres au sommet; ligules $20-30$; pl. inodore. . . . M. inodora L. 742 Ch., lieux incultes. - Mai-0ct.

+ Fl. sans ligules; fol. de l'invol. larg. ovales ou oblongues d'un vert jaunâtre, avec un large bord scarieux blanc; achaines légèr. anguleux, à côtes fines jaunàtres ou légèr. brunâtres à disque épigyne non ou à peine oblique, aussi large ou à peine plus étr. que l'achaine; f. bipennatiséquées à segments lin., mucronulés; pl. odorante .......... . M. discoidea DC. 743

Ch., lieux sablonneux, plante américaine subspontanée. - Mai-Sept.

\section{Genre 266. - ANTHEMIS L.}

+ Fl. du centre (tubul.) prolongées à la base en une sorte de coiffe ou de couronne qui enveloppe le sommet des achaines; ceux-ci à 3 côtes saillantes sur la face interne.

Ligules jaunes à la base, blanches dans la partie sup.; fl. tubul. à coiffe append. d'un côté; écailles du récept. aig., pliées longit., poilues au sommet; f. pennatipartites à segments ent. ou incisés; pl. ann.; achaines mûrs renfermés dans les écailles du récept. soudées par leurs bords. . . . . . . . . A. mixta L. 744 Ch. sabl., bords des rivières. - Jt-Sept.

Ligules ent. blanches; fl. tubul. non append. à la base; écailles du récept., membr., obtuses, souvent lacérées au sommet; f. pennati ou bipennatiséqués à lobes courts; pl. vivace aromatique; achaines mûrs non retenus par les écailles du récept.

A. nobilis L. 745

Pelouses sabl. - Jt-Sept.

+ Fl. du centre non prolongées en coiffe à la base; achaines à 10 côtes; f. bipennatiséquées.

Ecailles du récept. lanc., brusq. cuspidées; achaines lisses surmontés d'un rebord; pl. pub., inodore. . . . . A. arvenșis L. 746 Ch., sables. - Jn-Sept. 
Ecailles du récept. lin., sub.; achaines fort. tuberc. dépourvus de rebord; pl. presque gl., fétide. . . . . . A. Cotula L. 747 Ch. - Jn-Sept.

\section{Genre 267. - AGHILLEA L.}

F. indivises, gl., lin.-lanc., aig., dentées en scie ; cap. assez gros, $15 \mathrm{~mm}$., long. pédic. en corymbe lâche; invol. hémisph., vel., ligule blanche.

Prés hum., fossés. - Jt-Sept.

A. Ptarmica L. 748

F. tr. profond. découpées, pub., bipennatiséquées à segments lin. non disposés dans un mème plan; cap. petits, 2-3 mm., en corymbe compact; invol. ovoïde, poilu; ligules blanches ou purpurines.

Prés, coteaux. - Jn-0ct.

A. Millefolium L. 749

\section{Genre 268. - BIDENS Tourn.}

+ Cap. penchés; f. oblongues-lanc., sessiles, un peu soudées par leur base, simples, dentées profond.; achaines oblongs-cunéiformes, 5-6 mm., atténués à la base surmontés de 4-3 arêtes sub.; fl. de la circonférence rar. ligulées (var. radiatus Bor.); invol. à fol. herb.

Bords des eaux, fossés. - At-0ct.

B. cernuus L. 750

+ Cap. dress.; achaines à 2-3 arêtes; f. à 3-3 segments, rar. indivises; invol. à fol. ext. foliacées.

T. ord. rougeâtre à rameaux étalés, achaines assez gr., "3-6 mm., oblongs, à base large, surmontés de $2-3$ arêtes.

Lieux humides, fossés. - At-0ct.

B. tripartitus L. 751

T. ord. jaunâtre, assez épaisse, à rameanx dressés-fastigiés; achaines petits, $2-4 \mathrm{~mm}$., oblongs triang., à base étroite, surmontés de 2 arêtes; cap. assez gros, $2 \mathrm{~cm}$. de diamètre, en corymbe fastigié. . . . . . B. radiatus Thuill. 752 Bords des étangs. - Sept-0ct.

\section{Genre 269. - helianthus L.}

+ Cap. tr. gros, penchés, solit. ou 2-3 sur des rameaux, ord. plus petits que le term.; invol. tr. large; récept. tr. épais, charnu spongieux; bract. ovales-acum., cil.-hispides; f. gr., rudes, dentées, les inf. ovales cordées, les sup. ovales; ligules tr. nombr., 30-50 et audessus; pl. ann., robuste. ....... H. annuus L. 753 Cult. (Soleil). - Jt-Sept.

+ Cap. médiocres, dress., assez nombr., f. ovales-lanc., les inf. un peu cordées; invol. hémisph.; ligules peu nombr., 12-25; pl. vivace.

Fol. de l'invol. lanc.-acum., hér. ou cil., squarreuses; ligules peu nombr., 12-18; f. ovales ou ovales-oblongues, acum., fin. pub. en dessous; souche donnant naissance à des tuberc. charnus; cap. peu nombreux. . . . . . H. tuberosus L. 754

Cult. (Topinambour). - Sept.-Oct.

Fol. de l'invol. oblongues-lanc., dress.-imbriq. sur 2-3 rangs, cil., quelquefois gl. ; ligules assez nombr., 130-25; f. ovales-lanc., rudes, long. acum.; souche dépourvue de tuberc. charnus; cap. assez nombr. . . . . . . H. laetiflorus Pers. 755 Cult. - Sept.-Oct. 


\section{CINAROCÉPHALES (Flosculeuses)}

+ Achaines à aigrette caduque se détachant plus ou moins rapid. en une seule pièce, à soies réunies à la base en anneau.

X Et. à filets compl. soudés en tube; aigrette à soies dentic.; achaines oblongs compr.. dépourvus de côtes; récept. à écailles sub.

SILYBUM 270

$X$ Et. à filets ent. libres.

= Récept. dépourvu de soies, profond. alvéolé; achaines compr., subtétragones, striés transvers. . . . ONOPORDUM 271

$=$ Récept. hérissé.

$\sigma^{1}$ Aigrette de l'achaine à soies long. plum.

- Invol. à fol. charnues à la base; fl. bleues en tr. gros cap.; anth. à append. term. tr. obtus . . . GINARA 272

- Invol. à fol. non charnues; fl. jamais bleues.

Achaines vel.; soies du récept. laciniées; invol. à fol. int. scarieuses, colorées, rayonnantes ayant l'aspect de fl. ligulées; soies de l'aigrette sur un seul rang, soudées par faisc.

GARLINA 273

Achaines gl., lisses; soies du récept. filiformes, ent.; soies de l'aigrette sur plus. rangs, soudées en anneau à la base; anth. à append. term. lin.-sub. . . . . . GIRSIUM 274

ơ Aigrette de l'achaine à soies scabres soudées en anneau à la base.

F. plus ou moins décurrentes; récept. hér. de long. soies; aigrette à soies dentic.; pl. épin.; fl. ord. rouges; achaines striés en long . . . . . . CARDUUS 275

F. non đécurrentes; récept. hér. de soies tr. courtes; aigrette à soies étr. plum.; pl. non épin.; fl. bleues; achaines lisses.

GARDUNGELLUS 276

+ Achaines à aigrette persist., quelquefois nulle, rar. cad., à soies se détachant isolément.

Fol. de l'invol. term. par un append. orb., ou lanc., ent. ou cilié.

Fol. de l'invol. dépourvues d'append.

GENTAUREA 277

'o Fol. ext. de l'invol. lobées, gr. égalant ou dépassant le cap. et semblable aux f. caul.; pl. épin. à fl. jaunes.

CENTROPHYLLUM 278

Fol. de l'invol. de forme bien différente des f. caul.

† Aigrette de l'achaine à soies libres jusqu'à la base se détachant isolément; cap. en corymbe ou en grappes; fl. rouges.

Fol. de l'invol, à pointe jamais courbée en crochet, les ext. aig., les int. membr. scarieuses au sommet; anth. sans append. à la base; cap. ovoïdes oblongs, petits, 5 -8 $\mathrm{mm}$.; f. dentées, ent. ou pennatifides........... SERRATULA 279

Fol. ext. de l'invol. à pointe recourbée en crochet, les int. lanc.; anth. à lobes prolongés inf. en append. sub. ; cap. glob. gros, $15 \mathrm{~mm}$. à $4 \mathrm{~cm}$.; f. gr., ovales, cordées à la base. LAPPA 280

む Aigrette de l'achaine à arêtes persist. dentic., élargies à la base; invol. à fol. scarieuses, les int. colorées plus long. que les fl.; récept. hér. d'écailles; cap. solit.; f. sessiles, lin., blanches tom. en dessous. . . . . . . . XERANTHEMUM 281

\section{GenRe 270. - SILYBUM Vaill.}

Pl. bisann., presque gl., robuste, rameuse; f. ord. marbrées de blanc en dessus, les caul. sessiles, non décurrentes, embrass. auriculées, sinuées dentées ou pennatifides, à lobes bordés d'épines et de cils épin.; invol. 
gros, au moins 3 cm., hémisph. à fol. gl., les ext. à append. étalé, triang., atténué en forte épin.; achaines gros, noir, ruguleux; cap. solit., term.; fl. purp. . . . . . . S. Marianum Gaertn. 756 Lieux incultes, décombres. - Jn-At.

\section{GeNre 271. - ONOPORDUM Vaill.}

Pl. bisann., pub. aranéeuse, blanchâtre, robuste, larg. ailée, épin., rameuse; f. pub.-aranéeuses, blanches-tom. en dessous, oblongues, sinuées-anguleuses à bords épin.; invol. gros, glob., aranéeux à fol. term. par un append. long. lanc.-sub., épin., les fol. extér. réfléchies.

Lieux incultes. - Jn-Sept.

0. Acanthium L. 757

\section{Genre 272. - CINARA Vaill.}

Pl. viv. dress., raide, robuste; f. blanchâtres ou tom. en dessous, sans épin., pennatipartites, les sup. pennatifides ou presque ent.; fol. de l'invol. larg. ovales, échancrées et mucronées au sommet.

$$
\text { Cult. (Artichaut). - At-Sept. }
$$

G. Scolymus L. 758

\section{GENRE 273. - GARLINA Tourn.}

Pl. bisann., dress., raide, ord. rameuse au sommet; f. pub.-aranéeuses ou tom.-blanchâtres en dessous, sinuées pennatifides à épin. étalées, les caul. amplexicaules; invol. à fol. int. rayonnantes blanchâtres ou d'un jaune pâle. . . . . . . . . . C. vulgaris L. 759 Lieux incultes secs et pierreux. - Jt-Sept.

\section{Genre 274. - GIRSIUM Tourn.}

+ F. hér. en dessus de petites épin. couchées; pl. bisann., robustes; fl. purp.

F. caul. pennatipartites, vertes ou blanches aranéeuses en dessous, tr. long. décurrentes à ailes épin.; cap. ovoïdes, rar. subglob., assez gros, $3.5 \mathrm{~cm}$.; invol. un peu aranéeux, à fol. étalées-dress., lin.-lanc. insensibl. atténués en pointe épin.

Lieux incultes. - Jn-Sept.

C. lanceolatum Scop. 760

F. caul. embrass. et auriculées non décurrentes, blanches tom. en dessous, pennatipartites à segments épin.; cap. glob., tr. gros, ö-6 cm.; invol. fort. laineux à fol. moyennes et int. lanc., term. par une long. pointe étalée, lin., élargie et spathulée au sommet brusq. mucroné. . . . . . C. eriophorum Scop. 761

Lieux incultes. - Jt-At.

+ F. gl. ou pub., mais dépourvues en dessus de petites épines.

X T. ailée-épin. dans toute la long. des entre-nœeuds; f. long. décurrentes, un peu aranéeuses en dessous, hispidules en dessus; cap. ovoïdes, petits, 1-2 cm., agglom.; fl. purp.; pl. bisann.

Lieux hum., bois maréc. - Jt-Sept.

C. palustre Scop. 762

X' T. non ailée : f. non ou à peine décurrentes.

= Cap. unisexués, ovoïdes, petits, 1-2 cm., nombr. en pan. corymbiforme; f. pennatifides ou pennatipartites à bords cil.-épin.; fl. purp.; souche long. traçante. . . . C. arvense Scop. 763 Lieux incultes. - Jt-Sept.

Var. à f. presque ent., dentic. ou sinuées, à cils non épin. (var. mite Koch.)

= Cap. hermaphrodites, solit. ou agglom., assez gros.

๙ Cap. agglom. au sommet de la t. et des rameaux; fl. jaunâtres, quelquefois lavées de rouge. 
Cap. ovoïdes, médiocres, $3 \mathrm{~cm}$., dépassés par les f. florales larges, ovales, jaunâtres; f. caul. à oreillettes larges, arrondies, non décurrentes. . . . . C. oleraceum Scop. 764 Bois et prés tourb. - Jt-At.

ot Cap. ovoïdes, assez petits, $2 \mathrm{~cm}$., ord. dépassés par les f. florales étr., vertes; f. caul. auriculées, un peu décurrentes; fl. jaunàtres lavées de rouge. . . . . G. hybridum Koch 765 Bois et prés tourb. - Jt-At.

of Cap. médiocres, 2-3 cm., solit. au sommet de la t. ou des rameaux; f. non décurrentes.

- T. feuillée dans toute sa long. ou nulle, non aranéeuse; fl. purpurines ou d'un blanc jaunàtre.

Fl. d'un blanc jaunâtre quelquefois lavées de pourpre; f. caul. sessiles ou subsessiles demi-embrass., cil. épin.; cap. solit. au sommet des rameaux; fol. de l’invol. dress. ou légèr. étalées au sommet. ......... C. rigens Wallr. 766

Prés et bois hum. - Jt-At.

Fl. purp.; t. ord. tr. courte, rar. élevée de $150-20 \mathrm{~cm}$., à f. caul. pétiolées, naissant au milieu d'une rosette de f., fort. épin.; cap. unique ou 2-3 capitules term.; fol. de l'invol. appliq.

\section{Lieux secs. - Jt-Sept.}

G. acaule All. 767

- T. nue ou presque nue dans sa moitié sup. blanche ou pub. aranéeuse ; f. caul. amplexicaules; souche à fibres rad. épaissies ou renfl.; fl. purp.

F. blanches et presque tom. en dessous, sinuées ou pennatifides, cil. spinuleuses, les inf. pétiolées, les caul. sessiles, demi-embrass.; cap. solit., rar. 2-3; invol. ovoïde, non déprimé à la base, aranéeux, à fol. lanc.-lin. aig.; fibres rad. cyl.. . . . . . . . . . C. anglicum Link 768 Marais, prés tourb. - Mai-Jt.

F. hispidules en dessus, pub. et d'un vert pâle en dessous, jamais blanches-tom., profond. pennatipartites à segments bi-trifides à lobes diverg., cil. spinuleuses, les caul. demiembrass., un peu auriculées, cap. 2-3; invol. subglob., déprimé à la base, gl. ou aranéeux, à fol. moyennes et ext. lanc., obtusiuscules. . . . . C. tuberosum All. 769 Prairies tourb. - Jn-At.

\section{Genre 275. - GARDUUS L.}

+ Cap. cyl.-oblongs, petits, sessiles, agglom. au sommet des rameaux, cad.; invol. un peu aranéeux, à fol. munies de petites glandes jaunâtres, et atténuées en longue pointe carénée, épin., arquée en dehors; pl. larg. ailée-épin. et feuillée jusqu'au sommet, à ailes continues. . . . . . . . G. tenuiflorus Gurt. 770

Lieux incultes, décombres. - Mai-Jt.

+ Cap. glob., ou ovoïdes subglob., pédonc., non caducs à la maturité.

$\times$ Cap. petits, 1 cm., dress., agglom. au sommet de la t. et des rameaux ; t. ailée jusqu'au sommet, à ailes crépues, sinuées-épin.; invol. gl. ou peu aranéeux, à fol. dress., lin., faibl. épin.

Lieux incultes. - Jn-At.

C. crispus L. 771

$X$ Cap. assez gros ou gros, 2-3 cm., dress. ou penchés; invol. plus ou moins aranéeux, à fol. étalées, rar. dress., term. par une épine forte; $t$. ailée interrompue, souvent brièv. nue sous les cap.

Cap. assez gros, $2-3 \mathrm{~cm}$., dress., solit. ou agglom., au sommet de rameaux plus ou moins ailés; fol. de l’invol., assez étr., lanc.lin., dress.-étalées. . . . . . . . C. acanthoides L. 772 
Cap. gros, 3-5 em., ordin. penchés, solit. au sommet de pédonc. nus; invol. aranéeux, à fol. assez larg. lanc., pliées au-dessous du milieu et réfractées ou étalées en étoile; rar. cap. plus petit, dressé; fol. de l'invol. étalées, non réfractées.

Lieux incultes. - Jt-Sept.

C. nutans L. 773

\section{GENRE 276. - GARDUNGELLUS Adans.}

Pl. viv. ord. acaule, rar. à tige de $20 \mathrm{~cm}$; f. étalées en rosette, pennatiséquées, à segments lin. ou lanc.; cap. ovoïde oblong, solit. au centre de la rosette et au sommet de la tige... G. mitissimus DC. 774 Pelouses sèches des coteaux calc. - Jn-Jt.

\section{Genre 277. - GENTAUREA L.}

+ Fol. de l'inv. term. par un appendice scarieux à bord ent., lacéré ou cil., jamais épin.

$\times$ Fol. de l'invol. à append. fort. et long. décurrent sur les bords; achaines à ombilic barbu surmontés d'une aigrette rousse égalant à peu près leur long.; fl. ext. rayonnantes.

F. blanchâtres aranéeuses en dessous, les inf. pennatipartites, pétiolées, les suivantes sessiles, étroites, linéaires; fl. bleues, rar. roses ou blanches; inv. ovoïde; append. fauve, brun ou noir, à cils courts, ord. argentés; pl. ann. vert blanchâtre.

Champs, moissons. - Jn-Sept.

C. Cyanus L. 775

F. gł. ou un peu hispides, toutes pennatiséquées, les inf. pétiolées, les caul. sessiles; fl. purp., rar. blanches; invol. gros, glob. ; append. noiràtres, cil.; viv...... G. Scabiosa L. 776 Ch., coteaux calc. - Jt-At.

$\times$ Fol. de l'invol. à append. non ou faibl. décurrents; achaines ì ombilic non barbu.

$=$ Append. des folioles de l'involucre suborb. courts, concaves, bien plus larges que la fol., ent. ou irrégul. fendus ; achaines dépourvus d'aigrette; fl. ext. rayonnantes.

Rameaux étalés, allongés, grêles; f. lin.-lanc. ou lin., les florales courtes n'atteignant pas la longueur de l'invol.; append. concaves, blancs ou d'un brun clair, ent. ou lacérés.

C. amara L. 777

Coteaux calc. - At-Sept.

Rameaux dress., courts, épais; f. oblongues lanc., les sup. atteignant ou dépassant linvol.; append. peu concaves, ord. bruns, irrég. lacérés-frangés . . . . . . . C. Jacea L. 778 Prẻs. - Jn-Sept.

$=$ Append. des fol. de l'invol., au moins des moyennes et des ext., régul. cil. ou pectinés.

ô Invol. glob.; append. élargis, à cils dépassant à peine la larg. de l'app.; fl. ext. rayonnantes.

Fol. de l'invol. non compl. cachées par les append. brunâtres ou fauves; achaines pub. dépourvus d'aigrette, rar. à quelques cils courts au sommet. . . . C. pratensis Thuill. 779 Prés, lieux herbeux. - Jn-At.

Var. à cap. plus petits, flor. plus tardive, invol. ovoïde, achaines gl., f. plus étroites (C. serotina Bor.) ou à fol. de l'invol. courbés en dehors, achaines pub. à aigrette courte, invol. ovoïde ( $C$. microptilon Godr.).

Fol. de l'invol. ent. cachées par les append. noirs; achaines à aigrette courte. . . . . . . . C. nigra L. 780 Prés, bois. - Jt-Sept. 
ơ Invol. ovoïde; append. étr., long. cil.-pectinés à cils beaucoup plus longs, 2-3 fois, que la larg. de l'append.; fl. ext. non rayonnantes; achaines pub. à aigrette tr. courte.

C. nemoralis Jord. 781

Bois ombragés. - Jt-Sept.

Var. à fl. d'un pourpre clair; append. fauves ou brun pâle à longs cils presque blanchàtres; invol. petit, aranéeux à la base $(C$. consimilis Bor.).

+ Fol. de l'invol. munies d'épines.

Fl. jaunes; t. ailée-ondulée à rameaux allongés; f. inf. lyrées-pennatipartites, les suivantes sessiles, long. décurrentes, lin., ent. ou sinuées; invol. glob.-conique à fol. moyennes term. par une tr. long. épine jaune, non canal. à la base, qui est munie de.2-3 petites épines de chaque côté ; fol. ext. à append. palmé à épines courtes; achaines à aigrette blanche plus longue qu'eux.

C. solstitialis L. 782

Prairies artificielles. - Jt-Sept.

Fl. purpurines; t. non ailée, tr. rameuse à rameaux divariqués; f. rad. pennatipartites, les caul. rudes, pennatiséquées à segments lin.; invol. ovoïde, à fol. term. par une épine robuste, canal.à la base, accompagnée de $4-6$ spinules basilaires; achaines dépourvus d'aigrette.. . . . . . . G. Calcitrapa L. 783 Lieux stériles, berges des rivières. - Jt-Sept.

Var. ¿̀ cap. petits, invol. oblong-cyl.; append. à épines tr. courtes, arquées, la term. dépassant à peine les lat. (C. myacantha DC.).

\section{Gexre 278. — GENTROPHYLLUM Neck.}

Pl. ann., dress., pub., rameuse au sommet; f. coriaces, demi-embrass., pennatifides, à lobes lanc., fort. épin., les sup. auriculées; invol. gros, subglob., aranéeux, à fol. ext. pennatifides, épin.; achaines grisâtres, lisses, égalant les poils les plus longs de l'aigrette.

Lieux incultes, coteaux secs, calc. - Jt-At.

C. lanatum DC. 784

\section{GERre 279. - SERRATULA L.}

Pl. viv., dr., rameuse, polycéphale à rameaux dress.; f. inf. long. pétiolées, les sup. sessiles; cap. en corymbes. . . S. tinctoria L. 785 Bois, prés. - Jt-Sept.

\section{GeNRE 280. - LAPPA Tourn.}

+ Fol. de l'invol. toutes retournées en crochet au sommet ou quelquefois les int. atténuées en pointe sub. dr.; invol. gl. ou un peu aranéeux-grisâtre.

$\times$ Cap. petits ou médiocres 15 -25 mm., brièv. pédonc. ou subsessiles disposés en grappes; achaines fauves ou grisâtres à disque épigyne non ondulé; fol. int. de l'invol. rougeâtres ou violacées.

Cap. petits, 15 -20 mm., subsessiles ou brièv. pédonc.; invol. resserré au sommet, gl. ou un peu aranéeux, à fol. int. plus courtes que les fl. . . . . . . . . L. minor DG. 786 Lieux incultes. - Jt-At.

Cap. médiocres, 20-25 mm., pédonc.; invol. ouvert au sommet, aranéeux, à fol. int. aussi longues que les fl.

Lieux incultes. - Jt-At.

L. pubens Bor. 787

Cap. gros, 3-4 cm., disposés en corymbes ou en grappes; achaines assez gros, 6-8 $\mathrm{mm}$. 
Cap. long. pédonc. disposés en corymbe lâche ; invol. gl., à fol. toutes vertes plus long. que les fl.; achaines grisâtres ou d'un brun pâle à disque épigyne ondulé. . . L. officinalis All. 788 Lieux incultes un peu humides. - Jt-Sept.

Cap. brièv. pédonc. disposés en grappes ; invol. un peu aranéeux; achaines d'un brun noirâtre à disque épigyne non ondulé.

L. nemorosa Kornicke. 789

Bois hum., chemins. - Jt-Sept.

+ Fol. int. de l'invol. purp., lanc., obtuses, surmontées d'un mucron droit, plus courtes que les fl.; cap. médiocres, 20 -25 mm., pédonculés et disposés en corymbe serré couverts d'un duvet aranéeux blanc, tr. abondant; achaines assez gros, 6-7 mm., grisâtres, à disque épigyne non ondulé . . . L L tomentosa Lamk. 790 Berges des rivières, lieux incultes. - Jt-Sept.

\section{Genre 281. - XERANTHEMUM Tourn.}

P1. ann., dress., raide, blanchâtre, à rameaux grêles, allongés, long. nus au sommet; cap. oblongs-cyl. à 10-15 fl. ; invol. à fol. mutiques, les ext. tom. sur le dos; achaines surmontés de 10 arêtes inég.; fl. purp. ou violacées. . . . . X. cylindraceum Sibth Sm. 791 Ch. arg. calc. - Jt-At.

\section{Sous-FAMILLE III. - LIGULIFLORES}

\section{(Semi-flosculeuses, Cichoracées).}

+ Achaines nus au sommet ou surmontés d'une couronne tr. courte, toujours dépourvus d’aigrette.

X Achaines surmontés d'une couronne tr. courte; fl. bleues.

$X$ Achaines nus au sommet; fl. jaunes.

CICHORIUM 282

T. feuillée à fl, portées sur des pédonc. filiformes en panicule.

LAMPSANA 283

T. non feuillée; f. toutes rad. ent. ou dentées; pédonc. tr. renfl. et fistuleux sous le cap.; achaines surmontés d'un court rebord membr. . . . . . . . . . . . . ARNOSERIS 284

+ Achaines, au moins ceux du centre, surmontés d'une aigrette de soies capill. souvent un peu élargies à leur base.

$\times$ Soies de l'aigrette toutes plum. ou les soies ext. seules parfois scabres ou dentic.

= Récept. garni d'écailles caduques ; achaines long. atténués en bec, au moins ceux du centre, except. sans bec; invol. à fol. tr. inég. imbriq. sur plus. rangs; fl. jaunes.. . . . HYPOCHÆRIS 285

= Récept. nu ent. dépourvu de soies ou d'écailles.

ơ Invol. à fol. disposées sur deux ou plus. rangs; fl. jaunes.

- Soies de l'aigrette à barbes libres, quelquefois soudées à la base en anneau, jamais entrecroisées.

Fol. ext. de l'invol. jamais largement ovales; achaines à bec nul ou presque nul.

־ Fol. de l'invol. strictement dress. appliq.

Achaines de la circonf. surmontés d'une petite couronne scarieuse, ceux du centre pourvus d'une aigrette; achaines striés en long. . . . . . . . . . . THRINCIA 286

Achaines tous couronnés d'une aigrette de soies, toutes plumeuses ou les ext. seules scabres ou dentic.; achaines rugueux en travers et striés en long. . LEONTODON 287 ol. de l'invol. lâches, les ext. étalées ou réfléchies; soies de l'aigrette soudées en anneau à la base; achaines finement rugueux................... PICRIS 288 
Fol. de l'invol. disposées sur 2 rangs, les ext., au nombre de 3-̋, larg. ovales-cordées, les int. étr. atténuées en longue pointe ; achaines jaunâtres ou rougeàtres ridés transvers. et surmontés d'un long bec capill. à soies blanches, plumeuses.

- Soies de l'aigrette à barbes diffuses, entrecroisées.

HELMINTHIA 289

lchaines dépourvus de support, insérés directement sur le récept.; f. ent., rar. denticulées. . . SCORZONERA 290

Achaines portés sur un pédicule ou support creux, renfl., un peu plus court que l'achaine; f. profond. laciniées rar. ent.

PODOSPERMUM 291

$\sigma^{7}$ Invol. à fol. disposées sur un rang; achaines subcyl. ou fusiformes long. atténués en bec; f. long. lin. tr. ent.; fol. du récept. réfractées à la maturité; fl. jaunes ou violettes.

TRAGOPOGON 292

X Soies de l'aigrette scabres ou dent., jamais plum. ni dilat. à la base ; récept. nu, rar. chargé de soies ou de fibrilles.

む Achaines compr. lenticulaires prolongés en bec ou cylind. fusiformes non compr. pourvus d'écailles au sommet el prolongés en bec.

- Achaines cyl. ou fusiformes non compr.; fl. jaunes.

Invol. nett. cyl. à fol. dress. ou dress.-étalées à la maturité; achaines muriqués au sommet terminé par une couronne d'écailles........... . . . . CHONDRILLA 293

Invol. ovale, réfléchi à la maturité; achaines fort. muriqués comme épin. au sommet...... TARACECUM 294

- Achaines tr. fort. compr., lenticulaires, brusq. atténués en bec; fl. jaunes ou bleues........... LACTUCA 295

む Acliaines dépourvus de bec, ord. tronqués au sommet ou pourvus de bec mais subcyl. ou fusiformes dépourvus d'écailles; fl. jaunes.

Achaines compr., sans bec, striés en long, rugueux transvers. ou lisses................................... SONUS 296

送 Achaines subcyl. ou cyl.

Achaines subcyl. atténués au sommet ou fusiformes munis ou non d'un bec ; aigrette blanche, tr. rar. roussàtre, à soies dispo-

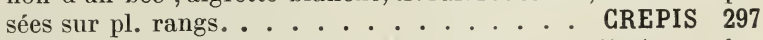

Achaines cyl. nullement atténués au sommet, nett. tronqués ; aigrette roussâtre, tr. rar. blanche, à soies disposées sur un seul rang............................. 298

\section{GenRe 282. - GIGHORIUM Tourn.}

Pl. viv.à t. dress., tr. rameuse, à rameaux raides, diverg., glabrescente ou pub.-hispide; f. inf. ord. roncinées, les suivantes lanc., ent., embrass., réduites à des bractées dans i'infl. ; cap. solit., term. ou axill.

C. Intybus L. 792

Bords des chemins. - Jt-Sept.

On cult. C. Endivia L. (Escarole, chicorée frisée et étiolée artific., barbe de capucin) qui se reconnait à ses f. sup. à base élargie, cardée-amplexicaule, à ses cap. plus nomb.

\section{GenRe 283. - LAMPSANA Tourn.}

Pl. ann., à t. dress., gl. ou pub. inf., rameuse à rameaux étalés-dressées ; f. inf. lyrées à lob. term. tr. gr., denté, tronqué ou cordé à la base, les sup. lanc. atténuées inf.; cap. petits.

Lieux incultes ou cult. - Jn-At。

L. communis L. 793 


\section{GENRE 284. - ARNOSERIS Gærtn.}

Pl. ann. à t. dress., gl., rougeâtres à la base, simples ou portant 2-3 cap.; f. rad. obovales-oblongues, pub., atténuées à la base; cap. petits portés par de longs pédonc. renfl. . . . . . A. minima Koch. 794 Ch. des terrains sil. - Jn-At.

\section{GenRe 283. - HYPOCHÆRIS L.}

+ Aigrette à soies toutes plum. et disposées sur un seul rang; achaines tous atténués en bec; t. vel.-hispide nue ou offrant 1-2 f. caul., simple ou bi-trifurquée, term. par des cap. gros, solit.; invol. à fol. hér., les int. bien plus courtes que les fl. jaunes; f. souvent maculées de noir en dessus. . . . . . . . . H. maculata L. 795 Bois secs, sabl., bruyères. - Jn-At.

+ ligrette à soies disposées sur 2 rangs, les ext. dentic. (non plum.), les int. plum.; f. toutes rad. sinuées ou pennatifides.

Fol. de l'invol., gl. ou hér. sur la nervure, toutes plus courtes que les fleurs; f. ord. tr. hispides; achaines ord. tous atténués en bec; pl. viv.. dress. . . . . . . . . H. radicata L. 796 Prés pâturages. - Mai-Sept.

Fol. int. de l’invol. égalant à peu près les fl.; f. gl. ou légèr. cil.; ord. achaines du centre atténués en bec, les ext. dépourvus de bec rar. tous atténués en bec (var. Balbisii) ou dépourvus de bec (var. arachnoidea); pl. ann. ì t. dress. ou ascend., simples ou rameuses. . . . . . . . . . . . . H. glabra L. 797

Champs et lieux sablonneux. - Mai-At.

\section{Genre 286. - THRINGIA L.}

Pl. bisann. ou viv. à souche courte, fibreuse ou à racine pivotante (var. arenaria $\mathrm{DC}$.) émettant des pédonc., term. par des carp. sol.; invol. gl. ou hispide, à fol. enveloppant les achaines de la circonf. surmontés d'une couronne de petites écailles scarieuses; achaines striés en long. . . . . . . . . . . . T. hirta Roth. 798 Pelouses, sables, ch. - Jt-Sept.

\section{Gente 287. - LEONTODON L.}

Soies de l'aigrette disposées sur un seul rang, toutes plum.; t. rameuse, polycéphale, rar, simple et monocéphale, pourvue de $f$. caul. peu nombr., lin., ent.; f. rad. gl. ou légèr. cil., pennatifides ou pennatipartites; cap. dress. avant la flor. . . . . L. autumnalis L. 799 Prés, pâturages. - Jt-0ct.

Soies de l'aigrette disposées sur 2 rangs, les int. plum., les ext. dentic.; t. (pédonc. rad.) toujours simple et monocéphale, à une ou quelques bractéoles; f. radic. sinuées ou pennatifides hér., rar. gl. (ainsi que toute la pl., var. hastile L.); cap. penchés avant la flor.

Prairies, pâturages. - Mai-Sept.

L. hispidus L. 800

\section{Genre 288. - PIGRIS Juss.}

Pl. bisann., hispide, rude, à poils roides term. en double crochet (glochidiés); tige dress., à rameaux étalés, rar. étalée-diffuse à rameaux ascendants; f. inf. oblongues, ent., ondulées ou sinuées-dentées, les sup. demi-embrass.; cap. en corymbe lâche, souvent irrégul.

P. hieracoides L. 801

Ch., lieux pierreux calc. - Jt-Sept. 


\section{GENRE 289. - HELMINTHIA Juss.}

Pl. ann. ou bisann. à t. dressée, rameuse, hispide; f. tr. rudes, hispides, hér. de poils bifurqués et aux bords et sur la nervure de poils simples spinescents à base élargie; cap. peu nombr., term., disposés en grappe corymbiforme. ....... H. echioides Gaertn. 802 Ch., fossés, lieux incultes un peu hum. - Jn-Sept.

\section{GENRE 290. - SCORZONERA Tourn.}

+ Base des t. garnie au collet de la racine d'un abondant chevelu de fibrilles; aigrette blanche un peu plus longue que l'achaine à côtes lisses ou scabres; f. rad. long. lanc. ou lin. rétrécies en pétiole; tige simple et monocéphale . . . . S. austriaca Willd. 803 Lieux secs ; coteaux calc. - Mai-Jn.

+ Base des t. dépourvue de chevelu au collet de la racine; aigrette blanc sale.

Achaines à côtes lisses ou faiblement rugueuses; t. simple, monocéphale, rarement bi-trifurquée, peu feuillée; bract. ext. ovaleslanc., obtuses . . . . . . . . . S. humilis L. 804 Prés et bois humides ou marécageux. - Mai-Jn.

Achaines muriqués-spinuleux; t. rameuse et polycéphale, rar. monocéphale, feuillée; bract. ext. larges, ovales-aig.

Cult. (salsifis noir, scorzonère).

S. hispanica L. 805

\section{GenRe 291. - PODOSPERMUM DC.}

Pl. bisann. à racine pivotante; t., dress., feuillées, rameuses; f. pennatipartites ou pennatiséquées, à segments lin., le term. tr. long, rar. réduites au rachis ( $P$. subulatum DC.); achaines lisses; aigrette d'un blanc sale; fl. jaune pâle; cap. solit. au sommet de la t. et des rameaux.

Ch., lieux incultes. - Mai-Jt.

P. laciniatum DC. 806

\section{Genre 292. - TRAGOPOGON Tourn.}

+ Fl. jaunes, achaines à peu près de la long. du bec ou un peu plus courts.

Pédonc. cyl., à diamètre à peu près égal, non ou très faibl. renfl. au sommet; fl. égalant l'invol., rar. plus courtes (T. minor Fr.) ou dépassant long. l'invol. (T. orientalis L.); achaines égalant le bec ou un peu plus longs. . . . . . . T. pratensis L. 807 Prairies, ch. - Jn-Jt.

Pédonc. fistuleux et larg. renflés en massue au sommet, surtout à la maturité; fl. long. dépassées par les fol. de l'invol.; achaines plus courts que le bec...... T. dubius Scop 808 Lieux secs, coteaux. - Mai-Jn.

+ Fl. violet rougeâtre, plus courtes que les fol. de l'invol.; achaines ext. 2 fois plus courts que le bec; pédonc. fort. renfl. en massue au sommet........... T. porrifolius L. 809 Cult. (salsifis). - Mai-Jn.

\section{GENRE 293. - GHONDRILLA Tourn.}

Pl. bisann. dress., gl., hispide inf., presque nue, tr. rameuse à rameaux effilés, raides, étalés; f. inf. sinuées ou roncinées, les sup. ent., lin.; cap. petits, subsessiles, solit. ou réunis par 2-3 en fasc. espacés le long des rameaux. ................... juncea L. 810 Ch. pierreux ou sabl. - Jt-Sept. 


\section{GenRe 294. - TARAXACUM Juss.}

Fol. ext. de l'invol. étalées ou réfléchies; f. toutes rad., étalées en rosette, roncinées, pennatifides ou pennatipartites à segments triang.-lanc. ou lin.-lanc.; fol. de l'invol. dentic. ou ent., avec ou sans callosité au sommet; capitules gros solit. sur des pédonc. rad., achaines grisâtres ou rouges (T. erythrospermum And.) . . . T. officinale Wiggers 811

Prés, lieux herbeux. - Avr.-Oct.

Fol. ext. de l'invol. dress., appliq. contre les int., f. presque dress., oblongues-obovales ou presque lin., lâchement sinuées ou ent., rar. pennatifides; fol. de l'invol. ent. et sans callosité; cap. médiocres, sol. sur des pédonc. rad.; achaines ord. grisâtres. . . T. palustre DC. 812 Prés tourb. et maréc. - Avr.-Mai.

\section{Genre 295. - LACTUCA Tourn.}

+ Invol. à 5 fol. égales, disposées sur un seul rang, muni à sa base d'écailles extrèm. courtes; fl. jaunes peu nombr., $气$, sur un seul rang; achaines noirâtres à côtes lisses, à bec court portant une aigrette à poils simples disposés sur plus. rangs; f. roncinées-pennatipartites, rétrécies en pétiole ailé embrass. et auriculé à la base; pl. ann. gl., souvent rougeâtre. . . . . L. muralis Fresen 813 Bois et murs ombragés. - Jt-At.

+ Invol. à fol. inég. imbriq. sur plus. rangs, les ext. plus petites; fl. nombr. sur 2-3 rangs; achaines à bec long, capill., portant une aigrette de poils disposés sur un seul rang; pl. bisann. ou viv.

$X$ Fl. jaunes assez petites; $f$. à oreillettes aig.; t. élevées.

= F. caul., lin., ent., long. acum., embrass. à oreilles tr. aig., les inf. ord. roncinées à lobes aig., rar. ent. ; cap. sessiles ou subsessiles le long des rameaux, disposés en grappes làches grêles et effilées; achaines noirs, fusiformes, à 5-7 côtes fines sur chaque face. . . . . . . . . . . . L. saligna L. 814 Ch., lieux pierreux. - Jn-At.'

= F. oblongues, embrass. auriculées, jamais lin.-ent.; cap. en pan. Achaines petits, 3-4 mm., grisâtres, munis de cils courts au sommet, à peine marginés; f. ét. dress., roncinées pennatifides, rar. ent. (L. dubia Jord.), spinuleuses sur les bords et sur la nervure dorsale; pl. de $60 \mathrm{~cm}$. à $1 \mathrm{~m}$. vert glauque ou un peu violacée.

Ch., lieux incultes. - Jt-At.

L. Scariola L. 815

Achaines assez gr., 5-6 mm., noirs, lisses, rar. hispidules au sommet, marginés-épaissis aux bords; f. étalées, sinuées ou ent., rar. roncinées, dentées-spinuleuses, à nervure dorsale ord. aiguillonnée; pl. de 1-2 m., ord. violacée. . . L. virosa L. 816 Lieux incultes, clairières des bois. - Jt-At.

Fl. bleues ou violacées; pl. viv. à t. de 2-50-50 cm., gl. rameuses; f. gl. pennatipartites à segments oblongs ou linéaires, les caul. embrass. à oreillettes arrondies; cap. long. pédic. en pan. corymbiforme; achaines d'un beau noir, à côtes très visibles, à bords épaissis . . . . . . . . . . L. perennis L. 817 Ch. pierreux, surtout calc. - Nai-Jt.

On cult. L. sativa L. pl. ann., dress., tr. rameuse, tr. feuillée; f. inermes, embrass., cordées à la base, cap. petits, jaunes, en pan. corymbiforme contractée; achaines grisàtres.

\section{GeNRe 296. - SONGHUS Tourn.}

+ F. embrass. à oreillettes lanc., aig. ou mucronées.

F. caul. moyennes lanc., ent. ou offrant inf. 1-3 lobes profonds, les rad. roncinées; cap. pédonc. à corymbe étalé; invol. couvert 
de poils gland., ainsi que les pédonc. ; oreillettes lanc.-aig. ; achaines jaunàtres, subtétragones, à 4 côtes plus saillantes, épaissies, faibl. striés transvers.; pl. viv., dress. de $2-3 \mathrm{~m}$.

Lieux tourb., bois maréc. - Jt-At.

S. palustris L. 818

F. toutes pennatipartites, roncinées, les caul. à oreilletles acum., étalées, les inf. à pétiole larg. ailé; capit. pédonc. en corymbe irrégul.; achaines brunàtres compr., à tr.côtes; scabres, fort. striées transvers.; pl. ann., dress.; t. de $30-80 \mathrm{~cm}$., gl., rar. quelques poils gland. . . . . . . . . . S. oleraceus L. 819 Lieux cult. - Jn-0ct.

+ F. embrass. à oreillettes arrondies; cap. en corymbe irrégul.

Achaines brun clair compr. à côtes lisses; pl. ann., gl., ou à quelques poils glandul. sup.; f. oblongues, sinuées dentées, pennatifides ou entières et lanc., fort. spinuleuses, à oreillettes larges, contournées. . . . . . . . S. asper All. 820 Lieux cult. - Jn-0ct.

Achaines brun foncé, subtétragones compr., à côtes scabres, fort. striées transvers.; pl. viv. à souche ramp. fort. poilue glaud. sup., rar. invol. et pédonc. gl. (var. laevipes G. G.); f. gl., pennatipartites ou pennatifides, à segments peu nombr., denticulés spinuleux, à oreillettes courtes. . . . . S. arvensis L. 821 Ch., lieux cult. - Jt-Sept.

\section{Genre 297. - GREPIS L.}

+ Achaines prolongés, au moins ceux du centre, en bec long, grêle, filiforme.

$\times$ Cap. penchés avant la flor. en corymbe irrégul., à pédonc. bractéolés, un peu renfl. au sommet; achaines du centre term. en long bec tr. grêle, ceux de la circonf. à bec tr. court, entourés par les fol. int. de l'invol.; pl. ann., fétide, grisàtre; f. pub. hispides, roncinées-dentées ou pennatipartites, les sup. demi-embrass. incisées à la base. . . . . . . . . . . . . C. fœtida L. 822 Lieux incultes, surtout calc. - Jn-At.

X Cap. dressés avant la flor., en corymbe, à pédonc. non bractéolés; achaines à becs tous égaux; pl. vertes, à f. caul. auriculées ou sagittées embrass.

Invol. tom. blanchàtre, avec quelques poils gland. noirs, à fol. ext. brunàtres, glabrescentes; achaines à côtes fin. rugueuses; pl. bisann. à f. presque toutes rad., oblongues-lanc. pennatipartites, les caul. lanc., incisées à la base, auriculées.

Prés, ch. - Mai-Jn.

C. taraxacifolia Thuill. 823

Invol. ni tom., ni gland., à fol. int. carénées, les ext. étalées, hér., ainsi que toute la pl., de long. soies raides, étalées, jaunâtres, non gland.; bec plus court que l'achaine à côtes muriquées; pl. ann. à f. 'oblongues-lancéolées, pennatifides ou dentées, les caul. sessiles, lanc.-aig., entières ou incisées à la base, sagittées-embrass. . . . . . . . . C. setosa Roem. 824 Ch., prairies artific., nat. - Jn-At.

+ Achaines un peu atténués au sommet, mais jamais prolongés en bec.

= Invol. oblong-cyl. tr. gl., à fol. ext. tr. courtes, appliq.; pl. pub.gland. et visq. inf., gl. dans sa partie sup.; f. inf. oblongues-obovales, dentées ou sinuées, les sup. embrass.; achaines jaunâtres, ceux du centre lisses, ceux de la circonf. spinuleux.

Lieux pierreux et calc. incultes. - Mai-Jt.

G. pulchra L. 825

= Invol. ovoïde pub., souvent un peu hispide; pl. non gland., ni visq.inf. 
Q Achaines d'un brun marron, scabres, un peu spinuleux au som met; f. caul. auriculées, à bords roulés en dessous; invol. à fol. un peu tom., blanchâtres, offrant quelques poils gland., les ext. courtes, làches, étalées; pl. annuelle, dress., rameuse.

Vieux murs, ch. sabl. - Mai-Jn.

G. tectorum L. 826

a Achaines blonds ou jaunâtres à côtes lisses; f. caul. planes.

Fol. de l'invol. gl. sur la face interne, les ext. lin., appliq.; cap. petits; achaines à 10 côtes, longs de $2-3 \mathrm{~mm}$.; t. gl. ou presque gl. ainsi que les f., rar. vel.-hér. inf.; f. caul. sagittées; plante ann. . . . . . . . . . . C. virens L. 827 Prés, lieux herbeux. - Jn-0ct.

Var. à t. courtes, diffuses, couchées, cap. tr. petits (C. diffusa DC.) pl. robuste dress., raide, vel.-hér. à la base, cap. assez gros à invol. hér. de poils noirâtres, gland. (C. agrestis W. K.).

Fol. de l'invol. pub. sur la face interne, les ext. lanc.-lin., étalées; cap. gros; achaines à 13 côtes, longs de $4-5 \mathrm{~mm}$. ; t. et f. hispides, les caul. à oreillettes dentées, non sagittées; pl. bisann., robuste . . . . . . . . . . G. biennis L. 828 Prés, lieux hum. - Mai-Jt.

\section{GeNre 298. - HIERACIUM Tourn.}

+ F. ent.; t. scapiformes ou pédonc. rad.; souche ord. stolon.; achaines petits, longs de 1 1/2 à 2 1/2 $\mathrm{mm}$. dentic. au sommet par le prolongement des côtes; aigrette formée de soies roussâtres presque égales.

$\times$ F. tom.-blanchâtres en dessous; t. nue ne portant aucune f. (pédonc. rad., tige scapiforme) term. par un seul cap.; ligules de la circonf. rougeàtres en dessous.

Souche émettant de longs stolons feuillés à f. écartées, inég.; invol. à fol. pub., à poils raides, noirs ou soyeux assez courts; cap. médiocres; f. oblongues-lanc. ou oblongues-obovales, hér. de soies sur les 2 faces. . . . . . . . H. Pilosella L. 829 Lieux sees. - Mai-Sept.

Souche dépourvue de stolons ou à stolons tr. courts, épais, ascend., à f. rappr. peu inég.; invol. à fol. hér., à longs poils soyeux blancs, abondants; cap. assez gros; f. oblongues-lanc., hér. de longs poils soyeux sur les 2 faces. H. Peleterianum Mérat 830 Sables, rochers, lieux secs. - Mai-Jn.

$X$ F. jamais tom.-blanchàtres en dessous; $t$. aphylle ou portant quelques f., term. par plus. ou de très nombr. cap., rar. un seul.

Souche émettant des stolons allong., ramp., feuillés; t. de 10-30 cm., nue ou à 1 feuille caul., rar. 2 ou 3 term. par un petit corymbe de 2-6 cap., assez petits, rar. monocéphale par avortement; f. gl., glauques, cil. à la base ....... . H. Auricula L. 831 Pelouses hum. - Mai-At.

Souche courte, tronquée, tr. rar. stolonifère; t. de $30-60 \mathrm{~cm}$., gl. ou à quelques soies, avec pub. étoilée au sommet à 1-4 f. caul., term. par une pan. ombelliforme de 20-60 cap. petits; f. glauques, étr. lanc., aig., gl., cil. ou hérissées de soies.

Bois montueux, vieux murs. - Jn-Jt.

H. præaltum Vill. 832

+ F. plus ou moins dentées, rar. ent.; t. plus ou moins feuillées, robustes; souche non stolonifère; achaines gr., longs de $3-4$ mm., à sommet ent., non dentic.; aigrette formée de soies roussâtres inég.

= F. rad. persist. à la flor., formant une sorte de rosette à la base des ı. florifères (phyllopodes). 
T. aphylle ou n'offrant qu'une ou 2 f. caul. lanc., dentées, brièv. pétiolées; f. rad. ovales, lanc. ou elliptiques, dentées ou incisées à la base, rar. ent., à limbe tronqué, ou cordé, subit. rétréci en pétiole; invol. hispide-gland. . . . . . . H. murorum L. 833 Bois secs, coteaux, vieux murs. - Mai-At.

T. pourvue de 3-10 f. caul. bien développées, lanc., plus petites que les rad., les inf. pétiolées, les sup. sessiles; f. rad. ovaleslanc. ou oblongues lanc., presque ent., dentées ou incisées à la base, atténuées en pétiole; invol. hispide-gland.

Bois. - Jn-At.

H. vulgatum Fr. 834

$=\mathrm{F}$. rad. détruites à la floraison, les inf. parfois groupées en fausses rosettes vers le milieu ou le bas des $t$. (aphyllopodes).

Q Fol. de l'invol. toutes appliq., munies de poils étoilés et de rares poils simples, parfois gland.; pan. corymbiforme.

F. oblongues-lanc., lanc. ou ovales-lanc., dentées, les moyennes non atténuées à la base arrondie et presque demi-embrass., les inf. rétrécies en court pétiole ailé; styles bruns, rarement jaunàtres . . . . . . . . H. boreale Fr. 835 Bois, forèts. - At-Sept.

F. oblongues-lanc., acum., ou ovales-lanc., à 2-4 dents saillantes de chaque côté, rar. lanc. et presque ent., rétréciées à la base, jamais subembrass., les moyennes brièv. pétiolées, les inf. long.; styles jaunes ou livides. . . . . H. rigidum Hartm. 836 Bois. - Jt-At.

Q Fol. ext. de l'invol. à pointe courbée en dehors au sommet; corymbe ombelliforme, souvent accompagné de rameaux inf., à pédic. munis seulement de poils étoilés; f. sessiles lanc.-lin ou lin., à dents écartées ou ent.; styles jaunes. . . . H. umbellatum L. 837 Bois, coteaux. - At-Sept.

\section{FAMILLE 3\%. - AMBROSIACÉES}

\section{Genre 299. - XANTHIUM L.}

Pl. ann., rameuses, pub., à f. alt., pétiolées dentées-lobées ou ent.; fl. en têtes subsessiles, les mâles glob. situées au sommet, les femelles ovoïdes.

T. munies de long. épines tripartites jaunes; f. à $3-3$ lobes ou ent., pétiolées, $3-\mathbf{3}$ fois plus long, que larges, blanches-tom. en dessous; fr. elliptiques oblongs, longs de 10-13 mm., pubérulents, hér. d'épines jaunes, grèles, crochues au sommet, term. par 2 becs peu apparents, tr. inég. . . . . . . . . . . . X. spinosum L. 838 Décombres, lieux vagues, subsp. -- At-Sept.

T. sans épines; f. long. pétiolées, dentées-lobées, à 3-ว̆ lobes anguleuxdentés, presque aussi larges que longues, pub. rudes, grisâtres en dessous; fr. agglom., ovoïdes, longs de 12-10̈ mm., verdâtres, pub., nus au sommet, hér. d'épines coniques, crochues au sommet, term. par 2 becs coniques, dr. . . . . . . X. strumarium L. 839 Décombres, berges des rivières. - Jt-Sept.

\section{FAMILLE $30 \%$ - LOBÉLIACÉES}

\section{GenRe 300. - LOBELIA L.}

Pl. viv., gl. ou glabrescente; souche courte, à fibres épaisses, fasc.; t. dress., anguleuse, feuillée, simple ou rameuse; f. inf. obovales ou oblongues, inégal. dentées, atténuées en pétiole, les sup. lanc. sessiles; fl. bleues, assez grandes, 10-15 mm., nombr., dressées, en grappes allongées; cor. à lobes lanc., aig., presque égaux; capsule oblongue-cyl. . . . . . . . . . . . . L. urens L. 840 Bois hum., landes. - Jt-Sept. 


\section{Famile 5̋6. - CAMPANULACÉES}

+ Caps. s'ouvrant en dessus par 2-5े valves; filets des ét. non ou à peine dil. à la base.

Cor. en cloche à כ̆ lobes peu profonds; ét. incluses à filets un peu dil. à la base; anth. libres; style inclus à 3-"̈ stigmates courts; caps. courte s'ouvrant en dessus par 3-5 valves; fl. solit. bleues, penchées avant la flor., axill. et term. sur des pédonc. filiformes tr. longs; f. tr. minces, pétiolées, cordées à la base à 5-7 lobes triang. . . . . . . . . WAHLENBERGIA 301

Cor. divisée presque jusqu'à la base en J̈ lobes lin. d'abord soudés en tube au sommet, puis étalés en roue; ét. à filets filiformes non dilatés, à anth. soudées à la base; style filiforme terminé par 2 stigmates courts, dress., peu distincts; caps. subglob. à 2 loges, s'ouvrant par 2 valves courtes; fl. bleues, rar. blanches, pédic. réunies en tètes glob. term. munies d'un invol. à fol. imbriquées; f. sessiles, lin.-lanc. ondulées, hispides épaissies aux bords.

JASIONE 302

+ Caps. à plusieurs loges s'ouvrant chacune lat. par un trou; filets des ét. dil. à la base.

X Cor. divisée presque jusqu'à la base en lobes lin., d'abord soudés en tube, puis étalés en roue; fl. sessiles, réunies en têtes ou en épis munis de bract.; caps. subglob. à 2-3 loges. . PHYTEUMA 303

$\times$ Cor. ord. divisée peu profond. à lobes élargis, jamais soudés en tube.

Cor. en roue, plane, à tube très court; pl. ann.; fl. subsessiles en pan. ou en corymbes term.; caps. lin. prismatique à 3 loges; pl.

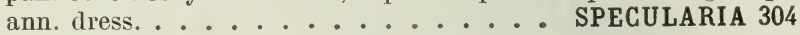
Cor. en cloche, ouverte au sommet; pl. viv. ou bisan.; fl. sessiles, ou plus ou moins long. pédic. diversement disposées; caps. en

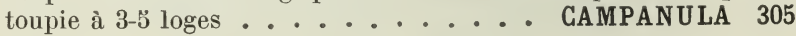

\section{GENRE 301. - WAHLENBERGIA Schrad.}

Pl. viv. de 10-30 cm., délicate, verte, gl., gazonnante à racine ramp., à t. filiformes, couchées, rameuses; f. palmatinervées; fl. bleu pâle, petites; caps. subglob. ........ W. hederacea Reich. 841 Pelouses hum. - Jt-Sept.

\section{GeNre 302. - JASIONE L.}

Pl. ann. ou bisann. à racine longue, pivotante; t. dress. ou ascend. nues dans la partie sup. feuillées et hispides dans le bas; cal. gl. à lobes lin. 1-2 fois plus longs que le tube ...... J. montana L. 842 Lieux secs, sabl. - Jn-Sept.

\section{Genre 303. - PHYTEUMA L.}

Fl. bleues en têtes glob., puis ovoïdes; bract. ovales-lanc. plus longues ou plus courtes que les fl.; souche dure, rameuse, non charnue; t. dress., simples, ord. peu feuillées; 3 stigmates; graines jaunâtres.

Pelouses herbeuses, coteaux calc. - Jn-At.

P. orbiculare L. 843

Fl. d'un blanc jaunàtre, rar. bleuâtres, en têtes oblongues-cyl.; bract. lin. en alène, dépassant les fl. inf.; souche renflée-charnue, pivotante; t. dress., simples, feuillées dans les $2 / 3$ inf.; 2 stigmates; graines brunes .............. P. spicatum L. 844 Coteaux boisés. - Mai-Jt. 


\section{GeNRE 304. - SPEGULARIA Heist.}

Cor. petite, presque fermée, violacée, peu apparente, égalant à peine la moitié des lobes du cal. scabre, à lobes elliptiques-lanc., dress., 3-4 fois plus courts que le tube; f. fort. ondulées-crén.; caps. de 20-30 mm.

Ch. pierreux. - Mai-Jt.

S. hybrida A. DG. 845

Cor. assez gr., violette, très apparente, étalée, égalant ou dépassant le cal. gl. ou pubérulent, à lobes lin. en alène, étalés, à peine plus courts que le tube, à la flor.; f. faibl. ondulées-crén.; caps. longue de 10-15 mm.

Ch., moiss. - Jn-Jt.

S. Speculum A. DC. 846

\section{GenRe 30כ. - GAMPANULA L.}

+ Fl. sessiles ou subsessiles disposées en têtes term. et souvent lat., entourées de larges bract. foliacées ; caps. dress. s'ouvrant à la base.

F. inf. lanc., atténuées en pétiole ailé, cal. à lobes ovales-obtus; cor. égalant à peine $2 \mathrm{~cm}$.; style saillant; t. assez épaisse, hér. de poils raides . . . . . . . C. Cervicaria L. 847 Clairières des bois. - Jn-Jt.

F. inf. arrondies ou en cœur à la base ; cal. à lobes lanc.-lin., aig.; cor. dépassant ord. $2 \mathrm{~cm}$; style inclus; t. assez grèle pub. ou glabrescente . . . . . . . . . G. glomerata L. 848 Coteaux calc., bois, prairies. - Jn-Sept.

+ Fl. distinctement pédonc., en pan., en grappe ou solit.

$X$ Caps. dress.

$=\mathrm{F}$. inf. oblongues, atténuées à la base; caps. s'ouvrant par des trous près du sommet.

Fl. gr., 3-4 cm., 2-6 en grappe simple et étroite; cal. à lobes lanc.; cor. aussi large que longue divisée à peine jusqu'au quart, à lobes larg. ovales; pl. gl. et lisse, viv. à souche ramp.; tube du cal. ord. gl., rar. hér.; f. faibl. crén. . C. persicifolia L. 849 Bois. - Mai-Jt.

Fl. moyennes, à peine $\mathbf{2} \mathrm{cm}$., en grappe long et étr.; cal. à lobes lin.; cor. plus longue que large, divisée jusqu'au tiers, à lobes lanc.; pl. pub. à la base, bisann., à racine charnue, en fuseau; cal. gl.; f. crén. . . . . . . . C. Rapunculus L. 850 Bois, prés. - Mai-At.

$=\mathrm{F}$. inf. ovales-oblongues, cordées à la base; caps. s'ouvrant par des trous situés près de la base; fl. assez gr., 2-3 cm., en grappe pyramidale souvent tr. long.; cal. à lobes lanc.; cor. aussi large que longue, divisée presque jusqu'au tiers à lobes larg. ovales; pl. gl., viv., tr. rameuse; f. dentées . . C. pyramidalis L. 851

Cult., nat. sur les vieux murs. - Jt-At.

Caps. penchée, s'ouvrant par des trous près de la base; f. rad., souvent détruites à la flor., ovales ou suborb., en cœur à la base.

Q F. gr., les caul. larges de 3-7 mm.; fl. en long. grappes multiflores; cal. à lobes lanc.; cor., à lobes lanc. et barbus.

Fl. gr., 3-4 cm., dress., en grappes feuillées, 2-3 fl. sur les pédonc. munis de 2 bractéoles à la base; cal. hispide à lobes lanc. dress.; t. robuste, anguleuse, vel.-hér., tr. rude; f. ovales-triang., en cœur à la base; souche sans stolons. . C. Trachelium L. 852 Bois. - Jn-At.

Fl. moyennes, 2-3 cm., penchées, en grappes làches, spiciformes, unilat., non feuillées; fl. solit. au sommet des pédone.; cal. glabrescent à lobes lanc., réfléchis après la flor.; t. assez robuste, arrondie, pub.; f. ovales lanc. un peu en cœur à la base; souche long. ramp. stolon. . . . . C. rapunculoides L. 853 Ch., lieux incultes et cult. - Jn-At. 
a F. petites, les caul. lin.-lanc.; fl. penchées, en pan. lâche, ord. pauciflore; cal. gl. à lobes lin.; cor. gl. à lobes étalés; t. grêles courbées ascend. gl. ou pub. inf.; f. rad., souvent détruites, arrondies en coeur, dentées . . . . C. rotundifolia L. 854 Pâturages, pelouses. - Jn-At.

On cult. C. Medium I. Pl. bisann., vel. hér.; t. arrondie, simple; f. ovaleslanc., dentées; fl. dressées, en grappes assez long.; cal. hispide muni de 5 append. réfléchis ; caps. à 5 loges s'ouvrant par $\breve{~ t r o u s . ~}$

\section{FAMille 57. - VACCINIÉES}

Cor. en roue, divisée presque jusqu'à la base en 4 lobes lanc.; pédonc. 6 fois plus longs que la fl.; f. tr. petites, $\breve{\mathrm{b}}-7 \mathrm{~mm}$. de long; t. filiformes couchées radicantes. . . . . . . . 0XYCOCGUS 306 Cor. en grelot ou en cloche, à lobes courts; pédonc. tr. courts n'égalant pas la cor.; f. longues de $1-3 \mathrm{~cm}$.; t. fortes dress. ou ascend.

VACGINIUM 307

Genre 306. - OXYCOGGUS Pers. - Canneberge.

Petit sous-arbriss. gl. à t. rougeâtres, tr. grêles, rameuses; f. persist., ovales, ent. à bords enroulés, vertes et luisantes en dessus, blanches en dessous; fl. d'un rose vif, 1-3 term., chacune penchée sur un long pédonc. capill. dépassant les f.; anth. sans cornes; baie glob. rouge, à la fin noirâtre, acidule . . . . . . 0. palustris Pers. 855 Marais tourb. sil. à sphagnum. - Fl. Jn-Jt; fr. Jt-Sept.

$$
\text { Genre 307. - VAGGiniUM L. - Airelle. }
$$

F. persist., coriaces, obovales, obtuses ou émarginées, ent. ou dentic. au sommet, à bords enroulés, vertes et luisantes en dessus, pâles et marquées de points gland. en dessous; jeunes rameaux fin. pub.; fl. blanches ou rosées en petites grappes term. penchées; cor. en cloche, divisée jusqu'au tiers; anth. sans cornes; baies glob., rouges, acidules.

Bruyères, hois montueux. - Fl. Mai-Jt; fr. At-Sept.

V. Vitis-idaea L. 856

F. cad., peu épaisses, ovales-aig., fin. dentées, non enroulées, vertes; jeunes rameaux gl.; fl. d'un blanc verdâtre ou rosées, penchées, solit. ou géminées à l'aisselle des f.; cor. en grelot subglob. à lobes courts et réfléchis; anth. munies sur le dos de 2 cornes; baies glob., d'un noir bleuâtre, douces et sucrées. . . . . . . V. Myrtillus L. 857 Bruyères, bois montueux. - Fl. Av.-Mai; fr. Jt-At.

\section{FAMILLE 58. - ÉRICINÉES}

Cal. pétaloïde, dépassant long. la cor., entouré à la base de petites bract. en forme de calicule; cor. en cloche à 4 lobes profonds; f. opp. imbriq. sur 4 rangs; caps. à 4 loges à cloisons opp. aux sutures des 4 valves; graines peu nombr. . . . . . . . CALLUNA 308 Cal. petit, bien plus court que la cor., sans calicule à sa base; cor. en grelot ou en cloche, à 4 lobes souvent courts; f. ord. aciculaires vert. par $3-5$; caps. à loges polysp., à 4 valves portant la cloison au milieu.

ERICA 309

\section{Genre 308. - GALLUNA Salisb.}

Sous-arbriss., tortueux, diffus à rameaux nombr., effilés, dress., rougeâtres, gl. ou vel.-grisàtres; f. petites, lin., sessiles et à 2 pointes à la base; fl. roses, brièv. pédonc., penchées. . C. vulgaris Salisb. 858 Bois, landes. - Jt-0et.? 
Gexre 309. - ERICA L.

+ F. et cal. longuement cil.; ét. incluses; f. blanchâtres en dessous.

Fl. purp. en grappes spiciformes presque unilat.; cor. en grelot tubul., 8-10 mm., un peu renfl. au milieu et courbée au sommet; anth. dépourvues de cornes; style long. saillant; caps. gl.; f. ovales-aig., long. cil., à cils ord. non gland., vert. par 3-4.

Landes et bois sil. - Jt-Sept.

E. ciliaris L. 859

F1. roses en têtes courtes, ombelliformes; cor. en grelot ovale, ๖-7 mm.; anth. munies de 2 cornes à la base; style à peine saill. rar. (var. anandra Rich.) saill.; caps. vel. soyeuse; f. lin-.oblongues, hér. de cils raides, ord. gland., vert. par 4 . E. Tetralix L. 860 Landes et bois tourb.-sil. - Jn-0et.

+ F. et cal. gl., non cil.

Anth. saillantes, sans cornes, à loges séparées jusqu'à la base ; pédonc. filiformes plus longs que les fl. roses, en grappes allongées compactes; f. lin. étr., marquées d'un sillon en dessous, vert. par 4-こ̆; cor. en cloche, presque aussi large que longue, 3-4 mm.

Landes et bois sil. - Jt-Sept.

E. vagans L. 861

Anth. non saillantes; cor. en grelot; pédonc. égalant à peine les fl.; f. vert. par 3-4.

Fl. roses ou d'un rouge violacé, en petits fasc. rapprochés, comme vert., formant des grappes composées, allongées, obtuses; cor. en grelot ovale, 5-6 mm., à dents courtes et réfléchies; anth. munies de 2 cornes; f. lin.-étr., marquées d'un sillon en dessous, vert. par 3. . . . . . . . . . E. cinerea L. 862 Landes et bois sil. - Jn-Sept.

F1. verdâtres, tr. nombr., fasc. 1-4 à l'aisselle des f., rappr. en grappes long. et étr.; cor. tr. petite, 1-2 mm., en grelot glob., fendue jusqu'au milieu en robes ovales-obtus; anth. sans cornes ; f. lin.-obtuses, marquées de 2 sillons en dessous, vert. par 3-4; arbriss. élevé, t. et rameaux dress., gl. . . E. scoparia L. 863 Landes et bois sil. - Mai-Jn.

\section{Famille 59. - LENTIBULARIÉES}

F. toutes rad., ent., visq., aériennes; fl. bleues solit. sur de longs pédonc. nus; cal. à 5 lobes; caps. en poire, élargie à la base, s'ouvrant en 2 valves; graines tr. nombr., presque cyl. . PINGUIGULA 310

F. alt., fin. découpées, munies de vésicules, submergées; fl. jaunes en petites grappes bractéolées; cal. à 2 lobes; caps. glob., s'ouvrant en travers au-dessus de la base; graines tr. nombr. suborb.

UTRIGULARIA 311

\section{Genre 310. - PINGUiGUla L.}

Pl. viv. à hampes grêles, gl. ou pub.; f. ovales-oblongues; cor. de 10-13̆ mm. de long, bilabiée, la lèvre sup. à 2 lobes, l'inf. à 3 , prolongée en éperon dr., grêle . . . . . . . P. vulgaris L. 864 Prairies maréc. - Mai-Jn.

\section{Genre 311. - UTRIGULARIA L.}

+ F. pennatiséquées, toutes munies de vésicules; grappes à 3-12 fl.; cor. jaune vif, assez gr., $150-18 \mathrm{~mm}$.; éperon conique égalant la moitié de la cor.

Lèvre sup. de la cor. aussi long. que le palais étr. et marqué de stries orangées peu nombr., l'inf. à bords réfléchis; grappes de 3-12 fl. à pédic. et cal. rouge brun-luisant. U. vulgaris L. 8005 Mares, étangs, fossés. - Jn-At. 
Lèvre sup. de la cor. une fois plus longue que le palais large et saillant, marqué de nombr. stries orangées, l'inf. large, plane et étalée; grappes de 3-8 fl. à pédic. et cal. rouge-pâle.

Mares, étangs. - Jn-At.

U. neglecta Lehm. 866

+ F. palmatiséquées à lobes rayonnants; grappes à 2-5 fl.; cor. jaune pâle assez petite ou petite, $6-14 \mathrm{~mm}$.

F. de 2 formes, les unes ovales ou en rein dans leur pourtour, dress., distiques, non vésiculeuses, les autres réduites à 1-3 lobes term. par une grosse vésicule; cor. assez petite, 10-14 mm., à lèvre sup. ent. une fois plus longue que le palais, l'inf. plane et étalée; éperon presque aussi long que la cor.

Marais tourb. - Jn-Jt.

U. intermedia Hayne 867

F. toutes conformes, étalées en tous sens, munies de vésicules tr. petites; cor. petite, 6-10 mm., à lèvre sup. émarginée et aussi longue que le palais, l'inf. à bords un peu réfléchis; éperon réduit à une petite bosse peu apparente. . . . . U. minor L. 868 Marais tourb. - Jn-Jt.

\section{FAMILLE 60. - PRIMULACÉES}

+ Pl. aquat. à f. submergées, découpées en lan. lin.; fl. en vert. écartés sur une hampe aérienne nue; caps. presque indéh., les 5 valves restant adhérentes au sommet et à la base. . . HOTTONIA 312

+ Pl. terrestres, à f. aériennes, simples; fl. jamais vert. sur une hampe; caps. nett. déh.

X F. toutes rad., en rosette, atténuées ou contractées brusq. en pétiole; fl. jaunes, solit. sur des pédonc. rad. ou en omb. sur une hampe nue; pl. acaules. . . . . . . . . PRIMULA 313

$X$ F. caul. alt., opp. ou vert.; fl. portées sur une t. feuillée; pl. caulescentes.

$=$ Cal. à 5 lobes profonds; cor. en roue, en grelot ou en cloche dépourvue d'écailles.

a Caps. glob., s'ouvrant au sommet par 2-5 valves; fl. jaunes axill. ou en pan.; f. opp. ou vert.; pl. viv. . . LYSIMAGHIA 314

a Caps. glob., s'ouvrant en travers par un couvercle; fl. blanches, roses, rouges ou bleues axill.; pl. ann. ou viv. de petite taille. Cor. blanche ou rosée plus courte que le cal.; f. alt., ovales aig; fl. subsessiles, dress.; 4 sép., 4 pét., 4 ét.; petite pl. ann. de $2-8 \mathrm{~cm}$. . . . CENTUNGULUS 315 Cor. rose, rouge ou bleue dépassant le cal.; f. opp.; fl. solit. sur des pédonc. opp., à la fin recourbés ; 5 sép., 5 pét., 5 ét. à filets barbus; pl. ann. ou viv...... ANAGALLIS 316

= Cal. à tube subglob. soudé avec l'ovaire, à है dents triang.; cor. en coupe, petite, blanche à tube court, à gorge munie de 5 écailles; caps. glob., incluse; s'ouvrant au sommet par 5 valves; pl. viv.; f. rad. en rosette, les caul. alt., toutes obovales, atténuées en pétiole, ent........................... 317

\section{GenRe 312. - hOTTONIA L.}

Pl. viv. à souche ramp., à tige oblique, radicante, submergée, émettant des hampes aériennes nues; f. alt., pennatiséquées-pectinées; fl. d'un blanc rosé à gorge orangée, 3-7, en vert.; pédic. étalés, puis recourbés; cor. dépassant le cal., en soucoupe, à tube court, à limbe plan, $2 \mathrm{~cm}$., à ö lobes obovales-émarg. . . . . . H. palustris L. 869 Marais, fossés. - Mai-Jn. 


\section{Genre 313. - PRIMULA L.}

+ Fl. jaune soufre, solit. sur des pédone. rad., vel.-laineux, égalant à peu près les f.; cal. fendu presque jusqu'au milieu à lobes étr., lanc.-acum.; cor. large de 2-3 cm.; f. obovales, insensibl. atténuées en pétiole, vel. et pâles en dessous . . . P. vulgaris Huds. 870

Prés hum., bois, haies. - Mars-Mai.

Var. à fl. plus petites réunies en omb. sur un pédone. ord. plus court que les f. (var. caulescens).

+ Fl. en omb. multiflores ord. unilat. sur des hampes pub. plus long. que les f.; cal. fendu jusqu'au quart, à lobes ovales; cor. large de moins de $2 \mathrm{~cm}$; f. ovales, souvent brusq. rétrécies en pétiole.

Cor. large, 12-18 mm., presque plane, inodore, jaune soufre, plus foncée à la gorge; cal. non renflé, vert sur les angles, à lobes triang-acum. ; caps. dépassant le tube du cal. appliqué sur elle; f. ovales-oblongues, atténuées ou brusq. contractées en pétiole, vertes et pub.. . . . . . . . . P. elatior Jacq. 871 Bois humides, bords des ruisseaux. - Mars-Av.

Cor. petite, 8-12 mm., concave, odor., jaune vif, offrant à la base 5 taches orangées; cal. renflé, tr. ouvert, blanchàtre-tom., à lobes ovales subobtus; caps. plus courte que le tube du cal. non appliq. ; f. ovales, Jorusq. contractées en pétiole, pub.-grisàtres en dessous.

Prés et bois. - Mars-Mai.

\section{GENRE 314. - LYSIMACHIA L.}

+ T. pub., robustes, dress.; fl. nombr., en pan. ou en vert.; f. ovaleslanc. gr., $6-10 \mathrm{~cm}$. de long, au moins 3 fois plus long. que larg., pub. en dessous.

Fl. en pan. term. feuillée à la base; cal. à lobes lanc.-aig., cil., bordés de rouge; cor. d'un beau jaune, 2-3 fois plus gr. que le cal., à lobes aig. ou obtus non frangés et munis de petites glandes jaunâtres à la face sup.; pl. pub., non gland. L. vulgaris L. 873 Lieux maréc., bords des eaux. - Jn-At.

Fl. en vert. axill. formant une longue grappe feuillée; cal. pub. gland., à lobes long. acum., non bordés de rouge; cor. fin. gland. à lobes aig.. cil.-frangés; caps. plus courte que le cal.; pl. toute poilue gland................ Lunctata L. 874 PI. subsp. - Jn-At.

+ T. gl., grêles, couchées; fl. solit. à l'aisselle des f.; f. orb. ou largr. ovales, petites, $2-3 \mathrm{~cm}$. de long, aussi larges ou presque aussi larges que long., gl.

F. suborb.-obtuses ponctuées de brun; pédonc. ne dépassant pas les f.; fl. gr., 2 cm. de large; cal. à lobes ovales en cour, aig.; caps. plus courte que le cal.; fr. rar. . . . L. Nummularia L. 875 Prés hum., fossés. - Jn-At.

F. ovales-aig., non ponctuées, tr. fin. serrulées aux bords; pédonc. dépassant les $\mathrm{f}$.; fl. petites, $1 \mathrm{~cm}$. de large; cal. à lobes lanc.lin., en alène; caps. égalant à peu près le cal.

L. nemorum L. 876

Bois hum. - Mai-At.

\section{Genre 31כ̈. - GeNTUNGULUS L.}

Petite pl. à f. presque toutes alt.; fl. très petites, solit. à l'aisselle des f.; cal. à 4 lobes lanc.-lin.; cor. en grelot, à tube court et subglob., à't lobes redressés, ent., aig.; ét. saillantes; caps. plus courte que le cal. . . . . . . . . . G. minimus L. 877 Lieux sabl. hum. - Mai-Sept. 


\section{Genne 316. - ANAGALLIS Tourn.}

+ F. sessiles, ovales ou lanc., ponctuées de noir; t. couchées, mais non radicantes à la base; fl. rouges, carnées ou bleues, sur des pédonc. égalant ou dépassant peu les f.; cor. en roue, dépassant un peu le cal.; pl. ann. . . : . . . . . . A. arvensis L. 878 Lieux cult, ch. - Mai-0et.

Comprend les var. suivantes :

Pét. dentic. plus ou moins cil. gland.; cor. rouge ou carnée, rar. violacée, plus longue que le cal.; pédonc. fruclif. dépassant long. les f. Cor. rouge, pét. fort. cil. gland. . . . . . . A. phœnicea Lamk. Cor. violacée. . . . . . . . . var. violacea Delacour. Cor carnée, pét. faibl. cil. gland ..... A. carnea Schrank.

Pét. dentic., mais non cil. gland.; cor. bleue égalant le cal.; pédonc fructif. écalant les f. ou les dépassant à peine. A. cærulea Lamk.

+ F. un peu pétiolées, suborb., non ponctuées; t. couchées-radicantes à la base; fl. d'un rose tendre à veines plus foncées, sur des pédonc. capill. $2-3$ fois plus longs que les f.; cor. en cloche, $2-3$ fois plus longue que le cal., à lobes ent., non cil.-gland.

$$
\text { Marais tourb. - Mai-At. }
$$

A. tenella L. 879

\section{- Genre 317. - SAMOLUS L.}

Pl. gl., à souche courle et filbreuse; t. dress. peu rameuse; fl. en grappes term., formant une pan. long. et étr.; pédonc. coudés et munis d’une bractéole un peu au-dessus du milieu. . . . . S. Valerandi L. 880

Lieux hum. ou maréc. - Jn-At.

\section{FaMille 61. - OLÉACÉES \\ GENRE 318. - LIGUSTRUM L.}

Arbriss. à f. opp., lanc. ou obovales-elliptiques, ent., gl., brièv. pétiolées; fl. blanches, odor., en pan. ou thyrses term. petits et serrés; cal. petit, cad., à 4 dents; cor. en entonnoir, à tube dépassant le cal., à 4 lobes étalés, ovales, concaves; 2 ét. incluses, insérées sur le tube de la cor.; stigmate bifide; baie glob., noire, amère, de $3 \mathrm{~mm}$.

L. vulgare L. 881

Haies et bois. - Fl. Mai-Jt; fr. Sept.

on cult. fréfuemment le lilas, Syringa L. Le genre Syringa diffère du genre Ligustrum par son fr. caps. s'ouvrant en 2 valves, ses fl. lilas ou violacées en pan. gr. et ses f. larg. ovales ou oblongues-acum. syringa vulgaris L. a les $\mathrm{f}$. larg. ovales en cour, les fl. d'une odeur suave en pan. pyramidale tr. fournie: S. persica L. (lilas de Perse) a les f. oblongues lanc. ent., rar. pennatifides, les fl. en pan. làche.

\section{FAMILLE 62. - APOCYNÉES}

\section{Genre 319. - VINCA L.}

Pl. viv., à t. sarment, couchées radicantes, toujours vertes, à rameaux florifères redressés; cor. bleue ou violacée, rar. blanche, en soucoupe à tube obconique, à limbe élalé en roue, à 5 lohes tronqués obliq.; ¿ ét. incluses, à filets vel., genouillés à la base, hlargis au sommet; stigmate en anneau, surmonté d'une couronne de poils.

F. ovales-elliptiques, gl., fermes ; rameaux florifères de $10-20 \mathrm{~cm}$.; cal. à lobes lanc.-lin., gl. bien plus courts que le tube de la cor.; celle-ci

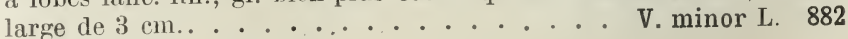
Bois, haies. - Mars-Mai 
F. larg. ovales, un peu en cour à la base, à bords pub.-cil.; rameaux florifères de $30-500 \mathrm{~cm}$.; cal. à lobes lin. en alène, cil., égalant presque le tube de la cor.; celle-ci large de 4-5̆ cm. . V. major L. 883 Haies, fossés, subspontané. - Mars-Mai.

\section{FAMILLE 63. - ASCLÉPIADÉES}

T. dress. ou un peu volubiles; fl. d'un blane verdàtre ou jaunàtre, en cymes corymbiformes pédonc.; cor. à lobes étalés; couronne des ét. en écuelle, charnue, à 5 lobes courts, arrondis au sommet; follic. étroits, $1 \mathrm{~cm}$. de large, renfl. inf., gl., étalés; f. brièv. pétiolées, ovales ou oblongues lanc., souvent en coeur à la base, à nervures et bords fin. pub............... VINGETOXIGUM 320

T. dress., robuste; fl. rosées en omb. tr. fournies et denses; cor. à lobes réfléchis; couronne des ét. formée de : cornets munis d'une corne à l'int.; follic. larges de $2-3 \mathrm{~cm}$., ovales allongés, tom.-blanchàtres, munis de rares épines courles et molles; f. gr., brièv. pétiolées, oblongues, obtuses, mucronées, blanchàtres tom. en dessous, à nervures lat. nombr. et parallèles en travers. . . ASCLEPIAS 321

\section{Genre 320. - VINCETOXIGUM Moench.}

Pl. viv. de 30-80 cm., fin. pub., à souche rampante; pédic. un peu plus longs que les fl.; corolle à lobes gl., rar. pub.; follic. longs de $4-6 \mathrm{~cm}$.

Bois, lieux incultes.

V. officinale Moench. 884

On trouvait autrefois dans le bois de Vincennes, nat., $V$. nigrum Monch qui se distingue de $V$. officinale par ses t. plus long., $40 \mathrm{~cm}$. à $1 \mathrm{~m}$., volubiles dans leur partie sup., par ses fl. rouge-noirâtre, en omb. brièv. pédone. ou subsessiles, à pédic. 2-3 fois plus longs que les fl., par sa cor. à lobes pub. et par ses follic. plus longs et plus long. acum., renflés vers le milieu.

\section{Genre 321. - ASGLEPIAS L.}

Pl. viv. robuste, pub., à souche long. traçante; t. herb. tr. feuillées.

Originaire de l'Amérique du Nord, nat.

A. Cornuti DC. 885

\section{Famille 64. - GENTIANÉES}

+ F. simples, ent., opp., les inf. souvent en rosette, non engainantes à la base ; cor. marcescente, contournée dans le bouton ; caps. s'ouvrant par 2 valves; pl. terrestres.

$X$ Style tr. distinct, filiforme, caduc; pl. ann. ou bisann. à fl. jaunes, roses ou blanches.

= Cal. ord. tub. à 4-3̆ lobes ; cor. en entonnoir à 4-3̆ lobes; 4-3̆ ét. ; pl. verte.

Cal. tubul. anguleux à 5 lobes; cor. à $气$ lobes; 3 ét. à anth. tordues en spirale après la flor. ; caps. cyl. aig.

ERYTHREA 322

Cal. non anguleux à 4 lobes; cor. à 4 lobes; 4 ét. à anth. non tordues; caps. ovale ou oblongue. . . . . CIGENDIA 323

$=$ Cal. divisé jusqu'à la base en 6-8 lobes lin.; cor. jaune, en roue à 6-8 lobes ; 6-8 ét.; pl. tr. glauques. . . . . CHLORA 324

$\times$ Style nul ou tr. court, stigmate sessile ou subsessile et persist. au sommet de la caps.; pl. viv. ou ann., à fl. bleues ou violacées.

Cal. tubul. ou en cloche, à $4-10$ lobes plus ou moins profonds; cor. tubul. ou en eloche à gorge nue ou frangée à 4-10 lobes dépourvus de fossettes nectarifères; fl. bleues ou violacées. 
Cal. divisé jusqu'à la base en ǒ lobes lin.-lanc.; cor. en roue à כ lobes lanc. portant chacun à la base 2 fossettes nectarifères à bords cil.; fl. d'un bleu violacé ponctuées de noir.

SWERTIA 326

+ F. à 3 fol., ou simples ot profond. échancrées en coeur à la base, alt., engainantes à la base; cor. cad., non tordue dans le bouten; caps. presque indéh.; pl. aquat.

F. suborb. en coeur; flottantes; fl. jaunes en fasc. axill. ombelliformes; cor. en roue à lobes cil. aux bords; 5 ét. alt. avec 气 glandes hypogynes; caps. ovoïde acum., indéh., à 1 loge, à graines ailées. . . . . . . LIMNANTHEMUM 327

F. à 3 fol., émergées; fl. rosées en grappes; cor. en entonnoir, à lobes barbus en dedans, étalés réfléchis; 今゙ ét.; caps. subglob., à 2 valves au sommet, à une loge à graines ovoïdes.

MENYANTHES 328

\section{GENRE 322. - ERYTHRAA Rich.}

Fl. pédonc. en cymes lâches, à rameaux ouverts, pauciflores; cor. petite, rose, à lobes oblongs de $3-5 \mathrm{~mm}$.; t. grêle, rameuse dès la base ou dès le milieu à $\mathrm{f}$. caul. inf. plus courtes que les sup.; f. rad. non en rosette d̀ la flor.; caps. égalant le cal. . E. pulchella Horn. 886

Pàturages hum. - Jn-Sept.

Fl. sessiles ou subsessiles en corymbe dense, à rameaux courts ou peu divisés ; cor. moyenne, rose, à lobes ovales de 5 - $6 \mathrm{~mm}$. ; t. quadrang., rameuse au sommet, à rameaux dr., à f. caul. inf. plus long. que les sup.; f. rad. en rosette, obovales-oblongues; caps. plus longue que le cal. . ....... E. Centaurium Pers. 887 Bois et pàturages. - Jn-Sept.

\section{Genre 323. - GICENDIA Adans.}

Pl. de $\ddot{b}-1 \breve{c m} \mathrm{~cm}$. simple ou peu rameuse à $\mathrm{t}$. filiformes, dress., presque nues; f. rad. oblongues, en rosette, les caul., minuscules, aciculaires; fl. jaunes, tr. petites, solit. sur de longs pédonc. dress.; cor. à tube renflé; cal. en cloche, à dents courtes, stigmate en tête, ent. ; caps. ovale, à 1 loge, dépassant le cal. . C. filiformis Delarb. 888 Allées hum. des bois sil., bords des étangs. - Jn-Sept.

Pl. de 3-12 cm., tr. rameuse dès la base à rameaux filiformes étalés ou divariqués; f. glaucescentes, lanc. ou lanc.-lin.; fl. d'un blanc jaunâtre ou rosées, tr. petites, assez long. pédonc., en cymes dichotomes tr. lâches; cor. à tube cyl.; cal. divisé jusqu'à la base en lobes lin.; stigmate fendu en 2 lamelles; caps. oblongue, à 2 loges incomplètes, dépassant le cal................ C. pusilla Grisel. 889 Bruyères hum., allées hum. des bois sil., bords des étangs. - Jn-Sept.

$$
\text { Genre 324. - CHLORA L. }
$$

Pl. glauque à t. élancée, rameuse au sommet; f. rad. obovales, en rosette, les caul. opp. et soudées à la base dans toute leur larg.; fl. d'un jaune vif, en corymbe souvent multiflore, à cor. dépassant le cal.; caps. ovoïde. . . . . . . . . C. perfoliata L. 890 Prés herbeux, coteaux incultes. - Jn-At.

$$
\text { Genre 325. - GENTIANA L. }
$$

+ Cor. frangée à la gorge ou aux bords des lobes, sans plis ni lobules dans les sinus; pl. à racine grèle.

Cal. en cloche à 4 lobes acum. plus courts que le tube; fl. bleues, 
$4 \mathrm{~cm}$. de long, solit. sur la t. ou les rameaux; cor. en cloche, nue à la gorge, divisée jusqu'au milieu en 4 lobes oblongs, cil.frangés et denticul.; stigmates ovales, conniv.; t. simple ou peu rameuse; f. dress., lanc.-lin., aig., à 1 nervure; vivace.

\section{G. ciliata L. 891}

Talus calc. - At-0ct.

Cal. en cloche à 3 lobes lanc., égalant le tube; fl. d'un bleu violet, 25-33 mm. de long, pédonc., axill. et term., assez nombr. et serrées; cor. en cloche, barbue à la gorge, à 5̌ lobes lanc.-aig., ent.; stigmates roulés en dehors; t. dress., simple ou rameuse; f. tr. étalées, les rad. obovales, les autres ovales-lanc. à 3-כ̆ nervures; ann........... G. germanica Willd. 892

Pàturages secs, pelouses rases calc. - At-0et.

+ Cor. bleue non frangée à la gorge et aux bords des lobes; pl. viv.,

à souche émettant des rejets ou des rosettes stériles.

T. courbées-ascend. un peu épaisses; f. gr. oblongues-lanc. obtuses à 3-ö nervures; les caul. long. connées-engainantes, les sup. dépassant les fl. sessiles, fasciculées au sommet des t.; cor. tubul. en massue à 4 lobes lanc.-aig,; anth. libres. G. cruciata L. 893 Bois et patturages calc. - Jn-At

T. dress. ou ascend., élancées; f. Janc. ou lanc.-lin., obtuses, à 1 nervure, à bords un peu roulés, courtement connées, dépassées par les fl. gr., pédonc., alt. et solit. à l'aisselle des f. supér.; cor. tubul. en cloche à 5̆ lobes ovales-aig.; anth. soudées.

G. Pneumonanthe L. 894

Prairies et marais tourb., landes hum. - Jt-Sept.

\section{GenRe 326. - SWERTIA L.}

Pl. viv., gl., à t. dress., raides peu feuillées; f. ovales ou oblongueslanc. à 3゙-7 nervures, les inf. long. pétiolées, les sup. sessiles; fl. pédonc. en pan. term, interrompue; כ̋ ét.; style nul; 2 stigmates sessiles; caps. ovoïde; graines ailées. . . . . . S. perennis L. 895

Marais tourb. - Jt-Sept.

\section{Genre 327. - LIMNANTHEMUM Gmel.}

Pl. viv., aquat., à t. allongées, rameuses, submergées; f. nageantes suborh. en cour, luisantes en dessus, tuberc. en dessous, à pétiole engainant, alt., les sup. opp.; fl. long. pédonc.; cor. cad.; style filiforme, persist.. ........ L. peltatum Gmel. 896 Etangs, rivières. - Jt-Sept.

\section{Genre 328. - MENYANTHES L.}

Pl. viv., aquat., gl., à souche allongée, ramp., charnue, articulée-écailleuse; f. alt. et comme rad., robustes, à long pétiole engaînant; fl. en grappes simples bractéolées sur une hampe axill., nue; style filiforme, saillant, persist.; caps. demi-adhérente.

Marais, prés tourb., fossés maréc. - Av.-Mai.

M. trifoliata L. 897

\section{Famille 65. - CONVOLVULACEES}

T. feuillées à f. ayant plus de $1 \mathrm{~cm}$. de long; fl. souvent gr. de $2-6 \mathrm{~cm}$. de long; cor. presque ent. à 5 plis; ét. incluses; caps. indéh. à 2 loges, chaque loge à 2 graines......... . . CONVOLVULUS 329

T. sans f., filiformes, s'enroulant et se fixant par des suçoirs autour des végétaux; fl. petites 2-5̉ mm., en glom.; cor. à క̌ lobes profonds; caps. s'ouvrant circul. en travers vers la base (pyxide) ou irrégul. au

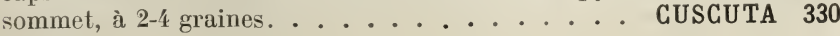




\section{Genre 329. - GONVOLVULUS L.}

Bract. petites, lin., éloignées de la fl.; cal. non recouvert de bract.; fl. moyennes, $2 \mathrm{~cm}$., blanches ou roses, solit. ou géminées, sur des pédonc. axill. plus longs que la f. ; pl. gl. ou pub., à souche grèle, long. traçante; t. couchées ou volubiles grimp.; f. petites, sagittées ou hastées, ovales ou lin.-lanc., ent., à oreillettes diverg. plus ou moins aig. . . . . . . . . . . . . . arvensis L. 898 Ch. - Nai-0et.

Bract. foliacées, ovales-lanc., en cœur à la base, recouvrant le cal.; fl. gr., 4-6 cm., blanches, solit. sur des pédonc. axill. plus courts ou plus longs que la f.; pl. gl., à souche tr. longue, rameuse; t. volubilesgrimp.; f. gr., sagittées ou hastées, en cour à la base, ent., à oreillettes tronquées . . . . . . . . . . C. sepium L. 899 Haies, buissons. - Jn-Sept.

Var. à fl. moitié plus petites; f. petiles, étr., longues de 3- $4 \mathrm{~cm}$., larges de 12-18 mm., à oreillettes arrondies, peu diverg.; t. faibles, couchées sur le sol (var. minor).

Var. aussi à fleurs roses.

\section{Genre 330. - GUSGUTA L.}

+ Fl. blanchâtres, pédic., à pédic. 2-4 fois plus longs que le cal., en corymbes làches, rameux, bractéolés; cor. en cloche, à 5 lobes ovales-triang., incurvés au sommet, un peu plus courts que le tube ; écailles arquées-conniv., frangées, fermant le tube de la cor.; èt. égalant la cor.; 2 styles plus longs que l'ovaire; stigmates en tête; caps. s'ouvrant irrégul. au sommet.

C. corymbosa Ruiz et Pavon. 900

Pl. américaine, parasite sur la luzerne.

+ Fl. sessiles ou subsessiles, en glom. glob., serrés, sessiles ; 2 styles à stigmates allongés, linéaires ou oblongs; caps. s’ouvrant circul. en travers vers la base (pyxide).

$X$ Ecailles petites, appliq. contre le tube de la cor. et ne le fermant pas ; styles bien plus courts que l'ovaire; ét. incluses; cal. à lobes obtus.

T. simples; fl. d'un blanc jaunàtre, sessiles, en glom. de $1 \mathrm{~cm}$., sans bractée à la base; cor. large, glob. en grelot, à :" lobes de moitié plus courts que le tube; graines fin. écailleuses.

Parasite sur le lin d'été. - Jt-At.

C. Epilinum Weihe 901

T. rameuses; fl. d'un blanc rosé, munies d'un pédic. charnu, en glom. de 10-15 mm. pourvus d'une bract. à la base; cor. en cloche, à 4-5̆ lobes presque aussi longs que le tube; graines lisses.

C. europaea L. 902

Parasite sur l'ortie, le houblon, le chanvre. - Jn-Sept.

$\times$ Ecailles gr., frangées, arquées-conn., fermant plus ou moins le tube de la cor.; styles bien plus longs que l'ovaire; ét. saillantes, mais plus courtes que la cor.; cal. à lobes acum.; glom. munis d'une bract.; graines lisses.

Cor. d'un blanc rosé, à écailles conniv. au sommet, fermant le tube, séparées à la base par un intervalle étroit. aig.; cal. en cloche, fendu jusqu'aux $3 / 4$; pl. rougeàtre, croissant d'une manière irrégul.; glom. assez petits de $\ddot{3}-8 \mathrm{~mm}$.

\section{Epithymum Murr. 903}

Parasite sur le serpolet, le genêt, les bruyères, ele. - Jn-Sept. 
Cor. blanche, à écailles moins conniv., ne fermant pas ent. le tube, séparées par un intervalle tr. obtus, plus large qu'ellesmêmes; cal. obconique, fendu jusqu'au milieu; pl. jaunâtre, s'étendant en cercles régul.; glom. de 8-10 $\mathrm{mm}$.

C. Trifolii Babingt. 904

Parasite sur le trèfle et la luzerne cultivés. - Jn-Sept.

\section{FAMILLE 66. - BORRAGINÉES}

+ Carpelles libres.

= Cor. régul., en rowe; ét. saillantes au-dessus du tube de la cor., conniv., rappr. en còne......... BORRAG0 331

= Cor. régul., en tube, en entomnoir ou en soucoupe; rar. irrégul.; ét. non conniv., saillantes ou incluses.

X Cor. tubul. régul., à gorge munie de כ̌ écailles allongées, cil.gland., conniv. en cône; tube allongé, à :̋ dents courtes, larges, obtuses; carp. à base concave entourée d'un rebord saillant plissé.

SYMPHYTUM 332

X Cor. régul. en entonnoir ou en soucoupe ou irrégul. lubul.

Q Ecailles de la gorge de la cor. cil. ou barbues; carp. ridés rugueux à base concave entourée d'un rebord saillant plissé.

ANGHUSA 333

Q. Ecailles gl., ou remplacées par des plis, des gibbosités, des faisc. de poils ou nulles.

- Des plis ou des gibbosités ou pas d'écailles.

Cor. régul. en entonnoir, à gorge ouverte nue ou munie entre les ét. de äplis ou gibbosités veloutées, à $\breve{~ l o b e s ~ e ́ t a l e ́ s ~ o b t u s . ~}$

LITHOSPERMUM 334

Cor. irrégul., tubul. presque en cloche à gorge ouverte, nue, à ๖̌ lobes inég. . . . . . . . . . . ECHIUM 335

- Des faisc. de poils ou des écailles gl.

Cor. en entonnoir à gorge garnie de ŏ faisc. de poils; cal. tubul., en cloche, à $̋$ lobes peu profonds; carp. lisses, en toupie, fixés au récept. par une base étroite, entourée d'un rebord; f. rad. lanc. ou ovales acum. de 10 à 30 cent. de long.; fl. gr. de plus de $1 \mathrm{~cm}$. . . . PULMONARIA 336 Cor. en entonnoir ou en soucoupe, à gorge resserrée par 5 écailles courtes, obtuses, colorées, gl.; cal. en cloche à ¿ lobes plus ou moins profonds; carp. lisses et luisants, ovoïdes-trigones, un peu compr., à bords tranchants, à base étr.; f. oblongues ou lanc. de moins de $5 \mathrm{~cm}$. de long.; fl. petites, de moins de $6 \mathrm{~mm}$.. . . . . MYOSOTIS 337 + Carpelles soudés.

然 Gorge munie d'écailles.

¿o Carp. munies d'épines ou d'aiguillons crochus; cal.à ह̋ lobes égaux; fl. en grappes; t. dress.

Carp. petits, dressés, trigones ou comprimés, hér. de longs aiguillons sur le bord seulement, soudés à l'axe central par toute leur long.; style court; sép. étr.; pl. hér. de poils raides.

EGHINOSPERMUM 338

Carp. gros, déprimés en dessus, couverts d'épines courtes sur toute leur surface, soudés à l'axe central par le sommet; style allongé; sép. larg. oblongs; pl. ord. à poils mous.

GYNOGLOSSUM 339

3 Carp. verruqueux soudés à l'axe central par le sommet; cal. irrégul., d’abord à 3 lobes lanc., ensuite foliacé, compr. en 2 valves planes contiguës, sinuées dentées, vein. en réseau; fl. 2-4 opp. aux f.; t. couchées diffuses, hér.-scabres. . . ASPERUG0 340

Gorge dépourvue d'écailles. 
Fl. jaunes brièv. pédic., en grappes nues devenant tr. longues et làches; cor. dépourvue de plis et de dents entre les lobes; $f$. caul. sessiles, lanc., hér. de longs poils raides.

AMSINCKIA 341

Fl. blanches, sessiles, en grappes nues, serrées, souvent courtes; cor. à lobes séparés par un pli longit. et souvent par une petite dent ; f. toutes pétiolées, couvertes de poils appliqués.

HELIOTROPIUM 342

\section{Gevre 331. - BORRAG0 L.}

Pl. ann., tr. hispide, à t. épaisse, dress., rameuse ; f. ridées, épaisses, les inf. orales long. pétiolées, les sup. embrass.; fl. bleues, rar. blanches, pédonc. en grappes, à la fin allongées, feuillées inférieurement; cal. profond. divisé en $\breve{~ l o b e s ~ l a n c .-l i n ., ~ a u s s i ~ l o n g s ~ q u e ~ l a ~ c o r . ; ~ c a r p . ~}$ bruns, gros, tr. obtus........ B. officinalis L. 905 Décombres, lieux cult., subsp. - Mai-Sept.

\section{GENRE 332. - SYMPHYTUM L.}

Pl. viv., vel.-hér., à souche épaisse, charuue; t. robuste, ailée, rameuse; f. épaisses, ovales-lanc., les inf. plus gr. que les moyennes loug. décurrentes; fl. blanches, roses ou violettes; cor. 2 fois plus longue que le cal., à lobes réfléchis; carp. lisses, luisants.

Prés hum., fossés. - Mai-Jt.

S. officinale L. 906

\section{Genre 333. - ANCHUSA L.}

+ F. ent. non ou à peine ondulées; cor. à tube dr.; pl. robustes, viv. ou bisann.

F. larg. ovales-acum., minces, transparentes, à peine rudes; fl. subsessiles, à têtes involucrées sur de longs pédlonc. axill.; cor. petite, 5̆-6 mm.; écailles cil.; carp. noirs munis d'un append. à la base. . . . . . . . . . A. sempervirens L. 907 IIaies, bois, nat. - Av.-Jn.

F. allongées, lanc., épaisses, opaques, rudes; fl. pédic. en grappes formant une pan.term.; cor. assez gr., 10-12 mm., bleue ou rose ; écailles saillantes, laciniées; carp. grisîtres dépourvus d'append.

Ch. pierreux ou calc. - Mai-Jt.

+ F. sinuées-ondulées, oblongues ou lanc., hér.-rudes; cor. petite, 7-8 mm. à tube courbé; pl. ann., hér.; fl. bleuâtres, petites, en grappes compactes à la flor., rappr. en pan. term.; écailles poilues; carp. grisàtres dépourvus d'append. . . A. arvensis Bieb. 909 Ch. cult. - Mai-Sept.

\section{Genre 334. - LithoSPERMUM L.}

+ Pl. viv. ; carp. blancs, lisses, luisants.

Fl. bleues ou purp. gr.; cor. de 14-16 mm. dépassant long. le cal.; f. lanc., acum., atténuées à la base, à nervure médiane seule saillante; pl. émettant des t. florifères dress. à poils étalés et des t. stériles couchées, ramp. . L. purpureo-cæruleum L 910 Bois montueux, buissons. - Av.-Jn.

Fl. d'un blanc jaunâtre, petites; cor. de $4-33 \mathrm{~mm}$. dépassant peu le cal., f. lanc. acum., sessiles, à nervures médiane et lat. saillantes; pl. couverte de poils appliq. à t. toutes dress.

Coteaux incultes, bois. - Mai-Jt.

L. officinale L. 911 
+ Pl. ann.; carp. trigones-coniques, d'un brun mat, rugueux-tuberc.; fl. blanches, rar. bleuâtres (var. cæruleum G. et G.), petites; cor. de 6-8 mm. dépassant peu le cal.; f. lanc. à nervure médiane seule saillante; pl. grisâtre, couverte de poils appliq., à racine pivotante.................. arvense L. 912 Ch. cult. - Av.-Sept.

\section{Genre 333. - EGHIUM L.}

Pl. bisann., pub. et hér. de poils raides, étalés, insérés sur des tuberc.; t. dress.; f. oblongues-lanc., hispides à 1 nervure; fl. bleues ou violacées, rar. carnées ou blanches, en grappes formant une pan. oblongue assez étr.; cor. de $12-18 \mathrm{~mm}$. à limbe élargi et irrégulier; ét. saillantes; carp. noirs, rugueux. . . . . . . E. vulgare L. 913 Lieux sees et pierreux. - Mai-At.

Var. à fl. petites, ét. incluses (E. Wierzbickii Hab.).

\section{Genre 336. - PULMONARIA L.}

+ F. rad. adultes larges, marbrées de blanc, ovales-acum., arrondies à la base, brusq. contractées en pétiole ailé aussi long que le limbe; 2 fois plus long que large; f. caul. sessiles; carp. gris, luisants, ovoïtles-obtus. ......... P. affinis Jord. 914 Bois. - Av.-Mai.

+ F. rad. adultes allongées, insensib. atténuées à la base en un pétiole plus court que le limbe 4-9 fois plus long que large.

$\times$ F. rad. adultes elliptiques lanc., longues de $20-30 \mathrm{~cm}$., marbrées ou non, elliptiques lanc.-acum., à limbe $4-30$ fois plus long que large, plus courtes que la t.; f. caul., 4-6 un peu embrass.; fl. d'abord rouges, puis d'un beau bleu; carp. luisants, ovoïdesobtus. (P. tuberosa Schrank.) . . . P. vulgaris Mérat 915 Bois. - Av.-Mai.

$\times$ F. rad. adultes lanc. ou lanc.-lin., 6-9 fois plus long. que larges, à la fin dépassant la tige.

F. rad. adultes long. lanc., atteignant 40-60 cm., marbrées de blanc, les caul. demi-embrass.; t. dépourvues d'écailles à la base; fl. rouges et bleues; carp. tr. compr. et munis au sommet d'une marge en forme de crète. . P. longifolia Bast 916 Bois. - Av.-Mai.

F. rad. adultes étr. lanc., long. de $20-30 \mathrm{~cm}$. non marbrées de blanc, les caul. sessiles et décurrentes; t. munies à la base d'écailles imbriq.; fl. roses puis d'un bleu d'azur; carp. peu compr., marginés-arrondis au sommet. . P. azurea Bess. 917 Bois. - Av,-Mai.

\section{Genre 337. - MYOSOTIS L.}

+ Cal. couvert de poils tous appliq. dr., non crochus au sommet; pl. des lieux hum. ou maréc.; cor. assez gr., 4-8 mm., à limbe plan.

Style plus long que le tube du cal.; cor. large de $6-8 \mathrm{~mm}$., à limbe plus long que le tube, à lobes émarg.; t. ascend., ramp. ou stolon. à la base, anguleuse; pl. viv. à fl. blenes, roses ou blanches.

Lieux maréc. - Mai-Sept.

M. palustris Roth. 918

Style plus court que le tube du cal.; cor. large de $4-6 \mathrm{~mm}$., à limbe aussi long que le tube, à lobes tr. ent.; t. dress. dès la base, tr. rameuse, ni ramp., ni stolon., cyl.; pl. bisann. ou pér. à fl. ord. d'un bleu pàle. . . . M. caespitosa śchultz 919 Lieux maréc. - Mai-Jt. 
+ Cal. à tube hér. de poils étalés, la plupart crochus au sommet; pl. ord. des lieux secs; cor. petite, 1-4 mm., à limbe concave.

$X$ Cor. tr. petite, 1-2 mm.; f. rad. atténuées en pétiole plus court que le limbe; pl. ann. de $3-30 \mathrm{~cm}$., à racine tr. grêle.

$=\mathrm{T}$, raides, florifères dès la base; grappes florales feuillées inf.; pédic. fructif. tous dress., peu écartés, 4-z̆ fois plus courts que le cal. fermé; pl. munie de poils crochus à l'insertion des f.

Lieux sabl. secs. - Av.-Mai.

M. stricta Link. 920

$=\mathrm{T}$. grêles, florifères dans les $2 / 3$ sup.; grappes florales nues jusqu'à la base; pédic. fructif. inf. étalés, écartés, à peine plus courts ou aussi longs que le cal.; pl. munie de poils droits à l'insertion des $\mathrm{f}$.

Cor. toutes bleues, à tube plus court que le cal.; cal. fructif. ouverts, les inf. égalant à peu près les pédic.; grappes fructif. plus long. que le reste de la t.. . . M. hispida Schlecht 921 Lieux sabi. secs. - Av. -Jn.

Cor. jaunes devenant ord. bleues ou violacées, à tube à la fin dépassant le cal.; cal. fructif. fermés ou peu ouverts tous plus longs que les pédic.; grappes fruclif. ord. plus courtes que

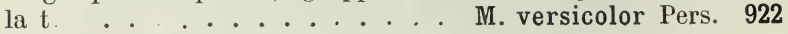
Lieux sabl. - Ar.-Jn.

Cor. petite, 2-4 mm.; à tube ne dépassant pas le cal.; f. rad. atténuées en pétiole plus long que le limbe; pl. bisann., rar. ann., de 10-60 cm., à souche oblique, courte; grappes florales nues, à la fin allongées, tr. làches; pédic. fructif. étalés, écartés, les inf. environ 2 fois plus longs que le cal. fermé à la maturité.

M. intermedia Link 923

Lieux sabl., ch. un peu hum. - Av.-Sept.

\section{GeNRE 338. - EGHINOSPERMUM Swartz.}

Pl. ann. ou bisann.; t. dress., raide, rameuse an sommet, à rameaux étalés; f. caul. lanc., rudes; fl. bleues, petites, en grappes spiciformes, à la fin, long. lâches, unilat.; cor. de $2-4 \mathrm{~mm}$., à tube plus court que le cal., à limbe concave. . . . E. Lappula Lehm. 924 Lieux secs, vieux murs. - Jn-At.

\section{GENRE 339. - GYNOGLOSSUM L.}

+ F. grisâtres, pub.-tom., molles; grappes florales ord. munies de 1-3 f. à la base.

Fl. d'un bleu pâle, vein. de violet; carp. un peu convexes en dehors, non entourés d'un rebord saillant, couverts sur toute la surface d'épin. également rappr. et entremèlés de tuberc. coniques.

Lieux secs, bords des chemins. - Nai-Jt.

C. pictum Ait. 925

Fl. d'un rouge vineux, sans vein. violettes; carp. plans, un peu concaves à la face ext., entourés d'un rebord saillant, couverts sur les faces d'épines espacées, sans tuberc.

Lieux incultes, bords des chemins. - Nai-Jt.

C. officinale L. 926

+ F. vertes, non tom., souvent un peu rudes; grappes florales ord. nues à la base; fl. rougeâtres ou violacées; carp. aplanis en dehors, couverts d'épines rappr., entremêlées de petits tuberc. coniques........... C. montanum Lamk 927 Bois ombragés. - Mai-Jt. 


\section{Genre 340. - ASPERUGO L.}

Pl. ann.; f. rudes, cil., elliptiques-oblongues pétiolées ou atténuées à la base, les florales opp.; fl. bleuâtres, petites, peu apparentes; pédic. tr. courts, à la fin recourbés; cor. égalant le cal., en entonnoir, à tube court, à gorge fermée par こ̌ écailles obtuses, convexes et conniv., à š lobes obtus . . . . . . A. procumbens L. 928 Décombres, lieux incultes. - Av.-At.

\section{Genre 341. - AMSINCKIA Lehm.}

Pl. ann., vel. hispide; t. dress.; f. long. lanc., scabres, atténuées à la base ou sessiles, alt.; fl. petites, d'un jaune orangé, en grappes formant une larg. pan.; cor. en entonnoir, à tube égalant ou dépassant le cal., à gorge ouverte et nue; carp. ridés tuberc., soudés à l'axe par la base de leur bord interue. . . . . . A. angustifolia Lehm 929 Originaire du Chili, subsp., lieux incultes, décombres. - Av.-Jn.

\section{GENRE 342. - HELIOTROPIUM L.}

Pl. ann., pub.-grisàtre; t. couvertes de poils appliq., dress. ou étalées, tr. rameuses; f. ovales ou elliptiques; carp. fort. tuberc.

Ch. secs. - Jn-0ct.

H. europaeum L. 930

\section{Famille 67. - SOLANÉES}

+ Fr. bacciforme ou caps. s'ouvrant en 4 valves ou circul. au sommet; ét. égales à anth. bilobées, à lobes s'ouvrant par une fente ou un pore term.

$\times$ Fr. bacciforme.

= Arbriss. plus ou moins épin.; baie ovale ou oblongue, petite, à 2 loges, rouge; cal. court en cloche à 2 lèvres ou à "̌̉ dents, cor. violette en entonnoir, à limbe étalé et à 3 dents; f. ovales

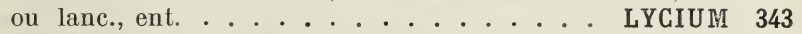

= Pl. non épin.; baie glob. ou ovoïde à 2 loges; rar. baie volumineuse, irrégul. à plus. loges; cal. à 5゙ lobes, quelquefois accrescent; cor. blanche, violette, jaunàtre en roue ou pourpre brunâtre et tubul. en cloche; f. entières ou pennatiséquées.

ơ Anth. conniv.; fl. blanches, violettes ou jaunes en cymes ombelliformes ou sol., axill.

- Lobe de l'anth. s'ouvrant par un pore term., baie glob. ou ovoïde; fl. blanches ou violettes, en cymes ombelliformes; feuilles sinuées dentées ou pennatiséquées; cor. en roue.

SOLANUM 344

- Lobe de l'anth. s'ouvrant par une fente longit.; cor. en roue, Fl. jaunes en cymes ombelliformes, baie irrégul., d'un rouge vif, à plusieurs loges; f. pennatiséquées, vel.

LYCOPERSICUM 345

Fl. blanches; baie à 2 loges, glob., d'un rouge vif, de la grosseur d'une cerise compl. enveloppée dans le cal. gonflé en vessie tr. ample et vein. en réseau, devenant jaune orangé ; f. simples............ . . PHYSALIS 346

ơ Anth. non conniv. s'ouvrant en long; fl. pourpre brunâtre, axill. solit. ou géminées; cal. à 5 lobes ovales acum., en cloche à la flor. puis étalés en étoile sous le fr.; cor. tubul. en cloche, à lobes courts; baie glob., à 2 loges, de la grosseur d'une cerise, noire et luisante; 1 . ent. ....... ATROPA 347 
FI. solit., blanches ou violacées; cal. long. tubul., pentagonal, à 5 lobes, se rompant en travers après la flor. et ne recouvrant pas la caps.; stigmate fendu en 2 lobes; cor. en entonnoir, à tube tr. long, à limbe fort. plissé, à 5 lobes brusq. term. en pointe courte; caps. grosse, épin., à 4 valves; f. sinuées dentées.

DATURA 348

Fl. jaunes, en grappes spiciformes unilat., d'abord roulées en crosse; cal. en cloche, tout entier persist. et recouvrant la caps. jusqu'à la maturité; stigmate en tête; cor. irrégul., en entonnoir oblique, à lobes inég.; caps. non épin., s'ouvrant en travers par un couvercle; f. sinuées pennatifides.

HYOSCYAMUS 349

+ Caps. à 2 loges, s'ouvrant au sommet par 2 valves souvent bifides; ऍ ét. inég., les 2 inf. plus longues et à filets glabrescents ou moins vel. que ceux des 3 courtes; anth. à 1 loge s'ouvrant en long.

VERBASGUM 350

\section{GeNre 343. - LYGIUM L.}

Cal. fendu en 2 lèvres ent. ou à 2-3 dents; baies oblongues; f. étr. lanc., insensibl. alténuées en pétiole, vertes sur les 2 faces.

\section{IIaies. - Mai-0et.}

L. vulgare Dunal 931

Cal. non bilabié, à 3 dents presque égales; baies ovoïdes; f. ord. larges et ovales, assez brusq. rétrécies en pétiole, plus pàles en dessous.

L. sinense Lamk 932

Haies. - Mai-0ct.

\section{Genre 34y. - SOLANUM L.}

+ Pl. viv., à f. simples ou pennées; fl. violettes, rar. blanches; baies glob., grosses ou ovoïdes, petites.

T. lign., sarment., cyl.; f. simples ou les sup. triséquées, les 2 segments lat. plus petits; cor. assez petite, 12-20 mm., à lobes marqués vers la base de 2 taches vertes; baies ovoïdes, rouges, petites.

Bois humides. - Jn-Sept.

S. Dulcamara L. 933

T. herb., anguleuse, dress., à rameaux souterrains munis de gros tuberc.; f. toutes pennatiséquées; cor. gr., 2-4 cm., à lobes non tachés; baies grosses, glob., verdàtres. . S. tuberosum L. 934 Cult. (pomme de terre). - Jn-Sept.

+ Pl. ann. à f. ovales plus ou moins sinuées-dentées; fl. blanches, petites; baies subglob., petites.

$\times$ Plante grisàtre, mollement vel., presque tom.; t. et rameaux cyl.; cor. 3-4 fois aussi long. que le cal. tom.; baies d'un jaune orangé................ villosum Lamk 935 Lieux cult., décombres. - Jn-Sept.

$X$ Pl. vertes, vel. ou presque gl.; t. et rameaux plus ou moins anguleux et tuberc.; cor. 1-3 fois aussi longue que le cal., pub. ou gl.; baies rouges, verdâtres ou noires.

Baies rouges, ovoïdes-glob., un peu plus hautes que larges; cor. pub., 2-3 fois aussi longue que le cal. pub.; pl. plus ou moins vel. à odeur musquée. . . . S. miniatum Mart. et Koch 936 Décombres, lieux cult. - Jn-Sept.

Baies noires ou d'un jaune verdâtre ( $S$. ochroleucum Bast), glob.; cor. glabrescente, petite, 1-2 fois aussi longue que le cal. glabrescent; pl. gl. ou à peine vel., non odor. S. nigrum L. 937 


\section{GenRE 3ł5. - LYGOPERSICUM Tourn.}

Pl. ann. tr. rameuse, f. inégal. pennatiséquées à segments incisés; baie ord. d'un rouge vif, irrégul., volumineuse, multiloculaire.

Cult. (tomate). - Jt-0ct.

L. esculentum Dun 938

\section{GeNRE 346. - PHYSALIS L.}

Pl. viv., verte, pub. à souche traçante; t. dress. simple ou rameuse, anguleuse; f. géminées. pétiolées, ovales-acum., ent. ou sinuées; fl. solit. et penchées sur des pédonc. axill. aussi longs qu'elles, courbés après la flor.; cal. florifère vert, vel., en cloche, à " ' lobes lanc.

Vignes, lieux cult., coteaux boisés. - Mai-0et.

P. Alkekengi L. 939

On rencontre quelquefois dans les décombres Nicandra physaloides Gærtn., originaire du Pérou; pl. ann. gl.; t. dress. rameuse, anguleuse; f. ovales, pétiolées, sinuées-dentées; fl. d'un bleu clair à fond blanc, solit. sur des pédonc. axill.; cal. profond. divisé en 5 lobes larg. ovales mucronés, tr. accrescents, coriaces, veinés en réseau, fauves, prolongés au-dessous de la base, recouvrant une baie glob., brune, à 3-5 loges; cor. en eloche; anthères s'ouvrant en long.

\section{GENRE 347. - ATROPA L.}

Pl. viv., verte, fin. pub. à t. dress.; f. ovales-acum., pétiolées, ent. ou un peu sinuées, les sup. géminées; pl. fétide, tr. vénéneuse.

\section{A. Belladona L. 940}

Bois frais. - Jn-At.

\section{Genre 348. - DATURA L.}

Pl. ann., verte, glabrescente à odeur vireuse ; t. dress., robuste, rameusedichotome; f. gr., ovales-acum., fort. sinuées dentées à dents acum.; fl. blanches, longues de 6-10 cm., brièv. pédonc.; pl. vénéneuse.

D. Stramonium L. 941

Origrinaire d’Orient devenue A. C. dans les décombres. - Jt.-Sept.

Var. à fl., t. et nervures des f. violacées, pl. plus robuste (D. Tatula L.) originaire de l'A mérique du Nord.

On rencontre quelquefois dans les décombres le Nicotiana rustica L. Le genre Nicotiana diffère du genre Datura par le calice persistant appliqué sur la caps. non épin. membraneuse mince s'ouvrant en 2 valves qui se fendent ensuite à leur sommet; par ses f. tr. ent., ses fl. en panicule, ses t. gland. Nicotiana rustica L. a les tiges dress., les fl. jaune-verdatre, les f. ovales-obtuses, pétiolées.

\section{GENRE 3\%9. - HYOSGYAMUS L.}

Pl. ann. ou bisann., robuste, vel. visq. à odeur vireuse; f. molles, ovalesoblongues, sinuées pennatifides, les rad. pétiolées, les caul. sessiles ou embrass.; fl. presque sessiles, jaunàtres, veinées en réseau de violet, rarement non veinćes ( $H$. pallidus WK.), à gorge d'un pourpre noir; caps. renfl. à la base . . . . . . . . H. niger L. 942 Décombres, lieux incultes. - Mai-Jt.

\section{GeNRE 3̋0. - VERBASGUM L.}

+ Filets des ét. munis de poils blanes ou jaunâtres ou gl.; pl. bisann., robustes, couvertes d'un tom. ou duvet blanc, jaunâtre ou gris.

X F. caul. plus ou moins décurrentes; t. simple ou peu rameuse; fl. en grappes spiciformes; anth. insérées obliq. ou lat. sur les filets; pl. couvertes d'un tomentum blanc-jaunâtre. 
Cor. assez petite, 12-23 mm., concave, d'un jaune pàle; anth. des 2 ét. longues en rein, insérées obliq., 3-4 fois plus courtes que leurs filets; stigmate en tète, aussi large que haut, à bords peu ou pas prolongés sur le style; f. caul. moyennes décurrentes d'une f. à l'autre, ou (var. montanum) demi-décurrentes.

Lieux incultes. - Jn-Sept.

V. Thapsus L. 943

Cor. gr., 2ö- ‘̆ mm., presque plane, d'un jaune assez vif; anth. des 2 ét. long. gr., insérées lat., 1-2 fois plus courtes que leurs filets; stigmate allongé en spathule, bien plus long que large, long. décurrent sur le style; f. caul. brièv. décurrentes ou (var. thapsiforme) décurrentes d'une f. à l'autre. . V. phlomoides L. 944 Lieux incultes. - Jn-Sept.

X F. caul. sessiles ou un peu embrass., non décurrentes; $t$. rameuse sup.; fl. en pan. pyramidale, anth. toutes insérées en travers sur les filets; pl. à tomentum grisâtre ou couvertes d'un duvet blanc.

F. courertes sur les 2 faces, ainsi que toute la pl., d'un duvet blanchâtre, floconneux, caduc; t. arrondie; pan. à rameaux étalés ascendants; cor. assez petite, 20-20 mm., jaune; stigmate ovoïde lanc., 1 fois plus long que large.

Lieux incultes. - Jn-Sept.

V. pulverulentum Vill. 945

F. vertes et peu poilues en dessus, couvertes en dessous, ainsi que toute la pl., d'un tomentum ras, grisâtre, persist.; t. anguleuse sup.; pan. à rameaux dressés; cor. assez petite, 15 -20 mm., jaune ou (var. album Mœnch) blanche; stigmate en tête déprimée, plus large que haut. . . . . . . V. Lychnitis L. 946 Lieux incultes.

+ Filets des ét., tous ou la plupart munis de poils violets; pl. ord. bisanm., assez robustes, vertes à tom. grisàtre ord. peu abondant, ou plus ou moins pub. gland.; f. caul. non décurrentes; stigmate aussi long que large; fl. jaunes à gorge violacée.

= Fl. assez petites, $130-20 \mathrm{~mm}$., fasc., ord. en pan. pyramidale; anth. toutes insérées en travers sur les filets; caps. petites; pl. couverte d'un tomentum grisàtre, ord. peu abondant; f. inf. ovales en cœur, crén.; pédic. 1-2 fois aussi longs que le cal.; bract. petites,

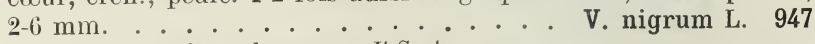
Lieux incultes, champs. - Jt-Sept.

= Fl. assez gr., $2 \ddot{3}-40 \mathrm{~mm}$., solit. ou fasc., en longue grappe spiciforme; anth. des 2 ét. long. insérées obliq. sur les filets; caps. grosses; pl. pub.-gland. au sommet; f. inf. oblongues, atténuées en long pétiole crén. ou sinuées-pennatifides; bract. gr. $12 \mathrm{~mm} .-3 \mathrm{~cm}$. Pédic. plus courts que les bract., que le cal. et que la caps.; fl. solit. ou fasc. 2-3̆ à l'aisselle de chaque bract.; stigmate en tête, plus large que haut...... V. virgatum With. 948 Lieux incultes sil. - Jt-Sept.

Pédic. plus longs que les bract., le cal. et la caps.; fl. toujours sol. à l'aisselle des bractées; stigmate arrondi, un peu décurrent de chaque còté du style, aussi long que large. V. Blattaria L. 949

Lieux incultes un peu frais, bords des rivières. - Jt-Sept.

Var. à fl. blanche.

\section{FAMILE 68. - SCROFULARIÉES}

+ Cal. à 3 lobes, égaux ou peu inég., toujours bien distincts; anth. mutiques.

$\times$ Fl. d'un brun rougeattre ou verdâtre en cymes axill. ou en pan. term.; cor. irrégul. à tube ventru et subglob. à limbe court à 2 lèvres inég., la sup. plus gr., bilobée, souvent munie en dedans 
d'une petite écaille ou staminode; 4 ét. didynames; anth. mutiques à 1 loge s'ouvrant en travers; stigmate en tète; caps. polysp. à 2 valves; f. opp. simples ou composées.

\section{SGROFULARIA 351}

$\times$ Fl. solit., en grappes ou en épis; fl. blanches, rouges, bleues, jaunes.

= Cor. à tube prolongé à la base en bosse ou en éperon; caps. s'ouvrant par des trous ou par plus. valves.

Cor. gr., en masque, à tube large renflé-bossu à la base, à gorge compl. fermée par un palais saillant; caps. à 2 loges s'ouvrant au sommet par 2-3 trous . . . . . ANTIRRHINUM 352

Cor. souvent petite, en masque, à tube atténué à la base en éperon lin. ou conique, à gorge fermée ou à peine ouverte munie d'un palais saillant; caps. à 2 loges s'ouvrant chacune au sommet par 3-4 valves, ou par un trou à 3 dents on par un

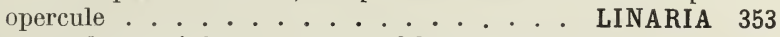

$=$ Cor. sans hosse ni éperon; caps. à 2 loges polysp.

Q F. opp.; 4 ét., dont 2 sans anth.; caps. polysp. à 2 valves devenant bifides................. GRATIOLA 354

Q F. alt. ou toutes rad.

- Fl. gr. 1,5-4 cm. de long sur 15-20 mm. de large en grappes term. unilat.; style filiforme à stigmate bifide; 4 ét. didynames; anth. à 2 loges s'ouvrant en long; pl. robustes.

DIGITALIS 355

- Fl. tr. petites., solit. sur des pédonc. rad. ou axill.; style court à stigmate en tête; 2 ou 4 ét. presque égales; anth. à 1 ou 2 loges; pl. petites.

F. toutes rad., à pétiole plus long que le limbe, oblongues ou spathulées, ent.; fl. blanches ou rosées tr. petites, solit. sur des pédonc. rad. bien plus courts que les pétioles; cal. gl., en cloche, à 3 dents; anthères à 1 loge; caps. molle, ovoïde, dépassant le cal. à 2 loges incomplètes; pl. gl., acaule.

LIMOSELLA 356

F. alt, orb., en cœur, crén.; fl. blanc rosé tr. petites, solit. sur des pédonc. axill. bien plus courts que les pétioles; cal. vel. à 3 lobes lanc.; anth. à 2 loges; caps. vel. membr., ovoïde compr.; pl.vel., à t. couchées radicantes. SIBTHORPIA 357

+ Cal. à 4 lobes presque égaux, rar. à ${ }^{3}$ dont l'un tr. petit, ou à 2 lèvres.

Cor. en roue, à tube presque nul, à limbe plan, à 4 lobes un peu inég.; 2 ét.; anth. mutiques; fl. ord. bleues. . VERONICA 358

Cor. tubul. bilabiée, à lèvre sup. plus ou moins concave ou en casque, l'inf. trilobée; 4 ét. didynames; fl. blanches, rouges, jaunes.

o Caps. polysp., à graines nombr.

む Cal. non ou à peine renflé; anth. à loges mucronées ou aristées à la base; caps. ord. pub. à graines nombr. et tr. petites.

$\odot$ Lèvre inf. de la cor. à 3 lobes émarg. ou bilobés; loge inf. de l'anth. des 2 ét. courtes plus long. aristée que la sup.; pl. grèles peu élevées............. EUPHRASIA 359

$\odot$ Lèvre inf. de la cor. à 3 lobes ent., obtus; loges des anth. toutes également mucronées à la base; pl. de 10 à $60 \mathrm{~cm}$.

Fl. petites, 4-8 mm. de long, nombr. en grappes unilat.; f. ent. ou à dents peu profondes; pl. ord. tr. rameuses.

ODONTITES 360

Fl. assez gr., $2 \mathrm{~cm}$. de long, en grappes allongées et assez làches; f. crén. dentées; pl. peu rameuse vel. visq. 
む Cal. renfl. ventru; anth. à loges mutiques; caps. à plus. graines grosses.

F. opp. simpl. dentées ou crén.; cal. à 4 dents courtes et régul.; caps. suborb. compr.; graines en rein, aplaties, ailées; fl.

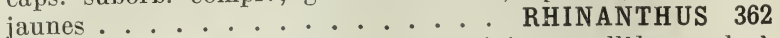

F. alt., 1 ou 2 fois pennatiséquées à divis. parallèles; cal. à 4-5̆ lobes irrégul. ou à 2 lèvres; caps. ovoïde ou lanc., acum.; graines ovoïdes trigones; fl. rouges . . PEDIGULARIS 363 Caps. ne renfermant que 2-4 graines; cal. tubul. en cloche à 4 lobes; cor. bilabiée i en masque, à tube cyl., à lèvre sup. en casque, compr. carénée, émarg.; l’inf. plane trilobée, à 2 bosses vers la gorge; 4 ét. didynames; anth. à 2 loges mucronées, caps. gl. compr.; fl. rouges ou jaunes. . . . MELAMPYRUM 364

\section{Genre 3ä1. - SCROFULARIA L.}

+ F. pennatiséquées, à lobes incisés ou pennatipartits; t. cyl. rigides, un peu lign. à la base, formant buisson; cor. petite, 4-6 mm.; staminode lanc.-aigu ou nul; caps. petite, 3-4 mm., subglob.-apic.; fl. d'un brun rougeàtre, en pan. pyramidale rameuse et multiflore; pédic. à peine aussi longs que le cal., munis de glandes subsessiles; cal. à lobes suborb., scarieux aux bords.; pl.viv. . . S. canina L. 950 Lieux secs, pierreux, carrières. - Mai-At.

+ F. dentées ou crén., simples ou accompagnées de 1-:̈ fol. à la base; t. quadrang., herb., ne formant pas buisson; cor. assez gr. 6-9 mm.; staminode ovale., orb. ou nul; caps. de 4-10 mm.

$X$ Cal. herb. à lobes oblongs obtus non scarieux; fl. d'un vert jaunâtre, en cymes axill. corymbiformes formant une pan. feuillée tr. làche; staminode nul; f. largo. ovales en coeur, fort. et inégal. incisées-dentées; caps. ovö̈de-conique de $8-10 \mathrm{~mm}$.; pl. bisann.

S. vernalis L. 951

Lieux ombracrés, buissons, vieux murs, nat. - Avr.-Jn.

$X$ Cal. à lobes plus ou moins scarieux aux bords; fl. d'un brun rougeâtre en pan. non feuillée; un staminode; pl. viv.

F. plus ou moins aig., assez fin. dentées en scie, ovales-lanc., en cour ou tronquées à la base; t. pleine, à 4 angles aig. non ailés; pédic. 2-4 fois plus longs que le cal. à lobes ovales à peine scarieux; caps. ovoïde conique de 6-10 $\mathrm{mm}$.; souche renflée-noueuse.

Bois, haies, lieux frais. - Jn-At.

S. nodosa L. 952

F. ovales-oblongues, obtuses, crén. dentées à dents inf. plus petites, en coeur à la base, parfois munies de 1-2 segments à la base; t. creuse, à 4 angles étr. ailés; pédic. 1-2 fois plus longs que le cal. à lobes arrondis-scarieux; caps. subglob. apic. de 4-6 mm.; souche courte, fibreuse. . . . . . . S. aquatica L. 953

Lieux hum., fossés. - Jn-At.

\section{GenRe 332. - ANTIRRHINUM L.}

Cal. vel. à lobes lin., tr. inég., dépassant la cor. ou à peine plus courts; caps. vel. plus courte que le cal.; fl. roses, à palais jaunâtre, assez petites, 10-15 mm., axill., solit., subsessiles, en grappe spiciforme feuillée; pl. ann., vel., à f. lanc. ou lin. . . . A. Orontium L. 954 Lieux cult., ch. sabl. - Jn-Sept.

Cal. poilu à lobes ovales obtus, $\mathbf{4}-3$ fois plus courts que la cor.; caps. poilue, plus longue que le cal.; fl. purp. ou d'un blanc jaunattre, gr., 3-4 cm., en grappe term. munie de courtes bract.; pédic. égalant le cal.; pl. viv., gl. inf., pub. gland. sup., à f. lanc. ou lanc.-lin.

Cult., subsp., vieux murs. - Mai-Sept.

A. majus L. 955 


\section{Genre 39̈3. - LINARIA Juss.}

+ F. nett. pétiolées, élargies, plus ou moins en coeur ou hastées à la base; fl. isolées à l'aisselle des f., à pédonc. plus longs que la fl.; t. couchées ou ramp.

X F. lobées, palmatinervées, à pétiole plus long que le limbe; caps. à loges s'ourrant au sommet en 3 valves; pl. viv., gl.; fl. d'un violet pàle, à palais jaune; pédonc. égalant ou dépassant la f., à la fin réfléchis; cal. à lobes lanc.-lin.; graines ovoïdes, à crêtes flexueuses épaisses: . . . . . . . L. Cymbalaria Mill. 956 Vieux murs. - Mai-0ct.

$X \mathrm{~F}$. ent. ou hastées, pennatinervées à pétiole bien plus court que le limbe; caps. à loges s'ouvrant en travers par un opercule; pl. ann. ou pér., vel.-hér.; fl. jaunes à lèvre sup. d’un violet foncé; graines alvéolées, brunes,

F. orb. ou ovales, non hastées; pédonc. vel., la plupart dépassant la f.; cal. à lobes ovales-aig. un peu en cocur à la base; pl. vel. gland.

L. spuria Mill. 957 Ch. - Jn-Oct.

F. la plupart hastées; pédonc. gl., la plupart dépassant la f.; cal. à lobes lanc. ou lanc.-lin.; pl. vel. . . . L. Elatine Mill. 958 Ch., surtout sabl. - Jn-0ct.

+ F. sessiles ou subsessiles, ent., lanc.-lin. ou lin., ni en coeur, ni hastées à la base; fl. en grappes term. nues ou feuillées.

$=$ Pédonc. aussi longs ou plus longs que le cal.

Q Fl. axill., écartées, en grappes làches fenillées; pédonc. environ 3 fois plus longs que le cal.; cor. de $6-8 \mathrm{~mm}$. d'un violet pâle à palais jaune ne fermant pas la gorge, à éperon conique, obtus, 2-3 fois plus court qu'elle; cal. pub. à lobes lin. spathulés; caps. un peu plus courte que le cal. s'ouvrant au sommet par 2 larges trous; graines brunes à crêtes longit.; pl. ann., pub.-gland. rar. (var. praetermissa G. et G.) tout à fait gl.. L. minor Desf. 959 Ch. incultes, vieux murs. - Mai-0ct.

Q Fl. en grappes term. non feuillées; pédonc. un peu plus longs que le cal. gl.; graines ridées tuberculeuses ou marginées.

— Fl. violettes à palais blanchâtre; cor. de $12-18 \mathrm{~mm}$. à éperon dr., en alène, plus long qu'elle; cal. à lobes lin. aig. plus longs que la caps. échancrée-didyme; graines grisâtres, orb. planes, bordées d'une aile cil.; pl. ann., à t. dress., simples, effilées; f. des rejets stériles ovales-lanc., ternées ou opp., les autres alt. et lin............... L. Pelliceriana 960 Pelouses arides, coteaux sabl. - Mai-Jt.

- Fl. jaunes ou blanchâtres strićes de violet, rar. non striées; pl. viv.; caps. dépassant le cal.; graines non cil.

Fl. d'un blanc lilas striées de violet, rar. non striées; cor. de 8-14 mm. à éperon obtus 3 fois plus court qu'elle; caps. subglol. dépassant le cal.; graines ovoïdes anguleuses, ridées en travers, non ailées; f. inf. vert. par 3-4, les sup. éparses, lin.-lanc., aig. . . . . . . . . L. striata DC. 961

Lieux pierreux incultes. - Jn-Sept.

F1. d'un jaune soufre à palais orangé; cor. de $20-30 \mathrm{~mm}$. à éperon un peu courbé, conique en alène, aussi long qu'elle; caps. de $6-8 \mathrm{~mm}$. courtement ovoïde, 2 fois plus longue que le cal.; graines noires. tuberc. orb.-ailées; f. éparses lanc.-lin.

Lieux incultes. - Jn-0ct.

L. vulgaris Mill. 962

$=$ Pédonc. plus courts que le cal.; pl. ann., souvent peu élevées, à f. lin.; cal. pub.-gland. dépassé par la caps. subglob. 
Tiges étalées, arquées-ascendantes; fl. jaunes, rar. tachées de violet, à palais plus foncé, gr.; cor. d'environ $2 \mathrm{~cm}$. à éperon presque dr., sub., aussi long qu'elle; graines orb. concaves, noires, lisses, larg. ailées. . . . . . . . L. supina Desf. 963 Lieux sabl. ou pierreux. - Mai-Oet.

T. dress. simples ou à rameaux dress.; fl. d'un bleu pâle, veinées de bleu, à palais blanchàtre, petites; corolle de 4-ä mm., à éperon lin. en alène, recourbé, égalant à peine son tiers; graines orb., grisàtres, lisses, larg. ailées . . L L. arvensis Desf. 964 Champs secs et sabl. - Jt-Sept.

\section{Genre 33̈4. - GRATIOLA L.}

Pl. viv., gl., à souche ramp. stolon.; t. dressée, creuse, quadrang. au sommet; f. sessiles, lanc., trinervées, dentic. dans le haut; cal. muni à la base de 2 bract. lin.; cor. de $150-18 \mathrm{~mm}$. blanc rosée, tubul. à 2 lèvres peu distinctes, la sup. à 2 lobes, l'inf. à 3.

G. officinalis L. 965

Prairies maréc., bords des eaux. - Jn-Sept.

\section{GENRE 35̋. - DIGITALIS L.}

Fl. rouges, tachées de pourpre foncé en dedans, quelquefois blanches, tr. gr., 4-j̈ cm. de long; cal. pub. à lobes larg. ovales-oblongs; f. ovales-oblongues, tom. blanchâtres en dessous, ridées en réseau, crén., la plupart long. pétiolées; plante bisann. ou viv. D. purpurea L. 966 Bois sabI. - Mai-Sept.

Fl. d'un blanc jaunâtre, assez petites. $15-20 \mathrm{~mm}$. de long; cal. gl. ou cil., à lobes lanc. lin.; f. oblongues lanc., luisantes en dessus, gl. sur les 2 faces, cil., non ridées, dentées en scie, les caul. sessiles, et arrondies à la base, demi-embrass.: pl. viv. presque gl. D. lutea L. 967 Bois et coteaux calc. - Jn- It.

Var. à t., f. et fl. pub.

\section{GeNRe 3̋̋6. -- LIMOSELLA L.}

Petite pl. ann. de $2-6 \mathrm{~cm} .$, gl., gazonnante, stolon. sans tige; cor. de $2 \mathrm{~mm}$., tubul. en roue, à tube court, dil. et égal au cal., à limbe plan à 5 lobes presque égaux; 4 ou 2 ét.; graines ovoïdes d'un brun rougeâtre striées en long. . . . . . . . L. aquatica L. 968

Bords des mares, grèves des étangs. - Jn-Sept.

\section{GenRe 3:7. - SIBTHORPIA L.}

Pl. ann., vel., gazonnante, à t. molles, filiformes, diffuses et couchées radicantes; cor. de $2 \mathrm{~mm}$., égalant le cal., presque en roue, à 3 lobes, rar. 4, un peu inég., obtus ; 4 ét.; graines ovoïdes, grises, réticulées et convexes sur le dos, sillonnées à la face interne. S. europæa L. 969 Talus hum. - Jn-Sept.

\section{GENRE 358. - VERONIGA L.}

+ Fl. en grappes naissant à l'aisselle des f.; axe central foliifère non term. par une inflor.

X F. ovales ou lanc., gl. ou f. lanc.-lin. presque ent. gl., rar. pub. gland.

= F. larg. ovales ou lanc., dentées; t. robustes, épaisses ; fl. bleues ou lilacées; caps. suborb. renfl., ne dépassant pas le cal., à peine émarg. 
T. cyl., pleine; f. brièv. pétiolées, ovales ou obovales-elliptiques, obtuses, crén.-dentelées; fl. ord. d'un bleu vif.

Lieux inondés, bords des eaux. - Mai-Sept.

V. Beccabunga L. 970

T. subquadrang., creuse; f. sessiles et demi-embrass., ovales-lanc. ou lanc., aig. un peu dentées en scie; fl. d'un bleu pàle ou rose lilas. . . . . . . . . . . V. Anagallis L. 971 Lieux inondés, bords des eaux. - Mai-Sept.

Var. ì inflor. pub. gland. ( $V$. anagalliformis Bor.).

= F. étr. lanc.-lin., presque ent. sessiles; t. grêles, faibles; fl. blanchâtres, vein. de lilas; caps. suborb. didyme, compr.-ailée, tr. échancrée, plus large que haute, débordant de tous côtés le cal.; pl. gl. ou vel. gland. (var. pubescens C. et G.). V. scutellata L. 972

Marais, fossés, bords des étangs. - Mai-Sept.

$\times$ F. dentées ou incisées, vel., ainsi que les tiges.

Q F. fin. dentées, ovales, atténuées à la base en court pétiole; fl. bleupâle sur des pédic. plus courts que le cal.; caps. triang. obcordée bien plus longue que le cal. . . . . . . V. officinalis L. 973 Bois, pâturages. - Mai-Jt.

Q F. fort. dentées ou incisées, plus ou moins élargies vers la base.

- Cal. à ž lobes tr. inég., le sup. tr. court; f. ord. étr., rar. larges de plus de 1 cm., peu nervées; souche presque lign., non ramp.

Cal. gl.; cor. assez petite, d'un bleu pàle ou rougeâtre, à lobes tous obtus; caps. gl., petite, aussi large que haute; f. lanc. ou lin., peu dentées; pl. de 3̈-20 cm., couchée-étalée.

Pelouses et coteaux secs. - Av.-Jn.

V. prostrata L. 974

Cal. vel. et cil.; cor. gr. d'un beau bleu, à lobes inf. tous 3 aig.; caps. pub. ou glabrescente, obovale; f. lanc. oblongues ou ovales, fort. dentées; pl. de 10-40 cm., à t. ascend.

Lieux secs, prés. - Mai-Jt.

V. Teucrium L. 975

- Cal. à 4 lobes peu inég.; f. larges de 2-3 cm., un peu en cœur ou tronquées à la base, fort. nervées; souche grèle, ramp.

Tiges poilues sur 2 lignes oppos.; f. inég. incisées, dentées, subsess., rar. un peu pétiolées; fl. gr., d'un beau bleu en grappes multiflores; caps. cil., compr., triang., obcordée plus courte que le cal. . . . . . . . . V. Ghamædrys L. 976 Bois, haies. - Av.-Jn.

T. poilues tout autour; f. fort. dentées en seie, ovales obtuses, long. pétiolées; fl. petites, d'un bleu pàle, vein.; caps. denticcil. compr.-ailée, débordant de tous côtés le cal.

Bois montueux ombragés ou humides. - Av.-Jt.

V. montana L. 977

+ Fl. solit. à l'aisselle des f., ou en grappes term.; axe centr. term. par une inflor.

缘 Fl. solit. et écartées à l'aisselle de presque toutes les f., celles-ci conformes entre elles; pédonc. fructif. à la fin courbés-réfléchis; pl. ann., couchées-diffuses.

○ F. long. pétiolées, aussi larges que longues, palmatilobées à 3-3̈ lobes, le term. 2-3 fois plus gr.; caps. gl., renfl., ì 4 lobes à 2-4 graines; cal. à lobes ovales-aig. élargis en cœur à la base plus long que la cor. d'un bleu pàle . . V. hederæfolia L. 978

Lieux cult. ou sabl. - Avr.-Oct.

م F. brièv. pétiolées, plus long. que larges, ovales, assez régul. crén. dentées; caps. didyme, poilue, à loges polyspermes. 
む Pédonc. fructif. atteignant 15̈-20 mm., 1-3 fois plus longs que les f.; cor. grande, 10-12 mm., d'un beau bleu; caps. de 6-7 mm., bien plus large que haute, nervée-réticulée, à lobes compr., diverg. . . . . . . . . . . V. persica Poir. 979

Lieux cult. - Avr.-Oct.

む Pédonc. fructif. dépassant rar. $1 \mathrm{~cm}$., plus courts ou un peu plus longs que les f.; cor. petite, 4-6 mm. de diamètre, dépassant peu ou point le cal., un peu plus large que haute, à lobes renfl., non diverg.

F. d'un vert clair, ovales; cal. à lobes ovales-oblongs, obtus, cil.; cor. blanche ou d'un bleu pâle; style court égalant ou dépassant à peine l'échancrure de la caps.; caps. un peu réticulée à 4-6 graines par loge . . . . . V. agrestis L. 980 Lieux cult et incult. - Avr.-Oct.

F, d'un vert foncé ou un peu glauque, ovales-arrondies; cal. à lobes ovales, subaig. glabrescents; cor. d'un bleu vif; style long de $1 \mathrm{~mm}$., dépassant l'échancrure de la caps.; caps. non réticulée, à 7-10 graines par loge. . . . V. polita Fr. 981 Lieux cult. et incultes. - Avr.-0ct.

䴕 Fl. en grappe term., placées à l'aisselle de bract. non conformes aux f.; pédonc. fructif. dress. ou ascend.

- Pl. ann. à racine grêle, à t. dress. ou ascend.

送 Pédonc. plus longs que le cal. et que les bract.; fl. d'un bleu vif, en grappes làches; pl. pub.-gland.

F. moyennes palmatiséquées, à 3-7 segments spathulés ou oblongs; cal. à lobes plus longs que la cor. et que la caps.; caps. suborb large de 5̆-6 mm.; t. un peu diffuses, à rameaux làches, divariqués . . . . . . . . . . V. triphyllos L. 982 Ch., sabl. - Avr.-Mai

F. caul. ovales, fort. dentées ou à peine crén.; cal. à lobes un peu plus courts que la cor. et rfue la caps.; celle-ci large d'environ $4 \mathrm{~mm}$.; t. raides, simples ou à rameaux dress.-ascend.

F. fort. dentées, à dents nombr. et profond.; pédonc. seulement un peu plus longs que le calice; style long. saillant sur la caps. renfl., longue de $5 \mathbf{m m}$., plus haute que large, peu échancrée. . . . . . . . V. præcox All. 983

Ch. sabl. ou pierreux. - Avr.-Mai.

F. à peine crén., à dents écartées et superf.; pédonc. 2-3 fois aussi longs que le cal.; style ne dépassant pas la caps. compr., long. seul. de $2 \mathrm{~mm}$. 1/2, bien plus large que haute, échancrée jusqu'au milieu. . . . . . . . . V. acinifolia L. 984 Ch. sabl. ou argil. un peu hum. - Avr.-Mai.

Pédonc. plus courts que le cal. et que les bract.; fl. d'un bleu pâle; pl. pub.

F. moyennes, la plupart divisées en 3-7 lobes; grappes fructif. assez serrées; caps. plus large que haute, émarg., à sinus obtus ; pl. raide, dress., gland. sup. . . . . . V. verna L. 985 Ch. et lieux sabl. - Avr.-Jn.

F. toutes dentées-crén., non lobées; grappes fructif. plus ou moins làches; caps. aussi large que haute, fort. échancrée, à sinus aigu; pl. dress. ou ascend., pub. . V. arvensis L. 986 Ch. inculles, lieux sabl. - Avr.-Oct.

Pl. viv.

Souche grêle, émettant des t. faibles, herb., radicantes à la base; f. ovales ou oblongues, obtuses, ent. ou à peine dentic.; fl. blanchâtres, vein., petites en grappes bractéolées làches; pédic. plus longs que le cal., mais plus courts que les bract.; cal. pubéru- 
lent un peu plus court que la cor.; style aussi long que la caps., glabrescente, plus large que haute, un peu échancrée.

Pelouses hum., bois frais. - Mai-0ct.

V. serpyllifollia L. 987

Souche sublign. émettant des tiges ascend., assez robustes, non radicantes; f. elliptiques ou oblongues-lanc., fin. crén.-dentées; fl. d'un bleu vif, assez gr., en longues grappes spiciformes compactes; pédic. bien plus courts que le cal. velu dépassé long. par la cor.; style 3 fois plus long que la caps. vel. gland., subglob., à peine émarg. . . . . . . . . . . . V. spicata L. 988 Piturages sees ou sabl. - Jt-0et.

On trouve rar. subsp. V. peregrina L. Pl. ann., tr. gl., à f. obovales ou oblongues, ent. ou faibl. dentées; fl. petites, bleues, en grappes term., bractéolées; caps. plus courte que le cal., suborb., à peine émarg.

\section{GeNRE 39ั9. - EUPHRASIA L.}

+ F., bract. et cal. plus ou moins couverts de poils gland.; cor. de 10$16 \mathrm{~mm}$., accrescente, à tube dépassant notablement le cal., blanche, striée de violet, avec gorge jaunàtre; caps, de $8 \mathrm{~mm}$., égalant ou dépassant à peine le cal., brièv. poilue . . E. officinalis L. 989

Prés, pàturages. - Jn.-Sept.

+ F., bract. et cal. gl. ou munis de poils non gland., cor. à lèvre infér. tachée de jaune.

Cor. longue de 7-10 mm., d'un violet pâle, striée de bleue à lèvre sup. dentic., à caps. de $3 \mathrm{~mm}$., glabrescente ou poilue, cil. de longs poils, ne dépassant pas le cal.; f. et bract. à dents aristẻes.

Pàturages, bois. - Jn-Sept.

E. stricta Host. 990

Cor. longue de 4-6 mm., blanchàtre ou violacée, à lèvre sup. à lobes ent.; caps. de $4 \mathrm{~mm}$., glab., cil. aux bords, dépassant lo cal.; f. et bract. petites, à dents aig., non aristées.

Pàturages, bois. - Jn.-Sept.

E. gracilis Fries 991

\section{Genre 360. - oDONTITES Hall.}

+ Cor. d'un beau jaune, larg. ouverte, à lobes cil.-barbus, à lèvres tr. ouvertes, la sup. dr. et tronquée; ét. tr. saillantes; anth. d'un jaune orangé gl. et libres; style saillant; caps. ovale, à la fin dépassant le cal.; f. lin. ou lin.-lanc., ord. ent.; bract. lin., ent., un peu plus courtes que les fl. . . . . . . . . 0. lutea Reich. 992 Coteaux calc. - Jt.-0ct.

+ Cor. rougeàtre ou d'un jaune rougeàtre; ét. un peu saillantes ou non; caps. plus courte que le. cal. ou l'égalant.

$\times \mathrm{F}$. et bract. lanc.-lin., étr., non ou à peine dentées; fl. rose pâle ou d'un jaune ochracé, en grappes un peu làches; cor. peu ouverte, à lèvres conniv. presque égales; anth. jaunes, libres, à peine cil., à papilles saillantes; filets des ét. à glandes allongées, noires à la base, un peu arquées; style ne dépassant pas la cor.; caps. oblongue, plus courte que le cal. . . . 0. Jaubertiana Ijietr. 993 Ch. calc - At.-0et.

$X$ F. et bract. lanc. ou lanc.-lin., plus ou moins dentées; fl. rougeâtres ou roses en grappes plus ou moins serrées; cor. ouverte, à lèvres écartées, l’inf. bien plus petite; anth. purp., agglutinées, fort. barbues; style dépassant la cor. 
F. lanc.-lin., un peu atténuées à la base, superf. dentées; bract. ne dépassant pas ord. les $\mathrm{fl}$; pl. de 20-50 cm. élancée, à rameaux ouverts ou étalés à angle droit; anth. à papilles petites; filets des ét. à glandes noires, épaisses, recourbées-arquées en bas; fl. en grappes long. et serrées . . . 0 0. serotina Reich. 994 Ch., lieux secs. - At-Oct.

F. lanc.-acum., élargies à la base, fort. dentées; bract. plus long. que les fl.; pl. de 10-30 cm., moins élancée, plus feuillée, à rameaux assez rappr., dressés-étalés; fl. en grappes longues, un peu lâches; cor. de 8 mm. . . . . . . . 0. verna Reich. 995 Ch., pâturages. - Mai-Jt.

Var. ì rameaux étalés, f. munies de 2-3 grosses dents de chaque côté, fl. plus gr., 10-11 mm., plus pâles, flor. tardive, At-Sept., prés et lieux frais (O. longifolia Corb.) Vernon.

\section{Genre 361. - BARTSIA L.}

Pl. ann., vel.-visq.; t. raides, dress., simples, feuillées; fl. jaunes, gr. ; bract. inf. lanc.-dentées plus long. que les fl.; cal. tubul., fendu jusqu’au milieu, à lobes lin.-lanc.; cor. de $2 \mathrm{~cm}$. dépassant 1 fois le cal. à lèvre inf. 1 fois plus long. que la sup. ; caps. poilue, oblongue-lanc., dépassant à peine le tube du cal. . . . . . . B. viscosa L. 996

Lieux et ch. un peu hum.

\section{GeNre 362. - RHINANTHUS L.}

Cor. assez petite, de 10-15 mm., à tube dr., à lèvres écartées, à gorge ouverte; dents du casque tr. courtes, ovales-arrondies, d'un jaune pâle; cal. gl.; bract. gl., vertes, dentées; graines lisses.

Prés, pâturages. - Mai-At.

R. minor Ehrh. 997

Cor. gr., de 15̆-20̈ mm., à tube un peu courbé, à lèvres rappr., à gorge fermée; dents du casque subconiques, violacées; cal. hér. de longs poils blancs, flexueux, rar. glabre; bract. pub., blanchâtres, dentées; graines rugueuses . . . . . . . R. Alectorolophus Poll. 998 Prés, ch. - Jn.-At.

\section{GeNRE 363. - PEDICULARIS L.}

T. solit., dress., à rameaux dress. ou ascend.; cal. poilu à lobes gl. aux bords; cor. à lèvre sup. aussi longue que l'inf., tr. arquée, offrant sous les 2 dents term., 2 autres petites dents; caps. dépassant le cal.

Maréc., prairies tourb. - Mai-Jt.

P. palustris L. 999

T. nombr., simples, étalées-diffuses, la centr. seule dress.; cal. gl., à lobes cil. aux bords; cor. à lèvre sup. plus long. que l'inf., à peine arquée, offrant seulement 2 petites dents sous le sommet; caps. plus courte que le cal. . . . . . . . . . P. silvatica L. 1000 Prés et bois hum. - Mai-Jt.

\section{GENRE 364. - MELAMPYRUM L.}

+ Fl. disposées en épis quadrang. ou cyl., serrés; f. sessiles.

F. en épis quadrang. courts et compacts; bract. verdâtres ou rougeâtres, en cœeur à la base, pliées en long, recourbées en bas, à bords relevés en crête et découpés-cil.; cal. à lobes plus courts que son tube muni de 2 lignes de poils et que la caps. à 4 graines; fl. d'un blanc jaunâtre à palais jaune; f. lanc.-lin., scabres, les sup. découpées-cil. à la base. . . . . . M. cristatum L. 1001 Bois secs. - Mai-Jt. 
Fl. en épis cyl. assez longs et peu serrés; bract. rougeàtres, rar. jaunâtres, ovales à la base, planes, dress., à bords découpés en lan. lin.; cal. pub. à lobes sét. plus longs que son tube et que la caps. obovale à 2 graines; fl. purp., rar. blanches, à gorge jaune; f. lanc.-lin., rudes, les sup. incisées-laciniées à la base.

Ch. surtout calc. - Jn.-Jt.

M. arvense L. 1002

+ Fl. jaunâtres ou lilacées, opp. 2 à 2, disposées en grappes feuilléesunilat., tr. làches et interrompues; f. brièv. pétiolées, lanc. ou lanc.lin., rudes aux bords; bract. vertes, subsessiles, lanc., les sup. munies à la base de quelques long. dents; cal. gl., à lobes lin. en alène un peu plus longs que son tube, bien plus courts que la caps. lanc. à 4 graines. . . . . . . . . M. pratense L. 1003 Bois et pâturages. - Jn.-At.

\section{FaMilLe 69. - OROBANCHÉES}

+ Fl. pédic., en corymbe dressé ou en grappe unilat.; lèvres de la cor, dress. presque parall.; souche souterraine couverte d'écailles charnues arrondies en cour. ....... LATHRÆA 365

+ Fl. sessiles ou subsessiles disposées en tous sens en épis dress.; lèvre sup. de la cor. dress., l’inf. étalée; point de souche souterraine écailleuse.

Fl. accomp. chacune de 3 bract., les 2 lat. plus petites; cal. monosépale à 4 lobes disposés par paires; caps. à valves s'ouvrant au

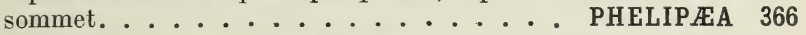

Fl. accomp. d'une seule bract. qui leur est opp.; cal. fendu en arrière ou compl. partagé en 2 segm. bifides ou ent.; caps. s'ouvrant au

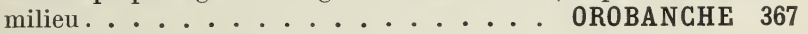

\section{GENRE 363. - LATHREA L.}

T. nulle ou tr. courte; fl. d'un violet pourpre, gr., 4-6 cm., dress., long. pédonc., en corymbe au niveau du sol; cal. gl.; caps. glob. à 2 valves, à 2 placentas à 4 graines anguleuses. . . . L. Clandestina L. 1004

Bois hum., bords des ruiss. - M.-Mai.

T. longue de 10-20 cm.; fl. blanchàtres ou rosées, petites, 15 - $20 \mathrm{~mm}$., incl., brièv. pédic., en grappe spiciforme unil.; bract. obovales tr. larg. ; cal. vel. gland. ; caps. ovale, à 2 valves, à 4 placentas, à nombr. graines glob. . . . . . . . . . . L. Squamaria L. 1005 Lieux frais et ombragés. - M.-Mai.

\section{Genre 366. - PhELip $Æ$ A C. A. Neyer}

Fl. petites, long. de 10-1弓̆ mm.; t. de כ̈-40 cm., peu épaissie à la base, grêle, rameuse, rar. simple, à écailles peu nombr. et petites, $1 \mathrm{~cm}$. de long.; cor. jaunâtre lavée de bleu violet pàle, à lobes obtus, cil. à tube resserré vers le milieu; anth. gl.; cal. à lobes triang. acum. plus courts que son tube; épis allongés, lâches, multiflores, à fl. un peu penchéescourbées .......... P. ramosa C. A. Mey. 1006 Parasite sur le chanvre (Cannabis sativa).

Fl. gr., long. de 20-3ว mm.; écailles de la tige assez long., $2 \mathrm{~cm}$. et plus; cor. bleue, dil. à la gorge ou au sommet, anth. gl., à quelques poils ou vel.; t. robuste, épaisse, ord. simple. 
T. un peu épaissie à la base, faibl. écailleuse; épi ord. làche, arrondi au sommet, à fl. de 18-30 mm. un peu penchées-courbées; cal. à lobes lanc.-aig. souvent plus courts que le tube; cor. d'un bleu violet à lobes acum., aig. brièv. poilus; anth. gl.; stigmate blanc.

P. cærulea C. A. M. 1007

Parasite sur Achillea Millefolium; pelouses. - Jn.-Jt.

Var. à lobes de la cor. obtus, ì anth. munies de 2-3 longs poils au sommet de chaque loge (P. Millefolii Corb.).

T. robuste, épaissie à la base, abond. écailleuse; épi ord. dense, souvent acum., à fl. de 2003 mm., presque dress. ; cal. à lobes lanc.-aig., aussi longs que le tube; cor. d'un bleu d'améthyste, à lobes arrondis-obtus, cil.; anth. vel.-lain.; stigmate d'abord blanc, puis jaunâtre.

Sur Artemisia campestris; coteaux arides. - Jn.-At.

P. arenaria Walp. 1008

\section{GeNRE 367 . - OROBANGHE L.}

+ Et. insérées à la base du tube de la cor. ou au-dessous du quart inf. du tube.

$\times$ Et. à filets gl. à la base, insérés à la base de la corolle; anth. jaunâtres, puis blanchâtres; écailles long. de 2-6 cm.; fì. long. de 20-2כ mm. en épi compact; cor. fauve ou rose jaunâtre, poiluegland., arquée à lèvre inf. à lobes inég., non cil.; sép. bidentés plus courts que le tube de la cor.; stigmate jaune citron.

Sur Sarothamnus scoparius. - Mai-Jt.

0. Rapum Thuill. 1009

$X$ Et. à filets plus ou moins poilus à la base, insérés à 1-2 mm. de la base de la cor. ; anth. blanchàtres ou brunâtres après dess.; écailles long. de 10-23 mm.; fl. en épi làche.

= Sép. bidentés ou bifides; filets tr. vel. à la base; lèvre inf. de la cor. à 3 lobes peu inég.; tige de 10-60 $\mathrm{cm}$.

Sép. bidentés dépassant le tube de la cor.; bract. ord. plus long. que les fl.; anth. blanchàtres après dess.; stigmate jaune, cerclé de pourpre; fl. de 15 -2: $\mathrm{mm}$.; cor. jaune rougeâtre et poilue gland. en dehors, rouge-sang, gl. et luisante en dedans, arquée, à lobes dentic. cil.; t. de $10-50 \mathrm{~cm}$., un peu renflée à la base.

0. cruenta Bert. 1010

Sur Hippocrepis comosa, Lotus corniculatus. - Mai-At.

Sép. bifides égalant le milieu du tube de la cor. ou le dépassant peu; bract. plus courtes que les fl.; anth. brunâtres après dess. ; stigmate d'un pourpre noiràtre, rar. jaune; fl. de 20-30 mm.; cor. rouge pâle ou blanc jaunàtre, poilue gland., renfl. en cloche, arquée, à lobes dentic.-cil.; t. de 20-60 cm., à peine renfl. à la base. . . . . . . . 0. caryophyllacea Smith 1011 Sur les Galium, - Mai-Jt.

= Sép. ent., égalant le tube de la cor., filets munis de quelque poils à la base; lobe médian de la lèvre inf. de la cor. du double plus long que les lat.; anth. brunes; bract. ord. plus courtes que les fl.; stigmate d'un brun rougeàtre, rar. jaune; fl. de $15-2.5 \mathrm{~mm}$.; cor. rougeâtre ou blanc jaunàtre, vein., poilue gland., tubul. en cloche, lég. arquée, à lobes dentic.-cil.; t. de $10-30 \mathrm{~cm}$., un peu renfl. à la base . . . . . . . . 0. Epithymum D.C. 1012 Sur Thymus serpyllum. - Nai-At.

+ Et. insérées au-dessus du quart inf. du tube de la cor.

Q Sép. uninervés égalant presque le tube de la cor. gl., à lobe médian de la lèvre inf. plus grand ou sép. multinervés égalant la moitié du tube de la cor. gland. ou poilue.

- Ecailles de 2-3 cm.; sép. multinervés égalant la moitié du tube; bract. lanc. presque aussi long. que la fl.; stigmate jaune; fl. de 
20-30 mm. ; cor. poilue-gland., d'un rouge fauve, insensibl. élargie à l'insertion des ét.; lèvre inf. de la cor. à 3 lobes presque égaux, non cil.; filets insérés à $4-30$ mm. de la base de la cor., tr. vel. à la base; tige de 20-50 cm., renfl. en bulbe à la base.

Sur les Medicago falcata et sativa. - Mai-Jn.

$$
0 \text {. rubens Walbr. }
$$

- Ecailles de 1-2 cm.; bract. aussi long. que la cor.

Sép. uninervés égalant presque le tube; stigmate jaune; fl. de 10-20 mm.; cor. gl., blanchàtre-violacée, un peu resserrée sous le limbe dil.; lèvre inf. à lobe médian plus grand; lobes non cil.; filets insérés à 3-4 mm., glabrescents; t. de $10-50 \mathrm{~cm}$. renfl. en bulbe à la base . . . . . 0 0. Hederæ Duby 1014

Sur le lierre (Hedera helix). - Nai-Jt.

Sép. obscur. plurinervés égalant la moitié du tube; stigmate rougebrun; fl. de 20-30 mm.; cor. brièv. poilue-gland., rouge-violacée, tr. ouverte; lèvre inf. à 3 lobes presque égaux, cil.; filets insérés à 3-3 mm., vel. à la base; tige de $10-30 \mathrm{~cm}$. peu renfl. à la base. . . . . . . . . . . . . . 0. Teucrii Hol. 1015 Sur les Teucrium Chamaedrys. - Jn-Jt.

Q Sép. égalant ou dépassant le tube de la cor., gland. ou glabrescente soit uninervés à lobes de la lèvre inf. de la cor. presque égaux, soit faibl. plurinervés à lobes de la cor. égaux ou inég. non cil. Sép. faibl. plurinervés; fl. de $15-22 \mathrm{~mm}$.

Cor. glabrescente, blanchâtre lavée et vein. de lilas à tube brusq. coudé vers le tiers inf.; lobe médian de la lèvre ini. plus gr.; filets des ét. insérés à 3-4 mm., pubérulents à la base; bract. dépassant long. les fl.; stigmate rougeàtre ou violacé; tige rougeviolacée, non ou à peine renfl. à la base; écailles de $2-3 \mathrm{~cm}$. fl. en épi dense; sép. ent. ou bidentés.

Sur Eryngium campestre. - Jn.-Jt.

0. amethystea Thuill. 1016

Cor. poilue, gland. ou glabrescente, blanc jaunàtre, tein tée et vein. de violet, presque dr. sur le dos; lèvre inf. à 3 lobes presque égaux; filets des ét. insérés à 3-3̆ mm., densément poilus à la base; bract. égalant environ les fl.; stigmate rouge-violacé; t. jaunàtre ou rougeàtre, à peine renfl. à la base; écailles de 8-20 mm.; fl. en épi plus ou moins làche inf.; sép. bifides.

Sur Picris hieracoides.

0. Picridis Schultz 1017

Sép. uninervés ent. ou bidentés; fl. de 10-16 mm.; cor. gland. ou glabrescente blanchâtre, teintée et vein. de violet ou toute jaunâtre, régul. arquée sur le dos, à lobes de la lèvre sup. infléchis, à lobes de la lèvre inf. presque égaux; filets des ét. insérés à $2.3 \mathrm{~mm}$., presque gl.; bract. égalant environ les fl.; stigmate rouge ou violacé, rar. jaune; t. rougeâtre, $10-30 \mathrm{~cm}$., renfl. en bulbe à la base; écailles de $8-20 \mathrm{~mm}$.; fl. en épi plus ou moins làches inf. . . . . . . . . . 0. minor Sutt. 1018 Sur le trèfle (Trifolium pratense) plus rar. sur heaucoup d'autres plantes : Eryngium campestre (ì Etrechy), sur Daucus Carota (ì Champagne), sur Dipsacus fullonum, etc. - Mai-Jt.

\section{Famille 70. - LABIÉES}

+ Cor. en entonnoir à 4 lobes presque égaux, ét. écartées et diverg. presque égales.

F. simpl. dentées ou ent.; fl. rose lilas ou blanches; 4 ét.; anth. à 2 loges parall.; carp. ovoïdes, arrondis au sommet; pl. tr. odor. 
F. inf. incisées pennatifides; fl. blanches tachées de pourpre; 2 ét. ; anth. à 2 loges diverg.; carp. tetraédriques, tronqués au sommet; pl. inodore . . . . . . . . . . LYCOPUS 369

+ Corolle à 1 ou 2 lèvres.

$X$ Cor. à 2 lèvres distinctes.

= Et. 4 diverg. ou arquées conniv. ou 2 fertiles.

Q 4 ét. à filets dr. diverg., s'écartant les uns des autres, dépassant ord. la lèvre sup. de la cor. presque plane.

- F. caul. larges de 1-2 cm., un peu dentées, pétiolées; bract. larges recouvrant le cal. à 5 dents égales; fl. en épis ovoïdes subtétragones agglom. formant une pan. rameuse. ORIGANUM 370

- F. petites ayant moins de $1 \mathrm{~cm}$. de large, tr. ent. à pétiole tr. court; bract. étr., lin.; fl. en tète arrondie ou en épis oblongs.

Fl. roses ou blanches en têtes ovoïdes ou oblongues; cal. en cloche, à 10 nervures, à gorge tr. barbue, à $\breve{~ d e n t s ~ d i s p o s e ́ e s ~}$ en 2 lèvres tr. inég.; ét. diverg. dès la base. THYMUS 371

Fl. bleues ou violettes en épis unilat.; cal. tubul. à $13 ̈$ nervures, à gorge nue, à õ dents presque égales; ét. courbées ascend. à la base, puis brusq. diverg. . . . . . HYSSOPUS 372

Q 4 ét. à filets arqués ascend., se rapprochant les unes des autres sup., non ou à peine saillantes.

F. tr. ent., subsessiles, coriaces; cal. à 5 dents presque égales en alène, à 10 nervures princ.; sous-arbriss. à fl. tr. petites, blanches; lèvre sup. de la cor. presque plane. SATUREIA 373

F. plus ou moins dentées ou crén., pétiolées, molles; cal. à 5̌ dents nett. disposées en 2 lèvres inég.; pl. herb. à f. et fl. souvent gr.

Cal. cyl. à 11-13 stries, à gorge vel.; cor. purp. à tube presque dr., à lèvre sup. presque plane; style à lobes inég., l'inf. plus

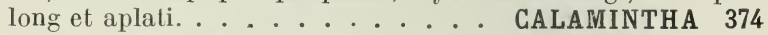

Cal. tubul. en cloche à 13 nervures saillantes, à gorge nue; cor. à tube arqué ascend., à lèvre sup. concave; style à 2 lobes

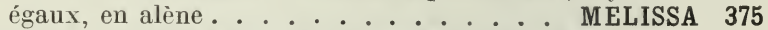

Q 2 ét. fertiles à filets courts surmontés d'un long pédic. ou connectif à 2 branches inég., la plus long. portant une loge de l'anth., la plus courte portant une écaille ou terminée en alène.

SALVIA 376

$=$ Et. 4 , à filets rappr. et parall. sous la lèvre sup. de la cor.

¿ Et. inf. (ou ext.) plus courtes que les sup. (ou int.); cal. à 13 nervures, non bilabié.

T. dress., rameuses; f. ovales, dentées, penninerviées; fl. en grappes term., cal. à tube courbé; anth. à loges compl. divariquées................ . . . NEPETA 377

T. couchées radicantes, émettant des rameaux florifères dress.; f. en rein ou en coeur, palminervées; fl. 2-3, en vert. axill.; cal. à tube dr. ; anth. à loges rapprochées en croix.

GLECHOMA 378

¿ Et. inf. (ext.) plus long. que les sup.; cal. à ว้-10 nervures, rar. 10-20.

ち Cal. en cloche ou tubul., à dents égales ou peu inég.

$\odot$ Carp. nett. tronqués au sommet; cal. en cloche.

Cal. à dents molles, en alêne, non épin.; cor. dil. à la gorge, à lèvre sup. voùtée en casque; carp. gl. au sommet; t. faibles, décombantes à la base, simples . . LAMIUM 379

Cal. à dents épin.; cor. à lèvre sup. un peu voùtée ou presque plane; carp. poilus au sommet; t. robustes, raides, rameuses, à tr. longs épis.

LEONURUS 380

$\odot$ Carp. arrondis au sommet, non tronqués.

Cor. à lèvre sup. fort. voûtée en casque; cal. à dents spin. anth. à loges opp. . . . . . . . GALEOPSIS 381 
Cor. à lèvre sup. faibl. concave ou presque plane dress.

ㅇ Cal. à dents spinescentes.

Et. déjetées hors de la cor. après la floraison; anth. à loges compl. divar., opp. bout à bout; t. ord. rameuses et à f. nombr., avec des épis plus ou moins interr.

STAGHYS 382

Et. non déjetées hors de la cor. après la flor.; anth. à loges parall. ou peu diverg.; t. simples portant $1-4$ paires de f. écartées et un épi compact rar. interr. BETONICA 383

ㅇ Cal. à dents non spinescentes.

Cal. tubul. en entonnoir à 10 nervures, à つ̋ dents presque égales, élargies à la base, pliées en long, mucronées; cor. à lèvre sup. dressée un peu concave; ét. saillantes hors du tube de la cor.; anth. rappr. 2 à 2, à loges tr. diverg. ; fl. ord. rouges ........ . . . BALLOTA 384

Cal. tubul. à 10 stries, à bั-12 dents recourbées en crochet au sommet; cor. à lèvre sup. dress. presque plane; ét. incluses dans le tube de la cor.; anth. à loges compl. divar. et opp. bout à bout; fl. blanches. . . MARRUBIUM 385

む Cal. bilabié, membr. ou compr. ou bossu sur le dos.

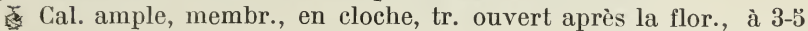
lobes ovales; carp. gros, bruns, velus. . . MELITTIS 386

Cal. non membr., à lèvres fermées après la flor.; carp. petits 1-2 $\mathrm{mm}$.

Cal. court, à 2 lèvres ent. et obtuses, la sup. portant sur le dos une écaille arrondie en forme de bosse; cor. à tube long, saillant à lèvre inf. ent., carp. tuberc. SGUTELLARIA 387

Cal. allongé, compr. et sans bosse sur le dos, lèvre sup. à 2 dents courtes, l'inf. à 2 lobes tr. aigus; cor. à tube large, peu saillant, à lèvre inf. trilobée; carp. lisses. BRUNELLA 388 Cor. réduite à la lèvre inf., tr. irrégul. à 3 ou š lobes inég., 4 ét. rapp. et paral., les deux ext. plus long.

Cor. marcescente, à lèvre sup. presque nulle, échancrée; l'inf. à 3 lobes inég., à tube muni en dedans d'un anneau de poils; pl. souvent inodores . . . . . . . . . . AJUGA 389

Cor. cad., à lèvre sup. nulle, l’inf. à ö lobes tr. inég., le médian concave; tube sans anneau poilu en dedans; pl. aromat.

TEUGRIUM 390

GeNre 368. - MENTHA L.

+ Fl. en épis cyl. term.; cor. à tube toujours gl. à l'int.; f. sessiles ou subsessiles, dentées.

X F. brièv. ovales, obtuses ou subaig., bosselées-ridées en réseau; bract. lanc. cil.; cal. fructif. non contracté à la gorge, à dents brièv. triang.-lanc.; pl. à poils crépus, ondulés, la plupart rameux; carp. ovoïdes, lisses. . . . . . . . . M. rotundifolia L. 1019 Lieux hum. - Jt-Sept.

F. ovales-oblongues ou lanc. dentées en scie, aig., à nervation simple, non réticulée; bract. lin.; cal. à gorge resserrée à la maturité, à dents lin. en alène; pl. à poils simples ou presque gl.

F. tom.-blanchâtres ou grisâtres, surtout en dessous; fl. en épis compacts, cyl. subaig.; bract. plum.; pédic. et cal. ent. vel.; carp. ovoïdes, fin. ponctués.. . . . . . M. silvestris L. 1020 Lieux hum., spontané? - Jt-Sept.

F. gl. ou presque gl., vertes sur les 2 faces; fl. en épis peu denses, grêles, lin.-aig. ; bract. et dents du cal. glab. ou cil.; pédic. el tube du cal. gl.; carp. ovoïdes . . . . . . M. viridis L. 1021 Lieux cult. au voisinage des habitations, subsp. - Jt-Sept. 
+ Fl. en vert. axill. ou en cap. term.; cor. à tube souvent velu en de dans; cal. velu.

= F. assez gr., 2-4 cm. de large, dentées en scie, assez long. pétiolées; cal. fructif. à gorge nue, à 3 dents égales et régul., cor. toujours vel. en dedans, à lobe sup. souvent échancré.

T. florifères term. par des fl.; fl. en vert. peu nombr., tous, ou les sup., rapprochés en tète term.; cal. tubul., à nombr. nervures saillantes, à dents lanc.-acum. . . . M. aquatica L. 1022 Lieux hum. - Jt-Sept.

T. term. par un petit faisceau de f.; fl. en vert. tous axill., ćcartés, bien plus. court que les f.; cal. court, en cloche, à $̋$ nervures un peu saillantes, à dents triang.-aig., à peine plus longues que larges. . . . . . . . . M. arvensis L. 1023

Ch. et lieux hum. - Jt-Sept.

$=$ F. petites, moins de $1 \mathrm{~cm}$. de large, ovales ou oblongues, brièv. péliolées, dentic. ou presque ent.; cal. fructif. velu à la gorge, subbilabié à $\breve{~ d e n t s ~ i n e ́ g ., ~ l e s ~} 2$ inf. plus étr.; cor. gl. ou à peine poilue en dedans, gibbeuse d'un côté à la gorge, à lobe sup. ent.; fl. en vert. nombr., tous axill., écartés, plus gr. que les f. flor. ord. réfléchies; carp. ovoïdes, lisses. - M. Pulegium L. 1024 Lieux hum. - Jt-Sept.

\section{Genre 369. - LYCOPUS L.}

Pl. viv., glalor. ou pub., à souche ramp.; t. dress., sillonnée; f. brièv. pétiolées, ovales lanc., dentées-incisées; fl. en vert. axill. sessiles, écartés, tr. denses ; cor. en entonnoir, à tube inclus, à 1 lobes presque égaux; carp. lisses. . . . . . . . . L. europæus L. 1025 Lieux hum. - Jt-Sept.

\section{Genre 370. - ORIGANUM L.}

Pl. viv., poilue, dress., à f. ovales ou ellip.; bract. ovales-lanc., d'un rouge violet, dépassant le cal. tubul., en cloche à 13 nervures, à gorge barbue, à 5 dents presque égales; cor. rose bilabiée à tube saillant à lèvre sup. émarg., l'inf. trilobée; carp. ovoïdes, lisses.

Lieux sees. - Jt-Sept.

0. vulgare L. 1026

Var. ì fl. blanches et bract. vertes (O. viridulum Martr.).

\section{GENRE 371. - THYMUS L.}

ণ Tiges lign., dress. ou ascend., non radicantes, formant un petit buisson tortueux; f. lanc. ou lin. obtuses, enroulées par les bords, couvertes, au moins en dessous, d'un tomentum court et dense, non cil. à la base; rameaux tom. blanchàtres.

T. vulgaris 1027

Cult. (thym), planté à Nemours, Malesherbes sur les coteaux calc.

đ T. herb. ou sous-lign., couchées ramp. à la base, souvent radicantes, gazonnantes; f. souvent cil. ou vel.

F. assez long. pétiolées, gr., $1 \mathrm{~cm}$, obovales ou oblongues, gl. ou à pétiole cil., à nervures peu saillantes, brusq. rétrécies en pétiole ; inflor. en tètes glob. ou ovales, interr. à la base; t. grêles, couchées ascend., làch. gazon. ; rameaux allongés gl. ou poilus sur 2 faces altern. opp. ou sur les angles; cal. poilu tout autour ou gl. en d́essus. . . . . . . T. Chamædrys Fries. 1028

Pelouses. - Jt-Sept. 
F. long. atténuées en pétiole fort. cil., petites, 4-8 $\mathrm{mm}$., à nervures saillantes; inflor. en tètes glob. ou ovoïdes, denses; t. grêles couchées-ramp., lens. gazon.; rameaux assez allongés, brièv. pub. tout autour; cal. poilu tout autour ou gl. en dessus.

Pelouses sèches. - Mai-Sept.

T. Serpyllum L. 1029

Var. ¿̀ $\mathrm{f}$. hér. de longs poils blanes, ovales ou obovales-oblongues, à rameaux hér. de poils assez longs, sur 2 faces opp. altern., à cal. hér. (T. humifusus Bernh.). Pelouses calc.

\section{GenRe 372. - HYSSOPUS L.}

Pl. viv., gl. ou glabr., verte, aromat.; t. lign. à la base, à rameaux dress, gl. ou pubérulents; f. oblongues-lanc. ou lin., uninervées, ponctuées gland.; fll. en épis compacts et allongés; cal. gl. dépassé long. par la cor. à lèvre inf. à 3 lobes, le médian émarg., bien plus gr. que les lat. . . . . . . . . . . H. officinalis L. 1030

Nat. sur les vieux murs, ruines des vieux châteaux.

\section{Gerre 373. - SATUREIA L.}

Sous-arbriss., vert, à t. ascend. ou dress., à rameaux raides, dress., tr, feuillés; f. lanc.-lin., tr. aig., ciliolées aux bords, dépassant les entrencuds; fl. en petits corymbes pédonc. rappr. en long. grappes feuillées; cor. long. saillante; cal. tubul., à dents plus courtes que le

tube ou l'égalant. . . . . . . . . . . S. montana L. 1031

Nat. sur les coteaux calc. à Nemours, Moret, Malesherbes. - Jt-Sept.

On cult. S. hortensis L. (Sarriette) Ann., herb., à rameaux étalés ascend.; $\mathrm{f}$. mutiques, lin., ou lin.-lane., plus courtes que les entre-nœuds; cor. petite, dépassant à peine le cal. en cloche à dents plus long. que le tube.

\section{Genre 374. - GALAMintha Møench.}

+ Fl. en vert. subsessiles; cal. à tube courbé ; pl. peu odor.

Fl. nombr., purp., en vert. axill. et term., gros, serrés, hér.-plum., entourés d'un invol. de nombr. bractéoles sét., pectinées-cil., aussi longues que le cal. dressé sur le pédic., non bossu à la base; f. ovales ou oblongues, larges de près de $2 \mathrm{~cm}$., superf. dentées; cor. dépassant de $8 \mathrm{~mm}$. la gorge du cal.; pl. viv., dress.

Bois, lieux secs. - Jt-Sept.

C. Clinopodium Moris. 1032

Fl. 3-8, purp. ou blanches, en vert. tous axill., petits, làches, vel. ou glabr., non entourés d'un invol.; cal. incliné sur le pédic., fort. bossu à la base; f. ovales ou lanc., petites, ayant moins de $1 \mathrm{~cm}$. de large, un peu dentées sup.; cor. dépassant de 4-̋̈ mm. la gorge du cal.; pl. ann. ou bisann., ascend. ou diffuse.

\section{Ch. secs. - Mai-At}

C. Acinos Clairv. 1033

+ Fl. en cymes dichotomes axill. nett. pédonc.; cal. à tube dr., non bossu à la base; pl. viv., odor.

X Cal. à lèvres tr. inég., à dents cil., muni à la gorge de poils subinclus; $\mathbf{f}$. assez gr. à long pétiole.

F. nett. dentées en scie, à limbe plus long que large; fl. gr. de 10̆-18 mm., en vert. lâches, rappr., à pédonc. communs dépassant les pétioles; cal. glabr., long de 7-10 mm.; carp. ovoïdes, lisses; souche stolon. . . . . C. officinalis Mœnch. 1034 Bois herbeux. - Jit-Sept. 
F. moyennes ovales-arrondies, crén. ou superf. dentées, à limbe aussi large que long; fl. moyennes de 10-12 $\mathrm{mm}$. en vert. courts et rappr., à pédonc. communs égalant à peine les pétioles; cal. pub., long. de 6-8 mm.: carp. subglob., ponctués; souche non stolon.

Lieux secs et incultes. - Jt-Sept.

Cal. glabr., long. de $4-50$ mm., à lèvres rappr., à dents presque égales et glabr., à poils de la gorge saillants; f. petites, pub., brièv. ovales, à limbe presque aussi large que long, fin. dentées à pétiole court; fl. gr. de 10-10̆ mm. en vert. nombr., compacts à axes courts et rappr.; carp. ovoïdes, lisses; souche courte; pl. vel. gris. . . . . . . . . C. Nepeta Savi. 1036 Lieux secis et pierreux. - Jt-Sept.

\section{GeNRe 37\%. - MELISSA L.}

Pl. viv., glabr. ou vel., à odeur de citron; f. gr., ovales, pétiolées, larg. crén.; fl. blanchàtres ou rosées en vert. axill., espacés, unilat., brièv. pédonc. et bien plus courts que les $\mathrm{f}$.; lèvre inf. de la cor. à 3 lobes inég. . . . . . . . . . . . . M. officinalis L. 1037 Cult. et subsp. dans les haies. - Jn-Sept.

\section{GenRe 376. - SALVIA L.}

+ Cor. à tube muni d'un anneau de poils en dedans près de la base ; f. pétiolées, larg. ovales en cœur, molles et vertes, irrégul. crén. dentées, les inf. à pétiole muni de 1-2 fol.; fl. d'un bleu violet, petites, pédic., en vert. multiflores écartés formant des grappes allongées ; cal. violacé, poilu; bract. petites, brunes scarieuses, réfléchies; cor. petite, $1 \mathrm{~cm}$., 2 fois aussi longue que le cal., à lèvre sup. dressée . . . . . . . S. verticillata L. 1038 Pl. introduite, nat. çà et là. - Mai-At.

+ Cor. à tube dépourvu d'anneau de poils en dedans.

× Bract. tr. amples, membr., lilacées, cil., dépassant le cal. pub. à dents épin.; f. pétiolées, larg. ovales en cour, pub.-gris., tr. rugueuses, érodées-crenelées ; fl. blanches lavées de bleu, en vert. rapprochés en pan. contractée visq.; cor. de $18-20 \mathrm{~mm}$., 3 fois aussi long. que le cal., à lèvre sup. en faux.

S. Sclarea L. 1039

Lieux secs et incultes, vieux châteaux, pl. nat. - Jn-Sept.

Bract. moyennes ou petites, souvent réfléchies; cal. tr. apparent, à dents non épin.; f. sup. vertes sessiles ou subsessiles; fl. bleues, rar. roses ou blanches.

F. crén. ou un peu incisées; cal. pub. ; cor. de 15゙-20̆ mm., 3 fois aussi long. que le cal., à lèvre sup. courbée en faux; style long. saillant............ . . . . pratensis L. 1040 Prés. - Jn-At.

F. incisées-lobées ou crén.-lobées; cal. liér. de poils étalés; cor. petite $10-15 \mathrm{~mm} ., 1$ fois plus longue que le cal., à lèvre sup. un peu arquée au sommet; style non ou à peine saillant.

\section{S. Verbenaca L. 1041}

Bords des chemins, coteaux herbeux ou sees. - Mai-Jt et automne. $S$. officinalis L. est quelquefois planté sur les coteaux (Etampes, Etréchy). Sous-arbriss., très aromat.; f. rugueuses, pétiolées, oblongues ou lanc., obtuses ou aig.; fl. d'un bleu violacé, assez gr., 3-6 en vert. formant une grappe; cal. pub.; bract. ovales-lanc.; cor. de $2-3 \mathbf{c m}$., 2-3 fois plus long. que le cal., à tube muni en dedans d'un anneau de poids, à lèvre sup. presque dr.

S. silvestris L., voisin de S. pratensis L., s'en distingue par les fl. plus petites, son cal. velu-blanchâtre, ses bract. colorées et ses f. oblongues. 


\section{Genre 377. - NEPETA L.}

Pl. viv., gris., odor.; f. étalées, toutes pétiolées, ovales en cœur, fort. crén.-dentées, blanchâtres-tom. en dessous; fl. blanches ponctuées de rouge en vert. multiflores serrés formant une grappe assez courte obtuse, interr. à la base. . . . . . . N. Cataria L. 1042

Lieux incultes. - Jn-Sept.

\section{GeNRE 378. - GLECHOMA L.}

Fl. violettes, tachées de pourpre, réunies 2-3 à l'aisselle des f. et tournées du même côté; cor. de $150-20 \mathrm{~mm}$., à tube dr. et saillant, à lèvre sup. dress., échancrée, l'inf. à 3 lobes, le médian gr., en coeur renversé................ G. hederacea L. 1043 Haies, bois. - Mars-Mai.

\section{GeNRE 379. - LAMIUM L.}

+ Cor. à tube dr.; pl. ann., à racine grèle ; anth. barbues.

$\times$ F. florales orb. en rein, sessiles-embrass., crén.-lobées; cal. tr. vel. à dents conniv. après la flor.; cor. de 15 mm., à tube 3 fois plus long que le cal., sans anneau de poils en dedans; fl. en vert.

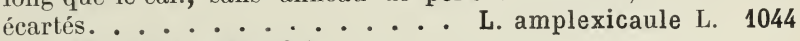
Lieux eult. - Mars-0ct.

Var. à cor. tr. petite, s'ouvrant à peine, ne dépassant pas les dents du cal. (var. clandestina).

× F. florales pétiolées; cal. peu poilu à dents étalées-divar. après la flor.; cor. de 10-12 mm. à tube 1 fois $1 / 2$ plus long que le cal. ou l'égalant, avec ou sans anneau de poils; fl. en vert. rappr.

F. ovales-obtuses en coeur, crén.; cor. d'environ $12 \mathrm{~mm}$. à tube 1 fois $1 / 2$ plus long que le cal., muni d'un anneau de poils en dedans............ . . . purpureum L. 1045 Lieux cult. et incultes. - Mars-0ct.

F. sup. ovales-triang., profond. incisées-dentées; cor. à peine de $1 \mathrm{~cm}$. à tube peu ou point saillant, nu en dedans.

Lieux cult. et incultes. - Mars-0ct.

L. hybridum Vill. 1046

+ Cor. à tube courbé, brusq. contracté au-dessus de la base, puis dil., muni d'un anneau de poils en dedans au niveau du rétrécissement; pl. viv., à racine long. et tenace; anth. barbues ou gl.; $\mathbf{f}$. pétiolées, les inf. ovales en cœeur, fort. dentées.

ơ Anth. barbues; fl. blanches ou purp.; cal. à dents molles aussi long. ou plus long. que son tube; cor. de 20 - $23 \mathrm{~mm}$., à tube plus long que le cal.,

Cor. purp, rar. blanche, à tube non renversé en arrière, muni d'un anneau de poils horizont.; lèvre sup. brièv. poilue aux bords, l'inf. à 1 seule dent de chaque côté à la base; f. souvent tachées de blanc. . . . . . . L. maculatum L. 1047 Haies, lieux hum. - Avr.-0ct.

Cor. hlanche, souvent tachée de vert, à tube renversé en arrière, muni d’un anneau de poils oblique; lèvre sup. long. vel. aux bords, l'inf. à 2-3 dents de chaque côté à la base.

Haies, bords des chemins. - Avr.-Oet.

L. album L. 1048

đ Inth. gl.; fl. jaunes; cal. fructif. à dents spin., plus courte que son tube; cor. d'environ $2 \mathrm{~cm}$., pub. sur le dos, à tube presque dr., égalant le cal., muni en dedans d'un anneau de poils oblique, à lèvre inf. à 3 lobes un peu inég., lanc. aig.; souche long. ramp. émettant des t. flor. dress. et des rejets stériles couclı́s, radicants.

Haies et bois. - Avr.-Jn.

L. Galeobdolon Cr. 1049 


\section{Genre 380. - LEONURUS L.}

F. la plupart palmatipartites, à 5゙-7 lobes incisés-tlentés; fl. purp. en vert. plus courts que les pétioles; cal. anguleux ì dents inf. réfléchies; cor. assez gr., tr. vel., à tube égalant le cal., muni d'un anneau de poils en dedans; carp. hispides au sommet; viv.

Haies, décombres. - Jn-Sept.

L. Gardiaca L. 1050

F. toutes ovales ou ovales-lanc., fort. dentées; fl. d'un blanc rosé, en vert. égalant les pétioles; cal. non anguleux à dents toutes dress.étalées; cor. petite, pub., à tube inclus dépourvu d'anneau de poils ; bisanı. . . . . . . . . L. Marrubiastrum L. 1051 Haies et buissons humides. - Jt-Sept.

\section{Genre 381. - GALEOPSIS L.}

+ T. hispide, renfl. (sur le sec étranglée) sous les nocuds ; f. minces, à dents nombr.; carp. gros, $3 \mathrm{~mm}$., presque aussi larges que longs ; cal. hispide au sommet à dents long. sub. épin. ; cor. de $130-20 \mathrm{~mm}$., purp. ou blanche, à tube inclus ou dépassant le cal., à lobe médian de la lèvre inf. carré, ent. . . . . . . G. Tetrahit L. 1052 Lieux frais, fossés, buissons. - Jt-Sept.

Var. à fl. plus petites, blanches, ì lobe médian de la cor. bifide (G. bifida Bœnn).

+ T. mollement pub. ou gl., jamais renflée ni étranglée au-dessous des nouds; f. assez épaisses à dents peu nombr.; carp. petits, $2 \mathrm{~mm}$.. bien plus longrs que larges.

F. ovales-lanc. ou lanc., veloutées-soyeuses surtout en dessous, régul. dentées en scie, à nervures saillantes, rappr., un peu déprimées en dessus; cal. pul. soyeux à dents presque égales; fl. de 2-3 cm. janne pàle ou rosées panachées de jaune, rar. purp., 3-1 fois plus longue que le cal. . . . . . G. dubia Leers. 1053 Ch. pierreux des terrains sil. - Jt-0ct.

F. étr., lin.-lanc. ou lanc.-oblongues, long. atténuées en coin à la base, pub. ou glabr., mais jamais veloutées-soyeuses, superf. dentées ou presque ent., à nervures peu saillantes et écartées, non déprimées en dessus ; cal. pub. blanchàtre à poils appliqués, quelquefois glabr., non pub. soyeux, à dents souvent tr. inég. ; fl. de $2 \mathrm{~cm}$. environ purp., rar. blanches, 2-3 fois plus long. que le cal. . . . . . . . . . . G. Ladanum L. 1054 Ch. incultes calc. - Jt-0ct.

Yar. ì fl. petites, à peine ouvertes, ì tubes inclus (var. parviflora).

\section{Genre 383. - STAGHYS L.}

+ Fl. blanc jaunàtre; bractéoles tr. petites, peu apparentes.

Pl. viv, à souche presque lign., produisant de nombr. t. étaléesascend.; cal. à dents triang.-acum.; cor. à tube à peine saillant muni d'un auneau de poils oblique, à lèvre int. tachée de brun.

$$
\text { Coteaux calc. - Jn-Sept. }
$$

S. recta L. 1055

Pl. aun. dress., rameuse, à racine grêle et pirotante; cal. à dents arquées, lanc. en alène à pointe brièv. cil.; cor. à tube saillant muni d'un anneau de poils transvers. à lèvre inf. non tachée.

Ch. cale. - Jn-0ct.

S. annua L. 1056

+ Fl. purp. ou rosées, jamais jaunes.

$\times$ Pl. ann., à racine grèle, à t. faibles; f. ovales-obtuses, tronquées ou un peu en coeur à la base, pétiolées, long. de 1-3 cent. et presque aussi larges que longues; bractéoles nulles ou tr. petites; cal. 
hér., à dents presque égales, lanc., à peine mucronées, cil. aussi long. que le tube; cor. rosée à tube à peine saillant muni d'un anneau de poils transvers. . . . . . S. arvensis L. 1057 Ch. sabl. - Mai-0ct.

X Pl. viv., à souche épaisse, à t. robustes; f. ayant plus de $3 \mathrm{~cm}$. de long, bien plus long. que larg.; fl. gr., purp.

= Bractéoles nulles ou dépassant à peine le pédic.; cal. à dents peu inég., à peine plus courtes que le tube; cor. pub. en dehors; pl. ent. vertes, à souche ramp., à f. dentées; tube de la cor.muni d'un anneau de poils oblique.

F. oblongues-lanc., sessiles ou brièv. pétiolées, fin. pub., larges de $2-3 \mathrm{~cm}$; fl. roses, 4-8 par vert.; cal. vel., mais sans glandes stipitées; pl. inodore.. . . . . . . S. palustris L. 1058

Lieux hum., fossés. - Jn-Sept.

F. ovales en cour, acum., long. pétiolées, vel., larges de 4-9 cm.; fl. d'un rouge-noirâtre, 3-6 par vert.; cal. hér. de poils et de glandes stipitées; pl. à odeur fétide. . . S. silvatica L. 1059 Haies et bois. - Jn-Sept.

Le $S$. ambigua $\mathrm{Sm}$. est considéré comme hybride entre les deux dernières espèces; f. oblongues-lanc., un peu cordées, à pétiole court; fl. purp.; pl. non ou à peine gland.

= Bractéoles lin., égalant presque le cal.; cal. à dents inég., bien plus courtes que le tube; cor. vel. soyeuse ou lain. en dehors; pl. vel. blanchâtres, au moins au sommet, à souche non rampante.

$\sigma$ F. vertes sur les 2 faces, vel., non tom., ovales-obtuses, en cœur à la base, fort. crén. dentées; épi floral vert ou rougeâtre à vert. écartés; cal. à dents ovales-obtuses, mucronées, couvert de poils entremêlés de glandes stipitées; fl. d'un rouge brun.

Bois, surtout calc. - Jn-At.

S. alpina L. 1060

F. blanches-tom. ou lain., au moins en dessous ; épi floral d'un blanc soyeux argenté; cal. vel.-lain., sans glandes stipitées; t. dens. lain., à vert. rappr., les inf. seuls écartés.

F. régul. crén., ridées-réticulées, souvent un peu vertes en dessus, les inf. ovales-oblongues, tronquées ou en cceur à la base; pl. vel.-lain., d'un blanc verdàtre.

Lieux incultes, pierreux, calcaires. - Jn-Sept.

S. germanica L. 1061

F. paraissant ent. et sans nervures, couvertes sur les 2 faces d'un épais feutre d'un blanc argenté, les inf. oblongues-spathulées, atténuées à la base; pl. dens. lain. et d'un beau blanc.

Nat. à Malesherbes. - Jn-At.

S. lanata Jacq. 1062

\section{Genre 383. - BETONICA L.}

Pl. viv., vel. au moins à la base; f. pétiolées oblongues en cœur, fort. nervées-réticulées, régul. crén.; cal. tubul. en cloche, vel. ou glabr.; cor. purp., environ $15 \mathrm{~mm}$., à tube saillant, nu, à lèvre sup. ent., pub. ............... B. officinalis L. 1063 Bois, prés, landes. - Jn-Sept.

\section{Genre 384. - BALLOTA L.}

Pl. viv., vel., à odeur fétide; f. ovales ou arrondies, crén.; fl. purp., rar. blanches. en vert. compacts, écartés; bractéoles sét., cil.; cal. à כ̈ dents égales brièv. mucronées; cor. à tube dépassant la gorge du cal., à lèvre sup. couverte en dehors de poils blancs appliqués.

Décombres, haies, chemins. - Mai-Sept.

B. nigra E. 1064 


\section{GeNRe 383. - MARRUBIUM L.}

Pl. viv., tom.-blanchâtre, à odeur pénétrante; f. pétiolées, ovales-orb., en cœur ou en coin à la base, crén., ridées, tom., vertes en dessus ; fl. blanches, en vert. axill., multiflores, compacts, espacés ; bractéoles en alène, gl. et crochueg au sommet, ainsi que les 6-12 dents inég. du cal.; cor. à lèvre sup. bifide, à lobes rappr., parall.

Lieux incultes. - Mai-Sept.

M. vulgare L. 1065

Var. à $f$. cunéiformes, insensib. atténuées en pétiole, incisées-palmées au sommet, cal. à 15 -20 dents, cor. à lèvre sup. profond. bifide; à lobes plus ou moins diverg. (M. Vaillantii Coss. et G.). Fontainebleau, Etréchy.

\section{Genre 386. - MELITTIS L.}

Pl. viv., vel. hér., à odeur forte, à souche traçante; f. gr., vertes, pétiolées, ovales, fort. crén.; fl. blanches, tachées de rouge, gr., pédic., 1-2 à l'aisselle des f., inclinées du mème côté; cal. à 10 nervures, à lèvre sup. ent. ou à 2-3 petites dents, l'inf. à 2 lobes obtus ; cor. longue de $3-4 \mathrm{~cm}$., à tube tr. saillant et nu en dedans, à lèvre sup. ent., l'inf. à 3 lobes, le médian plus gr.; ét. saillantes.

Bois, taillis. - Mai-Jt.

M. Melissophyllum L. 1066

\section{Genre 387. - SGUTELLARIA L.}

+ Fl. disposées â l'aisselle des f.; f. florales conformes aux autres et à peine plus petites; cor. long. de $6-15 \mathrm{~mm}$.

Fl. bleues, long. de 6-15 mm.; cor. 4-5 fois plus longue que le calice, à tube courbé vers la base; cal. gl., souvent gland.; f. princ. long. de 3-4 cm., oblongues-lanc., en cœur à la base, crén.

Bords des eaux. - Jn-Sept.

S. galericulata L. 1067

Fl. rosées, long. seul. de 6-8 mm.; cor. à peine 2 fois plus long. que le cal., à tube dr. dès la base; cal. un peu hér.; f. long. de 2-3 cm., ovales ou lanc., souvent tronquées et presque hastées, ent. ou à quelques dents vers la base. . . . S. minor L. 1068 Prés, landes et chemins hum. - Jn-Sept.

+ Fl. disposées en grappes term.; f. florales bractéiformes, petites, lanc., herb., plus courtes que le cal.; cor. d'un pourpre violet, gr., long. de $2-3 \mathrm{~cm}$., tr. saillante, pub.-visq., à tube courbé près de la base; f. gr., long. pétiolées, ovales en cœur ou tronquées, fort. crén.; pl. pub., gland. sup. . . . . . . . S. Columnæ All. 1069

Nat. dans les bois. - Jn-Jt.

\section{GenRe 388. - BRUNELLA L.}

+ Fl. petites ou moyennes atteignant à peine $13 \mathrm{~mm}$., en épi invol. à la base par une paire de f.; lèvre inf. du cal. fendue jusqu'au milieu; cor. à tube dr.; filets des ét. longues, term. en pointe sub. Fl. d'un blanc jaunâtre, long. d'environ $15 \mathrm{~mm}$.; cal. vel. hér., à dents fort. cil.; pointe des filets des ét. arquée en avant; $t$. et $f$. couvertes de poils blancs; f. basilaires oblongues-elliptiques, les caul. souvent lyrées ou pennatifides . . . . B. alba Pall. 1070

Lieux incultes, pelouses, surtout des terrains calc. ou argil. - Jn-At.

Fl. d'un bleu violet, rar. roses ou blanches, long. d'environ $12 \mathrm{~mm}$; cal. un peu hér., à dents fin. cil.; pointe des filets des ét. dr.; tig. et $\mathrm{f}$. faibl. pub.; f. toutes ent., superf. dentées, pennatifides ou pennatipartites. . . . . . . . B. vulgaris L. 1071 Lieux incultes, pelouses. - Jn-Sept. 
+ Fl. gr., long. de 20-23 mm., d'un bleu violet, en épi nọ invol. par la paire sup. des f.; lèvre inf. du eal. hér. fendue à peine jusqu'au tiers en 2 lobes fin. cil; cor. à tube courbé; filets des ét. tous term. par un mamelon arrondi; f. ellipt. oblongues en coin ou subarrondies à la base, ent. ou dentées, quelquefois pennatifides ou pennatipartites. . . . . . . . B. grandiflora Jacq. 1072 Pelouses et coteaux cale. - Jt-Sept.

\section{Genre 389. - AJUGA L.}

+ Fl. bleues, rar. roses ou blanches, 6-8 en vert. rappr. en épi term. feuillé; anneau de la cor. éloigné du point d'insertion des ét.; f. obovales ou oblongues; pl. inodores, viv., à t. florifères simples, dress.; fl. en épis allongés, les sup. plus long. que les bract.; carp. ridés en réseau.

Souche émettant de longs stolons, épigés, feuillés, couchés, souvent radicants; $t$. poilue altern. sur 2 faces opp.; f. rad. persist. plus gr., glabr. . . . . . . . . A. reptans L. 1073 Bois et prés. - Avr.-Jt.

Souche dẻpourvue de stolons; t. vel.-lain. sur les 4 faces; f. rad. ord. détruites à la flor., à peine plus $\mathrm{gr}_{\text {r, }}$ toutes vel.

A. genevensis L. 1074

Coteaux secs et lieux herbeux, surtout calc. - Mai-At.

A. pyramidalis L. diffère de A. genevensis par ses f. rad. persist., bien plus grandes que les caul. et surtout par ses fleurs réunies en épi tétragone-pyramidal serré, toutes beaucoup plus courtes que les bract.

+ Fl. jaunes, géminées, axill.; anneau de la cor. tr. rappr. du point d'insertion des ét.; f. caul. tripartites à segments lin.; pl. odor. ann. à t. tr. rameuses, diffuses; carp. striés un peu ridés en réseau.

Ch. surtout ealc. - Mai-Oct.

A. Chamæpitys Schr. 1075

\section{GenRe 390, - TEUGRIUM L.}

+ F. pétiolées bipennatifides à segm. lin. oblongs, les florales pennatifides; pl. ann., mollement vel.; fl. purp. pédic., axill., 3-8 en demi-vert. tout le long des rameaux; cal. vel.-gland., bossu à la base, à dents triang.-aig. presque égales; carp. ridés-alvéolés.

Ch. pierreux et calc. - Jn-0ct.

T. Botrys L. 1076

+ F. ent., crén. ou dentées; pl. viv.

$\times$ Fl. purp., pédic., axill., 2-6 en vert. unilat, dépassés long. par les f. florales semblables aux autres f.; pl. herb., mollement vel., stolonifère, à t. couchées radicantes, ascend., tr. feuillées, à f. sessiles ou subsessiles, oblongues, fort. dentées; carp. ridés en réseau.

Lieux hum. et maréc. - Jn-0ct.

T. Scordium L. 1077

$X$ Fl. en grappes spiciformes ou en tètes term.; f. florales plus petites ou bractéiformes, plus courtes que les fl. sup.; pl. raides, souvent
lign., sans stolons.

= Fl. en grappes spiciformes term., plus ou moins unilat.; f. nervées, crén. ou dentées, à bords non enroulés en dessous, vertes, jamais blanches en dessous, ni uninervées.

Cal. bilabié, vert, glabr., nettement bossu à la base, à dent sup. bien plus large, ovale suborb.; f. toutes pétiolées, ridées-réticulées, assez gr., ovales ou oblongues, en cœur à la base, crén.; fl. jaunâtres, pédic., solit., en long. grappes term. effilées; bract. tr. petites, les sup. ne dépassant guère le pédic.; carp. lisses. . . . . . . . T. Scorodonia L. 1078 Bois et buissons. - Jt-Sept. 
Cal. non bilabié, rougeàtre, poilu, à peine bossu à la base, à dents presque égales, lanc.; f. atténuées en court pétiole, nervées, petites, ovales ou oblongues en coin, fort. crén.; fl. purp. subsessiles, 3-6 par vert., en grappes peu allongées, feuillées, assez serrées, à f. florales sup. plus courtes que les fl.; carp. faibl. ridés en résual . . . . . . . T. Chamædrys 1079

Lieux arides, surtout calc. - Mai-Sept.

= Fl. d'un blanc jaunâtre en tête term., glob., jamais unilat.; f. uninervées atténuées en court pétiole, ent., un peu enroulées aux bords, vertes en dessus, blanches, tom. en dessous, les sup. entourant les fl.; cal. gl., vert, à dents lanc.-acum.; carp. ridésalvéolés .......... T. montanum L. 1080 Coteaux calc. Jn-At.

\section{FAMILLE 71. - VERBÉNACÉES}

\section{Genre 391. - VERBENA L.}

Pl. viv., verte, à tiges dress. ou ascend., rameuses, quadrang., rudes sur les angles, canal. altern. sur 2 faces opp.; f. inf. pétiolées, ovales ou oblongues en coin, incisées-dentées ou pennatifides; fl. bleuâtres ou lilacées, petites, sessiles, en longs épis filiformes lâches, disposés en pan. term.; bract. acum., plus courte que le cal., pub., subtétra-

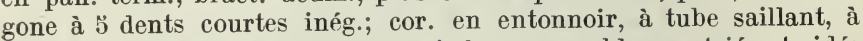
limbe presque plan, à ö lobes peu inég.; carp. oblongs striés et ridés en réseau ............ . . . . . officinalis L. 1081 Lieux incultes, bords des chemins. - Jn-0ct.

\section{FAMILLE 72. - PLANTAGINÉES}

Fl. hermaphrodites, réunies en épis ou en capit. denses long. pédonc.; fr. caps., s'ouvrant en travers, à 2 ou plus. graines; pl. terrestres.

PLANTAGO 392

Fl. monoïques, les mâles solit. sur un long pédonc. portant à sa base 1-3 fl. femelles sessiles; fr. osseux, indéh. à une seule graine; pl. aquat. ...................... LITTORELLA 393

\section{Genre 392. - Plantag0 L.}

+ F. étr., lin. ou pennatifides, à peine plus larges au milieu qu'à la base; tube de la cor. velu ou ridé.

T. feuillée, à f. opp. ou vert., lin., sessiles; fl. en têtes ovales sur des pédonc. axill. plus longs que les f.; cor. blanche, gl., à tube ridé en travers; caps. à 2 graines oblongues, brunes, luisantes, canal. à la face interne; pl. ann. dress., vel. gland.

P. arenaria Waldst. et Kit. 1082

Lieux sabl. - Mai-At.

T. nulle, à f. pennatifides, à segments lin. ou lanc., toutes étalées en rosette rad.; fl. en épis cyl. sur des pédonc. rad.; cor. jaunâtre à tube velu, non ridé; caps. à 3-4 graines ovoïdes, brunes, planes à la face int.; pl. ann. ou bisan., pub. ou vel.; hampes étalées ou ascend., dépassant les f. . . . . P. Coronopus L. 1083 Pelouses, lieux secs, sabl., chemins. - Mai-0ct.

+ F. élargies, lanc.-lin., oblongues ou ovales, ent. ou dentic., toutes rad.; cor. à tuhe gl. et lisse

X F. lanc.-acum., presque gl., rar. lain., atténuées en long pétiole, au moins らँ-6 fois plus long. que larg.; graines canal. à la face int.; épi ovoïde ou oblong; bract. ovales-acum., noiràtres sur le dos; 
caps. à 2 graines, oblongues, hampe anguleuse, sillonnée, dépassant beaucoup les f.; cor. et anth. blanches.

Prés, pâturages. - Avr.-0ct.

P. lanceolata L. 1084

F. larg. ovales ou ellipt., à peine 2-3 fois plus long. que larg.; graines planes à la face int.; épi cyl.; bract. ovales obtuses, vertes sur le dos.

F. pub. sur les 2 faces, ovales ou ellipt., ent. ou dentic., à pétiole large et court; cor. et anth. blanches; caps. à 2 graines; épi compact; hampes ascend. fin. striées, 4-5̆ fois plus long. que les f.

P. media L. 1085

Pelouses sèches, bords des chemins. - Mai-Sept.

F. glabr., larg. ovales, ent. ou peu dentées, à pétiole allongé; cor. grisàtre; anth. brunes; caps. à 2 loges, chaque loge à 4-8 graines; épi un peu lâche à la base ord. tr. allongé; hampes dress. ou ascend., non striées, égalant à peine les f. ou les dépassant.

Lieux incultes, chemins. - Mai-0ct.

P. major L. 1086

Var. pl. plus petite, épi court, hampes arquées ascend. (P. intermedia Gilib.) ou dress. (P. minima DC.).

\section{GenRe 393. - LITTORELLA L.}

Pl. viv. de 3̈-20 cm., acaule, gl., à souche courte produisant des rejets filiformes ramp.; f. dress., lin., demi cyl., toutes rad., dépassant les fl.; fl. màles, 4 sép., cor. en entonnoir, blanchâtre, à 4 lobes ovales lanc.; 4 ét. tr. saillantes, insérées sur le récept.; fl. femelles, 3-4 sép.; cor. urcéolée à $3-4$ petites dents, style très long, sub.

Mares des terrains sil., grèves des étangs. - Mai-At.

L. lacustris L. 1087

\section{Famille 73. - PLOMBAGINÉES}

\section{GenRe 394. - ARMERIA Willd.}

Pl. viv. à f. toutes rad., lin.-lanc. ou lanc., acum., planes, à 3-7 nervures; hampes simples, nues, enveloppées sous les fl. dans une gaine membr., allongée, tubul., déchirée à la base, 2-4 fois plus long. que le cap. subglob.; fl. roses; invol. fauve, à fol. ext. triang.-lanc., acum. en pointe égalant ou dépassant les fl.; cal. à côtes aussi larges que les sillons, à lobes ovales-lanc. atténués en arête aussi longue qu'eux.

Lieux sabl. - Jt-Sept.

A. plantaginea Willd. 1088

On cult. en bordures A. maritima Wild. F. obtuses, à 1 nervure; gaîne plus courte que le cap. ou l'égalant; cal. à lobes ovales, atténués en arête beaucoup plus courte qu'eux.

\section{FAMILLE 74. - GLOBULARIÉES \\ GERRE 39\%. - GLOBULARIA L.}

Pl. viv., à souche verticale presque lign.; hampes dress., d'abord courtes, puis allongées, bien plus long. que les f., couvertes de petites f. sessiles, lanc.-aig.; f. rad. en rosette, gr., planes, obovales, atténuées en long pétiole, ent., échancrées ou tridentées au sommet; fl. bleues en têtes; invol. et récept. hér.; cal. vel. à lobes presque 2 fois aussi longs que le tube. . . . . . . . . . G. vulgaris L. 1089

Coteaux calc. - Mai-Jn. 


\title{
IV. - MONOCHLAMYDÉES OU APÉTALES
}

\author{
FAMILLE 7\%. - SALSOLACÉES \\ (Amarantacées et Chénopodacées)
}

+ Périanthe non muni sur le dos d'ailes transvers., rar. absent et remplacé par 2 valves; graine lenticulaire.

$\times$ Fl. accompagnées de $2-3$ bractéoles scarieuses.

F. planes, élargies, ov. rhomb. ou lanc. larg. de $1 \mathrm{~cm}$. et plus, pétiolées; fl. monoïques ou polygames en glom. ou en pan., entourées chacune de 3 bractéoles; 3 - 5 ét. libres.

AMARANTUS 396

F. lin., en alène, larg. de 1 à $2 \mathrm{~mm}$., sessiles et dil. à la base; fl. hermaphrodites, sessiles, solit. ou géminées, axill., munies de 2 bractéoles; 3 ét., à filets soudés à la base.

POLYGNEMUM 397

$\times \mathrm{Fl}$. dépourvues de bractéoles.

= Fl. monoïques, polygames ou dioïques ; 3-5 ét.

Fl. monoïques ou polygames, les mâles et les femelles sur le même individu; 2-3 styles; périanthe à 5 divis. dans les fl. mâles ou hermaphrodites, à 2 valves opp. dans les fl. femelles.

ATRIPLEX 398

Fl. dioïques, les mâles et les femelles portées sur des individus différents; 4 styles tr. longs soudés à la base; périanthe à 4-5 divis. dans les fl. mâles; dans les fleurs femelles périanthe subglobuleux, à 2-4 dents au sommet enveloppant l'ovaire et devenant coriace, 4 styles. ...... SPINAGIA 399

$=\mathrm{Fl}$. hermaphrodites.

Périanthe fruclif. à tube devenant dur et ligneux à la maturité, soudé avec la base du fr.; 5 ét. subpérigynes, insérées sur un disque charnu qui unit le périanthe à l'ovaire; pl. charnues.

BETA 400

Périanthe fructif. jamais ligneux à la maturité, non soudé avec le fr.; 5 ét. hypogynes insérées sur le récept. ou au fond du périanthe....................... CHENODIUM 401 + Périanthe à lobes profonds munis sur le dos après la flor. d'ailes
transvers. étalées en rosace; graines subglob.; ’3 ét. soudées à la base en cupule tr. courte; 2-3 stigmates filif.; fl. hermaphrodites, axill., accomp. de 2 bract. lat; f. lin. triquètres charnues, les inf. opp., les autres altern.; graine subglob.. . . SALSOLA 402

\section{GeNRe 396. - AMARANTUS L.}

$X$ T. rameaux et pétioles plus ou moins pub.; inflor. term. en pan. compacte non feuillée.

Pl. viv., à souche épaisse émettant de nombr. t. couchées-étalées, faibles, ram.; bract. non piquantes; périanthe à 3 divis.; 3 ét.; fr. indéh. . . . . . . . . A. deflexus L. 1090

Décombres, nat. - Jn-0ct.

Pl. ann., à racine pivotante, émettant une seule t. dress., robuste, simple ou à ram. courts; bract. spin.; périanthe à 5 divis. ; 5 ét.; fr. déh., s'ouvrant en travers par un couvercle.

Décombres, lieux cult. - Jt-0ct.

A. retroflexus L. 1091

K T., rameaux et pétioles gl. ou glabr.

Inflor. term. en pan. compacte non feuillée; fr. indéh.; bract. triang.-aig. plus courtes que le périanthe à sép. lanc.; f. ov.rhomb., obt. ou échancrées.. . . . . A. Blitum L. 1092 
Inflor. en glom. tous axill., accomp. de f. jusqu'au sommet; fr. ov. arrondi. dépassant beaucoup le périanthe, déh., s'ouvrant en travers; bract. lanc. aig. de la longueur du périanthe à sép. aig.; f. ov. rhomb. ou lanc., atténuées au sommet, aig. ou obt.

Décombres, lieux cult. - Jt-0ct.

A. silvestris L. 1093

\section{Gexre 397. - POLYGNEMUM L.}

Bract. lanc. en alène, term. en longue pointe qui dépasse le périanthe; fr. ov., assez petit, environ 1 1/2 mm., dépassant le périanthe; f. long. de 6-15 mm. . . . . . . P. majus Al. Braun 1094 Ch. pierreux ou sabl. - Jn-Sept.

Bract. en alène, tr. brièv. mucr., égalant à peine le périanthe; fr. ov., tr. petit, à peine $1 \mathrm{~mm}$., ne dépassant pas le périanthe; f. long. de 4-8 mm., dress. imbriq., à peine piquantes; t. ord. verruqueuses.

Ch. sabl. ou argil. - Jn Sept.

P. arvense L. 1095

\section{Genre 398. - ATRIPLEX L.}

Valves fructif. membr., ov.-orb. subaig., arrondies à la base, tr. ent., lisses, veinées en réseau, libres ou à peine soudées; pl. dress. de 1-2 m., à f. hastées ou oblongues. . . A. hortensis L. 1096 Cult. et subsp. - Jt-Sept.

Valves fructif. herbacées, ov.-triang. ou en coin à la base, souvent muriquées tuberc. sur les faces, non rétic., soudées à la base.

F. caul. hastées triang., ent. ou sinuées-dentées, tronq. ou en cœur à la base, larges, à pétiole long, égalant souvent la moitié du limbe; valves fructif. triang., à base tronquée ou en cœur.

Lieux cult. - Jt-0ct.

A. hastata L. 1097

F. oblongues-lanc. ou lin., allongées, atténuées à la base, à pét. court égalant au plus le quart du limbe, les $\mathrm{f}$. inf. souvent subhastées, dil. au dessus du pétiole; valves fructif. rhomb., un peu hastées, cunéiformes à la base, lisses ou muriquées.. . A. patula 1098 Lieux cult. - Jt-0et.

$$
\text { Genre 399. - SPINAGIA L. - Epinard. }
$$

Pl. ann. de 30-80 cm., gl. à t. dress., ram.; f. alt., pétiolées, sagittées ; fl. sans bract., en glom. axill. formant de long. grappes feuillées; fr. soit compr. et muni au sommet de $2-4$ pointes raides diverg., soit (S. glabre Mill.) subglob. et lisse. . . . . . S. oleracea L. 1099 Cult. - Jn-Sept.

$$
\text { GenRe 400. - BETA L. }
$$

Pl. ann. ou bisann. d'environ 1 m., gl., à racine dure, cyl. ou charnue, tr. grosse, colorée (betterave); t. dress. robuste, anguleuse, à ram. dress., effilés, f. rad. gr., ov. en cœur, pétiolées, à côtes épaissescharnues; 2 stigmates ov.; périanthe à lobes appliq. sur le fr. petit.

Cult. et subsp. - Jt-Sept.

B. vulgaris L. 1100

\section{GeNre 401. - GHENOPODIUM L.}

$\times$ Pl. pub.-gland., à odeur aromat. pénétrante; embryon annulaire, n'entourant que les $2 / 3$ de l'albumen; f. oblongues ou lanc. sinuées-dentées ou presque ent.; périanthe cachant le fr., à lobes non car.; graine tr. pet., horiz., luisante, à bord obt.

Décombres, nat. - Jt-0ct.

C. ambrosioides L. 1101 
Pl. gl. ou farineuses, jamais pub., ni gland., inodores ou fétides; embryon annulaire, entourant compl. l'albumen.

$=\mathrm{F}$. plus ou moins hastées ou toutes tr. ent.

$\mathrm{O}^{1} \mathrm{~F}$. hastées ou triang. rhomb.; graines toutes ou la plupart verticales, grosses ou tr. pet., brunes, lisses, à bord épais.

Pl. viv., à souche épaisse; f. ent. ou faibl. sinuées-dentées, pulvérulentes en dessous dans leur jeunesse; glom. verdâtres en long épi ram. nu; graines grosses, diamètre $2 \mathrm{~mm}$.

Pied des murs. - Jn-Sept.

C. Bonus Henricus L. 1102

Pl. ann.; f. fort. dentées, luisantes, non pulvérulentes en dessous; glom. rougeâtres en grappes ou pan. feuillées; graines tr. pet., diamètre $3 / 4$ mm., luisantes. . . . G. rubrum L. 1103 Décombres, lieux humides - Jt-0ct.

Var., pl. assez pet., f. spath., ent.

$0^{*}$ F. ov.-oblongues, non hastées, toutes tr. ent., graines toutes horiz., moyennes, $1 \mathrm{~mm}$., fin. ponct., luisantes.

Pl. toute pulvérulente-blanchâtre, à odeur tr. fétide; t. couchées, cyl.; f. ov.-rhomb.; glom. en grappes courtes nues au sommet; périanthe cachant ent. le fr. . . . . G. Vulvaria L. 1104

Pied des murs, décombres. - Jt-Sept.

Pl. verte ou rougeâtre, non pulvérulente, inodore; t. dress. ou diffuses, striées-anguleuses; f. ov. ou lanc.; glom. en grappes feuillées; périanthe laissant voir le fr.

Lieux incultes. - Jt-Sept.

G. polyspermum L. 1105

$=\mathrm{F}$. plus ou moins lobées ou dentées, non hastées; graine horiz.

- F. assez larg., 3-6 cm., fort. et inég. dentées, vertes sur les 2 faces, peu ou point farineuses; glom. verdâtres.

F. tronq. en cœur à la base, bordées de chaque côté de $2-4$ dents. tr. fortes et term. en lorgue pointe lanc.; périanthe à lobes car. laissant voir la graine, grosse, $2 \mathrm{~mm}$., ponct. rug., terne, à bord subaig. . . . . . . . C. hybridum L. 1106 Ch. cult., décombres, - Jt-Sept.

檫 F. atténuées en coin à la base, bordées de dents nombr. assez fortes, terminées en pointe courte; périanthe à lobes non ou faibl. car.

F. triang. en coin; grappes effilées, presque simples; périanthe laissant voir la graine luisante, fin. ponct., à bord épais et tr. obt. ... . . . . . C. urbicum L. 1107 Décombres, lieux cult. - Jt-Sept.

F. ov. rhomb. ou lanc.; grappes ram. plus ou moins étalées; périanthe cachant compl. la graine, terne, fin. granuleuse à bord aminci en car. aig. . . . . . . C. murale L. 1108 Décombres, pied des murs. - Jn-0ct.

- F. assez pet., 2-3 cm. de large en général, sinuées-dentées ou lobées, parfois presque ent., blanches farineuses ou d'un vert. glauque en dessous, glom. ord. farineux-blanchâtres.

'o Périanthe à lobes non car., laissant voir le fr. au sommet; graines tr. pet., moins de $1 \mathrm{~mm}$., quelques-unes verticales, les autres horiz., lisses, luisantes, à bord car. aig.; f. oblongues, obt., à dents courtes et obt., tr. glauques-blanchâtres en dessous; pl. ord. étalée-ascend. . . . . . C. glaucum L. 1109 Décombres. - Jt-Sept.

'o Périanthe à lobes car., cachant compl. le fr.: graines assez pet., 1-1 1/2 mm., toutes horiz.; f. ov., lanc., ov.-rhomb., trilobées, farineuses ou glauques, mais non glauques-blanchâtres en dessous; pl. ord. dress. 
む Graines à bord car. aig., $11 / 4 \mathrm{~mm}$., luisantes, lisses; f. ov. ou lanc., sinuées-dentées ou ent., blanches ou vertes en dessous; tr. variable. . . . . . . . C. album L. 1110 Lieux cult. - Jn-Oct.

む Graines à bords épaissis et obt.

$\mathrm{F}$. inf. et moyennes, environ 3 fois plus long. que larg., trilobées et presque hastées, à lobe term. beaucoup plus gr., ord. obt., les sup. lanc.-lin., ent.; graines pet., $1 \mathrm{~mm}$.

Décombres, lieux cult. - Jt-0ct.

C. ficifolium Sm. 1111

F. inf. et moyennes presque aussi larges que long., ov.-rhomb. ord. obt., irrégul. sinuées-dentées, les sup. conformes, plus étr., dentées; graines assez pet., 1 1/2 mm.

Décombres, lieux cult. - Jt-0ct.

C. opulifolium Schrad. 1112

\section{Genre 402. - SALSOLA L.}

Pl. ann., dress. ou étalée-diffuse, tr. ram.; f. lin. en alène, atténuées en pointe épin., les florales courtes, subtriang., épin., un peu élargies à la base; bract. ov. lanc., spin.; fl. solit. ou 2-3 rappr. en épis; périanthe fructif. cartilagineux, à ailes dorsales obovales ou réniformes, sinuées-rongées. . . . . . . . S. Kali L. 1113 Lieux sabl., décombres, nat. - Jt-0ct.

\section{FaMille 76. - POLYGONÉES}

Périanthe à 6 divis. sur 2 rangs, les 3 ext. petites et réfléchies, les 3 int. d'abord herb., puis accr. et appliq. sur le fr.; stigmates multifides en pinceau; fl. en faux vert. écartés ou rappr. . RUMEX 403

Périanthe à 5 divis. sur 1 seul rang, presque égales, ord. colorées, non ou peu accr., toutes appliq. sur le fr.; stigmates en tête; fl. non disposées en vert.

POLYGONUM 404

\section{GeNre 403. - RUMEX L.}

+ Fleurs dioïques ou polygames; styles soudés aux angles de l'ovaire; valves fructif. membr., transparentes ou herb., toutes ent.; f. hastées ou sagittées.

X Valves fructif. ailées-membr., suborb. en cœur, débordant larg. le fr.; f. ov. ou oblongues-hastées ou sagittées, larg. de plus de $2 \mathrm{~cm}$. Fl. polygames, les mâles et les femelles réunies sur le même individu; f. glauques, aussi larg. que long., ov.-hastées ou suborb., palminervées, à pétiole plus long que le limbe; valves fructif. sans granule; souche long. ramp.... . R. scutatus L. 1114 Eboulis calc., vieux murs. - Mai-At.

F1. dioïques, les mâles et les femelles sur des individus séparés; f. vertes beaucoup plus long. que larg., ov.-oblongues sagittées, penninervées, les rad. long. pétiolées, obt., les sup. subsessiles, lanc. et embrass.; valves fructif. munies d'une petite écaille à la

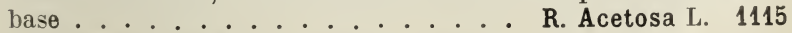
Prés, bois, pâturages (Oseille). - Mai-Sept.

Valves fructif. pet., ov., herb., sans écailles à la base, plus courtes que le fr.; f. lanc. ou lin.-hastées, étr., dépassant rar. $1 \mathrm{~cm}$. de large; pl. rougeâtre ou glauque, à t. grêles, à souche ramp.

Lieux secs et sabl. - Avr.-Sept.

R. Acetosella L. 1116

+ Fl. hermaphrodites, rar. polygames; styles libres; valves fructif. à la fin coriaces-membr. dentées ou lâch. dentelées, plus rar. ent.; f. atténuées ou arrondies en cour à la base, jamais hastées ni sagittées. 
= Valves fructif. bordées de longues dents acum. ou sét.

Q F. atténuées à la base, étr., ayant moins de $2 \mathrm{~cm}$. de large; vert. rappr. en pan. étr.; pl. bisann. ou pér. à rac. pivot., peu épaisses; fr. petit; valves fructif., toutes munies d'un granule oblong et bordées de long. dents sét.

Valves fructif. petit., long. $3 \mathrm{~mm}$., bordées, de ehaque côté, de 2-3 long. dents sét. flexueuses, les sup. dépassant le sommet de la valve; anth. pet., long. $3 / 4 \mathrm{~mm}$. larg. $0,5-0,6 \mathrm{~mm}$., ov., presque aussi larg. que long.; pl. ord. jaune dorée à la mat., à verticilles rapprochés et confluents, rar. vert.-jaunâtre ou foncé à vert. écartés ; achaines petits, long 1 1/2 mm., larg. 3/4 mm.

R. maritimus L. 1117

Etangs, surtout après le dessèchement, bords des rivières. -
Jt-0ct.

Valves fructif. assez gr., long. 4 mm., oblongues-lanc., bordées, de chaque côté, de 2-3 long. dents sét., les sup. long. dépassées par le sommet de la valve; anth. assez gr., long. 1-1,2 mm., larg. 0,6-0,7, oblongues-lin., presque 2 fois aussi long. que larg.; pl. verdâtre ou jaunâtre à la maturité à verticilles écartés, formant une panicule effilée, rar. jaune à vert. rappr. et confluents; achaines assez gros, long. $2 \mathrm{~mm}$.; larg. $1 \mathrm{~mm}$.

R. palustris Sm. 1118

Etangs, lieux maréeageux, bords des rivières. - Jt-0ct.

Q F. inf. tronq. ou éch. en cœur à la base, larg. de plus de $2 \mathrm{~cm}$. ; rac. épaisse, viv. ou bisann.; vert. en grappes formant une pan. large; fr. assez gros; valves fructif. toutes ou une seule munies d'un granule et bordées de dents lanc.; anth. oblongues-lin. ou lin.

Tige dress., flexueuse, à nombr. ram. raides étalés-divar.; f. pétiolées, les rad. en rosette, oblongues en cœur, obt., rétrécies ou éch. sur les côtés en forme de violon; vert. pauciflores, écartés, en longues grappes lâches un peu feuillées; pédic. courts. artic. vers la base; valves fructif., coriaces, fort. rétic., ov. triang., toutes munies d'un granule oblong, bordées de dents raides lanc.; pl. bisann. . . . . R. pulcher L. 1119 Lieux secs, bord des chemins. - Jn-Sept.

T. dress., robuste, à ram. ascend.; f. pétiolées, les inf. gr., ov. ou oblongues en cœur, sinuées-crén., obt. ou aig.; vert. multiflores assez rappr., nus ou les inf. seuls, feuillés en grappes allongées; pédic. assez longs, art. au-dessous du milieu; valves fructif. rétic., ov. triang., l'ext. seule granulée, toutes bornées de dents lanc. en alène. . . . . . . . R. obtusifolius L. 1120 Lieux frais, bords des chemins. - Jn-Sept.

= Valves fructif. ent. ou obscur. dentic. à la base.

- Valves fructif. lanc.-oblongues, bien plus long. que larg.; vert. ord. écartés, formant des grappes plus ou moins lâches, grêles; f. rad. arrondies ou en cœur à la base.

Vert. dépourvus de f. bract., sauf les inf., formant des grappes effilées; une seule valve fructif. pourvue d'un granule ov. bien développé . . . . . . R. sanguineus L. 1121 Lieux frais et ombragés. - Jn-Sept.

Vert. tous munis de $\mathrm{f}$. ou ceux du sommet nus, en grappes longues formant une pan. large; valves fructif. toutes pourvues d'un granule ov. bien développé. • R. conglomeratus Murr. 1122 Fossés, lieux humides ou frais. - Jn-Sept.

- Valves fructif. suborb. ou ov.-triang., presque aussi larg. que long.; vert. rappr. ou contigus, la plupart dépourvus de f.

Valves fructif. suborb. en cour, à granules très inég., ord. un seul bien développé. 
F. ondulées-crispées sur les bords, les rad. oblongues-lanc., atténuées ou tronq. à la base; valves fructif. larg. ov. en cœur, ent. ou dentic. à la base, égalant 4-5 mm.; pl. de $50 \mathrm{~cm} .-1 \cdot \mathrm{m}$.

R. crispus L. 1123

Lieux incultes. - Jt-Sept.

F. planes ou à peine ondulées, amples, les inf. larg. ov. lanc., arrondies ou brièv. atténuées à la base; valves fructif. gr., 6-7 mm., suborb. en cceur, ent. ou dentic. à la base, une seule portant un granule ov., pet.; pl. de 1-2 m. R. Patientia L. 1124 Cult. et subsp. (Patience). - Jn-Sept.

Valves fructif. ov.-triang. en cœur, ent. ou dentic. à la base, toutes munies d'un gros granule oblong; f. tr. amples, les inf. longues de $50 \mathrm{~cm} .-1 \mathrm{~m}$., lanc.-ellipt. aig., long. atténuées à la base; pl. tr. robuste, 1-3 m. R. Hydrolapathum Huds. 1125 Marais, bords des rivières. - Jt-At.

$R$, maximus Schreb diffère de $R$. Hydrolapathum par ses $\mathrm{f}$. inf. tronq. ou en cœur à la base, les valves fruct. cordées à la base, dentic. Dreux et Gisors.

\section{GenRe 404. - POLYGONUM L.}

+ F. sagittées, triang.-ovales, acum., larg. éch. en cœur à la base ; pl. ann. à fr. trigone; 8 étamines.

X T. dressées, non volubles; fl. en corymbe ou en pan.; styles assez longs, à stigmates à peine épaissis ; fr. long. saill. sur le périanthe non accr.

Fl. blanches ou rosées, tr. appar., en grappes courtes disposées en corymbes; fr. lisse à angles aig., dr. et ent., à saveur non amère. . . . . . . . . P. Fagopyrum L. 1126 Cult. (Sarrasin). - Jt-Sept.

Fl. d'un blanc verdàtre ou jaunâtre, en grappes allongées et interr. formant une pan.; fr. rug.-tuberc., à angles épaissis et onduléssinués, à saveur amère. . . . . . P. tataricum L. 1127 Cult. rar. - Jn-Sept.

$X \mathrm{~T}$. couchées ou volubles; fl. en fasc. ou en grappes axill.; styles presque nuls; stigmates en tête; fr. ent. renf. dans le périanthe acer.

T. ang.-striées, couchées ou grimp., long. de $20 \mathrm{~cm}$. à $1 \mathrm{~m}$.; anth. violacées : périanthe fructif. non ou obscur. ailé sur les angles; fr. d'un noir terne, fin. granuleux. P P. Convolvulus L. 1128 Lieux cult. - Jn-0ct.

T. cyl-arrondies, toujours volubles, longues de 1-2 m.; anth. blanches; périanthe fructit. larg. ailé-membr. sur les angles; fr. d'un noir très luisant, lisses.. . . . . P. dumetorum L. 1129 Haies, bois. - Jn-0ct.

+ F. ni sagittées, ni triang. en cœur, atténuées, tronq. ou un peu éch. à la base.

= Fl. disposées en épis ou en pan. nus au sommet de la t. ou des ram.; pl. des lieux hum.

$\sigma^{7}$ Pl. viv.; f., au moins les inf., arrondies ou en cœur à la base; épis solit. au sommet des t.; $\boldsymbol{B}$ ou 8 ét., saill.

T. simple, dress., de 20-80 cm., term. par un seul épi, peu feuillée; f. inf. élargies en cour à la base et décurrentes sur le pétiole, les sup. embrass.; gaine stipulaire obliq. tronq., non cil.; souche épaisse, contournée; 8 ét.. . . . . . P. Bistorta L. 1130

Prairies hum. - Mai-Jt.

T. ram., submerg., ou terrestres, radicantes à la base; f. oblongues ou lanc. arrondies ou en coeur à la base, pétiolées; gaine stipulaire tronq. horiz., souvent fendue en long, court. cil.; sonche long. ramp.; 氵 ét. . . . . . . P. amphibium L. 1131 Etangs, mares, quelquefois lieux asséchés. - Jn-Sept. 
ত̛ Pl. ann., à rac. fib.; f. atténuées à la base; épis pan. au sommet des t. ; 6 ét. incluses.

- Epis oblongs-cyl., compacts, larg. de 6-10 mm.

Pédonc. et périanthe gland.-rudes; fr. uniformes, tous lenticulaires, concaves sur les 2 faces ; f. égalant ou dépassant la long. de 2 entre-nœuds; graines peu ou point cil.

Lieux hum. - Jt-Sept.

P. lapathifolium L. 1132

Pédonc. et périanthe lisses, non gland.; fr. biformes, les uns trigones, les autres lentic.-aplatis; f. n'égalant pas la long. des entre-nœeuds ; gaines long. cil... . . P. Persicaria L. 1133 Lieux hum. - Jt-Sept.

— Epis grêles, subfilif., làches ou interr., larg. de 2-5̆ mm.; fr. les uns trigones, les autres lentic.

Périanthe couvert de points gland.; fr. fin. rug., ternes; bractéoles nues; gaines presque gl., à cils, la plupart courts; f. à saveur poivrée, brûlante ; épis lâch. arq. pend.

Lieux hum. - Jt-0ct.

P. Hydropiper L. 1134

* Périanthe non gland.; fr. lisses et tr. luisants; bractéoles cil.; gaines pub., long. cil.; f. à saveur herb., fade; épis dress. ou pench.

Pl. de 20-80 cm. à tiges dress. ou ascend.; f. oblongues-lanc. ou lanc., atténuées à la base, dress.-étalées; fl. vert rougeâtre en épis penchés; fr. pet., long. $3 \mathrm{~mm}$.

Lieux hum. - Jt-0ct.

P. mite Schrank. 1135

Plante grêle de 10-ว̆0 cm., à tiges couchées diffuses; f. étr. lanc. ou lin., à peine atténuées à la base, étalées horiz.; fl. vert rouge-vineux, en épis à la fin dress. fr. tr. pet., long. $2 \mathrm{~mm}$............ . . minus Huds. 1136 Lieux hum. silic. - Jt-Oct.

= Fl. solit. ou fasc., 2-5̆, à l'aisselle de presque toutes les f., les f. sup. parfois réduites à de courtes bract.; pl. ann. des lieux secs, à fr. trigones.

T. non feuillées au sommet; fl. en longs épis term. lâches et nus ; fr. luisants, à peine ponctués, long. 2 1/2-3 mm.; f. ellipt. lanc., à peines veinées . . . . . . . . P. Bellardi All. 1137 Ch. arides, moiss. - Jn-Sept.

T. feuillées jusqu'au sommet des ram.; fl. subsessiles à l'aisselle des f.; fr. ternes ou vaguement luisants, tr. fin. striés en long, long. 2-2-12 mm.; f. ov., ellipt. ou lanc., fin. veinées en dessous. variable.

P. aviculare L. 1138

Lieux cult. et incultes. - Jn-Nov.

\section{Famille 77. - DAPHNOIDÉES (Thymélées).}

Périanthe persist.; fr. sec renf. dans le périanthe; fl. petites, peu appar., jaunàtres ou verdâtres; herbe ann. à f. pet. lanc. lin. larges de $3 \mathrm{~mm}$. au plus. . . . . . . . . . . . . . PASSERINA 405

Périanthe caduc avant la mat. du fr.; fr. charnu, drupacé nu; fl. général. tr. appar. et odor.; arbriss. ou sous arbriss. à f. assez gr. oblongues lanc. larges de 1-3 cm......... DAPHNE 406

\section{GenRe 40\%. - PASSERINA L.}

Pl. de $20-30 \mathrm{~cm}$. à t. et ram. dress., grêles, effilés, feuillés dans toute leur long.; f. lanc.-lin., aig. à 1-3 nervures; fl. munies de 2 bract., dépassant le fr., en longs épis feuillés, lâches, filif.; périanthe persist. à lobes ov.-obl., 2 fois plus courts que le tube. P. annua Wikstr. 1139 Ch. calc. - Jt-Sept. 


\section{GENRE 406. - DAPHNE L.}

Fl. rouges ou roses, tr. odor., naissant avant les f. cad., disposées 2-4 en petits faisceaux étalés-dress. non feuillés; f. gl. ou cil., minces, cad., oblongues-lanc., atténuées en court pétiole; périanthe vel. à lobes égalant le tube; baie ov., rouge... . D. Mezereum L. 1140 Bois, surtout calc. - Févr.-Mars.

Fl. jaune-verdâtre, odor., naissant après les f. persist., disposées 3-10 en petites grappes pench. axill.; f. gl., coriaces, obovales-lanc., atténuées en court pétiole; périanthe gl., à lobes 2-3 fois plus courts que le tube; baie ov., noire. . . . . . . . . D. Laureola L. 1141 Bois, surtout cal. - Févr.-Mars.

\section{Fanille 78. - SANTALACÉES}

Pl. viv., dress., ascend. ou couchées, à t. herb.; f. lin., uninervées; fl. blanchâtres à 4-ž divis., 4-5̆ ét.; fr. sec, ellipsoïde, vert, strié, couronné par le limbe du périanthe....... THESIUM 407

\section{GeNre 407. - THESIUM L.}

Souche épaisse, ligneuse, émettant des t. dress. ou ascend., raides, de $30-30 \mathrm{~cm}$.; fl. en pan. pyramidale à ram. allongés, lisses; fr.oblong, 2 fois plus long que son pédic. lisse; bract. pet., un peu scabres, toutes plus courtes que le fr. ......... T. divaricatum Jan. 1142 Coteaux calc, pelouses sèches. - Jn-At.

Souche grèle ou à peine lign., émettant des t. couchées-étalées, grêles, subfilif., de10-30 cm.; fl. en grappe simple ou composée, à ram.courts, scabres; fr. ov., 3-4 fois plus long que son pédic. scabre; bract. scabres, la moyenne égalant ou dépassant un peu le fr.; périanthe fructif. 2 fois plus court que le fr. . . . . . T. humifusum DG. 1143 Pelouses sèches. - Jn-At.

\section{FAMILLE 79. - LORANTHACÉES}

\section{GenRe 408. - VISGUM L.}

Sous-arbriss. de 20-50 cm., vert jaunâtre, à t. arrondies, artic., di-trichotomes; f. oblongues, obt., atténuées à la base, coriaces, à 5̆-6 nervures parall.; fl. jaunâtres, en petites têtes sessiles au sommet des ram. et à l'aisselle des feuilles; baie sessile, glob., blanche à pulpe visqueuse. . . . . . . . . . V. album L. 1144

Parasite sur les arbres; peupliers, pommiers, robinia, chênes, bouleaux, etc. - Fl. Mars-Mai ; fr. At-Nov.

\section{FAMILLE 80. - ELÉAGNÉES \\ GeNRE 409. - HIPPOPHAE L.}

Arbriss. de 1-3 mm., à ram. étalés, dens. feuillés ; f. lanc.-lin., uninervées, presque sessiles; fl. verdâtres, entourant la base des jeunes ram., les mâles en courts chatons lat., sessiles à l'aisselle d'écailles, à périanthe biséqué, les fem. solitaires, axill., brièv. pédic. à périanthe bifide; stigmate en languette; îr. à saveur acide, comestible.

Nat. dans les sables. - Fl. Mars-Mai; fr. At-Sept.

H. rhamnoides L. 1145 


\section{Famille 81. - ARISTOLOCHIÉES}

Fl. term., solit. entre les $2 \mathrm{f}$. sup. opp. et en forme de rein; périanthe persist., régul., en cloche, à 3 lobes ; 12 ét. libres; caps. subglob., couronnée par le périanthe persist., s'ouvrant irrégul., à graines ov., creuses en dedans; t. ramp., gazonn. . . . . ASARUM 410 Fl. axill., solit. ou fasc. à l'aisselle des f. caul. alt. et en cœur; périanthe cad., irrégul., tubul., en languette; 6 ét. soudées avec le style; caps. coriace à 6 loges polysp., s'ouvrant régul. par 6 valves.

ARISTOLOCHIA 411

\section{GenRe 410. - ASARUM L.}

Pl. viv., vel., à odeur poivrée; t. émettant des ram. tr. courts, dress., écailleux, portant 1-2 paires de f. orb. en rein long. pétiolées et au sommet une fl. pourpre noiràtre, vel., court. pédonc.

$$
\text { Bois frais. - Mars-Mai. }
$$

A. europæum L. 1146

\section{Genre 411. - ARISTOLOCHIA L.}

Pl. viv., dress., gl., à odeur fétide; souche profonde, long. ramp., à rac. grêles; f. larg. ov. obt., en cœur à la base, fin. dentic. et rudes aux bords; fl. jaunàtres; périanthe gl. à languette aussi longue que le tube; caps. grosse, en poire, pend.. . . . A. Clematitis L. 1147 Lieux pierreux, vignes, berges des rivières. - Mai-Sept.

\section{FAMILLE 82. - EUPHORBIACÉES}

+ Arbriss. tr. ram. à f. opp., coriaces et persist.; 4 ét.; 3 styles périphẻriques; caps. sessile term. par 3 cornes, s'ouvrant en 3 valves, chacune à 2 graines. .............. BUXUS 412

+ Pl. herb. ou lign. à la base, à f. rar. persist. ; ว̆-1ว̈ ét.; 2-3 styles centr.; caps. pédic., sans cornes, contenant 2-3 graines, 1 dans chaque loge.

Pl. à suc laiteux; fl. monoïques, ord. en omb. et munies à la base de larg. bract. étalées; périanthe remplacé par un invol. contenant un ovaire centr. entouré de plus. ét. et $4-5$ glandes ext. pétaloïdes; caps. à 3 coques. . . . . . . E E EPHORBIA 413

Pl. à suc aqueux incolore; fl. dioïques, les mâles et les fem. portées sur des individus séparés; fl. màles en grappes spiciformes, non entourées de larges bract.; périanthe à 3 divis. ne contenant que les ét. ou que le pistil, sans glandes pétaloïdes en dehors; caps. à

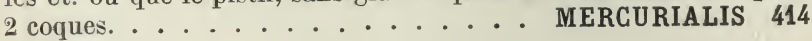

$$
\text { Genre 412. - BUXUS L. - Buis. }
$$

Arbriss. à bois jaunâtre tr. dur, à jeunes ram. tétr.; f. ov. ou lanc., ent., gl. et luisantes; fl. jaunâtres sessiles en glom. axill.; monoïque, plus. fl. màles entourant $1 \mathrm{fl}$. femelle centr.; 4 sép. inég. entourés de bractéoles . . . . . . . . . B. sempervirens L. 1148 Bois et coteaux secs calc. - Mars-Avril.

\section{GenRE 413. - EUPHORBIA L.}

+ F. caul. opp. sessiles, lanc., ent., uninervées, à paires alt. en croix; fl. en omb. à 2-5 rayons dichotomes; glandes en croiss.; caps. tr. grosse, gl., lisse; graines rétic. rug. . . . E. Lathyris L. 1149 Voisinage des habitations. - Mai-Jt. 
+ F. caul. alt. ou éparses.

X Glandes de l'invol. ent. non éehancrées en croissant.

$=\mathrm{Pl}$. ann. à rac. pivot., à $\mathrm{t}$. souvent uniq.

Q Caps. lisse, non tuberc.; graines rétic.-alv., ternes; f. obovales en coin, les caul. spath. dentic. sup. ; omb. à š ray. ; bract. obovales. . . . . . . . E. helioscopia L. 1150 Lieux cult. - Avr.-0et.

Q Caps. tuberc.; graines lisses, luisantes; f. obovales lanc. aig.; bract. ov.-triang., mucr.

Caps. subglob.; tuberc. petits, hémisph., peu saillants; graines brun. de $2 \mathrm{~mm}$......... E. platyphylla L. 1151 Ch. argil. calc. - Jn.-Sept.

Caps. nett. trigone; tuberc. cyl. saillants; graines brun rougeàtre de 1 1/2 mm. . . . . . . E. stricta L. 1152 Ch. argil., fossés. - Jn-Sept.

- Pl. viv. à souche épaisse à t. nombr.; caps. tuberc., graines brun., lisses.

Pl. robuste à t. épaisse à nombr. rameaux axill. stériles; omb. jaune à ray. nombr.; caps. à tuberc. arrondis.

Marais, fossés. - Mai-Jt.

E. palustris L. 1153

Pl. grêles, peu élevées, à t. ord. simples; omb. à 5 ray.

م 0 mb. vertes à la flor.; t. écailleuses à la base; souche charnue, artic., horiz.; glandes de l'invol. ord. pourpres; caps. gl. ou poilue à tuberc. brièv. cyl.; f. ent. ou dentic.

E. dulcis L. 1154

Bois ombragés. - Mai-Jn.

Omb. jaunes à la flor.; t. non écailleuses à la base sortant nombr. d'une souche lign.

F. fin. dentic.; caps. à petits tuberc. cyl. tr. rappr.; omb. à 5 ray.; bract. obovales dentic. . . E. verrucosa L. 1155 Prés secs. - Mai-Jt.

F. tr. ent. ; caps. lisse ou tr. fin. chagrinée; omb. à ray. nombr.; bract. ov. triang. mucr. . . E. Gerardiana Jacq. 1156 Lieux secs, coteaux calc. - Mai-Jt.

X Glandes de l'invol. échancrées en croissant à 2 cornes.

† Pl. ann. à rac. pivot.; gr. rug., ponct. ou sill.; caps. gl. lisse.

Caps. à coques ayant chacune sur le dos 2 car. ailées séparées par un sill. étr.; graines hex., caronc., à sill. longit. à 2 fossettes allongées sur 1 face et 2 lignes de 3-4 fossettes sur l'autre; f. obovales ent. . . . . . . . . E. Peplus L. 1157 Lieux cult. - Mai-0ct.

Caps. à coques non ailées sur le dos.

Bract. lin. ou lanc.; f. lin., aig., obt. ou tronq.-rét. ; graines ov.tétr., tuberc., caronc. . . . . . E. exigua L. 1158 Ch. cult: - Mai-0et.

Bract. ov.-acum. mucr.; f. ellipt. ou lanc., 3 nerv.; graines ov.tétr., sill. en travers, sans caronc. . . E. falcata L. 1159 Ch. calc. - Jn.-0et.

む Pl. viv. ù souche épaisse ou lign.; graines lisses.

- F. persist. pub., oblongues ou obovales, les inf. en rosette; bract. flor. soudées en un disque orbic. concave, tr. rar. non soudées (var. ligulata Chaub.); glandes jaunes ou purp. à cornes long. converg. . . . . . . . E. amygdaloides L. 1160 Bois frais. - Mai-Jt. 
F. cad. gl.; bract. libres; glandes à cornes courtes.

F. lin.; celles des rameaux stériles tr. étr., rappr. en pinceau; bract. non mucr.; caps. chagrinée papilleuse sur toute sa surface. ............ E. Cyparissias L. 1161 Lieux secs. - Avr.-Sept.

F. lin. lanc. ou oblongues, celles des rameaux stériles jamais en pinceau; bract. mucr.; caps. chagrinée seul. sur le dos des coques ............ . . E. Esula L. 1162 Bois et coteaux calc. - Mai-At.

Var. dans les prés hum. : T. robustes, f. oblongues-lanc. (E. salicetorum Jord). Vallée du Loing ou t. assez robustes $f$. étroites aig. (E. pseudocyparissias Jord.) Bray-sur-Seine.

\section{GENRE 414. - MERCURIALIS L.}

Viv. ; souche long. ramp.; t. simple; fl. fem. long. pédonc.; caps. large de $6.8 \mathrm{~mm}$., tr. pub. .......... M. perennis L. 1163

Bois ombragés. - Avr.-Jn.
Ann. ; rac. grèle pivot.; t. rameuse, feuillée dès la base; fl. fem. presque sessiles; caps. large de $3-4 \mathrm{~mm}$., hispide . . M. annua L. 116† Lieux cult. - Avr.-Oct.

\section{FAMiLLE 83. - URTICÉES}

F. tr. ent., alt.; t. faibl., à poils mous, peu élevées; périanthe à 4 divis. presque égales ............ PARIETARIA 415

F. dentées, lobées ou digitées, toutes ou la plupart opp.; pl. raides, élevées.

Pl. mon. ou dioïques hér. de poils raides, contenant un liquide tr. irritant; fl. fem. à 4 sép., les 2 ext. pet. ou nuls, stigmate en pinceau.

URTICA 416

Pl. dioïques sans poils piquants; f. palmées ou digitées; fl. fem. à périanthe monosép.; fendu en long; 2 stigmates allongés, filiformes.

T. dress., raide, non grimp. ; 1. palmatiséquées, à ร̌-7 segments lanc.

š ét. à anth. pend.; fl. fem. en fasc. formant une pan.; ann.

CANNABIS 417

T. voluble, sarment., grimp.; f. palmatilobées, à 3-ä lobes ovales ; ̋̈ ét. à anth. dress.; fl. fem. disposés en cônes ovales pédonc.; viv.

HUMULUS 418

\section{GenRe 415. - PARIETARIA L.}

Viv. pub.; fl. en glom. pluriflores axill.; bract. décurr. plus courtes que les fl.; t. diff. ou dress. ( $P$. erecta M. et K.).

Vieux murs, décombres. - Jn.-0ct.

P. officinalis L. 1165

\section{GenRe 416. - URTIGA L.}

Fl. fem. en têtes glob. pédonc., les mâles en grappes grêles rameuses interr.; périanthe fructif. tr. accr. ; pl. mon., ann. ou bisann.

Décombres, pied des murs, nat. - Mai-0ct.

U. pilulifera L. 1166

Fl. toutes en grappes lâches; périanthe fructif. peu accr.

Pl. ann. ram., peu élevée, hér. à rac. fibr.; fl. mon., les mâles et les fem. sur la même grappe simple, dress. ou étalée.

Lieux cult, décombres. - Mai-0ct.

U. urens L. 1167

Pl. viv. élevée, hispide, ord. simple à souche ramp.; fl. ord. dioïques, en grappes ram. plus long. que le pétiole; grappes fruct. pend.

Lieux incultes. - Jn,-0ct.

U. dioica L. 1168 
Genre 417. - GANNABIS L. - Chanvre.

Pl. pub. rude à odeur forte; périanthe mâle à 5 divis.; fr. subglob. lisse. . . . . . . . . . . G. sativa L. 1169 Cult. rar. et subsp. - Jn.-Sept.

\section{GeNRe 418. - HUMULUS L.}

Fl. mâles en grappes ram.; fl. fem. 2 à l'aisselle des écailles foliacées du cône; fr. ovoïde compr. à glandes jaunes aromat.

Haies, lieux frais. - Jn.-Sept.

H. Lupulus L. 1170

\section{FAMILLE 84. - ULMACÉES \\ Genre 419. - ULMUS L.}

Fl. et fr. long. pédonc. pend.; samares ellipt.-orb. plus courtes que leur pédonc., vel. cil. aux bords, à gr. située vers le milieu; 3 - 8 ét.

Forêts et parcs, planté. - Fl. Mars-Avr.; fr. Mai-Jn.

U. pedunculata Foug. 1171

Fl. et fr. presque sessiles, non pend.; samares gl. plus long. que leur pédonc.

Samare obovale, atténuée à la base, à graine située au-dessus du centr. du fr. et arrivant jusqu'à l'éch.; ram. quelquefois ailés subéreux (U. suberosa Nœnch.) . . . . . U. campestris L. 1172 Bois. - Fl. Févr.-Avr.; fr. Mai.

Samare suborb. à graine située vers le centr. du fr. et n'atteignant pas l'éch. . . . . . . . . . U. montana With. 1173 Forèts et parcs, planté. - Fl. Mars-Avr.; fr. Mai.

\section{Famille 85. - ARTOCARPÉES}

Genre 420. - FIGUS L.

Arbuste à suc laiteux abond.; f. alt. pub. rudes; fl. mâles à la partie sup. du récept., 3 ét., 3 sép.; fl. fem. inf., périanthe à 5 lobes, 2 styles lat.; fr. tr. petits drupacés. . . . . . . . F. Carica L. 1174 Cult. et subsp. - Jn-Sept.

\section{FAMILLE 86. - MORÉES}

\section{GENRE 421. - BROUSSONETIA}

Arbre ou arbuste à suc laiteux; racine stolonifère; f. vel. inf., tr. scabres sup., irrég. dent., soit ent. en cœur à la base, soit irrégul. lobées............ B. papyrifera Vent. 1175

Cult. et subsp. - Mùrier à papier.

On rencontre rar. Morus alba $\mathbf{L}$. Arbre monoïque, à fleurs en épis; périanthe devenant succulent et renfermant les akènes; fruit charnu, blanc ou rose; f. larg. ovales en cœur à la base, inég. dent.; cult. pour ses feuilles servant de nourriture aux vers à soie. Le Morus nigra diffère par ses fruits (mûres) presque noirs.

\section{Famille 87. - JUGLANDÉES}

Genre 422. - JUGLANS L. - Noyer.

Arbre élevé à écorce lisse; f. alt. arom.; fol. ov. aig. ent. ; périanthe à 3̈-6 lobes inég.; 14-36 ét.; 2 larges stigmates. . . J. regia L. 1176 Cult. - Fl. Avr.-Mai ; fr, Sept.-Oct. 


\section{Famile 88. - CUPULIFÈrES}

+ Fl. mâles en chatons glob. ou grêles et interr.; périanthe mâle à 4-8 divis.; invol. fructif. coriace, garni d'épines ou d'écailles; 3-6 styles; ovaire à $3-6$ loges bi-ovulées.

$X$ Fl. mâles en chatons glob. pend.; fr. à 3 angles tranchants, renf. dans un invol. hér. d'épines molles et s'ouvrant en 4 valves; $f$. FAGUS 423

$X$ Fl. mâles en chatons grèles et interr.; fr. arrondis, jamais trigones; f. plus ou moins dentées, lobées ou pennatifides.

Chatons mâles allongés et dress.; invol. fructif. coriace, hér. d'épines vulnérantes, enveloppant compl. les fr.; fr. normalement 3 , ovoïdes-compr. dans chaque invol.; f. oblongues lanc.

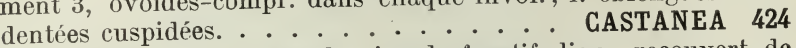

Chatons mâles filif. et pend.; invol. fructif. lign., recouvert de petites écailles imbriq., en coupe, n'entourant que la base du fr.; fr. unique, ov. ou oblong, non compr.; f. ord. ov. oblongues profond. sinuées. ................ QUERGUS 425

+ Fl. màles en chatons cyl., continus, non interr.; périanthe mâle nul remplacé par une écaille; invol. fructif. simple, foliacé, sans épines ni écailles; 2 styles; ovaire à 2 loges uniovulées.

Fl. màles seules en chatons, naissant longtemps avant les f., à écailles trilobées; invol. fructif. en cloche, lacéré-denté et ouvert au sommet; fruit ov. on subglob., à péricarpe lign.; f. suborb. acum. ............................ CORLUS 426

Fl. mâles en chatons, les fem. en grappes, paraissant avec les f.; les mâles à écailles ent.; invol. fructif. non en cloche, unilat., inégal. trilobé; fr. ov. compr. muni de côtes longit.; f. ov. ou oblongues-acum............................ 427

$$
\text { Gevre 423. - FAgUS L. - Hètre. }
$$

Arbre élevé à écorce lisse et blanchàtre; f. ov. ent. ou un peu sinuées dentées, pub.-soyeuses aux bords et sur les nervures; 8-12 ét.; périanthe tr. vel. en cloche à $\breve{b}-6$ lobes; fl. fem. 2-3 dans un invol. à 4 divis., périanthe vel., lacinié; 3 styles filiformes.

Bois montueux. - Fl. Avr.-Mai; fr. At-Sept.

$$
\text { Genre 424. - GASTANeA Mill. - Châtaignier. }
$$

Arbre élevé, à écorce fendillée gris.; 8-13̈ ét.; fl. fem. réunies par 3 dans un invol. à nombr. bract.; invol. fructif. subsessile s'ouvrant en 4 valves

Bois siliceux. - Fl. Jn.-Jt.; fr. Oct.'?

C. vulgaris Scop. 1177

\section{Genre 42\%. - QUERGUS L.}

+ Cupules grosses, hér. d'écailles long., lin., étalées ou recourbées, tortillées; glands à maturation bisann. placés sur les rameaux défeuillés de l'année précédente . . . . . . . . Q. Cerris L. 1179 Bois, forêts, nat. - Fl. Avr.-Mai; fr. Automne.

+ Cupules petites, à écailles courtes appliq.; glands à maturation ann. placés sur les rameaux feuillés de l'année.

X F. pub. ou vel.-tom. en dessous, pétiolées; cupules gris-tom., à écailles appliq., les sup. à pointe libre et saill., arbre peu élevé, souvent tortueux, fr. sessiles ou à pédonc. court ne dépassant pas le pétiole......... Q. pubescens Willd. 1180 Bois secs, surtout ealc. - Fl. Avr.-Mai; fr. Sept. 
F. gl. ou faibl. pub. en dessous; cupules gl. ou glabr. à écailles exact. appliq., uniformément courtes, tuberc., arbres souv. élevés, dr.

F. nett. pétiolées, non auriculées à la base, souvent pub. en dessous sur les nervures; fl. fem. et fr. subsessiles ou à pédonc. commun ne dépassant pas le pétiole.

Bois. - Fl. Avr.-Mai; fr. Sept.-0ct.

Q. sessiliflora Salisb. 1181

F. sessiles ou subsessiles, presque auriculées à la base, ent. gl.; fl. fem. et fr. portés sur un pédonc. commun beaucoup plus long que le pétiole . . . . . . . Q. pedunculata Ehrh. 1182 Bois. - Fl. Avr.-Mai; fr. Sept.-Oct.

Q. Ilex L.; arbrisseau à f. persist. existe à Roncevaux près Malesherbes où il a été planté.

\section{Genre 426. - GORYLUS L. - Noisetier.}

Arbriss. à ram. flexibles pub.; f. doublement dentées; chatons mâles fasc. par 2-3̈; 6-8 ét. barbues; fl. fem., 1-ว̈, peu appar., dans un bourgeon écailleux; 2 longs styles rouges . . . . G. Avellana L. 1183 Bois. - Fl. Janv.-Mars; fr. Sept.

\section{Genre 427. - CARPINUS L. - Charme.}

Arbre à écorce lisse, gris.; f. doublement dentées; chatons mâles solit. ; 6-20 ét. barbues; fl. fem. en grappes lâches pédonc.; 2 styles filiformes . . . . . . . . . . . G. Betulus L. 1184 Bois. - Fl. Avr.-Mai ; fr. Sept-Oet.

\section{Fanille 89. - SALICINÉES}

Chatons dressés, à écailles ent.; périanthe représenté par 1-2 glandes ; 2-ə̃ ét. ; arbriss. ou arbres à f. peu élargies et court. pétiolées.

SALIX 428

Chatons à la fin pend., à écailles incisées ou lacérées ; périanthe représenté par une cupule oblique; 8-20 ét.; arbres souvent élevés, à f. larges et long. pétiolées.......... POPULUS 429

\section{Genre 428. - SALIX L.}

+ Sous-arbriss. de 20-80 cm., à t. souterraine ramp.; chatons pet., subsessiles, ov. ou oblongs, long. 12-15 mm., larg. 5-7 mm.; écailles vel., discolores, brun. au sommet; 2 ét.; caps. tom. ou gl., à pédic. 3-4 fois plus long que la glande; f. oblongues, lanc. ou ov., soyeuses-argentées en dessous ou gl., pub. ou gl. en dessus, long. 2 1/2-3 cm.; larg. 8-11 mm.; stip. lanc.-aig. . S. repens L. 1185 Tourb., prairies hum. - Avr.-Nai.

+ Arbres ou arbriss. dress., dépassant $1 \mathrm{~m}$.; chatons assez gros ou gros. $X$ Chatons sessiles ou subsessiles, paraissant avant les $\mathrm{f}$.; écailles brun. ou noir. au sommet, rar. jaunâtres.

$=$ Arbuste ou arbriss. à ram. plus ou moins divar.; caps. tomenteuse à pédic. 3-5̆ fois plus long que la glande; bois nu à lignes saillantes.

Arbriss. à ram. tr. divar., ang.; chatons pet., les mâles ovoïdes, long. $13 \mathrm{~mm}$., larg. $10 \mathrm{~mm}$.; les fem. oblongs, long. $2 \mathrm{~cm}$., larg. $1 \mathrm{~cm}$.; jeunes ram. et bourgeons gl. ou pubérulents; $\mathrm{f}$. assez pet., brièv. pétiolées, obovales, ondulées-crén., tom. et rétic.-bosselées en dessous, pub, en dessus, long. $21 / 2-5 \mathrm{~cm}$. larg. 15-2: mm. . . . . . . . S. aurita L. 1186 Lieux maréc. ou tourb. - Mars-Arr. 
Arbriss. ou arbuste à ram. un peu divar., peu ang.; chatons assez gros, oblongs ou cyl., long. $2-4 \mathrm{~cm}$., larg. $12 \mathrm{~mm}$.; jeunes ram. et bourgeons tom.-cendrés; f. assez gr., pétiolées, obovales ou oblongues lanc., un peu ondulées, glauques-blanchâtres et devenant glabr. en dessous, pub. ou gl. en dessus.

\section{S. cinerea L. 1187}

\section{Lieux hum. - Mars-Avr.}

= Arbuste ou arbriss. à ram. plus ou moins allongés, dress. ou étal.dress.; caps. tomenteuse subsessile ou pédic.; bois nu muni ou dépourvu de lignes saillantes.

$\sigma^{7}$ Chatons souvent gros, les mâles oblongs, larg. 6-12 mm., les fem. cyl., larg. 6-14 mm., à filets libres: caps. subsessile ou à pédic. long.

- Bois dépourvu de lignes saillantes.

Ram. assez courts, tortueux, gros d'abord pub., bientôt gl., ainsi que les bourgeons; f. ov., gr., à pointe recourbée, vertes et luisantes en dessus, blanches-tom. en dessous; caps. à pédic. 3-4 fois plus long que la glande; style court; chatons gros, les mâles oblongs, long. $3 \mathrm{~cm}$., larg. $12-13 \mathrm{~mm}$., les fem. oblongs ou cyl., long. $4 \mathrm{~cm}$., larg. $12-15 \mathrm{~mm}$.

Lieux frais ou hum. - Mars-Avr.

S. Caprea L. 1188

Rameaux tr. allongés; bourgeons pub.; f. lanc. ou lanc. -lin. ; caps. sessile ou à pédic. 1 fois plus long. que la glande; style souvent long.

Chatons assez pet., les mâles ov. ou oblongs, long. $3 \mathrm{~cm}$., larg. 6-10 mm., les fem. cyl., long. 1-3 cm., larg. Зّ-8 mm.; caps. subsessile, à pédic. plus court que la glande; style allongé; f. lanc. ou lanc.-lin. acum., long. 4-8 cm., larg. 3-7 mm.; stip. pet., lanc.-lin. . . . . S. viminalis L. 1189 Lieux hum., bords des eaux. - Mars-Avr.

Chatons assez gros, les mâles ov., long. 3-4 cm., larg. $12 \mathrm{~mm}$. ; les fem. cyl. allongés, long. 3-7 cm., larg. 12-14 m. ; caps. à pédic. ord. 1 fois plus long que la glande; style médiocre; f. oblongues ou lanc. aig., glabres en dessus, ord. blanchestom. en dessous; stip. pet., ov. arq.

S. affinis Gren. Godr. 1190

Lieux hum. - Mars-Avr.

- Bois muni de longues lignes saill.; ram. allongés, subtom.; bourgeons vel.; chatons assez gros, les mâles ov., long. $2-3 \mathrm{~cm}$., larg. 10-12 mm., les fem. cyl., assez allongés long. 31/2-4 cm., larg. 8-10 mm.; caps. à pédic. 1-2 fois plus long que la glande; style médiocre; f. oblongues ou lanc., aig., glabresc. en dessus, blanches-tom. en dessous, long. 8-10 cm., larg. 10-23 mm.; stip. lanc-arq.. . . . . . . S. Smithiana Willd. 1191

Lieux hum. - Mars-Avr.

$\sigma^{7}$ Chatons grêles, ord. cyl.; les mâles rar. oblongs, larges de 4-8 mm., les fem. larges de 4-6 mm.; ét. à filets plus ou moins soudés ; caps. sessile ou à pédic. court.

o Ecailles jaunes ou rougeâtres au sommet, glabresc.; caps. gl. à pédic. court dépassant la glande; style allongé; filets des ét. soudés à la base ; anth. jaunes; chatons cyl.; ram. et bourgeons d'abord pub., puis gl.; f. court. pétiolées, lin., vertes en dessus, blanches-tom. en dessous.

S. incana Schrank. 1192

Lieux humides; planté. - Mars-Avr.

Ecailles brun. ou noirâtres au sommet, vel.; caps. tom., sessile; anth. pourpres, puis brunes ou noires; f. oblongues ou lanc., bientôt gl. ou glabresc. en dessous. 
Filets des ét. ent. soudés, simulant une anthère à 4 loges; style tr. court; chatons cyl. souvent opp.; f. gl., glauques en dessous. . . . . . . . . . S. purpurea L. 1193 Lieux hum. - Mars-Avr.

Filets des ét. soudés dans la moitié inf. ; style allongé; chatons màles ,ov.-oblongs, long. 15̆-20 mm. ; f. d'abord pub. soyeuses, puis glabresc. en dessous.. . . . . S. rubra Huds. 1194 Lieux hum. - Mars-Avr.

X Chatons pédonc., naissant avec ou après les $\mathrm{f}$.

む Ecailles persistantes.

- Ecailles gl. au sommet, d’un jaune verdàtre; 3 ét.; caps. gl. à pédic. 2-3 fois plus longs que les glandes; stipules larges, semicordiformes, dentic. et assez allongées, long. $16 \mathrm{~cm}$.; f. oblongues ou lanc. gl., rar. glauques en dessous, à base arrondie ou brusq. atténuée; chatons assez grêles, long. 3 1/2-0̃ cm., larg. 4-5 mm.

Lieux hum. - Avr.-Mai.

S. triandra L. 1195

- Ecailles vel. au sommet, rosées ou jaune verdâtre ; 2 ét.; plante màle tr. rar.; stipules lanc. falciformes, peu dentic.; f. allongées, long. 7-11 cm., d'abord pub., puis gl., au moins en dessus, souvent luisantes.

Caps. à pédic. 2 fois plus long que la glande; f. lanc., bientôt gl., souvent ondulées aux bords, larges, $15 \mathrm{~mm} .-3 \mathrm{~cm}$., souvent brusq. atténuées à la base; chatons assez gros, long. 2 1/2-3 cm., larg. 5̌-6 mm. ; écailles jaune-verdâtres.

Lieux hum. - Avr.-Mai.

S. undulata Ehrh. 1196

Caps. à péd. égalant à peine la glande; f. lanc.-lin., gl. ou pub. en dessous, quelquefois un peu ondulées, étr., 8-12 mm., ord. long. 'atténuées à la base; chatons assez petits, long. 2-2 1/2 cm., larg. $4 \mathrm{~mm}$.; écailles rosées. S. hippophaefolia Thuill. 1197

Lieux hum. - Avr.-Mai

ち Ecailles caduques, jaunâtres.

Ecailles gl. ou glabrescentes; ram. grêles tr. longs, flexibles, pendants; f. étr. lanc. dentic., gl., pâles ou blanchàtres en dessous ; stip. lanc. en faux; chatons petits, long. $21 / 2 \mathrm{~cm}$., Jarg. $4 \mathrm{~mm}$., denses; style court; caps. sessile... S. babylonica L. 1198 Bord des eaux, seulement individu fem. - Avr.-Mai.

Ecailles velues, ciliées.

ㅇ Ram. étalés-dress., robustes, très fragiles à leur point d'insertion; stip. larges, ov.; chatons gros, épais, les mâles, long. ว้-7 cm., larg. 8-10 mm., les fem. làches, long. $7 \mathrm{~cm}$. larg. $8 \mathrm{~mm}$; style assez court; capsule à pédic. $2-3$ fois plus long que les 2 glandes; f. gl. . . . . . . . . S. fragilis L. 1199

Lieux hum., bords des rivières. - Avr.-Mai.

‡ Rameaux plus ou moins dress. ou pendants, grêles ou assez robustes, flexibles, non ou peu fragiles à leur point d'insertion; chatons ord. assez grêles plus ou moins allongés, larg. こ̆-7 mm.; cap. à pédic. égalant ou dépassant peu les glandes; style court.

Chatons assez gros, les màles long. 3-6 cm., larg. 6-7 mm., les femelles lâches, long. 4 1/2-5 cm., larg. 4-7 mm.; caps. à péd. dépassant les glandes; f. glauques en dessous, bientôt gl. ou glabresc., dentées-gland.; ram. souvent pend., rougeàtres. . . . . . . . . S. viridis Fr. 1200

Lieux hum. - Avr.-Mai. 
Chatons souvent pet., les màles, long. $3 \mathrm{~cm}$. , larg. $ّ \mathrm{~mm}$., les fem. denses, long. $21 / 2-3 \mathrm{~cm}$., larg. 4-7 mm.; caps. subsessile ou à pédic. égalant à peine les glandes; $\mathrm{f}$. soyeuses argentées des 2 côtés ou seulement en dessous, dentées-gland.; ram. ascend. ou dressés, rougeàtres ou jaunàtres.

$$
\text { Lieux hum. - Avr.-Mai. }
$$

\section{Genre 429. - POPULUS L.}

+ F. lobées ou sinuées-dentées, jeunes pousses, bourgeons et écailles des chatons poil.; 8 ét.

X F. suborb., irrég. sinuées dentées, gl., rar. pub. grisàtres en dessous; chatons à écailles incisées-tigitées ; stigmates purp. à lobes en croix; écorce lisse. . . . . . . P. tremula L. 1202

Bois hum. (Tremble). - Mars-Avril.

X F. ov. ou ov. suborb., ang., sinuées dentées ou lobées tom. en dessolls.

F. ang. ou sinuées-dentées tr. blanches-tom. en dessous; chatons à écailles crén.-dentées; stigmates jaunes à lobes en croix; écorce crevassée.

P. alba 1203

Lieux hum. (Peuplier blanc). - Mars-Avr.

F. dentées-angul., gris.-tom. en dessous; chatons à écailles incisées-digitées; stigmates purp. à lobes presque en éventail ; écorce ord. lisse... . . . P. P. canescens Sm. 1204

Planté cà et là (Grisard). - Mars-Avr.

+ F. fin. et rég. dentées; jeunes pousses, bourgeons et écailles gl.; 12-20 ét.; écorce crevassée.

F. tr. glauque, ovales rhomb.; jeunes pousses arrondies; caps. ov. à 4 sill. s'ouvrant en 2 valves.. . . . . P. nigra L. 1205

Lieux hum. (Peuplier noir). - Mars-Avr.

Var. ì ram. dress., formant une cyme pyramidale, étr. (P. pyramidalis Rozier).

F. pub. aux bords dans leur jeunesse, larg. ovales en cœur; jeunes pousses sill. anguleuses; caps. glob. à 6 sill. et $3-4$ valves.

P. monilifera Ait. 1206

Bords des routes, prés, planté (Peuplier de Virginie). - Mars-Avr.

\section{Famlle 90. - PLATANÉES \\ Genke 430. - PLATANUS}

Arbre élevé à écorce unie, l’épiderme se détachant par plaques ; 2-כ̆ glom. fructif. sur le mème pédonc.; fr. à sommet conique, aigu surmonté par le style; f. soit palmatifides à limbe décurrent sur le pétiole au-dessous des nervures ( $P$. orientalis $L$.), soit palmatilobées à limbe ord. non décurrent sur le pétiole au-dessous du point d’intersection des nervures ( $P$. acerifolia Willd.). P. vulgaris Spach. 1207 Souvent planté. - Fl. Avr.-Mai; fr. Automne.

$P$. occidentalis L. rar. planté, a les f. anguleuses, lobées, 1 seul glom. fructif. par pédonc., fr. à sommet tronqué, un peu déprimé surmonté par le style.

\section{Famille 91. - BÉTULINÉES}

Chatons fem. cyl., à écailles minces, membr., cad., trilobées, supportant chacune 3 pet. fr. ailés; périanthe màle réduit à 1 seule écaille

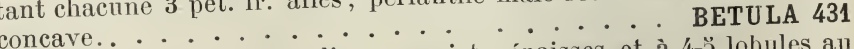
Chatons fem. ov., à écailles lign., persist., épaisses et à 4-ö lobules au sommet, supportant chacune 2 pet. fr. compr.; périanthe mâle à 4 divis...................... ALUS 432 


\section{Gerre 431. - BetUla L.}

F. long. acum. doublement dentées, ent. gl.; jeunes ram. pend. gl., souvent verruqueux; aile du fr. 2 fois plus large que la graine égalant ou dépassant le sommet des styles; écorce blanche et papyracée; bourgeons gl. . . . . . . . . . . B. alba L. 1208 Bois. - Fl. Avr.-Mai; fr. Jn-At.

F. aig. irrégul. dentées, pub., puis vel. seul. à l'aisselle des nervures ; jeunes ram. dress., pub., lisses; aile du fr. à peine plus large que la graine, ne dépassant pas les styles; écorce blanche ou brune; bourgeons un peu poilus. . . . . . . B. pubescens Ehrh. 1209 Fl. Avr.-Mai. -- Fr. Jt-Sept.

\section{Genre 432. - ALNUS Gaertn.}

F. suborb. ou obovales, obt., irrégul. sin.-dentées, tronq. ou émarg., vertes et gl. sauf les aisselles des nervures poils à 6-9 paires de nervures second.; cònes pédonc.; jeunes ram. gl.; écorce brunâtre crevassée; bourgeons gl., obt. . . . . A. glutinosa Gaertn. 1210 Bois humides. - Fl. Févr.-Avr.; fr. Sept-0ct.

F. ov. aig. ou brièv. acum., doubl. et fin. dentées, gris. et pub. tom. en dessous, à 10-13̈ paires de nervures second.; cònes presque sessiles; jeunes ram. pub.; écorce lisse gris.; bourg. pub., obt.

A. incana Willd. 1211

Bois, parcs, nat. - Fl. Févr.-Mars; fr. Sept.-0et.

On plante souvent A. cordata Desf. F. larg. ov. ou suborb. en cœur, fin. dentées gl.; ; bourgeons aig. gl.

\section{Famille 92. - MYRICINÉES}

\section{Genre 433. - MYRIGA L.}

Arbriss. buissonneux odor.; f. alt. ent. ou dentées sup., gl. ou pub. Marais tourb.-silic. - Fl. Avr.-Mai; fr. Jt-Sept.

\section{V. - GYMNOSPERMES}

\section{FAMILLE 93. - CONIFĖRES}

+ Fr. subglob., charnu, indéh., noir-bleuâtre, formé par les écailles soudées entre elles en forme de baie,à 2-9 graines osseuses, ang.,non ailées ; fl. dioïques; arbriss. ou arbuste dressé de $3-6 \mathrm{~mm} ., 2$ cotylédons. . . . . . . . . . . JUNIPERUS 434

+ Fr. en forme de còne, sec, déh., formé d'un grand nombre d'écailles lign. ou coriaces, non soudées entre e̊lles, imbriq.,spiralćes ; graines nombr., ailées, géminées à la base de chaque écaille; fl. mon.; arbres élevés.

$\times$ F. lin., cad., molles, herb., d'un vert clair, réunies, 13-20, en faisc. naissant de tuberc. saill.; ramification éparse, irrégul., non vert., chatons màles, glob., solit., term.; "艹-7 cotylédons. LARIX 435

X F. persist., raides, vertes ou glauques, éparses ou réunies, 2-5, dans une gaine écailleuse; ramification régul., vert.; chatons màles ov. ou oblongs.

F. toutes éparses, solit., sans gaine à leur base; chatons mâles solit.; cônes oblongs cyl., à écailles coriaces, minces, non épaissies au sommet; mat. ann.; 4-10 cotylédons. . . A ABIES 436 
F. réunies, 2-5, dans une gaine écailleuse; chatons males agglom. à la base des ram. de l'année; cônes général. coniques, à écailles lign., épaissies en écusson au sommet; mat. bisann. ou trisann.; 5-12 cotylédons........................... PIN 437

\section{Genre 434. - JUNIPERUS L.}

Arbuste à f. lin. en alène, piquantes, vert. par 3 ; chatons mâles jaunâtres, solit., pet., subglob., à écailles peltées portant chacune 3-12 anth.; chatons fem. verdàtres, solit., axill., à écailles peu nombr., appliq., les sup. portant chacune à leur base 1 ovule dress.

J. 'communis L. 1213

Coteaux arides, bois secs. - Fl. Avr.-Mai; fr. Automne de la deuxième année.

On cultive souvent dans les parcs l'if (Taxus baccata L.). Arbriss. ou arbre peu élevé, à bois rouge, peu résineux; f. éparses, étalées sur deux rangs opp., pétiolulées, lin., mucronées; fl. dioïques, axill.; chatons mâles solit. ou géminés, pet., subglob., jaunâtres à écailles peltées portant chacune en dessous $30-8$ anth. disposées en cercle; chatons fem. verts, solit. sur un pédic. court, à ovule unique, dress.; fr. en coupe ouverte, charnu-succulent rouge vif à 1 graine ovoïde, osseuse.

\section{GenRe 433. - LARIX Mill.}

Arbre élevé, pyramidal, à écorce gerçurée-écailleuse, à branches étalées ou réfléchies; chatons fem. violacés, composés d'écailles imbriq., accomp. chacune en dehors d'une bract. membr.; cônes dress., solit., ov. oblongs, pet., long. $3-4 \mathrm{~cm}$., gris-brunâtres, à écailles trong ou échanc. égalant ou débordant les bract.; graines géminées obovalestronq., larg. ailées. . . . . . . . L. europaea IJC. 1214 Bois, pares, planté. - Fl. Avr.-Jn; fr. Automne de la mème année.

\section{GeNRe 436. - ABIES DC.}

F. planes, distiques, non piquantes, marquées de 2 raies blanches en dessous; ram. tous étalés dans le même plan; cônes dress., cyl., long. 8-10 cm., vert brun, à écailles brièv. pétiolées et tombant avec les graines ; arbre élevé à écorce lisse, blanchâtre ; graines tronq. en coin, à aile adhérente, 1 fois $1 / 2$ plus longue qu'elles.

A. pectinata DC. 1215

Bois, pares; planté (Sapin). Se reproduit spontanément de graines à Vaumoise (Oise). - Fl. Avr.-Mai; fr. Oct.

F. subtétr., entourant le rameau, piquantes, vertes sur les 2 faces; ram. retombants de chaque côté des branches; cônes pend., cyl., long. 10-15 cm., rouges ou verts, sans bract., à écailles sessiles et persist. ; arbre élevé à écorce écailleuse rougeàtre; graines pet., obovales en coin, à aile cad. 2-3 fois aussi longue qu'elle. A. excelsa DC. 1216

Bois, pares; planté (Epicéa)• - Fl. Mai-Jn; fr. Oct.

$$
\text { Genre 437. - PINUS L. - Pin. }
$$

+ F. vert. par 5, long. 6-8 cm., à graine tr. cad.; écorce gris-verdâtre, lisse; écussons des cònes à protubérance term.; cònes grêles, cyl., long. 10-13 cm., larg. 20-23 mm., pédonc. pend.; graines de 5-6 mm., à ailes 2-3 fois plus longues qu elles. P. Strobus L. 1217 Planté et naturalisé dans quelques bois, originaire de l'Amérique du Nord. - Fl. Mai; fr. Automne de la deuxième année.

+ F. réunies par 2, à gaine persist.; écorce rougeâtre ou brune, gerçurée-écailleuse; écussons des cônes à protubérance centr.; cônes oblongș-coniques aig. subsessiles ou court. pédonc. 
$\times$ F. courtes, long. 5้-6 cm.; cònes pet. ovoïdes-coniques, long. $3-6 \mathrm{~cm}$., gris verdâtre ou brun., court. pédonc., réfléchis dès la $1^{\text {re }}$ année; chatons màles oblongs, long. 6-8 mm.; graines pet., long. 4 mm., à aile 3 fois plus longue qu'elles. . . . P Pilvestris L. 1218

Fréquemment planté dans les bois. - Fl. Mai-Jn.; fr. Automne de la deuxième année.

X F. allongées, long. 10-20 cm.; cônes gros, long. 4-18 cm., roux, luisants ; graines de $\mathbf{6 - 1 0} \mathrm{mm}$. à aile 3 -5̆ fois plus long qu'elles.

Cônes longs de 4-8 cm., d'un jaune roussâtre clair, subsessiles, étalés presque horizont., presque toujours arqués; chatons mâles longs d'environ 2-ö mm.; f. de 10-15̈ cm., épaisses, d'un vert foncé; graines assez grosses, $6 \mathrm{~mm}$., mates, à aile $3-4$ fois plus longue qu'elles.. . . . . . . P. Laricio L. 1219 Planté dans les bois. - Fl. Mai-Jn.; fr. Automne de la deuxième année.

Cônes oblongs-coniques, long, $12-18 \mathrm{~cm}$., d'un roux vif presque sessiles et réfléchis, dr.; chatons màles longs d'environ $1 \mathrm{~cm}$.; f. longues de 10-20 cm., épaisses, raides, d'un vert blanchàtre; graines grosses, long. 8-10 mm., d'un noir luisant sur une face, à aile 4-5̆ fois plus longue qu'elles. . P. Pinaster Soland. 1220 Planté dans les bois. - Fl. Avr.-Mai; fr. Automne de la deuxième année.

\section{VI. - MONOCOTYLÉDONES}

\section{FAMILLE 94. - HYDROCHARIDÉES}

+ Fl. gr., blanches, dépassant $1 \mathrm{~cm}$. de diamètre; divis. int. du périanthe suborb. beaucoup plus long. que les ext.; 12 ét.; 6 stigmates; fr. à 6 loges.

F. orb. réniformes à bords ent., long. pétiolées, fasc. aux nceuds; fl. blanches tachées de jaune à la base; ét. à filets soudés à la base ................... HYDROCHARIS 438

F. lanc.-lin., acum., à bords dentés épin., sessiles, rad., en rosette ; fl. d'un blanc pur; ét. à filets libres.. . STRATIOTES 439

+ Fl. pet., 2-4 $\mathrm{mm}$. de diamètre, d'un blanc rosé ou violacé; divis. int. du périanthe rudim. ou dépassant peu les ext. ; 2-9 ét. ; 3 stigmates; fruit à 1 seule loge.

F. lin., tr. allongées en ruban, obt. et dentic. au sommet, planes, toutes rad.; souche grêle stolon.; fl. mâles en tète ov. sur un court pédonc., les fem. solit. dans une spathe tubul. bifide, sur un tr. long pédonc. tordu en spirale; 2-3 ét. VALLISNERIA 440

F. oblongues, courtes, ondulées, dentic., vert. par 3 et tr. rappr.; souche épaisse, non stolon. ; fl. mâles et fem. solit. sur des pédonc. dr.; 3-9 ét. à filets soudés à la base . . HELODEA 441

\section{GeNRE 438. - HYDROGHARIS L.}

H. Morsus-ranae L. 1221

Eaux stagnantes. - Jn-At.

\section{Genre 439. - STRATIOTES L.}

S. aloides L. 1222

Eaux stagnantes, nat. pl. mâle. - Jn-At.

Genre 440. - VALLISNERIA Micheli.

V. spiralis L. 1223

Eaux stagnantes, pl. fem. - Jt-Oct. 
Genre 441. - HELODEA Rich.

H. canadensis Rich. 1224

Eaux courantes ou stagnantes, nat. pl. fem. Originaire de l'Amérique du Nord. Mai-At.

\section{FAMille 9ð. - ALISMACÉES}

Ét. 9 ou nombr.; fl. assez gr. atteignant 15 -20 mm. de diamètre.

F. aériennes gr. sagittées, long. pétiolées; fl. mon., en vert. écartés formant une grappe étr. ; carpelles nombr., libres, monosp., indéh. ; ét. nombr. . . . . . . . . . SAGITTARIA 442

F. toutes étr., lin.-triquètres, tr. long., dress., sessiles; fl. hermaphrodites en omb. term.; carpelles 6 , soudés à la base, polysp., s'ouvrant en dedans; ét. 9................ BUTOMUS 443

Ét. 6, opp. par paires aux pétioles; fl. hermaphrodites, assez pet., 5-15 mm. de diamètre.

Fr. formés de 6-8 carpelles soudés inf. par la suture ventrale, long. 9-14 mm., atténués en pointe presque spin., diverg. en étoile; 2 graines dans chaque carpelle; pl. ann.. . . DAMASONIUM 444

Fr. formés de carpelles ord. nombr., libres, long. 2-3 mm., arrondis au sommet ou à peine mucr., en cap. sphériques ou un peu déprimés, non rayonnants en étoile; carpelles monosp.; pl. viv.

ALISMA 445

\section{Gente 442. - SAgITTARIA L.}

F. les unes submerg., lin. allongées ou oblongues obt., les autres émergées triang.-sagittées à oreillettes divariq.; fl. fem. inf., peu nombr., les màles au-dessus; fl. blanches . . . . . S. sagittæfolia L. 1225 Bord des eaux. - Mai-At.

GeNRE 443. - BUTOMUS L.

T. dress. cyl.; fl. rosées . . . . . . B. umbellatus L. 1226 Bords des eaux. - Jn-At.

\section{Genre 444. - DAMASONIUM Juss.}

F. toutes rad., long. pétiolées, ov. ou oblongues arrondies ou en cœur à la base, trinervées; fl. blanches ou rosées; fl. en omb. term. ou en 2-3 vert. superposés . . . . . . . D. stellatum Daléch. 1227 Mares, étangs. - Mai-Sept.

\section{GENRE 440̈. - ALISMA L.}

+ Fl. assez gr., 10-13 mm., axill. ou 1-3 omb. superposées; carp. mucr. par le style persist.; f. trinervées.

Fl. en omb. term. ou à 2-3 vert. superposés; carp. à 5 còtes saill. sur plus. rangs en tête glob. sur un récept. arrondi; f. toutes rad., lanc.-lin., acum.; t. dress., rar. couch. radicantes à nœuds feuillés et flor:fères (A. repens Car.) . . . . A. ranunculoides L. 1228 Maräis, fossés. - Mai-Sept.

Fl. axill. solit. ou géminées, les term. 3-§ en vert.; carp. à stries nombr., vert. sur 1 rang sur un récept. presque plan; f. caul. flottantes, ov. ou ellipt., obt. . . . . A. natans L. 1229 Mares des terrains sil. ou tourb. - Mai-Sept.

+ Fl. petites, $5-7 \mathrm{~mm}$., en vert. formant une large panic. pyramidale; carp. nombr. mutiques, tr. compr., vert. sur 1 seul rang; style cad.; f. plurinervées toutes rad. 
Divis. int. du périanthe cad., 4-5 fois plus long que les ext.; carpelles de 2 mm., faibl. éch. à la base du còté int., à 1-2 sillons sur le dos, inclinés ext. sur le récept., laissant ainsi un vide au centre; f. ord. ov.-lanc., en coeur, arrondies à la base, rar. lanc., atténuées aux 2 extrémités; t. dress.; souche bulbiforme grosse 1 1/2-4 cm.; graines ponctuées noiràtres. . A. Plantago L. 1230 Nares, bords des eaux. - Mai-Sept.

Div. int. du périanthe persist., de moitié plus longue que les ext.; carpelles de $3 \mathrm{~mm}$., fort. éch. à la base du côté int., à 3 còtes dorsales, dress. sur le réceptacle contigus int. sans aucun vide au centre; f. lanc. ou lanc. lin., atténuées à la base, jamais en coeur; les submerg. quelquefois lin. allongées; t. non submerg., étaléesarquées ainsi que les ram., les submerg. dress. à ram. souvent recourbés; souche bulbiforme petite, $1 \mathrm{~cm}$. environ; graines brun clair, fin. striées. . . . . A. arcuatum Michalet 1231 Grèves sabl des étangs. - Jt-Sept.

\section{FAMLLE 96. - COLCHICACÉES}

Fl. roses, gr., 1-3̈ naissant de la souche bulbeuse; périanthe à divis. prolongées à la base en onglets tr. longs soudés en tube.

GOLGHICUM 446

\section{GeNRE 446. - GOLGHIGUM L.}

Fl. naissant avant les f. toutes rad., larg. lanc., qui apparaissent avec le fr. l'année suivante; bulbe à tunique noirâtre; caps. form. de 3 carp. libres déhisc. au sommet. . . . . C. autumnale L. 1232 Prés hum. - Fl. At-0et.: fr. Avr.-Jn.

\section{FAMILLe 97. - LILIACÉES}

+ Souche bulbeuse.

X Fl. solit., en grappe ou en corymbe.

$=\mathrm{T}$. munie de f. caul., fl. jaunes.

Fl. gr. solit. penchée, périanthe en cloche; caps. oblongue, triTULIPA 447

Fl. pet., dress. en corymbe entouré de f. florales, périanthe à divis. étalées ord.; 2 bulbes dans une tunique commune, caps. ov-trigone ............. GAGEA 448

$=\mathrm{F}$. toutes rad.

Divis. du périanthe libres jusqu'à la base.

Fl. blanches ou d'un blanc jaunâtre; caps. ov. à 3 ou 6 angles.

Fl. bleues, rar. blanches; caps. glob. ou glob. trigone.

SGILLA 450

Divis. du périanthe soudées à la base.

Périanthe tubul. en cloche à divis. étalées ou recourbées; ét. ext. ou toutes soudées aux divis. du périanthe, caps. ov.-trigone; graines subglob............. ENDYMION 451

Périanthe glob., ov. ou cyl. à divis. soudées en tube dans le quart inf., resserré à la gorge et urcéolé à 6 dents tr. courtes, étalées réfléchies; ét. incluses insérées au milieu du tube du périanthe; caps. trigone; graines ov... . . MUSCARI 452

Fl. en omb., renfermées avant la flor. dans une spathe de 1-3 divis.; caps, trione. ALLIUM 453

+ Souche fibr.; fl. blanches en grappes ou en pan. à pédic. artic., périanthe étalé; caps. obscur. trigone . . . ANTHERICUM 454 
GENRE 447. - TULIPA L.

Fl. gr., 3-3 cm.; divis. du périanthe acum. et barbues au sommet; f. alt., lin.-lanc., allongées, d'un vert glauque; caps. oblongue-trigone bien plus longue que large; plante non florifère à 1 seule $\mathrm{f}$. rad.

Vignes, parcs. - Avr.-Mai.

T. silvestris L. 1233

Genre 448. - GAGEA Salisb.

Pl. naine, 3-8 cm. ; bulbes tr. pet., entourés de nombr. bulbilles graniformes; t. portant 2-z f. alt. lanc. acum. vel. cil. ; 1-2 f. rad. filif.-sét., sill. arq. ; périanthe à divis. oblongues-spath., obt.

Lieux silic. - Févr.-Mars.

G. bohemica Rœm. et Sch. 1234

Pl. basse, 5̈-20 cm.; bulbes pet., rug., t. nue à corymbe de 3-12 fl., quelquefois remplacées par des bulbilles, à 2 f. invol. opp., lanc., vel., plus larges que les 2 f. rad. lin.-canal.; périanthe à divis. lanc. aig., pub. ext. . . . . . . . G. arvensis Rœm. et S. 1235 Ch. argil., parcs, pied des arbres. - Mars-Avr.

G. Iutea lier. indiqué à Neuville (Loiret), bulbe unique; 1 f. rad. plane, large, 6-12 mm. ; 2 f. involucr. cil. ; 2-3̈ fl. en omb. ; divis. du périanthe oblonguesobtuses.

\section{GENRE 449. - ORNITHOGALUM L.}

+ Fl. blanches, З̌-15, en corymbe, à pédic. allongés inég.; f. lin., à ligne blanche longitud.; caps. à 6 côtes saill. longit.; pl. peu élevées, $10-30 \mathrm{~cm}$.

Pédic. d'abord ascend. puis étalés à mat.; périanthe de $150-20 \mathrm{~mm}$., de moitié plus long que les ét.; bulbe entouré de bulbilles ord. foliifères. . . . . . . . . . . 0. umbellatum L. 1236 Ch. sabl., bois, prés. - Avr.-Jn.

Pédic. d'abord étalés-dress., puis réfractés après la flor.; périanthe de 20-2: mm., d'un tiers plus long que les ét.; bulbe entouré de bulbilles ord. non foliifères. . . . 0. divergens Bor. 1237 Lieux incultes. - Avr.-Mai.

+ Fl. en grappes à péd. égaux; f. larg. lin.; caps. à 3 ou 6 sillons; pl. robustes, $30-80 \mathrm{~cm}$.

F. égalant ou dépassant la t.; fl. gr., 2\%-30 mm., penchées, blanches en dedans, vertes en dehors, en grappes unilat.; ét. à filets trifides au sommet; bract. ov.-acum.; caps. à 6 sillons.

Champs, vignes. - Avr.-Mai.

0. nutans L. 1238

F. bien plus courtes que la t., ord. desséchées à la flor.; fl. pet., 10-12 mm., dress., d'un blanc jaunàtre ou verdàtre en long. grappe; ét. à filets simples; bract. lanc.-acum.; caps. à 3 sillons.

$$
\text { Bois, prés. - Mai-Jt. } \quad \text { 0. pyrenaicum L. } 1239
$$

\section{Genre 4ว0. - SGILLA L.}

Fl. pet., lilas, en grappes courtes, s'allongeant après la flor., paraissant avant les f. lin. dress. nombr., 丂̆-10; caps. subglob.; loges à 2 graines sans arille . . . . . . . . . . S. autumnalis L. 1240 Coteaux et pelouses sèches ou sabl. - At-0ct.

Fl. assez gr., bleues, rar. blanches, en grappe lâche, presque corymbiforme; f. peu nombr., ord. 2, dress. étal., embrass. la t. jusqu'au milieu et paraissant en mème temps que les fl.; caps. glob. trigone; loges à 3-6 graines munies d'un arille. . . . . S. bifolia L. 1241 Bois ombragés. - Mars-Avr. 


\section{GeNRE 451. - ENDYMION Dum.}

Fl. bl., rar. blanches, en grappe courbée au sommet, à fl. penchées, unilat., odor.; bract. bifides, inég.; f. toutes rad., larg. lin., ent., dress., puis étalées; caps. ovoïde-tronq. . E. nutans Dumort. 1242 Bois. - Avr.-Jn.

\section{GenRe 452. - MUSCARI Mill.}

+ Grappe allongée et làche; fl. inodores, les inf. fertiles d'un brun roussâtre, tr. étalées, les sup. stériles rappr. en houppe bleue-violette et long. pédic.; pér. tubul. en cloche; f. larges, rudes aux bords............. M. comosum Mill. 1243

Ch., moiss. - Avr.-Jt.

+ Grappe courte et serrée; fl. penchées à odeur de prune, d'un bleu foncé, les sup. presque sessiles; périanthe ov.ou ov.-oblong; f. lin. canal. ou sill., lisses aux bords.

Caps. à valves éch. en cœur au sommet; fl. en grappe ovale serrée; périanthe ov., 3-4 mm., à orifice peu ouvert; f. lin. étr. 1-3 mm. de large, cyl., sill.. ....... M. racemosum Mill. 1244 Champs sabl. - Mars-Mai.

Caps. à valves non échancr., subaig.; fl. en grappe ov.-oblongue dens. serrée ; périanthe ov.-oblong, 4-6 mm., à orifice bien ouvert; f. lin., 2-5 mm., demi-cyl., canal.. . M. neglectum Guss. 1245 Ch., vignes. - Mars-Mai.

\section{GeNre 433. - ALLIUM L.}

.+ F. cyl. ou f. lin. étr., demi-cyl., rar. planes, ord. creuses.

X F. exactement cyl. sans sillon en dessus; périanthe à divis. étalées en étoile; t. creuse, feuillée dans le tiers inf.

$=$ Ét. saill.; pédic. 4-5̆ fois plus longs que la fl. blanchâtre; t. renfl. en fuseau; bulbe glob. ou ov., solit.

T. renfl.-ventrue au-dessous de son milieu; ét. int. munies à la base de chaque côté d'une dent triang.; style court; bulbe ord. sub glob. déprimé gros rar. ov. pyriforme. A. Cepa L. 1246 Cult. (Oignon). — Jt-Sept.

T. renfl.-ventrue en son milieu; ét. toutes dépourvues de dents; style allongé; bulbe peu renflé. . . . A. fistulosum L. 1247 Cult. (Ciboule). - Jt-Sept.

= Ét. non saill.; pédic. plus courts ou à peine plus longs que la fl.; t. cyl.; bulbes oblongs en touffe.

Fl. blanc bleuâtre, souvent entremèlées de bulbilles; pédic. un peu plus longs que la fl.; ét. égalant environ le périanthe, les 3 int. munies à la base de chaque côté d'une dent courte; 1 l. tr. rar.; bulbe oblong.. . . . A. ascalonicum L. 1248 Cult. (Echalotte). - Jn-At.

Fl. roses, sans bulbilles; pédic. plus courts que la fl.; ét. de moitié plus courtes que le périanthe, toutes dépourvues de dents............. A. Schœnoprasum L. 1249 Cult. (Ciboulette). - Jn-At.

X F. demi-cyl. ou planes, souvent sill. ou canal. en dessus; périanthe à divis. conniv. en cloche; t. presque pleine, feuillée au moins dans la moitié inf.

$\overbrace{}^{7} \mathrm{Fl}$. blanchâtres ou rosées.

- Et. saill. à filets alternativement simples et à 3 pointes; spathe à $1-2$ valves ov. aig. plus courtes que l'omb.; bulbe entouré de nombr. bul-billes. 
Fl. rose pâle ou blanchàtres, peu nombr., souvent toutes remplacées par des bulbilles serrés en tête compacte; péd. renfl.glob. sous la fl., 4-3̈ fois plus longs qu'elle; caps. à sommet ombiliqué; bulbe ov. entouré de nombr. bulbilles.

$$
\text { Lieux incultes. - Jn-Jt. }
$$

A. vineale L. 1250

Fl. rose vif, tr. nombr., t. rar. entremèlées de bulbilles; pédic. graduell. épaissis sous la fl., un peu plus longs qu'elle; caps. à sommet non ombiliqué; bulbe ov. surmonté de plus. bulbilles pédicellée.

Lieux secs sabl.; vignes. - Jn-At.

A. sphaerocephalum L. 1251

- Ét. non saill., à filets tous simples et en alène; spathe à 2 long. pointes lin. dépassant beaucoup l'omb.; bulbe simple ov. sous la tunique; pédic. inég.

Fl. rose-brun sale, ord. peu nombr., entremêlées de bulbilles assez nombr. ; caps. obovale, tronq. au sommet.

Lieux incultes. - Jt-At.

A. oleraceum L. 1252

Fl. blanchâtres ou rosées, nombr., en omb. diffuse, tr. rar. bulbillifère; caps. ellipsoïde rétrécie aux 2 bouts.

Vignes, lieux incultes. - Jt-At.

A. paniculatum L. 1253

ơ Fl. jaune-doré, en ombelle multiflore non bulbillifère; ét. tr. saill. toutes à filets simples; spathe à 2 valves term. en pointe lin, tr. long.; bulbe ov. simple à tuniques brunes épaisses; caps. arrondie trigone. . . . . . . A. flavum L. 1254

Lieux secs, vieux murs. - Jt-At.

+ F. lin. élargies ou ov.-lanc.

Bulbes jamais implantés dans une souche horiz.

○F. lin. élargies; périanthe conniv. en cloche.

† Fl. peu nombr. en omb. munies de bulbilles ou mème toute bulbillifère; ét. incluses.

Spathe univalve, term. en pointe tr. long. dépassant l'omb.; fl. blanc sale on rongeàtre; filets des ét. int. à 3 pointes presque égales; f. lisses; t. en cercle avant la flor.; bulbe bulbillifère.

Cult. (Ail), - Jn-At.

A. sativum L. 1255

Spathe à 2 valves ov., brusq. term. en pointe plus courte que l'ombelle; fl. purp.; filets des ét. int. à 3 pointes inég.; f. rudes aux bords; t. droite; bulbe à bulbilles pédicellés.

Lieux secs, berges, vignes. - Jn-Jt.

A. Scorodoprasum L. 1256

† Fl. tr. nombr., blanches ou carnées, en omb. non bulbillifère; ét. saill.; filets des ét. int. à 3 pointes; bulbe allongé simple.

A. Porrum L. 1257

Cult. (Poireau). - Jn-At.

F. ov.-lanc., long. pétiolées à nervures converg.; périanthe étalé à divis. lanc.-aig.; fl. nombr., blanches, en omb. non bulbillifère; spathe ent. ou à 2-3 valves égalant les péd.; ét. incluses à filets simples; bulbe oblong. simple. . A. ursinum L. 1258 Bois ombragés. - Avr.-Mai.

Bulbes oblongs, naissant d'une souche horiz. ramp.; f. lin.; fl. nombr. en omb. non bulbillifère; ét. à filets ent. égalant le périanthe en cloche à divis. obt.; spathe à 2-3 lobes plus courts que les pédic. (A. acutangulum Schrad.). . . A. angulosum L. 1259

Prairies hum. - Jn-At. 


\section{GENRE 450 4. - ANTHERIGUM L.}

Fl. pet., $1 \mathrm{~cm}$., en pan. à ram. étalés; bract. lin., ¿̈-6 fois plus courtes que le pédic. dress. étalé et artic. près de la base; style dr.; caps. petite, glob., obt........... A. ramosum L. 1260 Coteaux calc. - Jt.-At.

Fl. gr., $2 \mathrm{~cm}$., en grappe simple; bráct. lanc., 1-2 fois plus courtes que le pédic. dressé et artic. au-dessous du milieu; style arq. ascend.; caps. assez grosse, ov.-aig. . . . . . . A. Liliago L. 1261 Coteaux calc. ; bois. - Mai-Jt.

\section{Famile 98. - ASPARAGINÉES}

+ T. simple; pl. herb. à fl. hermaphrodites.

X Fl. dress., term. ; périanthe à 4 ou 8 divis. étalées, libres jusqu'à la base; 4 ou 8 ét., baie à 2 ou 4 loges.

T. cyl., dr., nue, portant au sommet, sous la fl., un vert. de 4, rar. כ้ ou 6 , f. ov. en coin et subsessiles; fl. verdàtre, solit., à 8 divis. inég., 8 ét., 4 styles; baie glob. noir bleuâtre à 4 loges à 2 graines.. . . . . . . . . . . . . PARIS 455

T. ang., coudée-flexueuse sup. à l'insertion des $2 \mathrm{f}$. alt., ov. en coeur et nett. pétiolées ; fl. blanches, géminées en grappe courte, à 4 divis. égales; 4 ét.; 1 style; baie glob. rouge, à 2 loges à 1-2 graines...................... MAIANTEMUM 456 X Fl. penchées unilat.; périanthe tubul. cyl. ou en cloche, à 6 divis. soudées inf.; 6 ét.; baie glob. à 3 loges à 2 graines.

F. 2, rad., à pétioles enveloppés, ainsi que la t. nue, par des gaînes membr.; fl. d'un blanc pur, en cloche subglob. ou en grelot, 4-8 en grappe term.; baie rouge . . . CONVALLARIA 457

F. nombr., toutes caul., alt. ou vert., sessiles ou subsessiles; fl. blanches, vertes au sommet, tubul. cyl., solit. ou 2-6 en pet. grappes axill. baie noir bleuàtre.. . POLYGONATUM 458

+ T. ram. ; pl. herb. ou lign., à fl. diö̈ques par avortement.

Périanthe en cloche à 6 divis. conniv., soudées à la base, étalées au sommet, 6 ét., style filif. à stigmate trilobé ; f. réduites à des écailles, remplacées par des ramuscules stériles simulant des f. filif. fasc.; fl. blanc verdàtre, 1-2 ou fasc. sur des pédic. artic.; baie rouge à plus. graines; pl. herbacée. . ASPARAGUS 459

Périanthe en roue, à 6 divis. étalées et libres jusqu'à la base; les 3 int. bien plus pet.; 3 ét. à filets soudés en tube ov. ; style presque nul, stigmate en tête; sous-arbriss. dress. raides; f. réduites à des écailles, remplacées par des cladodes aplatis, épin. ; fl. verdâtres, pet., naissant sur les faces des cladodes, à l'aisselle d'une pet. bract. baie rouge à 1-2 graìnes . . RUSCUS 460

$$
\text { GenRe 49ั5. - PARIS L. }
$$

P. quadrifolia L. 1262

Bois hum. - Mai-Jt.

\section{Gente 4:36. - MAIANTHEMUM Wigg.}

M. bifolium DC. 1263

Bois ombragés. - Mai-Jn.

GeNRE 40ั7. - CONVALLARIA L.

C. maialis L. 1264

Bois. -- Avr -Jn. 


\section{Genre 40̈8. - POLYGONATUM All.}

T. cyl.; pédonc. à 2-6 fl. petites, long. 12-15 mm., larg. 2-4 mm.; ét. à filets velus. .......... P. multiflorum All. 1265 Bois. - Avr.-Jn.

T. tr. anguleuse; pédonc. à 1-2 fl. grandes, long. 2 cm., larg. 5̆-8 mm. ; ét. à filets glabres. . . . . . . P. officinale All. 1266 Bois surtout calc. - Avr.-Jn.

$$
\text { Genre 459. - ASPARAGUS L. - Asperge. }
$$

Lieux sablonneux, - Mai-Jt.

A. officinalis L. 1267

$$
\text { GenRe 460. - RUSGUS L. }
$$

R. aculeatus L. 1268

Bois et coteaux, - Janv.-Avr.

\section{Famille 99. - DIOSCORÉES}

Tige volubile, grimp. ; baie ov. arrondie, rouge, rar. jaunâtre.

TAMUS 461

GenRe 461. - TAMUS L.

F. larg. ovales en cœur, acum. pétiolées ; fl. vert. jaunàtre en grappes, les mâles multiflores et allongées, les fem. courtes et pauciflores ; souche grosse, noire, cyl. en navet. . . . T. communis L. 1269 Bois, buissons. - Mai-Jt.

\section{FAMILLE 100, - IRIDÉES}

Fl. gr. réunies 1-4, dans une spathe à 2 valves; périanthe à 6 divis. égales 3 à 3 , les 3 ext. étalées ou réfléchies, les int. dressées ; stigmates grands, pétaloïdes, recouvrant les ét.. . . . IRIS 462

\section{Genre 462. - IRIS L.}

Fl. bleuâtres; divis. int. du périanthe un peu plus courtes que les ext., égalant ou dépassant les stigmates ; caps. atténuée, non apiculée ; $\mathrm{f}$. persist.; graines subglob., rouges. . . . . I. foetidissima L. 1270 Bois, buissons des coteaux calc. - Jn-Jt.

Fl. jaunes; divis. int. du périanthe 3 fois plus pet. que les ext., plus courtes que les stigmates; caps. apic.; f. non persist.; graines compr. brun.. . . . . . . . . . I. Pseudacorus L. 1271 Bords des eaux. - Mai-Jt.

\section{FaMILLE 101. - AMARYLLIDÉES}

+ Périanthe non prolongé en tube au-dessus de l'ovaire, à divis. presque libres; ét. insérées sur le disque qui surmonte l'ovaire; stigmate simple; fl. blanches penchées, solit.; caps. charnue.

Périanthe à divis. de forme différente et inég., les 3 int. de moitié plus courtes, conniv. en cloche, éch.; anth. term. en pointe aig., s'ouvrant par 2 pores term.; caps. subglob.. GALANTHUS 463

Périanthe à divis. de même forme, égales, ouvertes en cloche, ent. et épaissies au sommet; anth. à sommet obt., s'ouvrant par 2 lignes longit.; caps. en poire. . . . . . . LEUCOIUM 464

+ Périanthe prolongé au-dessus de l'ovaire en un tube plus ou moins long, à divis. soudées inf. ; ét. insérées sur le tube du périanthe au-dessous de la couronne; stigmate tronqué ou trilobé; caps. obscur. trigone; f. lin .......... NARCISSUS 465 
GenRe 463. - GALANTHUS L.

Bulbe ov.; f. 2, lin.-obt.; divis. ext. du périanthe obovales-oblongues, obt. un peu étalécs............ G. nivalis L. 1272 Bois, prés, probablement nat. - Févr.-Mars.

\section{Genre 464. - LEUGOIUM L.}

Bulbe subglob.; f. 3-6, larg. lin. obt.; divis. du périanthe ov., brusq. contractées en pointe obt., verte...... L. vernum L. 1273 Coteaux boisés, prés. - Mars-Avr.

\section{Genre 463. - NARGISSUS L.}

Fl. jaune à couronne jaune en forme de tube, dilat. en entonnoir, égalant les divis. du périanthe jaune pàle étalées ou ascend.

Bois. - Mars-Avr.

N. Pseudo-Narcissus L. 1274

Fl. blanche tr. odor. à couronne en coupe tr. courte, jaune pàle, à bord rouge vif, crén. 8-10 fois plus courte que les divis. du périanthe étalées d'un blanc pur. . . . . . . . N. poeticus L. 1275 Cult. et subsp. - Avr.-Mai.

$N$. incomparabilis Mill. Fl. jaune, à couronne en coupe égalant la moitié des divis. du périanthe. Non spontané.

\section{Famille 102. - ORCHIDÉES}

+ Souche munie de tuberc. ou de bulbes.

$\times 2$ tuberc. arrondis ou palmés, rappr.

= Labelle non prolongé en éperon; tuberc. arrondis.

Ovaire non tordu, 2 rétinacles, 2 bursicules. . O OPHRYS 466

Ovaire tordu, 1 rétinacle, 1 bursicule. . . . ACERAS 467

$=$ Labelle prolongé en éperon, ord. 2 réticules, 1 bursicule, rar. 1 rétinacle, 1 bursicule ou pas de bursicule. . . . ORGHIS 468

$\times 1-5$ tuberc. arrondis, distants ou allongés fusiformes rapprochés ou

2 bulbes, labelle non prolongé en éperon.

$\times$ 1-ב tuberc. arrondis, ovaire tordu, 2 rétinacles, pas de bursicule;

labelle étalé ascend.; fl. vert jaunàtre. . . HERMINIUM 469

2 bulbes tuniqués, ovaire non tordu, 1 ou 2 rétinacles; labelle dirigé en haut; fl. vert jaunâtre. . . . . . . . MALAXIS 470

2-5 tuberc. allongés; épi unilat., en spirale, ovaire non tordu, 1 rétinacle; labelle dirigé en bas; fl. blanches.

+ Souche ramp. ou fibr.

SPIRANTHES 471

ơ Souche grèle, ram. ramp. stolon.; fl. blanches en épi unilat., en spirale; labelle sans éperon........ GOODYERA 472

o Souche fibr.

- F. réduites à des écailles; un rétinacle.

Plante violacée, labelle indivis prolongé en éperon.

LIMODORUM 473
4 lante d'un blanc roussâtre, labelle bifide non prolongé en éperon.

- F. développées.

NEOTTIA 474

F. paraissant opp, au milieu de la t., labelle bifide; un rétinacle; ovaire non tordu............. LISTERA 475

F. alt., labelle ent. ou trilobé, sans éperon.

Pas de rétinacle; ovaire tordu. . . CEPHALANTHERA 476

Un rélinacle; ovaire non tordu ..... EPIPACTIS 477 


\section{GeNRE 466. - OPHRYS L.}

+ Divis. ext. du périanthe vertes ou jaunàtres.

$X$ Labelle ent. ou obscur. trilobé; divis. int. du périanthe lin., gl.; gynostème term. en bec court et 'dr.

Labelle moyen, obovale, velouté, d'abord d'un brun pourpre, à la fin jaunàtre, muni au centre de $2-4$ raies symétriques.

$$
\text { Coteaux calc. - Mai-Jn. }
$$

0. aranifera Huds. 1276

Labelle assez pet. ov. arrondi, velouté, d'un brun verdâtre ou grisàtre, gl. et pâle au centre.. • 0. litigiosa E. G. Camus. 1277 Coteaux calc. - Avr.-Mai.

Labelle nett. trilobé plus long que large; divis. int. du périanthe lin. filif., veloutées, brun pourpre; gynostème obt. sans bec.

Bois, coteaux calc. - Nai-Jn.

0. muscifera Huds. 1278

+ Divis. ext. du périanthe roses ou blanches; labelle brun pourpre velouté, marqué d'une tache et de lignes gl.

Labelle suborb., trilobé à lobes lat. pet. verticaux, coniques, le moyen gr., subglob., à bords roulés en dessous, term. par un appendice recourbé en dessous ; gynostème à bec long et flexueux.

Coteaux calc. - Jn-Jt.

0. apifera Huds. 1279

Labelle obovale suborb. élargi au sommet, ent., convexe, muni de 2 gibbosités à la base, term. par un appendice recourbé en dessus; gynostème à bec court, dr. . 0. Arachnites Murr. 1280 Coteaux calc. - Mai-Jn.

\section{Genre 467. - ACERAS R. Br.}

Fl. d'un vert jaunâtre bordées de rouge en épi long, étr., serré; périanthe à divis. conniv. en casque; labelle pend., à 4 lobes lin. presque paral.; gynostème sans bec ...... A. anthropophora R. Br. 1281 Prés secs, coteaux calc. - Mai-Jn.

\section{GeNre 468. - ORGHIS L.}

+ Eperon tr. court, 1-3 mm., en forme de sac, égalant au plus le tiers de l'ovaire; 1 divis. ext. du périanthe conniv. en casque.

$\times$ Fl. gr, en épis larg., 4-6 cm.; bract. 2 fois plus long. que l'ovaire; 1 rétinacle; 1 bursicule; labelle tr. allongé à 3 lanc. lin. tordues en spirale, la moyenne $3-4 \mathrm{f}$. plus longue que les lat.; pl. robuste.

\section{Lieux secs. - Jn-Jt.}

0. hircina Crantz. 1282

X Fl. petites, en épis étr., 1-2 cm., bract. plus courtes ou plus longues que l'ovaire ; 2 rétinacles libres ; pl. peu robustes.

Fl. verdâtres en épi un peu lâche; labelle pend., lin., divisé au sommet en 3 dents, la moy. plus courte; pas de bursicule; tuberc. palmés; bract. dépassant l'ovaire. . . 0. viridis Crantz. 1283 Prairies hum. - Nai-Jt.

Fl. pourpre noir au sommet, en épi serré; labelle trilobé à lobe moyen bifide, blanchâtre ponctué de pourpre; 1 bursicule; tuberc. arrondis; bract. plus courtes que l'ovaire.

Prairies, coteaux calc. - Mai-Jt.

0. ustulata L. 1284

+ Eperon plus ou moins allongé, conique ou lin., égalant au moins la moitié de l'ovaire, tr. rar. le tiers.

= Divis. ext. du périanthe conniv. en casque; tuberc. ent. 
Q Bract. tr. petites, comme des écailles, beaucoup plus courtes que l'ovaire, labelle tripartit, à lobe moyen profond. bifide avec une dent dans l'échancrure; pl. élevées.

- Casque d'un pourpre noir, ov. aig.; labelle à lobes lat. lin. oblongs, rappr. du lobe moyen dilat. dès la base et divis. au sommet en 2 lob. larges, crén. . . . . . 0. purpurea Huds. 1285 Bois, coteaux calc. - Avr.Jn.

- Casque d'un rose clair ou cendré, ov. acum. ; labelle à lobes lat. lin. écartés du lobe moyen étr. à la base et divis. en 2 lobules lin. ou oblongs.

Lobe moy. du labelle dil. au sommet et divisé en 2 lob. diverg. plus courts et 2-3 fois plus larges que les lat. 0. militaris L. 1286 Coteaux calc., prairies. - Mai-Jn.

Lobe moy. du labelle non dil., divisé en 2 lob. aussi long et aussi étr. que les lat... . . . . . 0. Simia Lamk. 1287 Coteaux calc., prairies. - Mai-Jn.

a Bract. moyennes, oblongues ou lanc.-lin., égalant presque l'ovaire ; labelle trilobé ou ent.; pl. peu élevées.

Labelle trilobé, à lobe moyen, aig. ent. dépassant les lat.; casque à divis. soudées inl. aig.; fl. rouge brun en épi assez serré.

Prairies hum., coteaux calc. - Mai-Jn.

0. coriophora L. 1288

Labelle subtrilobé, plus large que long à lobe moy. émarg., les lat. plus gr., réfléchis, crén. casque à divis. libres, courtes, obt.; fi. purp. en épi làche. . . . . . . . . Morio L. 1289 Prés, pelouses, prairies. - Avr.-Jn.

= Divis. ext. du périanthe plus ou moins étalées ou redressées, au moins les 2 lat.

Labelle simple, lin.-allongé, ent; fl. blanches ou un peu verdâtres, nombr.; éperon grèle presque horiz., 1-2 fois plus long que l'ovaire tordu ; pas de bursicule: tuberc. en fuseau aigu.

Anth. à loges rappr. et paral.; fossette stigmatique à bord épais ; éperon filif. en alène . . . . . . 0. bifolia L. 1290 Bois, prés. - Jn.Jt.

Anth. à loges écartées, diverg. à la base; fossette stigmatique à bord étr.; éperon en massue grêle. 0. montana Schmidt. 1294 Bois, prés. - Mai-Jt.

Labelle trilobé.

ڤ Eperon horizontal ou dirigé en haut, cyl. ou conique; épi génér. làche; tuberc. entiers, ov. ou subglob.; fl. purp.

‡ T. nue au sommet; f. basilaires oblongues obt. étalées ord. tachées de noir; bract. à 1-3 nervures; éperon aussi long que l'ovaire ; labelle à lobes peu inég., le moyen éch.

Bois, prés. - Avr.-Jn.

0. mascula L. 1292

む T. feuillée jusqu'au sommet à f. dress., lanc.-lin., aig. non tachées; bract. à 5 -7 nervures ; éperon d'un tiers plus court que l'ovaire.

Labelle à lobe moyen presque nul, dépassé par les 2 lat. larg. et rabattus ; éperon dil. éch. au sommet; bract. plus courtes que l'ovaire. . . . . . . 0. laxiflora Lamk. 1293 Prés hum. - Mai-Jn.

Labelle à lobe moyen égalant ou dépassant les lat. étalés ; éperon atténué, obt. au sommet; bract. dépassant l'ovaire.

Prairies hum., surtout calc. - Jn-Jt.

0. palustris Jacq. 1294

Eperon pendant ou dirigé en bas; épi multiflore, serré.

$\odot$ Fl. pet., non rayées, ni ponct. de pourpre; éperon grêle, filif., allongé ; bract. à 3 nerv. simples. 
醚 Fl. d'un rose vif, en épi court ov. conique, obt.; labelle tripartit muni de 2 petites lamelles à la base; 1 rétinacle; 1 bursicule; tuberc. ov. ent. . . . . . 0. pyramidalis L. 1295 Prés, coteaux calc. - Mai-Jt.

Fl. d'un rose pàle, en épi allongé, cyl. aig.; labelle trilobé sans lamelles; 2 rétinacles; pas de bursicule; tuberc. palmés.

Eperon allongé tr. grèle, 1-2 foịs plus long que l'ovaire; labelle obovale, plus large que long; fl. pet. 8-10 mm., en épi assez serré et assez grêle . . . . 0 0 conopea L. 1296

Coteaux calc., prairies hum. - Mai-Jt.

Eperon court, légèr. épaissi, égal. l'ovaire; labelle plus long que large; fl. tr. pet., కొ-7 mm., en épi serré et grêle.

Coteaux calc., prairies hum. - Mai-Jt.

O. odoratissima L. 1297

- Fl. assez gr., rayées ou ponctuées de pourpre; éperon assez épais, cyl. ou conique, presque dr.; bract. inf. à nervures ramifiées; 2 rétinacles libres ; 1 bursicule; tuberc. incisés-lobés.

ㅇ Fl. d'un blanc lilas ou jaunàtres, rar. purp.

Fl. jaunàtres, rar. purp. tachées de jaune, en épi ov. court; bract. inf. dépassant les fl.; éperon gros, conique, égalant ou dépassant l'ovaire; f. non maculées; tuberc. incisés-lobés; t. creuse. . . . . . . 0. sambucina L. 1298 Bois, pàturages. - Mai.

Fl. d'un blanc lilas ou rosées, rar. purp., en épi compact cyl.conique; bract. herb. trinervées ne dépassant pas les fl.; éperon cyl. plus court que l'ovaire; f. ord. tachées de noir; tuberc. palmés. ....... 0. maculata L. 1299 Bois, prairies. - Jn-Jt.

아. purp. ou rose carné; t. creuse ord. robuste; bract. au moins les inf. plus long. que les $\mathrm{fl}$.

F. étalées-dress. oblongues-lanc., plus larges vers le milieu, souvent tachées de brun; fl. d'un pourpre foncé ; labelle à lobes lat. rejețés en arrière; tuberc. à lobes presque paral.

0. latifolia L. 1300

Prairies hum., marais. - Mai-Jt.

F. dress. lanc., plus larges à la base et insensib. atténuées, non tachées; fl. pâles, carnées ou roses; labelle à lobes lat. à peine repliés; tuberc. à lobes nett. diverg.

Prairies hum., marais. - Mai-Jt.

0. incarnata L. 1301

\section{GENRE 469. - HERMINIUM L.}

Pl. pet., 6-20 cm. feuillée; f. rad., 2-3, ov. ou oblongues lanc.; épi effilé, multiflore; fl. d'un vert jaunâtre, pet., pench.; labelle horizontal ou conniv., trifide, à lobes lat. lin., diverg. H. Monorchis R. Br. 1302 Coteaux et pelouses calc., prairies hum. - Jn-Jt.

\section{Genre 470. - MALAXIS Swartz}

Pl. petite, 丂ั-15 $\mathrm{cm}$., à souche munie de 2 tuberc. presque superposés, écartés pet.; t. grêle, pentagone; f. pet. ov.-spat.; fl. nombr., tr. pet., en épi long et effilé; lab. ov: aig. plus court que les divis. inég. du périanthe; 1 rétinacle ...... . M. paludosa Swartz 1303

Marais tourb. sil. - At-Sept.

Pl. assez pet., 8-20 cm., à souche munie de 2 tuberc. juxtaposés, contigus assez gros; t. assez grêle, triquètre sup. engaìnée inf. par 2 f. oblongues lanc. gr.; fl. peu nombr., 2-8, en épi court et lâche; labelle oblongobt. plus large et aussi long que les autres divis. lin.; 2 rétinacles.

Marais tourb, surtout calc. - Jn-Jt.

M. Loeselii Swartz 1304 
GENRE 471. - SPIRANTHES Rich.

F. rad., lanc-lin., entourant la tige,-développées à la flor.; tuberc. allongés, cyl.; labelle en languette ov. oblongue, à bords frangés, arrondie au sommet......... S. æstivalis Rich. 1305 Marais tourb. - Jn-At.

F. rad., ov. ou oblongues, en rosette lat. à la t., non développées à la flor.; tuberc. oblongs en navet; labelle en languette obovale-émarg., à bords frangés . . . . . . . . S. autumnalis Rich. 1306 Pelouses et prés secs. - At-Sept.

\section{Genre 472. - GOODYERA R. Br.}

Pl. peu élevée, 10-30 cm., pub. sup.; f. inf. étalées, ov. subaig., pétiolées, nervées en réseau, les caul. lin.; labelle ent., concave gibbeux à la base; 1 rétinacle ........... G. repens R. Br. 1307 Bois de pins, dans la mousse. - Jt-At.

\section{GeNRE 473. - LIMODORUM Rich.}

Pl. élevée, 30-80 cm., robuste, gl., munie d'écailles engainantes; fl. violettes, gr., dress., en épi long et làche; labelle oblong, crén.

Bois montueux calc. - Jn-Jt.

L. abortivum Sw. 1308

\section{Genre 474. - NEOTTIA L.}

Pl. peu élevée, 20-40 cm.; fl. roussâtres en épi, serré au sommet et lâche à la base; labelle 2 fois plus long que les divis. à lobes diverg. crén.

Bois ombragés. - Mai-Jt.

N. Nidus-avis Rich. 1309

\section{Genre 475. - LiSTERA R. Br.}

Pl. assez élevée, 20-60 cm., pub. sup.; f. ov. arrondies; fl. vert jaunâtre, assez pet., dress., nombr., en longue grappe spiciforme.

Bois ombragés.

L. ovata R. Br. 1310

\section{GeNRE 476. - GEPHALANTHERA Rich.}

Fl. rose vif; divis. du périanthe acum. égalant le labelle; ovaire pub. gland.; t. pub. sup. . . . . . . . C. rubra Rich. 1311 Bois et coteaux calc. - Jn-Jt.

Fl. blanches ou jaunâtres; divis. toutes ou les int. obt., dépassant le labelle; ovaire gl.; tige glabre.

Périanthe d'un blanc pur, à divis. ext. aig. ; bract. pet., membr., beaucoup plus courtes que l'ovaire; f. lanc. rappr.

Bois et coteaux calc. - Mai-Jn.

C. ensifolia Rich. 1312

Périanthe blanc jaunâtre, à divis. toutes obt.; bract. allongées, foliacées, dépassant au moins l'ovaire; f. ov. lanc., écartées.

Bois, prés, coteaux calc. - Mai-Jn.

G. pallens Rich. 1313

\section{Genre 477. - EPIPAGTIS Hall.}

+ Fl. gr., blanchâtres; labelle blanc, strié de pourpre, trilobé à lobe term. artic. inf., suborb., obt., creus.-plissé; divis. ext. du périanthe aig. plus courtes que le labelle ou l'égalant, les 2 int. obt.; f. ov. 
lanc., lisses aux bords et sur les nervures. gr., plus long. que les entrenouds, larges de 1-3 cm., longues de 4-9 cm.; souche ramp. stolon.; ovaire lin. oblong .... . E. palustris Crantz 1314 Marais. - Jn-At.

+ F1. pet., verdâtres ou rougeâtres, rar. blanchàtres; labelle à languette ov., aiguë ou acuminée; divis. du périanthe aigues plus long. que le labelle; f. ov., oblongues ou lanc., rudes aux bords; souche non stolon.

X T. peu feuillée; f. lisses sur les nervures, oblongues ou lanc., pet., ord. plus courtes que les entrencuds, larges de $3-8 \mathrm{~mm}$., longues de $1-4$ cm.; fl. en grappe làche, grêle; labelle purpurin, à gibbosités plissées crépues, à lang. ov. apic. crénelée; pl. gris.; ovaire obovale en toupie........ E. microphylla Swartz 1315 Bois et coteaux calc. - Jn-At.

T. ord. dens. feuillée; f. scabres sur les nervures, ov. lanc., gr., plus longues que les entrenœuds, larges de $10 \mathrm{~mm} .-7 \mathrm{~cm}$.; fl. ord. en grappe dense, assez robuste; labelle à languette ov. aig. ou acum. recourbée au sommet.

Bract. toutes plus courtes que les fl., ou les inf. un peu plus longues; fl. rouge-foncé, assez pet., souvent peu ouvertes; gibbosités du labelle plissées-crépues; grappe assez grêle; f. ord. courtes, long. 3-7 cm., ovaire obovale-arrondi.

Bois secs, coteaux calc. - Jn-At.

E. atrorubens Schult. 1316

Bract. inf. dépassant long. les fl.; fl. assez gr., ord. tr. ouvertes; gibbosités du labelle presque lisses; grappe ord. assez robuste, ovaire obovale-oblong.; f. long. de $7-15 \mathrm{~cm}$., larges de $3-7 \mathrm{~cm}$.; labelle rose violacé. . . . . . . E. latifolia All. 1317 Bois. - Jt-Sept.

Var. f. plus étr., labelle blanchàtre ou verdâtre, fl. précoce, Jn-Jt (E. viridiflora Reich.), coteaux calc,

Var. f. étr., larg. 10-18 mm., peu allongées, long $1-7 \mathrm{~cm}$., nombr., t. et labelle violacé, flor. tardive, At-Sept. ( $E$. violacea Dur. Duq.), bois argil.

\section{FAMILle 103. - POTAMÉES}

Fl. hermaphrodites régul. en épi simple; périanthe hẹrb. à 4 divis. libres, étalées; 4 ét. à filets tr. courts opp. aux divis.; anth. à 2 lobes; styles tr. courts; 4 stigmates subsessiles en forme de bouclier oblique; fr. composé de 4 carpelles (ou moins par avortement) à 1 seule graine.

POTAMOGETON 478

Fl. mon., entourées par une.spathe ovale formée de 2 stipules soudées; fl. mâle solit. ou placée à côté d'une fl. fem., consistant en 1 ét. à long filet filif.; anth. à 2-4 loges; fl. fem. à périanthe court membr., en forme de coupe entourant la base de l'ovaire; style persist. à stigmate en bouclier ou en languette; fr. composé de 2-4 carpelles libres, sessiles ou pédic., monosp., indéh. .... ZANNICHELLIA 479

\section{GENRE 478. - POTAMOGETON L.}

+ F. toutes opp., lanc. embrass., souvent tr. serrées et réfléchies; pédonc. fructif. courts, recourbés en crochet; épis pauciflores, subglob. . . . . . . . . . . . P. densus L. 1318

Mares, ruiss. - Mai-Sept.
+ F. flor. opp., les autres alt.; pédonc. fructif. dr. ou un peu courbés; épis à fl. ord. nombr.

$\times$ F. toutes lin. rubannées, étr., submerg., sessiles, ord. munies de 2 glandes à la base. 
= Stipules soudées en une long. gaîne entourant la t. subcyl.;.f. lin., munies de nervures transvers.; pédonc. fructif. grêles, dr. plus longs que l'épi formé de 4-5 vert. écartés; carp. assez gros, 2 1/2 sur 3 1/2 mm., obovales, convexes, à dos obt., à bec latéral.

P. pectinatus L. 1319

Mares, rivières. - Mai-Sept.

= Stip. soudées en forme de spathe axill.; f. non engainantes, sans nervures transv.

Q F. tr. étr., 1/2-1 1/2 mm., à 1-å nervures, la médiane étr.; t. filiformes, subcyl.; pédonc. au moins 2 fois plus long que l'épi.

Pédonc. fructif. dr.; carp. nombr., rappr., petits, 1 1/2-2 1/2 mm., à peine compr., à dos arrondi, à bord int. sans dent, à bec à peine latéral. . . . . . . P. pusillus L. 1320

Mares, rivières. - Jn-Sept.

Pédonc. fructif. courbé; carp. peu nombr., 2-4, écartés, assez gros, 2-3 mm., compr. carénés, à carène ondulée-crén., à bord interne muni d'une dent vers la base, à bec latéral.

Mares, étangs. - Jn-Sept.

P. trichoides Chamisso 1321

Q F. assez étr., 2-3 mm., à 3 ou plus. nervures, la médiane plus ou moins large; t. ord. plus ou moins compr., rar. cyl.

- T. un peu compr., non ailée; f. obt. ou subaig., mucr., à nervures peu nombr., 3-3; carp. nombr. à dos arrondi, non crén., à bord interne sans dent, à bec médiocre, à peine lat.

Pédonc. ord. 2 fois plus long que l'épi; carp. petits, 1,3 sur 2,: $\mathrm{mm}$.; f. subaig., mucr., à ๖ nervures dans la partie moyenne; stip. lanc., déchirée-cil. au sommet; fl. rar.

P. mucronatus Schrad. 1322

Nares, fossés, canaux. - Jn-Sept.

Pédonc. ord. de la long. de l'épi; carp. assez gros, 2 sur 3,5 mm.; f. obt., mucr., à 3 , rar. 5 , nervures dans la partie moyenne; stip. ligulées, obt., ent. P. obtusifolius Mert. et Koch. 1323 Nares, étangs. - Jn-Sept.

- T. compr.-ailée, presque foliacée; f. long. acum. à nervur. nombr.; carp. peu nombr., 2-5̆, assez gros, 2 sur $3 \mathrm{~mm}$., un peu compr., à dos convexe, ondulé-crén., à bord interne muni d'une dent, à bec lat. long, crochu. . . . P. Pcutifolius Link 1324 IIares, étangs. - Jn-Sept.

$\times$ F. lanc., oblongues ou ov. plus ou moins élargies, dépourvues de glandes à la base.

F. toutes semblables, submerg., membran.-transparentes, sessiles ou subsessiles.

م Epi fructif. assez court, 1-3 cm.; stipules courtes.

F. lin. oblongues, peu larges, 4-10 mm., ondulées-crispées, à nervures second. écartées; t. compr.; carp. ov. compr. à bec long, aigu et arqué. . . . . . . . P. crispus L. 1325 Iares, rivières. - Jn-Sept.

F. ov. ou ov.-lanc., larges, $130-30 \mathrm{~mm}$., embrass. en coeur, un peu ondulées, à nervures second. rapp.; t. cyl.; carp. assez gros, 2 sur $3 \mathrm{~mm}$., obovales renfl. à bec tr. court.

P. perfoliatus L. 1326

Etangs, rivières, canaux. - Jn-Sept.

Epi fructif. long., $4-6 \mathrm{~cm}$; stip. gr.; f. oblongues-lanc., larges, 2-6 cm., ondulées et rudes aux bords, alténuées en court pétiole; péd. renfl. sup. plus gros que la t.; carp. gros, 2 1/4 sur $31 / 2 \mathrm{~mm}$., ov. renfl., peu compr. à bec tr. court, obt.; var. à 1 . allongées, long. acum.-cuspidées (var. fluitans C. et G.).

Mares, étangs, rivières. - Jn-Sept. 
F. dissemblables, les sup. flottantes, plus larges, coriaces; rar. toutes les f. submerg.

ち Pédonc. renflés sup., plus gros que la $t$.

F. submerg. larges, 12-22 mm., atténuées en court pétiole, à bords lisses; épi fructif. long., 3-3̆ cm.; carp. ov. ventrus, à peine compr., à bec tr. court, obt. P. Zizii Mert. et K. 1328 Mares. - Jn-Sept.

F. submerg. lanc. lin., ẻtr., 3-6 mm., atténuées à la base et sessiles, à bords un peu rudes; épi fructif. assez court, $2-3 \mathrm{~cm}$.; carp. ov. compr. à bec court, arqué. P. gramineus L. 1329 Mares, étangs. - Jn-Sept.

む Pédonc. non renfl.

$\odot$. F. sessiles, les submerg. long. lanc. persist., les flottantes lanc., insensib. atténuées en pétiole, devenant rougeâtres; épi fructif. court, $2-4 \mathrm{~cm}$.; carp. assez gros, 2 sur $3 \mathrm{~mm}$., devenant rougeâtres, compr., à carène aiguë, à bec compr.; pédonc. de la grosseur de la tige. . . . P. alpinus Balbis 1330

$\odot$ F. toutes pétiolées.

$$
\text { Mares, étangs. - Jn-Sept. }
$$

Epi fructif. court, 2-4 cm., compact; carp. petits, 1 sur 2, ov.compr.; f. sup. arrondies ou un peu en cœur à la base.

F. ord. toutes submerg., minces, les inf. lanc., les sup. ov. ellipt.; pédonc. de la grosseur de la t.; carpelles verdâtres, à carène un peu aiguë, à bec court et arqué.

P. coloratus Hornem. 1331

Fossés, étangs des terrains calc. - Jn-Sept.

F. submerg. lanc., les flottantes en rosette, coriaces, ov.-oblongues; pédonc. moins gros que la tige; carpelles rougeâtres, à carène obt., à bec presque nul.

\section{Ruiss., fossés tourb. sil. - Jn-Sept.}

P. polygonifolius Pourr. 1332

Epi fructif. long., 3-6 cm., assez lâche; carp. gros, verdâtres, $21 / 2-3$ sur $31 / 2-3$; ov. renfl., à peine compr., à bec un peu arqué.

F. flottantes oblongues-lanc., atténuées à la base, sans plis saill., à pétiole convexe en dessous, les sulımerg. à limbe élargi translucide, persist. à la flor.; carp. médiocres, 2 1/2

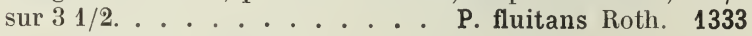
Rivières. - Jn-Sept.

F. flottantes ovales ou oblongues, arrondies ou en cœur à la base, à 2 plis saillants au-dessus du pétiole canal., les submerg. oblongues, à limbe cad. à la flor.; carp. gros, 3 sur $41 / 2 \mathrm{~mm} . \ldots . . . . . .2$. . natans L. 1334 Eaux stagnantes. - Jn-Sept.

\section{Genre 479. - ZANNIGHELLIA L.}

F. toutes submerg., opp., lin. filif., obt., mucr.; stipules membr., soudées 2 à 2 , engainantes; style court et épais; stigmate en bouclier; anth. à 4 loges . . . . . . . . . Z. palustris L. 1335 Mares, rivières, canaux. - Mai-Sept.

\section{Famille 104. - NAIADÉES \\ Genre 480. - NAIAS L.}

T. cyl., ram.-dichotomes plus ou moins épin., formant des touffes compactes de 30-60 cm.; f. lin. élargies, larges de 2-4 mm., sessiles, sin. dentées, onduléés, à gaînes ent.; fl. dioïques, solit., les mâles pédic., les 
fem. sessiles; anth. tétr. à 4 loges s'ouvrant en 4 valves; 3 styles; fr. ov. oblong, assez gros, 4-3 mm. sur 2, presque lisse.

$$
\text { Rivières, étangs, canaux. - Jt-Sept. }
$$

N. major All. 1336

T. filif., ram.-dichotomes, non épin., fragiles, formant de petites touffes, 10-25 cm.; f. lin. étr., $1 \mathrm{~mm}$., sessiles bordées de petites dents mucr., souvent arquées, à gaìnes cil.-dentic. ; fl. mon., 2-ว̆ en glom., toutes sessiles; anth. oblongue, à loge unique se déchirant au sommet; 2 styles; fr. oblong-cyl., pet., $3 \mathrm{~mm}$. sur $3 / 4$, strié en long.

$$
\text { Rivières, canaux. - Jt-Sept. } \quad \text { N. minor All. } 1337
$$

\section{FAMILLE 10\%. - LEMNACÉES}

Frondes au moins $2 \mathrm{~mm}$. de long, émettant en dessous une ou plus. fibres rad.; fl. naissant d'une fente longit. placée sur le bord de la fronde, renf. dans une tr. pet. spathe bivalve; ét. ord. 2, à filet filif., anth. à 2 loges; stigmate en coupe; fr. à 1-7 graines.

LEMNA 481

Frondes minuscules, ayant à peine $1 \mathrm{~mm}$. de long, dépourvue de fibres rad.; fl. naissant à la surface de la fronde, dépourvues de spathe; 1 ét. à anth. subsessile uniloc.; fr. à une graine. . WOLFFIA 482

\section{Genre 481, - LEMNA L.}

+ Frondes larges de plus de 2 mm., planes des 2 côtés, munies de nervures fines en dessus; fl. rar.

Frondes brun rougeàtre en dessous, épaisses, opaques, à nervures converg., émettant chacune plus. fibres rad.

Fossés, mares, rivières. - Avr.-Jn.

L. polyrrhiza L. 1338

Frondes d’un vert clair, minces, transparentes, ellipt.-lanc., aig., atténuées ou pétiolées à la base et réunies en croix, émettant seulement 1 radicelle . . . . . . L trisulca L. 1339 Mares. - Avr.-Jn.

+ Frondes larges d'environ $2 \mathrm{~mm}$., ov. ou suborb., opaques, sans nervures en dessus, émettant 1 seule radicelle; fl. assez communes.

Frondes lenticulaires, planes des 2 côtés non spongieuses en dessous; fr. monosp. indéh. . . . . . . L. minor L. 1340 Mares. - Avr.-Jn.

Frondes hémisph., un peu convexes en dessus, tr. renfl., spongieuses et blanchâtres en dessous; fr. 2-7 gr. s'ouvrant en travers.

$$
\begin{array}{ll}
\text { Mares. - Avr.-Jn. } & \text { L. gibba L. } 1341
\end{array}
$$

\section{Genre 482. - WOLfFiA Horkel.}

Frondes ellipsoïdes-hémisph., planes en dessus, fort. convexes et blanchâtres en dessous, émettant de nouvelles frondes par un pore circul. placé au-dessous de sa face sup.; ne fleurit pas dans notre région.

Mares.

W. arrhiza Wimm. 1342

\section{Famille 106. - AROIDÉES}

Spathe ample roulée en cornet à la base, fendue dans toute sa longueur; spadice long. nu, term. en massue, portant les fl. mon. à sa base ; ét. subsessiles; souche tubéreuse ; f. hastées ou sagittées; baies rouges subglob. .............................. 483 


\section{Genre 483. - ARUI L.}

Spadice à massue term. rouge-violacée, rar. jaunàtre, ord. une fois plus courte que son pédic.; f. hastées-sagittées paraissant à la fin de l'hiver, tachées de noir ou vertes, sans veines blanches; spathe jaunàtre ou violacée. . . . . . . . . . A. maculatum 1343 Bois, - Avr.-Mai.

Spadice à massue term. jaune, rar. violacée, aussi longue ou plus longue que son pédic.; f. triang. hastées à oreillettes diverg., paraissant en automne, plus ou moins veinées de blanc; spathe blanchàtre.

Coteaux, haies, bois. - Fin Avr.-Mai.

A. italicum Mill. 1344

On a planté le Calla palustris L. à Marly, les Essarts. F. larg. en cour: spathe persist. ov. obt., apiculée; épi ovale formé de fl. mon. entremêlées; baie rouge; pl. aquat.

On a planté aussi au bois de Boulogne, sur le bord des ruisseaux, Acorus balainus L. F. long. lin. en glaive; spathe foliacée, verdàtre, lin., tr. long.; épi lat., cyl., formé de fl. hermaphrodites; fr. caps.

\section{FAMILLE 107. - TYPHACÉES}

Fl. en 2 épis cyl., sortant chacun d'une spathe membr. caduque; le supér. màle, formé d'ét. et de filaments stériles; l'infér. fem. formé d'ovaires fertiles entremèlés de soies et d'ovaires stériles en forme de massues; anth. à 4 loges; style long, capill., à stigmate en languette; fr. tr. pet., en fuseau porté sur un pédic. capill., entouré de nombr. soies fines; f. toutes rad., dress., très allongées, engaìnant longuement la t.; souche ramp. . . . . . . . . TYPHA 484

Fl. en plus. capit., glob., les infér. accomp. d'une long. f. persist.; les supér. màles, les infér. fem.; anth. à 2 loges ; style court, épais à stigmate lin. ou oblong; fr. assez gros, sessile ou subsessile, term. en bec.; f. rad. et caul. allongées; souche fibreuse. . . SPARGANIUM 485

\section{GeNRe 484. - TYPHA L.}

F. larg., 6-8 mm., glaucescentes, planes; épis contigus, rar. espacés, le mâle à axe garni de poils blanchâtres, le femelle cyl. large brun-noirâtre, à axe sans poils et fl. sans bractéoles; stigmate lanc. spathulé.

Mares, étangs. - Jn-At.

T. latifolia L. 1345

F. étr., 4-6 $\mathrm{mm}$., vertes, un peu convexes; épis espacés, le mâle à axe garni de poils roux, le femelle cyl. étr. brun fauve, à axe muni de poils blanes spathulés et fl. bractéolées; stigmate lin. en alène.

$$
\text { Nares, étangs. - Jn-At. }
$$

T. angustifolia L. 1346

\section{GENRE 480. - SPARGANIUM L.}

+ Cap. disposés en pan. étalée, les mâles nombr. sur chaque ram.; écailles flor. arrondies au sommet; f. larg., 6-16 mm.; fr. en toupie, ang., brusq. contracté en bec court ou (S. neglectum Beeby) fusiforme, à peine ang., graduellement atténué en bec long.

Bord des eaux. - Jn-At.

S. ramosum Huds. 1347

+ Cap. disposés en grappe simple, les màles nombr. ou solit.; écailles florales dentées-érodées; f. étr., $2-6 \mathrm{~mm}$.

Plus., 3-7, cap. mâles; cap. fem., assez gros, 12-15 mm., les inf. pédonc.; fr. stipités, oblongs en fuseau, atténués en long bec grêle; f. assez étr., $4-6$ mm., dress., rar. flottantes; $t$. dress. rar. flottante.......... . . S. simplex Huds. 1348

Bord sles eaux. $\rightarrow$ Jn-At. 
Un seul cap. màle rar. plus.; cap. fem., petits, $1 \mathrm{~cm}$. , tous sessiles; fr. petits, sessiles, ovoïdes, brusq. term. en bec court; f. étr. $2-5 \mathrm{~mm}$. flottantes; t. ord. flottantes.

Marais, fossés. - Jn-At.

S. minimum Fries. 1349

\section{Famile 108. - JONCAGINÉES \\ GENRE 486. - TRIGLOGHIN L.}

Pl. viv. à hampe grèle, élancée, dépassant long. les f. lin., demi-cyl.; grappe fructif., tr. allongée, à pédonc. dressés, plus courts que le fr. appliqué contre l'axe, lin. en fuseau, long. atténué à la base, formé de 3 carpelles subcyl. . . . . . . . . T. palustre L. 1350 Marais, prairies hum. - Jn-Sept.

\section{Famille 109. - JONCÉES}

F. gl., cyl., lin. canal. ou réduites à des gaines; caps. à 3 loges, à 3 valves, portant chacune une cloison au milieu; graines nombr. tr. pet., fixées au bord int. de chaque cloison .... JUNGUS 487

F. ord. poil., graminoïdes, planes; caps. à 1 loge, s'ouvrant en 3 valves, contenant 3 graines assez grosses. . . . . . . LUZULA 488

\section{GRNRE 487. - JUNGUS}

+ Pl. ann., peu élevées, à f. sét. canal., à racine fibr., peu tenace.

$\times$ F. toutes radicales, courtes; t. nues, terminées par un seul glomér. de 5 -12 fl. brun.; divisions extér. du périanthe à pointe arquée en dehors .......... J. capitatus Weig. 1351 Lieux sabl. hum. - Mai-At.

$\times$ F. caul., 1-3; t. feuillées portant plus. glom. ou de nombr. fl. en pan.; divis. du pér. toutes dress. ou appliq. sur le fr.

$=$ Fl. réunies par 3-8 en glom. peu nombr., formant une cyme courte et étr.; f. sét. canal. à gaine auriculée; inflor. dépassée par une long. bract. foliacée; périanthe à divis. lanc.-aig., conniv., dépassant la caps. oblongue-aig.. . . . J. pygmæus Thill. 1352 Bord des mares, grèves sabl. - Jn-At.

= Fl. solit. et écartées, ou rapprochées en fasc. étalés, formant une cyme ou pan. tr. làche.

Périanthe long, : $\mathrm{mm}$. environ, à divis. inég. lanc. en alène, les ext. plus long, dépassant la caps. oblongue; fl. solit. ou fasc., vert. pâle; f. à gaine non auriculée. . . J. bufonius L. 1353 Lieux hum. - Mai-Sept.

Périanthe court, 1-2 mm. à divis". égales, ov.-aig., égalant ord. la caps. subglob.; fl. solit. et espacées, brun.; f. à gaine auriculée.

J. Tenageia L. 1354

Lieux sabl. hum. - Mai-Sept.

+ Pl. viv., à souche traçante ou fibr. gazon., tr. tenace.

Q. T. nues rar. un peu feuill. inf.; f. nulles ou toutes rad.

- F. toutes rad. rar. t. feuill. inf.; inflor. term.

F. molles, dress.; t. grêle, un peu feuillée à la hase; inflor. dépassée par 1-2 bract., foliacées; périanthe à divis. acum. en pointe fine, plus long. que la caps. . . J. tenuis Willd. 1355 Lieux sabl. hum., chemins, nat. - Jn-Sept.

F. raides, étalées-arq.; t. raides, nues; inflor. 2 fois plus long. que les bract.; périanthe à divis. obt. ou subaig., égalant la caps.

Lieux hum, et tourb. silic. - Jn-Sept. 
- F. nulles, réduites à des gaînes basilaires membr.; inflor. lat., dépassée par une bract. qui semble continuer la t.; souche horiz. traçante.

缩 T. glaucescentes, difficiles à rompre, fort. striées, à moelle interrompue; gaines d'un pourpre noir, luisantes; 6 ét.; caps. égalant le périanthe . . . . . . . J. glaucus Ehrh. 1357 Lieux hum. - Jn-At.

T. vertes, faciles à rompre, lisses ou fin. striées, à moelle continue; gaines roussàtres, opaques; 3 ét.; caps. plus courte que le périanthe.

Fl. verdàtres en pan., ram. plus ou moins làche et diffuse, à gaine de sa base non renflée; caps. dépourvue de mamelon au-dessous du style; t. lisse à l'état frais. J. effusus L. 1358 Lieux hum. - Jn-At.

Fl. brunâtres, en pan. ord. compacte, à gaine renfl.; caps. surmontée d'un petit mamelon qui porte le style.

Lieux hum. - Jn-At.

J. conglomeratus L. 1359

Q T. feuillées; inflor. term.; graines non appendiculées.

¿ Fl. solit., non réunies en glom., formant une pan. à ram. dress.;

f. jamais noueuses; caps. subglob. plus longue que le périanthe.

Lieux hum. - Jn-Sept.

J. compressus Jacq. 1360

¿ Fl. rappr. en petits glom., disposés en pan. souvent étalée ou divariq.; f. plus ou moins renflées-noueuses.

む F. toutes filif., molles, à peine noueuses; pl. stolon., à t. grêles, radicantes, souvent flottantes ou submerg.; glom. souvent foliacés, à $5-20$ fl. pet.; caps. obt. mucr., égalant ou dépassant le périanthe; 3 ét. . . . . . . J. supinus Mœench. 1361 Bord des eaux. - Jn-Sept.

む F. raides cyl. compr., creuses, tr. renfl. cloisonnées; souche à rhizomes tracants, rar. à f. radicantes.

$\odot$ Périanthe à divis. toutes obt. et d'égale long.; fl. tr. pâles. d'un vert jaunâtre, 4-12 en glom. formant une pan. à rameaux divariq. ou réfractés; caps. d'un vert roussâtre égalant le périanthe . . . . . . J. obtusiflorus Ehrh. 1362 Marais. - Jn-At.

$\odot$ Périanthe à divis. toutes ou au moins les ext. aig.; fl. brun. ou verdâtres.

Périanthe à divis. extér. aig., les int. obt. et scarieuses aux bords; caps. ov. oblongue, brunâtre ou noirâtre, luisante, brusq. et brièv. mucr.

T. et f. cyl. compr.; t. ascend. ou couchées de 10 à $60 \mathrm{~cm}$; glom. moyens, 4-15 fl. assez gr., en pan. à rameaux ètalés et écartés. . . . . . . J. lamprocarpus Ehrh. 1363

Lieux hum. - Jn-Sept.

T. et f. tr. compr., presque à 2 tranchants; t. dress., élevées, 40-80 cm.; glom. pet., à 3-6; fl. tr. pet., en pan. à ram. dress. et rappr. . . . . . J J. anceps Laharpe 1364

Marais tourb. - Jn-At.

Périanthe à divis. toutes acum. en alène, les int. plus long. que les ext. et souvent recourbées; cap. roussâtre, insensib. atténuée en bec allongé .... J J. silvaticus Reichard. 1365

Marais. - Jn-At.

\section{Genre 488. - LUZULA DG.}

+ Inflor. formée de fl. solit., la plupart long. pédic., jamais réunies en glom.; graines appendic. au sommet. 
F. rad., larges, 5゙-10 mm.; ram. et pédonc. fructif., divar. ou réfr.; pér. à divis. aig., plus courtes que la caps. obt.-mucr.$$
\text { Bois. - Mars-Mai. }
$$

L. pilosa Willd. 1366

F. étr., 2-4 mm.; ram. et pédonc. fructif., dress. ou ascend.; périanthe à divis. acum. plus long. que la caps. aig.-acum.

$$
\text { Bois. - Mars-Mai. }
$$

L. Forsteri DG. 1367

+ Inflor. formée de fl. réunies en glom., sessiles ou subsessiles.

$X$ Inflor. tr. décomposẹe, à ram. tr. divar.; fl. 2-6 à chaque glom.; graines term. par un tuberc.; pl. rohuste; f. larg., 6-12 mm.

Bois montueux. - Mai.

L. silvatica Gaud. 1368

Inflor. en omb. dense, à ram, simples, inég. ou presque nuls; fl. nomb. en glom.; gr. append. à la base; pl. grèle; f. étr., $2-4 \mathrm{~mm}$. Inflor. à 2-6 ram.; fl. brun., en glom. à la fin penchés; anth. 3 fois plus longues que leur filet; souche stolon.

Bois, pelouses sèches. - Avr.-Mai.

L. campestris DC. 1369

Inflor. à 4-10 ram.; fl. brun. ou rouss. en glom. dress., quelquefois sessiles agglom; ; anth. égalant leur filet; souche fibr. gazon.

Bois, pâturages, marais. - Mai-Jn.

L. multiflora Lej. 1370

L. albida DG. Inflor. lâche, décomposée, à ram. divar.; fl. blanches ou rosées subsessiles; glom. par $2-6$; gr. term. par un tuberc. ; pl. assez élevée à f. long., étr., 3-6 mm. Nat. à Boulogne.

\section{FAMILle 110. - CYPÉRACÉES}

+ Fl. hermaphrodites, contenant chacune les ét. et le pistil.

$\times$ Epillets compr. à écailles distiques, régul. imbriq. sur 2 rangs opp.; inflor. entourée de bract. foliacées.

Épillets multiflores à 10-40 écailles toutes ou presque toutes égales et fertiles, stigmates gl.; 1-3 bract. . . . . CYPERUS 489

Épillets pauciflores, en tête noirâtre, chacun à 5-6 écailles, dont les 1-3 sup. seules fertiles, les inf. plus pet. stériles; stigmates pub.; 2 bract. inég. . . . . . . . SGHENUS 490

X Épillets non ou à peine compr., à écailles imbriq. tout autour sur 3 ou plus. rangs.

= Écailles inf. plus pet.que les sup., épillets pauciflores; style à base renflée persist. sur le fr.

Pl. robuste, 1-2 mètres, à f. et bract. larges de 5-10 mm., tr. scabres et dentic. coupantes, achaine ov. conique, brun luisant.

CLADIUM 491

Pl. grêle de 10-50 cm., à f. et bract. lin. étr. 1-2 mm., ent. et presque lisses, achaine obovale-compr., brun, entouré à la base de $6-12$ soies raides ...... RHYNGHOSPORA 492

$=$ Écailles presque égales ou les inf. plus gr. que les sup.

Fr. entourés de nombr. soies blanches réunies en anneau à la base, bien plus long. que l'épillet et le faisant ressembler à la fin à une houppe cotonneuse; style filif. cad.; 3 stigmates; achaine trigone, f. trigones au moins au sommet.

ERIOPHORUM 493

Fr. nus à la base; style filif. cad. ou à base renfl. et persist.; 2-3 stigmates; achaines trigones ou compr., mucr., quelquefois entourés de $3-6$ soies incluses. . . . . . SCIRPUS 494

+ Fl. mon. ou dioïques, en épis ou épillets androgyns ou unisexuels; ovaire renf. dans un utricule ou enveloppe accr. en 
forme de sac ouvert au sommet pour laisser passer le style; écailles imbriq. sur plus. rangs; épillets disposés en épi ou en pan................................. 495

\section{GENRE 489. - GYPERUS L.}

+ Pl. pet., basses, y̌-30 cm., ann., à rac. fibr. ; f. tr. étr., 1-3 mm. Épillets brun-noirâtre, rar. verdâtres, pet., larg. $11 / 2 \mathrm{~mm}$.; 3 stigmates; achaines trigones, blanchàtres; $t$. triquètre à faces égales, excavées; f. à carène saill. . . . . . . . G. fuscus L. 1371 Lieux sabl. hum. - Jt-Sept.

Épillets jaunâtres ou bruns, assez pet., larg. 2-3 mm.; 2 stigmates; achaines compr., obovales, brunâtres; t. obt. trigone, à faces tr. inég.; f. à carène saill. . . . . . . . . C. flavescens L. 1372 Lieux sabl. hum. - Jt-Sept.

+ Pl. gr., élevées, $40 \mathrm{~cm} .-1 \mathrm{~m}$. , viv., à souche long. traçante; f. larg., 4-10 mm.; épillets brun rougeâtre, lin., allongés; 3 stigmates; achaine trigone; $t$. triquètre; $f$. carénées, scabres, tr. long., ainsi que les bract. . . . . . . . . . . G. longus L. 1373 Bords des rivières, fossés. - Jt-Sept.

\section{Genre 490. - SGHCENUS L.}

Pl. viv. assez élevée, $30-80 \mathrm{~cm}$., à souche fibr., gazonn. ; t. nombr., raides, cyl., nues, munies à la base de 2-3 f. à gaines noires, luisantes; 3̈-12 épillets en tête dépassée par la bract. inf.; achaine ov. trig., blanc; 3 ét. . . . . . . . . . . S. nigricans L. 1374 Marais. - Mai-Jt.

\section{Genre 491. - Gladium R. Br.}

Pl. viv. robuste, dépassant $1 \mathrm{~m}$., à souche traçante; t. cyl. creuse, lisse, feuillée; f. et bract. engainantes; épillets fasc., roussàtres, en omb. pédonc. formant une longue panic.; 2-3 stigmates pub.; 2 ét.

$$
\text { Marais. - Jn-At. }
$$

G. Mariscus R. Br. 1375

\section{GENRE 492. - RHYNGHOSPORA Vahl.}

Pl. assez ćlevée, 10 - $00 \mathrm{~cm}$., gazon.; épillets blanchåtres, puis fauves, en fase. corymbiformes plus larges que longs, ord. non dépassés par la bract. inf., 12 soies hypogynes égalant l'achaine, lisses ou à dents dirigées en bas. . . . . . . . . . R. alba Vahl. 1376

Marais tourb. sil. - Jn-Sept.

Pl. peu élevée, 10-30 cm., à souche long. traçante; épillets brun roussâtre, en fasc. ov.-oblongs plus longs que larges, long. dépassés par la bract. inf.; au plus 6 soies scabres, 2 fois plus longues que l'achaine, à dents dirigées en haut. . R. fusca Rœem. et Sch. 1377 Marais tourb. sil. - Mai-At.

\section{GENRE 493. - ERIOPHORUM L.}

+ Épillets solit., ov.; en tête term. dress., sans bract. foliacées; t. lisse, trigone sup., presque nue, munie de gaines lâches et renfl.; soies tr. nombr., long. de $2-3 \mathrm{~cm}$.; achaine brun, obovale, peu ou point mucroné . . . . . . E. vaginatum L. 1378 Marais tourb. - Avr.-Jn.

+ Épillets en omb. munie de bract., inég., pédonc. plus ou moins penchés après la flor.; t. feuillées. 
Pédonc. lisses et gl.; soies long. de $3-4 \mathrm{~cm}$.; achaine brun, ellipt. lanc., apic.; f. caul. allongées, lin.-canal., trigones sup.

\section{Marais tourb. - Mai-Jt.}

E. angustifolium Roth. $\mathbf{1 3 7 9}$

Pédonc. scabres ou tom.; soies long. de 1-2 cm.; achaine fauve, arrondi, mutique; f. caul. courtes.

Cap. nombr., 4-12, assez gros, tous penchés après la flor.; pédonc. allongés, scabres et gl.; soies long. de $2 \mathrm{~cm}$.; f. larges, 4-6 mm., planes, scabres, à pointe trigone; souche fibr. gazonn.

Marais, tourb., surtout calc. - Mai-Jt.

E. latifolium Hoppe 1380

Cap. peu nombr., 2-6, petits, à peine pench., à pédonc. courts, rudes et tom.; soies longues de $10-100 \mathrm{~mm}$.; f. lin. étr., canal. puis trigones, presque lisses; souche long. ramp.

Marais, tourb. - Mai-Jt.

E. gracile Koch. 1381

\section{GenRe 494. - SGIRPUS L.}

+ Épillets plus ou moins nombr. formant une inflor. term. ou lat. munie d'une ou de plus. bract. foliacées.

X Inflor. term., entourée de bract.; $t$. trigones au moins au sommet, munie de $\mathrm{f}$; ; pl. viv.

= Pl. grêle, peu élevée, $5-30 \mathrm{~cm}$. ; f. étr., 1-3 mm.; inflor. en épi distique, oblong, compr., brun-roussàtre; 1 seule bract.; achaine ov. compr., mucr., entouré de 3-6 soies.

Marais, pelouses hum. - Mai-At.

S. compressus Pers. 1382

$=$ Pl. robustes, élevées, $50 \mathrm{~cm}$. à $1 \mathrm{~m}$.; f. larg., 3-15 mm.; inflor. en pan. ombelliformes ou en glom.; 2-ว̆ bracț. long.; achaines mucr.; 6 soies scabres.

Épillets gr., $12-40 \mathrm{~mm}$., brun roussâtre, en omb. simple ou 1 seul glom.; écailles bifides et aristées; achaine brun, assez gros, long. $3 \mathrm{~mm}$., ov. trig., rar. compr.; 3 stigmates, rar. 2.

Marais, bord des eaux. - Jn-At.

S. maritimus L. 1383

Épillets pet., 3-6 mm., vert noirâtre, en pan. composée tr. ample; écailles obt. ent.; achaine jaunâtre, pet., long. $1 \mathrm{~mm}$. , ov. trigone; 3 stigmates. . . . . . . . S. silvaticus L. 1384

Prés hum., fossés. - Mai-At.

$\chi$ Inflor. paraissant lat. par le prolongement d'une bract. qui semble continuer la tige arrondie ou trigone munie à la base de gaines à limbe nul ou peu développé.

Q. Pl. viv. élevées, à souche ramp.; achaines lisses, mucr.; écailles florales émarg.-mucr., cil.; épillets ov., gros, nombr., fasc.; t. munies à la base de gaînes souvent prolongées en limbe court.

- T. ent. cyl.; inflor. non ou peu dépassée par la bract.; 50-6 soies scabres dépassant l'achaine; gaines prolongées ou non en limbe court en alène.

T. robustes, élevées, 1-3 m., vertes; inflor. en omb. assez lâche ou en tête; écailles lisses, non ponctuées; 3 stigmates; achaine obovale subtrigone ... . . S. lacustris L. 1385 Bord des eaux, rivières, étangs. - Mai- $\Lambda$ t.

T. peu robustes, peu élevées, $50 \mathrm{~cm} .-1 \mathrm{~m}$.; glauques; inflor. ord. en tête assez dense; écailles ponctuées-rudes; ord. 2 stigmates; achaine obovale, convexé bombé.

S. Tabernæmontani Gmel. 1386

Marécages. - Mai-At. 
- T. ent. trigones à faces planes; inflor. en omb. un peu làche ou compacte, long. dépassée par la bract.; $3-6$ soies scabres plus courtes que l'achaine obovale plan-convexe; gaine sup. term. en limbe coart foliacé; 2 stigmates. . . S. triqueter L. 1387 Bord des rivières. - Jt-Sept.

Q Pl. ann. basses, à racine fibr.; achaines ridés ou striés; écailles florales striées-plissées, ent., mucr.; épillets ov. ou ov. oblongs, pet. ou assez gros. peu nombr., sessiles en glom. paraissant lat., long. dépassé par la bract.; gaine inf. term. ou non en limbe en alène ou sét.; t. fasc. cyl., striées.

Épillets assez gros, ov. oblongs, roussâtres, peu nombr., 2-12 ; achaines noirs, trigones-mucr., assez gros, 1 1/2 mm., ridés en travers; bract. en alène tr. long. égalant presque la t.

Bords des mares et des étangs. - Jt-Sept.

S. supinus L. 1388

Épillets pet., 3-4 mm., ov. verdâtres, tr. peu nombr., 1-3; achaines bruns, obovales subtrigones, pet., $3 / 4 \mathrm{~mm}$., striés en long; bract. sét. plus courte que la t. . . S. setaceus L. 1389 Sables hum. - Jn-Sept.

+ Épillet solit., term., dress., sans bract. foliacées.

T. rameuses, couchées-radicantes ou flottantes convexes-canal., feuillées jusqu'au sommet; épillets verdàtres, pet., term. de longs pédonc. axill.; 2 stigmates; achaine blanchàtre, obovale-compr., lisse, mucr.; soies nulles . . . . . . S. fluitans L. 1390 Mares tourb., fossés. - Jn-Sept.

T. simples, dress., jamais flottantes, cyl. ou tétr., nues, munies à la base de gaines tronq. ou prolongées en pointe foliacée; épillet term.

م T. tr. grêles, capill., tétr.-sill., courtes, 4-20 cm., épillet tr. pet., brun., lanc.; achaine obovale-oblong, blanchâtre, strié en long, term. par un petit mamelon conique; $3-6$ soies tr. courtes, cad.

Bord des étangs, des rivières. - Jn-Sept.

S. acicularis L. 1391

T. grêles ou assez épaisses, non capill., assez élevées, 10-80 cm.; épillet pet. ou assez gr.

ち Épillet pauciflore, 2-6 fl., ov.; écaille inf. gr., embrass., aussi long. ou presque que l'épillet; achaine trigone-mucr. sans renfl. conique; 3-6 soies scabres ; 3 stigmates.

Souche à rhizomes filif. traçants; gaines basilaires tronq., sans pointe foliacée; écailles brunâtres, mutiques, l'inf. plus courte que l'épillet; achaine grisàtre. . S. pauciflorus Lightf. 1392 Marécages, sables hum. - Mai-At.

Souche dens. gazon.; gaine basilaire sup. term. en pointe verte; écailles roussâtres, l'inf. mucr., aussi longue que l'épillet.

Landes tourb. - Mai-At.

S. cæspitosus L. 1393

む Épillets multiflores, brun. ov. ou oblong; écaille inf. n'atteignant pas le milieu de l'épillet; achaine couronné par la base renfl. conique du style; 4-6 soies scabres.

$\odot$ Souche courte, gazonn.; pl. peu élevées, $8-40 \mathrm{~cm}$.; achaines lisses. Epillet ov. obt., long 4-6 mm.; écaille inf. demi-embrass.; 2 stigmates; achaine fauve, obovale compr. dépassé par les soies; ann. . . . . . . . . S. ovatus Roth. 1394 Grèves sabl., étangs desséchés. - Jn-Sept.

Épillet ov. oblong, long. 6-13 mm., souvent vivipare; écaille inf. embrass.; 3 stigmates; achaine brun., obovale trigone, dépassant les soies; viv. . . S. multicaulis Smith. 1395 Landes hum., marécages. - Jn-At. 
Souche ramp. stolon.; pl. assez élevées, $130-80 \mathrm{~cm}$; 1-2 gaines brun. tronq. horiz. au sommet; épillet oblong, long. 8-20 mm. ; 2 stigmates; achaine obovale-compr., jaunâtres, lisses, dépassés par 4-6 soies.

Écailles obt. ou subaig., les 2 inf. stériles embrassant chacune la moitié de l'épillet; t. cyl. compr., compress.; achaine jaunâtre, lisse, petit, long. 1 1/2-2 mm. . S. palustris L. 1396 Lieux hum., marécages. - Mai-Sept.

Écailles obt., l'inf. seule stérile, large, suborb. embrass. toute la base de l'épi; t. cyl., grêles, fermes; achaine brun., fin. ponctuée, assez petit, long. 2 1/2 mm. S. uniglumis Link. 1397 Lieux hum., marécages. - Mai-At.

\section{Genre 493. - CAREX L.}

+ T. term. par un épi simple ou composé d’épill. androgyns; 2 stigmates.

× Épi simple solit. term., formé d'un seul épillet à plus. fl.; utric., plans convexes.

= Epi dioïque, le mâle lin., le fem. oblong ou ovale; écailles fem. persist., rouss.

Souche ramp. stolon.; t. cylind., lisse; f. filif., lisses; éc. fem. obt.; utric. étalés à bec court; achaine ov. biconvexe.

Marais tourb. - Mai-Jt.

C. dioica L. 1398

Souche fibr. gazonn.; t. trigone, scabre; f. sét., rudes; écailles fem. ov. aig.; utric. tr. étalés ou réfléchis, oblongs-lanc., peu nervés à bec long; achaine oblong plan convexe.

Marais tourb. - Mai-Jt.

G. Davalliana Sm. 1399

= Épi androgyn, oblong-lin., mâle au sommet; écailles fem. cad., oblong-obt.; souche fibr., gazonn.; t. cyl., lisse; f. sét., lisses excepté au sommet; utric. étalés puis réfléchis, oblongs fusiformes, lisses, sans nervures, à bec court; achaine oblong, biconvexe . . . . . . . . C. pulicaris L. 1400 Marais tourb. - Mai-Jn.

X Épi composé ou panicule spiciforme, formée de plus. épillets multiflores, ord. androgyns.

Q Épillets agglom. en tête glob. compacte verdâtre ou jaunâtre, aussi large que longue, entourée et long. dépassée par un invol. de 2-ǒ bract. foliacées allongées; épill. mâles à la base à écailles et utric. lin.-lancéol. en alène; t. feuillée triquètre; souche fibr.

Grèves sabl., étangs desséchés.

G. cyperoides L. 1401

Q. Épillets en épi ovale ou oblong ou en panicule spiciforme.

- Souche à rhizome long. traçant; utric. bordés d'une aile dentic.cil., atténués en bec allongé.

Épill. nombr., les uns unisexuels, les autres androgyns, mâles au sommet, en long épi interr. ou lobé; bract. inf. dépassant l'épillet; f. larg., 2-5̆ mm.; rhizome épais.

Épill. sup. et inf. fem., les interm. mâles, rar. androgyns; utric. bordés depuis la base d'une aile étr. dentic.

Prés maréc. - Mai-Jt.

G. disticha Huds. 1402

Épill. sup. mâles, les inf. fem., les interm. androgyns; utric. bordés à partir du milieu d'une aile large, dentic.

C. arenaria L. 1403

Terrains et bois sabl. - Mai-At.

Var. à t. grêles, f. étr., épillets inf. mâles à la base, ord. stériles, à utric. allongés (Compiègne, Laigue). (C. Reichenbachii Ed. Bonnet). 
Épill. peu nombr., ord. 3-8, tous androgyns, màles à la base, rappr. en épi assez dense; bract. inf. plus courte que l'épill.; 1. étr., 1-3 mm.; rhizome grêle; utric. à aile étr.

Épill. assez gr., fauves, 5̌-12, en épi ov.. ou oblong.-lanc.; écailles oblongues-lanc., acum.; utric. bordés d'une aile étr.

Terrains et bois sabl. - Mai-At.

C. ligerica Gay 1404

Épill. assez pet., roussâtres, 3-6, en épi ov.-oblong court; écailles ov. acum.; utric. bordés dans la moitié sup. d'une aile tr. étr. . . . . . C. Schreberi Schrank 1405

Pelouses sabl. - Avr.-Jn.

- Souche courte, gazonn. ou à courts stolons.

Q Épill. androgyns, mâles au sommet, fem. à la base.

○ Inflor. en pan. ou en épi roussâtre ou brunâtre; écailles larg. ov.-aig. scar. aux bords; utric. pet., à bec égalant l'écaille.

む Inflor. en pan. étalée dres.; écailles larg. scar.; utric. à peine striés à la base ov. triang., plans convexes; f. larges, $4-6 \mathrm{~mm}$. ; t. robuste, triquètre, à faces planes; souche gazonn.

Marais. - Mai-Jt.

C. paniculata L. 1406

†. Inflor. en pan. étr. ou en épi; écailles étr. scar., utric. fort. nervés sur le dos; f. étr., 1-3 mm.; t. grèle, trigone, à faces convexes.

Inflor. en pan. étr., un peu làche inf.; utric. ov.-triang. à bec étr., biconvexes, fort. nervés sur les 2 faces; souche gazonn., non traçante, surmontée des nervures persist. des f. détruites.

Marais tourb. - Mai-3t.

C. paradoxa Willd. 1407

Inflor. en épi oblong, dense; utric. ov. lanc. à bec élargi à la base, plans et lisses sur la face int., convexes et nervés sur le dos; souche un peu traçante, à peine gazonn.

C. teretiuscula Good. 1408

Marais tourbeux. - Mai-Jt.

Inflor. en épi verdâtre ou fauve tr. pâle; écailles ov. mucr., rousses avec nervure verte, ou totalement vert pâle; utric. assez gros, à bec dépassant l'écaille; souche gazonn.

๑ T. robuste, compressible, triquètre, à faces concaves, à angles ailés tr. scahres; f. larges, 4-8 mm.; épi gros, ord. dense; utric. à $5-7$ nervures saillantes sur chaque face.

Bord des eanx. - Mai-Jt.

C. vulpina L. 1409

- T. grêle, non compressible, triquètre, à faces planes, à angles aigus et rudes sup.; f. étr., 2-3 mm.; épi grêle ou moyen; utric. presque lisses.

Épi ord. dense; utric. à la fin étalés en étoile; achaine aussi large que long.

Utric. verdâtres, assez gr., long. 5 mm., ov. lanc. à bec long; ligule ov. lanc., à bord antérieur tronqué en ligne droite.

Lieux incultes. - Mai-Jt.

C. muricata L. 1410

Utric. brun noiràtre, pet., $31 / 2 \mathrm{~mm}$., larg. ov. à bec court; ligule ov. obt. à bord antérieur éch. en courbe arrondie.

C. Pairæi F. Schultz 1411

Lieux secs, bois. - Mai-Jt.

Épi tr. làche, interr. à la base; utric. étalés-dress., assez gr. 5 mm., non diverg., verdâtres, ov. lanc. à bec long; achaine plus long que large; ligule ov. obt. à bord antérieur éch. en courbe arrondie........ G. divulsa Good. 1412

Lieux incultes, bois. - Mai-Jt. 
Épill. androgyns, fem. au sommet, mâles à la base.

ㅇ Epill. écartés, disposés en épi plus ou moins interrompu, verdâtre, rar. brunâtre.

Utric. assez pet., long. 3 1/2 mm., atténués en long bec scabre bidenté; t. obscur. trịone, peu rude, sauf entre les épillets verdâtres ou brunâtres.

Épi tr. allongé, à 5̆-10 épillets ov. tr. écảrtés, les inf. à long. bract. foliacée dépassant la t.; utric. verdâtres, dress. à bec dépassant peu l'écaille. . . . . . . C. remota L. 1413 Lieux hum., ruiss. - Mai-Jt.

Épi court, à 2-5 épill. glob., peu écartés, à bract. scar. courtes non foliacées ord. dépassées par la t.; utric. verdàtres ou brunâtres, à la fin étalés en étoile, à bec dépassant beaucoup l'écaille .......... C. echinata Murr. 1414 Marais tourb. - Mai-Jt.

Utric. pet., $21 / 2 \mathrm{~mm}$., atténués en bec court, lisse, tronqué; t. triquètre et scabre sup.; épill. blanchâtres, ov., peu écartés, à bract. scar. courtes, rar. foliacée - C. canescens L. 1415 Marais tourb. souvent sil. - Mai-Jt.

† Épill. rappr., formant un épi continu, rar. un peu interrompu à la base, brun ou fauve.

T: triquètre, scabre; épi allongé de 6-12 épill. oblongs étr., à écailles ov. arrondies; utric. bruns, oblongs, étalés à la mat., non ailés, multinervés, atténués en bec tronq. dépassant beaucoup l'écaille ov.-obt. scar. aux bords. C. elongata L. 1416 Marais tourb. souvent sil. - Mai-Jn.

T. obscur. trigone, scabre sup.; épi court, de 4-8 épill. obovales élargis, à écailles ov. lanc.; utric. verdâtres ou brunâtres, dress:, larg. ailés dentic., atténués en bec bidenté égalant à peine l'écaille ov. lanc. à peine scar. aux bords. C. leporina L. 1417 Pelouses et bois hum. - Mai-At.

+ T. portant plus. épis distincts, ord. unisexuels.

Epis naissant, les uns au sommet de la t., 2-4 épis fem. subglob. paucifl., rappr. de l'épi mâle solit. term., les autres fem. $1-3$, solit. sur de longs pédonc. basilaires filif.; 3 stigmates; utric. gris fauve, pubérulents, obovales-trigones, fort. nervés, à bec tr. court dépassant l'écaille acum. fauve scarieuse.

C. Halleriana Asso 1418

Coteaux calc. - Avr.-Jn.

| Épis naissant normalement tous sur la t., de sexe différent, le term. ou les sup. mâles, les inf. fem.

II 2 stigmates; utric. gl. et achaines ov. compr.; bract. non engainantes.

- Souche gazonn.; f. et bract. plus courtes que l'inflor.; utric. imbriq. sur 8 rangs, nervés jusqu'au sommet; écailles brun., obt.; 1-2 épis mâles. . . . . . . . C. stricta Good. 1419 Marais, bord des eaux. - Avr.-Jn.

- Souche ramp. stolon.; f. souvent aussi long. que l'inflor.

Utric. striés seulement à la base; écailles noirâtres tr. obt.; 1 seul épi mâle, rar. 2 ; bract. plus courtes que l'infl.

Marais tourb. souvent sil. - Mai-Jt.

C. vulgaris Fries 1420

Utric. faibl. nervés; écailles brun., lanc.; 2-ł épis mâles; bract.

inf. plus long. que l'inflor.. . . . . . . C. acuta L. 1421 Marais, bord des eaux. - Avr.-Jt.

II 3 stigmates; utric. et achaines plus ou moins trigones.

$\times$ 2-כ épis mâles, tr. rar. un seul; utric. gl. ou poil. 
$=$ Utric. ov.-compr. plus ou moins garnis d'aspérités, sans nervures, à bec tr. court égalant l'écaille. . . . . C. glauca Murr. 1422 Lieux hum. - Avr.-Jn.

$=$ Utricules convexes ou subtrigones à bec tr. distinct ord. plus long que l'écaille.

a Epis mâles brun noir ou rougeâtres; utric. bruns ou grisâtres; pl. gl.

- Utric. gl., nervés; épis mâles 2-3 cyl.-ellipt. brun foncé.

Ecailles des épis mâles toutes lanc. aristées; utric. ov. conique, à faces convexes, à bec bifide; ne dépassant pas l'écaille lanc. aristée; f. larges, 6-15 mm. . . C. riparia Curt. 1423 Bord des eaux. - Avr.-Jn.

Écailles inf. des épis mâles oblongues-obt.; utric. ov., compr., à bec bidenté, dépassant l'écaille lanc. acum. ; f. assez larges, 4-8 mm. . . . . . . G. acutiformis Ehrh. 1424 Bord des eaux. - Avr.-Jn.

- Utric. tom., ov. subtrigones, renfl., à bec bidenté.

T. grêle, à peine trigone, lisse ou rude; f. filif. canal., étr., 1-1/2 mm., scabres; épis mâles, 1-3, grêles, lin.-oblongs; épis fem. 2-3, oblongs, sessiles ou brièv. pédonc., longs de 1 1/2$21 / 2 \mathrm{~cm}$.; écailles ov., brunes, mucr.; utric. longs de $4 \mathrm{~mm}$.

Marais tourb. profonds. - Mai-At.

C. filiformis L. 1425

T. robuste triquètre, à faces planes, ou canal., rude; f. planes, triquètres au sommet, larges, 3-3 1/2 mm., scabres; épis mâles, 3-4, épais, oblongs-aig.; épis fem., 2-3, cyl., sessiles, les inf. pédonc., longs de $3-6 \mathrm{~cm}$.; écailles brièv. lanc., brunes, mucr. aristées; utric. longs de $5 \mathrm{~mm}$.

Marais tourb. profonds, fossés. - Mai-Jt.

C. evoluta Hartm. 1426 .

Q Épis mâles fauve pâle ou jaunâtres, grêles, lin. ou oblongs; utric. vert fauve, à la fin roussâtres ou jaunâtres à bec bifide dépassant l'écaille.

Bract. inf. long. engainante; utric. non renfl. en vessie, vel. ou à. bords dentic.-scabres.

Utric. vel.-hér., ov. coniques, nervés, long. $6 \mathrm{~mm}$; épis fem. oblongs-cyl., à écailles pub. long. aristées; souche long. rampante; f. et gaines poil. ou gl: (var. hirtæformis C. et G.).

C. hirta L. 1427

Lieux hum. sabl. - Mai-At.

Utric. gl., ellipt.-lanc., à bords dentic.-scabres, peu nervés, long. $10 \mathrm{~mm}$.; épis fem. ov., à écailles obt. ou tronq.; souche. gazonn., compacte; f. gl., raides, dépassant long. la t.; gaines gl. . . . . . . C. hordeistichos Vill. 1428. Lieux hum. argil. - Mai-Jt.

Bract. jamais engainantes; utric. renfl. en vessie, gl., nervés.

F. planes, vertes, larges, 4-8 mm., égalant la t.; utric. dress., long. $6 \mathrm{~mm}$., ov. coniques, insensibl. atténués en long bec: bifide; t. triquètre, à angles aig. et scabres.

Bord des eaux. - Mai-Jt.

C. vesicaria L. 1429 .

F. canal., glaucescentes, étr., $2-4 \mathrm{~mm}$., dépassant ord. la tige; utric. étalés-diverg., long. $4 \mathrm{~mm}$., en vessie subglob., brusq. atténués en bec fin bidenté; t. trigone, à angles obt. et lisses.

Bord des eaux, fossés. - Mai-Jt.

C. rostrata With. 1430

$\times 1$ seul épi mâle, tr. rar. 2.

Utric. pubescents ou tomenteux. 
む Bract. inf. non engainante; épis courts et rappr.; utric. à bec tr. court.

$\odot$ Souche gazonn. sans stolons; épis fem. ov.-subglob.

Ecailles fem. noirâtres, plus courtes que l'utric. nervé, plan à la face int.; épi màle noirâtre, en massue; bract. inf. membr. aristée; t. dress., égalant environ les f. C. montana L. 1431 Coteaux calc. - Avr.-Jn.

Écailles fem. brunes, égalant l'utric. sans nervures et biconvexe; épi mâle brun fauve, lanc.; bract. inf. foliacée; t. arq. décombantes plus longues que les f. . C. pilulifera L. 1432 Bois secs sabl. - Avr.-Jt.

$\odot$ Souche ramp. stolon.; épis fem. ov.-oblongs; utric. sans nervures. Ecailles obt., cil. égalant l'utric.; épi màle en massue; bract. inf. membr., noiràtre, courte, aristée; t. peu élevées, faibles, ascend., subtrigones . . . . . G. ericetorum Poll. 1433 Coteaux sees sabl. - Avr.-Jt.

Écailles mucr., non cil. plus courtes que l'utric.; épi mâle lanc.; bract. inf. foliacée, assez long., étalée; t. assez élevées, dress., triquètres. . . . . . G. tomentosa L. 1434 Prés et bois argil. ou calc. - Avr.-Jt.

ち Bractée inf. distinctement engainante.

Epi mâle épaissi en massue, souche ramp. ou gazonn.; épis fem. denses; utricules sans nervures, à bec court.

Souche long. rampante stolon.; utric. rétrécis en bec court, à peine émarg., égalant l'écaille; achaine muni au sommet d'une cupule blanchàtre tronquée; f. ord. plus courtes que la t.

Pelouses sèches. - Avr.-Jt.

G. præcox Jacq. 1435

Souche gazonn.; utric. rétrécis en bec assez long, bidenté, dépassant l'écaille; achaine muni au sommet d'une colonne en forme de mucron; f. ord. plus long que la t.

Prairies tourb. bois hum. - Avr.-Jt.

C. polyrrhiza Wallr. 1436

Épi màle lin. ou oblong.; souche gazonn.; épis fem. lâches ou pauciflores; utric. à bec tr. court.

T. non cachée par les f. planes, larges, 2-4 mm., et les égalant; épis rapprochés, comme digités, le màle lin., brun pâle, dépassé par l'épi fem. sup. lin. à ว̆-8 fl.; utric. verdâtres, sans nervures, égalant l'écaille rougeâtre, tronq.-mucr. ; bract. rougeâtres. . . . . . . . . C. digitata L. 1437 Bois montueux calc. - Avr.-Mai.

T. cachée dans les f. longues, filif., canal., étr., $1 \mathrm{~mm}$., beaucoup plus long. qu'elles, épis espacés, les fem. tr. pet., à 2-4 fl., le mâle oblong, blanchàtre dépassant l'épi fem. sup.; utric. gris fauve, nervés, égalant à peine l'écaille blanchâtre suborb.-mucr.; bract. membr. blanchàtres.

Coteaux calc. - Avr.-Mai.

G. humilis Leyss. 1438

O Utric. glabres.

Epis fructif. peu denses ou lâches, grêles ou pauciflores.

Utric. ov.-renfl. ou subglob. à bec court; écailles ov.-obt., apiculées; souche ramp. stolon.

Épis fem., 1-3, ov. ou oblongs, rappr. et subsessiles ou l'inf. écarté pédonc.; utric. ov. subglob., roussâtres, luisants, nervés, à bec assez court bidenté; écailles rougeàtres, ov. apiculées ; épi mâle lanc., fauve; t. peu élevée, 10-30 cm., grêle, triquètre, rude au sommet; f. étr., 1-2 mm., carénées.

Pelouses sèches, sabl. - Avr.-Jt.

C. nitida Host. 1439 
Épis fem., 2-3, oblongs cyl., assez lâches, écartés, pédonc.; utric. ov.-renfl., olivâtres, peu nervés, à bec court, tronq.; écailles brun-rougeâtres, ov.-lanc.; épi mâle oblong-lin., brunâtre ; t. assez élevée, $20-50 \mathrm{~cm}$., subtrigone, lisse; f. assez larges, 2-4 mm., planes, glaucescentes. C. panicea L. 1440 Prés et bois hum. - Mai-Jn.

Utric. à bec long ou long. atténués en bec; écailles ov. lanc. aig. ou acum.; souche gazonn. ou ramp.

E Épis fem. ov., courts, pauciflores, 3-6 fl. dress.; utric. ov.renfl., gros, long. $8 \mathrm{~mm}$., nervés, à bec long bidenté; écailles ov.-mucr.; souche gazonn. . . C. depauperata Good. 1441 Bois, forêts. - Avr.-Jn.

Épis fem. lin. allongés, multiflores, ord. pench.; utric. petits, 3 1/2-3 mm.; écailles lanc., aig. ou cuspidées.

Utric. pet., $31 / 2 \mathrm{~mm}$., trigones fusiformes, nervés, insensibl. atténués en bec peu distinct; écailles fem. lanc.-aig.; f. larges, 4-10 mm.; souche ramp. . G. strigosa Huds. 1442 Bois hum. - Mai-Jt.

Utric. assez gros, long. 5 mm., ov. trigones, sans nervures, brusq. rétrécis en bec long; écailles fem. lanc.-cuspidées; $f$. assez étr., 3-6 mm.; souche gazonn.

Bois hum. - Mai-Jt.

G. silvatica Huds. 1443

† Épis fructif. denses, à utric. fort. imbriq.

I Epis fructif. 3-6 cyl. allongés; f. larges 5-15 mm.; pl. robustes, élevées.

II Épis fem. arq.-pend. à la mat.; souche gazonn.

Epis fem. rappr., assez longs, $4-6 \mathrm{~cm}$., à écailles vertes, lin. en alène; utric. ov.-lanc., devenant réfléchis, nervés, atténués en long bec bifide; $t$. à faces concaves, scabre; f. larges, 6-10 mm., dépassant la t.. . G. Pseudo-Cyperus L. 1444 Bord des eaux. - Mai-Jt.

Épis fem. espacés, tr. longs, 10-20 cm., à écailles brun., lanc. mucr.; utric. ellipt.-trigones, dress.-étalés, sans nervures, brusq. rétrécie en bec court émarg.; t. lisse; f. tr. larges, 8-15 mm., plus courtes que la tige.

Bois hum. - Mai-Jt.

C. pendula Huds. 1445

II Épis fem. long. 3-ð cm., dress., ou l'inf. penché; souche ramp.; écailles rousses, lanc.-cuspidées; utric. ov. trigones, long. $5 \mathrm{~mm}$., dress., nervés, atténués en bec assez long bifide; $t$. trigone lisse; f. assez larges. 4-10 mm.

Bois tourb.-silic. - Nai-Jt.

C. lævigata Smith 1446

Épis fructif.; 1-4, oblongs ou ov. subglob., ord. dress.; f. étr., 1-6 mm.; pl. assez robustes.

o+ Épis fem. espacés et dress.; utric. nervés.

Epi fem. oblong, long. 2-3 cm.; écailles brun rougeâtres, mucr.; utric. ov. trigone, à bec scabre cil., bifide; ligule oblongue . . . . . . . . . C. distans L. 1447 Marécages, prés hum. - Mai-Jt.

Épi fem. ov. oblong, long. 1-2 cm.; écailles brunes bordées de blane, ov. aig.; utric. ov.-renfl. à bec lisse, bifide; ligule courte et tronq. . . . . C. Hornschuchiana Hoppe 1448 Prés tourb. - Mai-Jt.

o+ Épis fem. rapprochés de l'épi màle, ou l'inf. écarté et pédonc.; épi mâle fauve; souche gazonn. 
+ F. et gaines pub.; épis fem. courts, à la fin penchés, tous pédonc., long. dépassés par la bract. inf. à peine engainante; utric. ov. obt. sans nervures ni bec, égalant l'écaille.

Bois frais, prés. - Mai-Jn.

C. pallescens L. 1449

+ F. gl.; épis fem. dress., les sup. sessiles, l’inf. souvent écarté et pédonc.; utric, nervés, term. en bec, dépassant l'écaille.

X Utric. ov. trigones, étalés, verdàtres, à bec bifide bordés de cils raides; écailles roux pâle, ov.-mucr., dentic.-cil.; bract. étalées. . . . . . C. Mairii Coss. et G. 1450 Marécages. - Mai-Jn.

X Utric. ov.-renfl., étalés ou réfléchis, jaunâtres, à bec bifide non cil.; écailles ov. lanc., ni mucronées ni cil.; épis fem. ov.-subglob. à bract. devenant étalées réfléchies.

Utric. obovales, assez gros, כૅ mm., réfléchis, à bec long courbé en bas; t. dressée, assez élevée, 20-50 cm., dépassant les f. . . . . . . . . C. flava L. 1451 Marais. - Mai-Jt.

Utric. subglob., petits, $3 \mathrm{~mm}$., étalés, à bec court et dr.; t. courte ou ascend., peu élevée, $3-25 \mathrm{~cm}$., souvent égalée ou dépassée par les f.. . . . . C. Ederi Ehrhart 1452 Marécages sil. - Avr.-0ct.

\section{FaMille 111. - GRAMINÉES}

+ Epill. mon., les épill. mâles et les épill. fem. formant deux inflor. distinctes; les mâles biflores, une pan. term., les fem. uniflores, des épis axill., sessiles, cyl., enveloppés dans de larges bractées foliacées ; stigmates longs de 12-20 cm........ ZEA 496

+ Epill. hermaphrodites ou polygames, tous semblables ou presque semblables, constituant une seule inflor.

× Epill. en pan., pas de glumes ; glumelles égales, mutiques, comprimées en carène vel.-cil.; pl. à nœuds vel., à f. scabres; ligule courte et tronq................. LEERSIA 497

$\times$ Epill. en pan., munis de glumes ou en épis quelquefois dépourvus de glumes.

$=$ Epill. non enfoncés dans des excavations du rachis, ou rar. enfoncés dans les excavations, mais inflor. en épi et arête genouillée.

a Une seule fl. fertile, rar. plus. fl., alors pan. et de longs poils dans les fleurs ou épi compact.

- Epi simple ou pan. spiciforme, rar. pan. allongée, ram. lobée, deux petites écailles cil. à la base de la fl.; glumelles gl. et luisantes.

Epi filif.; to capill.; glumelles vel. cil., arrondies sur le dos mutiques........................... MIBORA 498

Epi non filif. ou pan.

¿ Epill. uniflores ; pas de soies, ni d'aiguillons; glumes carénées.

t Pan. spiciforme peu serrée; glumelles stériles arist.; la sup. à arête tordue, glumes inég.; 2 ét. ANTHOXANTHUM 499

ち Pan. allongée, ram. ou spic., dense, glumes presque égales ; 3 ét.

- Pan. allongée, ram., lobée, étalée à la flor. puis resserrée ; 2 pet. écailles cil. à la base de la fl.; glumelles gl. et luisantes; glumes à carène non ailée.

PHALARIS (part.) 500

- Pan. spiciforme dense.

喽 Pan. ov. ou ov.-oblongue; glumes à carène ailée sup.

Pan. cylindrique. 
ㅇ Ligule remplacée par des poils; glume et glumelles uninervées, mutiques. . . . . . . GRYPSIS 501

\& Ligule membr.; glumes trinervées, mucr., ainsi que les glumelles.

2 glumelles, dépourvues d'arète ; glumes libres mucr. ou arist. . . . . . . . . PHLEUM 502

1 seule glumelle à arète dorsale, insérée au-dessous du milieu; glumes plus ou moins soudées à la base.

ALOPEGURUS 503

'o Epis ou pan. spic., munis de soies ou d'aiguillons, à épill. uniflores ou pan. spic. dense à épill. multiflores.

Pan. spic. oblongue ou ov., assez dense, bleuàtre; épill. à 2-3 fl. hermaphrodites; ligule membr. . SESLERIA 504

Pan. spic. cyl.; une seule fl. hermaphrodite, accomp. d'un rudiment stérile; ligule poil.

Glume sup. hér. sur le dos de 5-7 rangées d'aiguillons crochus; f. courtes bordées de cils raides; t. genouillées aux nouds.................. TRAGUS 505 Epill. munis d'un invol. unilat. de soies raides et scabres.

SETARIA 506

- Epis rappr., digités ou pan.

Inflor. soit en épis, ligule membr. ou poil., rar. nulle, soit en pan., ligule poil.

II Pan.; épill. à 1 fl. hermaphrodite ou épis.

| Pan.; à épill. à'1 fl. hermaphrodite, accompagnée d'une fleur màle stérile; ligule poil. . . . . . PANICUM 507 | Epis composés ou digités.

‡ Epis denses, nombr., alt., unilat.; ligule nulle.

$\ddagger$ Epis digités.

ECHINOGHLEA 508

+ Ligule membr......... DIGITARIA 509

+ Ligule poil.

Glumelle mutique ou mucr.; glumes plus courtes que les fl.; pas d'arète .......... GYNODON 510 Glumelle inf. long. arist. à arète genouillée; glumes plus longues que les fl., munies de longs poils blancs.

ANDROPOGON 511

II Pan. à épillets multiflores munis de longs poils soyeux; ligule poil.; glumelle inf. larg. acum. . . . . . ARUNDO 512

F Inflor. en pan.; ligule nulle ou membr.

$\times$ Glumelles membr., herb., mutiques ou arist., à arête non plumeuse.

Fl. entourées de longs poils presque aussi longs que les glumes, à arête dorsale ou dans l'échancrure.

CALAMAGROSTIS 513

Fl. sans poils ou à poils courts, mutiques ou à arêtes dorsales ou sous le sommet.. . . . . AGROSTIS 514

$X$ Glumelles devenant coriaces à la mat., mutiques ou à long. arête term. plum.; glumes presque égales.

ơ Glumes concaves; glumelle inf. enroulée à sommet aristé; arète tr. long., tordue inf., artic. à la base et plum. dans la partie sup................ STIPA 515

ơ Glumes canal.; glumelle inf. concave, mutique.

MILIUM 516

$\sigma$ Plus. fl. fertiles, quelquefois munies de poils courts.

- Glumelle inf. arist. à arète dorsale, genouillée et tordue; rar. pet. arète dr. naissant dans l'éch., ou glumelle non arist. et glumes plus grandes que les fleurs. 
Epill. pet., $2 \mathrm{~mm}$. non arist.; glumes obt. dépassant beaucoup la fl. sup. stipitée; glumelle inf. tronq., subtrilobée, trinervée, la sup. bicar. . . . . . . AIROPSIS 517

Epill. arist. ou gr., $1 \mathrm{~cm}$. et plus, non arist.

む Arète dorsale ord. genouillée.

$\odot$ Inflor. en pan.

Glumelle des fl. fertiles long. arist.

ㅇ Fl. sessiles; pl. ann., pet......... AIRA 518

† Fl. inf. sessile, les sup. stipitées.

Glumelle inf. portant au-dessus de sa base, sur le dos, une arète dr. artic. et munie d'une petite collerette de poils au milieu, un peu renflée en massue au sommet.

GORYNEPHORUS 519

Glumelle inf. à arète ni poilue, ni en massue.

\$ Glumelle tronq., dentée au sommet.

F Glumelle bicuspidée ou bifide.

DESCHAMPSIA 520

Glumes peu inég.; caryopse velu au sommet, sill.; glumelle quelquefois mutiques. ..... AVENA 521

Glumes tr. inég.; caryopse oblong, gl., non sill.

TRISETUM 522

Glumelle des fl. màles seule long. aristée ; celle des fl. fertiles lég. arist. ou non ; pl. viv.

Caryopse ellipt., canal.; fl. sessiles; l’inf. màle, la sup. fertile, brièv. arist.; glumes tr. inég.; arète naissant vers le quart inf. de la glumelle. . ARRHENATHERUM 523

Caryopse oblong, convexe, non sill.; fl. sup. måle péd.; l'inf. fertile subsessile et mutique, arête naissant sous le sommet de la glumelle; glumes presque égales. HOLCUS 524

- Inflor. en épis ou en grappes; épill. compr. par le côté à 3-10 fl. stipitées.

Epi fragile à la mat.; fl. arist.; caryopse vel. lin.-oblong canal., term. en cupule cil. au sommet; glumes inég. plus courtes que les fl.; pl. ann... . . GAUDINIA 525

Grappe presque simple; fl. non arist., rar. avec une petite arète; caryopse gl., obovale, déprimé et un peu canal. à la face interne lanc. aig.; glumes égales nervées égalant les fleurs; pl. viv. . . . . . . . . DANTHONIA 526

ち Arète droite, pet. dans l'éch. de la glumelle ; épillets à 2-4 fl.;

l'inf. sessile, les autres stipitées; épill. en pan. contractée ou spiciforme; ligule courte, tronq.; pl. viv. KOELERIA 527

- Glumelle inf. arist. à arète term. ou naissant un peu au-dessous du sommet, ou glumelle non arist. à glumes plus pet. que les fl.

II Glumelle ent., obt. ou aig.

I Epillets non tremblotants.

‡ Glumelles égales ou peu inég.

+ Glumes obtuses.

Epillets 3-14 fleurs; glumelle inf. à b̈-11 nervures à sommet obt. ent. ou denté. . . . . . GLYGERIA 528

Epillets biflores; glumelle inf. trinervée, à sommet scar. tronq. denté .......... CATABROSA 529

+ Glumes aiguës.

Ligule membr.; glumes peu inég.; glumelles inf. et sup. se détachant ensemble; styles courts. . . . . P0A 530

Ligule formée de poils courts, entourés d'un faisc. de longs poils; glumes inég.; glumelle inf. cad., la sup. persistant plus longtemps sur le rachis ; styles assez longs. 
‡ Glumelles inég., mutiques, rar. mucr. à 3 nervures ; glumes inég.

Caryopse oblong cyl. non sill.; glumes uninervées aig. plus courtes que les fl. espacées; ligule formée de poils courts.

MOLINIA 532

Caryopse oblons, plan sill.; glumes mutiques égalant les fl., 1-2 inf. fertiles, 1-2 sup. rudim. réunies en massue; ligule membr.............. MELICA 533

Epill. ov. orbic., violacés ou verdàtres, tremblotants sur de longs pédonc. filif. à ว̆-9 fl. dens. imbriq. formant une pan. dressée, ample............... BRIZA 534

II Glumelle acum. aig., bidentée ou bicuspidée.

+ Ligule oblongue, déchirée; épill. à 3-11 fl. persist.; glumes scar. plus courtes que les fl.

Caryopse oblong, déprimé ; glumes presque égales; épill. lin. oblongs, à b-11 fl., long. 1 1/2-2 mm. SCLEROPOA 535

Caryopse oblong, canal.; glumes inég.; épill. agglom., ov.oblongs, à 3-6 fl., long. "̆-6 mm. . . . DACTYLIS 536 .

+ Ligule entière.

$X$ Epill. de deux sortes, les uns fertiles, à 3-7 fl. brièv. arist.; les autres sans glumes, réduits à la glumelle inf. et formant une sorte de bractée ou d'invol. pectiné; glumelle inf. bidentée, arist. dans l'éch. . . . GYNOSU RUS 537

$\times$ Epill. tous semblables.

Glumelle fusiforme en alène, artic., arist. au sommet; épill. oblongs eunéiformes; f. enroulées.. . . . VULPIA 538

Glumelle acum. aig. arist. au sommet ou non arist.; ligule ord. tr. courte, biauriculée, rar. oblongue. FESTUCA 539

Glumelle bidentée ou bifide, arist. au-dessous du sommet ou non arist. . . . . . . BROMUS 540

$=$ Epill. enfoncés dans les excavations du rachis.

$\sigma^{\top}$ Epill. géminés ou ternés sur chaque dent de l'axe de l'épi.

Epill. ternés, les 2 lat. pédic. ou rar. tous sessiles, uniflores avec un pédic.; axe de l'épill. plus ou moins fragile; glumelles à ॐ̀ nervures; ligule courte, tronq. HORDEUM 541

Epill. géminés ou ternés, tous sessiles biflores, la sup. souvent rudim.; axe de l'épill. non fragile. . . . . ELYMUS 542

- Epill. solit. sur chaque dent ou excavation de l'axe.

- Epill. rappr. en épi plus ou moins cyl. et compact; pl. ann.

Epill. contenant chacun 2-3 fl. fertiles; glume. étr., lin. ou en coin, herb. car., acum. ou term. en arète. . SEGALE 543

Epill. contenant 3-ə̆ fl.; glumes larges, coriaces, convexes, plurinervées, tronq., arist. ou obt.

Epi artic. avec la t. et tombant tout d'une pièce à la mat.; glumes et glumelle inf. non car., tronq. et term. chacune par 2-4 arêtes ou dents; pl. vel. . . . EGILOPS 544

Epi continu avec la t. et persist. avec elle; glumes car., tronq. mucr. ou obt.; glumelle inf. car., mucr. ou term. en arète................ TRITIGUM 545

- Epill. disposés en épi lin. ou distique.

o Epill. multiflores, 1 ou 2 glumes; caryopse canal.

† Epi raide, distique, souvent làche; pl. viv. à f. planes.

$\odot 2$ glumes, glumelle inférieure aiguë ou aristée; caryopse vel. au sommet.

Epillets sessiles; glumes presque égales; glumelle inf. mutique ou aristée....... AGROPYRUM 546 Epillets tr. brièv. pédic.; glumes inég.; glumelle inf. arist. 
$\odot 1$ glume, excepté l'épillet term. muni de 2 glumes; glumelle inf, oblongue; caryopse glabr...... LOLIUM 548

t Epi grêle et long, distique ou unilat.; pl. ann. à f. enrouléessét.; glumelle inf. obt.; caryopse gl. . . NARDURUS 549

¿ Epill. uniflores; pas de glumes ; épi grêle, unilat.; épill. sessiles à $1 \mathrm{fl}$. arist.; caryopse gl., lin.-trigone; pl. viv. à souche gazonnante........................ 550

$$
\text { Genre 496. - ZEA L. - Maïs. }
$$

Pl. ann., robuste, 1-3 m., à f. tr. larg., lanc. acum., cil.-rudes; ligule courte, cil.; 3 ét.; caryopses arrondis en rein, durs, jaunes, blancs ou violacés, luisants, disposés sur 8-10 rangs, dans les excavations de

Cult. - Jt-0ct.

\section{Genre 497. - LEERSIA Sw.}

Pl. viv., $50 \mathrm{~cm} .-1 \mathrm{~m}$., à souche stolon.; inflor. en pan. lâche, à ram. flexueux, rudes, soit exserte, àépillets ord. stériles, soit incluse plus ou moins compl. dans la gaine de la f. sup., à épill. ord. fertiles; glumelle inf. trinervée; 3ét. . . . . . . L. orysoides Sw. 1454 Bord des eaux, rivières. - Jt-0ct.

\section{Genre 498. - MIBORA Adans.}

Pl. ann., tr. pet., $3-10 \mathrm{~cm}$., croiss. en touffes ; f. toutes rad., sét.-canal., obl.; ligule oblongue; épi lin. de 4-12 épillets pet., subsessiles, solit; glumes presque égales, oblongues-obt., uninervées, dépassant la fl.; glumelle inf. à 5 nervures; 3 ét. . . . . . M. minima Desv. 1455

Lieux sabl. - Mars-Mai.

\section{GenRe 499. - ANTHOXANTHUM L.}

Pl. viv., gazonn., assez élevée $20-80$ cm., gl. ou vel., à t. simple, dress. ou ascend.; pan. oblongue cyl.; glumelles stériles dépassant d'un quart la fl. fertile; arête sup. dépassant à peine, $1 \mathrm{~mm}$., le sommet de l'épillet............. A. odoratum L. 1456 Bois, prés. - Avr.-Jt.

Pl. ann., grèle, peu élevée, gl. ou peu velue, à t. rameuses inf.; pan. ov.-oblongue; glumelles stériles dépassant de moitié la fl. fertile; arête sup. dépassant long., $2 \mathrm{~mm}$., le sommet de l'épillet (A. Puelii Lec. et Lamot.). . . . . . . . . A. aristatum Boiss. 1457

Lieux sabl. - Avr.-Sept.

\section{Genre 500. - PHALARIS L.}

Inflor. en pan. allongée, lobée, étalée pendant la flor.; épill. convexes sur les 2 faces ; glumes lanc.-mucr. à car. non ailée; pl. viv., élevée, à souche ramp. . . . . . . . P. arundinacea L. 1458 Bord des eaux. - Mai-Jt.

Inflor. ou pan. spic. ov.-oblongue, dense; épill. concaves sur la face int.; glumes obovales-mucr. à car. ailée dans la moitié sup.; pl. ann.

P. canariensis L. 1459

Cult. et subsp. - Mai-Jt.

\section{Genre 501. - CRYPSIS Ait.}

Plante ann. basse, à t. de $5-30 \mathrm{~cm}$. étalées ou ascend.; pan. spic. noirâtre, d'abord enveloppée dans la gaine sup., puis saill.; glumes subobt., scabres ou cil. sur la car.; glumelle sup. binervée.

Grèves et lieux hum. sabl. - At-0ct.

C. alopecuroides Schrad. 1460 


\section{GenRe 502. - PHLEUM L.}

+ Pl. ann. à rac. fibr., peu tenace; glumes à nervures lat. écartées de la car.; glumelles munies d'un rudiment stérile.

Pl. peu élevée, วั-25 cm.; pan. spic. assez courte, 1-4 cm., en massue oblongue ou cyl.; glumes lanc. atténuées en pointe fine, cil. sur la car.; glumelles vel.-cil. égalant le tiers des glumes.

Lieux sabl. - Mai-Jn.

P. arenarium L. 1461

Pl. assez élevée, 10-50 cm.; pan. spiciforme longue, 3-10 cm., cyl., tr. dense; glumes obovales en coin, élargies au sommet et brusq. mucr., scabres-tuberc., non cil.; glumelles atteignant $2 / 3$ des glumes. . . . . . . . . . P. asperum Jacq. 1462 Vignes, champs calc. - Nai-Jt.

+ Pl. viv. à souche gazonn., tenace; glumes à nervures lat. rappr. de la carène.

Épillets subsessiles sur de tr. courts ram.; glumes obliq. tronq., insensibl. acum., à peine cil. sur la car.; glumelles d'un tiers plus courtes que les glumes, munies d'un rudiment stérile; ligule courte, tronq.. . . . . . . . P. Bœhmeri Wibel 1463 Pelouses sèches, coteaux calc. - Jn-Jt.

Épillets subsessiles sur l'axe; glumes tronq. en travers, brusq. rétrécies en arête dr., fort. cil. sur la car.; glumelles de moitié plus courtes que les glumes, sans rudiment stérile; ligule ov.; t. quelquefois renfl. en bulbe à la base.. . . P. pratense L. 1464 Prés, pâturages. - Nai-At.

\section{GeNRE 503. - ALOPECURUS L.}

+ Pan. spic. ov., courte, 1-2 cm.; à ram. portant 1-2 épill. gr., 6-7 mm.; gaine sup. fort. renfl. en vessie; glumes lanc., brusq. acum., soudées jusqu'au milieu, à car. cil. dans la moitié inf.; glumelle aig. munie au-dessus de la base d'une arête saill.; ann.

Prés hum. (quelquefois subsp.). - Mai-Jn.

A. utriculatus Pers. 1465

+ Pan. spic. cyl., plus ou moins allongée, $3-10 \mathrm{~cm}$.; gaine sup. peu renfl., cyl.

$\times$ Pan. spic. ord. allongée, long. 4-8 cm., épaisse, large de 4-8 mm. ; épill. gr., long. 5-6 mm.; glumes aiguës ou acum., soudées inf.; glumelle munie au-dessus de la base d'une arète saill.; t. dress. ou ascend.

Pl. ann. à rac. fibr.; pan. spic. glabr., atténuée aux 2 bouts, à ram. portant 1-2 épill.; glumes soudées jusqu'au milieu, brièv. pub. sur la carène ailée; glumelle subobt.

Champs. - Mai-Jt.

A. agrestis L. 1466

Pl. viv. à souche stolon.; pan. spic. vel.-soyeuse, obt., à ram. portant 4-6 épill.; glumes acum., soudées dans le tiers inf. long. cil. sur la carène non ailée; glumelle aig.

Prés. - Mai-Jt.

A. pratensis L. 1467

$\times$ Pan. spic. courte, 3-5 cm., obt. cil. peu épaisse, larg. 2-4 mm.; épill. pet., 2-3 mm.; glumes à peine soudées; t. couchée-rad. et genouillée inf.

Glumelle munie vers le quart inf. d'une arête 1-2 fois plus long. que les glumes; anth. jaunâtres, puis brunes; pan. blanchâtre ou violacée. . . . . . . A. geniculatus L. 1468

Mares, fossés. - Mai-At. 
Glumelle munie vers le milieu d'une arète courte ne dépassant pas ou très peu les glumes; anth. blanchâtres, puis orangées; pan. glauque ............ A. fulvus Sm. 1469 Mares, fossés sil. - Mai-At.

\section{Gexre 504. - SESLERIA Scop.}

Pl. viv. gazonn. ; f. basilaires long. obt., brun. mucr., les caul., 2-3 espacées et tr. courtes; épill. inf. pourvus d'une bract. ov., lobuléedentée; glumes presque égales, car., uninervées, plus courtes que les fl. ; glumelle inf. pub., à $\mathbf{3}$ nervures, à $\mathbf{2}$ dents et $\mathbf{3}$ arêtes, la médiane plus longue. . . . . . . . . S. cærulea Arduin. 1470 Coteaux calc. - Mars-Avr.

\section{GeNre 50ð. - TRAGUS Hall.}

Pl. ann. à t. couchées-étalées, ram.; pan. spic. lâche, hér., purp., à ram. courts portant 2-4 épill. subsessiles; glume inf. tr. petite; glumelles membr., lisses . . . . . . . . T. racemosus Hall. 1471 Lieux sabl. secs. - Jt-0ct.

\section{Genre 506. - SETARIA P. Beauv.}

+ Pan. spic. assez courte, 2-3̈ cm., ord. dense, ni vert., ni lobée; soies nombr., fasc. à la base de chaque épill., à dentic. dress.

Pan. spic. jaune roussâtre, à axe scabre; épill. ov., à glumes peu inég., la sup. de moitié plus courte que la fl.; glumelles de $3 \mathrm{~mm}$., fin. ridées en travers; t. lisse. . . . . S. glauca 1472 Lieux cult. ou sabl. - Jn-Sept.

Pan. spic. verte ou rougeâtre, à axe vel.; épill. ellipt. à glumes tr. inég., la sup. égalant la fl.; glumelles de $2 \mathrm{~mm}$., fin. ponct.; $t$. rude au sommet. . . . . . . . . S. viridis P. B. 1473 Lieux cult. - Jn-0ct.

+ Pan. allongée, 50-30 cm., vert. ou lobée, souvent interr. à la base; soies peu nombr., 1-3, à la base de chaque épill.

Pan. cyl. et comme vert., long. "̆-10 cm.; larg. $1 \mathrm{~cm}$., à axe scabre; glume sup. égalant la fl.; soies 2 , vertes ou violacées, à dentic. réfléchis, rar. (S. ambigua) à denticules dress.; glumelles fin. ponct.. . . . . . . . S. verticillata P. B. 1474 Lieux cult. - Jn-0ct.

Pan. grosse, lobée-décomposée, long. 20-30 cm., larg. 2-3 cm., à axes vel.; glume sup. plus courte que la fl.; soies, 1-3, à dentic. dress.; glumelles lisses . . . . . . . S. italica P. B. 1475 Cult. et subsp. (Millet des oiseaux). - Jn-Sept.

\section{Genre 507. - PANIGUM L.}

Pl. ann., vel., dress. ; f. larges, 10-15 mm.. à gaines hér. de longs poils; pan. allongée à ram. longs, dress. ; glumes inég. plurinervées, acum.; 2 glumelles stériles . . . . . . . P. miliaceum L. 1476 Cult et subsp. (Millet). - Jt-0ct.

\section{Genre 508. - ECHiNOGHLOA P. Beauv.}

Pl. ann. gl., sauf l'inflor.; t. dress. ou couchée, ram.; f. larges, 5̆-12 mm.; épill. vel.-hér., 3-4 mm., ov., sur 4 rangs irrégul., à glumes et glumelles mucr. ou arist.; glume inf. 3 fois plus courte gue la sup.

Lieux hum., ch. sabl, - Jt-0ct.

E. Crus-Galli P. B. 1477 


\section{Genre 509. - DigitARIA Scop.}

F. et gaines vel.; 3-10 épis allongés, dress. puis étalés; épill. lanc., long. $3 \mathrm{~mm}$.; glum. sup. vel.-cil., de moitié plus courte que l'épill.

Lieux sabl., cult. - Jt-0ct.

D. sanguinalis Scop. 1478

F. et gaines gl. ou à quelques poils près de la ligule; 2-6 épis grêles plus ou moins étalés; épill. ellipt.-aig., long. $2 \mathrm{~mm}$.; glume sup. pubérulente égalant l'épill.. . . . . . D. filiformis Koel. 1479

Lieux sabl. - Jt-0ct.

\section{Gexre 5010. - GYNODON Rich.}

Pl. viv. à rhizômes long. traçants; t. couchées genouillées et ascend., ram.; f. distiques, glauques, poilues; 4-7 épis unilat., lin., en panicule digitée; glumes uninervées, aig., plus courtes que la fl.; glumelles mutiques, pliées car. ...... G. Dactylon Rich. 1480

Lieux sabl. arides. - Jt-Sept.

\section{GENRE 511. - ANDROPOGON L.}

Pl. viv. à souche un peu ramp.; f. lin. canal.; 4-10 épis digités fasc., vel. hér., à axe artic., fragile, tr. vel.; épill. géminés, l'un stérile, pédic., non aristé, l'autre fertile, sessile, à glumes presque égales, mutiques, à glumelle inf. tr. étr., portant une long. arête scabre.

Lieux secs et arides. - Jt-0ct.

A. Ischæmum L. 1481

\section{GENRE 512. - ARUNDO L.}

Pl. viv. élevée, 1-4 m., à rhizômes long. ramp.; f. gr., larges, 1-3 cm., rudes aux bords, à ligule formée d'une rangée de poils courts, égaux; pan. brun.-violacé, rar. noirâtre; épill. à $2-7$ fl.; glumes tr. inég. plus courtes que les fl.; glumelle inf. acum.

A. Phragmites L. 1482

Bord des eaux, marais. - At-Sept.

\section{Genre 513. - GALAMAGROSTIS Roth.}

Glumes lanc.-subul. fermées après la flor.; glumelle inf. bifide, de moitié plus courte que les glumes, portant vers le milieu du dos une arête dr. plus courte que les poils et les glumes; t. robustes, raides, scabres au sommet . . . . . . C. Epigeios Roth. 1483 Landes, bois humides. - Jn-At.

Glumes lanc-acum., écartées divar.; glumelle inf. émarg., d'un tiers plus courtes que les glumes, portant dans l'éch. term. une arête dr. tr. courte dépassant peu les dents de l'éch.; t. assez grêle, faible, presque lisse au sommet; pl. fleurissant rar. produisant des t. stériles nombr. fasc. . . . . . . . . C. lanceolata Roth. 1484 Marais, bois tourb. - Jn-Jt.

\section{GeNRE 3 14. - AGROSTIS L.}

+ Pl. ann.; glumes inég., la sup. plus gr., trinervée; glumelle inf. aig. long. aristée sous le sommet, la sup. munle à la base d'un rudiment stérile; ligule lacérée.

Pl. assez robuste; f. larges, 3-6 mm.; pan. pyramidale, étalée à la flor. à ram. longs et nus; anth. lin.-oblongues.

Moiss., eh. sabl. - Jn-At.

A. Spica-venti L. 1485

Pl. grêle, effilée; f. étr., 1-2 mm.; pan. étr., contractée, à ram. courts garnis d'épillets presque jusqu'à la base; anth. ov.

Lieux sabl. - Mai-Jn.

A. interrupta L. 1486 
+ Pl. viv. à souche ramp. ou stolon.; glumes peu inég., la sup. plus pet.; glumelle inf. mutique, à arête courte sous le sommet; pas de rudiment stérile; ligule ent.

X F. rad. filif. enroulées, les caul. planes; glumelle sup. nulle; glumelle inf. tronq.-dentée à arête dorsale genouillée, saill.; glumes fermées, aig.; pan. violacée ou jaunâtre, contractée après la flor.; ligule oblongue; glumelle inf. quelquefois mutique (A. varians Thuill.).. . . . . . . A. canina L. 1487 Prés et lieux hum. - Jn-At.

X F. toutes planes; 2 glumelles inég., l’inf. mutique; rar. à arête tr. courte.

Pan. violacée, rar. verte, étalée après la flor. à axe et ram. nus presque lisses; glumes ouvertes, aig. ; ligule courte, tronq.

A. vulgaris With. 1488

Bois, pâturages. - Jn-Sept.

Var. pl. naine 3-10 cm. (A. pumila L.)

Pan. vert pâle ou violacée, contractée après la flor. à axe et ram. fasc. rudes; glumes fermées, aig. ; ligule oblongue.

Lieux hum., fossés. - Jn-Sept.

A. alba L. 1489

\section{GeNRE 513. - STIPA L.}

Pl. viv. à souche épaisse, gazonn.; t. raides, dress.; f. glauques, long., filif.-enroulées, la sup. engainant la base de la pan. étroite, peu fournie et peu rameuse; glumes carénées insensibl. et long. acum.; ligule lanc. pub. . . . . . . . . . S. pennata L. 1490 Coteaux et rochers. - Mai-Jn.

\section{Genre 516. - MILIUM L.}

Pl. viv. à souche court. stolon.; t. dress., élevée, $50 \mathrm{~cm}$. à $1 \mathrm{~m}$.; f. assez long., planes, larg. 6-12 mm., rudes aux bords; pan. ample, pyramidale, à ram. demi-vert., étalés, puis réfléchis; glumes ov.-aig., trinervées; ligule oblongue. . . . . . . . M. effusum L. 1491 Bois ombragés. - Mai-Jt.

\section{Genre 517. - AIROPSIS Desv.}

Pl. viv. à souche grêle ramp.-stolon.; t. genouillées et rad., ascend.; f. glauqnes, planes; pan. ov., lâche, violacée, à ram. et pédic. longs, presque lisses, étalés; ligule lanc. .... A. agrostidea DG. 1492 Bord des mares tourb. - Jn-Jt.

\section{Genre 518. - AIRA L.}

+ Pan. lâche, plus ou moins étalée à rameaux presque lisses, à épill. écartés ou fasc.; pédic. égalant ord. l'épill. ou plus longs; glumelle inf. un peu plus courte que les glumes.

Épill. assez pet., $3 \mathrm{~mm}$., ord. écartés formant une pan. étalée ou divar.; arête de la glumelle inf. presque 1 fois plus long. que les glumes; t. tr. grêles, ord. solit. ou en touffes peu fournies, peu élevées, Lieux sabl. - Mai-Jn.

Épill. pet., 2 1/2 mm., rappr. en fasc. au sommet des ram., formant une pan. étalée-dress.; arête de la glumelle inf. 1-2 fois plus long. que les glumes; t. assez grêles, fasc., assez élevées, $20-50 \mathrm{~cm}$.

$$
\text { Ch., lieux sabl. - Mai-Jt. }
$$

A. multiculmis Dumort 1494

+ Pan. étr., contractée, presque spic., à ram. courts, dress. rudes ; pédic. ord. plus courts que les épill. rappr. assez petits, $3 \mathrm{~mm}$; arête de la glumelle inf. 1-2 fois plus long. que les glumes; $t$. dress. ou ascend., fasc., peu élevées, ๖-20 cm. A. præcox L. 1495 
Genre 519. - GORYNEPHORUS P. Beauv.

Pl. viv. dens. gazon.; f. glauques, enroulées-sét., scabres; pan. lanc. oblongue, étr., étalée puis resserrée, blanchâtre ou violacée, à ram. courts, épill. fasc.; ligule oblongue. . . . C. canescens P. B. 1496 Lieux sabl. - Mai-At.

\section{Genre 520. - DESCHAMPSIA P. Beauv.}

+ Arète dr., incluse ou tr. peu saill.; pan. étalée à axe et ram. scabres ; f. tr. rudes; ligule lanc.

F. planes, vertes, souvent tr. longues; pan. tr. ample; arête incluse ou peu saill., insérée vers la base de la glumelle; souche formée de fasc. tenaces, difficiles à séparer. . D. cæspitosa P. B. 1497 Lieux hum. - Jn-At.

F. enroulées-sét., glauques, souvent assez courtes; pan. assez ample; arète non saill. insérée vers le milieu de la glumelle; souche formée de nombr. fasc. peu adhérents, faciles à séparer.

Prairies hum., cot. calc. secs. - Jn-Jt.
+ Arète genouillée, dépassant long. les glumes; pan. contractée après
la flor. à axe et ram. peu rudes; f. lisses ou peu rudes, enroulées-

D. media Rœm. et Sch. 1498 la flor. à axe et ram. peu rudes; f. lisses ou peu rudes, enrouléessét.

Ligule tr. longue, acum. ; pédic. plus courts que l'épill.; épill. rappr., longs d'environ $4 \mathrm{~mm}$., violacés; pédic. de la fl. sup. égalant la moitié de sa long.. . . . . . D. discolor Rœm. et Sch. 1499 Marais tourb. sil. - Jn-At.

Ligule assez courte, tronq.; pédic. plus longs que l'épill. ou l'égalant; épill. écartés, longs de 5 mm., violacés ou blanchâtres; pédic. de la fl. sup. 5-6 fois plus court qu'elle.

$\begin{array}{ll}\text { Bois et rochers sil. - Mai-At. } & \text { D. flexuosa Griseb. } 1500\end{array}$

\section{Genre 521. - AVENA L.}

+ Pl. ann. à rac. fibr., à f. larges, planes; épill. gr. 18-20 mm., devenant pend. ou horiz., tr. ouverts; glumes gr., 7-9 nerv.; ligule courte, tronq.

$X$ Glumelle inf. couverte de longs poils soyeux roussâtres term. par 2 dents fines, à arête longue, tordue, 1 fois plus longue que les glumes; fl. art. sur l'axe vel. de l'épill.; glumes de $25 \mathrm{~mm}$. dépassant les fl.; panicule pyramidale. . . . . A. fatua L. 1501 Moiss., ch. - Mai-At.

Moiss., ch. - Mai-At.
$\times$ Glumelle inf. gl. ou glabr. plus ou moins bidentée, mutique ou arist.; fl. non artic. sur l'axe gl. de l'épill.

$=$ Glumes dépassant les fl. de $25 \mathrm{~mm}$.; fl. inf. sessile ou subsessile; glumelles presque égales, l'inf. bidentée, faibl. nerv. dans la partie inf.

Pan. pyramidale, étalée en tous sens, tr. lâche, à ram. allongés; glumelle inf. mutique ou à arête genouillée tordue.

Cult. en grand (Avoine). - Mai-Jt.

A. sativa L. 1502

Pan. allongée, étr., resserrée, assez dense, unilat., à ram. courts ; glumelle inf. mutique ou à arète dr. ou arq.-flexueuse, non tordue ......... A. orientalis Schreb. 1503

Cult. avec le précédent, rar. seul (Avoine à grappes, avoine [de Hongrie). - Jn-At.

= Glumes égalant les fl. de $18 \mathrm{~mm}$.; fl. pédic., arist. ou la sup. mutique; glumelles un peu inég., l'inf. scabre, fendue jusqu'au tiers en 2 lobes long. aristés, à nerv. bien marquées dès la base; pan. 
lâche dress., puis pench. et presque unilat., à ram. allongés; glumelle inf. à arête longue, genouillée et tordue, noirâtre inf. ; épill. étr. . . . . . . . . A. strigosa Schreb. 1504 Moiss., ch. d'aroine, nat. - Jn-At.

+ Pl. viv. gazonn. à f. étr., 1,3 à 5 mm., planes ou pliées; épillets dress., pet., 10-12 mm., presque fermés, à 2-6 fl. articulées et aristées; glumes à 1-3 nervures; glumelle inf. tronq. laciniée ou dentelée au sommet; ligule oblongue.

Pan. oblongue, à ram. inf. réunis par 3-5̆; épill. à 2-3 fl., à poils égalant la moitié de la glumelle; glumes égalant les fl.; f. ' et gaines inf. ord. poil. . . . . A. pubescens L. 1505 Prés, coteaux. - Nai-Jt.

Pan. dress., tr. étr., presque simple, à ram. solit. ou géminés; épill. à $3-8 \mathrm{fl}$., à poils 10 fois plus courts que la glumelle; glumes plus courtes que les fl.; f. et gaines gl.. . . . A. pratensis L. 1506 Prés, coteaux. - Mai-Jt.

\section{Genre 522. - TRISETUM Pers.}

Pl. viv. à souche un peu ramp., ord. pub. sur les f., les gaines et autour des nœuds; pan. làche, luisante, jaunâtre, rar. violacée; épill. assez pet. 5̆-6 mm., à 2-4 fl., l’inf. subsessile, les autres stipitées, à axe poilu sous chaque fl.; glumelle inf. term. par 2 soies à arète long. genouillée; f. étr., 2-4 mm. planes, à ligule courte, tronq. cil.

Prés, pâturages. - Mai-At.

T. flavescens P. Beauv. 1507

Genre 523. - ARRHENATHERUM P. Beauv.

Pl. viv. à souche fibr.; pan. gr., étalée, puis contractée, làche, verdâtre ou violacée; épill. assez gr., 7-10 mm.; fl. sup. fertile brièv. arist. sous le sommet de la glumelle poil. et bidentée; souche souvent surmontée de 2-6 renfl. bulbeux superposés (A. bulbosum Presl.).

A. elatius Mert. et K. 1508

Prés, ch. - Mai-At.

\section{Genre 524. - HOLGUS L.}

Epill. assez pet., 4-\$ mm., à arète courbée en crochet ne dépassant pas les glumes; pan. ovale-oblongue, pub.; ligule courte tronq., déchirée; pl. mollement pub. à souche courte, fibr.. . . . H. lanatus L. 1509 Prés, bois. - Mai-At.

Epillets assez gr., 6 mm., à arête flexueuse dépassant assez long. les glumes; pan. oblongue, pub. puis glabr. ; ligule ov.-oblongue; pl. pub. devenant glabr. à souche long. traçante. . . . . H. mollis L. 1510

Pàturages et bois hum. sil. - Jn-Sept.

\section{Genre 525. - GAUdinia P. Beauv.}

Pl. mollement vel. sur les f. et les gaines; t. fasc. dress. ou ascend.; f. planes, à ligule courte, tronq.; épill. distiques, sessiles et solit. dans chaque dent de l'axe, à 4-10 fl. espacées; glumelle inf. bidentée à arète dorsale, genouillée, saill.. . . . . G. fragilis P. B. 1511

Prés hum., pelouses herbeuses. - Jn-Jt et Automne.

\section{Genre 526. - DANTHONIA DC.}

Pl. gazonn. vel. sur les gaines ou les f.; t. décombantes ou redressées; f. planes ou enroulées, à ligule formée de longs poils; épill. ov., 3-丂̆ fl.; glumelle inf., cil. aux bords au milieu, term. par 3 dents courtes, égales, la médiane parfois mucr. D. decumbens DC. 1512

Landes, pâturages sil. hum. - Mai-At. 


\section{GenRe 327. - KOELERIA Pers.}

Souche renfl. bulbeuse, recouverte par les gaines des anc. f. déchirées, entrecroisées en réseau filamenteux; f. rad. ord. enroulées-sét., gl., ainsi que les gaines; pan. oblongue, épaisse, courte, $2-3 \mathrm{~cm} .$, assez dense.. . . . . . . . . . K. setacea Pers. 1513 Coteaux calc. - Nai-Jt.

Souche peu renfl., recouverte de gaines à peine déchirées en long, non entrecroisées en réseau; f. rad. ord. planes, plus ou moins pub. ainsi que les gaines; pan. longue de $4-15 \mathrm{~cm}$., lobée et souvent interr., à ram. courts, flexneux, étalés à la flor., dress.-appliqués avant et après.

Pelouses sèches; coteaux. - Nai-Jt.

K. cristata Pers. 1514

Var. à pan. grêle, étr.; f. tr. étr. (K. gracilis Pers.).

\section{GenRe 528. - GLYGERIA R. Br.}

+ T. plus ou moins couchées-radicantes inf. ou nageantes; gaines compr.; pan. unilat., épillets lin., à

Pan. étalée pendant la flor., puis dress. après, à ram. inf. géminés; épill. lin. compr., 2-3 cm., à ว̌-11 fl. lanc. oblongues, ne se recouvrant pas; glumelles inf. oblongues-lanc., scar. et subaig. au sommet; jeunes f. simpl. pliées . . . G G. fluitans R. Br. 1515 Mares, fossés. - Jn-Sept.

Pan. dress. pendant la flor., puis étalée, à ram. inf. ord. vert. par 4-3̈ ; épill. étr., subcyl., 1-1 1/2 cm., à ̌-11 fl. ov. oblongues, obt., rappr. et se recouvrant l'une l'autre; glumelle inf. ellipt. obt., scar., et arrondie-crénel. au sommet; jeunes f. plusieurs fois pliées.

Fossés. - Jn-Sept.

G. plicata Fr. 1516

+ T. dress.; gaines cyl.; pan. à ram. dress. étalés en tous sens; épill. oblongs, à $4-9 \mathrm{fl}$.

T. de 1-2 m. grosses; f. larges, 10-18 mm.; pan. tr. ample, à ram. nombr., semi-vert; épill. gr., 4-8 mm., à 4-9 fl. de $3-4 \mathrm{~mm}$. ; glumelle inf. oblongue, obt., à 7-9 nervures saill.; ét. 3.

Bord des eaux. - Jt-At.

G. aquatica Wahl. 1517

T. grèles, $50 \mathrm{~cm} .-1 \mathrm{~m}$; ; f. étr., $2-5 \mathrm{~mm}$; pan. grèle, à ram. capill. réunis par 2-3; épill. pet., 3-4 mm., à $4-8$ fl. de $2 \mathrm{~mm}$.; glumelle inf. obt. à 7 nervures saill.; ét. 2. . . G. nervata Trin. 1518 Marais, nat. - Mai-Jn.

\section{Genre 529. - GATABRoSA P. Beauv.}

Pl. viv., peu élevée à souche ramp.-stolon.; t. couchées-radicantes, puis redressées; f. courtes, planes, larges, 4-10 mm., obt., lisses ; pan. étalée, làche à ram. demi-vert. . . . . . . C. aquatica P. B. 1519 Mares, fossés. - Mai-At.

\section{Genre 530. - P0A L.}

+ Pl. à souche long. ramp. ou à t. fort. compr.; ligule courte, tronq. $X$ Pan. oblongue, ord. courte, étr., presque unilat., à ram. courts, les inf. géminés ou ternés; épillets lanc. à 5 -9 fl. ; glumelle inf. sans nerv, saill. . . . . . . . . P. compressa L. 1520 Vieux murs secs. - Jn-Sept.

$\times$ Pan. pyramidale, à ram. longs, les inf. réunis par 2-5̆ épill. ov. ou ov.-oblongs à 3 -ă fl. ; glumelle inf. à $̋$ nerv. saill.

Pl. à rhizomes long. traçants; épillets ov. 3-ŏ fl. réunies à la base par des poils laineux; glumelle inf. vel. cil. inf. ; t. cyl. ou un 
peu compr. inf., grèle à f. long. assez étr., 1-5 mm., quelquefois tr. étr., les rad.-filiformes ( $\boldsymbol{P}$. angustifolia L.) ou pl. ord. peu élevée, $t$. fort compr. à angles aig. ainsi que les gaines, f. larg., courtes (P. anceps Bor.) . . . . . . . P. pratensis L. 1521 Prés, pâturages, la var. anceps. au bord des chemins. - Mai-At.

Pl. à souche court. ramp. ; épillets ov.-oblongs à $3-3 \mathrm{fl}$. gl.; glumelle inf. non cil.; t. compr. à 2 tranchants; f. larges, $4-10 \mathrm{~mm}$.

Bois, parcs, nat. - Jn-Jt.

P. Chaixii Vill. 1522

+ Pl. à souche fibr. ou à peine ramp.; f. étr.; t. cyl. ou peu compr.

= Pan. allongée, oblongue ou pyramidale, à ram. scabres, les inf. réunis par 3-7 en demi vert.

Q Gaines scabres, la sup. plus long. que le limbe; glumes inég., l'inf. uninervée; glumelle inf., ov.-aig., à 5 nervures saill.; lig. oblongue, aig. . . . . . . . P. trivialis L. 1523 Lieux hum. - Mai-Jt.

Q Gaines et t. lisses; glumes peu inég. trinervées; glumelle inf. à כ nervures peu saill.

F. sup. à gaine plus long. que le limbe; ligule ov. ou oblongue; glumelle inf. lanc.; pan. pyramidale, à ram. inf. lanc.; pan. pyramidale, à ram. inf. réunies par 4-7 en demi-vert.

Prairies hum. - Jn-At. et automne.

P. palustris L. 1524

F. sup. à gaine plus courte que le limbe; ligule tr. courte; glumelle inf. ov.-obt.; pan. longue, lâche ou contractée, souvent peu fournie, à ram. inf. réunis par $3-5$; f. sup. souvent étalées horizon. . . . . . . . P. nemoralis L. 1525 Bois, murs. - Jn-0ct.

$=$ Pan. courte, ov. ou oblongue, à ram. lisses ou scabres; les inf. solit. ou géminés; $t$. et gaînes lisses.

T. dress., renfl. en bulbe à la base, cyl., raide; pan. ov., dense, contractée ou un peu étalée, souvent vivipare, à ram. courts, solit. ou géminés, scabres; épill. ov., rappr., à 4-6 fl. réunies par de longs poils laineux; glumes presque égales, trinervées; glumelle inf. subaig. à nerv. faibles; pl. viv. gazonn.

Lieux secs et arides. - Avr.-Jn.

P. bulbosa L. 1526

T. étalées-ascend., un peu compr., flasques; pan. ov., presque unilat., lâche dress., à ram. assez longs, les inf. solit. ou géminés, lisses: épill. ov. oblongs, à 3-6 fl. non poilues; glumes inég., l’inf. uninervée; glumelle inf. obt. à 5 nerv. distinctes; pl. ann. ou bisann. . . . . . . . . . P. annua L. 1527 Lieux incultes toute l'année.

\section{Genre 531. - ERAGROSTIS P. Beauv.}

Epill. lanc. ou lin. oblongs, larges de $2-3 \mathrm{~mm}$; glumes ov.-lanc.; f. fin. dentic. et tuberc. aux bords; caryopses subglob.

+ Pan. étalée à ram. solit. ou géminés; épill. lanc. ou lin.-oblongs, larges de 2-3 mm; glumes ov. lanc.; f. fin. dentic. et tuberc. aux bords, gl. ou à poils épars, assez larg.

Pan. oblongue, assez dense à ram. épais, courts ainsi que les pédic.; épill. gr., larg. $3 \mathrm{~mm}$., rappr.-fasc.; gaines gl. excepté autour de la ligule . . . . . . . . . E. major Host. 1528 Lieux sabl. - Jt-0ct.

Pan. oblongue, assez làche, à ram. grêles, longs, ainsi que les pédic.; épill. médiocres, larg. $2 \mathrm{~mm}$., non fasc.; gaines hér. de longs poils............... E. minor Host. 1529 Lieux sabl., les voies ferrées, nat. - Jt.-0ct. 
+ Pan. d'abord contractée puis étalée, d'un violet rougeâtre, à ram. capill. réunis par 4-̋̋ en demi-vert. ; épill. lin., étr., 1 mm.; glumes lanc.; f. "non tuberc. aux bords, gl., étr.; gaines gl., barbues autour de la ligule . . . . . . . . . E. pilosa P. B. 1530 Mares silic. desséchées, grèves sabl. des rivières. - Jt-0ct.

\section{GenRe 5332. - MOLINIA Schrank.}

Pl. viv., gl., à souche épaisse; t. dress., raides, long nues, à nœud unique caché par les gaines basilaires; pan. allongée, contractée après la flor., dress., étr., ord. interr., à ram. dress., scabres, multiflores.

Bois et landes hum. - Jt.-Oct. M. cærulea IIønch. 1531

\section{Genre 533. - MELiGA L.}

+ Pan. resserrée, comme spic., vel. soyeuse; glumelle inf. lanc.-aig.; long. cil. aux bords; f. plus ou moins enroulées, rudes; souche courte, ramp.; t. dress., en touffes; ram. primaires portant 5-10 épillets; glumes inég., acum.; ligule oblongue, souvent déchirée. . . . . . . . . . . M. ciliata L. 1532 Coteaux pierreux calc. - Mai-Jt.

+ Pan. làche, étalée ou contractée en grappe, non vel.-soyeuse; glumelle inf. gl., non cil.; f. planes, scabres; souche grèle long. stolon.

Pan. simple, en grappe étr., unilat., à ram. tr. courts portant 1-2 épillets pench. sur des pédic. courbés, à 3 fl. dont 2 fertiles; glumes peu inég., obt.; glumelles inég., l’inf. oblongue à nervures nombr. tr. saill.; lig. tr. courte, arrondie.

Bois ombragés. - Mai-Jt.

M. nutans L. 1533

Pan. très làche, pauciflore, à ram. inf. étalés-dress., allongés, long. nus, portant 2-3 épillets dress. ou inclinés sur des pédic. dr., à 3 fl. dont l'inf. seule fertile; glumes un peu inég., mucr.; glumelles peu inég. l'inf. ovale en cuiller, à "3-7 nerv. peu saill.; ligule courte, brusq. term. en arète opp. à la f.

Bois ombragés. - Mai-Jt.

M. uniflora Retz. 1534

\section{Gevre 534. - BRIZA L.}

Pl. viv. à souche ramp. stol.; t. dress.; f. courtes, planes, rudes, à gaine sup. tr. long; ligule courte, tronq. ; glumes un peu plus courtes que les glumelles contiguës. . . . . . . . B. media L. 1535

Prés, bois, coteaux. - Mai-Jt.

\section{Genre 53כ. - SGLEROPOA Gris.}

Pl. ann. petite, $\breve{b}-30 \mathrm{~cm}$. ; t. genouillées ascend. ou dress., raides, lisses; f. planes, puis enroulées, rudes; pan. étr., obl. lanc., unilat., à ram. garnis d'épill. jusqu'à la base; glumelle inf. subobt. à nerv. lat. peu visibles . . . . . . . . . . . S. rigida Griseb. 1536 Lieux secs, vieux murs. - Maî-Jt.

\section{GenRe 336. - DAGTYLIS L.}

Pl. viv., assez gr., $20 \mathrm{~cm}$. à $1 \mathrm{~m}$., à souche gazonn.; t. dress. ou arq. à la base long. nues au sommet; f. planes. ou canal.; gaines compr.; pan. ord. ram. rar. spic. et dense, unilat., à épill. agglom. tr. brièv. pédic. . . . . . . . . D. glomerata L. 1537

Prés, bois. - Mai-Sept. 


\section{Genre 537. - GYNOSURUS L.}

Pl. viv., gazonn.; t. dress., nues sup.; pan. spic. étr., long., dense, à ram. tr. courts; glumes plus courtes que les fl.; glumelle inf. lanc., à 3-̋̆ nerv., à arête plus courte qu'elle; ligule courte, tronq.

Prés. - Mai-Jt.

C. cristatus L. 1538

C. echinatus L. se rencontre rar. subsp. Pl. ann.; pan. spic. ov. ou oblongue, hér. de long. arêtes; ligule oblongue.

\section{Genre 338. - VUlPIA Gmel.}

+ Glume inf. tr. pet., 10 fois plus courte que la sup. atténuée en arète aussi longue qu'elle; épill. à 2-4 fl.; pédic. artic., se détachant facil. de l'axe, rudes, longs de $4 \mathrm{~mm}$.; ovaire gl., ligule tr. courte.

Lieux sabl. arides. - Mai-Jn.

V. longiseta Heckel. 1539

+ Glume inf. assez pet., 2-3 fois plus courte que la sup. acum., non arist.; épill. à 3-8 fl. à axe gl.; pédic. $2-3$ fois plus longs que large;

Pan. long., 10-20 cm., arquée-penchée, à base engainée ou rappr. de la f. sup. ; glume inf. égalant le tiers de la sup. ; celle-ci égalant environ la moitié de la glumelle contiguë, arète non comprise; ligule courte.. . . . . . . . V. myuros Gmel. 1540 Lieux sabl. - Mai-Jt.

Pan. assez courte, $2-8 \mathrm{~cm}$., dr., éloignée de la f. sup.; glume inf. égalant presque la moitié de la sup., celle-ci presque aussi longue que la glumelle contiguë, arète non comprise; ligule presque nulle.

Lieux sabl. - Mai-Jt.

V. sciuroides Gmel. 1541

$V$. ciliata Link a été rencontré accidentellement. Voisin de $V$. myuros, s'en distingue par sa pan. vel. soyeuse, l'axe velu, sa glumelle long. cil., ses pédic. aussi larges que longs, sa glume inf. tr. pet. $\ddot{0}-6$ fois plus courte que le sup.; 1 ét.

\section{GenRe 339. - FESTUCA L.}

○' F. rad. et caul. planes.

$=$ Epill. כ̌-9 fl., arist., à arètes 2 f. plus long. que la glumelle bidentée au sommet; pan. ample, làche, à ram. inf. géminés; ovaire gl.; pl. gl. à nœuds ord. violacés . . . . . F. gigantea Vill. 1542 Bois ombragés. - Jn-Sept.

= Epill. mutiques ou brièv. arist.

Pan. long., étr., étalée pendant la flor., contractée avant et après, à ram. peu rudes solit. ou géminés portant 1-כ̌ épill. ou nuls à épill. sessiles ou subsessiles.

Pan. en grappe spic. allongée, à épill. distiques, solit., rar. géminés, à pédic. nul ou tr. court, tr. rar. ram. gém. inég., les inf. pédonc. portant 1-5̌ épill. ; épill. lin.-oblongs à ǒ-10 fl. mutiques, rar. arist. ; glumes ord. tr. inég., larg. scarieuses, acum., l'inf. petite trinervée, la supér. gr., à $\breve{~ n e r v . ~ e ́ g a l a n t ~ o r d . ~} 2 / 3$ de la fl. contiguë.......... . . . . loliacea Huds. 1543 Prés hum. - Jn-Jt.

Pan. lâche à ram. ord. géminés, inég., les inf. portant 1-å épill. ; rar. pan. en grappe spic. à épill. distiques, les inf. pédonc.; épill. oblongs à ว̌-11 fl. mutiques; glumes inég., larg. scar., la sup. obt., trinervée, égalant la moitié de la fl. contiguë.

Prés. - Jn-Jt.

F. pratensis Huds. 1544

Pan. gr., oblongue, lâche, étalée, puis contractée, à ram. tr. rudes, réunis par 2-4, les inf. allongés, ov. ou ov. lanc. à 3-7 fl. mutiques ou brièv. arist. 
Ligule tr. courte, réduite à 2 oreillettes lat.; pan. lâche, à ram. filif. géminés, inég.; épill. ov. lanc., 10-15, à 4-7 fl. ord. brièv. arist.; glumes un peu inég., larg. scar.; ovaire gl.

\section{F. arundinacea Schreb. 1545}

Prairies hum. - Jn-Jt.

Ligule oblongue, déchirée; pan. lâche pench., à ram. capill. flexueux, réunis par 2-4; épill. ov., 6-7 à 3-こ fl. mutiques; glumes inég., tr. étr., en alène ; ovaire vel. au sommet.

Bois, nat. - Jn-At.

F. silvatica Vill. 1546

o F. rad. enroulées sét.; les caul. planes ou enroulées-sét.

$X$ F. caul. planes, canal. ou souche ramp. ; rejets des f. stériles naissant la plupart en dehors des gaines inf.; fl. arist.; pan. à ram. inf. géminés.

F. glauques, enroulées jonciformes, lisses; épill. gr., 12-15 mm., à 5-10 fl. ord. poil.; arête courte, 1-2 mm. ; souche long. traçante; pan. oblongue, lâche. . . . . F. arenaria Osbeck. 1547 Lieux sabl. - Mai-Jt.

F. vertes, les caul. planes ou un peu canal.; épill. assez pet., 4-12 mm., à 4-8 fleurs ord. gl. ; souche gazonn.

F. rad. lisses; ovaire gl.; souche ramp. stolon: ; arête courte, 1-2 mm. égalant au plus le tiers de la glumelle; pan. ram., épill. longs de 7-12 mm. . . . . . . F. rubra L. 1548

Lieux sabl., pâturages. - Mai-Jn.

F. rad. scabres; ovaire poilu au sommet; souche fibr. sans stolons, arête assez long., 2-4 mm., égalant la moitié de la glumelle; épillets longs de 8-12 $\mathrm{mm}$.

F. heterophylla Lamk. 1549

Bois montueux. - Mai-Jt.

$\times$ F. caul. et rad. enroulées-sét.; souche fibr. gazonn.; rejets des f. stériles sortant ord. des gaines inf.; pan. à ram. solit.

Fl. mutiques; f. tr. fines, capill., rudes, vertes; t. grêles, lisses ou un peu rudes sup.; épill. pet., 4-6 mm., à 3-6 fl.; glumelle courte, $3 \mathrm{~mm}$., aig. ou mucr. . . . . F. capillata Lamk. 1550 Bois. - Mai-Jt.

Fl. arist.; f. sét. ou subjonciformes.

F. cyl., sét., rudes, vertes ou glaucescentes; t. grêles plus ou moins ang. et rudes sup. ; épill. assez pet., 4-8 mm., à 3-8 fl.; glumelle assez courte, $3-5 \mathrm{~mm}$. atténuée en arête n'égalant pas la moitié de sa long. . . . . . . . F. ovina L. 1551 Prés, lieux secs. - Mai-At.

F. plus ou moins compr. par le côté, subjonciformes, ord. lisses et glaucescentes; t. un peu raides, cyl. ou striées sup.; épill. assez gr., 6-10 mm., à 4-9 fl.; glumelles de 4-6 mm. atténuée en arête courte ou dépassant un peu sa moitié. F. duriuscula L. 1552 Lieux secs et arides. - Mai-At.

\section{GENRE 540. - BROMUS L.}

× Pl. viv., élevées, $50 \mathrm{~cm}$. à $2 \mathrm{~m}$., à souche ramp. ou gazonn.; épill. atténués au sommet, mutiques ou brièv. arist., à arêtes plus courtes que la glumelle car. et émarg.; ligule courte, tronq.

Q Pan. oblongue, dress., à ram. scabres vert. ou réunis par 3-6; épill. oblongs ou lanc., dress., à 5 -9 fl. mutiques ou arist.; pl. pub. inf. ou gl., haute d'environ $1 \mathrm{~m}$.

Glumelle inf. oblongue, trinervée, obt. ou éch., mutique ou mucr.; pan. étalée pendant la flor., puis contractée; souche long. ramp.; f. planes, larges, 5-12 mm., distiques sur les rejets stériles.

Fossés, chemins, nat. - Jn-Sept.

B. inermis Leyss. 1553 
Glumelle inf. lanc., à らั-7 nervures, bidentée, term. en arète de moitié plus courte qu'elle; pan. dress.; souche fibr. ou un peu ramp.; f. rad. étr., pliées-car., pub.-cil., les caul. planes, 2 fois plus larges, 2-4 mm. . . . . . . B. erectus Huds. 1554 Prés et coteaux secs. - Mai-Jt.

Q. Pan. tr. ample, làche, étalée et pend., ram., à ram. tr. scabres réunis par 2-4; épill. lanc., pend., à 7-9 fl. arist.; glumelle inf. lanc., un peu car., à 5̆-7 nerv. faibles, term. en arête de moitié plus courte qu'elle; souche courte, fibr.; f. planes, larges, pub. ; pl. vel. surtout sur les gaines, haute de 1-2 m.

\section{Bois. - Jn-At.}

B. asper Murr. 1555

× Pl. ann., à rac. fibr.; épill. élargis ou rétrécis au sommet, plus ou moins long. arist.

Epill. élargis au sommet après la flor.; glume inf. uninervée, la sup. trinervée; glumelle inf. en fuseau, car. sur le dos; arêtes des fl. lat. égalant ou dépassant celles des fl. sup.

= Pan. à ram. et épill. pend. après la flor.; glumelle inf. à 7 nerv. Pan. assez étr., peu làche, à ram. assez courts, flexueux, lisses ou presque lisses; épill. lisses, pub. ou gl., longs de $2-3 \mathrm{~cm}$., arêtes comprises; glumelle faibl. nervée à arête à peine plus longue qu'elle; ligule courte, obt. . . . . . B. tectorum L. 1556 Lieux sablonneux, murs. - Mai-Jn.

Pan. ample, tr. lâche, à ram. allongés, dr. ou peu flexueux, tr. scabres; épillets tr. scabres, gl., longs de $3-30 \mathrm{~cm}$., arètes comprises; glumelle fort. nerv., à arète bien plus longue qu'elle; ligule ov. oblongue... . . . . . B. sterilis L. 1557 Ch., murs. - Mai-At.

= Pan. à ram. et épill. dress., ou un peu pench. au sommet après la flor.; glumelle inf. à ̆-7 nerv. saill., à arète 2 fois plus longue qu'elle; pan. assez courte, peu lâche, à ram. assez courts ou assez longs, dr., pub.; épill. tr. scabres, gl., longs de 5’-8 cm.; ligule oblongue. . . . . . . . . B. maximus Desf. 1558 Coteaux incultes, talus. - Mai-Jn.

Epill. rétrécis au sommet, mème après la flor.; glume inf. à 3-3̆ nerv., la sup. à 7-9; glumelle inf. demi-cyl., arrondie sur le dos; arètes lat. n'atteignant pas le sommet des fl. sup.; ligule courte, obt. ov. ou lanc.

+ Epill. à ò-13 fl. écartées après la flor. laissant voir l'axe; gaines gl.; pan. làche, dress., puis pench.; glumelle inf. subcyl. à 7 nerv. faibles, à bords régul. courbés en arc; arète courte.

$$
\text { Moiss. - Jn-Jt. }
$$

B. secalinus L. 1559

+ Epill. à fl. toujours imbriq., ne laissant pas voir l'axe; gaines vel. ; glumelle inf. à arète aussi longue qu'elle.

¡ Pan. ample, pyramidale, tr. làche, étalée, puis pench., à ram. long. nus; épill. lanc. lin., étr., à ร̌-13 fl. ; glumelles égales, l'inf. à bords formant un angle tr. obt., à 7 nerv. faibles.

$$
\text { Ch. prés. - Jn-Jt. }
$$

B. arvensis L. 1560

¿ Pan oblongue ou ov., assez étr., làche ou dense dress. ou à la fin penchée, à ram. souvent courts.

- Pan. assez làche; épill. et t. gl. ; glumelle inf. faibl. nerv.

Pan. ord. assez gr. devenant pench. et subunilat., à ram. réunis par 2-ă, les plus longs portant 2-3 épill;; glumelle inf. formant vers le tiers sup. un angle obt.; pl. élevée, $40 \mathrm{~cm} .-1 \mathrm{~m}$.

Prés. - Mai-Jt.

B. commutatus Schrad. 1561 
Pan. presque simple, dress., contractée après la flor., à ram. souvent géminés, à un seul épill.; glumelle inf. à bord insensib. arqué; pl. peu élevée.. . . . B. racemosus L. 1562 Prés. - Mai-Jt.

- Pan. contractée, plus ou moins dense après la flor.; à ram. courts, demi-vert.; épill. ord. mollement pub.; t. pub. sup.; glumelle inf. fort. nerv., à bords formant un angle obt. au dessus du milieu. . . . . . . . B. mollis L. 1563 Prés, lieux incultes. - Avr.-Jt.

\section{GenRe 5\%1. - HORDEUM L.}

+ Pl. élevées, 80 cm.-1 m., ent. gl. à t. robustes; f. larges, auriculées; épi compr., tétragone ou hexagonal, épais, muni d'arêtes robustes, caryopse gros; pl. cult.

- Epi compr. par le côté, à grains disposés sur deux rangs opp.; épill. moyen de chaque groupe seul fertile, les 2 lat. stériles, mutiques.

Epi allongé, 8-12 cm., non élargi inf., à arêtes dress.; épill. lat. pédic............. H. distichum L. 1564 Cult. (Paumelle). - Jn-At.

Epi court, 4-6 cm., pyramidal, élargi inf., à arêtes étalées dîv. en éventail; épill. tous sessiles. . . H. Zeocriton L. 1565 Cult. rar. (Orge en éventail). - Jn-At.

- Epi à 4-6 angles, à grains disposés sur 4 ou 6 rangs; épill. tous fertiles, sessiles et arist., à arêtes dress.

Epi allongé, 6-10 cm., inégal. tétr.; épill. mûrs imbriq. sur 4 rangs, les lat. plus saill. . . . . . . . H. vulgare L. 1566 Cult. (Orge, escourgeon). - Jn-At.

Epi gros, court, 4-6 cm., régul. hexagonal; épill. mìrs imbriq. sur 6 rangs égal. saillants. . . . . . H. hexastichum L. 1567 Cult. (Orge carrée). - Jn-At.

+ Pl. peu élevées, 10-80 cm., à f. ou gaines poil. à t. grêles; f. étr. ou assez étr.; épi cyl. ou subcyl., grèle ou peu épais, muni d'arêtes assez grêles; pl. spont. non cult.

Pl. ann. à t. basses, en touffes, ord. genouillées-ascend., feuillées jusqu'à l'épi assez gros, à axe fragile; gaines gl. ; épill. fertile à glumes lin.-lanc., cil., à glumelle inf. atténuée en arête 3 fois plus longue qu'elle, ainsi que les glumelles inf. des $2 \mathrm{fl}$. stériles.

H. murinum L. 1568

Lieux incultes, décombres. - Mai-At.

Pl. viv., gazonn., à t. assez élevées, 40-80 cm., grêles, dr., nues sup.; épi assez grêle, à axe peu fragile; gaines inf. pub.; épill. fertile à glumes sét., scabres, à glumelle inf. à arête aussi longue qu'elle.

$$
\text { Prés. - Mai-Jt. }
$$

H. secalinum Schreb. 1569

\section{Gexre 5\%2. - ELYMUS L.}

Pl. viv., assez élevée, :00 cm.-1 m., à noeuds et gaines poilus, à souche ramp.; f. planes, scabres, auric.; épi cyl.; glumes lin. en alène, arist. dress.; glumelles inf. scabre à らٌ nerv., atténuée en arête dress.; 1-2 fois plus long qu'elle . . . . . . E. europæus L. 1570 Bois. - Jn-At.

$$
\text { Genre 343. - SEGALE L. - Seigle. }
$$

Pl. assez élevée, $60 \mathrm{~cm} .-1 \mathrm{~m}$. 30, à t. dress.; f. planes, larges, rudes; épi long, 8-1: cm., un peu compr., carré cyl. à la mat.; glumelle inf. lanc., à carène lat. fort. cil., term. par une arête longue.

Cult. surtout dans les terrains sil. - Mai-Jt.

S. cereale L. 1571 


\section{GenRe 344. - ÆGILOPS L.}

Epi court, 1-3 cm., ov.; épill. 2-4, dont 1 ou 2 sup. pet. stériles et 2 inf. gros, imbriq., brusq. renflés ventrus au milieu, portant chacun 12 arètes tr. étalées, scabres, long. de $2-3 \mathrm{~cm}$.; glumes term. par 4 arêtes; glumelle inf. à 2 arêtes long. . . . . . Æ. ovata L. 1572 Lieux arides, chemins. - Mai-Jt.

Epi long, 4-6 cm., lin.-lanc.; épill. 4-7, le sup. stérile, les autres fertiles, oblongs, non imbriq., à peine renfl., portant chacun 4-8 arêtes dress.-étalées, lisses à la base, plus longues dans le term., longues de 5-8 cm.; glumes term. par 2-3 arêtes; glumelles à 3 dents ou arêtes courtes, la principale tr. long. dans l'épillet term.

Lieux secs et arides. - Mai-Jt.

Æ. triuncialis L. 1573

\section{GenRe 弓้̋ว. - TRITIGUM L.}

Epill. allongés, 3 fois plus longs que larges; glumes presque foliacées, lanc., longues, $2 \mathrm{~cm}$., car., cil. sur les bords et la car., inégal. bidentées, dépassant les fl.; glumelles de la fl. inf. tr. inég., la sup. égalant la moitié de l’inf.; t. pleine ; caryopse oblong, dur, à cassure cornée; épi gros et long, un peu compr.

Cult. rar. (Blé de Pologne). - Jn-At.

T. polonicum L. 1574

Epill. aussi longs ou un peu plus longs que larges; glumes non foliacées, ov. ou oblongues, pet., à peine $1 \mathrm{~cm}$., plus courtes que les fl.; glumelles égales ou presque égales; épi tétr., rar. compr.

of Glumes tronq. mucr. arrondies sur le dos jusqu'au milieu, car. seulement au sommet; glumelle inf. mutique ou arist; caryopse ov., tendre, à cassure farineuse; t. creuses; épi subtétr. gl. ou pub.

\section{Cult. Blé.}

T. sativum Lamk. 1575

$\sigma^{7}$ Glumes fort. car. de la base au sommet; glumelle inf. long. arist.

Epill. courts, aussi larges que longs; glumes ov., fort. ventrues tronq. mucr.; t. pleine ou presque pleine au sommet; caryopse ov., renfl. bossu, à cassure demi farineuse, épi carré, ord. velu soyeux. . . . . . . . . . T. turgidum L. 1576 Cult. (Blé barbu). - Jn-At.

Var. à épi volumineux, ram. ( $T$. composituin L. f., Blé de miracle).

Epill. allongés, plus longs que larges; glumes oblongues, peu ventrues, assez long. mucr.-arist.; t. pleine; caryopse oblong, tr. dur, à cassure cornée; épi subtétr. ou cyl. compr.

Cult. (Blé dur). - Jn-At.

T. durum Desf. 1577

\section{Genre 546. - AGROPYRUM Pal. Beauv.}

+ Souche courte. fibr., sans stolons; glumelle inf. aristée à arètes plus long. qu'elle; f. minces, planes, rudes sur les 2 faces, à nerv. fines; glumes lanc. arist., à 3 -ă nerv., égalant $3 / 4$ de l'épill.

Bois, haies. - Mai-At.

A. caninum Rom. et Sch. 1578

+ Souche long. traçante; glumelle inf. mutique, ou arist. à arc̀te plus courte qu'elle; f. soit planes, rudes en dessus, soit canal. enroulées, rudes; glumes acum., arist. ou obt., à "艹-7 nerv.

$X$ Glumes lanc., acum. ou arist., égalant les $3 / \mathbf{k}$ de l'épillet; glumelle inf. lanc.-aig., mucr. ou arist.; f. minces, planes à nerv. fines, vertes ou glaucescentes. . . . . A. A. repens P. Beauv. 1579

Lieux incultes. - Jn-Sept. 
Glumes subobt., mutiques ou brièv. arist., égalant la moitié ou 2/3 de l'épillet à 4-9 fl. ; glumelle ord. obt. mucr. ou brièv. arist. ; f. planes à nerv. saill. ou canal.-enroulées, ord. glauques ou glaucescentes.

Épill. un peu écartés, compr., en forme de losange, à fl. mutiques ; glumes subobt. égalant la moitié ou $2 / 3$ de l'épill.; glumelle ord. obt., échancr.-mucr.; f. canal.-enroulées, fermes, à nervures saill. en dessus, glaucescentes. . A. acutum Rœm. et S. 1580 Lieux sabl. - Jn-Sept.

Épillets rappr. peu compr., ov., à fl. mutiques ou rar. arist.; glumes mucr. ou brièv. arist., égalant ord. la moitié de l'épill.; glumelle inf. obt., mucr. ou brièv. arist.; f. planes, fermes à nerv. saill. en dessus, tr. glauques.

Lieux secs. - Jn-Jt.

A. campestre Godr. et Gr. 1581

\section{Genre 3 '́t. - BRAGHYPOdIUM Pal. Beauv.}

Arètes de la glumelle inf., dans les fl. sup. de l'épill., plus longues que la glumelle, et formant ord. pinceau au sommet; pl. à souche courte fibr., poil., à t. assez grêles, feuillées presque jusqu'au sommet.

Bois ombragés. - Jn-Sept.

B. silvaticum Rom. et S. 1582

Arètes de la glumelle inf. 2-3 fois plus courtes que la glumelle ne formant jamais pinceau au sommet, pl. à souche ramp., ram., gl. ou pub., à t. raides, nues au sommet; à f. planes ou un peu enroulées, raides. . . . . . . . . . B. pinnatum P. Beauv. 1583 Lieux incultes et arides, bois secs. - Jn-Sept.

\section{GenRe 3\%8. - LOLIUM L.}

+ Fl. elliptiques-oblongues, làches et renfl., à la mat.; glumelle inf. coriace, ov. oblongue, à la fin débordée en tout sens par la sup.; ord. long. aristée sous le sommet, plus rar. mutique ou brièv. arist. à arête courte, flexueuse (L. speciosum Stev.); épill. oblongs, en coin ; pl. ann., n'émettant pas de fasc. stériles de f., à t. robustes, dress., raides; f. larges, planes, rudes; pl. vénéneuse.

Moiss., ch. cult. (Ivraie). - Mai-At.

L. temulentum L. 1584

+ Fl. lanc., serrées, non renfl. à la mat.; glumelles membr., l'inf. lanc. non débordée par la sup.; épill. lanc.; f. planes.

$X$ Épill. mutiques, à 3-10 fl., plus ou moins appliqués contre l'axe, ord. d'un tiers plus long que la glume; pl. viv. à souche émettant des fasc. de f. d'abord pliées en long.; t. dress. ou ascend.;

f. lisses . . . . . . . . . . L. perenne L. 1585 Prés, pâturages (Ray-grass). - Mai-Oct.

$\times$ Épillets arist., multiflores, plus ou moins étalés et écartés de l'axe, 2-3 fois plus longs que la glume; $f$. un peu rudes.

Pl. bisann. ou pérennante, à t. accomp. à leur base de fasc. de f. d'abord étr. enroulées par leurs bords; épill. à 5̈-12 fl. arist., au moins les sup., 2 fois plus longs que leur glume.

Prairies, souvent cult. - Mai-Oct.

L. italicum A. Braun. 1586

Pl. ann., à t. dépourvues de fasc. stériles de f.; épill. à 10-23 fl., .3 fois plus longs que leur glume. L. multiflorum Lamk. 1587 Ch. cult., nat. - Mai-At. 


\section{GENRE 5ั49. - NARDURUS Reichb.}

Épi unilat., au moins sup., grèle, dress. ou arq., épill. à 3-7 fl., élargis au sommet après la flor., ov. oblongs, aristés, rar. mutiques; glumes inég., la sup. moitié plus longue, tr. aig.; glumelle inf. lanc. lin., aristée ou mucronée. . . . . . . N. unilateralis Boiss. 1588 Lieux secs. - Avr.-Jt.

Épi nettement distique, raide, dressé ; épill. à 5-9 fl., atténués au sommet, ov. obtus, ord. non arist.; glumes presque égales, la sup. un peu plus longue, oblongue, subobt.; glumelle inf. elliptiq.-oblongue, subobt., mutique ou mucr. (var. aristata) . . . . N. Lachenalii Godr. 1589 Rochers et pelouses sil. - Mai-Jt.

\section{GenRe 5ว0. - NARDUS L.}

Pl. viv. à souche épaisse, dens. gazonn.; t. filif., raides, nues sup.; f. raides, enroulées sét.; ligule ov. ou lanc.; épill. lin., alt. sur 2 rangs; stigmate tr. long . . . . . . . . . N. stricta L. 1590 Bruyères et landes hum. - Mai-Jt.

\section{VII. - CRYPTOGAMES}

\section{FAMILLE 112. - FOUGËRES}

+ Frondes non roulées en crosse dans leur jeunesse, à pétioles verdâtres (dépourvus de sclérenchyme, ou fibres lignifiées brunàtres; sores provenant d'un groupe de cellules épidermirfues); frondes ord. 2, soudées inf. par leur rachis, la sup. fertile réduite aux rachis, l'inf. foliacée; simulant 1 seule fronde, fertile sup.; fructif. en épi ou en panic. term.; sporanges sessiles, sans anneau ni indusie, s'ouvrant en 2 valves par une fente transvers.

Fructif. en épi simple lin., unilat. distique; sporanges soudés entre eux et avec le rachis s'ouvrant par une fente perpendiculaire au rachis; fronde stérile ov. ou ov. lanc. à nervation anastomosée.

OPHIOGLOSSUM 551

Fructif. en pan. ord. rameuse; sporanges libres entre eux s'ouvrant par une fente longitudinale ; fronde stérile oblongue, ord. pennatiséquée à nervation libre, non anastomosée.

\section{BOTRY்GHIU M 552}

+ Frondes roulées en crosse dans leur jeunesse à pétioles noiràtres au moins inférieurement (sclérenchyme); (sores provenant d'une seule cellule épidermique); sporanges pédicellés ord. munis d'un anneau vertical s'ouvrant transversal., rar. à anneau rud. ou nul, s'ouvrant par une fente; fructif. ord. disposées à la face inf. des fr., rar. en pan.

$X$ Fructif. en pan. term. ram., rar. médiane; sporanges subglob., réticulés; à anneau tr. court lat. ou nul, s'ouvrant en long en 2 valves égales; pas d'indusie ni d'anneau vertical, nervation libre non anastomosée.. . . . . . . . OSMUNDA 553

$X$ Fructif. disposées à la face inf. des frondes; sporanges munis d'un anneau vertical, se rompant transvers., réunis en groupes, sores, recouverts par une membrane mince, indusie, ou nus.

= Fructif. entremêlées d'écailles luisantes qui couvrent toute la surface inf. des frondes pennatiséquéés; sores allongés sur de petites veines ou nervures, obliques entre eux et avec la nervure médiane; nervation plus ou moins anastomosée aux bords. 
= Fructif. nues ou recouvertes par une indusie; écailles et poils, s'ils existent, peu nombr.; nervation ord. libre.

Q Sores arrondis, nus ou à indusie fixée par le centre ou par sa base.

Sores sans indusie; souche longuement traçante.

POLYPODIUM 555

Sores munis d'une indusie; pl. en touffes, rar. stolonifères.

- Indusie orbiculaire ou arrondie fixée par le centre ou par un pli allant du centre à la circonférence; pl. robustes.

Indusie orbiculaire en bouclier, fixée par le centre; frondes bipennatiséquées, oblongues-lanc., à segments ov. en coin dentic.-spinuleux, à pétiole et rachis fort. écailleux.

ASPIDIUM 556

Indusie arrondie en rein, fixée par un pli déprimé rayonnant du centre à la circonférence; frondes 2-t fois pennatiséquées.

POLYSTIGHUM 557

- Indusie lancéolée ou ov., plus longue que le sore fixée par sa base sous le sore et le recouvrant comme un capuchon; pl.

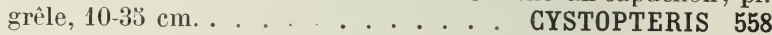

Q Sores ov., oblongs ou lin., placés le long des nervures secondaires ou aux bords de la fronde, à indusie plus ou moins allongée fixée à la nervure ou formée du bord de la fronde, libre de l'autre côté.

Sores placés le long des nervures secondaires.

$\curvearrowright$ Sores placés obliquement par rapport à la nervure médiane.

Ð Sores ov. ou oblongs; indusie oblongue, frangée, fixée par le côté, persist. . . . . . . . . ATHYRIUM 559

† Sores lin. ou oblongs; indusie lin. ou oblongue, fixée par toute sa long.

Sores plus ou moins également disposés de chaque côté de la nervure moyenne des segments à indusie s'ouvrant du côté de la nervure moyenne; fronde plus ou moins divisée.

ASPLENIUM 560

Sores parallèles rapprochées 2 à 2 , et simulant un sore unique à indusie s'ouvrant au milieu, le supérieur placé sur la branche inf. de la nervure secondaire, à indusie s'ouvrant inf.: l'inférieur sur la branche sup. de la nervure secondaire, à indusie s'ouvrant sup.; fronde simple.

SCOLOPENDRIUM 561

ڤ Sores placés parallèlement à la nervure médiane formant une ligne ord. continue; indusie ord. continue, fixée à la nervure second. continue ou interr. parallèle à la médiane et s'ouvrant du còté interne; nervation libre dans les frondes stériles, anastomosées près la nervure dans les frondes fertiles; frondes lanc. atténuées aux 2 extrémités, pennatiséquées ............. . . . . BLEGHNUM 562

Sores marginaux, à indusie s'ouvrant en dedans.

Sores formant une ligne continue à sporanges placés sur un réceptacle lin., continu dans l'axe de la courbure, sous le bord enroulé des frondes, indusie ord. double, l'externe ou bord membr. de la fronde, l'interne fimbrié (Pteridium Kuhn.).

PTERIS 563

Sores formant une ligne interrompue à sores placés sur les nervures sous le bord replié et membraneux des frondes formant indusie ...................... ADIANTUM 564 


\section{Genre วొ5̆. - OPHIOGLOSSUM L.}

Plante de 10-30 $\mathrm{cm}$. à rhizòme émettant ord. 1 seule fronde stérile ov. lanc. ou ov. arrondie à la base, rar. 2-3 fr., les stériles étr., atténuées inf. (O polyphyllum Br.). . . . . . . . . 0. vulgatum L. 1591 Prés argil., marais. - Mai-Jt.

La var. polyphyllum, pelouses hum. sil.

\section{GENRE 552. - BOTRYGHIUM Swartz}

+ Fronde stérile pétiolée, rapprochée de la souche, obovale en cneur, obt., ent., dentée incisée ou triséquée à lobes arrondis.

Pàturages secs. - Mai-Jn.

B. simplex Hitch. 1592

+ Fronde stẻrile, sessile ou subsessile, à limbe inséré vers le milieu ou au-dessus, de la plante, oblongue dans son pourtour.

Fronde stérile à limbe pennatiséqué ou pennatipartit, à segments plus longs que larges, ov. ou oblongs incisés ou pennatilobés.

Pàturages secs. - Mai-Jn.

B. matricariæfolium A. Br. 1593

Fronde stérile à limbe pennatiséqué, à segments tr. rapprochés, plus larges que longs, semi-lunaires ou obovales en éventail, ent. ou crén. . . . . . . . . . B. Lunaria Šw. 1594 Pâturages secs. - Mai-Jt.

\section{GenRe 033 . - OSMUNDA L.}

Frondes en touffes, de $60 \mathrm{~cm}$. à $1 \mathrm{~m}$. 30 à souche épaisse; frondes bipennatiséquées à segments oblongs-lanc., tronq. ou auric. à la base, ent. ou dentic. . . . . . . . . . regalis L. 1595 Marais et bois tourb. - Nai-Jt.

\section{Genre 3̋ว. - CETERACH Willd.}

Frondes étr. oblongues, pennatipartites à segments courts ov.-obt., ent. ou crén., alt., confluents, gl. et verts en dessus, couverts en dessous d'écailles brillantes d'abord argentées, puis roussâtres.

Vieux murs, rochers calc. - Mai-Oct.

C. officinarum Willd. 1596

\section{GENRE วొว̆. - POLYPODIUM L.}

+ Sores term. sur de courtes veines int. n'atteignant pas le bord des segments; veines épaissies au sommet; pétiole artic. avec le rachis; frondes oblongues-lanc., pennatipartites; rhizòme épigé, gros, couvert d'écailles roussâtres, gr . . . P. vulgare L. 1597 Vieux murs, talus ombragés. - Avr.-0ct.

Var. à frondes larges, ord. ov. deltoïdes, sores gr. orangés ( $P$. sematum DC.).

+ Sores dorsaux, non term., placés sur des veines alteignant le bord de la fronde et non épaissies au sommet; pétiole non articulé; frondes tripennatiséquées, triangul.-deltoïdes aussi larg. que long. à segments inf. pétiolés et bipennatiséqués; rhizôme plus ou moins grêle, hypogé, nu ou à écailles éparses, brunàtres ou noiràtres, petites.

Frondes molles, délicates, d'un vert tendre à pétioles secondaires et rachis lisses et gl.; rhizôme mince; sores distincts à la mat.

Bois ombragés. - Jn-Sept.

P. Dryopteris L. 1598

Frondes fermes, coriaces, d'un vert terne, à pétioles secondaires et rachis fin. pub.-gland.; rhizôme assez épais; sores confluents à la mat. . . . . . . P. Robertianum Hoffm. 1599 Vieux murs, rochers calc. - Jn-Sept. 


\section{Genre 5ั5̆6. - ASPIDIUM Sw.}

Frondes raides, coriaces, atténuées inf. brièv. stipitée; lobes des segments primaires atténués à la base, ord. non pétiolulés ni auriculés, tr. inég.; sores gr. ord. confluents, souvent médiaux.

Lieux ombragés, haies, ravins. - Mai-0ct.

A. lobatum Sw. 1600

Frondes assez molles, peu atténuées inf. long. stipitée; lobes des segments primaires nettement pétiolulés, tronqués, la plupart auriculés, inég. ; sores petits, ord. non confluents, souvent term.

Bois ombragés. - Mai-0ct.

A. aculeatum Sw. 1601

\section{GENRE 5̋7. - POLYSTIGHUM Roth.}

+ Lobules des frondes ent. ou à dents obt. et mutiques; frondes bipennatiséquées à segments étr. lanc., pennatipartits, à lobes nombr., confluents à la base.

$\times$ Frondes peu ou pas atténuées à la base, à pétiole tr. long, sans écailles ; souche grèle long. traçante ; lobes triangul.-lanc., subaig., à bords un peu repliés; sores pet., devenant confluents; indusie cad., nervures bifides.. . . . . P. Thelypteris Roth. 1602 Marais et bois hum. - Jn-Sept.

$\times$ Frondes fort. atténuées à la base à pétiole court, écailleux; souche épaisse, gazonn.; lobes lanc.-obt., à bords non repliés; sores distincts.

Frondes parsemées en dessous de glandes résineuses, jaunàtres, à pétiole faiblement écailleux et rachis nu; lobes ent. ou faibl. crén., larg. confluents à la base; sores nombr., alignés aux bords des lobes; indusie cad.; nervures souvent simples.

Bois mont. sil. hum. - Jn-Sept.

P. Oreopteris DC. 1603

Frondes non gland. en dessous, à pétiole et rachis tr. écailleux; lobes dentés-crén. à dents mutiques, étr. confluents à la base; sores assez gr., peu nombr., alignés près de la nervure médiane des lobes; indusie persist.; nervures bifides.

P. Filix-mas Roth. 1604

Bois. - Jn-0ct.

+ Lobules des frondes dentés-mucr. ou arist.; frondes 2-4 fois pennatiséquées à segments oblongs ou triangul.-lanc., pennatipartits ou 1-2 fois pennatiséqués; nervures bifides; indusie persistante.

Frondes étr. oblongues-lanc., un peu atténuées à la base, bipennatiséquées; lobes dentés-mucr. à dents souvent courbées; écailles courtes, larges, acum., concolores, roussàtres ; fronde fertile à segments repliés, dressés.... . P. cristatum Roth. 1605 Bois marécageux, marais. - Jn-Sept.

Var. fronde plus étalée, segments plus allongés, à dents long. acuminées (var. uliginosum Newman).

Frondes ov.-oblongues ou triangul.-lanc., non atténuées, mais souvent plus larges à la base, 2-3 fois pennatiséquées ; lobes mucr.arist.; écailles ord. larges brusq. mucr., souvent tronquées, concolores, roussâtres. . . . . P. spinulosum DC. 1606 Bois hum. - Jn-Sept.

Varic à frondes amples ord. larg. triang., 3-4 fois pennatiséquées; écailles du pétiole allongées, subaig., ord. bicolores, noirâtres au milieu, P. dilatatum DG. 


\section{GeNRE כ̋วั8. - GYSTOPTERIS Bernh.}

Fronde oblongue-lanc., 2-3 fois pennatiséquées, à segments secondaires pennatipartits ou lobés-dentés ; lobes élargis, ov., dentic.; sores épars devenant confluents; nervures secondaires atteignant le bord des lobes............... C. fragilis Bernh. 1607 Talus ombragés, vieux murs. - Mai-Sept.

\section{Genre อ๊ร9. - ATHYRIUM Roth.}

Fronde oblongue-lanc., 2-3 fois pennatiséquée, à segments primaires long. lanc. acum. portant $150-30$ paires de segments secondaires, lanc., pennatifides, à lobes ov. term. ord. par 3-4 dents aig.; pl. de $40 \mathrm{~cm}$. à $1 \mathrm{~m}$. à souche épaisse; nervures secondaires n'atteignant ord. pas le bord des lobes . . . . A. Filix-fœmina Roth. 1608 Bois hum., marais. - Jn-Sept.

\section{GENRE 500. - ASPLENIUM L.}

+ Frondes plus oll moins triang. dans leur pourtour, jamais divisées au sommet en segments lin-étr., aigus.

× Frondes triang.-lanc., bitripennatiséquées à segments et lobes nombr., ord. tr. rappr.; indusie à bord entier ; pl. assez robuste de $15 \%-40 \mathrm{~cm}$., à pétiole noirâtre, luisant.

Talus ombragés, vieux murs. - Jn-Sept.

\section{A. Adiantum-nigrum L. 1609}

X Frondes ov. triang., à pétiole noirâtre à la base, ou vert, à segments etlobes souvent peu nombr., et lâchement écartés ; indusie à bord cil. ou crén.; pl. grêles de ǒ-15̆ cm., d'un vert terne.

Frondes d'un vert terne, ov.triang., 1-3 fois pennatiséquées, à lobes obovales, souvent lobulés, arrondis et dentic. au sommet.

A. Ruta-muraria L. 1610

Vieux murs, rochers surtout calc. - Jn-Sept.

Frondes d'un vert luisant, ov. triang. ou triang., 1-2 fois pennatiséquées, ou réduites à 3-4 segments; lobes obovales ou lanc., long. atténués en coin à la base, souvent lobulés, atténués ou arrondis au sommet, dentic. ou incisé.

Rochers silic. - Jn-Sept.

A. Murbeckii Dörfler 1611

+ Frondes oblongues, lanc. ou lanc.-lin. dans leur pourtour, ou divisées au sommet en segments lin.-étr., tr. aig.

= Frondes bipennatiséquées, à segments ov. ou ov.-lanc., dentésmucr., les inf. plus courts que les moyens.

Segments inf. un peu réfléchis, ov., les moyens ov.-lanc. ou ov., à lobes obovales arrondis, peu atténués à la base, à dents divariq.; pl. étr. assez grêle de 8-20 cm. A. foresiacum Le Grand. 1612 Rochers sil. ombragés. - Mai-0ct.

Segments inf. tr. étalés, tous ov.-lanc., à lobes ov.-lanc. ou obovales, long. atténués à la base, à dents dress.; pl. assez robuste de $10-30 \mathrm{~cm}$. . . . . . . A. lanceolatum Huds. 1613 Rochers sil. ombragés. - Mai-0ct.

= Frondes pennatiséquées ou divisées seulement au sommet, rarement les segments inf. bitriséqués.

ơ Segments nombr. $130-40$ paires, ov. ou suborb., rappr., crén.dentés, tronqués et un peu en coin à la base, rachis brun noirâtre ainsi que le pétiole bien plus court que le limbe.

\section{A. Trichomanes L. 1614}

Talus et murs ombragés. - Mai-Oct

Segments peu nombr., étr., écartés; pétiole aussi long ou plus long que le limbe, brun seulement à la base. 
Fronde oblongue-lanc., plus large à la base, pennatiséquée à ¿-11 segments oblongs en coin, les sup. simples, incisés-dentés, les inf. plus gr., bi-trifides ou bi-triséqués.

Rochers silic. - Jn-Sept.

A. germanicum Weiss. 1615

Fronde divisée au sommet en 2-ð̊ segments allongés, lin-étr., ord. tr. aig., ent. ou à dents effilées en alène.

Rochers silic. - Mai-0et.

A. septentrionale Swartz. 1616

\section{GENRE 561. - SCOLOPENDRIUM Sm.}

Fronde lanc., 4-6 fois plus long. que larg., un peu rétrécie au-dessus de la base échancrée en cœur ; souche épaisse, gazonn.

Vieux murs, puits. - Nai-0ct.

S. officinale Smith. 1617

\section{GeNRe 562. - BLEGHNUM L.}

Frondes en touffes, pennatiséquées, dimorphes, les stériles étalées, brièv. pétiolées à segments oblongs, rappr. et confluents, les fertiles dress., plus longues que les stériles, long. pétiolées, à segments étr., lin.. . . . . . . . . . B. Spicant Roth. 1618 Bois et lieux tourb. sil. - Jn-Sept.

\section{Genre 563. - PTERIS L.}

Frondes amples, ov.-triang., 3-4 fois pennatiséquées, à segments nombr. et tr. divisés, les primaires souvent opposés; lobes entiers, obtus, coriaces, à face inf. souvent pubescente; pl. de $20 \mathrm{~cm}$. à $2 \mathrm{~m}$., à souche profonde, long. traçante . . . . . . . P. aquilina L. 1619 Bois sabl. - Jt-0ct.

\section{GenRe 561. - ADIANTUM L.}

Frondes ov.-oblongues, bipennatiséquées; segments pétiolés, ov., à lobes peu nombr., demi-circulaires ou obovales en coin, arrondis et lobés-palmatifides au sommet, les stériles dentic.; nervation en éventail; pétiole brun noirâtre, luisant. . A. Capillus-Veneris L. 1620 Rochers hum. - Jn-0et.

\section{FAMILLE 113. - RHIZOCARPÉES \\ Genre 563. - PILULARIA L.}

Pl. viv. à rhizôme filif., allongé, ramp. ou nageant; t. fasc., filif.; sporocarpes gros, 3-4 mm., solit., sessiles ou subsessiles à la base des f., glob., bruns, pub.-feutrés, puis gl. à 4 loges et 4 valves.

Bruyères hum. mares sil. - Jn-Sept.

P. globulifera L. 1621

\section{FAMILLE 114. - LYCOPODIACÉES}

\section{GenRe 566. - LYCOPODIUM L.}

+ Fructif. placées à l'aisselle des f. ou de bract. semblables aux f.; plantes petites, $\breve{5-20} \mathrm{~cm}$., feuillées.

Fructif. axillaires ne formant pas d'épi distinct, occupant toute la long. des ram.; t. redressées, à ram. dichotomes, nombr.

Bruyères, rochers sil. - Jn-Sept.

L. Selago L. 1622

Fructif. en épi distinct, à l'aisselle de bract. semblables aux f.; $t$. couchées-radicantes, à ram. fertiles dress., simples, peu nombr.

Bruyères hum. ou tourb. - Jt-0et.

L. inundatum L. 1623 
+ Fructif. disposées en épis, 1-7, term., cyl., munis de bract. tr. différentes des f., portés sur un long pédonc. commun faibl. feuillé; plantes atteignant $1 \mathrm{~m}$. à ram. dichotomes.

F. étr. appliq. contre les ram. et imbriq. sur \& rangs. aig.; ram. second. dress. fastigiés; épis 3-7.. . L. complanatum L. 1624 Bruyères. - Jt-Sept.

F. làch. appliq., ascend. ou unilat., term. par une long. soie; ram. ascend.; épis 1-3. . . . . . . . L. clavatum L. 1625 Bruyères, landes. - Jt-Sept.

\section{FAMtLie 115. - EQUISÉTACÉES}

\section{GeNre 567. - EQUISETUM L.}

+ T. de 2 sortes, les unes fertiles, blanchâtres ou roussâtres, term. par un épi, les autres stériles, vertes, à ram. nombr. dépourvus de lacune centr.

X T. fertiles paraissant avant les stériles, se desséchant après la sporose, simples, sans ram. vert.; t. stériles à ram. dress.

T. fertiles épaisses, à gaines amples, rappr., term. par 20-30 dents lin. en alène ; épi gros, long. 4-־ cm., larg. 1-2 cm.; t. stériles robustes, d'un blanc d'ivoire, fin. striées, à vert rappr. et à ram. octogones; premier entrenœud des ram. tr. court égalant 1/3-1/2 de la gaine caul...... E. maximum Lamk. 1626 Lieux argil. hum. - Mars-Mai.

T. fertiles assez minces, à gaines làches, espacées, term. par 6-12 dents lanc.-aig.; épi médiocre, long. $2-4 \mathrm{~cm}$., larg. 6-10 mm.; t. stériles grêles, d'un vert pàle, fort. sill. à vert. écartés et à ram. tétr.; premier entrenœud égalant la gaine caul. ou plus long. . . . . . . . . . . E. arvense L. 627 Lieux un peu hum. - Mars-Mai.

X T. fertiles paraissant avec les stériles, continuant à se développer après la fructif. et émettant des ram. vert.; t. stériles à ram. retombants, tr. ramifiés, tr. grèles, tétr.; épi assez petit, long.

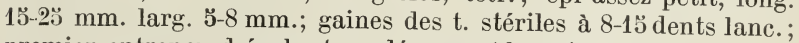
premier entrenœud égalant ou dépassant la gaine caul.

Bois hum. - Avr.

E. silvaticum L. 1628

+ T. toutes conformes, paraissant en mème temps, les fertiles vertes comme les stériles, simples ou ram., à ram. pourvus d'une lacune centr.

đ7 Epi obt., non apic.; t. lisses se desséchant en automne.

- T. grèles, fort. sill. à 6-8 côtes saill.; gaines lâches, bien plus long. que larges, term. par 6-8 dents, rar. 8-12, acum., bordées de blanc; épi grêle, làche, ov.-oblong.; ram. pentagones ; premier entrenceud tr. court égalant 1/3-1/2 de la gaine caul.

Lieux hum. - Mai-At.

E. palustre L. 1629

- T. ord. assez épaisses, quelquefois grèles et allongées, faibl. striées à 10-20 côtes peu apparentes; gaine term. par 10-20 dents étr. noiràtres ou d'un chatain plus ou moins foncé.

T. épaisse, creuse, à cavité centrale occupant $4 / 3$ du diamètre, simples ou munies sup. de ram. vert. pentagones; gaines étr. appliq., presque aussi larges que long., term. par 10-20 dents en alène, brunàtres ou noiràtres; épi assez gros, dense, ov., noirâtre. . . . . . . . . E. limosum L. 1630

Fossés aquatiques, marais. - Mai-At.

T. assez épaisse ou grêle, à cavité centrale occupant $2 / 3$ du diamètre ord. munie de ram. vert., tétr. ou pentagones, dans la 
partie moyenne, souvent long. nue et effilée sup.; gaines plus larg., presque appliq. inf., devenant très évasées et jaunâtres en approchant de l'épi, à 12-16 dents roussâtres; épi petit., dense, ov. oblong jaunâtre. . . . . . E. littorale Kühl. 1631

Lieux hum. - Mai-Jn.

$\sigma^{7}$ Epi mucr. au sommet; t. rudes persist.

T. plus ou moins robustes, dress. ou ascend., $50 \mathrm{~cm}$. à 1 m., à 10-30 côtes aplanies, à lacune centr. tr. gr.; gaines cyl. étr. appliq. contre la t., à dents en alène, unisill.; épi assez pet., noirâtre.

T. robustes, renfl. entre les nœuds, tr. rudes; gaines presque aussi larg. que long., à dents tr. cad., à car. pourvue de tuberc. proéminents sur 2 rangs régul. . . . . . E. hiemale L. 1632 Bois hum., tourb. - Jt-0ct.

T. assez grêles, raides, non renfl. entre les nœuds, assez rudes ; gaines souvent plus long. que larg. à dents persist. ou cad., à car. pourvue de tuberc. peu proéminents confluents en bandelettes transvers. . . . . . E. occidentale Hy. 1633

Champs sabl. hum., tourb. - Jt-0ct.

洛 T. tr. grêles, gazonn., couchées asceud., 10-40 cm., à 5̆-10 côtes convexes, à lacune centr. pet. ; gaines évasées en cloche, aussi larg. que long. à dents lanc., munies de 3 sillons, persist.; épi tr. pet. d'un noir orangé..... E. variegatum Schl. 1634 Sables argil. hum. - Nai-Sept. 
PLANCHES DU VADE-MECUM 


\section{FAM. 1 (1). - RENONCULACÉES}

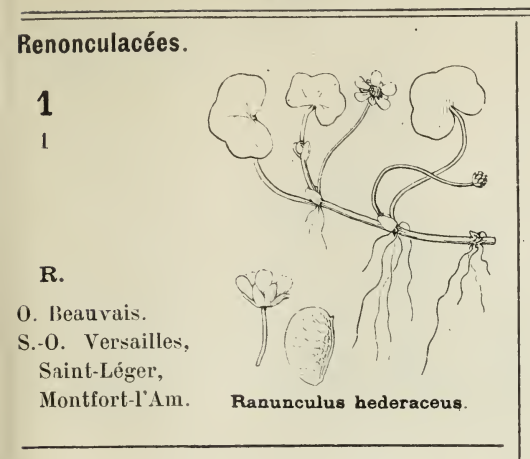

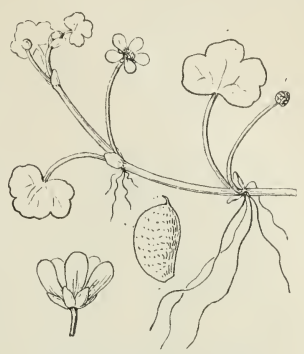

Ranunculus Lenormandi.

T. $\mathbf{R}$.

S. 0 . Versailles?
2

2

\section{3}

3

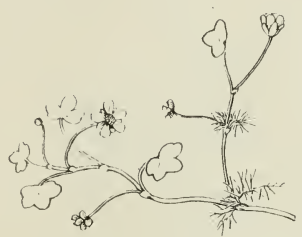

T. $\mathbf{R}$.

0. Beauvais.

S.- M. Fontaine bleau.

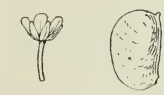

Ranunculus tripartitus.

T. $\mathbf{R}$.

S.- II. Fontaine bleau.

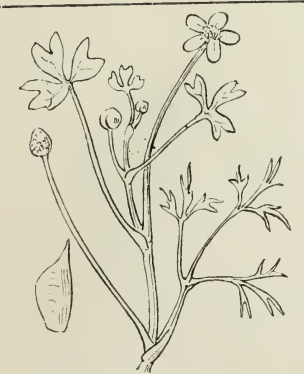

Ranunculus confusus

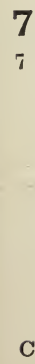

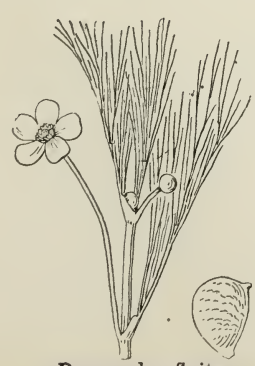

Ranuncalus fluitans.

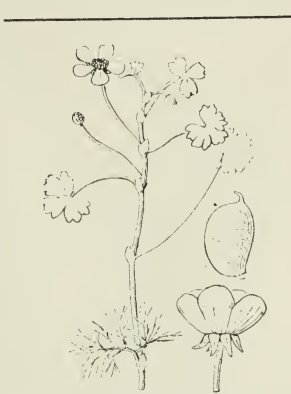

Ranunculus hololeucos

T. R.

0. Liancourt.

S.- M. Fontaine bleau.

S.-0. Versailles.

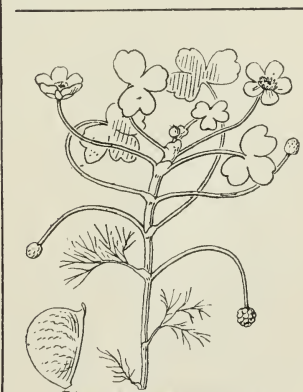

Ranunculus aquatilis.

T. C.

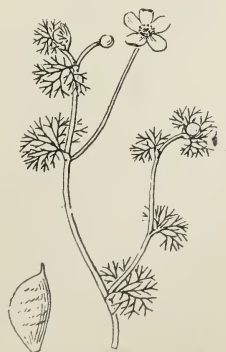

C. 
FAM. 1 (1). - RENONCULACÉES

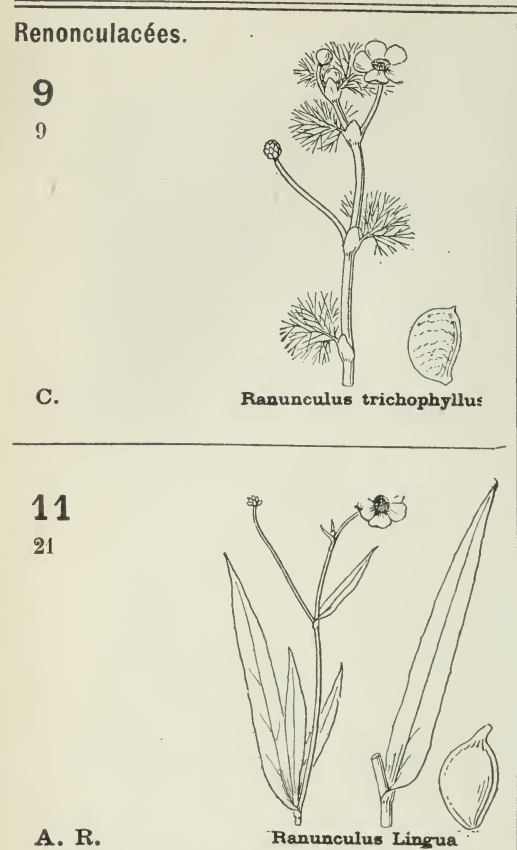

A. $\mathbf{R}$.

Ranunculus Lingraa

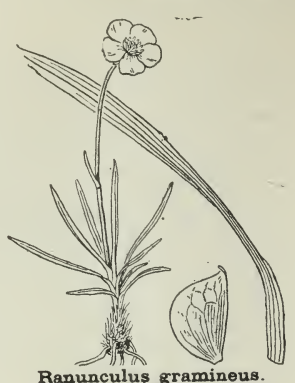

Ranunculus gramineus.

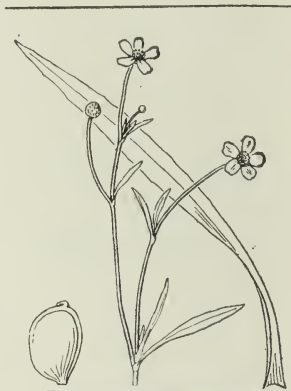

Ranunculus Flammula

c.

T. $\mathbf{R}$.

L. Malesherbes.

0. Savignies,

Ermenonville .

S. - M. Fontainebleau.

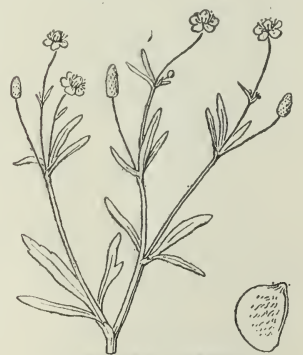

14

27

\section{3}

23

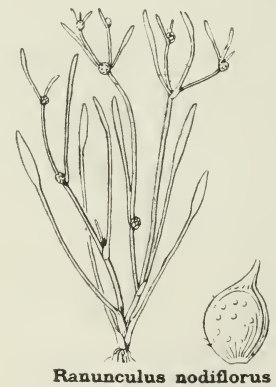

T. $\mathbf{R}$.

S. - M . Fontainebleau,

Nemours.

S.-0. La FertéAlais,

Itteville,

Boissy-le-Cuté.

Ranunculus nodiflorus

\section{5}

28

T. R.

S.-M. St-Fargeau, Rougeaux, Fontainebleau, Provins.

S.-O. Marly, Versailles.

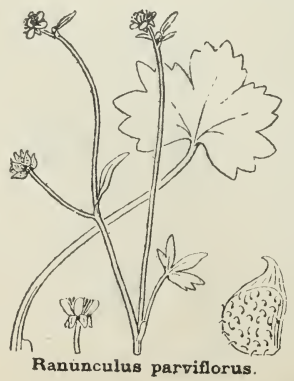

Ranunculus sceleratus.

c.

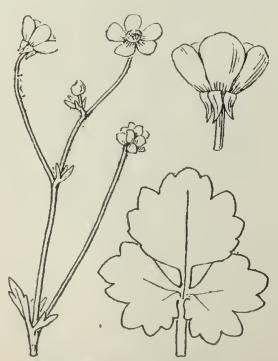

16

29 

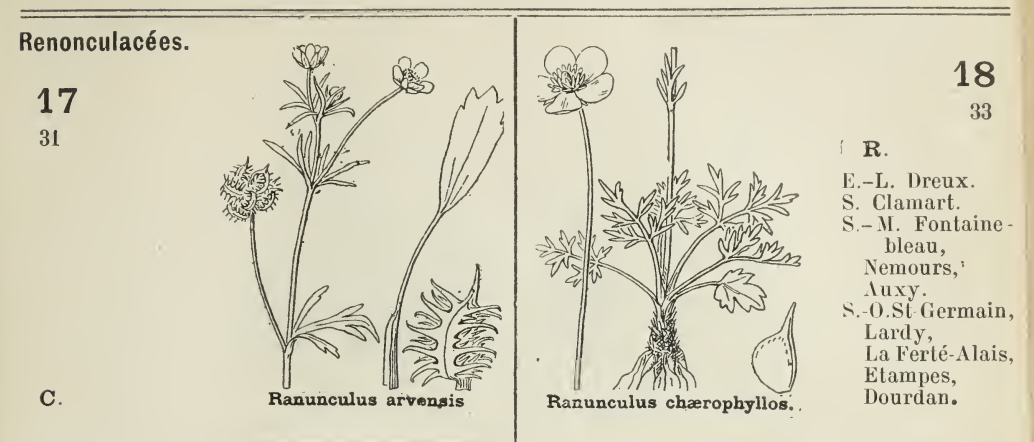

\section{9}

37

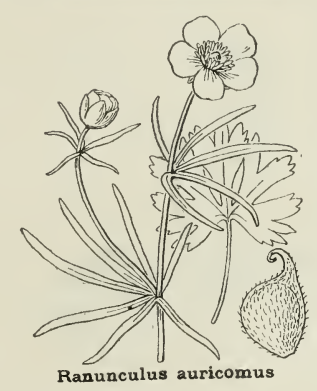

C.

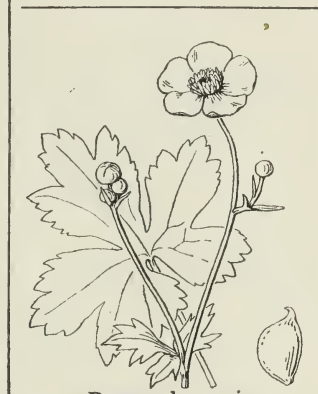

Ranunculus acris.

\section{1}

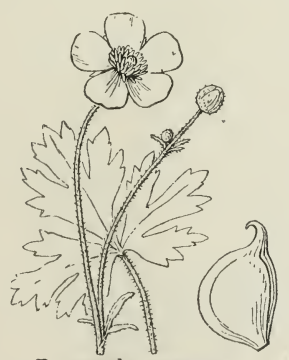

A. $\mathbf{R}$

Ranunculus nemorosus

23

44

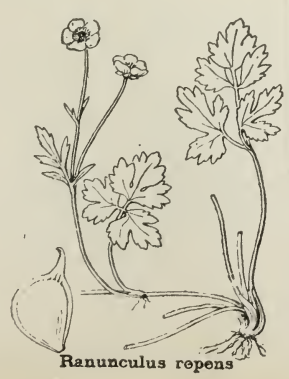

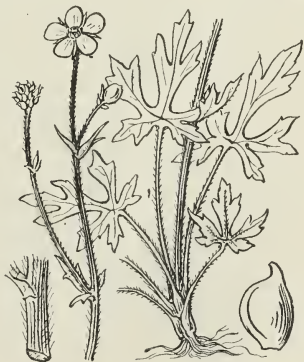

Ranunculus polyanthemoides
T. R.

S.-M. La Genevraye.

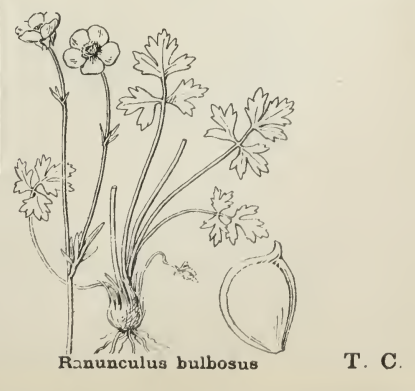



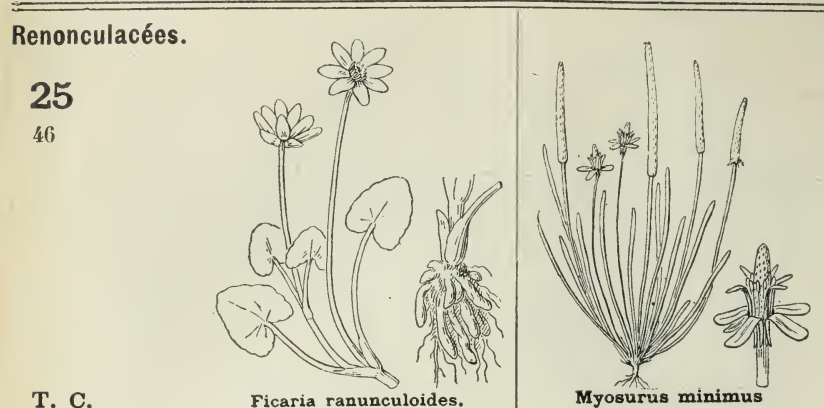

A. $\mathbf{R}$.

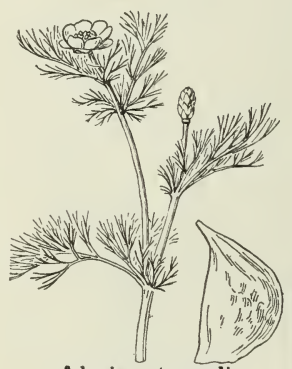

Adonis autumnalis.

29

ธ3

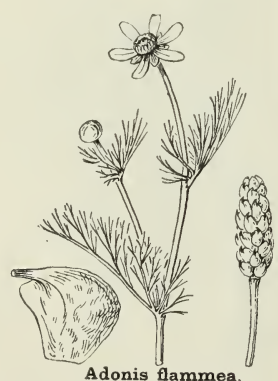

A. $\mathbf{R}$.

Adonis flammea.

\section{1}

64

A. $\mathbf{R}$.

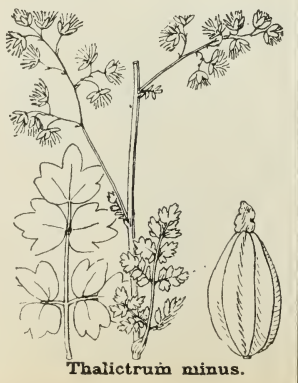

Myosurus minimus

A. C.

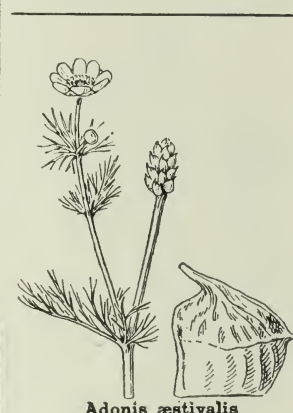

A. C.

26

48

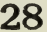

52

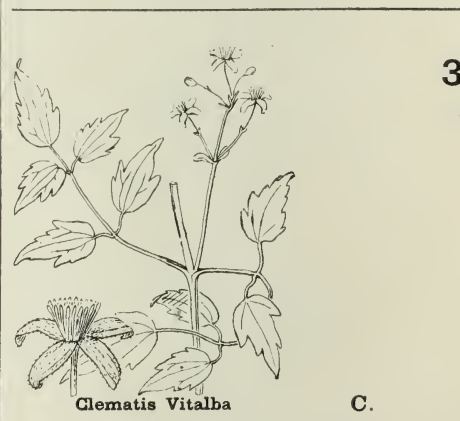

30

58

32

Me ${ }^{2}$ bis (Sup.)

and $\ln 2030$

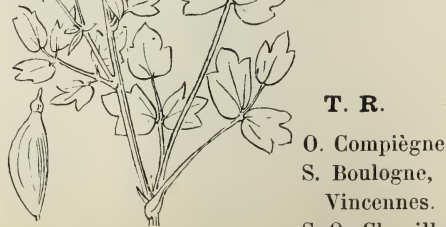

Thalictrum majus

cennes.

S. -0. Chaville. 


\section{FAM. 1 (1). - RENONCULACEES}

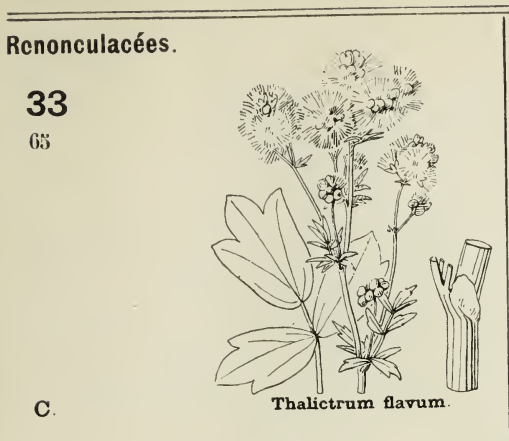

35

70

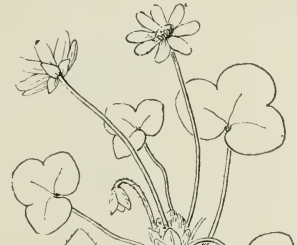

T. $\mathbf{R}$

0 . Russy.

S.-0. Magny, Jeufosse, Port-Villez.

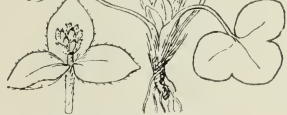

Anemone Hepatica.

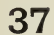

79

R.

A. Charly, Nogent - l'Ar taud.

0. Compiègne, Crépy, etc.

S.-M. Nanteuil.

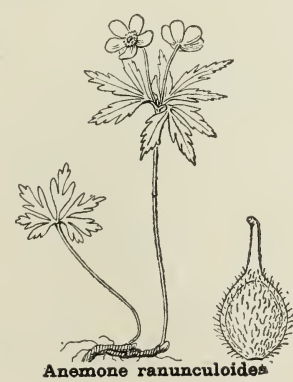

Anemone ranunculoides

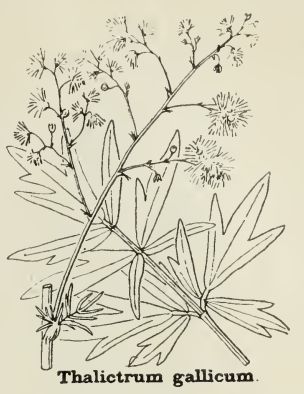

34

67

T. $\mathbf{R}$

L. Malesherbes

S. Boulogne, Vincennes, Meudon.

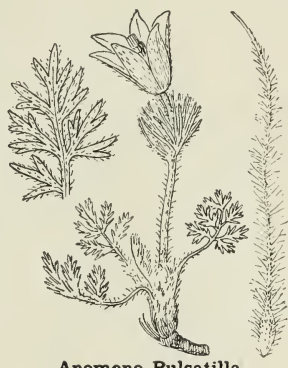

A. C.

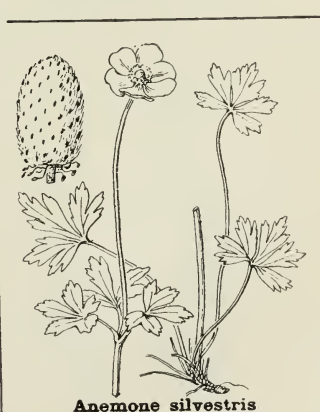

38

80

39

83

\section{R.}

E.-L. Dreux.

o. Chantilly, etc.

S'. - M . Fontainebleau.

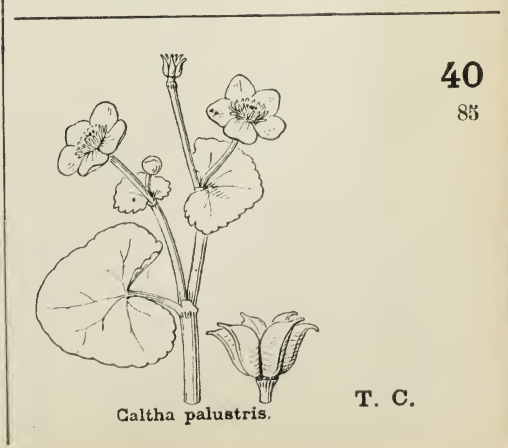


FAM. 1 (1). - RENONCULACÉES

\section{Renonculacées.}

41

87

R.

A. Villers-Cotterets.

E.-L. Chartres, Dreux.

L. Malesherbes.

II. Villeneuve-la

Lionne.

S.-M. Barbeanx Nemours.

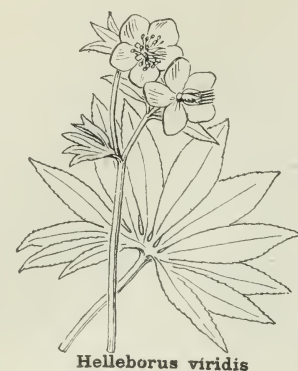

43

91

R.

A. Nogent-l'Artaud

S.-M. Souppes, Poligny,

La Ferté-sous Jouarre.

S.-0. Chaville,

Natur. Satory et Trianon

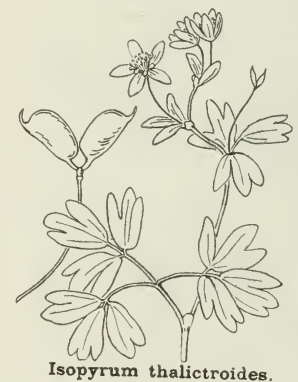

45

96

Cultivé et subspont.

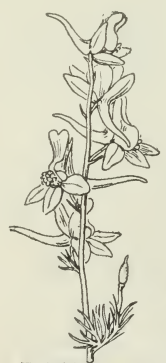

Delphinium Ajacis

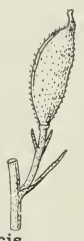

\section{7}

106

R.

A. Silly-la-Poterie.

0. Chaumont,

Vez, Chantilly S. -0 . Brignan court,

Santeuil

E. Aveny.

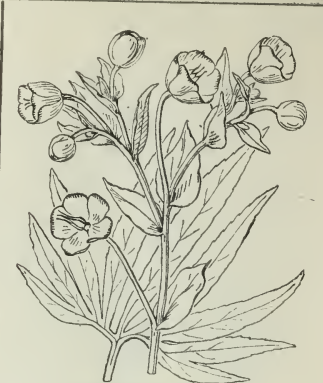

Helleborus foetidus

A. C.

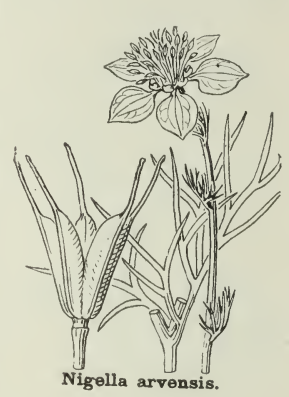

44

94

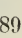

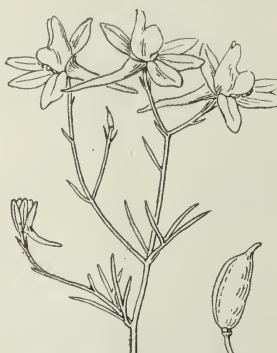

Delphinium Consolida.

T. C.

A. C.

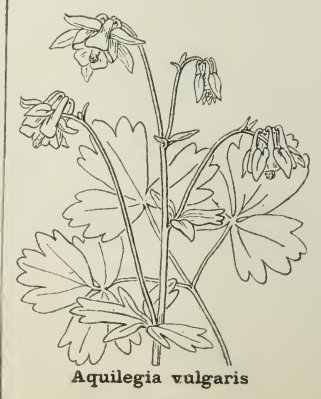


8 FAM. 4 (4). PAPAVÉRACÉES - FAM. 5 (3). FUMARIACÉES
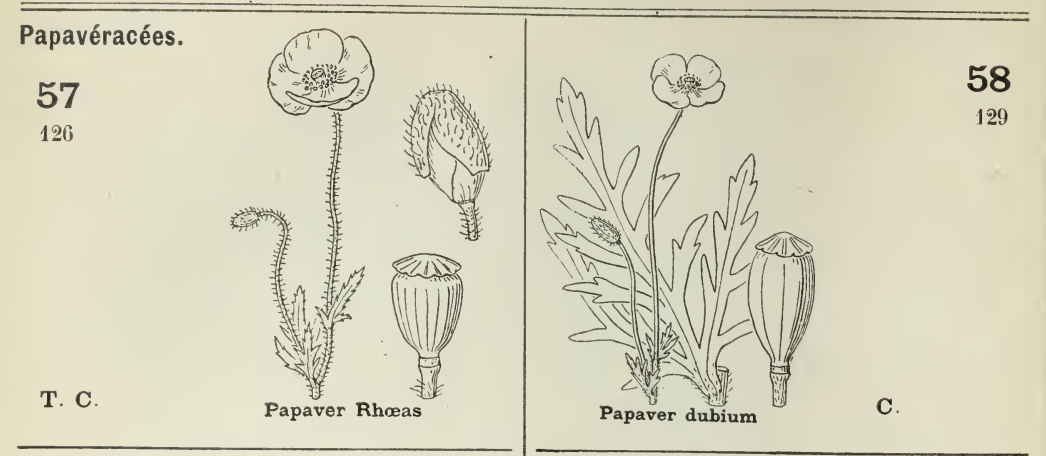

59

132

Natur. çà et là.
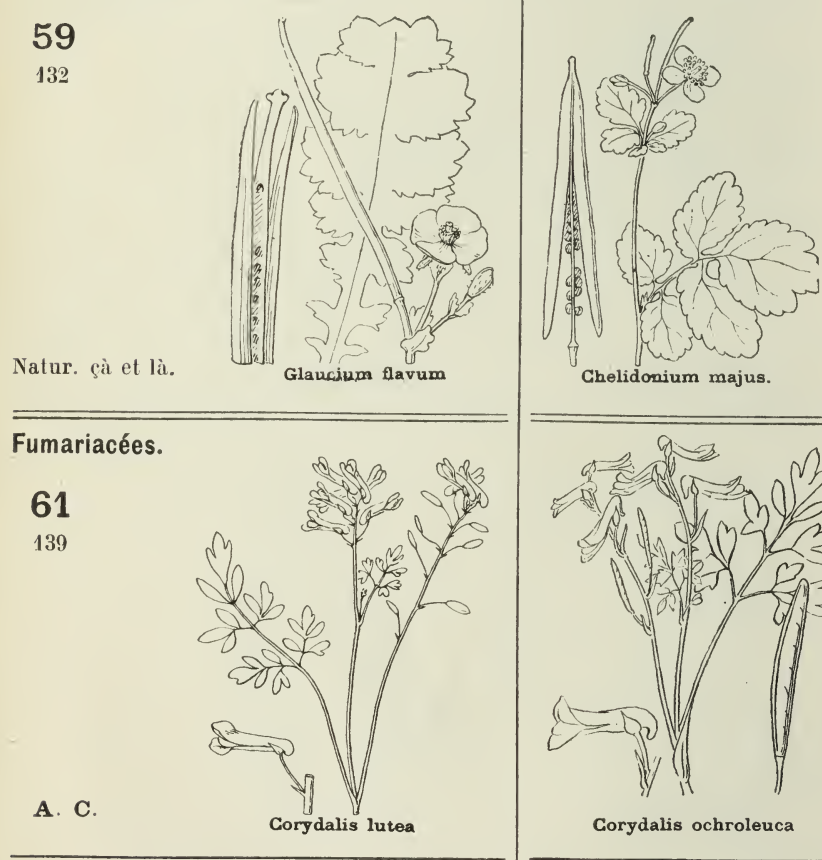

60

134

$$
\text { Ghelidonium majus. T. C. }
$$
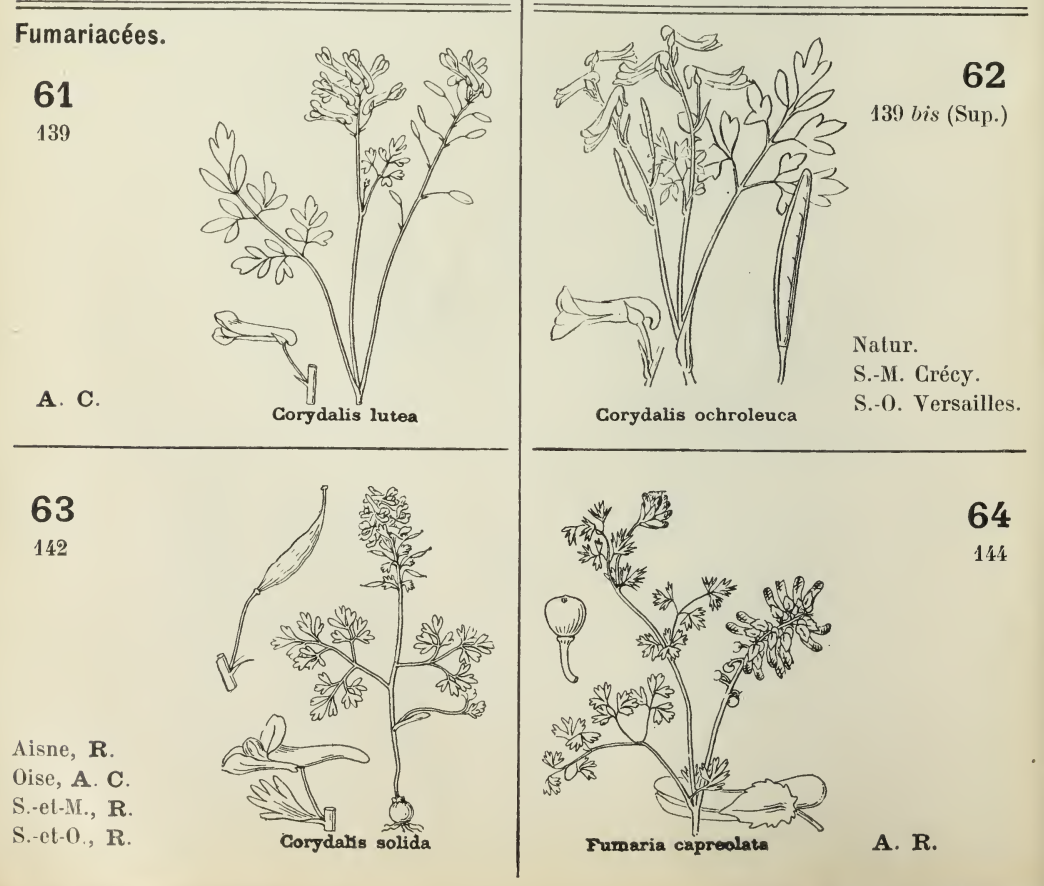
FAM. 6 (6). - CRUCIFÈRES
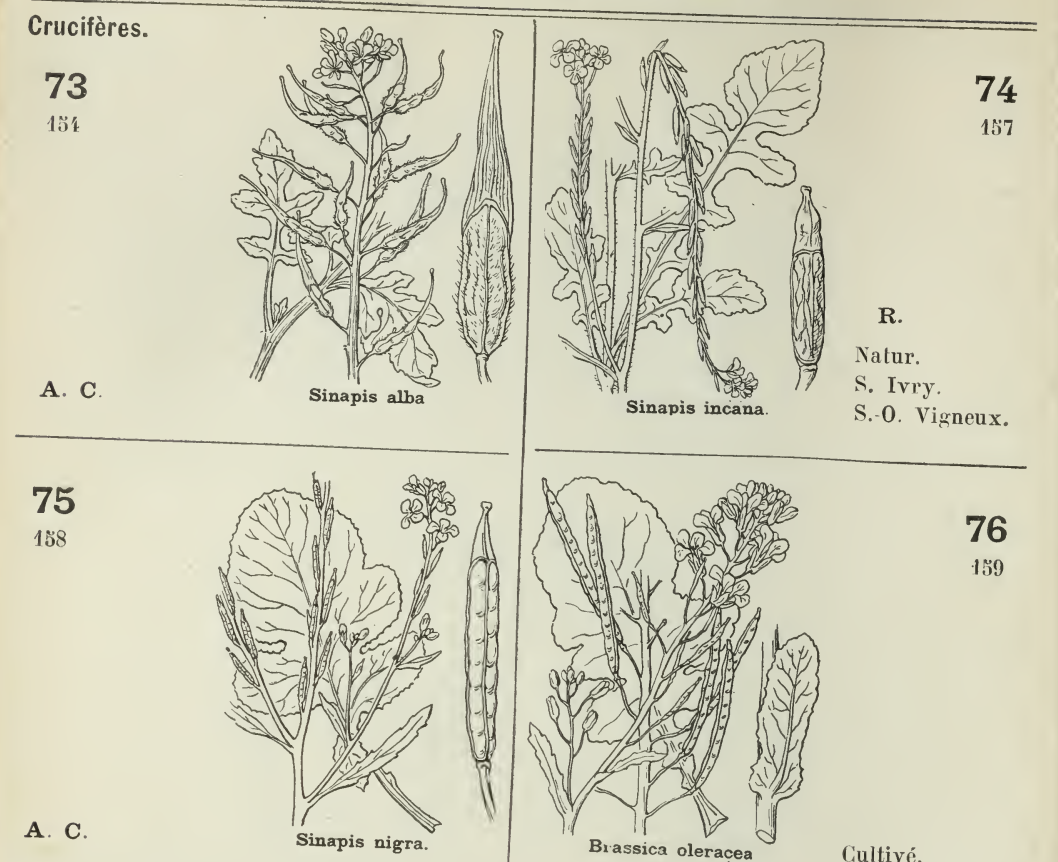

Natur.

S. Ivry.

Sinapis incana.

S. - 0. Vigneux.

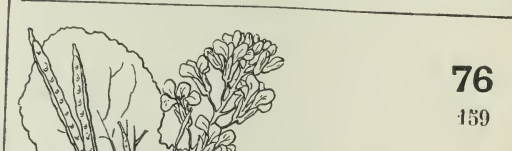

Cultivé.
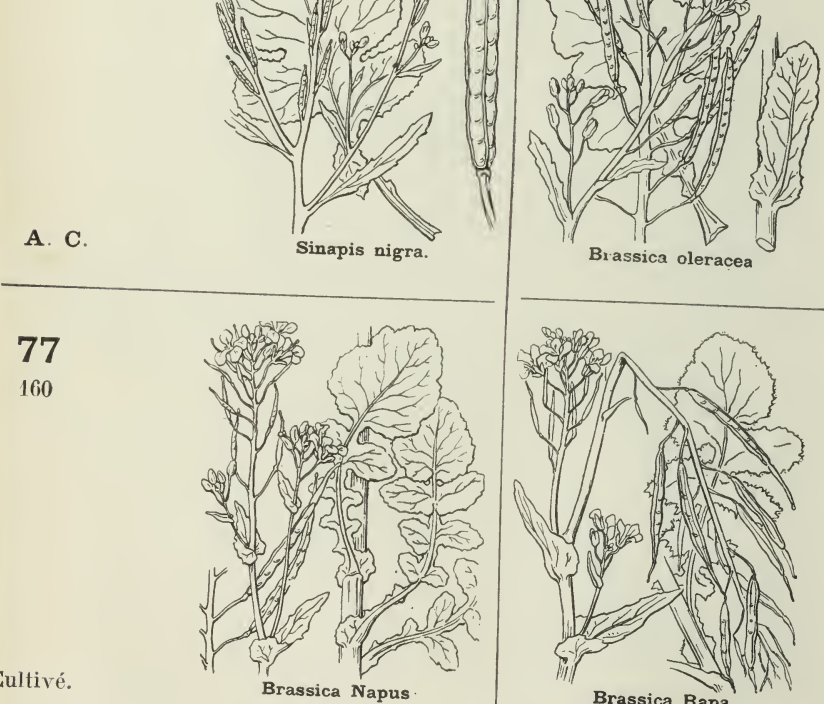

Cultivé.

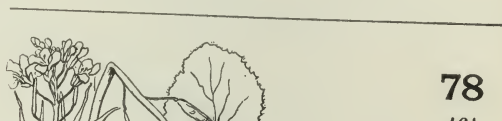

79

164
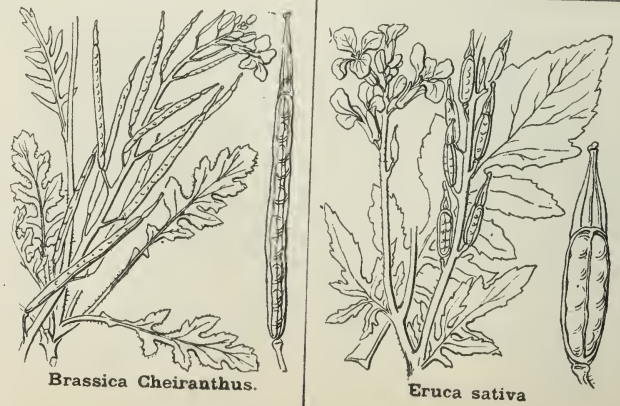

Cultivé.

161

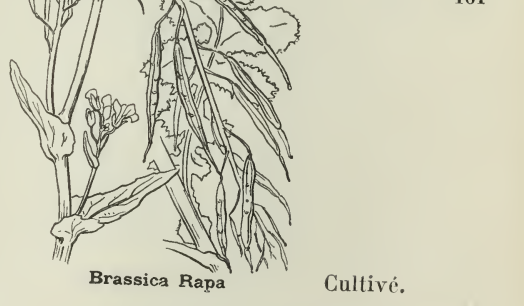

A. C. Brassica Cheiranthus.

T. $\mathbf{R}$.

E.-L. Dreux.

S.-O. La RocheGuyon. 


\section{irucifères.}

81

169

T. C.

nais pas partout.

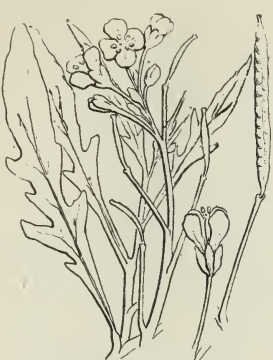

Diplotaxis tenuifolia

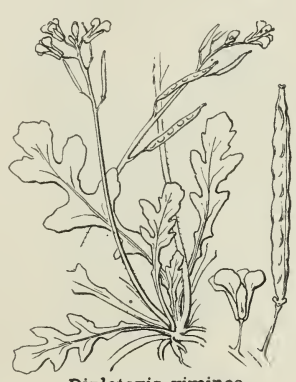

A. C.

Diplotaxis viminea

\section{5}

173

$\mathbf{R}$

E. Gisors,

Vernon,

Yézillon

S. Vincennes,

Saint-Maur

S.-.II. Chelles.

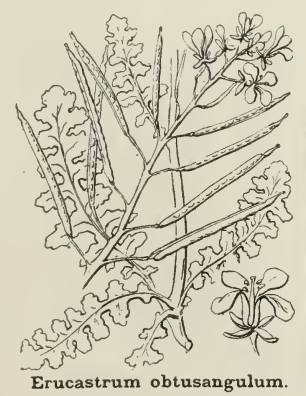

87

186

C.

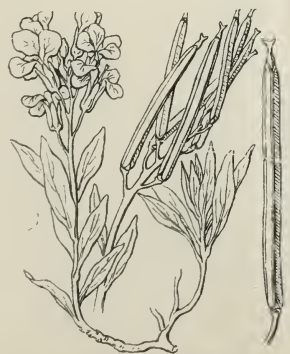

Cheiranthus Cheiri

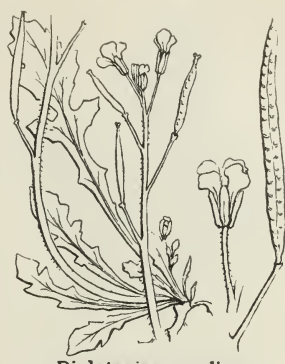

82

170
A. C.

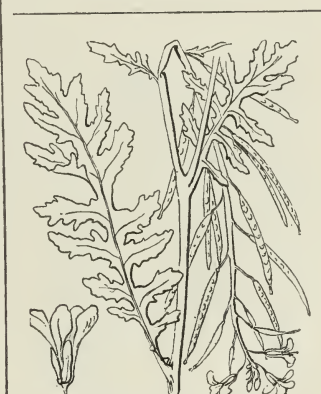

Erucastrum Pollichii

A. $\mathbf{R}$.

84

172

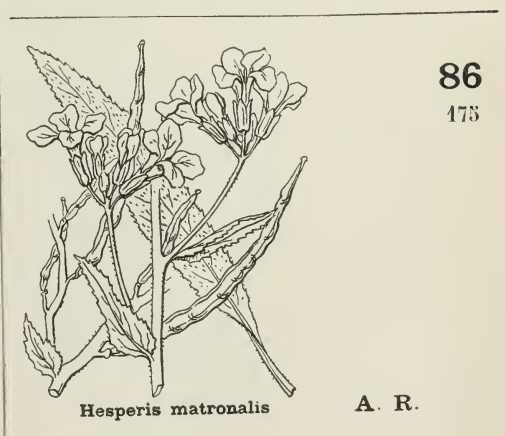

$-$

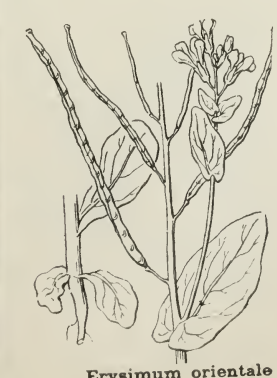

88

187

A. $\mathbf{R}$. 

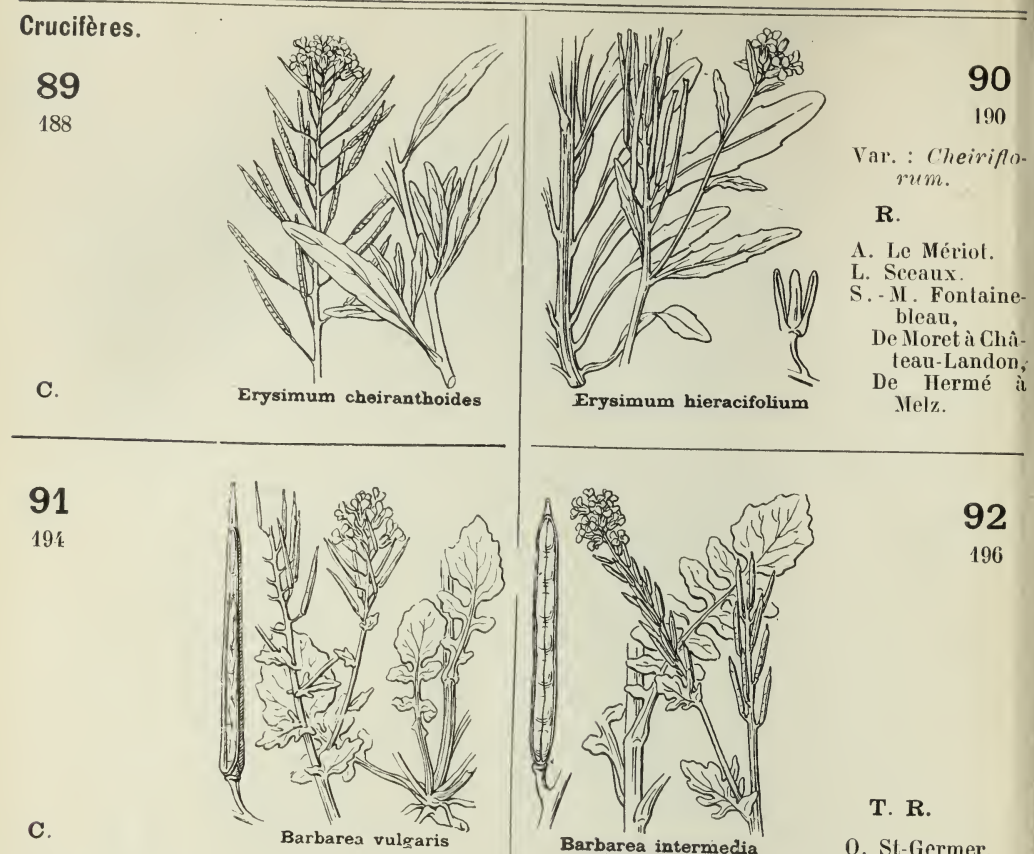

R.

A. Le Mériot.

L. Sceaux.

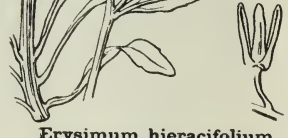

S. - M . Fontaineblean,

De Noret à Chìteau-Landon, Erysimum hieracifolium

De Hermé ì Melz.

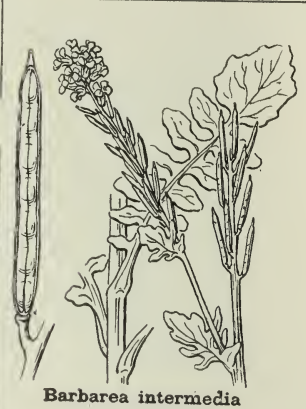

T. $\mathbf{R}$.

o. St-Germer.

\section{3}

198

Cultivé et subsp.

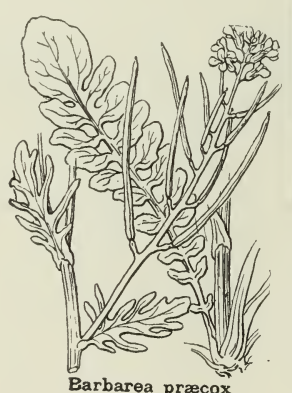

Barbarea præcox

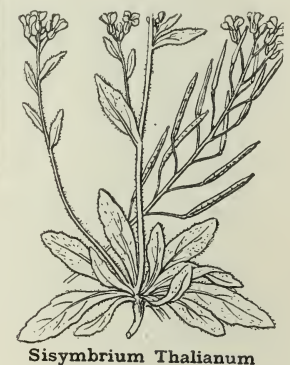

94

199

c.

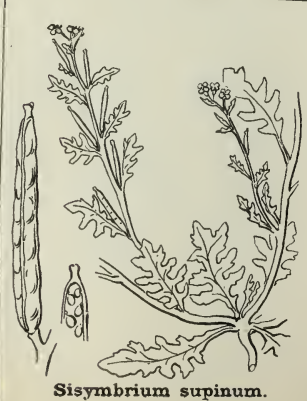

96

202

R.

o. Marais de Bresle, Bulles.

S. Bords de la Seine et de la Marne.

S.-M. Tourbières de Poigny. 
rucifères.

97

203

T. C.

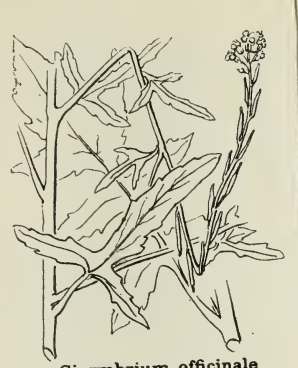

Sisymbrium officinale

\section{9}

211

C. pas partout-

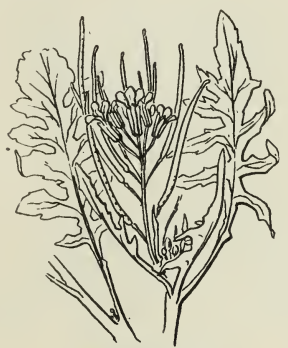

Sisymbrium Irio.

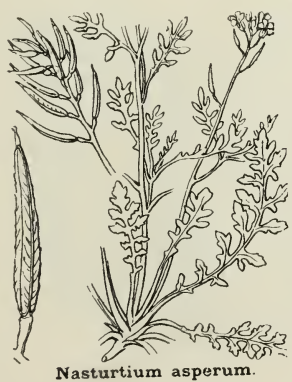

L. Thurelles, Dordives,

Fontenay.

S. Carrières,

Ivry.

S.-M. Grez,

Montigny,

Nelz.

Nasturtium asperum

103

217

c.

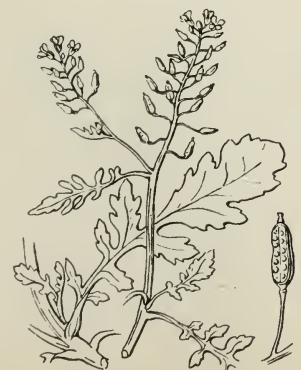

Nasturtium palustre

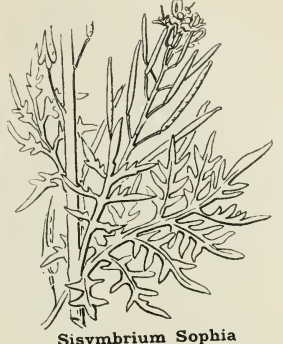

98

207

C. pas partout.

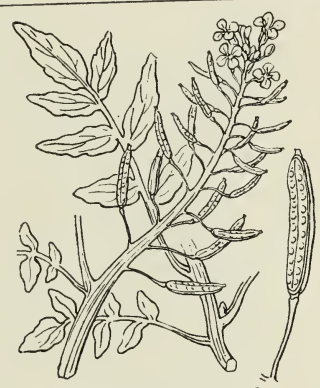

Nasturtium officinale

c.

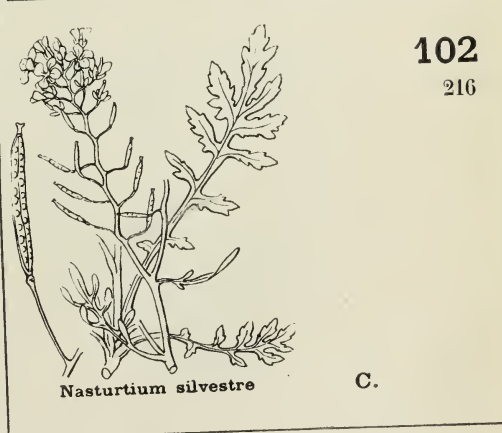

104

218

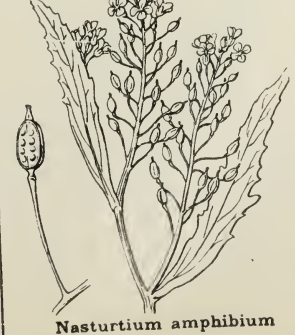

Nasturtium amphibium

C. 

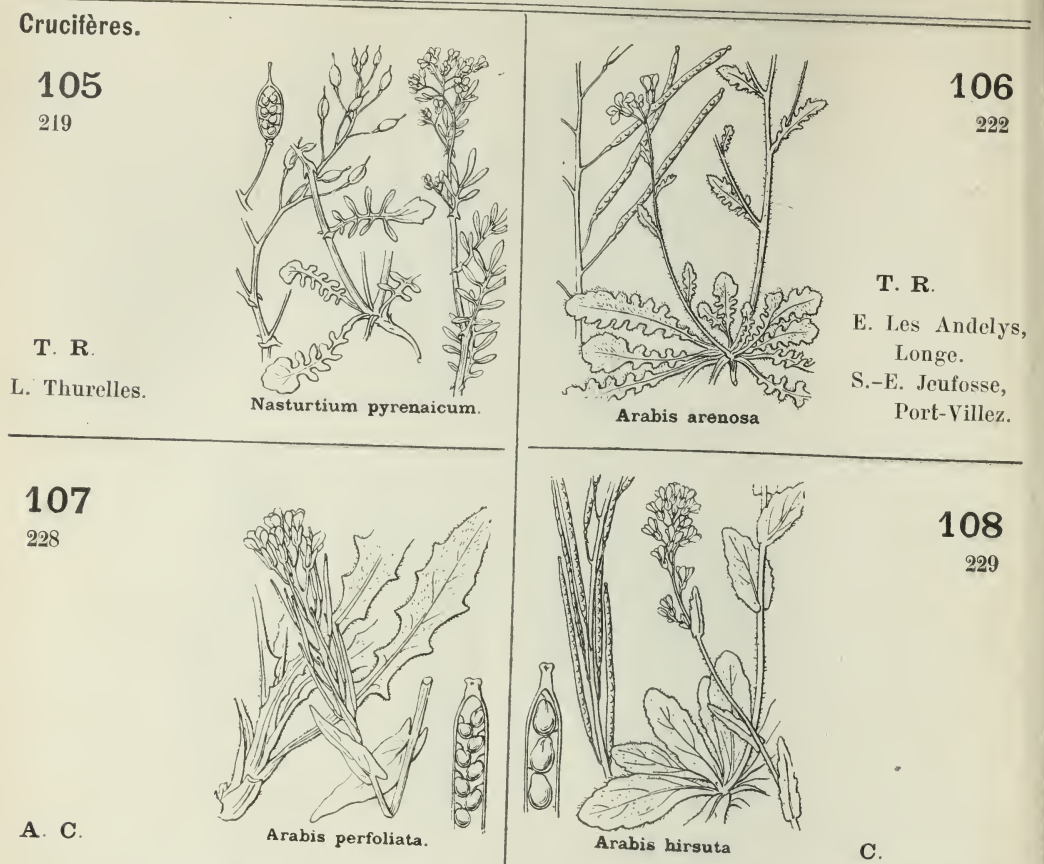

108

229
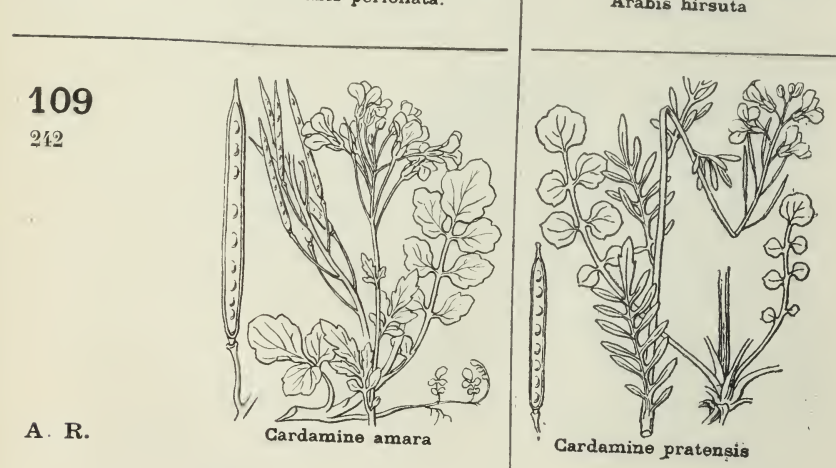

C.

c.

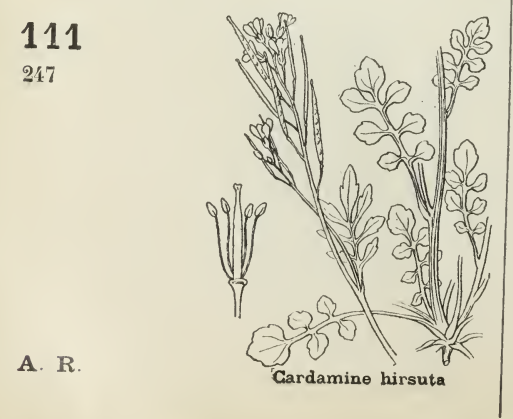

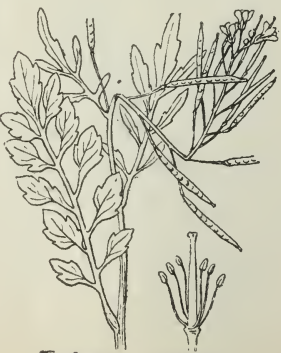

Cardamine silvatica
112

218
R.

0. Compiègne.

S.-O. Vaux-deCernay, Lozère. 


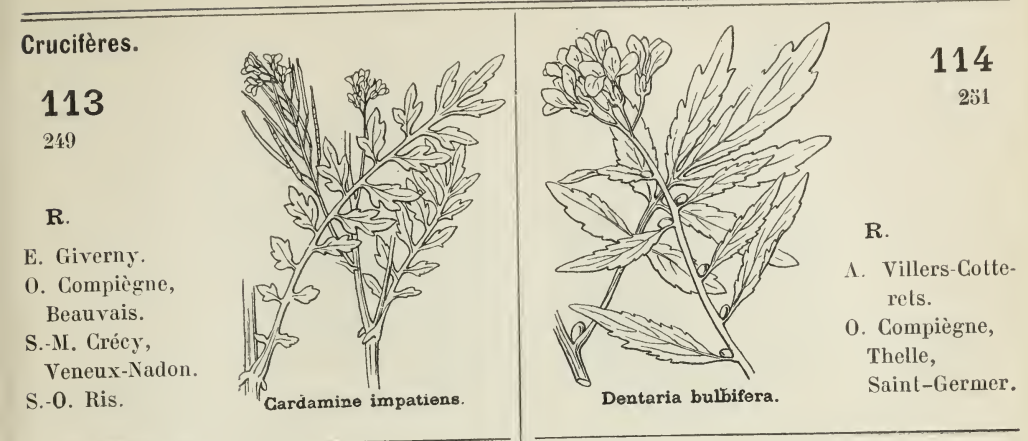

\section{5}

233

R.

A. Longpont.

II. Villeneuve-la Lionne.

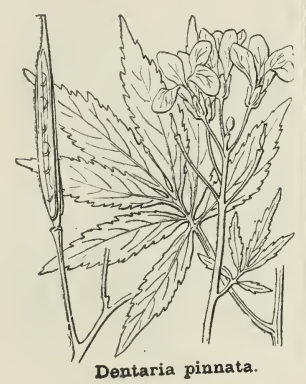

Dentaria pinnata.

\section{7}

257

Subspont.

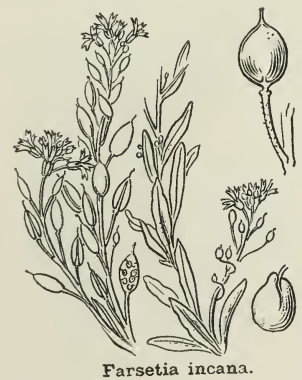

119

261

R.

S. Saint-Maur.

S.-II. Fontainebleau.

S.-0. Maisse.
Farsetia incana.

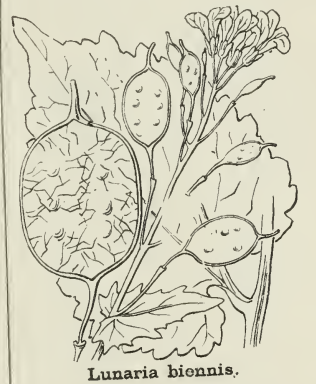

116

255

Cultivé et subspont.

\section{8}

259

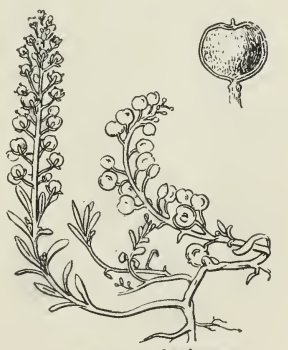

Alyssum calycinum

C.

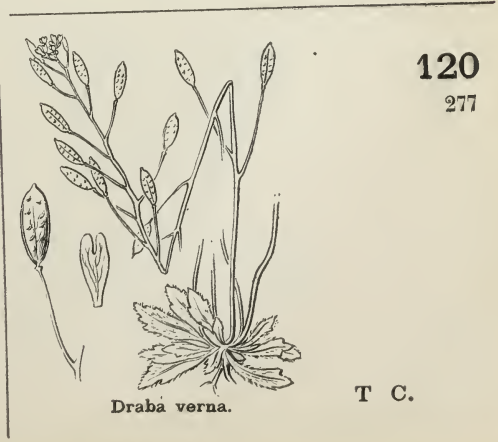



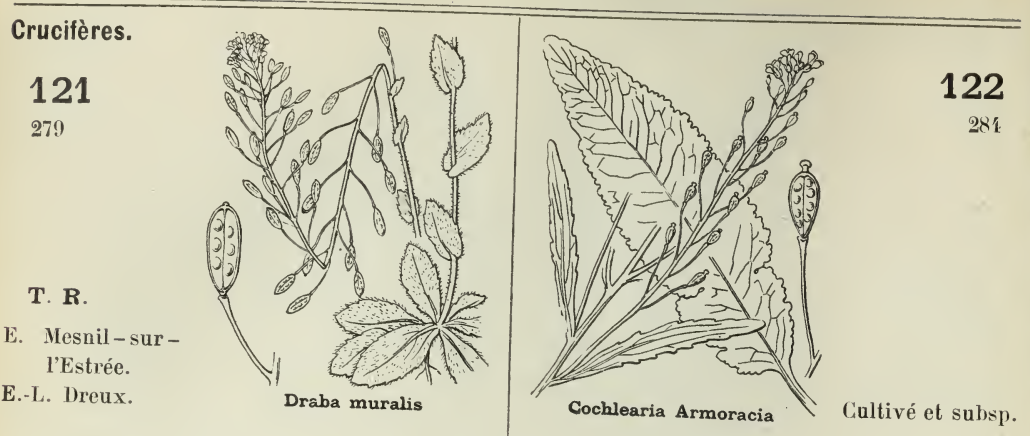

123

283

Naturahsé.

S.-M. Nemours.

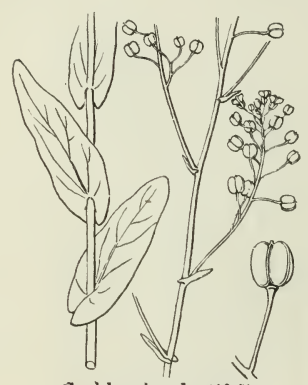

Cochlearia glastifolia.
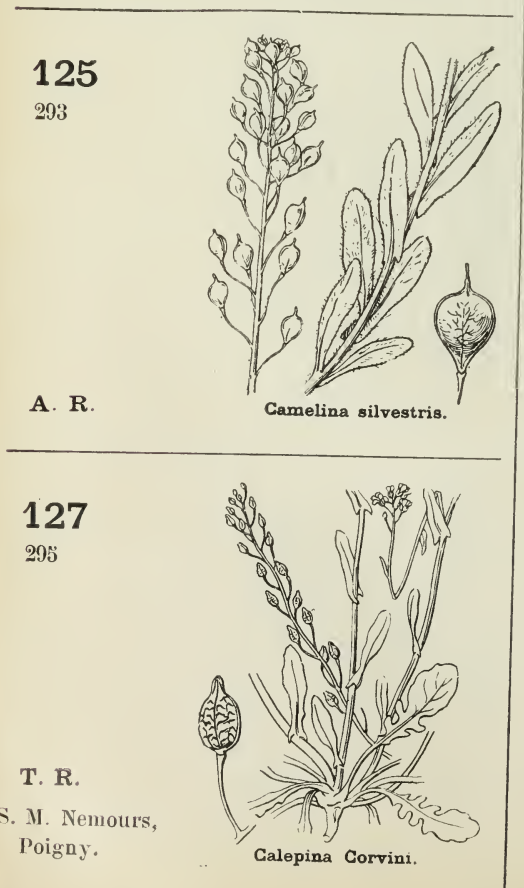
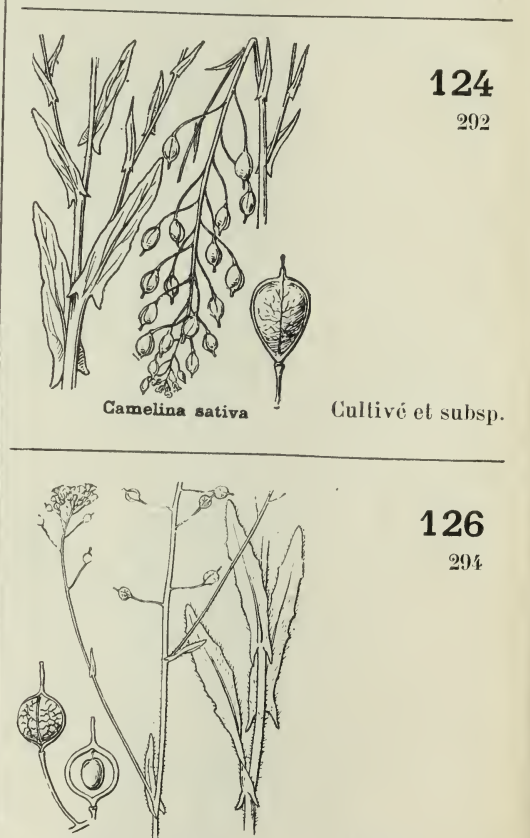

126

294

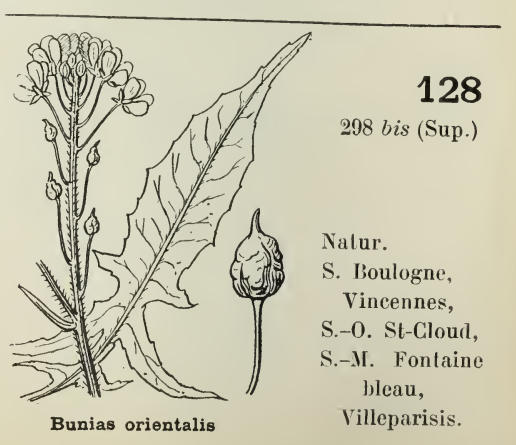




\section{Crucifères.}

129

299

A. C.

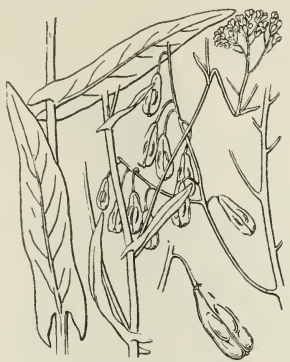

Isatis tinctoria
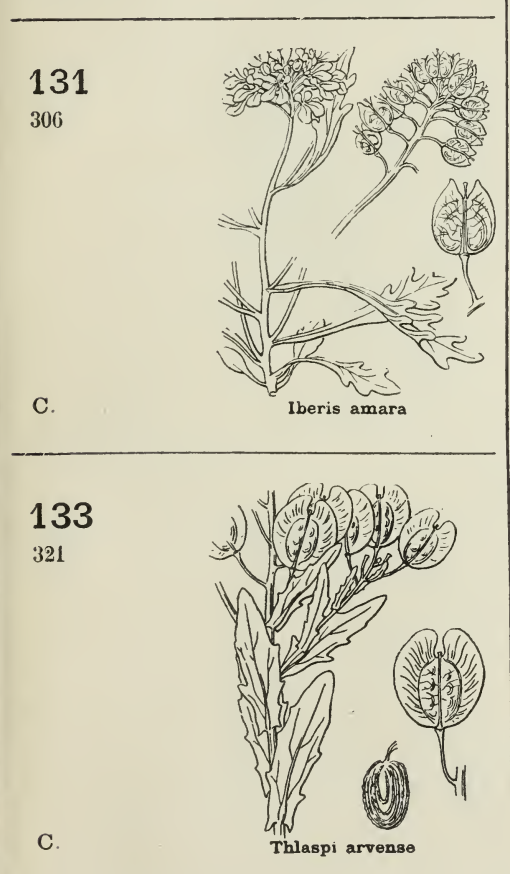

135

328

T. R.

E. Les Andelys S. -0. La RocheGuyon.

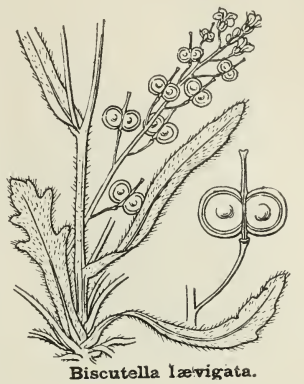

130

302

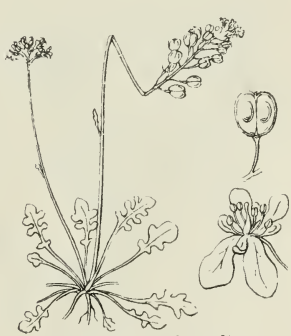

132

317

T. R.

E. Les Andelys, Tosny.

A. C.
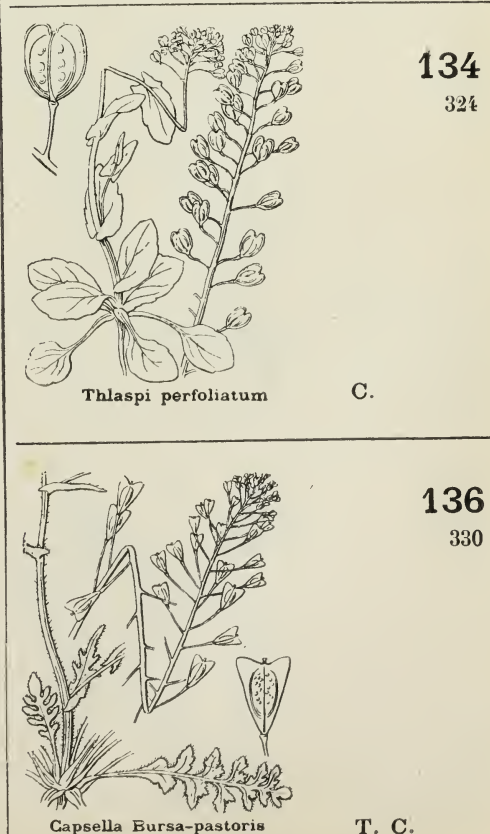

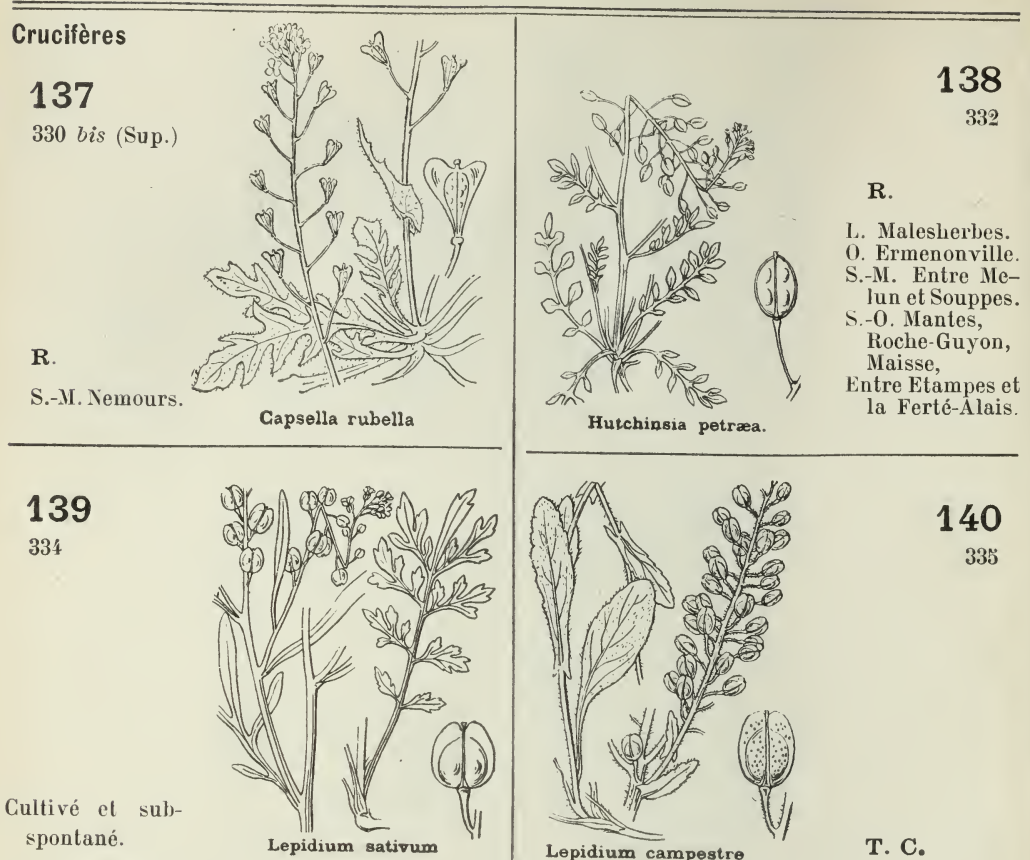

\section{1}

336
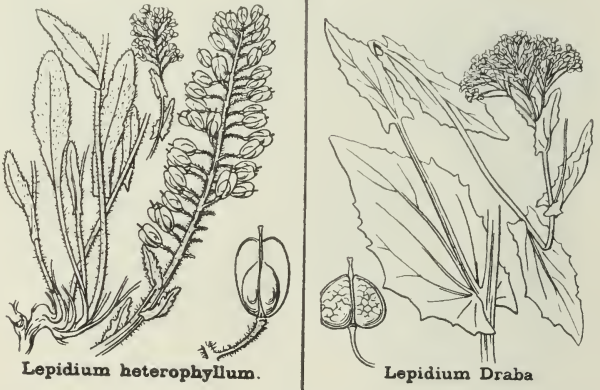

R.

S. Bois de Boulogne,

S.-0. Le Vésinet, Natur.

Lepidium heterophyllum.

\section{3}

341

R.

Bords de la Marne, de la Seine el du Loing.
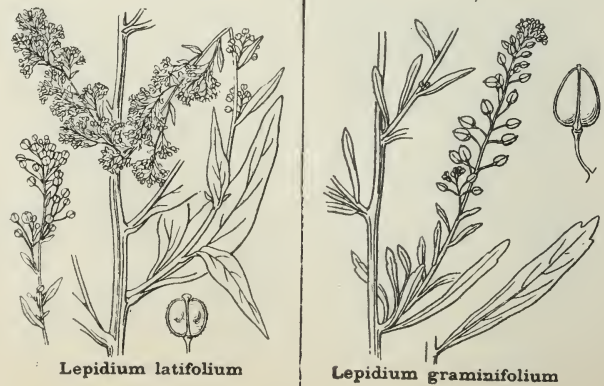

A. $\mathbf{R}$. 
Fam. 6 (6). CRUCIFÉRES. - Fam. 7 (8). CISTINÉES.
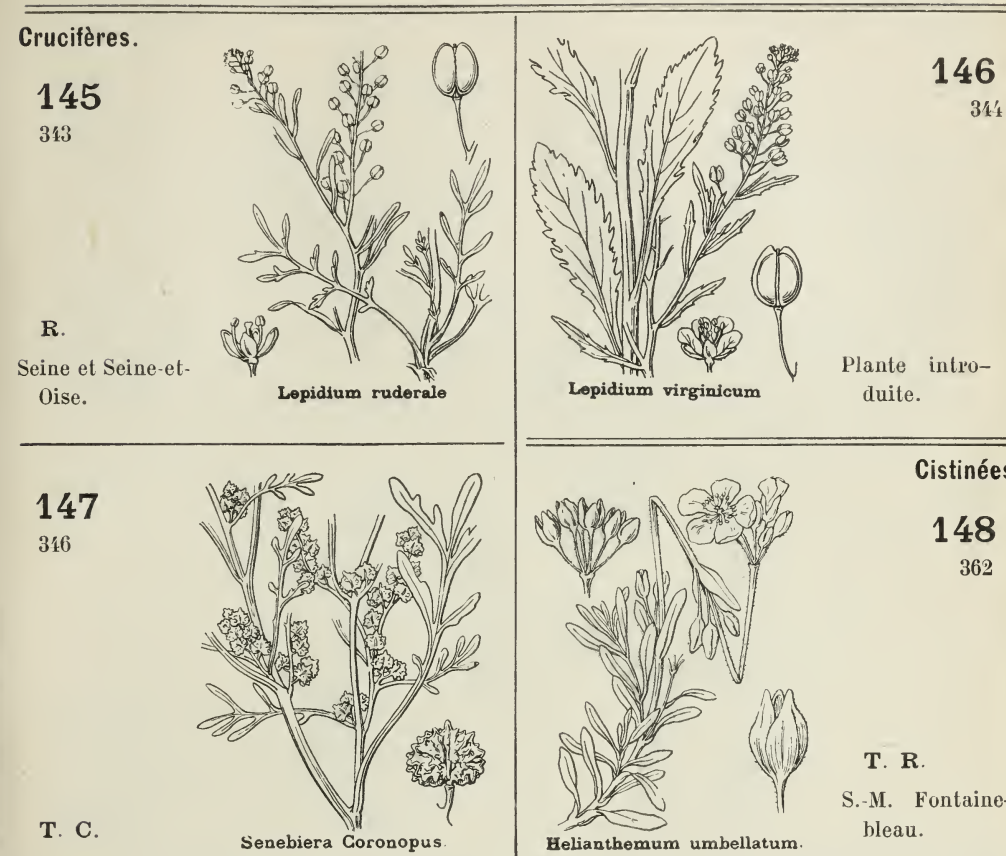

Cistinées

Helianthemum umbellatum

\section{8}

362
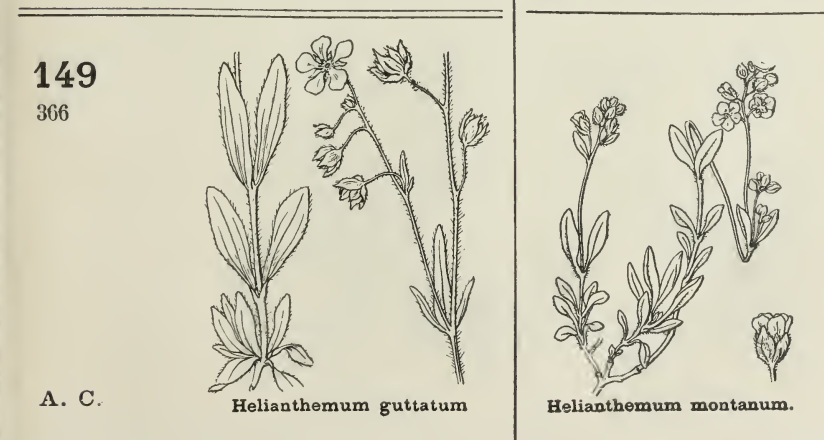

T. $\mathbf{R}$.

S.-M. Fontainebleau.

bleat.

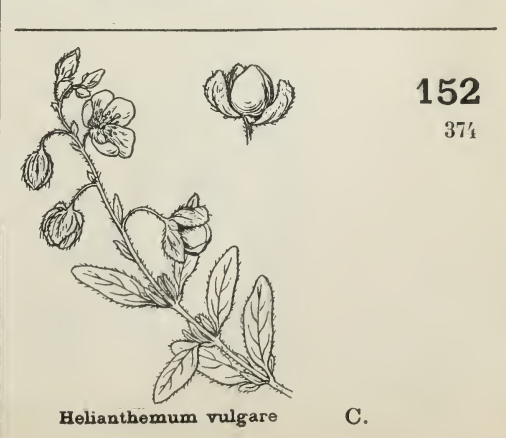

E., S.-0. De Mantes aux Andelys.

S.-M., Moret, 1 Le Genevraye.

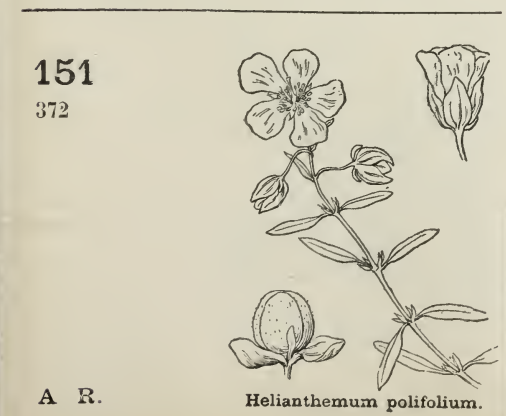



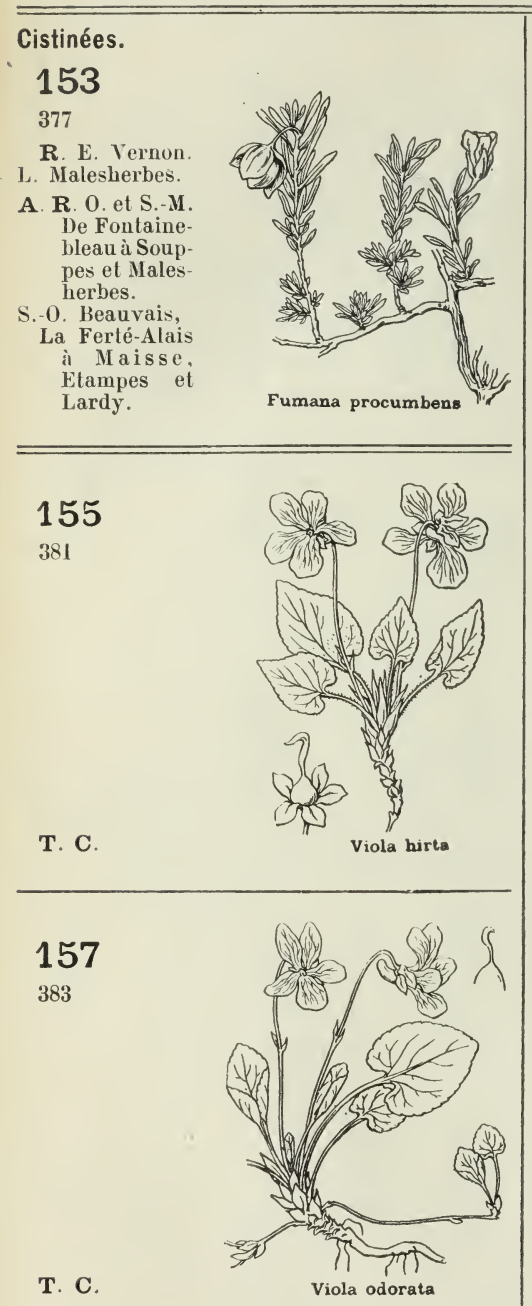

159

$385^{4}$ (Sup.)

T. $\mathbf{R}$.

0. Compiègne.

S.-M. De St-Sauveur à $\mathbf{H e r -}$ mé.
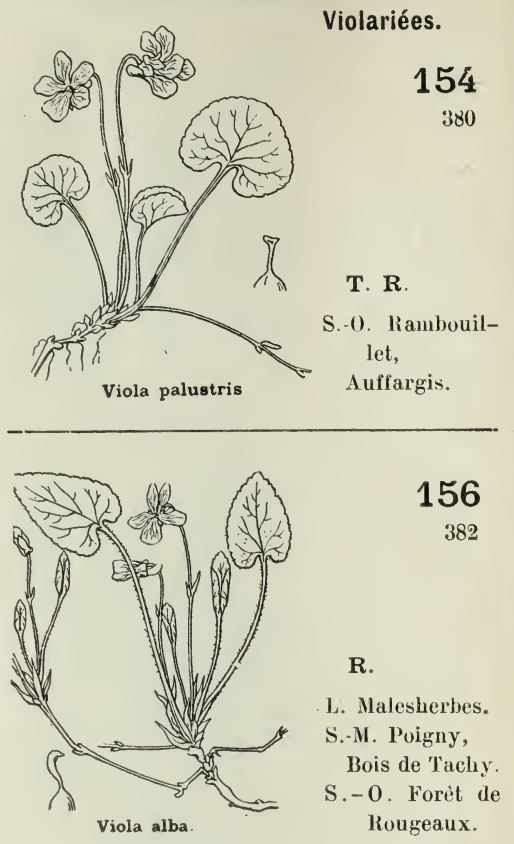

156

382

R.

1. Malesherbes.

S.-M. Poigny,

Bois de Tachy.

S. -0 . Forèt de

Rougeaux.

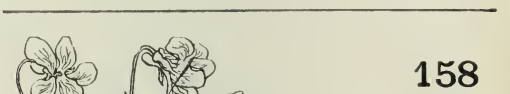

383
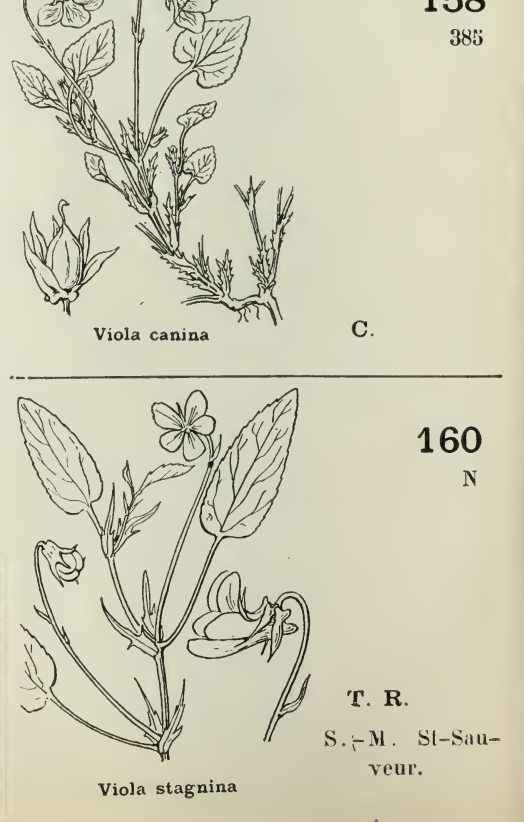
FAM. 8 (8). VIOLARIÉES - FAM. 9 (10). RÉSÉDACÉES
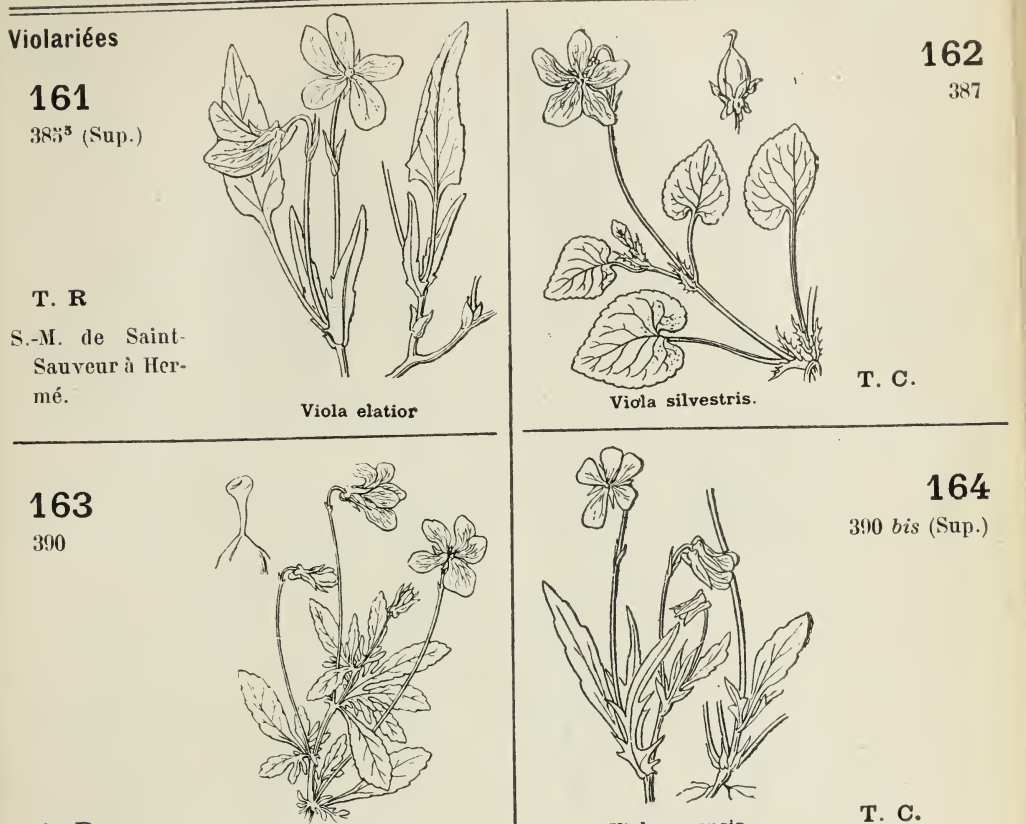

A. $\mathbf{R}$.

Viola tricolor

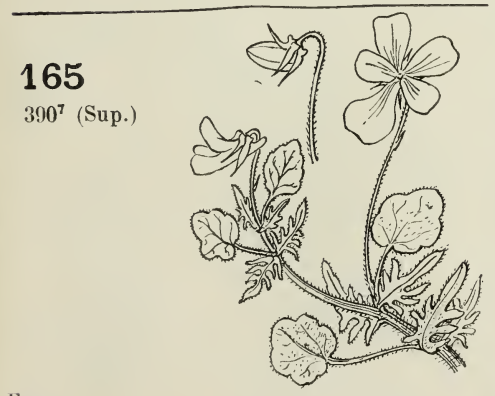

Eure. Viola rothomagensis

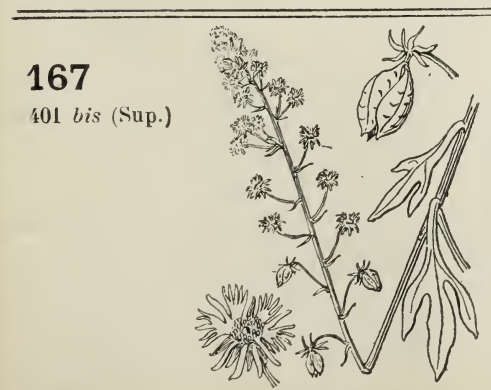

Cultivé.

Reseda odorata

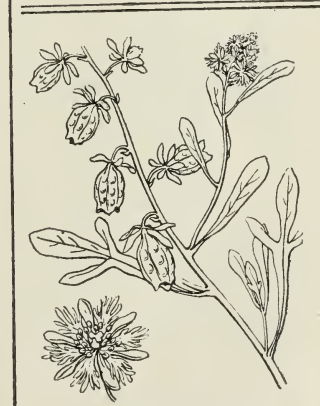

T. C.

390 bis (Sup.)
Résédacées

\section{6}

i01

R.

0. Senlis.

S. St-Maur.

S.-M. Provins.

S.-0. Vésinet, Draveil,

Ile-Adam.

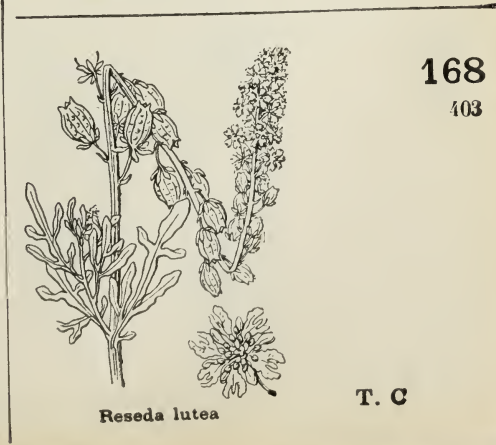


FAM. 9 (10), RÉSÉDACÉES. - FAM. 10 (11). POLYGALÉES. FAM. 11 (13). DROSÉRACÉES.

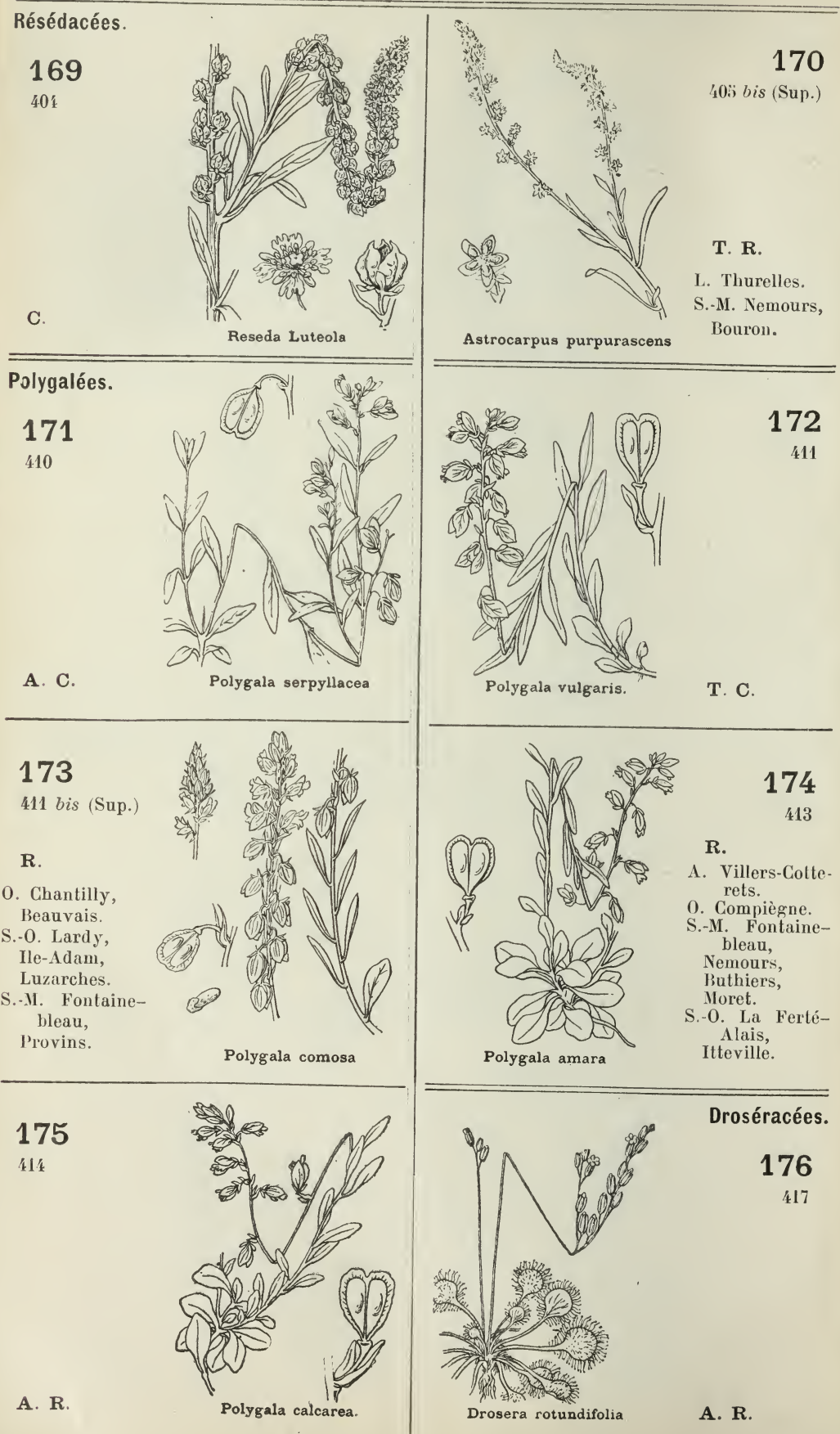


FAM. 11 (13), - DROSÉRACÉES

FAM. 12 (14), - CARYOPHYLLÉES

\section{Droséracées.}

177

418

T. R.

A. Villers-Collerets.

S.-M. Larchant.

S. - O. Rambouillet,

Environs de Magny.

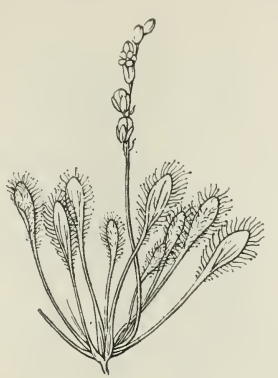

Drosera intermedia

\section{9}

419 bis (Sup.)

T. R.

0. Mortefontaine,

Pouilly.

S. - M. Environs de Malesherbes.

S.-0. Brignancourt.

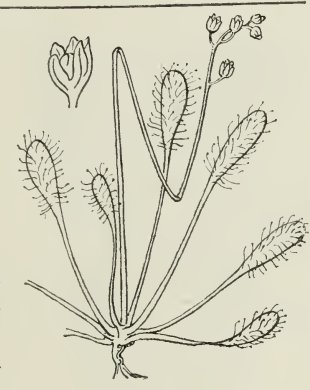

Drosera obovata

\section{Caryophyllées.}

181

422

\section{A. $\mathbf{R}$.}

Rare dans le Nord.
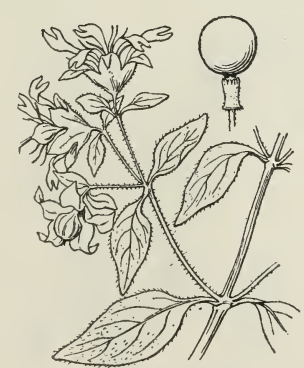

Cucubalus baccifer

183

424

T. C.

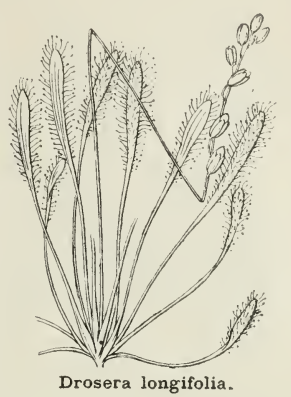

178

419

R.

S.-0. Brignancourt,

Arron ville.

1. Silly-la-Po terie.

L. Sceaux

o. Mortefontaine, Vez, Russy,

Neuville - Bosc

S.-M. Roncevaux.
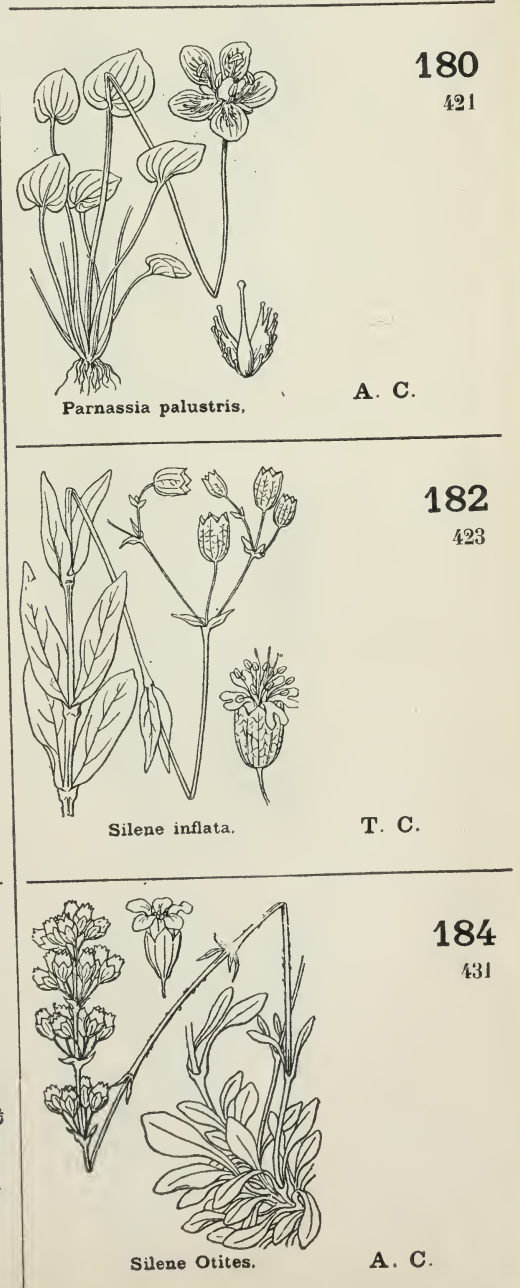
FAM. $12^{\circ}\left(1^{1}\right)$. - CARYOPHYLLÉES
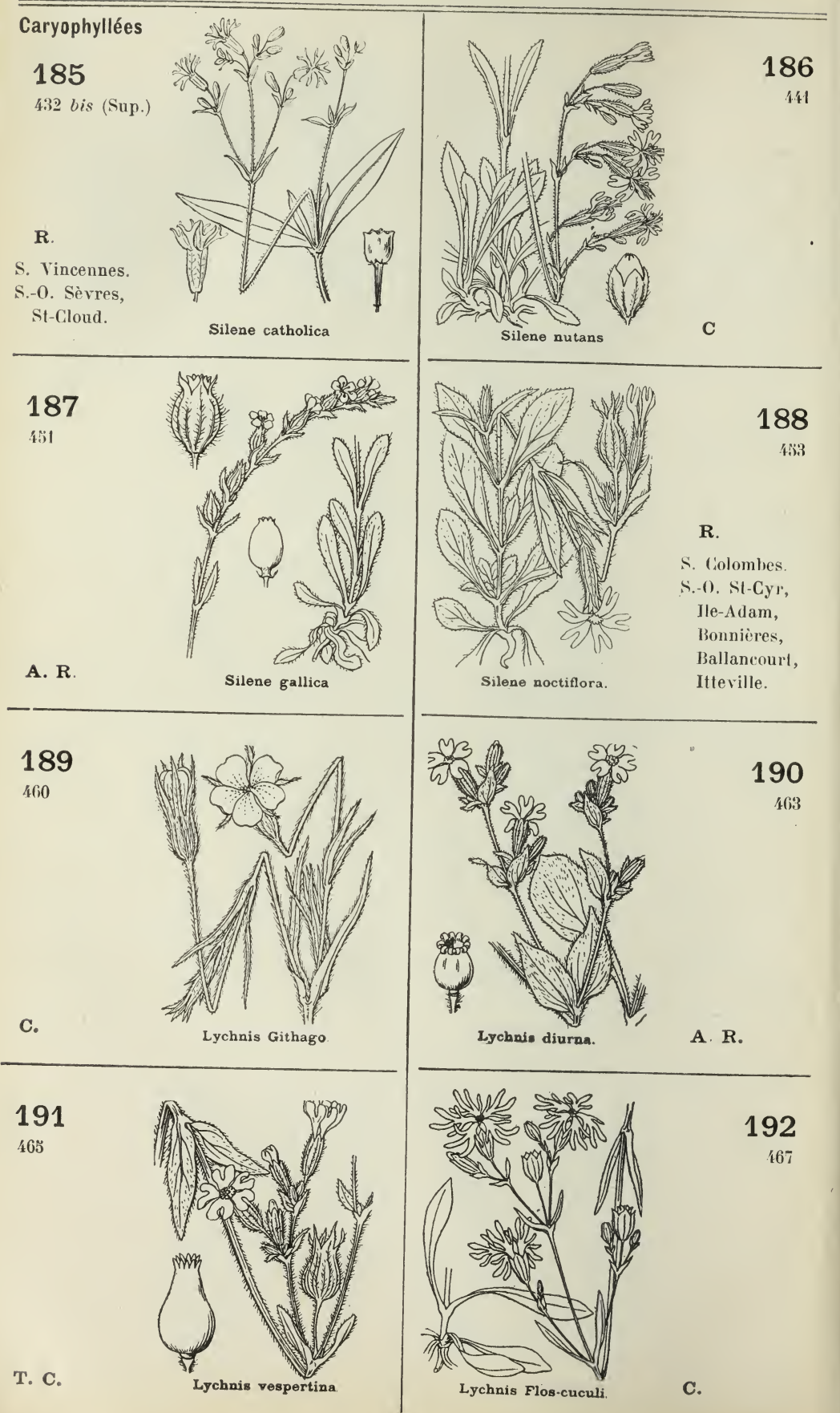


\begin{tabular}{l}
\hline Caryophyllées. \\
193 \\
$\mathbf{1} 98$ \\
R. \\
S.-Mompiègne. Fontaine- \\
bleau, \\
Nemours, \\
Samoreau. \\
S.-0. Vésinet, \\
Yerres, \\
Lardy, \\
Etrechy, \\
La Ferté-Alais. \\
Itteville.
\end{tabular}

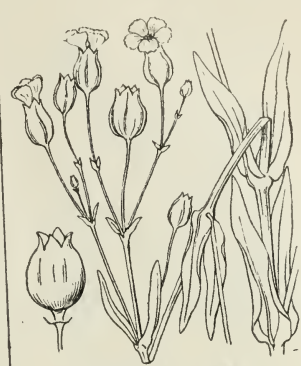

Saponaria Vaccaria

A. $\mathbf{R}$

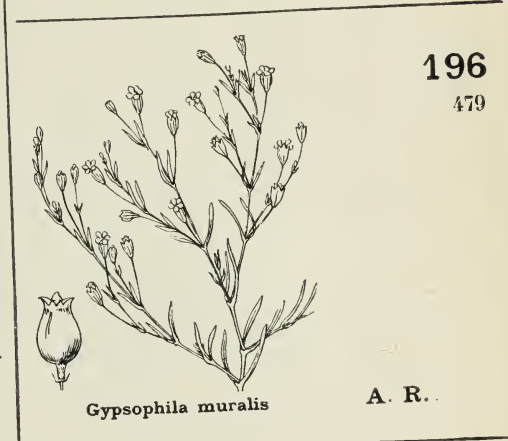

T. C.

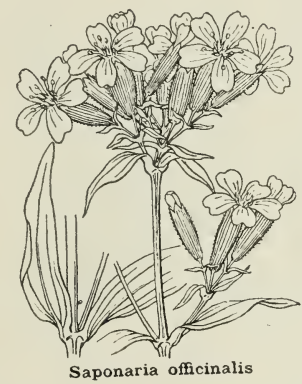

195

473

Gypsophila muralis

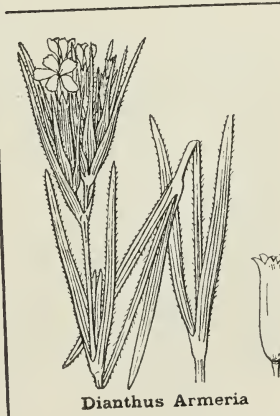

198

482

472
T. C.

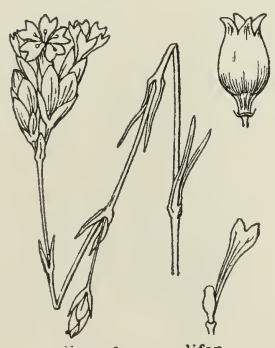

Dianthus prolifer.

199

483

c.

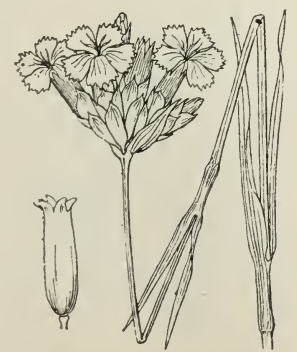

Dianthus Carthısianorum-

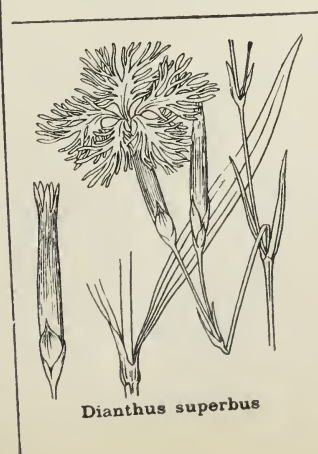

c. 


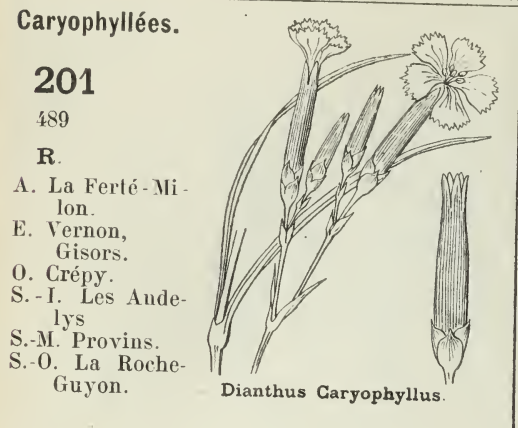

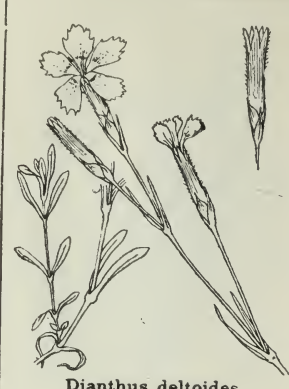

Dianthus deltoides

500

R.

0. Compiègne, Senlis,

Beauvais.

S. - M. Fontainebleau.

S. - 0. Rambouillet, Senart, Marcoussis.

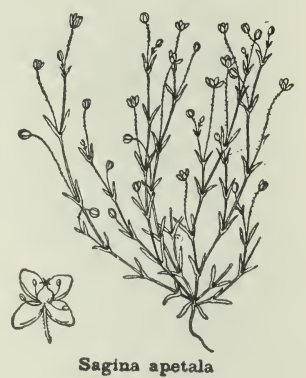

204

รั0ื

T. C.

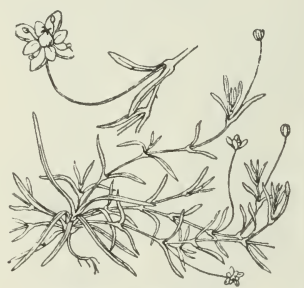

Sagina procumbens

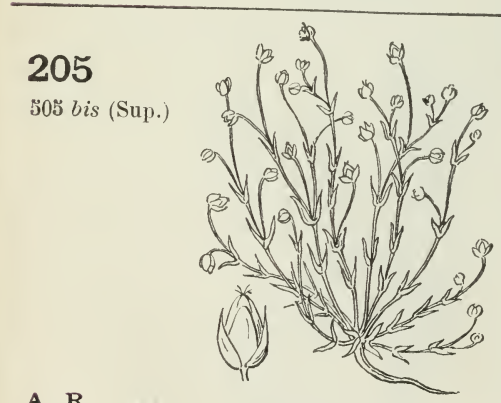

A. $\mathbf{R}$.

Sagina ciliata

\section{7}

510

T. $\mathbf{R}$.

\section{S.- M. Fontaine-} bleau.

S.-0. Rambouillet,

Montmorency.

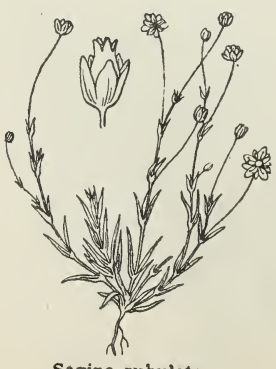

Sagina subulata

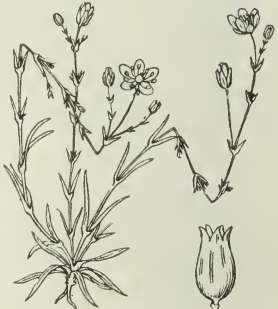

206

507
A. C.

A. $\mathbf{R}$.

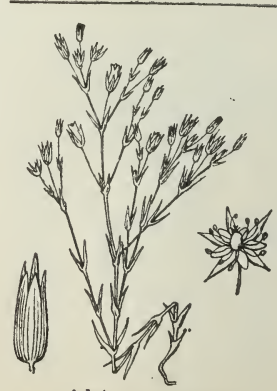

A lsine tenuifolia.

T. C. 
FAM. 12 (14). - CARYOPHYLLÉES

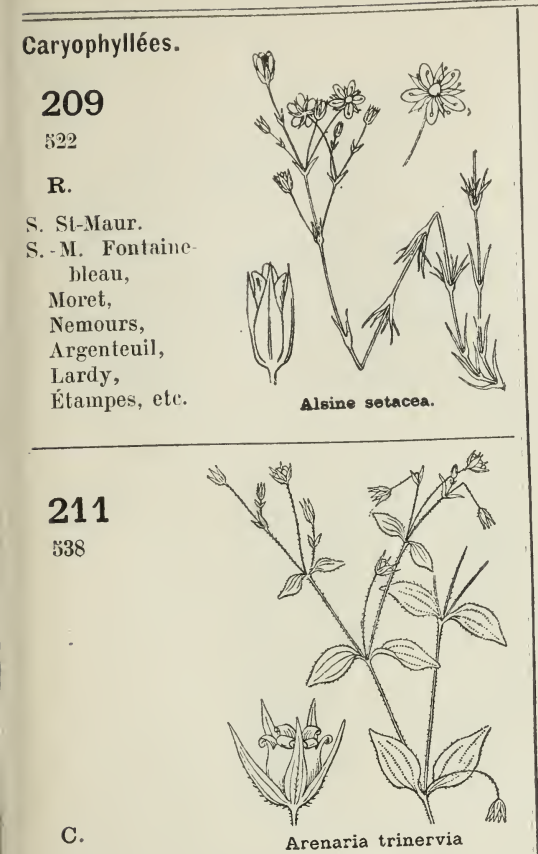

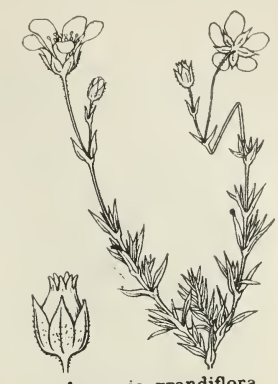

Arenaria grandiflora

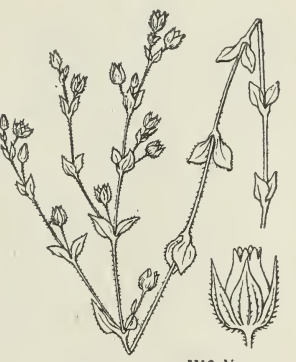

Arenaria serpyllifolia

T. C.

- M. Fontainebleau.

212

ร39

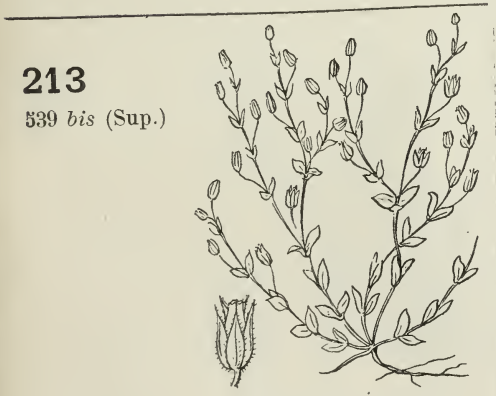

C.

$$
\text { Arenaria leptoclados }
$$

215

5ร1

T. C.

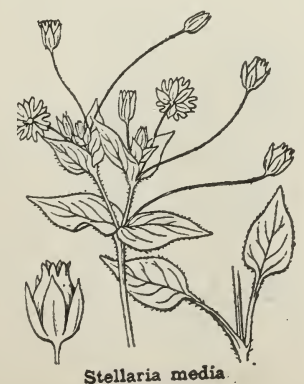

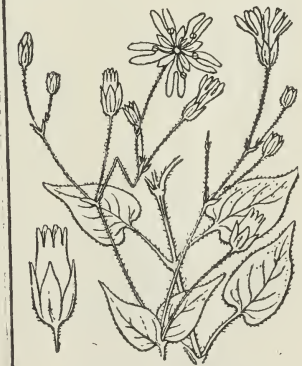

214

รัอั0

Stellaria nemorum

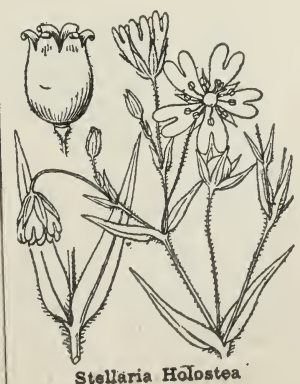

216

วอ2
0. Savignies, Compiègne, Chantilly, Betz. 
FAM. 12 (1k). - CARYOPHYLLÉES
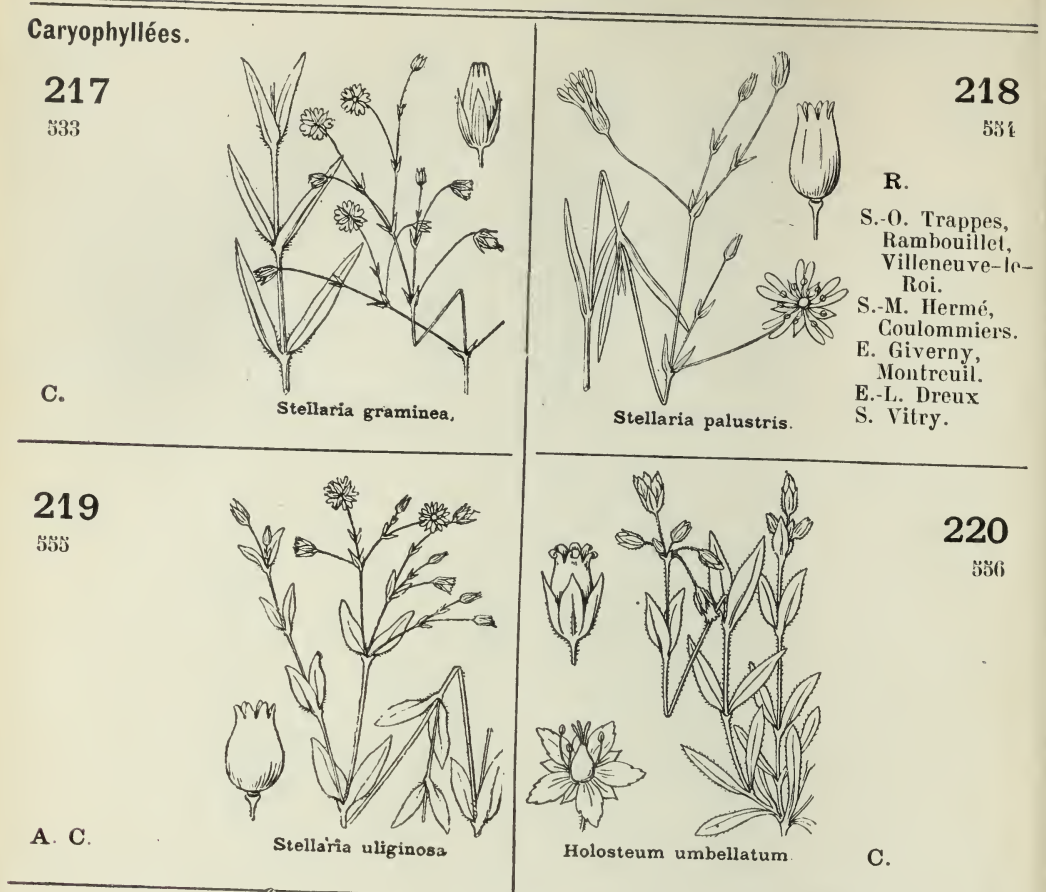

\section{1}

557

A. C.

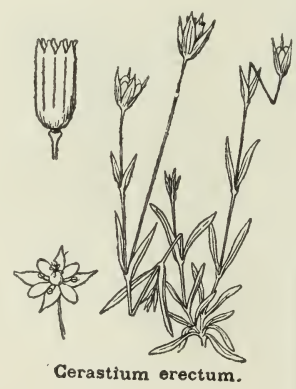

223

561

T. C.
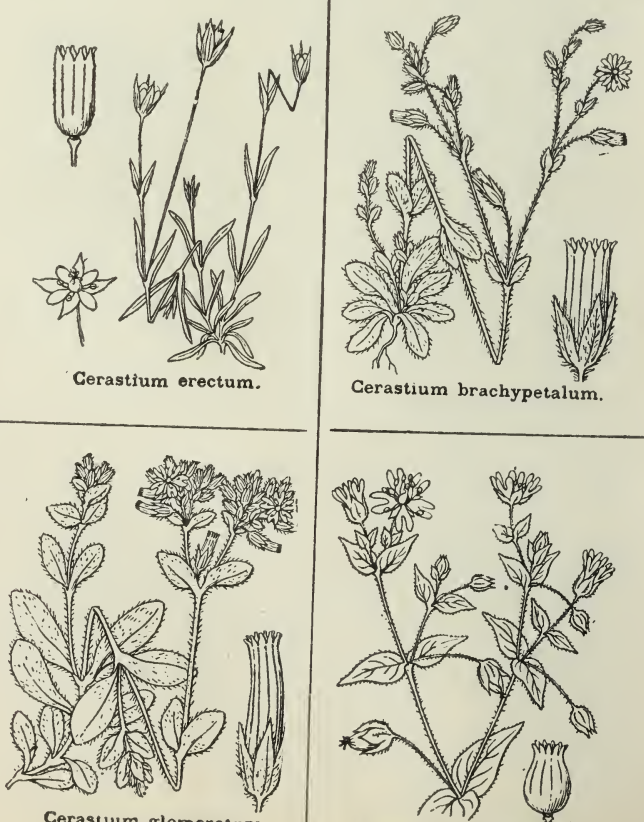

222

588

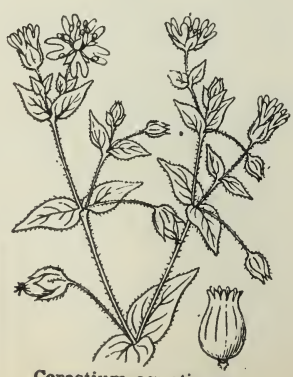

224

562

Cerastium aquaticum.

T. C. 
FAM. 12 (14). - CARYOPHYLLÉES
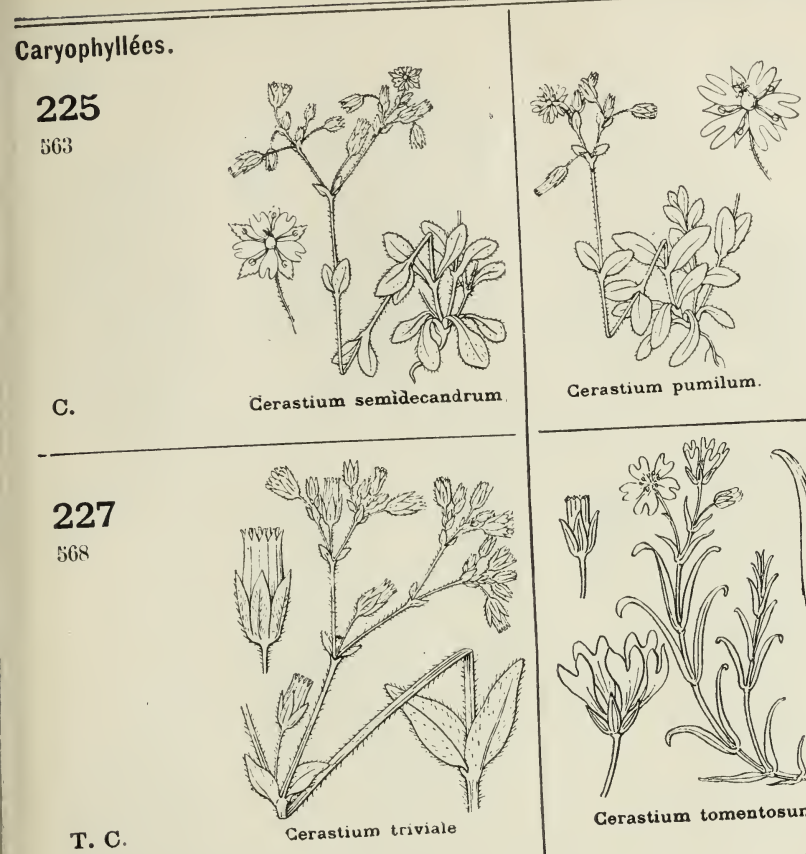

Cerastium pumilum

226

86 '

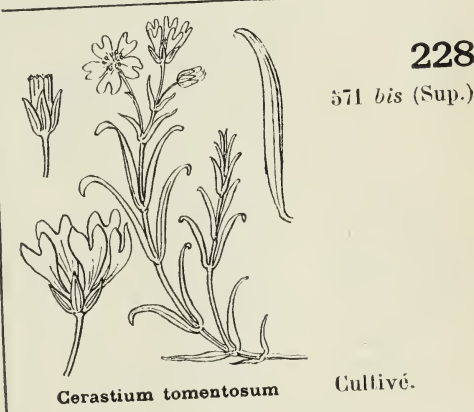

T. C.
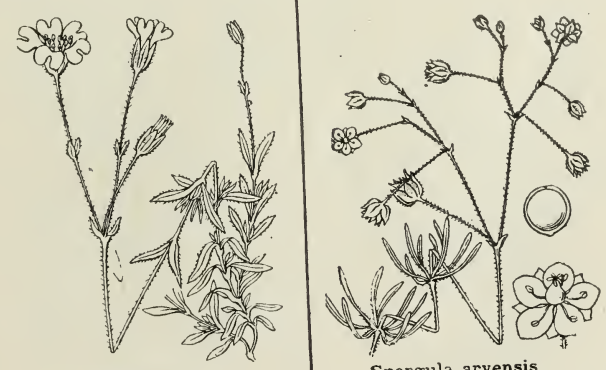

230

5ั3

374

Cerastium arvense.

Spergula arvensis

C.

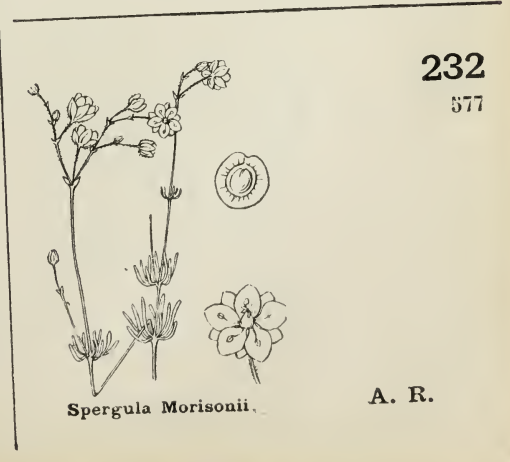


FAM. 12 (14). CARYOPHYLLÉES - FAM. 13 (1\%). ELATINÉES FAM. 14 (16). LINÉES
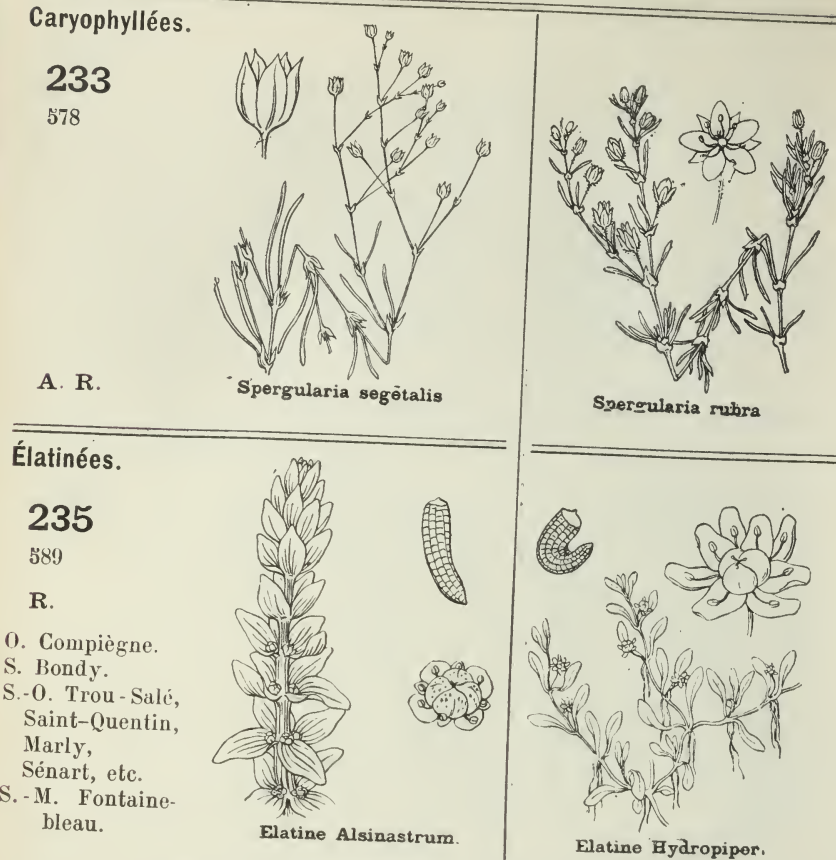

234

Speroularia rubra

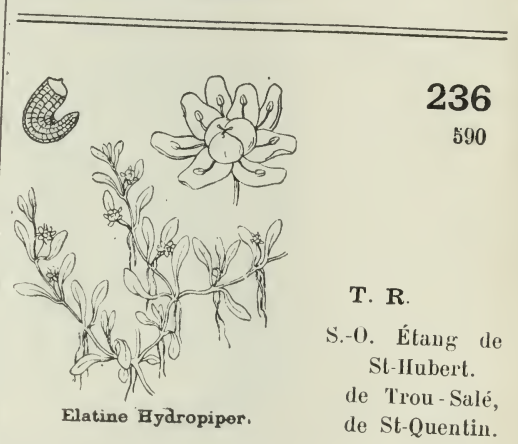

\section{7}

ธั92

R

o. Compiègne, Senlis.

S. - M. Fontainebleau.

S.-0. Sénart, Etang de SaintHubert,

Trou-Salé,

Saint-Quentin.
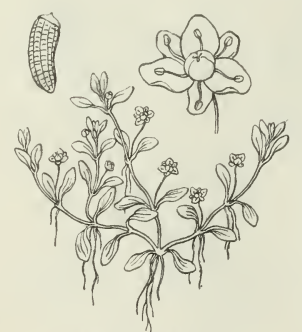

Elatine kexandra

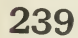

600

T. C

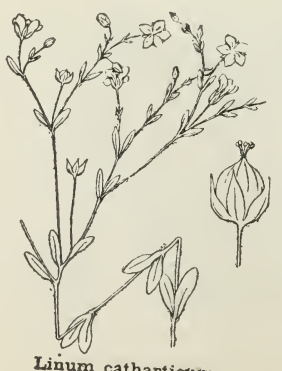

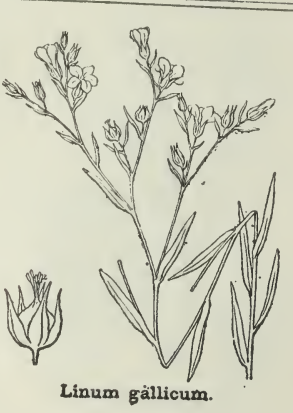

Linées

238

599

$\mathbf{R}$

A. Villers-Cotterets.

S.-M. Le Châte let,

La Ferté-Gaucher.

S.-0. Villededon près Corbeil.

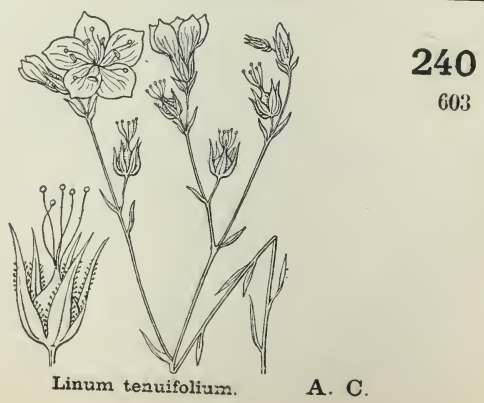


FaM. 14 (16). LINÉES - Fam. 15 (17). TILIACÉES

\section{Linées. \\ 241 \\ 603 \\ R.}

L. Nalesherbes.

o. Marolles.

S.-M. Fontaine-

Souppes, Maisse. bleau,

Jutigny près Longueville

S. - O. Etampes ì La Ferté-Alais,

Aube. Le Plessis.

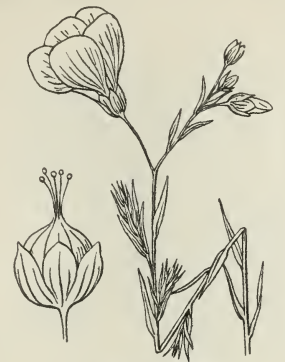

Linum alpinum

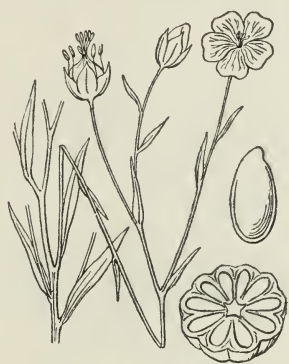

Cultivé.

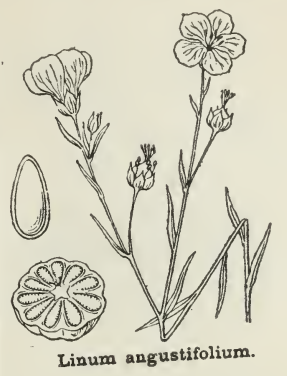

R.

E. Vernon, Les Andelys, Cocherel.

244

608
607

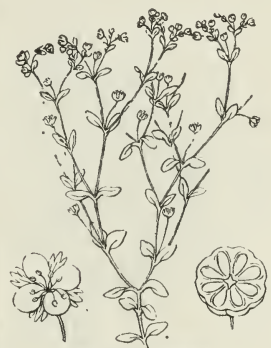

Radiola linoides.

A. C.

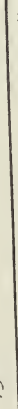

A. C.

Tilia platyphylla

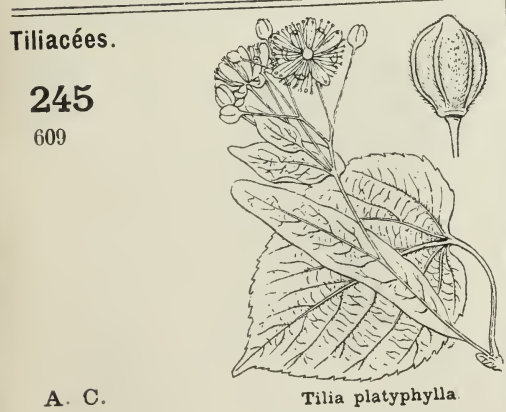

247

611

C.

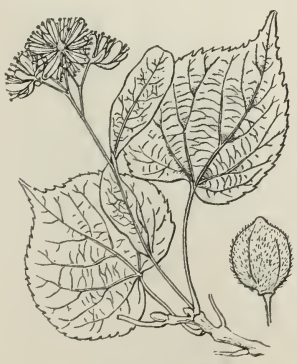

Tilia parvifolia.

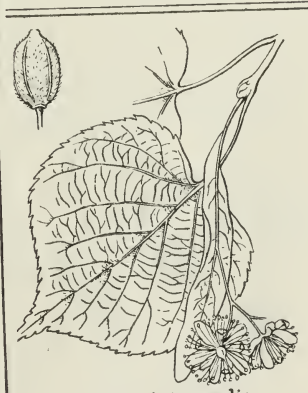

Tilia intermedia

Cultivé.

246

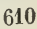

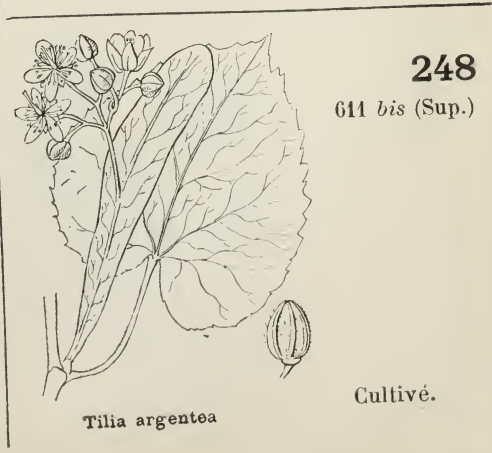


32 FAM. 16 (18). MALVACÉES - FAM. 17 (19). GÉRANIACÉES
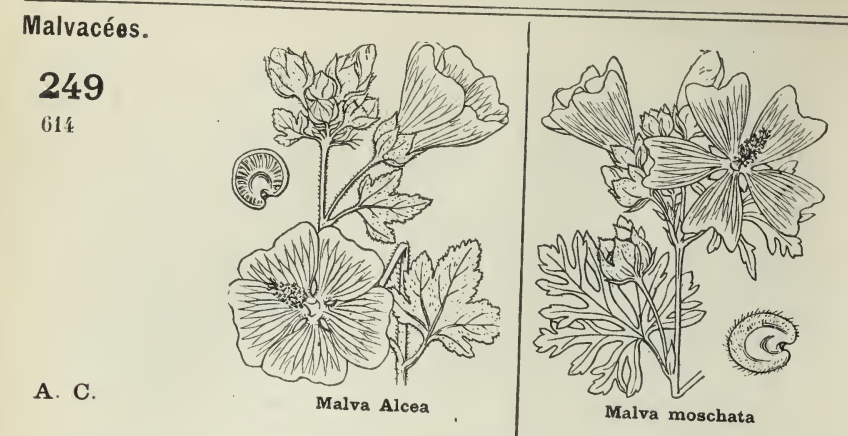

250

615

251

$6 \mathrm{i} 6$

c.
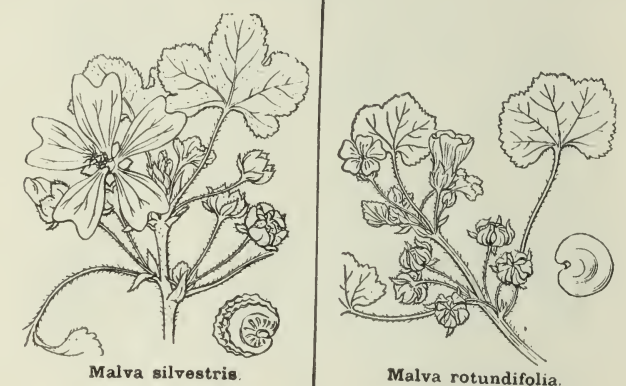

252

618

A. C.

Malva rotundifolia.

T. C:
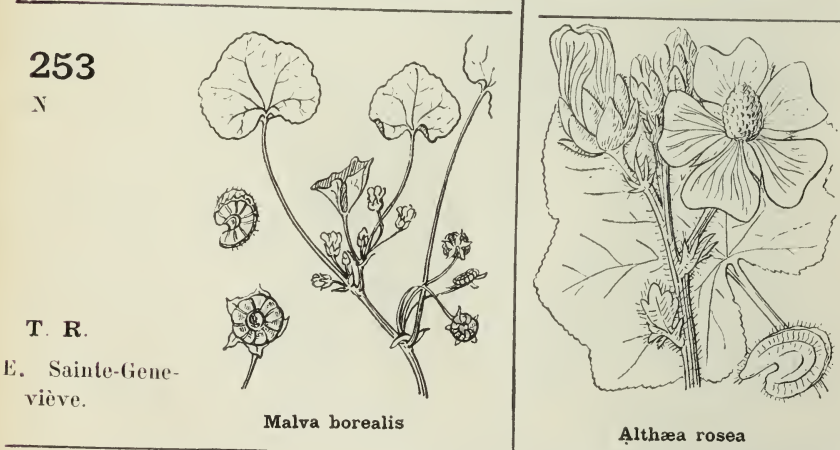

254

620 bis (Sup.)

\section{5}

629

A. R.
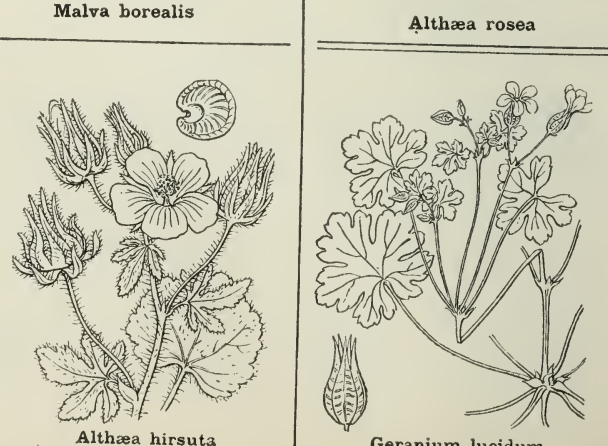

Cultivé.

Géraniacées.

256

633
Geranium lucidum
A. $\mathbf{R}$. 


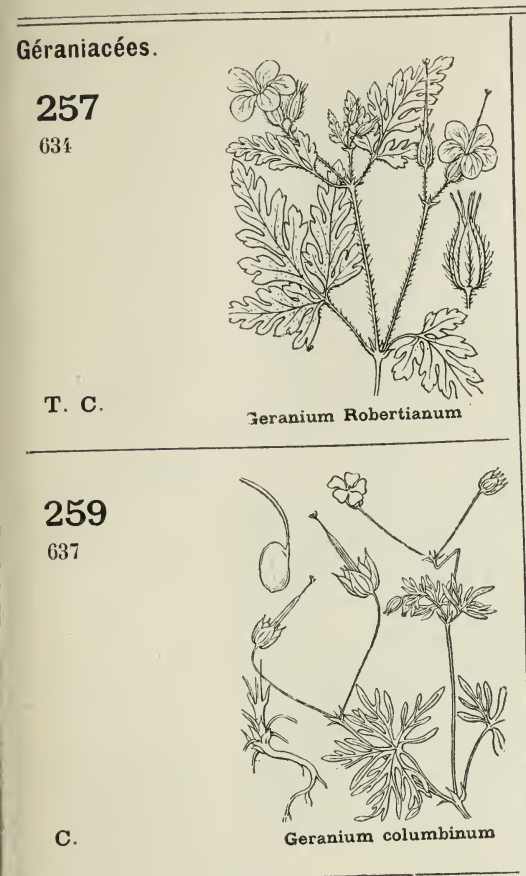

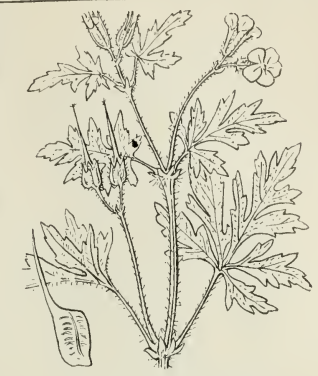

Geranium purpureum

\section{8}

634 bis (Sup.)

R.

E. Giverny,

Tison.

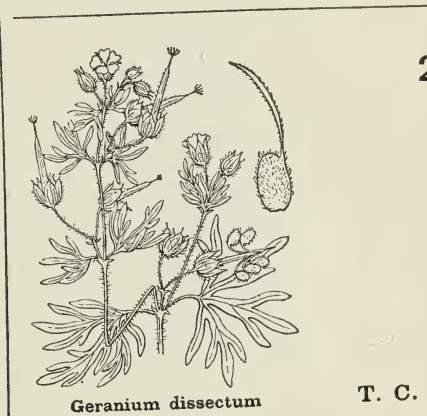

260

638

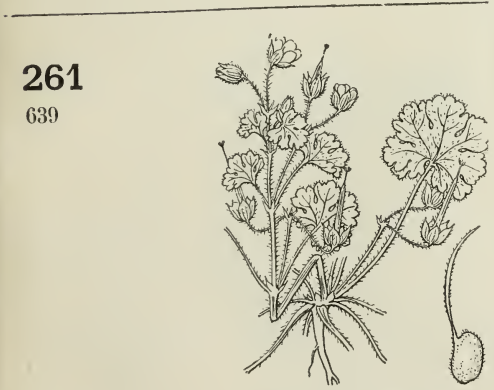

T. C.

Geranium rotundifolium

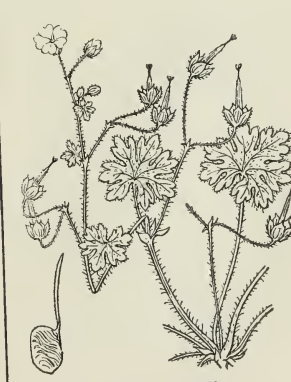

Geranium molle

262

610

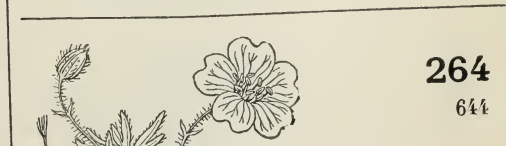

263

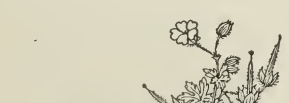

641

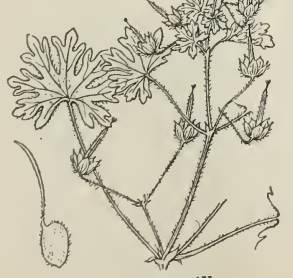

C.

Geranium pusillum

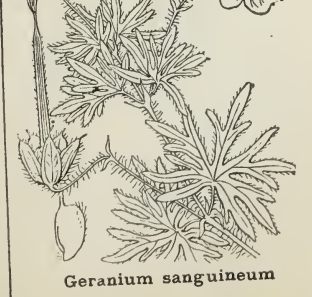

A. $\mathbf{R}$. 
Géraniacées.

265

643

A. C.

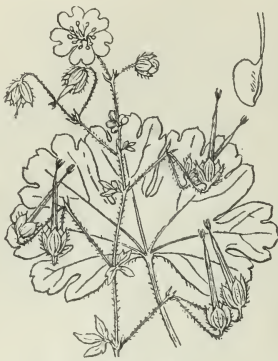

Geranium pyrenaicum

267

668

T. C.

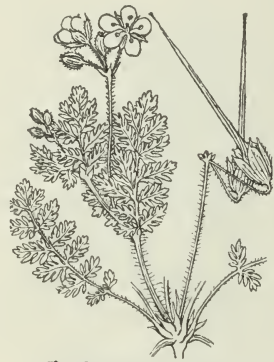

Erodium cicutarium

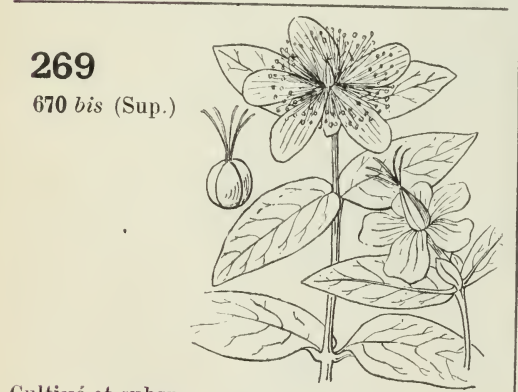

Cultivé et subsp.

Androsæmum calycinum

271

673

T. C

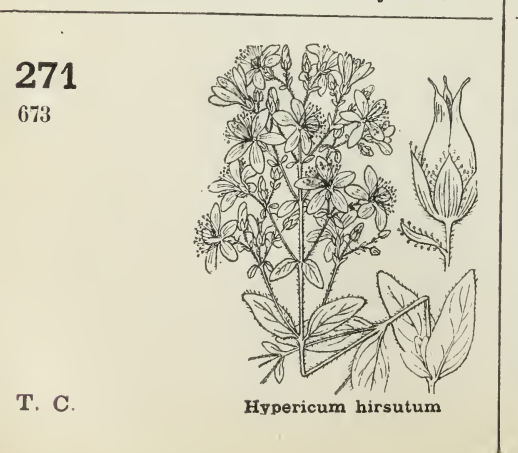

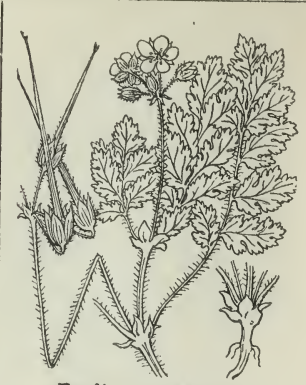

Erodium moschatum

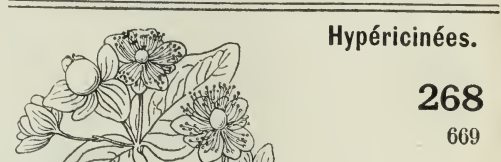

R.

A. Villers-Collerets.

0. Hallatte.

S.-0. Magny, Marly,
266

666
E. Giverny.

o. Compiègne.

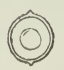

Androsæmum officinale
Carnelle.
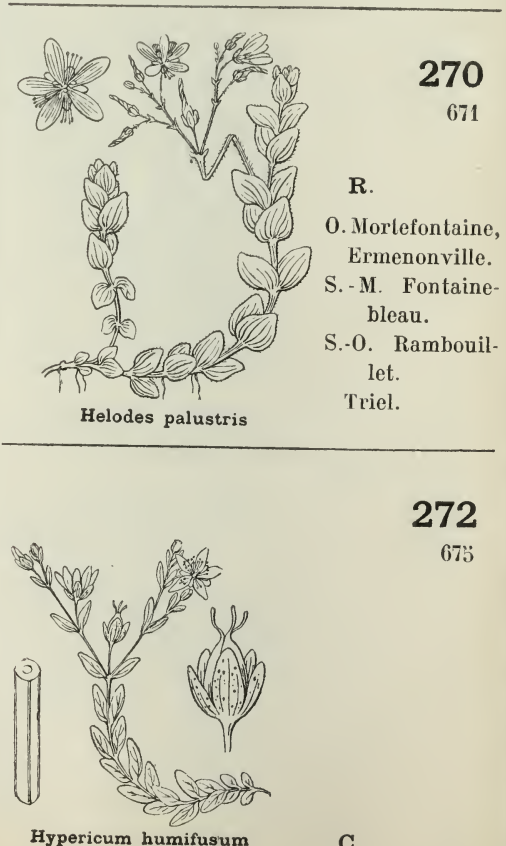

272

673

c. 
FAM. 19 (21). ACÉRINÉES - FAM. 20 (22). AMPÉLIDÉES 36 FAM. 21 (23). HIPPOCASTANÉES - FAM. 22 (2i). BALSAMINEES
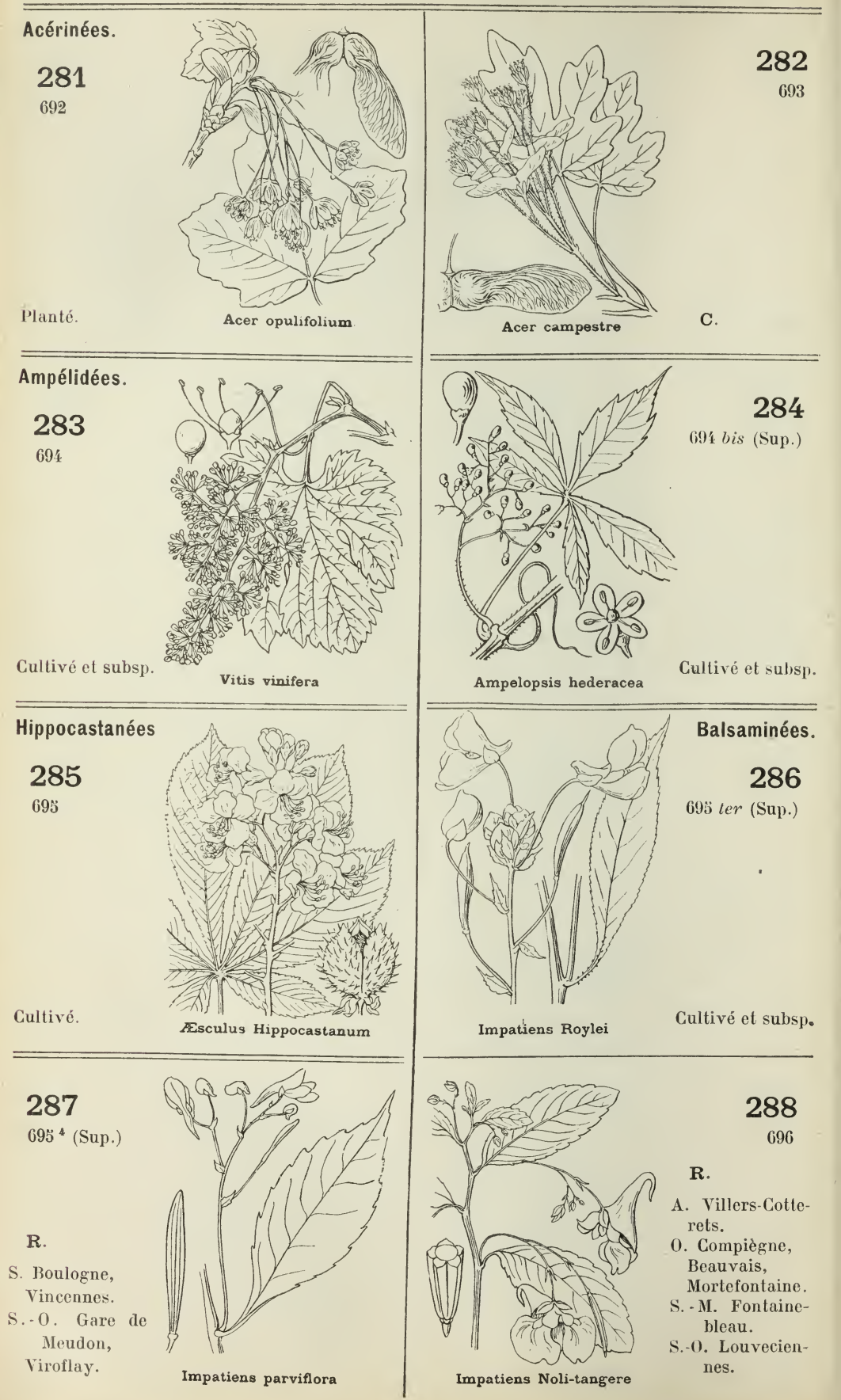

Impatiens Noli-tangere

288

696

R.

A. Villers-Cotterets.

o. Compiègne,

Beauvais,

Mortefontaine.

S. - M. Fontainebleau.

S.-0. Louveciennes. 
F. 23 (2ii). OXALIDEES - F. 24 (2i). RUTAGÉES - F. 25 (29). CELLASTRINEES FAM. 26 (31). ILICINÉES - FAM. 27 (32). RHAMNÉES 37

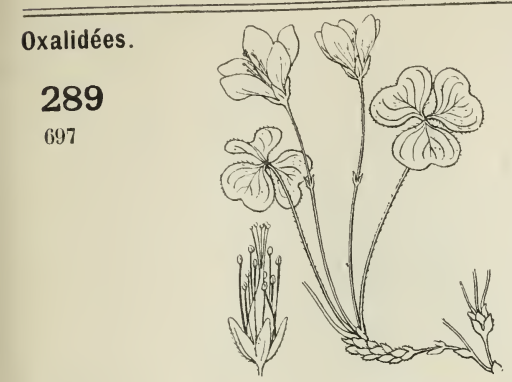

A. C.

Oxalis Acetosella

291

700

Introduit.

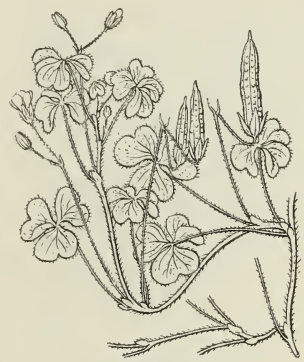

Oxalis corniculata

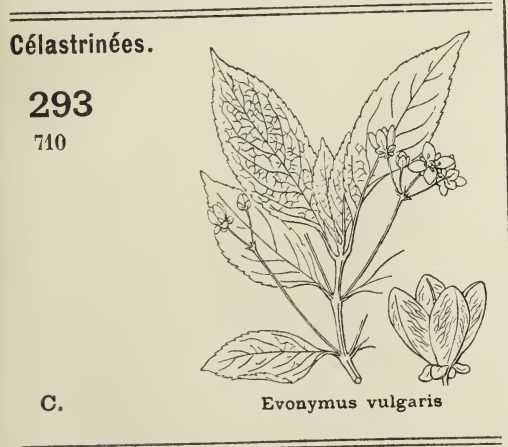

Rhamnées.

295

714

C.

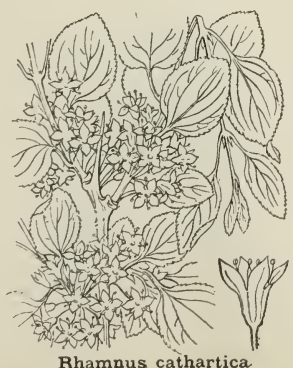

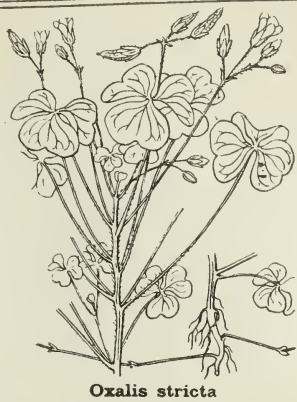

290

699

C.

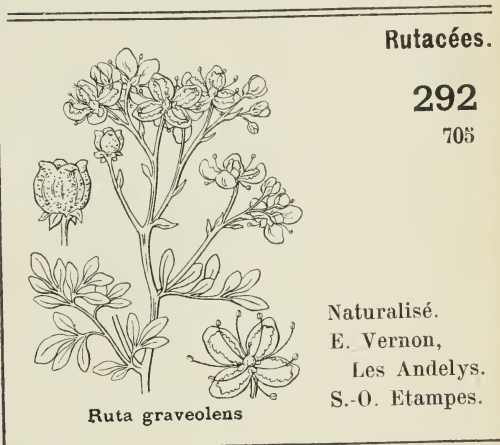

llicinées.

294

712

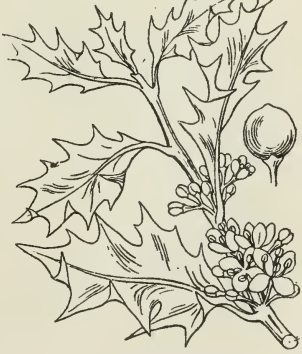

Ilex Aquifolium

C.

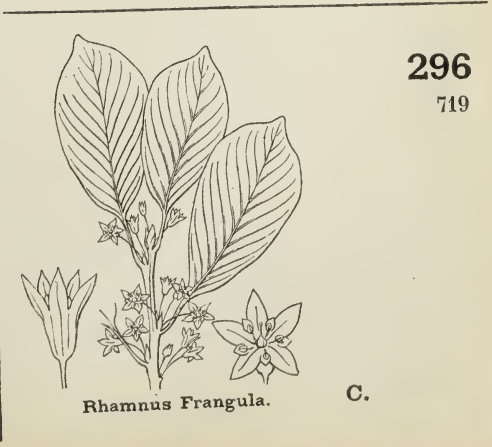


FAM. 28 (00). SIMABURACÉES - FAM. 29 (34). FRAXINÉES 38 Fam. 30 (37). PIROLÉES. - FAM. 31 (38). MONOTROPÉES

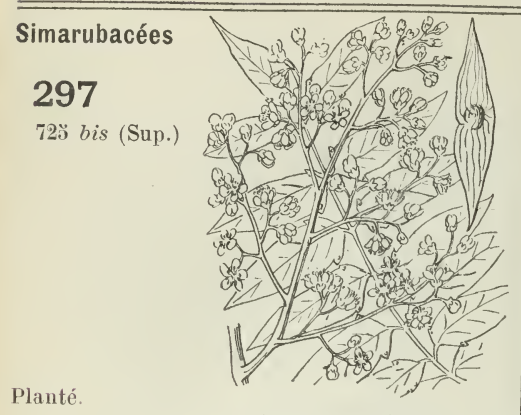

Ailanthus glandulosa

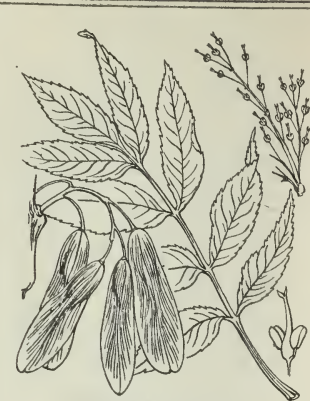

Fraxinus Ornus.

\section{1}

731 bis (Sup.)

T. R.

S.-II. Fontainebleau.
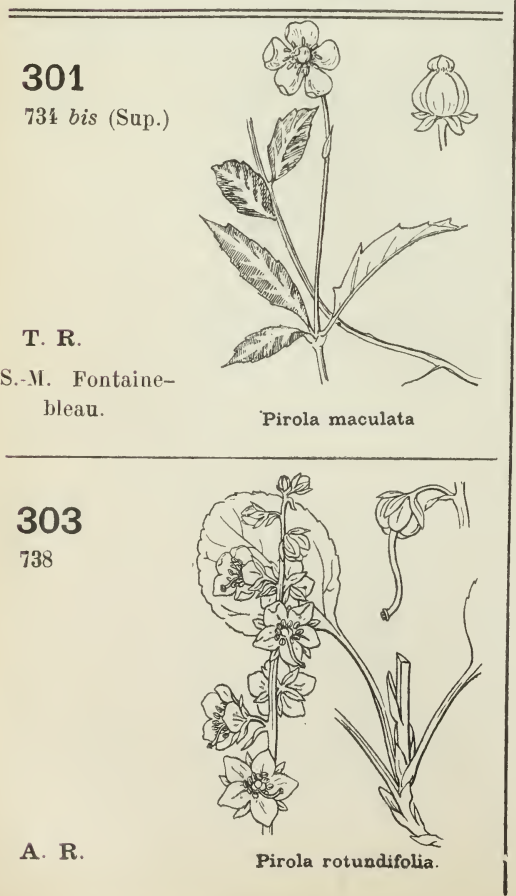

Fraxinus excelsior.

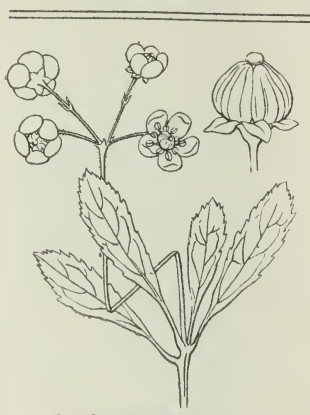

Pirola umbellata

Fraxinées.

298

726

C.

Pirolées.

300

734

T. $\mathbf{R}$.

S.-M. Nemours, Fontainebleau.
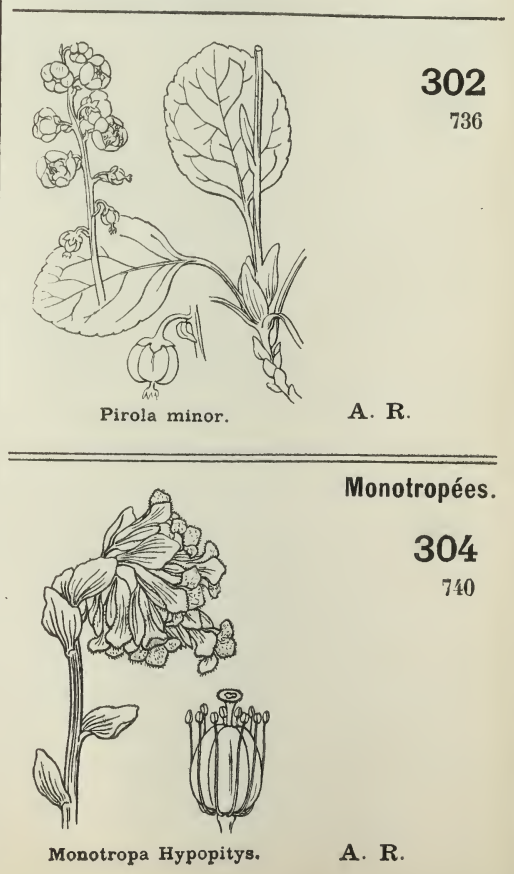
FAM. 32 (39). - PAPILIONACÉES
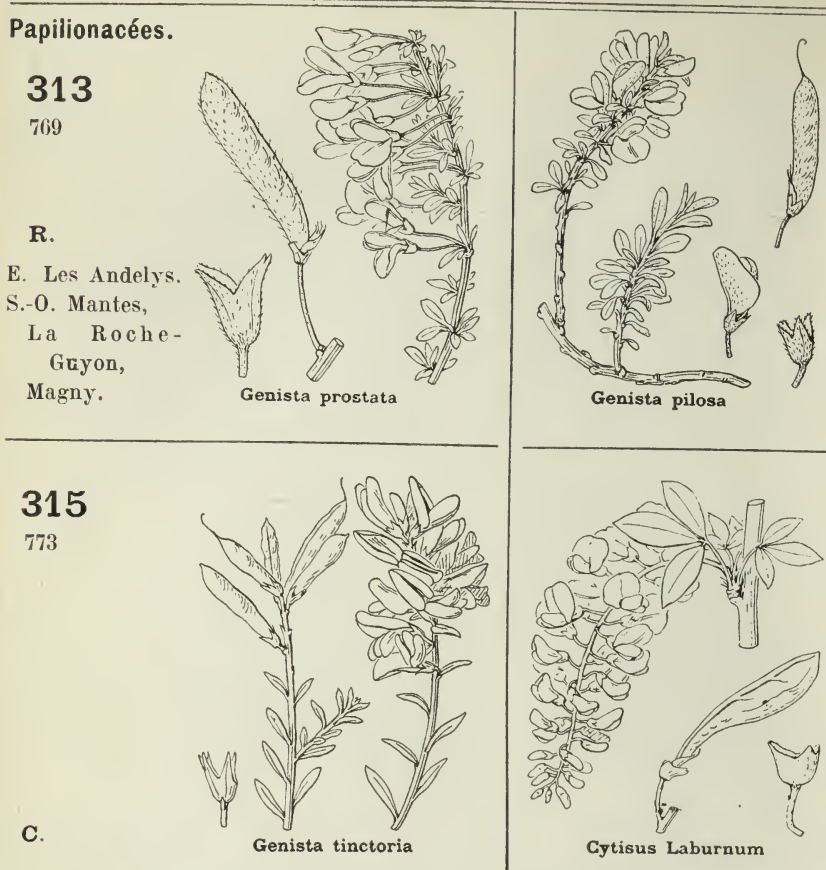

314
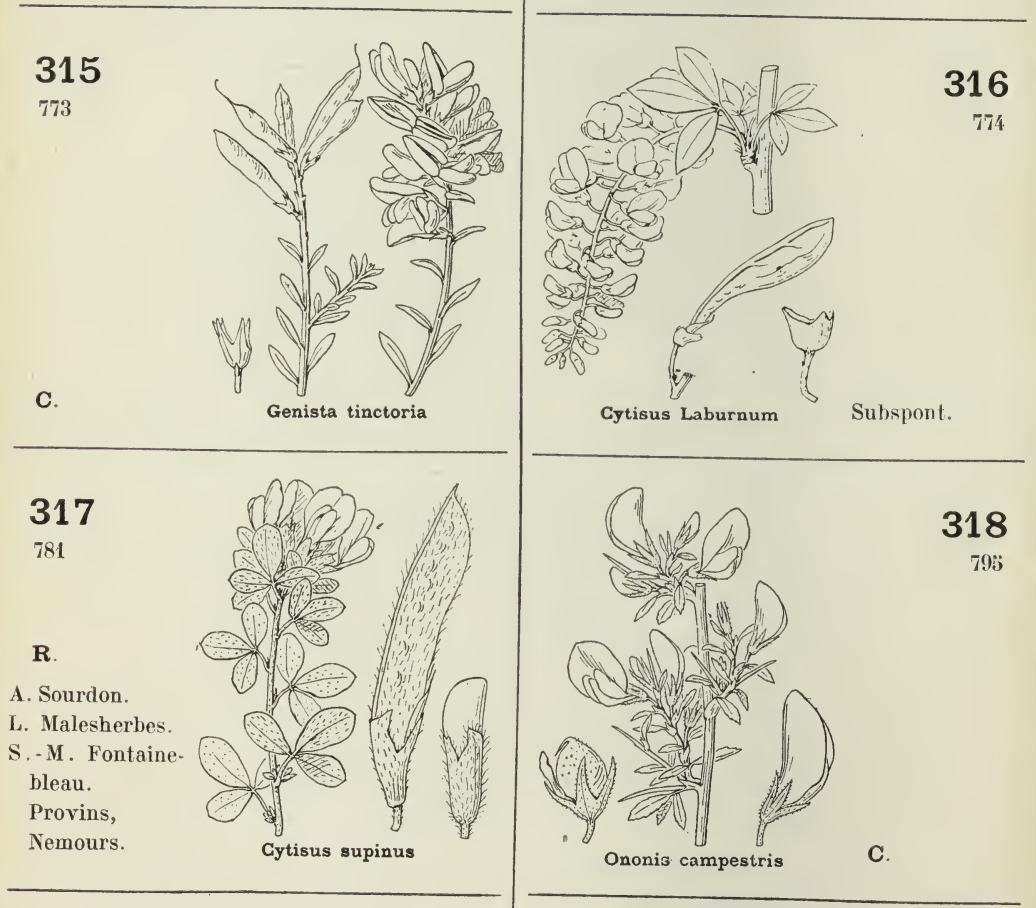

319

796
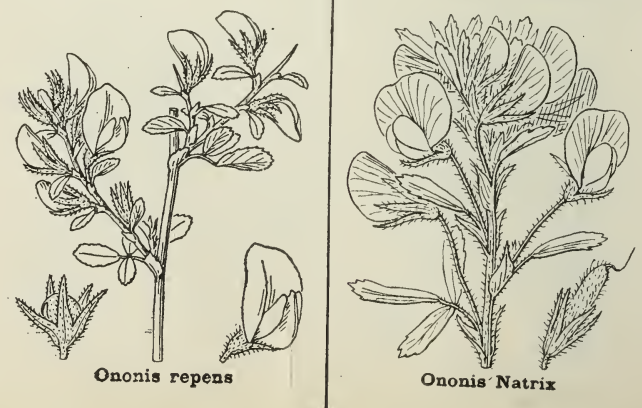

c.

$$
\text { Ononis repens }
$$

A. $\mathbf{R}$. 
FAM. 32. ${ }^{139}$ \%, - PAPILIONACÉES

\begin{tabular}{lll}
\hline Papilionacées. & \\
321 & \\
A. $\mathrm{R}$. & &
\end{tabular}

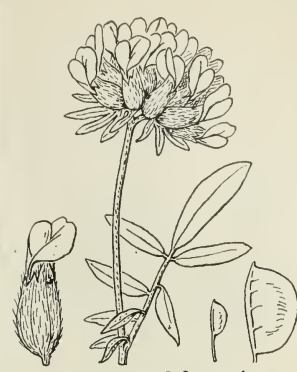

Anthyllis Vulneraria

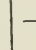

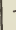$$
\text { 8 }
$$

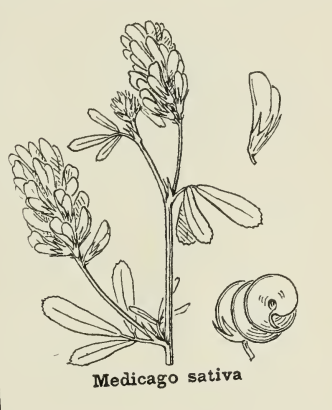

324

821
T. C.

Medicago Lupulina
C.

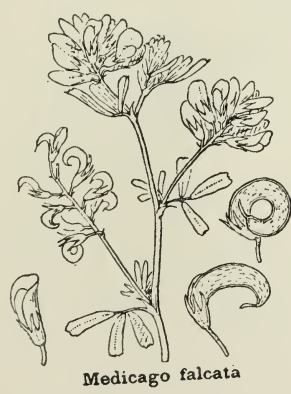

\section{7}

833

c.

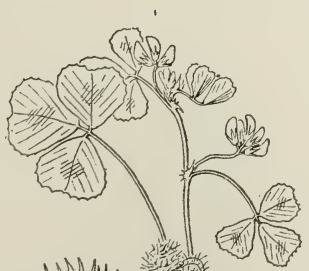

\section{(1)}

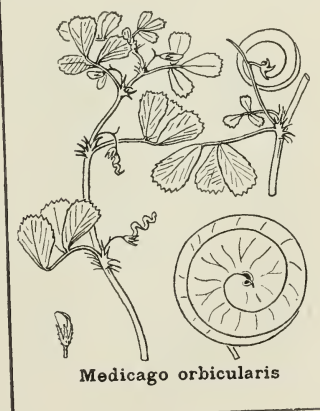

Cult. et subsp.
326

829
T. $\mathbf{R}$.

L. Nalesherbes.

S.-M. Montigny, Fericy.

S.-0. Mantes.
S. Boulogne.

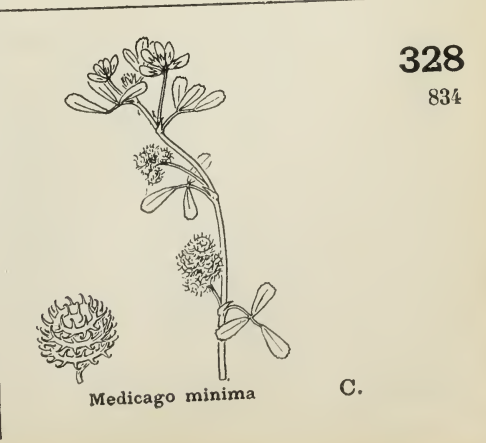


FAM. 32 (39). - PAPILIONACÉES
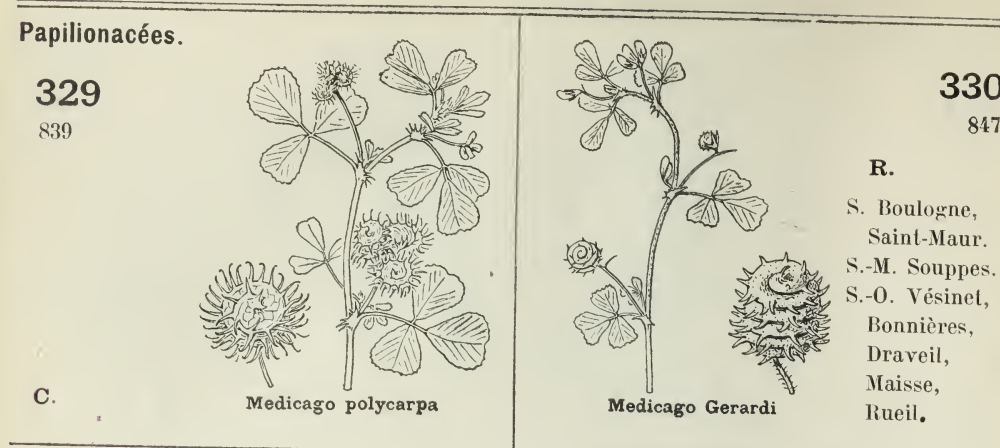

331

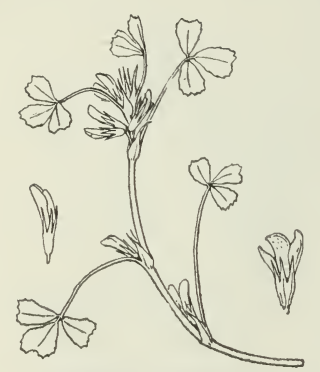

T. $\mathbf{R}$

S.-M. Recloses.

Trigonella ornithopodioides
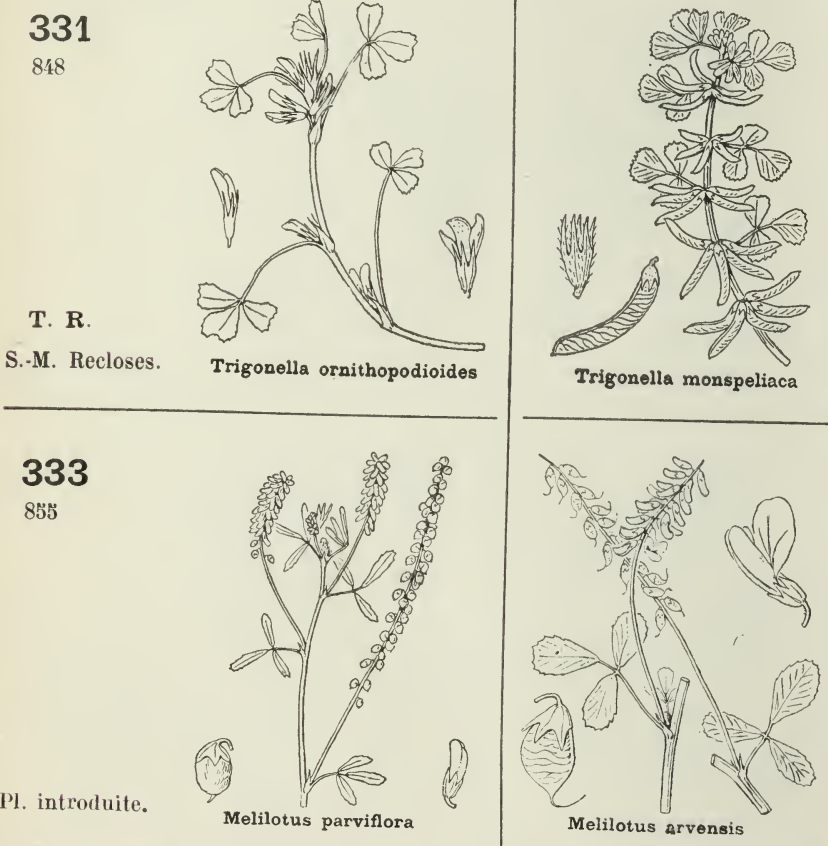

\section{2}

853

R.

S. -0. Étrechy, Lardy,

Vésinet, Poissy, etc.

L. Malesherbes.

S. Boulogne,

Saint-Maur.

Trigonella monspeliaca

S.-M. Nanteau.
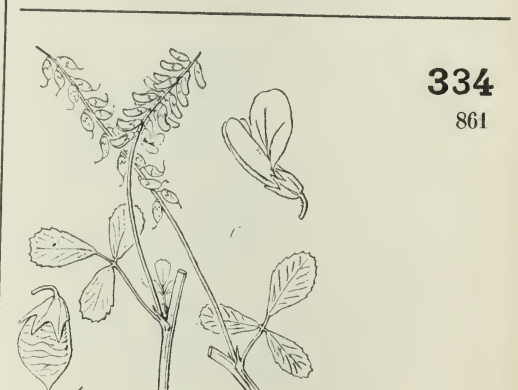

Melilotus arvensis

C.
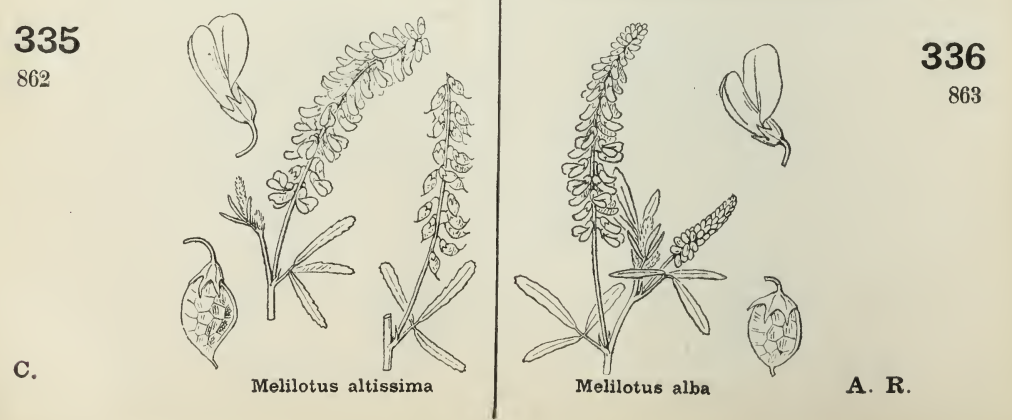

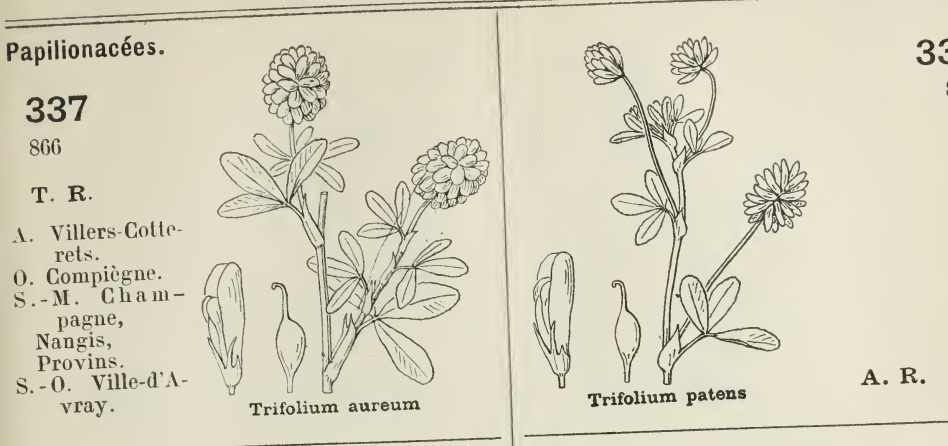

\section{9}

868

C.

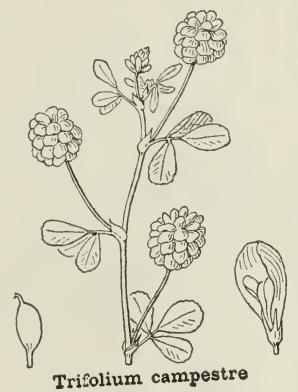

341

870

R

o. Beauvais. S.-M. Fontainebleau,

Nemours.

S. -0. Vaucresson, Versailles,

Trappes,

Rambouillet.

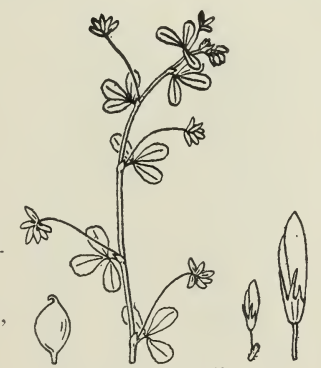

Trifolium micranthum

\section{3}

877

A. $\mathbf{R}$.

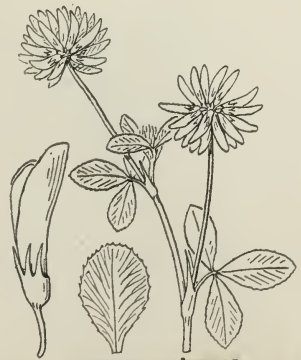

Trifolium paten

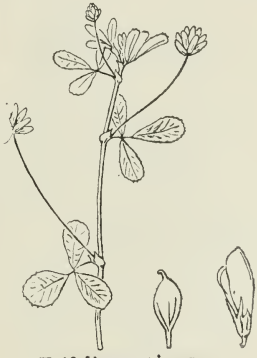

Trifolium minus

C.

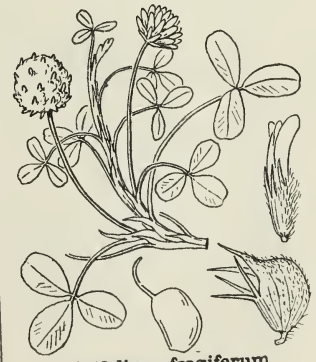

Trifolium fragiforum

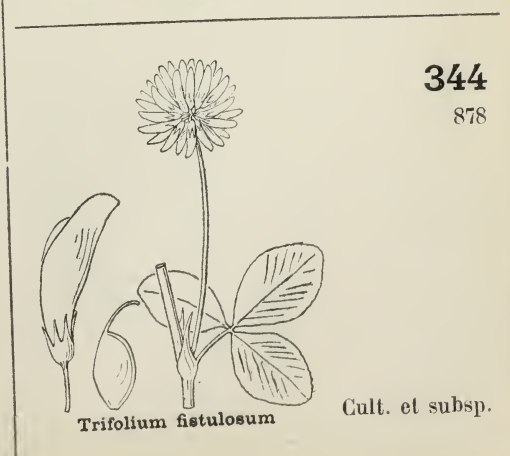



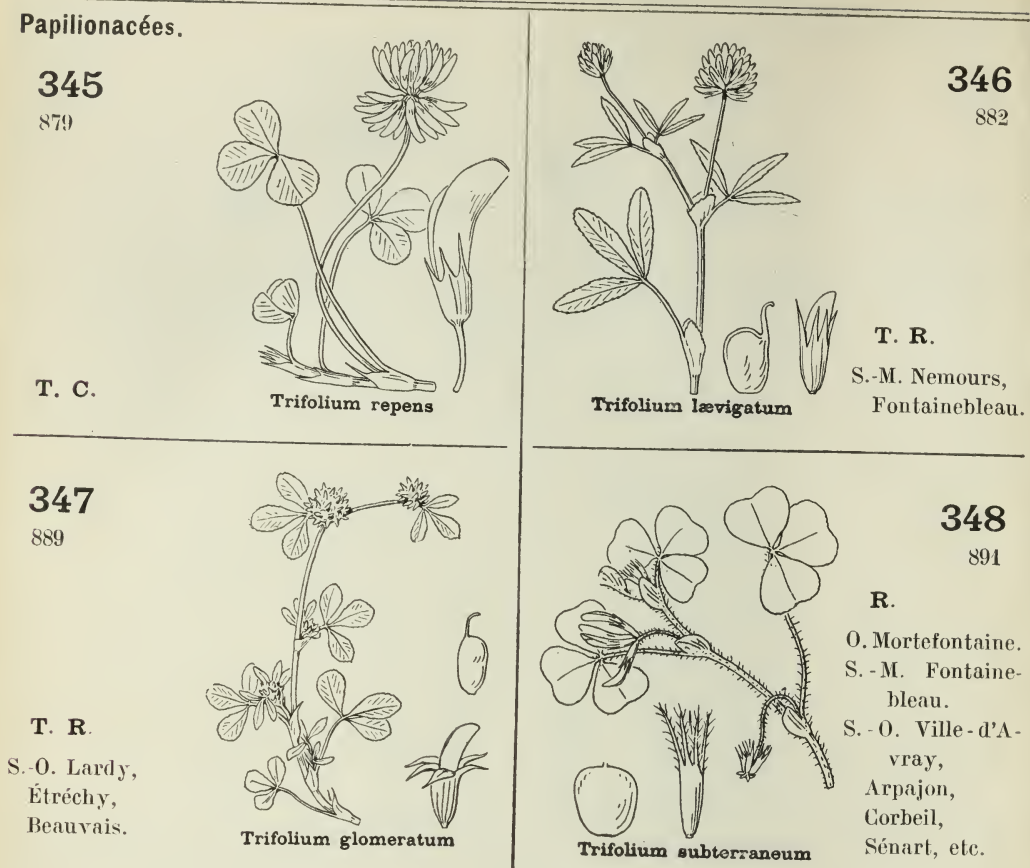

348

891

R.

O. Mortefontaine.

S. - M. Fontainebleau.

S. - 0. Ville-d'Avray, Arpajon, Corbeil, Trifolium subterraneum Sénart, ete.

\section{9}

892

R.

L. Malesherbes.

S. - M. Fontainebleau,

Barbeaux.

S.-0. Juvisy.

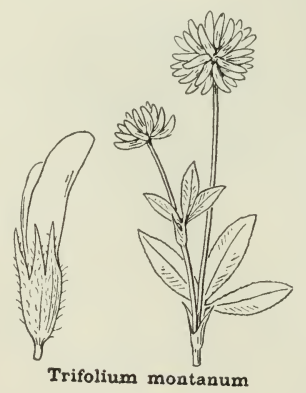

Trifolium montanum

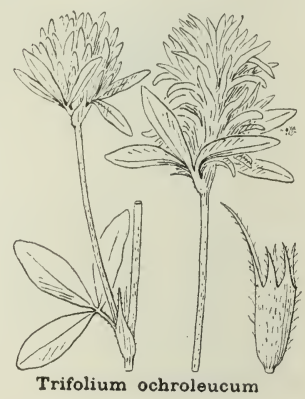

350

893

\section{1}

894

R.

L. Malesherbes.

S. Bondy, Châtillon.

S. - M. Fontaineblean,

Nemours.

S.-0. Lardy, " Sénart, La Ferté-Alais.
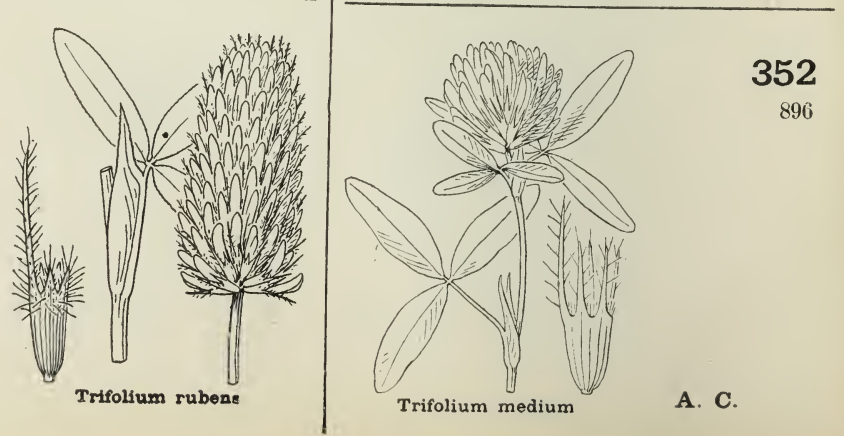


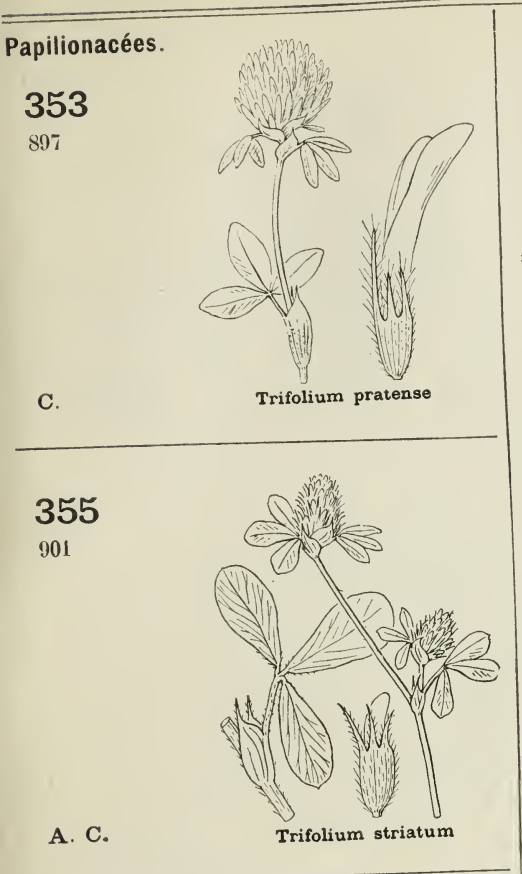

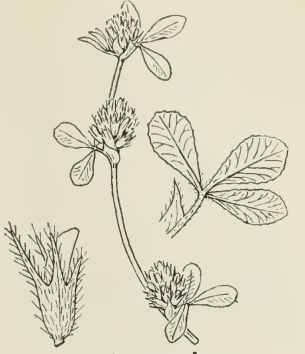

Trifolium scabrum

A. C.

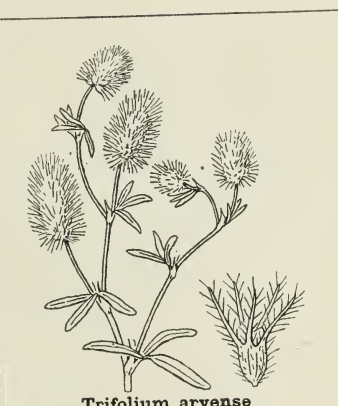

Trifolium arvense

T. C.

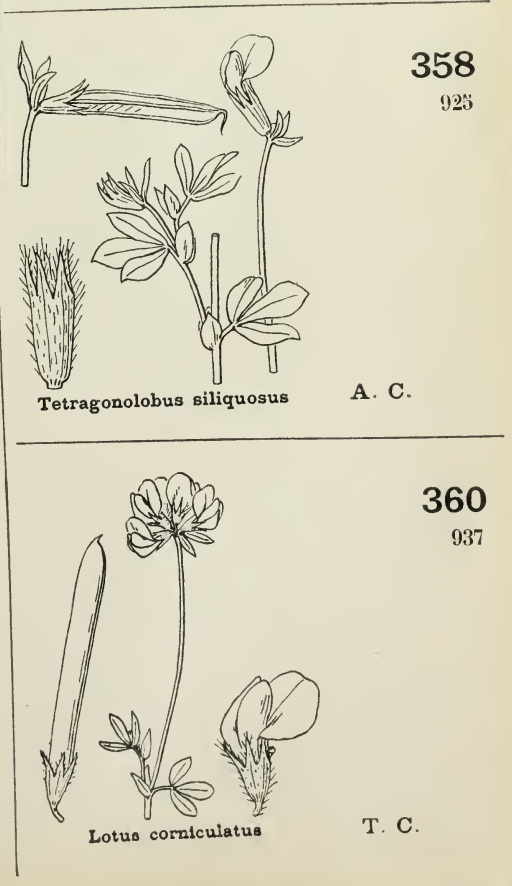



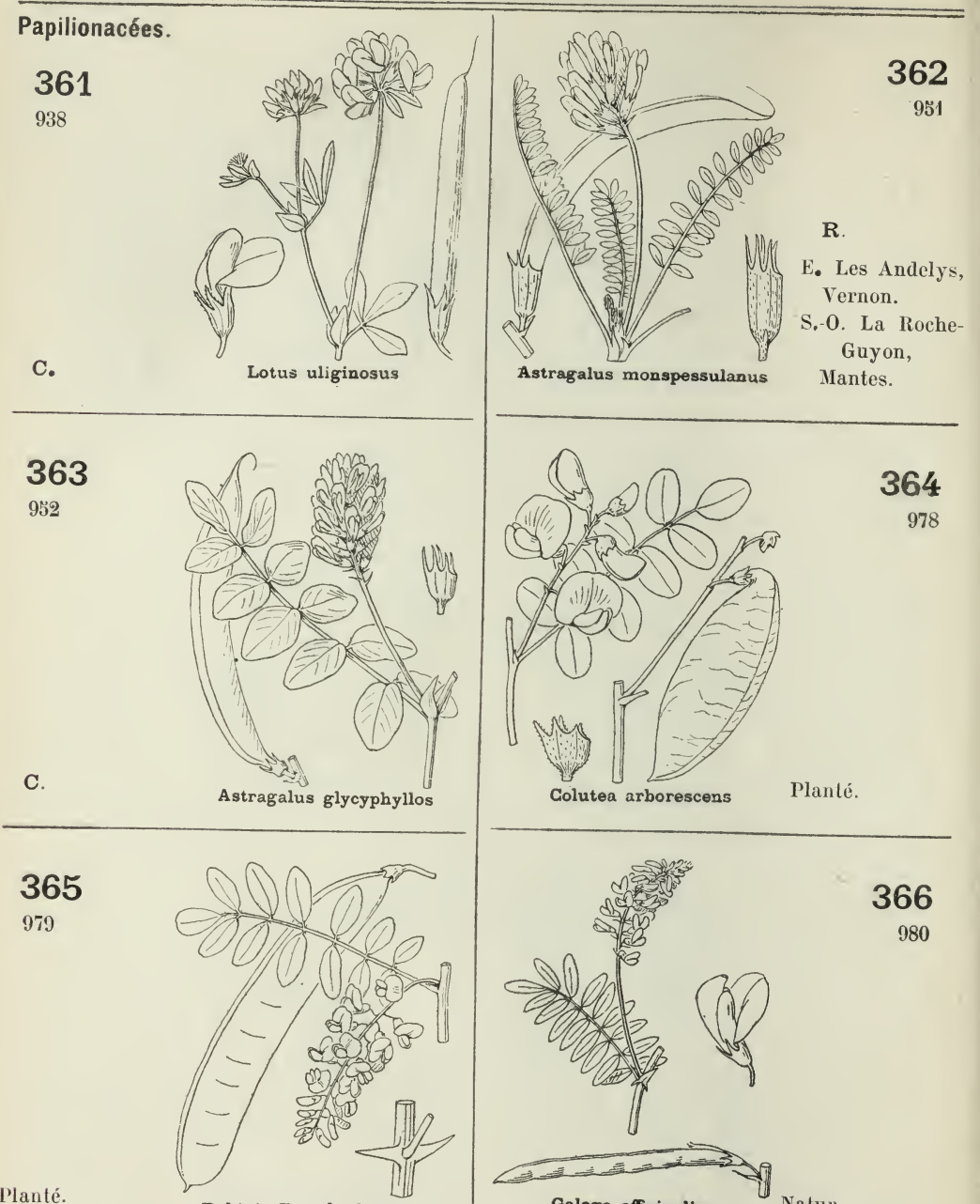

Planté.

Robinia Pseudo-Acacia

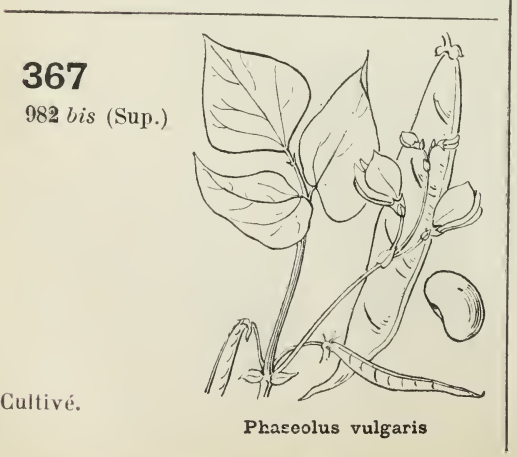

364

978
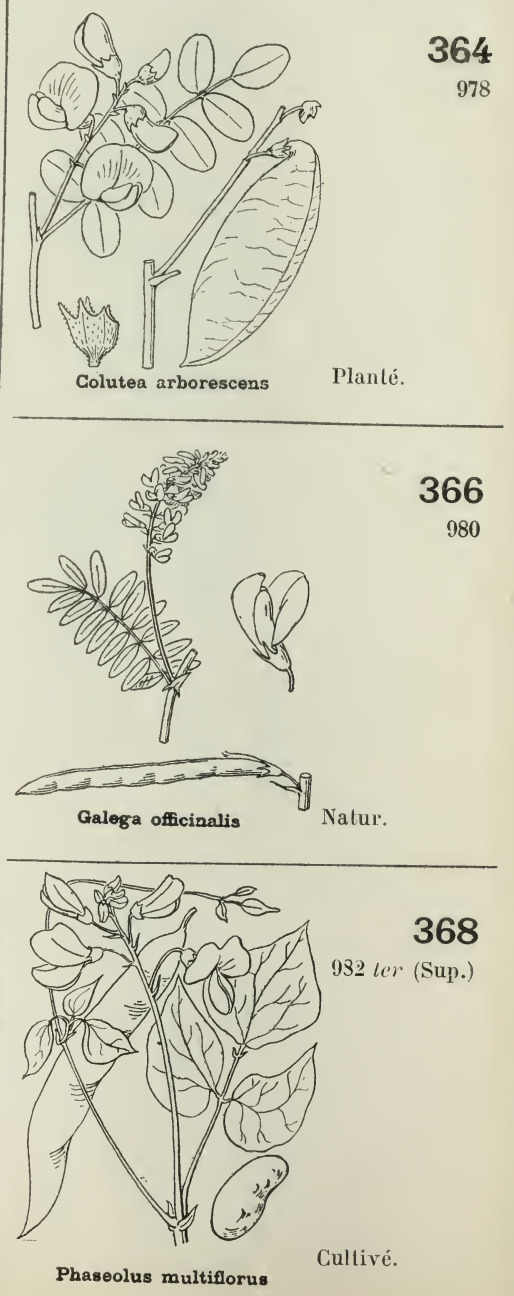

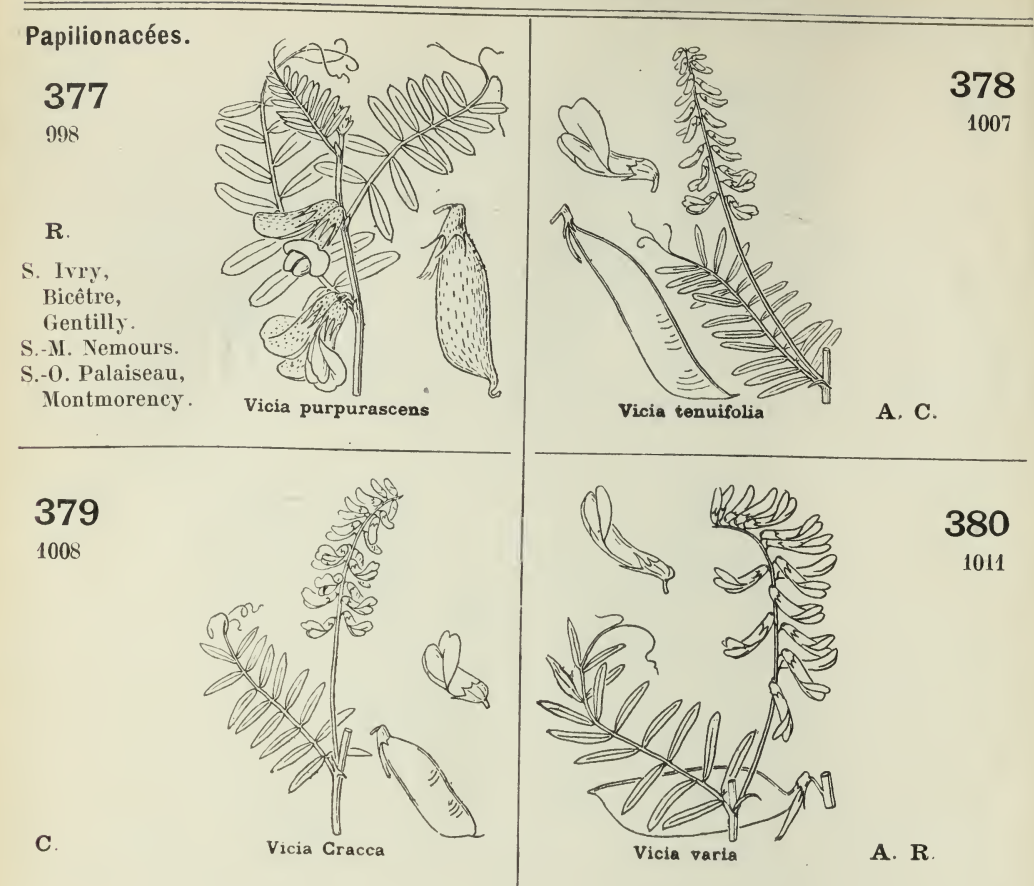

\section{0}

1011

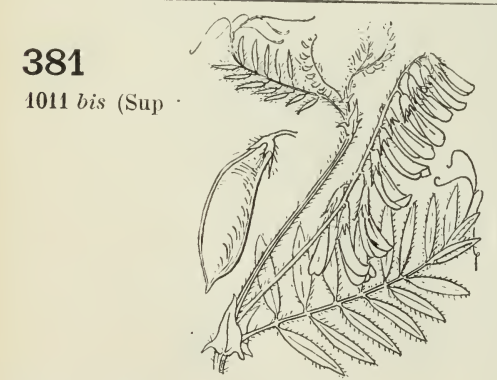

PI. introduite.

Vicia villosa

383

1016

A. $\mathbf{R}$
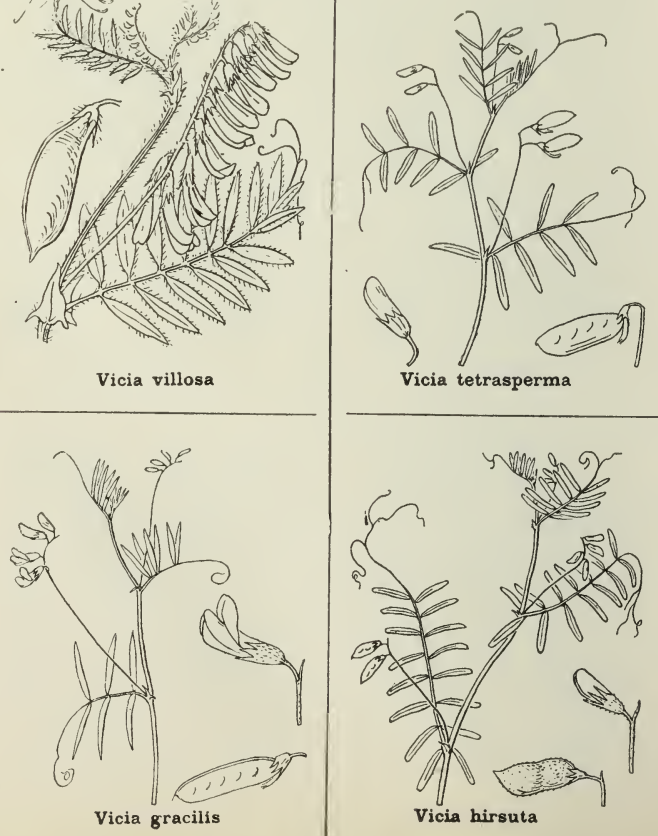

382

1015

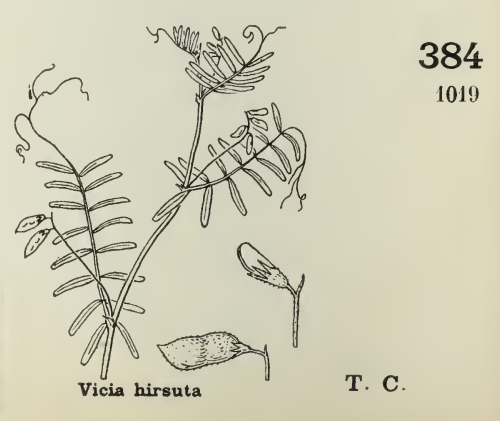



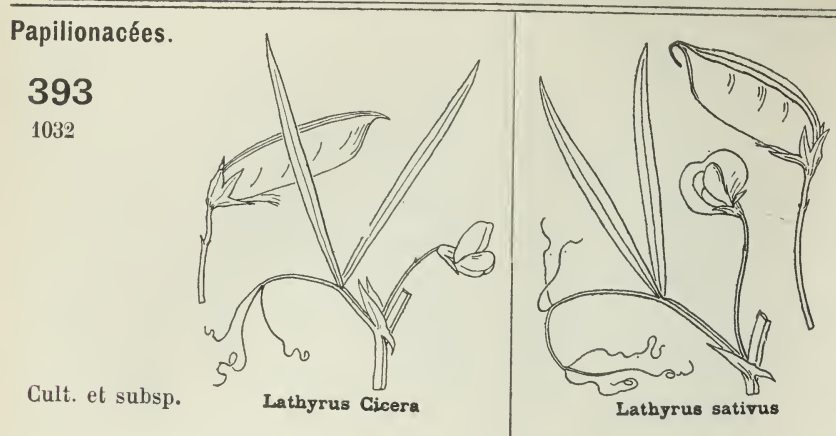

394

1033
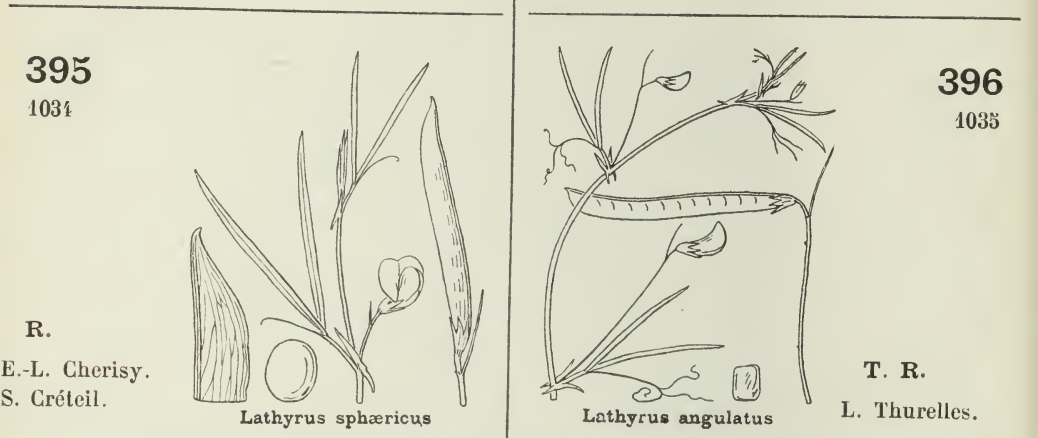

E.-L. Cherisy

Lathyrus sphæricus

\section{Lathyrus angulatus}

L. Thurelles.
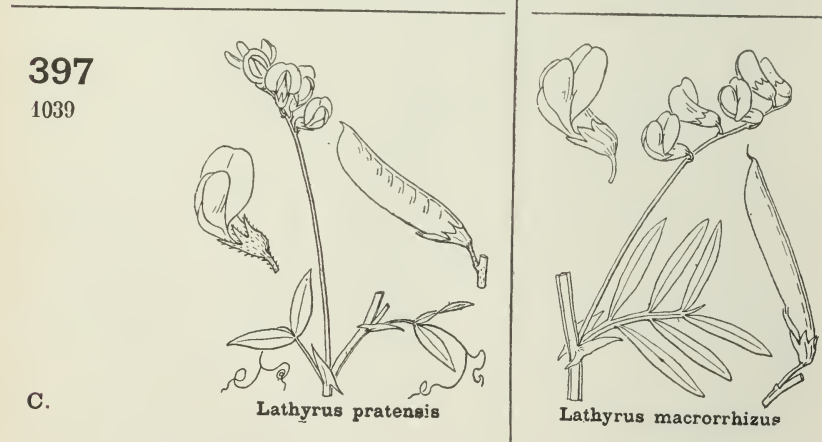

Cultivé et subsp.

$$
\text { . }
$$

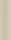


FAM. 32 (39). - PAPILIONACÉES
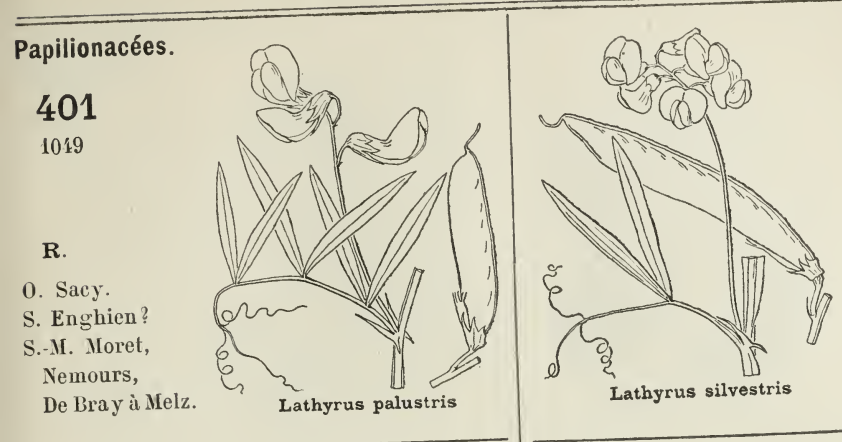

402

1032
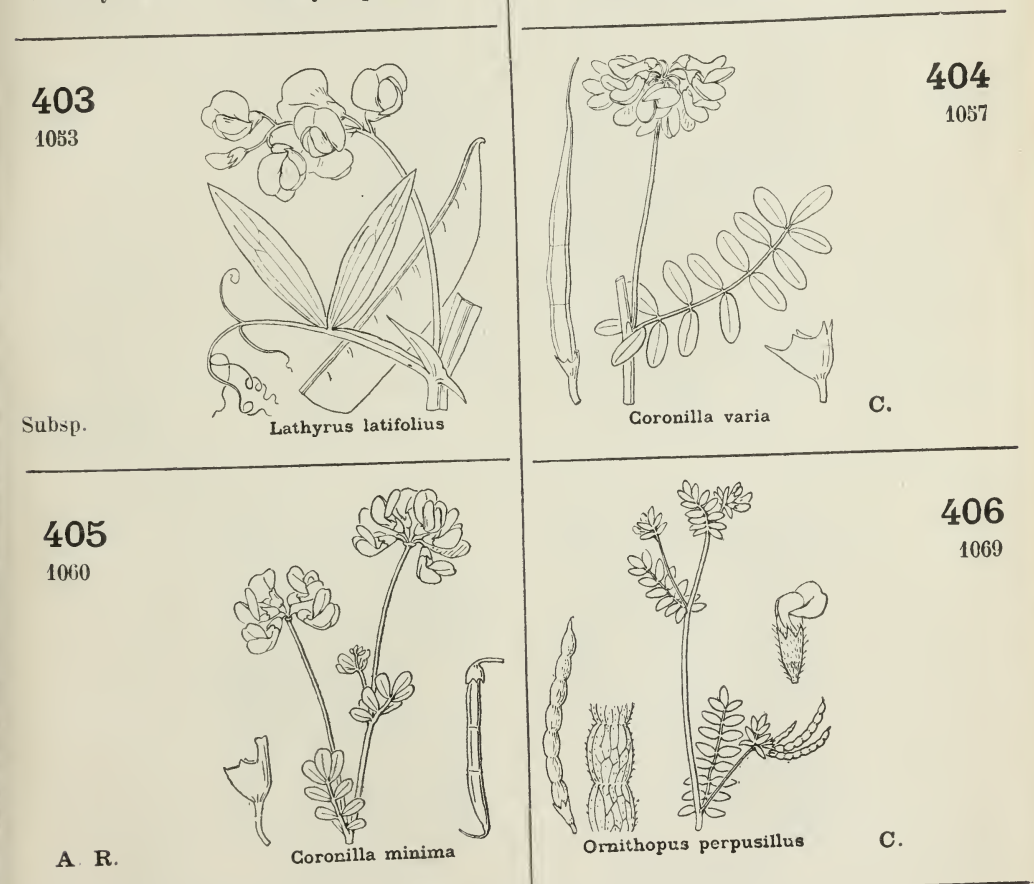

A. $\mathbf{R}$.

Coronilla minima
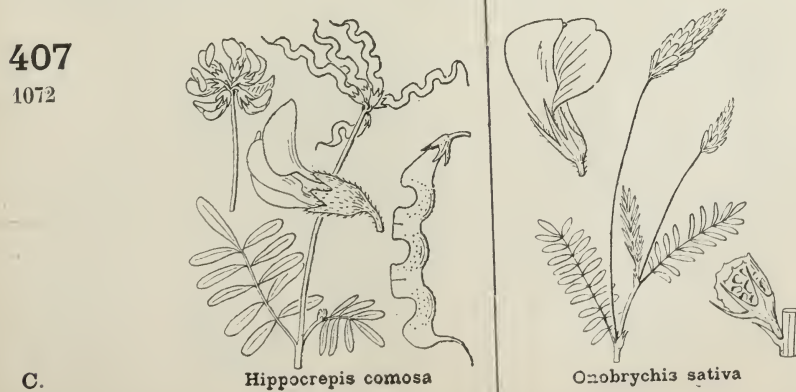

408

1082

Onobrychiz sativa 

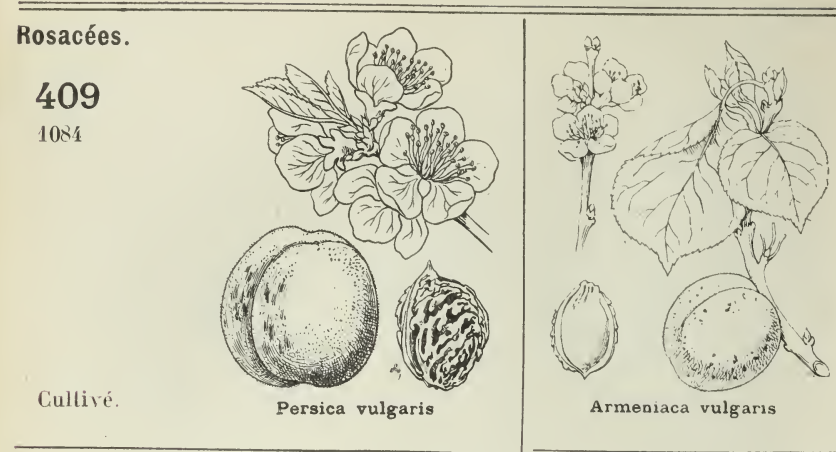

Armeniaca vulgaris

Cultivé.

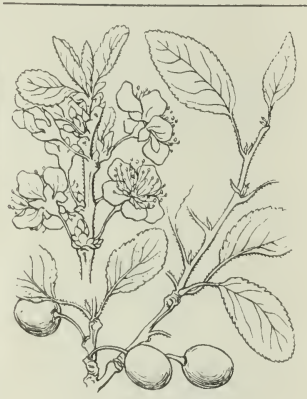

Prunus insititia

Cult. et subsp.

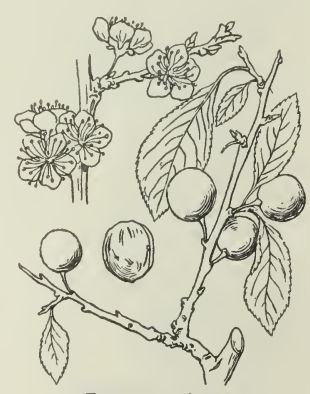

Prunus spinosa

412

1088

414

1090

A. $\mathbf{R}$.

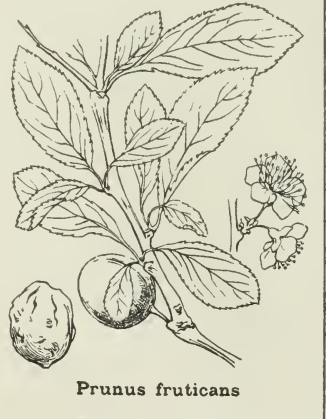

\section{5}

1086 bis (Suj.)

Subsjo.

E. Giverny,

S. Saint-Maur.

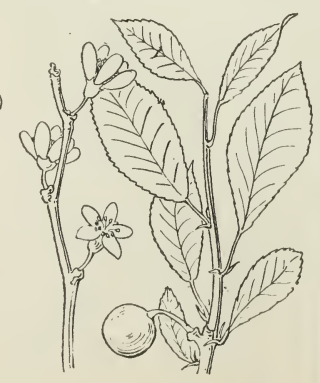

Prunus cerasifera
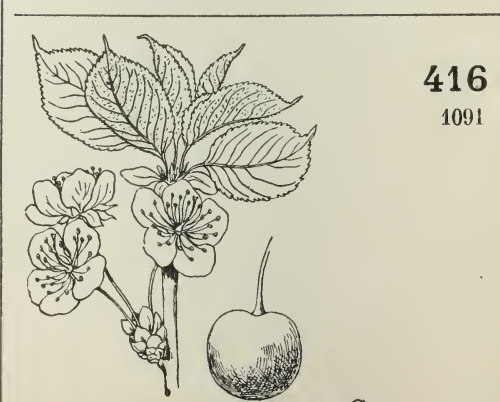

Cerasus avium 


\section{Rosacées.}

425

N.

T. $\mathbf{R}$.

E. Gisors.

0 . Sérifontaine,

Beauvais.

E. Les Andelys.
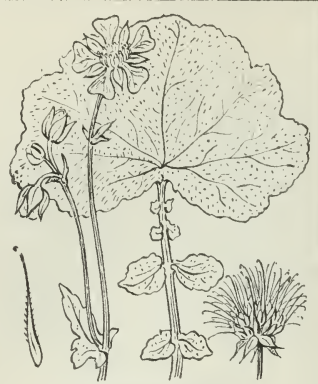

Geum intermedium

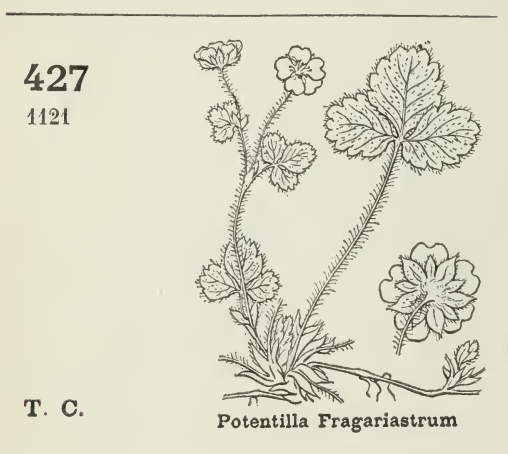

429

1127

A. $\mathbf{R}$.

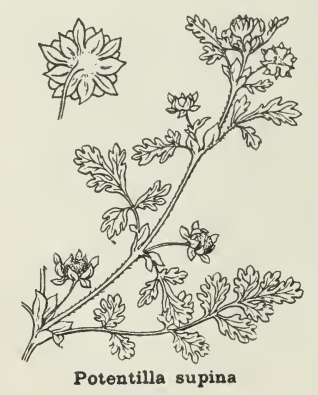

431

1129

A. $\mathbf{R}$.

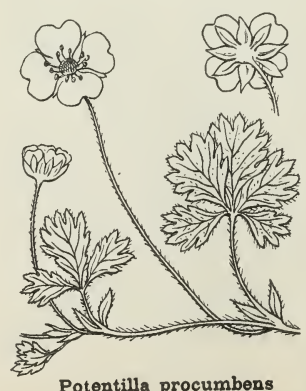

Potentilla procumbens

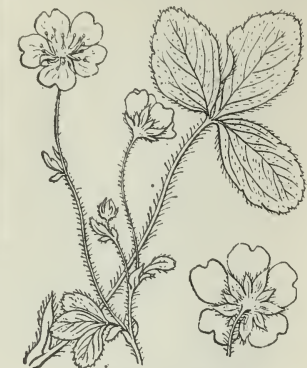

426

1120

Potentilla splendens

A. $\mathbf{R}$.

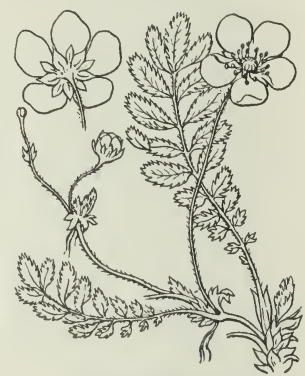

Potentilla Anserina

428

1126

T. C.

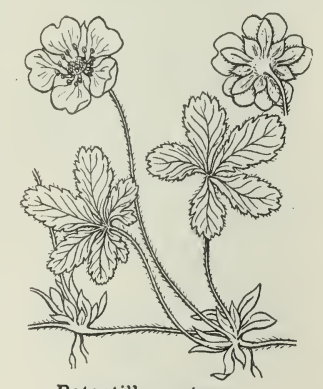

Potentilla reptans

T. C.

430

1128

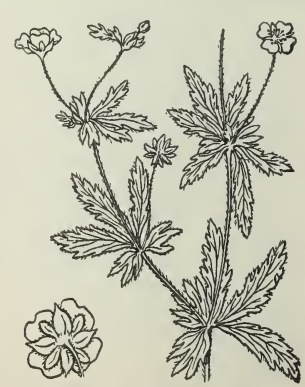

Potentilla Tormentilla

T. C. 


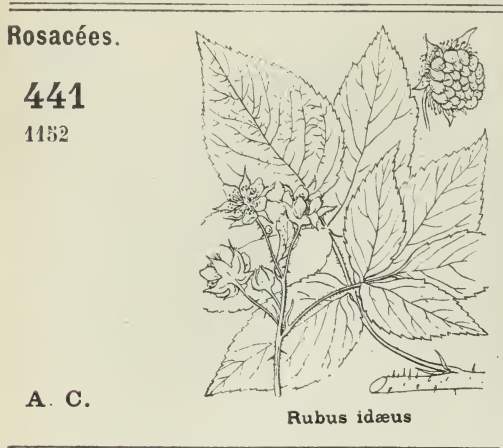

443

$115 \%$

R.

Oise.

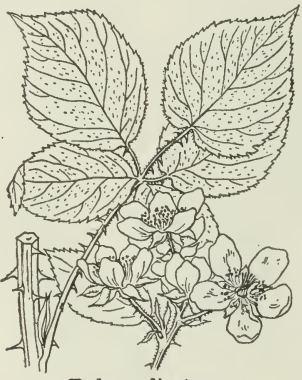

Rubus plicatus

\section{5}

1157

R.

Oise.

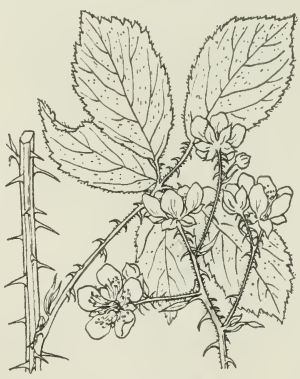

Rubus nitidus

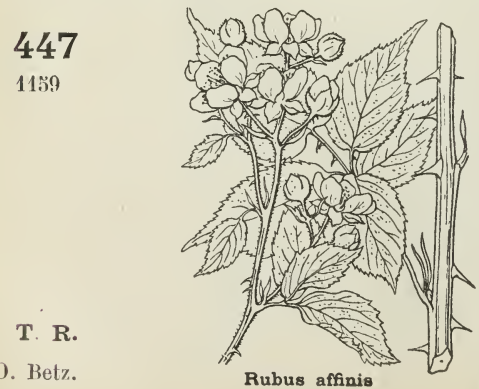

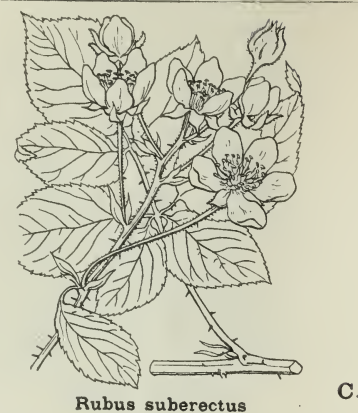

442

1153

C.

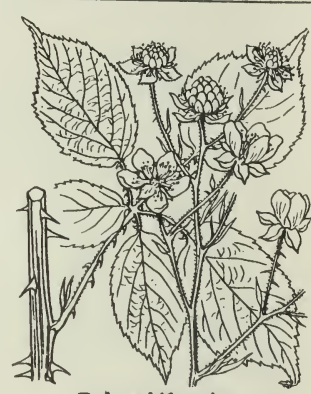

444

1130

R.

Oise.
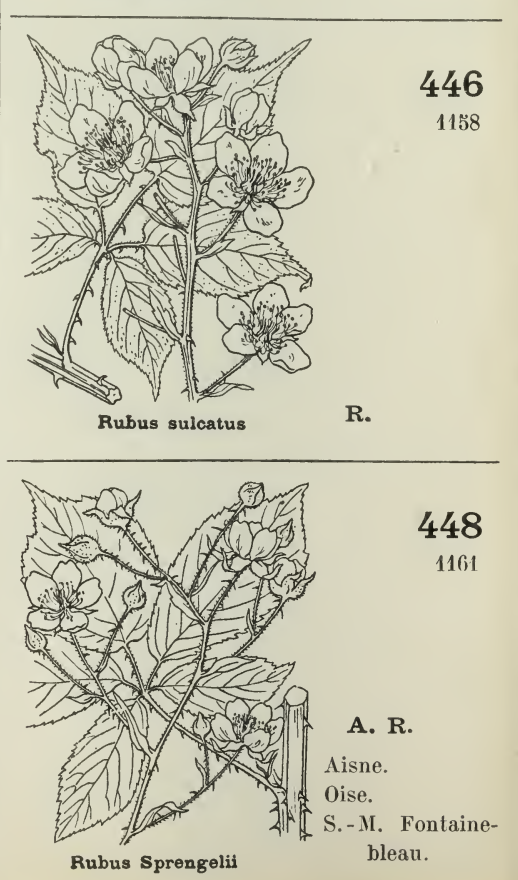
FAM. 33 (10). - ROSACÉES

\section{Rosacées \\ 449 \\ 1162 \\ T. R.}

0. Compiègne.

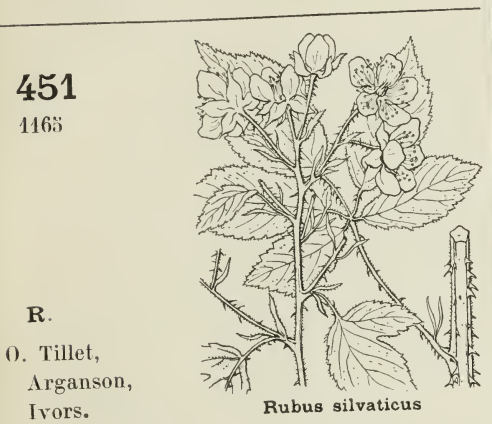

Aisne, A. C. Oise, A. C.

S.-M. Chailly.

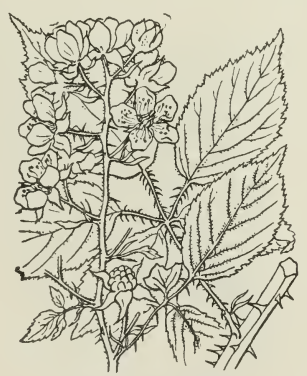

Rubus pyramidalis

\section{5}

1172

R.

S. - M. Fontainebleau.

S. -0. TLardy.
Rubus Schlechtendalii

Rubus silvaticus

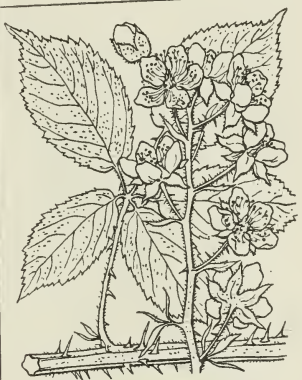

Rubus macrophyllus

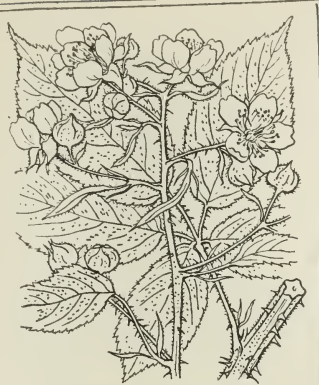

450

1164

R.

Aisne.

Oise.

452

1166

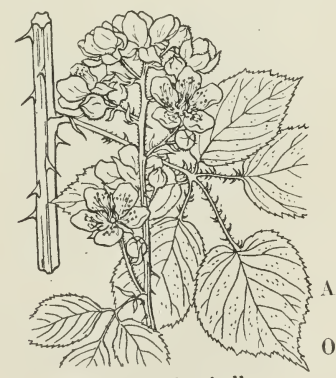

Rubus cardiophyllus

Levignen,

1171

\section{4}

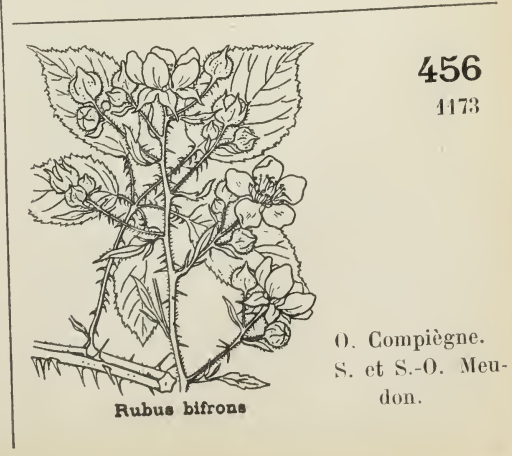




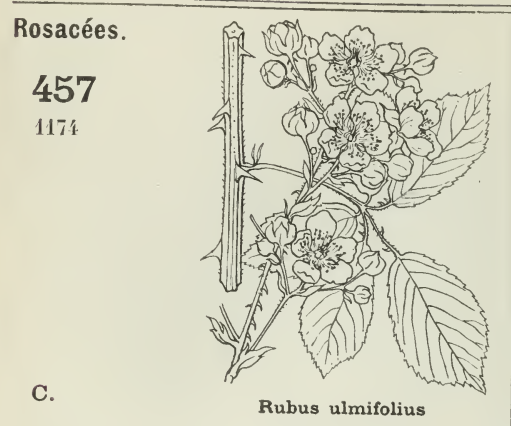

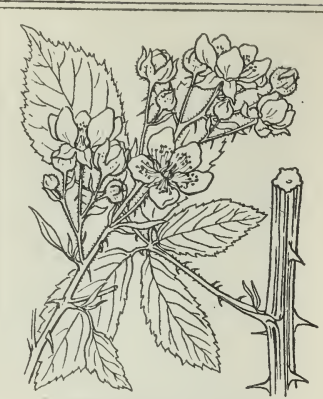

Rubus thyrsoideus

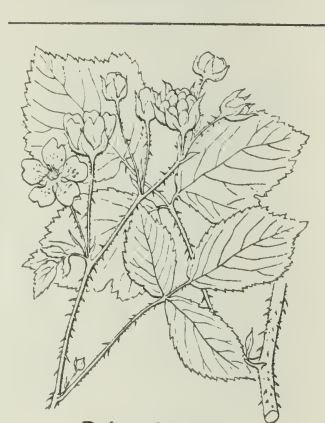

Rubus Cæesius

T. C.
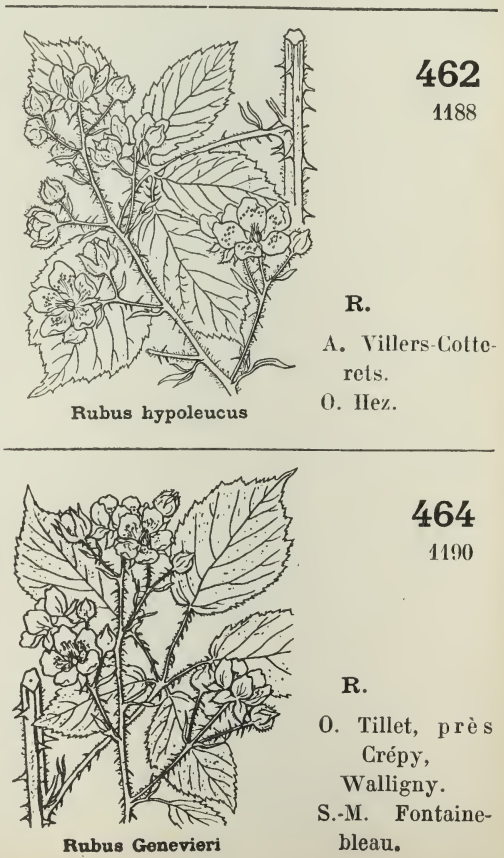

464

1190

R.

0. Tillet, prè s Crépy, Walligny.

S.-M. Fontainebleau. 


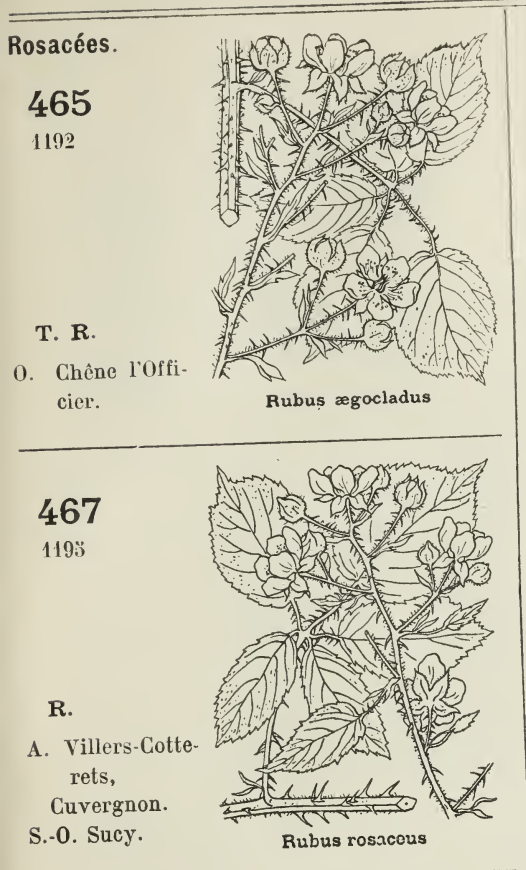

469

1200

T. R.

Oise.

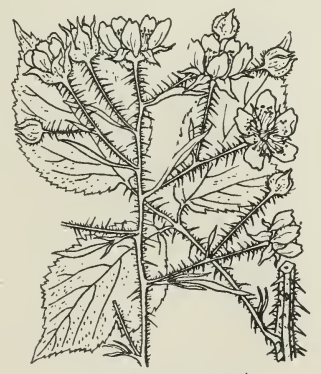

Rubus Schleicheri

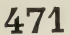

1210

T. C.

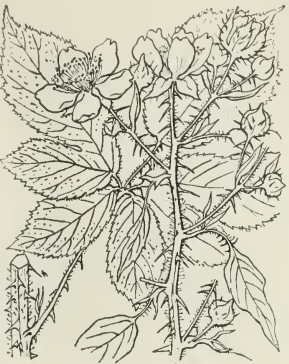

Rubus Lejeunei
466

1193

R.

A. Villers-Cotterets.

468

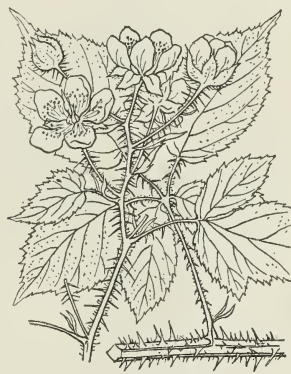

Rubus Koehleri

Buisson de

Walligny.

0. Ivors.
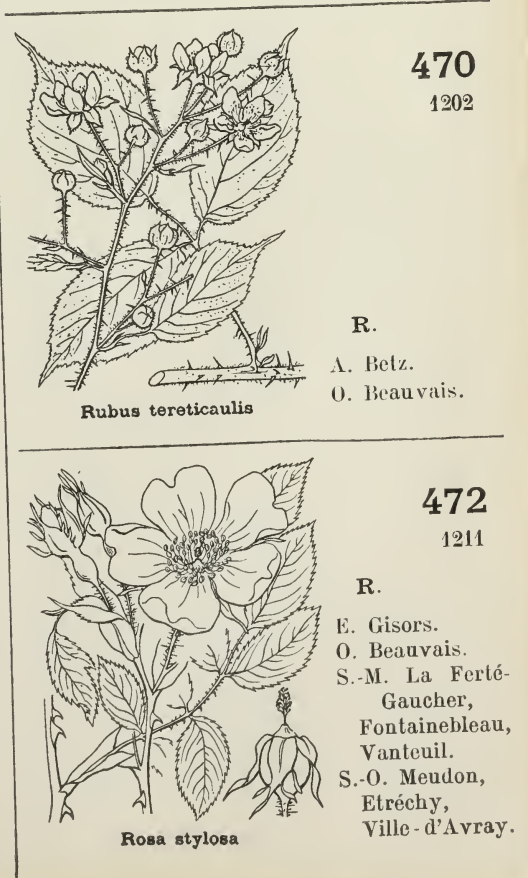


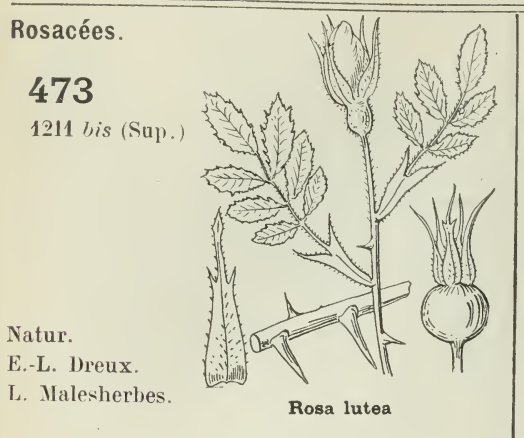

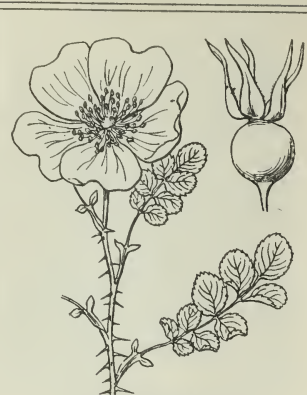

Rosa pimpinellifolia
474

1213

L. Malesherbes.

(). Giury,

Laigne.

S. - M. Fontainebleau,

Nemours.

S. - O. Mantes,

La RocheGuyon,

Rougeaux

Maisse.

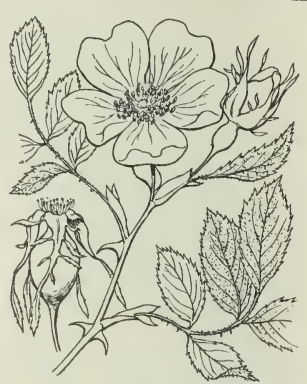

Rosa agrestis
476

1219
Pl. améric. nat

L. Malesherbes.

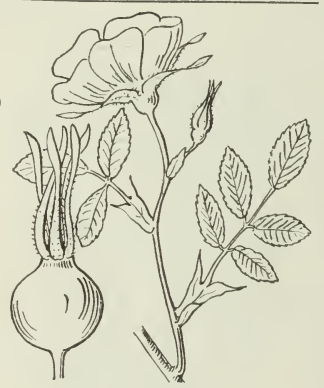

Rosa blanda
477

1221

A. $\mathbf{R}$.

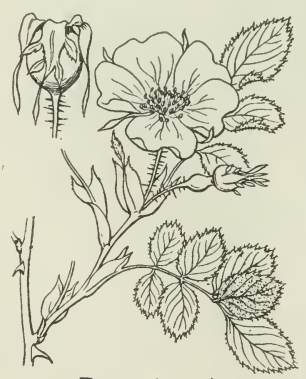

Rosa micrantha

\section{9}

1223

$\mathbf{R}$.

S.-M. De Melun à Champagne.

A. Villers-Cotterets.

L. Malesherbes.

o. Fleurines, Beauvais, Com piègne, Neuf chelles, Thury S.-0. Meudon, Verrières, Garches.

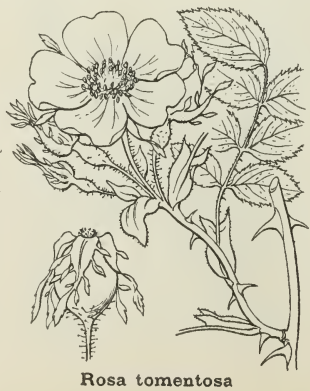

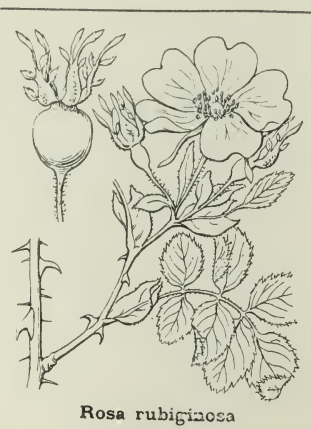

A. C.

\section{8}

1222

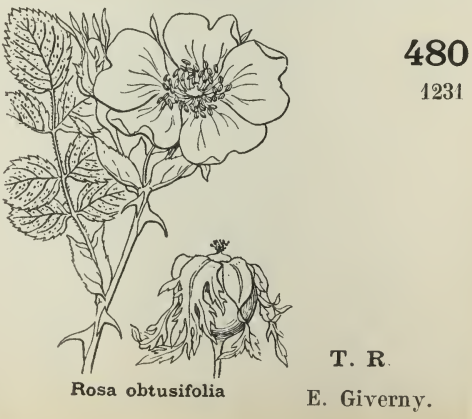




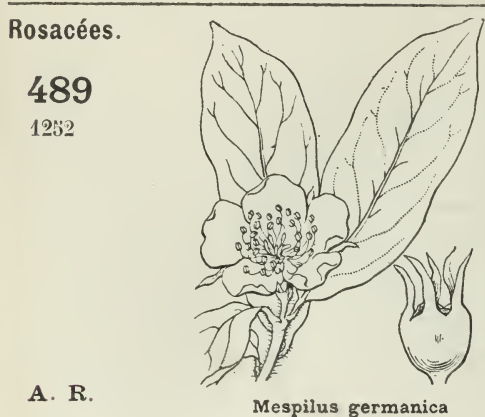

A. C

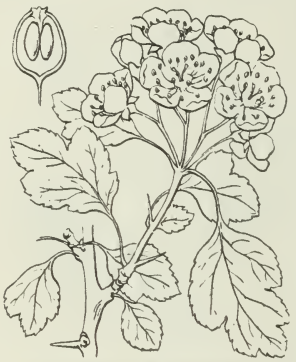

Cratægus oxyacanthoidoo

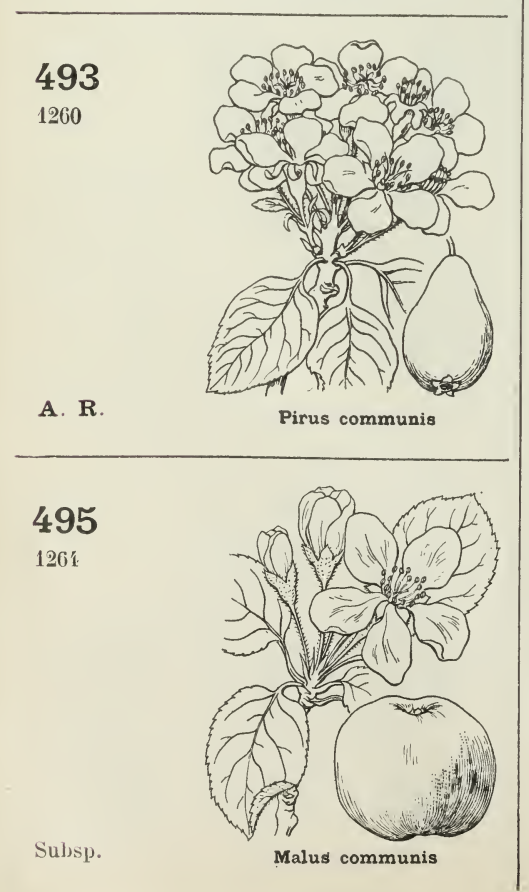

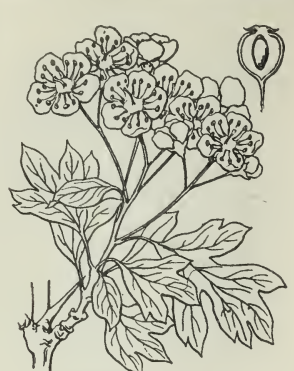

490

1254
T. C.

492

1259

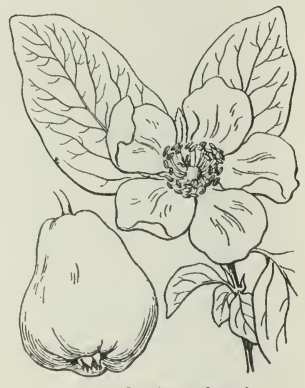

Cydonia vulgaris

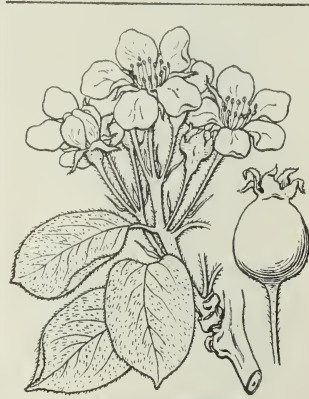

Pirus salvifolia

Planté.

S.-0. Trappes.

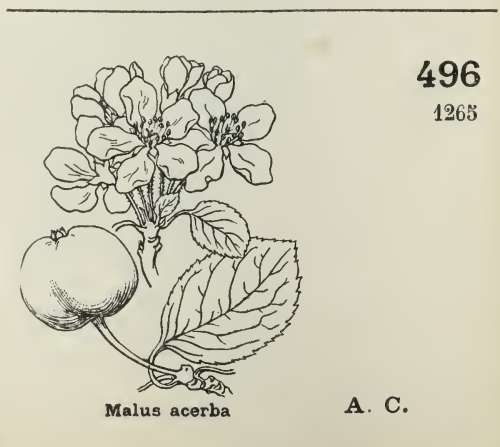




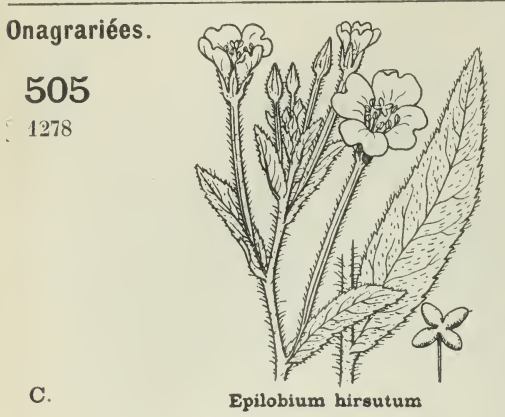

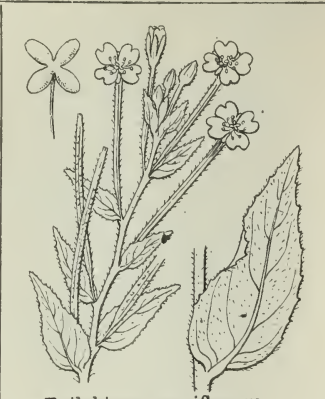

Epilobium parviflorum

C.

508

1282

506

1279
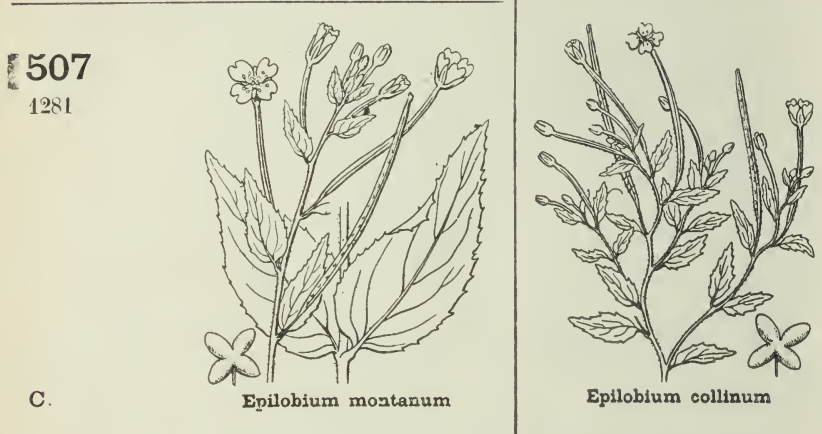

Epilobium collinum

A. $\mathbf{R}$.

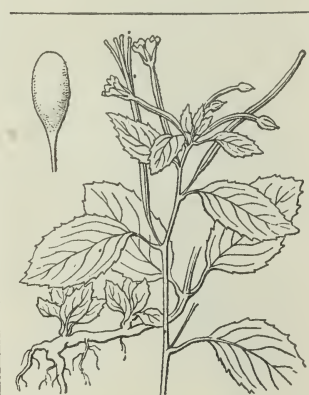

510

509

1283

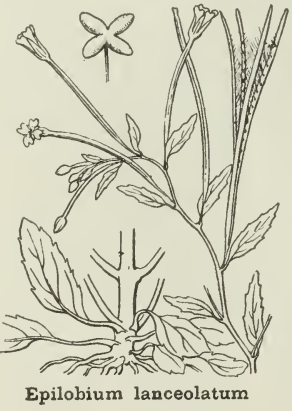

Epilobium roseum

A. R.

Fourqueux.

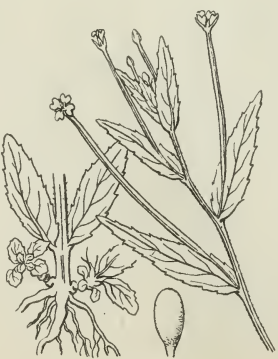

C.

Epilobium tetragonum

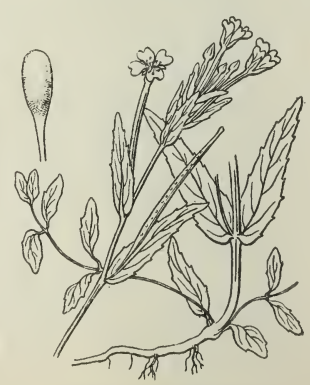

511

1286 
FAM. 35 ('3). ONAGRARIÉES - FAM. 36 (14). HALORAGÉES 63 Onagrariées.

\section{3}

1288

A. $\mathbf{R}$.

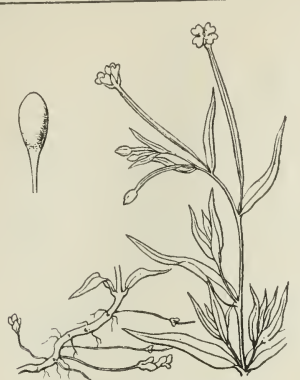

Epilobium palustre

515

1297

T. $\mathbf{R}$.

E. Giverny.

S.-II. Nemours.

S.-0. Rambouil-

let.

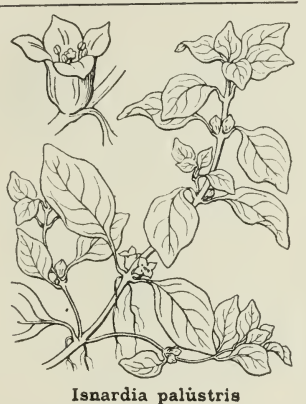

517

1302

Natur.

1. La Ferté-Milon.

S. - 0. Meudon,

Versailles.

S. Boulogne.
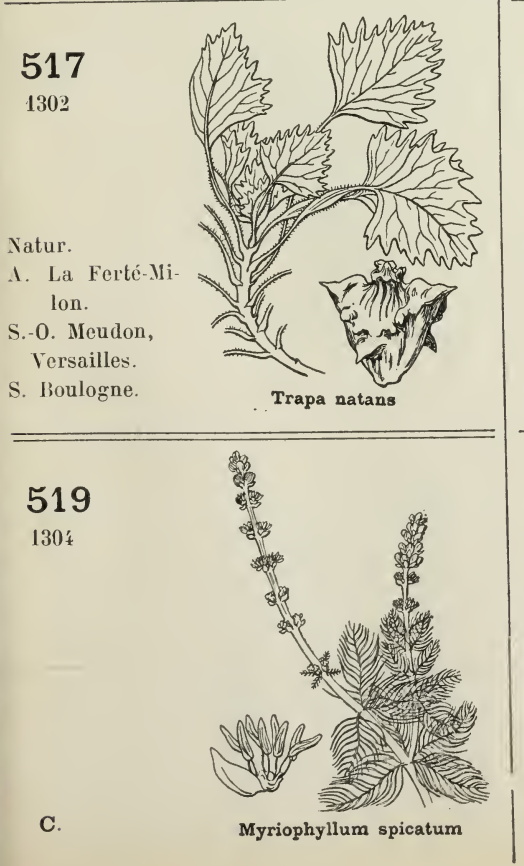

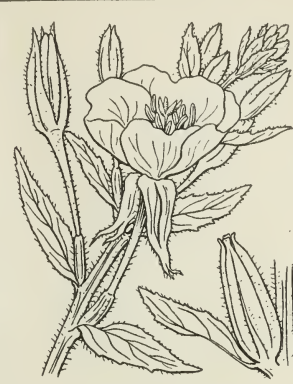

Enothera biennis

514

$129 \%$

T. C.
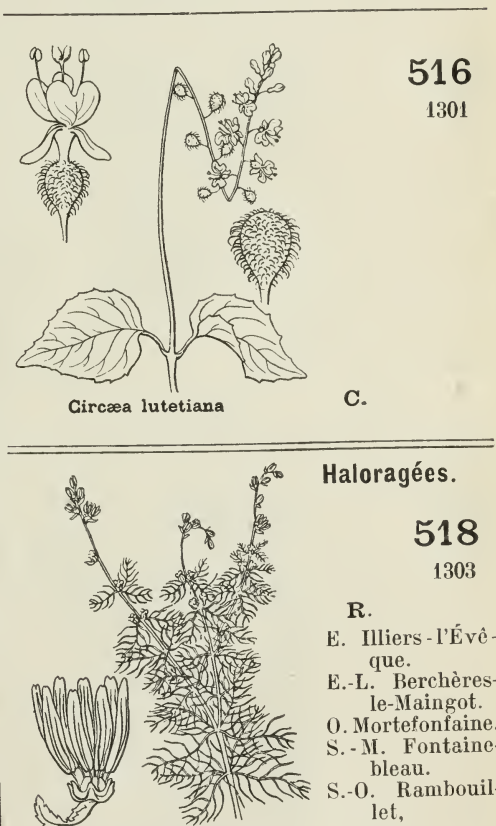

Haloragées.

\section{8}

1303

R.

E. Illiers - l'Évê que.

E.-L. Berchèresle-Maingot.

0 . Mortefonfaine.

S. - M. Fontainebleau.

S.-0. Rambouillet,

Magny.

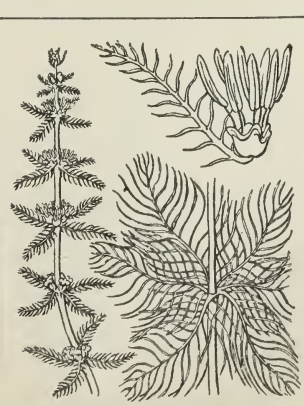

Myriophyllum verticillatum
520

1303 
FAM. 37 (45). HIPPURIDÉES - FAM. 38. (46). CALLITRICHÉES 66 FAM. 39 (4i). GERATOPHYLLÉES - FAM. 40 (48). LYTHRARIÉES
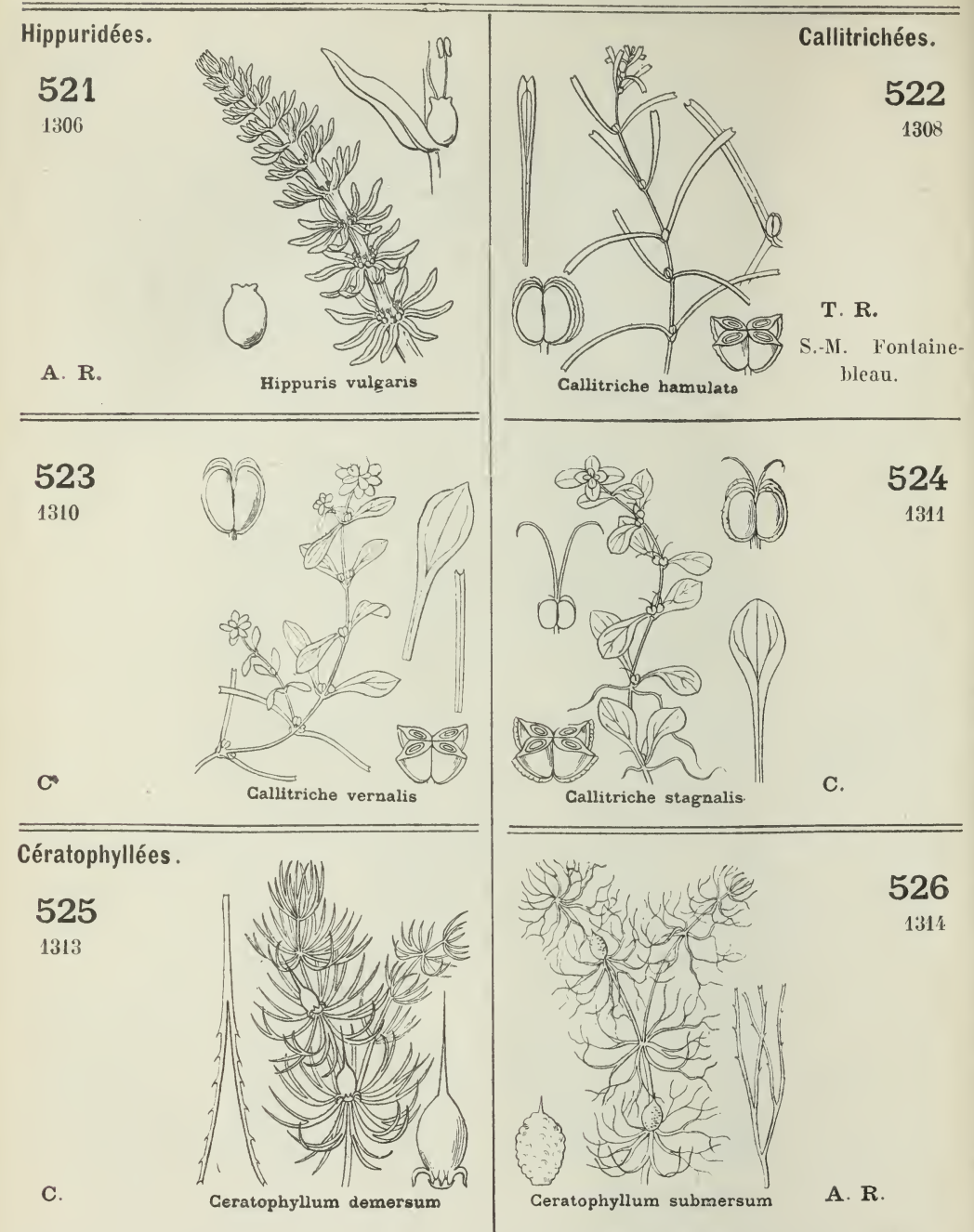

524

1311

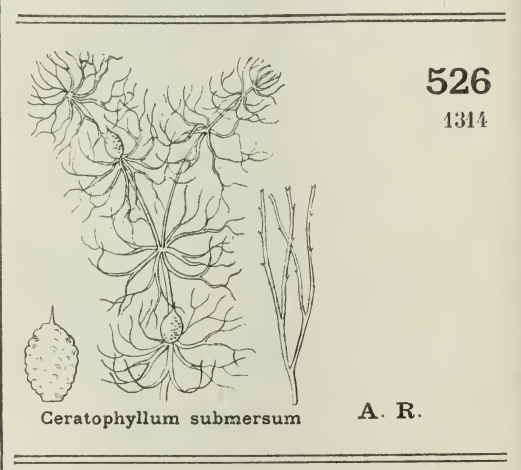

Lythrariées.

527

1313
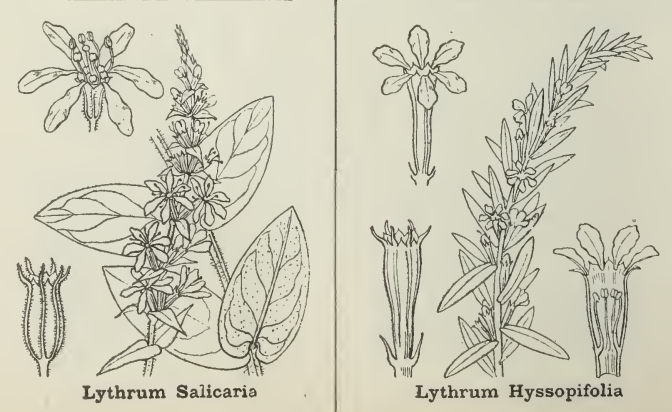

528

1317

C. 


\section{FAM. 43 (\$1). - PARONYCHIÉES}

Portulacées.

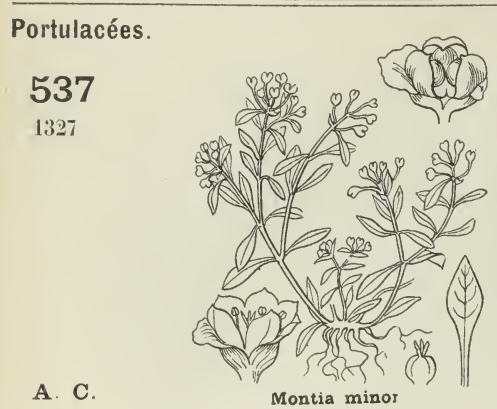

\section{Paronychiées.}

539

1310

$$
\mathbf{R} \text {. }
$$

S. N1. Eontainebleau,

Nemours.

S.-0. Rambouillet,

Beauvais, près

Mennecy.

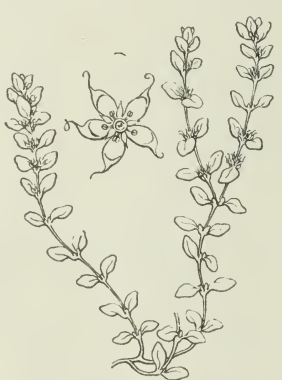

Illecebrum verticillatum

\section{1}

1313

C.

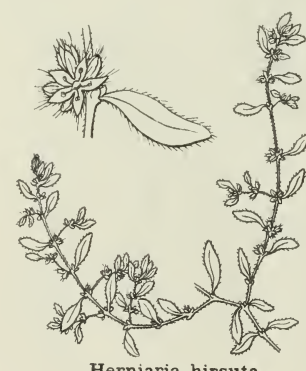

Herniaria hirsuta

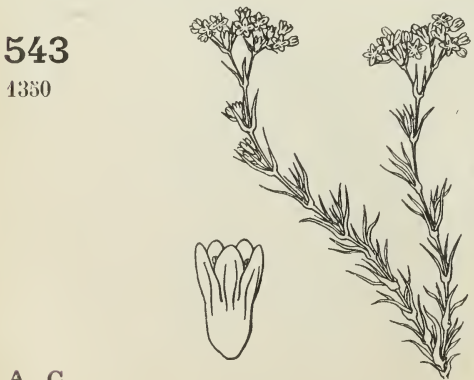

A. C.

Scleranthus perennis

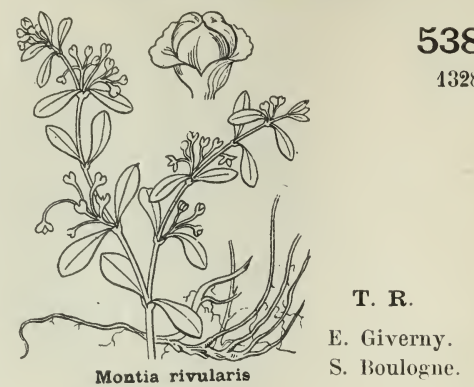

540

1341

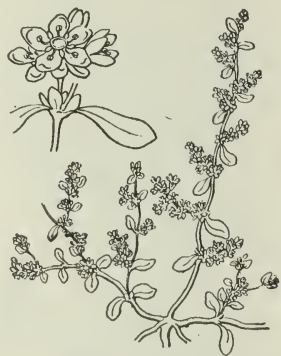

Herniaria glabra

c.

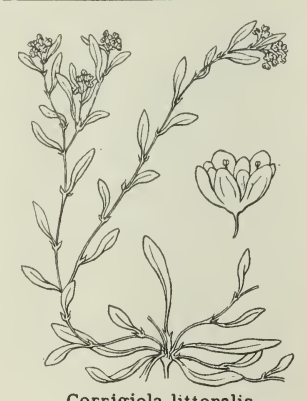

Corrigiola littoralis

A. C.

542

1318

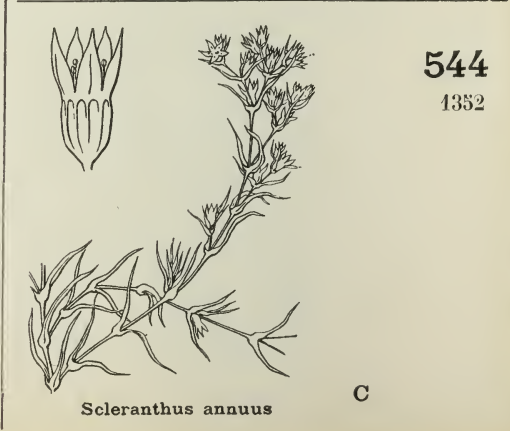



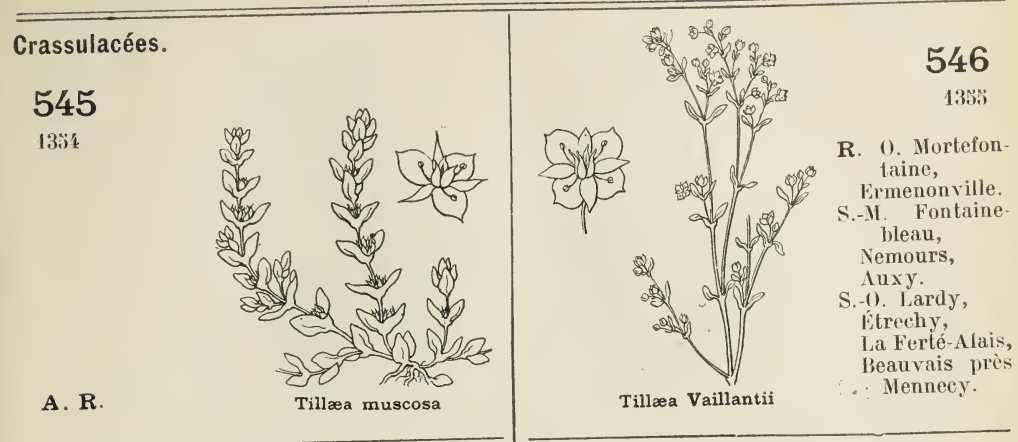

\section{7}

1339

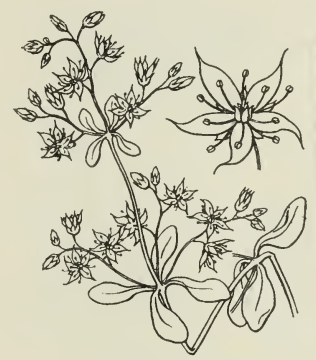

A. C.

Sedum Gepæa

\section{9 \\ 1363}

R.

O. Neufmoulin.

S.-M. Fontainebleau,

Nemours.

S. - 0. Ballan court,

Beauvais, près Mennecy.

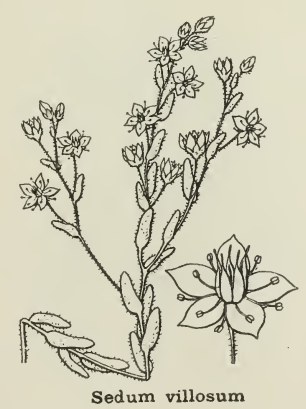

551

1373

C.

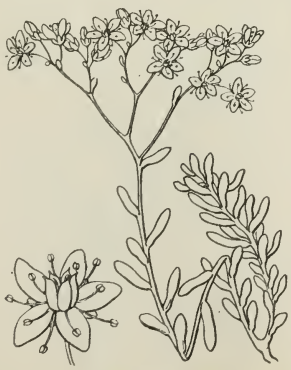

Sedum album

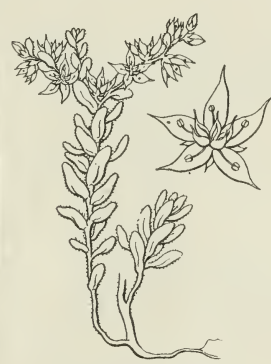

Sedum rubens

548

1360
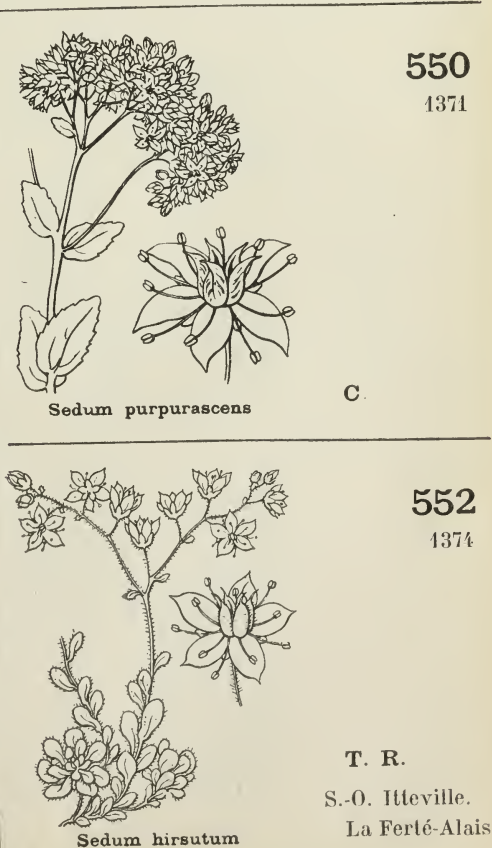

552

137 亿

T. R.

S.-0. Itteville.

La Ferlé-Alais. 
FAM. 44 (52), - CRASSULACÉES

FAM. 45 (5\%). - GROSSULARIÉES
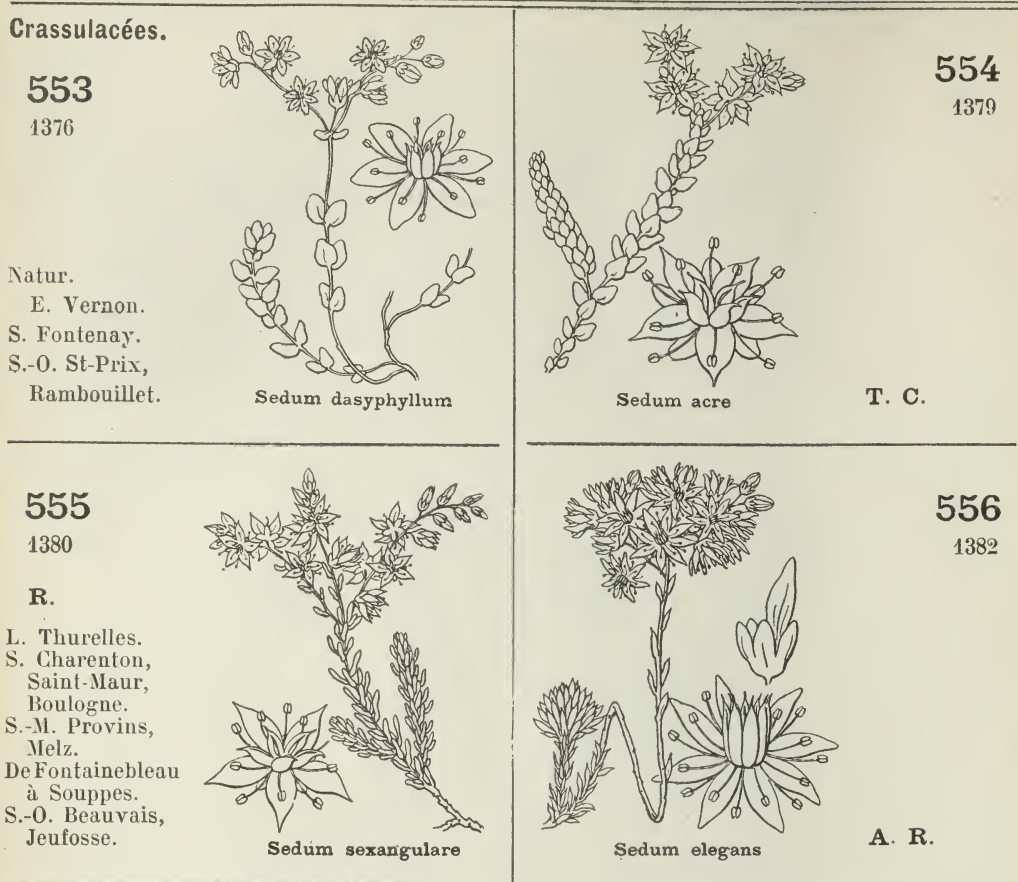

557

1383

T. C.

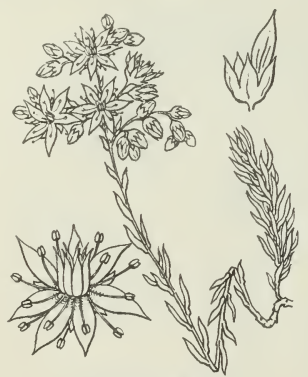

Sedum reflexum

559

1392

T. $\mathbf{R}$.

S.-I. Auchy-Ferrières prês Gournay.

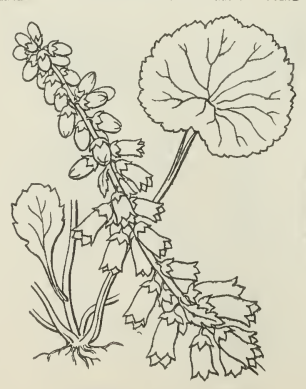

Umbilicus pendulinus

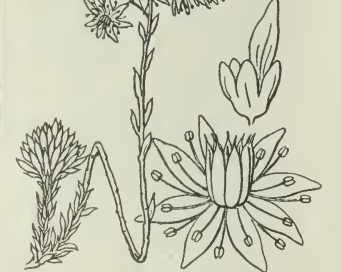

A. $\mathbf{R}$.
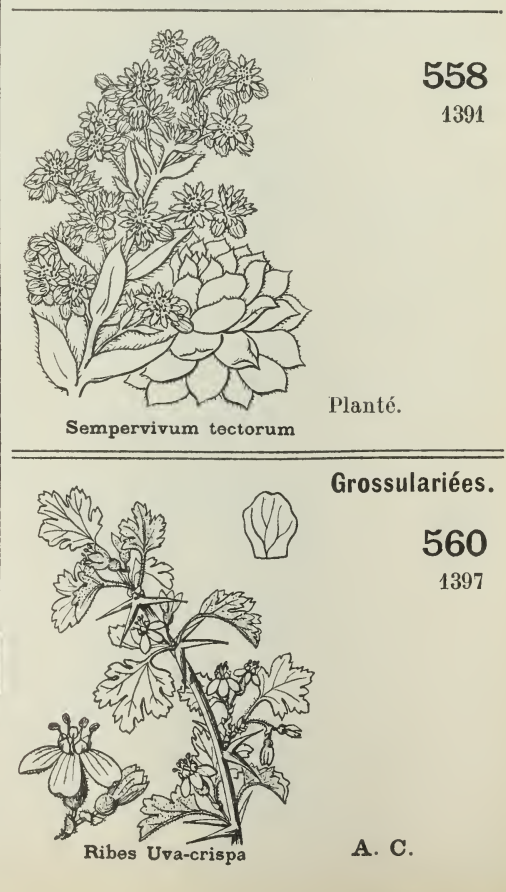
FAM. 45 (57). GROSSULARIÉES - FAM. 46 (36). SAXIFRAGÉES
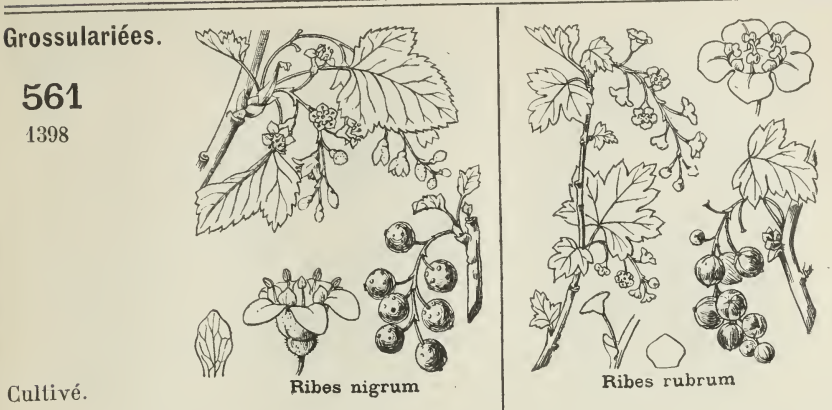

562

Saxifragées.

563

1112

C.

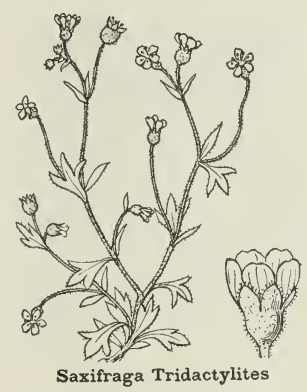

\section{5}

1493

R.

A. Villers-Cotterets.

0. Ermenonville, Ivors, Compiègne, Beauvais, St-Germer S.-0. Senlisse, La Minière.
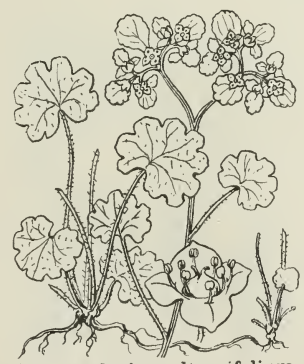

Ghrysosplenium alternifolium

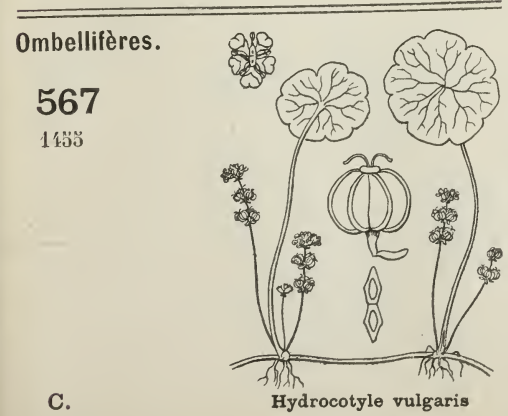

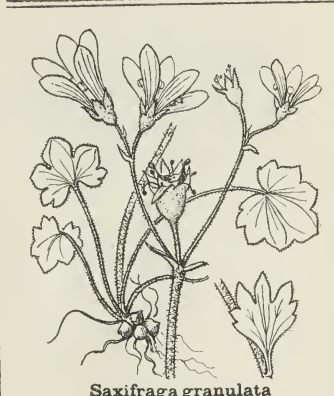

Saxifraga granulata

C.

564

1413

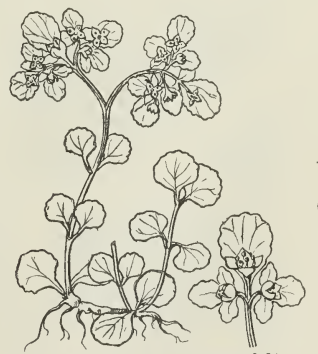

566

1434

R.

A. Villers-Cotterets.

o. Beauvais, Compiègne, Hallatte, Thusy, Verberie, La Neuville-en Hez.

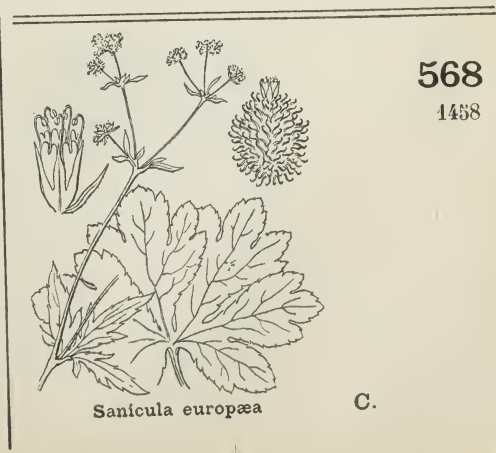




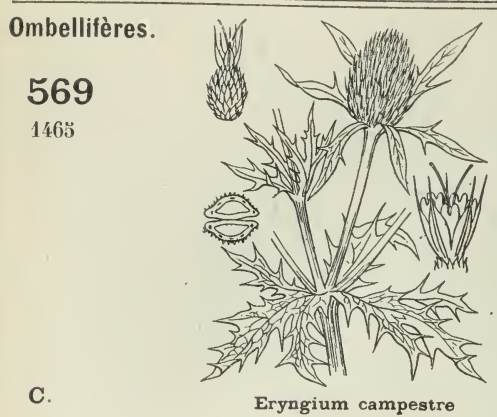

571

1476

$\mathbf{R}$

A. Villers-Cotterets.

0. Compiègne, Beauvais, etc S.-M. Nemours, Provins.

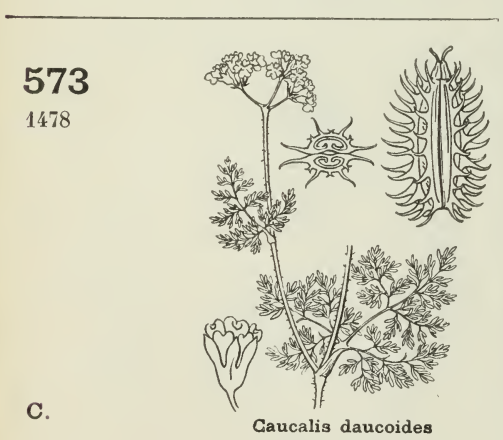

575

1482

T. C.

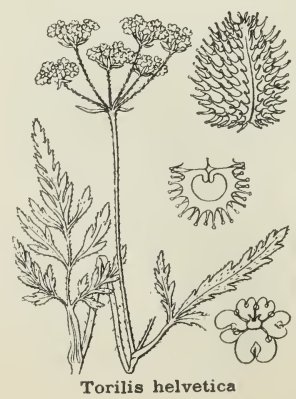

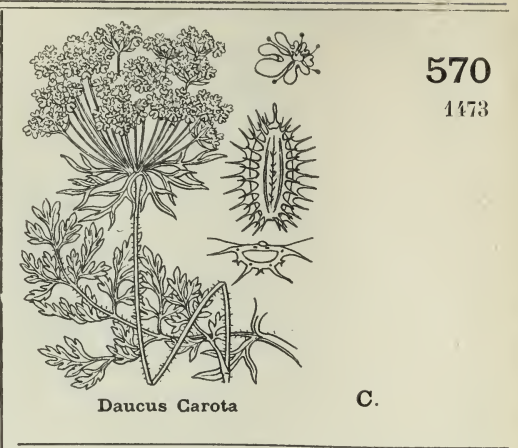

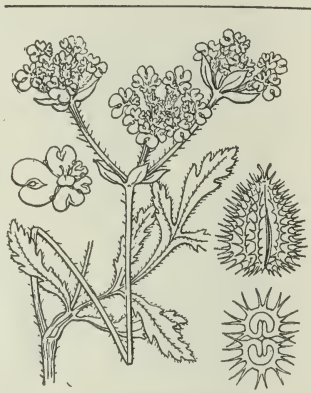

Turgenia latifolia

A. R.

572

1477

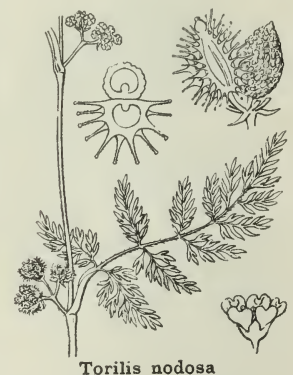

574

1480

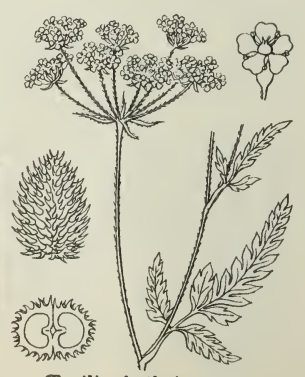

C.

Torilis Anthriscus

C.
576

1483 


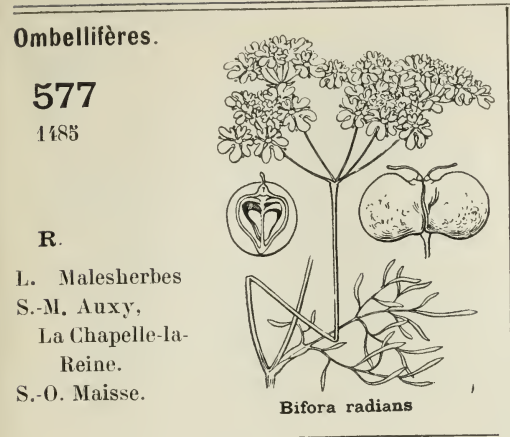

\section{9}

1495

\section{R.}

L. Dordives.

S. - M. Fontainebleau, Champagne, Cesson,

Nemours.
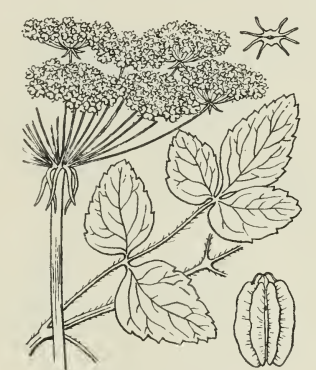

Laserpitium latifolium
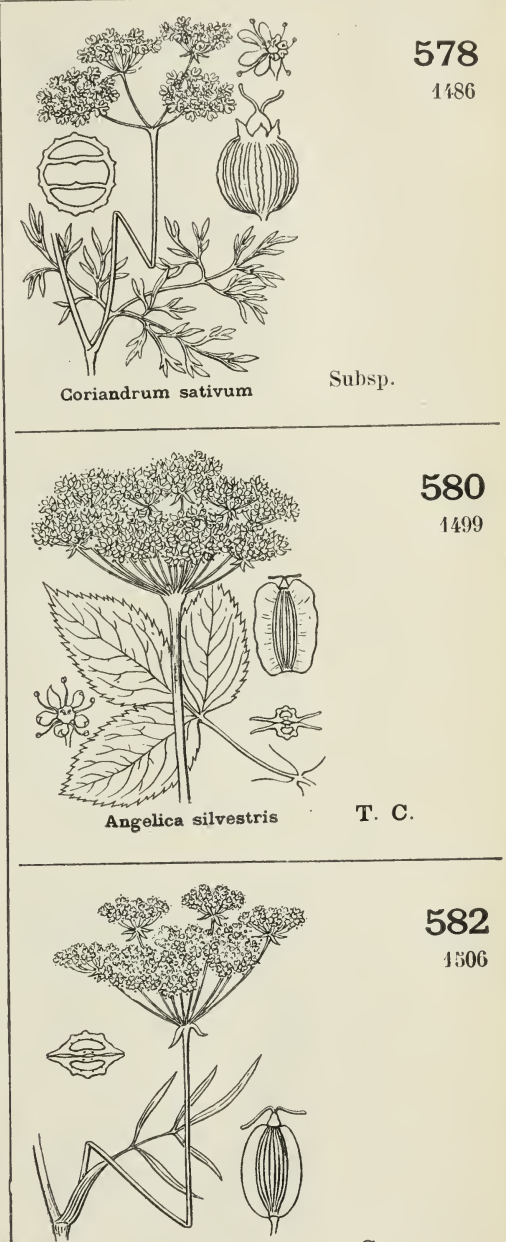

Peucedanum gallicum

C.

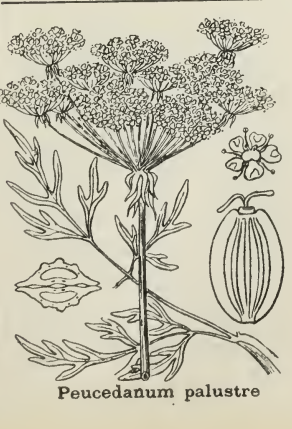

582
A. C.

Selinum Garvifolia
583

1308

A. $\mathbf{R}$.

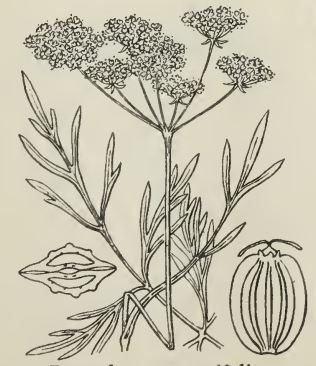

Peucedanum carvifolium 

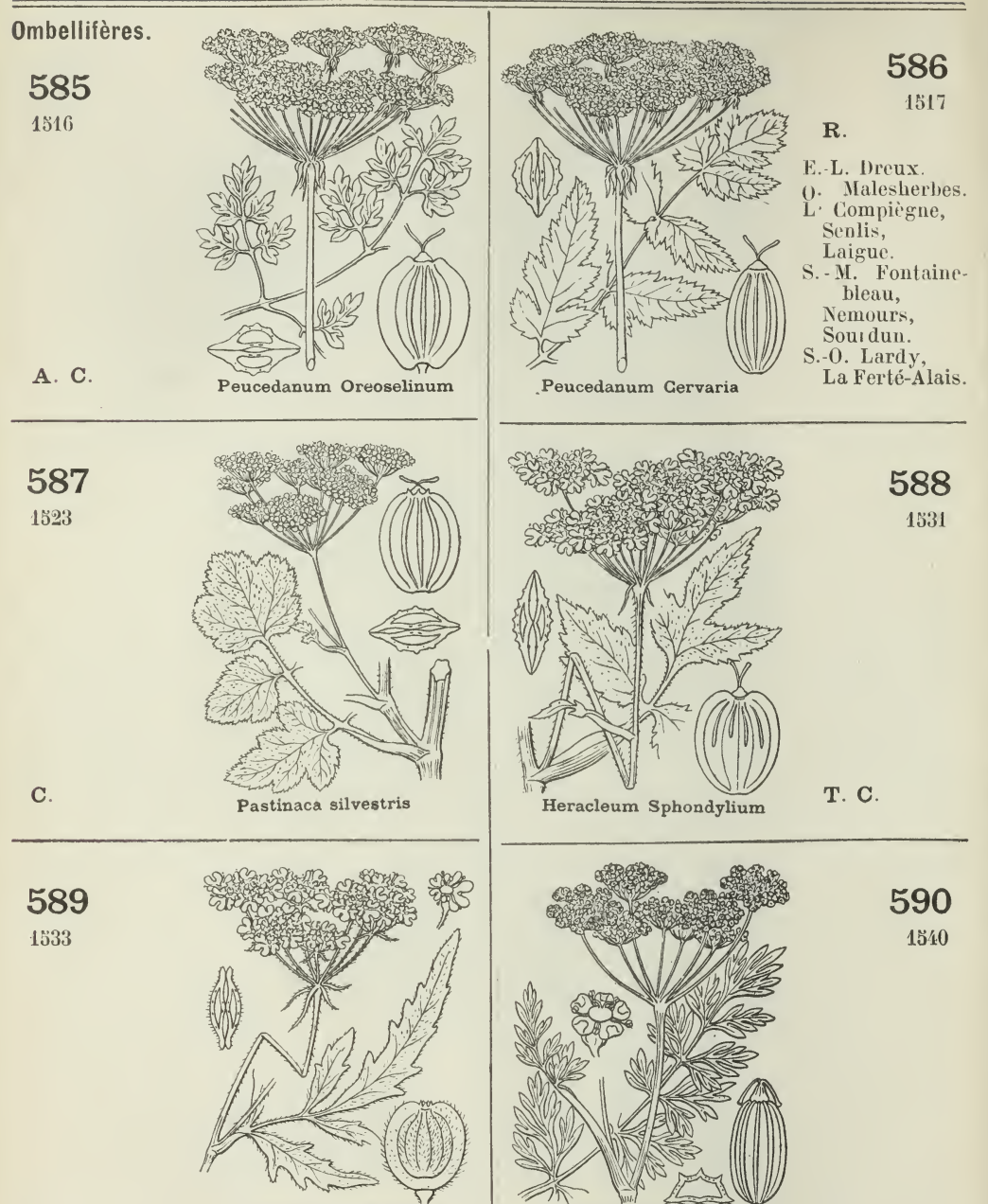
A. $\mathbf{R}$.
Tordylium maximum

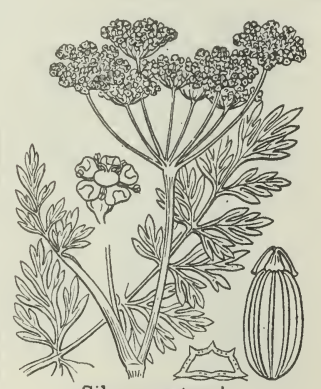

Silaus pratensis

590

1540
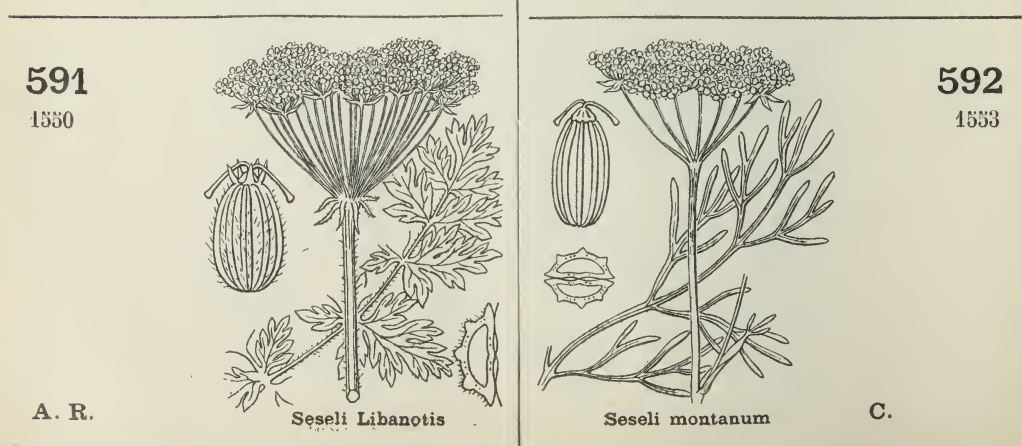
FAM. 47 (37). - OM BELLIFÈRES

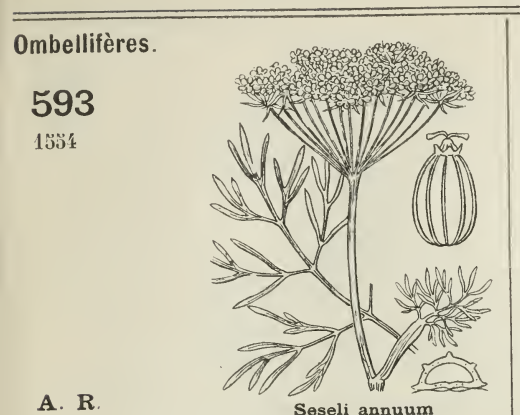

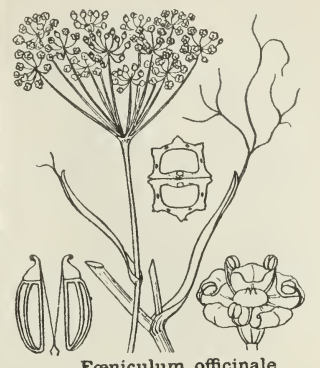

Fœniculum officinale

C.
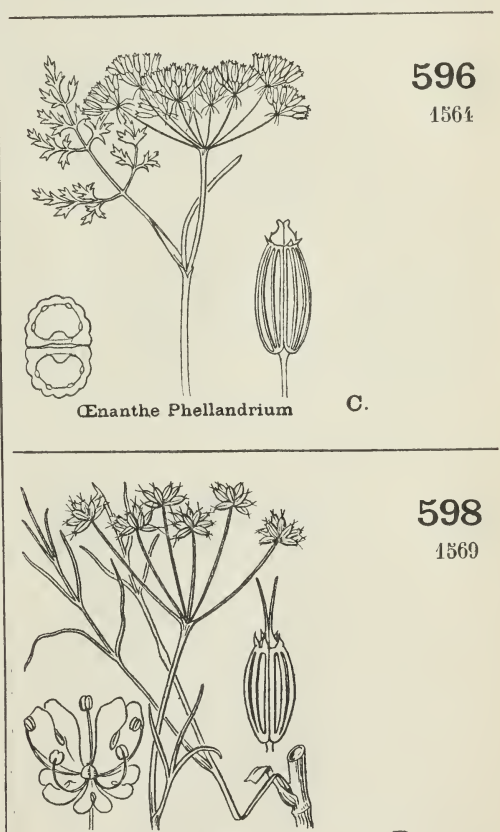

Enanthe peucedanifolia

A. $\mathbf{R}$.

598

1569
A. C.

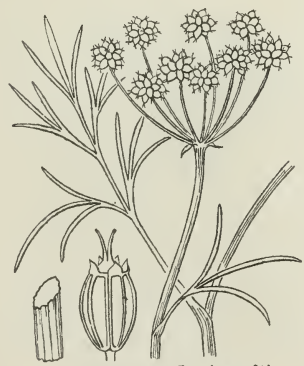

Enanthe Lachenalii
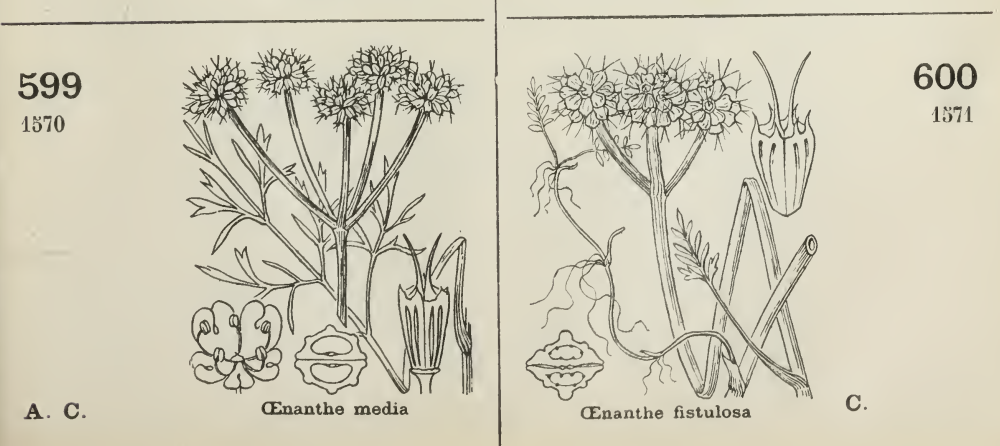

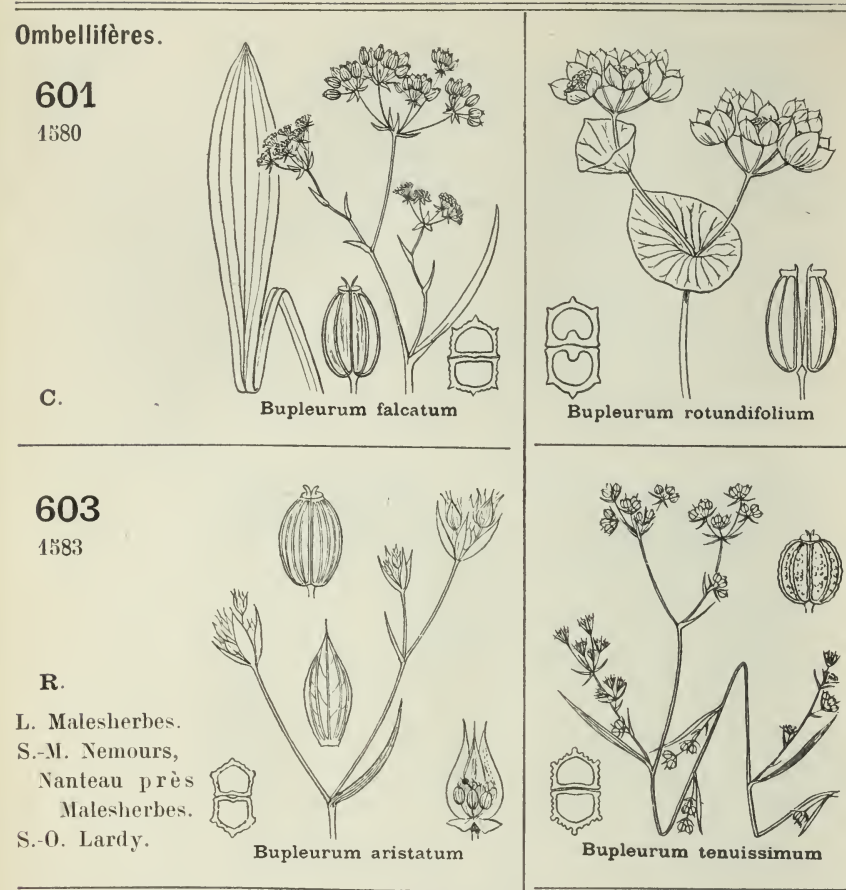

602

Bupleurum rotundifolium

A. $\mathbf{R}$

1581

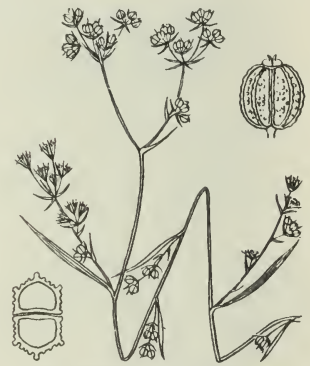

604

1586

Bupleurum tenuissimum

A. $\mathbf{R}$.
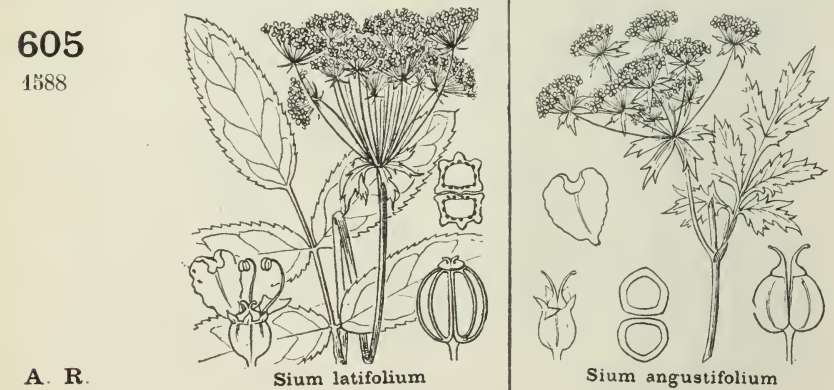

606

1589

Sium latifolium
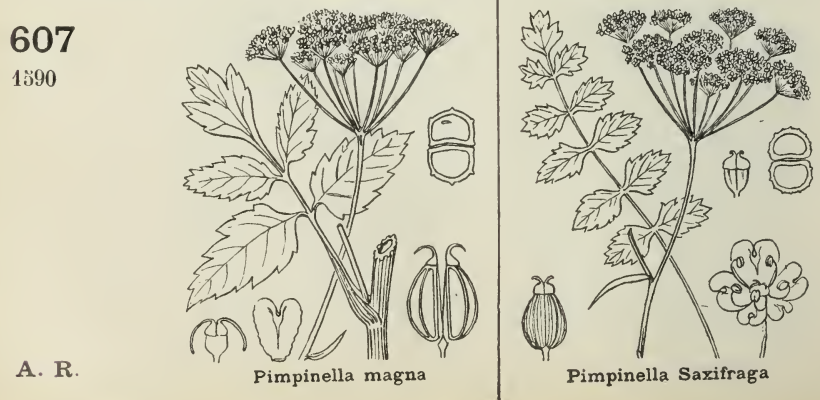

608
Pimpinella Saxifraga
C. 

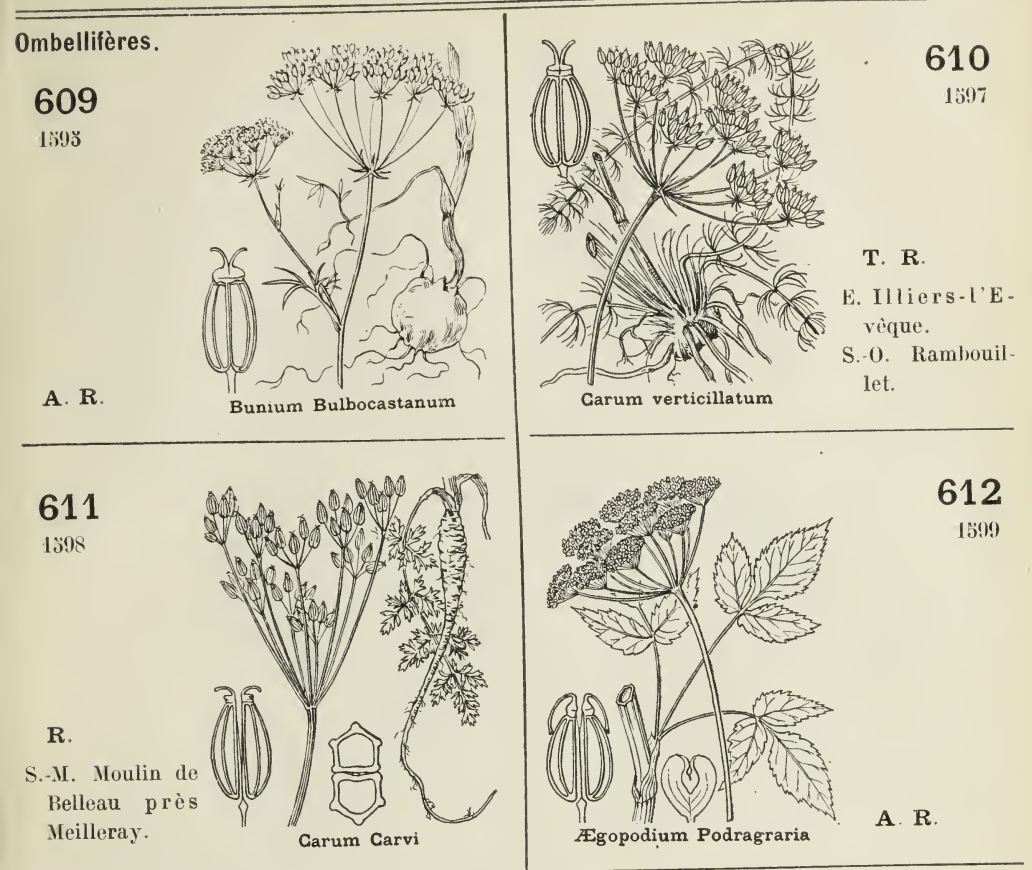

A. $\mathbf{R}$.

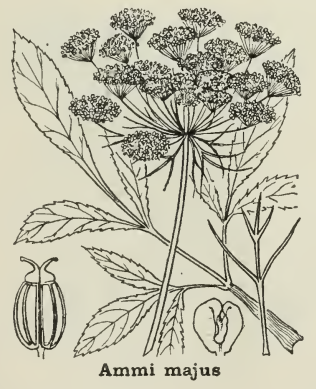

613

1600

\section{5}

1603

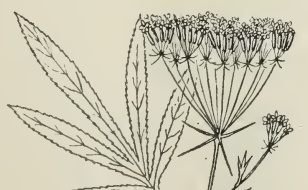

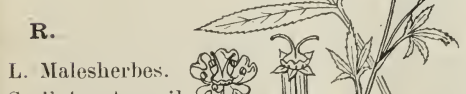

S. Entre $\Lambda$ rcueil et Antony.

S.-0. Saint-Germain.

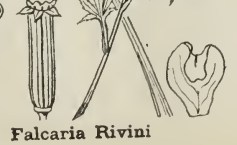

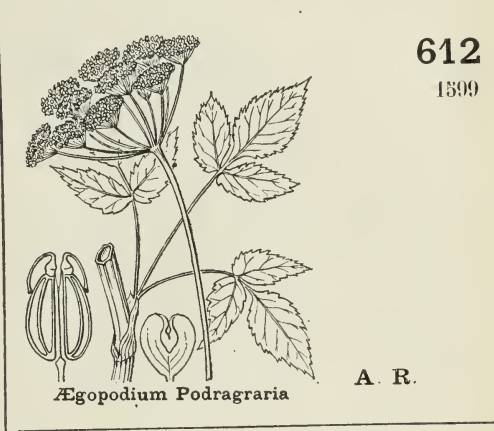

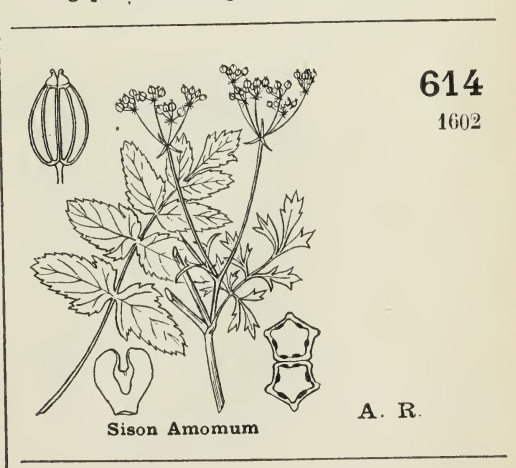

612

1509

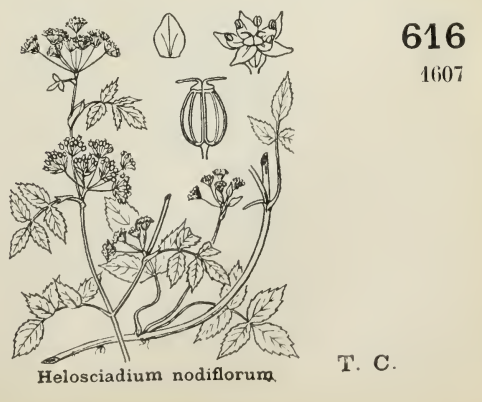



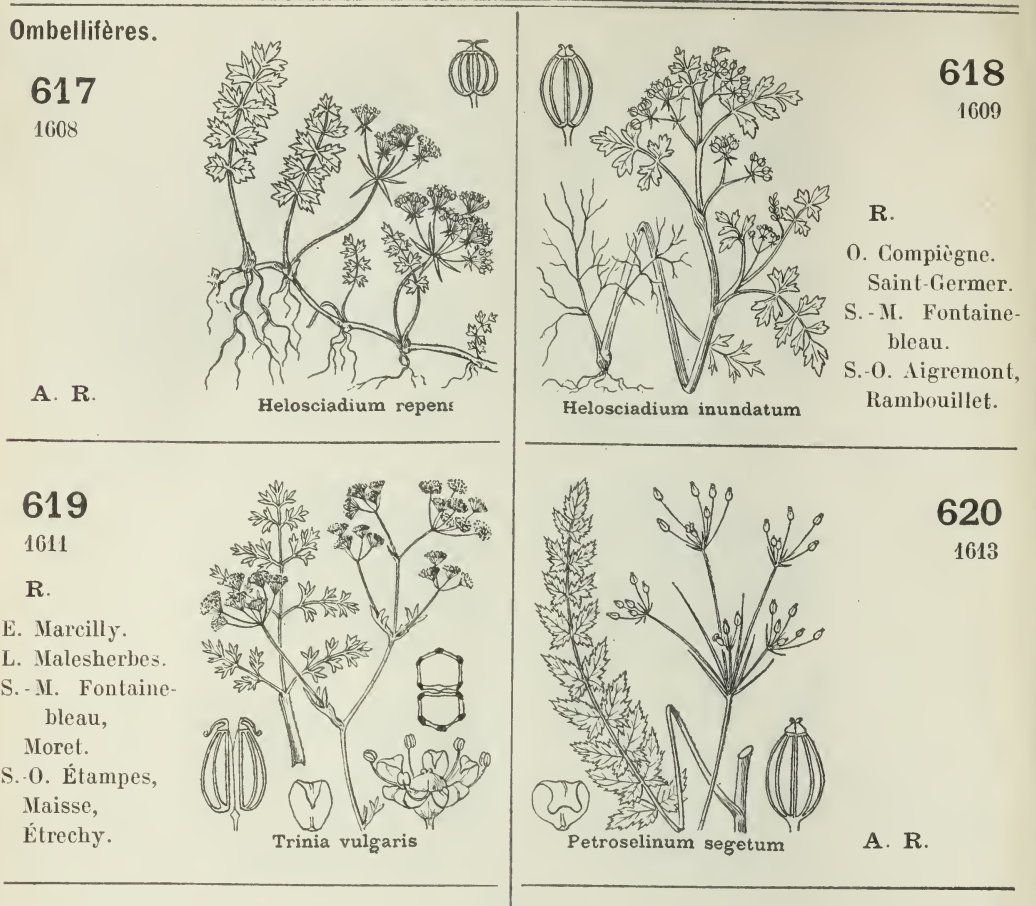

\section{1 \\ 161 '}
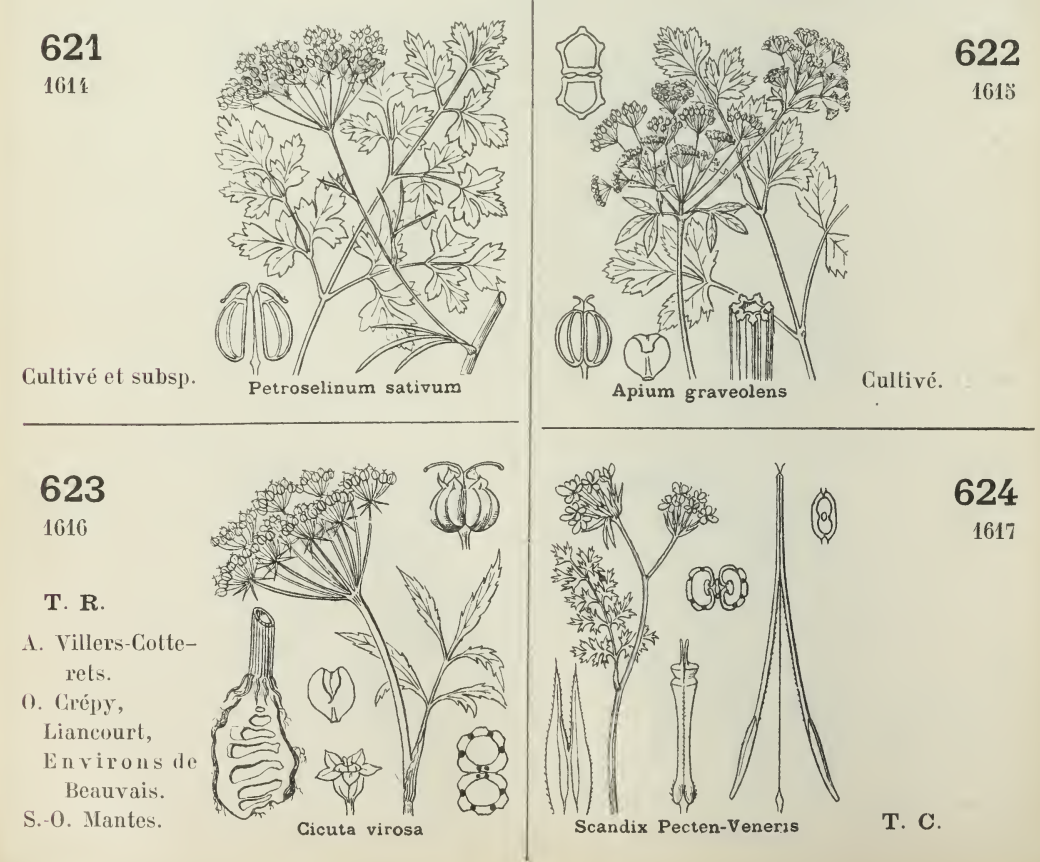
FAM. 47 (ร7)。 - OIMIBLLIFÈRES

FAM. 48 (38). - ARALIACÉES
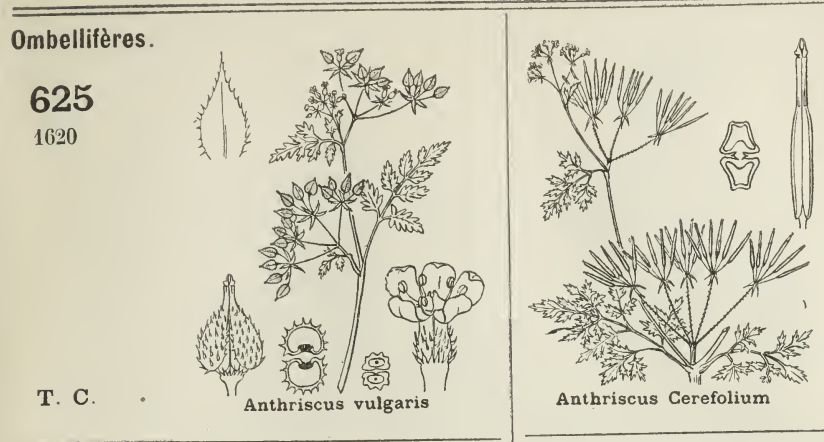

626

1621

Anthriscus Cerefolium

Cultivé.

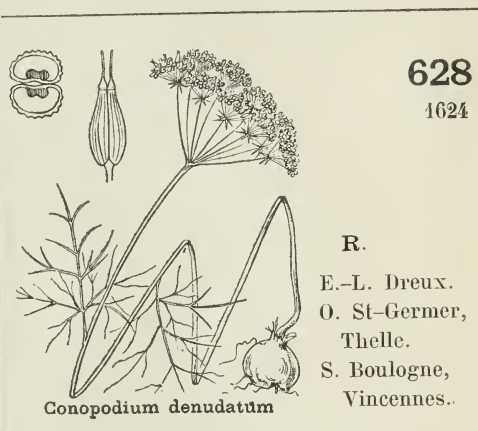

C.
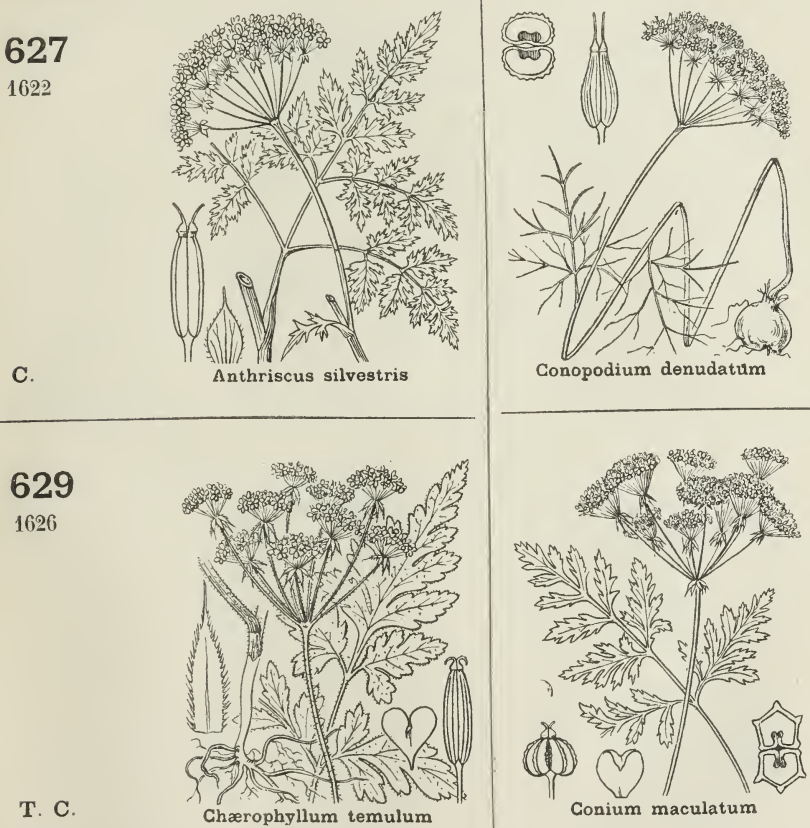

T. C.

\section{Chærophyllum temulum}

Conium maculatum

630

1639
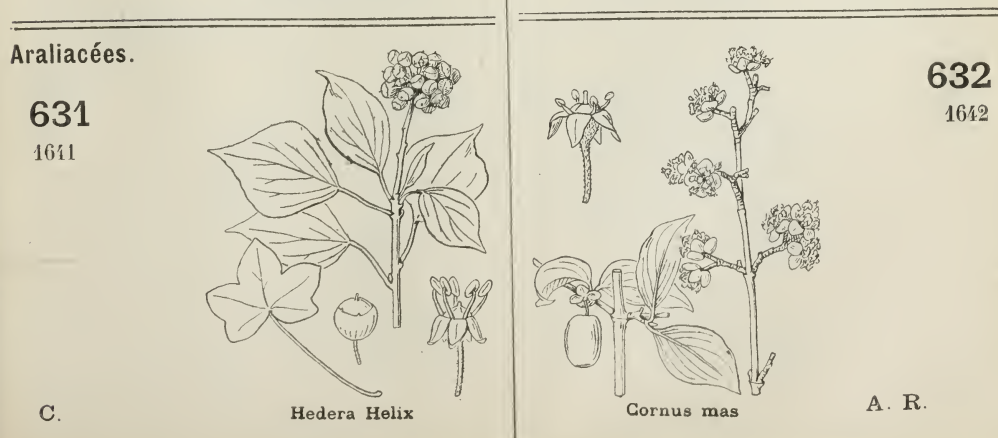
FAM. 48 (58). - ARALIACÉES

\section{FAM. 49 (59). - CAPRIFOLIACÉES}
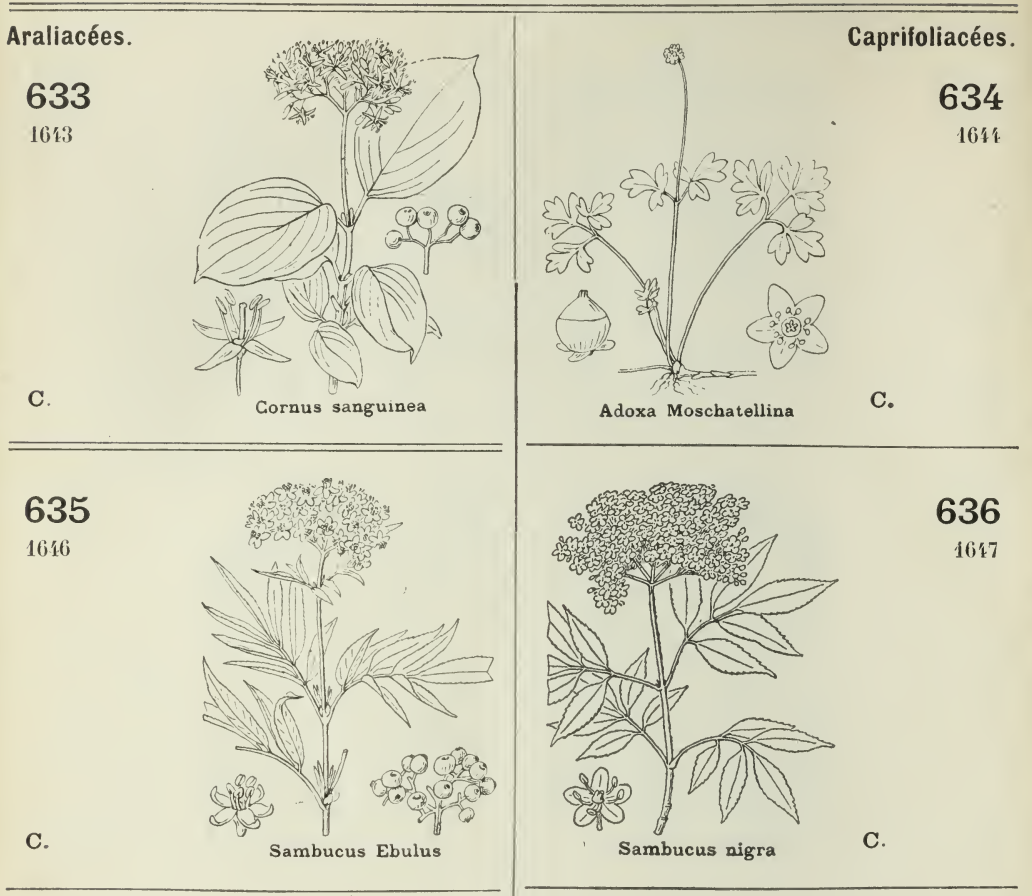

637

1618

Planté.

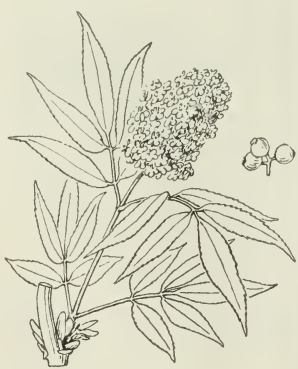

Sambucus racemosa

639

$16 \div 0$

C.

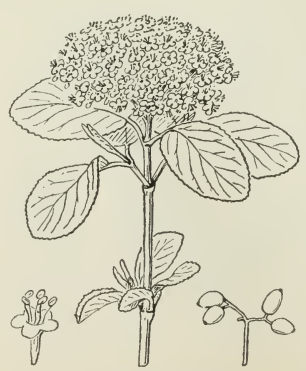

Viburnum Lantana

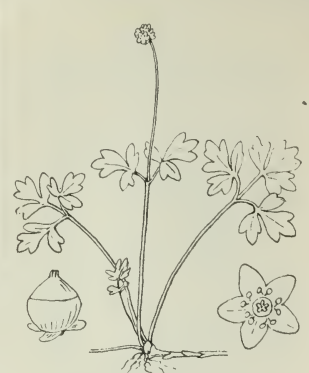

Adoxa Moschatellina

c.

Caprifoliacées.

634

161 '

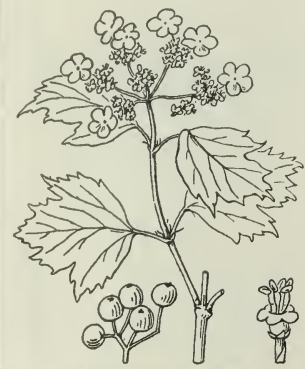

638

16.49

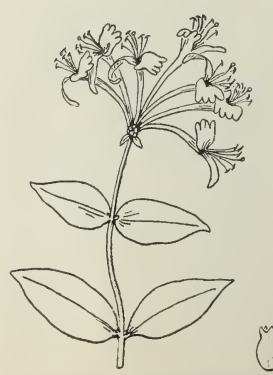

Viburnum Opulus
640

1653

C.

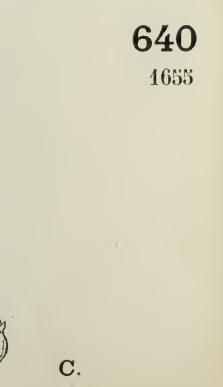


FaM. 49 (59). GAPRIFOLIAGÉES - FAM. 50 (60). RUBIAGÉES

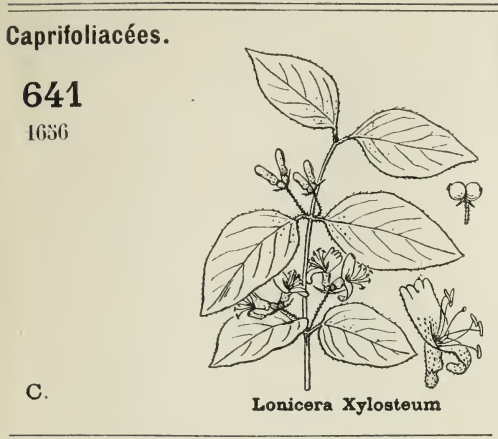

\section{Rubiacées.}

643

1661

R.

E. Vernon.

E.-L. Dreux.

L. Malesherbes.

0 . Beauvais, La Neuville en-Hez.

S. - M. Champagne,

Rougeaux.

S. -0 . Lardy, Etréchy,

Mantes,

Port-Villez.

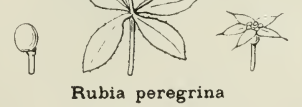

645

1663

T. C

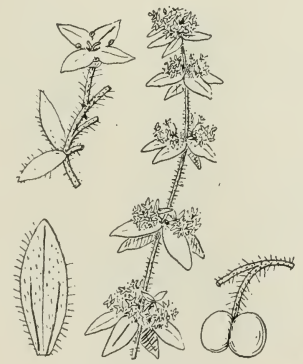

Galium Cruciata

\section{7}

1660

T. $\mathbf{R}$.

S. - II. Entre Flamboin et Portmontain.

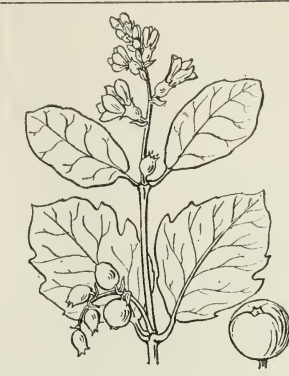

Symphoricarpos racemosa

Cultivé.

ב.

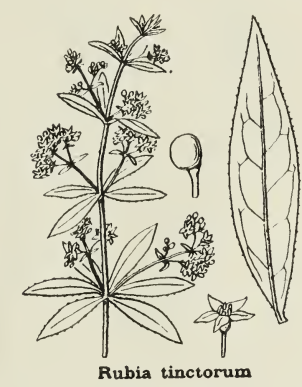

644

1662

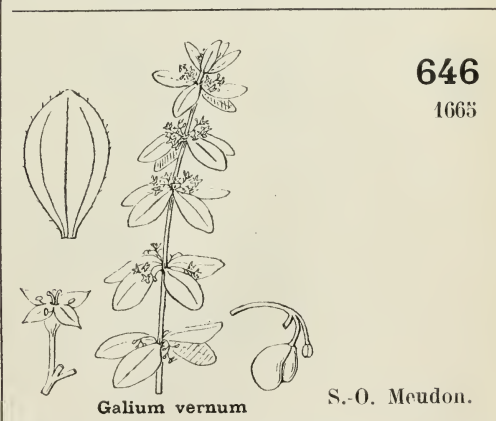

Natur. cà et là.

646

1663

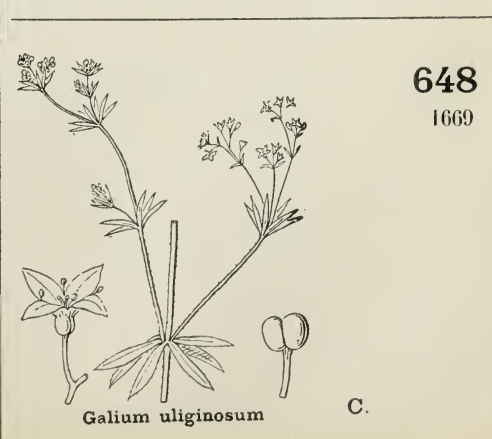



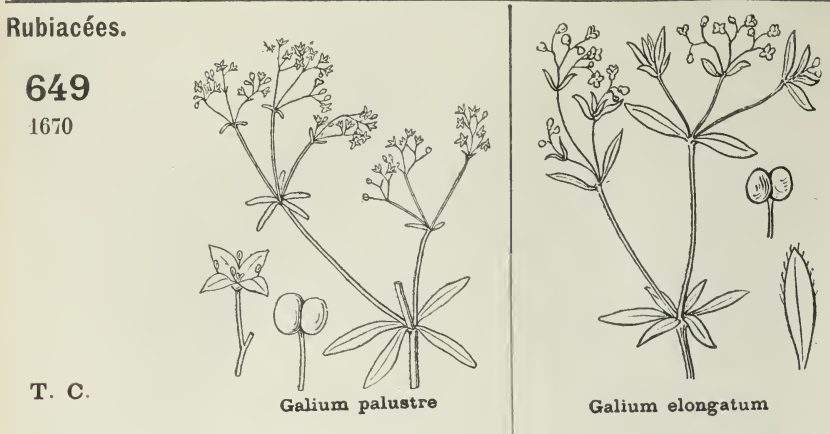

650

Galium elongatum
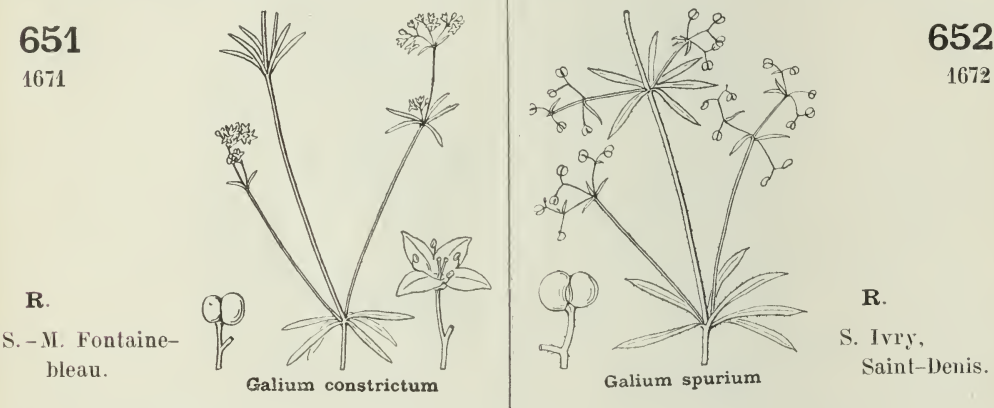

652
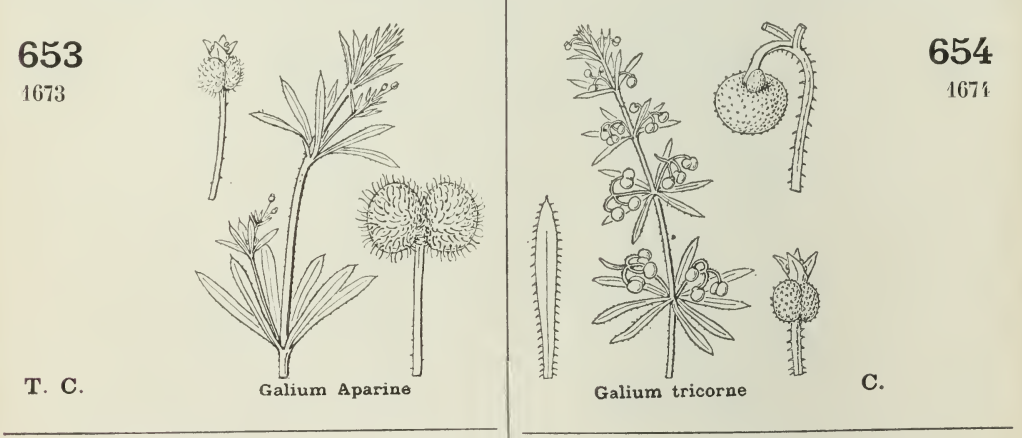

\section{5}

1677

R.

0. Savignies, Senlis, Verberie.

S. - M. Fontainebleau.

S. -o. La fertéAlais,

Lardy.

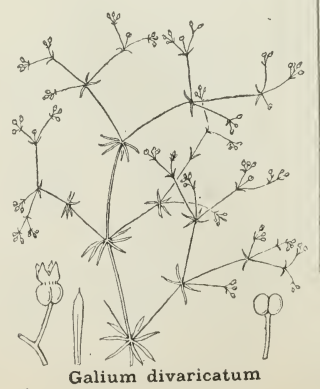

656

1678 

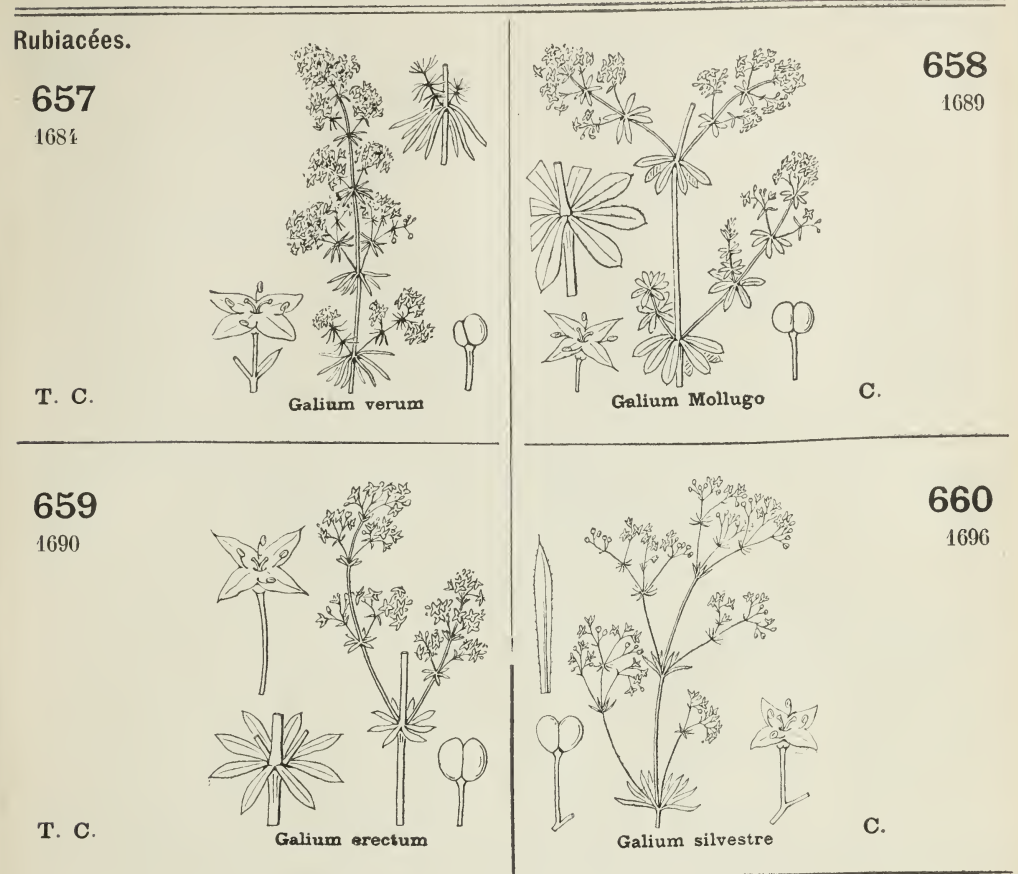

\section{1}

1702

\section{T. $\mathbf{R}$.}

o. Saint-Germer, Saint-Paul, Savignies, Ons-en-Bray. S. - M. Malesherbes.

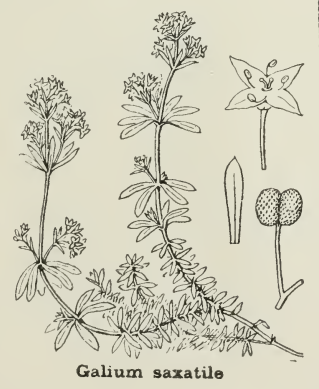

663

1712
A. $\mathbf{R}$.

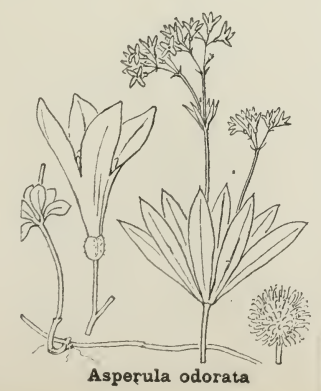

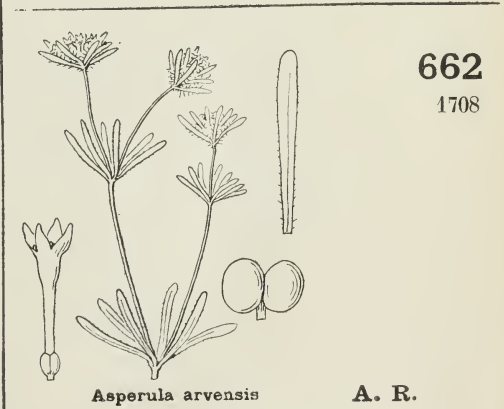

C.

A. $\mathbf{R}$.

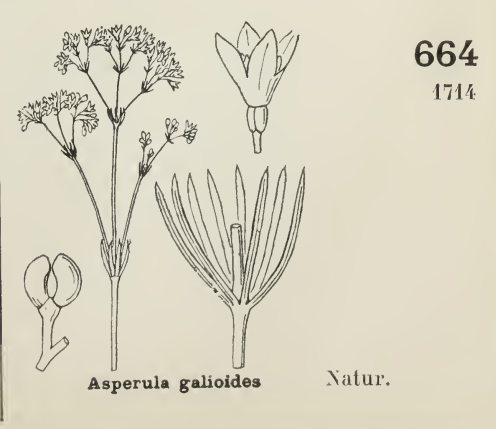


84 FAM. 50 (60). RUBIACÉES - FAM. 51 (61). VALÉRIANÉES
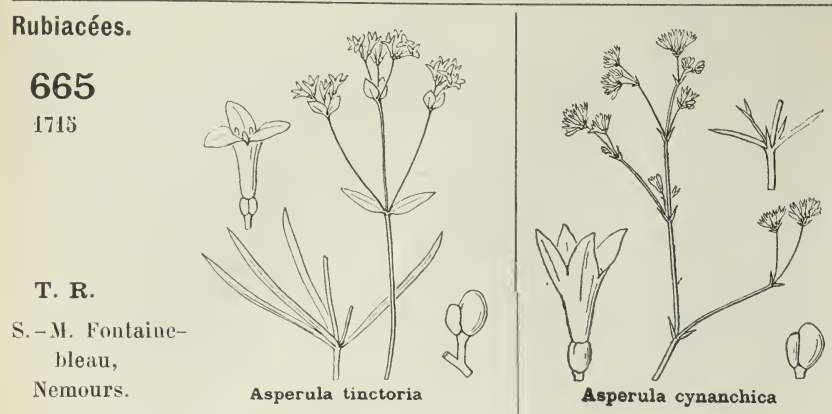

666
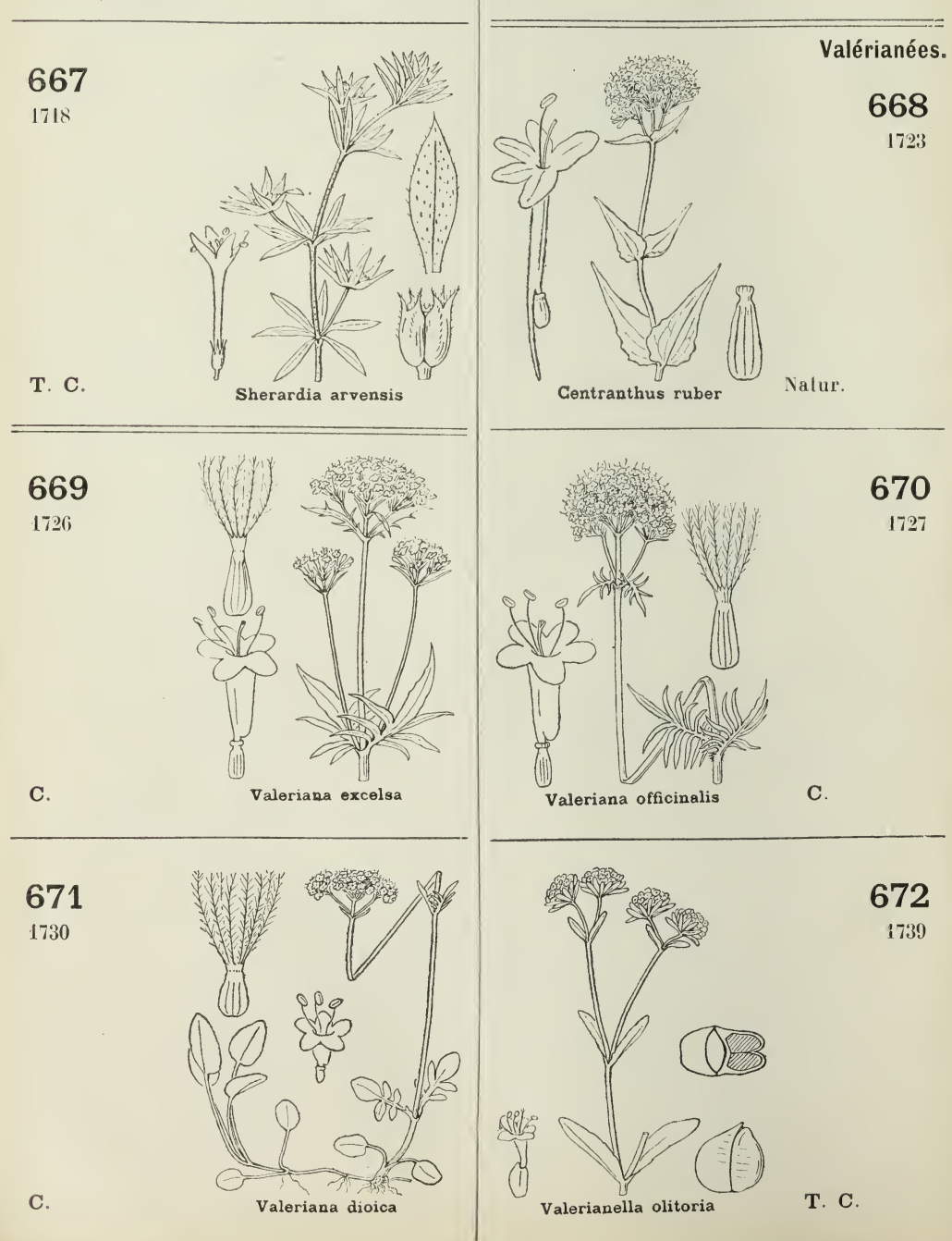
FAM. 51 (61). VALÉRIANÉES - Fam. 52 (62). DIPSACÉES 85

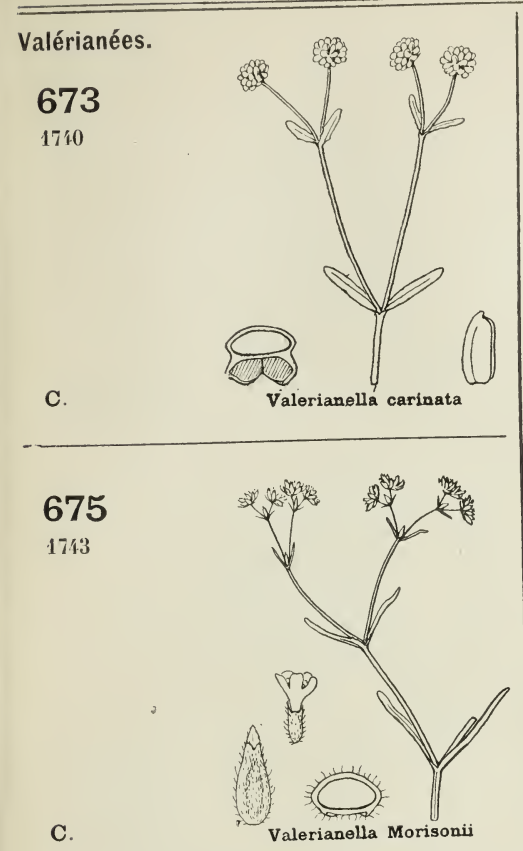

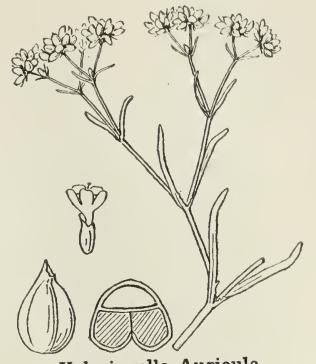

Valerianella Auricula

C.
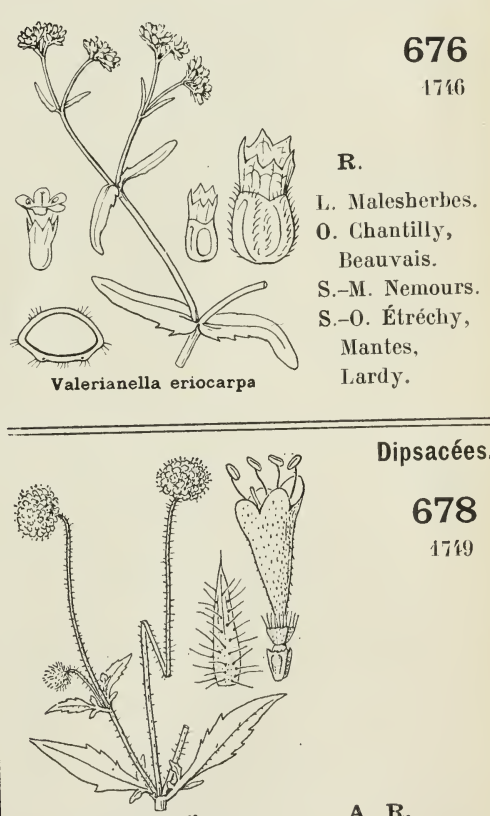

Dipsacus pilosus

A. $\mathbf{R}$.

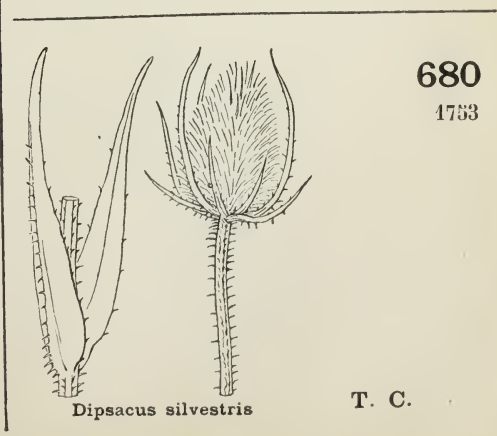


FAM. 52 (62). - DIPSACÉES FAM. 53 (63), - COMPOSÉES (Corymbifères)
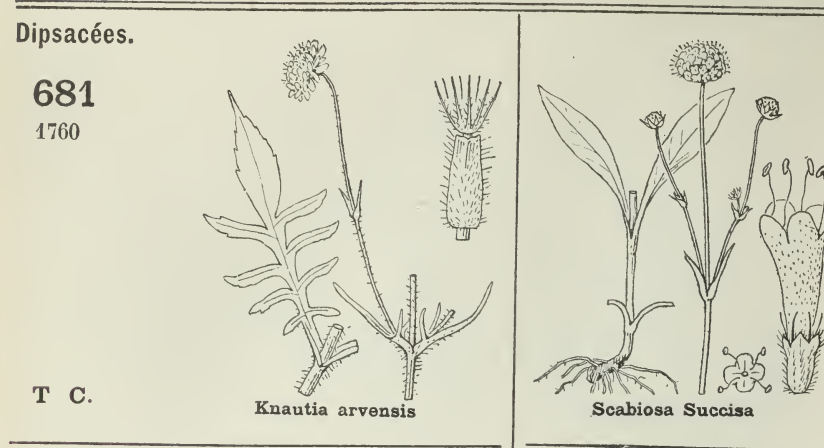

682

1763

Scabiosa Succisa

T. C.

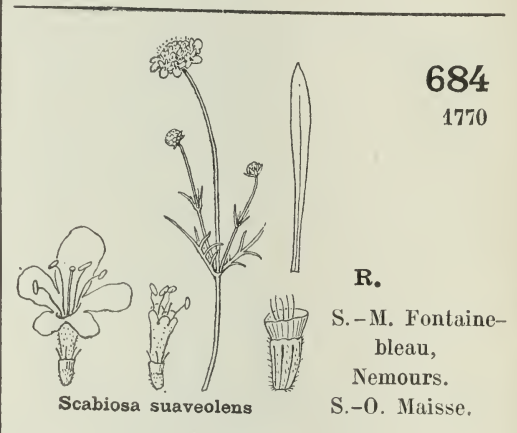

Malesherbes.

S. M. Roncevaux,

Entre Malesherbes et Nanteau.

Introduit a

Fontaine-

bleau.

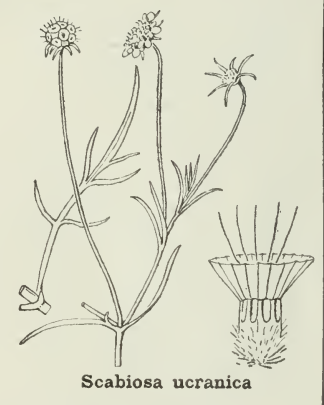

685

1772

T. C.

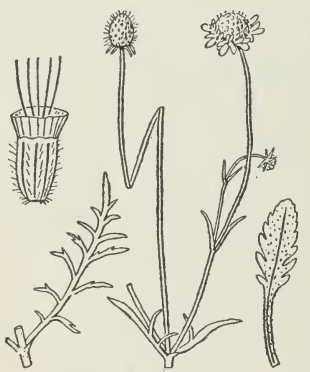

Scabiosa columbaria

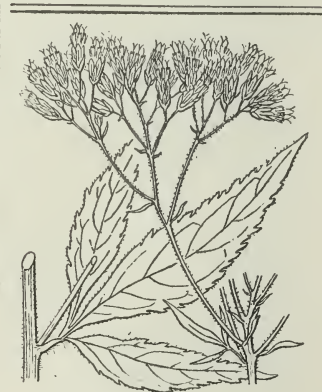

Composées

Corymbifères.

\section{6}

1775

T. C.
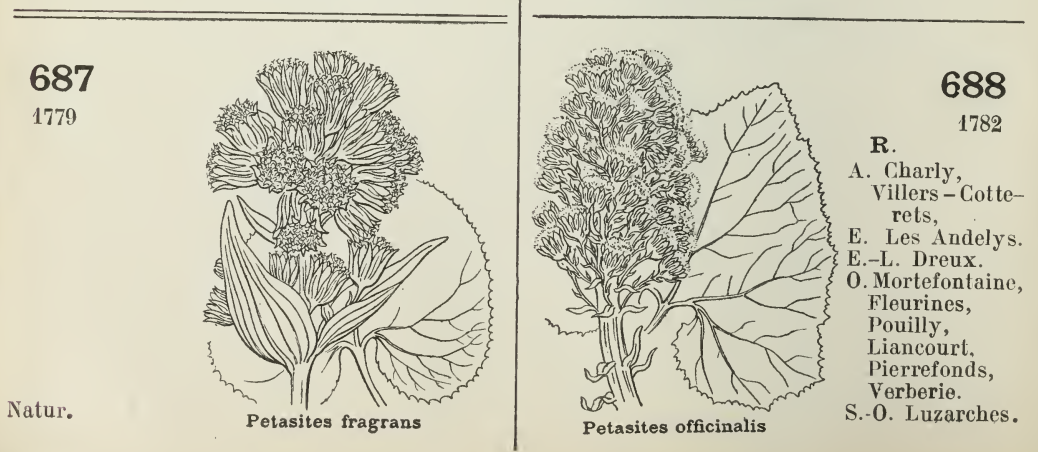
FAM. 53 (63). - COMPOSÉES (Corymbifères)

\section{Composées}

Corymbifères.

689

i 781

T. C.

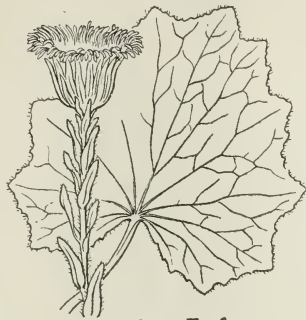

Tussilago Farfara

\section{Natur. et çà et là.}

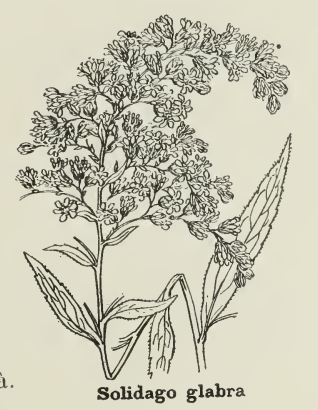

\section{3}

1787

R.

E.-L. Dreux.

E. Vernon,

Les Andelys.

O. Gouvieux

S. - M. Fontainebleau,

Nemours.

S. -0. Santeuil,

Noisement,

L a Roche -

Guyon,

Valmondois,

Isle-Adam,

Mantes.

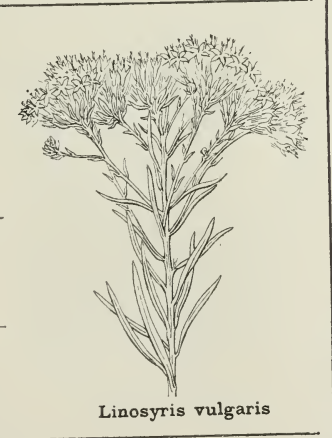

695

1792

C.

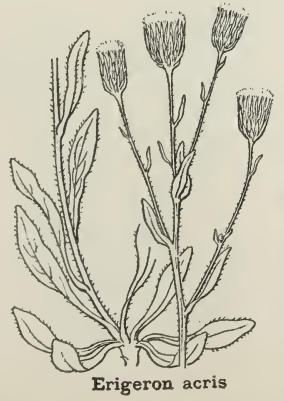

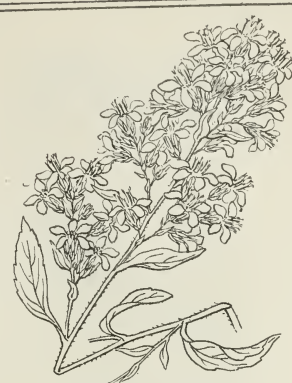

Solidago Virga-aurea

c.

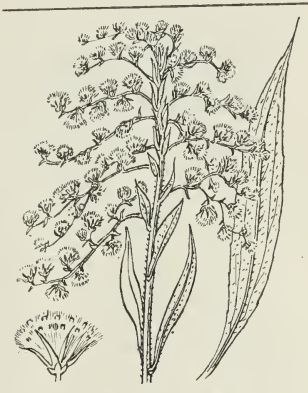

Solidago canadensis

690

$178: 3$

692

Natur.

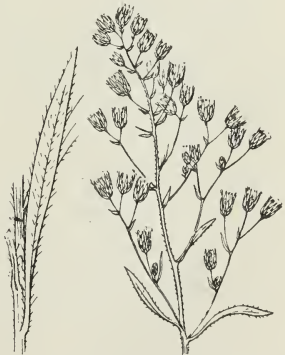

694

1791

Erigeron canadensis

T. C.

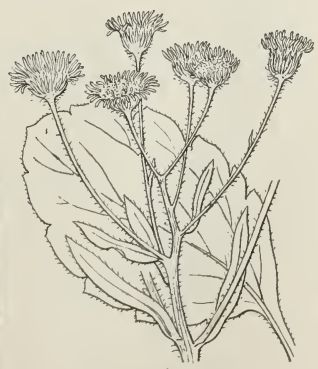

696

1799

T. $R$.

A. Haramont près VillersColterets.

Stenactis annua 
FAM. 53 (63). - COMPOSÉES (Corymbifères)
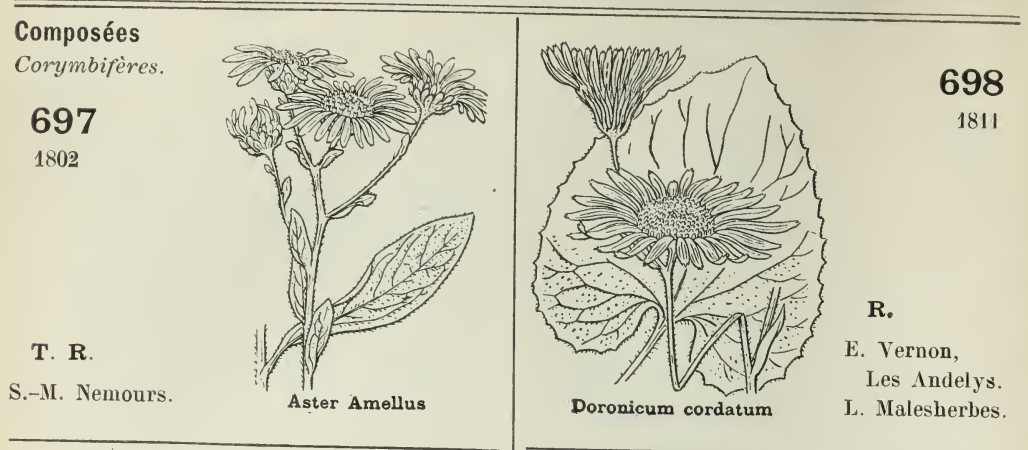

E. Vernon,

Les Andelys.

Doronicum cordatum

L. Malesherbes.

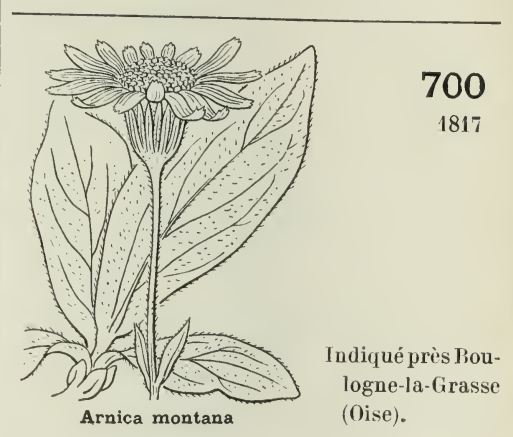

A. $\mathbf{R}$.

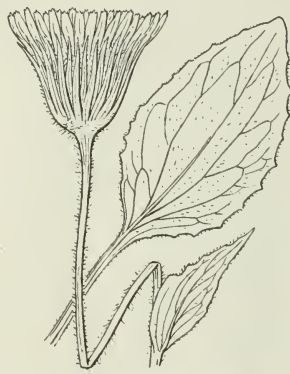

Doronicum plantagineum

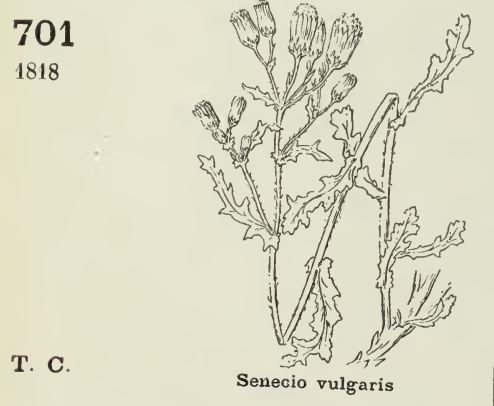

703

1820

C.

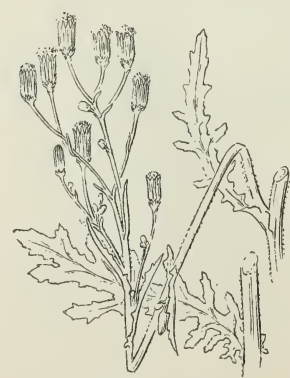

Senecio silvaticus

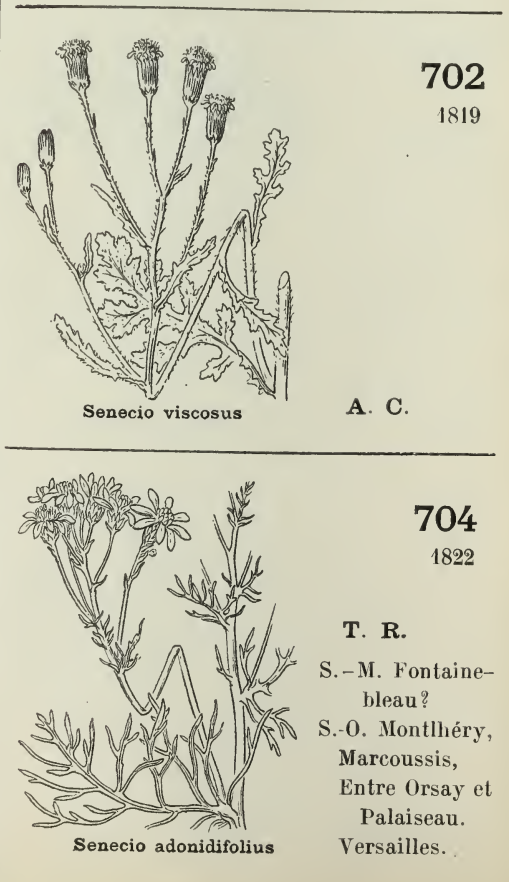


FAM. 53 (63). - COMPOSÉES (Corymbifères)

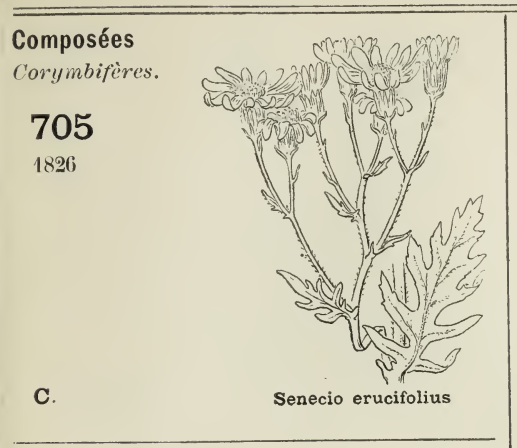

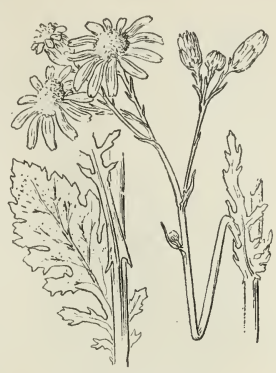

Senecio Jacobæa

T. C.

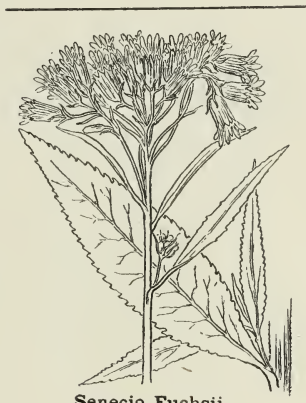

706

1827

T. $\mathbf{R}$.

A. Montign y l'Allier, rets. Mans.

708

1837
A. $\mathbf{R}$.

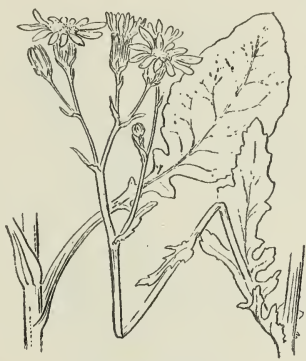

Senecio aquaticus

709

1810

A. C.

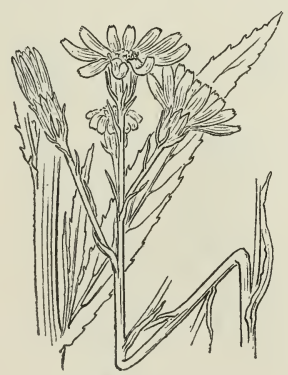

Senecio paludosus

\section{1}

1853

A. $\mathbf{R}$.

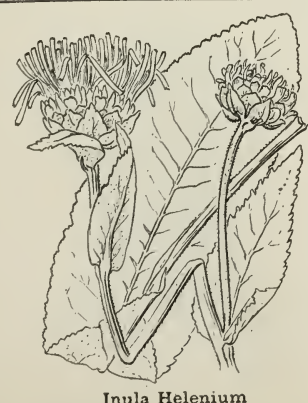

Senecio Fuchsii

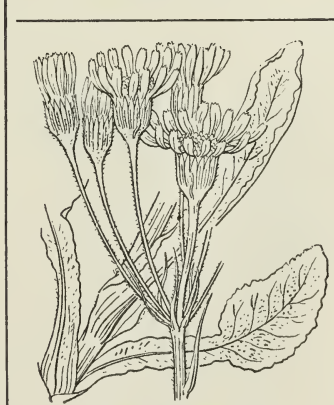

Senecio lanceolatus

Villers - Cotte-

S.-M. Forêt du

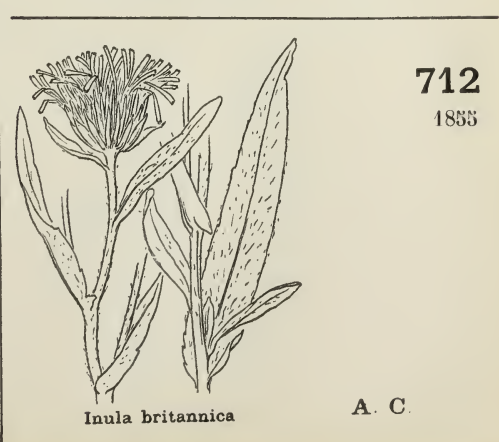




\section{Composées}

Corymbifères.

\section{3 \\ $18: 6$ \\ R.}

L. Malesherbes.

S.-M. Fontainebleau,

Montigny,

Nemours.

S.-0. Maisse.

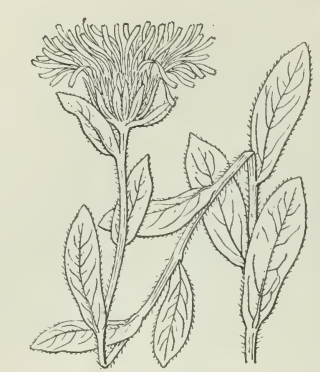

Inula hirta
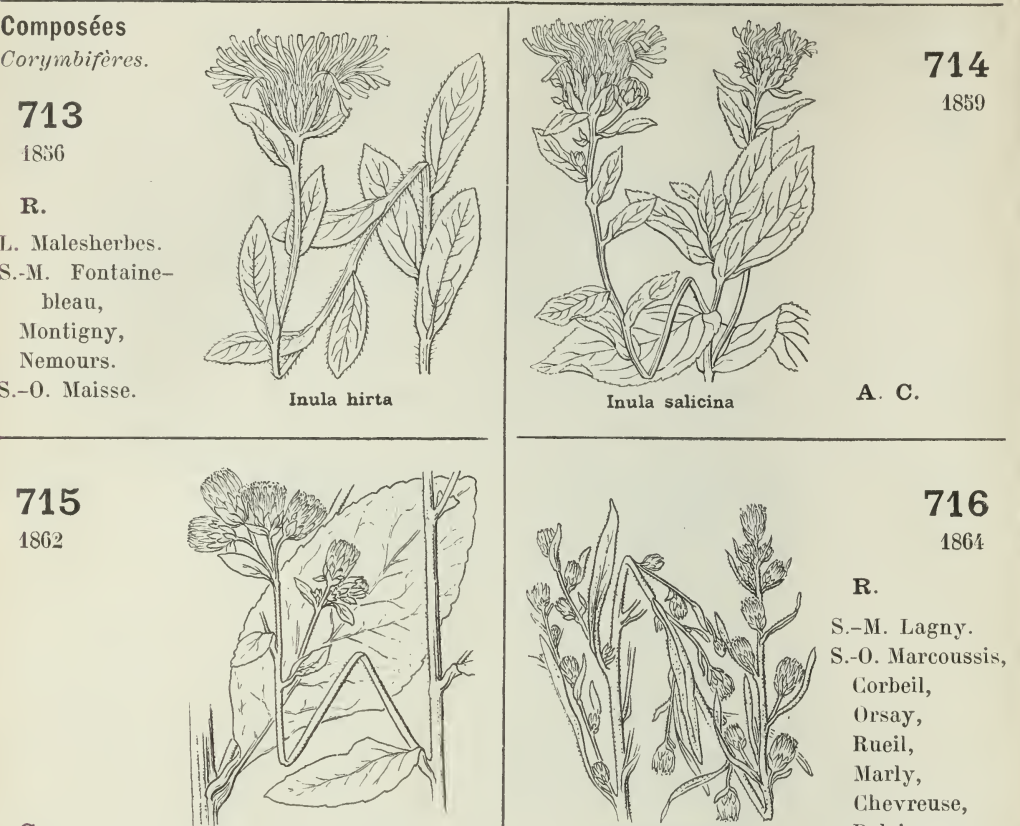

C.

Inula Conyza

\section{7}

1867

T. C.

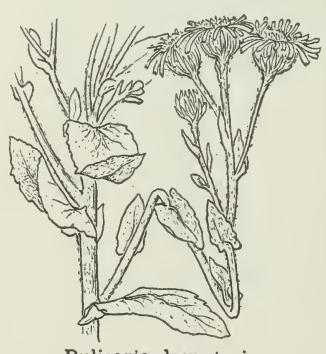

Pulicaria dysenterica

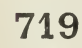

1881

A. C.

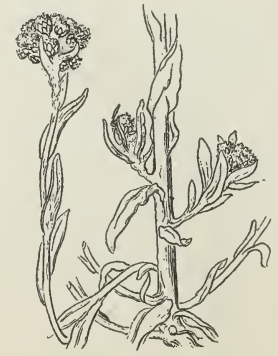

Gnaphalium luteo-album

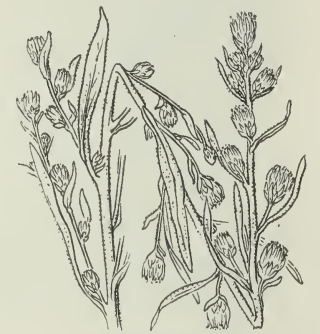

716

1864

R.

S.-M. Lagny.

S.-0. Marcoussis, Corbeil, Orsay, Rueil, Marly, Chevreuse, Palaiseau.

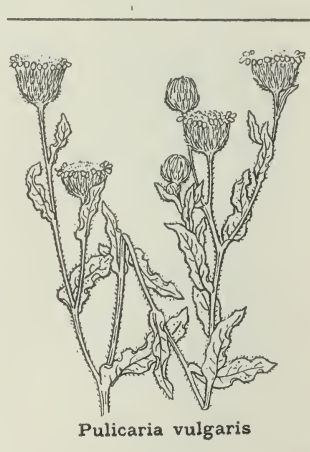

C.

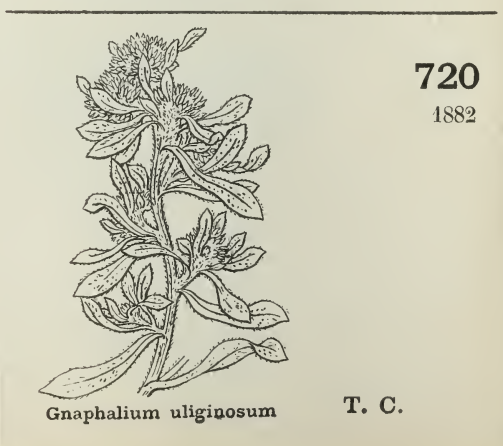


FAM. 53 (63). - COMPOSÉES (Corymbifères)
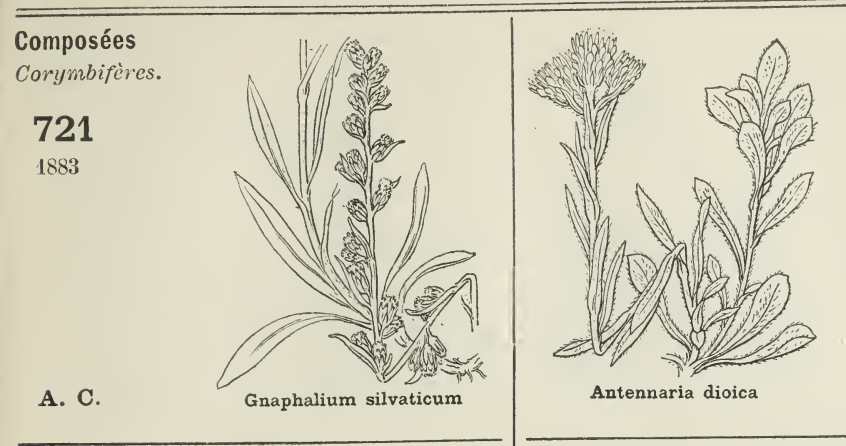

722

1887
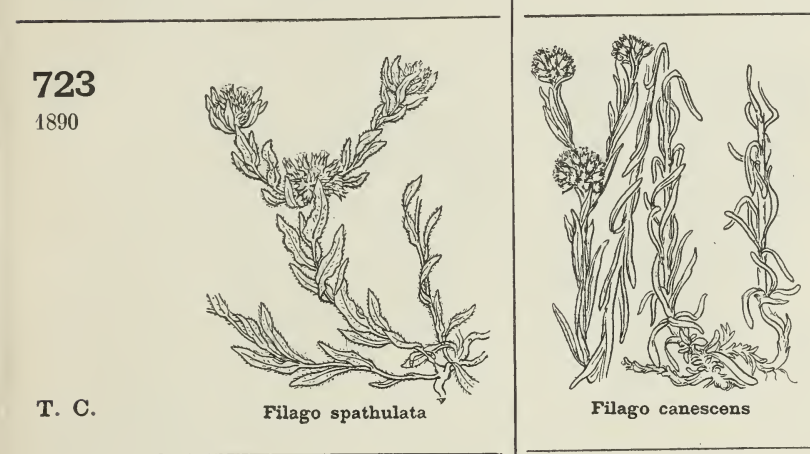

A. $\mathbf{R}$.

$$
\text { Filago canescens }
$$

c.

724

1891

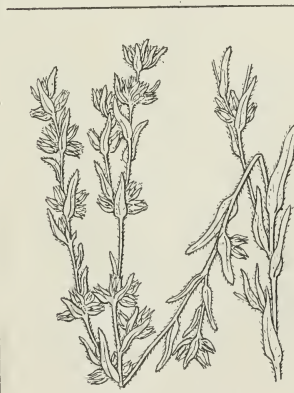

726

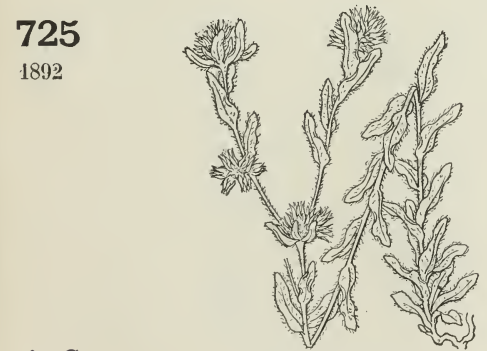

A. C.

Filago apiculata

Filago arvensis

A. C.
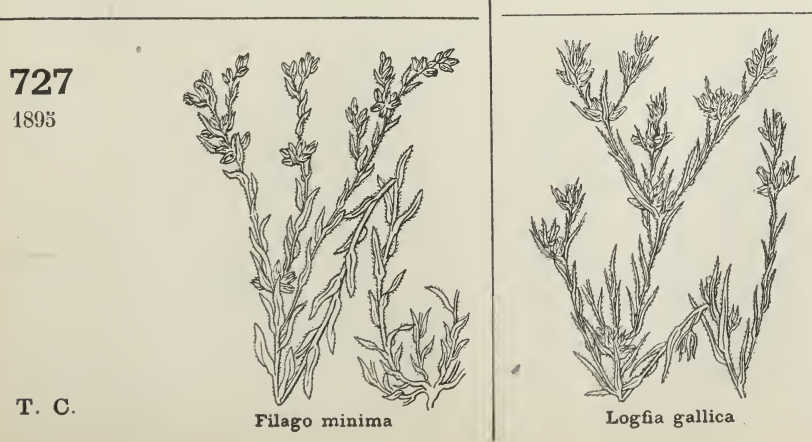

728

1896

$$
\text { Logfia gallica. }
$$

A. C. 
FAM. 53 (63). - COMPOSÉES (Corymbifères)
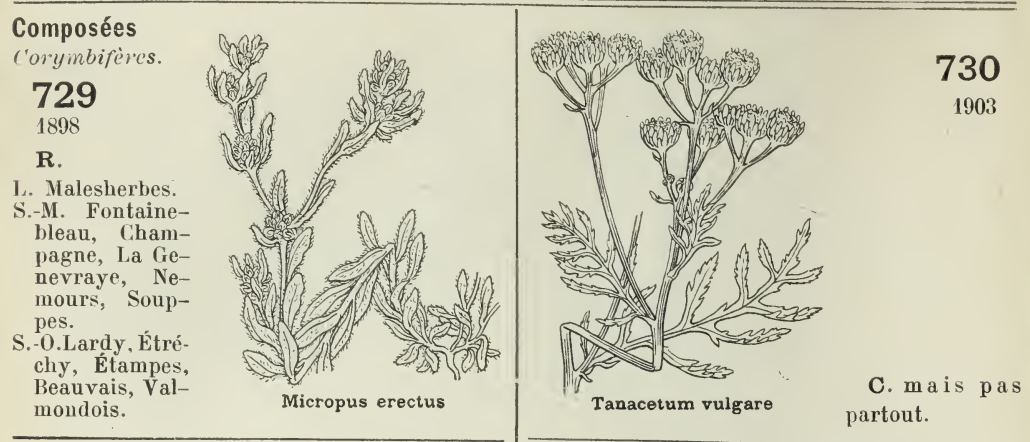

731

1912

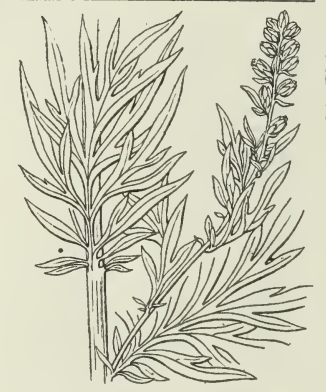

T. C.

Artemisia vulgaris

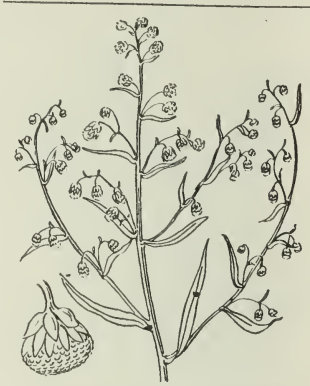

732

Artemisia Dracunculus

Cultivé.

733

S. Ivry,

Issy,

liharenton,

Boulogne,

Sceaux,

Paris.

S. -0. Cormeilles en-Parisis, Saint-Prix, Taverny,

Lardy.

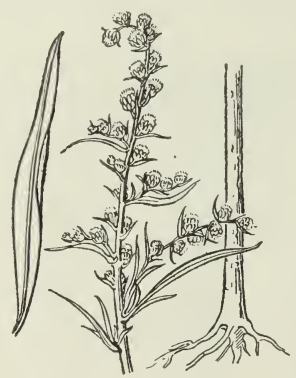

Artemisia selengensis

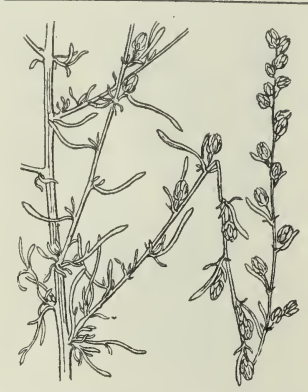

734

1919

Artemisia campestris

C.
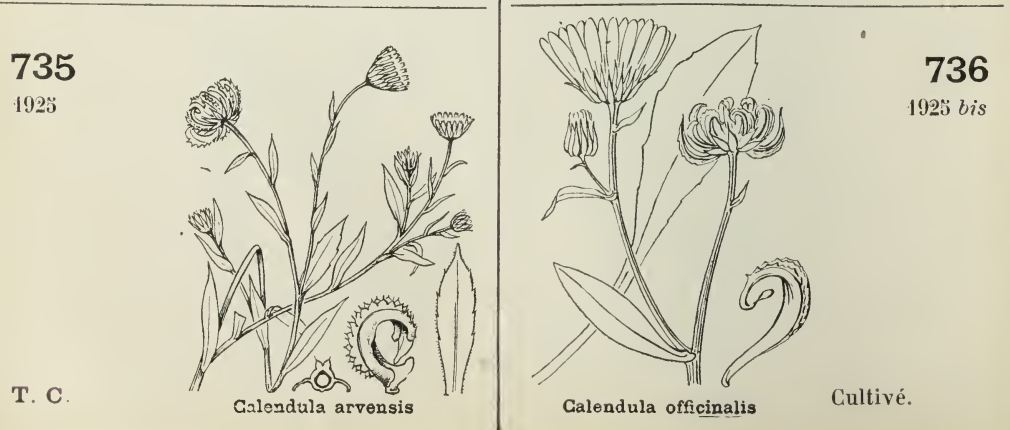
FAM. 53 (63). - COMPOSÉES (Corymbifères)
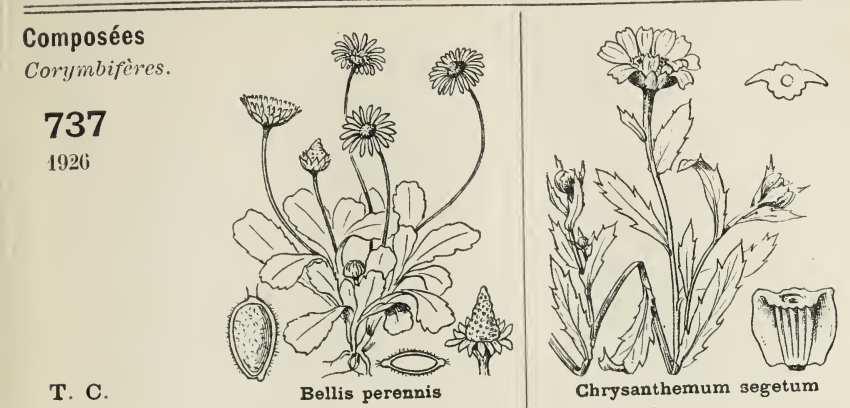

738

1932

Chrysanthemum segetum

A. C.
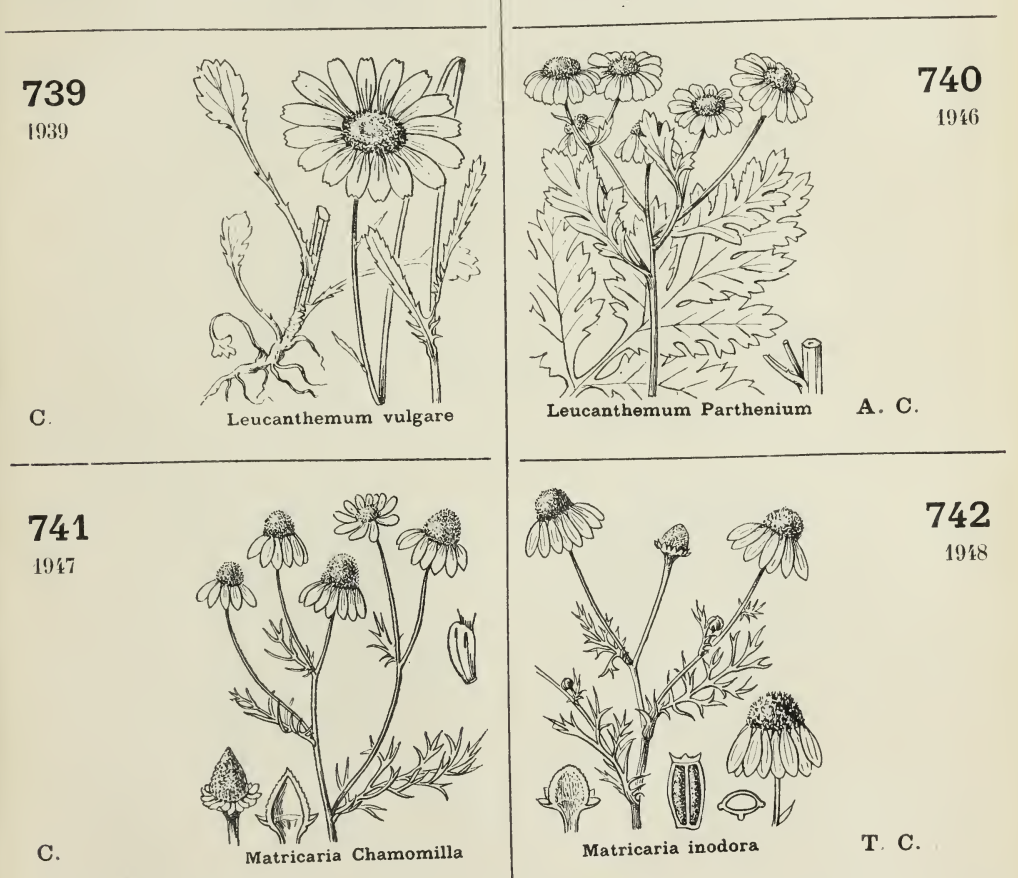

742

1948
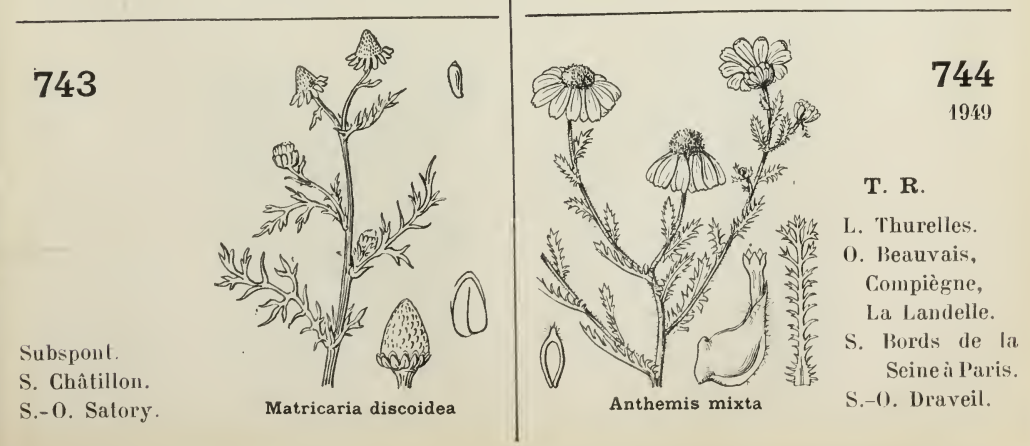
FAM. 53 (63). - COMPOSÉES (Corymbifères)

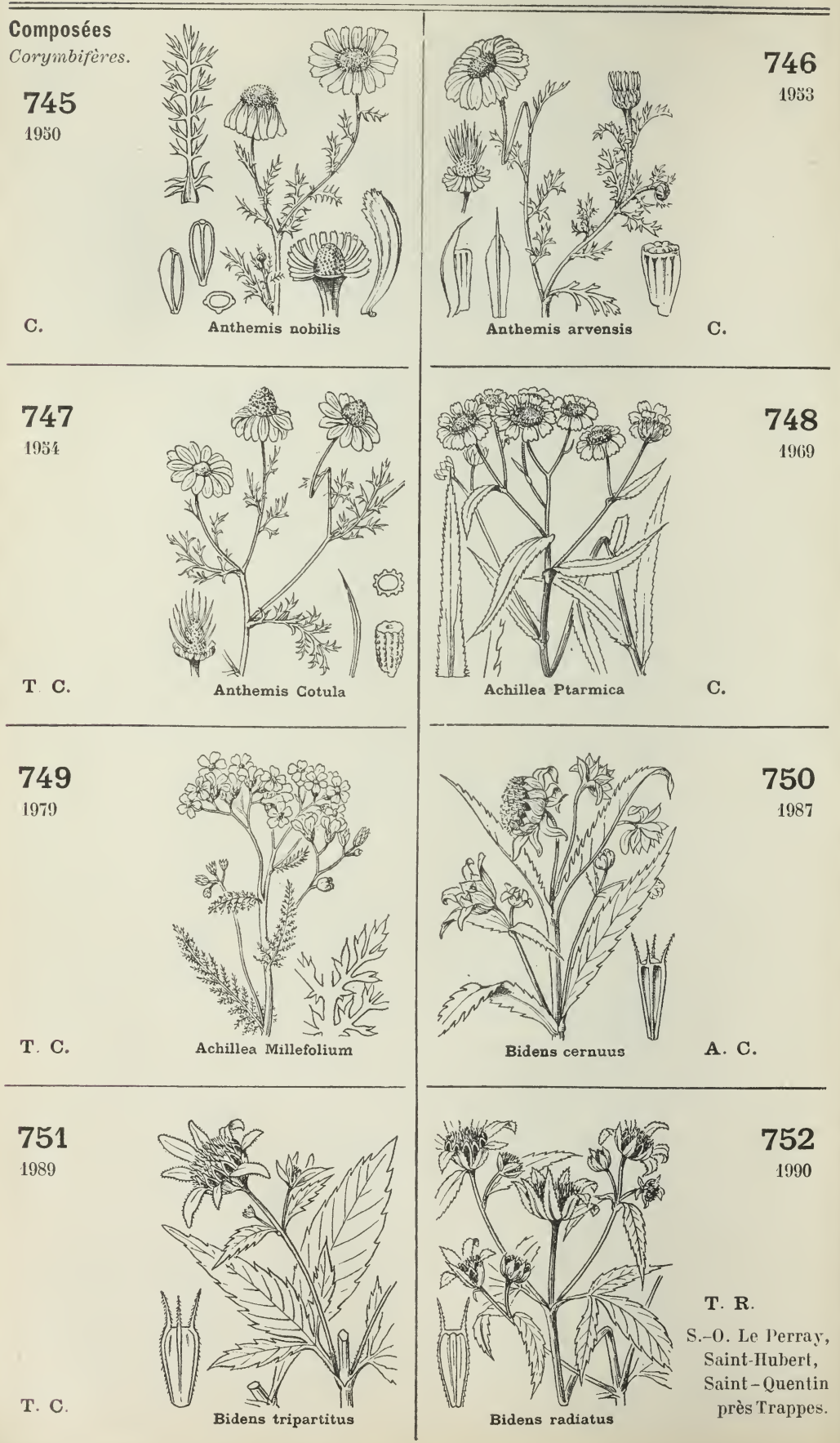


FAM. 53 (63). - COMPOSÉES (Corymbifères, Cinarocéphales) 95

\section{Composées}

Corymbifères.

\section{3}

Cultivé.

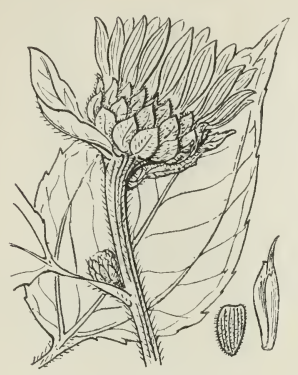

Helianthus annuis

\section{5}

Cultivé.

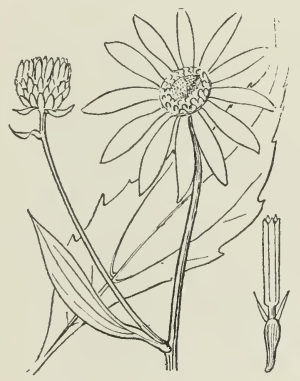

Helianthus lætiflorus

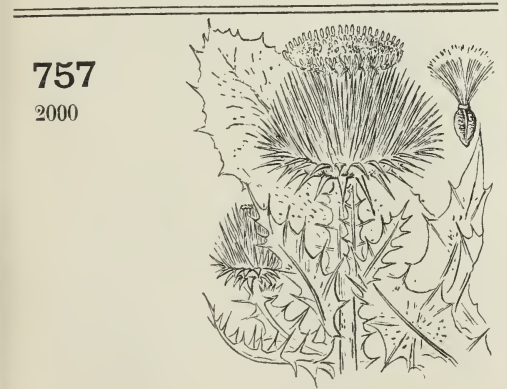

T. C.

Onopordum Acanthium

\section{9}

2010

T. C.

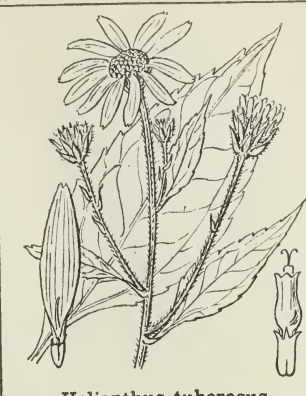

754

Helianthus tuberosus

Cultivé.
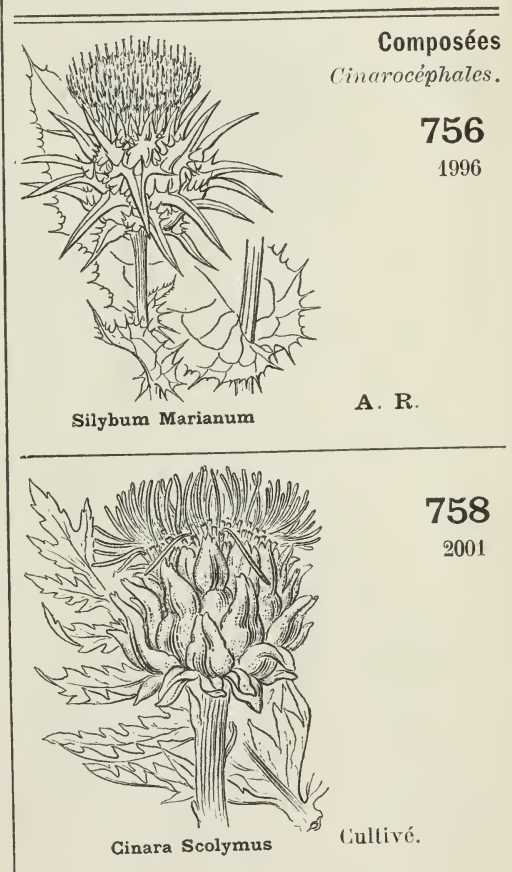

Cinara Scolymus

Cultivé.

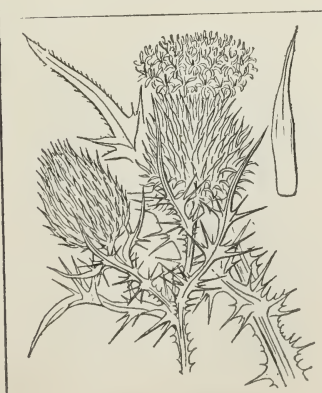

Cirsium lanceolatum

T. C
760

2017 
FAM. 53 (63). - COMPOSÉES (Cinarocéphales)
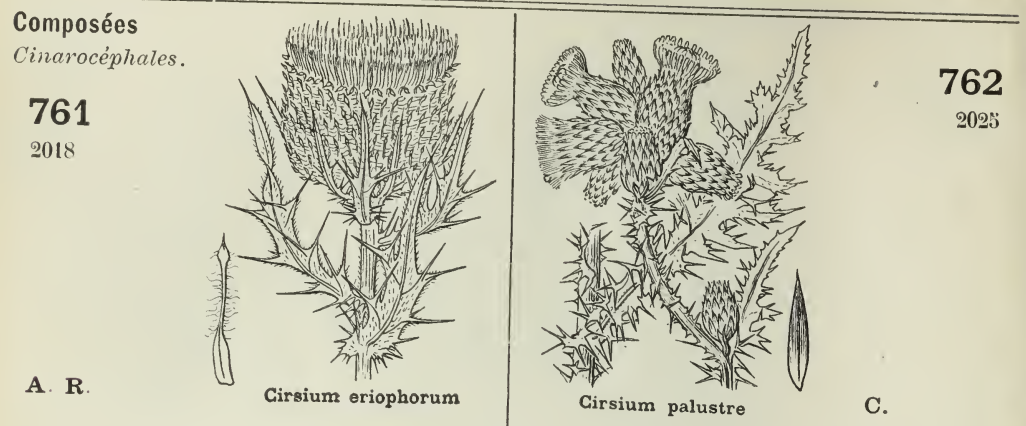

763

2027

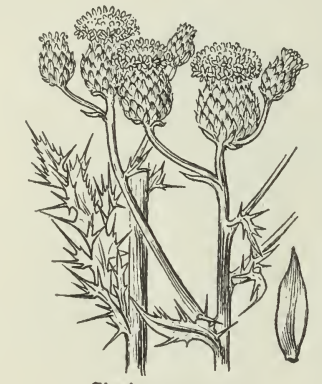

T. C.

Cirsium arvense

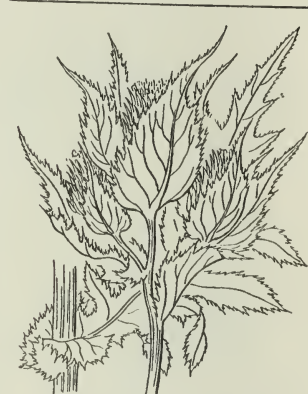

764

2030

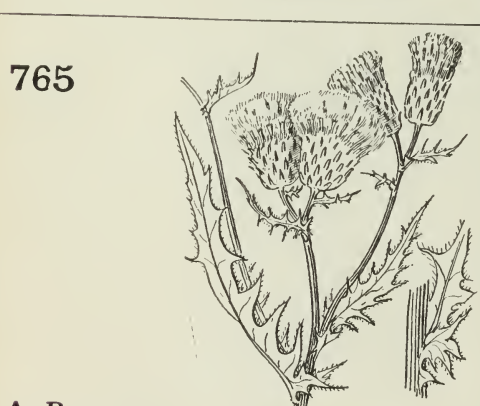

A. $\mathbf{R}$

Cirsium hybridum

\section{7}

2033

C.

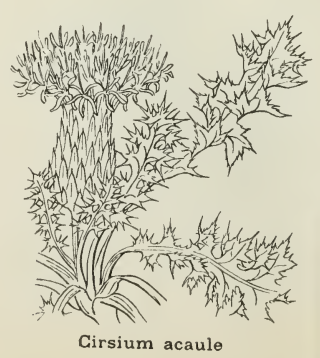

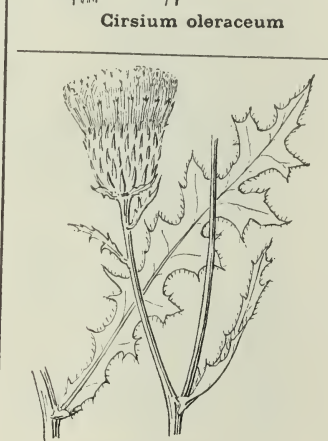

Girsium rigens

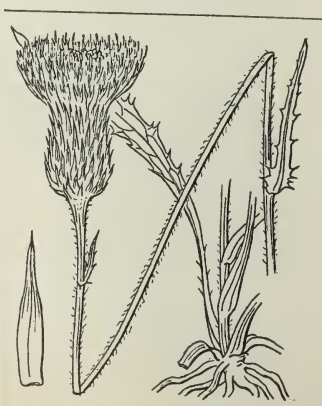

Cirsium anglicum
T. C.

\section{6}

R.

O. Chantilly.

S.-M. Épisy.

S. - 0. Brignancourt,

Ballancourt,

Buc,

Pontchartrain.
768

2037
A. C. 
FAM. 53 (63). - COMPOSÉES (Cinarocéphales)

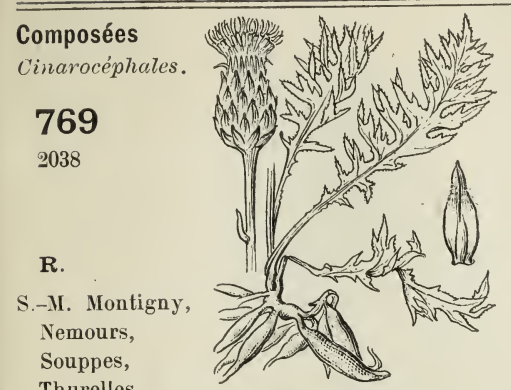

Thurelles.

Cirsium tuberosum

771

2048

T. C.

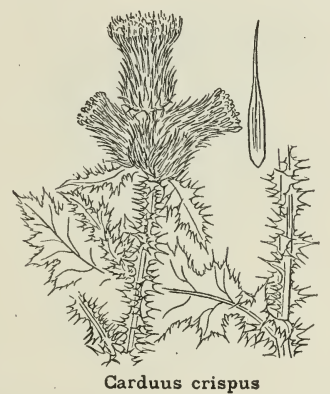

773

2033

T. C.

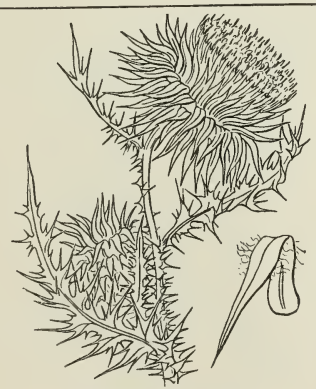

Carduus nutans

775

2062

T. C

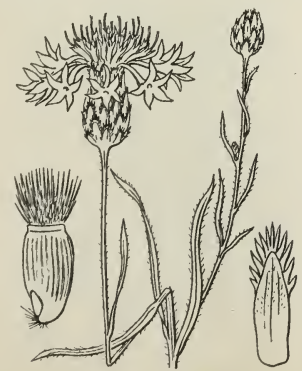

Centaurea Cyanus

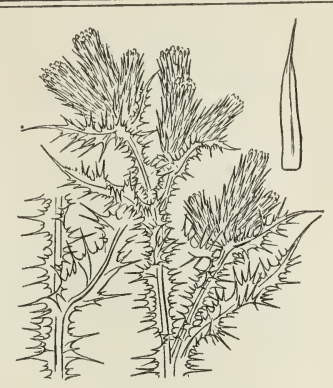

Carduus tenuiflorus

C.

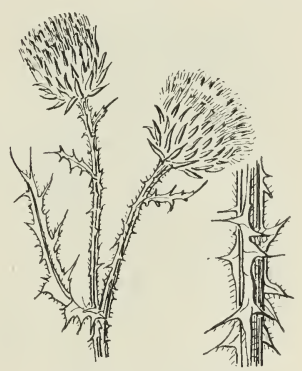

Carduus acanthoides

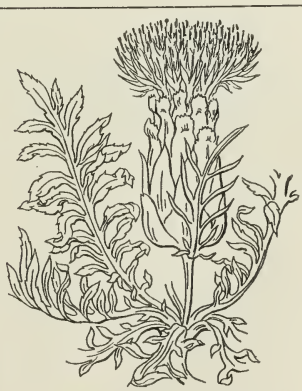

774

2057

R.

L. Malesherbes.

S.-M. Épisy,

Bouron,

Nemours.

S.-0. Lardy,

Étampes,

La Ferté-Alais, Étréchy.

Carduncellus mitissimus

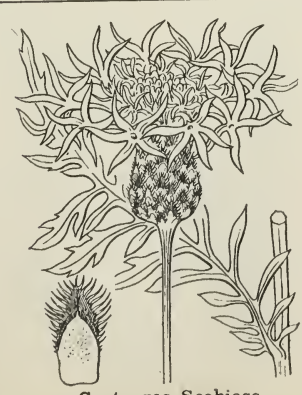

776 
FAM. 53 (63). - COMPOSÉES (Cinarocéphales)

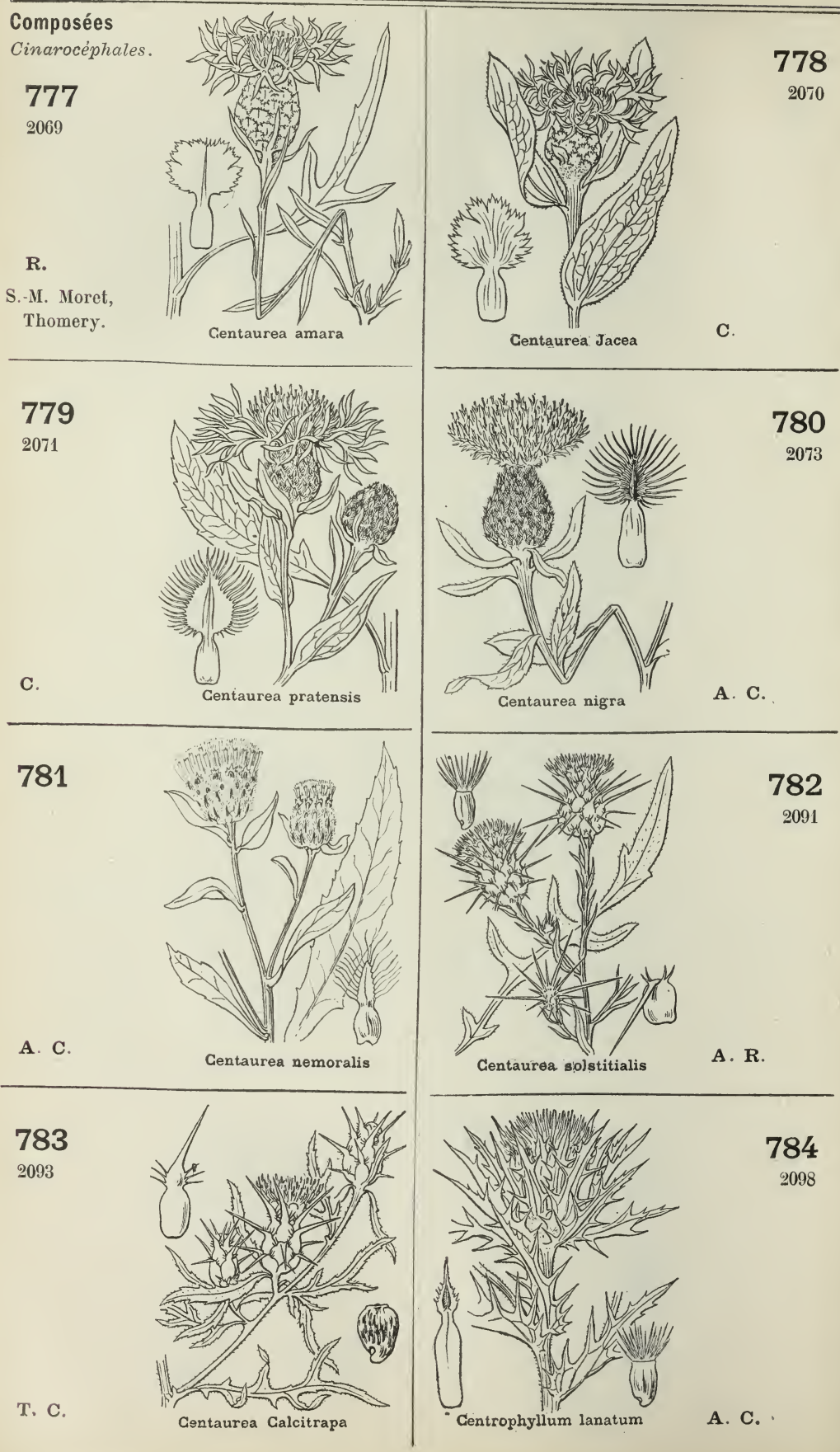



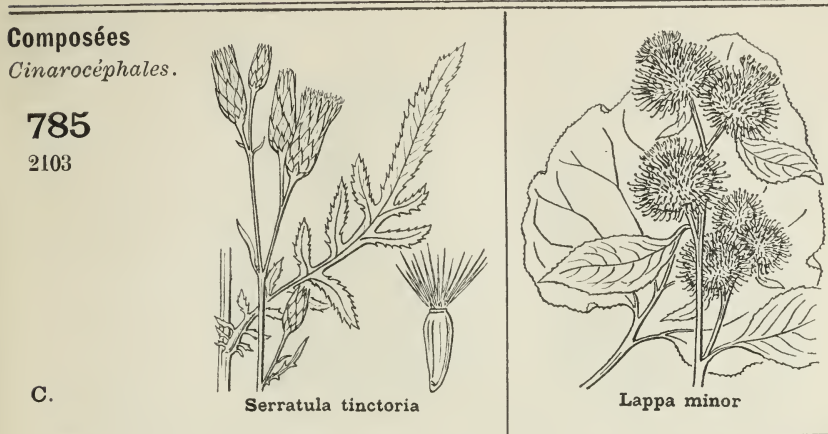

786

Lappa minor

787

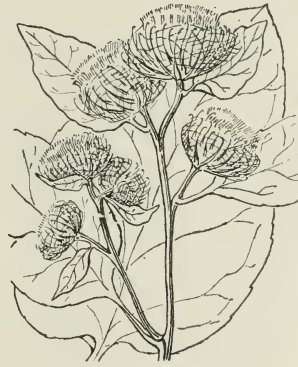

C.

Lappa pubens

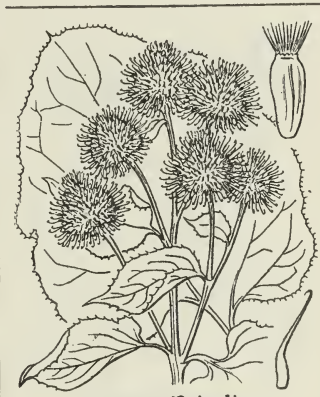

T. C.

Lappa officinalis

A. $\mathbf{R}$.

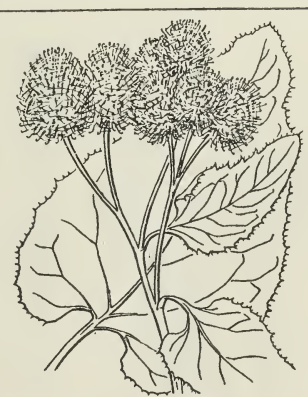

Lappa tomentosa
T. $\mathbf{R}$.

S. Alfortville

S.-M. Esbly,

de Trilport à

Nanteuil.

S.-0. Sèvres,

Choisy,

Rocquencourt.

Carnelle,

Senart.

Lappa nemorosa

\section{1}

2116

T. $\mathbf{R}$

S.-I. Larchant

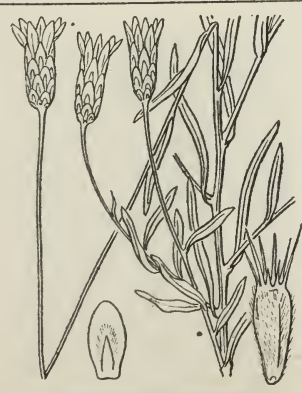

Xeranthemum cylindraceum

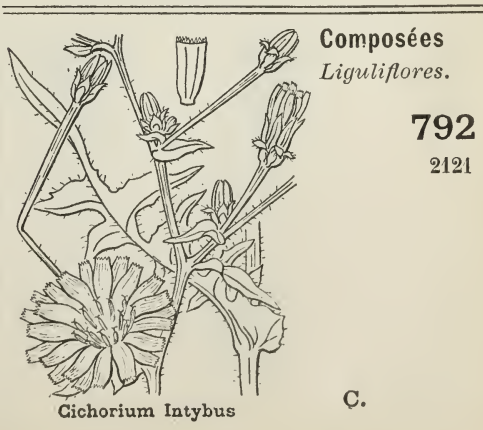



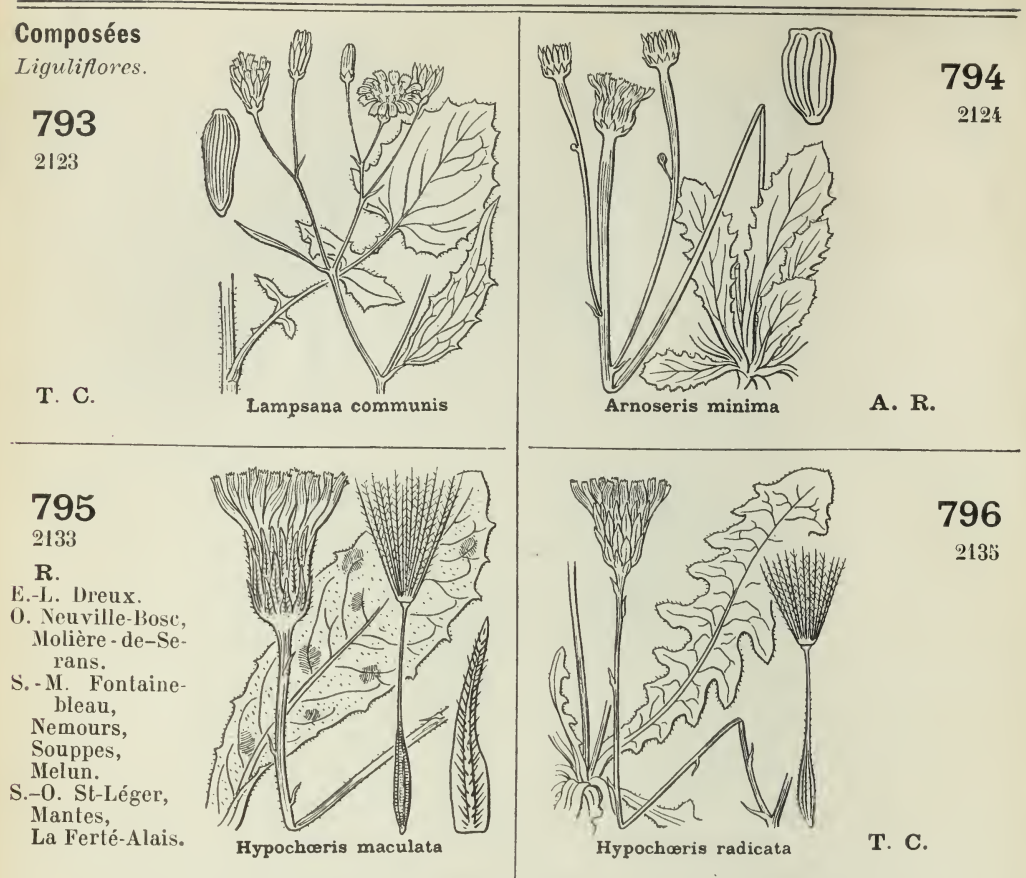

A. $\mathbf{R}$.

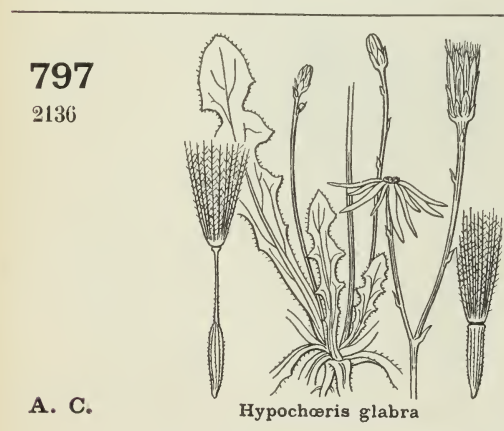

Hypochøeris radicata

796

2133

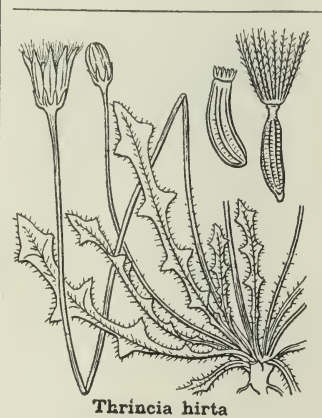

T. C.

798

2138
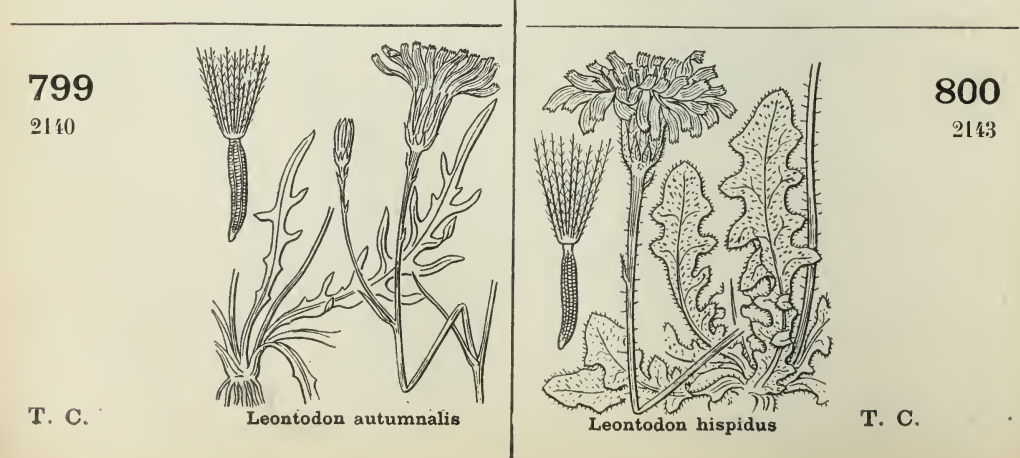
FAM. 53 (63). COMPOSÉES (Liguliflores)
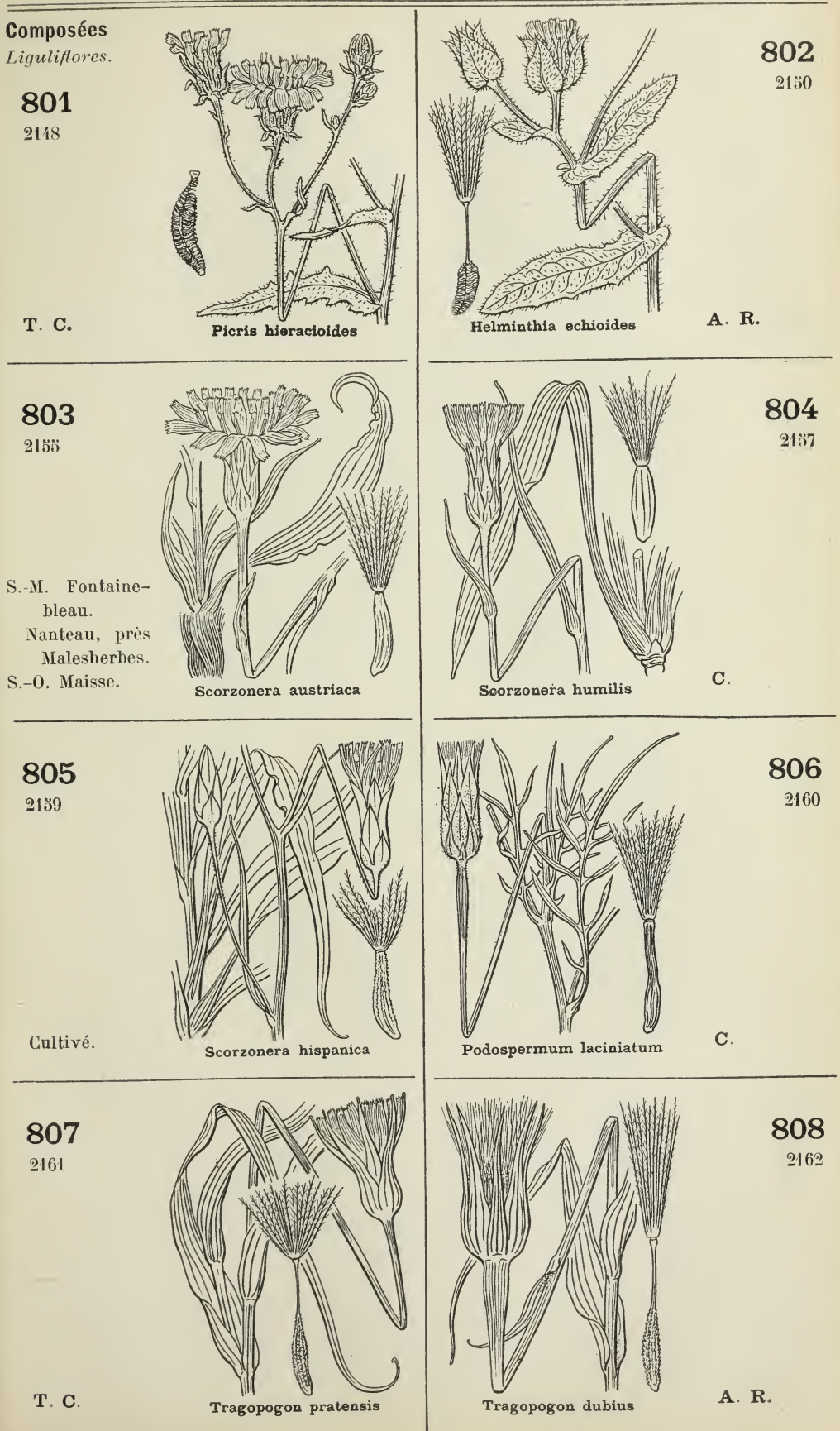

808

2162 
FAM. 53 (63). - COMPOSÉES (Liguliflores)
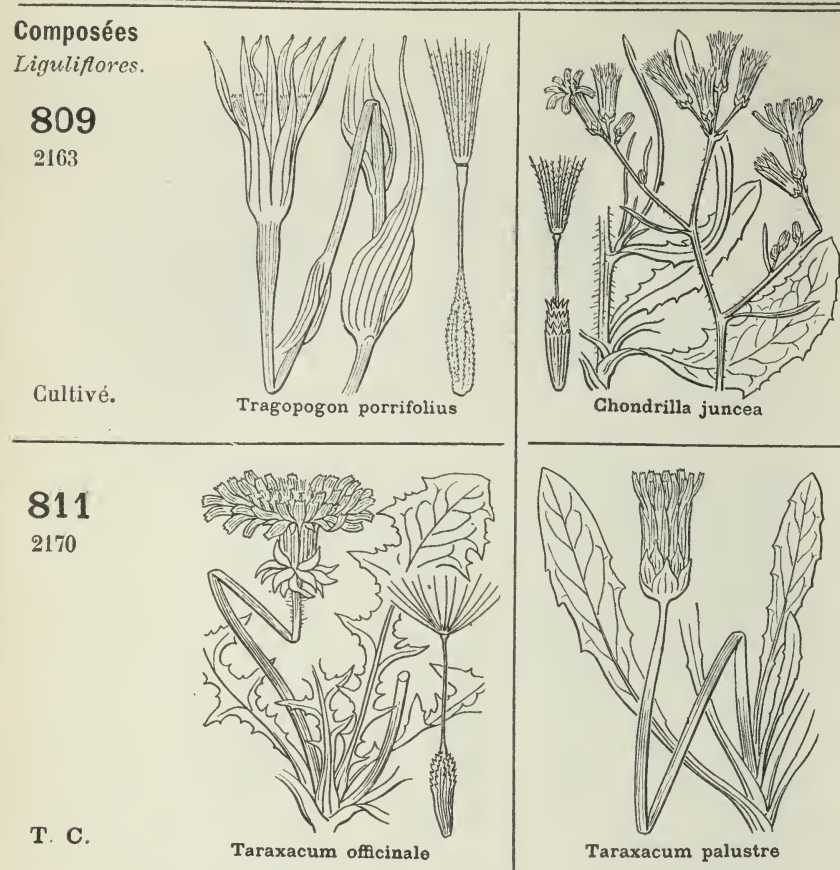

A. C.

A. $\mathbf{R}$.
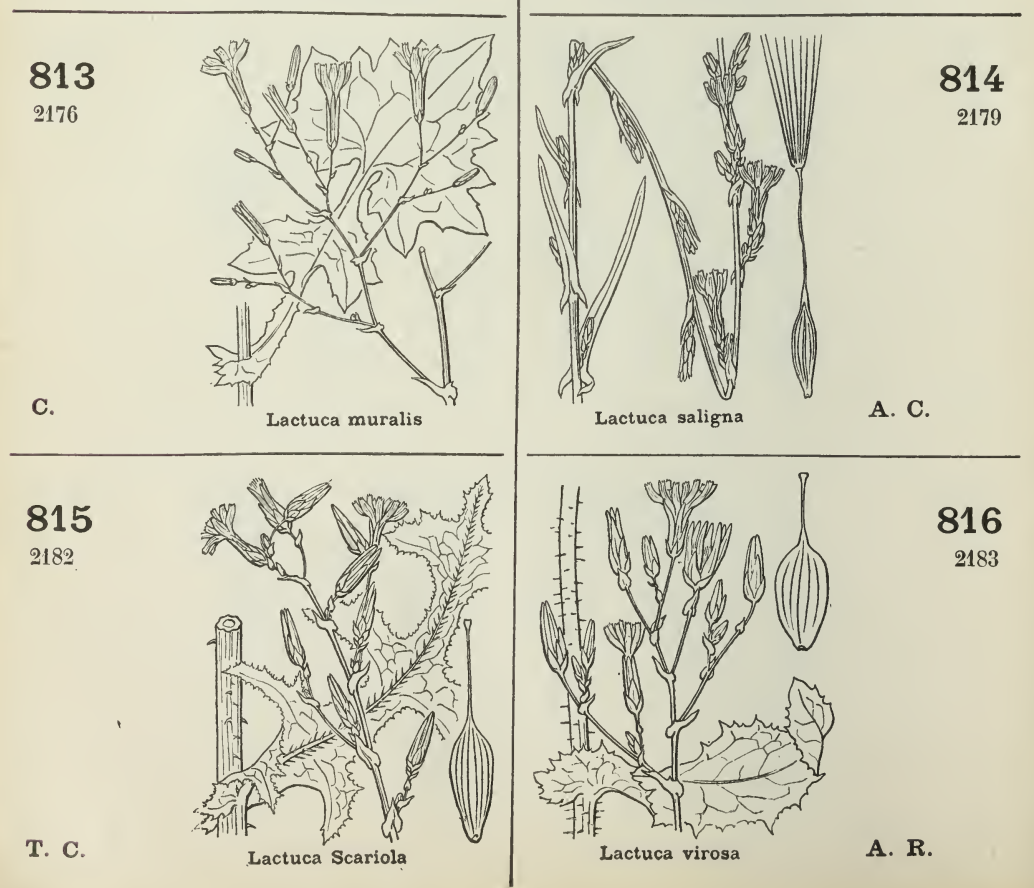

816

2183

$$
\text { Lactuca virosa A. R. }
$$


FAM. 53 (63), - COMPOSEÉS (Liguliflores)

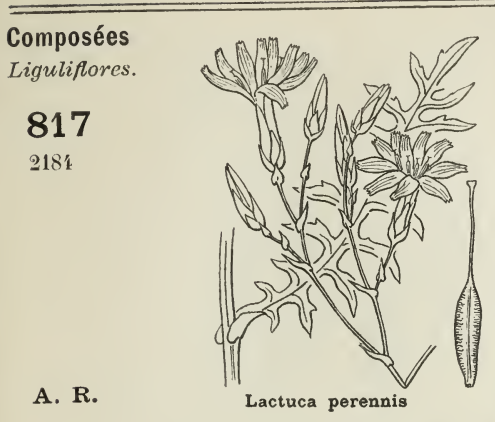

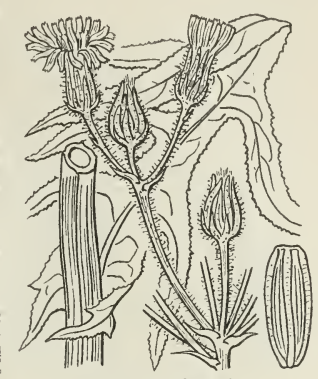

Sonchus palustris

818

2189

Gisors. R.

o. A. R.

S. -0. Montmo-

rency,

Enghien (au-

trefois).

Itteville,

Le Bouchet.
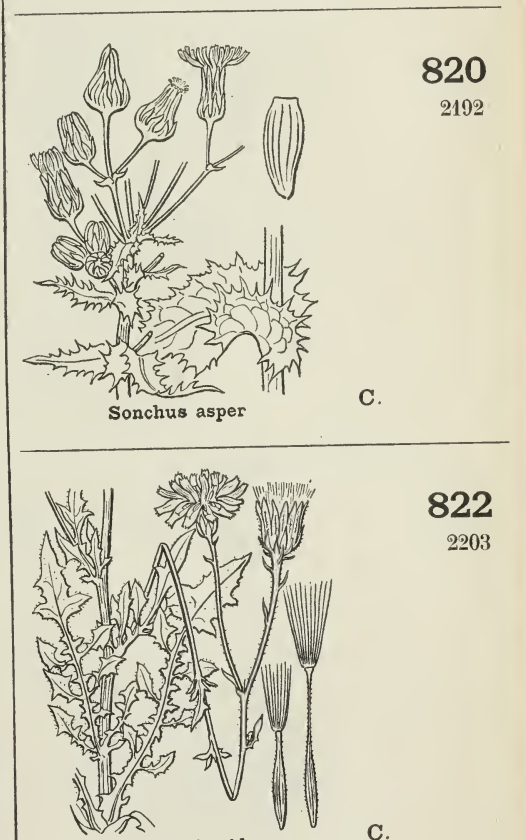

Crepis foetida

C.

822

2203
T. C.
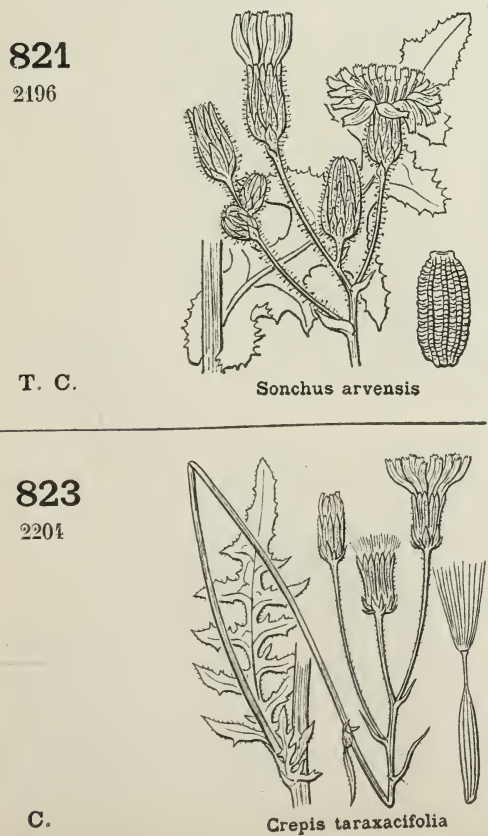

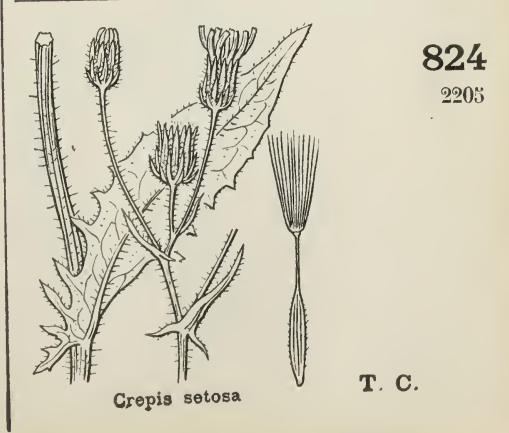


FAM. 53 (63). - COMPOSÉES (Liguliflores)
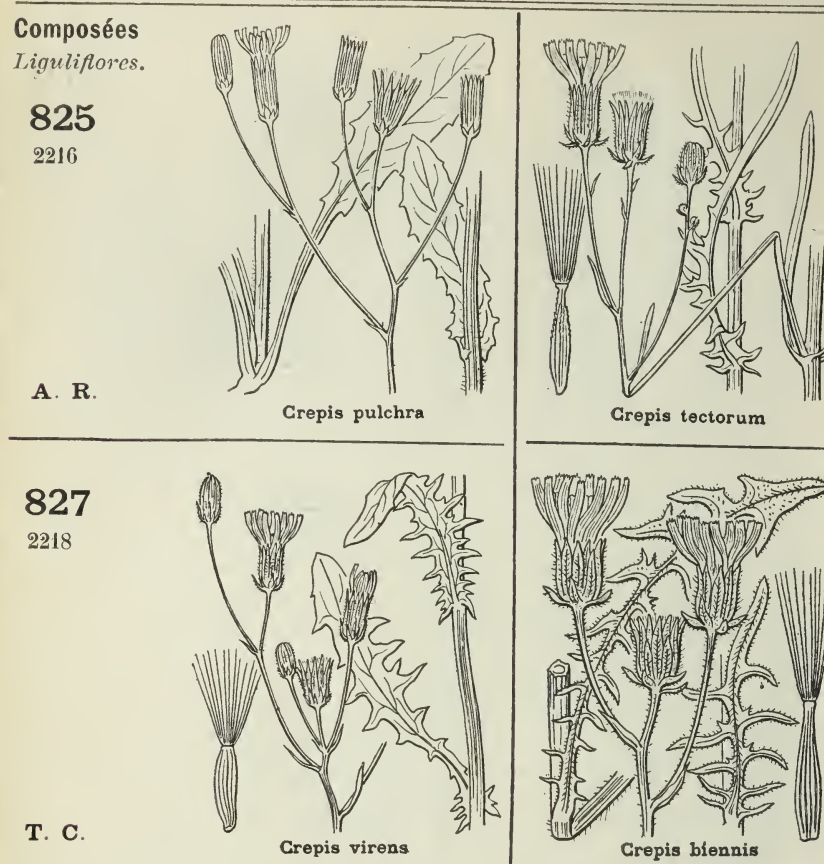

A. $\mathbf{R}$.
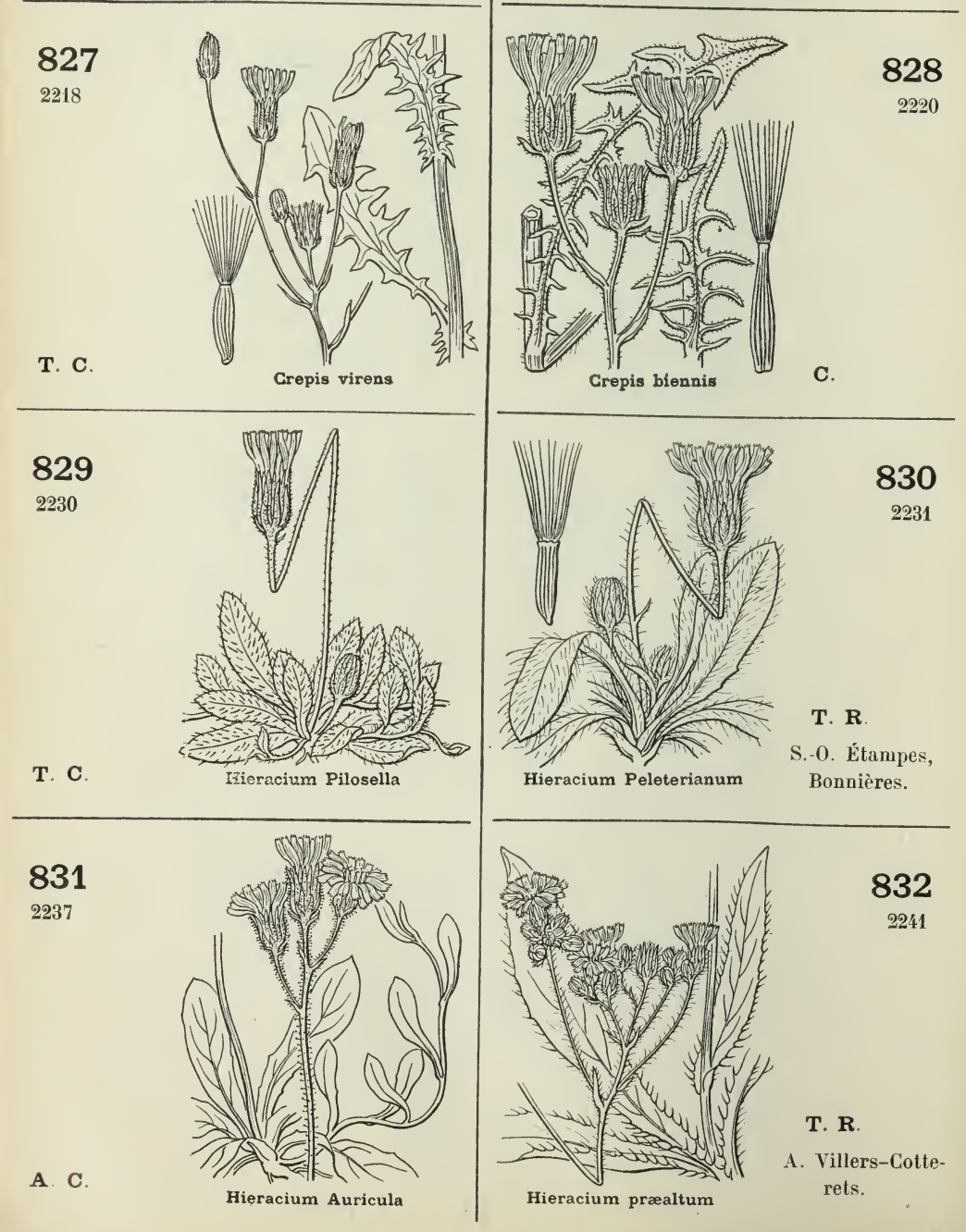
FAM. 53 (63). COMPOSÉES (Liguliflores) - FAM. 54 (64). A MBROSIACÉES FAM. 55 (63). LOBÉLIACÉES

Composées

Ligulifores.

833

2291

T. C.

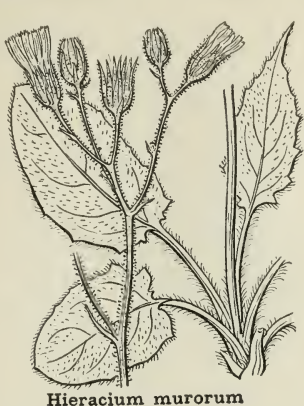

835

2310

A. C.

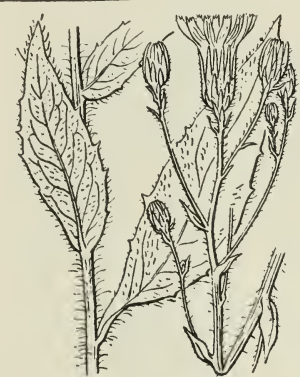

Hieracium boreale

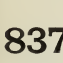

T. C.

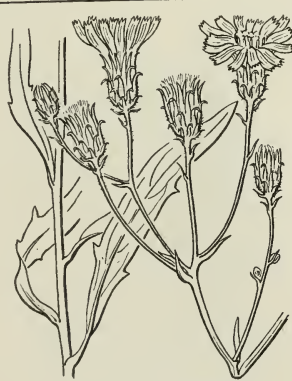

Hieracium umbellatum

\section{9}

2316

R.

0. Crépy.

S. Saint-Denis, Charenton,

Saint-Maur.

S.-M. Sivry,

Lizy-sur-Ourg.

S.-0. Gassicourt, Le Pecq, Marly.

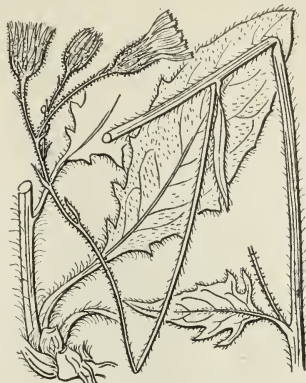

Hieracium vulgatum

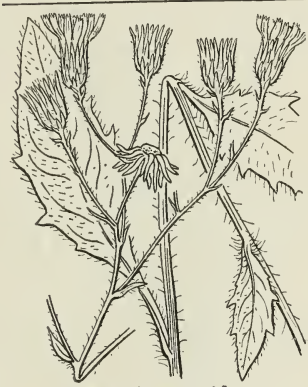

Fieracium rigidum

A. C.

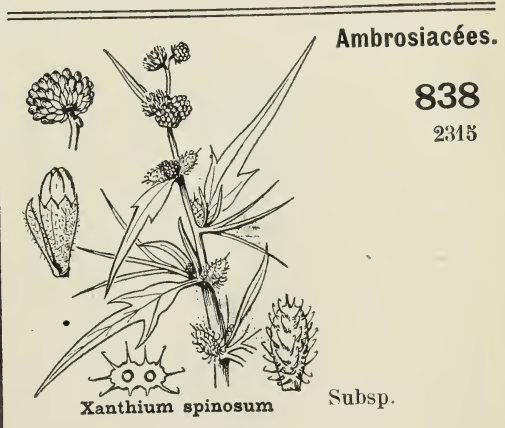

834

2292
C.

836

2311

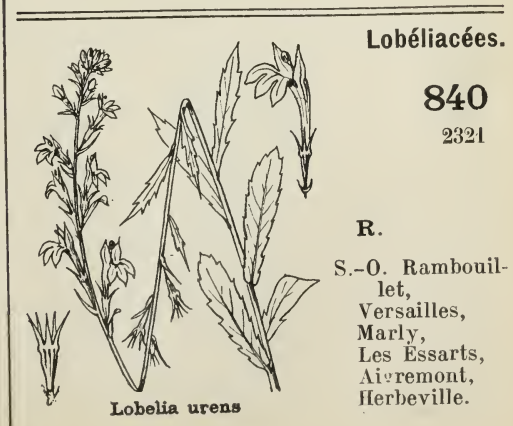



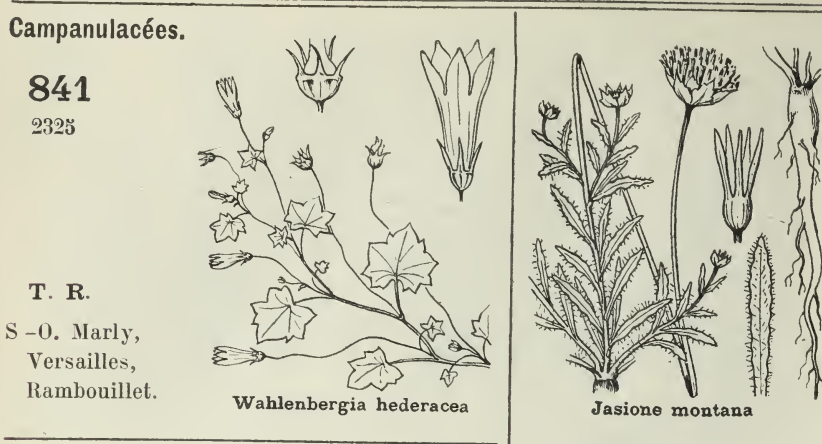

842

2327

\section{3}

2333

A. $\mathbf{R}$.

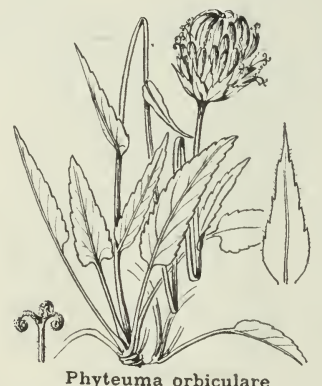

Phyteuma orbiculare

\section{5}

2342

A. C.
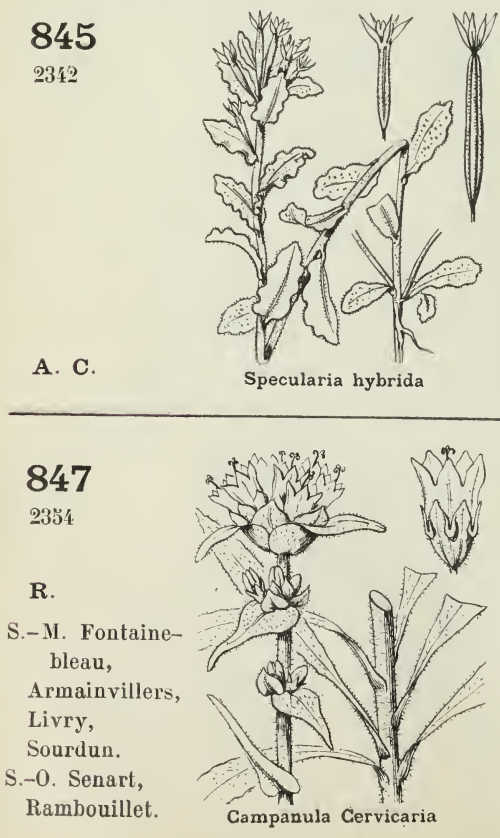

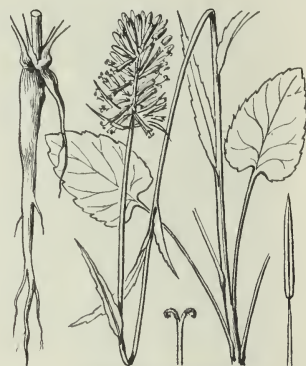

Phyteuma spicatum

A. $\mathbf{R}$.

844

2338

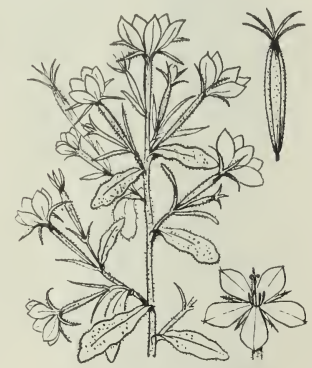

846

23 १3

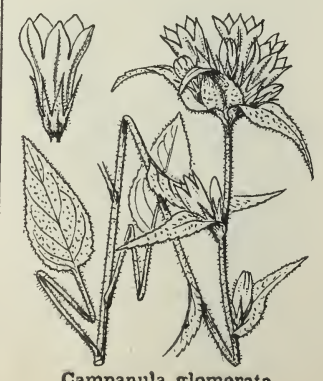

848

2355 
FAM. 56 (66). CAMPANULAGEES - Fam. 57 (67). VAGGINIEES 107 Campanulacées.

849

2356

A. C.
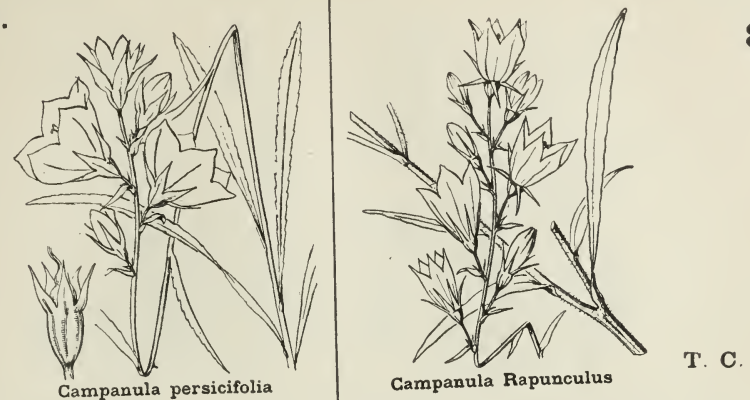

850

2357
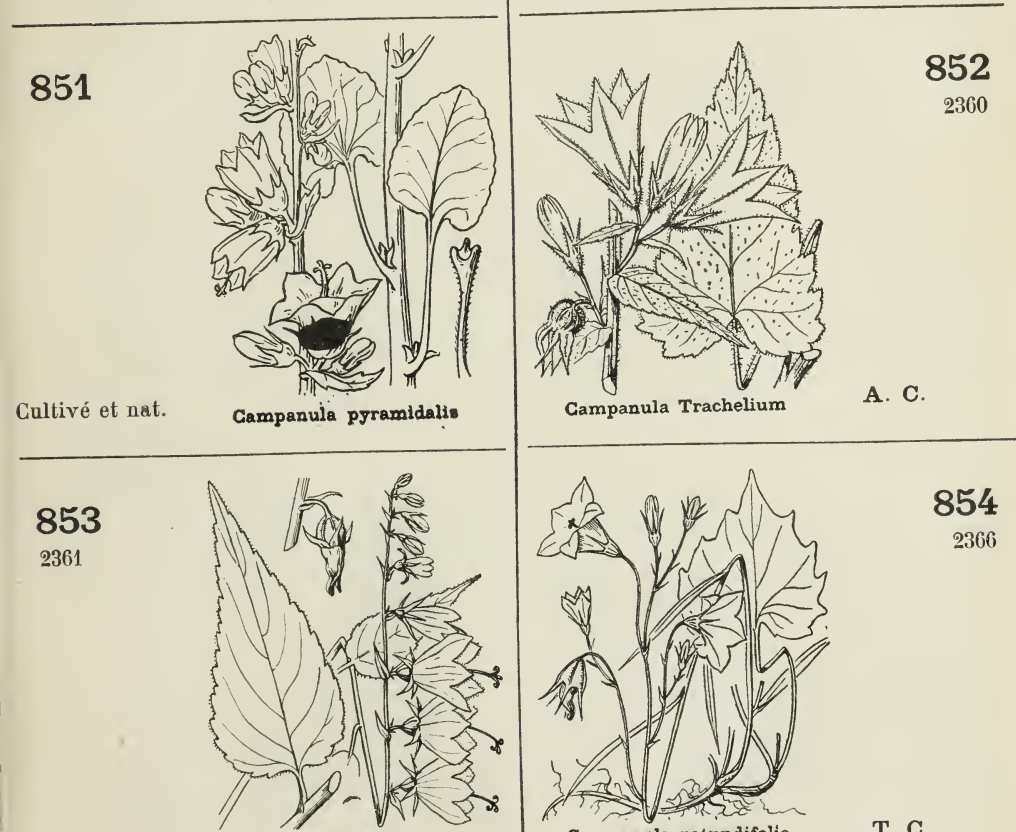

A. $\mathbf{R}$.

Campanula rapunculoides

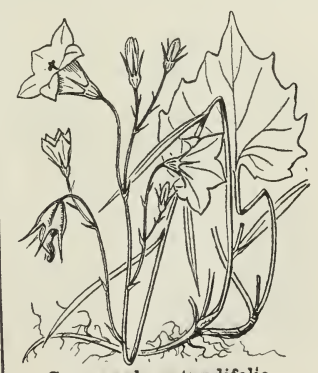

Campanula rotundifolia

854

2366
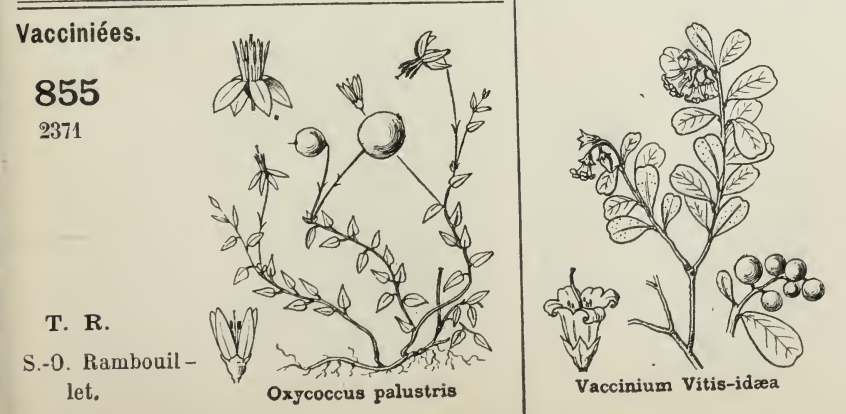

T. $\mathbf{R}$.

0. Savignies, Bains,

La Hérelle. 
FAM. 57 (6i). VACCINIÉES - FAM. 58 (68). ÉRICACÉES FAM. 59 (69). LENTIBULARIÉES
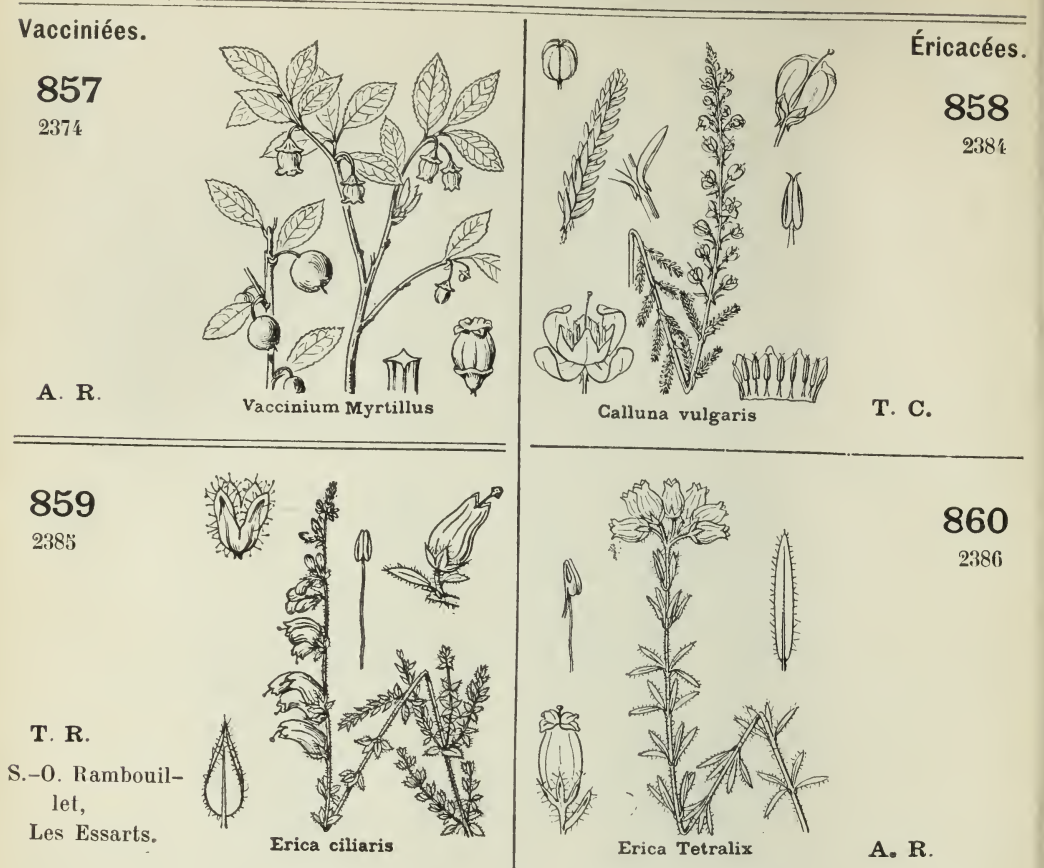

T. R.

S.-0. Rambouillet,

Les Essarts.

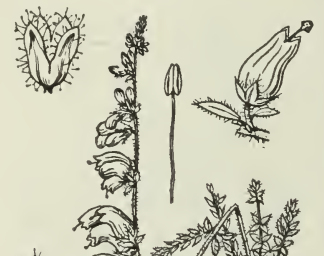

Erica Tetralix

A. $\mathbf{R}$.

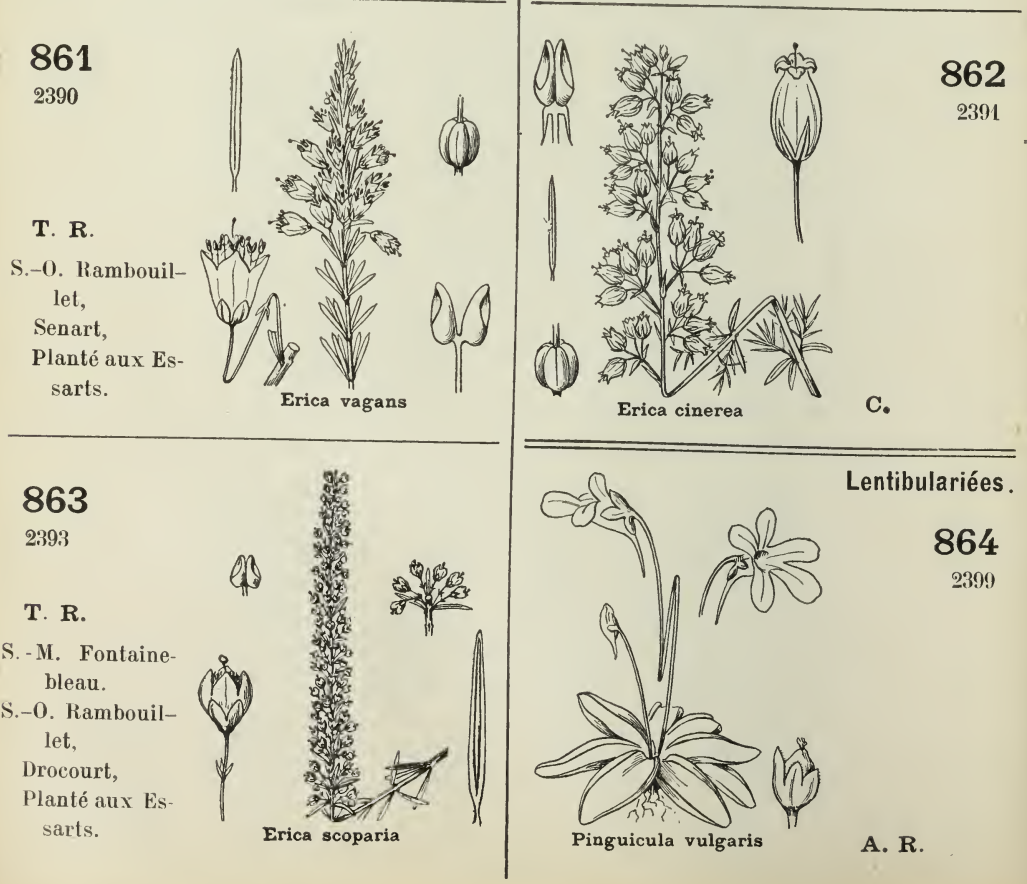


FAM. 59 (69). - LENTIBULARIÉES

FAM. 60 (70). - PRIMULACÉES

Lentibulariées.

865

2403

C.

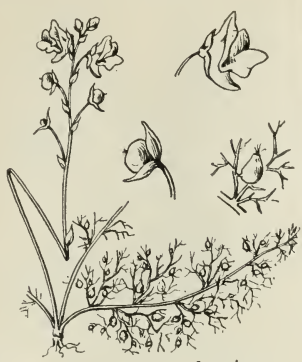

Utricularia vulgaris

\section{7}

2ห0ะ

T. R.

S.-M. Buthiers, Roncevaux où il ne fleurit pas.<smiles>C1=CC2C=C12</smiles>

教

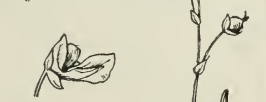

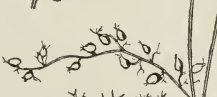

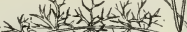
Utriculoria intermedia Utriculeria intermedia

Primulacées.

869

2407

A. $\mathbf{R}$.

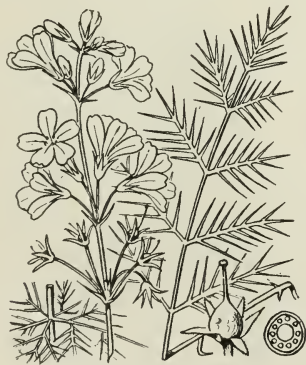
Hottonia palustris

871

240

C.

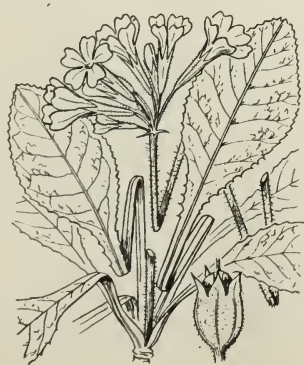

Primula elatior

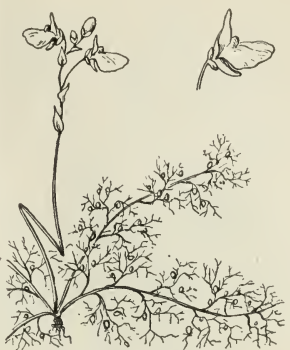

866

2104

R.

S.-0. Meudon, Sénart,

Rambouillet.

Utricularia neglecta

868

2406

A. $\mathbf{R}$.

Utricularia minor

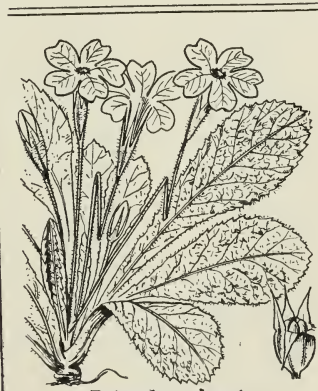

Primula vulgaris

A. $\mathbf{R}$.

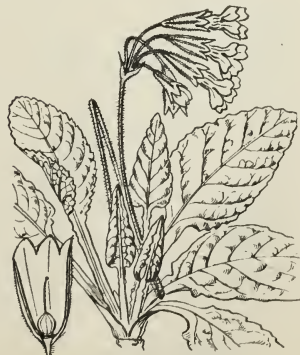

872

211 


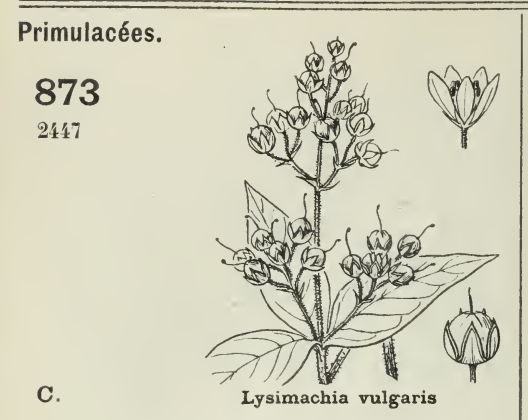

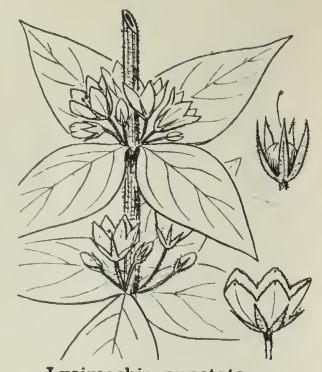

Lysimachia punctata Subsp.

\section{5}

2449

C.

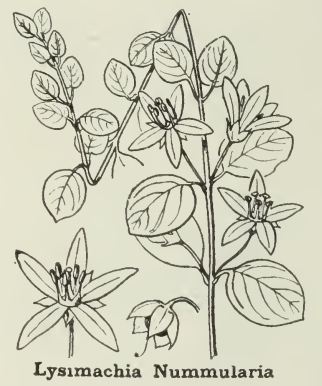

877

2453

A. C.

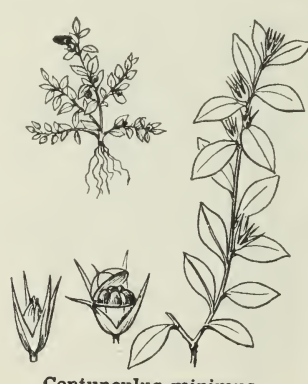

Centunculus minimus

879

2450

A. C.

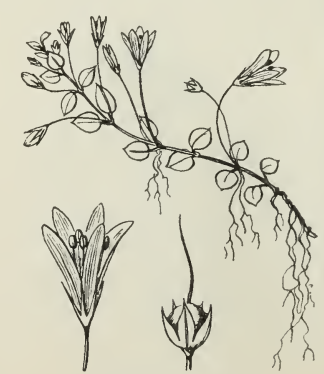

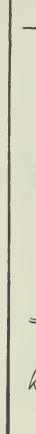

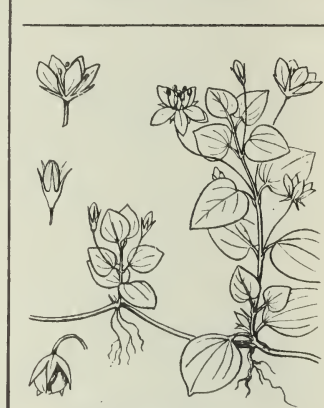

Lysimachia nemorum

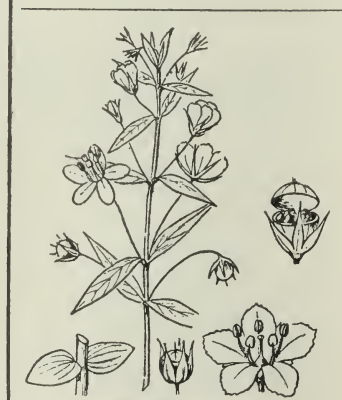

Anagallis arvensis

876

2450

R.

A. Villers-Cotterets.

0. Beauvais, Compiègne.

S. -0. Montmo-

rency,

Marly,

Magny.

878

2454

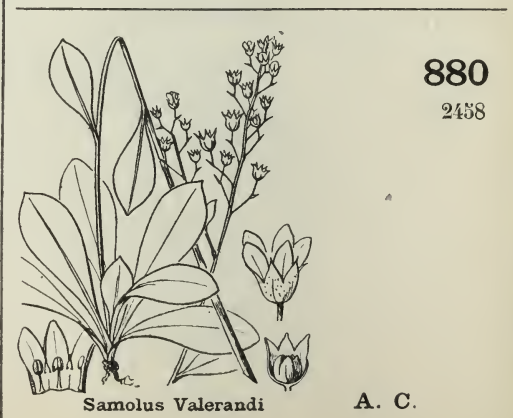


FAM. 61 (72). OLÉACÉES - FaM. 62 (73). APOCYNÉES FAM. 63 (74). ASGLÉPIADÉES - FaM. 64 (70). GENTIANÉES

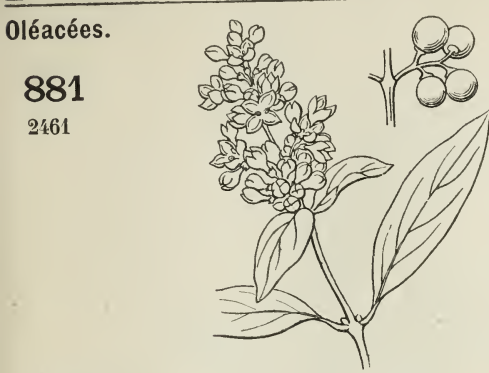

T. C.

Ligustrum vulgare

883

2471

Subsp.

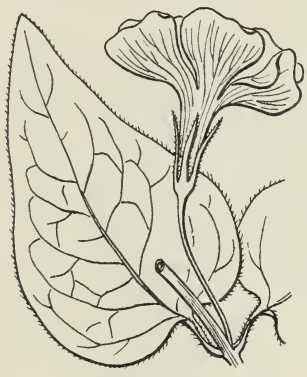

Vinca major

\section{5}

247ร

\section{Natur.}

L. Malesherbes.

0. Compiègne.

S. - O. Isle- Idam.

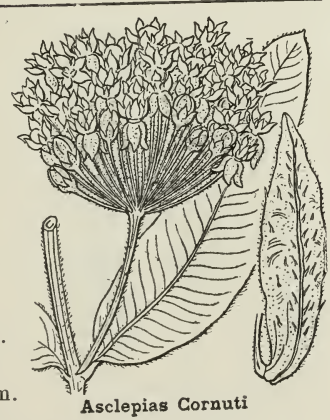

887

2187

T. C.

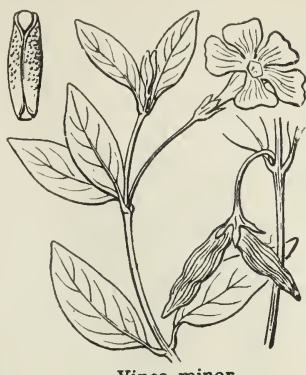

Vinca minor
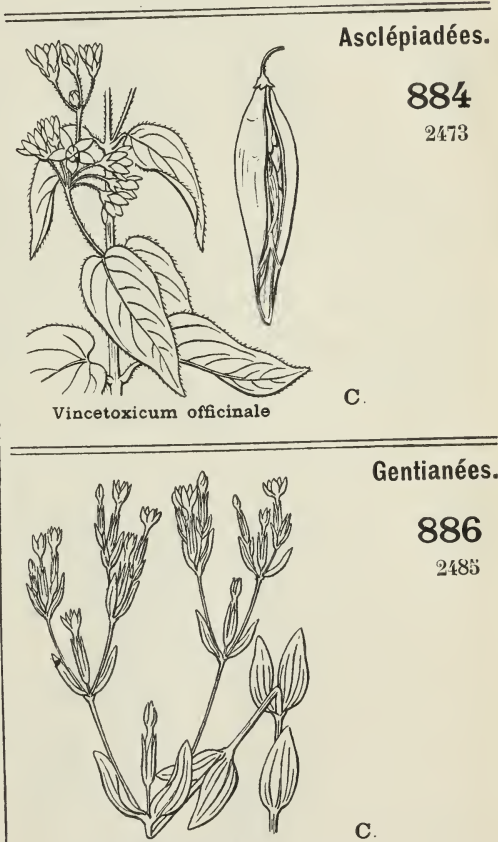

Erythræa pulchella

Apocynées.

882

2469
Gentianées.

C.

886

2483

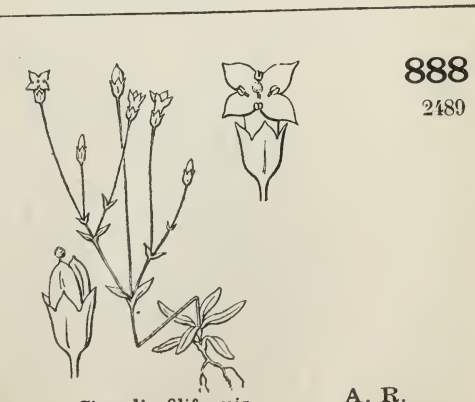

A. $\mathbf{R}$. 

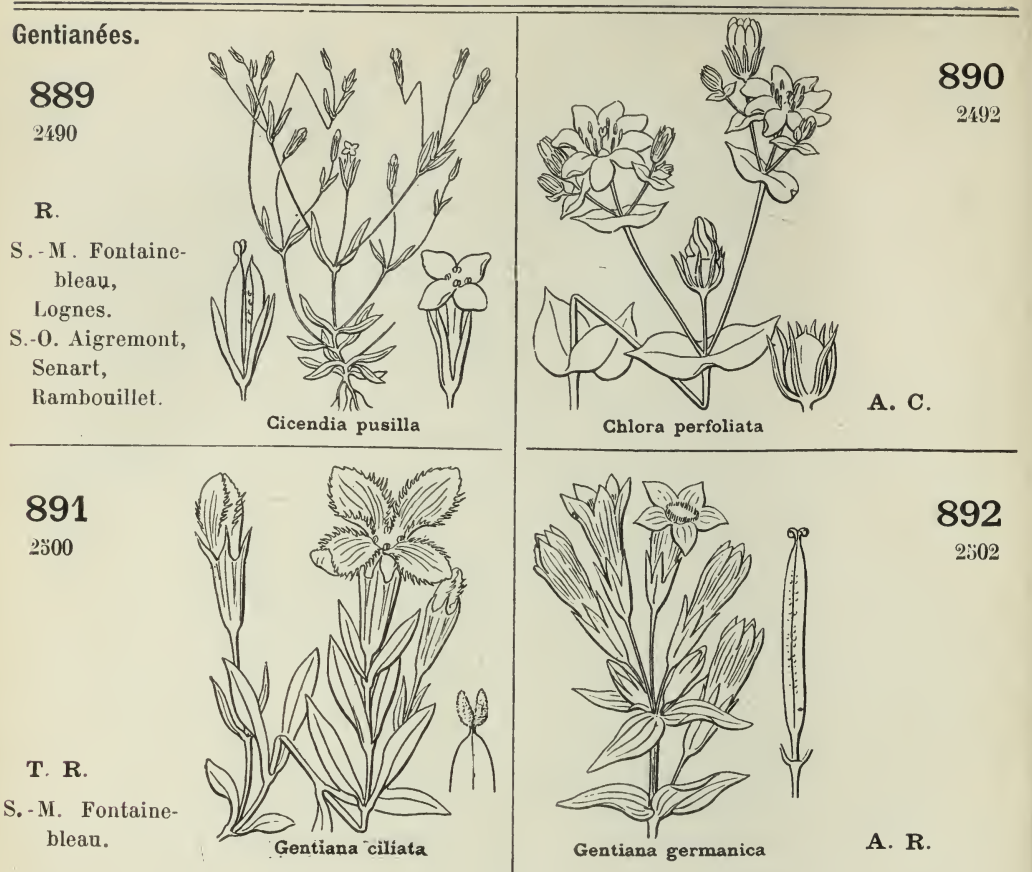

892

Gentiana germanica

A. $\mathbf{R}$.
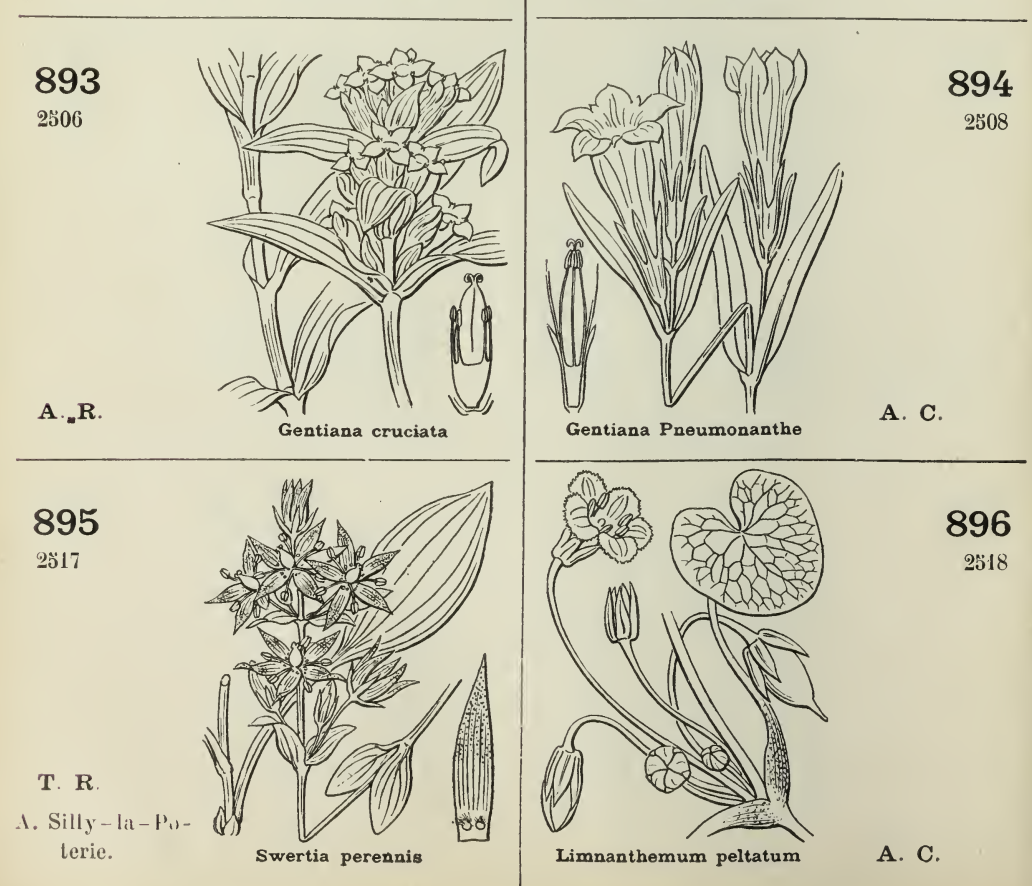
Fam. 64 (75). GENTIANÉES - Fam. 65 (77). GONVOLVULACÉES 113
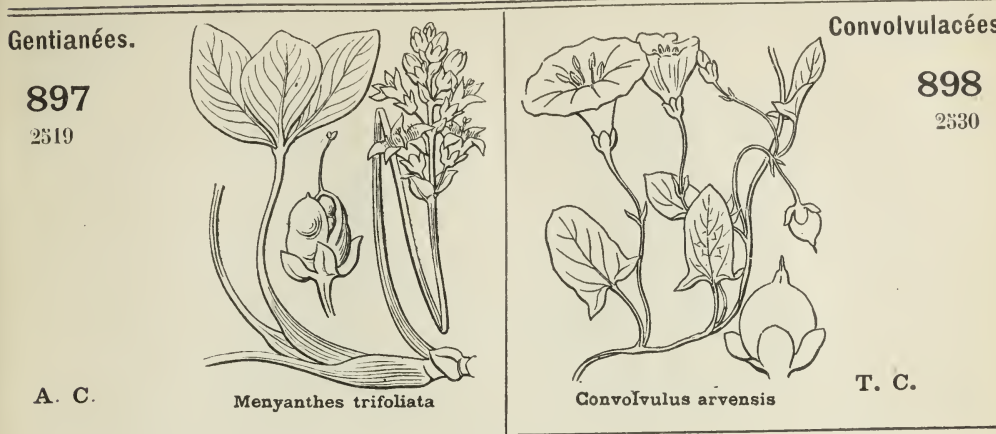

898

Convolvulus arvensis

T. C.

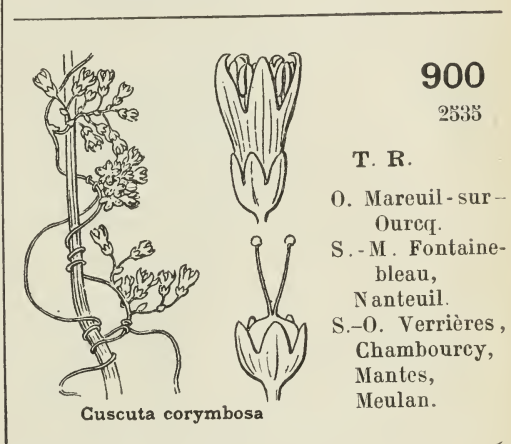

c.

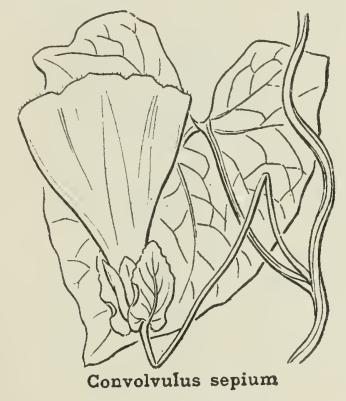

899

$2 \% 31$

901

2537

\section{T. $\mathbf{R}$.}

E. St-Georges, Notel.

o. Halincourt.

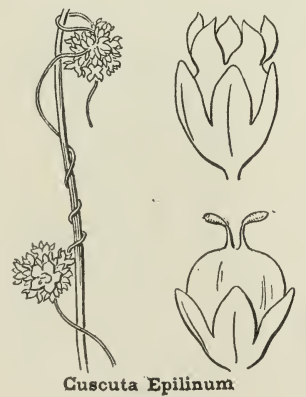

\section{3}

2541

c.

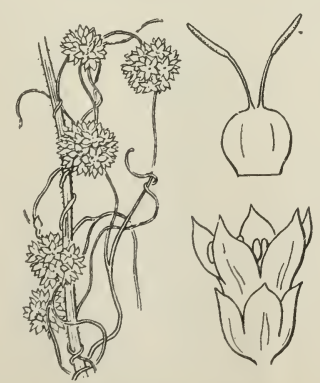

Cuscuta Epithymum
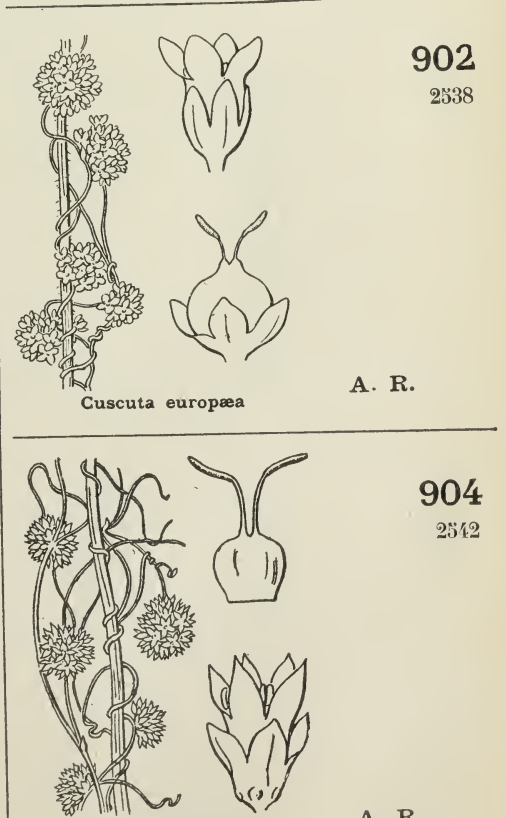

904

2342 


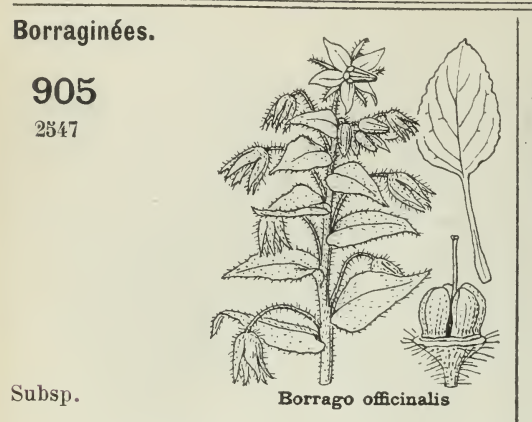

R.

S. Boulogne.

S.-0. Domont,

Versailles,

Magny.

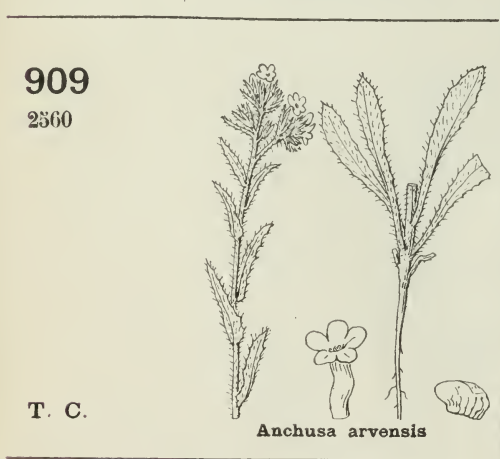

911

2569

C.

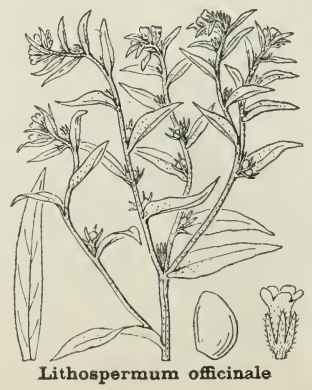

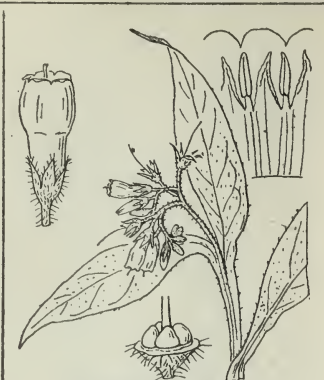

Symphytum officinale

T. C.

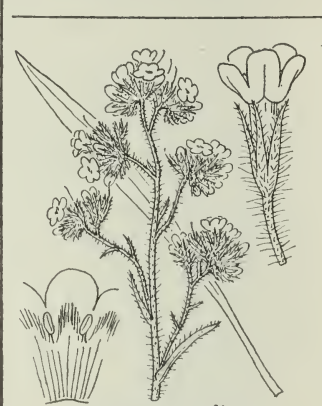

Anchusa italica

A. $\mathbf{R}$.

\section{8}

25ั5ว

906

2549
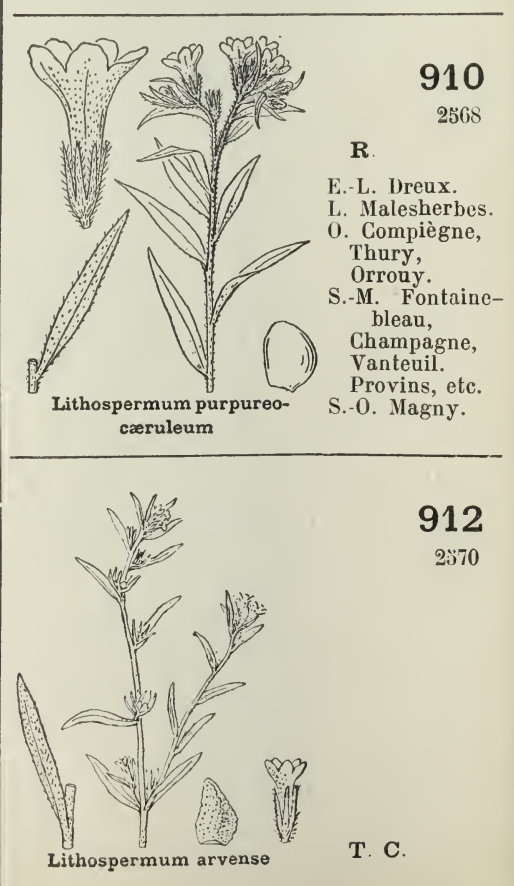


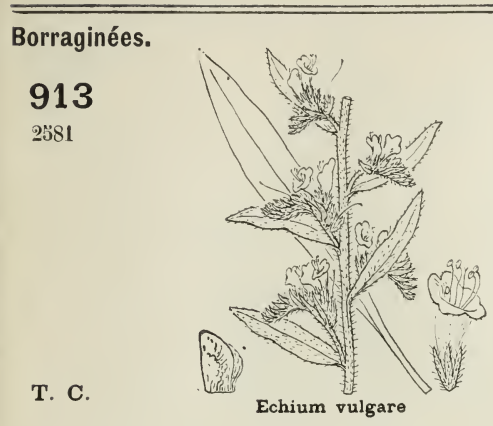

C.

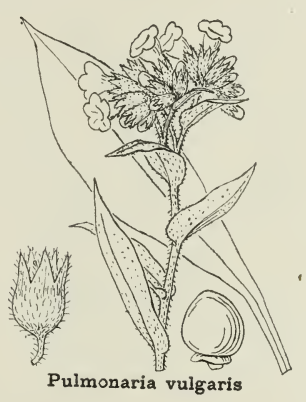

A rechercher.

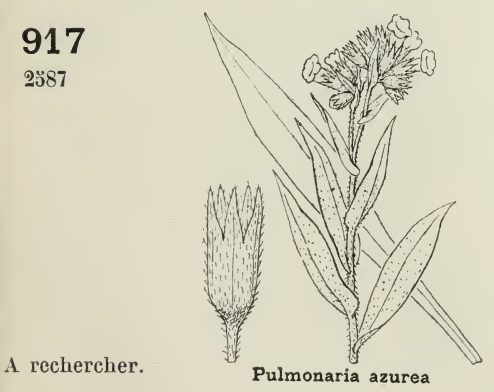

Pulmonaria azurea

919

2๖89

A. C.

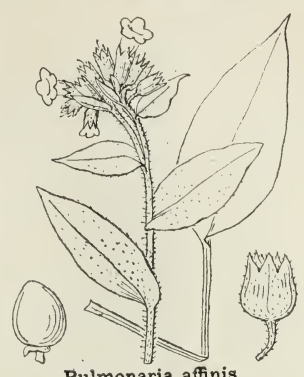

Pulmonaria affinis
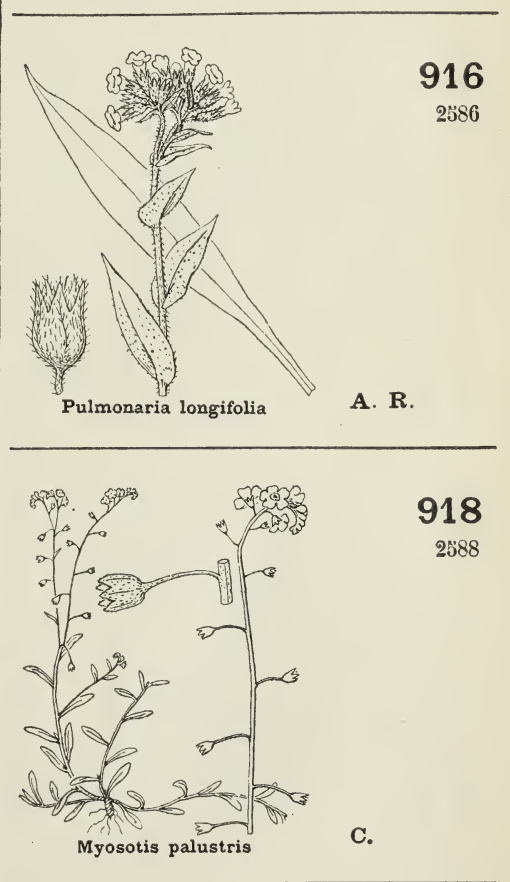

T. $\mathbf{R}$.

S.-M. Provins?

916

2586 


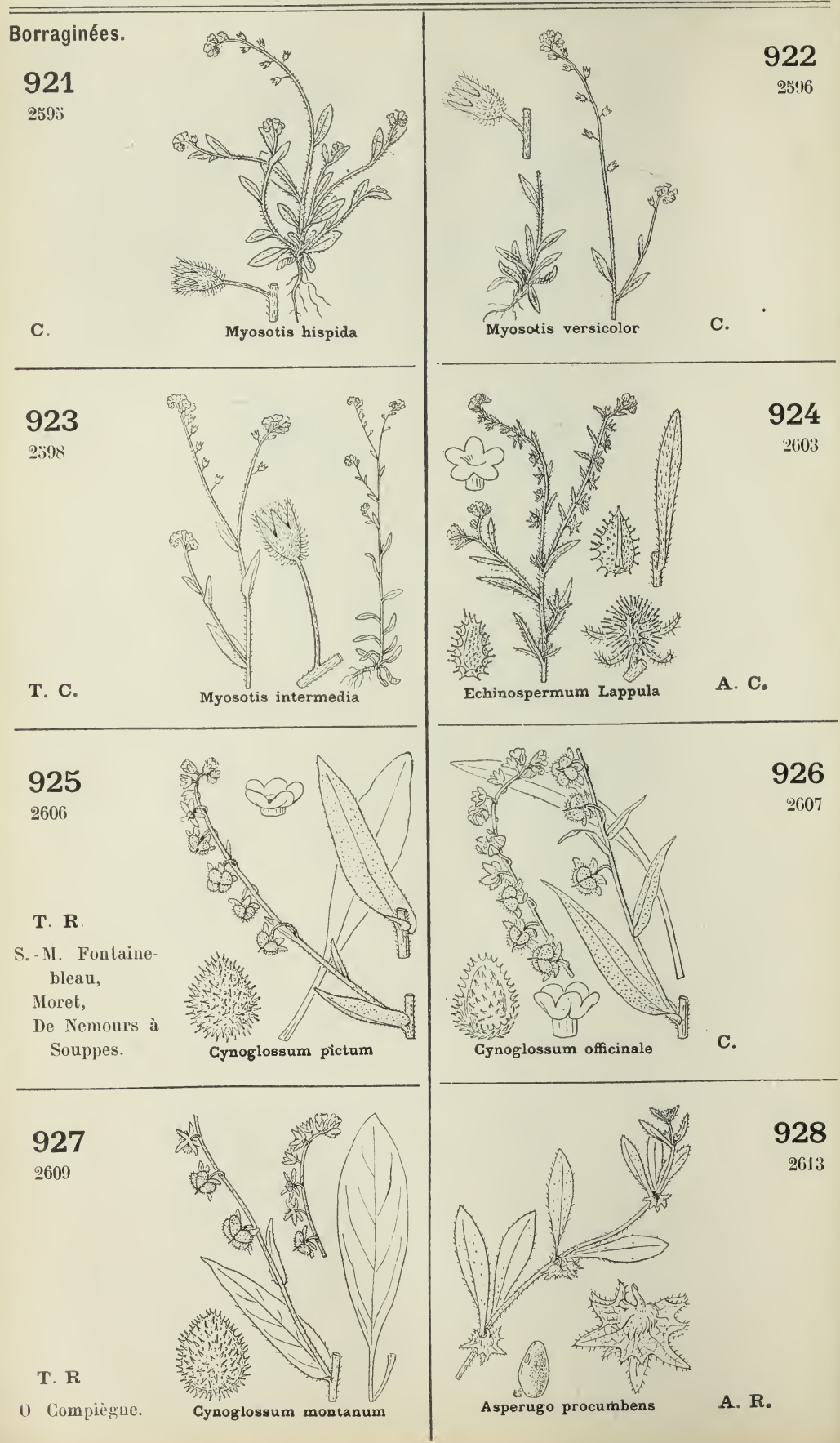



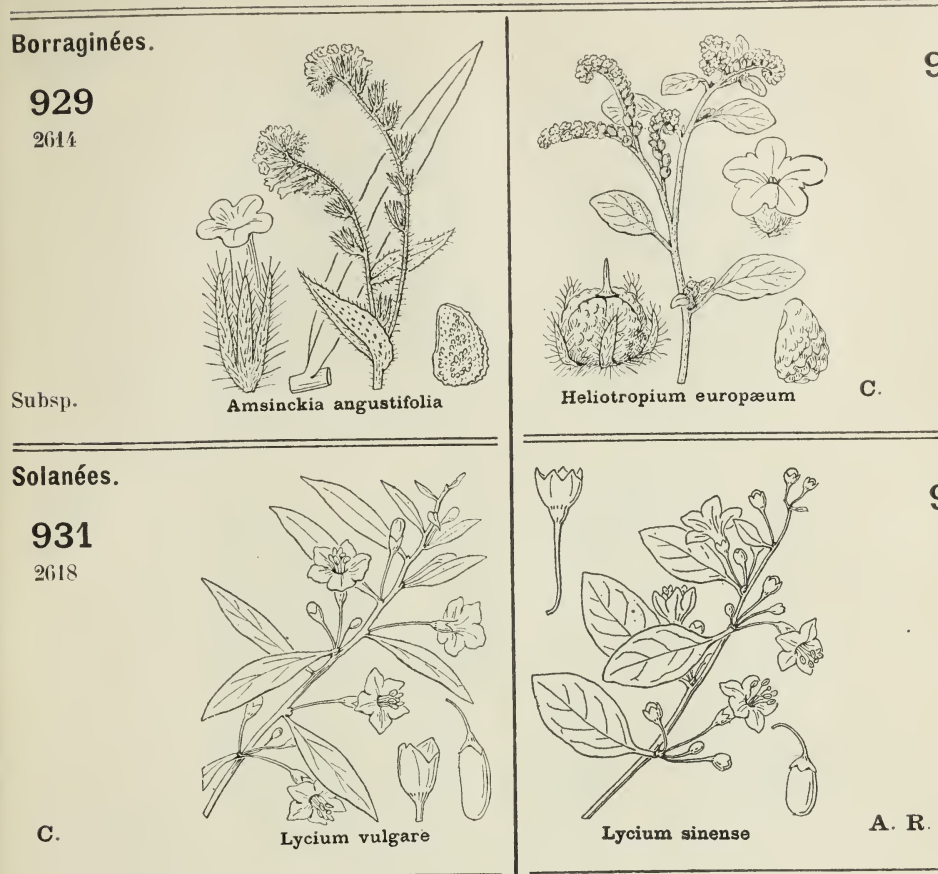

930

2617

Heliotropium europæum

C.
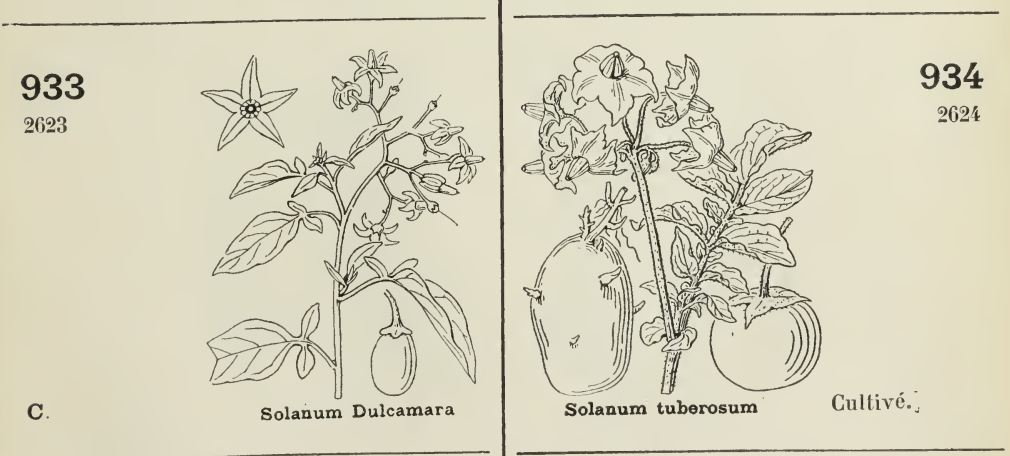

ycium sinense

A. $\mathbf{R}$

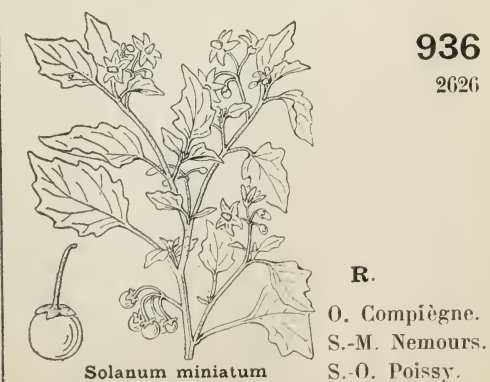

E.-L. Dreux.

0 . Senlis.

S. Enghien,

Issy.

S. - 0 . Versailles,

Trou-Salé.

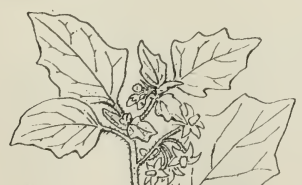

936

2626

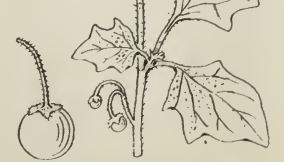

Solanum villosum

S.-M. Nemours. 

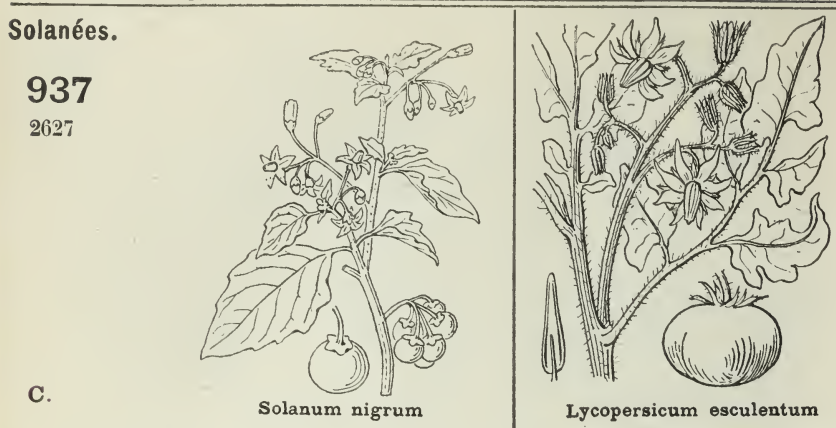

Lycopersicum esculentum

A. C

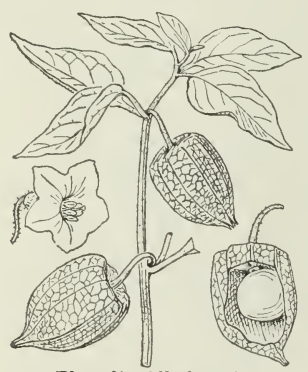

Physalis Alkekengi

941

2631

A. C.

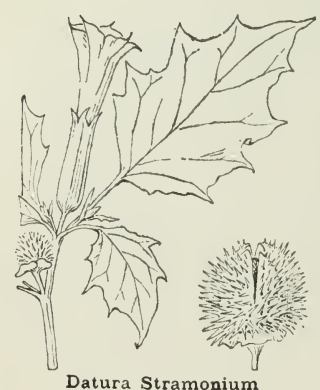

Datura Stramonium

943

2638

C.

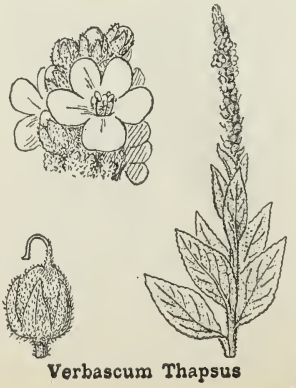

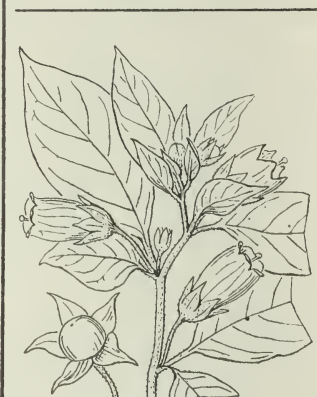

Atropa Belladouna

A. $\mathbf{R}$.

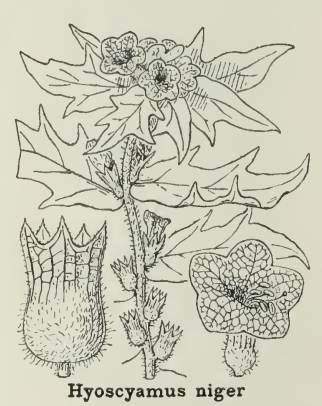

942

2636

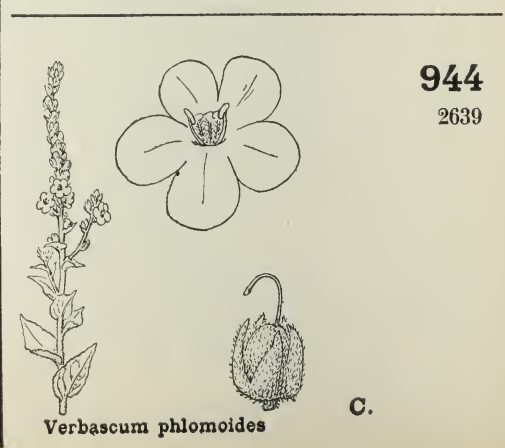


FAM. 67 (80). SOLANÉES - FAM. 68 (81). SCROFULARIÉES
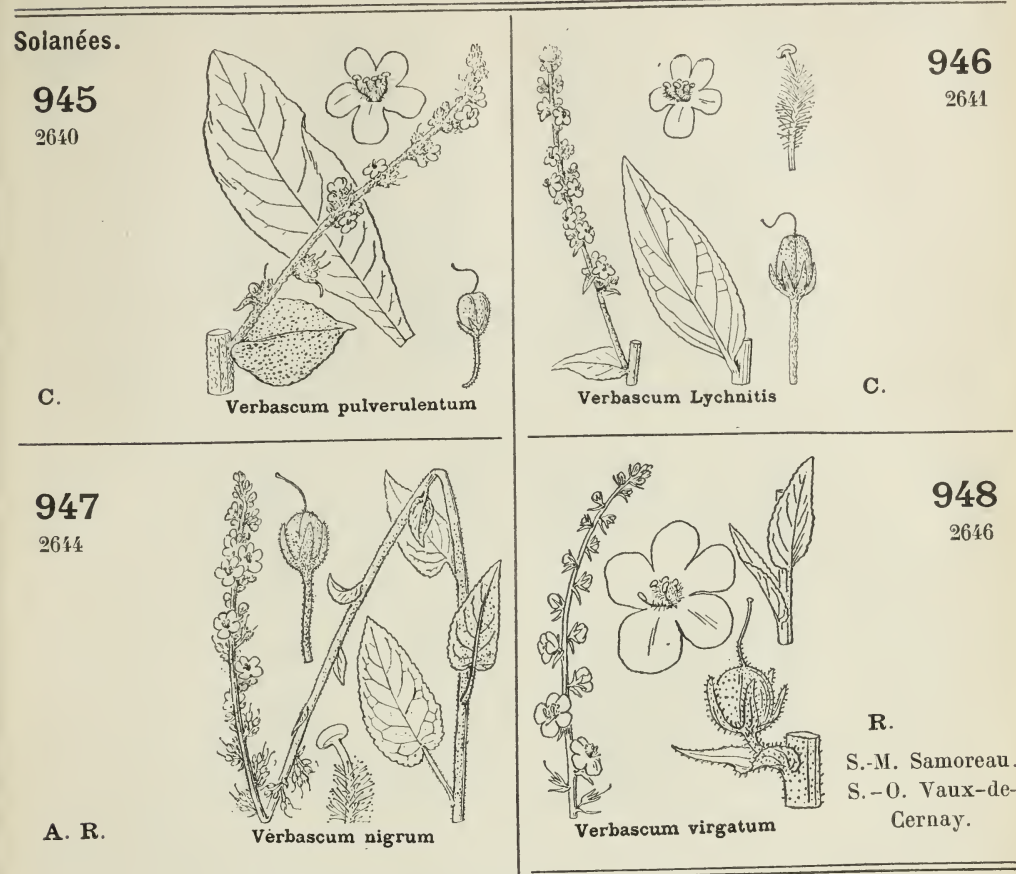

948

2646

R.

S.-M. Samoreau .

S. - 0. Vaux-de-

Cernay.
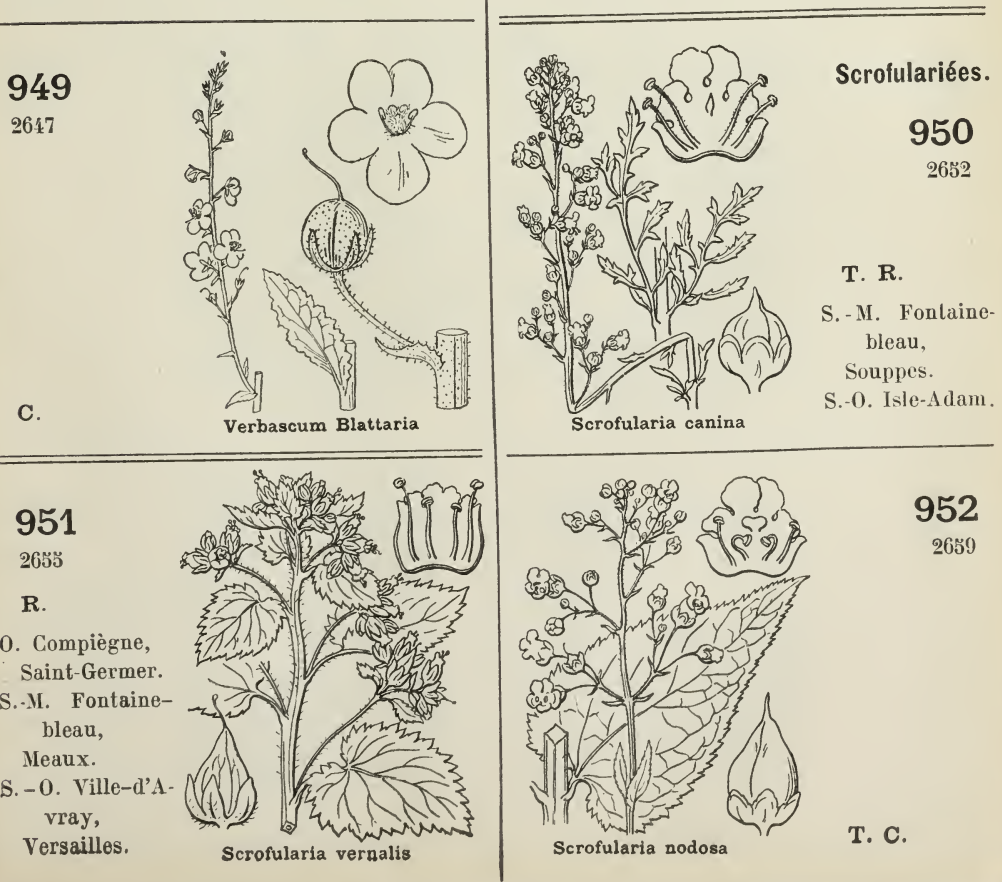

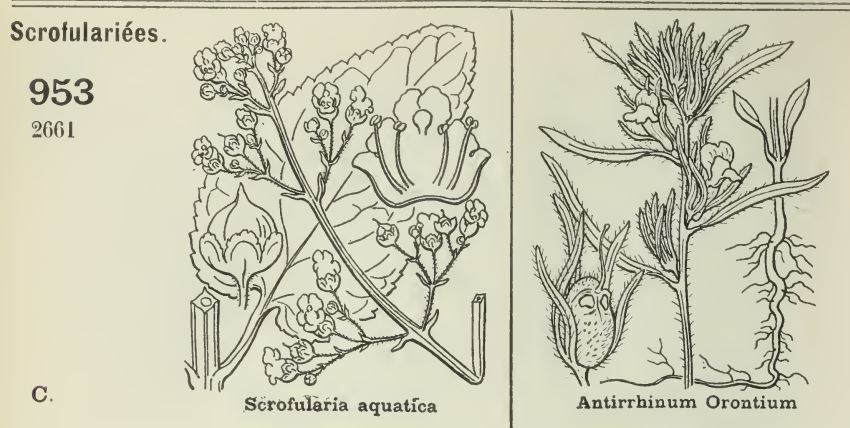

954

2667
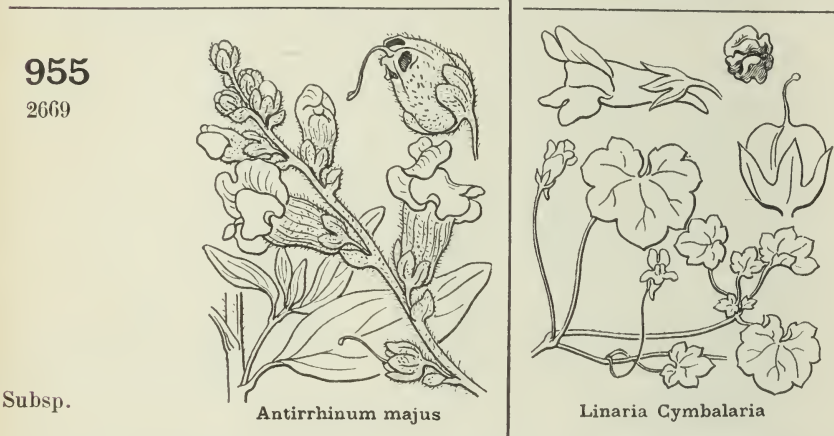

A. C.

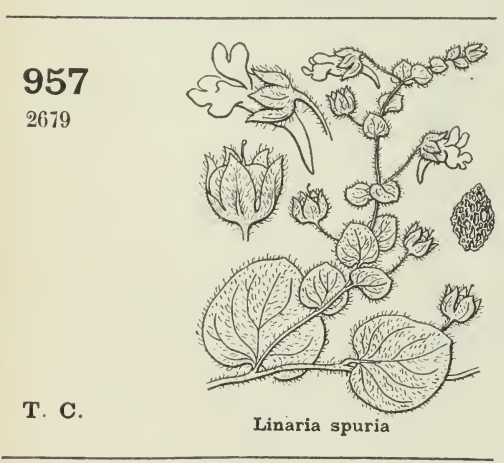

Linaria Cymbalaria

956

2674

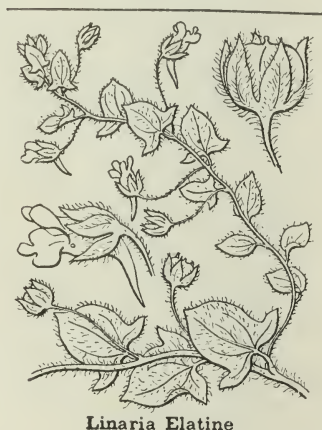

958

2681

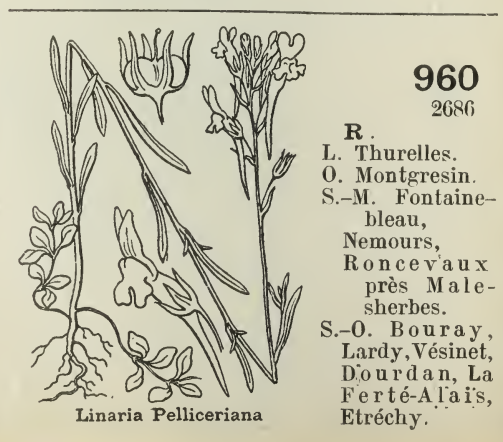




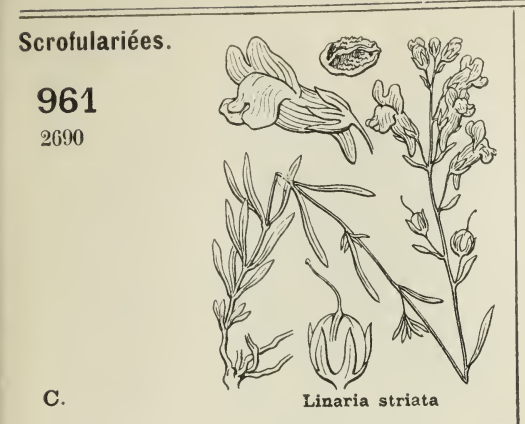

T. C.

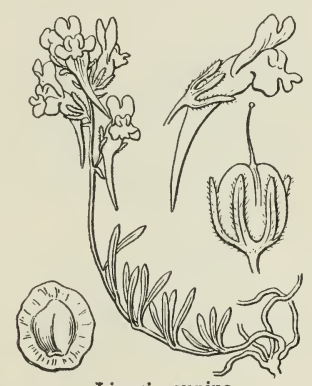

Linaria supina

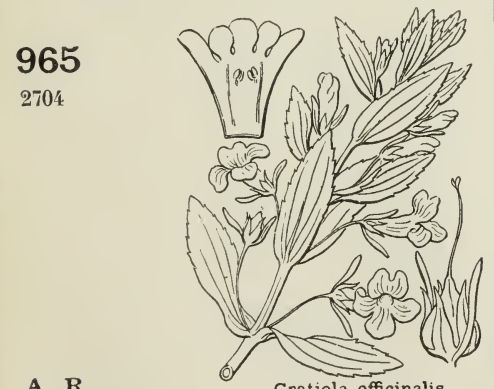

A. $\mathbf{R}$.

Gratiola officinalis

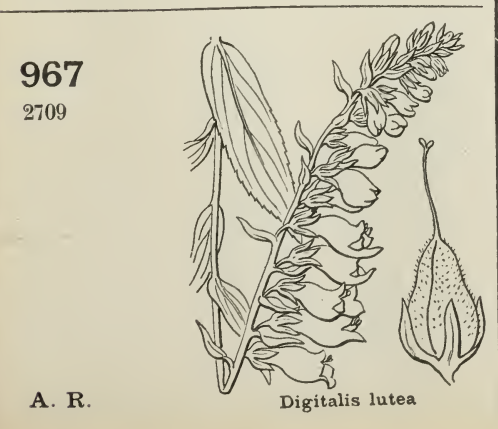

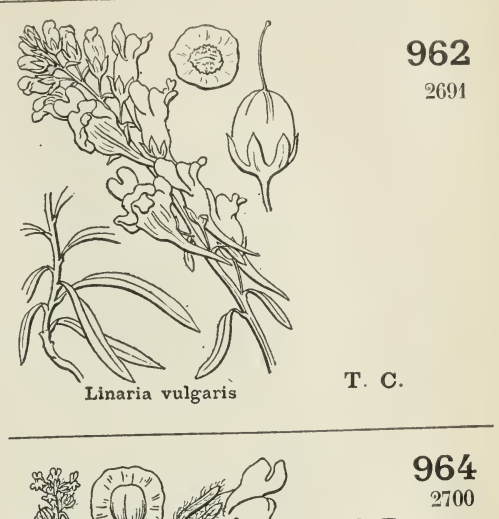

T. $\mathbf{R}$.

E. Milleville.

L. Malesherbes.

o. Beauvais,

Méru,

Le Mesnil-St-

Firmin,

Antheuil - en -

Valois,

Compiègne

S.-M. Sivry,

Nemours.

S.-0. St-Léger,

Poigny,

Verrières.

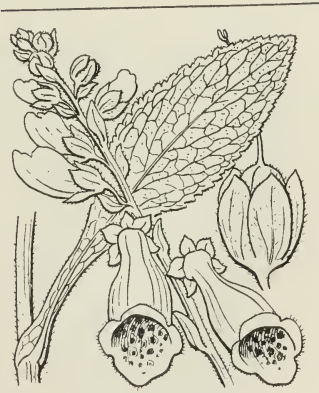

966

2707

c.

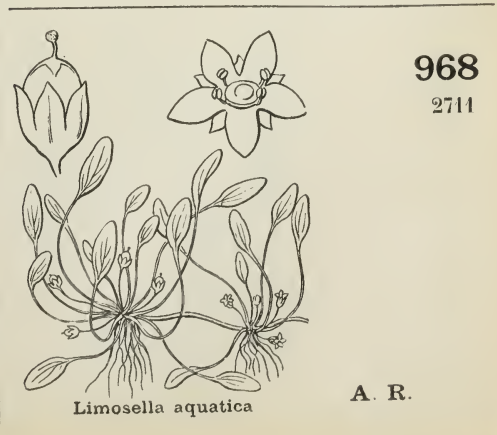



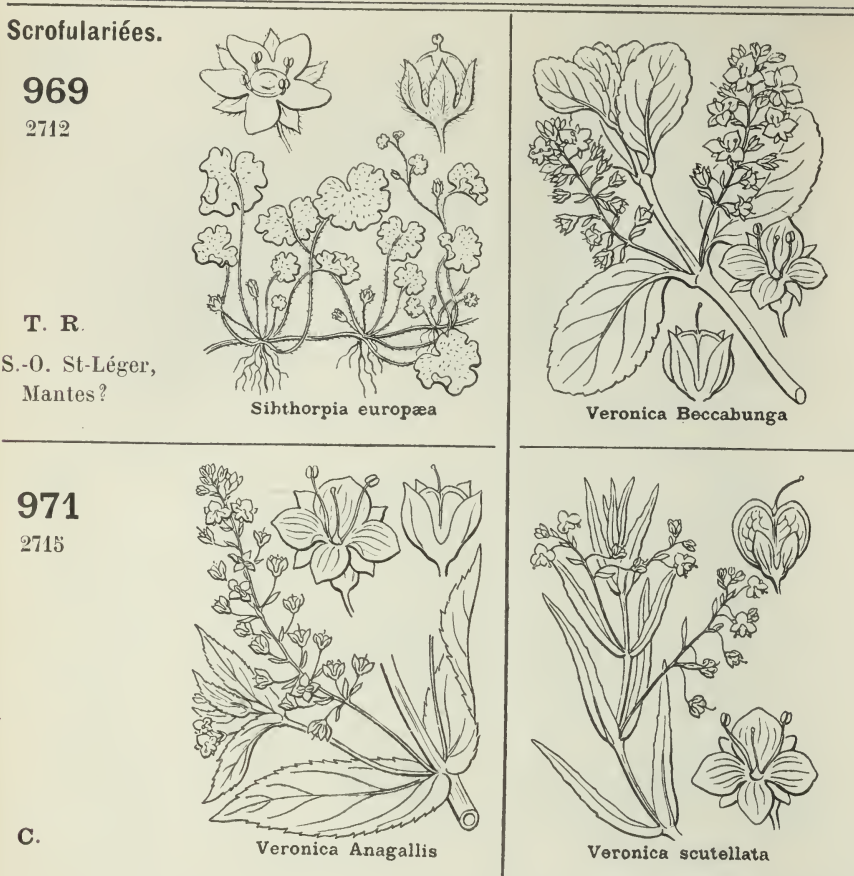

970

2714

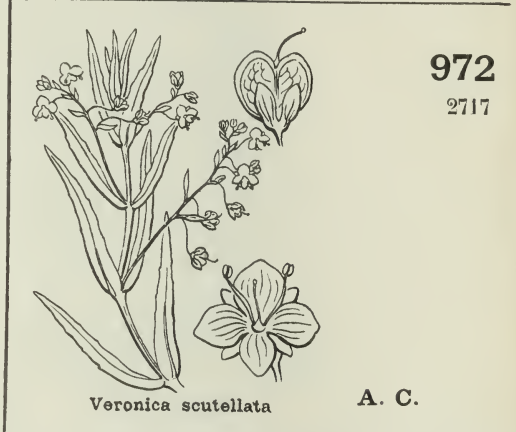

T. C.
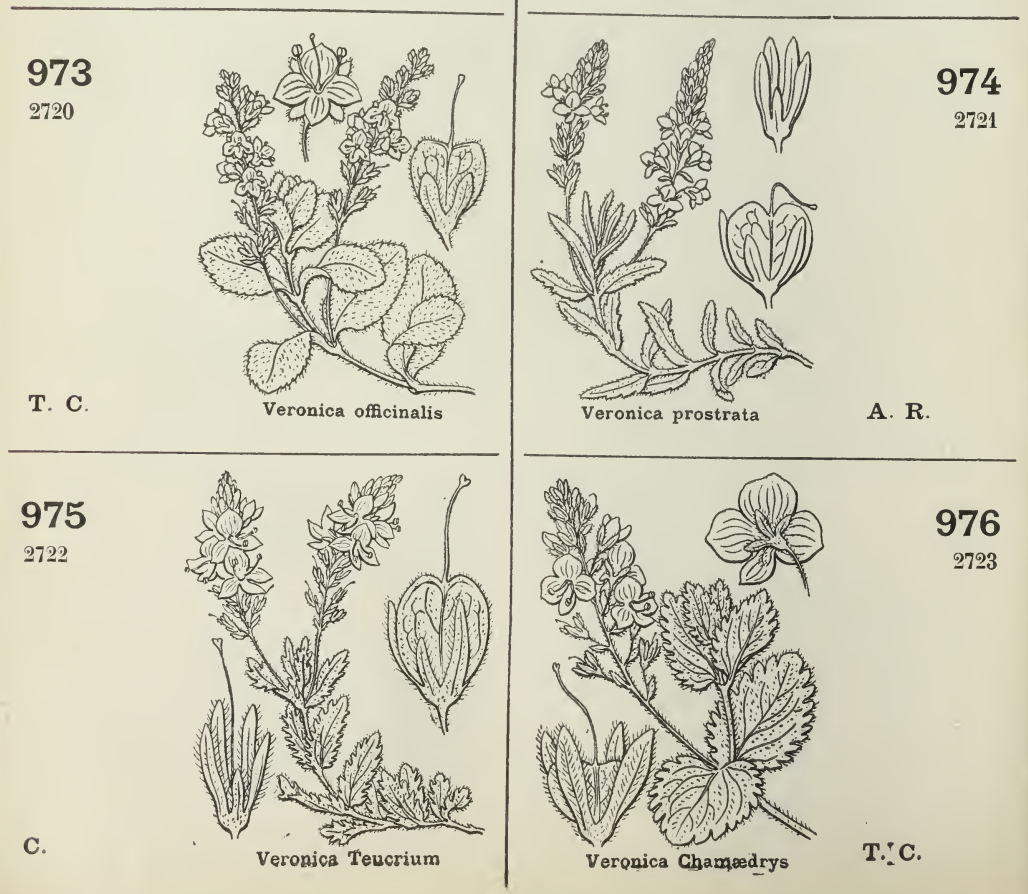

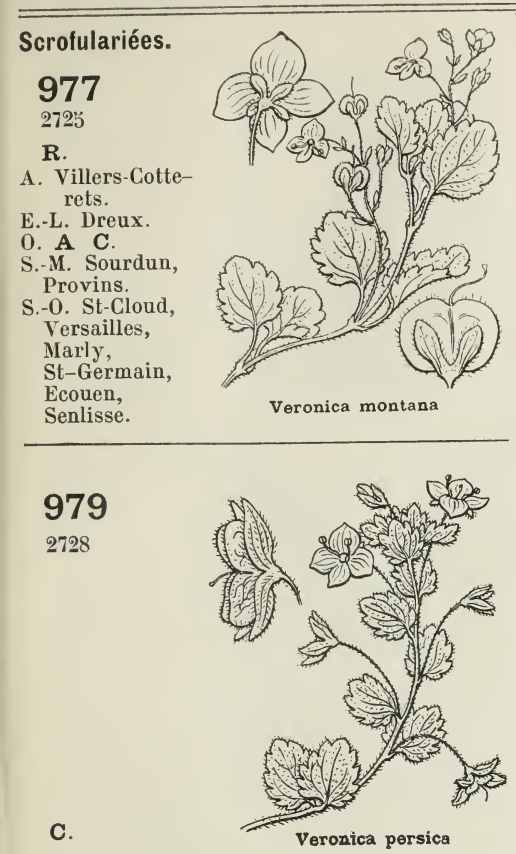

A. C.
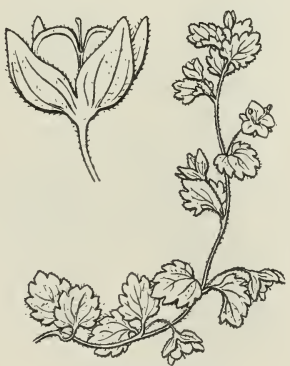

Veronica polita

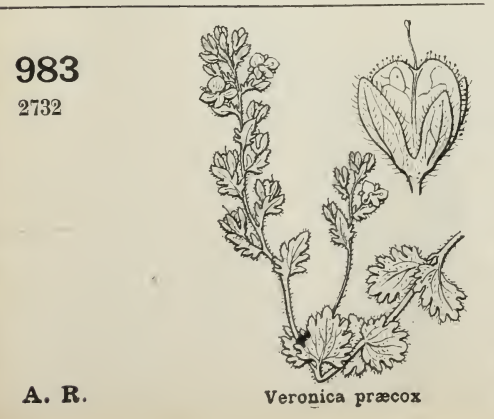

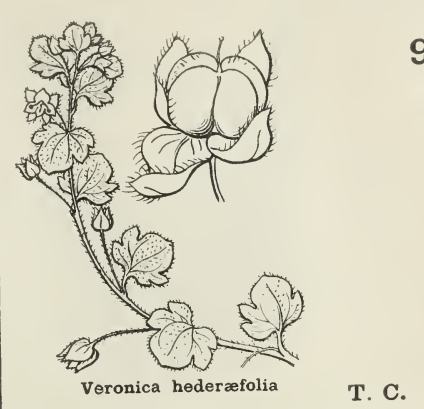

978

2726
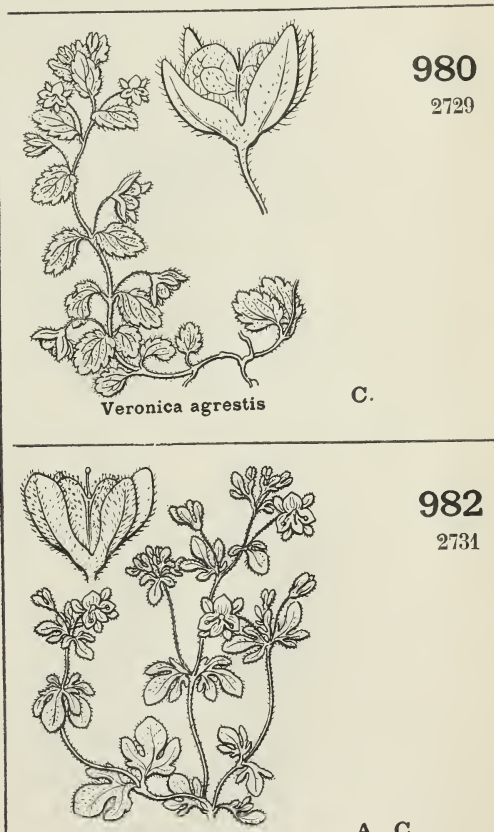

Veronica triphyllos

982

2731

A. C.

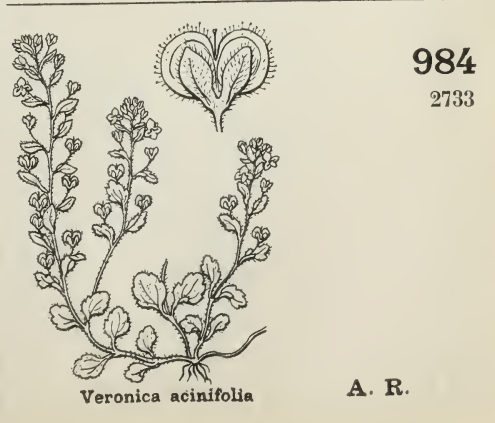



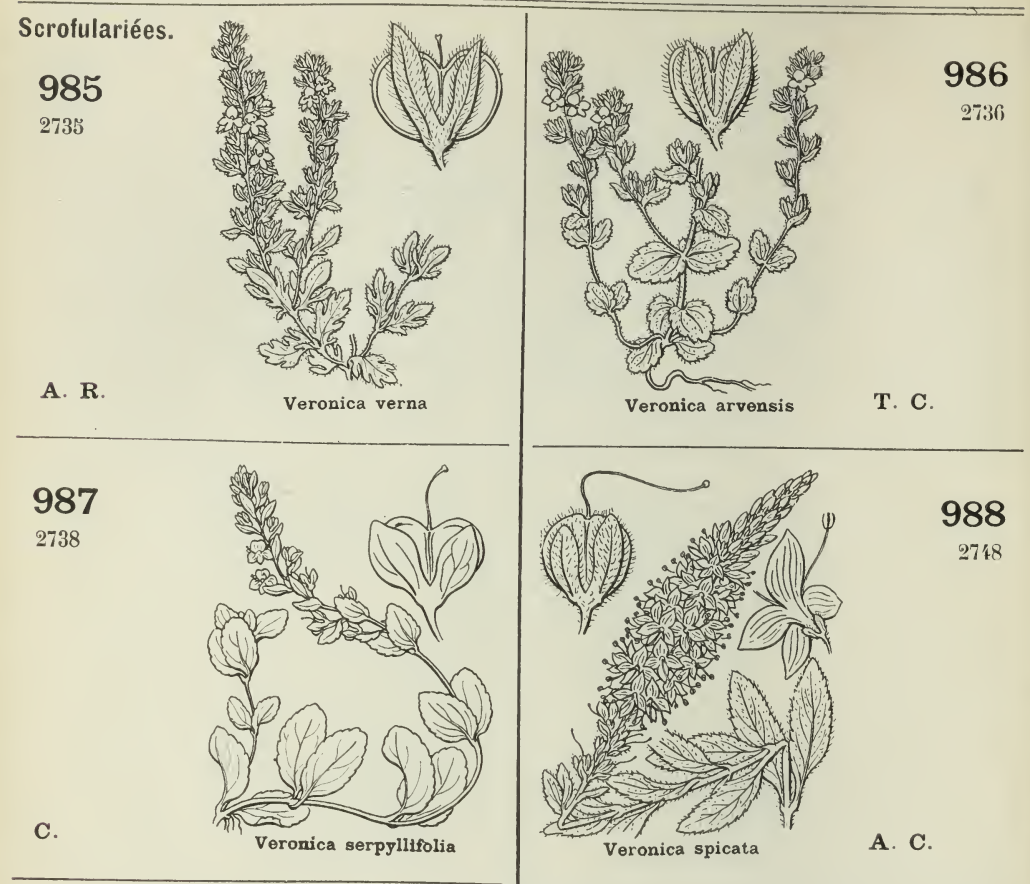

988

2718
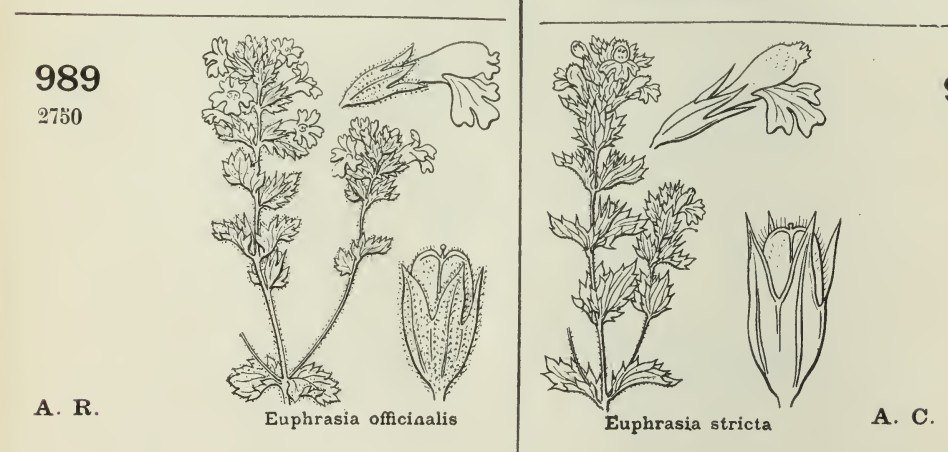

A. C.
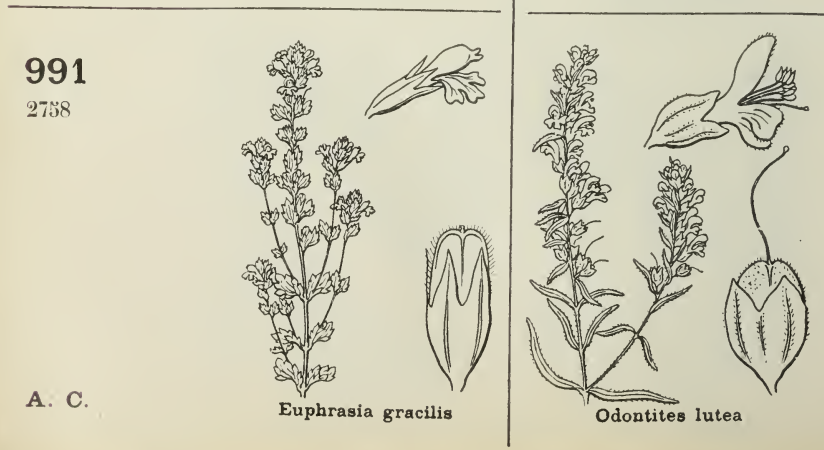

A. C.

T. $\mathbf{R}$.

A. Corcy.

0. Orrouy, Compiègne, Liancourt, Roherval. 

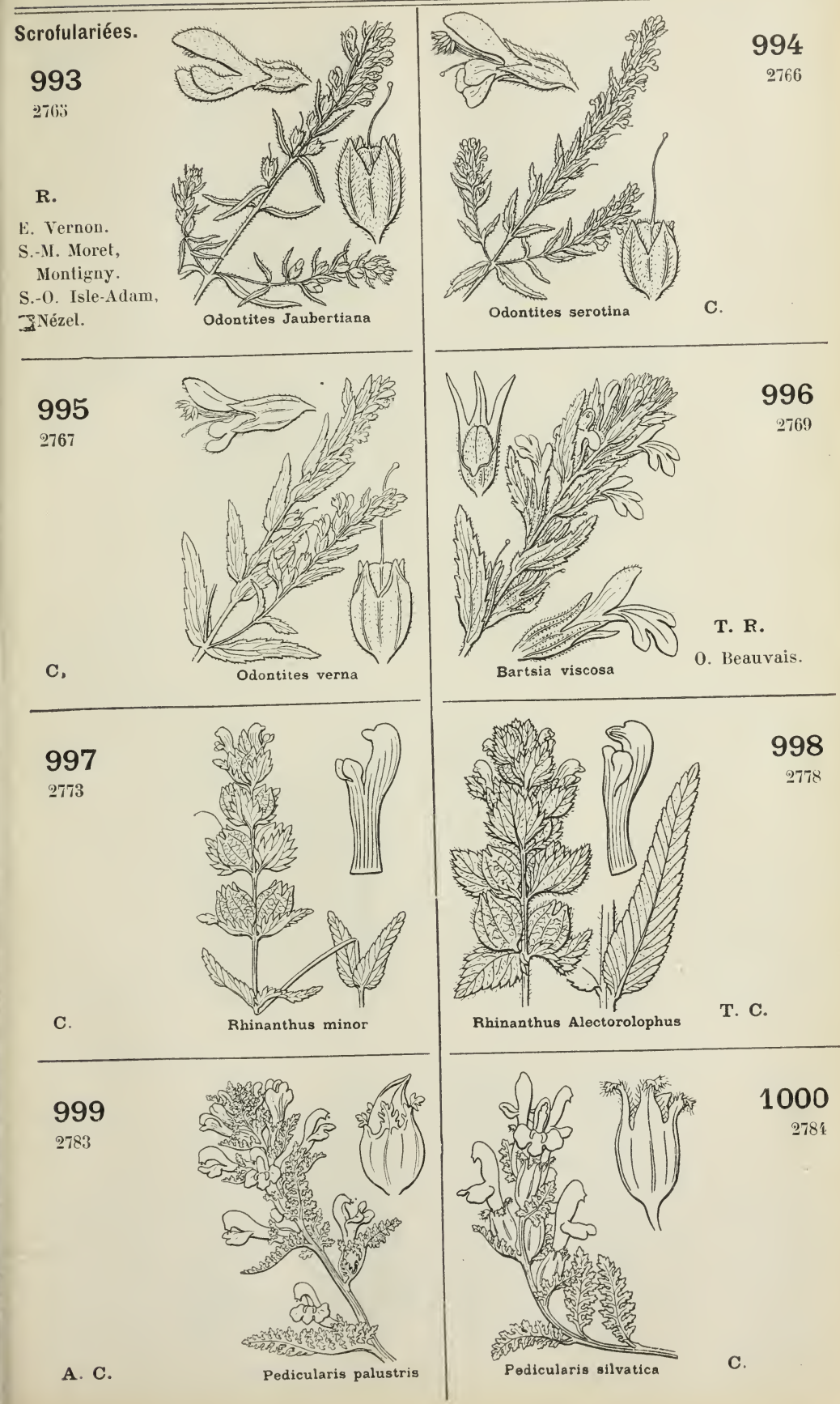
126 FAM. 68 (81). SGROFULARIÉES - FAM. 69 (83). OROBANGHÉES
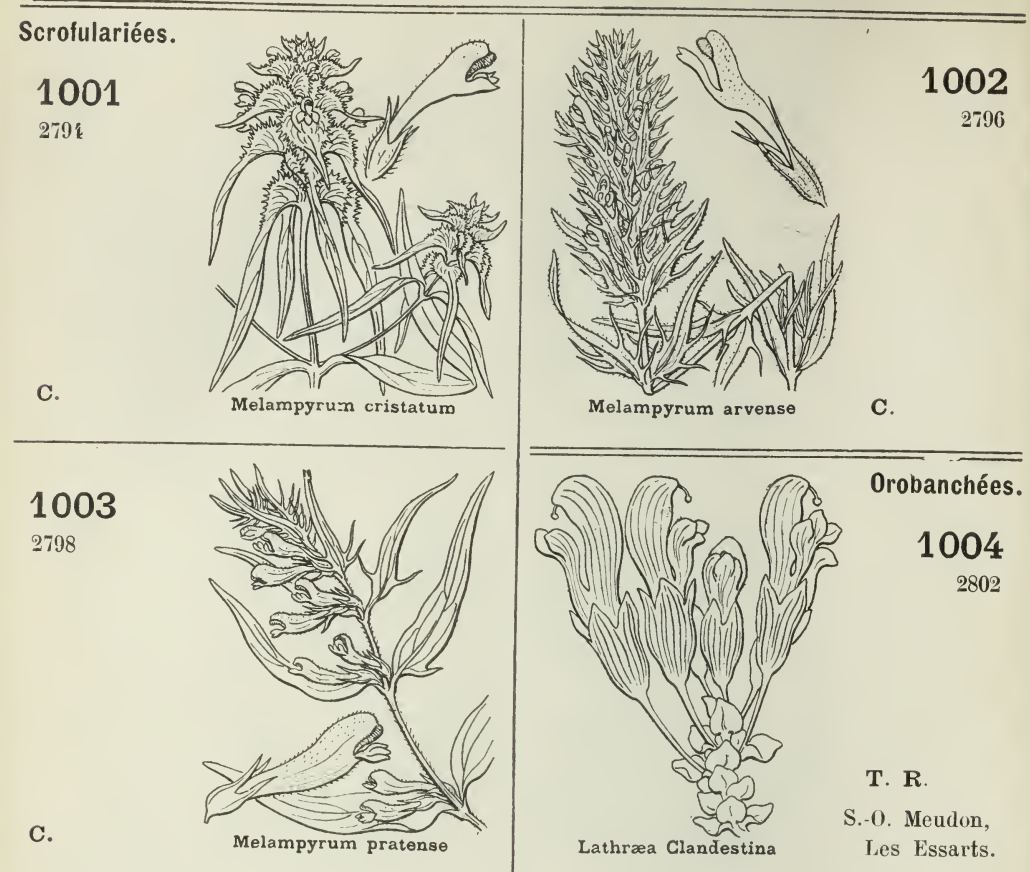

$=$

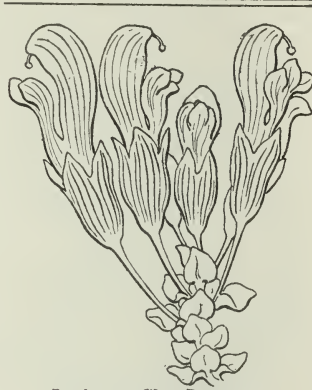

Lathræa Clandestina

Orobanchées.

1004

2802

T. R.

S.-0. Meudon,

Les Essarts.

\section{5}

2803

T. R.

A. Chézy.

M. Villeneuve-laLionne.

0. St-Deniscourt, Formerie.

S.-M. La Ferté-

s.-Jouarre.
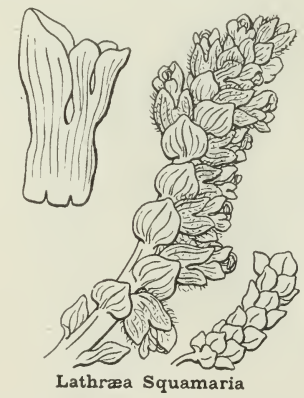

\section{7}

2808

R.

E. Les Andelys. 0 . Chaumont, Clermont.

S.-M. Nemours, Champagne.

S.-0. Mantes, La RocheGuyon, Chamarande, Louveciennes.

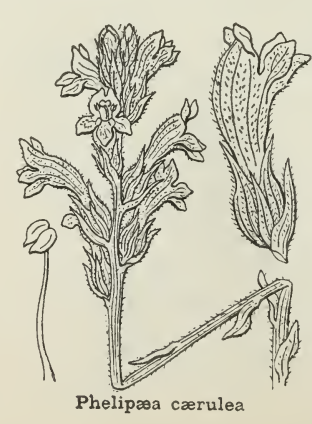

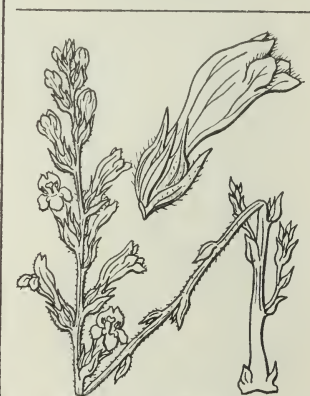

Phelipæa ramosa

1006

2804

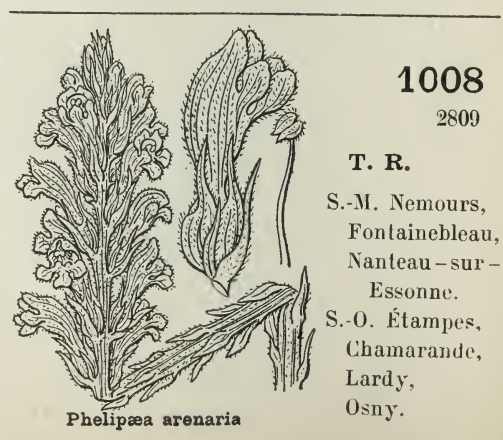



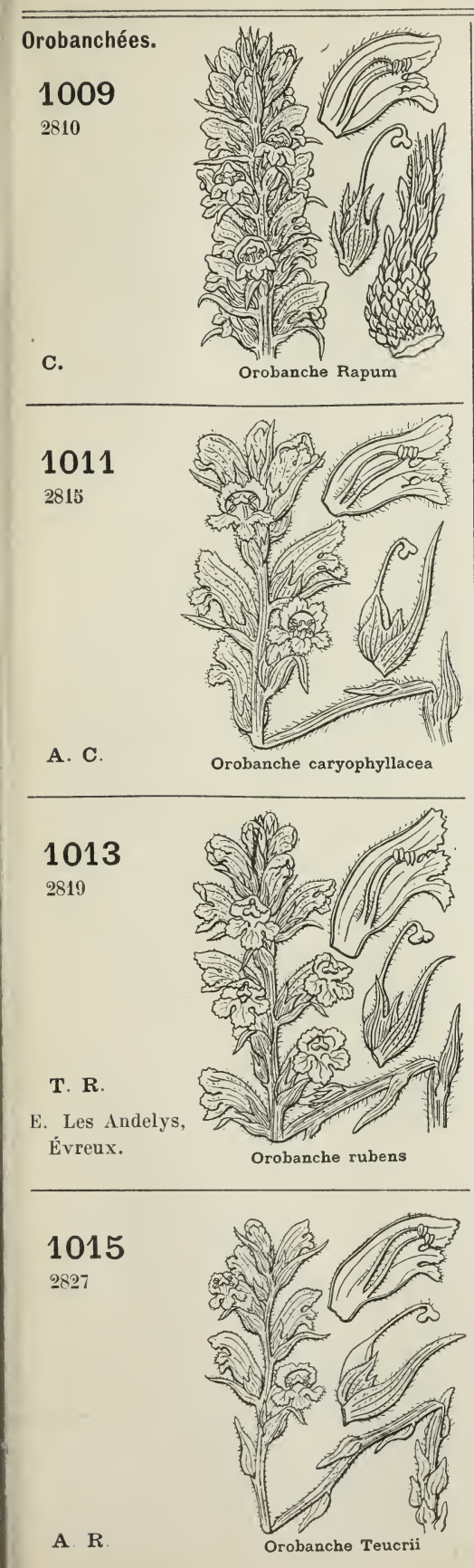
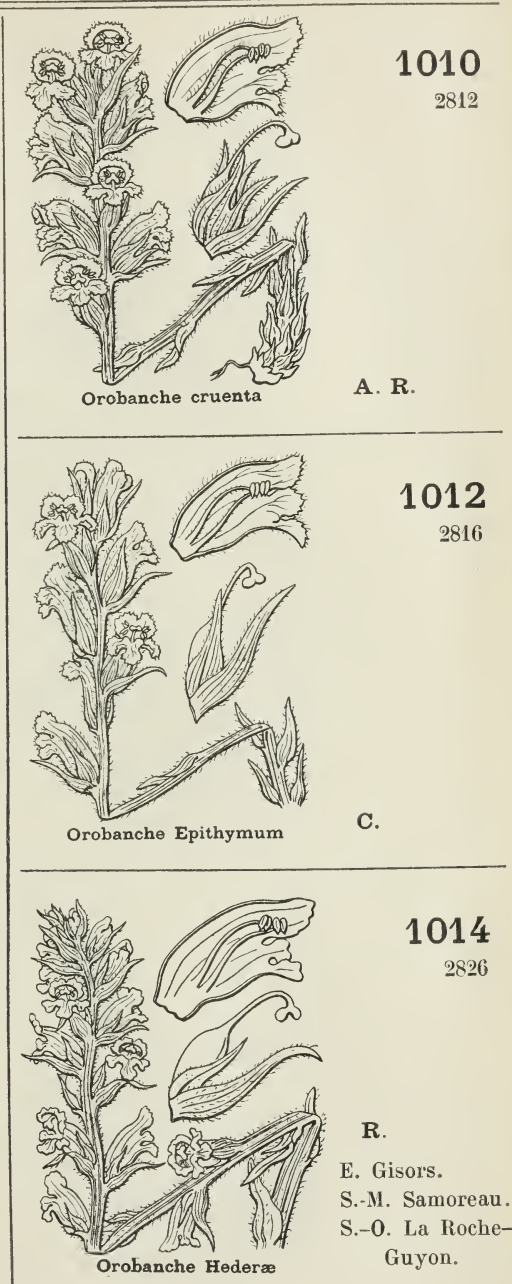

1014

2826

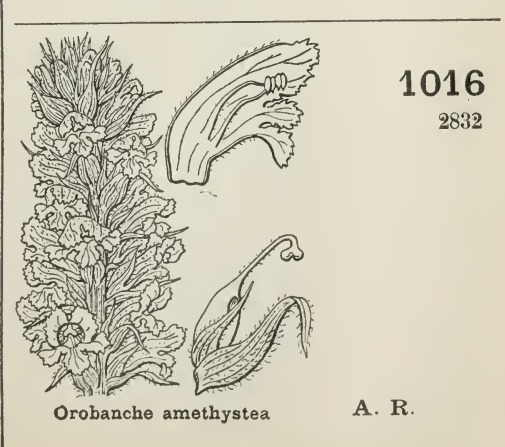


128 FAM. 69 (83). OROBANCHÉES - FAM. 70 (84). LABIÉES
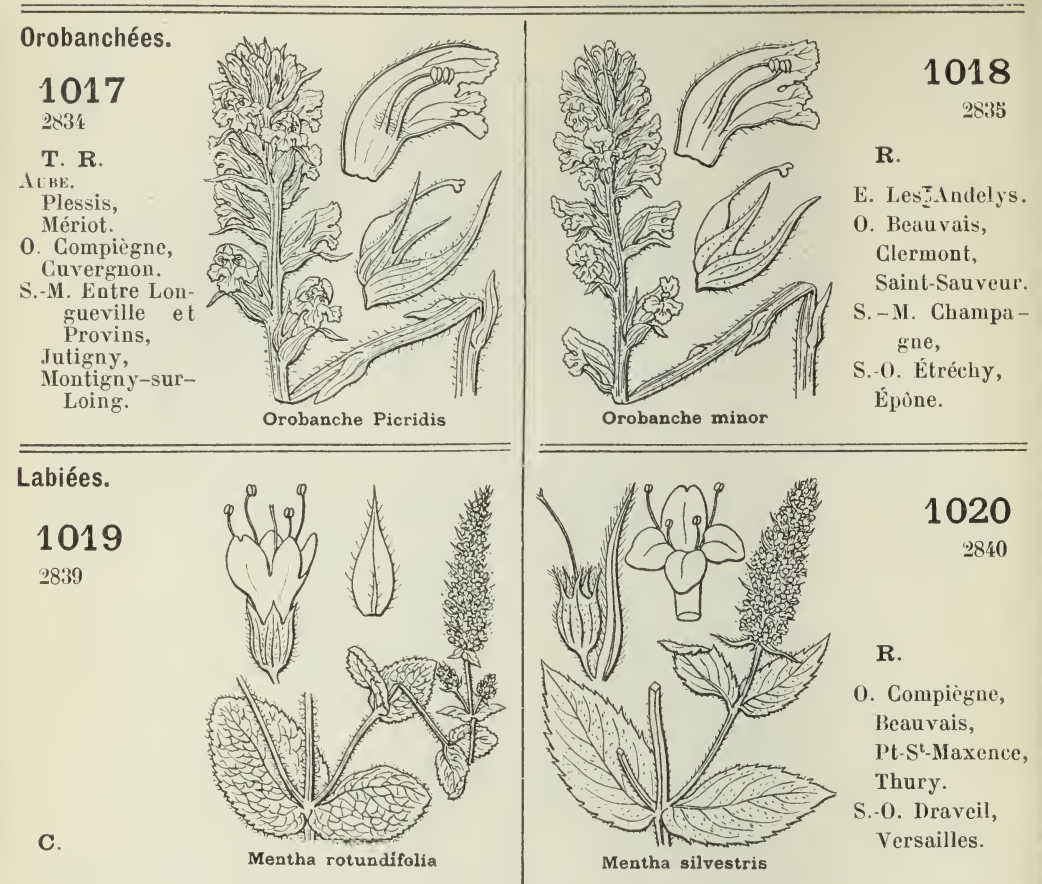

1020
2840
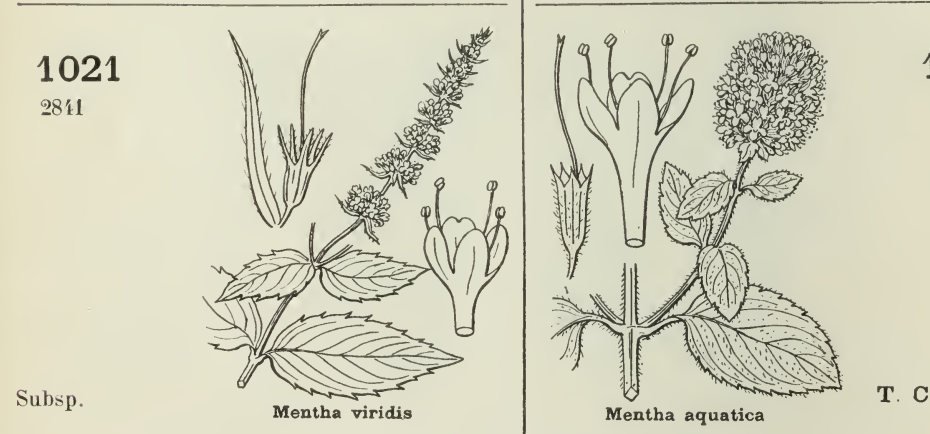

1022

2842

R.

0. Compiègne, Beauvais,

Pt-St-Maxence,

Thury.

S.-0. Draveil,

Versailles.


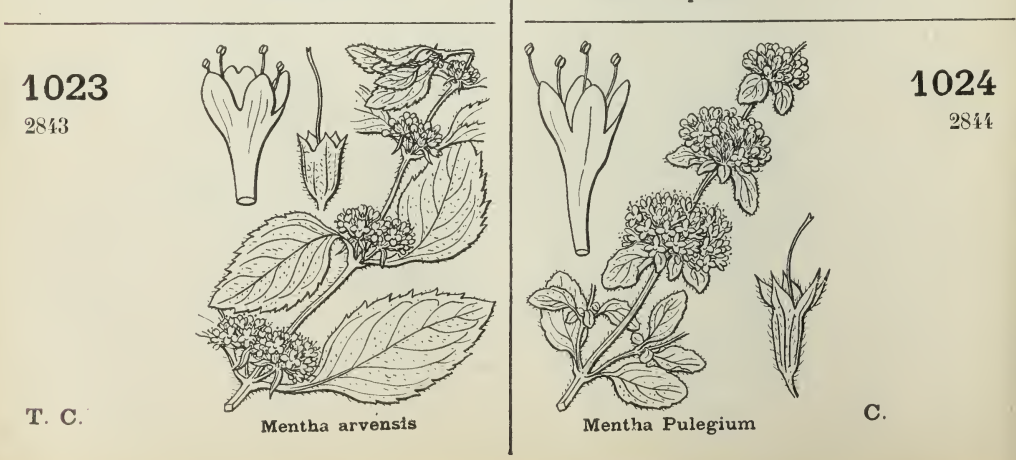


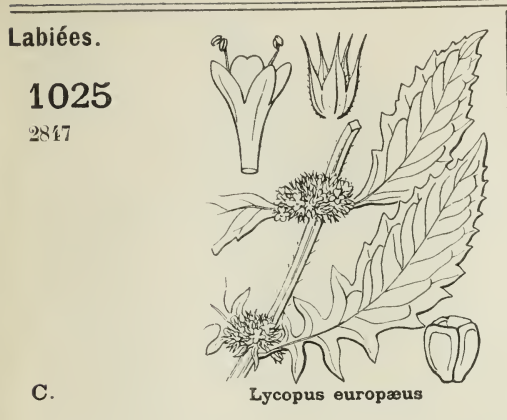

Cultivé.

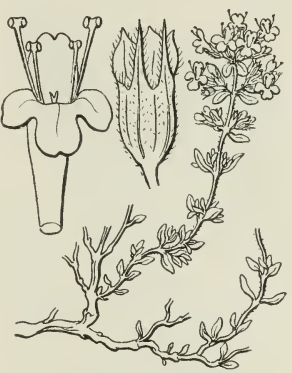

Thymus vulgaris
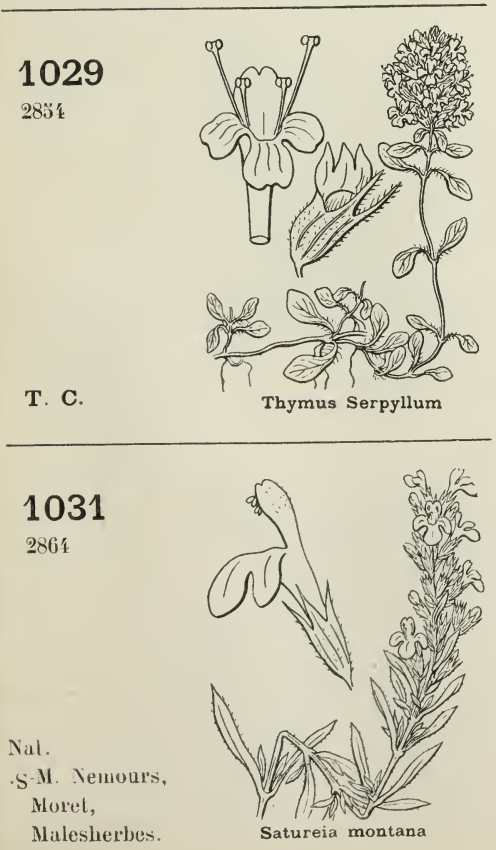

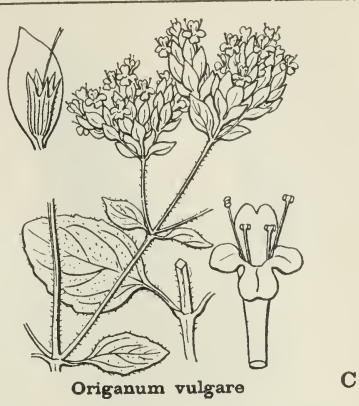

1026

2848

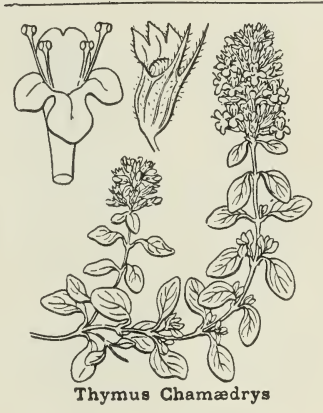

C.

2853

A. C.
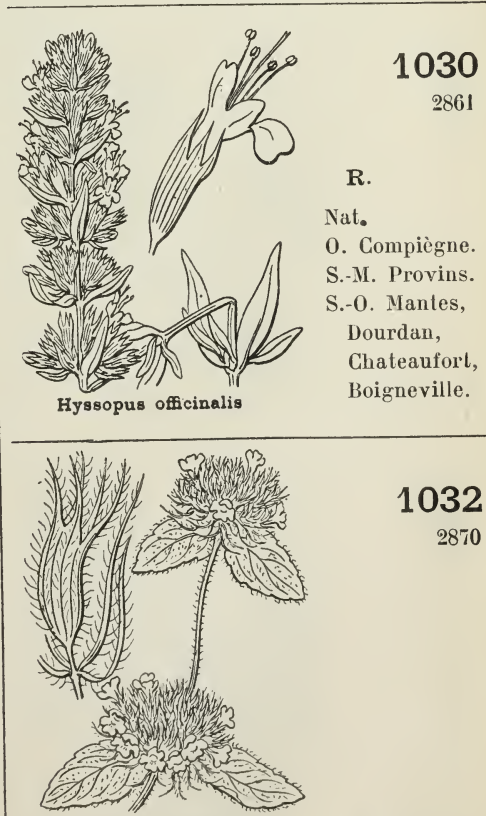

Calamintha Glinopodium

1032

2870 

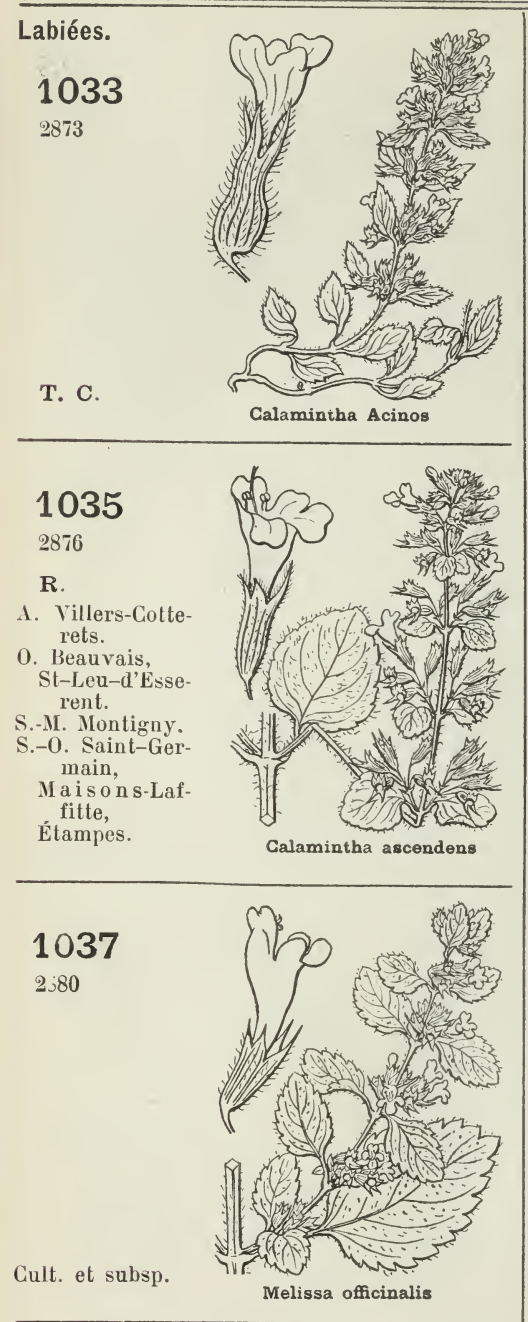

1039 2808

A. $\mathrm{R}$.

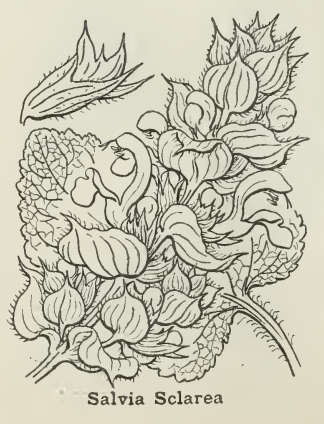

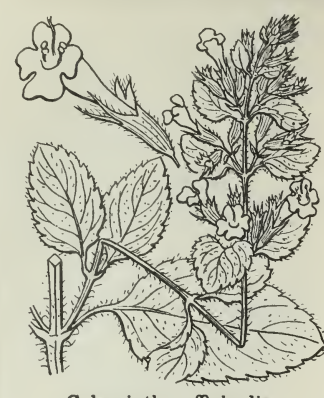

1034

2873

C.

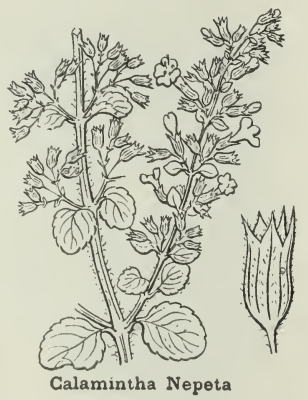

1036

2878

R.

A. Villers-Cotterets.

o. Senlis,

Chantilly,

Compiègne.

S. - M. La Fertésous-Jouarre. S.-0. Lieusaint, Chatou.

1038

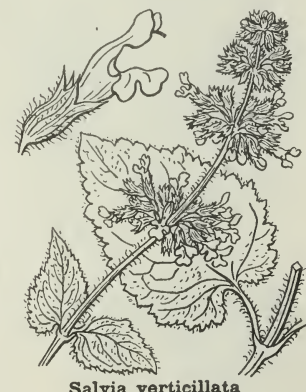

Nat.

o. Chantilly, Gare de Crépy. S. Arcueil. S.-0. Sevran.

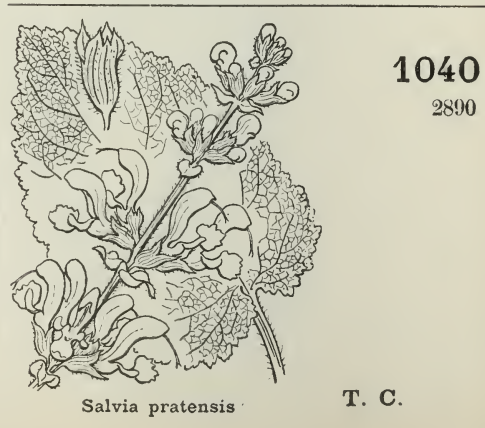



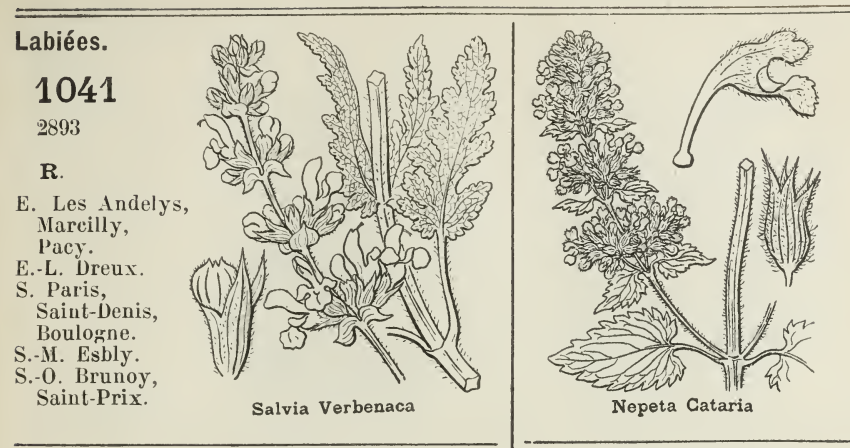

1042

2897

A. C.

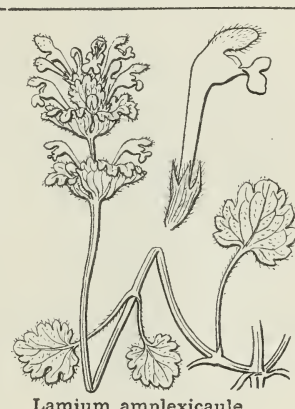

1044

2903

T. C.

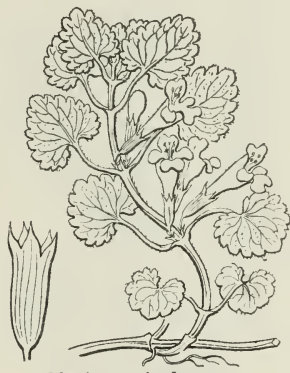

Glechoma hederacea

1045

2901

T. C.

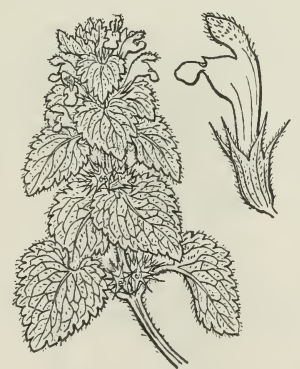

Lamium purpureum

\section{7}

2909

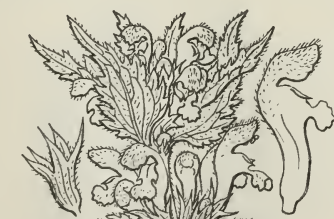

T. R.

ᄀ. Saint-Maur.

S.-0. Mignaux

près Poissy,

Mantes,

Montgeron.

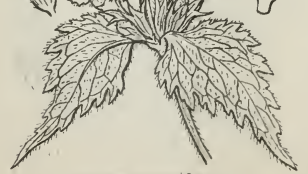

Lamium maculatum
Lamium amplexicaule

T. C.!

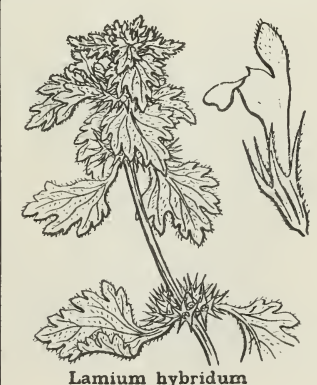

1046

2905

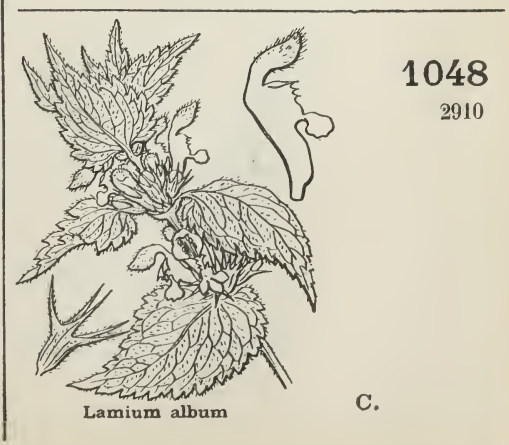



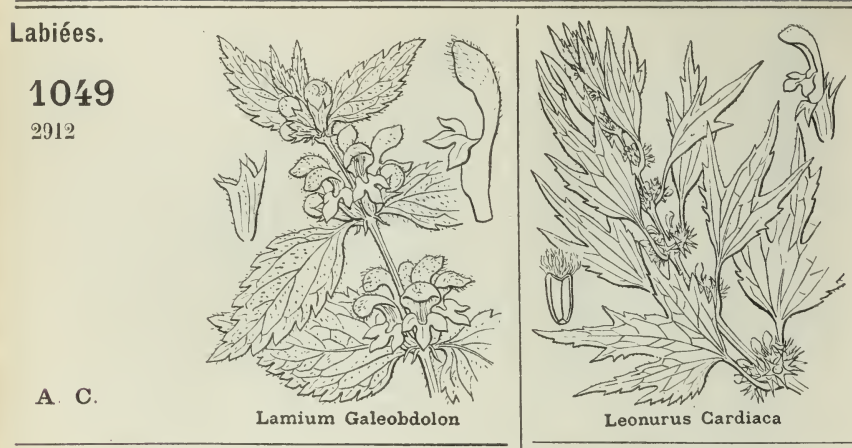

1050

2913
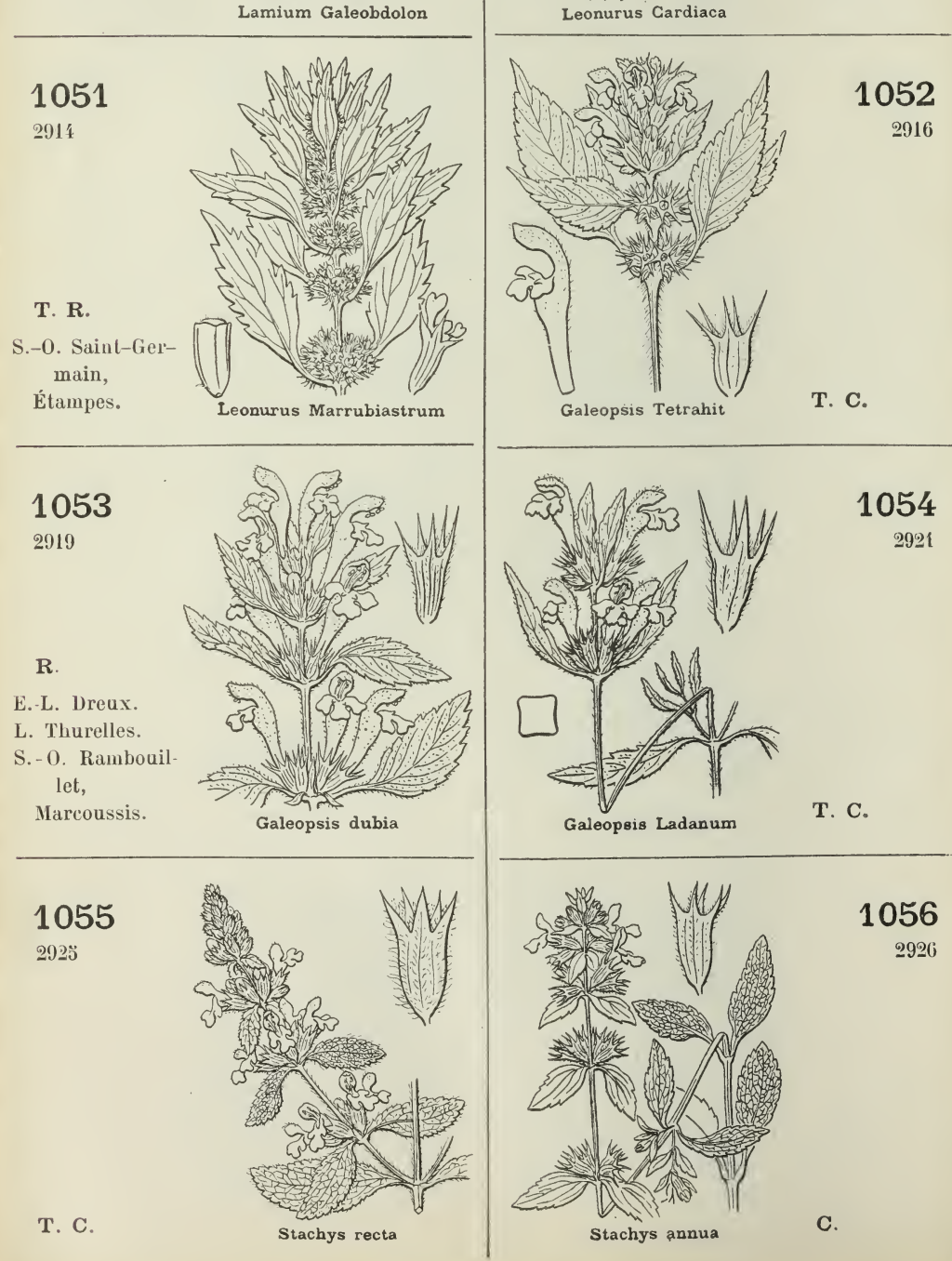

1056

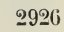


FAM. 70 (8î)。 - LABIÉES
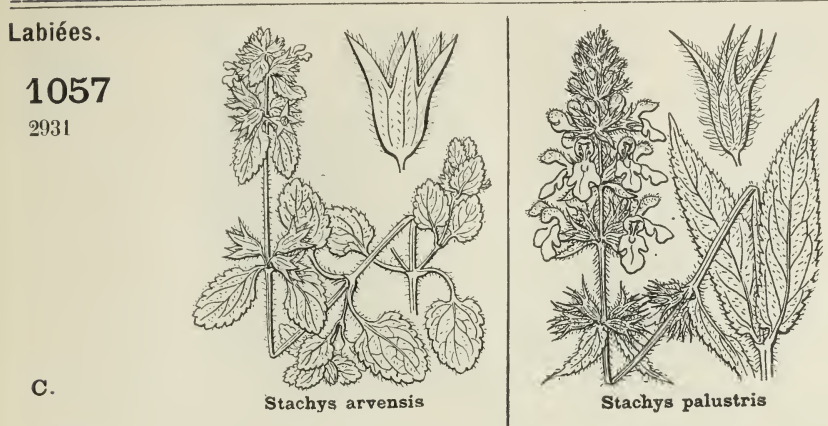

1058

2932
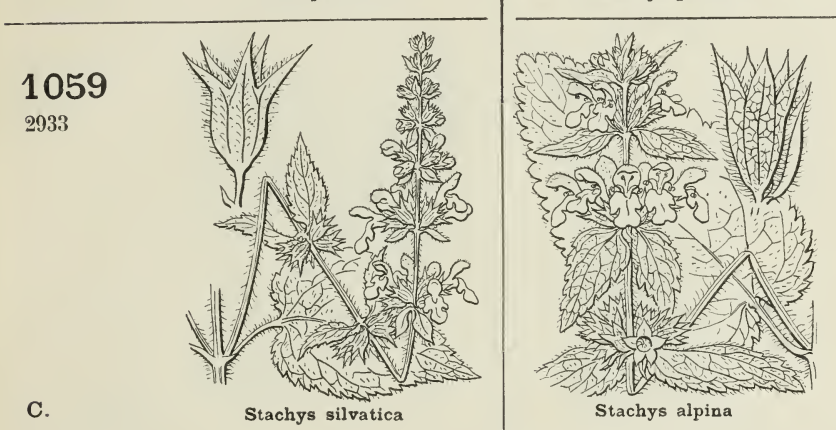

c.
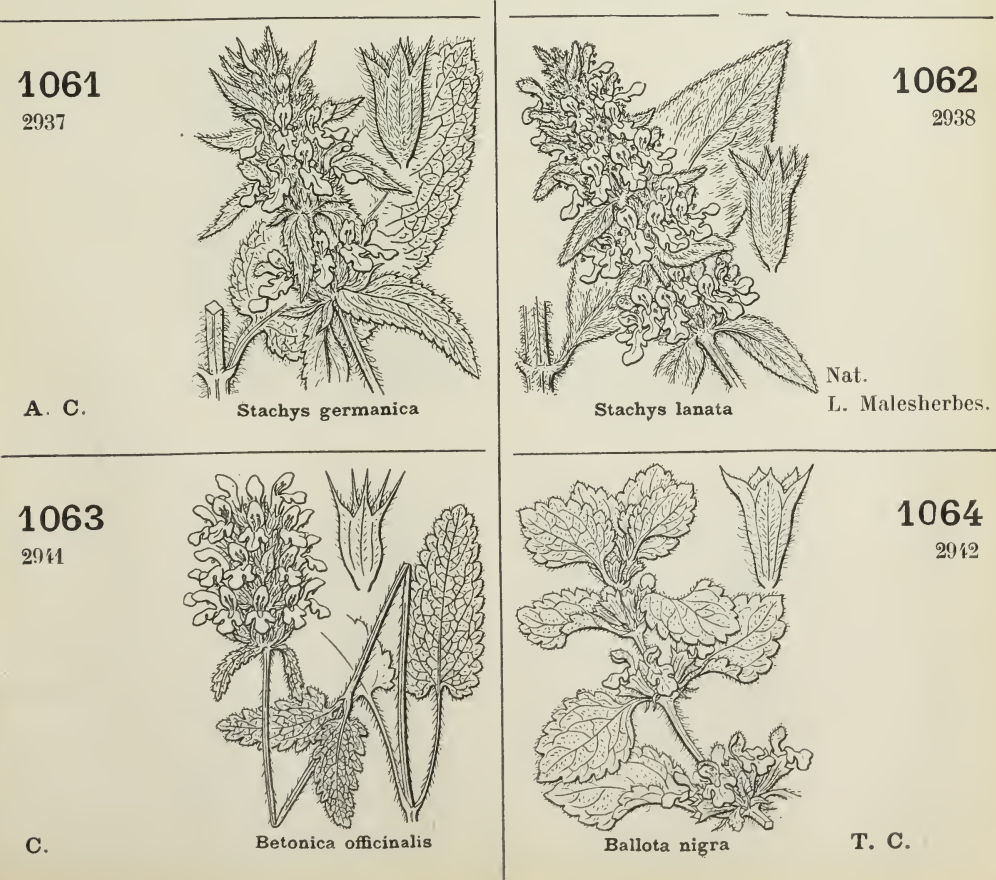


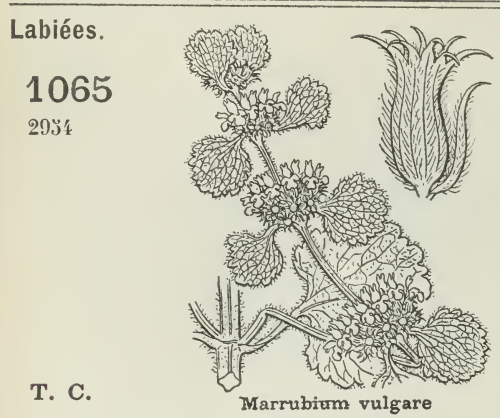

C.

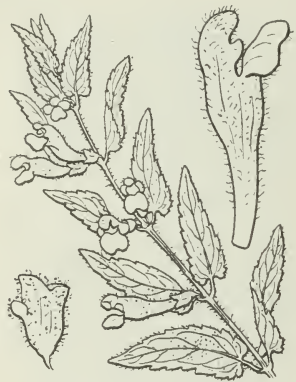

Scutellaria galericulata

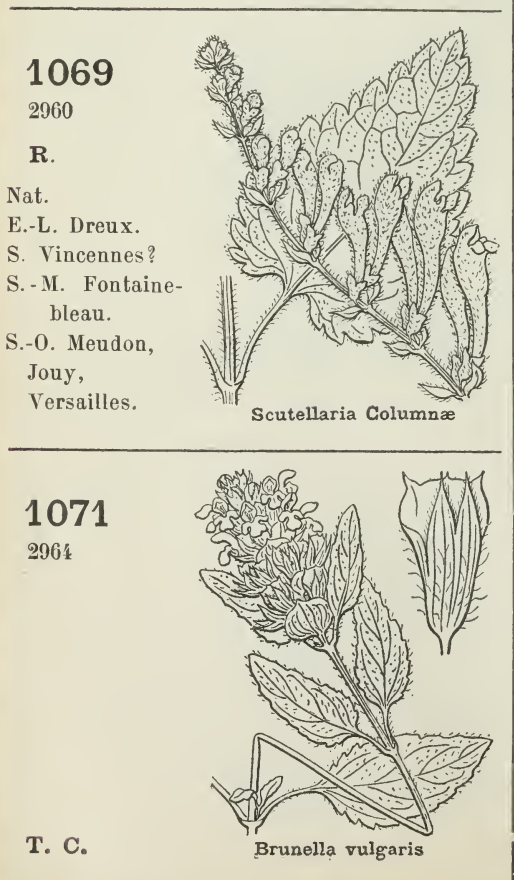

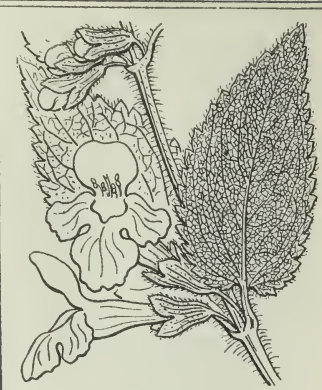

Melittis Melissophyllum

c.

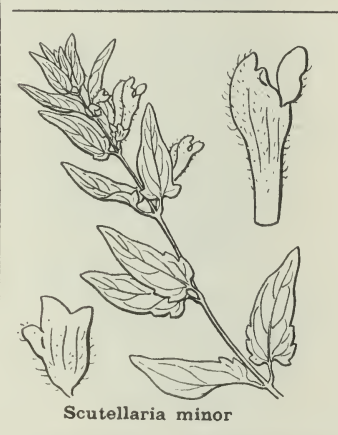

1068

2958

1066

2936

A. $\mathbf{R}$.

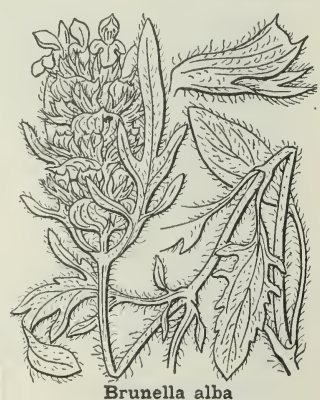

1070

2963

A. C.

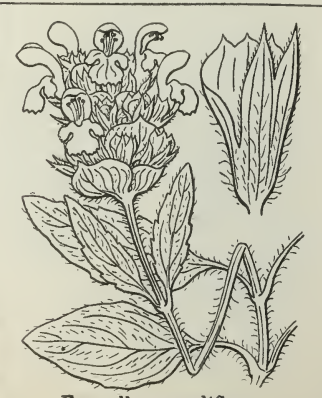

1072

290 sั
Brunella grandiflora
A. $\mathbf{R}$. 


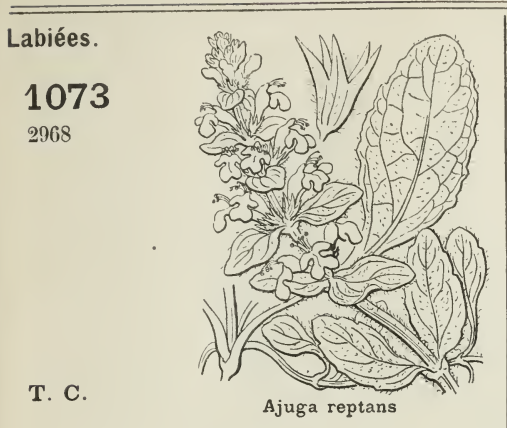

c.

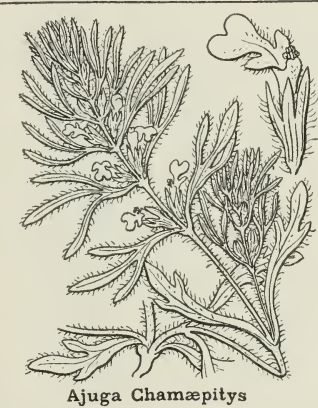

\section{7}

2973

A. C.
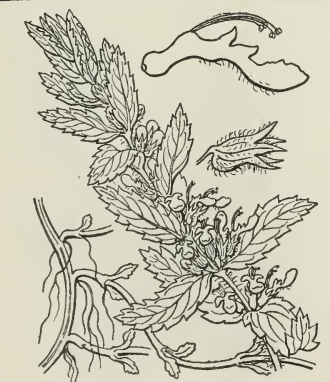

Teucrium Scordium
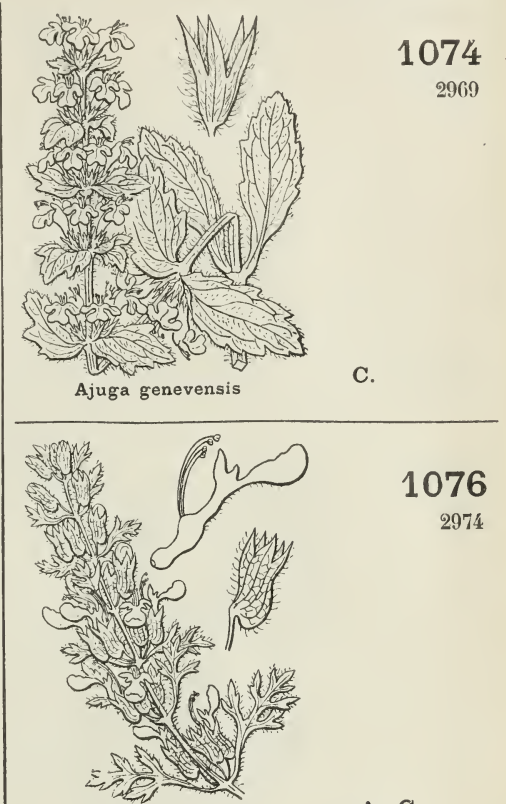

1076

2974

A. C.

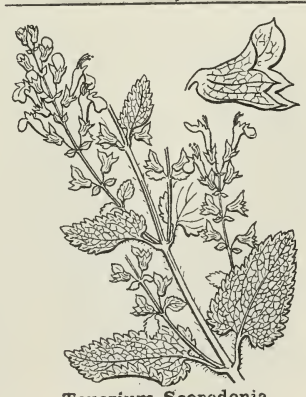

Teucrium Scorodonia

T. C.

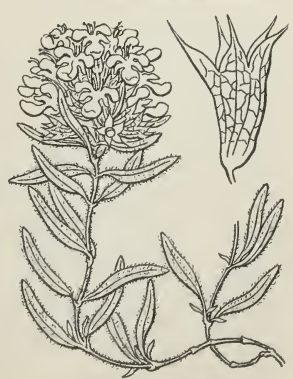

Teucrium montanum

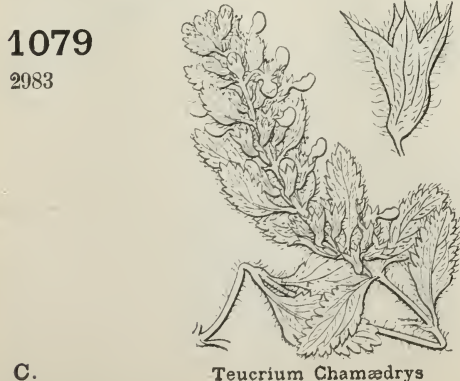


FAM. 71 (8ï). VERBÉNAGÉES - FAM. 72 (86). PLANTAGINÉES FAM. 73 (87). PLOMBAGINÉES
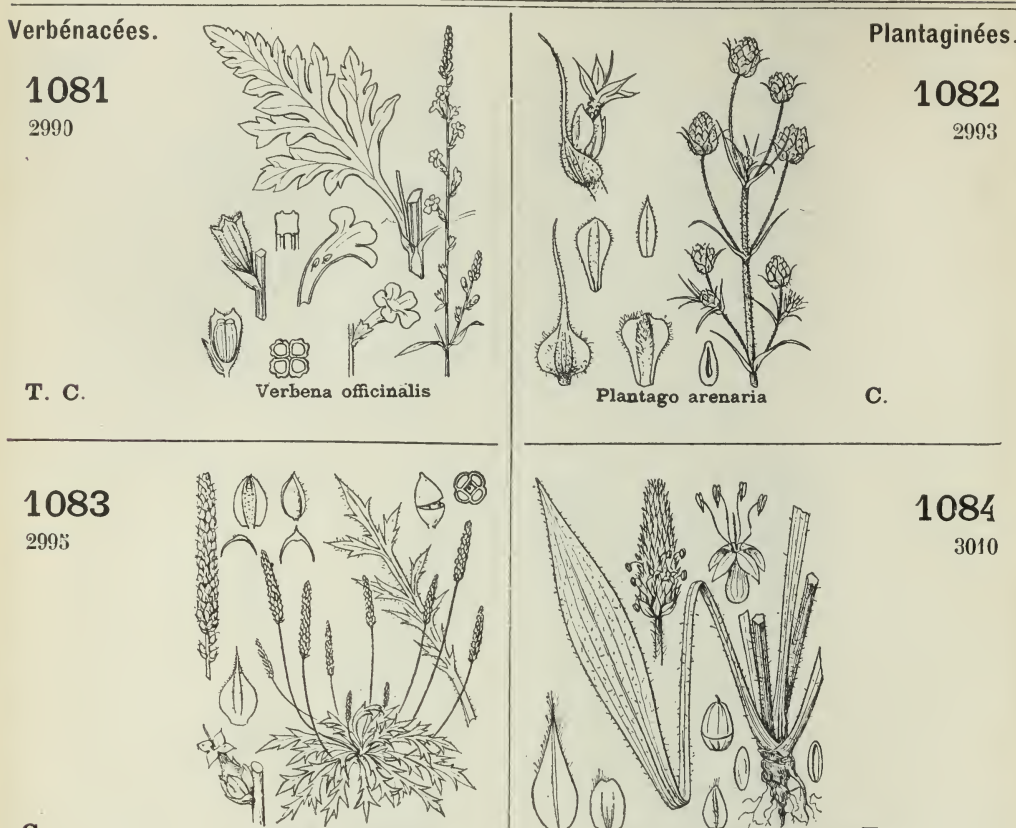

C.

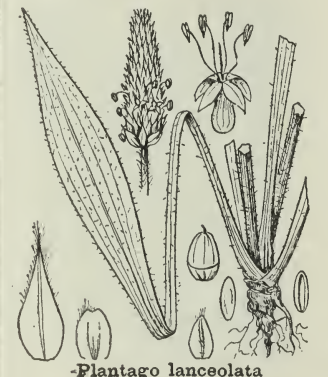

1084

3010
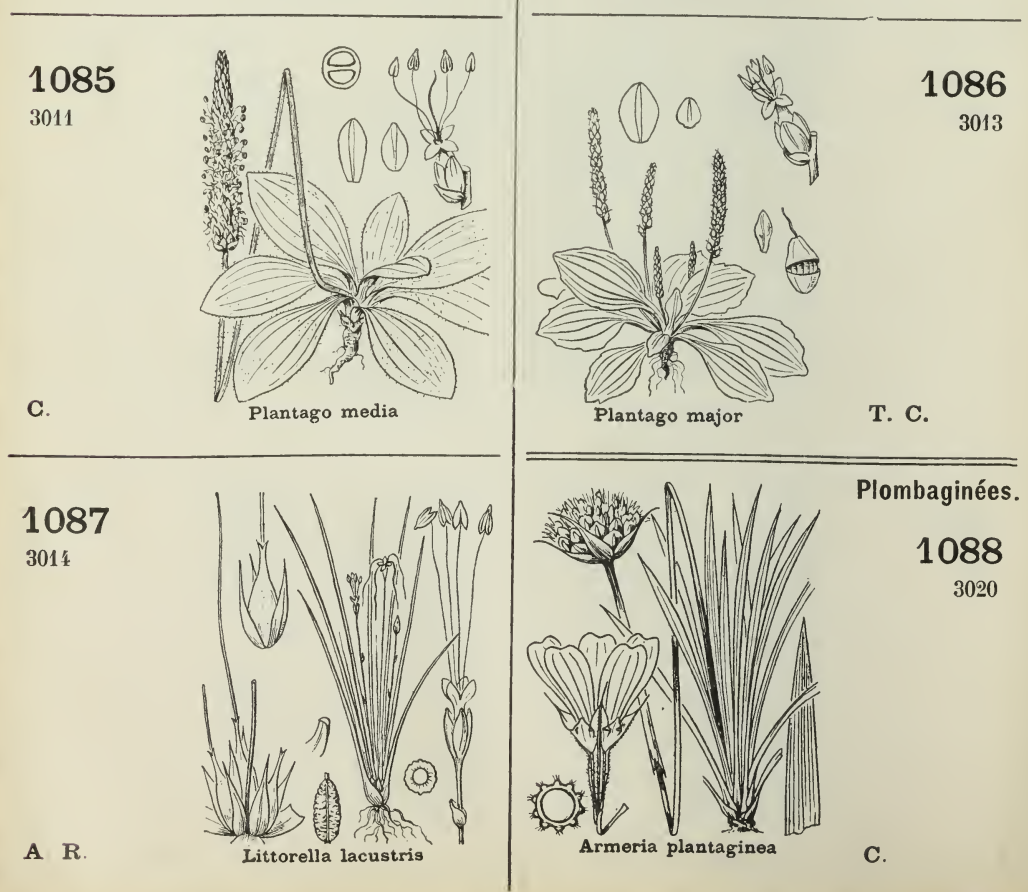
Fam. 74. GLOBULARIÉES - Fam. 75. SALSOLACÉES 137
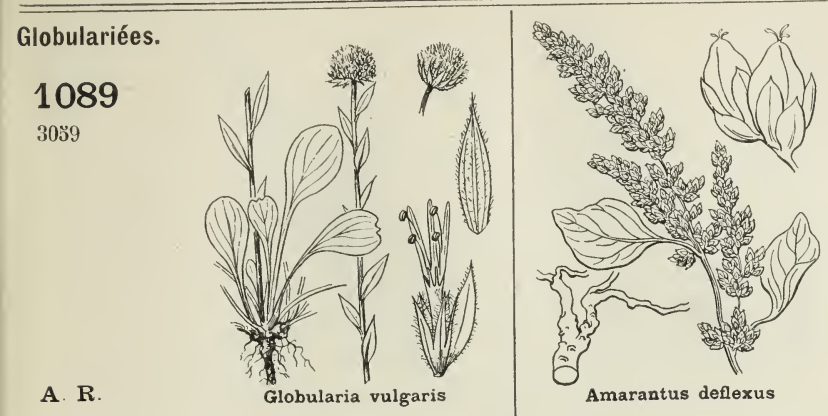

Salsolacées.

1090

3061
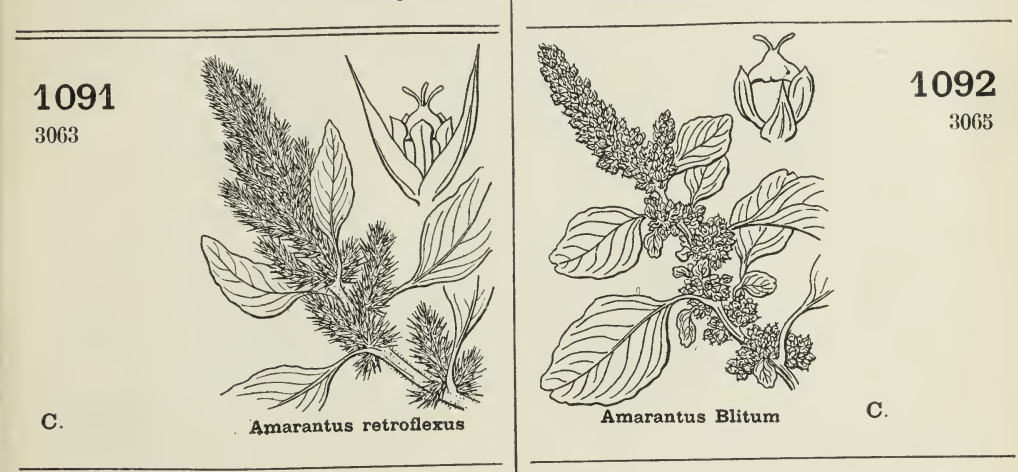

Paris

S. 0 . Versailles

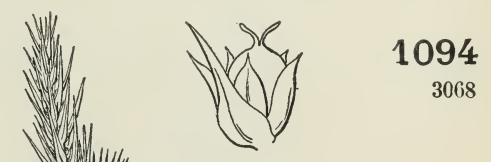

\section{3}

3066

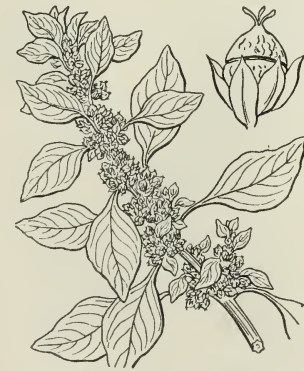

C

Amarantus silvestris

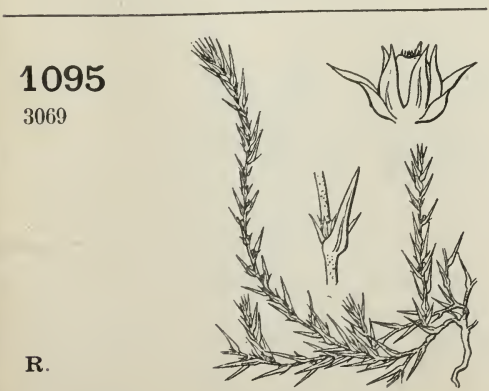

S. 0. Corbeil.

Polycnemum arvense

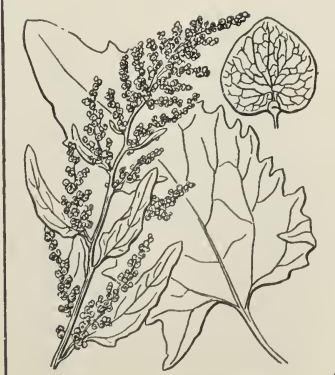

Atriplex hortensis
1096

3076 

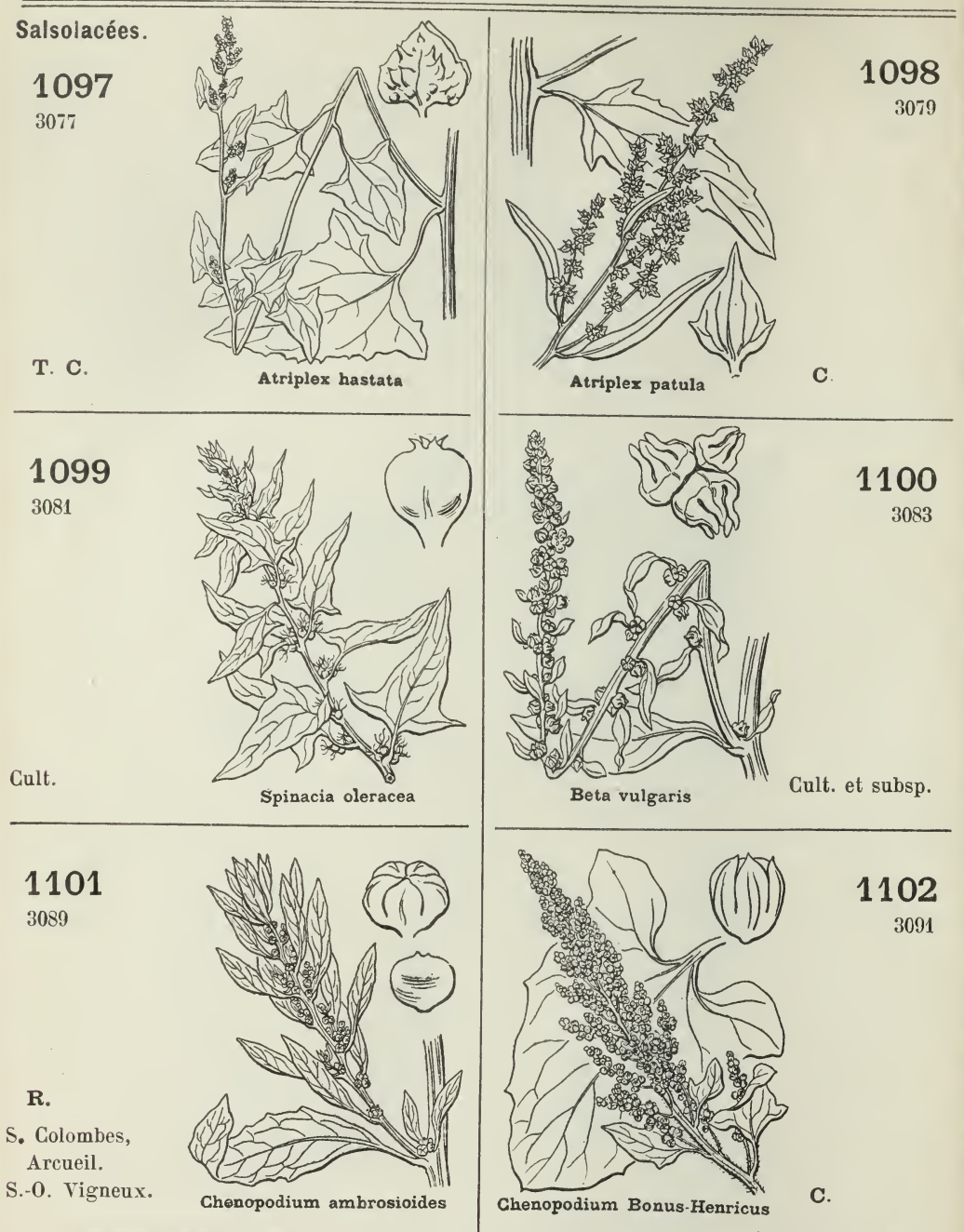

1102

3091

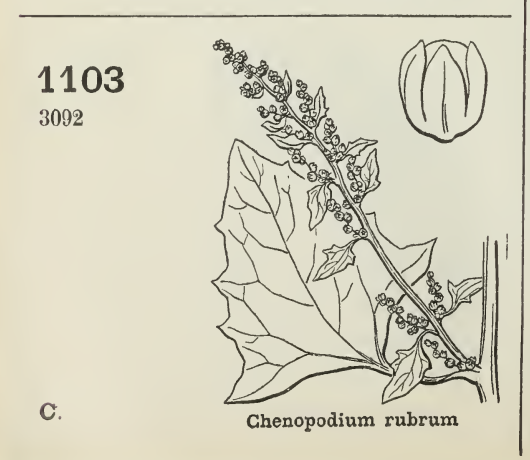

c.

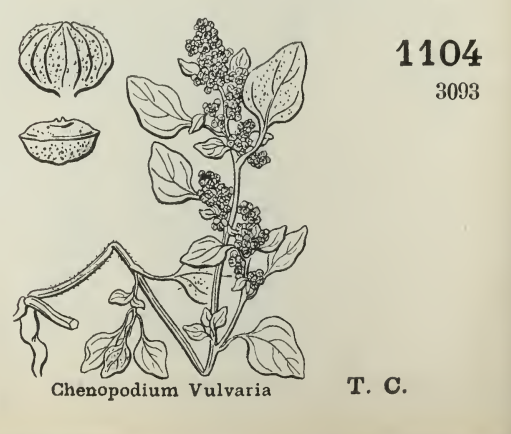


140 FAM. 75. SALSOLACÉES - FAM. 76. POLYGONEES
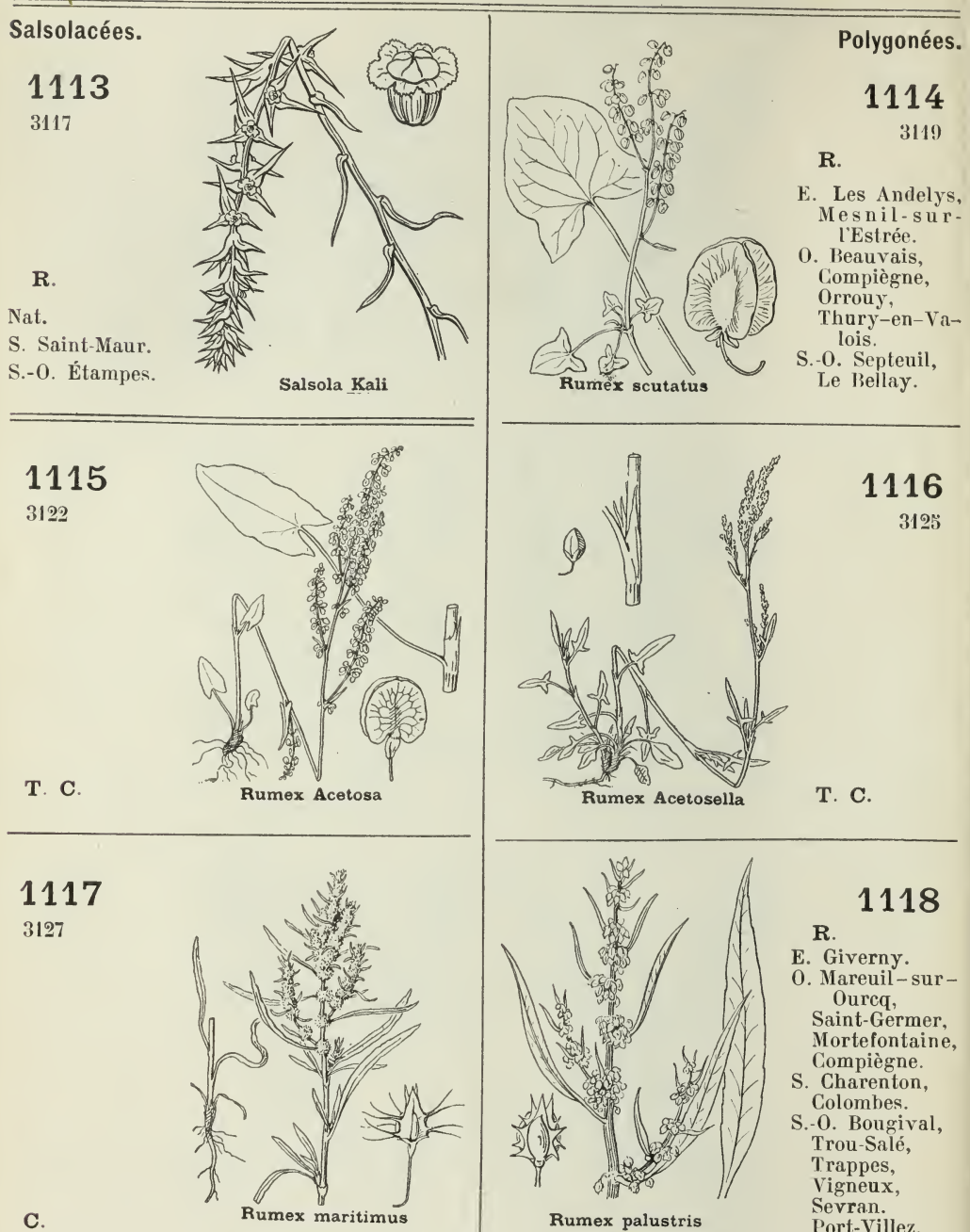

E. Giverny.

0. Mareuil-surOureq, Saint-Germer, Mortefontaine, Compiègne.

S. Charenton, Colombes.

S.-0. Bougival, Trou-Salé,

Trappes, Vigneux,

Sevran. Port-Villez,

1119

3128
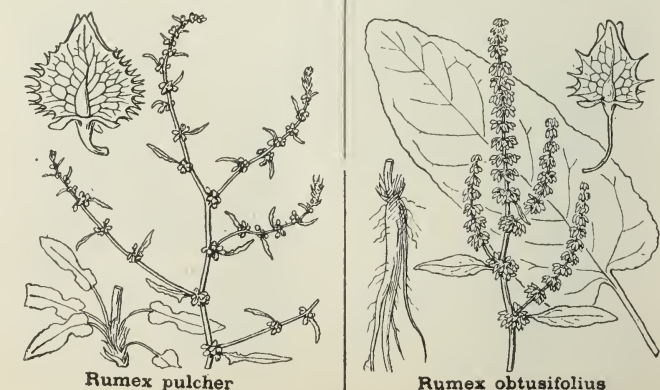

1120

3129

A. C.

Rumex pulcher

T. C. 


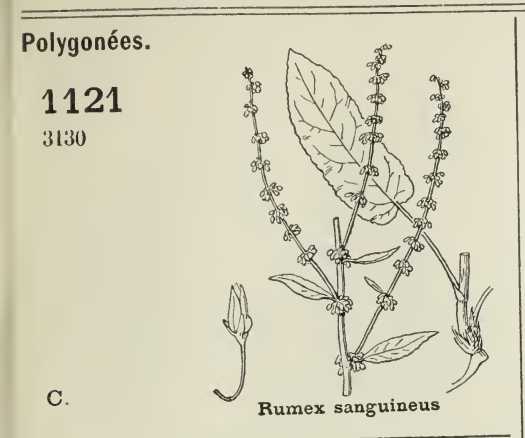

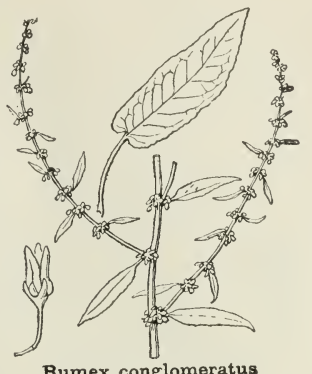

Rumex conglomeratus

T. C.

1122

3131

\section{3}

3133

T. C.

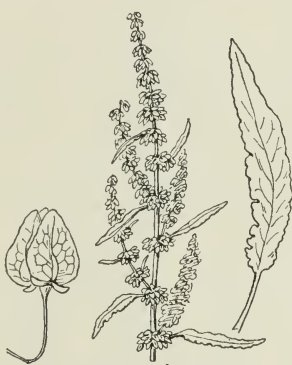

Rumex crispus

\section{5}

3133

C.

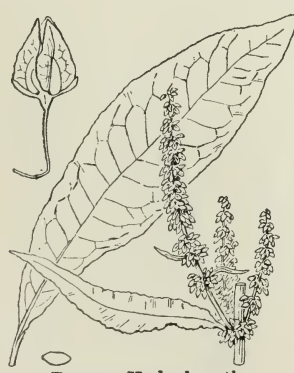

Rumex Hydrolapathum

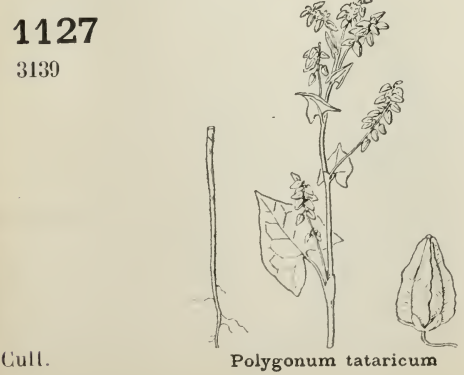

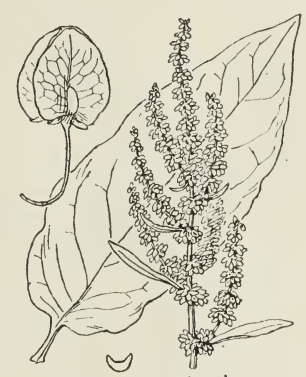

Rumex Patientia

Cult. et subsp.
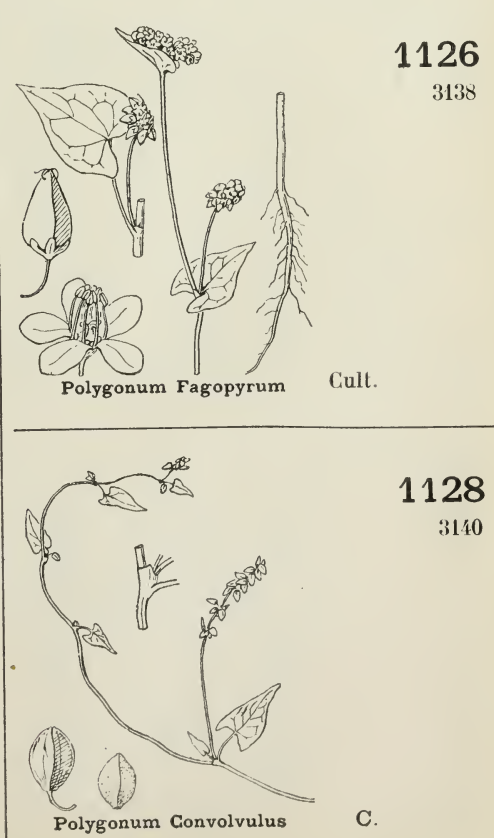


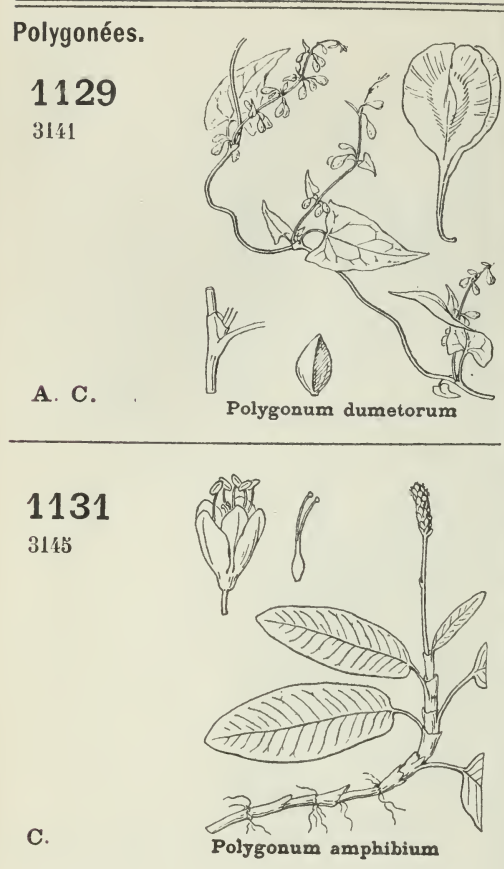

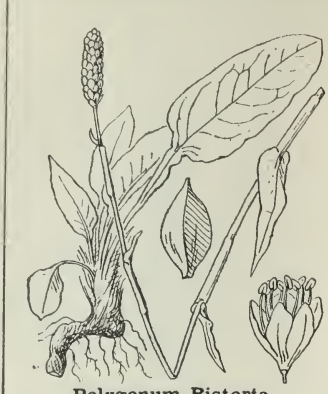

\section{0}

314 ' R.

E. Gisors.

0. Compiègne, Beauvais, Saint-Germer, Senlis, Ermenonville. S.-M. Combreux. Polygonum Bistorta

S.-0. Senlisse.

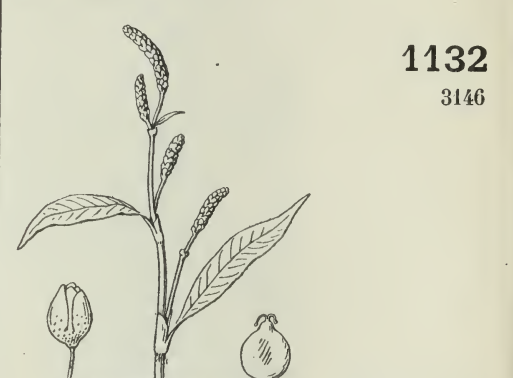

Polygonum lapathifolium T. C.

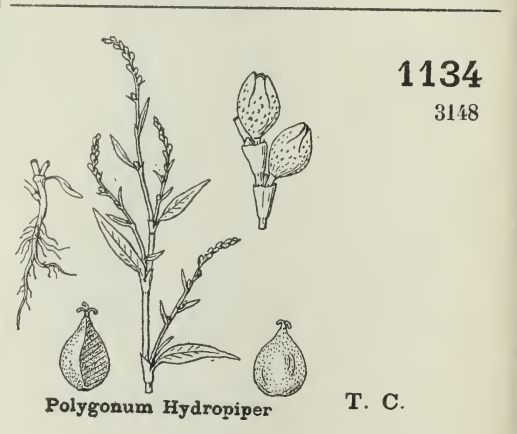

Polygonum Hydropiper T. C

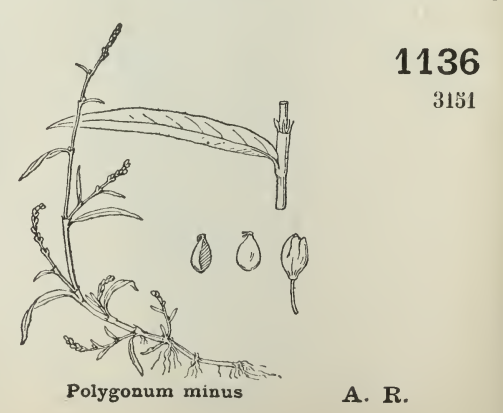

A. C.

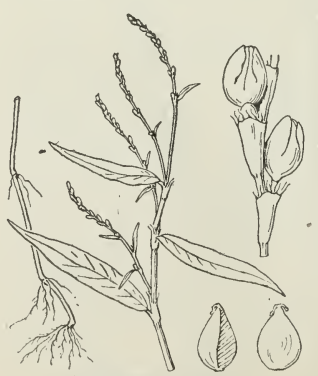

Polygonum mite

1135

3150

c.

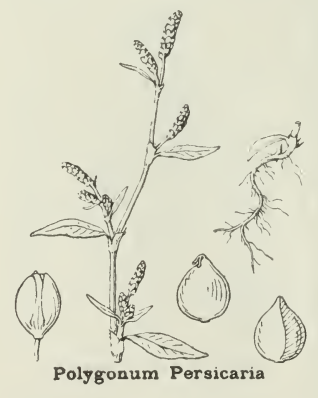


FAM. 76.' POLYGONEES - FAM. 77. DAPHNOIDEES

FAM. 78. SANTALACEES - FAM. 79. LORANTHACÉES
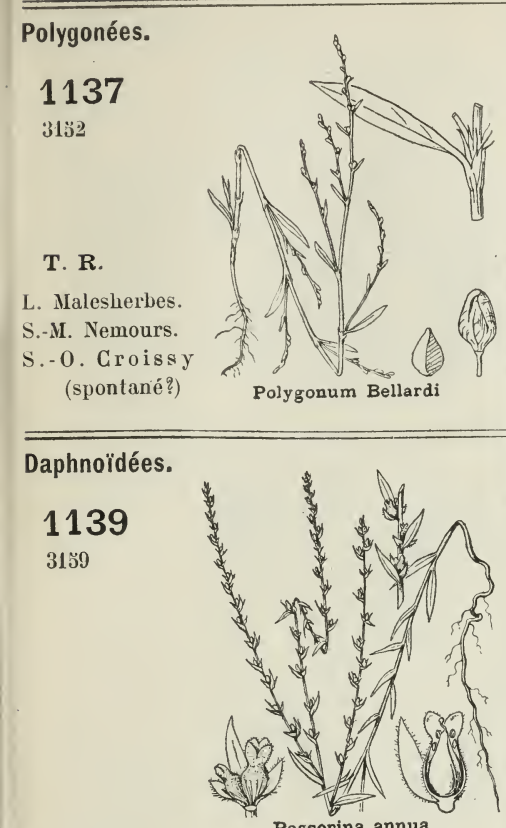

A. $\mathbf{R}$.

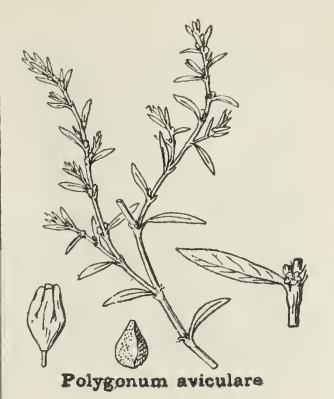

1138

3134

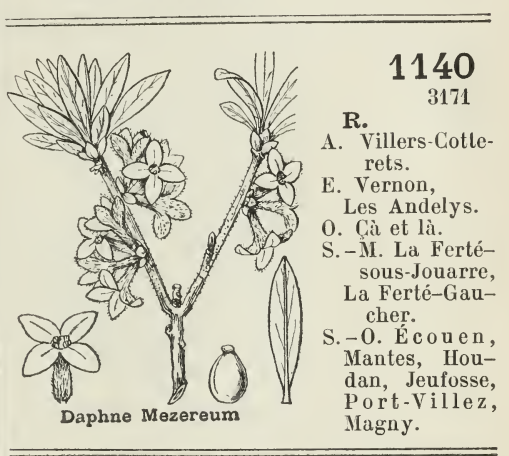

1141

3172

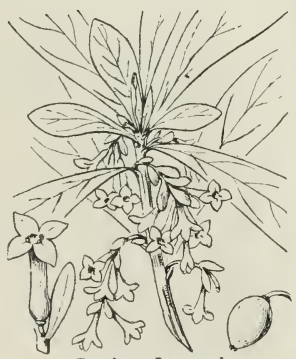

A. $\mathbf{R}$.

Daphne Laureola

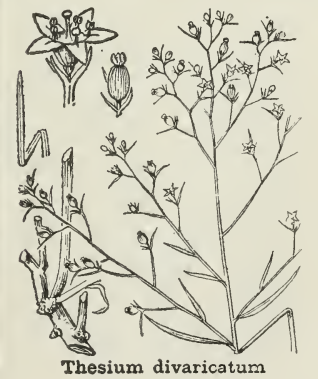

Santalacées.

1142

3179

R.

S. - M. Fontainebleau,

Nemours,

Moret.

S.-0. Saint-Germain.

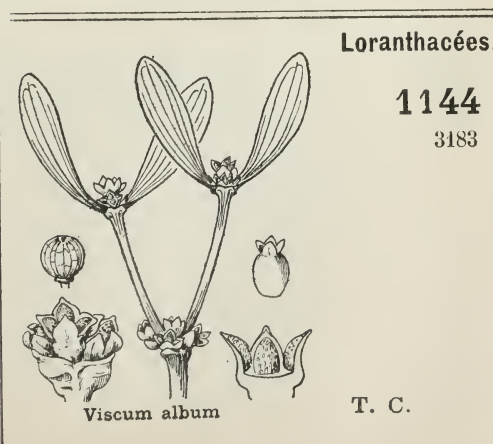

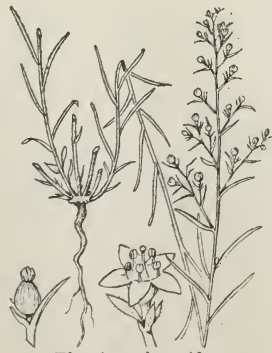

Thesium humifusum

A. C.

1143

3180 
FaM. 80. ÉLÉAGNÉES - Fam. 81. ARISTOLOCHIÉES 144 FAM. 82. EUPHORBIACÉES
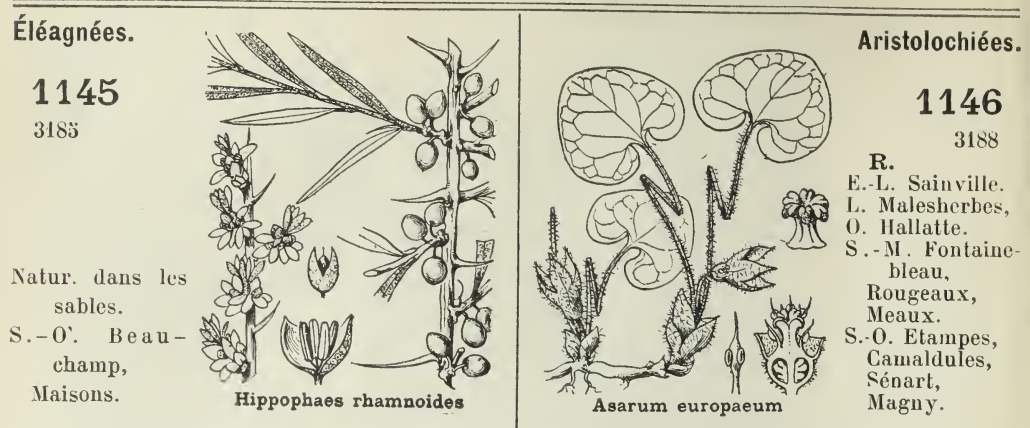

\section{7}

3189

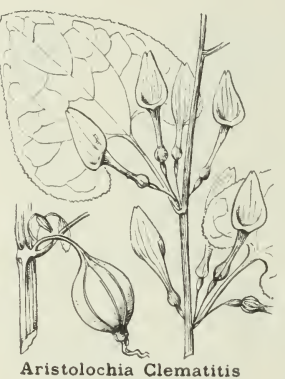

c.

Aristolochia Clematitis
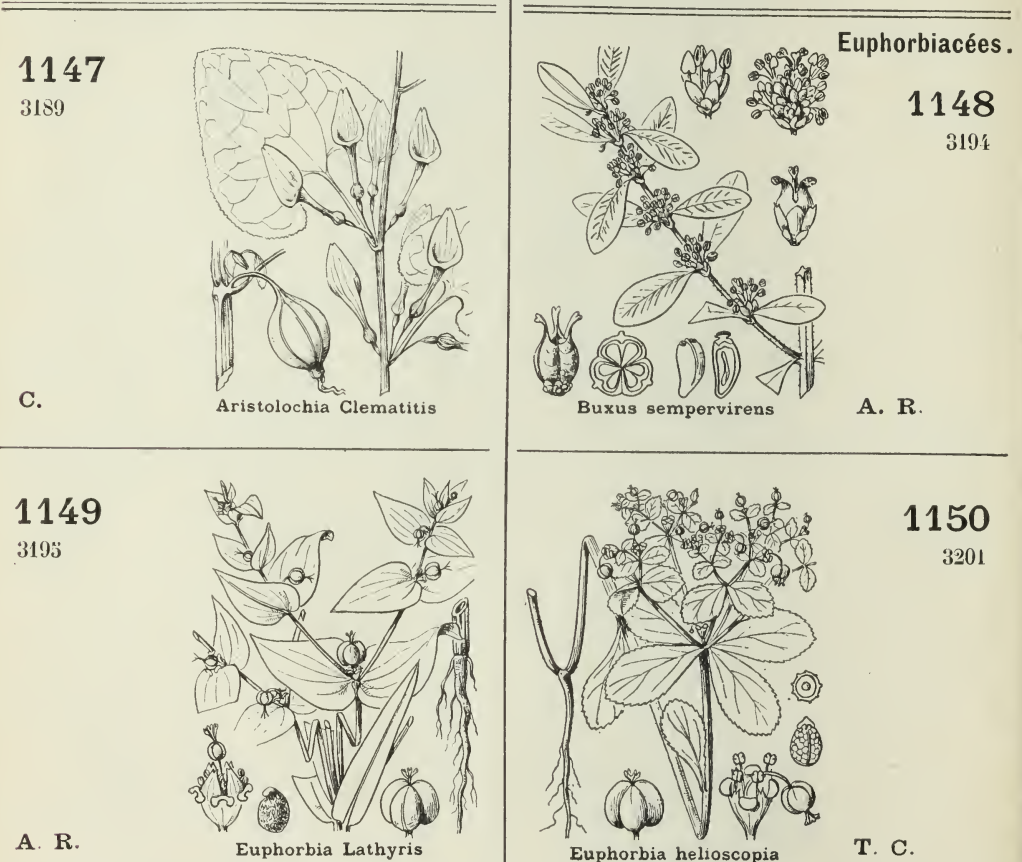

1150

3201

1151

320 '

A. $\mathbf{R}$.

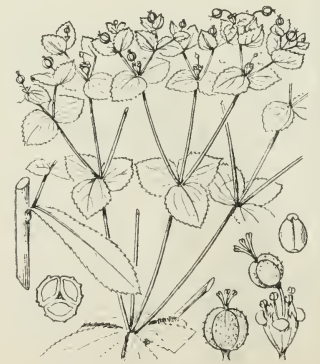

Euphorbia platyphylla

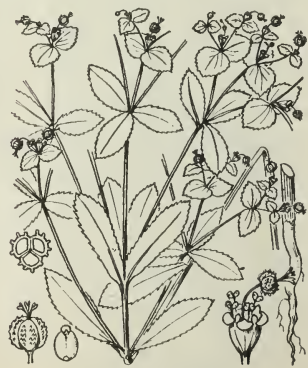

1152

3203

Euphorbia stricta

A. C. 


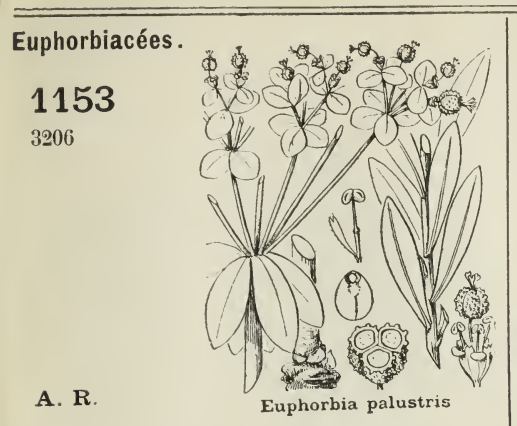

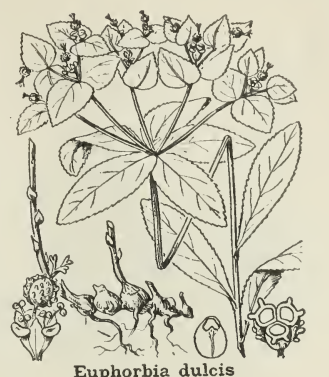

Euphorbia dulcis

A. $\mathbf{R}$.

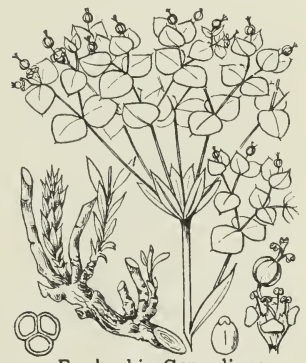

Euphorbia Gerardiana

c.

1156

3218
1154

3211

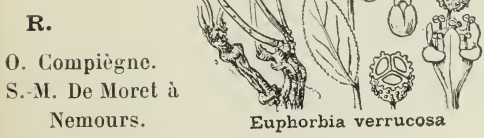

\section{7}

3219

T. C.

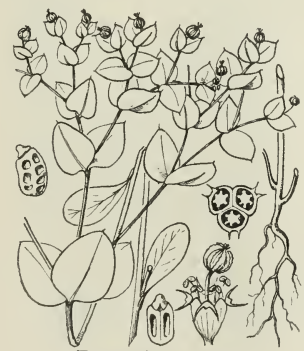

Euphorbia Peplus

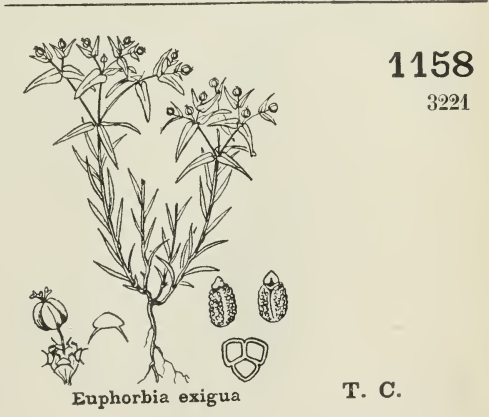

\section{9}

$322 \mathrm{t}$

R.

S.-O. Draveil,

Lia Frelte,

Étréchy,

Elampes.

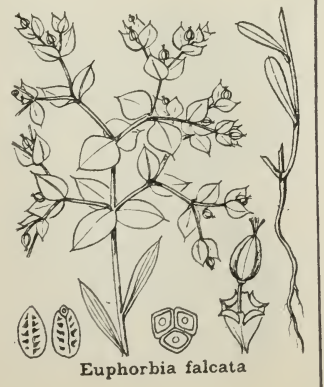

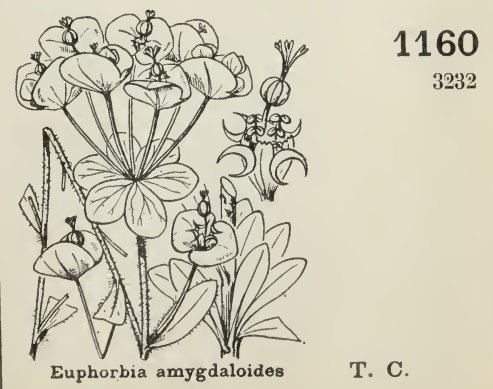


146 FaM. 82. EUPHORBIACÉES - FAM. 83. URTICÉES
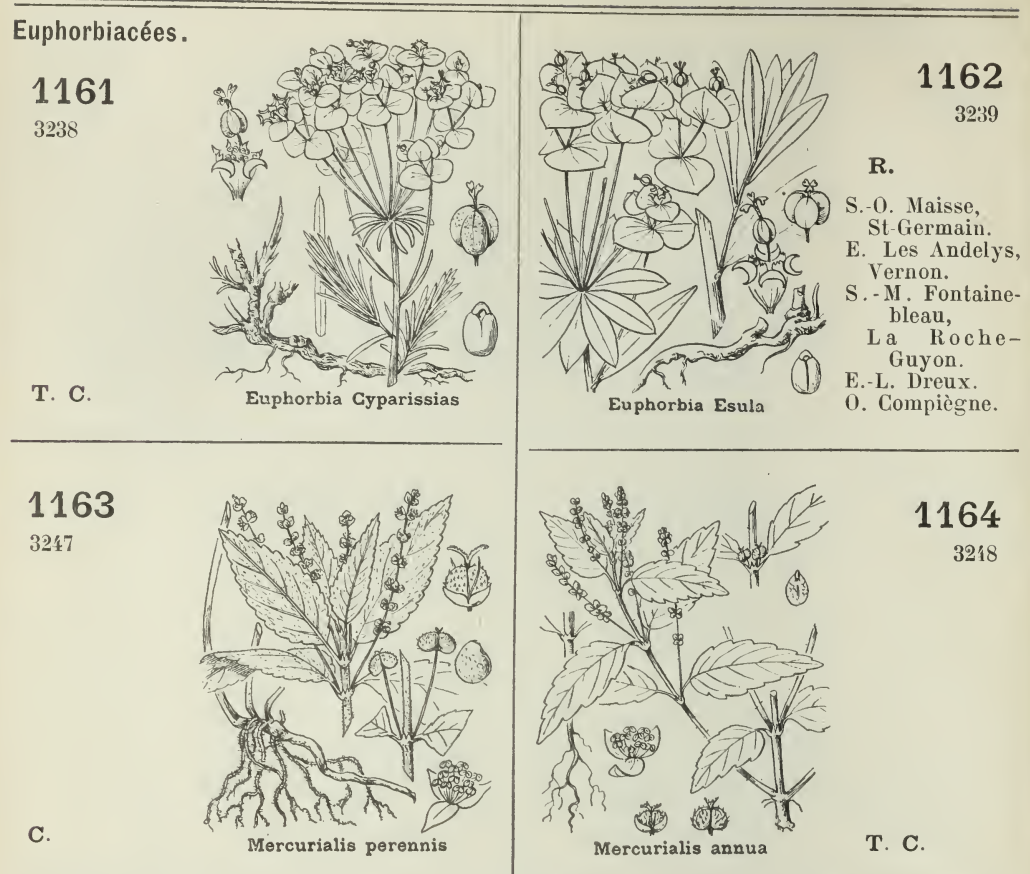

1164

3248
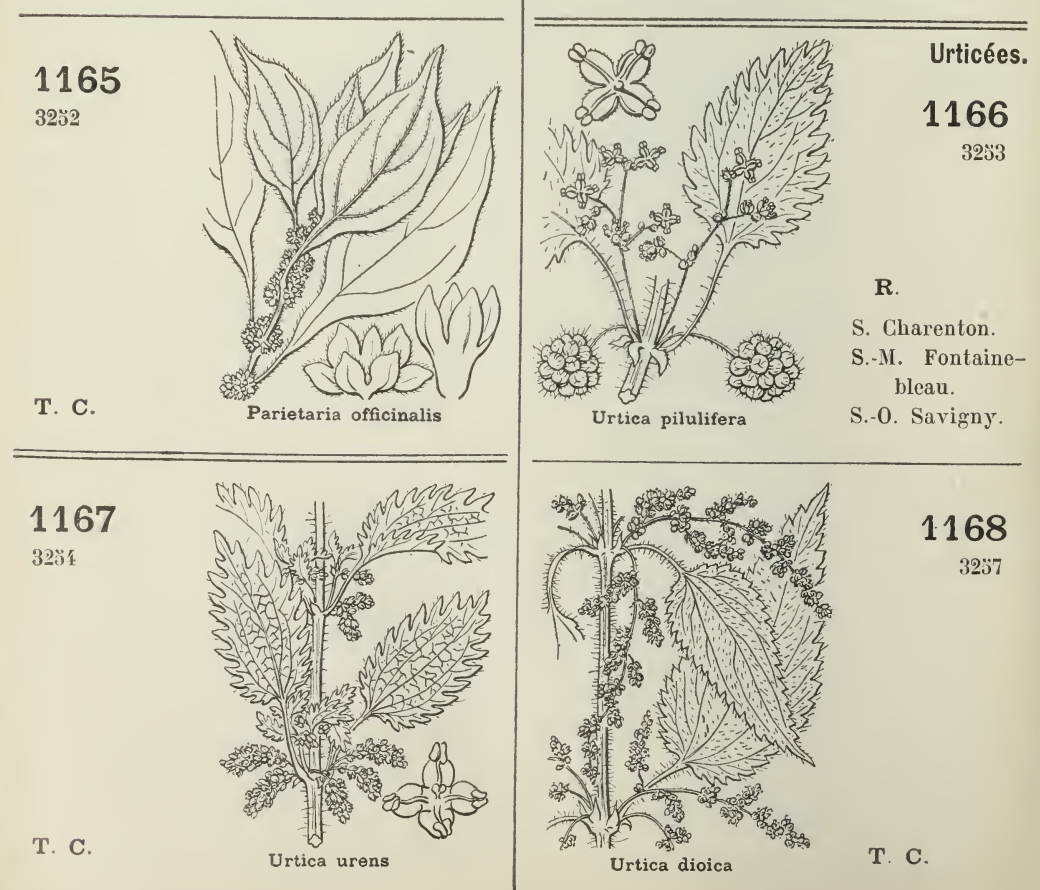
FAM. 83. URTiGéeS - FAM. 84. ULMAGÉES - FAM. 85. ARTOGARPÉES FAM. 86. MORÉES - FAM. 87. JUGLANDÉES
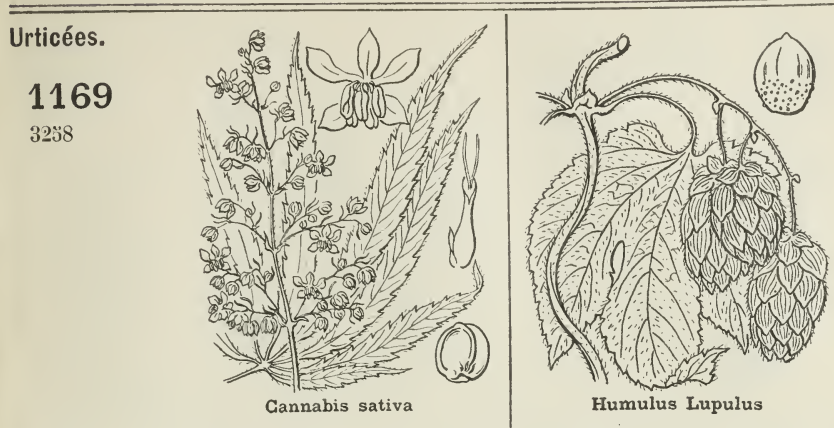

1170

3259
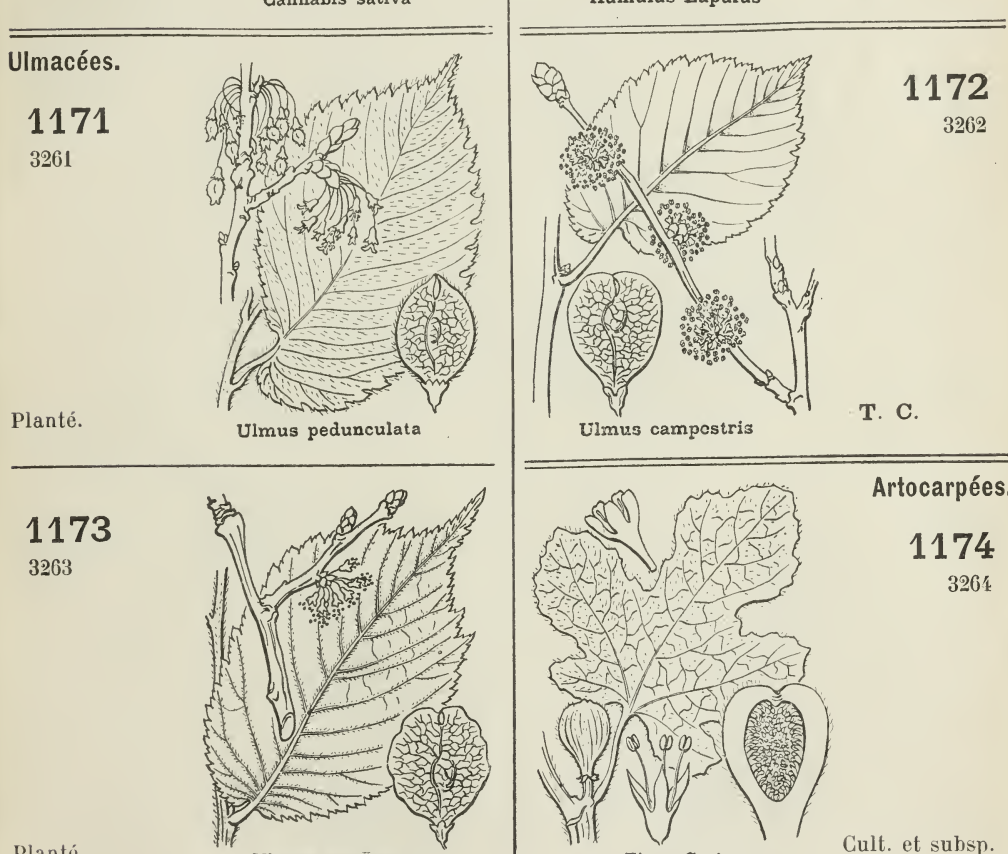

Artocarpées.

\section{4}

3264

Planté

Ulmus montana

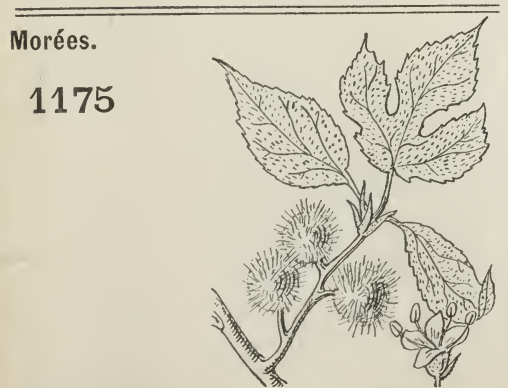

Cult. el subsp.

Eroussonnetia papyrifera

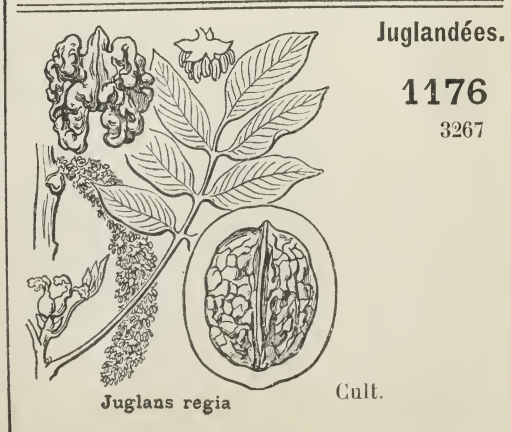




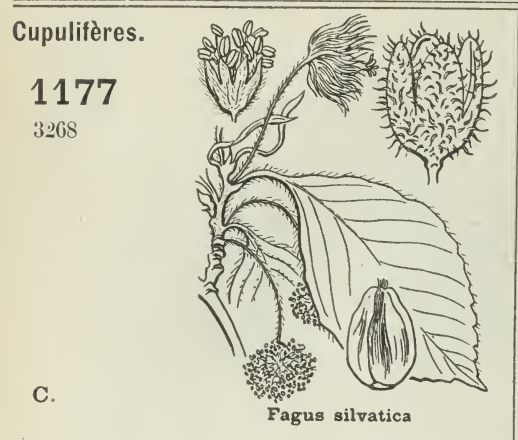

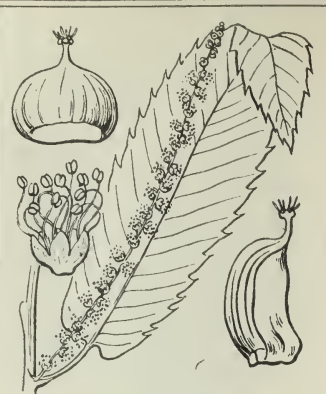

Castanea sativa

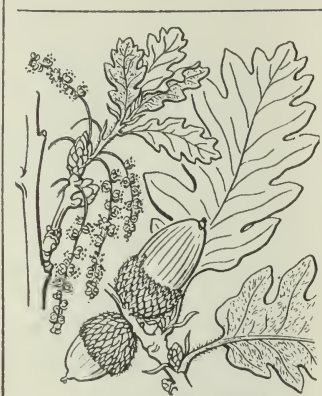

Quercus pubescens

A. C.

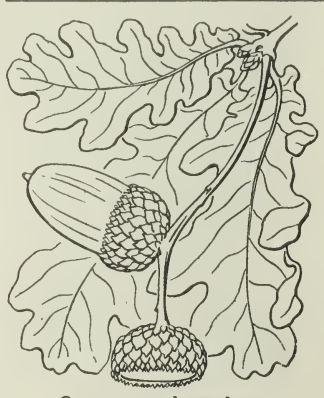

1182

3278
1178

3269

1180

3276
C.

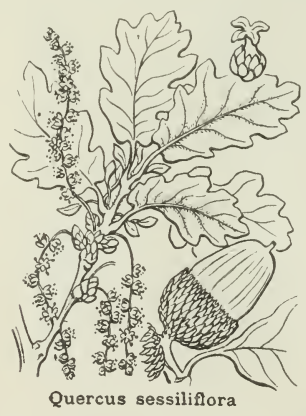

1183

3279

C.

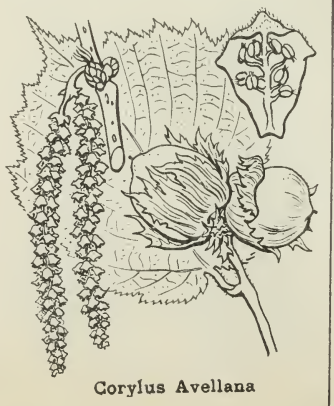

Quercus pedunculata

T. C.

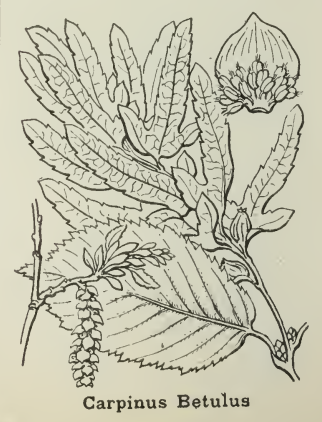

1184

3280 

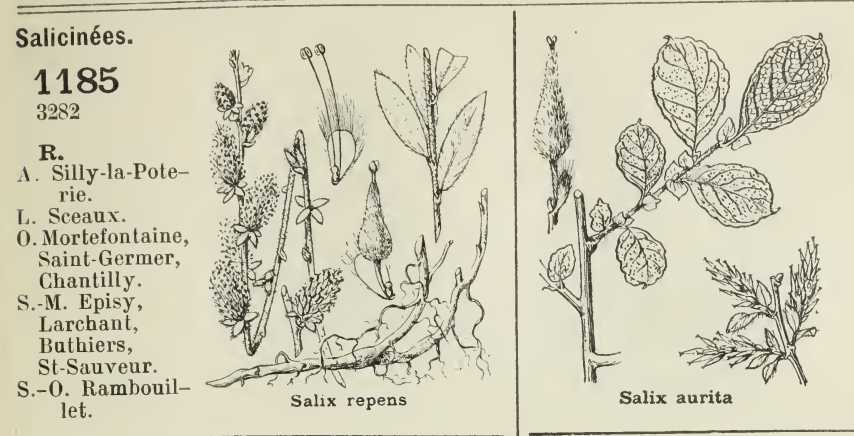

1186

3297

A. C.

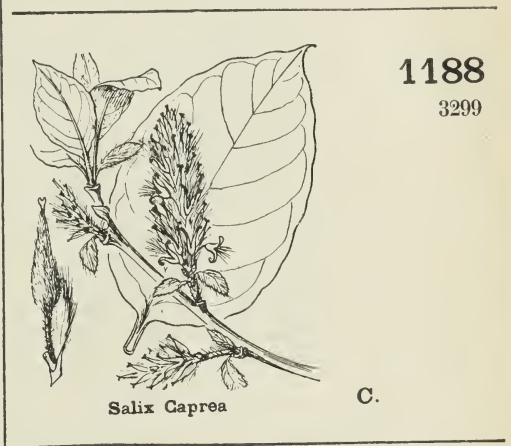

T. C.
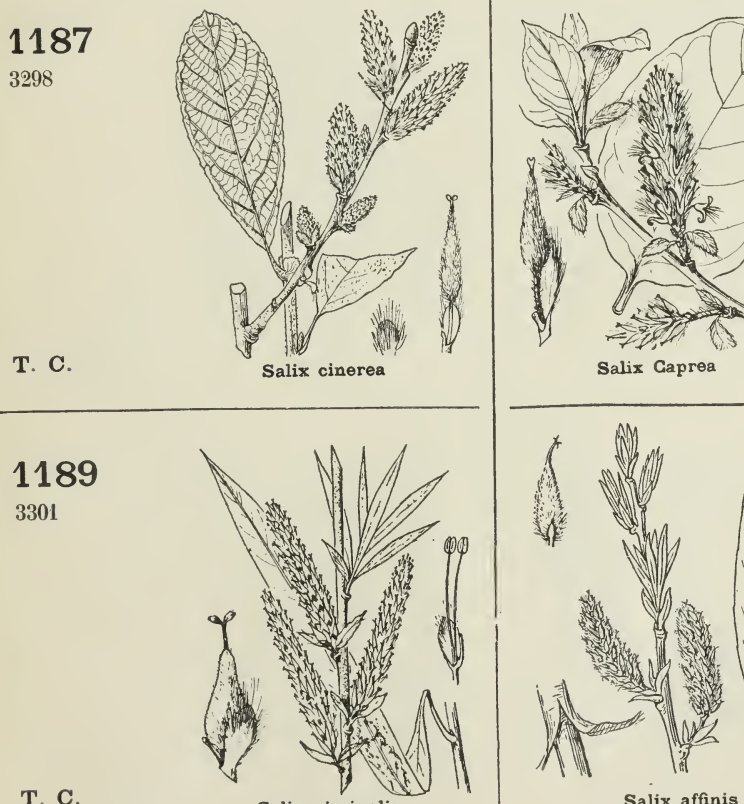

1190

T. C.

Salix viminalis

Salix affinis

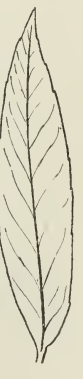

A. 5 C.

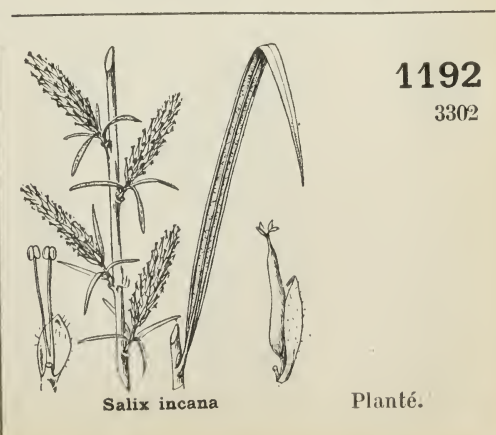



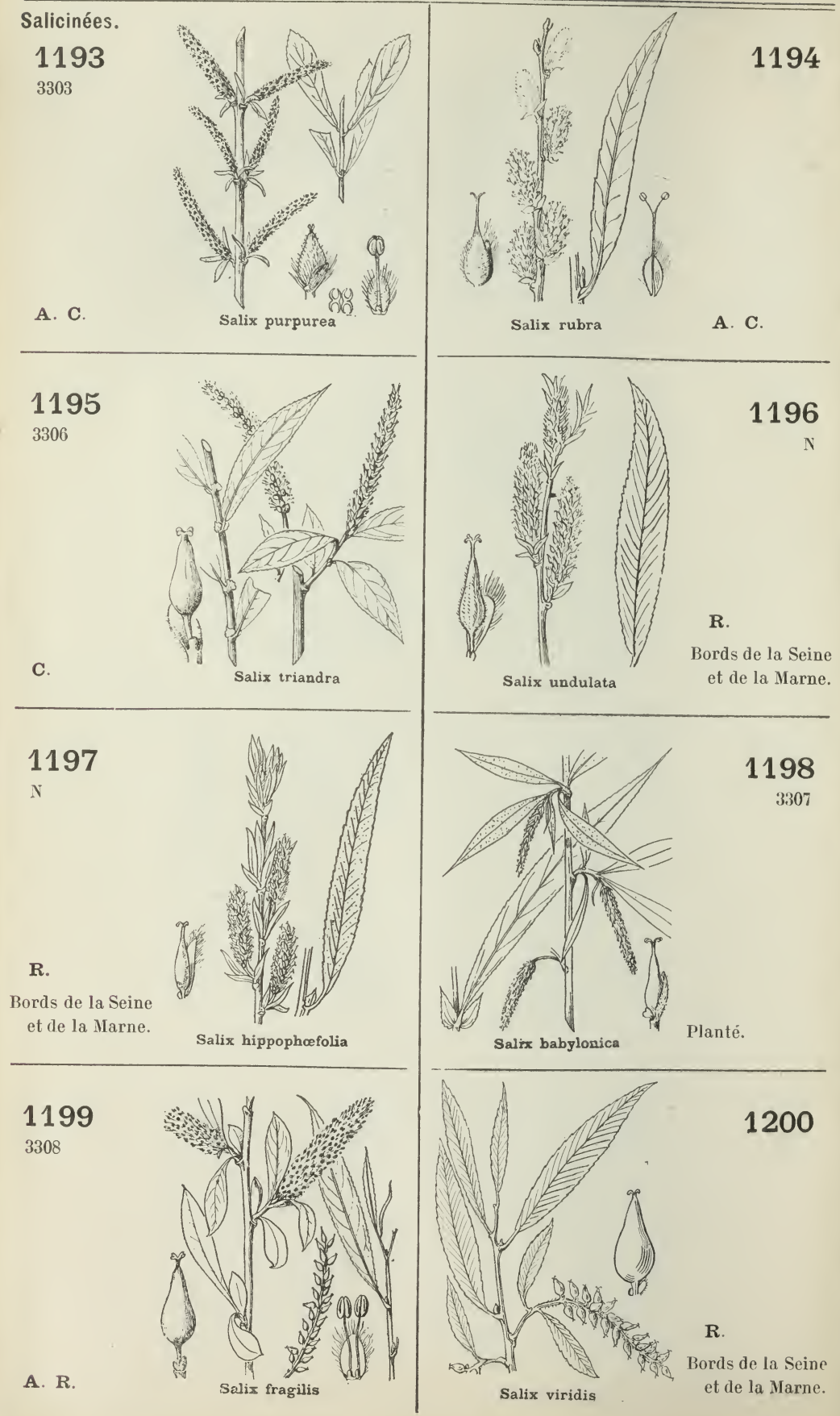
FAM. 89. SALICINÉES - FAM. 90. PLATANÉES FAM, 91. BÉTULINÉES
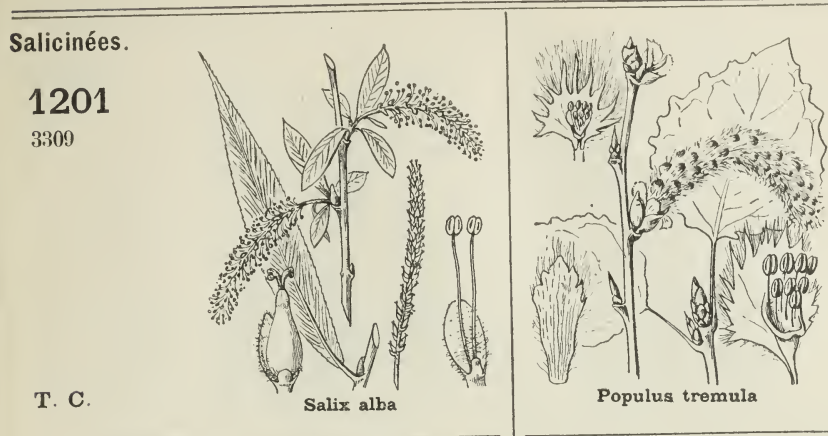

1202

3310

Populus tremula

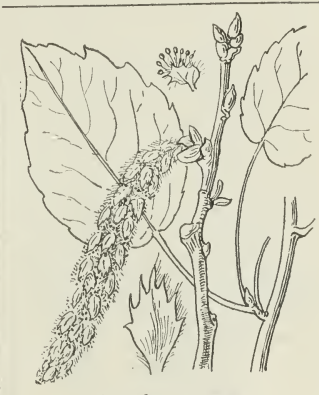

1204

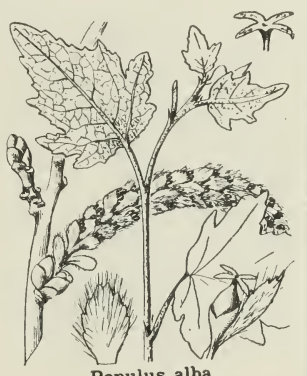

c.

Populus alba

Populus canescens

Planté çà et là.

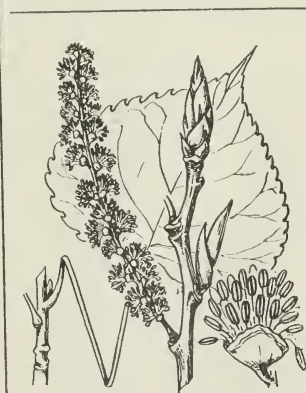

1206

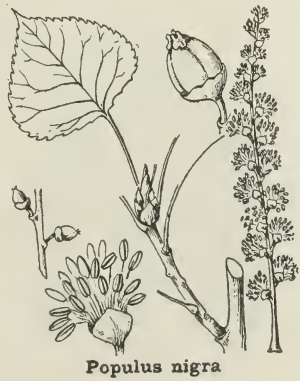

C.

Populus monilifera

3313

3312
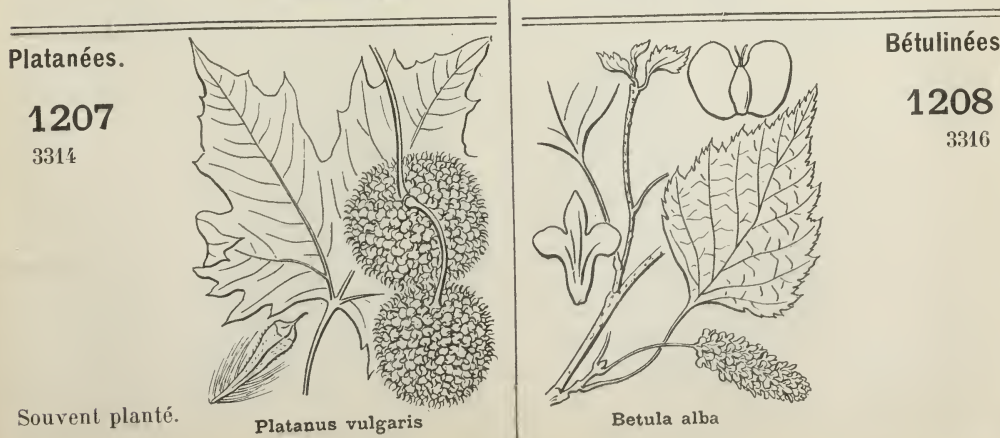


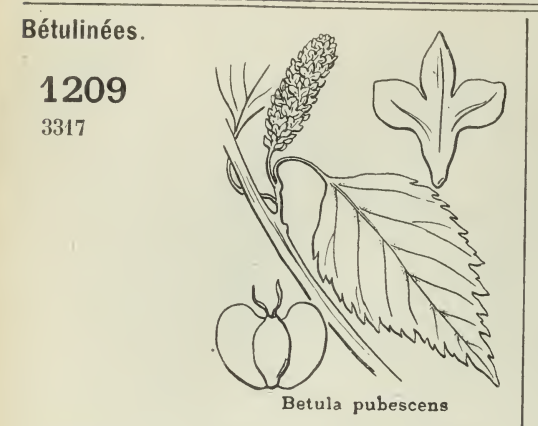

\section{FAM. 93. CONIFÈRES}

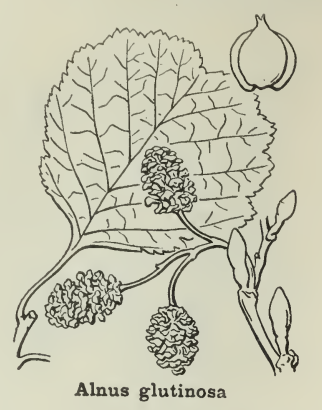

1210

3320

\section{1}

3321
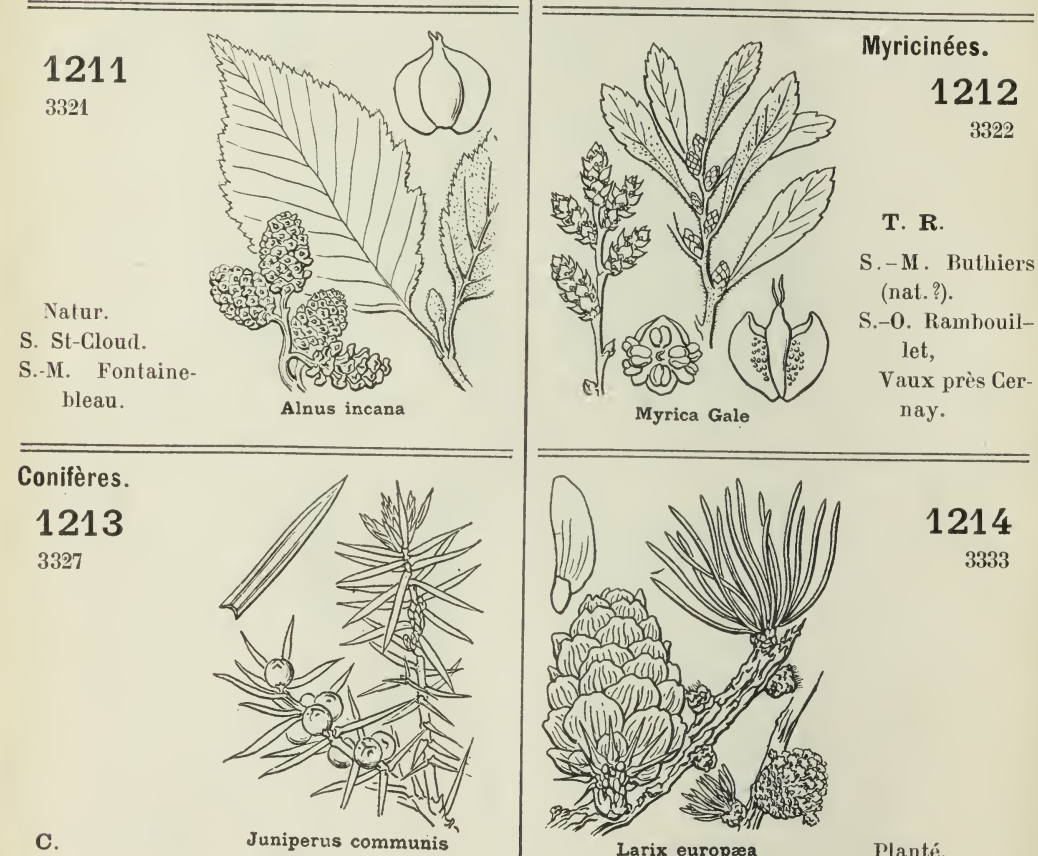

S. St-Cloud.

S.-M. Fontainebleau.

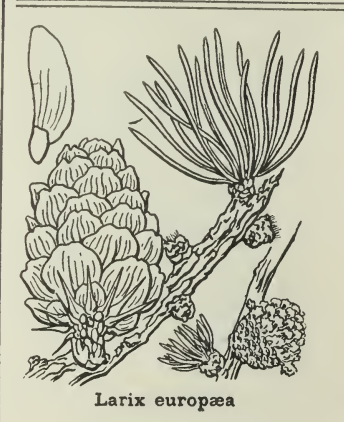

1214

3333
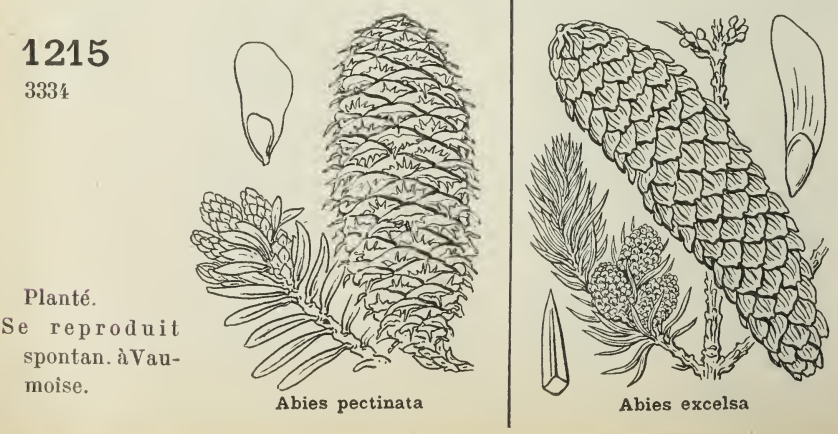

1216

3335 
FAM. 93. CONIFÈRES - FAM. 94. HYDROCHARIDÉES 153
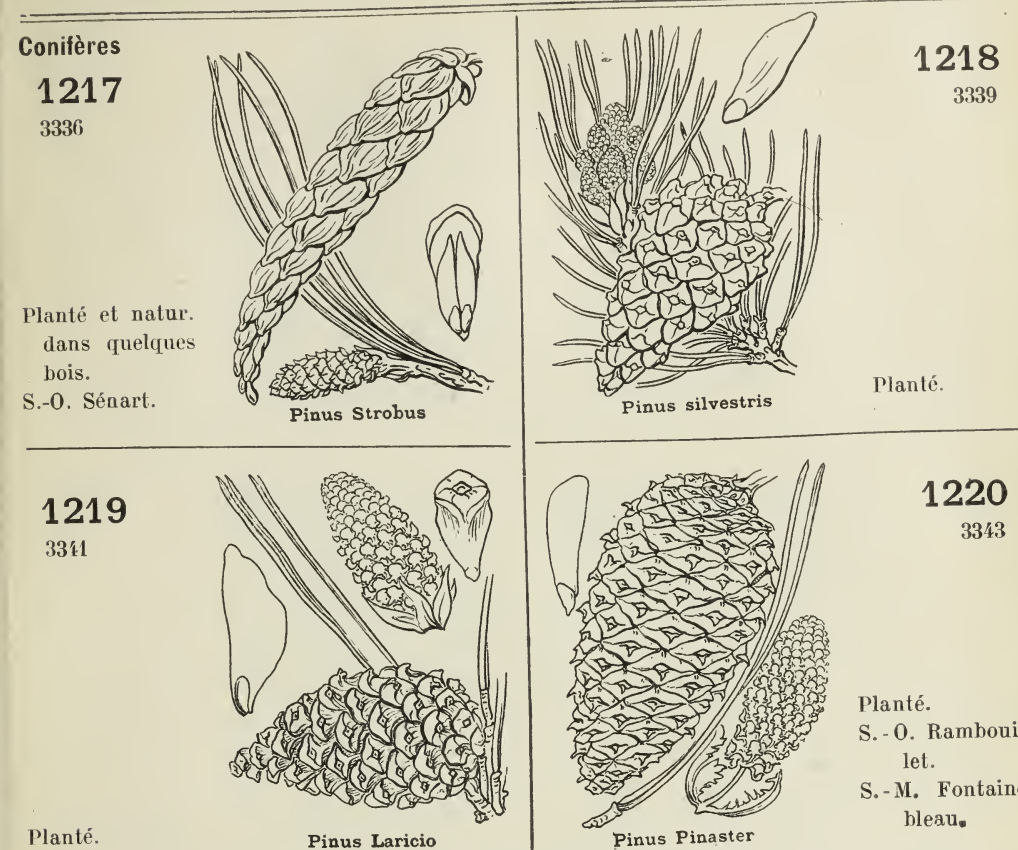

1220

3343

Planté.

S. - 0. Rambouillet.

S. - M. Fontainebleau.

Pinus Pinaster
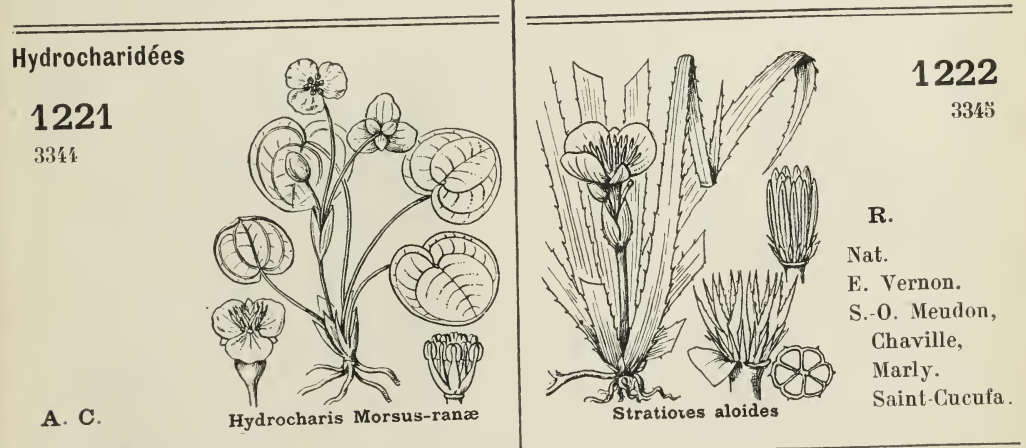

A. C. Hydrocharis Morsus-rane

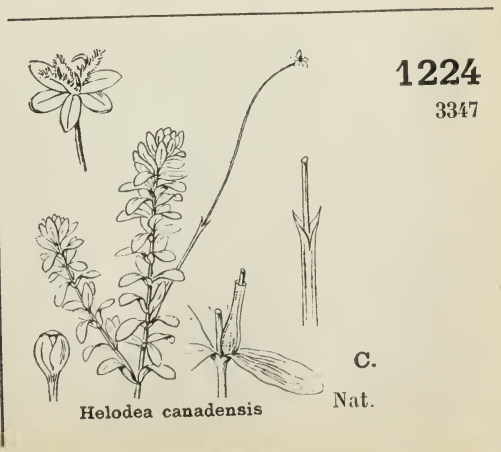


154 FAM. 95. ALISMACÉES - FAM. 96. COLCHICACÉES
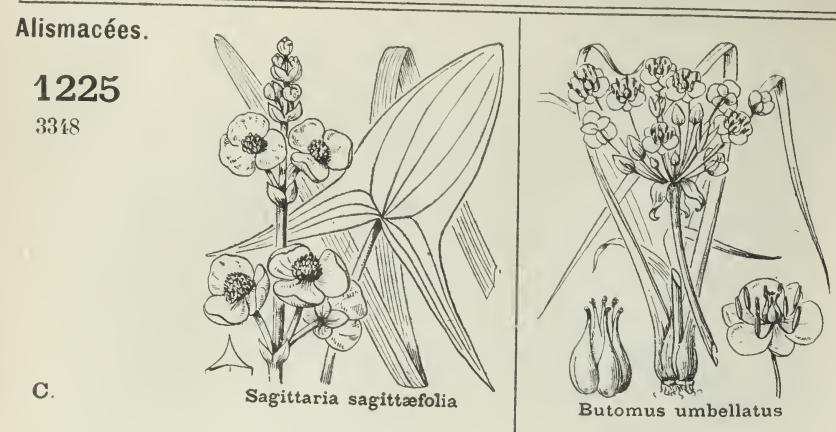

1226

3350
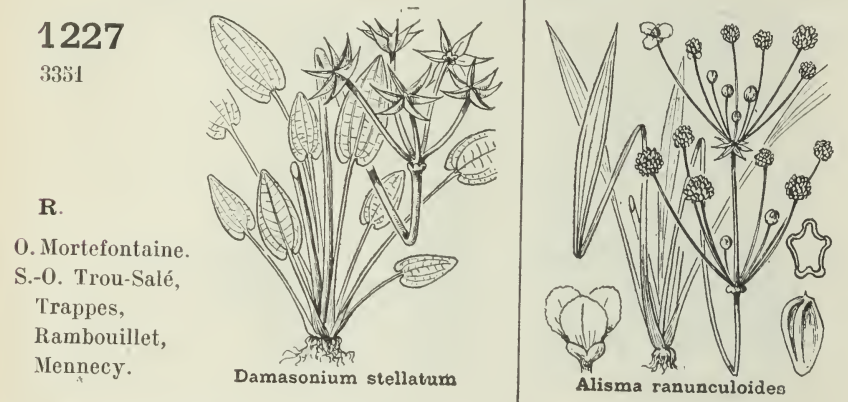

1228

3352

A. $\mathbf{R}$.

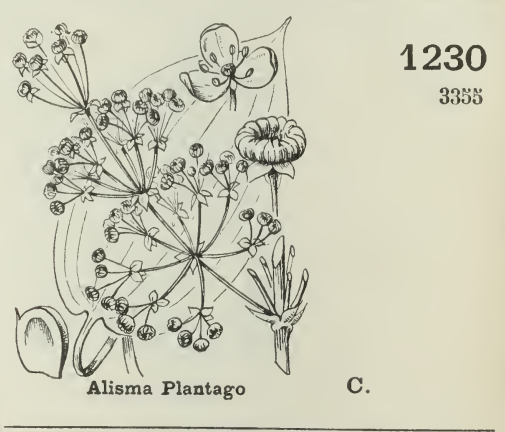

\section{9 \\ 3353 \\ R.

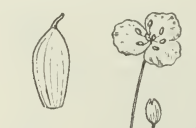

E.-L. Dreux.

o. Beauvais.

S. - M. Fontainebleau,

Villefermoy.

S. - 0. Rambouillet,

Sénart.

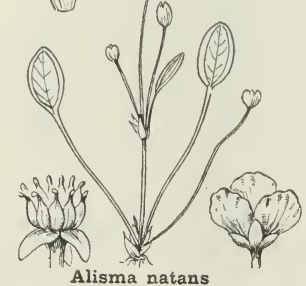

1231

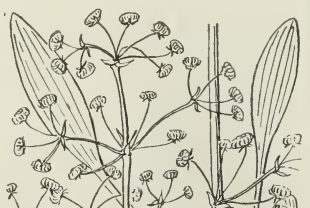

R.

S.-O. Étangs de Trou-Salé, de St-Quentin, de St-Hubert, du Perray.
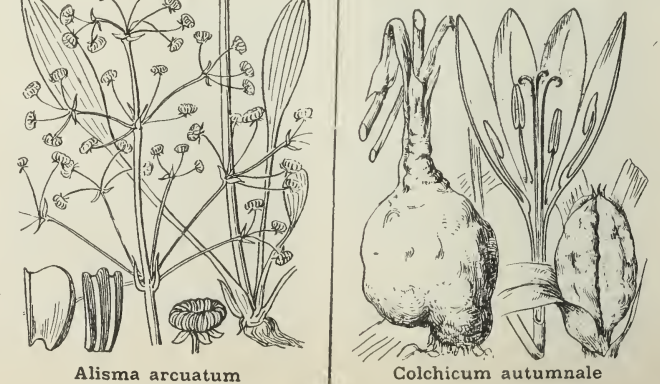

Colchicacées. 

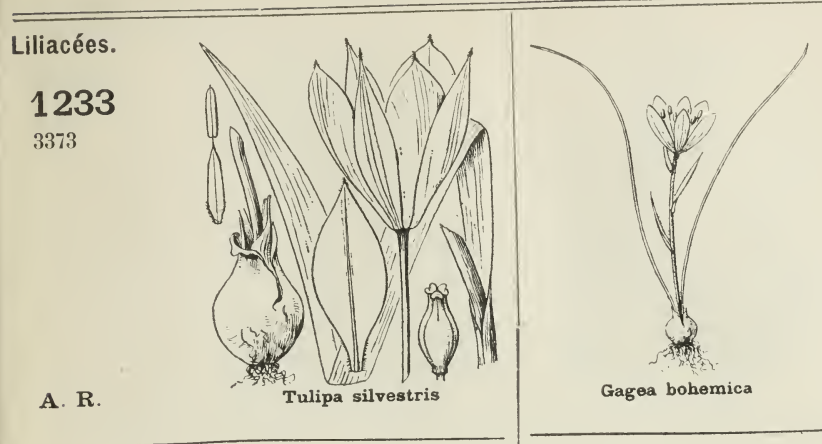

Gagea bohemica

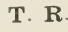

S.-M. Poligny.

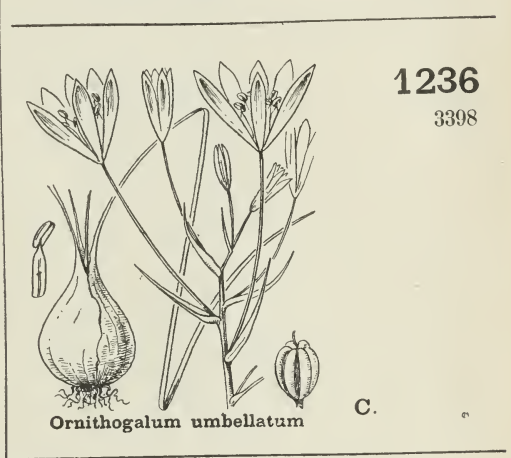

A. $\mathbf{R}$.

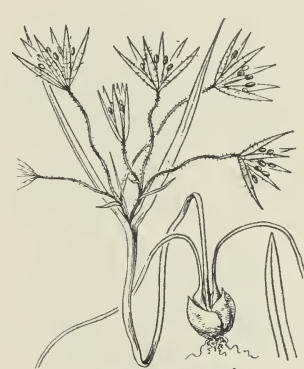

Gagea arvensis

\section{7}

3399

T. R.

S. La GarenneBezons.

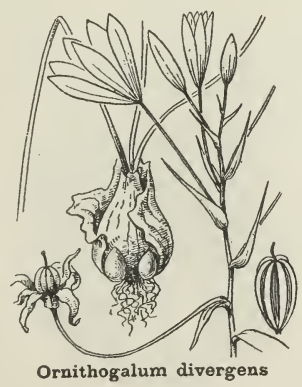

\section{9}

3 103

C.

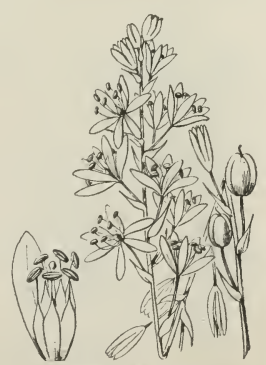

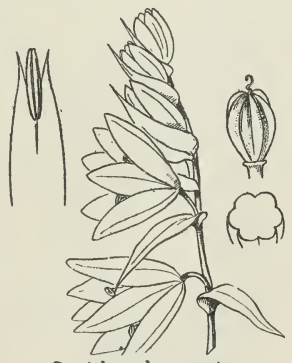

1238

$3 k 01$

\section{Ornithogalum nutans E. Gisors.}

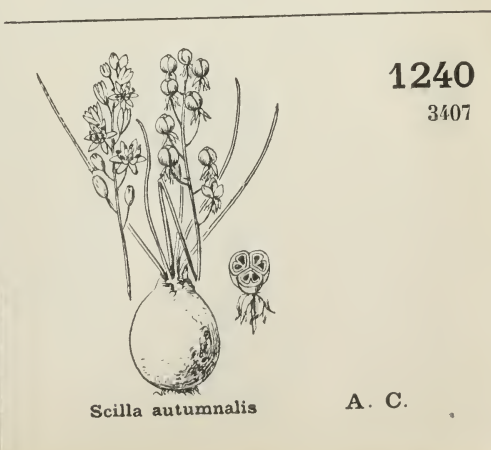



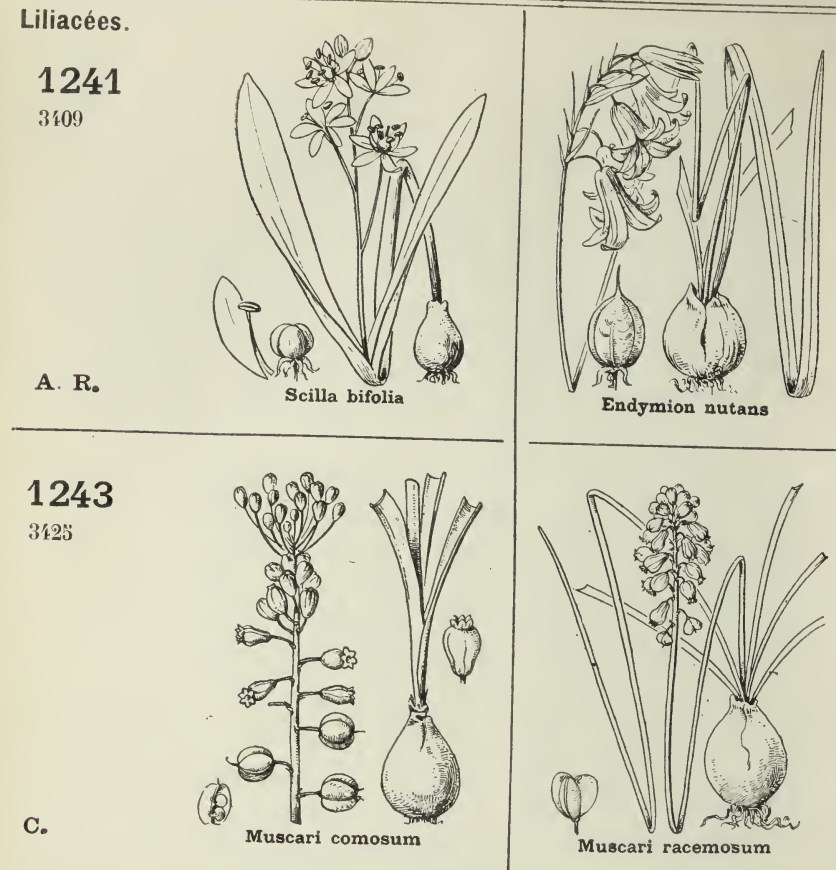

c.
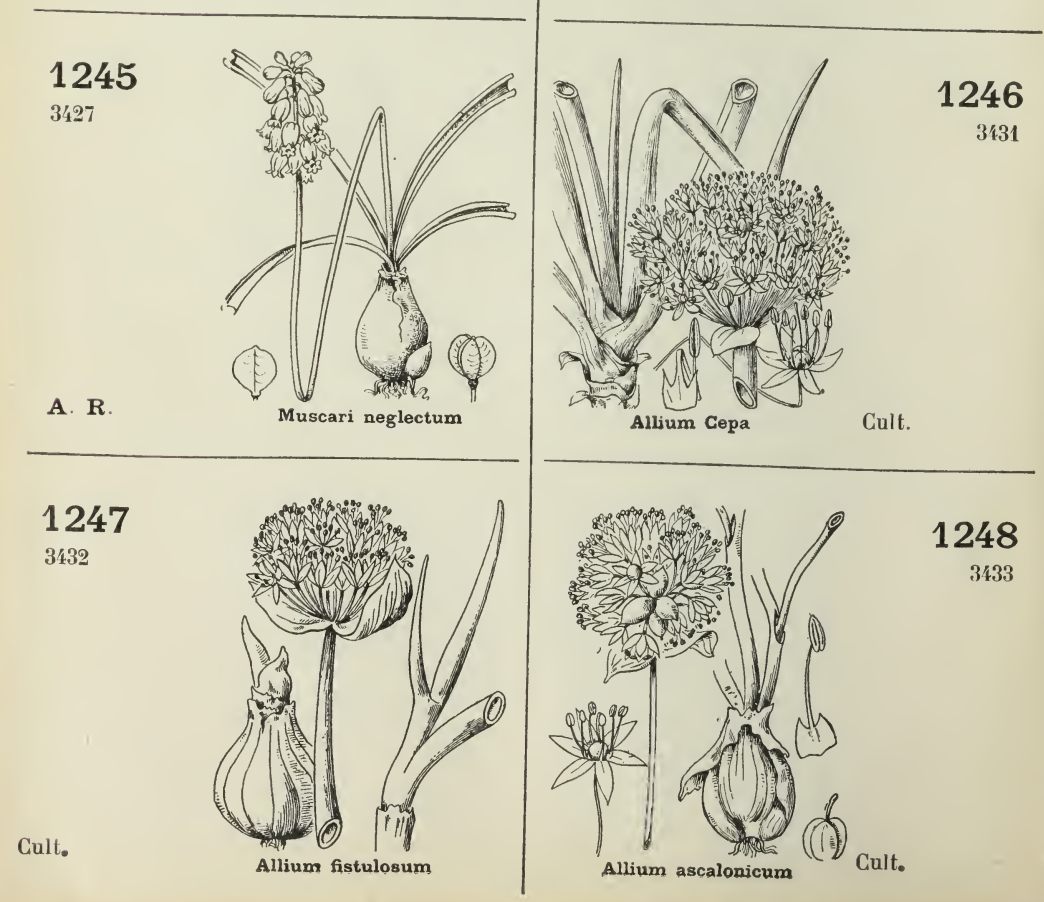
Fam. 97. - LILIACÉES

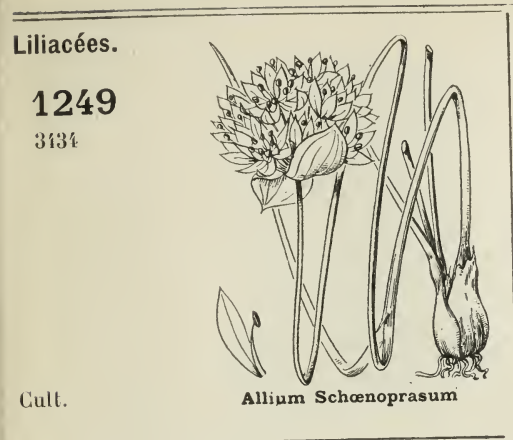

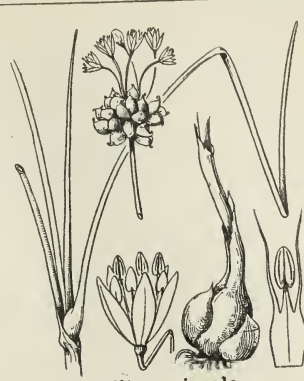

Allium vineale

C.

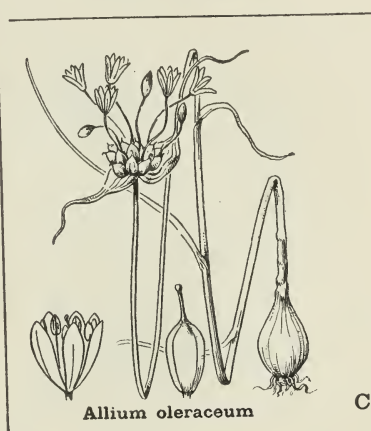

1252

3437
C.

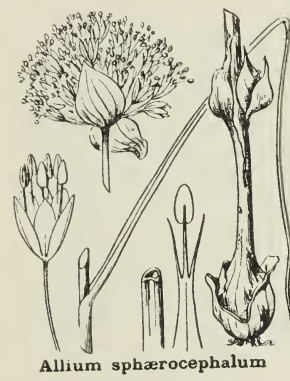

\section{3}

3 彳38

T. R.

E.-L. Chartres. S.-0. Sèvres.

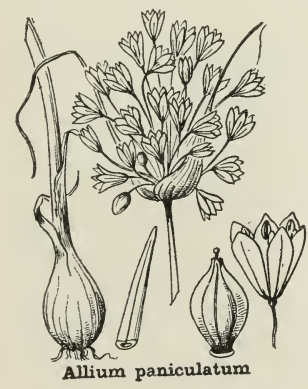

\section{5}

348

Cull.

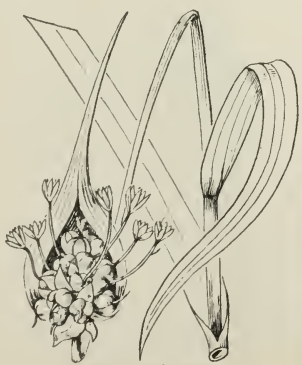

Allium sativum

\section{.

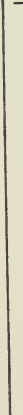

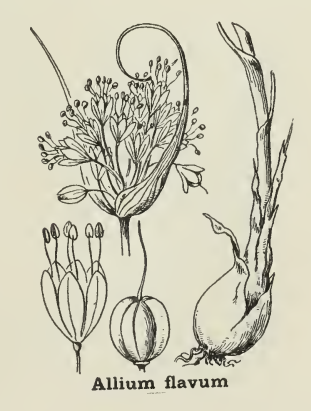

1254

3'10

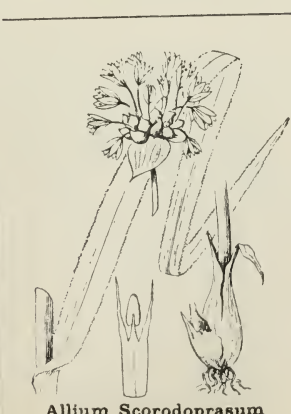

T. $\mathbf{R}$

S. - M . Fontainebleau.

R.

\section{6 \\ 3149}

A. Nogent-l'Artaud.

S.-o. Sevran.

S.-M. Fontainebleau,

Meaux.

s. Charenton, Vincennes, Bisulogne. 
138 FaM. 97. LILIACÉES - FaM. 98. ASPARAGINÉES
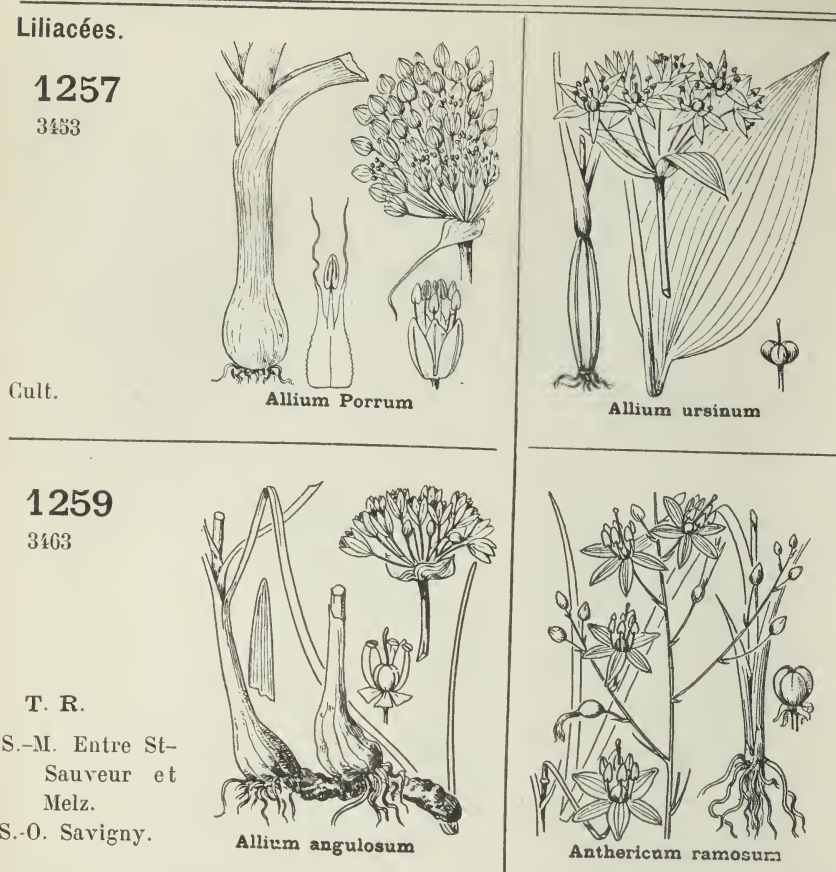

0. Senlis,

Compiègne.

S.-M. Fontaine bleau,

Nemours.

S.-0. Beauvais,

Maisse.

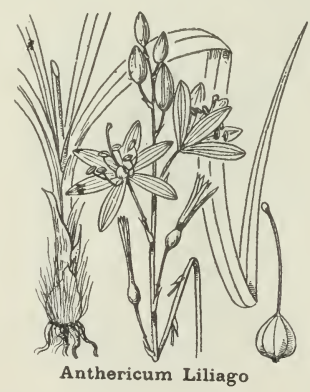

1263

3486

A. $\mathbf{R}$.

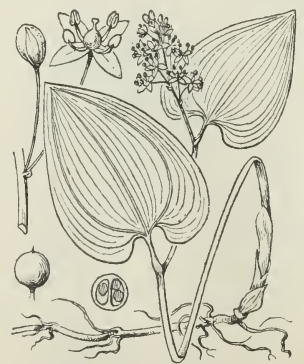

Maianthemum bifolium
Allium ursinum

A. $\mathbf{R}$.

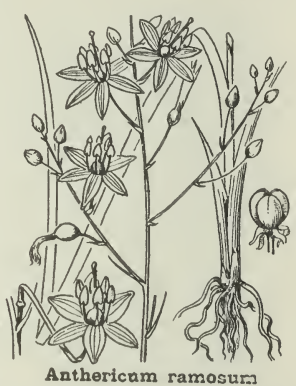

1260

3173

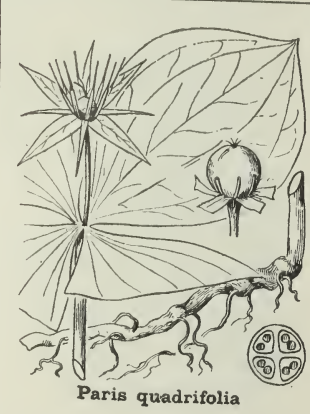

A. $\mathbf{R}$.

Asparaginées.

1262

3183

1258

3437

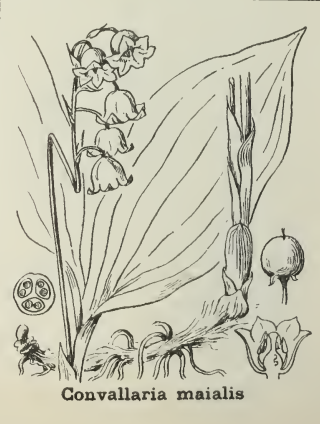

1264 
FaM. 98. ASPARAGINÉES - FaM. 99. DIOSCORÉES FAM. 100. IRIDÉES - FAM. 101. AMARYLLIDÉES
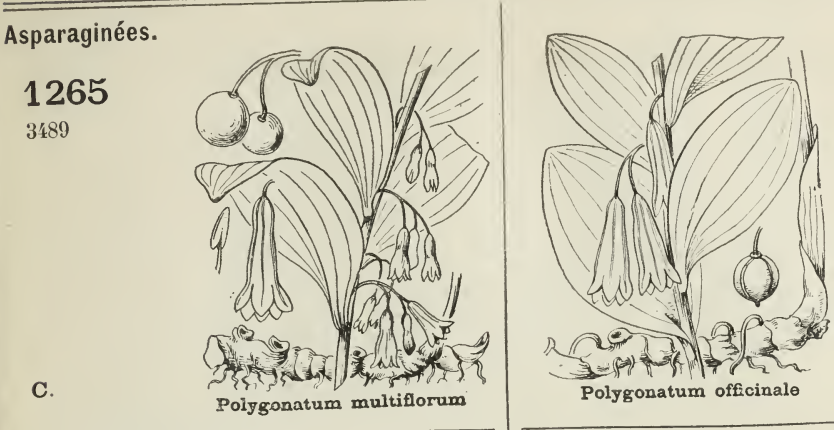

1266

3490
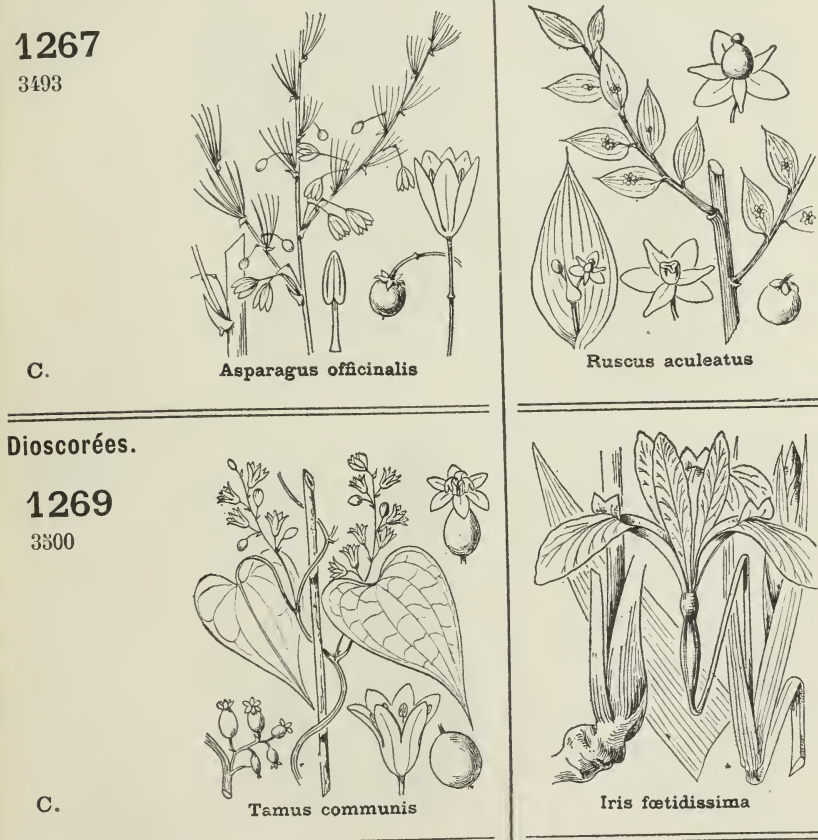

1268

Ruscus aculeatus

A. C.

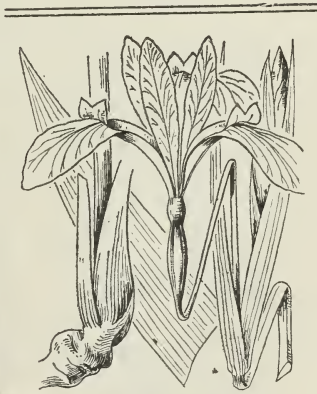

Iridées.

Iris fœetidissima

A. $\mathbf{R}$

1270

3523

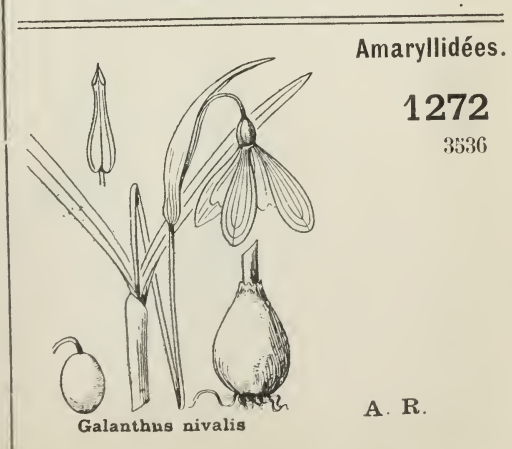


160 FAM. 101. AMARYLLIDÉES - FAM. 102. ORCHIDÉES
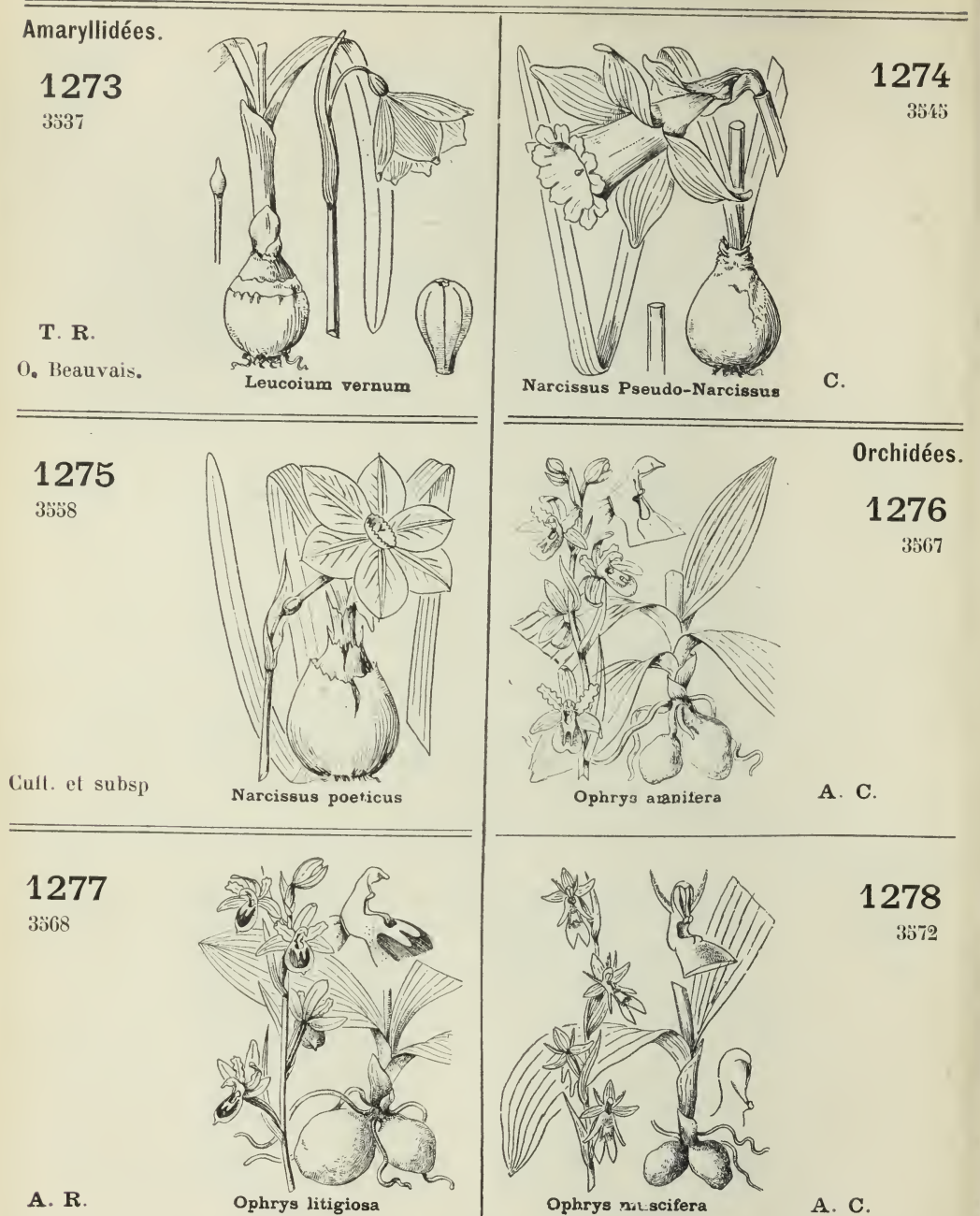

1276

3567

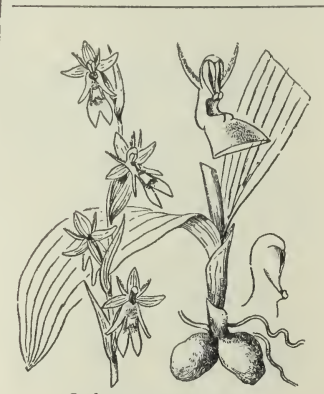

A. C.

Ophrys malscifera

1278

3572

A. C.
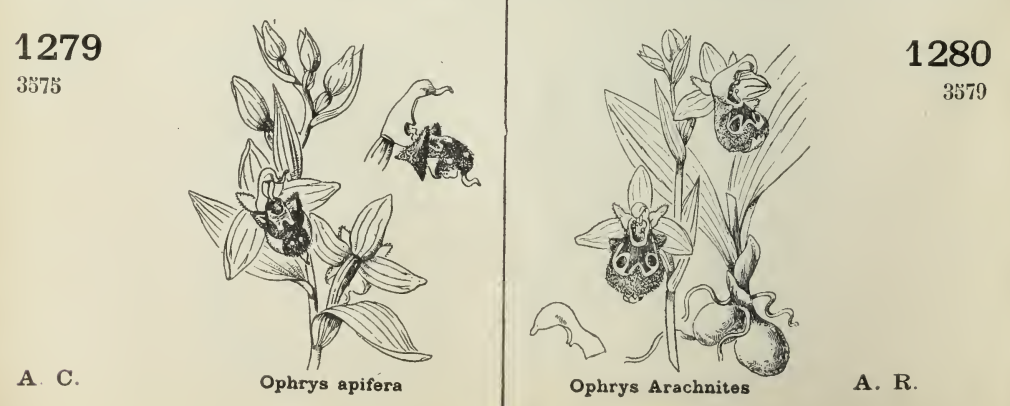


Orchidées.
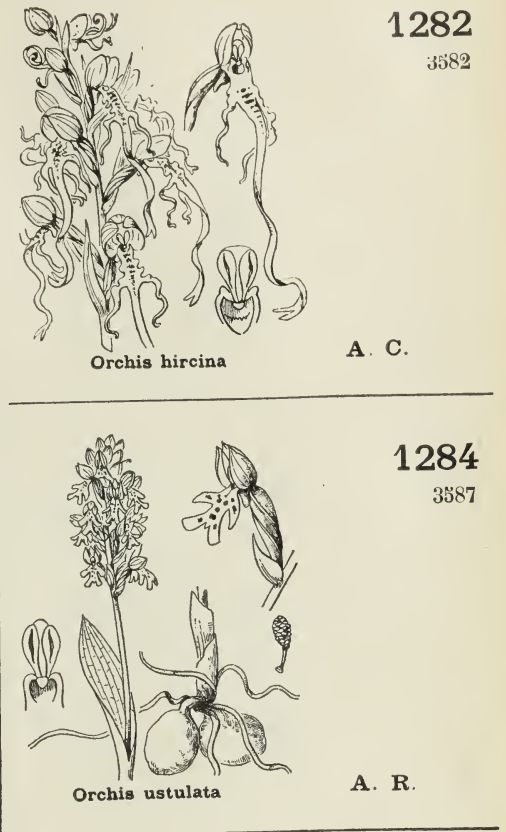

A. $\mathbf{R}$.

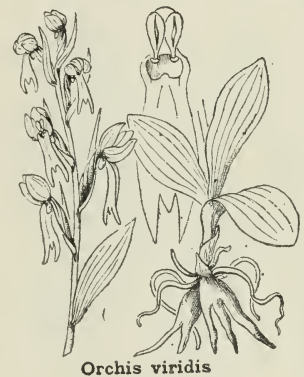

1285

3588

A. C.

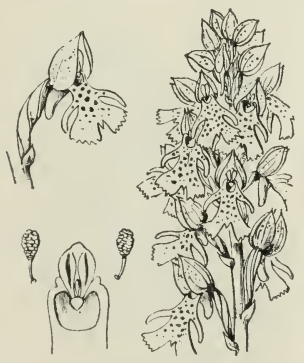

Orchis purpurea

1287

3500

A. $\mathbf{R}$.

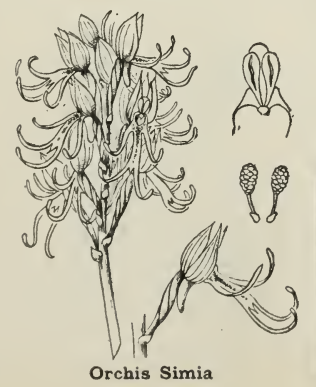

Orchis hircina

A. C.

1282

3582

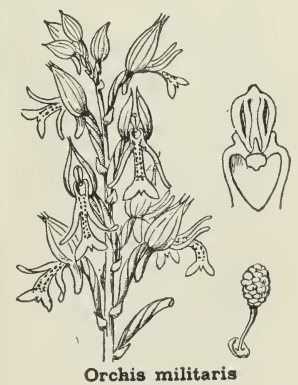

1286

3589

A. C.

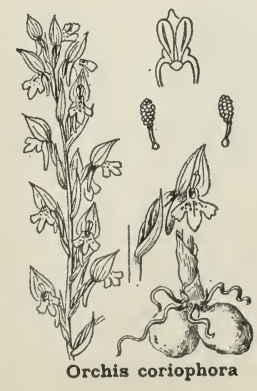

1288

3593 
FAM. 102. - ORCHIDÉES
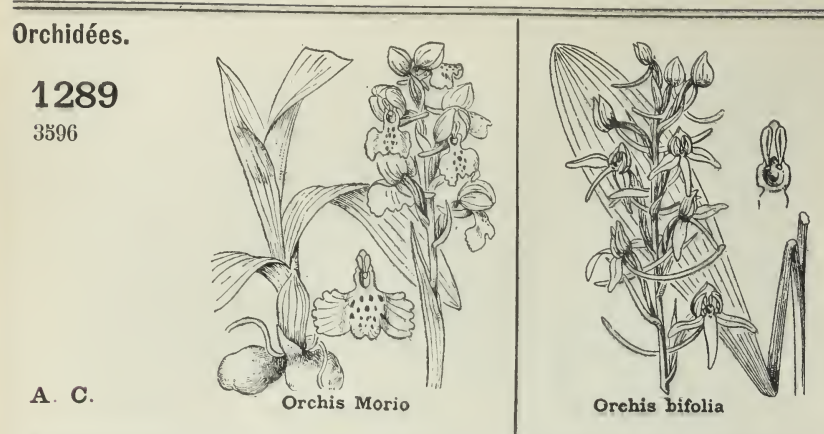

1290

3001

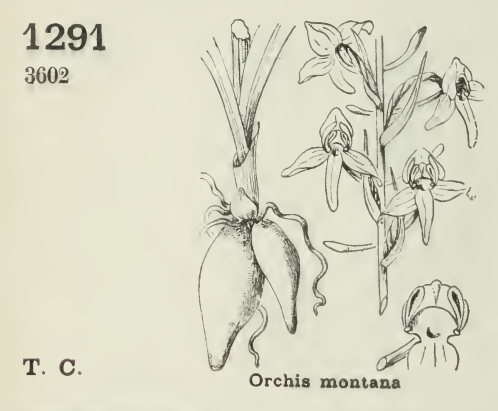

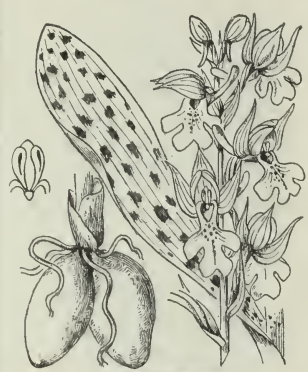

Orchis mascula

A. C.

1292

3606

A. $\mathbf{R}$.

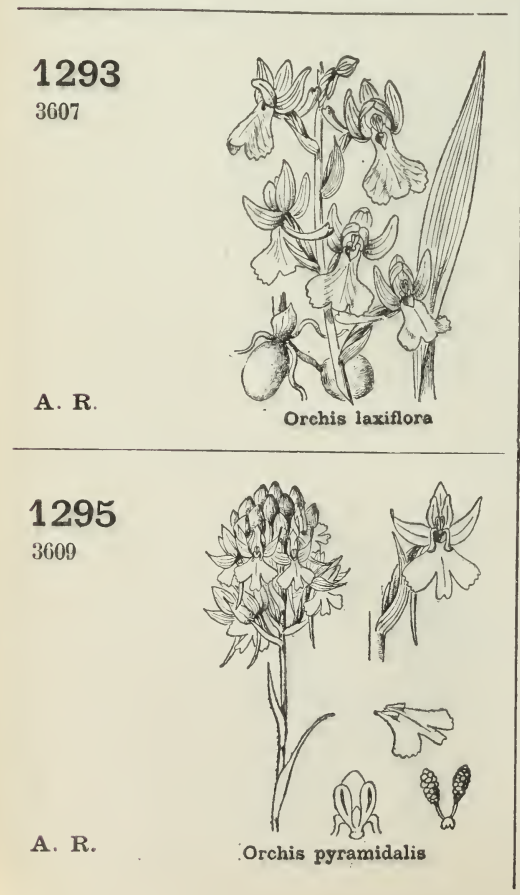

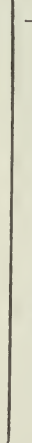
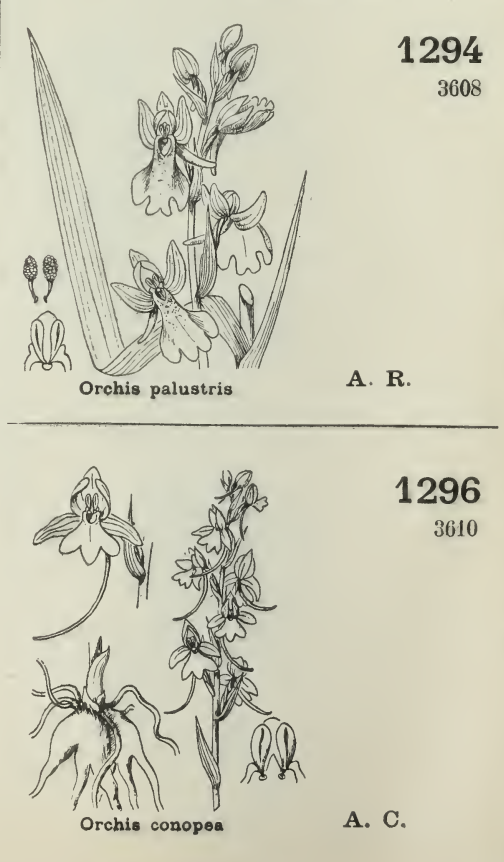


\section{Orchidées.}

1297

3611

R.

E. Vernon.

L. Malesherbes, Sceaux.

o. Compiègne, Laigue.

S.-M. Épisy. La Genevraye.

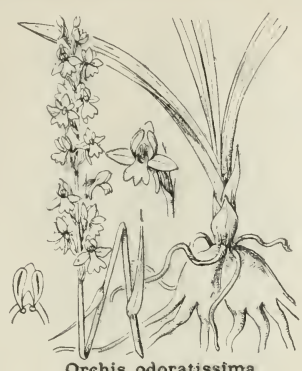

Orehis odoratissima

c.

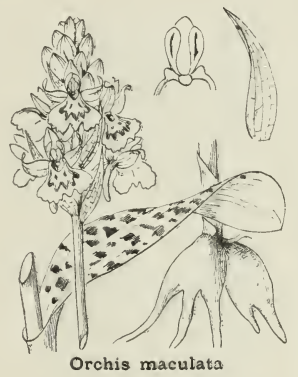

1301

3615

A. C.

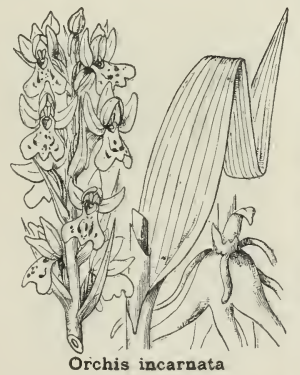

\section{3}

3619

\section{S.-0. Autrefois à} Rambouillet.

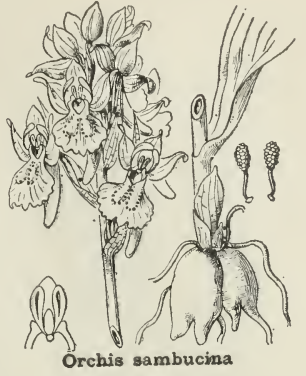

1298

3612

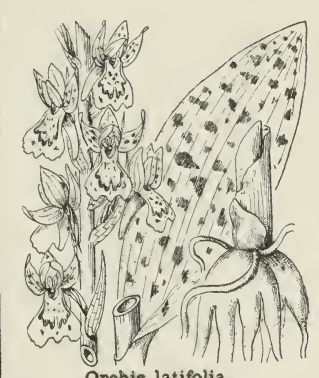

1300

3614

C.

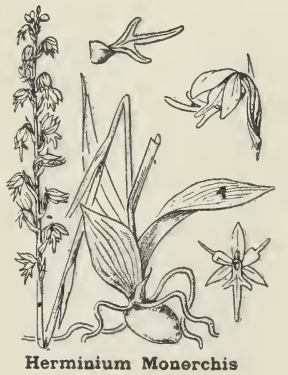

1302

3618

R.

E. Gisors,

St-Clair - surEpte, Vernon,

Vezillon.

0 . Beauvais,

Méru,

Compiègne.

S.-O. Mantes,

La Roche -

Guyon.

S.-I. Neufmarché.

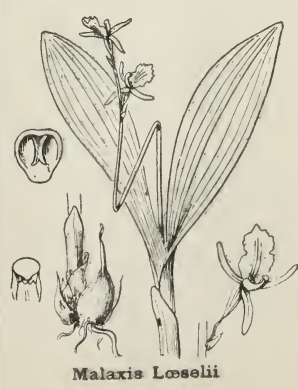

1304
R.

A. Silly-la-Poterie.

0. Russy,

Mortefontaine.

S. - M. D'Episy ì Souppes,

Buthiers.

S. - 0. Brignancourt, Marly. 
Orchidées.

1305

3621

A. $\mathbf{R}$.

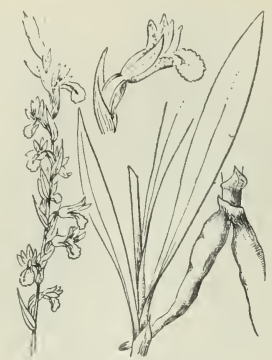

Spiranthes astivalis

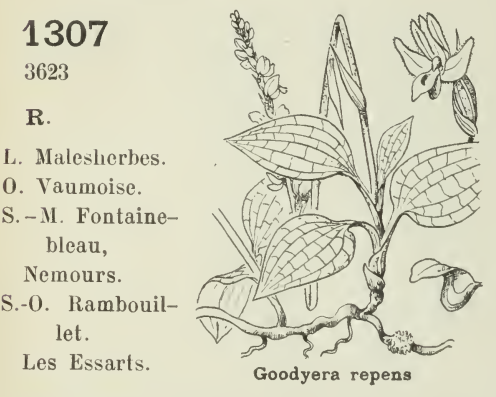

1309

3027

A. C.

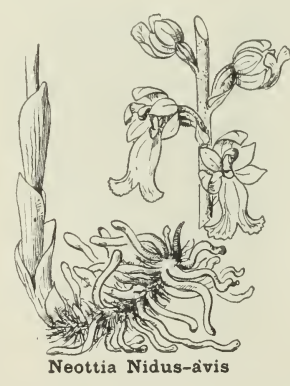

1311

3630

T. $\mathbf{R}$.

I. Les Andelys.

o. Compiènne,

Laigue.

S. - M. Fontainebleau.

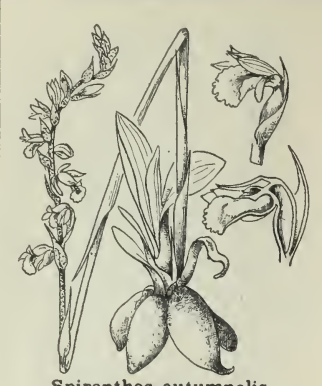

1306

3622

\section{Spiranthes autumnalis A. R.}

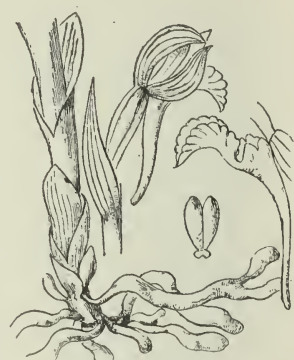

A. $\mathbf{R}$.

\section{8}

3626

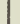
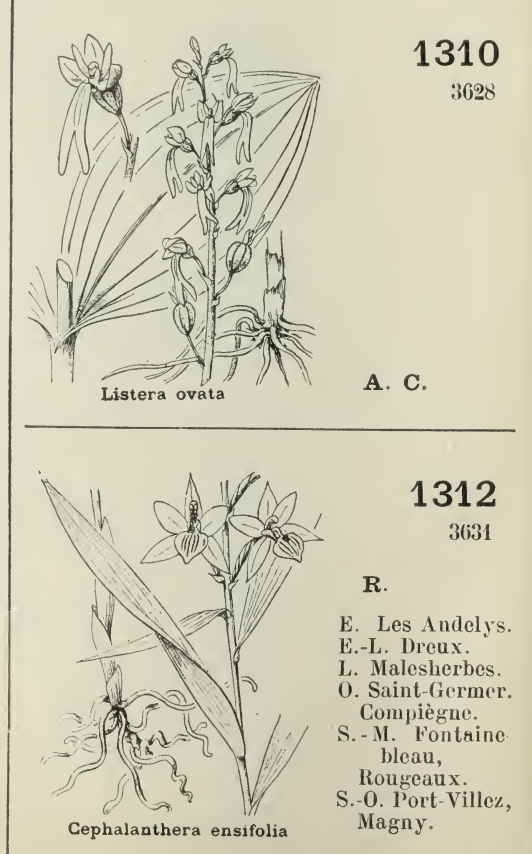


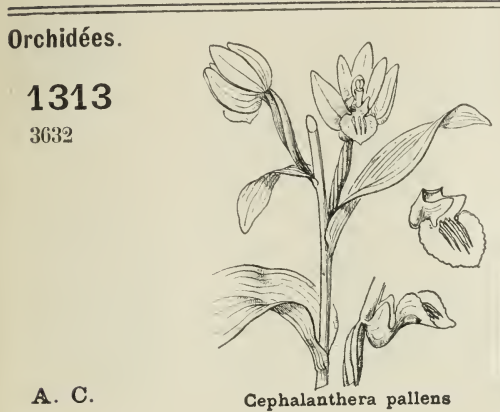

T. R.

A. Villers-Cotterets.

0. Compiègne.

S. - M. Fontainebleau.

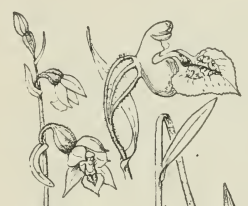

Epipactis microphylla

1317

3636

C.

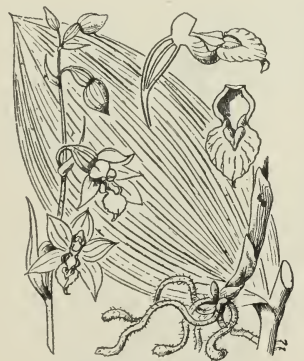

Epipactis latıfolia

1319

3610

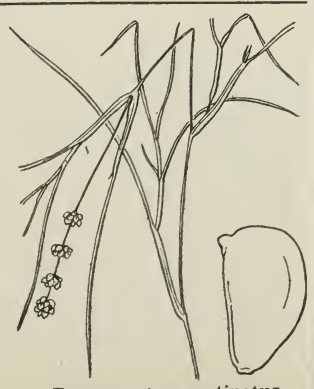

C.

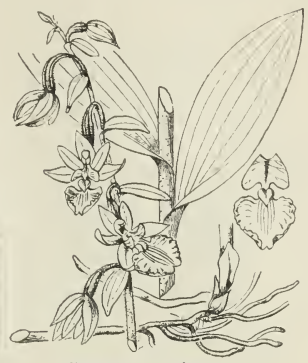

Epipactis palustris

A. C.

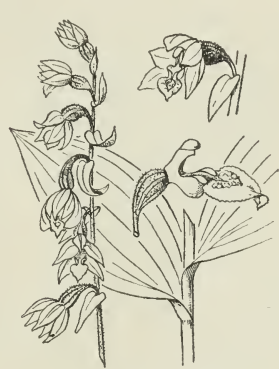

1316

3635

1314

3633
Epipactis atrorubens

A. C.



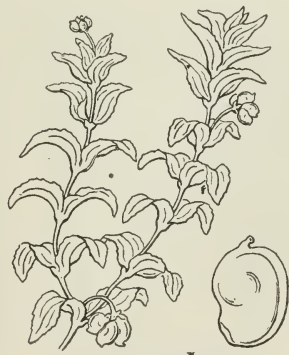

Potamogeton densus

C.

1318

3638

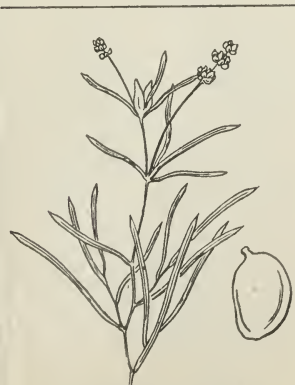

1320

3641

Potamogeton pusilkus

A. C. 


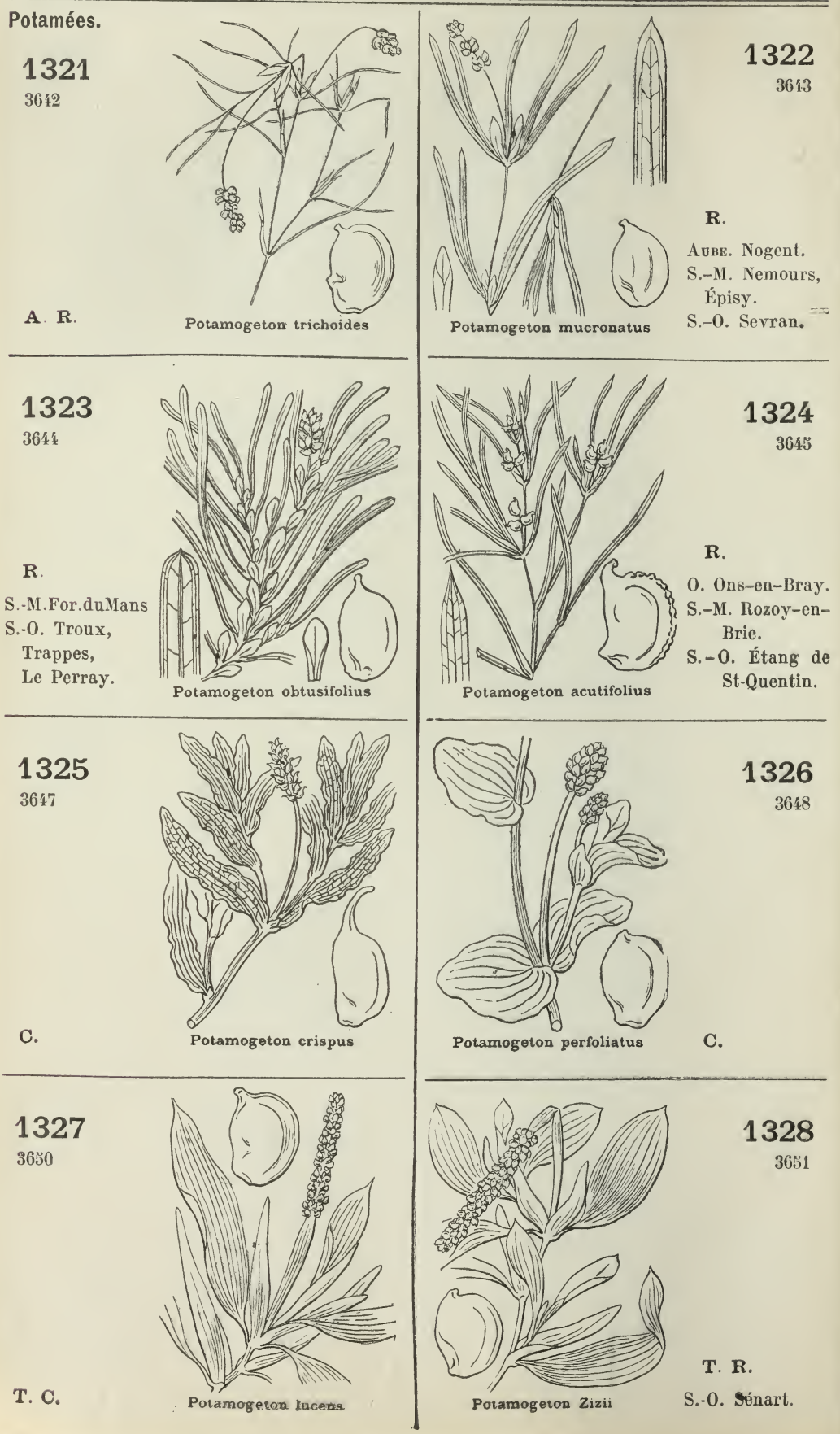



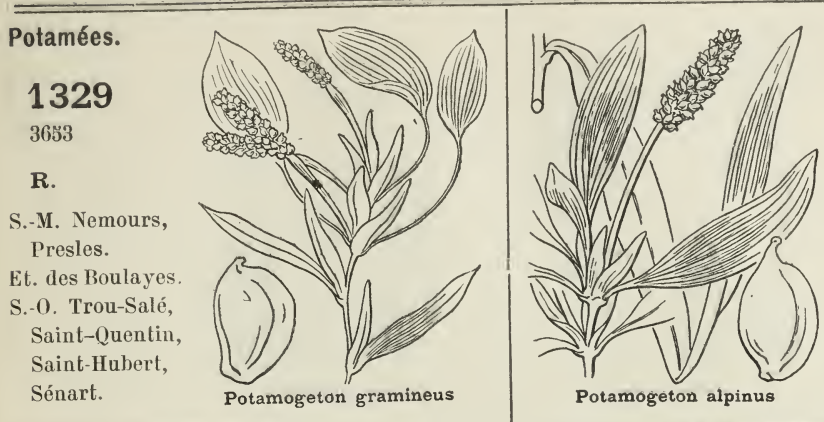

1330

3654

T. R.

E.-L. Dreux, Chartres.
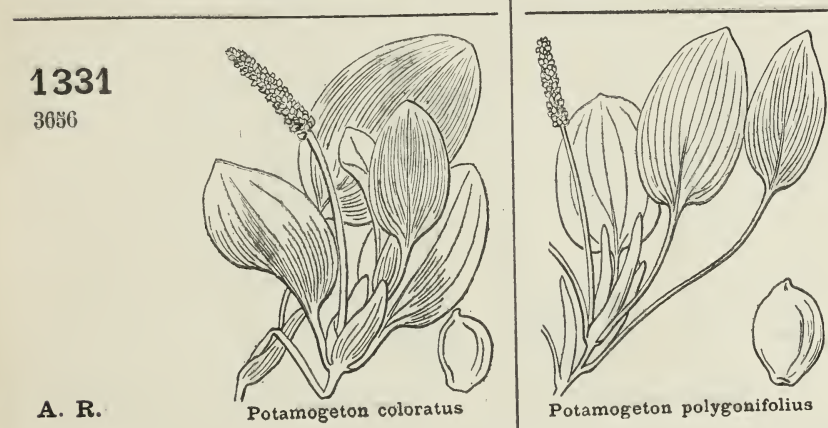

\section{2}

3657

R.

0. Neumoulin,

Mortefontaine, Compiègne.

S.-M. Larchant,

Fontainebleau.

S.-0. Rambouillet,

Potamogeton polygonifolius Cernay.

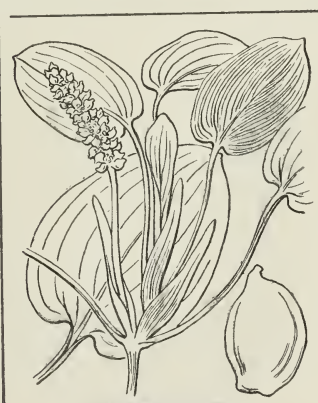

Potamogeton natars

1334

3659

3658

C.

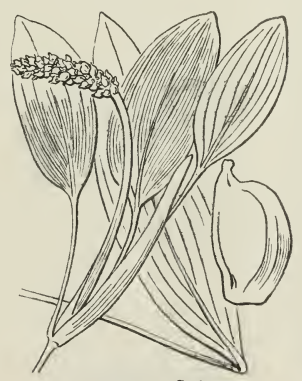

Potamogeton fluitans

1335

3663

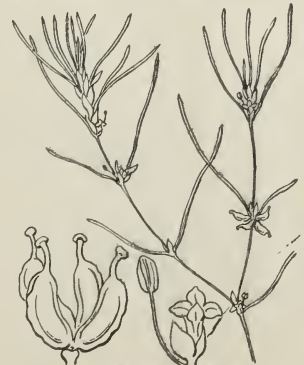

A. C.

Zannichellia palustris

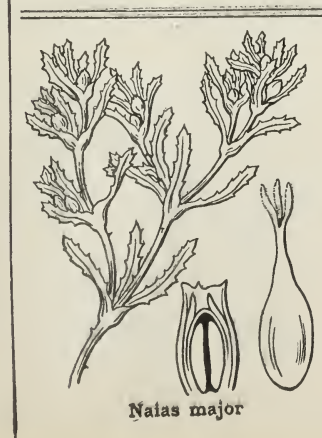

Naias major
Naiadées.

1336 3671 
FAM. 104. NAIADÉES - FAM. 105. LEMNACÉES FAM. 106. AROIDÉES
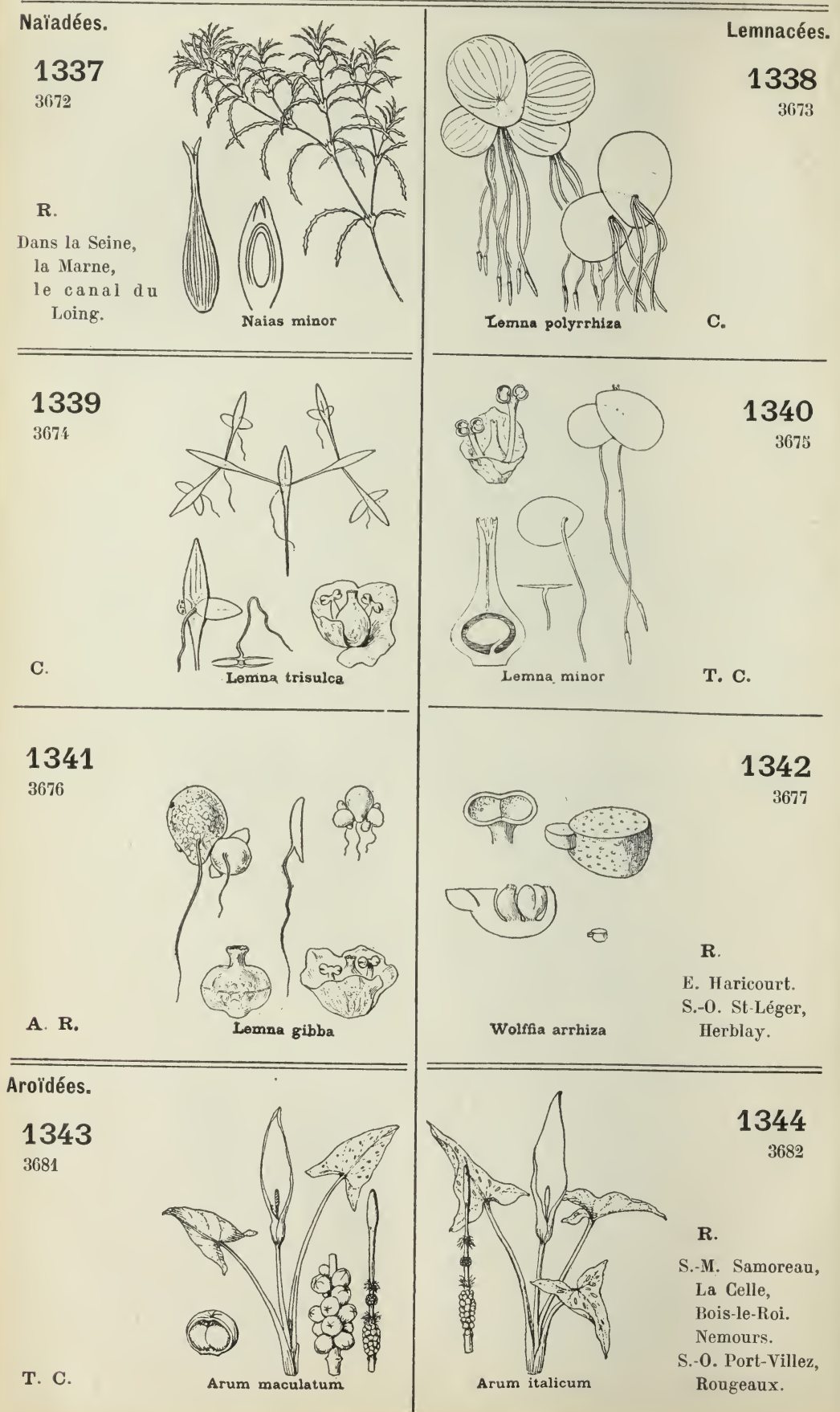
FAM. 107. TYPHACÉES -. FAM. 108. JONCAGINÉES FAM. 109. JONCÉES
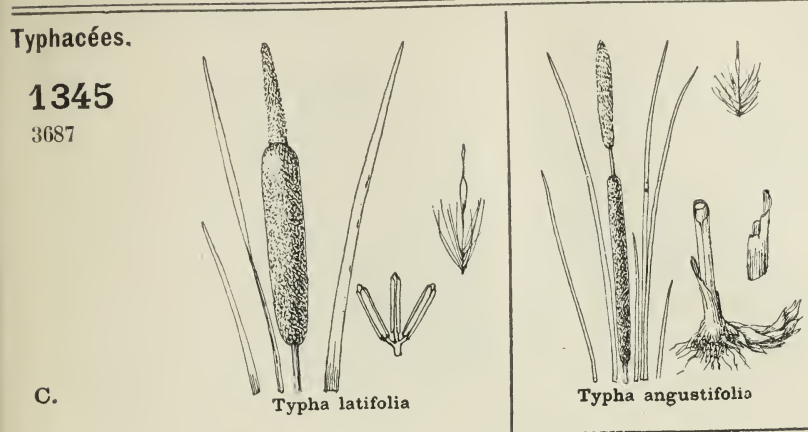

Typha angustifolio

1347

3693

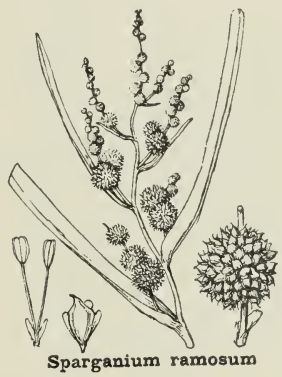

1349

3696

A. $\mathbf{R}$.

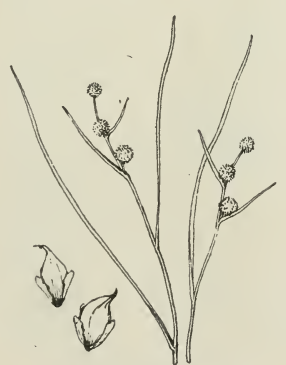

Sparganium minimum

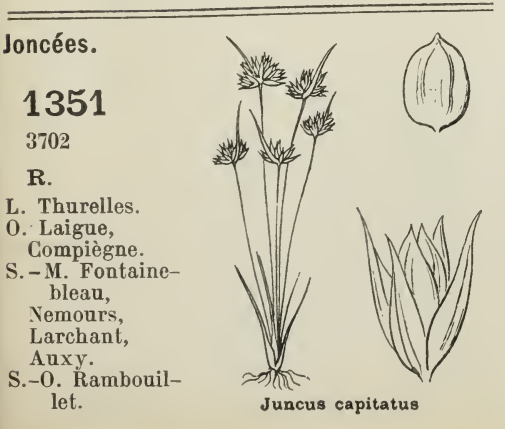

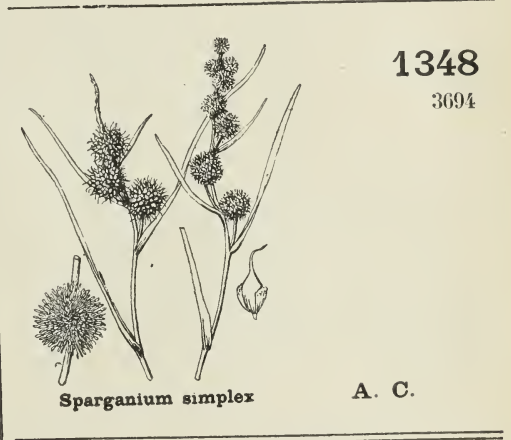
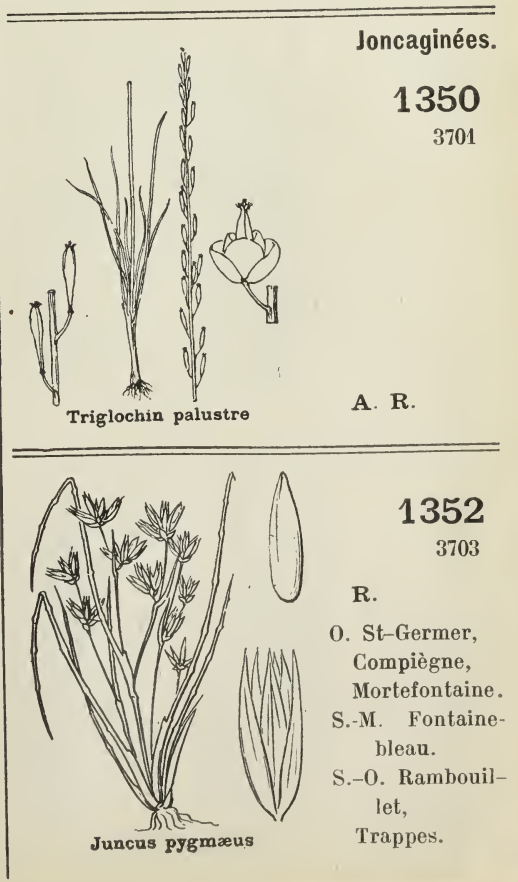
FAM. 109. - JONCÉES
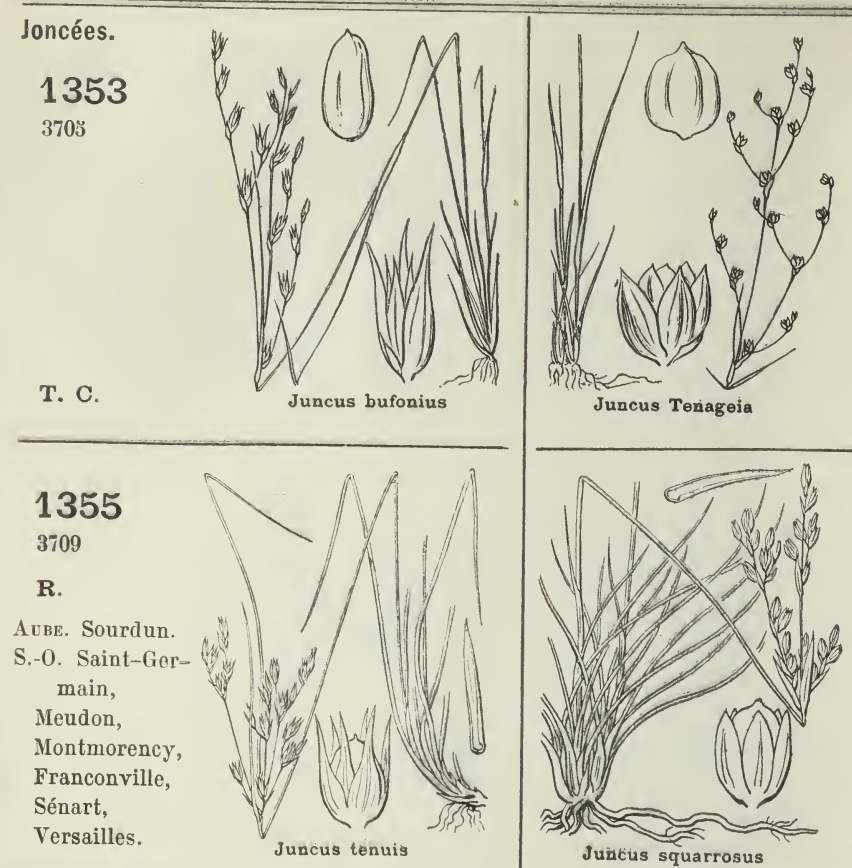

1354

3706

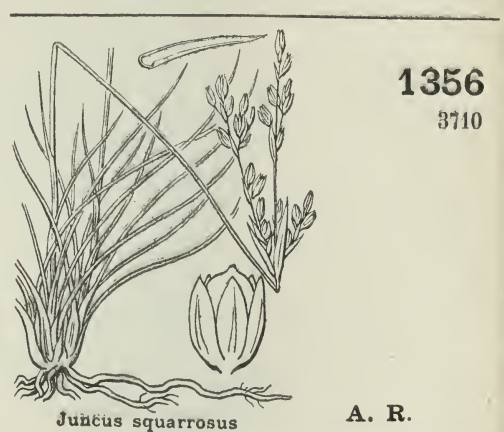

A. C.
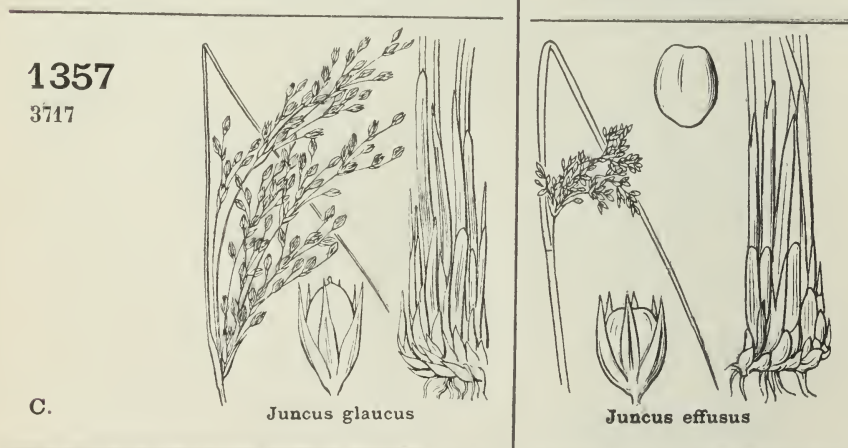

1358

3718
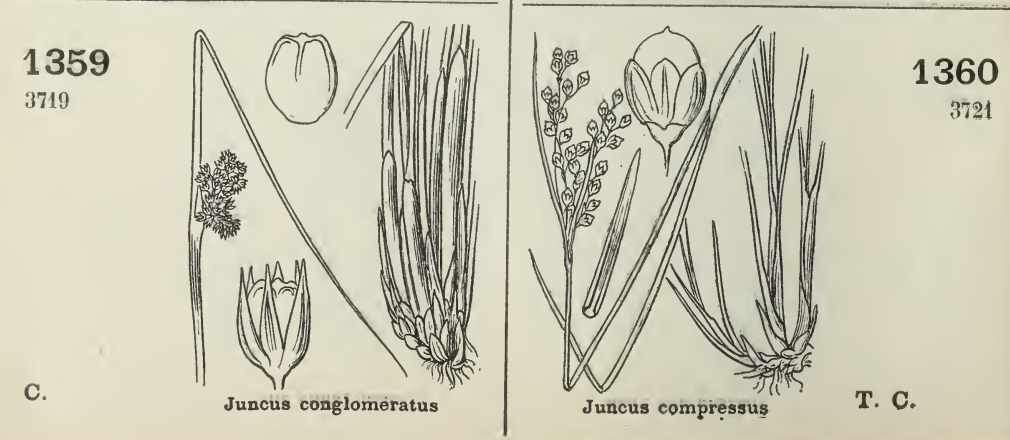
FAM. 109. - JONCÉES
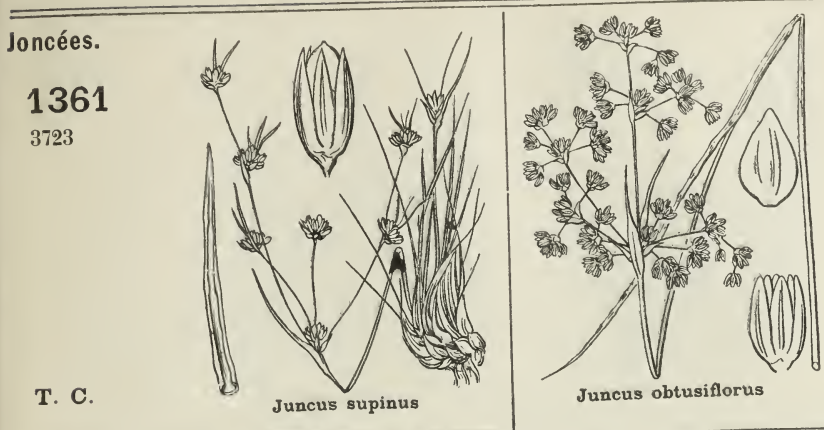

Juncus obtusiflorus

1362

3723
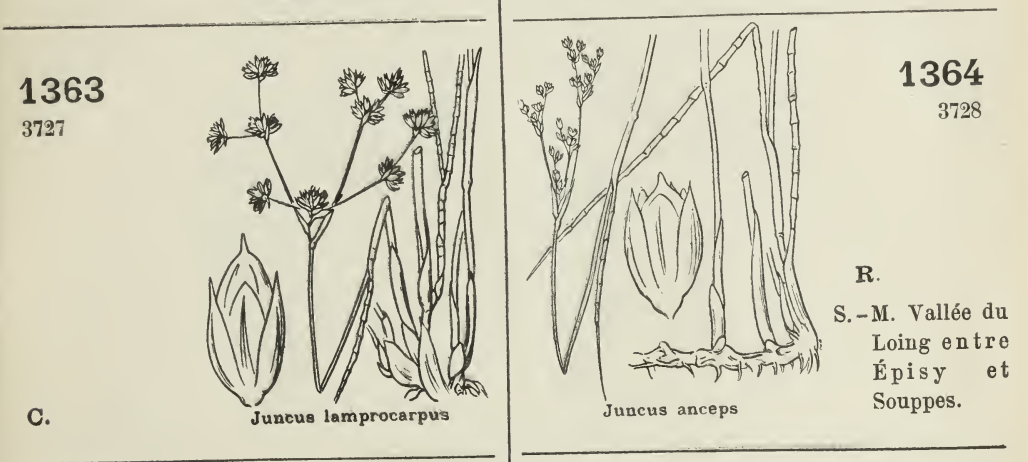

c.

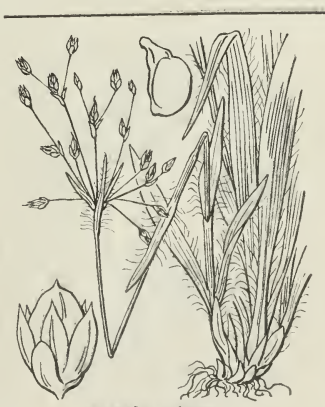

1366

1365

3729

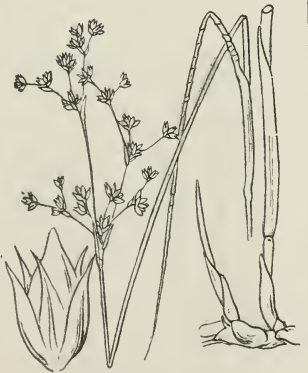

c.

Juncus silvaticus

Luzula pilosa

3732

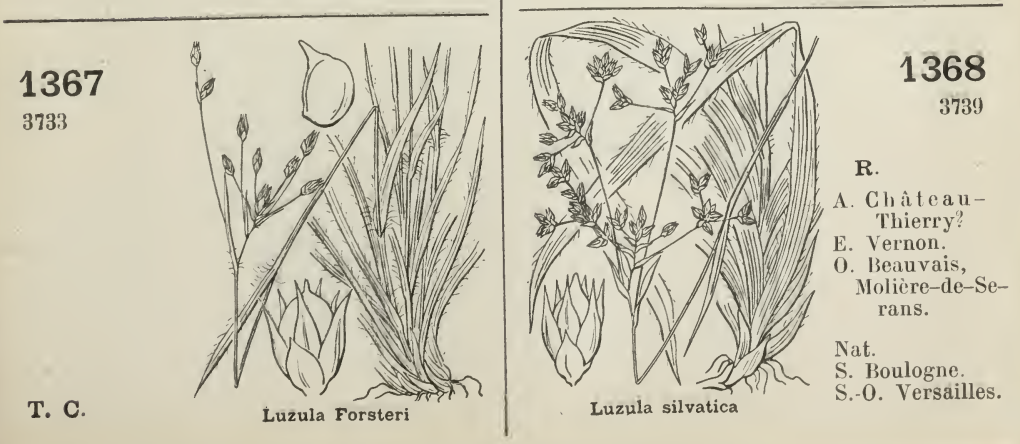

T. C.

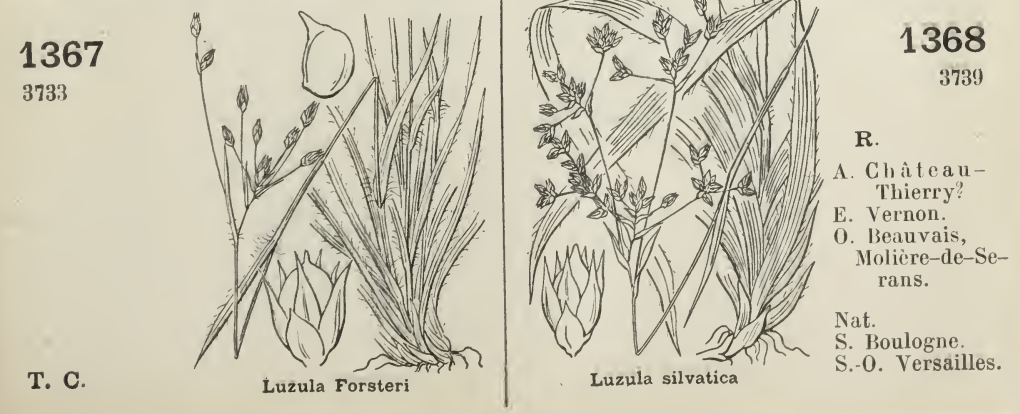

Luzula Forsteri

Luzula silvatica

c. 
172 FAM. 109. JONCÉES - FAM. 110. CYPÉRACÉES

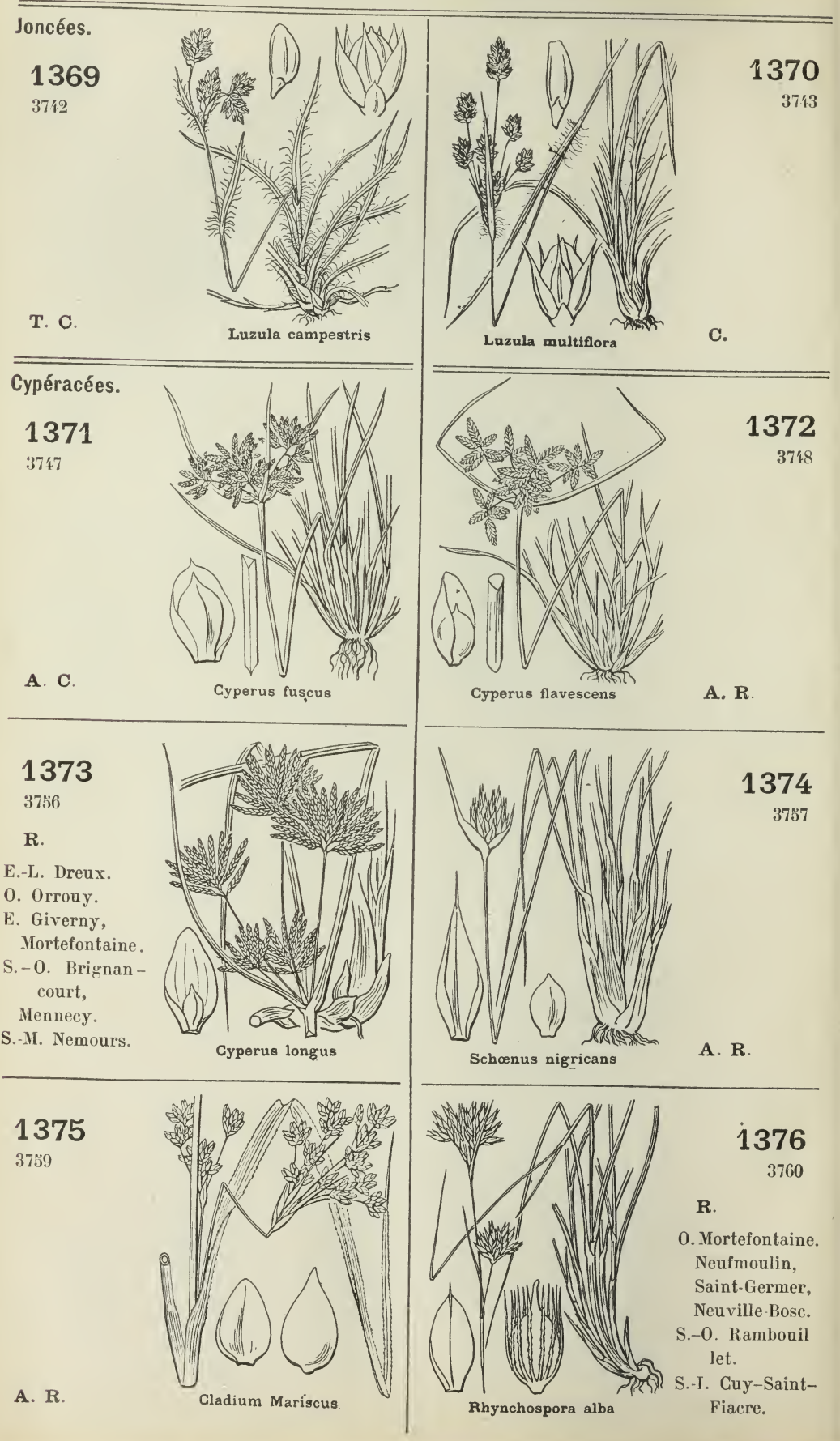



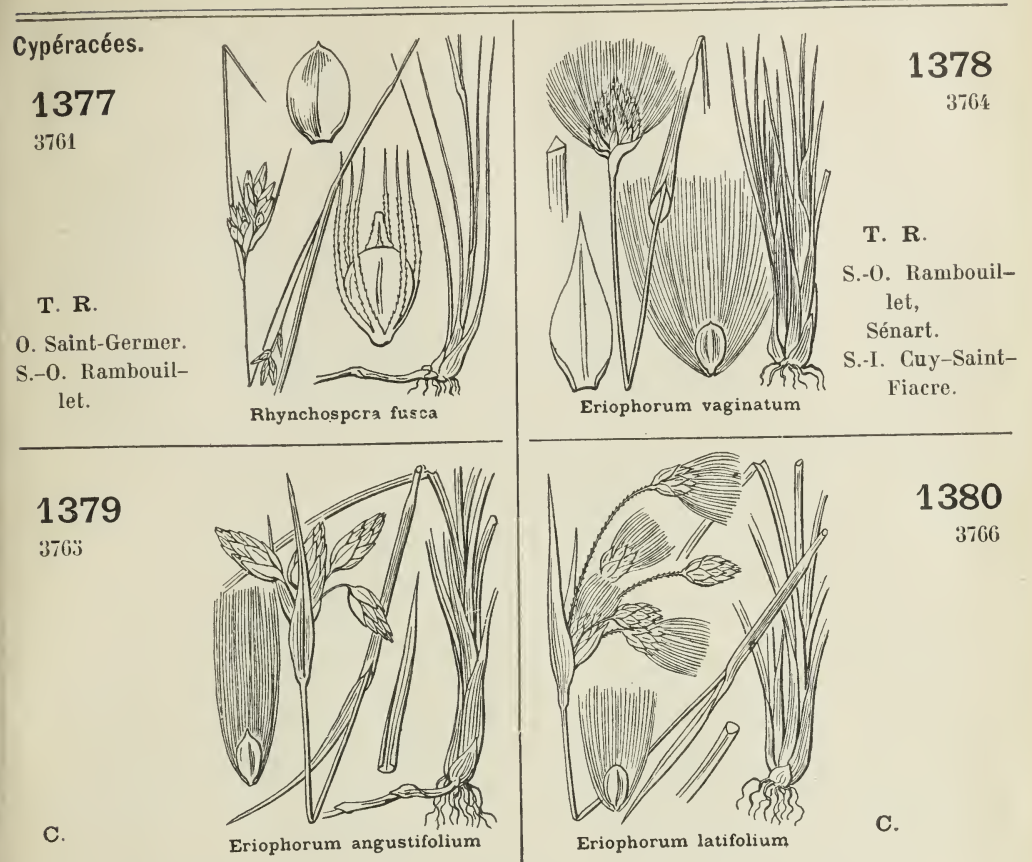

1380

3766

Eriophorum latifolium

C.

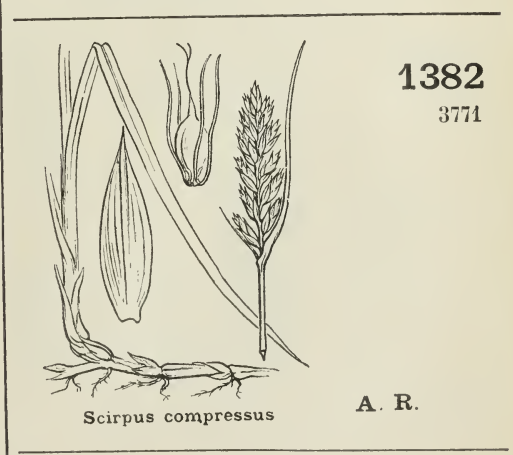

0. Besmont.

S.-M. Moret,

La Genevraye.

S. - 0. Rambouillet,

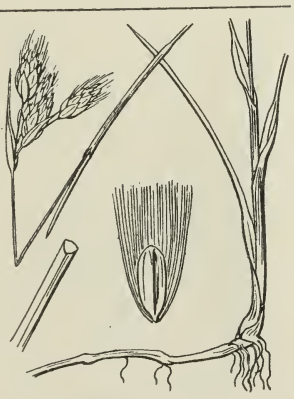

Les Essarts.

Eriophorum gracile

\section{3}

3772

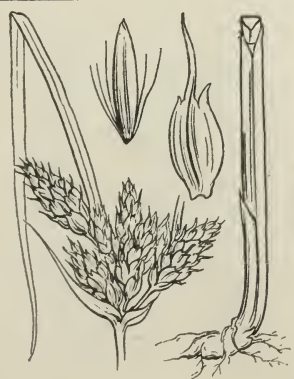

T. C.

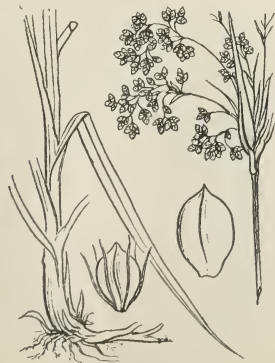

Scirpus silvaticus
1384

3773 


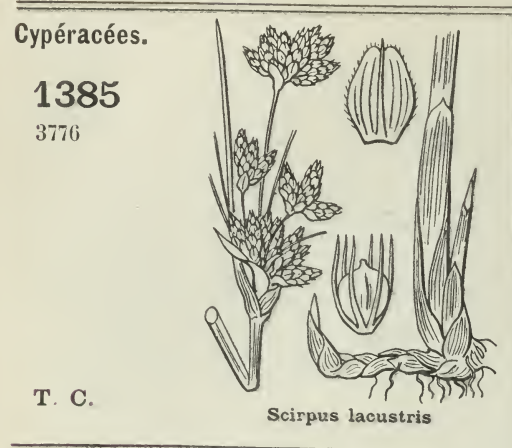

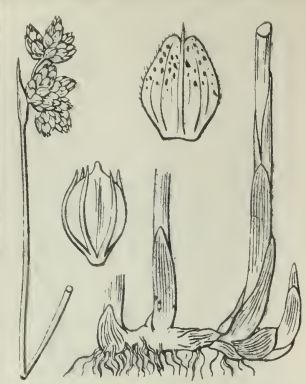

Scirpus Tabernzmantani

A. $\mathbf{R}$.
1386

3777
1387

3780

T. $\mathbf{R}$.

S.-0. Bords de la Seine à Villez.

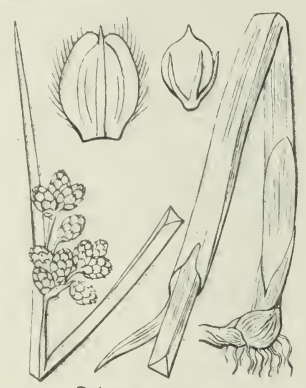

Scirpus triqueter
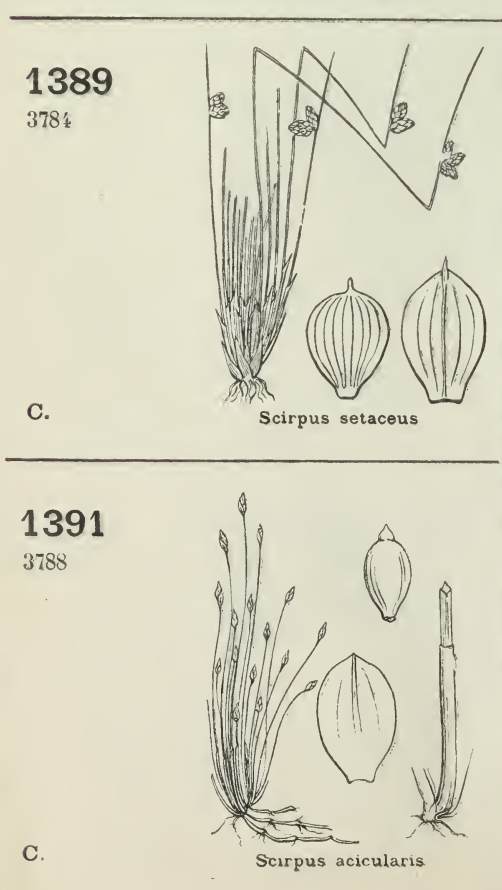

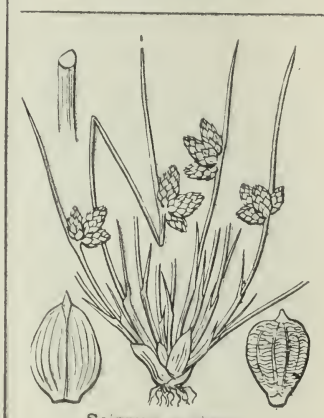

Scirpus supinus

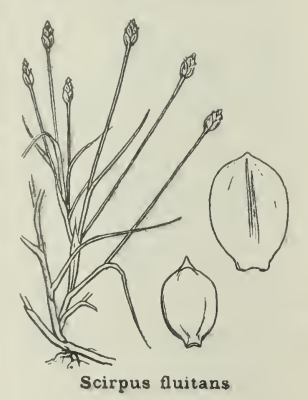

1390

3786

R.

0. Mortefontaine,

S.-M. Fontainebleau.

S.-0. Rambouillet,

Aigremont.

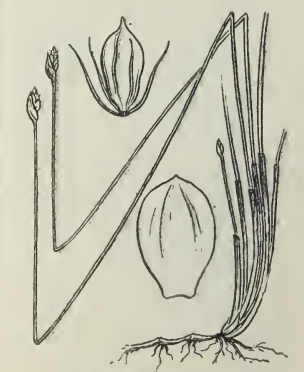

1392

3790
Scirpus pauciflorus
A. $\mathbf{R}$. 


Cypéracées.
1393
T. R.
O. Villers
Saint-Barthé-
lemy,
Belloy.
S.-0. Rambouil-
let.
S.--. Cuy-Saint-
Fiacre.

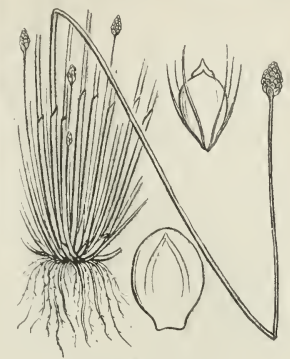

Scirpus ovatus
1394

3792

R.

A. Charly.

0. Mortefontaine, Compiègne.

S.-0. Meudon,

Trou-Salé,

Saint-Quentin, Rambouillet.

\section{6}

3795
A. $\mathbf{R}$.

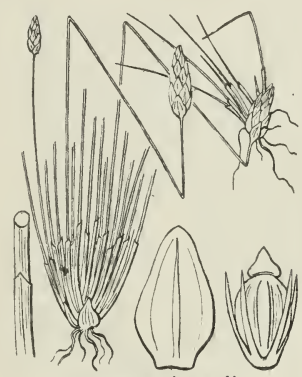

Scirpus multicaulis

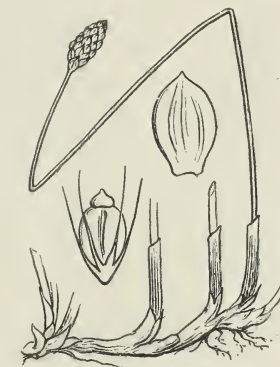

Scirpus palustris
T. C.

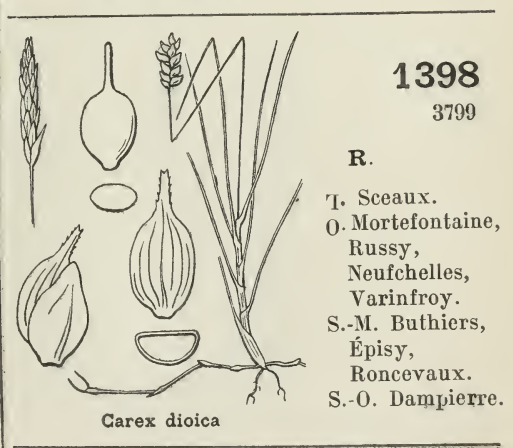

A. C.

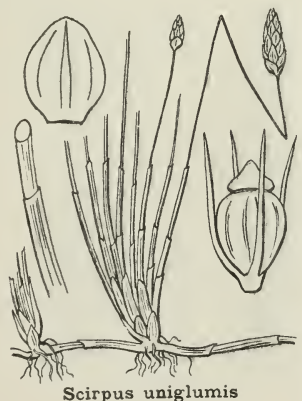

Scirpus uniglumis

\section{9}

3800

R

A. Silly-la-Poterie.

o. Chantilly, II a reuil-suroureq.

S.-MI. Crouy-surOureq.

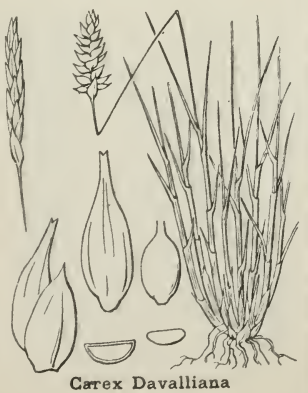

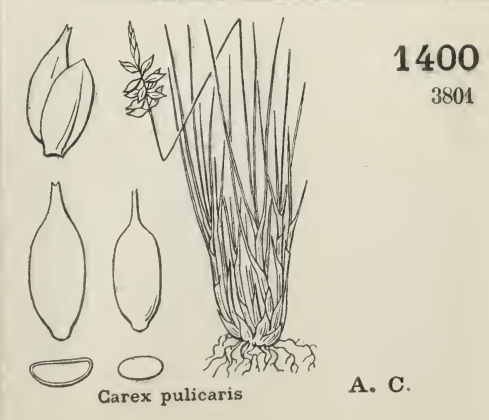



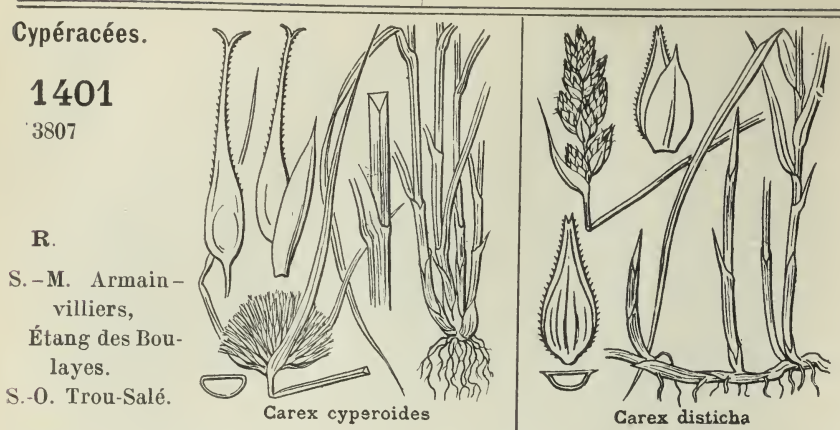

Carex disticha
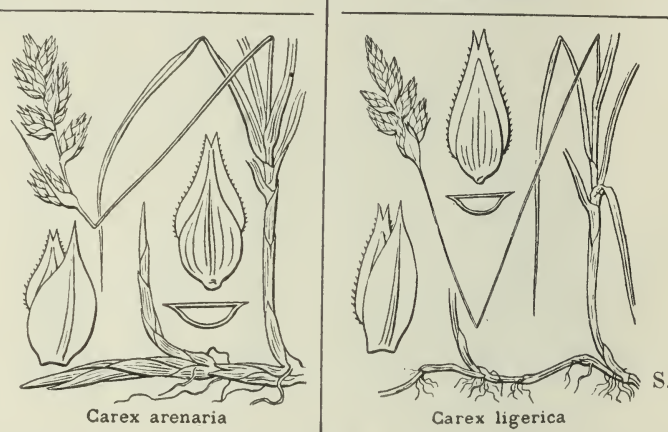

1405

3817

A. $\mathbf{R}$.

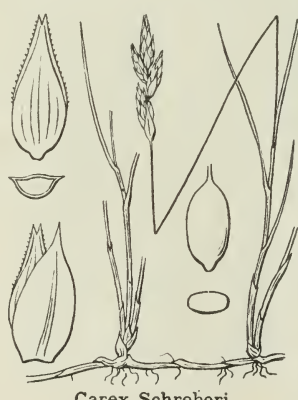

Carex Schreberi

\section{7}

3820

R.

A. Silly-la-Poterie.

E. Sainte-Geneviève.

I. Malesherbes.

o. Ermenonville.

s.-M. Buthiers,

Nemours.

S.-0. Mennecy,

Maisse,

Lardy.

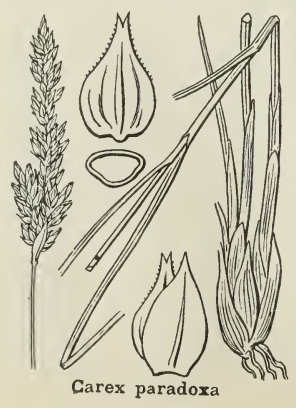

1402

3814
1404

3816
Carex ligerica

T. R.

S.-0. Lévy près Dampierre.

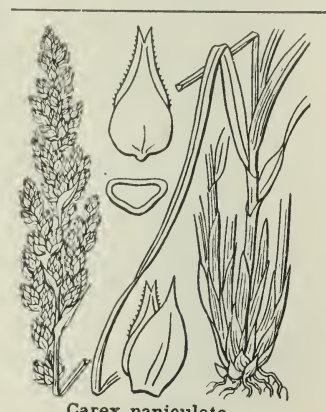

Carex paniculata

C.

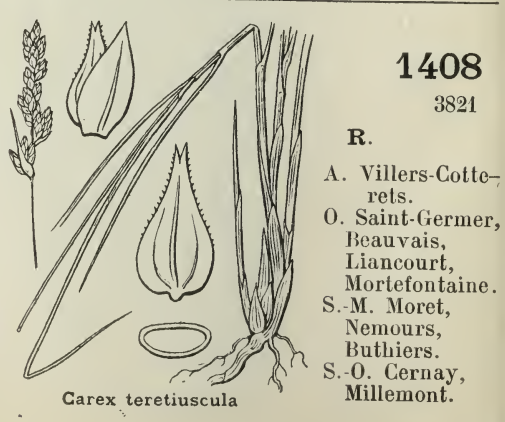

1406

3819 
FAM. 110. - CYPÉRACÉES

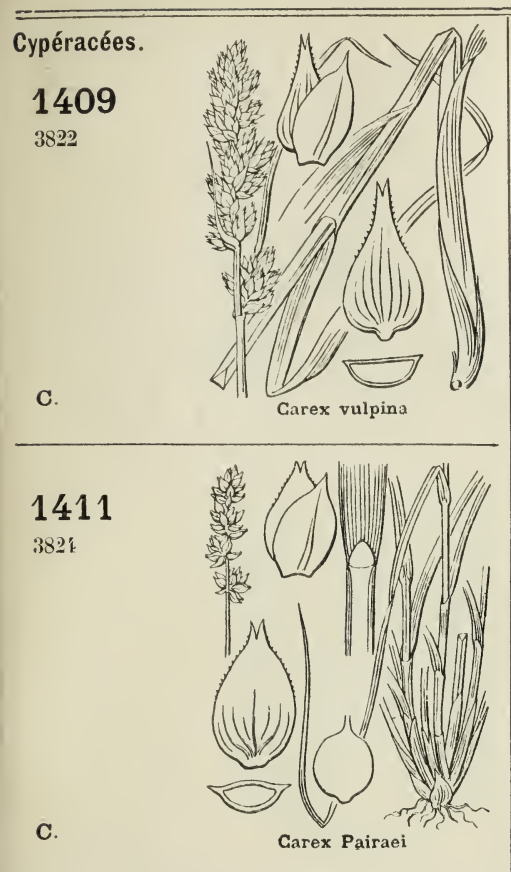

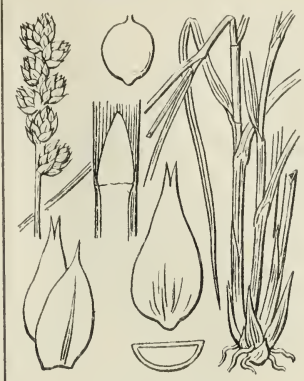

Garex muricata

T. C.

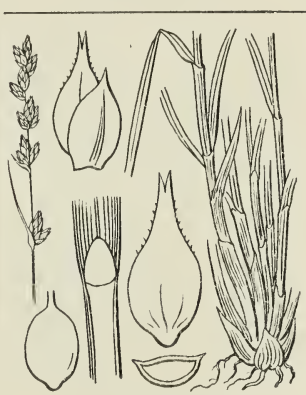

1412

3825
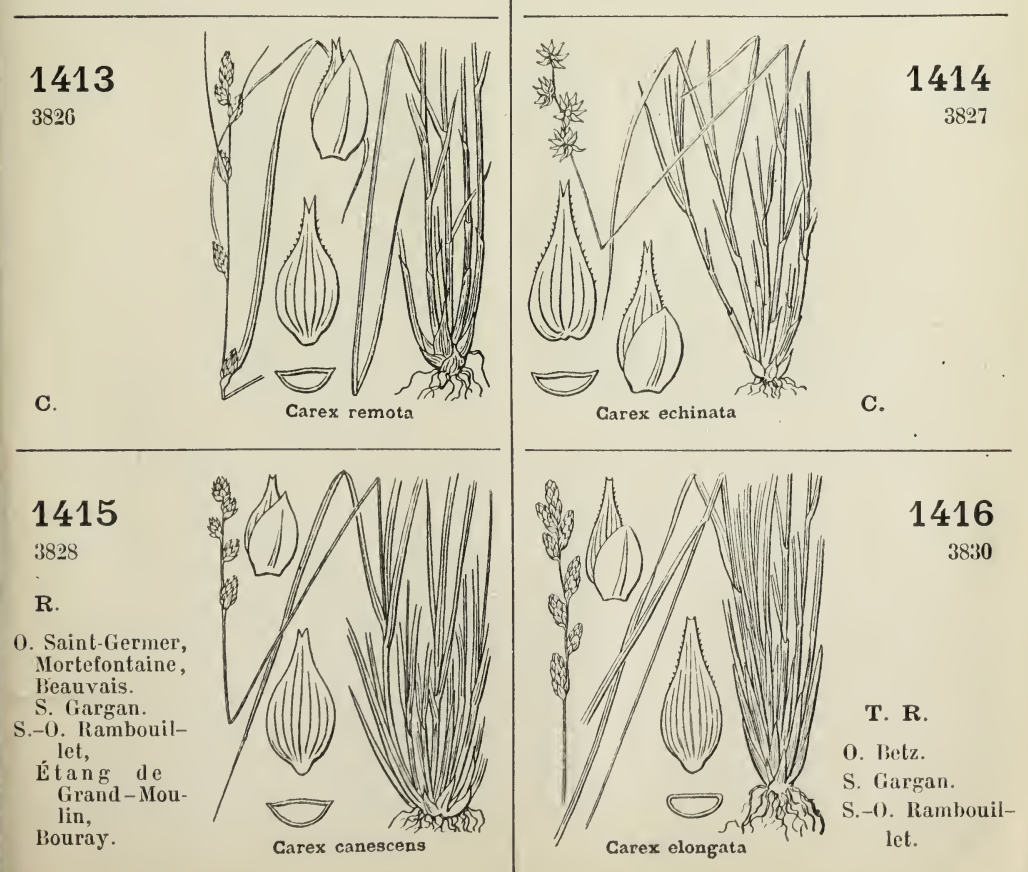

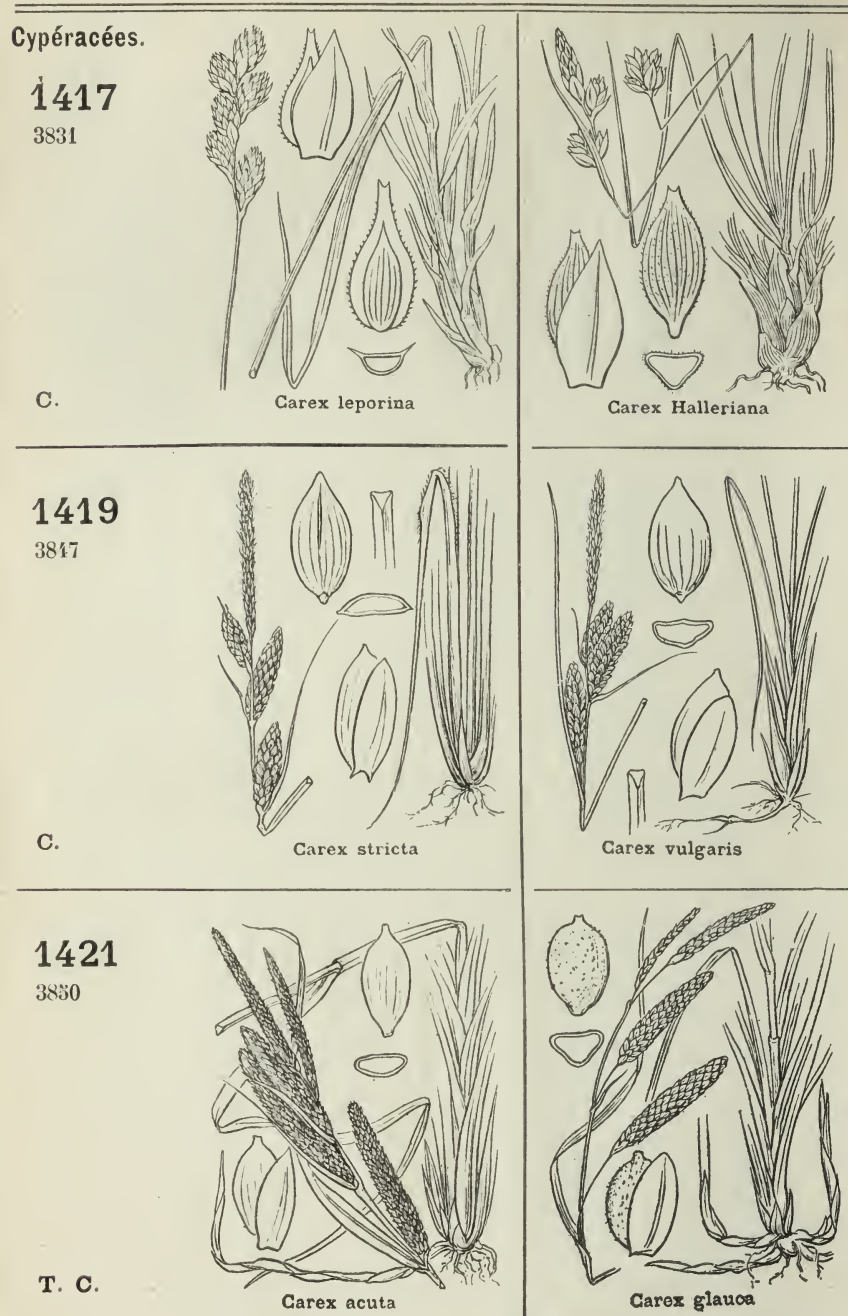

1423

3856

T. C.

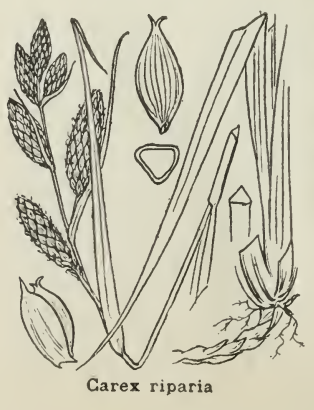

Carex Halleriana

$$
\text { Carex vulgaris }
$$

Cares glauoa

1418

3836
T. $\mathbf{R}$

S. - 0. Boinveau près Lardy, Boissy-le-Cuté, Étampes.

1420

3819

A. $\mathbf{R}$.

1422

$38 \% 2$

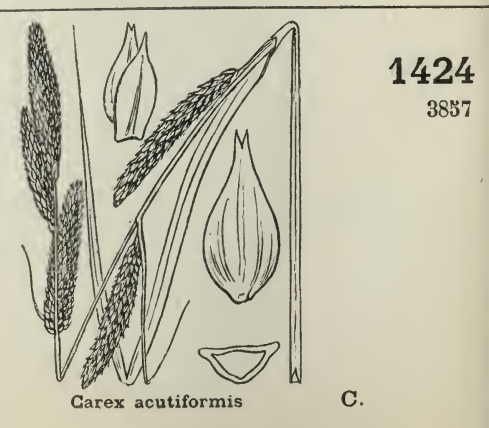



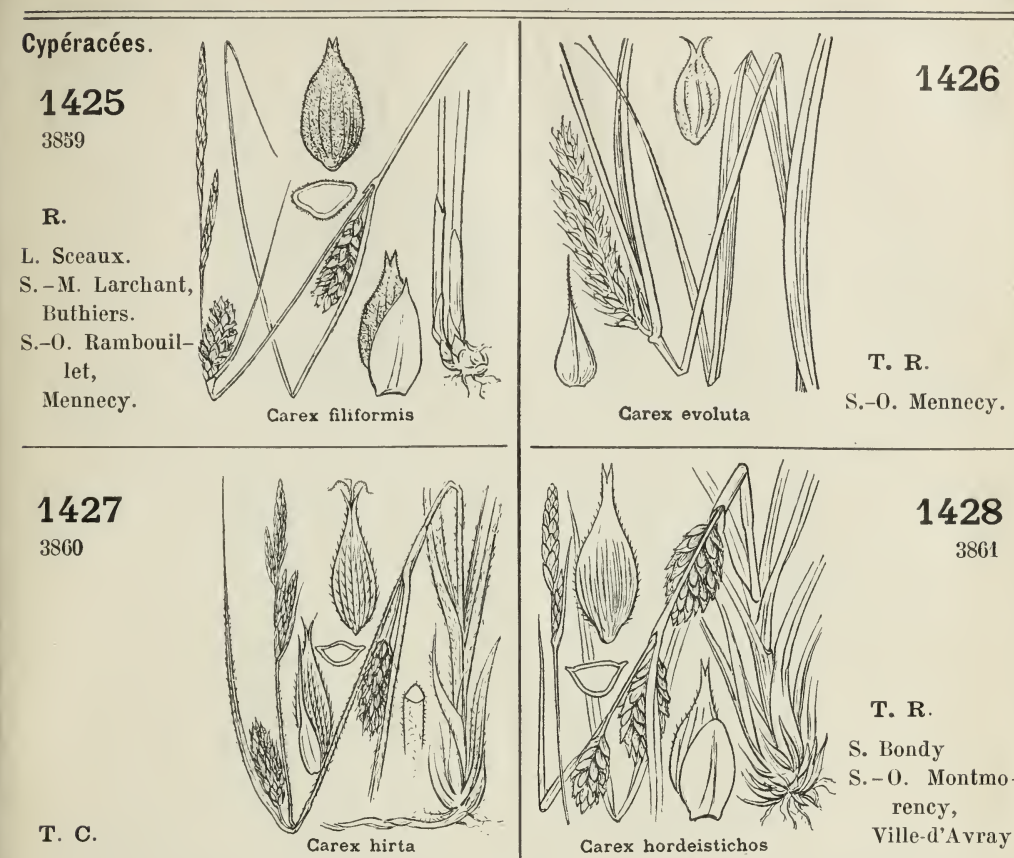

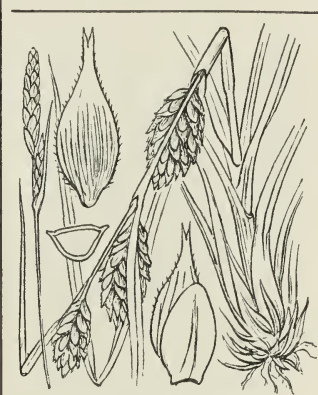

Carex hordeistichos
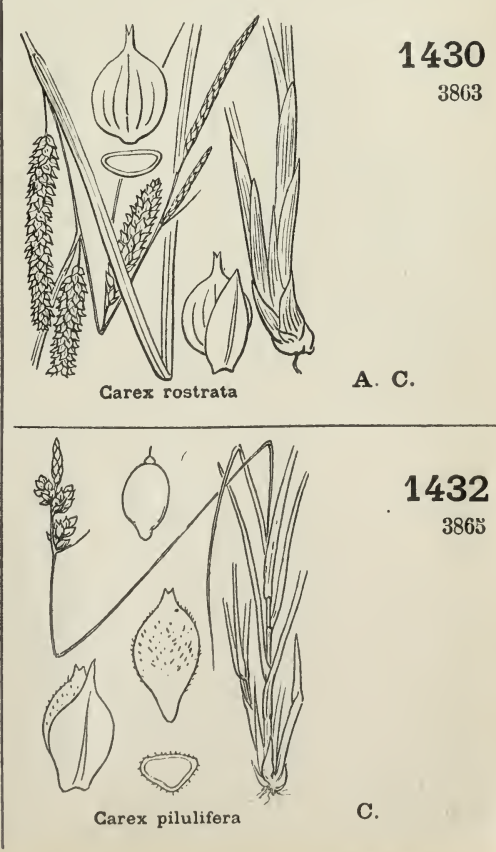

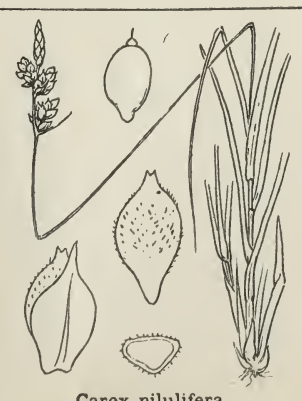

Carex pilulifera
1428

3861

S. Bondy

S. - O. Montmorency,

Ville-d'A vray?
T. $\mathbf{R}$.
1432

$386{ }^{\circ}$

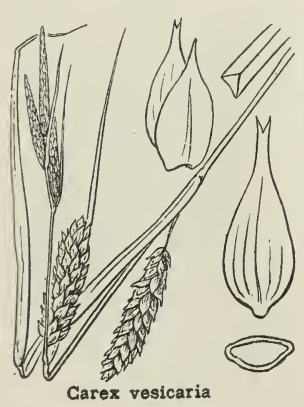

\section{1}

3864

T. $\mathbf{R}$.

E.-L. Dreux.

S.-M. Fontainebleau.

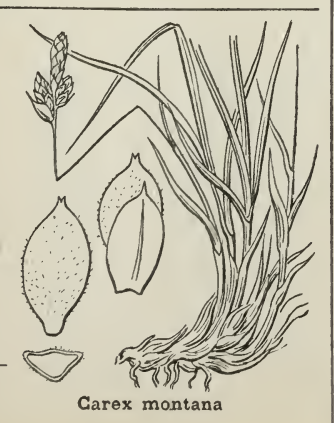




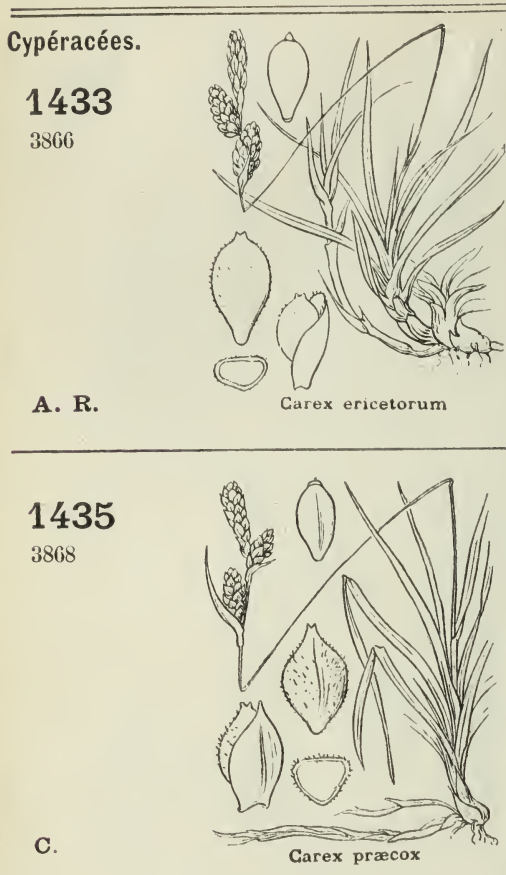

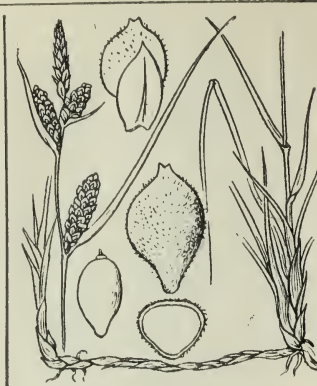

Carex tomentosa

A. C.

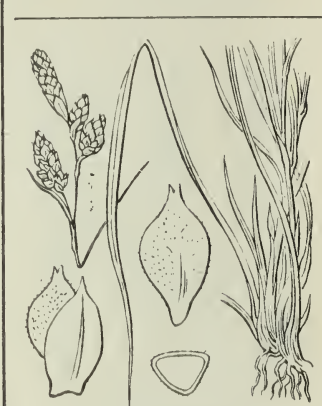

Carex polyrrhiza

A. $\mathbf{R}$.

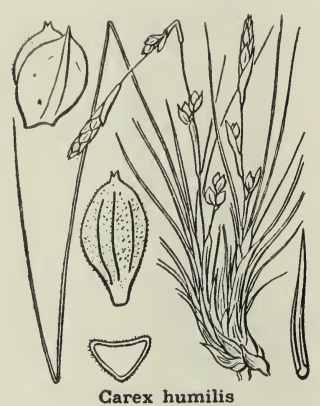

1440

3891
1434

3867
3873

A. Villers-Cotterets.

0. Compiègne, Tillet, Hermes.

S. - M. Fontainebleau.

S.-0.Valmondois.

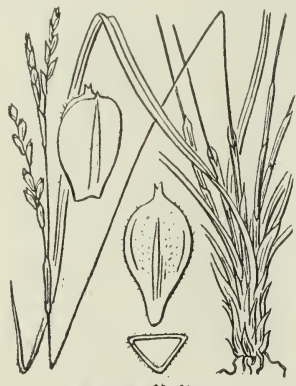

Carex digitata

\section{9}

3878

T. $\mathbf{R}$.

S - M . Fontainebleau.
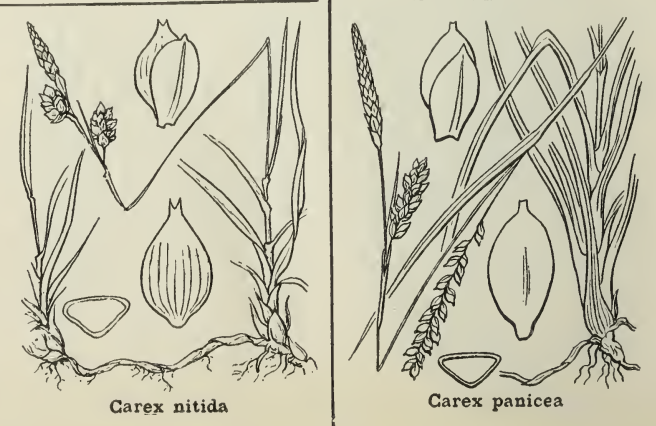

1436

3869

T. $\mathbf{R}$.

0. Grépy.

S.-M. Vallée du Loing,

Épisy, Montigny, Nemours. 
FAM. 110. - CYPÉRACÉES

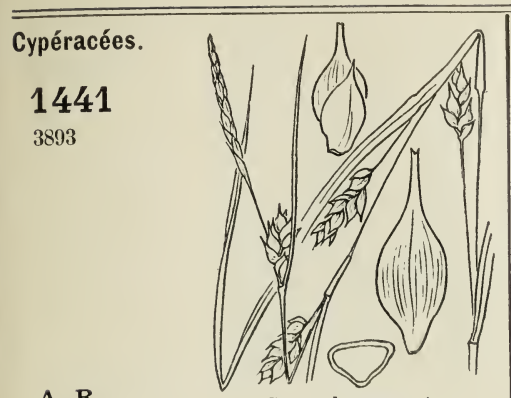

A. $\mathbf{R}$.

Carex depauperata

\section{3}

3896

T. C.

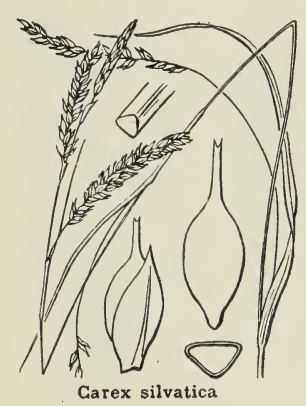

1445

3898

A. $\mathbf{R}$

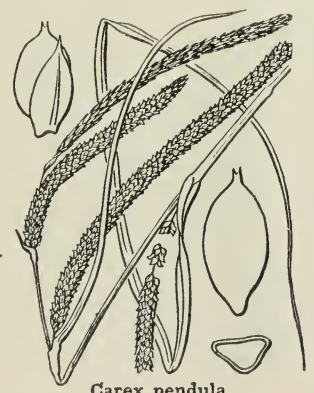

1447

3902

c.

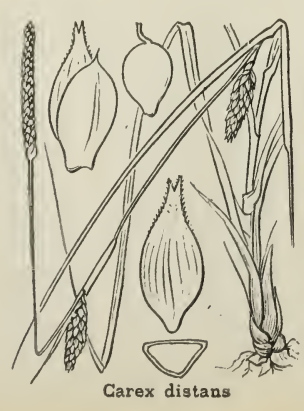

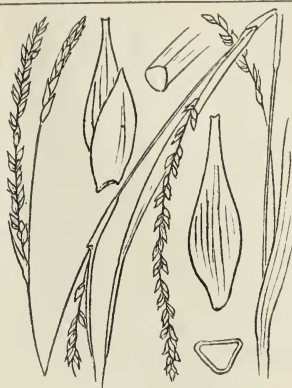

Carex strigosa

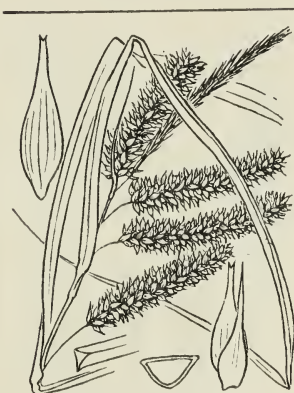

Carex Pseudo-Cyperus

R.

A. Villers-Cotterets.

0. Compiègne, Beauvais,

Serans,

Hallatte,

Laigue.

\section{4}

3897

A. C.

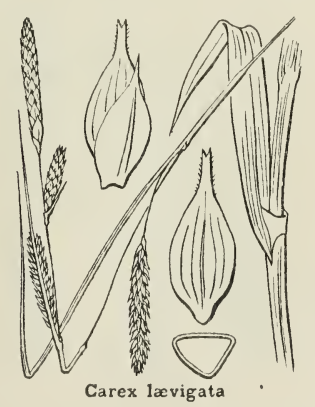

1446

3900

R.

A. Villers-Cotterets.

E. Gisors.

0. Neuville-Bosc.

S.-0. Rambouillet,

Arthies.

\section{8}

3903

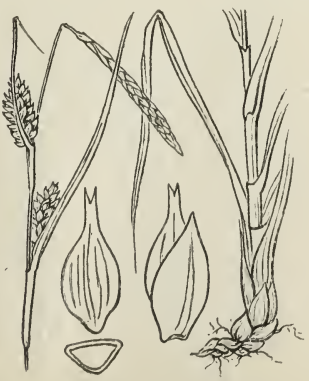

Carex Hornschuchiana
A. C. 
182 FAM. 110. CYPÉRACÉES - FAM. 111. GRAMINÉES
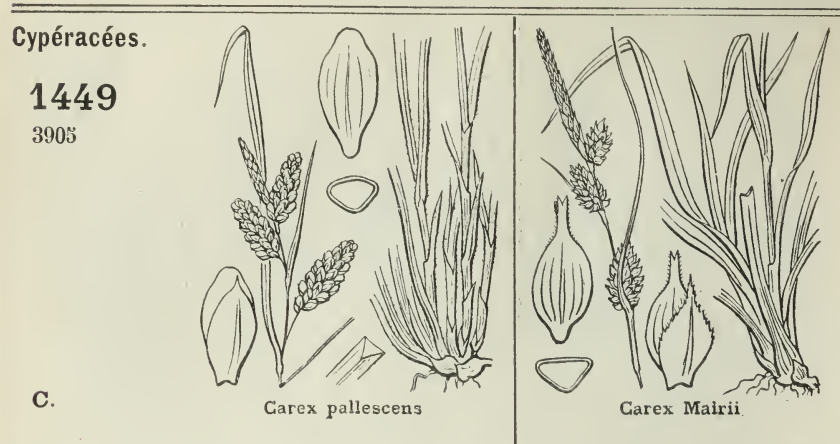

1450

3907
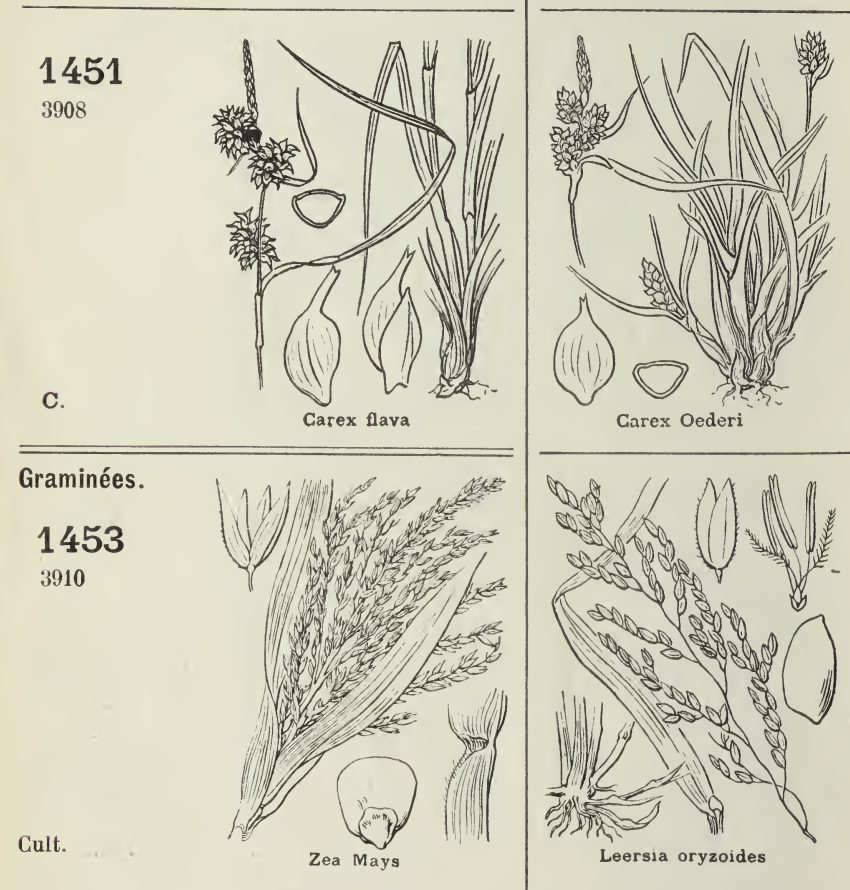

1452

3909

A. $\mathbf{R}$.

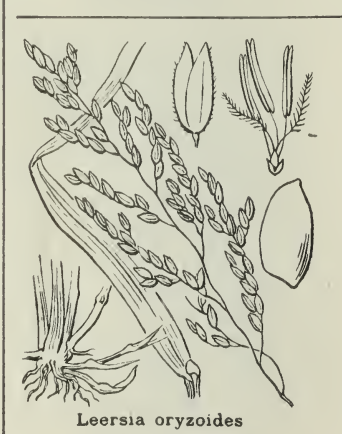

A. C.

1454

3913
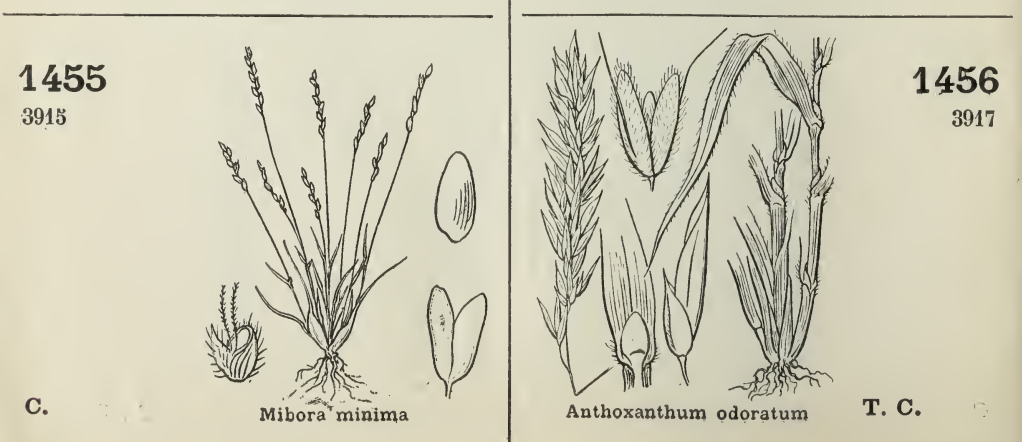


Graminées.
$\begin{aligned} & \text { S. -0. Vaux-de- } \\ & \text { Cernay. }\end{aligned}$

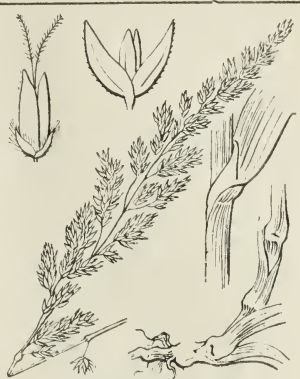

Phalaris arundinacea

C.

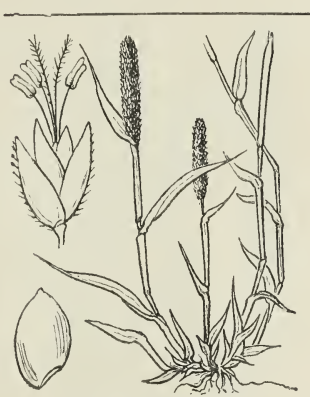

Phalaris canariensis

Cult. et subsp.
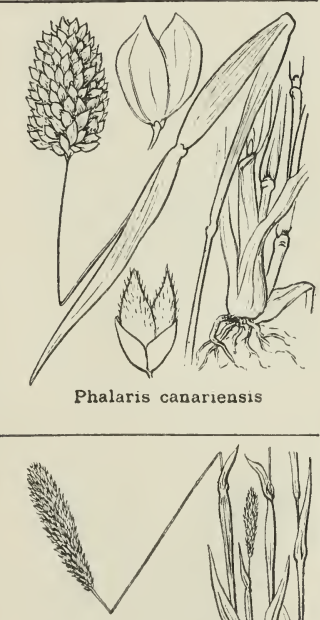

R.

o. Fleurines, Ermenonville.

S. -0. Beauchamp. Entre Argenteuil et Bezons.

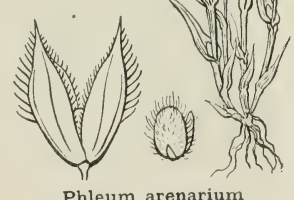

Phleum arenarium

\section{3}

3934

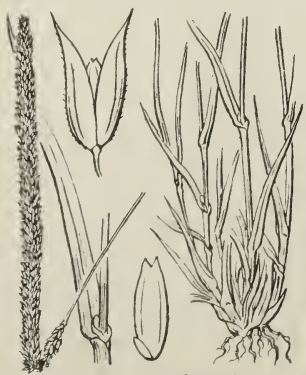

C

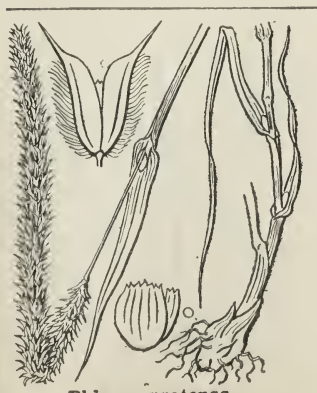

Phleum pratense
1458

3919

3930

Crypsis alopecuroides

T. $\mathbf{R}$.

S. Bords de la Seine.

S.-0. Étangs du Trou-Salé et de St-Quentin.

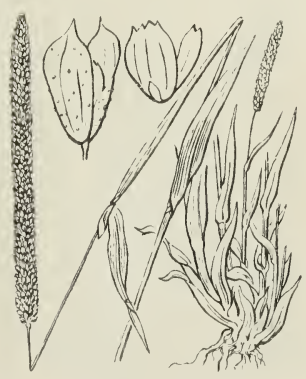

1462

3933

T. $\mathbf{R}$.

0. Beauvais.

S.-M. Provins.
1464

3936 


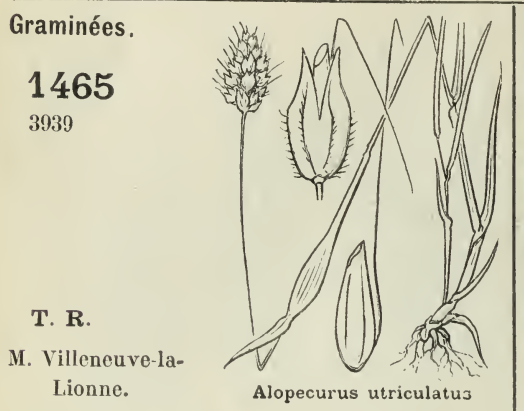

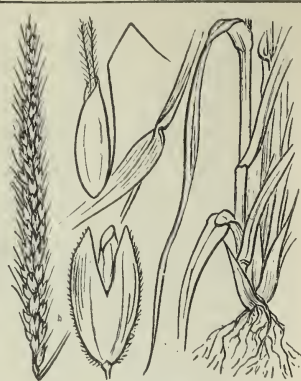

Alopecurus agrestis

T. C.

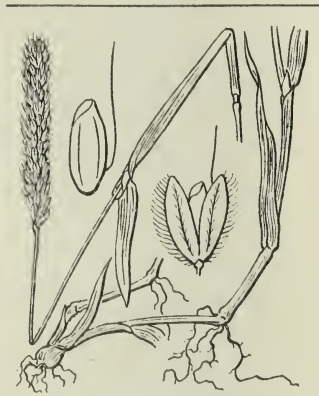

Alopecurus geniculatus

C.

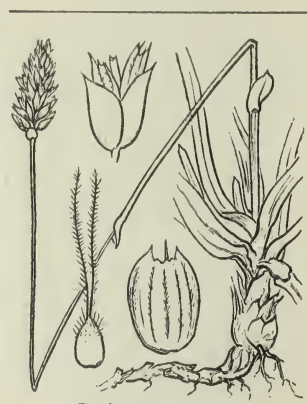

Sesleria cærulea

A. $\mathbf{R}$.

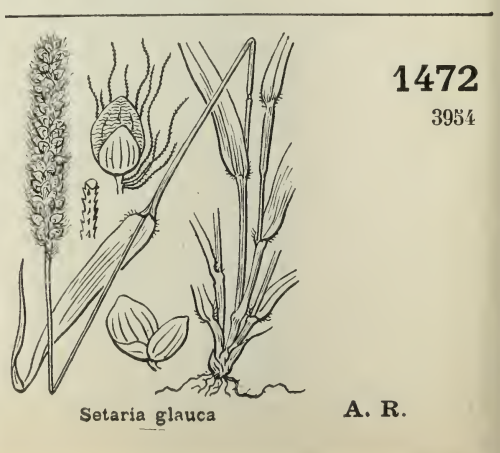




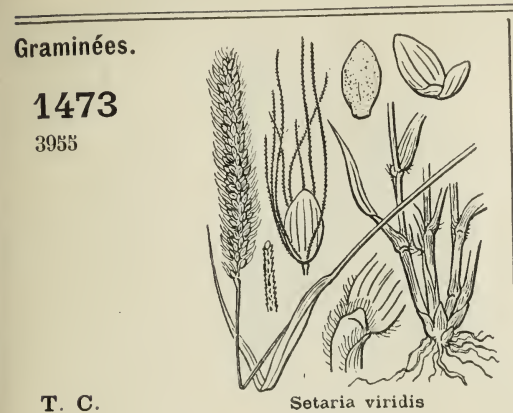

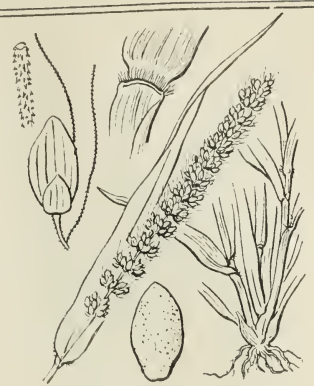

Setaria verticillata

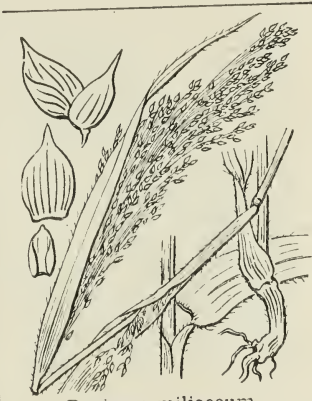

Panicum miliaccus
1474

3956
Cult. et subsp.

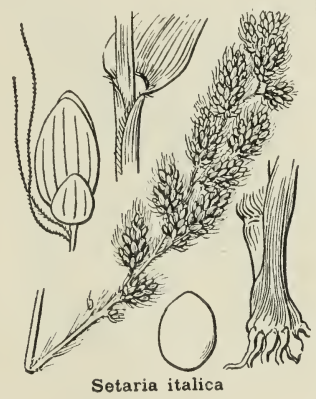

1477

3963

C.

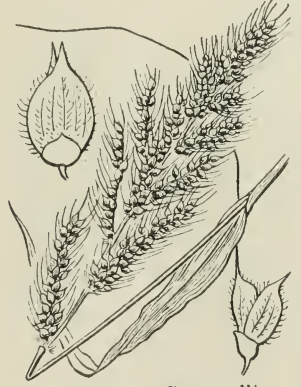

Echinochloa Crus-galli

1479

3963

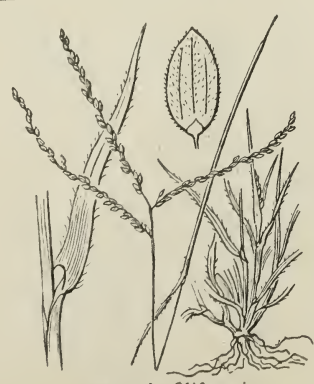

A. C.

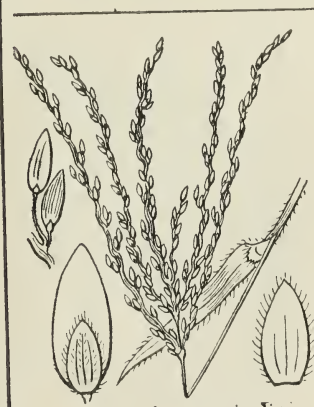

Digitaria sanguinalis

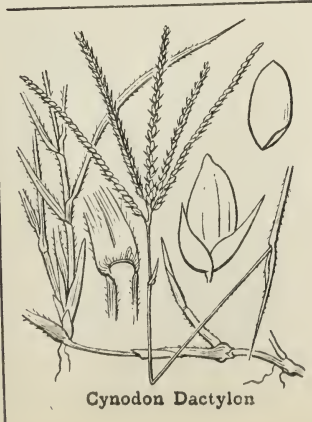

c.

1476

3958

Cult. et subsp.

1478

3964

1480

3968 

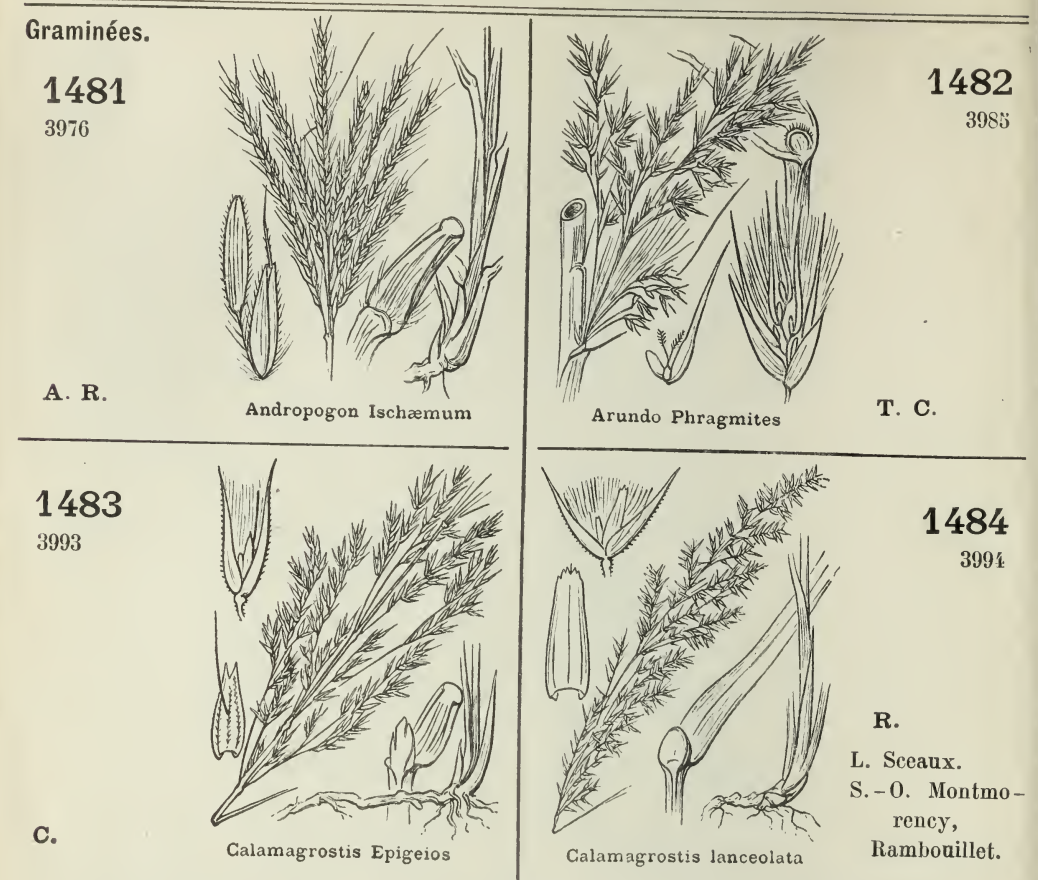

T. C.

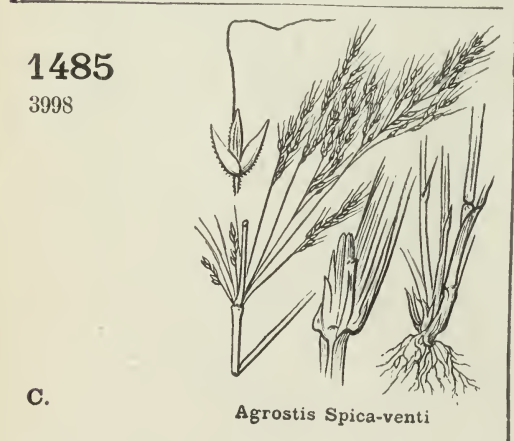

Calamagrostis lanceolata

\section{4}

3994

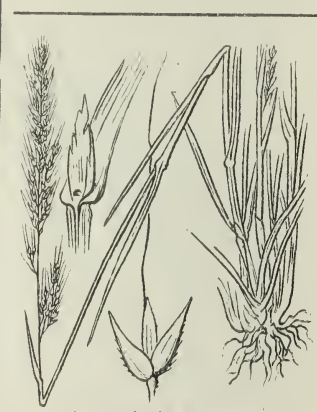

R.

L. Sceaux.

S. - 0. Montmorency,

Rambouillet.

Agrostis interrupta

1486

3999

A. $\mathbf{R}$.

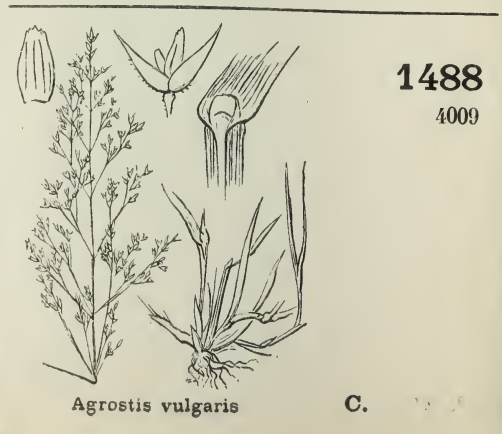

c.

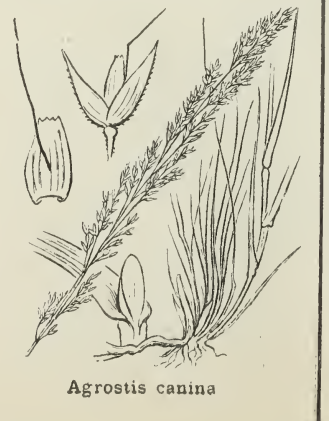

4009 
FAM. 111. - GRAMINÉES

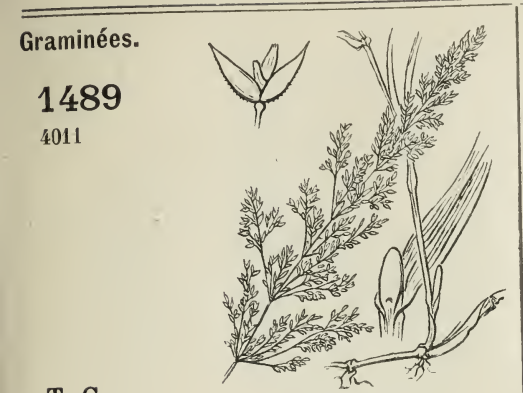

T. C.

Agrostis alba

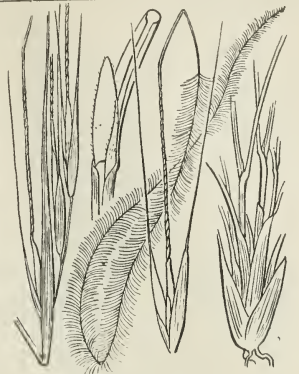

Stipa pennata

\section{0}

4022

R.

E. Les Andelys.

S. - M. Fontainebleau,

Nemours,

Auxy.

S.-0. La RocheGuyon, Maisse, Lardy.
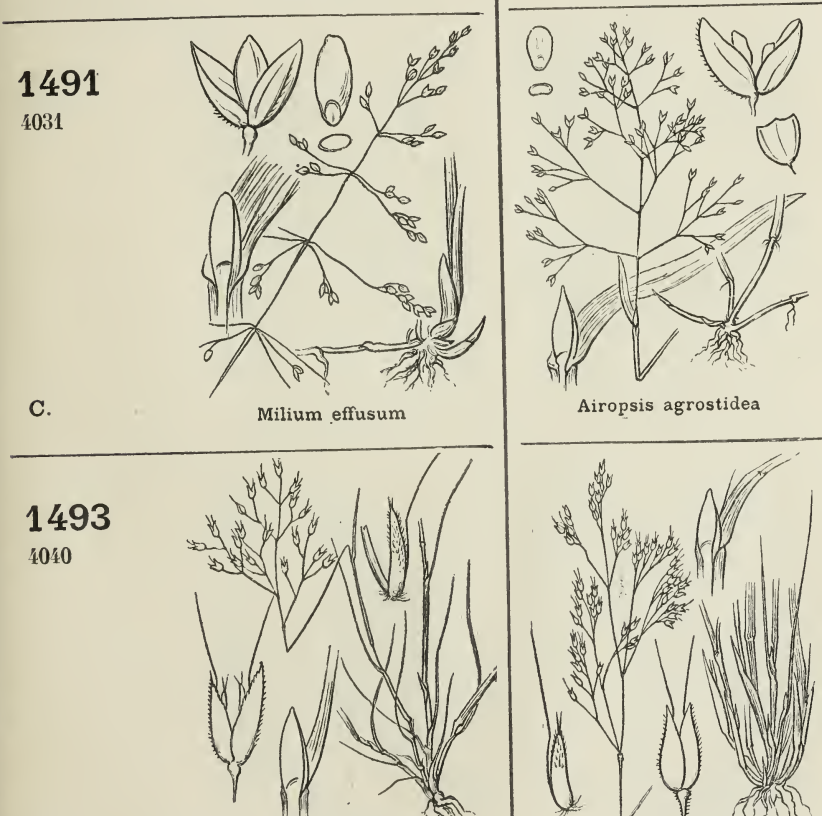

C.

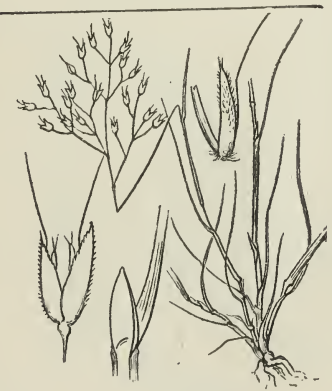

Aira caryophyllea

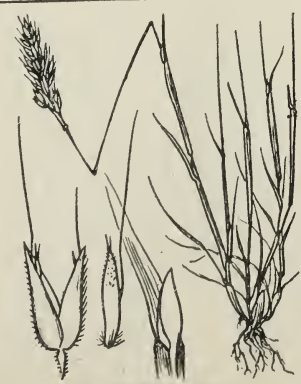

C.

Aira præcox

\section{5}

4043

c.
Airopsis agrostidea

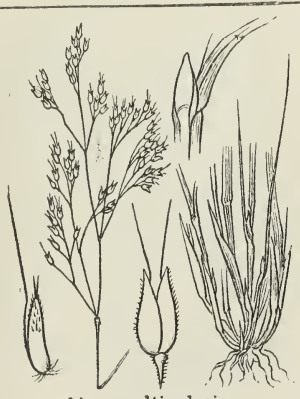

Aira multiculmis

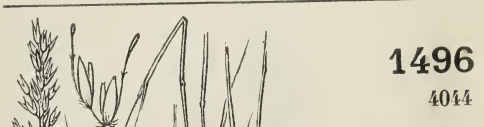

S. - M. Fontaine- bleau.

1494

4041

T. $\mathbf{R}$

A. $\mathbf{R}$.

4044

1492

4033 
FAM. 111. - GRAMINÉES

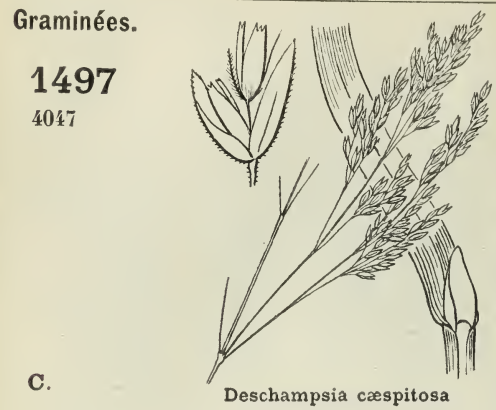

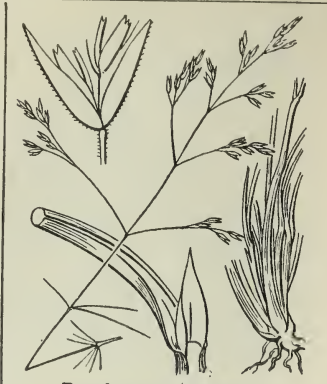

Deschampsia media
1498

4048

T. $\mathbf{R}$.

Aube. Prairies du Mériot.

S. -M. Melz,

Saint-Sauveur, Cote au calcaire à la Genevraye.
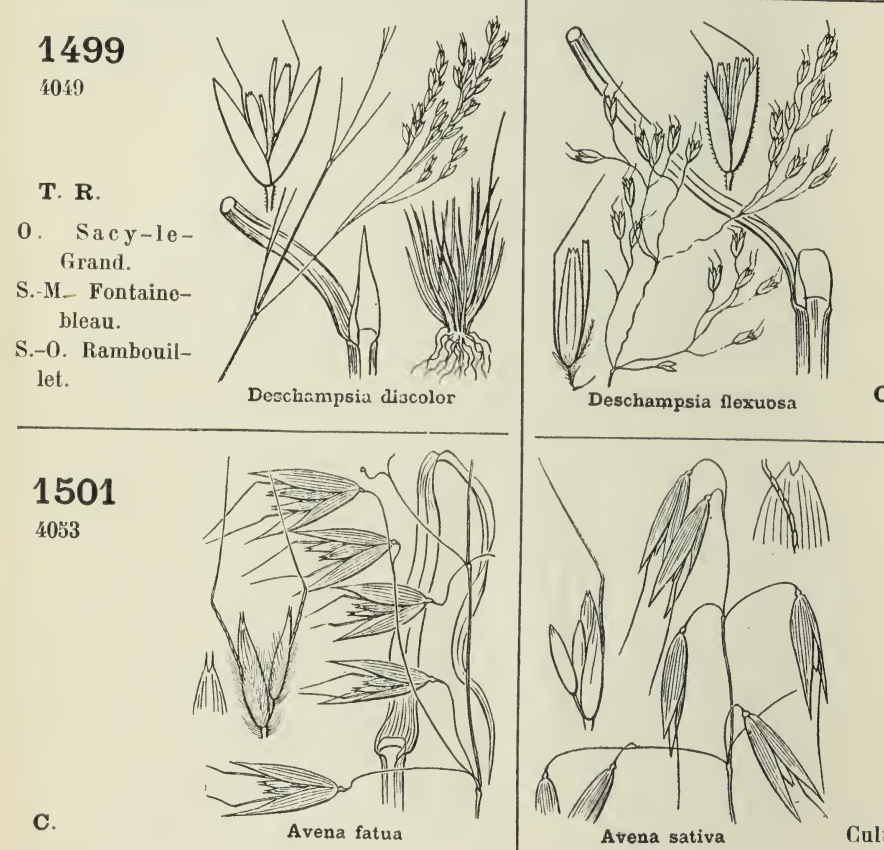

1500

$40 \% 0$
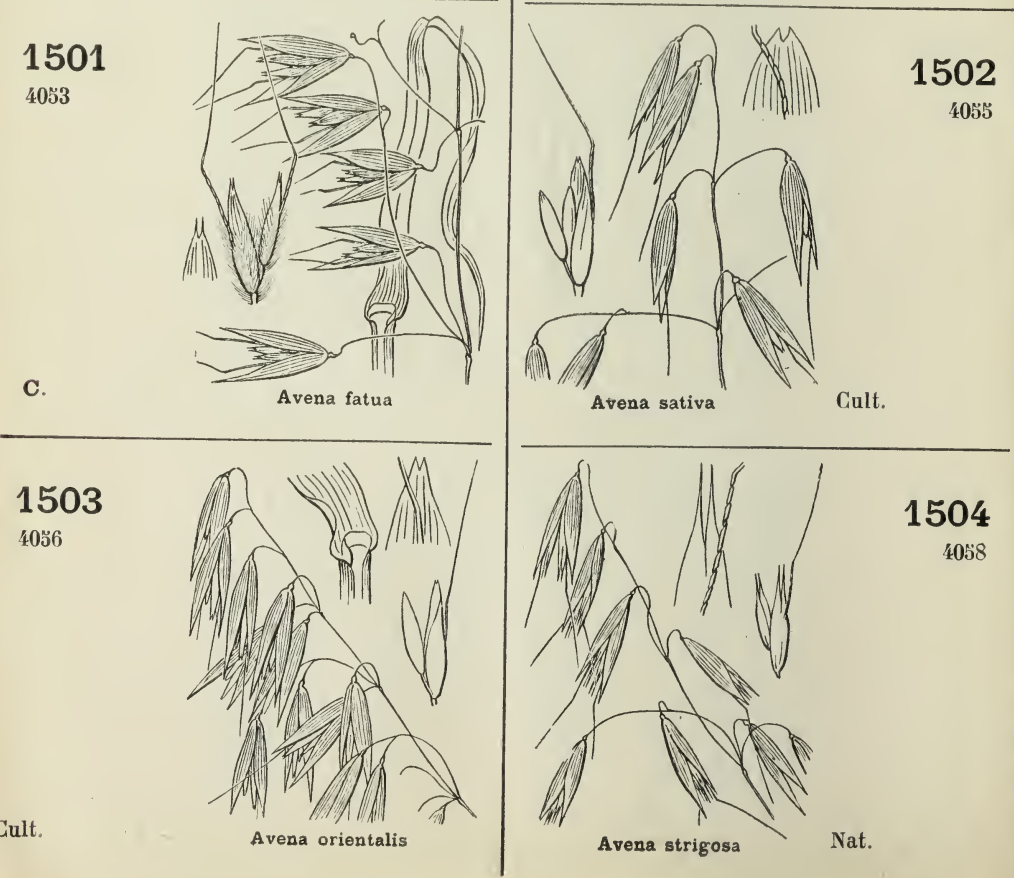
FAM. 111. - GRAMINÉES
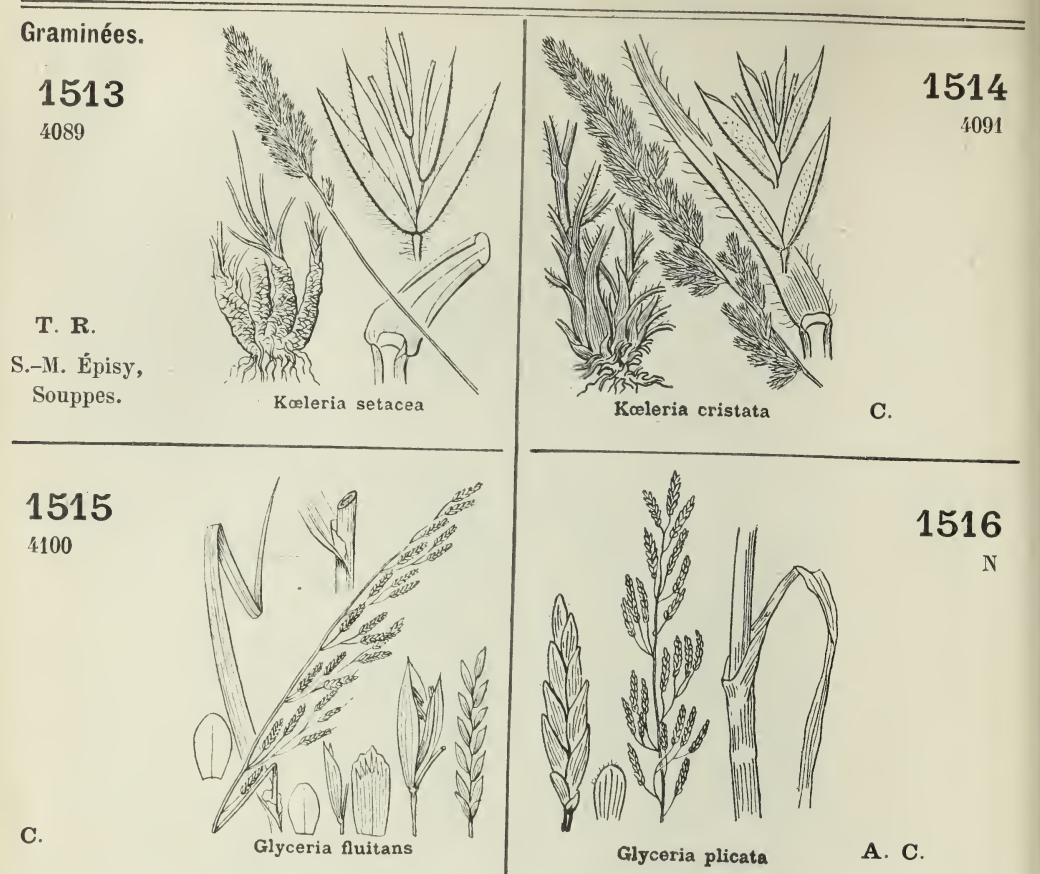

1516

Glyceria plicata

A. C.
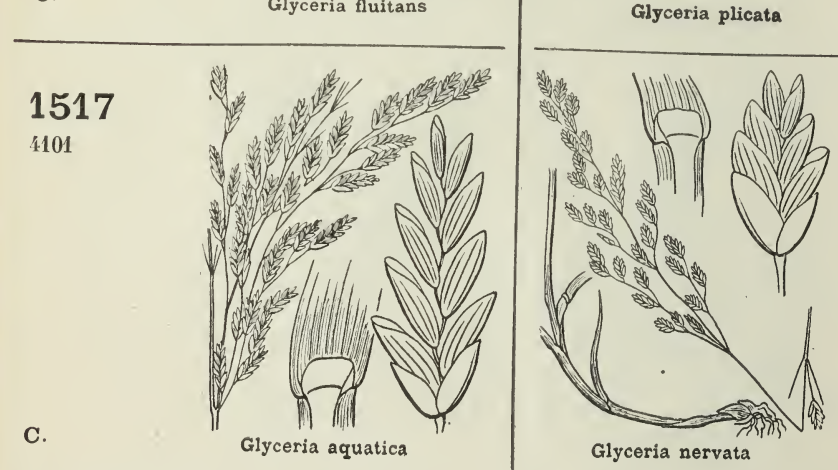

-

1518

4102

Nat.

S. et S.-0. Meudon et Boulogne.

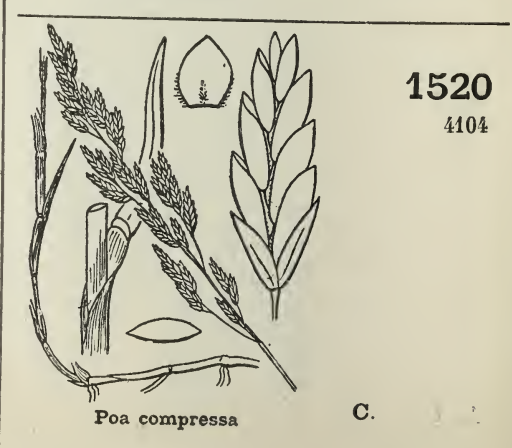



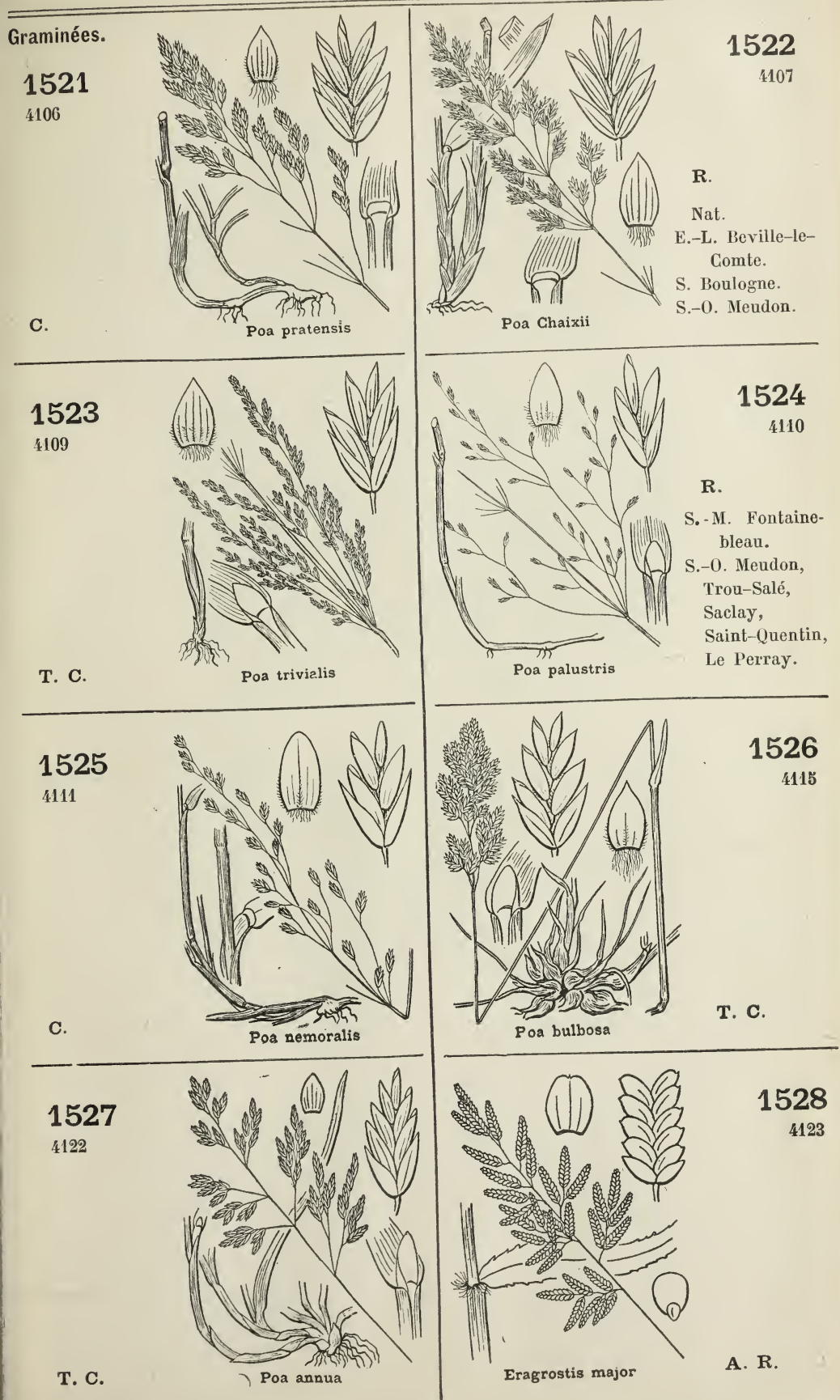

T. C.

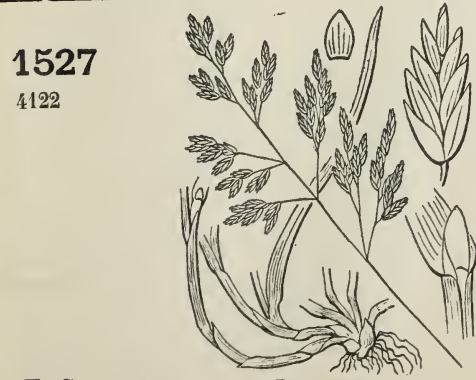



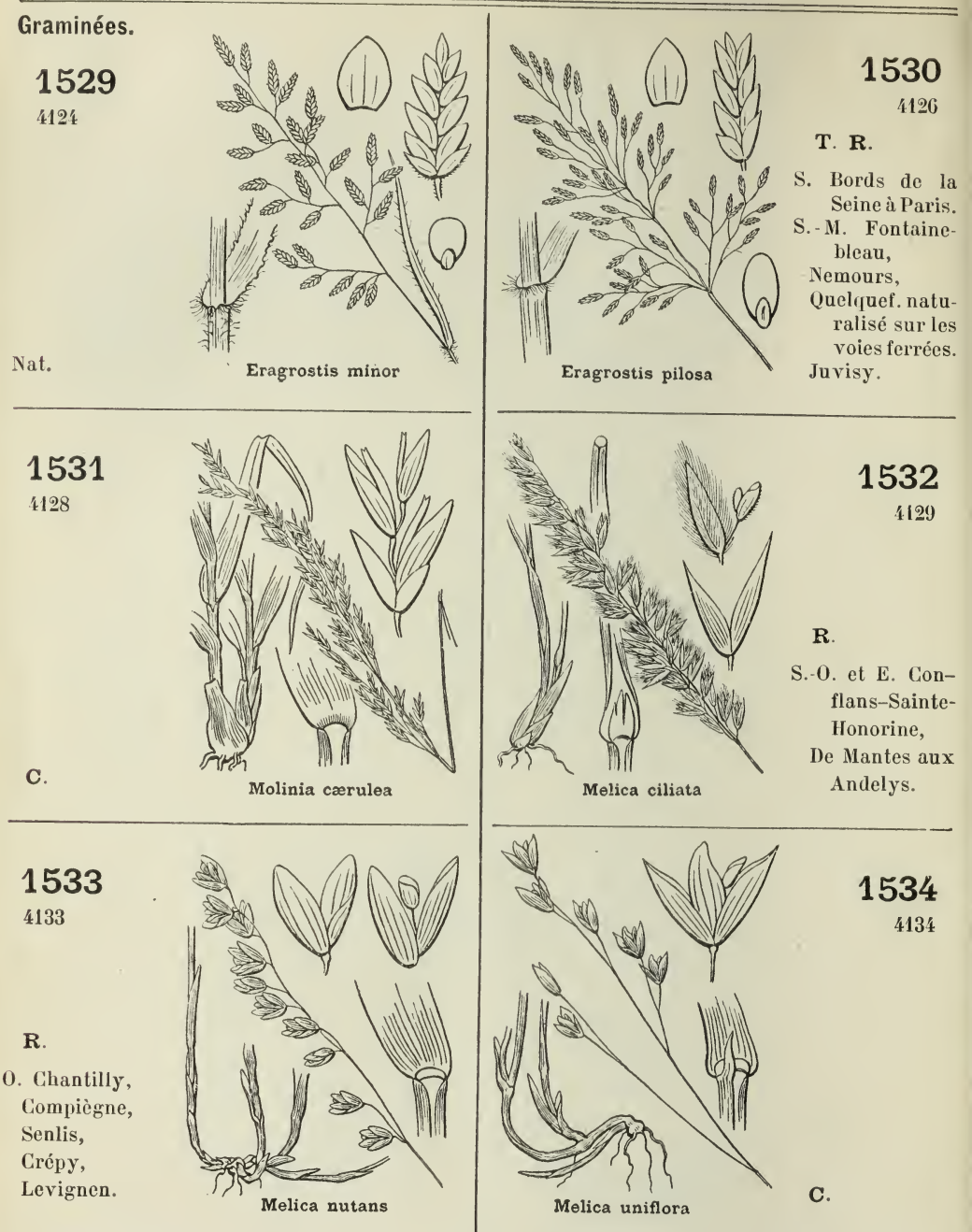

\section{2}

4129

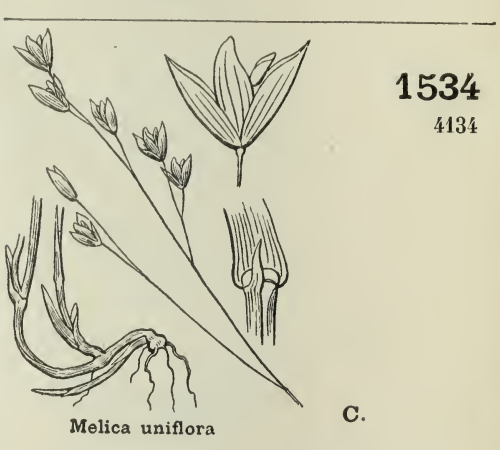

R.

S.-0. et E. Conflans-SainteHonorine,

De Mantes aux Andelys.

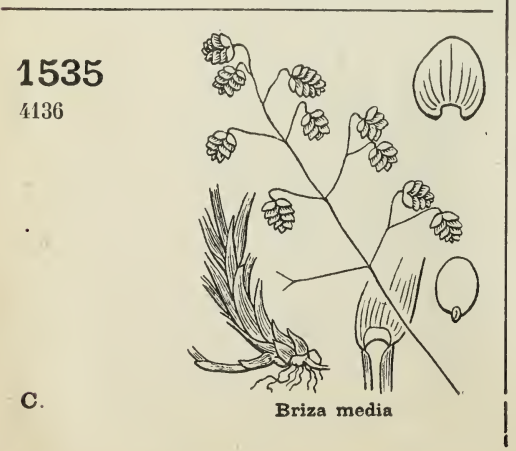

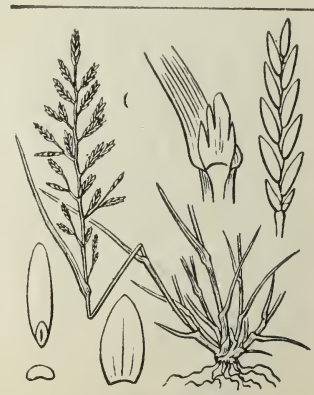

Scleropoa rigida
1536

4141 

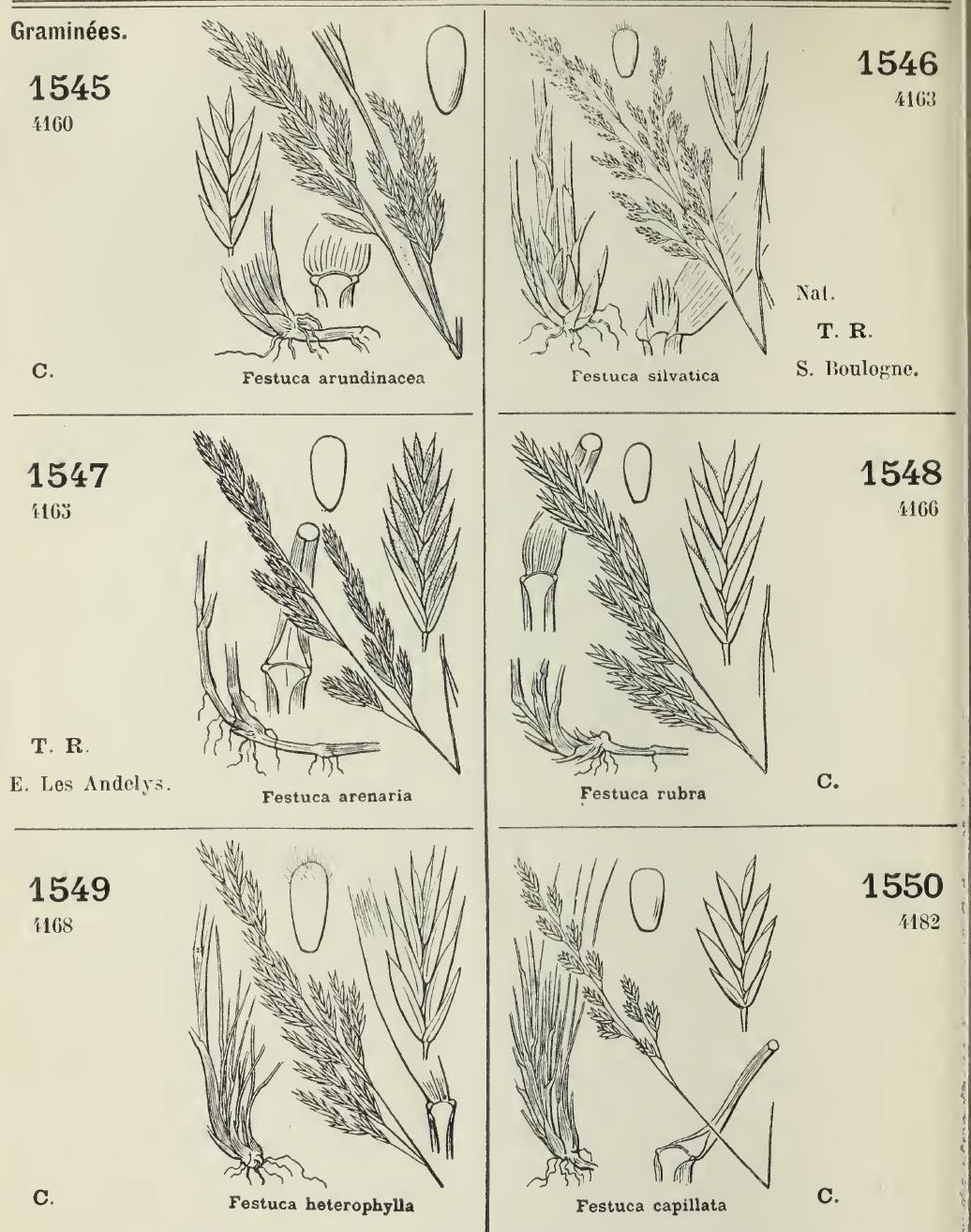

1550

4182

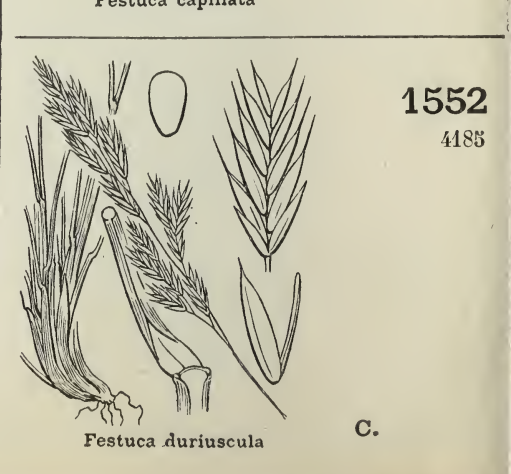




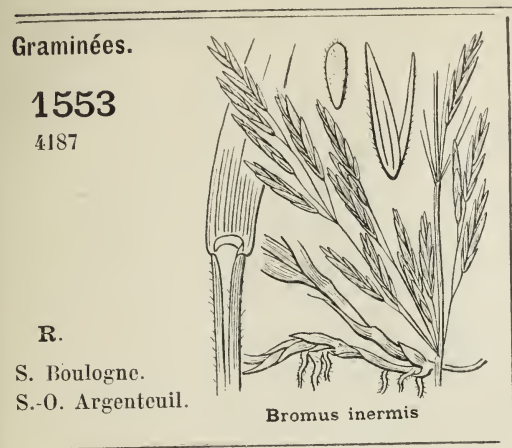

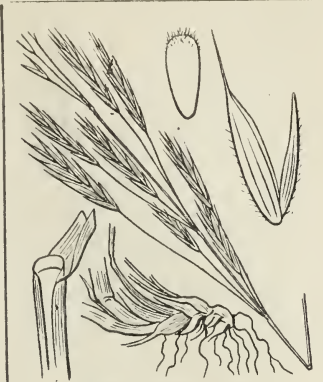

Bromus erectus
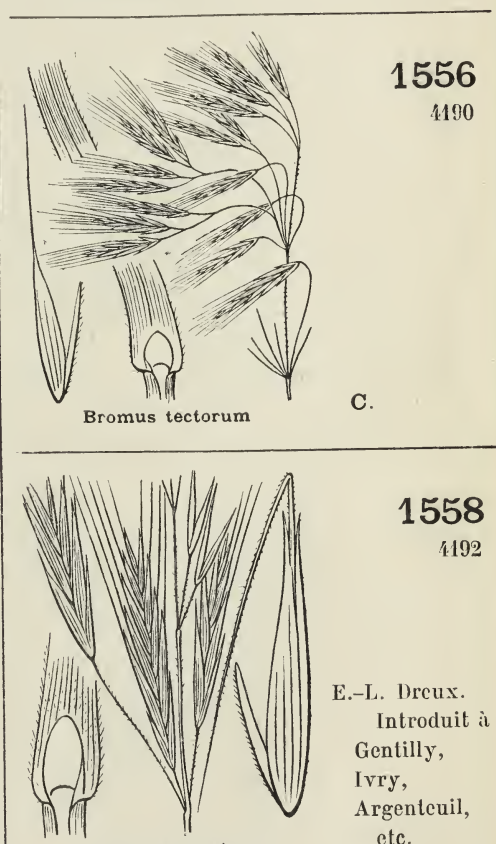

Bromus maximus

1558

4192
1554

1188
T. C.

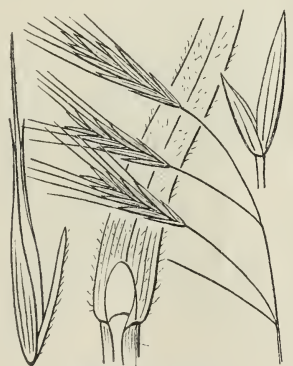

Bromus sterilis

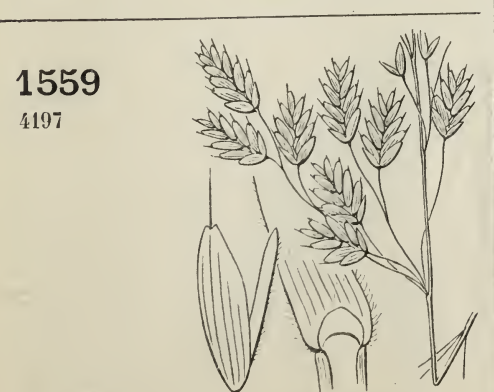

Bromus secalinus

1557

191
A. C.

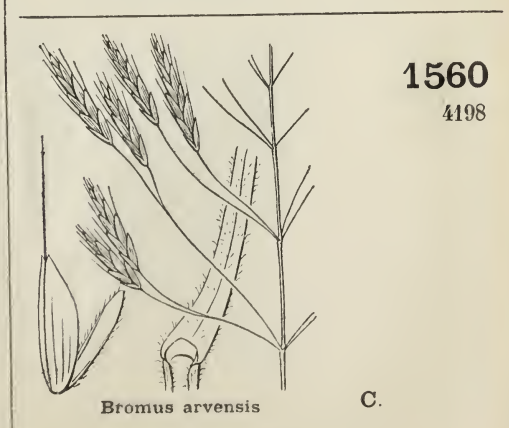




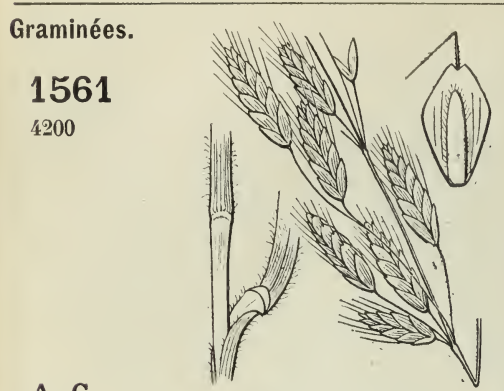

A. C.

Bromus commutatus

1563

4202

T. C.

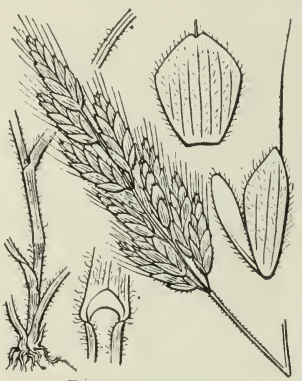

Bromus mollis

Cult. rarement.

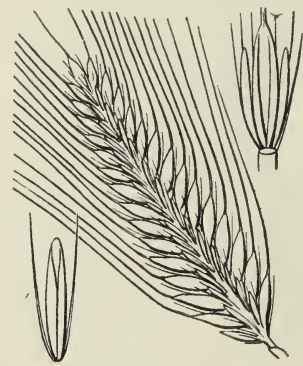

Hordeum Zeocriton

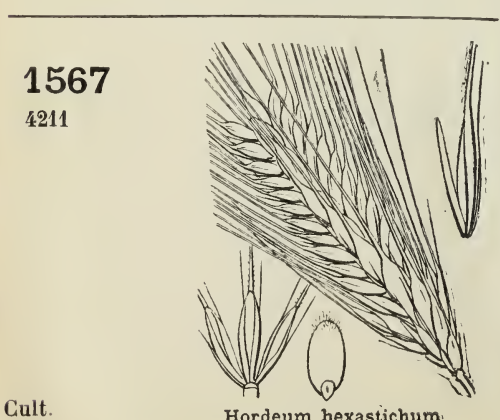

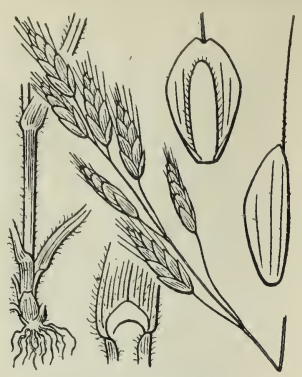

1562

4201
A. C.

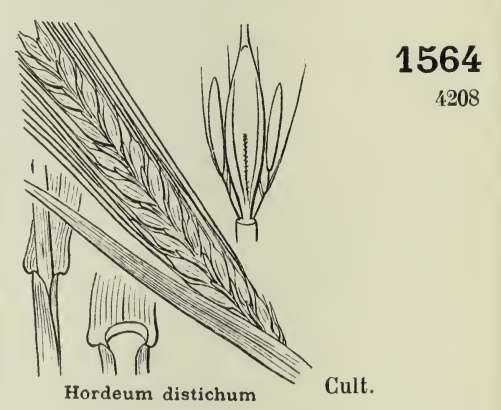

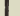
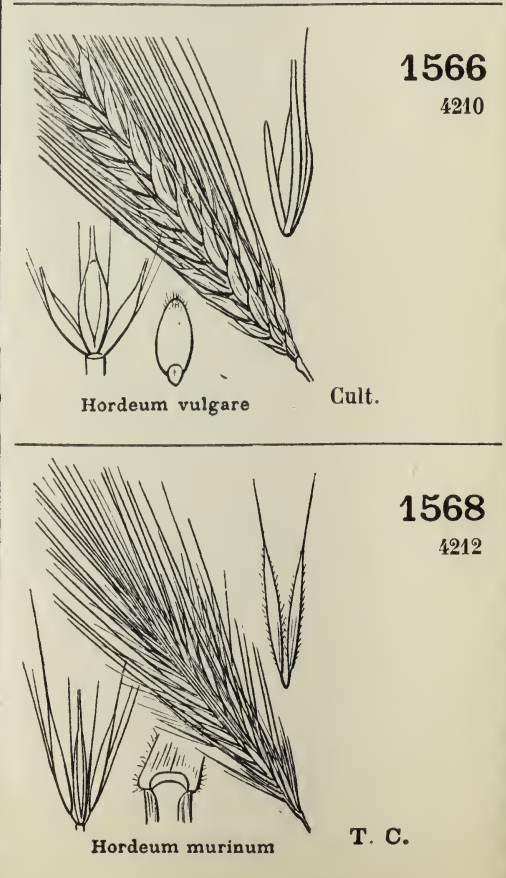

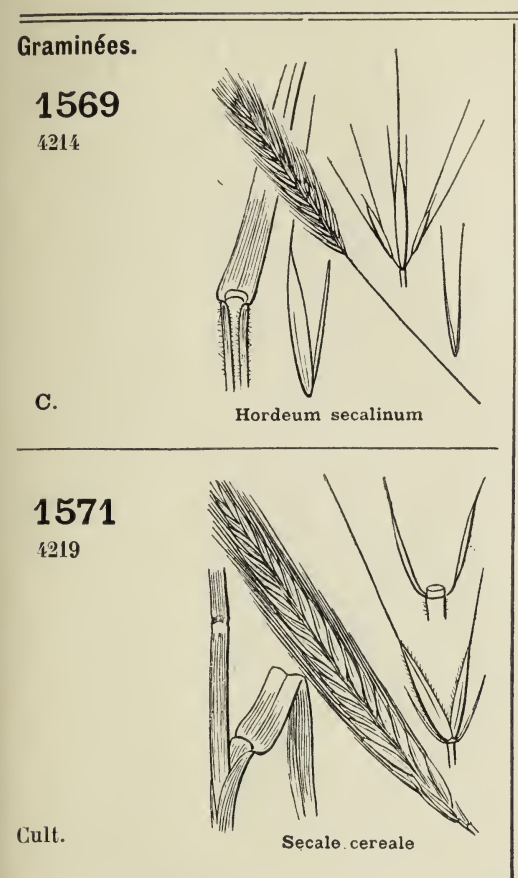

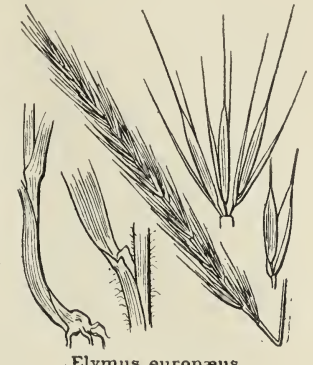

Elymus europæus

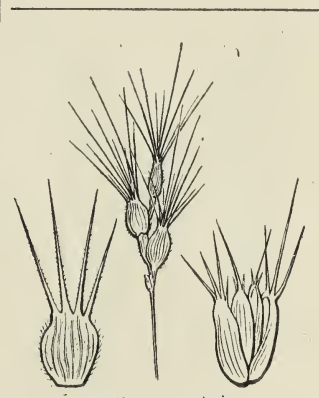

Ægilops ovata

1570

4217

T. R.

A. Villers-Cotterets,

Montigny-l'Allier.

0. Compiègne,

Bourneville.

1572

4.221

T. R.

0. Rieux près Beauvais?

S.-M. Fontainebleau?
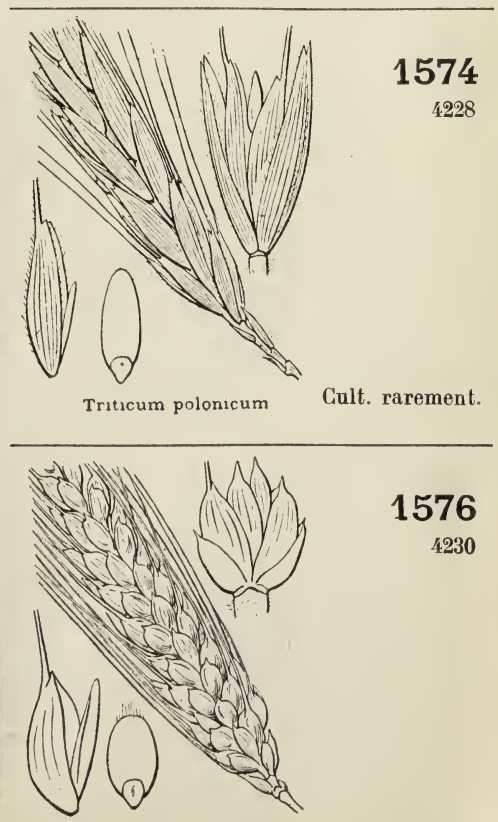

1576

4230

Gult.

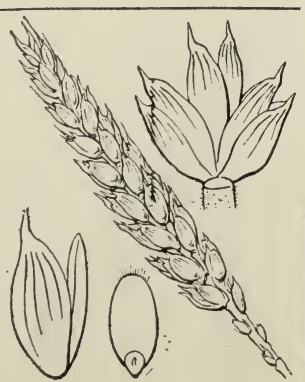

Triticum turgidum Cult. 


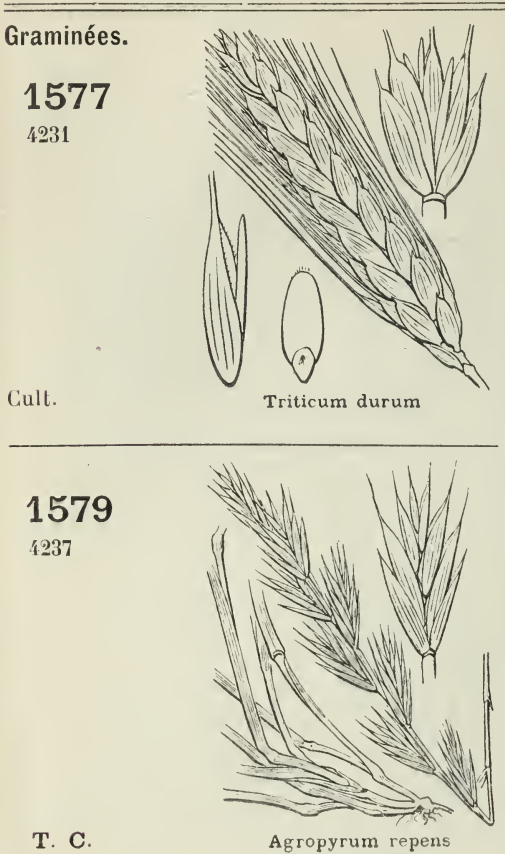

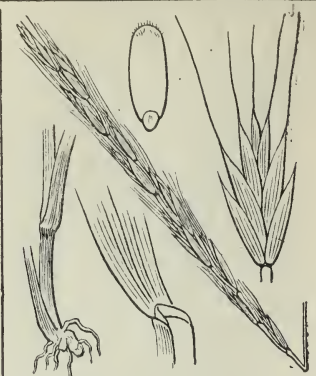

Agropyrum caninum

C.

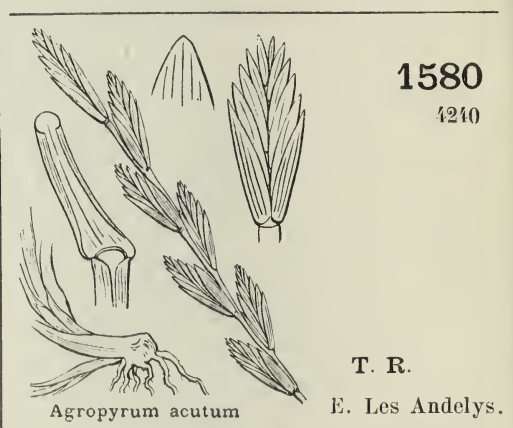

1578

4233
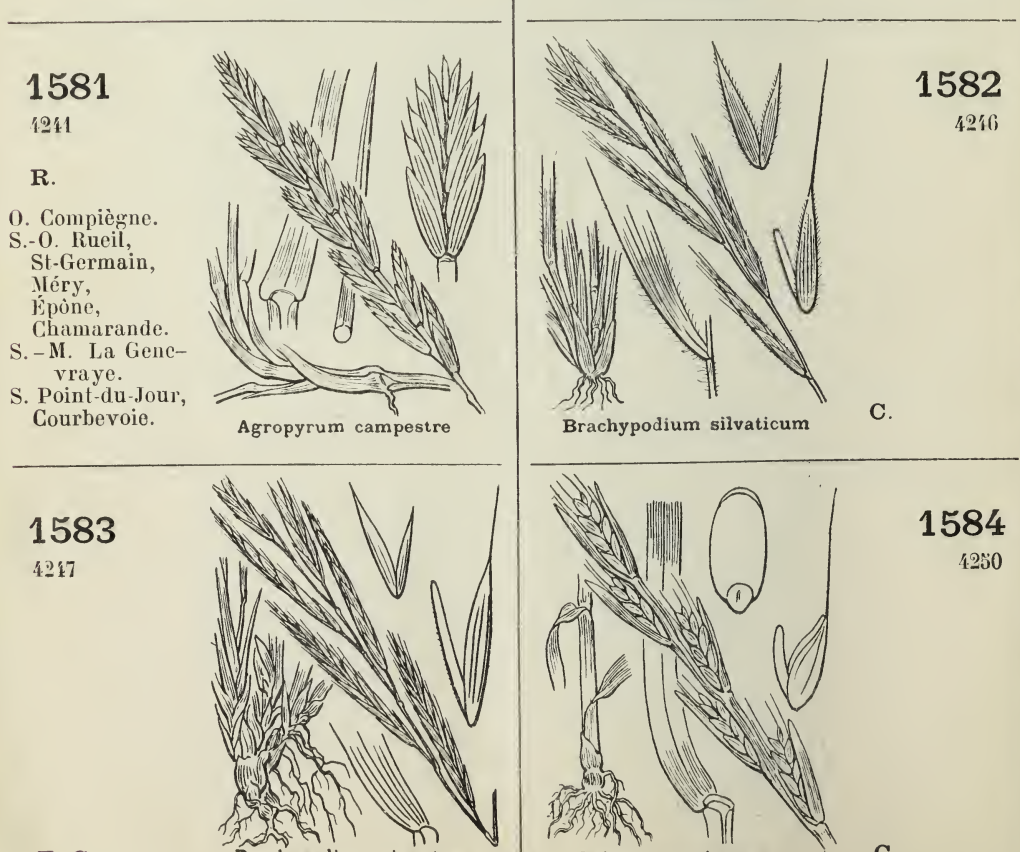

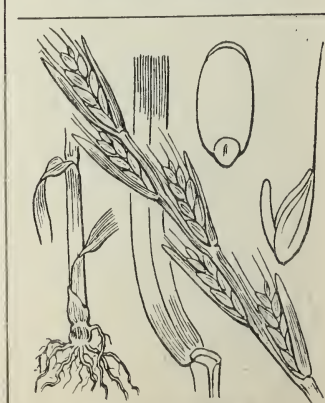

Lolium temulentum
1584

4250
C. 

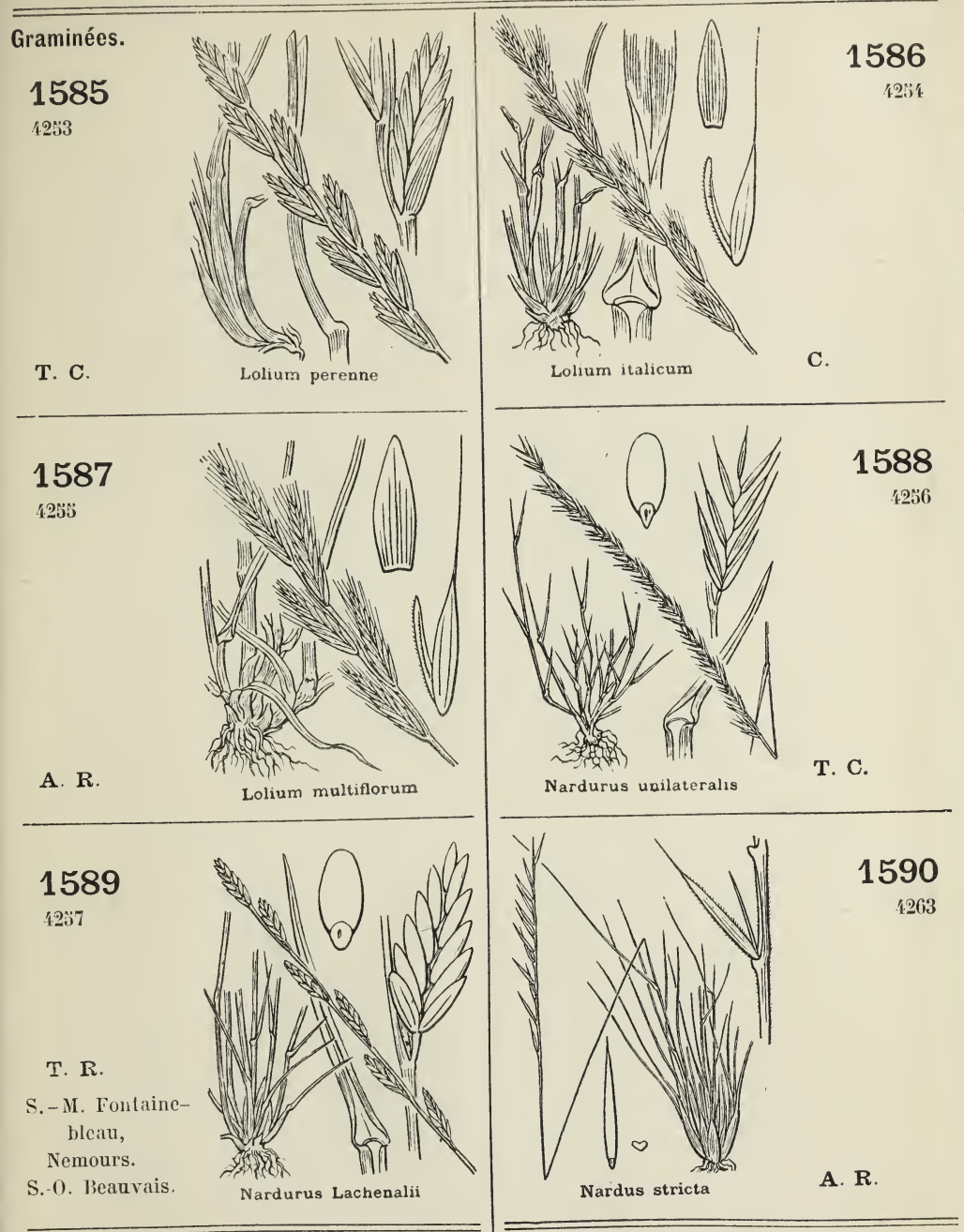

T. R.

S. - M. Fontaineblcau,

Nemours.

S.-0. Beauvais.

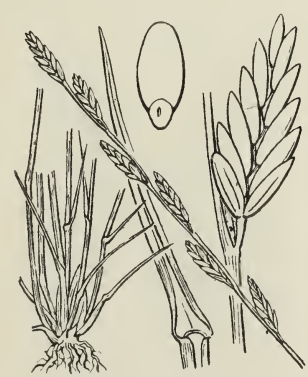

Nardurus Lachenalii

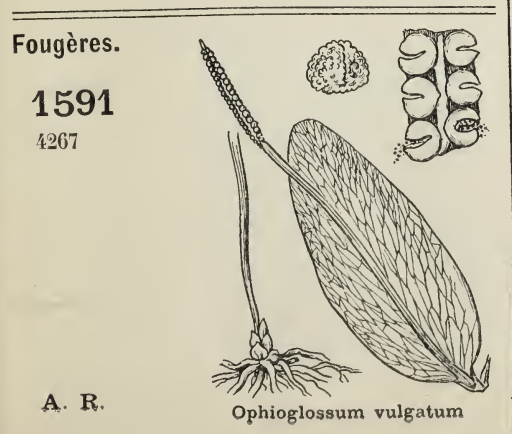

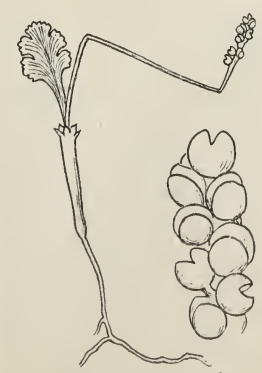

Botrychium simplex
1592

4269

T. R.

L. Malesherbes. 
FAM. 112. - FOUGÈRES
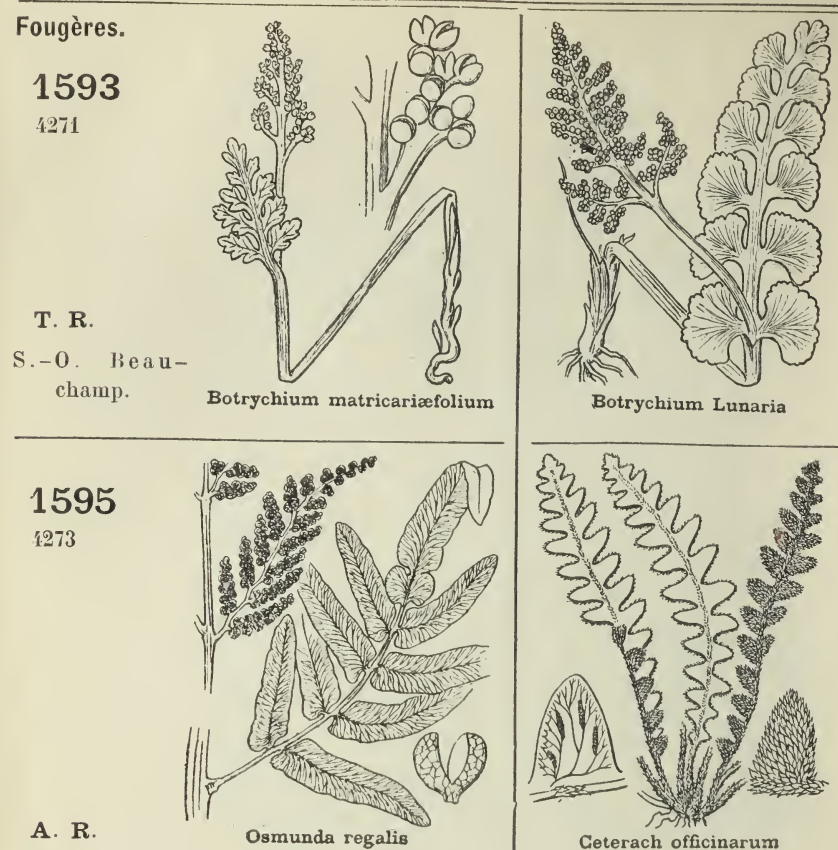

Botrychium Lunaria

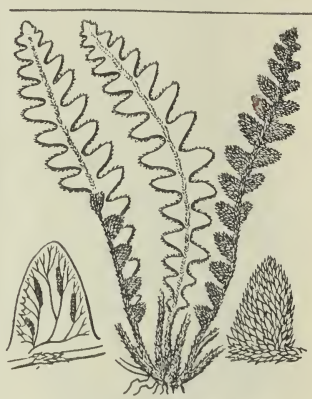

Ceterach officinarum

A. $\mathbf{R}$.

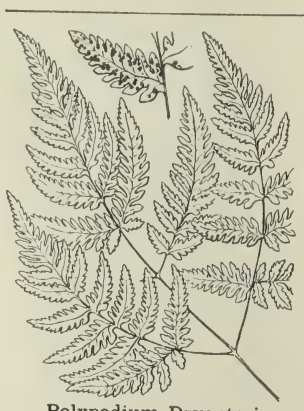

Polypodium Dryopteris

Polypodium vulgare

T. C.

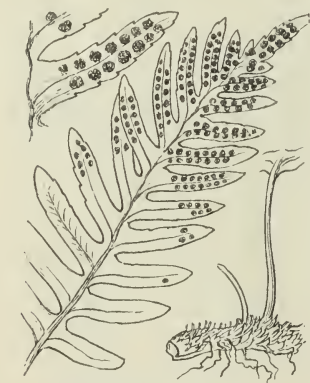

1599

4282

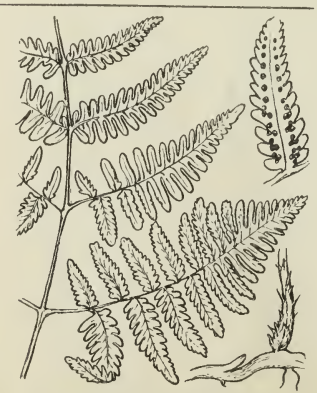

A. $\mathbf{R}$

Polypodium Robertianum

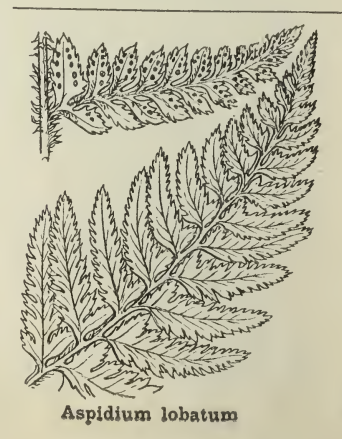

\section{R.} rets.

Marly.

\section{4}

4272
A. $\mathbf{R}$.

1596

$427 \%$

\section{8}

4281

A. Villers-Cotte-

S.-0. Satory,

o. Compiègne. 

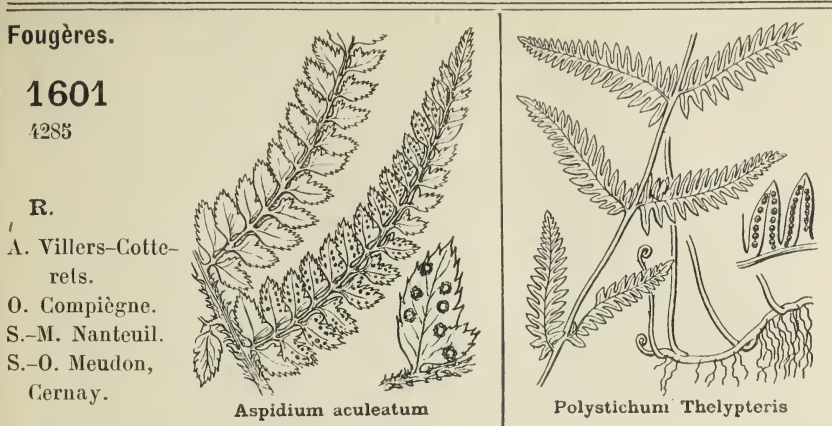

1602

4287

Polystichum Thelypteris

A. $\mathbf{R}$.

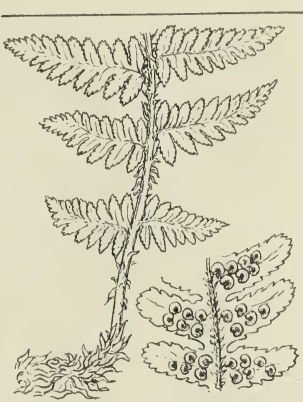

1604

4289

R

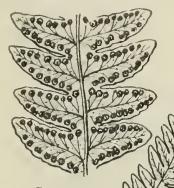

I. Villers-Cotterels.

O. Hallatte

S. - II . Ch a mpagne.

S.-0. Marly,

Rambouillet.

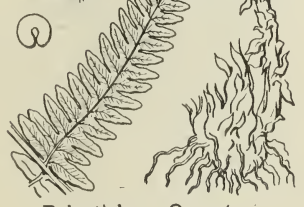

Polystichum Oreopteris

\section{5}

4290

T. $\mathbf{R}$.

o. Mortefontaine. S.-0. Rambouillet,

Étang de GdMoulin près Cernay.

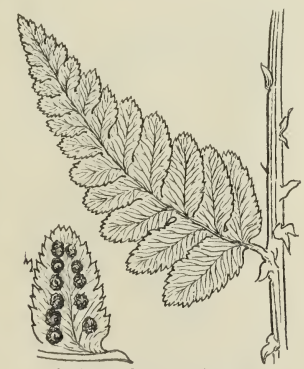

Polystichum cristatum

\section{7}

4296
A. $\mathbf{R}$

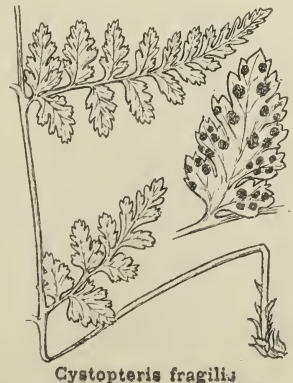

Polystichum Filix-mas

T. C

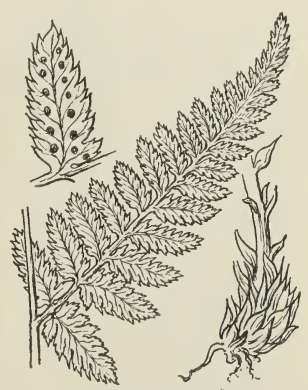

1606

1292

\section{Polystichum spinulosum}

T. C.

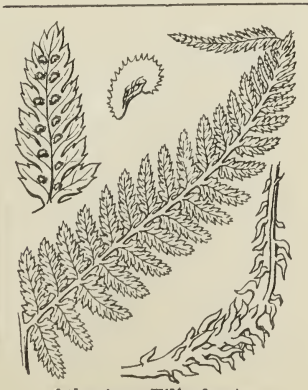

Athyrium Filix-femina

\section{8}

4298 


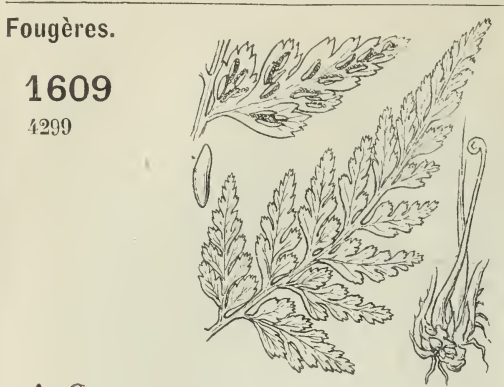

A. C.

Asplenium Adiantum-nigrum

\section{1}

T. $\mathbf{R}$

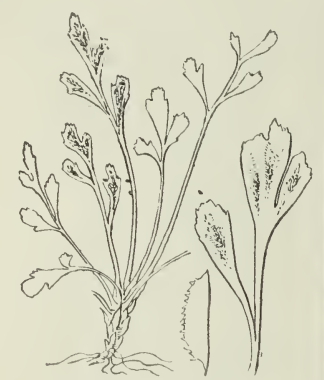

S.-M. Nemours.

Asplenium Murbeckii

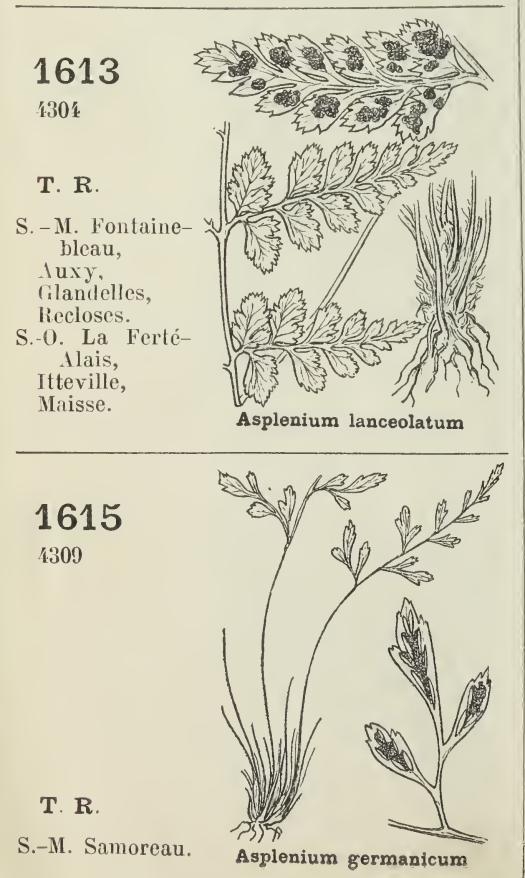

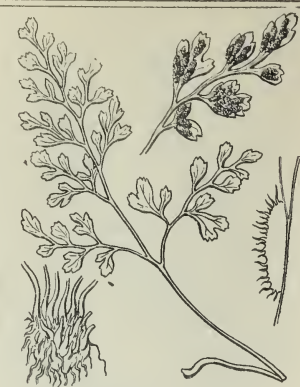

Asplenium Ruta-muraria

C.

\section{0}

1300

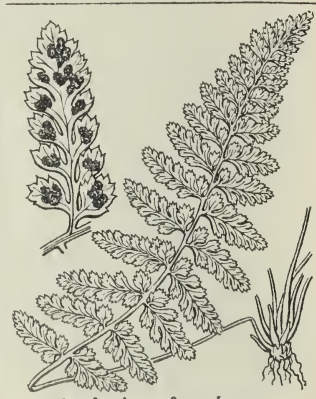

Asplenium foresiacum

1612

4303

T. $\mathbf{R}$.

S. - M. Fontainebleau,

Nemours.

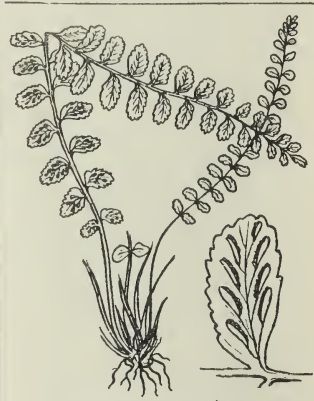

Asplenium Trichomanes

1614

4307

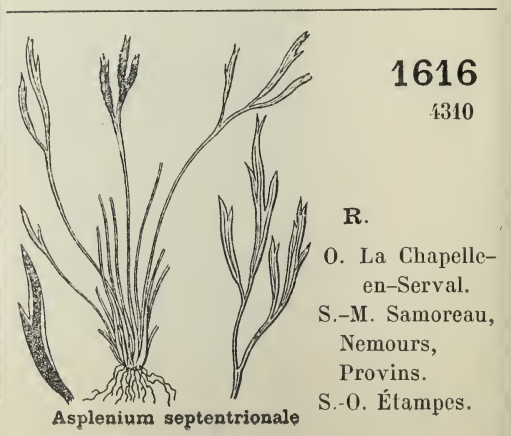


FAM. 112. FOUGĖRES - FAM. 113. RHIZOCARPEES FAM. 114. LYCOPODIACÉES

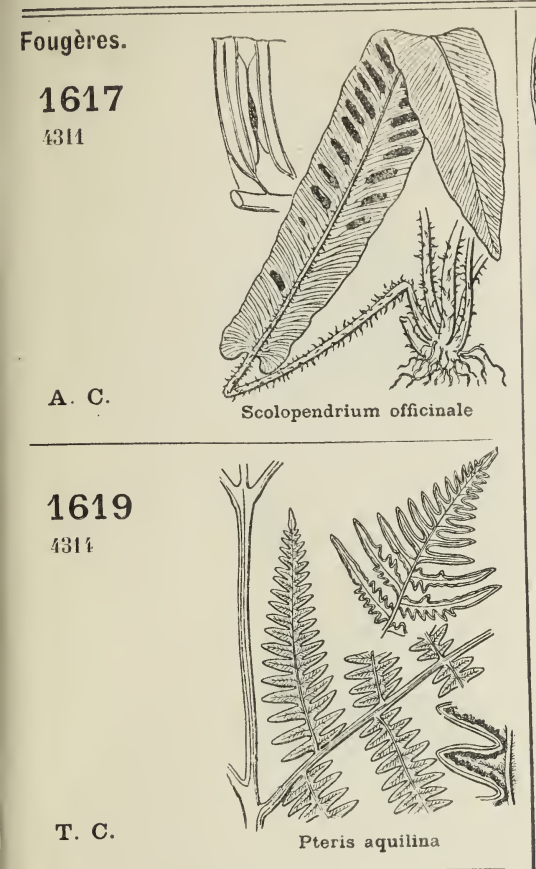

\section{Rhizocarpées. \\ 1621 \\ 1322 \\ R. \\ E.-L. Berchires- la-Maingot. \\ 0. Chantilly, \\ Beauvais, \\ St-Germer. \\ S. - M. Fontaine- bleau. \\ S.-0. Rambonil- let, Sćnart}
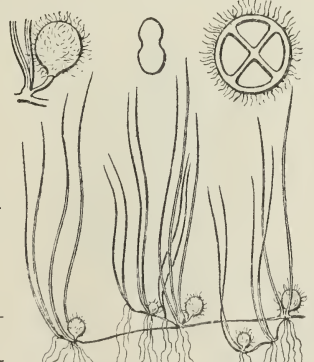

Pilularia globulifera

\section{3}

4336

T. R.

O. Mortefontaine Neumoulin,

Neuville-Bosc.

Savignies.

S.-I. Cuy-St-Fiacre.

S.-M. Larchant.

S.-0. Rambouillet,

Cernay.

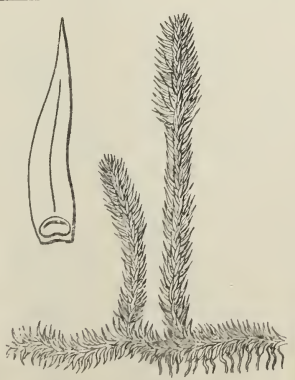

Lycopodium inundatum

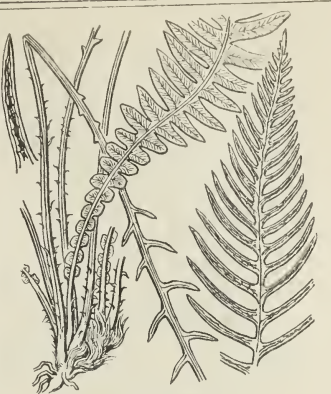

1618

4313
A. $\mathbf{R}$.

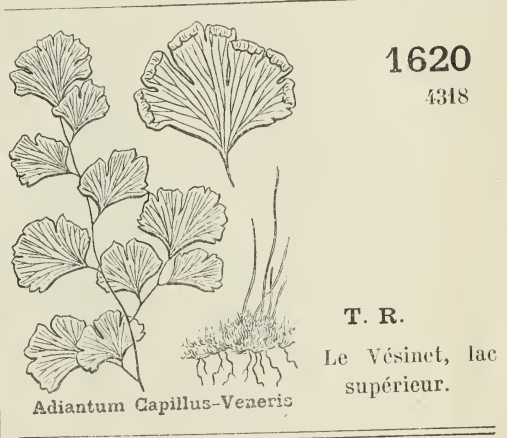

$\overline{\text { Lycopodiacées. }}$

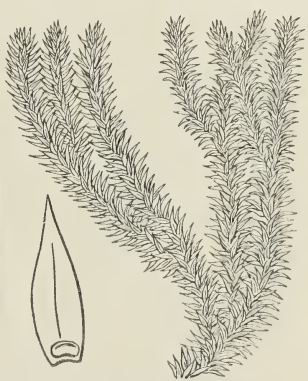

1622

1333

Lycopodium Selago

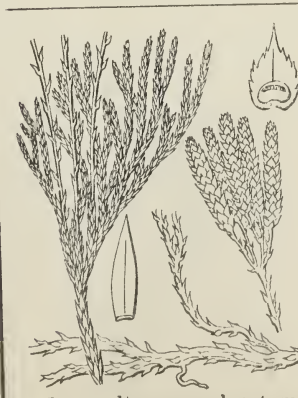

Lycopodium complanatum

1624

4339
T. R.

1. Villers-Cotterets.

S.-M. Irbonne. S. - O. St-Cyr. 


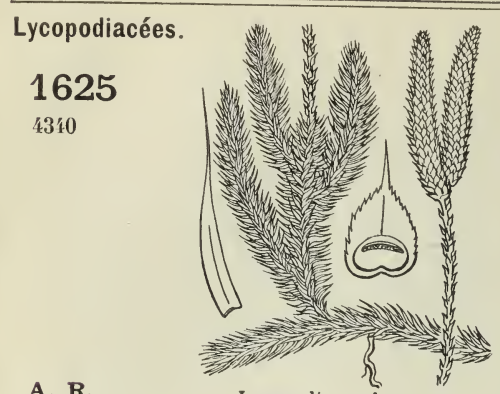

A. $\mathbf{R}$.

Lycopodium clavatum
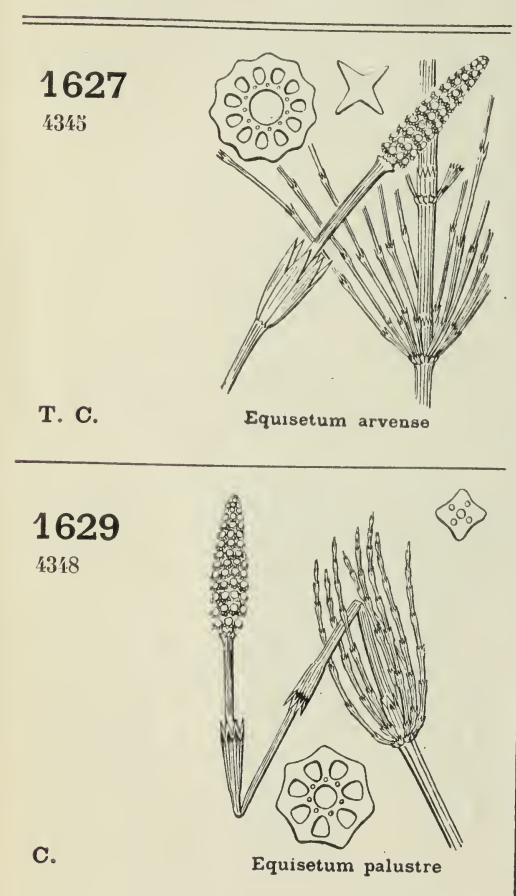

\section{1}

4349 bis

T. R.

S. Orly, pr. Choi-

, sy.

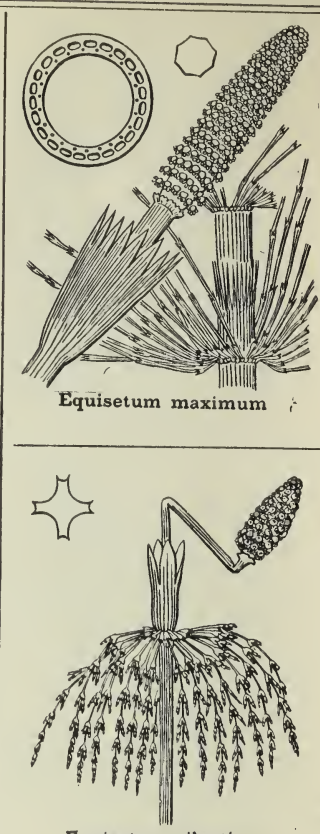

Equisetum silvaticum

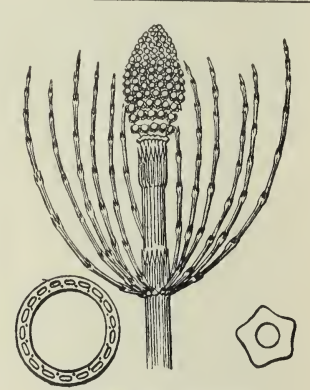

Equisetum limosum

c.

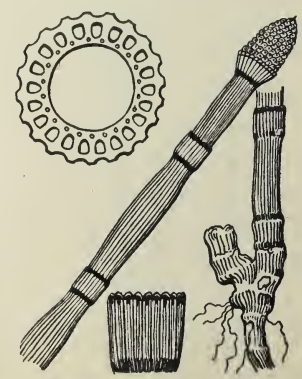

Equisetum hiomale
Équisetacées.

1626

4314

c.

1628

4317

A. Villers-Cotterets.

1630

4349

1632

4350

R.

0. Compiègne.

S.-M. Valvins,

Ferme de Chapelottes, pr. Nemours.

S.-0. Rambouillet. 
FAM. 115. - ÉQUISETACÉES.
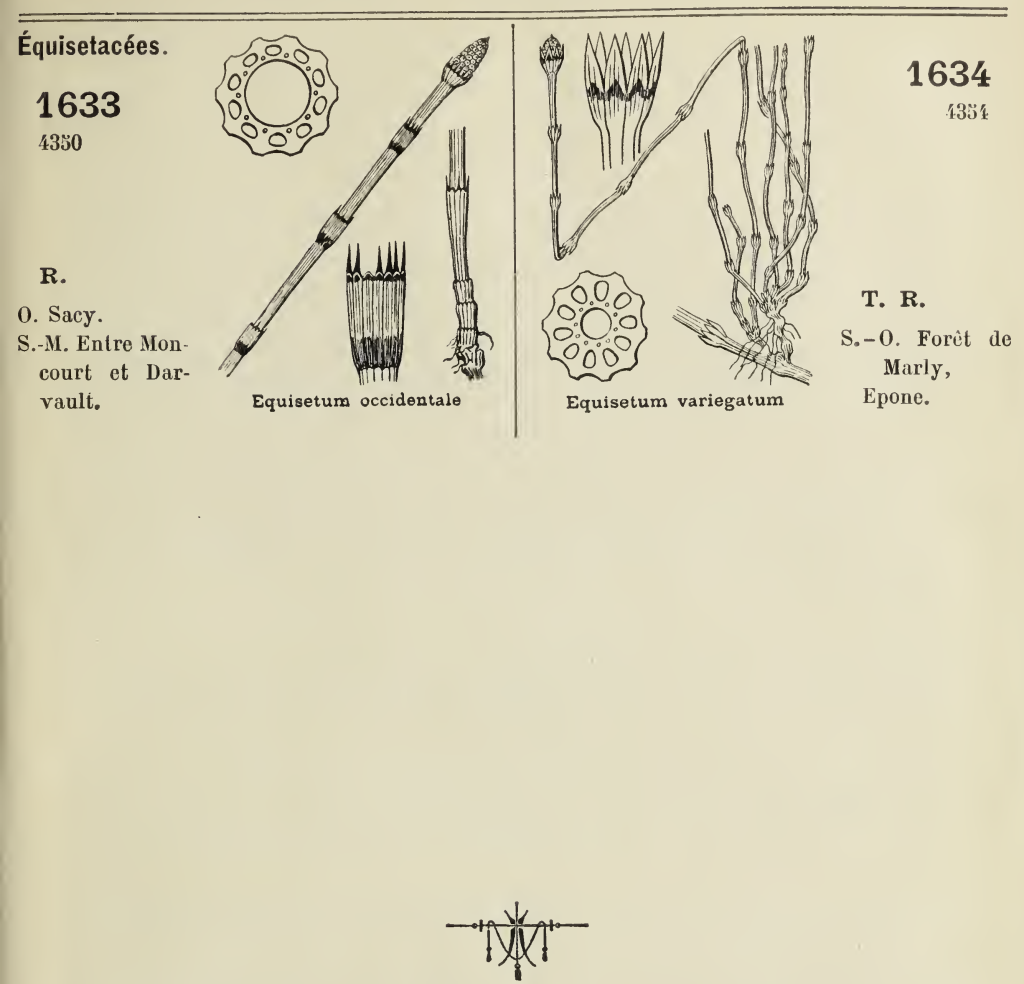


\section{EXCURSIONS}

Les Andelys. - Station de Gaillon, Petit-Andelys, coteaux de la Vacherie, rocher saint-Jacques, Chitleau-Gaillard.

Dipsacus fullonum. Arabis arenosa, Anchusa ilalica, Isatis tincloria, Phelipa crerulea, Orobanche cruenta, Rumex scutalus, Euphorbia Esula, Melica ciliata, Bisculella levigata, Digitalis lutea, Tlılaspi montanum, Sesleria cierulea, Teucrium montanum, Ononis Natrix, Amelanehier rulgaris, Ruta graveolens, Dianthus caryophyllus, Ophrys litigiosa, Orchis pyramidalis, Orobanche minor.

Argenteuil. - Carrières, bords de la Seine, Bezons, bois des Champions.

Crepis pulchra, Lepidium ruderale, Chenopodium opulifolium, Artemisia Selengensis, Tragopogou dubius, Inula britannica, Igropyrum campestre, Anemone Pulsalilla, Seseli annum, Phleum arenarium, Ononis Natrix, Leonurus Cardiaca, Medicago Gerardi.

\section{Beauvais. - $1^{\circ}$ Marissel, Bracheux.}

Egopodium Podagraria, Cardamine amara et impatiens, Geum rivale, intermedium: Pimpinella magna, Catabrosa aquatica, Festuca gigantea, Phleum asperum.

\section{Goincourt, fontaine de litalienne, marais et bois de Belloy.}

Cardamine amara, Chrysosplenium alternifolium et opposilifolium, Lychnis diurna, Ranunculus hedericeus, Carex teretiuscula, Blechnum Spicant, Pirola rotundifolia, Epilobium lanceolatum, Ranunculus nemorosus, Selinum Carvifolia, Lycopodium clavatum.

$3^{3}$ Station de l'llnyère, bois des Bonshommes, Mont-Bénard, Savignies, bois du Pare, ferme du Gros-Chine.

Rosa tomentosi, Scolopendrinm officinale, Staclys alpina, Ranunculus sardous, Galium saxatile, Chrysospleniun oppositifolium, Carex strigosa, Lysimachia nemorum, Geum rivale, Stellaria nemorum, Cihysosplenium alternifolium, Epilobium palustre, Erica Tetralix, Blechnum Spicant, Vaccinium Vitis Idwa, Myrtillus; Lycopodium clavatum, Osmunda regalis, Ranunculus nemorosus, Drosera rolundifolia, Ulex nanus, Rubus Idieus, Asperula odorata, Paris quadrifolia, Juncus squarrosus, Carex maxima, vulgaris; Mespilus grermanica, Malva Alcea el moschala, Veronica montana, Carex digitata, Fragaria elalior, Festuca gigantea, Cuseuta еuropæa.

\section{Bonnières. - Jeufosse, Port-Villez, Vernon.}

Nepatica triloba, Daphne Mezereum, Orchis purpurea, mililaris, mascula; Ophrys litigiosa, Sesleria cerulea, Sedum sexangulare, Doronicum plantagineum, Cytisus Laburnum, Phytenma orbiculare, Plıalangium ramosum, Arabis arenosa, Cerastium brachypetalum, Arum italicum, Scolopendrium officinale, Rubia peregrina, Digitalis lutea, Buxus sempervirens.

Chantilly. - Station de Coye, carrières, marais de Comelle, Chantilly.

Melica nutans, Gentiana Cruciata, Chlora perfoliata, Orobanche Epithymum, Teucrii ; Epipactis atrorubens, Orchis pyramidalis, militaris; Ophrys aranifera, apifera, Arachnites, muscifera; Limodorum aborlivum, Polygala comosa, Agrostis interrupta, Carex arenaria, depauperata, digilata; Ophioglossum vulgatum, Pinguicula vulgaris, Schœnus nigricans, Cladium Mariscus, Potamogeton plantagineus, Carex Mairii, flava, Hornschuchiana, Pseudo Cyperus; Salix repens, Polystichum Thelypteris, Aquilegia vulgaris, Sonclıus palustris, Campanula persicæfolia, Pirola rotundifolia, Iris fotidissima, Atropa Belladona, Fragaria collina, Anemone silvestris, Doronicum plantagineum, Botrychium Lunaria, Scilla bifolia, Turritis glabra, Polygonalum vulgare, Teesdalia nudicaulis, Verbascum phlomoides, Salvia verticillala, Crepis tectorum. 
Charenton. - Bords de la Marne et du canal.

Salix viridis, hippophofolia, undulata, purpurea, rubra; Lepidium lalifolium, Draba; Cucubalus baccifer, Allium Scorodoprasum, Populus canescens, Lamium hybridum, Thalictrum minus, Leersia oryzoirles, Petasites fragrans, Naias major, minor; Zannichellia pa!ustris, Vallisneria Spiralis.

Saint-Gloud. - Parc, eascades, Lanterne, Ville-d'Avray, élangs, Jardy, Versailles.

Gagea arvensis, Veronica triphyllos, Tulipa silvestris, Cucubalus baccifer, Cornus Mas, Asperula odorata, Veronica montana, Cephalanthera grandiflora, Ophrys muscifera, Allium ursinum, Oxalis Acetosella, Trifolium subterraneum, Salix affinis, Sambueus racemosa, Euphorbia duleis, Maianthemum bifolium, Lycopodium clavatum, Blechnum Spicant, Tilliea muscosa, Luzula maxima, Lobelia urens, Asarum europaum.

\section{Dreux. -- Château, bois Yon, forìt de Dreux.}

Eruca sativa, Salvia Verbenaca, Bromus maximus, Tordylium maximum, Vicia serratifolia. Pol rgala comosa, Festuca loliacea, Euphorbia Esula, Epimedium alpinum, Peucedanum Cervaria, Linosyris vulgaris, Fumaria micrantha.

Étréchy. - Route de Chaufour, Vaucelas, saint-Martin de la Roche.

Valerianella coronata, eriocarpa; Turgenia latifolia, Caucalis daucoides, Nieropus erectus, Trigonella monspeliaca, Lactuca perennis, Epipactis atrorubens, Fumana vulgaris, Helianthemum polifolium, Carduncellus mitissimus, Gymnadenia Conopea, Ophrys aranifera, apifera: Daphne Laureola, Loroglossum hircinum, Limodorum abortivum, Epipactis latifolia var. viridiflora, Coronilla minima, Lychnis Viscaria, Fragaria collina, Sorbus torminalis, latifolia, aucuparia; Ornithogalum umbellatum, Ranunculus Charophyllos, Trinia vulgaris, Trifolium striatum, scabrum, glomeratum; Bulliarda Vaillantii, Spergula pentandra, Morisonii; Linaria Pelliceriana, Tillea muscosa, Ceterach officinarum.

Fontainebleau. - $1^{\circ}$ Station de Bois-le-Roi, Bellecroix, Franchard, Gorges du Houx, Fontainebleau.

Thlaspi perfoliatum, Carex depauperata, Vicia lutea, Cynoglossum pictum, Rosa pimpinellifolia, Spirea Filipendula, Carex humilis, Phalangium ramosum, Physalis Alkekengi, Ononis Columne, Ranunculus gramineus, Euphorbia dulcis, Esula; Phyteuma orbiculare, Epipactis atrorubens et microphylla, Ranunculus hololencos, tripartitus, aquatilis, confusus, trichophyllus; Ilelosciadium inundatum, Alisma natans, Juncus squarrosus, capitatus, pygmaus; Pilularia globulifera, Elatine Alsinastrum, Callitriche hamulata, Galium debile, Sedum villosum, sexangulare ; Bulliarda Vaillantii, Ranunculus sardous, nodiflorus; Carex Schreberi, Trifolium striatum, scabrum, strictum; Ophioglossum vulgatum var. polyphyllum, Eragrostis pilosa, Sorbus latifolia, Aria; Helianthemum umbellatum, Illecebrum verticillatum, Asperula tinctoria, Orchis ustulata, Phalangium Liliago, Stipa pennata, Inula hirla, Spergula pentandra et Morisonii; Scirpus fluitans, Heleocharis multicaulis, Polygonum minus, Montia minor, Ilelodes palustris, Ranunculus chærophyllos, Asplenium lanceolatum, Elatine hexandra; Airopsis agrostidea, Amelanchier vulgaris.

$2^{\circ}$ Station de Fontainebleau, Valvins, Croix de Tonlouse, champ de courses, fontaine Sanguinède, chemin du Grand-Veneur, Gros-Fouteau, route de Paris, Mont-Pierreux.

Carex digitata, tomentosa ; Scolopendrium officinale, Eqquisetum hiemale, Polygala Austriaca, Ophrys apifera, Arachnites; Euphorbia dulcis, Ruscus aculeatus, Orchis pyramidalis, Carex Schreberi, Sedum sexangulare, Carex humilis, ericetorum; Orchis Simia, militaris, Morio; Aceras anthropophora, Euphorbia Esula, Asperula tinctoria, Anemone silvestris, Thalictrum minus, Rosa pimpinellifolia, Myosotis stricta, Genista sagittalis, pilosa; Scleranthus perennis, Mespilus germanica, Malus acerba, Trinia vulgaris, Galium divaricatum, Ranunculus gramineus, chærophyllos; Spergula Morisonii, Phalangium Liliago, Botrychium Lunaria, Trifolium strictum, Ranunculus hololeucos, nodiflorus; Alisma natans, Sedum villosum, Cephalanthera ensifolia, Neottia Nidus-A vis, Lathyrus niger, Inula salicina, hirta; Fragaria collina, Trifolium rubens, medium; Carum Bulbocastanum. 
$3^{\circ}$ Station de Fontaineblean, parc, Mail IJenri IV, rocher Bouligny, Mont-Merle, la Chaise à l'abbé, Montmorillon.

Cucubalus bacciferus, Orobanche cruenta, Impatiens Noli Tangere, Gentiana Cruciata, Pneumonanthe; Polygala Austriaca, Gagea arvensis, Allium Scorodoprasum, Cystopteris fragilis, Polypodium Robertianum, Amelanchier vulgaris, Sorbus Aria, latifolia; Goodyera repens, Sesleria carulea, Carex montana, ericetorum; Orobanche Teucrii, Epithymum; Teucrium montanum, Hutchinsia petrae, Phalangium Liliago, Thalictrum minus, Arenaria grandiflora, Epipactis atrorubens, Helianthemum umbellatum, Scirpus fluitans, Ranunculus hololeucos, Potentilla splendens, Coronilla minima, Ranunculus gramineus, Phyteuma orbiculare, Scabiosa suaveolens, IIelianthemum polifolium, Allium flavum, Trifolium montanum, Cephalanthera rubra, Euphorbia Esula, Scorzonera Austriaca, Carex nitida.

$4^{\circ}$ Station de Fonlaincbleau, tramway du pont de Valvins, Samoreau, Champagne, Thomery.

Peucedanum Oreoselinum, Vicia varia, Mibora minima, Ranunculus nemorosus, Goodyera repens, Lychnis Viscaria, Asplenium septentrionale, Iieracium Auricula, Juncus tenuis, Cicendia filiformis, Trifolium medium, Laserpilium latifolium, Trifolium aureum, Tordylium maximum, Orobanche minor var. Carotæ, Althæa hirsuta, Polygala comosa, Peucedanum Chabrei, Cuscuta major, Sium latifolium, Convolvulus sepium fl. roses.

Saint-Germer. - Station de Neufmarché, bois Sainte-Ilélène, SaintGermer, tourbière de Bretel.

Orchis mascula, Parnassia palustris, Gentiana germanica, Paris quadrifolia, Asperula odorata, Dentaria bulbifera, Digitalis lutea, Actæa spicata, Cephalanthera ensifolia, Turritis glabra, Scrofularia vernalis, Carex canescens, vulgaris, teretiuscula, pulicaris, ampullacea, stellulata, Pseudo Cyperus; Sagina nodosa, Cardamine amara, Montia minor, Tillaa muscosa, Comarum palustre, Pedicularis silvatica, Salix repens, Stellaria glauca, Cladium Mariscus, Pimpinella magna, Egopodium Podagraria

Forêt de Hallatte. - Station de Pont-Sainte-Maxence, Mont-Pagnotte, Fleurines, Senlis.

Chrysosplenium oppositifolium, Carex strigosa, maxima; Blechnum Spicant, Polystichum Greopteris, Asarum Europaum, Androsiemum officinale, Equisetum Telmateia, Helleborus foetidus, Silene Otites, Phleum arenarium, Calamintha Nepeta.

Étangs de Saint-Hubert. - Station du Perray, étang du Perray, de Saint-Hubert, de Ilollande, mares et bois de Villepert, retour au Perray.

Ceratophyllum demersum. Spiranthes autumnalis, Poa palustris, Potamogeton obtusifolius, Lemna gibba, Lythrum hyssopifolia, Artemisia selengensis, Lathyrus Nissolia, hirsutus; Bromus secalinus, Bidens radiata, Damasonium stellatum, Limosella aquatica, Potamogeton gramineus, Elatine hexandra, Potentilla supina, Littorella lacustris, Polygonum minus, Juncus pygmaus, Tenageia; Deschampsia discolor, Lobelia urens, Carum verticillatum, Carex OEderi, Scirpus ovatus, Cicendia filiformis, pusilla; Sagina subulata, Centunculus minimus, Radiola linoides, Wahlenbergia hederacea, Trifolium micranthum, Ranunculus nemorosus, Scutellaria minor, Sorbus torminalis, Ilottonia palustris, Myriophyllum alterniflorum, Inula IIelenium.

Itteville. - Station de Ballancourt, tourbière d'Itteville, rochers, Petit-Saussay, station de Ballancourt.

Agrostis interrupta, (iirsium eriophorum, Silene noctiflora, Selinum Carvifolia, Sonchus palustris, Sparganium minimum, Diplotaxis muralis, Cucubalus bacciferus, Peucedanum palustre, Ranunculus Lingua, Gentiana Pneumonanthe, Helminthia echioides, Malva mosehata, Utricularia vulgaris, Cladium Mariscus, Dianthus superbus, Iydrocharis Morsus Rane, Helianthemum polifolium, Sedum hirsutum, Asplenium lanceolatum, Lychnis Viscaria, Silene noctiflora, Cirsium rigens.

Saint-Léger. - Station du Perray, omnibus de Saint-Léger, route de Condé, tourbière en face l'Archet, Butte à l'Ane, Croix Pater, les Grands Coins, retour au Perray. 
Dianthus deltoides, Epilobium roseum, obscurum; Arnoseris minima, Ranunculus lederaceus, Comarum palustre, Carex canescens, Viola palustris, Potamogeton polygonifolius, pusillus; Erica Tetralix, Rhynchospora alba, fusca; Drosera intermedia, rotundifolia; Lycopodium inundatum, Scirpus multicaulis, Helodes palustris, Epilobiun palustre, Carex pulicaris, stellulata, lievigata; Blechnum spirant, Usmunda regalis, Scirpus caspitosus, Scutellaria minor, Salix repens, Juneus squarrosus, Nardus stricta, Polystichum Thelypleris, Juncus capitatus, Sagina subulata, Cicendia filiformis, Erica ciliaris, scoparia; Lohelia urens, Carum verticillatum, Juncus Tenageia, Erica vagans, Wolffia arrhiza, Lemna gibba, Silene gallica, Spergularia segetalis, Ranunculus sardous, Veronica acinifolia, Tillæa muscosa, Aira mulliculmis, Sedum elegans, Cepæa.

Malesherbes. - Butte de la Juslice, Chateaugay, bois du Château, marais de Roncevaux, rochers, marais de Buthiers, coteaux d'Auxy, chemin aux Vaches, retour à Malesherbes.

Neslia paniculata, Bupleurum rolundifolium, Asperula arvensis, Micropus erectus, Valerianella eriocarpa, Linum alpinum, tenuifolium, Cytisus supinus, Lactuca perennis, Inula hirta, Thalictrum minus, Ononis Columne, Carex humilis, Spiræa hypericifolia, Gentiana germanica, Brunella grandiflora, Fumana vulgaris, Teucrium montanum, Coronilla minima, Adonis astivalis, autumnalis, flammea Polygala calcarea, Althæa hirsuta, Nigella arvensis, Erysimum orientale, Turgenia latifolia, Anchusa italica, Veronica pracox, Specularia hybrida, Cirsium Eriophorum, Carduncellus mitissimus, Polycnemum majus, Tragopogon major, Gentiana Cruciata, Limodorum abortivum, Iris fotidissina, Trinia vulgaris, Rhus colinus, radicans, Viola alba, Helianthemum pulverulentum, Cytisus Laburnum, Sorbus latifolia, Aria ; Orchis conopea, odoratissima, ustulata; Orobanche Teucrii, Phyteuma orbiculare, Rubia peregrina, Phalangium ramosum, Aceras anthropophora, Epipactis atrorubens, Goodyera repens, Herminium Monorchis, Lithospermum purpureo-cœeruleum, Ornithogalum pyrenaicum, Doronicum Pardalianches, Viola alba, Fragaria collina, elatior; Quercus Cerris, Stachys lanata, germanica, Chlora perfoliata, Liparis Loeselii, Utricularia minor, intermedia; Carex filiformis, Spiranthes restivalis, Drosera longifolia, Cyperus flavescens, Sagina nodosa, Orchis palustris, Carex Schreberi, Juncus capitatus, Linaria Pelliceriana, Quercus Ilex, Orchis incarnata, Salix repens, Carex teretiuscula, dioica, paradoxa, ampullacea; Myrica Gale, Inula salicina, Polygala Austriaca, Scirpus compressus, pauciflorus; Ranunculus Lingua, Cladium Mariscus, Sparganium minimum, Potamogeton pusillus, plantagineus; Tragus racemosus, Cephalanthera grandiflora, Scabiosa ucranica, Bulliarda Vaillantii, Stipa pennata, Ononis Natrix, Tordylium maximum, Osmunda regalis, Helosciadium repens, Asplenium lanceolatum, Chenopodium Bonus-IIenricus, Hutchinsia petræa, Medicago orbicularis, Centrophyllum lanatum; à Nanteau: Phelipæa arenaria, Scorzonera austriaca; à Rouville : Cephalanthera ensifolia.

Mantes. - Les Célestins, ermitage Saint-Sauveur, Moulin à vent de Follainville, bois du Coudray, retour par les bords de la Seine.

Salvia Sclarea, Helianthemum polifolium, Polygala calcarea, Coronilla minima, Ophrys aranifera, apifera, Arachnites; Orchis militaris, Simia, pyramidalis; Epipactis atrorubens, Genista prostrata, Sesleria cierulea, Orobanche cruenta, Galii, Epithymum; Hyssopus officinalis, Astragalus monspessulanus, Melica ciliata, Camelina silvestris, Grepis pulchra, Gentiana germanica, Eryngium planum, Carex tomentosa, Ophioglossum vulgatum, Rhinanthus minor, Herninium Monorehis, Carex Mairii, Limodorum abortivum, Egopodium Podagraria.

\section{Marcoussis.}

Ceterach officinarum, Cucubalus bacciferus, Eragrostis vulgaris, Lathyrus niger, Arnoseris minima, Aira multiculmis, Melampyrum eristatum, Senecio adonidifolius, Inula graveolens, Galeopsis dubia, Setaria glauca, Peucedanum parisiense.

Marly. - 1 L'Étang-la-Ville, Route de la Muraille, Chemin du Gros Houx, station de Saint-Nom la Bretèche.

Pirola minor, rotundifolia, Epilobium roseum, obscurum; Tamus communis Glyceria plicata, Cirsium eriophorum, Euphorbia stricta, Sedum sexangulare, Androsæmum officinale, Blechnum Spicanl, Polystichum Oreopteris, Polypodium Dryopteris, Cicendia filiformis, Lappa nemorosa, Lycopodium clavatum, Lobelia urens, Epipactis palustris, Equisetum variegatum. 
$2^{\circ}$ Halte de Fourqueux, les Bois Noirs, forèt, chemin des Essarts, du Loup, la Jonction, Saint-Germain.

Lepidium Draba, Fumaria Bastardi, Epilobium lanceolatum, Sedum Cepæa, Stachys ambigua, Fragaria elatior, Sison Amomum, Pirola minor, Vaccinium Myrtillus. Mlaianthemum bifolium, Senecio viscosus, Lappa nemorosa, Polygonum dumetorum. Inula graveolens, Scutellaria minor, Lobelia urens, Wablenbergia hederacea, Blechnum Spicant, Polyslichum Oreopteris, Cicendia filiformis, Potentilla procumbens, Epipactis latifolia var. violacea, Lysimachia nemorum, Alropa Belladona, Epilobium obscurum, spicatum; Samolus Valerandi, Slachys germanica, Falcaria Rivini, Vicia gracilis.

Saint-Maur. - Station la Plaine Saint-Maur, pont de Bonneuil, la Chapelle.

Salsola Kali, Ononis Natrix, Alsine setarea, Silene Olites, Arlemisia campestris, Euphorbia Gerardiana, Reseda Plyteuma, Corynephorus canescens, Helianthemum gutlatum, Orobanche Epithymum, Artemisia Selengensis, Veronica verna, Trifolium scabrum, Ornithogalum umbellatum, Muscari racemosum, Nasturtium palustre, Urobanche amethystea, Ononis Columnie, Trigonella Monspeliaca, Vulpia longiseta, Planlago arenaria.

Montfort-l'Amaury. - Station, Méré, Montfort, mares Robert et moussues, Chène Rogneux, les Haizettes.

Orchis ustulala, Glyceria plicata, Ranunculus hederaceus, Asplenium Adiantum nigrum, Polygala depressa, Hieracium Auricula, Orchis mascula et morio, Pilularia globulifera, Comarum palustre, Carex canescens, elongala, vulgaris, ampullacea, Equisetum limosum, Eriophorum gracile, vaginatum; Atropa Belladona, Scirpus fluitans, Deschampsia discolor, Lobelia urens, Peucedanum parisiense, Erica Tetralix, Carum verticillatum, Cicendia filiformis, Aira multiculmis, Damasonium stellatum, Potamogeton trichoides.

Montmorency. - Station de Taverny, lisière de la forèt, vallon de la Fontaine du Four, retour à Taverny.

Corydalis solida, Cerasus Padus, Vaccinium Myrtillus, Epilobium roseum, obseurum; Chlora perfoliata, Tetragonolobus siliquosus, Aquilegia vulgaris, Schorus nigricans, Erica Tetralix, Drosera rotundifolia, Carex pulicaris, Calamagrostis lanceolata, Menyanthes trifoliata.

Mortefontaine. - Station de Survilliers, omnibus de Mortefontaine, pare, bords de la Thève, Thiers, bords de la forêt de Pontarmé, Neumoulin, la Chapelle-en-Serval, Survilliers.

Carex arenaria, Erica Tetralix, Cladium Mariscus, Carex Mairii, Polystichum Thelypteris, cristatum; Juncus squarrosus, Carex dioica, Silene gallica, Dianthus Carthusianorum, superbus, deltoides, Armeria ; Peucedanum Oreoselinum, Hypericum montanum, Sagina ciliata, Helodes palustris, Potamogeton polygonifolius, Salix repens, Tillæa muscosa.

Nemours. - Route de Sens, Rocher Vert, la Baraudière, Darvault, Moncourt, Grez, station de Nemours.

Pirola umbellata, Sinapis Cheiranthus, Amelanchier vulgaris, Goodyera repens, Vicia lutea, Valerianella coronata, Adonis autumnalis, flammea; Stipa pennata, Limosella aquatica, Trifolium micranthum, strictum, scabrum, striatum; Bulliarda Vaillantii, Sedum villosum, Orchis coriophora, ustulata; Laserpitium latifolium, Peucedanum Oreoselinum, Cervaria; Trifolium rubens, Lactuca virosa, Genista pilosa, germanica; Asperula tinctoria, Globularia vulgaris, Teucrium montanum, Satureia montana, Tragopogon major, Micropus erectus, Equisetum occidentale, Cardamine hirsuta, Pinguicula vulgaris, Carex teretiuscula, paradoxa; Liparis Loselii, Sanguisorba officinalis, Nasturtium asperum, Sagina nodosa, Carex polyrrhiza, præcox, Hornschuchiana; Hottonia palustris, Sedum elegans, Filago arvensis, Astrocarpus Clusii, Trifolium patens.

Étang de Saint-Quentin. - Station de Trappes, queue de l'étang, bords côté sud, grève côté nord, mares de Troux, Saint-Gyr.

Potamogeton acutifolius, gramineus, trichoides, pusillus; Elatine Hydropiper, lıexandra et var. major, Alsinastrum; Scirpus supinus, Poa palustris, Stellaria glauca, Bidens radiatus, Damasonium stellatum, Gypsophila muralis, Lythrum 
Hyssopifolia, Juncus Tenageia, pygmaus; Limosella aquatica, Littorella lacustris, Scirpus ovatus, Crypsis alopecuroides, Gaudinia fragilis, Bupleurum tenuissimum, Rumex maritimus, palustris; Potamogeton obtusifolius, Potentilla procumbens, Spiranthes autumnalis, Salvia verticillata, Lycopodium clavatum, Intennaria dioica.

Rambouillet. - Station de Gazeran, Guipéreux, étang d’Angènes, Poigny, étang du Serisaye, Rambouillet.

Cerastium brachypetalum, Cystopteris fragilis, Veronica precox, Primula grandiflora, Carex canescens, elongata, filiformis, pulicaris; Rhynchospora alba, Comarum palustre, Erica Tetralix, Salix repens, Stellaria glauca, Hottonia palustris, Polystichum Thelypteris, cristatum; Myrica Gale, Drosera intermedia, rotundifolia ; Viola palustris, Lycopodium inundatum, Nardus stricta, Parnassia palustris, Carum verticillatum, Lohelia urens, Tillaea muscosa, Cicendia filiformis, Centunculus minimus, Scutellaria minor, Helianthemum guttatum, Dianthus deltoides, Malus acerba, Sagina ciliata, Maianthemum hifolium, Calamagrostis lanceolata, Osmunda regalis, Liparis Loselii, Epilobium palustre, Vicia lutea, Lathyrus hirsutus, Aira multiculmis, Arnoseris minima, Hypochæris glabra, Sedum elegans, Linaria arvensis, Botrychium Lunaria, Spergula pentandra, Potentilla procumbens, Rhynchospora fusca, Erica ciliaris, Scirpus fluitans, Heleocharis multicaulis, Oxycoccos palustris, Polystichum Oreopteris, Cucubalus bacciferus, Sedum dasyphyllum.

La Roche-Guyon. - Station de Bonnières, sables de Moisson, la RocheGuyon, Roconval.

Medicago Gerardi, Carex Schreberi, Eruga sativa, Diplotaxis muralis, Isatis tinctoria, Helianthemum montanum, Orchis Simia, militaris, purpurea; Cerasus Mahaleh, Thlaspi montanum, Doronicum plantagineum, Thalictrum minus, Melampyrum cristatum, Phelipæa cirulea, Sparganium simplex, Potamogeton fluitans.

Forêt de Sénart. - Station de Ris-0rangis, bords de la Seine, les Meillotles, forèt, Ermitage, Épinay, Brunoy.

Euphorbia palustris, Salix rubra, hippophæfolia, fragilis, undulata; Trifolium ochroleucum, Orobanche minor, Cardamine impatiens, Cerastium brachypetalum, Fragaria collina, Geterach officinarum, Ruscus aculeatus, Phyteuma spicatum, Doronicum plantagineum, Primula grandiflora, Galanthus nivalis, Ilellehorus fotidus, Scilla bifolia, Euphorbia dulcis, Buxus sempervirens, Tillæa muscosa, Potentilla splendens, Pyrus communis, Narcissus Pseudo-narcissus, Cicendia filiformis, pusilla; Juncus Tenageia, Lobelia urens; Agrimonia odorata, Juncus tenuis, Asarum europæum, Muscari racemosum, Lamium hybridum, Scolopendrium officinale.

Vallèe de Senlisse. - Station de la Verrière, omnibus de Dampierre, . côteau de Lévy, Senlisse, étang de Grand-Moulin, bois des $500 \mathrm{ar}$ pents, les Essarts, bois Saint-Pierre, vignes.

Carex ligerina, Spergula Morisonii, Polygonum Bistorta, Cardamine amara, Carex pulicaris, Potamogeton pusillus, Cirsium hybridum, Spiræa hypericifolia, Hottonia palustris, Vicia lutea, Logfia gallica, Orchis morio, ustulata, viridis; Euphorbia dulcis, Aspidium aculeatum, Osmunda regalis, Pinguicula vulgaris, Veronica montana, Chrysosplenium alternifolium, Polystichum Thelypteris, cristatum; Carex teretiuscula, vulgaris, Hornschuchiana, elongata, canescens; Potamogeton polygonifolius, Triglochin palustre, Drosera rotundifolia, Cardamine Silvatica, Sedum elegans, Tilliea muscosa, Verbascum blattarioides, Cicendia filiformis, Scutellaria minor, Erica Tetralix, Lathyrus hirsutus, Veronica acinifolia, Lathra clandestina, Erica ciliaris, scoparia; Eriophorum gracile, vaginatum; 0xycoccos palustris, Goodyera repens, Limodorum abortivum, Anchusa italica.

Souppes. - Route de Nemours, retour à Souppes, route de Montargis, marais, Dordives, Thurelles, retour à Dordives.

Medicago Gerardi, Nicropus erectus, Linum alpinum, tenuifolium; Teucrium montanum, Koeleria setacea, Carduncellus mitissimus, Fumana procumbens, Helianthemum polifolium, Ranunculus nemorosus, Ophioglossum vulgatum, Andropogon Ischømum, Scirpus compressus, Juncus anceps, Liparis Loeselii, Osmunda regalis, Cirsium bulbosum, Orchis palustris, Spergula Morisonii, pentandra; Trifolium scabrum, ochroleucum; Fragaria collina, Teucrium Scordium, Juncus capitatus, Dipsacus pilosus, Cucubalus bacciferus, Nasturtium pyrenaicum. 
Étang de Trou-Salé. - Station de Versailles, hois des Gonards, Buc, étangs de Trou-Salé et de Saclay, Bièvres.

Lobelia urens, Polystichum spinulosum var dilatatum, Stellaria uliginosa, Wahlenbergia hederacea, Epipactis latifolia var. violacea, Salvia glutinosa, Scutellaria Columnie, Gleditschia triacanthos, Sparganium ramosum, Cirsium eriophorum, Gaudinia fragilis, Bupleurum tenuissimum, P'otentilla procumbens, Spiranthes autumnalis, Alisma arcuatum, Damasonium stellatum, Elatine IIydropiper, hexandra, Alsinastrum; Scirpus supinus, ovatus; Carex cyperoides, Potentilla supina, Rumex maritimus, Potamogeton gramineus, Trifolium subterraneum, striatum; Poa palustris, Gypsophila muralis, Agrimonia odorata.

\section{Vernon. - Coteaux, route de Magny, Camp de César.}

Scleropoa rigida, Istragalus monspessulanus, Melica ciliata, Mlthea hirsula, Atropa Belladona, Luzula maxima, liosa slylosa, Stratiotes Aloides, Polygala depressa, Gentiana Cruciata, Vaccinium myrtillus, Euphorbia Lathyris, Herminium Monorchis, Anemone Pulsatilla, Digitalis purpurea, lutea; Euphorbia Esula.

Villers-Cotterets. - $1^{\circ}$ Station d'Eméville, laie d'Eméville, de Cabaret, du Ravin, Jeanne d'Arc, route de Soissons, laie de Chavigny, route Tortue, Villers-Cotterets.

Polystichum Oreopteris, Osmunda regalis, Polypodium Dryopteris, Indrosiemum officinale, Carex maxima, strigosa; Scolopendrium officinale, Epipactis microphylla, Elymus europaus, Paris quadrifolia, Aspidium lobatum, Physalis Alkekengi, Maianthemum bifolium, Epilobium roseum, obscurum, Hieracium Auricula, Potentilla procumbens, Equisetum silvaticum, Lycopodium clavatum, Stachys alpina, Hieracium prealtum, Atropa Belladona, Hypericum Desetangsii, Alchemilla vulgaris, Epilobium lanceolatum.

$2^{\circ}$ Station de silly, marais des Hureaux, bois de Cresnes, bois du Buchet, retour à Villers-Cotterets.

Stachys germanica, Swertia perennis, Drosera longifolia, Salix repens, Liparis Leselii, Cladium mariscus, Schœnus nigricans, Pinguicula vulgaris, Carex paradoxa, Davalliana; Menyanthes trifoliata, Aconitum Napellus, Phyteuma spicatum, Cicuta virosa, Setaria glauca, Stachys ambigua, Impatiens Noli Tangere, Chrysosplenium oppositifolium, alternifolium; Digitalis lutea, Elymus europieus.

\section{Valmondois. $-1^{\circ}$ Valmondois, coleaux et marais de Nesles.}

Intennaria dioica, Daphne Laureola, Carex digitata, Cystopleris fragilis, Anemone Pulsatilla, Ononis Columux, Coronilla minima, Fumana vulgaris, Globularia vulgaris, Phyteuma orbiculare, Bupleurum aristatum, Nicropus erectus, Gentiana germanica, Phalangium ramosum, Orchis mascula, purpurea, militaris, Simia, ustulata, hircina; Ophrys museifera, aranifera, apifera, Arachnites; Cephalanthera grandiflora, Limodorum abortivum, Pinguicula vulgaris, Anagallis tenella, Menyanthes trifoliata, Gentiana Pneumonanthe, Selinum Carvifolia, Orchis conopea, Epipactis palustris, Carex Mairii, Cladium Mariscus, Schœnus nigricans.

\section{$2^{\circ}$ Vallangoujard, marais d'Arronville.}

Ranunculus Lingua, Menyanthes trifoliata, Drosera longifolia, Pinguicula vulgaris, Utricularia minor, Orchis incarnata, Epipactis palustris, Liparis Loselii, Spiranthes estivalis, Triglochin palustre, Carex teretiuscula, paradoxa, ampullacea, Schenus nigricans, Cladium Mariseus, Sparganium minimum, Potamogeton plantagineus, Ophioglossum vulgatum, Polystichum Thelypteris, Rosa slylosa, $i$ Epiais-Rhus, Aceras anthropophora, Bupleurum aristatum, Trigonella monspeliaca, Cardamine amara, Lychnis diurna.

\section{Flamboin. - Portmontain, Hermé.}

Stachys germanica, Verbascum flocesum, Cyperus fuscus, Carex OEderi, Salix purpurea, Inula salicina, Britannica; Lathyrus palustris, Galium boreale, firatiola officinalis, Alisma ranunculoides, Allium angulosum, Sium latifolium, Euphorbia palustris, Euphorbia platyphylla, Galium parisiense, Stellaria glauca, Viola elatior, pumila, Ophioglossum vulgatum, Erysimum hieracifolium var. cheiriflorum, Isatis tinctoria, Adonis autumnalis, Helosciadium repens, Erucastrum Pollichii. 


\section{TABLE DES MATIÈRES}

Nota. - Le premier chiffre indirgue le numéro d'ordre, le second celui des pages.

Abies excelsa. . . . $1216 \quad 18 \mathbf{k}^{\prime}$ - pectinata .... 1213 18'

Acer campestre. . . 282 4́

- Negundo ..... 278 't'

- opulifolium . . . . $281 \quad 4$ '́

- platanoides . . 280

- Pseudo-platanus

Aceras anthropophora

ACÉRINÉES.

Achillea Millefolium .

- Ptarmica ....

Aconitum Napellus. . Acorus calamus. . .

Actæa spicata . . . .

Adiantum CapillusVeneris.

Adonis aestivalis. .

- autumnalis... .

- flammea.... .

Adoxa Moschatellina .

Ægilops ovata. . .

- triuncialis....

Ægopodium Podagraria. . . . . .

Æsculus Hippocastanum ......

Ethusa Cynapium .

Agrimonia Eupatoria.

- odorata . . . . .

Agropyrum acutum. . 10380

- campestre. . . . 1381

- caninum . . . . 1378

- repens . . . 1579

Agrostis alba ... 1' 149

- canina . . . 1487

- interrupta. . . . 1486

- pumila .....

- Spica-venti ... 1483

- varians . . . . .

- vulgaris. . . . 1488

Ailanthus glandulosa. $\quad 297$

Aira caryophyllea. . . 1493

- multiculmis. . . 1494

- precox .... 1493

Airopsis agrostidea. . 1492

Ajuga Chamrepitys. . 1073

- genevensis. . . . 1074
Ajuga pyramidalis . .

Ajuga pyramidalis . . 105

- reptans.... $1073 \quad 163$

Alchemilla arvensis. . $487 \quad 70$

- vulgaris. ... 48870

Alisma arcuatum. . $1231 \quad 187$

- nalans. . . . . 1229186

- Plantago. . . . . 1230187

- ranunculoides. . . 1228186

- repens. . . . . 186

ALISMACEES . . . 186

Allium aculangulum . $\quad 190$

- angulosum ... 1259190

- ascalonicum. . . . 1218189

- Cepa .... 12'6 189

— fistulosum. . . 12亿7 189

- flavum . . . 123' 190

- oleraceum. . . . 1282 190

- paniculatum. . . 1253190

- Porrum . . . . . 1237190

- sativum. . . . . 12 \%ั 190

- Schœenoprasum . 1249 189

- Scorodoprasum . . 1236190

- sphaerocephalum . 1230190

- ursinum. . . . . 1238190

- vineale . . . . 1230190

Alnus cordata . . . 183

— glutinosa . . . . 1210183

- incana . . . . 1211183

Alopecurus agrestis . $1466 \quad 220$

- fulvus. . . . . 1469 221

- geniculatus ... $1468 \quad 220$

- pratensis . . . $1467 \quad 220$

- utriculatus . . 146320

Alsine selacea . . . $209 \quad 37$

- tenuifolia . . . . $208 \quad 37$

Althaea hirsuta . . 25304

- officinalis.... 41

- rosea. . . . . 231 4

Alyssum calycinum . $118 \quad 27$

- montanum . . . 11927

- saxatile..... 27

Amarantus Blitum . . 1092166

- deflexus. . . . . 1090166

- retrollexus ... 1091166

- silvestris . . . 1093167

AMARYLLIDÉES. . . 192

AMBROSIACÉES . . . 123 
Amelanchier vulgaris. Ammi majus

- var. glaucifolium.

AMPÉLIDÉES.

Ampelopsis hedera cea

Amsinckia angustifolia. . . . . . . Anagallis arvensis.

- cærulea.

- carnea.

- phenicea - var. violacea

- tenella... .

Anchusa arvensis. .

- italica.

- sempervirens . . .

Andropogon Ischæmum.

Androsæmum calycinum .

- officinale

Anemone Hepatica

- nemorosa.

- Pulsatilla.

- ramunculoid

- silvestris

Angelica silvestris .

Antennaria dioica . .

Anthemis arvensis. .

- Cotula

- mixta.

- nobilis .

Anthericum Liliago. .

- ramosum .... .

Anthoxanthum arislatum ......

- odoratum. . . .

- Puelii.

Anthriscus Cerefolium

- silvestris .....

- vulgaris.

Anthyllis Vulneraria.

Antirrhinum majus. .

- Orontium....

APÉTALES ...

Apium graveolens. .

APOCYNÉES .

Aquilegia vulgaris . .

Arabis arenosa. . .

- hirsuta....

- perfoliata....

- Turrita ....

ARALIAGÉES . . .

Arenaria grandiflora .

- leptoclados . . . .

- serpyllifolia. . . .

- trinervia.
502

89

89

1261

$1260 \quad 190$

$14377 \quad 219$

$1430 \quad 219$

219

$627 \quad 91$

62391

$322 \quad 51$

9 9ั 144

954 141

$622 \quad 91$

130

$\begin{array}{ll}48 & 17\end{array}$

$106 \quad 26$

$108 \quad 26$

$107 \quad 26$

26

92

37

37

37

37
Aristolochia Clemati-

tis. ... . . $1147 \quad 174$

ARISTOLOCHIÉES . . 174

Armeniaca vulgaris. . $\quad 410 \quad 62$

Armeria maritima . . $\quad 163$

- plantaginea . . . 1038163

Arnica montana . . . $700 \quad 10$ '

Arnoseris minima . . $794 \quad 118$

AROID上ES.

Arrhenatherum bulbo-

sum . . . . . 22马

- elatius . . . 1508 220

Artemisia Absinthium. $\quad 108$

- campestris. . . . $\quad 734 \quad 108$

- Dracunculus. . . . 732108

— selengensis . . . 733108

- Verlotorum .... 108

- vulgaris. . . . . $731 \quad 108$

ARTOCARPÉES. . . . 177

Arum italicum . . . 131' 202

- maculatum .. . 1343202

Arundo Phragmites. . 1482222

Asarum europaeum . . $1146 \quad 174$

ASCLÉPIADE்ES . . . 131

Asclepias Cornuli . . 8830131

ASPARAGINEES . . . 191

Asparagus officinalis. $\quad 1267 \quad 192$

Asperugo procumbens $\quad 928 \quad 139$

Asperula arvensis . . $\quad 662 \quad 97$

- cynanchica . . . 666097

- galioides . . . . 661 97

- odorata. . . . 66397

- tinctoria . . . 66307

Aspidium aculeatum $\mathbf{1 6 0 1} 238$

- lobatum. . . . . 1600238

Asplenium Adiantum-

nigrum. . . . . . $1609 \quad 239$

- foresiacum . . . $1612 \quad 239$

- germanicum. . . 161302

- lanceolatum. . . . 1613239

- Murbeckii. . . . 1611239

- Ruta-muraria . . 1610239

- septentrionale . . 1616240

- Trichomanes . . 1614239

Aster amellus . . . . $697 \quad 104$

- Novi Belgii . . . . 104

- salignus. . . . 104

Astragalus glycyphyl-

los. . . . . . 363 5̋

— monspessulanus. . $362 \quad 53$

Astrocarpus purpu-

rascens. . . . . $170 \quad 32$

AthyriumFilix-fœmina $1608 \quad 239$

Atriplex hastata . . $1097 \quad 167$

- hortensis . . . . $1096 \quad 167$

- patula. . . . . $1098 \quad 167$

Atropa Belladona. . . $940 \quad 141$

Avena fatua . . . $1501 \quad 224$ 
Avena orientalis . . . $1303 \quad 224$

- pratensis . . . . $1506 \quad 225$

- pubescens. . . . . 1503225

- sativa. . . . . 1002224

- strigosa .... 150' 223

Ballota nigra. . . 106' 161

BALSAMINÉES .

Barbarea arcuata. . .

- intermedia ....

- praecox....

- rivularis.

- vulgaris....

Bartsia viscosa. . .

Bellis perennis

BERBÉRIDÉES.

Berberis vulgaris. .

Beta vulgaris. . . . .

Betonica officinalis. .

Betula alba .....

- pubescens. . . .

Bidens cernuus.

- var. radiatus.

- radiatus.

- tripartitus.

Bifora radians.

Biscutella ling .

Blechnum Spicant. .

BORRAGINÉES.

Borrago officinalis . .

Botrychium Lunaria

- matricariæfolium .

- simplex . . . . . .

Brachypodium pinatum

- silvaticum. . . .

Brassica Cheiranthus.

- Napus. . . . . . .

- oleracea. . . . .

- Rapa .

Briza media.

Bromus arvensis. . .

- asper .

- commutatus...

- erectus . . . . . .

- inermis . . . . . 1533

- maximus . . . . $15 \% 3$

- mollis.... . . 1563

- racemosus. . . . 1562

- secalinus .... 1559

- sterilis . . . . 15557

- tectorum ....

Broussonetia papyrifera ......

Brunella alba . . . $1070 \quad 162$

- grandiflora ... $1072 \quad 163$

Brunella vulgaris. . . $1071 \quad 162$
Bryonia dioica . . . $530 \quad 76$

Bunias Erucago. . . $\quad 28$

- orientalis . . . . $128 \quad 28$

Bunium Bulbocas-

tanum . . . . . 60989

Bupleurum aristatum. $\quad 603 \quad 88$

- falcatum . . . . 60188

- truticosum. . . . 88

- rotundifolium . . . 60288

- tenuissimum . . . $604 \quad 88$

Butomus umbellatus . $1226 \quad 186$

Buxus sempervirens . $1148 \quad 174$

Calamagrostis Epigeios . . . . $1483 \quad 222$

- lanceolata.... 148' 222

Calamintha Acinos . . 1033157

— ascendens. . . . 1033158

- Clinopodium . . . $1032 \quad 157$

- Nepeta . . . . $1036 \quad 158$

- officinalis . . . $1034 \quad 157$

Calendula arvensis. . 733 105

— officinalis . . . . $736 \quad 108$

Calepina Corvini. . . $127 \quad 28$

CALICIFLORES. . 47

Calla palustris .... 202

Callitriche hamulata. 5222 74

- stagnalis . . . $524 \quad 74$

— vernalis. . . . . 52374

CALLITRICHINÉES .

$\begin{array}{llll}\text { Calluna vulgaris . . . } & 8508 & \mathbf{1 2 6}\end{array}$

Caltha palustris . . . $\quad 40 \quad 16$

Camelina fotida . . . 28

- sativa. . . . . 12428

- silvestris .... 1230

Campanula Cervicaria $847 \quad 125$

- glomerata. . . . . $848 \quad 12 \%$

- Medium . . . . $\quad 126$

- persicifolia . . . $849 \quad 12 \mathrm{y}$

- pyramidalis. . . 850125

- rapunculoides . . . $833 \quad 125$

- Rapunculus . . . . 830123

- rotundifolia . . . . 8504126

- Trachelium . . . . 852125

CAMPANULACÉES . 124

Cannabis sativa . . $1169 \quad 177$

CAPRIFOLIACÉES . . 92

Capsella Bursa-Pasto-

ris....... . $136 \quad 29$

- rubella ..... $\quad 137 \quad 29$

Cardamine amara . . 10926

- hirsuta ..... 11126

- impatiens. . . . $113 \quad 27$

- pratensis . . . $110 \quad 26$

- silvatica. . . . . . $112 \quad 26$

Carduncellus mitissi-

mus . . . . . . $774 \quad 114$

Carduus acanthoides . $\quad 772 \quad 113$ 


\begin{tabular}{|c|c|c|c|c|c|c|c|}
\hline . & & $\therefore$ & 771 & & 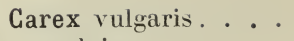 & 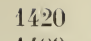 & \\
\hline$-n$ & & . & 773 & 114 & - vulpina & 1409 & 210 \\
\hline uiflorus & . & . & 770 & 113 & Carlina vulgaris & 7วิ9 & 112 \\
\hline arex acuta & & . & 1421 & 211 & Carpinus Betulus. & $118^{\prime}$ & 179 \\
\hline formis & & & $142 t$ & 212 & Carum Carvi. . & 611 & 89 \\
\hline ia. & & . & 1103 & 209 & - verticillatum & 610 & 89 \\
\hline ens & & & & 211 & LEESS & & 33 \\
\hline ides. & & . & & 209 & aris & 1177 & 178 \\
\hline ana & & & & 209 & atica. & $13 ̈ 19$ & 226 \\
\hline a & & & 1441 & 214 & ides. & 573 & 84 \\
\hline & & & 1437 & 213 & ÉES. & & 43 \\
\hline & & & 1398 & 209 & a amara. & 777 & 114 \\
\hline s. & & & 1147 & 214 & - Calcitrapa. . . & 783 & $1 \check{2}$ \\
\hline 1a. & & & 1 & 209 & milis. . . & & 115 \\
\hline a . & & & 1 & 210 & us... & 77 & 114 \\
\hline ta & & & 1414 & 211 & $-\mathrm{J}$ & 778 & 114 \\
\hline a. & & & 1416 & 211 & ptilon & & 114 \\
\hline um & . & & & 213 & tha. & & 15 \\
\hline . & & & 1 & $212-3-3-1$ & lis . & 781 & 115 \\
\hline & 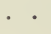 & & $\ddot{3}$ & 21 & 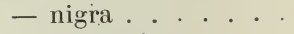 & 780 & 114 \\
\hline & & & 1 & $21 \ddot{3}$ & - & 779 & 114 \\
\hline & & & 1422 & 212 & - & 776 & 114 \\
\hline ana. & & & 1418 & 211 & - & & 114 \\
\hline & & & 1427 & 212 & $-s$ & 782 & 113 \\
\hline hirta & & & & 212 & ruber & & 97 \\
\hline cho & & & 1428 & 2 & yllum lana- & & \\
\hline & & & 1 & 2 & 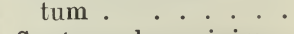 & & 1 \\
\hline . & ${ }^{\circ}$ & & 1 & 213 & Ius & & 12 \\
\hline & & & & 211 & Cepl & & \\
\hline & & & - & 2 & & 18 & 19 \\
\hline & & & 1 & 21 & & & 197 \\
\hline aа & & . & 1431 & 213 & [YLLÉES. & & 19 \\
\hline ata & & & 1410 & 210 & m demer- & & \\
\hline a. & • & & 1439 & $21:$ & & 52 & \\
\hline i. & & & 1452 & 21 & $\mathrm{~m}$ & 32 & 73 \\
\hline i & • & • & 14 & 21 & quaticum. & $\begin{array}{l}32 \\
23\end{array}$ & 5 \\
\hline us & . & • & . 14 & 21 & . . & 2 & 38 \\
\hline & - & • & . 14 & 21 & etalum & $\begin{array}{l}2 \\
2\end{array}$ & 38 \\
\hline ata. & . & & . 14 & 210 & - & 22 & 38 \\
\hline & • & & . 14 & 210 & $-\varepsilon$ & 22 & 38 \\
\hline 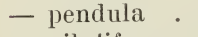 & • & & . & 21 & . . & & 3 \\
\hline & & • & . 14 & 21 & - & 22 & 38 \\
\hline za. & & & 14 & 213 & adrum & 2 & . \\
\hline & & & 1433 & 21 & sum & 22 & \\
\hline Суре & erus & & . 14 & 21 & . . & 22 & \\
\hline & & & . 1400 & 20 & vium. & 41 & \\
\hline bach & $i i$ & & & 20 & eb. . . & 41 & 6 \\
\hline a. & & & 3 & 21 & - & 4 & $60^{2}$ \\
\hline & & . & & 2 & & 41 & 68 \\
\hline & & . & & 21 & ficinarum. & 15396 & 237 \\
\hline eri & - & - & & 21 & im tem & & \\
\hline & . & & & (2) & & 62 & 92 \\
\hline & & & 14 & 21 & s Cheiri. & & 24 \\
\hline & - & & 1442 & 214 & um majus. & 60 & 19 \\
\hline & & & 14 & 210 & $-l$ & & 19 \\
\hline & . & & 1434 & 213 & m album & 1110 & 69 \\
\hline & & & 1429 & 212 & - ambrosioides. & 1101 & 167 \\
\hline
\end{tabular}


Chenopodium BonusHenricus . . . . 1102168

- ficifolium . . . $\quad 1111 \quad 169$

- glancum. . . . . $1109 \quad 168$

- hybridum. . . . 1106168

- murale ... 1108168

— opulifolium . . . 1112169

— polyspermum . . 1103168

- rubrum ..... 1103168

- urbicum. ... $1107 \quad 168$

- Vulvaria .. . 1104 168

Chlora perfoliata. . $890 \quad 132$

Chondrilla juncea . . $810 \quad 119$

Chrysanthemum segetum .....

Cicendia filiformis . .

- pusilla .....

Cicer arietinum ...

Cichorium Endivia. .

- Intybus. . . . .

Cicuta virosa. . . .

Cinara Scolymus. .

Circæa Lutetiana. . .

Girsium acanle. . .

- anglicum . . . .

- arvense.....

- var. mite.

- eriophorum ....

- hybridum. . . . .

- lanceolatum.

- oleraceum. . . .

- palustre. . . . .

- rigens.... . .

- tuberosum. . . .

CISTINÉES . . . .

Cladium Mariscus .

Glematis Flammula. .

- recta .....

- Vitalba .....

- Viticella. . . . .

Cochlearia Armoracia.

- glastifolia....

COLGHIGACÉES . .

Colchicum autumnale

Colutea arborescens .

Comarum palustre . .

COMPOSÉES . . . .

CONIFĖRES

Conium maculatum.

Conopodium denudatum .......

Convallaria maialis. CONVOLVULACÉES.

Convolvulus arvensis.

- sepium . . . . . var. minor.

Coriandrum sativum .

Cornus mas . . . .

$761 \quad 112$

7630113

$760 \quad 112$

$764 \quad 113$

$\begin{array}{ll}762 & 112\end{array}$

$\begin{array}{ll}766 & 113\end{array}$

$\begin{array}{ll}769 & 113\end{array}$

30

1373206

16
- -var. chlorocarpa.

Cornus Sanquinea . $633 \quad 92$

Coronilla minima . . 4030

- varia .... 40460

Gorrigiola littoralis. . $\quad 5 \% 2 \quad 77$

Corydalis cava . . . $\quad 19$

- lutea..... $61 \quad 619$

- ochroleuca. . . . 6219

— solida..... 6319

Corylus Avellana. . $\quad 1183 \quad 179$

Corynephorus canes-

cens.... . . $1496 \quad 22$ 't

GRASSULACÉES . . . 78

Crataegus monogyna. $\quad 490 \quad 71$

- oxyacanthoides . . $491 \quad 71$

Crepis agrestis.... 122

- diffusa. . . . 122

- biennis . . . . $828 \quad 122$

- fotida .... 822121

- pulchra. . . . 8230121

- selosa..... $824 \quad 121$

- taraxacifolia . . $\quad 823 \quad 121$

- tectorum .... $826 \quad 122$

— virens. $\quad 827 \quad 122$

CRUCIFERES. . . 20

Crypsis alopecuroides. $1460 \quad 219$

Chrysosplenium alternifolium . . . 56380

- oppositifolium. . . $\$ 56680$

CRYPTOGAMES . . . 233

Cucubalus baccifer. . 18134

Cucumis Nelo ... 53276

— sativus ..... 53376

Cucurbita maxima. . 533 76

- Pepo .... 534 76

CUCURBITAGÉES . . $7:$

GUPULIFĖRES. . . . 178

Cuscuta corymbosa. . $900 \quad 131$

- Epilinum .... 901 13'

- Epithymum . . . $903 \quad 131$

- europaea .... . $902 \quad 131$

— Trifolii . . . . . 904 13 ă

Cydonia vulgaris . . $\quad 492 \quad 71$

Cynodon Dactylon . . $1480 \quad 222$

Cynoglossum montanum _... $927 \quad 138$

- officinale . . . $926 \quad 138$

- pictum ..... 923138

Cynosurus cristatus . $\quad \mathbf{1 3 3 8} \quad \mathbf{2 2 9}$

- echnatus .... 229

CYPÉRAGÉES … 20:

Gyperus flavescens. . 1372206

- fuscus. . . . 1371206

- longus . . . . . 1373206

Cytisus capitalus . . .

- Laburnum. . . . $316 \quad 30$

- supinus.... $317 \quad 30$

Cystopteris fragilis. . $1607 \quad 239$ 
Dactylis glomerata. .

Damasonium stellatum

Danthonia decumbens

Daphne Laureola. . .

- Mezereum. .

DAPHNOIDÉES

Datura Stramonium .

- Tatula.

Daucus Carota

Delphinium Ajacis. .

- Consolida. . . .

- orientale.

Dentaria bulbifera. .

- pinnata... .

Deschampsia crspitosa ......

- discolor. . . . .

- flexuosa. . . . .

- media.

Dianthus Armeria

- Carthusianorum. .

- Caryophyllus . . .

- deltoides .....

- prolifer ......

- superbus .....

Digitalis lutea . . . .

- purpurea ....

Digitaria filiformis.

- sanguinalis ... .

DIOSCORÉES.

Diplotaxis muralis. .

- tenuifolia...

- viminea.

DIPSAGÉES

Dipsacus fullonum.

- pilosus . . . . .

- silvestris .... .

Doronicum cordatum.

- emarginatum. . . .

- plantagineum ...

- Willdenowii.

Draba muralis....

- verna.

Drosera intermedia

- longifolia....

- obovata.

- rotundifolia.

DROSÉRACÉES

Echinochloa Crus-

Galli. . . . . .

Echinospermum Lappula

Echium vulgare...

- Wierzbickii

Élatine Alsinastrum .

- hexandra....
1477

221

$1537 \quad 228$

$1227 \quad 186$

$1512 \quad 225$

$1141 \quad 173$

$1140 \quad 173$

172

$941 \quad 141$

141

$570 \quad 84$

$45 \quad 17$

$46 \quad 17$

17

$114 \quad 27$

$115 \quad 27$

$1497 \quad 224$

$1499 \quad 224$

$1500 \quad 224$

$1498 \quad 224$

$198 \quad 36$

199

201

202

197

200

967

966

1479

1478

82

81
83

679

678

680

698

699

104

104

$121 \quad 27$

$120 \quad 27$

$177 \quad 33$

$178 \quad 33$

$179 \quad 33$

$176 \quad 33$

33

92ㅜㄴ 138

$913 \quad 137$

137

23ว 39

$237 \quad 39$
Élatine Hydropiper. . 236

- major . . . . .

ELATINEES. . .

ELEEAGNÉES. . . . . 173

Elymus europaeus . . $1570 \quad 232$

Endymion nutans. . . $1242 \mathbf{1 8 8}$

Epilobium collinum . $308 \quad 73$

- hirsutum . . . . 50ว 72

- Lamyi. . . . . . 73

- lanceolatum. . . . $509 \quad 73$

- montanum . . . $507 \quad 73$

— obscurum ‥

— palustre. . . . . $513 \quad 73$

- parviflorum. . $\quad 506 \quad 73$

— roseum . . . . . 51073

- spicatum ... . 50\% 72

- tetragonum ... 511

Epimedium alpinum . $51 \quad 18$

Epipactis atrorubens. $1316 \quad 198$

- latifolia. . . 1317198

- microphylla. . . . 1313198

- palustris. . . . $1314 \mathbf{1 9 8}$

- violacea. . . . . $\quad 198$

- viridiflora.... 198

EQUISÉTA GÉES . . . 241

Equisetum arvense. . 1627241

- hiemale. . . . 1632242

- limosum. . . . $1630 \quad 241$

- littorale. . . . 1631 242

- maximum. . . . $1626 \quad 211$

- occidentale ... $1633 \quad 2,2$

— palustre. . . . . 1629241

- silvaticum .. . 1628241

— variegatum . . . $1634 \quad 242$

Eragrostis major . $1528 \quad 227$

- minor. . . . . 1529227

- pilosa. . ..... . 1530228

Eranthis hyemalis. . . 17

Erica ciliaris. . . . . $839 \quad 127$

- cinerea . . . . 862127

- scoparia. . . . . 863127

- Tetralix. . . . . 860127

- vagans ..... $861 \quad 127$

ÉRICINÉES . . . . . 126

Erigeron acris . . . . 693103

- canadensis ... 694 103

Eriophorum angustifolium. . . . . $1379 \quad 207$

— gracile . . . . . 1381207

- latifolium. . . . 1380207

- vaginatum . . . 1378206

Erodium cicutarium . $\quad 267 \quad 42$

- moschatum . . . . $266 \quad 42$

Eruca sativa. . . . . $\quad 80 \quad 23$

Erucastrum obtusangulum ..... 8324

- Pollichii .... $84 \quad 24$

Eryngium campestre . $\quad 569 \quad 84$ 
Eryngium campestris.

- planum

Erysimum cheiran-

thoides. . . . .

- hieracifolium . . - var. cheiriflorum. murale

orientale ...

Erythraea Centaurium - pulchella . .

Eupatorium cannabinum . . . .

Euphorbia amygdaloides . . . . .

- var. ligulata.

- Cyparissias ....

- dulcis. . . . . . .

— Esula . . . . . 116

- exigua . . . . 1138

— falcata . . . . 1139

- Gerardiana . . . 1130

- helioscopia . . . 1130

— Lathyris . . . . 1149

- palustris . . . 1183

- Peplus . . . . . 1157

- platyphylla. . . 1131

- stricta . . . 1132

- verrucosa. . . . 1193

EUPHORBIACÉES .

Euphrasia gracilis .

- officinalis. . . . .

- stricta

Evonymus latifolius .

- verrucosus....

- vulgaris. . . . .

Fagus silvatica. . .

Falcaria Rivini. . . 61

Farsetia incana... 117

Festuca arenaria. . 15\%7

- arundinacea. . . 13̆4ว

- capillata . . . . 1330

- duriuscula. . . . 1332

- gigantea. 10但

— heterophylla. . . . 1 ○年9

- loliacea. . . . 15043

- ovina. . . . 1 .

- pratensis .... 1514

- rubra. . . . . $13 \% 8$

- silvatica. . . . 1306

Ficaria ranunculoides.

Ficus Carica. . . . 117

Filago apiculata . . 72

- arvensis. . . . . 720

- canescens. . . . 72

- minima . . . . 727

— spathulata. . . . 728

Foeniculum officinale.
FOUGĖRES.

233

Fragaria collina . . $\quad 439$

- elatior . . . $437 \quad 6.3$

- Hagenbachiana. . 63

- vesea $\quad . .9438 \quad 63$

FRAXINÉES . . . . 46

Fraxinus excelsior $\quad 298 \quad \mathbf{4} 6$

- Ornus. . . . . $299 \quad 46$

Fumana procumbens. 19330

Fumaria Bastardi. . . $\quad 20$

- Boraei. . . . . 20

- capreolata. . . . 61 20

- micrantha. . . . $67 \quad 20$

- muralis .... 630

—officinalis . . . . $66 \quad 20$

- parviflora . . . $\quad 68 \quad 20$

- Vaillantii ..... $\quad 6920$

FUMARIACÉES . . . 19

Gagea arvensis. . . . 1233188

- bohemica . . . 1234 188

- lutea ..... 188

Galanthus nivalis . . 1272 193

Galega officinalis. . . $366 \quad 53$

Galeopsis bifida . . $\quad 160$

- dubia. . . . . 1033160

- Ladanum . . . . 1031 160 - var. parviflora 160

- Tetrahit. . . 1032 160

Galium Aparine . . . 63399

- boreale.... 647 94

- Cruciata. . . . . 643 9'

- constrictum . . . . 638193

- divaricatum. . . . 633396

- erectum. . . . . 65996

- elongatum. . . . 63093

- intermedium .... $\quad 98$

- Jordani . . . . 96

- laeve...... 96

— Mollugo. . $\quad . \quad 63896$

- nitidulum . . . . 96

— palustre. . . . 64998

— parisiense. . . 65696

- saxatile.... 66196

- silvestre. . . . 66096

- spurium. . . . . 60329

- tricorne. . . . 639 9:

— uliginosum . . . $648 \quad 93$

- Vaillantii .... . 9:3

- vernum. . . . $66^{\prime} 69^{\prime}$

- verum. . . . . $6: 3796$

Gaudinia fragilis . . $1311 \quad$ 22:3

Genista anglica. . . . $310 \quad 49$

- germanica. . . $311 \quad 49$

- pilosa..... 314 50

- prostata. . . . $313 \quad 49$

— sagittalis . . . . $\quad 312 \quad 49$

- tinctoria ... 31330 
Gentiana ciliata . . . 891

- Cruciata.

- germanica. .

- Pneumonanthe. . GENTIANÉES

GÉRANIAGÉES.

Geranium columbinum.

- dissectium $\cdot \cdots$

- lucidum. . . . .

- molle . . . . . .

- purpureum ... .

- pusillum ....

- var. trilobum.

- Robertianum ...

- rotundifolium. . .

- sanguineum ...

Geum intermedium.

- rivale

- rubifolium. . . .

- umbrosum.

- urbanum.

Glaucium flavum

Glechoma hederacea .

Gleditschia triacanthos

Globularia vulgaris. .

GLOBULARIÉES .

Glyceria aquatica...

- fluitans . . . .

- nervata. . . . .

- plicata . . . . .

Gnaphalium luteo-al-

bum ...... .

- silvaticum. . . .

- uliginosum . . .

Goodyera repens . . .

GRAMINÉES.

Gratiola officinalis. .

GROSSULARIÉES.

GYMNOSPERMES

Gypsophila muralis. .

HALORAGÉES . . .

Hedera Helix. . . . .

Helianthemum canum.

- gutlatum ....

- montanum ... .

- polifolium. . . .

- umbellatum. . . .

- vulgare. . . . .

- laetiflorus. . . .

- tuberosus....

Heliotropium euro-

paeum . . . . . .

Helleborus foetidus.
891
893

892

$89 '$

299

260

236

262

$2: 8$

263

263

237

261

264

493

423

121

:39

$1013 \quad 159$

$30 \% \quad 49$

$1039 \quad 163$

163

$1317 \quad 226$

$1313 \quad 226$

$1318 \quad 296$

$1316 \quad 226$

$719 \quad 106$

$721 \quad 106$

$720 \quad 108$

$\begin{array}{ll}1307 & 197\end{array}$

$21: 3$

$963 \quad 146$

79

183

$193 \quad 33$

631

\section{4}

92

\section{0}

$149 \quad 30$

$130 \quad 30$

$131 \quad 30$

$148 \quad 30$

$132 \quad 30$

$733 \quad 110$

$733 \quad 110$

73110

$930 \quad 139$

42
Helleborus niger. . .

- viridis .....

Helosciadium inundatum .

- nodiflorum . .

- repens

.

Helminthia echioides.

80 는 $\quad 119$

Helodea canadensis. . 122' 183

Helodes palustris. . . $270 \quad 43$

Heracleum Sphondylium.

- var. stenoplyyllum.

Herminium Monorchi:

Herniaria glabra. . - var. subciliata.

Hesperis matronalis

Hieracium Auricula.

- boreale . . . . .

- murorum ....

- Peleterianum

- Pilosella.

- rigi

- rimilin

- vulgatum

HIP POCASTANÉES .

Hippocrepis comosa .

Hippophae rhamnoi-

$$
\text { des....... }
$$

HIPPURIDÉES.

1143 173

Hippuris vulgaris. . .

Holcus lanatus. . . . 1609

$1309 \quad 22: 3$

- mollis.

$1310 \quad 22: 3$

Holosteum umbella-

tum ...... 22035

Hordeum distichum . $1334 \quad 232$

- hexastichum... 1567232

- murinum . . . . 1568232

— secalinum. . . . 1569232

— vulgare. . . . . 13666232

- Zeocriton .... 1363232

Hottonia palustris . . $869 \quad 129$

Humulus Lupulus . . $1170 \quad 177$

Hutchinsia petraea . $138 \quad 29$

HYDROGHARIDÉES

Hydrocharis Morsus-

ranae.

183

..... 122183

Hypericum Desetangsii 273042

- var. imperforatum.

- hirsutum . . . 27

- humifusum ... 272

- montanum ...

- perforatum . . . 273

- pulchrum . . . . 276

- tetrapterum . . . 274

HYPÉRIGINÉES 22 23 123

4

74

:3

2

2

7

3
17

17

90

90

90

3

86

86

996

77

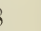


Hypochæris glabra. .
— var. arachnoidea.

Koeleria gracilis...

226 - var. Balbisii

118

118

- maculala . ... . . $\quad 798$

- radicala. . . . 796

Hyoscyamus niger. . 942

- pallidus.

Hyssopus officinalis . 1030

Iberis amara. . . . 131

- arratica

- intermedia. . . . .

- sempervirens. . .

- umbellata. . . . .

Ilex aquifolium . . .

ILIGINÉES

Illecebrum verticillatum . . . . . . .

Impatiens Noli-tangere.

- parviflora . . . .

- Roylei . . . . 236

Inula britannica . . $\quad 712$

- Conyza . . . . 715

- graveolens. . . . $\mathbf{7 1 6}$

- Helenium . . . 711

- hirta . . . . . 713

- salicina . . . 714

IRIDÉES.

Iris foetidissima . . 1270

- Pseudacorus. . . 127

Isatis tinctoria . . 129

Isnardia palustris . .

Isopyrum thalictroi-

$$
\text { des. . . . . . . }
$$

Jasione montana. . .

JONGAGINÉES.

JONGÉES

\section{JUGLANDÉES}

Juglans regia . . . 1176

Juncus anceps . . . 136't

- bufonius . . . . 1333

- capitatus. . . . 13:1 compressus . . 1360

- conglomeratus. . 1339

- effusus.... . 1338

- glaucus. . . . 1337

- lamprocarpus . . 1363

- obtusiflorus . . . 1362

- pygmæus . . . 13\%2

- silvaticus . . . 1368

- squarrosus ... 1336

- supinus. . . . . 1361

- Tenageia . . . . 13\%"

- tenuis. . . . . 13\%3

Juniperus communis. 1213

Knautia arvensis. . . 681

Koeleria cristata. . . 1314
- setacea

$1313 \quad 226$

LABIÉES

153

Lactuca dubia . . . 120

- muralis..... $813 \quad 120$

- perennis . . . $817 \quad 120$

- saligna . . . . $811^{\prime} 120$

- sativa ..... 120

- Scariola. . . . . $81 \ddot{3} 120$

- virosa. ... $816 \quad 120$

Lagenaria vulgaris. . $\quad 831 \quad 76$

Lamium album. . . 10's 139

- amplexicaule . . 10't $1: 39$ - var. clandestina. $\quad \mathbf{1 3 9}$

— Galeobdolon. . . $1049 \quad 139$

- hybridum. . . . $10 \% 60$

- maculatum . . . $104 \overline{7} 139$

- purpureum . . . 10\%: 139

Lappa minor. . . . $786 \quad 115$

- nemorosa . . . . $\quad 789 \quad 116$

— officinalis. . . . $788 \quad 116$

- pubens. . . . . $787 \quad 113$

- tomentosa. . . . $\quad 790 \quad 116$

Lapsana communis. . $793 \quad 117$

Larix europaea. . . . $1214 \quad 184$

Laserpitium latifolium . . . . $879 \quad 80 \ddot{3}$

Lathræa Clandestina. 100' 131

- Squamaria ... 100:3 131

Lathyrus angulatus . $\quad 396 \quad 39$

- Aphaca . . . . $389 \quad 58$

- Cicera. . . . . $393 \quad 59$

- hirsutus. . . . $391 \quad 38$

- latifolius . ... 40360

- macrorhizus. . . $398 \quad 89$

- niger . . . . . $\quad 399$ \$9

- Nissolia .... 390 : 38

— odoratus . . . . $392 \quad 88$

- palustris . . . $401 \quad 89$

- pratensis . . . 397 89

- sativus . . . . 39 \$ 89

- silvestris . . . . 40260

- sphaericus. . . . 39389

- tuberosus $\quad . \quad 400 \quad 89$

Leersia orysoides. . 1 13\% 219

Lemna gibba. . . . 13ł1 201

- minor. ...... 1340201

- polyrrhiza . . 1338201

- trisulca... . . 1339201

LEMNAGÉES. . . . 201

LENTIBULARIÉES. . $12 \pi$

Leontodon autumna-

lis....... $799 \quad 118$

- hispidus . . . 800118

118

Leonurus Cardiaca. . $10 \% 0160$

- Marrubiastrum . . 10:31 160 
Lepidium apetalum. .

- campestre. . . I 1'0

- Draba. . . . . 112

- graminifolium. . 14k

- heterophyllum. . . 1 '́l

- latifolium . . . 143

- ruderale. . . . 148

- sativum. . . . 139

- virginicum . . . 1 1'6

Leucanthemum Parthenium ... . . 710

- vulgare . . . . 739

Leucoium vernum . . 1273

Ligustrum vulgare.

LILIACEESS

Limnanthemum peltatum

Limodorum abortivum . . . .

Limosella aquatica. .

Linaria arvensis . . .

- Cymbalaria . . . .

- Elaline.....

- minor. .... - rar. praetermissa.

- Pelliceriana. . .

- spuria. . . . .

- striala ....

- supina .....

- vulgaris.

LINÉES

Linosyris vulgaris. .

Linum alpinum. . . .

- angustifolium . . .

- catharticum...

- gallicum . . . .

- tenuifolium ... .

- usitalissimum. .

Listera ovata . . .

Lithospermum ar-

vense .....

- officinale . . . . .

- purpureo-cæruleum

Littorella lacustris. .

Lobelia urens....

LOBÉLIACÉES .

Logfia callica...

Lolium italicum . .

- multiflorum. . . .

- perenne. ....

- speciosum . . . .

- temulentum..

Lonicera Caprifolium.

- etrusca

- Periclymenum. . .

- Xylosteum ...

LORANTHACEEES. .

Lotus corniculatus . .

1584
30

29

29

29

29

29

30

29

30

109

109

193

$881 \quad 130$

187

896

1308

968

96 '

930

$9: 38$

$9: 9$

960

937

961

963

962

693

241

242

239

238

240

213

1310

912

911

910

1087

810

728

1386

1587

1583

$\begin{array}{rr} & 94 \\ & 94 \\ 640 & 93 \\ 611 & 94 \\ & 173 \\ 3 & \end{array}$

Lotus tenuis. . . . . $339 \quad 33$

- uliginosus. . . . . $361 \quad$ อั3̆

Lunaria biennis . . $\quad 116 \quad 27$

Luzula albida . . . 203

— campestris . . . 1369203

- Forsteri. . . . 1367203

- multiflora. . . . $1370 \quad 203$

— pilosa. . . . . $1366 \quad 203$

— silvatica .... 1368203

Lychnis coronaria . . 3 3

— diurna . . . . $190 \quad 3 \%$

- Flos-cuculi . . . . $192 \quad 33$

— Githago. . . . $189 \quad 33$

- vespertina. . . . 19133

- Viscaria. . . . $193 \quad 3$

Lycium sinense. . . 932 140

$931 \quad 140$

Lycopersicum escu-

lentum...... 938 1't1

LYCOPODIAGÉES. . . 240

Lycopodium clavatum 1623 2:11

- complanatum . . 162't 2'1

- inunlatum ... $1623 \quad 210$

- Selago ..... 1622 20

Lycopus europæus . . $1023 \quad 136$

Lysimachia nemorum. $\quad 876 \quad 129$

- Nummularia. . . $\quad 873129$

- punctata... $\quad 871 \quad 129$

— vulgaris . . . $\quad 873 \quad 129$

LYTHRARIEEES . . . 73

Lythrum Hyssopifolia. $\quad 828 \quad 73$

- Salicaria ... $527 \quad 70$

Mahonia Aquifolium. . 18

Maianthemum bifo-

lium. . . . . 1263 191

Malaxis Loeselii . . . 130' $196^{\circ}$

- paludosa . . . . 1303196

Malcolmia maritima. . 2't

Malus acerba. ... $496 \quad 71$

- communis. . . . 49391

Malva Alcea . . . . 24940

- borealis. .... $233 \quad 41$

- moschata. . . . 25041

- rotundifolia... 252 41

— silvestris . . . . 231

MALVACEEES. . . . . 40

Marrubium Vaillantii. $\quad 162$

- vulgare. . . . 1063162

Matricaria discoidea. $\quad 743 \quad 109$

- Chamomilla. . . $741 \quad 109$

- inodora..... 742109

Matthiola incana .. 2't

Medicago cyclocarpa .

- falcata . . . 323031

— Gerardi . . . . $330 \quad 32$

- Lupulina . . . . $323 \quad 31$

- maculata ... 327 s1 
Medicago media...

- minima.....

- orbicularis ...

- polycarpa. . . .

- var. apiculata.

- var. denticulata.

- sativa.

Melampyrum arvense.

- cristatum . . . . .

- pratense.....

Melica ciliata ... .

- nutans......

- uniflora.

Melilotus alba . . .

- altissima . . . . .

- arvensis.

- parviflora. . . . .

Melissa officinalis . . 1037

Melittis Melissophyllum . . . . . .

Mentha afuatica. .

- arvensis. . . .

- Pulegium . . . .

- silvestris

- viridis.

Menyanthes trifoliata.

Mercurialis annua. .

- perennis.

Mespilus germanica .

Mibora minima . . .

Micropus erectus. .

Milium effusum . . . 149

Molinia caerulea. . . 1531

MONOCHLAMYDÉES

MONOCOTYLÉDONES

MONOPÉTALES .

Monotropa Hypopitys.

var. glabra.

MONOTROPÉES . . .

Montia minor . . . .

- rivularis . . . . .

MORÉES.

Morus alba. . . .

- nigra.

Muscari comosum . .

- neglectum. . . . .

- racemosum . . .

Myagrum perfoliatum.

Myosotis caespitosa. .

- hispida .... .

- intermedia ... .

- palustris. . . . .

- stricta ..... 920

— versicolor. . . . 92

Myosurus minimus. .

Myrica Gale . . . 1212

MYRICINÉES
328

326

329

32 '

1002 1:31

$1001 \quad 130$

1003 13้

1:32늘 28

1 i33 228

$1337 \quad 228$

$336 \quad$ 32

$333 \quad 52$

33 年

$333 \quad \because 2$

138

$1066 \quad 162$

102.2 136

$1023 \quad 1506$

$102 ' \quad 156$

$1019 \quad 13 \%$

$1020 \quad 193$

$1021 \quad 13 \%$

$897 \quad 133$

$1161 \quad 173$

$1163 \quad 176$

$489 \quad 70$

43:3 219

$\begin{array}{ll}729 & 107\end{array}$

223

228

166

183

92

$301 \quad 47$

47

47

837

ธ38

177

177

177

$1213 \quad 189$

12'午3 189

1ㄴ't 189

27

$\begin{array}{lll}919 & 137\end{array}$

$921 \quad 138$

$\begin{array}{ll}923 & 138\end{array}$

$918 \quad 137$

$920 \quad 138$

$922 \quad 138$

$26 \quad 15$

183

183
Myriophyllum alterni-

florum. . . . . $318 \quad 74$

- spicalum ..... $\quad 319 \quad 74$

— verticillatum . . $520 \quad 71$

NAIADÉES. . . . 200

Naias major . . . . $1336 \quad 201$

- minor .... 1337201

Narcissus incomparabilis . . . . . 193

— poeticus... . . . 1273193

- Pseudo-Narcissus . 127' 193

Nardurus Lachenalii . 1389233 var. aristata 233

- unilateralis . . . 1388 23:3

Nardus stricta. . . . 1590233

Nasturtium amphi-

bium . . . . 10' 26

- asperum . . . . 10126

— officinale ... $100 \quad 28$

- var. siifolium. 203

- palustre. . . . . $103 \quad 26$

- pyrenaicum . . . 10326

— silvestre. . . . $102 \quad 26$

Neottia Nidus-avis . . $1309 \quad 197$

Nepeta Cataria. . . 1012159

Neslia paniculata. . . $126 \quad 28$

Nicandra physaloides. $\quad 1,1$

Nicotiana rustica. . 1'1

Nigella arvensis . . $44 \quad 17$

- damascena .... 17

Nuphar luteum . . $\quad 53 \quad 18$

Nymphæa alba. . . $\quad \$ 218$

NYMPHÉÁ minor. 18

18

Odontites Jaubertiana...... $993 \quad 149$

- longifolia .... 150

- lutea ..... 992149

- serotina. . . . $994 \quad 130$

— verna. . . . . . 993150

Enanthe Crocata. . . 88

- filipenduloides. . . 87

- fistulosa . . . . 60088

- Lachenalii. . . . . $\quad 397 \quad 87$

- media. . . . . . 59987

- peucedanifolia. . $\quad 598 \quad 87$

— Phellandrium . . . $\quad 99687$

- pimpinelloides . . . $\quad 88$

- silaifolia .... 87

Enothera biennis . . $\quad 314 \quad 73$

OLÉACÉES. . . . 130

OMBELLIFËRES . . . 80

ONAGRARIÉES . . 72

Onobrychis sativa ... $408 \quad \mathbf{6 0}$

Ononis campestris. . $318 \quad: 30$

$321 \quad 30$ 


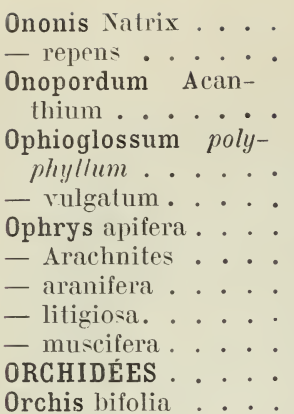

- conopea ....

- coriophora ... .

- hircina ....

- incarnata . . .

- latifolia . . . . .

- laxiflora ....

- maculata....

- mascula. . ...

- militaris.... .

- montana....

- Morio ..... .

- odoratissima...

- palustris ....

- pyramidalis. . .

— sambucina ...

- Simia .....

- ustulata. . . .

Origanum viridulum

- vulgare. . . . .

Orlaya grandiflora . .

Ornithogalum diver-

gens. . . . . .

- nutans.... .

- pyrenaicum...

- umbellatum.

Ornithopus perpusillus. .......

Orobanche amethystea ......

- caryophyllacea . .

- cruenta. . . . .

- Epithymum . . .

- Hederæ.....

- minor. . . . .

- Picridis.....

- rubens .....

- Teucrii ....

OROBANCHÉES ..

Osmunda regalis . .

OXALIDÉES

Oxalis Acetosella . .
320

319

737

(159)

1391

1279

1280

1276

127

1278

1290

1296

1288

128 ?

1301

1300

1293

1299

1292

1286

1291

1289

1297

1294

1283

1298

1298

1287

1284

1283

1020

371

1237

1238

1239

$1236 \quad 188$

406

1016

1011

1010

1012

1014

1018

1017

1009

1013

1013

1593

289
Oxalis corniculata. .

291

- Vacieri.....

- stricta .... 290

0xycoccus palustris . 830

Panicum miliaceum . 1476

Papaver Argemone. .

- dubium.... 58

- hispidum ....

- Rhmas.... 57

— somniferum . . . 50

PAPAVÉRACÉES.

PAPILIONACÉES.

Parietaria erecta.

- officinalis.... 1163

Paris quadrifolia. . 1262191

Parnassia palustris. $180 \quad 33$

PARONYGHIÉES.

77

Passerina annua. . $1139 \quad 172$

Pastinaca silvestris. . $\quad 587 \quad 86$

Pedicularis palustris. $\quad 999 \quad 150$

- silvatica .... 1000150

Peplis Portula . . . $\quad 52978$

Persica lavis . . . 62

- vulgaris. . . . 40962

Petasites fragrans. . $687 \quad 102$

- officinalis . . . $688 \quad 103$

Petroselinum sativim $621 \quad 91$

- segelum. . . . . 62090

Peucedanum carvifo-

lium. . . . . $\$ 83 \quad 83$

- Cervaria . . . $\quad 58686$

- gallicum ... $\quad 58285$

- Oreoselinum. . . . 58386

- palustre. . . $581 \mathbf{k} 83$

Phalaris arundinacea. $1438 \quad 219$

- canariensis . . 14009219

Phaseolus multiflorus $368 \quad 56$

— vulgaris. . . . . $367 \quad \$ 60$

Phelipæa arenaria . $1008 \quad \mathbf{1 5 2}$

- crrulea.... $1007 \quad 152$

- Millefolii .... 132

- ramosa .... 1006131

PHILADELPHÉES . . 72

Philadelphus corona-

rius...... $503 \quad 72$

Phleum arenarium. $1461 \quad 220$

- asperum ... $1462 \quad 220$

- Bochmeri .... 1463 220

pratense .... 1't6' 220

Physalis Alkekengi. . $\quad 939 \quad \mathbf{1 1 4}$

Phyteuma orbiculare. $843 \quad 124$

- spicatum .... 841 12k

Picris hieracoides . . $801 \quad 118$

Pilularia globulifera . $1621 \quad 240$

Pimpinella magna . . $\quad 607 \quad 89$

- var. dissecto. 89

- Saxifraga . . . 60889

1

9

9

7

5

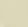

19

8

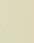

6

2


- val. dissectifolia.

Pinguicula vulgaris .

Pinus Laricio. . . . .

- Pinaster. . . . .

- silvestris. . . .

- Strobus. . . . .

Pirola maculata . . .

- rotundifolia . . .

- umbellata. . . .

PIROLEEES . . . .

Pirus communis . . .

F salvifolia . . . . .

Pisum arvense . • • •

PLANTAGINEES. . •

Plantago arenaria . .

- Coronopus. . . .

- intermedia . . .

- lanceolata. . . .

- major . . . .

- media .....

- minima . . . .

PLATANÉES. • • •

Platanus acerifolia. .

- occidentalis ...

- orientalis....

- vulgaris. . • .

Poa anceps . . . . .

- angustifolia. . .

- annua . . . . .

- bulbosa. . . .

- Chaixii . . . .

- compressa. . . .

- nemoralis. . . .

- palustris . . . 132't

- pratensis . . . 13221

- trivialis. . . . 1323

Podospermum laciniatum ......

- subulatum. . . .

Polycnemum arvense.

Polmas. . . . . .
Polygala ainara . .

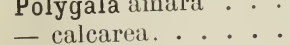

- comosa.....

- serpyllacea . . .

- vulgaris. . . .

POLYGALEES

Polygonatum multiflorum

- officinale . . .

POLYGONEES

Polygonum amphi-

bium..... $1131 \quad 171$

- aviculare.... $1138 \quad 172$

- Bellardi. . . . . $1137 \quad 172$
Polygonum Bistorta . 1130 171

- Convolvulus. . . 1128 171

- dumetorum . . . 1129171

- Fagopyrum . . . 1126171

- Hydropiper . . . 113' 172

- lapathifolium . . 1132 172

- mile..... 1133 172

- minus. . . . . 1136 172

- Persicaria. . . . 1133 172

- talaricum. . . . 1127171

Polypodium Dryopte-

ris . . . . . 1398237

- Robertianum . . $1399 \quad 237$

- serratum . . . . 237

- vulgare..... 1397237

Polystichum cristatum . . . . . 1603 238 - var. uliginosum. 238

- dilatatum . . . 238

- Filix-mas. . . 160' 238

- Oreopteris. . . . 1603238

- spinulosum . . . 1606238

- Thelypteris . . . 1602 238

Populus alba. . . . 1203182

- camescens... 1204 182

- monilifera. . . 1206182

- nigra. . . 12030

- pyramidalis . . . 182

- tremula. . . 1202 182

Portulaca oleracea . . 53676

PORTULACEES. . . . 76

POTAMEEES . . . . 198

Potamogeton acutifo-

lius...... 132 年 199

- alpinus . . . . 1330200

- coloratus . . . 1331200

- crispus. . . . 1323199

- densus. . . . . . 1318198

- fluilans. . . . 1333200

- gramineus. . . 1329200

- lucens. . . . . 1327199 - var. fluilans. 199

- mucronatus . . . 1322 199

- natans..... 133 ' 200

- obtusifolius . . . 1323199

- pectinatus. . . 1319199

- perfoliatus . . . 1326 199

- polygonifolius. . 1332 이

- pusillus. . . . 1320199

- trichoides. . . 1321 199

- Zizii...... 1328200

Potentilla Anserina. . $428 \quad 6 \%$

- argentea ... 43' 603

- Fragariastrum. . $427 \quad 64$

- hirla.... . 603

- inclinata . . . 133 6't

- pennsilvanica . . 6 (3:

- procumbens... 431 l't 
Potentilla recta ..

- reptans . . . . . 430

- splendens . . . 426

- supina . . . 429

- Tormentilla . . . 432

- verna. . . . . 43

Poterium dictyocarpum .

- muricatum

Primula elatior

— officinalis.

- vulgaris

- - var. caulescens

PRIMULAGÉES

Prunus cerasifera.

- domestica.

- fruticans

- insititia.

- spinosa .

Pteris aquilina.

Pulicaria dysenterica.

- vulgaris.

Pulmonaria affinis. .

- azurea .... .

- longifolia .... .

- vulgaris

Quercus Cerris. . . . 1179

- Ilex.

- pedunculata.

- pubescens.

- sessiliflora

Radiola linoides..

Ranunculus acris. .

- Amansii

- aquatilis

- arvensis.

- - var. reticulatus

- _ tuberculatus

- auricomus.

- Boræanus

- bulbosus

- chaerophyllos...

- confusus

- Delacouri ....

- divaricatus...

- Flammula.

- fluitans.

- gramineus...

- hederaceus. . .

- hololeucos.

- Lenormandi. . .

- Lingua . . . . .

- nemorosus. . . . .

- nodiflorus. . . .

- parviflorus ... .

- polyanthemoides
483

871

872

870

63

1182

1180

1181

\section{4}

\section{Ranunculus Questieri.}

- repens.

23

- sardous. . . . .

- sceleratus.

- trichophyllus

- tripartitus.

Raphanus Raphanistrum

- Sativus . .

Rapistrum rugosum .

RENONGULAGÉES

Reseda lutea.

- Luteola.

- odorata.

- Phyteuma.

RÉSÉDACÉES

RHAMNÉES

RHAMNUS Alaternus.

- cathartica. . . . 295

- Frangula . . . .

Rhinanthus Alectorolophus

- minor

RHIZOCARPÉES

150

$997 \quad 150$

nchospora alba . $1376 \quad 206$

— fusca . . . . . 1377206

Ribes Alpinum.

— nigrum . . . . . 561

- rubrum . . . . 562

- Uva-crispa . . . 560

Robinia Pseudo-Acacia

Rosa agrestis. . . .

- arvensis.

$476 \quad 69$

- blanda

$471 \quad 68$

- canina . . . . 48170

- gallica ..... 70

- lutea ..... $473 \quad 69$

- micrantha. . . . $\quad 477 \quad 69$

— obtusifolia ... $\quad 480 \quad 69$

— pimpinellifolia. . $\quad 474 \quad 69$

— rubiginosa. . . . . $478 \quad 69$

— stylosa ..... $472 \quad 68$

- tomentella. . . . 69

- tomentosa. . . . $479 \quad 69$

ROSACÉES . . . . . 60

Rubia peregrina . . 64394

- tinctorum. ... $644 \quad 94$

RUBIACEEES . . . . . 94

Rubus aegocladus . . $\quad 46308$

— affinis . . . . 44766

- biformis. . . . . 44466

- bifrons . . . . 45067

- caesius . . . . $460 \quad 67$

— cardiophyllus . . $434 \quad 67$

- cuspidifer . . . . 459967

- fuscus. . . . . 46368

- Genevieri . . . $\quad 46468$

- hypoleucos ... $462 \quad 67$

89

7

7

8

13

3.

1

23

23

12

32

2

32

32

32

46

46

40

6

80

80

79

8

0

69

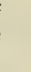

.


Rubus illaeus . . $441 \quad 63$

- Koehleri. . . . 468

- Lejeunei. . . . . . 466

- macrophyllus . . . 43\%2

- nitidus . . . . 440

- plicatus..... 4 43

- pyramidalis. . . . 453

- Ouestieri .... 400

- Radula ... . . 461

- rosaceus. . . . . 467

- saxatilis. . . . 440

- Schlechtendalii . . 449

- Schleicheri ... 469

- silvaticus . . . 450

- Sprengelii. . . $4 \mathbf{4 t 8}$

- suberectus. . . . 442

- sulcatus. . . . $4 \mathbf{4 6}$

- tereticaulis . . . 470

- thyrsoideus.... 458

- tomentosus . . . 40̈3

- ulmifolius. . . . 437

Rumex Acetosa. . . . 1113

- Acetosella . . . . 1116

- conglomeratus. . 1122

- crispus . . . . 1123

- Hydrolapathum . . 112:

- maritimus. . 1117

- maximus .....

— obtusifolius . 1120

- palustris . . . 1118

- Patientia .... 1124

- pulcher . . . . 1119

- sanguineus . . . 1121

- scutatus .... 1114

Ruscus aculeatus. . . 1268

Ruta graveolens . . . 292

RUTACEES

Sagina apetala. . . 20 '

- ciliata. . . . . 208

- nodosa . . . . 206

- procumbens . . . 203

- subulata .... 207

Sagittaria sagittæe-

lia.......

SALIGINEEES. . . .

Salix affinis . . . . 1190

- alba . . . . 1201

- aurita. . . . . 1186

- babylonica . . . 1198

- Caprea .... 1188

- cinerea . . . 1187

- fragilis . . . . 1199

- hippophaefolia. . . 1197

- incana . . . . 1192

- purpurea .... 1193

- repens. . . . . 1180

- rubra. .... 1194
68

67

67

66

67

66

67

68

63

66

68

66

66

66

66

68

67

67

67

169

169

170

170

170

170

170

170

170

170

170

170

169

192

43

43

36

36

36

36

36

186

179

180

182

179

181

180

180

181

181

180

181

179

181
Salix Smithiana . . $1191 \quad 180$

- triandra. . . . . 1193181

- undulata . . . 1196181

- viminalis . . . 1189180

- viridis ..... 1200181

Salsola Kali . . . 1113169

SALSOLACÉES . . . 166

Salvia officinalis . . $10 ّ 8$

- pratensis . . . $1040 \quad 158$

- Sclarea . . . . 1039158

- silvestris. . . . 158

- Verbenaca. . . $1041 \quad 158$

- verticillata . . $1038 \quad 158$

Sambucus Ebulus . . $\quad 635993$

— nigra . . . . . 63693

- laciniata. . . . 93

- racemosa .... 63793

Samolus Valerandi . $\quad 880 \quad 130$

Sanguisorba officinalis...... 48670

Sanicula europaea . . $\quad 0 \ddot{3} 68 \quad 83$

SANTALACÉES . . 173

Saponaria officinalis . 19333

- Vaccaria .... $194 \quad 35$

Sarothamnus scoparius .......

Satureia hortensis. .

- montana . 1031 1.57

Saxifraga granulata . $5564 \quad 80$

- Tridactylites. . . . $563 \quad 80$

SAXIFRAGÉES. . . . 80

Scabiosa atropurpurea. $\quad 100$

- columbaria . . . $68: 3100$

- suaveolens . . . 684100

- succisa . . . . $682 \quad 100$

- ucranica . . . $683 \quad 100$

Scandix Pecten-Veneris....... $624 \quad 91$

Schœnus nigricans. . 1374206

Scilla autumnalis. . . 1210188

- bifolia .... 124188

Scirpus acicularis . . 1391208

- caspitosus. . . . 1393208

- compressus . . 1382207

- fluitans . . . $1390 \quad 208$

- lacustris. . . . . 1383207

- maritimus. . . . 1383207

- multicaulis . . . 1393208

- ovatus .... 1394208

- palustris . . . . 1396209

- pauciflorus . . . 1392208

- setaceus. . . . . 1389208

- silvaticus . . . . 138; 207

- supinus. . . . . 1388208

- Tabernæmontani. . 1386207

- triqueter . . . 1387208

— uniglumis. . . . 1397209

Scleranthus annuus. 
Scleranthus perennis.

Scleropoa rigida . :

Scolopendrium officinale

Scorzonera austriaca.

- hispanica

- humilis

Scrofularia àquatica .

- canina :...

- nodosa.

- vernalis.

SGROFULARIÉES

Scutellaria Columnæ.

- galericulata. . . .

- minor

Secale cereale . .

Sedum acre . :...

- album. . . . .

- Cepaea

- dasyphyllum ...

- elegans . . . . .

- glanduliferum...

- hirsutum .....

- micranthum ...

- purpurascens ...

- reflexum ....

- rubens : . . . .

- villosum

Selinum Carvifolia .

Sempervivum tectorum

Senebiera Coronopus.

- pinnatifida . . .

Senecio adonidifolius.

- aquaticus....

- barbareifolius...

- erucifolius. . . .

- flosculosus....

- Fuchsii . . . . .

- Jacobaea ....

- lanceolatus ... .

- paludosus....

- palustris ....

- silvaticus....

- viscosus. ...

- vulgaris . ...

Serratula tinctoria. .

Seseli annuum... .

- Libanotis . . . .

- montanum ...

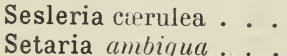

- glauca . . . . . .

- verticillata ...

- viridis . . . . .

Sherardia arvensis.

Sibthorpia europiea .
วั43

1336

1617

803

8003

$80{ }^{\prime}$

933

930

932

931

1069

1067

1068

$1571 \quad 232$

5ّ̋⿰

ชัวั1

药

ชั่3

536

วัวั2

วัธั0

$5 \% 7$

348

วัว

รั9

381

338

147

701

707

703

708

706

710

709

703

702

701

783

393

391

592

1470

1472

1473

1474

1473

667

969
228

Silaus pratensis

$390 \quad 86$

Silene catholica. . . 18334

- conica. . . . . 18:3 34

— gallica . . . $187 \quad 33$

- inflala. . . 182 34

— nuctiflora. . . . 188 33

- nulans . . . . $1 \& 6 \quad 33$

- Otites . . . 18 i 3 í

Silybum Marianum. . $736 \quad 112$

SIMARUBACÉES . . . 46

Sinapis alba . . . $\quad 73 \quad$ @3

- arvensis. . . . . 72 23

- incana..... 7 . 23

— nigra. . . . . 7323

Sison Amonuin. . . 6119

Sisymbrium Alliaria . $9 \ddot{3} \quad 2: 3$

- Columnxx .... $20 ̈$

- Irio. . . . . . 9923

— oflicinale .... $97 \quad 9$

var. leiocarpum. 23

- Sinapistrum... 23

- striclissimum. . . 20

- Sophia ..... $98 \quad 23$

- supinum. . . . $96 \quad 23$

- Thalianuı ... 9 9 ' 2

Sium angustifolium. . $\quad 606 \quad 89$

- latifolium .... 6 603 88

SOLANÉES. . . . 139

Solanum Dulcamara . 933140

- miniatum. ... $936 \quad 140$

— nigrum ..... $937 \quad \mathbf{1 4 0}$

- ochroleucum... 140

- tuberosum. . . . 931 140

— villosum .... 9330

Solidago canadensis . $\quad 692 \quad 103$

- glabra ..... 691103

- Virga-aurea. . . 690103

Sonchus arvensis .. $821 \quad 121$

121

$820 \quad 121$

$\begin{array}{llll}\text { - oleraceus .... } & 819 & 121 \\ \text { - palustris . . . . } & 818 & 121\end{array}$

Sorbus Aria . . . . $800 \quad 72$

- Aucuparia. . . . 49871

- domestica. ... $497 \quad 71$

- latifolia. . . . $501 \quad 72$

- torminalis.... $\quad 499 \quad 71$

Sparganium minimum $1349 \quad 203$

- neglectum. . . . . 202

- ramosum .... 1347202

- simplex.... $1348 \quad 202$

Spartium junceum . . $308 \quad 49$

Specularia hybrida . $8130 \quad 123$

- Speculum . . . $846 \quad 123$

Spergula arvensis . . $\quad 230 \quad 38$

- Morisonii . . . . . $232 \quad 39$

- pentandra. . . . 23138

Spergularia rubra . . $234 \quad 39$ 
Spergularia segelalis.

Spinacia oleracea. .

Spiraea Filipendula .

- hypericifolia. . .

- opulifolia :. . .

- Ulmaria. . . . 21

Spiranthes aeslivalis. 1:303

- autumnalis . . . . 1306

Stachys alpina. . . : 1060

- ambigua.

annua.

$10: 36$

I1):37

1061

106216

rermanica.

- lanata.

- recta.

— silvatica

$10: 38$

10335

1039

Stratiotes aloides . . 1222

Stellaria Borzana

- graminea . . .

- Holostea.

- media.

- neglecta.

- nemorum.

- palustris . . . .

- uliginosa. . . .

Stenactis annua.

Stipa pennala . . .

Swertia perennis

Symphoricarpos racemosus. . . . .

Symphytum officinale.

Syringa vulgaris . . .

- persica . . . . .

Tamus communis. . .

Tanacetum vulgare

Taraxacum erythrospermum . . ...

- officinale

- palustre.

Taxus baccala . . .

Teesdalia nudicaulis .

Tetragonolobus siliquosus.

Teucrium Bolrys.

- Chamaedrys. . .

- montanum

- Scordium

- Scororlonia

THALAMIFLORES

Thalictrum flavum.

- gallicum. . . .

- majus. . . .

- minus.

Thesium divaricalum.

- humifusum . . .

Thlaspi arvense ...
217

216

39

167

6.3

63

63

(i3)

197

197

161

161

160

161

161

161

160

161

185

37

37

21: 37

37

214 37

$218 \quad 37$

$219 \quad 37$

$696 \quad 103$

$1490 \quad 293$

89: 133

6429 年

$906 \quad 136$

130

130

$1269 \quad 192$

$730 \quad 107$

120

811120

812120

181

132 요

338

1076

1079

1080

1077

1078

$\begin{array}{ll}33 & 12 \\ 33\end{array}$

$31 \quad 16$

$32 \quad 16$

$31 \quad 16$

11 亿2 173

$1113 \quad 173$

$133 \quad 29$
Thlaspi montanim. . 13309

- perfoliatum . . . 134 2 !

Thrincia hirta. . . . $798 \quad 118$

118

Thymus Chamædrys . $1028 \quad 136$

$\begin{array}{rrrr}\text { - humifusus. . . . } 1029 & 1: 7 \\ \text { - Serpyllum. . . } 1029 & 1: 77\end{array}$

- vulgaris. . . . 11027 13̈0

Tillaea muscosa . . 范 78

- Vaillantii . . 096 78

Tilia argentea ... 2 \$8 40

- intermedia ... 2.46 (1)

- parvifolia.... 247 (1)

- platyphylla... . 2

TILIACEES. . . . .

Tordylium maximum. $\quad \$ 89 \quad 86$

Torilis Anthriseus . . $\quad \$ 76 \quad 8$ :

.- helvetica . . .

- nodosa . . . . 374 8,

Tragopogon dubius. . $\quad 808 \quad 119$

- minor . . . . . 119

- orientalis . . . . 119

- porrifolius . . . $809 \quad 119$

- pratensis . . . . 807,119

Tragus racemosus. . 1'71 221

Trapa natans. . . . : 817 7'

Trifolium arvense . . $3: 30$ 花

— aureum . . . . . $337 \quad 32$

— campestre. . . . 339

— elegans.... . 3 373 \$3

— fistulosum. . . . 31' 3̈3

- fragiferum .... 342 33

- vlomeratum ... . 347 33

- incarnatum . . . $3 \% 77$ 5

- lacvigatum . . . 316 \$3

- medium. . . . 332 3̈

— micranthum. . . 3 \$

— minus. ... 3 30 33

- montanum . . 349 3̈

- ochroleucum . . 330 引̈

- patens.... . 338 32

- pratense . . . 333 อ̆

- repens . . . . 340̈

- rubens.... 3ö1 ö

- scabrum .... 3:34 \$1

_ striatum . . . 3\%:

- subterraneum . . . 348 活

Triglochin palustre - 1330 203

Trigonella monspe-

liaca. . . . 332 32

- ornithoporlioides. . $\quad 3: 31 \quad 32$

Trinia vulgaris. . . $\$ 190$

Trisetum flavescens. 1:307 22:3

Triticum composilum. 233

- durum _... . 1:377 2:3:3

- polonicum. . . . 1;74 233

- sativum . . . . 1:37氵 233

- turgillum . . . $1376 \quad 233$ 
Tulipa silvestris . . $1233 \quad 187$

Turgenia latifolia. .

Tussilago Farfara.

Typha angustifolia.

- latifolia.

TYPHACÉES

Ulex europaeus

ULMACÉES

Ulmus campestris. .

- montana. ... 117

- pedunculata . .

Umbilicus pendulinus

Urtica dioica. ....

- pilulifera.

- urens.

URTICÉES

Utricularia intermedia

- minor.

- neglecta.

- vulgaris.

\section{VACCINIÉES.}

Vaccinium Myrtillus:

- Vitis-idaea.

Valeriana angustifolia

- dioica.

- excelsa

- officinalis.

\section{VALÉRIANÉES}

Valerianella Auricula - var. dasycarpa.

- carinata. .

- coronala

- eriocarpa.

- var. leiocarpa.

- olitoria . . . . .

- Morisonii . . . .

Vallisneria spiralis

Verbascum Blatlaria .

- Lychnitis . . . .

- nigrum.

- phlomoides.

- var. thapsiforne.

- pulverulentum. .

- Thapsus ....

- var. montanume.

- virgatum

Verbena officinalis.

VERBÉNACÉES . .

Veronica acinifolia.

-. agrestis.

- Anagallis... .

- anagalliformis.

- arvensis.

- Beccabunga. ...

$\begin{array}{rr}572 & 8 \\ 689 & 10 \\ 1346 & 20 \\ 1343 & 20 \\ & 20\end{array}$

$307 \quad 49$

$306 \quad 49$

\section{7.}

$1172 \quad 177$

$1173 \quad 177$

$1171 \quad 177$

:3099 79

$1168 \quad 176$

$1166 \quad 176$

$1167 \quad 176$

176

$\begin{array}{lll}867 & 128\end{array}$

$\begin{array}{ll}868 & 128\end{array}$

$\begin{array}{lll}866 & 128\end{array}$

863127

8.37

126

$\begin{array}{ll}87 & 126\end{array}$

836126

671

669

670

674

67

677

676

672

$67 \ddot{3}$

1223

949

946

947

9 '1

$94: 3$

913

948

1081

98

118

$980 \quad 148$

$971 \quad 147$

147

$986 \quad 148$

$970 \quad 117$
Veronica Chamadrys.

- montana . . . . 977147

- officinalis. . . . $973 \quad 147$

- peregrina. . . 149

- persica ..... $979 \quad 148$

- polita. . . . . 981148

- præcox. $\quad . \quad 998 \quad 148$

- prostrata ... $974 \quad 147$

- scutellata ... $972 \quad 147$ - var. pubescens.

$\begin{array}{lllll}\text { - serpyllifollia } & \ldots & 987 & 149\end{array}$

- spicata . . . $988 \quad 139$

- Teucrium. . . 973 117

— triphyllos. . . . $\quad .982 \quad 148$

- verna. . . , , 9851148

Viburnum Lantana. . $\quad 639 \quad 93$

- Opulus . . . . . $638 \quad 93$

$\begin{array}{llll}\text { Vicia angustifolia } \quad . \quad 372 \quad & \mathbf{3 6} 6\end{array}$

- Cracca . . . $\quad . \quad 379 \quad 37$

- Faba ..... 37 . 36

- gracilis . . . 38357

- hirsuta .... $384 \quad 37$

-- hybrida. . . . . $369 \quad 36$

- lathyroides . . . 37156

— Lens . . . . $38 \%$ : 88

- lulea.... $370 \quad 36$

- purpurascens . . . $377 \quad 87$

- var. pannonica.

— sativa. . . . . $373 \quad$ 60

- sepium ..... $376 \quad 37$

— serratifolia . . . $37 \%$ 36

- lenuifolia.... $378 \quad 57$

- tetrasperma. . . . $382 \quad 37$

- varia..... . $380 \quad 37$

- villosa . . . . $381 \quad 37$

Viola alba..... 136031

— arvensis. . . . 161 32

- canina . . . $138 \quad 31$

- elatior ..... 16131

- hirta . . . . 1533

- odorata..... $137 \quad 31$

- palustris .... $134 \quad 31$

- pumila. . . . . $159 \quad 31$

- Reichenbachiana. . 31

- Riviniana .... . 31

- rolhomagensis. . . 16332

- silvestris .... $162 \quad 31$

- stagnina . . . . $160 \quad 31$

- tricolor. . . . $163 \quad 31$

VIOLARIÉES. . . . . 31

Vinca major. . . . . $883 \quad 131$

- minor. . . . . 882130

Vincetoxicum nigrum. $\quad 131$

officinale .... $884 \quad 131$

Viscum album... $1144 \quad 173$

Vitis vinifera. . . . $283 \quad 44$

Vulpia ciliata. . . . . $\quad 229$ 
Vulpia longiseta . . $1539 \quad 229$

- myuros. . . . $15 \% 029$

- sciuroides. . . $15 \%$ 229

Xanthium spinosum . $838 \quad \mathbf{1 2 3}$

- strumarium . . . $839 \quad 123$

Xeranthemum cylin-

draceum ..... $791 \quad 116$

Wahlenbergia hederia-

cea....... 841 12't

Wolffia arrhiza. . . $1342 \quad 201$

Zannichellia palustris 1333 200

Zea Mays . . . . 14503219

\section{A D DEN DA}

5 Ranunculus confusus.

Localités : E.-L. Dallonville. - S.-0. Boullay-lès-Trous.

21 Ranunculus nemorosus. - S.-M. Rougeaux.

704 Senecio adonidifolius Lois. - S.-0. Poigny.

743 Matricaria discoidea DC. - E. Vernon.

766 Cirsium rigens. - L. Malesherbes.

1111 Chenopodium ficifolium. - S. Gesson.

1162 Euphorbia Esula. - Nat. S. Choisy.

1237 Ornithogalum divergens. - S.-0. Chevilly.

Page 108. Genre Artemisia.

II serait préférable de mettre dans l'ordre suivant : A. vulgaris, A. selengensis, A. campestris, A. Dracunculus.

Page 196, à Orchis maculata, ajoutez : tige non fistuleuse.

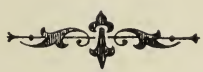


Tulipa

Turge

Tussil

Typha

- lat

TYPH

Ulex

- ni

ULM

Ulm

- $n$

Um

Urt

UF

Ut

-

$-$

V

V

i 


UNIVERSITY OF ILLINOIS-URBANA

581. 94436J34V

COO1

VADE-MECUM DU BOTANISTE DANS LA REGION P

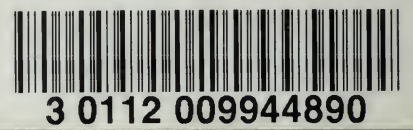

